International Cooperation and Competition in Civilian Space Activities

June 1985

NTIS order \#PB87-136842
International Cooperation and Competition in

Civilian Space Activities

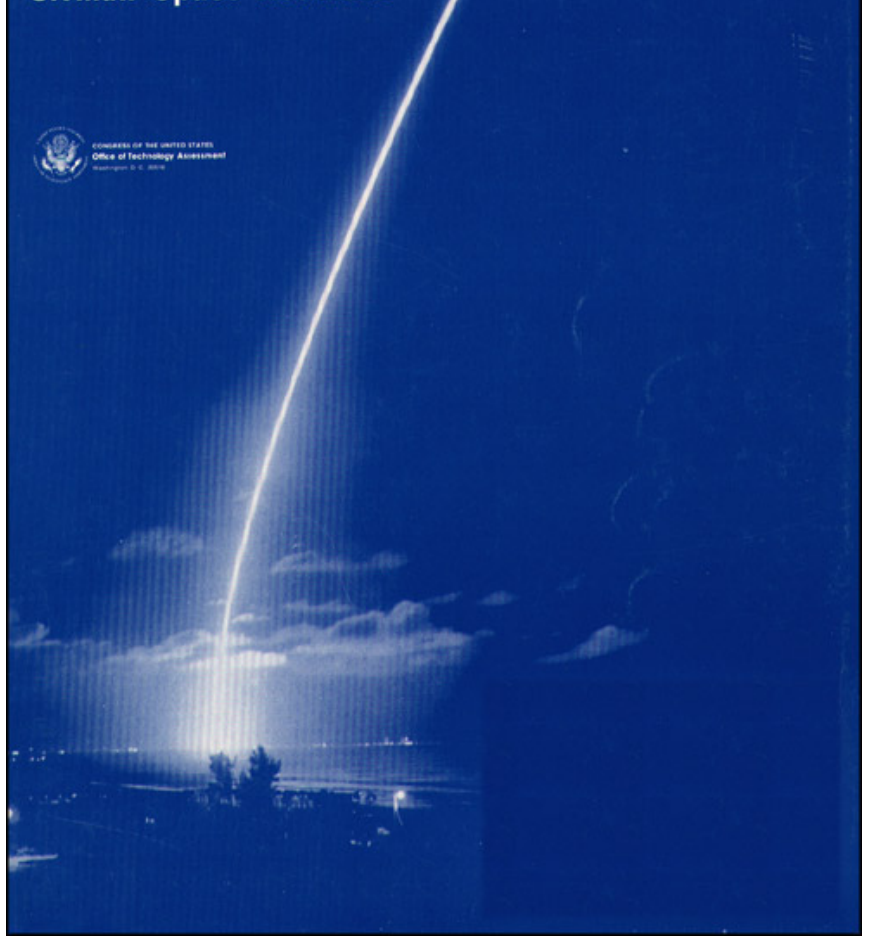




\section{Recommended Citation:}

International Cooperation and Competition in Civilian Space Activities (Washington, DC: U.S. Congress, Office of Technology Assessment, OTA-ISC-239, July 1985).

Library of Congress Catalog Card Number 84-601087

For sale by the Superintendent of Documents

U.S. Government Printing Office, Washington, DC 20402 


\section{Foreword}

The nature of global space activities has changed radically over the last decade. No longer are the United States and the Soviet Union the only countries capable of placing satellites into Earth orbit or sending interplanetary probes into deep space. Europe and Japan now have substantial space programs and have developed commercially competitive space systems. Several newly industrialized countries are well along in building their own space programs. In addition, the U.S. private sector has recently expanded its interest and investment in space technology. As this report makes clear, these changes have strong policy implications for the U.S. Government space program and for the U.S. private sector.

This report presents the major findings of an assessment requested by the House Committee on Science and Technology and the Joint Economic Committee, on international cooperation and competition in civilian space activities. The United States still enjoys a strong competitive position in most space technologies and in space science. There continues to be broad support for a long-term public commitment to civilian space activities. But precisely because of our achievements-and those of other space-faring nations - the number of opportunities (and associated costs) that lie before us require a thoughtful articulation of space goals and objectives. * Such goals should reflect a broad public consensus, including, but not limited to, those with obvious stake holdings in the space program. Defining these goals maybe essential if the United States hopes to maintain its position of leadership at a reasonable cost. The newly appointed National Commission on Space, which OTA proposed as one option in an earlier report (Civilian Space Policy and Applications), could help to focus the national debate.

Maintaining a space program well integrated with other national objectives will also require attention to the quantity and quality of cooperative international space projects. This report makes clear that the United States must cooperate in space in order to stay competitive.

In the course of this assessment OTA completed two technical memoranda, prepared at the request of congressional committees. UN/SPACE '82: A Context for Cooperation and Competition, was requested by the House Committee on Science and Technology and the Joint Economic Committee. Remote Sensing and the Private Sector: Issues for Discussion was requested by the House Committee on Science and Technology and the House Committee on Government Operations. Some material in this report is discussed in more detail in these technical memoranda. A list of these and other related OTA reports appears on the next page.

In undertaking this assessment, OTA sought the contributions of a wide spectrum of knowledgeable and interested individuals. Some provided information, others reviewed drafts of the report. OTA gratefully acknowledges their contributions of time and intellectual effort.

\footnotetext{
* For an initial suggested list of such goals and objectives, see Civilian Space Stations and the U.S. Future in Space (Washington, DC: U.S. Congress, Office of Technology Assessment, OTA-STI-241, November 1984).

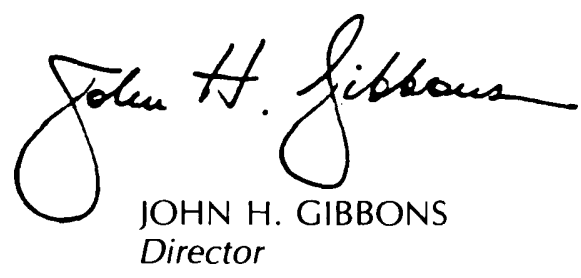




\section{Related OTA Reports}

\section{Civilian Space}

- Civilian Space Stations and the U.S. Future in Space. OTA-STI-241, November 1984. GPO stock \#052 -003-00969-2.

- Civilian Space Policy and Applications. OTA-STI-1 77, June 1982. GPO stock \#052 -003-00878-5.

- Radio frequency Use and Management: Impacts From the World Administrative Radio Conference of 1979. OTA-CIT-1 63, January 1982. GPO stock \#052 -003-O0863-7.

- Solar Power Satellite Systems and Issues. OTA-E-144, August 1981. NTIS order \#PB 82-108846.

Technical Memoranda

- U.S.-Soviet Cooperation in Space. OTA-TM-STI-27 (in press).

- Remote Sensing and the Private Sector: Issues for Discussion. OTA-TM-ISC-20, March 1984. GPO stock \#052 -003-00945-5.

- Salyut: Soviet Steps Toward Permanent Human Presence in Space. OTA-TM-STI-14, December 1983. GPO stock \#052 -003-00937-4.

- UNISPACE '82: A Context for International Cooperation and Competition. OTA-TM-ISC-26, March 1983. GPO stock \#052 -003-00962-5.

- Space Science Research in the United States. OTA-TM-STI-19, September 1982. NTIS order \#PB 83-166512.

\section{Military Space}

- "Anti-Satellite Weapons, Countermeasures, and Arms Control" (scheduled for publication summer 1985)

- "Ballistic Missile Defense Technologies" (scheduled for publication summer 1985).

- Arms Control in Space-Workshop Proceedings. OTA-BP-ISC-28, May 1984. GPO stock \#052 -003-00952-8.

- Directed Energy Missile Defense in Space-Background Paper. OTA-BP-ISC-26, April 1984. GPO stock \#052 -O03-O0948-0.

\section{International Competitiveness}

- Commercial Biotechnology: An International Analysis. OTA-BA-218. January 1984. GPO stock \#052-003-00939-1.

- An Assessment of Maritime Trade and Technology. OTA-O-220, October 1983. GPO stock \#052-003-00931-5.

- U.S. Industrial Competitiveness-A Comparison of Steel, Electronics, and Automobiles. OTA-ISC-1 35, July 1981. NTIS order \#PB 81-235749.

- Technology and Steel Industry Competitiveness. OTA-M-1 22, June 1980. NTIS order \#PB 80-208200.

- International Competitiveness in Electronics. OTA-ISC-200. November 1983. GPO stock \#052-003-00933-1.

NOTE: Reports are available through the US. Government Printing Office, Superintendent of Documents, Washington, DC 2040 783-3238; and the National Technical Information Service, 5285 Port Royal Road, Springfield, VA 22161, (703)487-4650. 
OTA Project Staff on International Cooperation and Competition in Civilian Space Activities

\author{
Lionel S. Johns, Assistant Director, OTA \\ Energy,Materials, and International Security Division \\ Peter Sharfman, International Security and Commerce Program Manager \\ Ray A. Williamson, Project Director \\ Douglas L. Adkins Richard DalBello Jane N. Hut-d* \\ Thomas H. Karas Gordon Law
}

Staff Contributors

$\begin{array}{rrl}\text { Eric Basques } & \text { Philip P. Chandler } & \text { Scott Finer } \\ \text { Darrell McElhaney }^{* *} & \text { Richard Parkinson } & \text { Adam Wasserman }\end{array}$

Contractors

Bert Cowlan Willard Demory Edward Downing Russell Drew Eilene Galloway Jerry Grey Roger Hoffer Roland Inlow Court Lewis

Lee Love Paul Maughan Earl Merritt Resource Development Associates

Edward Risley Donald Wiesnet William Wigton

Administrative Staff

Jannie Coles Dorothy Richroath Jackie Robinson

* In-house contractor,
* *On detail from National Oceanic and Atmospheric Administration 


\title{
Advisory Panel on International Cooperation and Competition in Civilian Space Activities
}

\author{
Paul Doty, Chairman \\ Center for Science and International Affairs \\ Harvard University \\ Benjamin Bova \\ president \\ National Space Institute \\ Robert Evans \\ Principal of Venture Capital \\ Hambrecht \& Quist, Inc. \\ Robert Frosch \\ Vice President \\ General Motors Research Laboratories \\ Eilene Galloway \\ Honorary Director \\ International Institute of Space Law of the \\ International Astronautical Federation \\ Ivan Getting \\ President-Emeritus \\ The Aerospace Corp. \\ Mireille Gerard \\ Administrator, Corporate and International \\ Programs \\ American Institute of Aeronautics and \\ Astronautics \\ Benjamin Huberman \\ Vice President \\ Consultants International Group, Inc. \\ Walter McDougall \\ Associate Professor of History \\ University of California, Berkeley \\ John Mayo \\ Vice President \\ Bell Laboratories \\ John L. McLucas \\ Executive Vice President and Chief Strategic \\ Officer \\ Communications Satellite Corp. \\ Martin Menter \\ Attorney-at-Law \\ Washington, DC \\ Arthur Morrissey \\ Director, Future Systems \\ Martin Marietta Aerospace \\ Fred Raynes \\ Vice President \\ Grumman International Inc. \\ Gary Saxonhouse \\ Professor of Economics \\ University of Michigan \\ Jerome Simonoff \\ Vice President \\ Citicorp Industrial Credit, Inc. \\ Leonard Sussman \\ Executive Director \\ Freedom House \\ John Townsend \\ President \\ Fairchild Space \& Electronics Co. \\ Laurel Wilkening \\ Vice Provost \\ University of Arizona \\ Elizabeth Young \\ Vice President, Marketing and Sales \\ COMSAT General Corp.
}

NOTE: OTA appreciates and is grateful for the valuable assistance and thoughtful critiques provided by these advisory panel members. The views expressed in this OTA report, however, are the sole responsibility of the Office of Technology Assessment.

$v i$ 
Workshop on UNISPACE '82 (Nov. 30, 1982)

Bert Cowlan

International Communications Consultants

Russell C. Drew

Science and Technology Consultants

Wolfram Drewes

World Bank

Eilene Galloway

Vice President

International Institute of Space Law

Jerry Grey

Publisher

Aeronautics and Astronautics
Martin Menter

Attorney at Law

Kenneth Pederson (observer)

National Aeronautics and Space

Administration

Irwin Pikus (Chairman)

National Science Foundation

Charles Schmidt

RCA Astro Electronics

Ambassador Jean Wilkowski

Volunteer International Technical Assistance

Workshop on Remote Sensing and the Private Sector (July 26, 1983)

Kenneth Craib

Resource Development Associates

Russeli C. Drew

Science and Technology Consultants

Robert A. Frosch

General Motors Research Laboratories

Roger Hofer

purdue University

Marvin R. Helter

ERIM

Terry Lehman

ARCO Oil \& Gas Co.

Earl S. Merritt

Earth Satellite Corp.
Arthur Morrissey

Martin Marietta Aerospace

Charles Paul (observer)

U.S. Agency for International Development

Bruce Rado

ERDAS Inc.

Jerome Simonoff

Citicorp Industrial Credit, inc.

Harry Stewart

Strategic Geoscience Applications

SUN, E\&T

Dennis Zimmerman

Congressional Research Service 
Executive Branch Meeting on Remote Sensing (August 18, 1983)

William M. Feldman

U.S. Agency for International Development

Raymond G. Kammer, Jr.

U.S. Department of Commerce

John H. McElroy

National Earth Satellite Service

Kenneth Pederson

National Aeronautics and Space Administration

\author{
Irwin Pikus \\ National Science Foundation \\ Victor H. Reis \\ Office of Science and Technology Policy \\ Lisle Rose \\ U.S. Department of State \\ John Townsend \\ Fairchild Space \& Electronics Co.
}

Workshop on the International Trading Regime for Space-Related Equipment and Services (June 1, 1983)

$\begin{array}{ll}\text { Edwin Barber } & \text { Sanford Rederer } \\ \text { Treasury Department } & \text { Kirth \& Co. } \\ \text { Willard Demory } & \text { Richard Self } \\ \text { Federal Communications Commission } & \text { Office of the United States Trade } \\ \text { Ava Feiner } & \text { Representative } \\ \text { Chamber of Commerce of the United States } & \text { John Suomela } \\ & \text { International Trade Commission }\end{array}$




\section{Acknowledgments}

The following individuals contributed to this study in a variety of ways. OTA is grateful for their assistance:

\author{
James Ball \\ James Baker \\ Nadine Binger \\ William Bishop \\ Denise Bletsos \\ Kate Bonner \\ Jane Bortnick \\ Daniel Brandel \\ Darrell Branscome \\ Tom Bruce \\ Radford Byerly \\ Charles Chafer \\ Barbara Cherry \\ Stuart Chiron \\ Lynne Cline \\ John Coles \\ John Coruthers \\ Anthony Cox \\ Raymond Crowell \\ Terry Dawson \\ James Dougherty \\ Fred Doyle \\ Robert Duffy \\ Otho Eskin \\ Steven Flasjer \\ Donna Fossum \\ Sybil Francis \\ Roy Gamse \\ Marc Giget \\ Isaac Gillam \\ Robert Gosse \\ Richard Halpern
}

\author{
Peter Hambling \\ Larry Heacock \\ Douglas Heydon \\ Ken Hodgkins \\ Glen Horning \\ Pat Humphlett \\ Peter Johnson \\ Diana Josephson \\ Daniel Kevin \\ Mark Kieffer \\ Martin Kress \\ Chester Lee \\ Kenneth W. Leeson \\ George Li \\ John Logdson \\ William Lovell \\ Mark McCarthy \\ James Mahoney \\ T. Allen McArtor \\ Wally McClure \\ Mark McCarthy \\ John McElroy \\ Thomas McNight \\ Ahmed Meer \\ Charles Miller \\ Walter Morgan \\ James Morrison \\ George Ojalehto \\ Richard O'Rorke \\ Jack Osland \\ Scott Pace \\ Robert Palmer
}

OTA wishes to acknowledge the contributions of the following organizations and Government agencies for their generous assistance:

Agency for International Development American Telephone and Telegraph

Arianespace, Inc.

Communications Center

COMSAT Corp.

Congressional Research Service

Embassy of the Federal Republic of Germany

Embassy of France

Embassy of Great Britain

Export-Import Bank

Federal Communications Commission

General Accounting Office

General Dynamics

GTE International Systems Corp.

IN MARSAT

INTELSAT

International Trade Administration

$\mathrm{MCl}$ Communications Corp.
National Aeronautics and Space Administration National Oceanic and Atmospheric Administration

National Space Development Agency of Japan National Telecommunications and Information Administration

Orbital Sciences Corp.

Orion Satellite Corp.

Rockwell International

SPOT Image Corp.

Department of State

Texas Instruments

TransSpace Carriers Inc.

United Nations Committee on the Peaceful

Uses of Outer Space

Walter Hinchman Associates, Inc.

World Bank 


\section{Contents}

Chapter Page

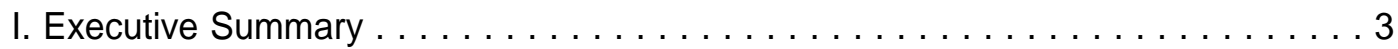

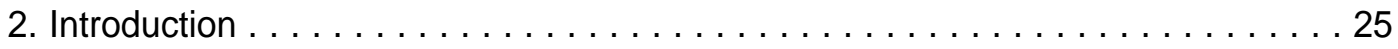

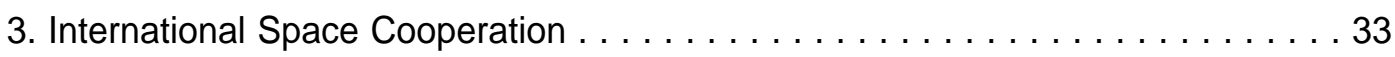

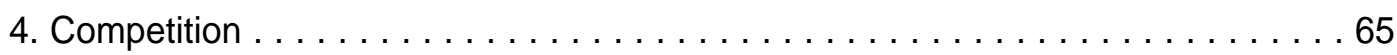

5. Space Transportation . . . . . . . . . . . . . . . . . . . . . . . . . 103

6. Satellite Communications. . . . . . . . . . . . . . . . . ................147

7. Remote Sensing From Space . . . . . . . . . . . . . . . . . . ...........253

8. Materials Processing in Space . . . . . . . . . . . . . . . . . . . . ....337

9. Space Science . . . . . . . . . . . . . . . . . . . . . . . . . . .

10. Policy Alternatives . . . . . . . . . . . . . . . . . . . . . . . . . . . . ....397

Appendix A: Search and Rescue Satellites . . . . . . . . . . . . . . . . . . . . 423

Appendix B: Alternative Forms ofIndustry Organization in the United States ..425

Appendix C: Public Law 98-365-July 17, $1984 \ldots, \ldots \ldots \ldots \ldots \ldots \ldots 429$

Appendix D: Public Law 98-575-Oct. 30, 1984 . . . . . . . . . . . . . . . .....446

Appendix E: Glossary of Acronyms . . . . . . . . . . . . . . . . . . ....456

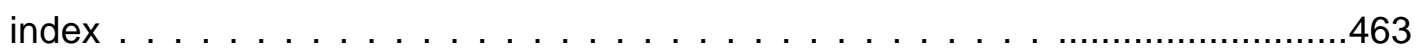


Chapter 1

EXECUTIVE SUMMARY 


\section{Contents}

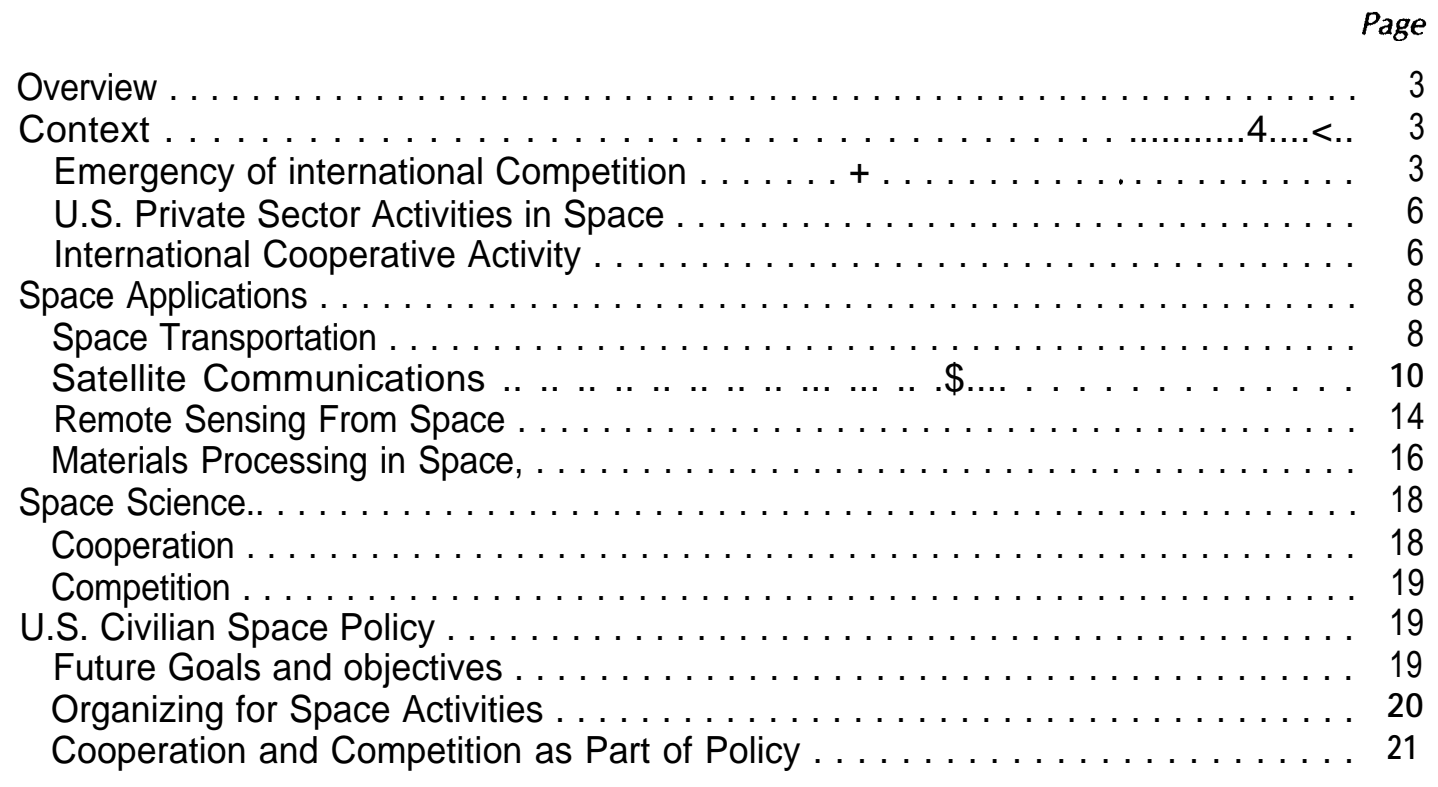




\section{Chapter 1 \\ EXECUTIVE SUMMARY}

\section{OVERVIEW}

The United States has lost its monopoly in Western space technology and operations; over the past decade, Europe and Japan have developed the means to compete as providers of space-related goods and services. At the same time, major U.S. firms have expanded their interest and investment in the commercial applications of the technologies of outer space. Both developments affect the ways that nations now cooperate in space. Unfortunately, U.S. policies have not adapted fully to the effects of increased foreign competition, nor, outside of satellite telecommunications, has the United States developed ways to involve its private sector effectively in applications of space technology. Moreover, it is less and less appropriate to make "space policy" in isolation from the broader agenda of domestic and international commerce and foreign affairs.

Alterations in the political, economic, and technical context of space activities raise four major international concerns for Congress: the state of U.S. competitiveness in space technologies, the role of the U.S. private sector in space, the access of U.S. firms to international markets, and the efficacy of U.S. participation in international cooperative space projects and organizations. Because of these concerns, and because of their interest in developing policies to enhance the overall scientific, technological, and economic strength of the United States, the House Committee on Science and Technology and the Joint Economic Committee requested this assessment.

The report assesses the state of international competition in civilian space activities, explores
U.S. civilian objectives in space, and suggests alternative options for enhancing the overall U.S. position in space technologies and space science. It also investigates past, present, and projected international cooperative arrangements for space activities and examines their relationship to competition in space. In keeping with the international focus of this assessment, the report discusses the relationship between space policy and foreign policy. It analyzes domestic policy issues only insofar as they affect our ability to sell goods and services abroad or to cooperate effectively with other nations. It does not assess policies related to the military and intelligence space programs except to the extent that they affect international civilian activities in space".

The executive summary of this report was pub lished as a separate document in July 1984. However, the chapters of this nprt are up to date as of May 1, 1985. Since July 1984, several issues identified in the summary as needing policy attention have been addressed by Congress and the Administration, at least in part. In order to preserve the integrity of the separately published summary, we have updated it by printing changes in boxes set \#@@from the original text. Any other additions or corrections are identified by being set in brackets. In all other resped\& this summary is identical to that published in July 1984.

\section{CONTEXT}

\section{Emergence of International Competition}

Although the U.S. civilian space program remains the benchmark by which other non-Communist nations judge the progress of their own space programs, Japan and the Western European space powers (especially France) are now able to compete with the United States in supplying some space-related goods and services. Other countries, notably the Soviet Union, Canada, India, Peoples Republic of China, and Brazil, produce space 


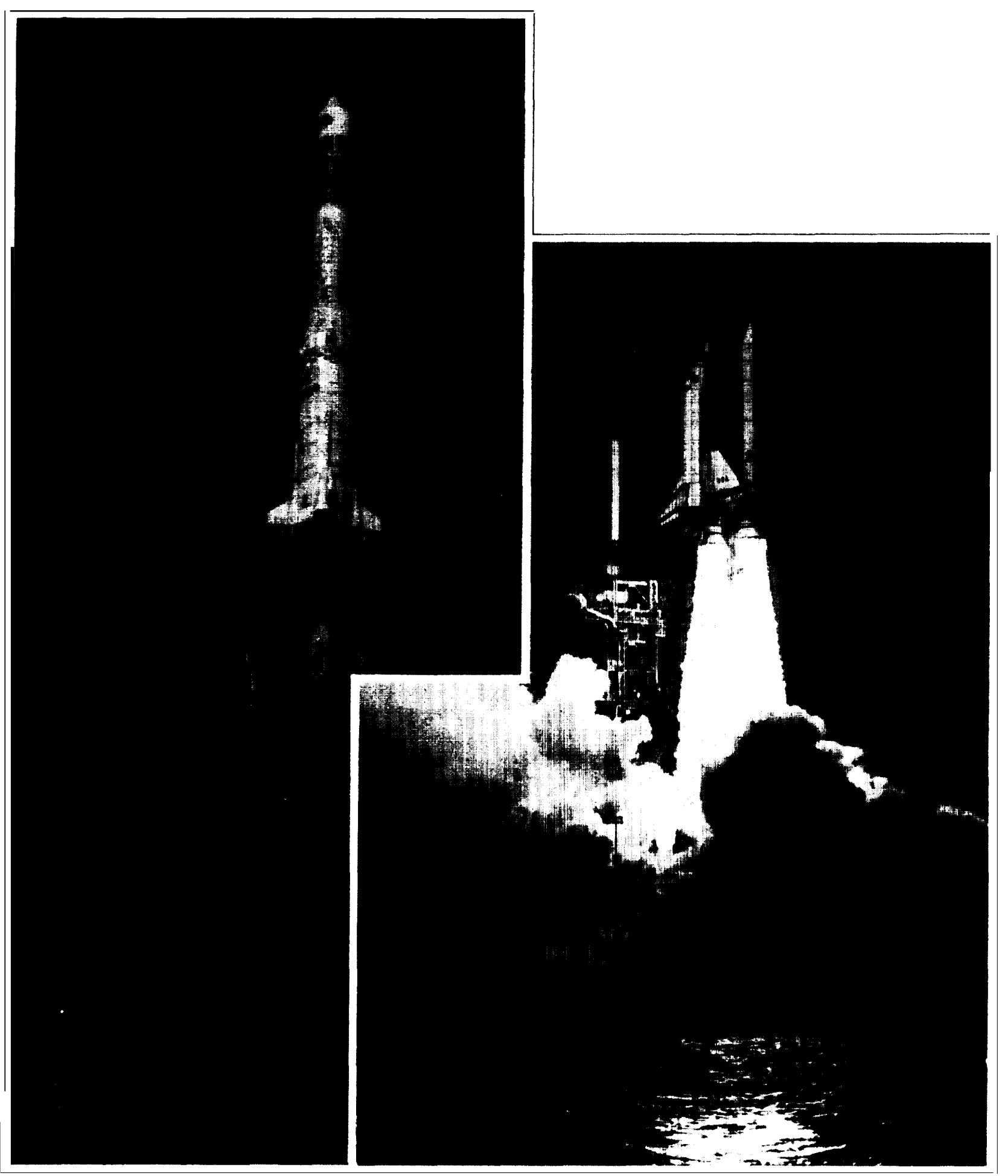

Photo credits: European Space Agency, complements of National Aeronautics and Space Administration

Launch of Ariane (left), developed by the European Space Agency and marketed by

the French corporation Arianespace, S. A. Launch of Space Shuttle

Columbia (right), Nov. 28, 1983, carrying the European-developed Spacelab 
items but do not participate [extensively]l in the international export market. Most space-capable nations have sought to use their space assets as political instruments for cementing ties with friends and allies and for winning new friends and influence in the developing world.

Space-related international commerce is likely to increase in the next decade, but, except for satellite communications, will continue to be shaped more by the political, military, and economic interests of national governments than by market developments. In the satellite communications sector, which has become part of the larger telecommunications industry, technology-driven market developments are forcing governments to change their regulatory structures.

The emergence of foreign competition presents both a challenge and an opportunity to the United States. The European Space Agency (ESA), which pools the space interests and the financial and industrial resources of several European countries, is an important vehicle for developing European competitive ability in space-related commerce. Its largest single project, the Ariane expendable launch vehicle (ELV), built under French leadership, now competes directly with U.S. launch services. ESA'S second largest project, the Spacelab, built under West German leadership, has increased European cooperation with the United States in activities involving humans in space. It has also assisted West Germany to gain important expertise in building space habitats, thereby helping to set the stage for possible later competition with the United States.

Outside of the ESA framework, the French Government has established and promoted particular space businesses (launch services and remote sensing) that compete in the world market. West Germany, as well as France, and to a lesser extent, the United Kingdom and Italy, invest in space activities for more general purposes: to conduct basic scientific research; to enhance the technological capabilities of national industries; to realize some of the technological and economic benefits of space applications; and to develop

\footnotetext{
' [Th is is beginning to change. Canada, for example, had more than $\$ 300$ million in export contracts in 1984. The Soviet Union and China have offered to sell space transportation services. ]
}

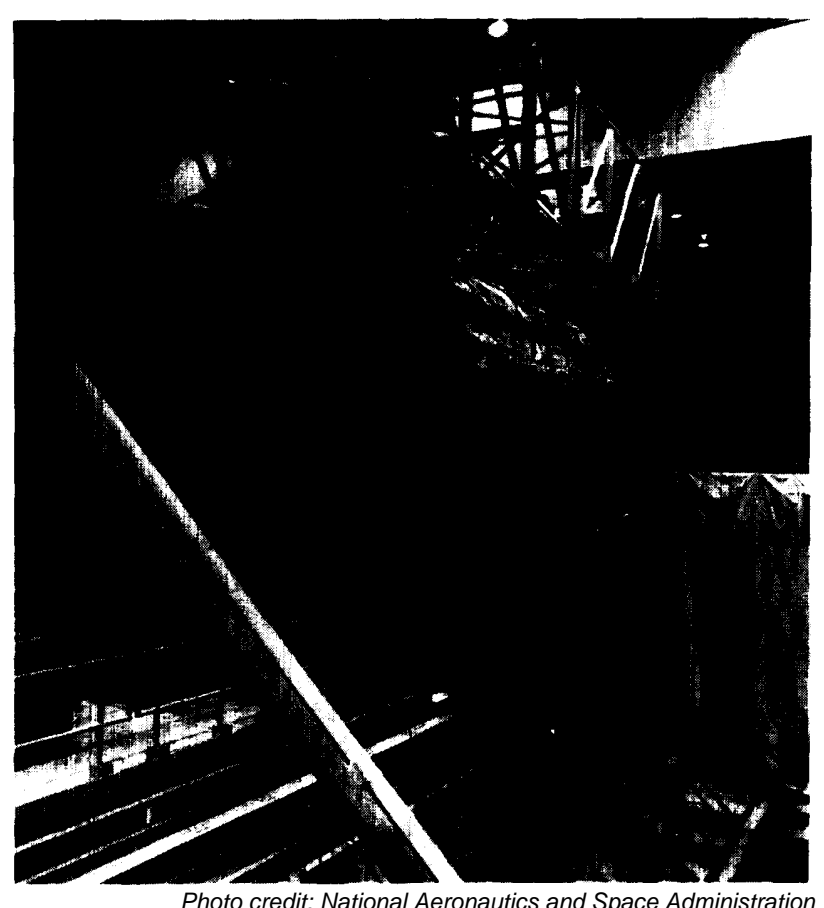

The European-built Spacelab-1 module and attached pallet being prepared for installation in the cargo bay of the space shuttle orbiter Columbia, Aug. 16, 1983

space-related equipment industries. European governments are developing their space-related industry behind protectionist barriers where buynational government procurement is the rule. A number of European firms are now able to participate in international space markets.

Like the other space powers, Japan has assumed that a government space program will ultimately contribute to national economic wellbeing. It has not specifically identified space industries as "targeted" for special emphasis in export competition; instead it seems to be aiming to create a sizable space-related industry increasingly independent of U.S. technology and equipment. Although they now compete internationally only in electronics components and ground stations, Japanese firms will be well positioned to become major competitors in international markets for space-related equipment and services by the early 1990s. Under internal and U.S. pressures, Japan has recently opened its market to a limited degree to U.S. suppliers of satellites and telecommunications equipment. 
Although the Soviet Union has the technological potential to compete with other countries for commercial services, space competition between the United States and the Soviet Union will continue to be more political and military than economic. Both nations today spend more on military than on civilian activities in space and make heavy use of space for purposes of geodesy, navigation, weather forecasting, reconnaissance, missile-launch warning, and communications. They are beginning to compete in developing weapons for use in space.

In space-related equipment and some service markets, international commercial competition outside of the European and Japanese markets occurs in countries like Brazil, India, and Australia, which desire to develop domestic satellite communications, and in INTELSAT and INMARSAT, ${ }^{2}$ but the largest market where substantial open competition in sales of equipment takes place is the U.S. domestic market. U.S. firms continue to dominate both markets, although Japanese groundequipment sales have been substantial in developing countries,

In satellite communications services, international competition is currently almost nonexistent, except to a limited extent in North America. Carriers typically must hand off communications at foreign borders or at the geostationary orbit, and are not allowed to sell full international services to consumers. In addition, INTELSAT has monopoly ownership of intercontinental satellite communications facilities, but major U.S. carriers and other firms are challenging this international regulatory management.

\section{U.S. Private Sector Activities in Space}

Some of the largest U.S. corporations are now heavily involved in space-related activities, especially satellite communications. Other firms are beginning to invest in developing their own space transportation, remote sensing, and materials processing systems. Many corporations derive sig-

INNTELSAT is a 108 [now 109]-country organization carrying twothirds of the world's international communications. INMARSAT is a 37 [now 42]-country organization which was established in 1979 to facilitate maritime communications across the world's shipping lanes. COMSAT Corp. has been designated by the U.S. Government to serve as the U.S. representative to both organizations. nificant revenues from producing specialized space-related equipment.

However, except for satellite communications, significant barriers of high cost and high technological and economic risk continue to deter investment. In space transportation and remote sensing, competition from U.S. Government-operated systems is a significant impediment. Nevertheless, fueled by technological advances and Government policy, the trend is toward more U.S. private investment in space systems. If current trends continue, there will be a wide array of privately financed space activities by the mid-199os.

One continuing difficult task facing the U.S. Government will be to foster, in concert with the private sector, an efficient transition from the current preponderance of Government investment in civilian space activities to greater private sector investment in the 1990s. Such a transition occurred easily in satellite communications, because the demand for telecommunication services was already established and satellite circuits were an immediate cost-effective way to accomplish what was already being done on Earth. In new technology sectors, with small and uncertain demand, and little institutional infrastructure, the process of transition is likely to be difficult and highly specific to the sector. The process will require periodic attention from Congress. In these sectors, Government may be able to foster effective transitions by orienting its research and development (R\&D) activities toward realistically evaluated market demand and by involving industry early in the process. One such strategy is the National Aeronautics and Space Administration's (NASA) Joint Endeavor Agreement (JEA), through which the private sector is encouraged to share costs with NASA on projects having significant research objectives and potential commercial application.

\section{International Cooperative Activity}

Space is by nature and treaty an international realm. The United States has played the leading role in international cooperative activities by sharing the fruits of its research with developing countries, assisting other industrialized nations develop their own space capabilities, and by helping to establish the international legal regime in space. 
U.S. cooperative space projects continue to serve important political goals of supporting global economic growth and open access to information, and increasing U.S. prestige by expanding the visibility of U.S. technological accomplishments. U.S. noncommercial international space projects have been managed principally by NASA, and aided by the National Oceanic and Atmospheric Administration (NOAA) and the Agency for International Development (AI D). These projects also support U.S. economic, scientific, and technological goals of obtaining access to countries for tracking stations and ground-receiving stations, influencing the space programs of other countries, and expanding research opportunities for U.S. scientists by sharing costs with other countries.

The examples of INTELSAT and INMARSAT, two commercially successful international cooperative organizations, illustrate that countries with political differences can cooperate to pursue common social, political, and economic goals in space. I NTELSAT, in particular, by establishing new communications links and using advanced technology, has served an expanding international market for telecommunications and services. It has been a large buyer of U.S. satellites.

Until recently, the United States had a virtual monopoly on the conduct of cooperative international programs in space (at least in the West). Now, in part because of the very success of U.S. efforts to involve the international community, other nations-especially Japan and some European nations-have developed their own bilateral cooperative programs. The Soviet Union continues to expand its international cooperative relationships in science and space applications. As a result of these circumstances, the United States is now one of several potential partners in cooperative space projects.

Developing countries will continue to depend on the United States and other industrialized nations for help in expanding their own capacity to use and develop space technology. If the United States wishes to reap the full economic and political benefits of its space program, its cooperative applications program must continue to involve the developing countries, especially because they are beginning to represent a significant market for space-related goods and services.

The United States participates in various international organizations and meetings on space. Improved U.S. preparation for these international forums could result in more favorable treatment of U.S. interests and concerns. U.S. experience at UN I SPACE ' $82^{3}$ and the International Telecommunication Union (ITU) Plenipotentiary ${ }^{4}$ demonstrated that such improvements will require longterm domestic policy goals for outer space; more effective coordination among U.S. agencies and the private sector; greater continuity of personnel; and recognition that our critics may also represent important future markets. The series of ITU meetings in the 1980s and 1990s, including ORB'85 on the geostationary orbit, will present occasions where U.S. policy will be tested.

The United States has signed agreements with Canada, Japan, and ESA to cooperate in the designphase (phase B) of NASA's space station program. Each country will assume its own cost for this and subsequent phases. The terms of Cooperation in the international development and operation of elements of permanent space infrastructure will require careful attention by Congress to ensure that the United States achieves its goals in international cooperation.

\footnotetext{
'See UNISPACE'82: A Context for Cooperation and Competition-A Technical Memorandum, OTA-TM-ISC-26 (Washington, DC: U.S. Congress, Office of Technology Assessment, March 1983).

${ }^{4}$ The ITU Plenipotentiary Conference was held in Nairobi in September 1982. See hearings before the Subcommittee on International Operations of the U.S. House Committee on Foreign Affairs, Feb. 22, 1983.
} 


\section{SPACE APPLICATIONS}

OTA examined a range of space technologies. Each is at a different stage of commercial development or Government operational status. Each therefore presents a different set of potential opportunities.

\section{Space Transportation}

The emergence of competition from foreign and U.S. private sellers of launch services requires a reassessment of the U.S. Government's traditional role as a provider of launch services to commercial interests. The Government must examine whether and how it should continue to use the Shuttle in competing for foreign and domestic commercial launches.

The entry of ESA's Ariane booster into the international launch vehicle market brought an end to NASA's monopoly in providing space transportation services to commercial entities and foreign governments. Eventually Japan will also be able to offer competitive commercial launch services; still other nations are developing their own means to launch payloads. In some respects, national launch vehicle programs can be compared to national airlines: some are conducted primarily for profit, while others play a role which is clearly linked to perceptions of "prestige" and "national self-image." For these reasons, U.S. competitive strategies based on price or superior technology alone will not prevent foreign entry into the launch services business. Nations that possess the commitment and the minimum economic and technical resources necessary to develop launch systems will take some share of the total world market.

Although there are a number of potential entrants, launch service competition for the next decade is likely to be primarily between NASA, operating the Shuttle, and Arianespace, S. A., the French corporations which markets the Ariane. Both systems use technology developed by governments and compete primarily for the launch of large geosynchronous communication satellites.

${ }^{5}$ [The French Government owns (through CNES) 34 percent of Arianespace. The balance is owned by European banks and aerospace firms.]
The Shuttle, although technically more sophisticated than the Ariane, has no special advantage in this market. In addition, several U.S. private firms are competing in offering launch services.

A large percentage of potential launch business will undoubtedly be removed from international competition. For instance, with few exceptions, neither the U.S. Government nor the Japanese or European governments are expected to make launch procurement decisions under competitive international bidding. Such restrictive trade practices could be altered by international agreement in the distant future; in the near future, however, it is unlikely that there will be effective coverage of launch services under either government-procurement or trade-in-services agreements.

Much of the competitive part of the market will consist of private U.S. communications carriers putting up U.S. domestic satellites, INTELSAT, INMARSAT, and a few countries will also purchase satellite launching services competitively. Customers will base their choice on price (including the cost of financing), the reliability of launch and schedule, the relative ease of planning and processing payloads, the cost of insurance, and the availability of coproduction and other offsets. As with all large international contracts, political considerations will undoubtedly play a role.

The Administration policy on launch vehicle commercialization is ambiguous. On May 16, 1983, President Reagan announced that the U.S. Government fully endorsed and would facilitate the commercial operation of ELVs by the private sector. ${ }^{6}$ However, the President also stated that the Shuttle is the "primary launch vehicle of the U.S. Government" and that it would continue to be available for domestic and foreign commercial users. The President's policy encourages "free market competition among the various systems and concepts within the U.S. private sector," yet leaves the Government-subsidized Shuttle as the main competitor to the private sector's efforts to market ELV services.

\footnotetext{
6The Titan, the Atlas-Centaur and the Delta launch vehicles have all been the target of efforts to commercialize existing ELVs. Other smaller, private expendable launch vehicles are in development.
} 


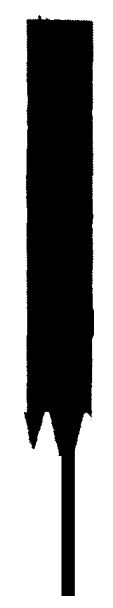

$\%$

Delta 3920 U.S.A.

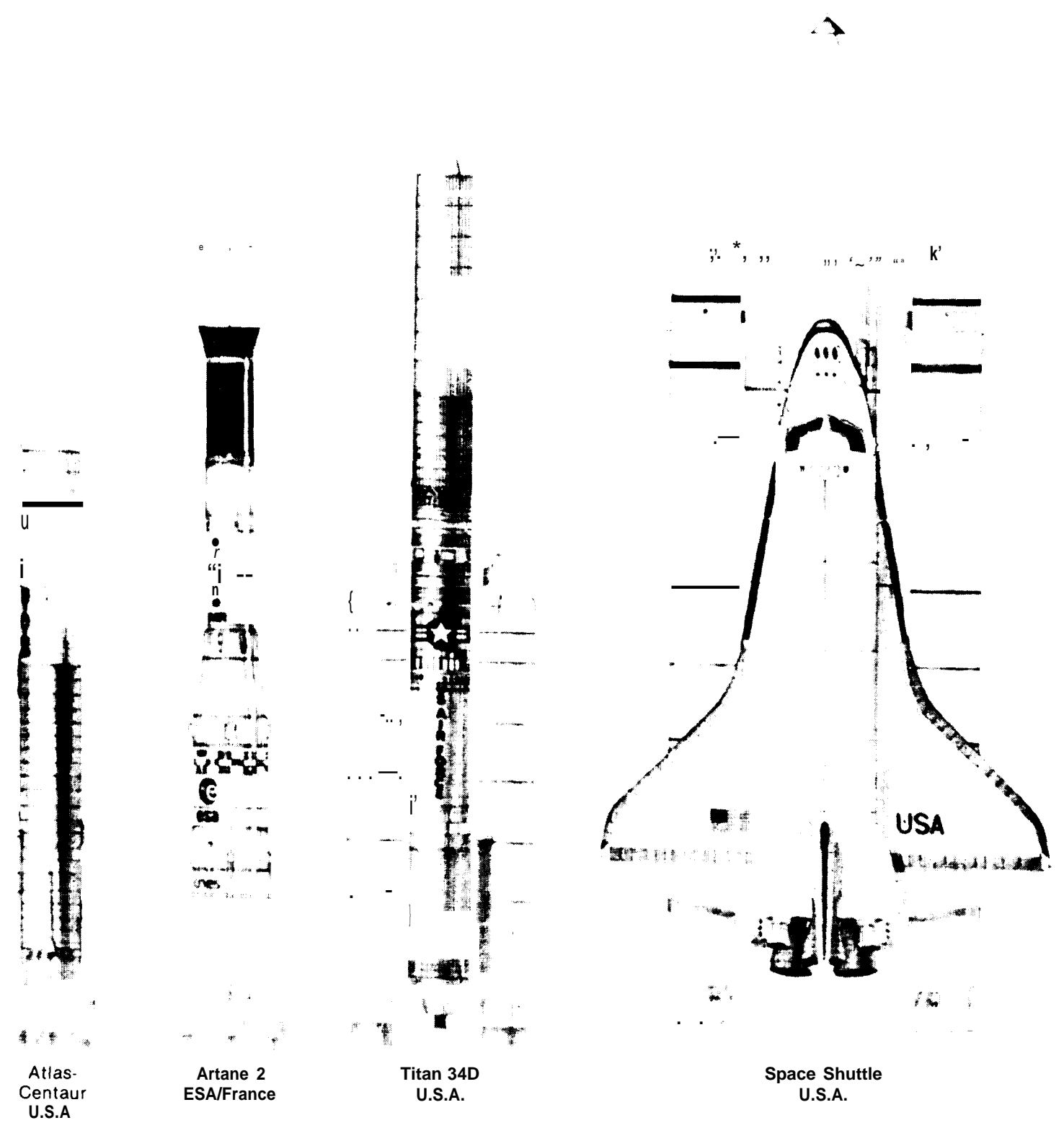

Photo credit: National Aeronautics and Space Administration

Current competition in space launching services from Earth to orbit is between these five launchers

Current Shuttle prices were developed to encourage users to transfer their business from the trusted ELVs, then operated by the Government, to the Shuttle. According to NASA, launch prices for the 1986-88 period will be based on the "outof-pocket" costs, that is, those costs which a commercial payload adds to a mission on the assumption that it would otherwise fly partially empty when carrying a Government payload. Current and projected pricing policies for commercial payloads allow the Shuttle to compete with Ariane's prices while earning some revenue and supporting other important national space goals; however, these policies decrease the probability that U.S. private firms will be economically successful in providing competitive launch services. 
The United States can meet the challenge of competitive foreign launch services by favoring either the Shuttle or private ELVs for commercial payloads. If the demand for launch services were to increase dramatically, both kinds of vehicles might successfully offer commercial launch services; but since a dramatic increase seems unlikely in the 1980s, the United States must choose which course it intends to follow.

Continuing to favor the Shuttle, by pricing policy or by other means, would reinforce its status as the centerpiece of the U.S. space program and support the pursuit of other long-term space goals such as building space stations, encouraging the development of manufacturing in space, and investigating new military space technologies. Such a decision would likely increase the cost to the taxpayer of the U.S. space program if it leads to additional subsidized Shuttle flights.

In order to spur the growth of an internationally competitive, private ELV industry, it would probably be necessary to limit the Shuttle primarily to Government launches or to increase the price of commercial Shuttle flights substantially. Additional support might be given to fledgling launch companies in the way of low-price access to Government launch facilities, assured launches (e.g., the Air Force's recent desire to purchase 10 ELVS), and a regulatory environment conducive to private investment.

Allowing commercial ELV firms to compete profitably might result in the emergence of a thriving, mature private space transportation industry in the United States by the 1990s. Because the Ariane and U.S. ELVs have comparable capabilities, such a decision might also allow the Government-subsidized Ariane to capture a larger portion of the international launch market than it would if it were competing against the subsidized Shuttle.

\footnotetext{
'Relatively powerful trade remedies for unfair foreign competition against U.S. goods and services are available to the Government. Recently, for example, Transpace Carriers, Inc., the company seeking to commercialize the Delta launcher, applied to the President to prohibit Arianespace from marketing its services in the United States and to penalize U.S. imports from the countries subsidizing Arianespace, S. A., under Section 301 of the Trade Act of 1974.
}

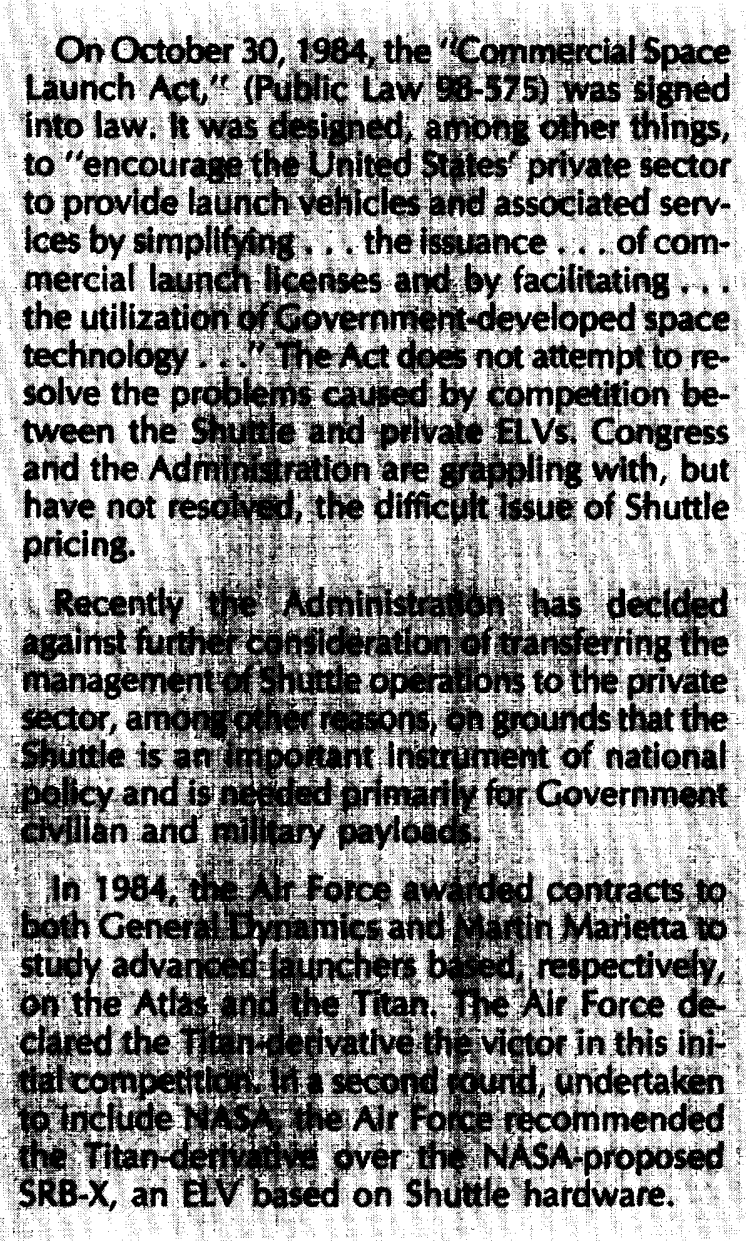

\section{Satellite Communications}

Unlike other technologies discussed in this report, satellite communications technology has passed from Government-dominated investment to commercial status. Civilian satellite communications is now fully established within the overall telecommunications industry.

\section{Competition in International Satellite Communication Services}

In the United States, increasing numbers of satellite communications service providers, and types of services, have forced examination of the structure of the international satellite communications industry. In particular, several U.S. communications corporations have recently applied 
for authority from the Federal Communications Commission (FCC) to launch satellites to provide transatlantic satellite communications services. The United States must soon decide whether it wishes to continue its past support of INTELSAT as the only provider of intercontinental satellite communications facilities or whether it will permit U.S. firms to launch independent and/or competitive satellites. Preventing U.S. firms from owning independent international satellite facilities would close off certain potentially profitable opportunities to them. But INTELSAT's monopoly status is strongly supported by many other governments. The United States must therefore weigh the interests of the U.S. private sector against other foreign policy objectives and existing international agreements.

In November 1984, the Administration endorsed U.S. private transatlantic satellite systems as "required" in the national interest but it also circumscribed their ability to compete with INTELSAT. The matter is currently the subject of a proceeding at the Federal Communications Commission (FCC). It is not yet clear how vigorously the Administration might support private U.S. applicants, nor what competing foreign commercial systems may be proposed. The INTELSAT Assembly of Parties meeting in January 1985 coordinated a significant additional number of U.S and Canadian satellites offering limited transborder satellite services for the developing Western Hemisphere regional system of independent satellite operators. Most of these services have now received final FCC approval.

The Government must also decide how vigorously to negotiate with other countries to advance the interests of its consumers and producers in other areas of international trade in satellite telecommunications services. Regulatory regimes in other countries prevent private carriers from competing freely in international communications service markets. Other nations typically require that communications reaching their territories be handled by their governmental tele-

${ }^{8}$ Although [almost] all commercial intercontinental satellite traffic must pass through INTELSAT, regional systems provide limited international services in the regions they serve. communications monopolies and accept traffic only from designated U.S. carriers in each market segment. Among the alternatives are: 1) bilateral negotiations with individual countries with the short-term objective of access for additional U.S. carriers; and 2) longer term multilateral negotiations on a general $\mathrm{GATT}^{9}$ code on trade-in services.

All of the foregoing has resulted in a situation where U.S. consumers have fewer price-service options in international than in domestic telecommunications markets. Moves toward freer international competition would be consistent with domestic steps toward deregulation and with recent U.S. efforts to secure fairer international trade.

\section{Demand for Satellite \\ Communications Services}

Demand for all international telecommunications services is now probably increasing at 10 percent or more per year. Within this, demand for satellite communications services is also increasing rapidly, but whether its growth will continue through the 1990s is highly uncertain. Satellite services will continue to dominate longdistance international communications at least until 1988, when the first transatlantic fiber-optic cable is scheduled for operation. In the 1990s, annual growth in the demand for international satellite communications services could range from zero to a rate equal to the growth of international communications as a whole, depending on the relative shares of satellites and fiber-optic cables. The shares of satellites and cables will depend in turn on consumer preferences, business incentives, industry structure, and above all, on regulatory decisions. It is unlikely that the total demand for international satellite communications will decline during the 1990s.

\section{Competition in Satellite Communications Equipment Market}

U.S. satellite communications equipment firms continue to dominate the relatively open international markets, including the U.S. domestic market. However, access by U.S. producers of

\footnotetext{
Generdl Agreement on Tariffs and Trade.
} 


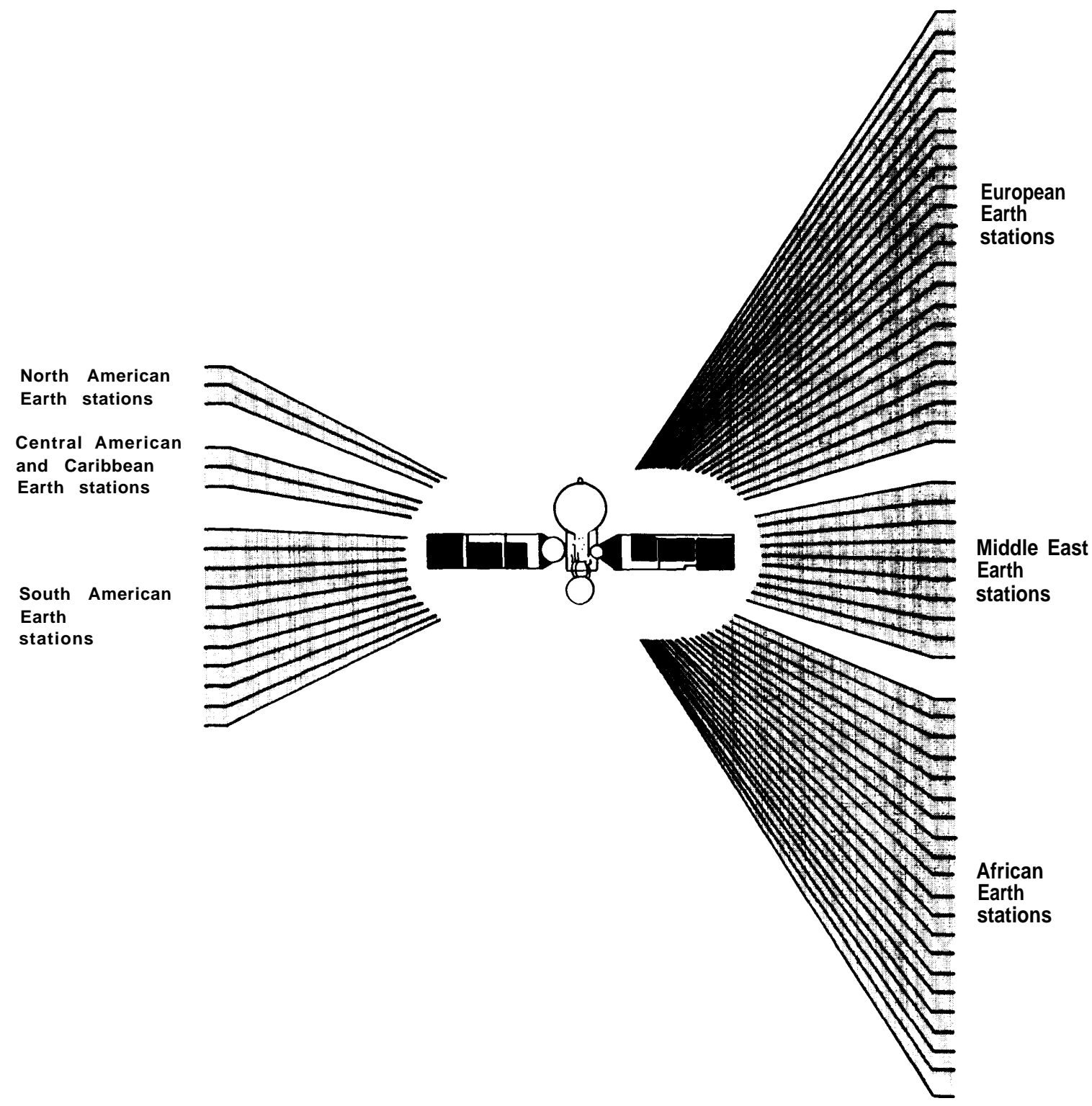

This is one of three INTELSAT communications satellites stationed over the Atlantic Ocean. INTELSAT'S two other Atlantic Ocean satellites, Major Path I $\left(325.5^{\circ} \mathrm{E}\right)$ and Major Path $2\left(341.5^{\circ} \mathrm{E}\right)$, have similar configurations.

SOURCE: National Aeronautics and Space Administration.

satellites and other satellite communications equipment to most industrial country markets is restricted by "buy national" policies on the part of post, telephone, and telegraph agencies (PTTs) or consortiums of PTTs, who are the primary purchasers of such equipment. Most governments purposely excluded their PTTs from coverage under the GATT code on government procure- ment, and thus mu tilateral trade remedies are not available.

Some bilateral progress has recently been made on opening up the Japanese communications satellite equipment market to U.S. suppliers, but European markets remain tightly protected. Meanwhile, deregulatory and antitrust actions in 
the U.S. domestic long-distance telecommunications market have opened up the U.S. equipment market to international competitors. Consequently, foreign communications equipment manufacturers have greater access to the U.S. market than U.S. sellers have to theirs.

\section{Advanced $R \& D$}

Although some level of Government R\&D funding may be necessary to maintain the competitiveness of the U.S. satellite communications equipment industry, Congress must determine how much is appropriate. Increasing congestion in the geostationary orbit over the Western Hemisphere for satellites using frequencies in the Cband $(6 / 4 \mathrm{GHz})$ and $\mathrm{Ku}$-band $(14 / 12 \mathrm{GHz})$ may create a market opportunity for Ka-band (30/20 $\mathrm{GHz}$ ) satellites in the 1990s. This opportunity, along with potential competition from foreign satellite system manufacturers, has led to the NASA Advanced Communications Technology Satellite (ACTS) program, which would develop a Ka-band system. ACTS components would be more advanced than Ka-band technology under development in Europe or Japan: ${ }^{10}$ some aspects of ACTS technology would also be applicable in satellites operating in the $\mathrm{C}$ - and Ku-bands.

Some satellites operating in the Ka-band may well be launched in the late 1980s, Hughes Aircraft Co. has already applied for permission to launch two. As planned, they would also be less advanced than the proposed ACTS system, but Hughes questions whether an ACTS-type system would be commercially viable. Depending on its perception of the threat of subsidized foreign competition and the capabilities of the U.S. private sector to meet it, Congress could: 1 ) continue to fund the full ACTS program through the flight testing stage, 2) fund only minimal communications satellite research, or 3) fund only that part of the ACTS research that can be carried out on the ground or in small-scale Shuttle experiments (on the assumption that the private sector will finance spacecraft tests of commercially viable innovations or that spacecraft tests could be postponed until foreign plans were clearer).

\footnotetext{
${ }^{10}[$ Two Ka-band satellites were launched by Japan in 1983. This year it expects to launch a third.]
}

Participation in the International

Telecommunication Union

Because most of the communications satellites over the Western Hemisphere belong to U.S. private firms or the Government, the United States has an interest in protecting the current method of allocating slots in this hemisphere's portion of the geosynchronous orbit. Slots are now registered by the International Telecommunication Union (ITU) according to a policy of "first-come, first served." * However, many countries of Central and South America, along with other developing countries, espouse the principle of a priori allotments, whereby countries would be assigned slots in advance of actual need.

The ITU has called the 1985-88 World Administrative Radio Conference ("Space WARC") to consider international arrangements for planning and implementing the use of communications satellites in the geosynchronous orbit. (The particular meeting which will do so in 1985 is known as ORB'85.) If the United States faced a limited allotment of geosynchronous slots, it would be obliged to deploy substitute capacity in the Kaband or in fiber-optic cables, presumably incurring additional costs.I'One such cost might be the premature obsolescence of certain $\mathrm{C}$ - and $\mathrm{Ku}$ band ground equipment. If $\mathrm{C}$ - and $\mathrm{Ku}$-band slots had to be rented from countries to which they had been assigned a priori, such rents would also be an extra cost to U.S. consumers of satellite communications. Participation in ORB'85 will require careful planning and coordination among several U.S. Government agencies and the private sector. An isolated, combative stance in ORB'85 on the part of the United States against a priori planning could lead to difficulties in solving other international telecommunications issues. In particular, ill-considered U.S. actions that disrupted the ITU's decisionmaking processes could lead to changes in international arrangements for allocating and assigning frequencies to civilian and military communications in general.

\footnotetext{
*[This does not, however, entitle the country or the private firm to retain the geostationary slot indefinitely. See ch. 6.]

"[This supposes that the $\mathrm{C}$ and $\mathrm{Ku}$ bands would be saturated, under given orbital spacing. If not, substitute capacity would not be required. Large amounts of domestic fiber optic cable capacity will be installed in the 1990s, in any case.]
} 


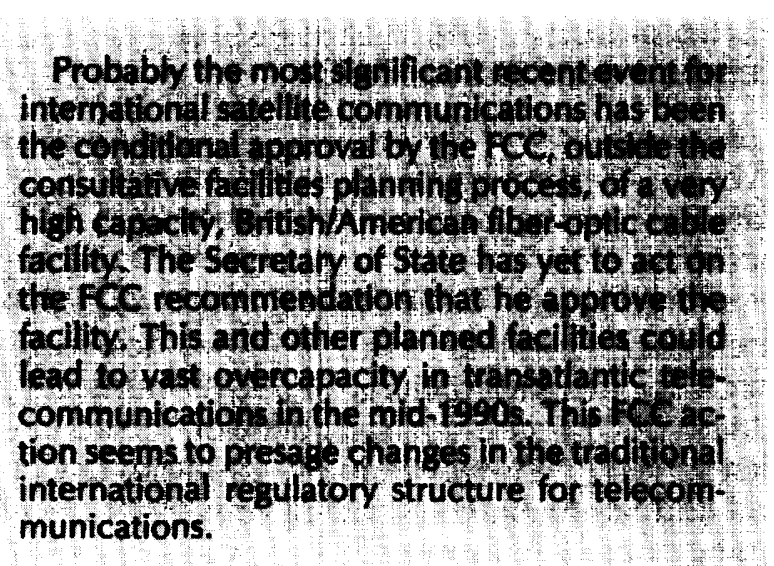

Remote Sensing From Space

\section{Land Remote Sensing ${ }^{12}$}

The U.S. Landsat system is currently the only civilian land remote sensing system from which worldwide data are available. By 1990, several other countries, including Canada, France, Japan, and perhaps the Soviet Union, expect to deploy competing systems to sense the oceans and the land. France is treating its Systeme Probetoire d'Observation de la Terre (SPOT) as a commercial enterprise and has organized to market Earth resources data when the system becomes operational in 1985.

NASA developed the Landsat system and managed it as an R\&D project until January 1983; Landsat is now managed by NOAA as a Government operational system. Landsat 5, launched in March 1984, is expected to be the last in the Government's Landsat series. Although NASA and NOAA will continue advanced research on new sensors and data processing techniques, using the Shuttle to test new methods, the Administration and Congress are now moving to transfer the operation of land remote sensing to the private sector.

Although the small size of the present market for Landsat data and consequent high economic risk' ${ }^{13}$ stand as major impediments to full commer-

\footnotetext{
'See also Remote Sensing and the Private Sector: Issues for Discussion-A Technical Memorandum, OTA-TM-ISC-20 (Washington, DC: U.S. Congress, Office of Technology Assessment, March 1984). ${ }^{13}$ The current annual market for Landsat data is about $\$ 10$ million. Satellite capital costs (for a 5-year lifetime) are likely to be greater than $\$ 100$ million.
}

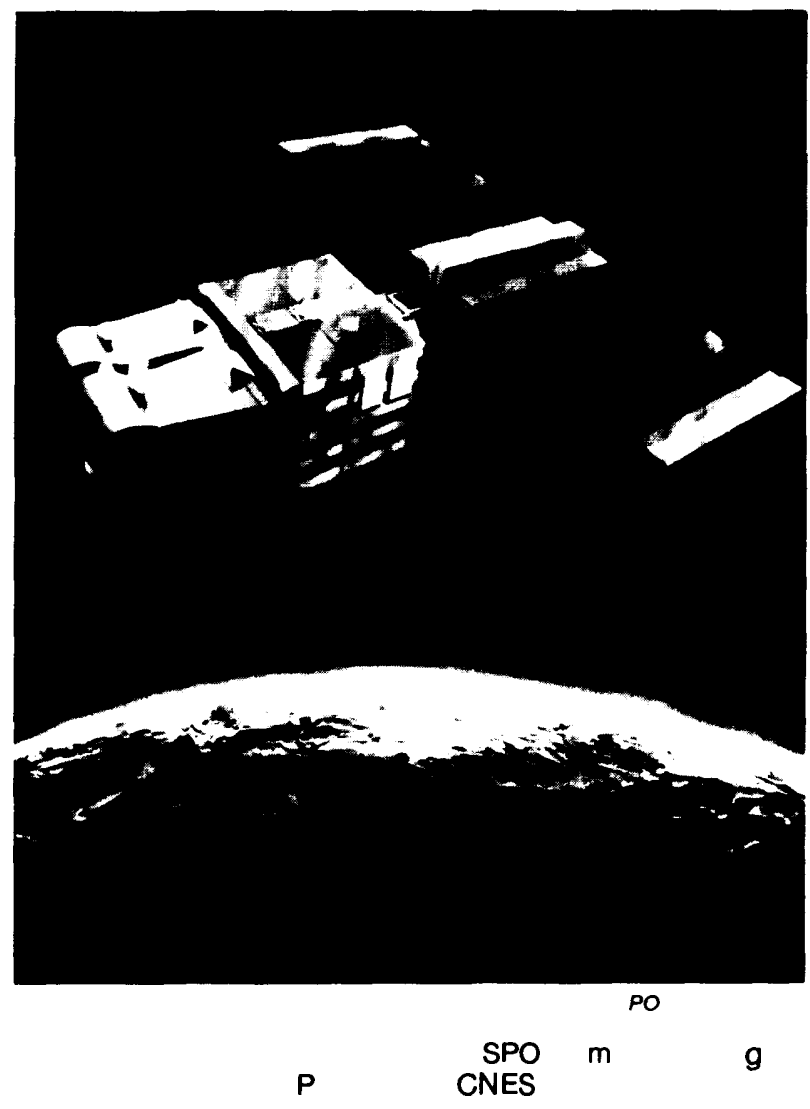

cialization, several private firms have expressed interest in providing land remote sensing data commercially. Phased transfer to private hands, in which a designated private firm uses its commercial skills to develop a market for Landsat data, may result in an overall market for data and services adequate to support both a self-sufficient land remote sensing business and the entrance of more than one data seller. ${ }^{14}$

Without sufficient oversight, transfer of land remote sensing to the private sector would negatively affect our relationships with other nations. In view of the continued importance of the "open skies" principle to the United States, recent legislation' ${ }^{15}$ continues the policy of nondiscriminatory sales of land remote sensing data. Not to do so would be harmful to many U.S. foreign policy interests, not just those involving outer space.

\footnotetext{
I AH. R. 5155, passed by Congress June 28, 1984, provides for a phased transfer [Public Law 98-365].

15H R. 5155 [Public Law 98-365].
} 
Because the first commercial U.S. land remote sensing data supplier will have a near monopoly position, it may also be appropriate to restrict it from entering into the value-added business ${ }^{16} u n$ til a competitive international remote sensing industry develops. Developing country buyers may otherwise realistically fear that there may be discriminatory access to data.

Lack of dependability of data delivery continues to be the single most important concern of current and potential domestic and international customers of remotely sensed data from space. The lengthy debate over the Landsat program has caused both domestic and foreign customers to limit their investment in land remote sensing hardware and services. Such limitation of investment, in turn, has impeded the development of international markets for Landsat-derived products. Building a substantial market for remotesensing data will likely require sizable subsidy for a period of years. It will also require system improvements that lead to low-cost data products, and a strong value-added industry. It will be especially important for the Government to avoid competing with value-added firms.

Remote sensing data services are part of the information industry; interpretation and integration of these data with other data require extensive use of information technology. Successful commercialization of Earth resources space-related systems is therefore directly dependent on advances in information technology that will make data manipulation, storage, and retrieval simpler and less expensive. I n particular, as microcomputers become more powerful, and as appropriate computer software is developed, even relatively unsophisticated users may eventually become purchasers of Earth resources data products-if their prices become sufficiently low.

The pressure for international agreements requiring "prior consent" to acquire remotely sensed data from another country will continue to mount as spatial and spectral resolution improve. However, if a strong, open, competitive market for data products and data services develops, such pressure is likely to diminish.

\footnotetext{
${ }^{16}$ Value-added remote sensing corporations process and ma nipulate remote sensing data to increase their value to the end user.
}

Beginning in September 1984, the Department of Commerce attempted to negotiate a contract with EOSAT Corp. ${ }^{*}$ according to the terms of the Landsat Commercialization Act of 1984. EOSAT, Commerce, and OMB have reached agreement (in May 1985) over the amount of the subsidy (\$50 miliion plus launch costs) and EOSAT'S fi-. nancial risk. It will now be up to Congress to appropriate the transfer funds. Should the experiment in commercializing land remote sensing eventually fail, Congress will be faced with a decision about the future of land remote sensing from space. It could then:

1. decide to reestablish Government ownership of the system,

2. attempt to establish an international land remote sensing system where costs could be shared, or

3 , cease to fund land remote sensing altogether.

Although Public Law 98-365 calls for continued $R \& D$ on remote sensors and applications techniques, in August 1984, NASA reduced its support for near-term $R \& D$ on land remote sensors. NOAA devotes less than $\$ 1$ million yearly to applications research (for land remote sensing). In contrast, other nations are increasing their investment in remote sensing $R \& O$.

- A corporation started by RCA and Hughes Aircraft Corp. specifically to market Landsat data and to construct, own, and operate follow-on Landsat satellites.

\section{Meteorological Satellites (Metsats)}

Public Law 98-166 prevents the sale or transfer of U.S. metsat systems to private industry and requires that they be operated in the public interest. At present, the commercial value-added market for weather data from satellites is extremely small. However, innovative applications of metsat data to agriculture and hydrology demonstrate that, when properly processed and integrated with other data, they can sometimes substitute effectively for moderate resolution land remote sensing data, Because metsat data have the advantage that they are sensed and delivered twice daily, their use for these purposes may reduce the market for higher resolution, Earth resources data. 
As meteorological satellite systems have grown sophisticated and consequently more complicated, costs of building and operating the systems have also grown. In contributing to the continuity of international collection and analysis of environmental data, the United States could follow one of the following policy options:

1. It could continue to operate two civilian polar orbiters and two geostationary satellites and share data internationally.

2. It could operate only one polar orbiter. Reducing polar-orbiter service would likely save roughly $\$ 25$ million per year, but would lead to reduced service to Hawaii and Alaska as well as to the U.S. military. It would also reduce our ability to share metsat data with other nations.

3. Alternatively, the United States could join with other industrialized nations in a joint international system, as the Administration has proposed. The United States could save money on building and operating meteorological satellites and demonstrate its leadership in developing space for peaceful purposes by joining with other nations to build and operate such a system.

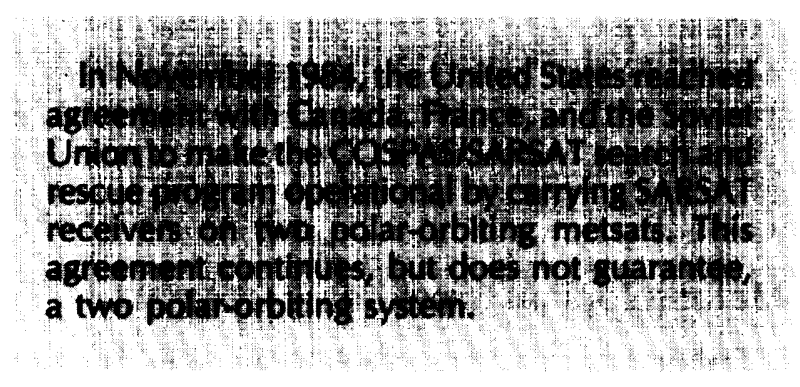

\section{Ocean Remote Sensing}

NASA's experimental Seasat ocean remote sensing satellite demonstrated in 1978 the utility of collecting data on properties of the ocean from space. Although no U.S. civilian system is now foreseen, the U.S. Navy is planning an operational ocean remote sensing satellite (Navy Remote Ocean Sensing Satellite-NROSS) for launch in 1988 or 1989. NOAA will collect and distribute data from NROSS. Canada, ESA, and Japan all expect to have operational civilian ocean remote sensing systems in the late 1980s or early 1990s.
None of the systems by themselves will produce the full range of useful ocean data. [f all parties were willing to coordinate satellite orbits and to supply their data in usable form, NOAA could play a crucial role in collecting, organizing, and distributing data from the U.S. Navy and the foreign ocean remote sensing systems. Alternatively, at some time in the future, it may be desirable to develop an international ocean remote sensing system.

\section{Remote Sensing in Developing Countries}

Most developing countries lack the basic infrastructure to use Earth remote sensing data efficiently. Because the meteorological terminals are relatively inexpensive to install and operate, gaining experience with receiving and processing weather data may be the best way for developing countries to build the infrastructure necessary to utilize remotely sensed land or ocean data. At the same time, advances in information technology that will make it easier and cheaper to process remotely sensed data will vastly improve the ability of the developing countries to use them. By continuing to support remote sensing programs in developing countries, the United States could help these countries develop their own resources and stimulate the international market for land remote sensing data products.

\section{Materials Processing in Space}

There is no international commercial competition in materials processing in space (MPS) because commercially significant MPS products have yet to be developed; governments are now responsible for most MPS research activities. Given the cost and complexity of research in space, and the limited understanding of space processing and its supporting technology, international cooperation in MPS research could contribute substantially to long-term U.S. objectives in space. A few firms, working with NASA, are studying specific processes which could result in commercial products.

The primary motivation for studying the properties of materials in space is to use a microgravity environment for extended periods for scientific and, perhaps, commercial applications. Operating in a near zero-gravity environment may lead 
to improvements in controlling process variables such as temperature, composition, and fluid flow, and afford opportunities for understanding and improving ground-based production methods. Where economical, it might eventually lead to manufacturing selected products in space.

Should MPS products prove to be commercially viable, the United States would eventually face market competition from other nations that are also gathering experience in microgravity research." Most foreign MPS activities have been conducted by ESA under the primary sponsorship of West Germany. European MPS activities include an active sounding rocket program, the development and use of Spacelab and related hardware, and the development of the reusable free-flying platforms, SPAS and EURECA. As a result of these activities, Europe will likely become an important source of information on the behavior of materials in microgravity. Japan has a small but active sounding rocket program directed toward MPS research; it has also used the Shuttle and Spacelab to carry out experiments. The Soviet Union has done a considerable amount of MPS research in its Salyut space station, but this research is unlikely to result in commercial competition for the United States.

At present, U.S. commitment to the Shuttle and to the development of an MPS science community, as well as NASA's encouragement of certain commercial space activities, have given U.S. industry a technological advantage. This advantage could diminish over the next decade as foreign access to space becomes more routine and the advantages and limitations of microgravity technology become more widely known.

MPS research and hardware development in Europe and Japan, in addition to raising the potential for future commercial competition, have made these countries valuable partners for international cooperation. Considering the current limited

\footnotetext{
I $^{7}$ Foreign ability to compete i n space manufacturing will depend strongly on availability of the Shuttle to foreign users or on the development of suitable foreign launch vehicles and carriers.
}

understanding of MPS and the high cost of investigating this technology, international cooperative activities would offer the benefit of expanding the base of knowledge while sharing costs. The United States should encourage international cooperation in basic scientific investigations or in areas in which the United States can benefit from foreign research (e.g., basic biomedical research and research in solidification). It should proceed cautiously in areas that might have nearterm commercial applications or in which the United States holds a clear technological lead (e.g., continuous flow electrophoresis and containerless processing).

Any decision to increase Government support for MPS research should probably include increases in funding for international cooperative activities such as formal and informal exchanges of scientific personnel and information, and sharing of facilities such as the Shuttle, Spacelab, and European- and Japanese-built hardware. Joint research projects such as the International Microgravity Lab proposed by NASA, which would allow the cooperative use of the Shuttle and foreign MPS hardware, seem to offer significant benefits and savings to NASA and the U.S. taxpayer.

It is impossible to predict the future size or vitality of the markets for MPS products, services, and equipment. Although in the near-term, a few commercial MPS products will be developed, the long-term potential of microgravity research will not be known until substantially more research has been accomplished. The potential for developing a U.S. MPS industry depends on: continued Government-funded basic research; the availability of reliable, low-cost space transportation; and access to medium- or long-term MPS facilities such as free-flyers or a space station. It depends most on the discovery of commercially viable MPS products.la

\footnotetext{
${ }^{18} \mathrm{MCD}$ Donnell Douglas and Johnson \& Johnson have been working since 1977 on processes to develop marketable pharmaceuticals. They hope to market their first product manufactured in space by 1987.
} 


\section{SPACE SCIENCE}

\section{Cooperation}

Cooperation between countries in space science continues to be a major source of cultural, political, and social benefits. Cooperation occurs in a variety of modes-among individuals, institutions, and governments. The Infrared Astronomical Satellite (IRAS), by which several major astronomical discoveries were made recently, is an excellent example of the high level of science that cooperative ventures can achieve.

Exploratory missions in astronomy and planetary science are increasingly complex and expensive. Although political considerations are important, the major driving force behind large cooperative space science projects will continue to be the prospect of sharing costs. Yet the complexity of such missions makes joint management by different governments, space agencies, and research institutions difficult. For this reason, international cooperative missions in which costs are shared should be designed so as to keep the management as simple as possible.

Now that ESA and Japan are able to mount major interplanetary missions, the terms of international cooperation have changed. in the international Halley Watch, for example, the United States has assumed a supportive, rather than a leading role. This change from its accustomed role reflects a recognition that the United States need no longer rely solely on unilateral efforts to maintain momentum in space science generally. The United States can now anticipate some return on our earlier investments in the space science programs of our cooperative partners.

Whatever part the United States assumes in cooperative space science activities, it is extremely important for the United States to adhere to its cooperative agreements. As a case in point, the U.S. decision in 1981 to reduce substantially its participation in the International Solar Polar

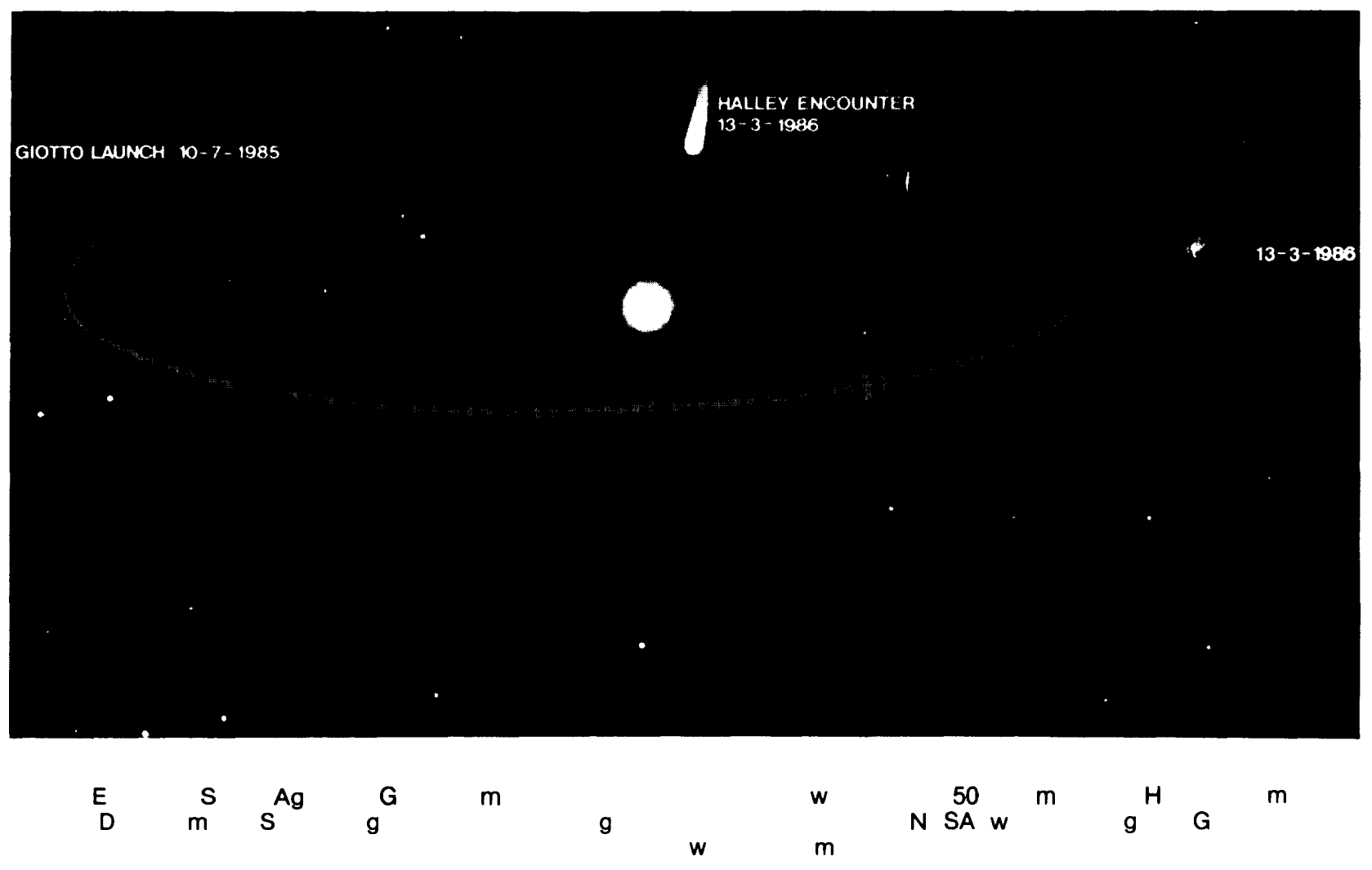


Mission continues to be named as an example of the difficulties involved in cooperating with the United States.

\section{Competition}

It is difficult to speak of direct competition in space science, at least among Western nations, as every nation's plans are known well in advance and there is little to be gained from duplicated research. (This was part of the reasoning behind the U.S. decision not to send a spacecraft to Halley's Comet.) Relative prestige is primarily a function of previous accomplishments and available resources.

Space science is also one way in which the United States demonstrates its leadership in space technology. Although the United States maintains a leadership position in space science, as other nations gain greater experience, the United States faces increased competition in certain subfields of space science from ESA, Japan, and the Soviet Union. One way in which the United States can maintain its broad base of knowledge and technology, while minimizing costs, is to continue to cooperate with other countries, and to be aggres- sive in proposing experiments for foreign spacecraft.

Another competitive aspect of space science, and one which is fairly new, is the competition for cooperative partners on scientific missions. The Soviet Union has used such cooperation as a way to branch out from its Intercosmos base of Soviet bloc countries, to extend its influence, and to acquire needed scientific/technological expertise, The recent flight of an Indian cosmonaut aboard the Salyut 7 space station is one example. The Soviets are continuing an elaborate program of joint scientific projects with France. The United States must not overlook this competitive factor with regard to Third World interest in space science as a means of building the infrastructure necessary for space applications. in the long run, the United States must remain cooperative in space science in order to remain competitive.

The international market for space science equipment and services is relatively small. Because the United States has a well-developed infrastructure for supplying this market, it will continue to dominate the market for the foreseeable future.

\section{U.S. CIVILIAN SPACE POLICY}

Analysis of the issues raised by this assessment reveals that two major problems dominate the organization and implementation of U.S. civilian policies toward space: 1 ) there is no national consensus about long-term goals and objectives in space, and 2) the political and economic dimension of space activities now exceed the purview of any one Government agency.

\section{Future Goals and Objectives}

To maintain focus on the Nation's goals in space, periodic high-level review and discussion are required. In recent years, the Administration's examination of space policy has centered in special committees organized within the White House, and has been dominated by military and national security, as well as yearly budgetary, concerns.

The current Administration's space policy committee, the Senior Interagency Group for Space (SIG space) reflects this emphasis. ${ }^{19}$ Neither the private sector nor several agencies ${ }^{20}$ with longstanding responsibilities in the U.S. civilian space program are represented.

Observers generally agree that the United States needs to establish new specific civilian space goals. One possible mechanism for encouraging a national debate over the U.S. future in space is the National Commission on Space, as author-

\footnotetext{
${ }^{19}$ The Senior Interagency Group is composed of representatives from the Departments of Commerce, Defense, and State, and the Central Intelligence Agency, the Joint Chiefs of Staff, the Arms Control and Disarmament Agency, and NASA.

20For example, the Departments of Agricultu re and Interior, the National Science Foundation, FCC, and AID.
} 
ized in H. R. 5154.21 A National Commission on Space could, among other things, provide a public forum for analyzing the needs of the Nation with respect to space. It could also help to develop a national consensus on new long-term goals and objectives. ${ }^{22}$

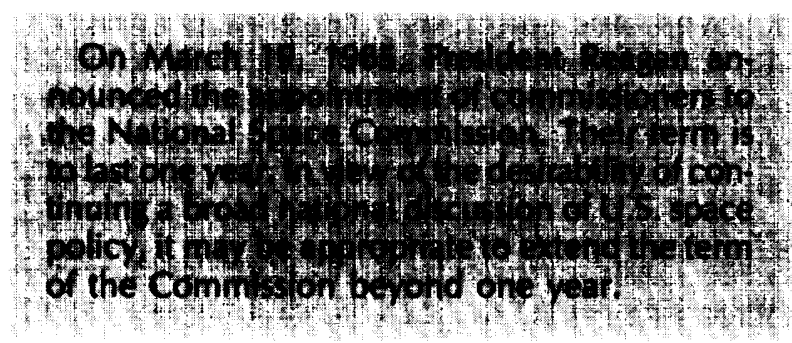

Given the widespread and expanding uses of space, the diversity of governmental and private users, and the increase in international commercial competition, a commission designed to recommend future policy should be as diverse and as broadly based as possible, and include members from the private sector. The Commission should seek input from all the Government agencies with responsibilities in space, but remain independent of them. In addition to recommending goals and objectives, the Commission should provide guidance for implementing its recommendations in the context of other national goals.

It will be important for the Commission to specify the relationship of new goals and objectives to other national goals, and to take account of the limitations, as well as the strengths, of space policy. Just as satellite communications have become integrated into the telecommunications industry, so will other space technologies, as they mature, become integral parts of larger, nonspace industries. They will then gradually become less appropriate objects of space policy, and more appropriate objects of policies related to those industrial sectors they serve.

It is inappropriate to use space policy (which provides direction about the future exploration and exploitation of space), for example, to make decisions on international trade in space-related goods and services in isolation from the U.S. Trade Representative, decide on the require-

\footnotetext{
21Passed by Congress, June 28, 1984. [Public Law 98-361.1

${ }^{22}$ For an initial suggested list of such goals and objectives, see Civilian Space Stations (Washington, DC: U.S. Congress, Office of Technology Assessment) [OTA-STI-241, November 1984.].
}

ments of international satellite telecommunications in isolation from the FCC, or to plan international programs in isolation from the Department of State. Nor should space policy per se be used to guide the overall planning of operational Government systems. For example, as the long debate over the Landsat program has demonstrated, systems that are expected eventually to provide continuing services should be planned primarily by those who will be expected to provide the technology, and use and pay for services.

\section{Organizing for Space Activities}

In the past, what this Nation sought to accomplish in space was achieved primarily by NASA within the broad principles and goals of the 1958 National Aeronautics and Space Act (NAS Act). Today, the increase in foreign and commercial activities means that other Government agencies now play a greater role in space. Already, the Departments of Agriculture, Commerce, Interior, and State, and the FCC, in conjunction with the private sector, manage most of the civilian applications of space technology. Recently the Department of Transportation (DOT) has been charged with promoting and regulating private sector space transportation systems. ${ }^{23}$ Strengthening U.S. competition with other space-capable nations, or improving our ability to cooperate effectively, will require careful attention to the means of coordinating the activities of all of the Federal agencies with an interest in space with each other and with those of the private sector. *

For example, the 1984 fiscal year authorization legislation for NASA, H.R. 5154,24 amended the NAS Act to include a provision directly related to private sector activity in space:

The Congress declares that the general welfare of the United States requires that the $\mathrm{Na}$ tional Aeronautics and Space Administration seek and encourage, to the maximum extent possible, the fullest commercial use of space.

\footnotetext{
${ }^{23}$ This assignment was mad $_{\mathrm{e}}$ by President Reagan. Congress is now considering DOT's role in space transportation. [Public Law 98-575, signed Oct. 30, 1984, now gives DOT regulatory authority over private sector launch activities.]

*[The Government must also authorize and supervise private sector activities in accordance with international treaties and agreements on space.]

${ }^{24}[$ Public Law 98-361.1
} 
This provision directs NASA to involve itself in the commercial exploitation of space. Yet NASA, by itself, is not well-equipped either to choose specific technologies for commercial exploitation or to foster the creation of new space industries.

Seeking the fullest commercial use of space will require the direct involvement of those agencies versed in domestic commerce and regulation, international trade, and foreign affairs, Government decisions regarding commercial space activities must above all be responsive to how the actual markets and industries involved work, and how international ,competition in space industries relates to international competition generally.

In order to foster effective coordination, it will be important for Congress to designate clearly a lead agency for regulating a particular private sector activity. As new specific commercial space technologies mature, agencies other than NASA should be given primary responsibility for their oversight. The recent designation of DOT as the lead agency for private space transportation services indicates how the responsibilities for overseeing commercial space activities could be organized in the future.

The ability to pursue foreign policy objectives through cooperative space activities is hampered by the fact that no single agency has control over U.S. cooperative activities. Currently, the responsibility for cooperative international civilian space activities is divided among the Department of State, Department of Commerce, Department of Transportation, FCC, and NASA. The conduct of foreign policy is the responsibility of the Department of State, which has little expertise in space. if the United States wishes to use its civilian space activities to pursue U.S. foreign policy interests more aggressively, it will be important to expand the Department of State's space expertise.

\section{Cooperation and Competition as Part of Policy}

Cooperation and competition with other nations are not ends in themselves; they are merely tools with which to carry out long-term national security, political, and economic objectives. Nations have cooperated for humanitarian reasons, for example, in the U.S. Advanced Telecommunications Satellite experiments of the 1970s or the current U. S., Canadian, French, and Soviet SARSAT project. They have also cooperated to obtain technology or resources which would later allow them to compete economically or politically. Examples of this include ESA'S work with the United States on Spacelab and NASA's cooperative programs involving remote sensing. European competition with the United States in launch services and remote sensing has helped to establish Europe as an important partner for cooperation with other nations.

If the United States wishes to retain an international leadership role in the continued exploration, development, and use of space it must be effective at both cooperation and competition. A clear understanding of long-term national goals and objectives and a workable division of responsibilities and coordination among the various Federal agencies as well as between Government and the private sector will therefore be essential.

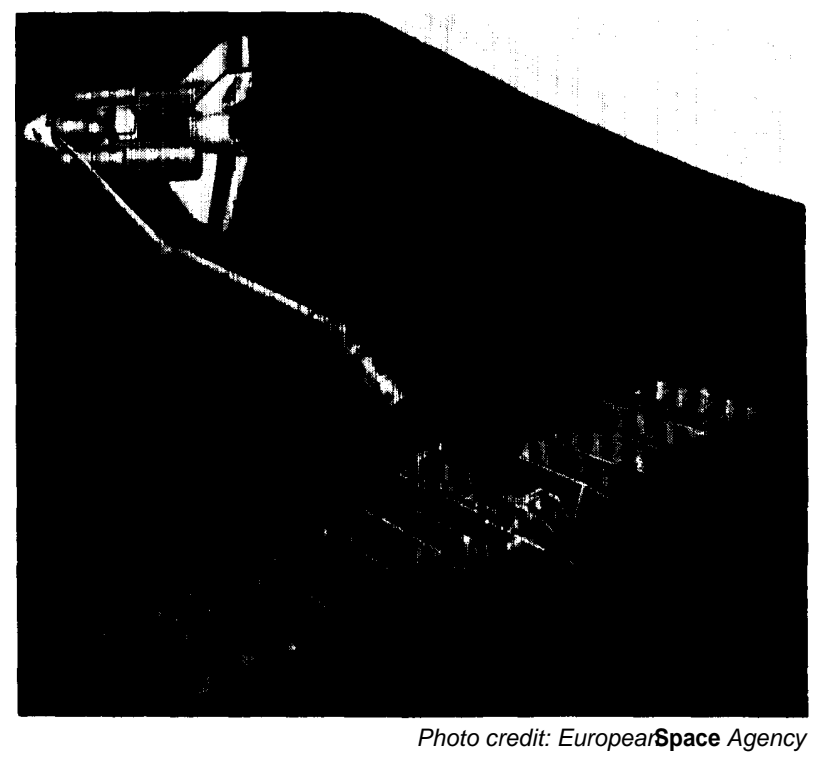

Artist's view of the European-developed EURECA space carrier being deployed from the U.S. Space Shuttle with the Canadian-built remote manipulator arm 


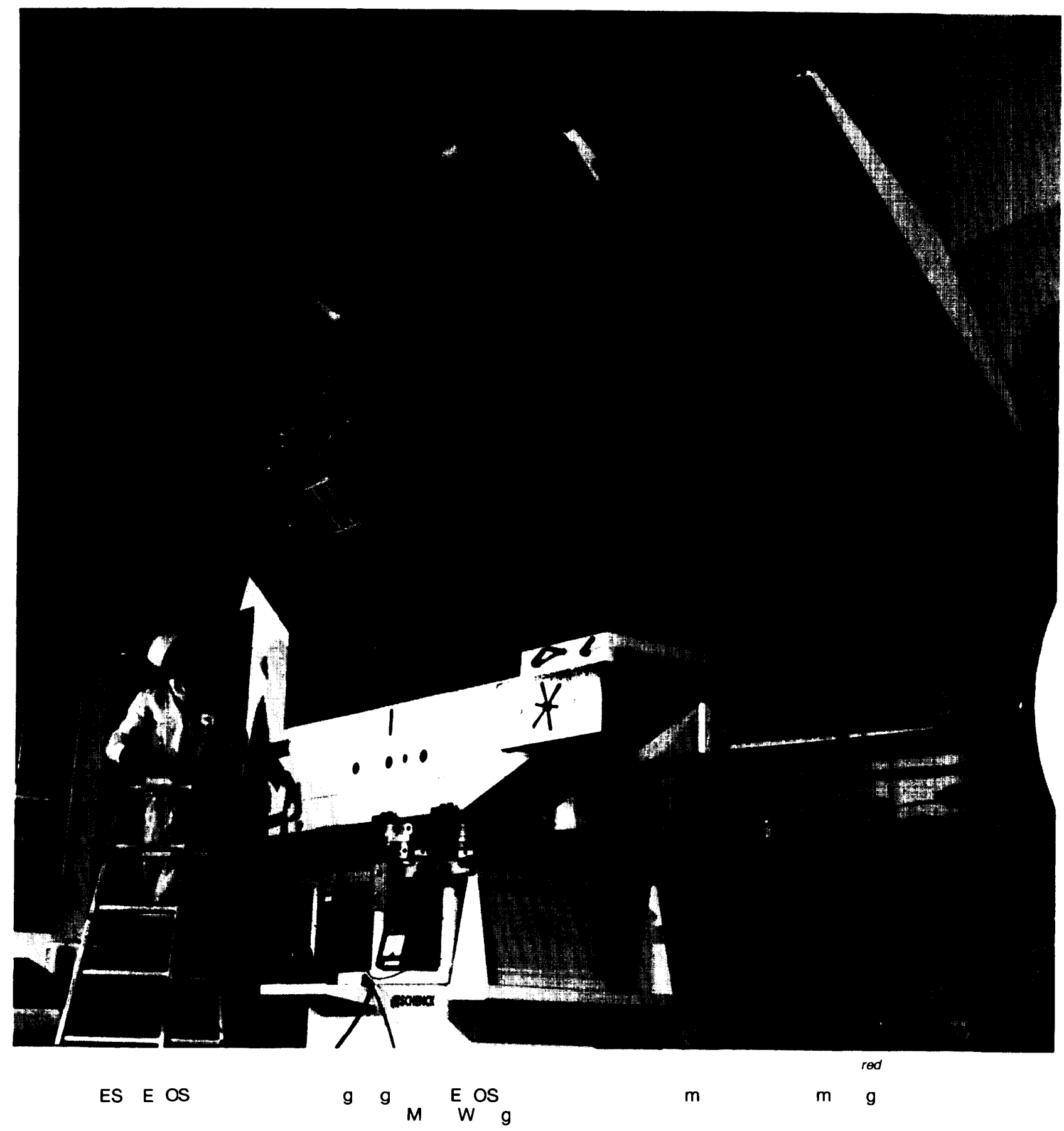


Chapter 2

\section{Introduction}




\section{Contents}

Foreign Competition . ................................... Page

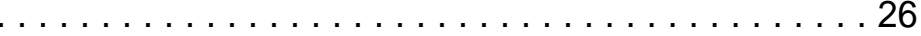

Private Sector Space Activities. . . . . . . . . . . . . . . . . . . . . . 27

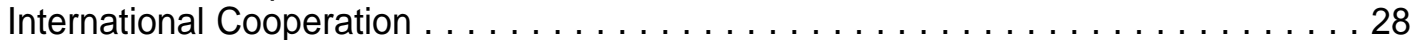

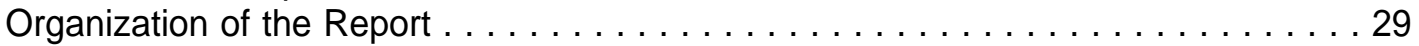




\section{Chapter 2 INTRODUCTION}

International cooperation and competition in space science and technology have played important roles in the U.S. civilian space program since its inception in 1958. Although the program was primarily established to meet a competitive challenge from the Soviet Union, the National Aeronautics and Space Act identifies international cooperation as a fundamental U.S. goal and declares that "activities in space should be devoted to peaceful purposes for the benefit of all mankind" (sec. 102a).

For many years only the United States and the Soviet Union had the capacity to build and launch complex space systems. In the last decade, the Western European countries and Japan have also succeeded in developing advanced space systems; in large part they have done this by assimilating U.S. technology and expertise through cooperative scientific and commercial ventures with the United States.

In the 1980s, advanced foreign capabilities have or will become comparable to those of the United States in virtually every area of civilian space technology except manned flight. Foreign accomplishments now provide new opportunities for bilateral and multilateral cooperation; they also present the challenge of greatly increased commercial, political, and military competition.

Significant changes have also occurred in the U.S. relationship with the developing world. A few developing countries, resolved upon using space technology to promote their economic growth, have begun to press for the establishment of international organizations and legal regimes with the power to ensure equitable access to space systems and resources. Such developments are often inconsistent with U.S. policies and objectives, particularly those designed to encourage private competition and investment in space activities. This has occasioned a reassessment of the traditional U.S. support for certain cooperative activities, particularly those sponsored by the United Nations or its specialized agencies.
Because of their interest in maintaining U.S. leadership in space technology, in capturing the economic benefits of commercial space activities, and in using space technology as an instrument of foreign policy, the House Committee on Science and Technology and the Joint Economic Committee asked the Office of Technology Assessment (OTA) to prepare this report.' The committees requested an assessment of "international cooperation and competition in space, "that would "compare the technical status of foreign space systems . . . and investigate ways that U.S. space applications and space science programs could be used more effectively to further U.S. commercial and foreign policy interests. "They asked OTA to examine U.S. relationships with developing as well as industrialized countries and to offer suggestions about how "this country can work together with other nations for mutual benefit. "

This study builds upon the OTA report Civil-ian Space Policy and Applications. ${ }^{2}$ That assessment identified international competition in space technology as a critical issue, described the current and projected space programs of other countries, and discussed domestic initiatives to make better use of our own space assets. During the course of the current study, OTA also published two technical memoranda each of which highlighted important issues of cooperation and competition. ${ }^{3}$ UN/SPACE '82: A Context for International Cooperation and Competition focused on U.S. participation in the second United Nations

\footnotetext{
' Letter from Congressmen Don Fuqua, Ronnie G. Flippo, Larry Winn, Jr., and Harold C. Hollenbeck of the U.S. House of Representatives Committee on Science and Technology to the Honorable Ted Stevens, Chairman, Technology Assessment Board, Mar. 8, 1982; Letter from the Honorable Roger W. Jepsen, Vice Chairman, Joint Economic Committee to the Honorable Ted Stevens, Chairman, Technology Assessment Board, Mar. 24, 1982.

${ }^{2}$ Civilian Space Policy and Applications (Washington, DC:U.s. Congress, Office of Technology Assessment, OTA-STI-177; June 1982).

${ }^{3}$ Technical memoranda are issued on specific subjects analyzed in recent or ongoing ОTA projects, They are issued at the request of Members of Congress who are engaged in committee legislative actions that are expected to be resolved before OTA completes its assessment.
} 
conference on the Exploration and Peaceful Uses of Outer Space. ${ }^{4}$ The conference offered a window through which to view the needs of the developing world, the formation of international space policy, the roles that the United States and its agencies play in this process, and the potential effect of the process on U.S. public and private interests. Remote Sensing and the Private Sector: Issues for Discussion investigated the recent proposal to transfer the meteorological and land remote sensing satellite systems to the private sectors Among other things, it discussed the size of the market, public good aspects of remote sensing, U.S. Government (including military and intelligence) needs for data, and the use of remotely sensed data to further foreign policy objectives.

In order to identify and refine the issues presented in this report, as well as the two previously published technical memoranda, OTA convened several workshops that assembled experts from different subject areas:

Space Technology and Foreign Policy: UNISPACE '82 offered an opportunity to review the development of international space policy, the role that the United States and its various agencies play in this process, and the potential effect

${ }^{4}$ UNISPACE '82: A Context for International Cooperation and Competition-A Technical Memorandum (Washington, DC: U.S. Congress, Office of Technology Assessment, OTA-TM- ISC-26, March 1983); requested by the House Science and Technology Committee and the Joint Economic Committee.

'Remote Sensing and the Private Sector: Issues for DiscussionA Technical Memorandum (Washington, DC: U.S. Congress, Office of Technology Assessment, (OTA-TM-ISC-20, March 1984); requested by the House Science and Technology Committee and the House Government Operations Committee. of this process on public and private U.S. interests, After OTA completed the first draft of the UNISPACE '82 Technical Memorandum, it held a workshop to discuss the draft and the issues raised by U.S. participation in international conferences.

Commercialization of Remote Sensing: OTA organized two different workshops on this subject. In the first, participants drawn primarily from the private sector discussed those broad issues implicit in the transfer of remote sensing systems related to international trade, use of remotely sensed data in foreign policy, public good aspects of land and meteorological remote sensing, and finally, national security issues. The second workshop, composed solely of participants from the executive agencies, discussed most of the same issues from the standpoint of Government policy and plans.

Internationa/ Trade in Space Equipment: This workshop discussed the applications and effects of current rules on trade in space-related services, equipment, and products. Additional issues discussed included potential Government responses to "unfair" practices in space markets, the likely evolution of the industrial organization of the space transportation industry, and the potential effect of deregulation on the international communications industry.

OTA is grateful to the workshop participants and to the many others who provided information or reviewed portions of this draft or of the drafts of the two technical memoranda. Their helpful and timely comments and suggestions helped to make it possible to complete this report.

\section{FOREIGN COMPETITION}

Having begun in many cases by building components and subsystems for U.S. and INTELSAT satellites, European and Japanese capacities now extend to the design and operation of complete systems for communications, land remote sensing, and weather observation, as well as the ve- hicles to launch them. Although no single country can yet match the U.S. range of technical abilities, nor its experience in systems operation, foreign technologies are now fully comparable in specific areas, such as expendable launch vehicles and satellite ground stations. 
Until recently, the United States benefited from the space programs of other nations because they provided markets for U.S. goods and services. Now, even though the overall market is increasing, foreign competition could threaten U.S. firms with the loss of significant sales and the country as a whole with potential loss of prestige and political influence. Already, technology developed by the European Space Agency (ESA) supplies a large portion of the satellite communications and space transportation needs of the European community. I n 1985, the French SPOT system is expected to begin supplying commercial remotely sensed data internationally. The Third World markets for space technology, once completely dominated by U.S. producers, are gradually opening to European and Japanese sellers.

These advances are part of an overall evolution of European and Japanese expertise in advanced technology. Influential opinion sectors in Europe and Japan believe that they must compete fully in advanced technology, and associated management skills as a prerequisite for economic growth, political status, and national security in a world dominated by the two superpowers. To obtain the necessary technology and skills they have targeted specific industries for special attention, particulady industries where international competition was thought to be important. Space technology is a prime exemplar of this phenomenon; it has not only been promoted domestically through research and engineering programs, but also imported from the United States via educational and scientific exchanges and through the activities of U.S. aerospace and communications firms.

In part because of its long-standing position as the unchallenged leader in space applications technology, the United States has been slow to recognize and respond to foreign challenges. This report offers a range of policy options which attempt to define appropriate roles for Government in its task of maintaining technological leadership in an increasingly competitive international environment.

\section{PRIVATE SECTOR SPACE ACTIVITIES}

The Carter and Reagan Administrations and Congress have encouraged private sector investment in space technology. Consequently, in addition to expanding its major role in satellite communications, the U.S. private sector would like to offer space transportation services. It may soon be obtaining and selling satellite remote sensing data, and has also offered limited expressions of interest in materials processing in space.

The U.S. Government attempts to avoid competing with private commercial activities. However, since the development and use of space technology is a long-term, expensive undertaking and certain specialized government needs cannot always be supplied by the private sector, governments have traditionally been the driver be- hind the evolution and growth of space technology. This preeminent government role, combined with the political sensitivity of the use of technologies that by nature transcend national boundaries, has inhibited the transfer of space technology to private sector hands.

In remote sensing and space transportation, although the U.S. Government creates a large part of the total demand for these services, it is also a potential competitor to private sector efforts. This report offers policy options which attempt to resolve the conflict between the Government's responsibilities for encouraging private sector investment in space and its responsibilities for maintaining the technological vitality of the Nation. 


\section{INTERNATIONAL COOPERATION}

International cooperation for peaceful purposes has been a central element of the U.S. civilian space program since its inception. Cooperative activities have taken primarily three forms: 1 ) bilateral agreements with other industrialized countries, usually with a technological goal; 2) multilateral agreements in United Nations and other international forums to develop the legal, regulatory, or organizational norms for using space; and 3) assistance projects undertaken by the U.S. Agency for International Development, with the help of the National Aeronautics and Space Administration (NASA) and the National Oceanic and Atmospheric Administration (NOAA), which use space technology to benefit developing nations.

To make up for lack of individual size, European countries have also developed methods of cooperating multilaterally in order to pool financial and technical resources. The multinational ESA is coordinating projects in advanced satellite communications, ocean and land remote sensing, and expendable launch vehicles. It is also the lead agency for extensive bilateral agreements with the United States in space science and in the design and construction of Spacelab, the manned Shuttle laboratory. In Japan, the national space agency, NASDA, is developing its own family of launch vehicles (based on technology leased from U.S. corporations), as well as advanced communication satellites and ocean remote sensing systems. Japan also has an active space science program. Much of this work is being pursued in cooperation with U.S. aerospace and electronics firms as well as with NASA. The Soviet Union cooperates most actively with allied socialist states. More recently, it has developed programs with India and also with France.

In the past 25 years, the United States has engaged in hundreds of bilateral and multilateral cooperative ventures in every area of space technology. U.S. launchers have orbited complete satellites and instrument payloads for dozens of countries. As others develop indigenous space capabilities they become potentially valuable partners for cost-constrained U.S. projects. Yet, cooperation in any high-technology venture can result in some transfer of valuable technical "know-how." As private sector commercial activities increase there will be less Government incentive to cooperate because successful cooperation may lead to a decrease in market share or create new competitors.

The U.S. cooperative relationship with developing countries is also undergoing a period of significant change. In the past, the United States used the Landsat or the Advanced Telecommunications Satellite (ATS) programs to demonstrate how space technology could benefit the developing world. In recent times, however, the United States has come under strong criticism from developing countries for failing to support an agenda dedicated to equal and guaranteed access to space technology and resources.

The dominant dispute over the use and acquisition of space technology is between the industrialized and the developing countries, In general, the developing countries seek to gain greater access to, and control over, the resources of outer space and the advanced space technologies of the industrialized nations. They do this primarily by advocating legal and regulatory regimes for space activities in international organizations, where they outnumber and can outvote industrialized countries. The developing countries also promote the establishment of multilaterally funded and controlled bodies to transfer know-how and technology to the Third World. Industrialized countries, on the other hand, fear turning over control to multilateral organizations. In the United States, the ideological emphasis has shifted from a policy of using space for "all mankind," to a desire to encourage the private exploitation of space. Yet private exploitation of space resources assumes acquiescence by other countries in U.S. goals. Increased private sector activities will require political as well as market accommodation by all countries, 


\section{ORGANIZATION OF THE REPORT}

The main body of this report begins with discussions of cooperation and competition in chapter 3 and chapter 4 . These chapters provide the conceptual and institutional context essential to understanding the technology-oriented policy options that appear in the report. The interaction between cooperation and competition is demonstrated concretely in each of the following technology chapters.

Chapter 5 describes the technology and the current issues involved in space transportation. It discusses commerce in space transportation equipment and services and the relative merits of their individual needs and products. Shuttle and Ariane price competition, launch vehicle demand, the role of the private sector and the longterm effects of government owned or sponsored technology are all examined. It also considers the history and future of cooperation in space transportation.

Chapter 6 examines international cooperation and competition $\mathrm{i}$ : I satellite communications, the only fully commercialized sector of space technology, in the context of the international telecommunications industry as a whole. International satellite communications, which has been highly structured by regulation in the past, is now an arena in which a deregulated U.S. domestic telecommunications industry is poised to implement new technologies in international markets if it can gain access to them. This chapter analyzes how the outcome of technological competition between fiber optic cables and communication satellites could affect the long-term demand for satellite communications services and equipment and how economic, political, and regulatory factors could affect this competition. It analyzes U.S. policy toward international institutions like INTELSAT and the ITU, NASA's advanced communication satellite research pro- gram, international trade in telecommunications equipment and services, and international facilities regulation.

Chapter 7 focuses on remote sensing and the technical, political, and economic issues involved in the operation of this technology. It pays particular attention to the worldwide market for meteorological, land, and ocean remote sensing services and summarizes civilian needs of the U.S. Government. The United States is attempting to transfer land remote sensing functions (the Landsat system) to the private sector. This chapter examines the transfer process and explores policy issues related to it. Because several foreign governments are planning to launch remote sensing systems, this chapter summarizes the attributes of these systems and examines the competitive challenge the systems pose for the United States.

Chapter 8 examines foreign and U.S. materials processing research and assesses the potential for the development of marketable products. It also discusses competitive foreign services and equipment. The value of pursuing cooperative MPS programs is discussed in detail, particularly with reference to basic scientific research.

Chapter 9 describes current cooperative and competitive aspects of space science. [t details the role of cooperation in reducing costs and expanding possible activities, and discusses the emergence of competition as a new factor in space science.

Finally, chapter 10 offers a broad examination of the cooperative and competitive policy options presented in the technology chapters and discusses the wider issues posed by U.S. involvement in international civilian space activities. The chapter suggests several options for addressing these issues. 
Chapter 3

INTERNATIONAL SPACE COOPERATION 


\section{Contents}

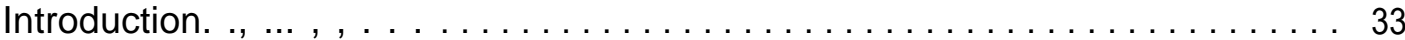

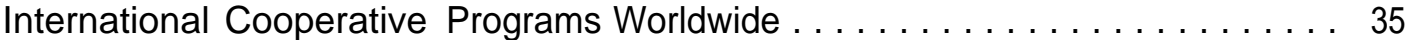

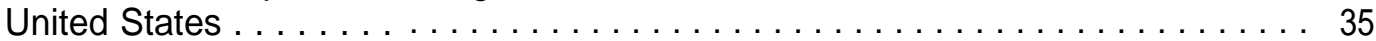

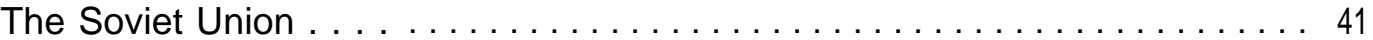

European Space Agency $(E S A) \ldots \ldots \ldots \ldots \ldots \ldots \ldots, \ldots \ldots \ldots \ldots, 43$

The United Nations . . . . . . . . . . . . . . . . . . . . . . . . . . . . 45

International Telecommunications Satellite Organization (INTELSAT“) . . . . . 49

International Maritime Satellite Organization (INMARSAT) . . . . . . . . . . . 50

World Meteorological Organization. . . . . . . . . . . . . . . . . . . 51

Issues in Cooperation . . . . . . . . . . . . . . . . . . . . . . . . . . 52

\section{List of Tables}

Table No. Page

3-1. NASA Cumulative Statistical Summary Through Jan. 1, $1984 \ldots \ldots$. . ......37

3-2. Current Membership of COPUOS . . . . . . . . . . . . . . . .....46

List of Figures

Figure No. Page

3-1. Patterns of Global Governmental Outer Space Activities. . . . . . . . . . . . .34

3-2. U.N. Bodies , . . . . . . . . . . . . . . . . . . . . . . . . ......54 


\section{INTRODUCTION}

International cooperation in civilian space activities has been a major component of U.S. space policy ever since specific provisions for cooperation were included in the 1958 National Aeronautics and Space Act (NAS Act). Later amendments strengthened the role of international cooperative agreements in pursuit of scientific and technical research. Because each successive administration and Congress have perceived international cooperation in civilian space activities to be beneficial to U.S. interests, U.S. involvement in international cooperation has stood the test of time and the annual appropriations process.

In the early days of the Space Age, the United States played a leading role in establishing the international legal regime for outer space. It was also a major force in establishing the multilateral communications organizations, INTELSAT and (to a lesser extent) INMARSAT, and in making the results of remote sensing from space available worldwide; in addition, it offered participation in scientific space projects to other countries (see fig. 3-I).

Recently, the National Aeronautics and Space Administration (NASA) opened its manned space flight program to other nations by flying foreign mission specialists on the Shuttle.

Cooperative programs in space, managed principally by NASA, but also by the National Oceanic and Atmospheric Administration (NOAA) and the Agency for International Development (AID), have supported the following U.S. technological, political, and economic goals:

\section{Technological:}

-Affording access to foreign countries for tracking stations, launch sites, and ground receiving stations.

-Expanding research opportunities for U.S. scientists by sharing costs and acquiring/ using knowledge from other countries.

-Allocating scarce resources such as the geostationary orbit.
-Political:

-Promoting international peace and reducing tensions through mutual understanding.

-Promoting greater openness and access to information.

-Increasing U.S. prestige by giving high international visibility to U.S. technical and scientific accomplishments.

-Affording political access to countries where U.S. influence is otherwise weak.

- Economic:

-Promoting economic development in developed as well as developing nations.

-Developing global markets for U.S. spacerelated goods and services.

-Sharing costs of expensive, long-term programs.

The very success of U.S. international cooperative programs has helped intensify international challenges to U.S. leadership in space science and space applications. The pressure comes not only from other nations competing in space. Developing countries, voting in blocs, now challenge U.S. leadership in international organizations that deal with space matters. These challenges raise critical questions about the future of Us. cooperative space projects:

1. How can the United States use its participation in international multilateral organizations and meetings on space to promote U.S. interests?

2. How can the United States cooperate most effectively with the developing countries?

3. On what terms might the United States most profitably cooperate with the industrialized nations?

This chapter summarizes the history of U.S. international cooperation in civilian space activities and describes its major accomplishments. it describes foreign cooperative programs and discusses issues arising from an altered international outlook with respect to space are discussed. 


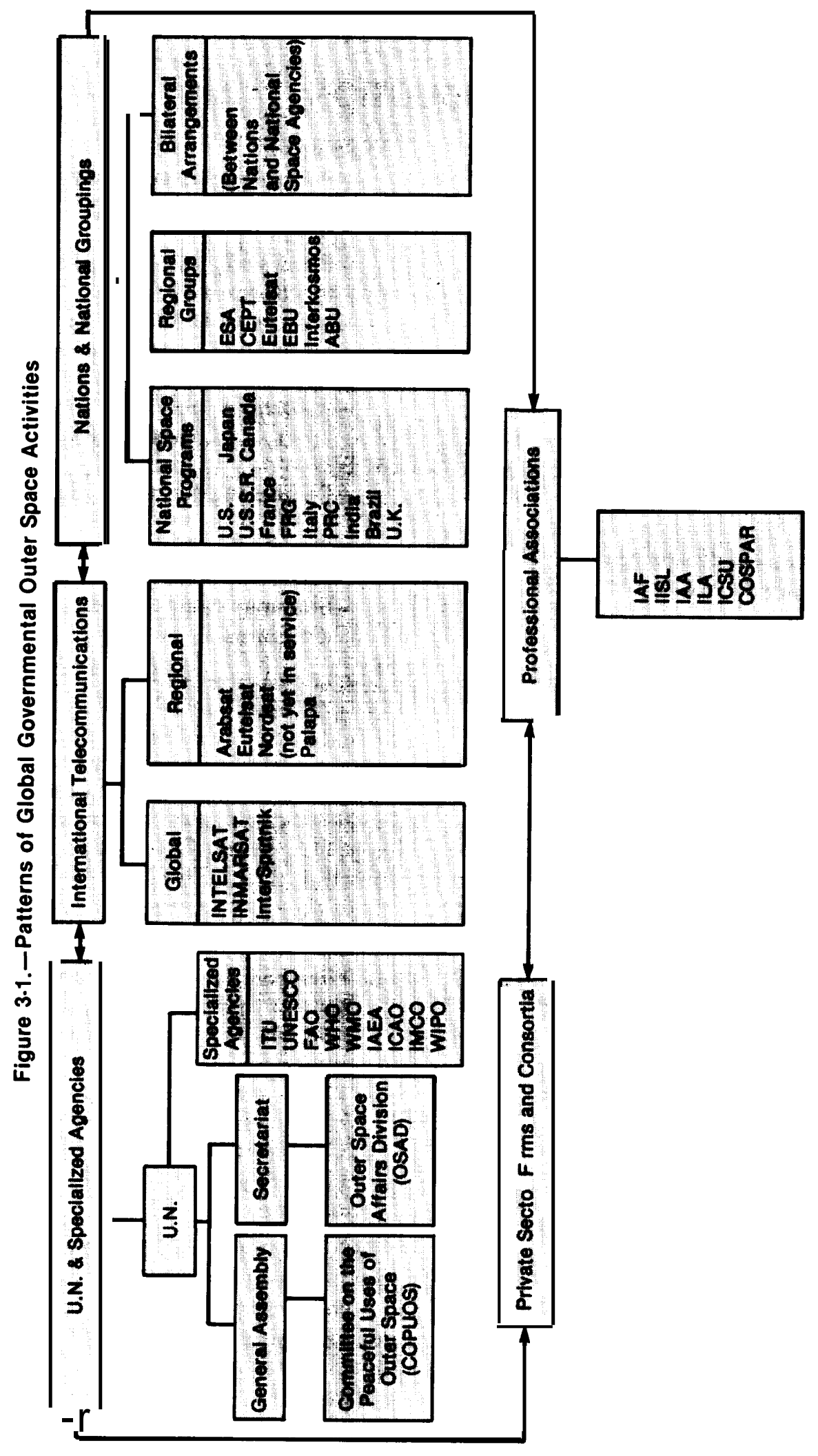




\section{INTERNATIONAL COOPERATIVE PROGRAMS WORLDWIDE}

\author{
United States \\ Early Legislation
}

The history of cooperation in the use of outer space for peaceful purposes bears the indelible imprint of the U.S. Congress. Influential Members of both houses, including Speaker of the House John W. McCormack and Senate Majority Leader Lyndon B. Johnson, recognized as early as 1957 that a strong national space program offered a basis for international cooperation in activities which could extend peaceful pursuits on a worldwide frontier.

On January 15,1958 , Senator Johnson called for U.S. leadership in developing the capacity to explore the space environment. lie suggested that we invite the scientists of other nations to work with U.S. scientists on projects to extend the frontiers of mankind and to find solutions to the problems facing the world:'

Our President ... has a rare opportunity to lead in this labor boldly and forcefully and in the vigorous pursuit of peace; he will find the $\mathrm{Na}$ tion undivided in its support ., . it would be appropriate and fitting for our Nation to demonstrate its initiative before the United Nations by inviting all member nations to join in this adventure into outer space together. The dimensions of space dwarf our national differences on Earth.

Later, on March 5, 1958, President Eisenhower approved a proposal for dividing control of space activities between the Department of Defense, which was to retain projects primarily associated with military requirements, and the National Advisory Committee for Aeronautics (NACA), which was to be the nucleus of a new civilian agency. The President's Science Advisory Committee published "Introduction to Space" on March 26, 1958, and on April 2, the President sent a special message on "Space Science and Exploration" to Congress with a draft proposal for legislation. The message stated that "a civilian setting for the administration of space functions will emphasize

\footnotetext{
'Address by Senator Lyndon B. Johnson before a meeting of the Columbia Broadcasting System Affiliates, Shoreham Hotel, Washington, DC, Jan. 14,1958.
}

the concern of our Nation that outer space be devoted to peaceful and scientific purposes."

Although the Eisenhower Administration and Congress agreed on dividing space activities between military and civilian agencies and expanding NACA into the National Aeronautics and Space Administration, the special congressional space committees made several changes in the administration's bill, particularly with regard to the need for international cooperation. These actions reflected the testimony of scientists and engineers who had been engaged in global projects of the International Geophysical Year. According to Senate Resolution 327, Report No. 1925, 85th Congress, 2nd session, July 24, 1958:

Particular attention should be paid to preserving and extending the patterns of cooperation which were formed during the International Geophysical Year. The IGY programs have been an inspiring example of cooperation between the scientists of 66 nations working through their own professional organization, the International Council of Scientific Unions (ICSU) and its Special Committee, the CSAGI (Comite Spécial de l'Année Geophysique Internationale). Another pattern of cooperation developed between scientists and their governments when public funds and facilities were provided for IGY research projects. Cosmic research and development can become an important force for world peace. We must not lose what has thus far been gained both on the international and national levels by scientists working with each other and with their governments.

The Senate also took account of certain technical facts:

... that the orbits of satellites are global in nature and pass over national boundary lines; tracking stations were needed throughout the world; and international space cooperation could promote peaceful relations among states and form the basis for avoiding harmful and destructive actions in space. (Emphasis OTA.' S.)

The NAS Act begins with a Declaration of Policy and Purpose:

The Congress hereby declares that it is the policy of the United States that activities in space 
should be devoted to peaceful purposes for the benefit of all mankind. (Sec. 102 (a).)

The policy declaration provides that:

The Administration, under the foreign policy guidance of the president, may engage in a program of international cooperation in work done pursuant to this Act, and in the peaceful application of the results thereof, pursuant to agreements made by the President with the advice and consent of the Senate (sec. 205).

Recognizing that not all of NASA's international arrangements could be in the form of treaties subject to the advice and consent of the Senate, President Eisenhower, in signing the bill on JUly 29,1958 , stated that while treaties may be made in this field, the section does not preclude "less formal arrangements for cooperation" since otherwise the section would "raise substantial constitutional questions. " A later (1975) amendment incorporating provisions on Upper Atmospheric Research further specified that NASA, under the President's direction and after consulting the Secretary of State "shall make every effort to enlist the support and cooperation of appropriate scientists and engineers of other countries and international organizations."

\section{NASA International Program}

In keeping with the spirit of the 1958 NAS Act, NASA has developed an extensive program of international cooperation which has opened the entire range of its space activities to foreign participation. Cooperation by the United States with other nations (who pay their share of the cost of a project on a fully proportional basis) contributes to the U.S. space research program and to broader national objectives by:

- stimulating scientific and technical contributions from abroad,

- enlarging the potential for developing the state of the art,

- providing access to foreign areas useful for data collection during space, flights,

- enhancing satellite experiments through foreign ground-support programs,

2|nternational Aspects of the National Aeronautics and Space Act of 1958, as amended (72 Stat. 426).
- developing cost-sharing and complementary space programs,

- extending international ties among scientific and national communities, and

- supporting U.S. foreign relations and foreign policy.

Cooperative activities have ranged from launching foreign-built spacecraft on U.S. launchers to ground-based studies, analysis of data, and information exchanges. They include, for example, contributions of experiments or payloads to be flown in space by NASA, joint projects to develop flight hardware, use of data or lunar samples provided by NASA missions, training, visits, and joint publication of scientific results. In addition, NASA provides certain services on a reimbursable basis, including launching satellites and data and tracking services (table 3-1).

Cooperative programs and activities involving nations and groups of nations are established by: 1) agency-to-agency memoranda of understanding (MOUs), 2) agency-to-agency letter agreements, or 3) more formal intergovernmental agreements. The relative complexity, total shared cost, and duration of the program or project dictate in part the type of arrangement used to establish the cooperative effort.

Bilateral arrangements between the United States and one other country are by far the most common. NASA prefers bilateral activities over multilateral ones because they are substantially less complex and easier to manage. ${ }^{3}$ Because of the complexities inherent in international cooperation by government agencies, the fewer involved the better. Technical and cost difficulties also arise in the joint development of hardware. For this reason, NASA has found that the most desirable arrangements involve the development of separate spacecraft or separate major components. In such missions the management and technical interactions can be kept simple. ${ }^{4}$ Joint ventures with the European Space Agency (ESA) tend to have some of the complexity of multina-

'UNISPACE '82: A Context for Cooperation and CompetitionA Technical Memorandum (Washington, DC: U.S. Congress, Office of Technology Assessment, OTA-TM-ISC-26, March 1983), app. B (prepared by NASA).

${ }^{4}$ See, for example: Working Group Report on Space Science, i $\mathbf{n}$ Global Space Activities: An AIAA Assessment, 1981, pp. 52-53. 
Table 3-1. -NASA Cumulative Statistical Summary Through Jan. 1, 1984

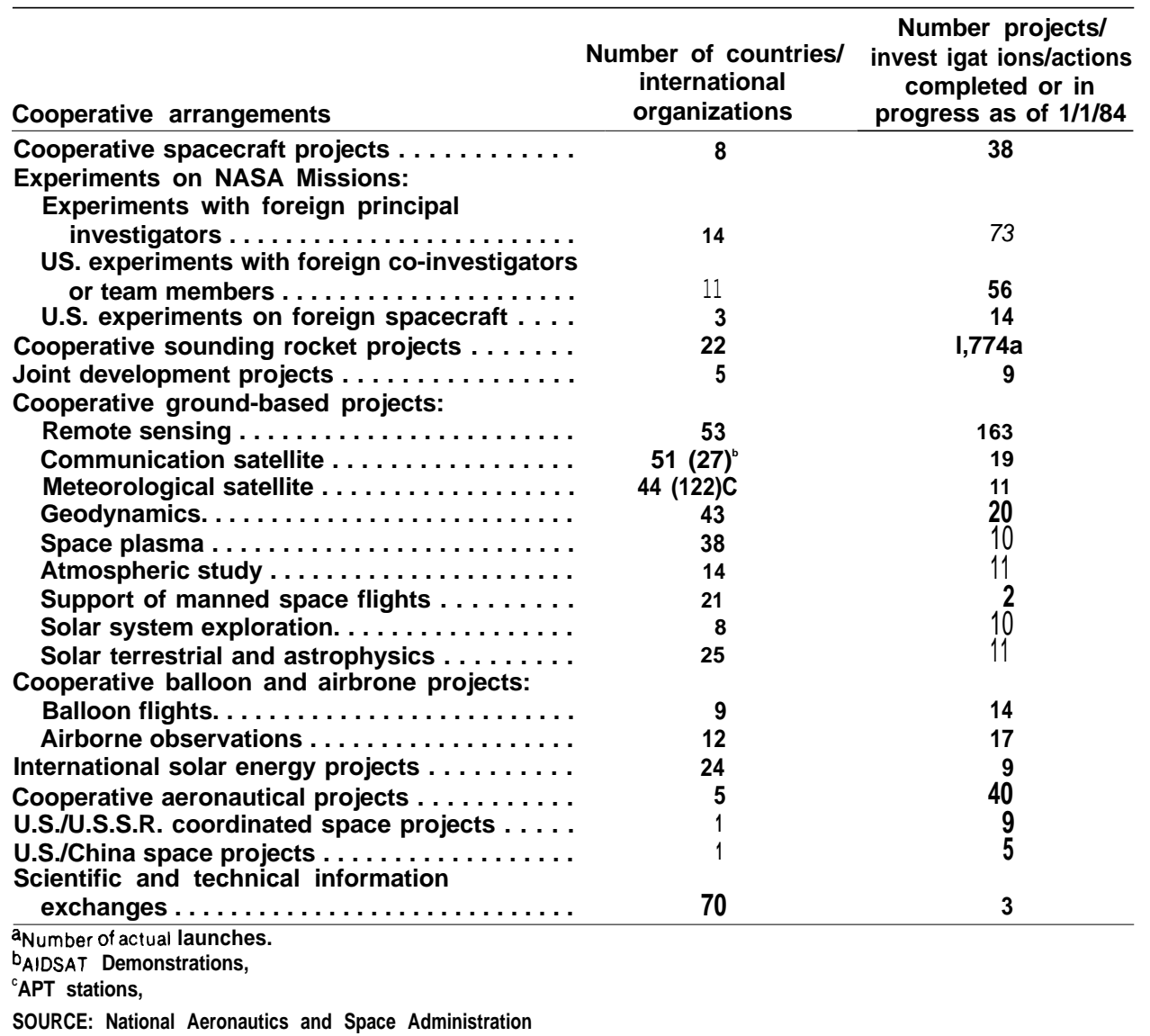

tional ventures (although they are considered by NASA to be bilateral), since ESA represents a multinational consortium and is subject to more complex internal political pressures than a national agency would be.

Some examples of major cooperative programs illustrate the breadth of the U.S. international space program: ${ }^{5}$

- Cooperative space projects involve cooperation between the United States and other nations to develop, launch, and operate communications satellites, scientific satellites, and Earth sensing satellites. A typical example is the Communications Technology Satellite (CTS), a joint effort with Canada in

${ }^{5} \mathrm{~A}$ complete list of NASA's cooperative programs can be found in 25 Years of NASA International Programs, NASA, January 1983.
1976. Canada built the satellite at its Communications Research Center (CRC), using special hardware supplied by the United States, which enabled the CTS to transmit at high power levels to small terminals. NASA launched the satellite and shared operations with Canada.

- Foreign experiments on NASA missions include, for example, an investigation of composite materials processing in space conducted by the Japanese National Research Institute for Metals in 1973 aboard the U.S. Skylab. The University of Bern, Switzerland, mounted a series of experiments on U.S. manned missions between 1969 and 1973 to measure the composition of solar wind. The Netherlands' Dekt Technical Institute built a telescope to measure cosmic ray elec- 


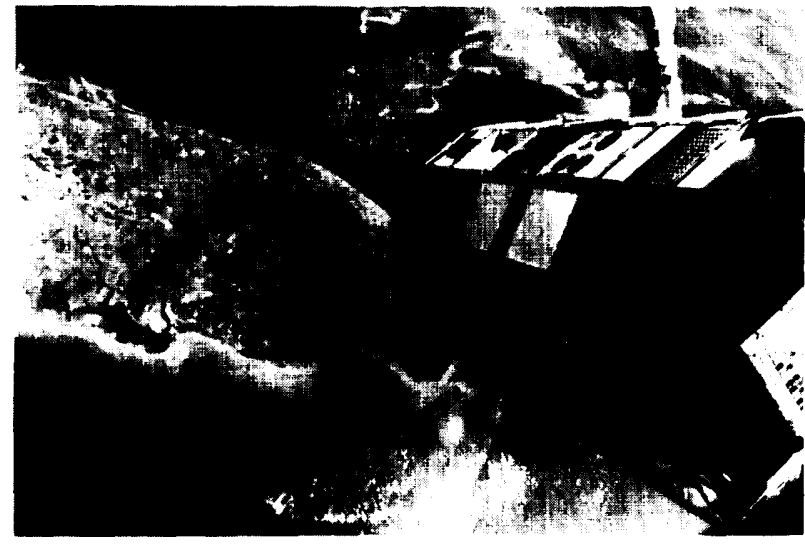

984

$\mathrm{S}$ g D
$E^{g}$

g 9 g $g$ DE around the world.

trons, which it mounted on NASA's fifth Orbiting Geophysical Observatory.

- U.S. experiments on foreign spacecraft are also supported, such as a NASA experiment to study aspects of spacecraft behavior on a European Space Agency flight.

- Cooperation on sounding rocket projects has involved scientific research with many nations in all regions of the world. The purpose of these flights is usually upper-atmosphere research, since sounding rockets follow a suborbital trajectory. An example is a series of flights in 1980 on NASA rockets carrying German and Norwegian experiments to study energetic processes in the upper atmosphere.

- Foreign ground stations are evidence of the widespread use of land and meteorological remote sensing. Ten foreign Landsat receiving, processing, and data distribution facilities now exist around the world. Some 125 countries own meteorological satellite receiving stations. Remote sensing projects have resulted in research on the oceans, winds, waves, snow cover, and snow melting. When nations report their national space activities to the United Nations, the most frequent (and often the only) entry is a remote sensing agreement on the use of Landsat data and derived information products to solve resource problems.

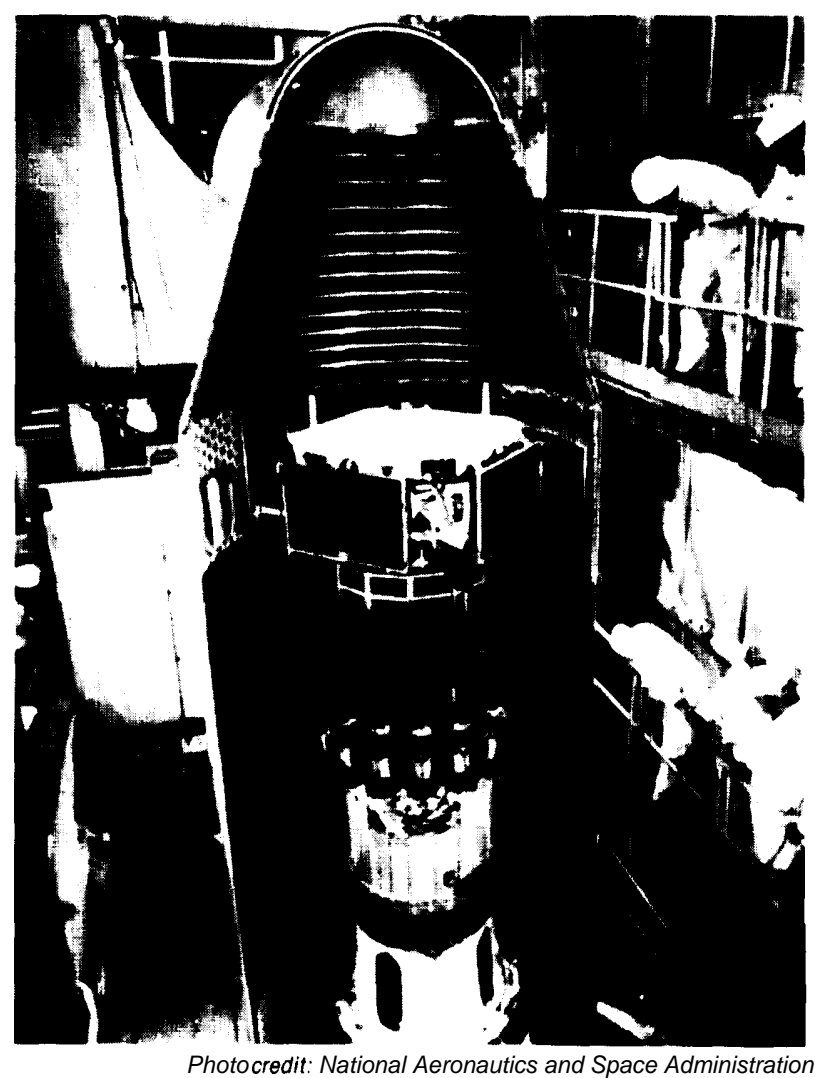

The Active Magnetospheric Particle Tracer Explorer (AMPTE) spacecraft is being encapsulated atop the Delta launch vehicle in preparation for launch (1984). AMPTE involves the United States, the United Kingdom, and the Federal Republic of Germany.

- Cooperative ground-based projects cover a wide spectrum of cooperative research and data analysis in such fields as remote sensing, communications, meteorology, and geodynamics. These often involve a combination of ground measurements with associated satellite data received at foreign stat ions.

- Cooperative educational projects. ${ }^{6}$ The Satellite Instructional Television Experiment (SITE) was a cooperative effort (1 975-76) between NASA, which furnished the ATS-6 communications satellite, and the Indian Space Research Organization, which devel-

6"United States Civilian Space Programs 1954- 1978," report prepared by Congressional Research Service for House Subcommittee on Space. 
oped programs on agriculture and family planning to broadcast to approximately 2,400 Indian villages. In 1976 the Agency for International Development (AID) and NASA sent films and discussions on remote sensing via the ATS- 6 experimental communications satellite to 27 participating developing countries. (Later the ATS-6 was moved to locations above the Western Hemisphere for further cooperative demonstrations.)

-U.S./U.S.S.R. cooperation. * These projects date from 1962, when NASA and the U.S.S.R. Academy of Sciences cooperated on meteorological studies. Between 1962 and 1964 there were experiments on telecommunications, and from 1962 to 1973 on geomagnetic mapping.

These early joint activities were based on agreements between NASA and the Soviet Academy of Sciences. In 1972, however, an intergovernmental agreement was reached between the Nixon Administration and the Soviet Government. One outcome of this agreement was the Apollo-Soyuz Test Project (ASTP), which culminated in 1975 in the only joint manned space flight between the two countries. Other areas of cooperation established under the agreement included meteorology, the natural environment, nearEarth space, the Moon and planets, and space biology and medicine. After the highly successful ASTP mission, the agreement was renewed by President Carter in 1977.

The centerpiece of the renewed agreement was the commitment to plan for a joint Salyut/Shuttle program. However, in 1978 and 1979 a series of events on the international political scene led to a progressive hardening in East-West relations. This trend culminated with the Soviet invasion of Afghanistan in late 1979 and the imposition of martial law in Poland. As part of the U.S. sanctions against the Soviet Union, the May 1977 ' agreement was allowed to expire without renewal in 1982. The only remnant was

\footnotetext{
*Seelssues in U. S.-Soviet Cooperation in Space (Washington, DC: U.S. Congress, Office of Technology Assessment, in press), for a comprehensive discussion of U.S./Soviet cooperation.

The "1 972 Intergovernmental Agreement on Cooperation in the Exploration and Use of Outer Space for Peaceful Purposes."
}

a low level of information exchange in space medicine and biology.

Recently, the climate in Congress and the Administration for renewed cooperation in space has improved. In the spring of 1984, members of the Senate Committee on Foreign Relations expressed interest in renewing and expanding U.S. cooperation with the Soviets. In July, the President proposed a joint U.S./Soviet mission to demonstrate the feasibility of space rescue. Such a mission cou ld serve as the cornerstone to increased cooperation in space with the Soviets. These interests culminated in a bill signed by President Reagan on October 30, 1984 (Public Law 98-562). Testimony presented at hearings on September 13, 1984 concerning the Senate bill indicated cooperation with the Soviets in several scientific disciplines related to space would be fruitful. ${ }^{8}$

The United States and the Soviet Union are both cooperating with France and Canada in the COSPAS/SARSAT search and rescue program. (See app. A.) The United States is also cooperating with the Soviet Union, through ESA, on the International Halley Watch (see ch. 9).

- The United States and China are cooperating on a communications broadcast satellite system, a Landsat ground receiving station, and aeronautical technology. The Shanghai Observatory of the Chinese Academy of Science is interested in cooperating with NASA on measuring Earth's crustal movements.

NASA's international program also encompasses resident research associateships for senior foreign scientists, international fellowships, technical training for foreign scientific and technical personnel, and hosting foreign officials and scientists who visit NASA's facilities.

\footnotetext{
${ }^{8}$ President Reagan discussed the subject in a meeting with Soviet representatives in June 1984, and in a speech on June 27. House Resolution 536 and the companion Senate Resolution 236 proposed the renewal of cooperation. See Issues in U.S./Soviet Cooperation in Space (U.S. Congress, Office of Technology Assessment, Technical Memorandum, in press); statement of Dr. Bernard Burke, before the Senate Committee on Foreign Relations, Sept. 13, 1984; "President Signs Bill Aimed at Restoring Cooperation in Space," Aviation Week and Space Technology, Nov. 5, 1984,p. 16; "U.S. Plans Soviet Talks on Joint Manned Mission, "Aviation Week and Space Technology, Jan. 7, 1985, pp. 16-18
} 
The U.S. capacity for international cooperative programs is dependent on a strong U.S. national program; if civilian space budgets become overconstrained, it becomes difficult to budget for the U.S. (NASA) share of planned joint international projects. In one case the United States had to back out of a major planned project because of budgetary constraints:

... NASA's success in international participation became a political liability in 1980-81 when, in order to absorb its share of the Administration's budget reductions, NASA found it necessary to reduce funding in one of its major science missions. The problem was that all three of its major science projects had significant international participation: Space Telescope (with ESA), Galileo/Jupiter orbiter probe (West Germany) and the International Solar Polar Mission (ESA). Because of the high cost of this international participation in space science, NASA, for the first time in its history, had to step back from an international commitment. NASA terminated development of the U.S. satellite for the international Solar Polar Mission. The project has been subsequently restructured and now includes only a single satellite built by Europe, but to be launched by NASA on the space Shuttle. ${ }^{9}$

Budget stringency has limited some of NASA's projects, but at the same time it has led to a different form of cooperation, relying on the newly developed capacities of other nations.

A prime example is the upcoming return of Halley's Comet. After reviewing its options, the United States decided not to mount a mission to Halley's Comet, while ESA, the Soviet Union, and Japan all decided to develop encounter missions. However, in order to provide important data and assure that U.S. scientists and the world scientific community would be able to fully participate in this historic event, NASA organized an International Halley Watch (IHW) program. IHW is an international network of groundbased observatories which will provide significant scientific and ephemeris [positional] data important for assisting the three Halley encounter missions... By sharing leadership in exploring the heavens with other qualified space-faring nations, NASA stretches its own resources and is free to pursue projects which, in

${ }^{9}$ UNISPACE '82, op. cit., app. B. the absence of such sharing and cooperation, might not be initiated. ${ }^{10}$ (Also see the more detailed discussion of IHW in ch. 9.)

Cooperation in building space infrastructure is perhaps the most important cooperative activity that the United States will embark upon this decade. It is keeping interested governments well informed of U.S. developments.' Japan and ESA have also funded their own studies of permanent stations in space. ${ }^{12}$ Recently, Canada and Japan have signed agreements with the United States entering upon phase $B$ (the preliminary design phase) of the space station planning. * ESA is expected to sign a similar agreement in June 1985.

Most future NASA international cooperation will raise a question as to whether bilateral arrangements can be emphasized as they have in the past. As shown by examples of multilateral cooperation in science such as the International Halley Watch, and on an even greater scale by international organizations governing satellite communications (i.e., INTELSAT and INMARSAT), multilateral cooperative efforts are manageable and may still be appropriate for certain technologies (e. g., navigation and search and rescue) in this era of emerging commercial competition. primarily because of the network of intergovernmental cooperation required, such technologies might not be implemented without multilateral cooperation.

Other U.S. Cooperative Programs in Space

\section{U.S. AGENCY FOR INTERNATIONAL DEVELOPMENT (AID)}

AID has over the years utilized new technology to support rural health, agriculture, and education programs in the Third World. In the early 1970s, immediately following its use of educational television in El Salvador and the Ivory Coast, AID examined the potential of satellites

\footnotetext{
${ }^{\circ}$ UNISPACE '82, op. cit., app. B.

'Aviation Week and Space Technology, Feb. 13,1984.

12 For a thorough discussion of possible international cooperation

in space stations, see Civilian Space Stations and the U.S. Future in Space (Washington, DC: U.S. Congress, Office of Technology Assessment, OTA-STI-241, November 1984),

*See Harry R. Marshall, Jr., "U.S. Space Programs: Cooperation and Competition From Europe, " Current Policy, No. 695, U.S. State Department, May 1985.
} 
for delivery of services to remote, isolated, and rural populations. It gave particular attention to the public service projects funded by NASA Goddard using the ATS/ 1 and the ATS/3 spacecraft. Providing very high frequency (VHF) voice channels, the spacecraft were used in the State of Alaska Medical Network project and in the Peace-Sat Network in the Central Pacific operated by the University of Hawaii.

Preliminary project prototype work by AID was started in the mid-1970s using ATS/6 in the Brazilian $\mathrm{SACl}^{13}$ project. AID also sponsored symposia for key Third World administrators to help them ascertain through "hands on" experience what indigenous needs might be met by applying lessons learned from the ATS/-I -3-6 demonstrations. They studied the use of various technology mixes (i. e., voice, slow-scan video, two-way audio interactions), and examined the variety of educational materials produced for parents, students, teachers, and administrators.

The results of these symposia prompted AID to fund a multinational 27-country demonstration project in 1976 called AI D/SAT, an immediate follow-on to the highly successful ATS/6 India Satellite Television Instruction Experiment (SITE) project. The AID/SAT project, simple in format but effective in its impact on the leadership of the participating nations, ${ }^{14}$ led eventually to AID's current University of West Indies project and its Rural Satellite Program. AID is now funding satellite programs in Peru, The Philippines, and Indonesia.

The Department of State is responsible for coordinating the diplomacy and policies of cooperative land remote sensing programs to assure consistent development of the international aspects of the Landsat program. AID has supported and encourages remote sensing activities in developing countries by providing U.S. experts, training, and demonstrations; project grants; financial and technical support for cooperative programs with U.S. industries and insti-

\footnotetext{
"3" SACI: USAID, Satellite Technology Demonstration, 1974-75," Towards International Tele-education (Boulder, CO: Westview Press, 1984), p. 115.

"See Civilian Space Policy and Applications (Washington, DC: U.S. Congress, Office of Technology Assessment, OTA-STI-177, June 1982), p. 208.
}

tutions; and financial support for education in U.S. universities, on-the-job training, and creation of national and regional remote sensing centers. Centers have been established in Nairobi, Kenya; Ouagadougou, Upper Volta; and Bangkok, Thailand. (See table 7A-1 in app. 7A.)

Other U.S. Government agencies have also assisted AID in providing foreign nations with Earth resources remote sensing information. The U.S. Geological Survey (of the Department of the interior) has sponsored numerous international remote sensing training programs at the EROS data center in Sioux Falls, SD, and in many foreign countries, all in support of the Landsat program. NASA provided technical support in the form of hardware, personnel, and computer software.

\section{The Soviet Union}

Like the United States, the Soviet Union has long recognized the value of international cooperation in space activities. Since the early 1960s the Soviet Union has stated its commitment in principle to such cooperation, but it was not until the 1970s that it began to practice what it professed-at least with a few partners. ${ }^{15}$ The most dramatic Soviet-U.S. cooperative activity was the Apollo-Soyuz Test Program, but the two countries engaged in a variety of other space science and remote sensing projects in the 1970s. More recently, the Soviet Union is cooperating with France, the United States, and Canada in the SARSAT/COSPAS project for locating lost ships and planes by satellite-relayed radio beacon (see app. A).

The Soviets have carried out several space science missions with France and have given considerable assistance to the Indian space program. They are active participants in multilateral organizations: governmental, such as the U .N. Committee on the Peaceful Uses of Outer Space (COPUOS); and nongovernmental, such as the

\footnotetext{
'5For a detailed description of overall Soviet international cooperation in space, see Joseph Whelan, "Soviet Attitude Toward International Cooperation Space" in U.S. Congress, Senate Committee on Commerce, Science, and Transportation Soviet Space Program: 1976-80, Part 1 Committee Print (Washington, DC: U.S. Government Printing Office, December 1982), pp. 205-305.
} 


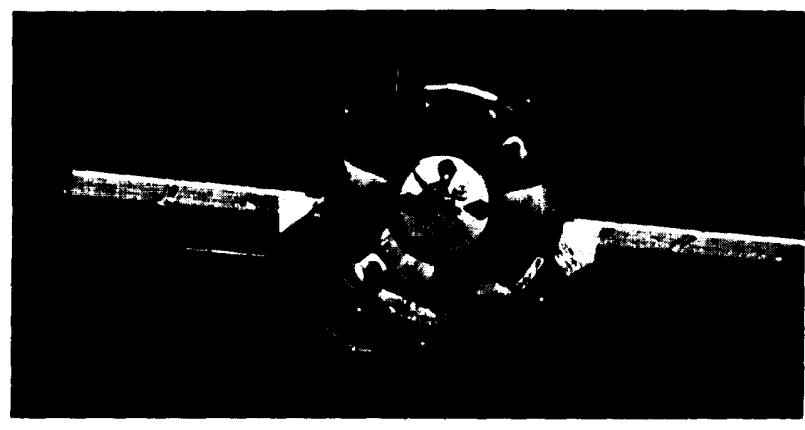

Photo credit: National Aeronautics and Space Administration

Photu of the Soviet Soyuz spacecraft taken from the Apollo spacecraft during the joint U.S.-U.S.S.R. Apollo Soyuz Test Project in 1975.

International Astronautical Federation. However their greatest cooperative activity has taken place within the confines of the Soviet-led Intersputnik and Intercosmos programs.

\section{Intersputnik}

The Soviet Union and its allies were reluctant to join INTELSAT when it was founded in 1964. The Soviet objected to U.S./COMSAT management, to the use of U.S. technology, and to the system of weighted voting whereby influence was determined by a country's percentage of use of the system. (Soviet need was for only 2 to 3 percent of global international traffic, compared with the United States' 50 to 60 percent.) In 1968, the Soviet Union and eight other socialist states (Poland, Czechoslovakia, East Germany, Hungary, Romania, Bulgaria, Mongolia, and Cuba) proposed an alternative system, which in 1971 was formally agreed to and called Intersputnik. Although its services are open for any state to use, few other countries have joined. ${ }^{16}$ There is relatively little commercial or private traffic between most Intersputnik members and the rest of the world. Since the Intersputnik network was initially based on use of the nongeosynchronous Molniya satellites, ' ' it was difficult and expensive for

\footnotetext{
${ }^{6}{ }^{6}$ Syria, Vietnam, and Laos joined for both political and technical reasons.

17 The Molniya communications spacecraft follow a highly elliptical orbit $(40,000 \mathrm{~km}$ by $500 \mathrm{~km})$ that allows them to linger for several hours over the northern latitude of the Soviet Union and spend very little time at southern latitudes. To provide continuous communications coverage, a total of 12 satellites have been employed. Although the Soviet Union is now beginning to deploy geostationary satellites as well, the Molniya satellites continue to provide most Soviet domestic and international services.
}

INTELSAT Earth stations, which are designed to work with fixed geosynchronous satellites, to make use of the moving Moiniyas.

In recent years, however, the Soviet Union has begun to orbit geosynchronous Statsionar satellites which are more accessible to global users. As their international communications needs have grown, the Soviet Union, Cuba, and Romania (to be followed soon by Poland) have also begun to use INTELSAT through Earth stations on their own territories. increasing de facto integration of global satellite communications appears to be occurring even in the absence of formal agreements.

\section{Intercosmos}

Most Soviet joint and cooperative projects have been conducted with allied socialist states. In 1967, the Intercosmos program was founded to coordinate activities among the Soviet Union, its East European allies, and other Communist states such as Mongolia, Cuba, and more recently Vietnam. Several scientific satellites have been flown, using instruments designed by member-states under the overall direction of the Soviet Union. Instruments and experiments, such as an East German multispectral camera built by Carl Zeiss Jena, have also flown on the Salyut series; many of these were associated with the flights of guest cosmonauts from participating states. To date, cosmonauts from Czechoslovakia, poland, East Germany, Bulgaria, Hungary, Romania, Mongolia, Vietnam, Cuba and, most recently, France and India, have been trained in the Soviet Union and spent time on board Salyut stations. The purpose of Intercosmos seems to be largely political; the Soviets thoroughly orchestrate these activities, and emphasize propaganda.

Intercosmos projects are designed and managed very differently from U.S. cooperative projects. The experiments and guest cosmonauts of member countries are invited, free of charge, onto Soviet spacecraft on a nearly rotating basis. However, it should be noted that this approach differs from that of the United States toward its

\footnotetext{
${ }^{18}$ See Nicholas Matte, Aerospace Law: Telecommunications Satellites, prepared by the Centre for Research of Air and Space Law, McGill University, for the Social Sciences and Humanities Research Council of Canada, 1980, pp. 118-123.
} 
allies only in degree and tone. Both nations are well aware of the manifold benefits of cooperation. A lengthy retrospective article on the subject by a former cosmonaut expressed it in the following way:

... space exploration requires considerable allocations. Quite often many costly space projects are beyond the means of individual states and demand the cooperation of a number of countries ... Now it is becoming important to create space vehicles through the joint efforts of various states and use them for peaceful scientific and practical purposes. ${ }^{19}$

\section{Remote Sensing}

The Soviet Union has also developed remote sensing systems for civilian as well as military purposes. Perhaps the most ambitious civilian-oriented remote sensing work has been done on manned missions, particularly aboard Salyut 6 . Some 50,000 photographs were taken using the large East German MKF-6m multispectral camera, and some of the data obtained has been shared with allied and developing countries, such as Cuba, Vietnam, Morocco, and Angola.

As a member of the World Meteorological Organization, the Soviet Union has distributed weather photos from its Meteor-series meteorological satellites since 1966. Meteor satellites have carried a variety of experimental sensors including, recently, advanced Earth resources instrumentation. In July 1980, the Soviet Union launched a prototype remote sensing satellite with three experimental multispectral sensors providing ground resolution up to $30 \mathrm{~m}$. They have offered to share data from this satellite with other countries.

\section{European Space Agency (ESA)}

One of the most successful examples of international cooperation in space is the European Space Agency, whose members devote anywhere from a third (France) to nearly all (United Kingdom) of their national space budgets to joint projects. In part, this organization was created to pool European expertise and place European

\footnotetext{
${ }^{19} \mathrm{~V}$. Sevastyanov and A. Ursul, "Cosmonautics and Social Development, 'International Affairs, No. 11, November 1977, pp. 76-77.
}

space industries in a better position to compete with U.S. industries. At the same time, ESA has proven to be a valuable partner for the United States in a variety of cooperative programs, not the least of which has been the development of Spacelab for the space Shuttle.

ESA was established on May 31, 1975, by combining two institutions: the European Space Research Organization (ERSO) (which had been in operation since March 20, 1964) and the European Launcher Development Organization (ELDO) (dating from March 29, 1962). The establishment of ESRO for space research and ELDO for launching satellites resulted from a desire on the part of Western Europe to achieve space capabilities independently of the United States and the U.S.S.R. The institutional separation of space research from the launching of satellites proved inefficient, however, and after 15 years of intercooperative effort these space functions were merged into ESA. ${ }^{20}$

Eleven European states are members: Belgium, Denmark, the Federal Republic of Germany, France, Ireland, Italy, The Netherlands, Spain, Sweden, Switzerland, and the United Kingdom. In addition, Austria is an associate member; Norway has observer status; and Canada has signed a memorandum of association with ESA. The 1984 budget is about $\$ 850$ million (compared with NASA's $\$ 7.3$ billion) and the staff numbers about $\mathrm{J}, 400$ persons, many of whom are highly accomplished experts in space science and technology, ${ }^{21}$

ESA coordinates the national programs of its members, developing missions in remote sens-

\footnotetext{
${ }^{20} \mathrm{ELDO}$ and ESROare described and analyzed in "International Cooperation and Organization for Outer Space, " staff report edited by Eilene Galloway for the Senate Committee on Aeronautical and Space Sciences, Senate Document No. 56, 89th Cong., 1st sess., Aug. 12, 1965. See Index, p. 564; "International Cooperation in Outer Space: A Symposium, " edited by Eilene Galloway for the Senate Committee on Aeronautical and Space Sciences, Senate Document No. 92-57. 92d Cong., 1st sess., Dec. 9, 1971; M. G. Bourely, "The Legal Status of the European Space Agency," Proceedings of the International Institute of Space Law published by the American Institute of Aeronautics and Astronautics, 1633 Broadway, New York, NY 10019, 23d Colloquium, Tokyo, Japan; M. G. Bourely (Legal Advisor to ESA). "Institutional Arrangements for Space Cooperation in Europe, " in the 24th colloquium volume for Rome, Italy, September 1981.

21 European Space Agency in U. N. document A/COBNF.101/BP/ 10, Jan. 30, 1981, pp. 34-40.
} 


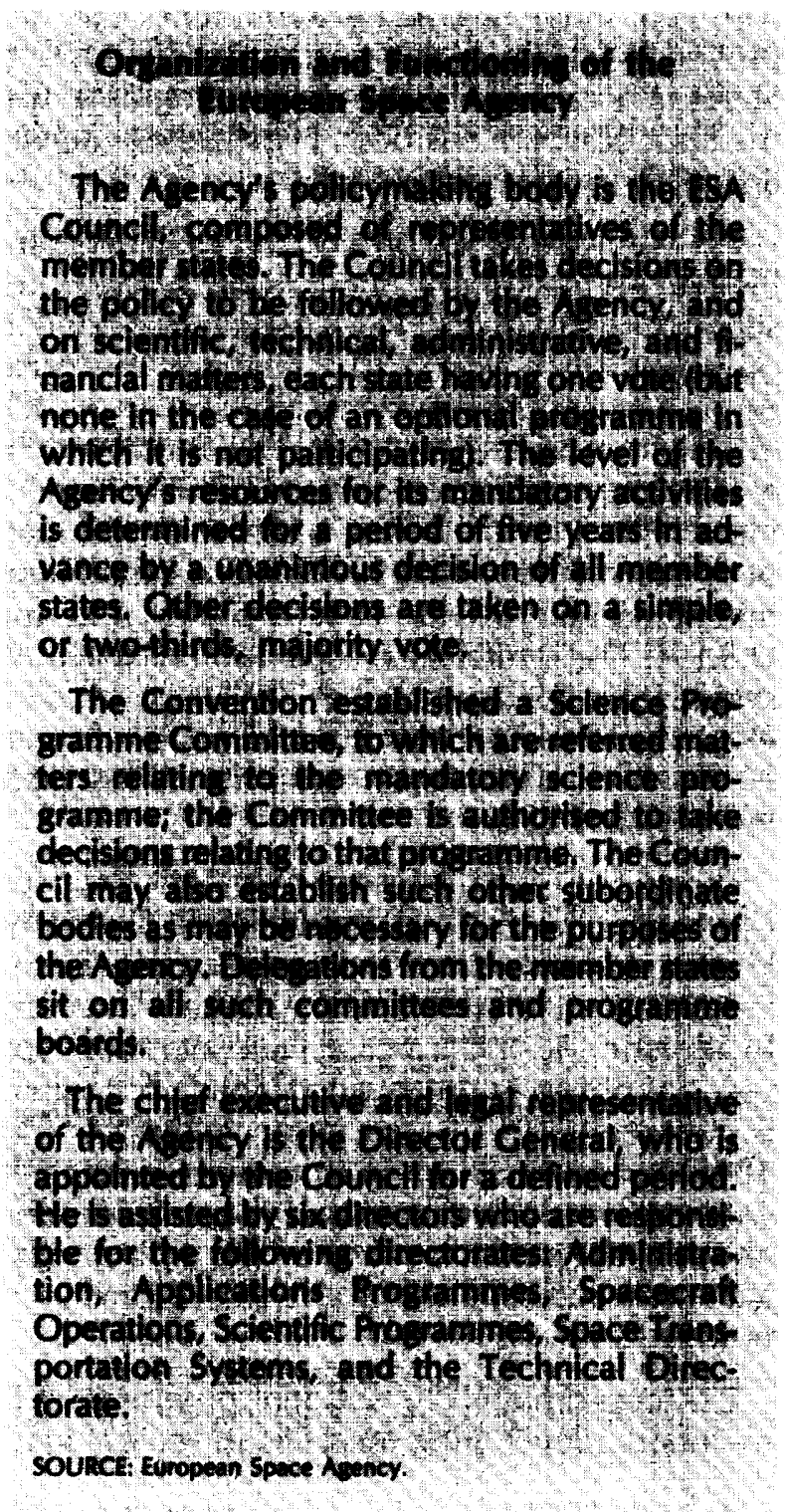

ing, telecommunications, and space science, in addition to the Ariane launcher, which can place satellites in geostationary orbit. Because of the relatively limited budget, cooperative ventures are quite important to ESA as a means of broadening the basic agenda of missions. Joint ventures with individual member countries having an interest in specific areas (e.g., Germany in materials processing, or the U.K. in astronomy) are the most prominent mechanism.
ESA has also developed major cooperative programs with the United States on the basis of memoranda of understanding with NASA (i.e., agency-to-agency agreements), The U.S. Space Shuttle has orbited the ESA-built Spacelab, a reusable laboratory for manned or unmanned experiments in life sciences, materials processing, etc. NASA and ESA are also cooperating on building the Space Telescope which will be launched in 1985 by the Shuttle. ESA has not cooperated formally with Japan. It is cooperating with them on the missions to Comet Halley.

Although only an observer at meetings of the United Nations Committee on the Peaceful Uses of Outer Space (COPUOS), ESA has developed stronger ways of participating with the United $\mathrm{Na}$ tions through representation by its member states. As an international intergovernmental organization, ESA has rights and obligations under three space treaties (assistance to astronauts and return of space objects, liability for damage, and registration of space objects). The 1967 Treaty on Outer Space applies only to sovereign states, but the other agreements have provisions which have been extended to ESA by legal actions taken by its member states. (See the discussion of these treaties in the following section.)

ESA has an International Relations Advisory Committee which reports directly to the ESA council and coordinates national positions on issues before COPUOS. The Committee plays a considerable role in the preparation of ESA members for International Telecommunication Union (ITU) conferences. ESA experts can advise its members concerning positions to take on space issues before COPUOS. The association of Canada with ESA can result in even stronger representation of any position ESA may decide to espouse .22

\footnotetext{
**See Roy Gibson, "International Regional Role: Focus on the European Space Agency" presented at the University of Mississippi Law Center at a conference on Law and Security in Outer Space held by the Standing Committee on Law and National Security and the International Law Section of the American Bar Association, University of Mississippi, May 21-22, 1982. See also Annual Reports of ESA, 8-10, rue Mario- Nikis, 75738 Paris, Cedex 15, France.
} 


\section{INTERNATIONAL ORGANIZATIONS}

\section{The United Nations \\ The Committee on the Peaceful Uses of Outer Space}

The first meeting of the United Nations Committee on the Peaceful Uses of Outer Space (COPUOS) was held on November 27, 1961, several years after the initial efforts had been made to establish a means for dealing with space issues. The Committee itself was a direct outgrowth of controversy over the militarization of space. The question of disarmament had prompted the U.S. delegation to the U. N., in January 1957, to make the following statement to the First Committee of the General Assembly (Political and Security Affairs):

Scientists in many nations are now proceeding with efforts to propel objects through outer space and to travel in the distant areas beyond the Earth's atmospheric envelope. The scope of these programs is variously indicated in the terms "Earth satellite," "intercontinental missiles," "long-range unmanned weapons" and "space platforms." No one can now predict with certainty what will develop from man's excursion into this new field. But it is clear that if this advance into the unknown is to be a blessing rather than a curse the efforts of all nations in this field need to be brought within the purview of a reliable armaments control system. The United States proposes that the first step toward the objective of assuring that future developments in outer space would be devoted exclusively to peaceful and scientific purposes would be to bring the testing of such objects under international inspection and participation. In this matter, as in other matters, the United States is ready to participate in firm, balanced, reliable systems of control .23

This was probably the first mention of "Earth satellites" in U.N. debate. In the same year, Canada, France, and the United Kingdom had also suggested that a subcommittee of the Committee on Disarmament establish a technical committee to study the possibilities for an inspection system which ensure that objects sent through

\footnotetext{
${ }^{23}$ U .S. statement to First Committee, Political and Security Affairs U.N. General Assembly, January 1957.
}

outer space would be used exclusively for peaceful and scientific purposes.

With the launch of Sputnik 1 on October 4, 1957, came a proliferation of statements and resolutions, including the following phrase, which the Soviet representative proposed be included in the provisional agenda of the 13th session of the U.N. General Assembly:

The banning of the use of cosmic space for military purposes, the elimination of foreign military bases on the territory of other countries, and international co-operation in the study of cosmic space.

The reaction of the United States to this Soviet proposal was to say that the elimination of defense bases, originally established and subsequently maintained by the mutual consent of the nations concerned, could not be characterized as "foreign" nor extracted as a price for international cooperation in the peaceful uses of the new environment of outer space.

Henry Cabot Lodge, Permanent Representative of the United States to the U. N., attached to his letter to the Secretary General a resolution sponsored by 20 nations which set out the need for what ultimately became the Committee on the Peaceful Uses of Outer Space (table 3-2). ${ }^{24}$

The General Assembly resolution 1348 (X111) December 13, 1958, authorized an "Ad Hoc Committee" on the Peaceful Uses of Outer Space. The Soviets, Czechoslovakia, Poland, India, and the United Arab Republic-all of which had been named to the Committee-did not participate, although they were careful to attend each subsequent meeting.

The ad hoc committee finished its work on June 25,1959 , and submitted its report to the General Assembly on July 14, 1959. Almost $2^{1}$ A years

\footnotetext{
${ }^{24}$ During the following months, Sept. 2-Nov. 18, 1958, the debate on the proposed U.N. management unearthed a number of issues of concern, not the least being questions of the sovereign rights of airspace, common heritage (then called res communisominum -benefit of all mankind), international training and an international space center. All of the foregoing were major issues at the UN ISPACE ' 82 conference in Vienna and most are far from being resolved.
} 
Table 3.2.-Current Membership of COPUOSt

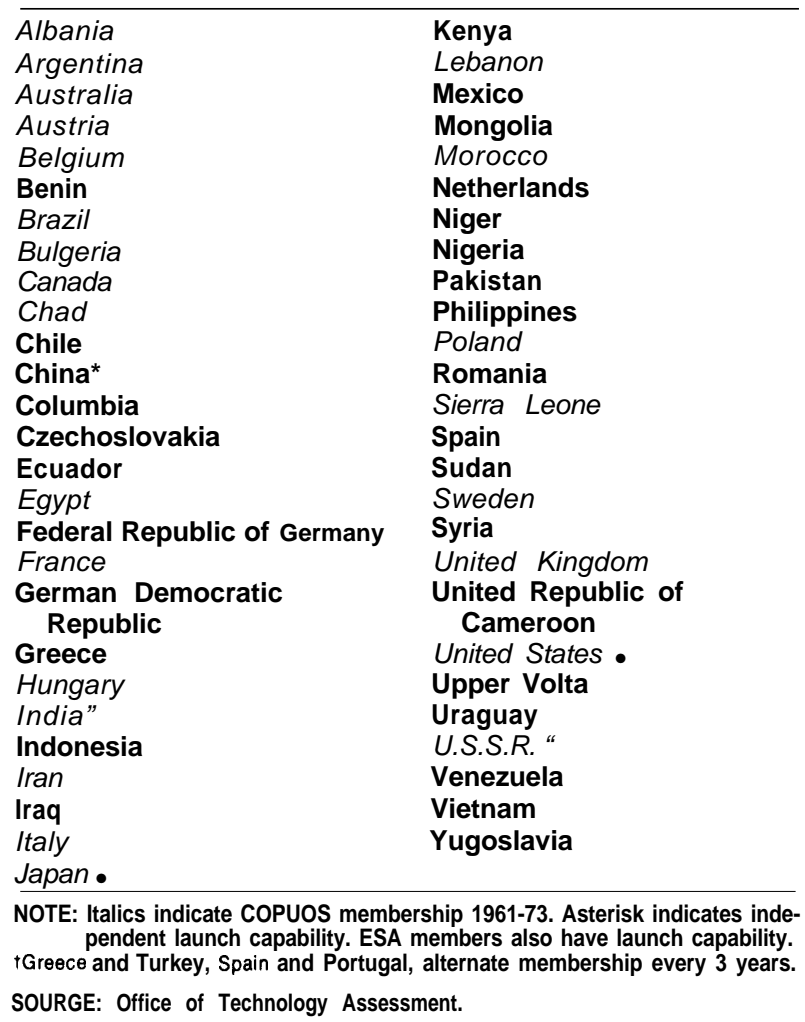

later, at the first meeting of the Committee on the Peaceful Uses of Outer Space. U Thant, Acting Secretary General of the U. N, was appointed temporary Chairman pending the election of officers. At the same time, the U.S.S.R. became an active participating member of the Committee. in the interim between ad hoc status and permanent committee approval, the members agreed to settle differences by consensus agreement, That the consensus process worked is borne out by the formation of five major space treaties and agreements which are now in force to guide international behavior in space. ${ }^{25}$

\section{Treaties and Agreements}

The United States is a party to four major international agreements formulated by COPUOS:

-Treaty on Principles Governing the Activities of States in the Exploration and Use of Outer Space, Including the Moon and

\footnotetext{
${ }^{25}$ See "International Cooperation in Outer Space: A Symposium, "
} op. cit.
Other Celestial Bodies (1967). ${ }^{26}$ This is the principal agreement on outer space. It holds that outer space, the Moon, and other celestial bodies are not subject to national appropriation. In addition, among other things, the treaty defines the principles for the exploration and use of outer space and holds States responsible for their own space activities and those of their citizens. The other agreements elaborate on elements of the 1967 Treaty.

- Agreement on the Rescue of Astronauts, the Return of Astronauts, and the Return of Objects Launched Into Outer Space (1968). ${ }^{27}$ This agreement provides for the rescue and return of downed or stranded astronauts as well as the return of a space object and "its component parts. "It specifies that "the State responsible for launching" shall pay the expenses for recovering and returning the space object or its parts.

- Convention on International Liability for Damage Caused by Space Objects (1972). ${ }^{28}$ This convention is an extension of articles VI and VII of the 1967 treaty. It defines "damage" as loss of life, personal injury, impairment of health, loss or damage to property or persons or property of international organizations. "Launching" is held to include attempted launching, and a "launching State" is one that either launches or procures the launch of a space object. It is also one "from whose territory or facility a space object is launched."

- Convention on Registration of Objects Launched Into Outer Space (1974). ${ }^{29}$ The information registered includes the name of

26UST 2410; TIAS 6347; Senate Report No. 8, 90th Cong., 1st sess. Apr. 17, 1967; Senate Committee on Aeronautical and Space Sciences, 90th Cong., 1st sess., staff report on "Treaty on Principles Governing the Activities of States in the Exploration and Use of Outer Space," committee print, 1967.

${ }^{27}$ UST 7570; TIAS 6599;" Agreement on the Rescue of Astronauts, the Return of Astronauts, and the Return of Objects Launched Into Space: Analysis and Background Data;" Senate Committee on Aeronautics and Space Science, 90th Cong., 2d sess., committee print, July 16, 1968

28UST 2389; TIAS 7762; Senate Committee on Aeronautics and Space Sciences, 92d Cong., 2d sess., staff report on "Convention on International Liability for Damage Caused by Space Objects, " committee print, 1972.

${ }^{29}$ TIAS 8480; Senate Committee on Aeronautical and Space Sciences; 94th Cong., 1st sess., staff report on "Convention on Registration of Objects Launched Into Outer Space," committee print, 1975. 
the launching State or States, an appropriate designator or a registration number, the date and territory of the launching, the initial basic orbital parameters including the nodal period, inclination, apogee, perigee, and the general function of the space object.

In addition to the four international agreements which the United States has signed and ratified, the General Assembly has recommended to States the adoption of the Agreement Governing the Activities of States on the Moon and Other Celestial Bodies (1979). ${ }^{30}$ Among other things this Agreement provides for the use of the Moon "exclusively for peaceful purposes. "It also provides that "the exploration and use of the Moon shall be the province of all mankind and shall be carried out for the benefit and in the interests of all countries, irrespective of their degree of economic or scientific development. "It further states that "the moon and its natural resources are the common heritage of mankind ..." Austria became the fifth nation to ratify the Moon Agreement on June 11, 1984; it is now in force, the other parties being the Philippines, Chile, Uruguay, and The Netherlands. The United States played a major leadership role in obtaining consensus in 1979 on the Moon Agreement in the COPUOS session. However, while the United States and U.S.S.R. are parties to all other space treaties, neither has signed this one.

Of particular importance to potential private operators of space systems is Article VI of the 1967 Outer Space Treaty which states:

States Parties to the Treaty shall bear international responsibility for national activities in outer space, including the Moon and other celestial bodies, whether such activities are carried on by governmental agencies or by nongovernmental entities ., . The activities of nongovernmental entities in space ... shall require authorization and continuing supervision by the appropriate State party to the treaty.

Although the terms "authorization" and "continuing supervision" have been interpreted in various ways, article VI clearly requires some form

\footnotetext{
${ }^{30}$ U.N. General Assembly Resolution A/34/68, Dec. 14, 1979; Senate Committee on Commerce, Science, and Technology, 96th Cong., 2d sess., "Agreement Governing the Activities of States on the Moon and Other Celestial Bodies, " committee print, 1980.
}

of licensing and adherence to government-imposed regulations.

Similarly, Article II of the 1972 Liability Convention makes the launching State responsible for personal and property damage caused by any satellites or launchers even if they are no longer under the operation or direct control of the government. At a minimum, the government would require assurance that the owner of the satellite system had purchased adequate insurance to cover possible damages.

The U.S. Government has not yet decided on the precise mechanisms of ensuring that private corporations comply with international treaty obligations. Given the importance of this technology to U.S. foreign affairs, it is clear that the Department of State must play a major role.

\section{International Telecommunication Union (ITU)}

The United States is one of 155 nations bound by treaty to cooperate within the structure of the ITU for the use of technical facilities for telecommunications of all kinds. The ITU, which became a specialized agency of the United Nations in 1947, has performed this regulatory function since 1932. Twentieth-century communications technology imposed the requirement for international cooperation to ensure technical efficiency and prevent harmful interference between nations and stations in the use of the radiofrequency spectrum. During the early development of space communications, the ITU began to study its implications, since all space objects communicating to Earth require radio services which are under ITU jurisdiction. ${ }^{31}$

\footnotetext{
${ }^{31}$ The ITU was formed from the International Telegraph $\mathbf{U} \mathbf{n}$ ion (begun in 1865) and signatories to the International Radiotelegraph Convention. For further information on the ITU, see "International Cooperation in Outer Space: A Symposium." This symposium covered 41 organizations in 1965, divided into four categories: U.S. and International Space Cooperation, United Nations and Outer Space, Intergovernmental International Organizations, and Inter. national Scientific Community and Professional Associations. For up-to-date information on these and other organizations, see the annual report of each and also testimony their officials have given before House and Senate Committees on Commerce, Space, Science and Technology, Foreign Relations, Foreign Affairs, etc.
} 
The ITU is organized into four permanent bodies: 1 ) the General Secretariat; 2) the International Radio Consultative Committee (CCIR); 3 ) the international Telegraph and Telephone Consultative Committee (CCITT); and 4) the International Frequency Registration Board (I FRB). The CCIR and CCITT are technical study groups; the IFRB is concerned with orderly and effective use of the radio spectrum and orbital slot allocations, in order to reduce communications interference. All member States are represented in the Plenipotentiary Conference, which meets every 5 to 8 years and elects an Administrative Council of 36 members to coordinate ITU work between sessions.

A Plenipotentiary Conference was held September-October 1982 in Nairobi, Kenya, to review the ITU Convention (adopted in Madrid in 1932 and amended in Malaga-Torremolinos, Spain, in 1973) ${ }^{32}$ There were a few important actions that are worthy of note: plans for a major world administrative conference on telegraph and telephone in 1988; greater status for the Consultative Committee on Telegraph and Telephone (CCITT); increased ITU involvement in development assistance for Third World members; clearer recognition of Third World needs with respect to the geostationary orbit; a newly elected leadership; and a relatively modest budgetary increase of 26 percent over the next 7 years.

ITU decisions are made by the regional or worldwide administrative conferences established to revise ITU regulations. The ITU concluded international agreements concerning space communications in 1959, 1963, 1965, $1971,1973,1977$, and 1979. When the final acts of a conference are concluded they are referred to each ITU member for ratification. [n the case of the United States, these final acts must be submitted to the Senate for its advice and consent. The jurisdiction of the ITU includes oversight of the geostationary orbit; it registers orbital positions and assigns satellite frequencies. The 1973 Telecommunication Convention and Final Protocol, Article 33, provides a basic agreement on space communications:

\footnotetext{
${ }_{32}$ " Final Acts of the Plenipotentiary Conference, " Nairobi, Kenya, 1982. ITU Document. See also, hearing before the Subcommittee on International Operations of the U.S. House Committee on Foreign Affairs, Feb. 22, 1983.
}

\begin{abstract}
Members shall endeavor to limit the number of frequencies and the spectrum space used to the minimum essential to provide in a satisfactory manner the necessary services. To that end they shall endeavor to apply the latest technical advances as soon as possible. In using frequency bands for space radio services Members shall bear in mind that radio frequencies and the geostationary satellite orbit are limited natural resources, that they must be used efficiently and economically so that countries or groups of countries may have equitable access to both in conformity with the provisions of the Radio Regulations according to their needs and the technical facilities at their disposal (emphasis OTA' $s)^{33}$
\end{abstract}

The ITU divides the world into three regions for regulatory purposes; in 1979 spectrum allocations were made for Region 1 (Europe, U. S. S. R., Mongolia, and Africa) and Region 3 (Asia except U.S.S.R. and Mongolia) and Australia. The United States is in Region 2, which is comprised of North and South America and Greenland. The ITU made spectrum allocations for Region 2 in 1983. It is at these regional conferences where decisions are made by majority vote that issues which significantly affect the future of this nation's communications are decided. The issues are technical but have become increasingly susceptible to political influences in a forum where each nation has one vote. ${ }^{34}$

The ITU has scheduled a World Administrative Radio Conference on the Use of the Geostationary Orbit for 1985 and 1988. Its first session will be held in 1985 in Geneva (ORB '85), and the second in 1988 (ORB '88). Policy is now being formulated for the U.S. delegation for this politically sensitive area. Some equatorial countries continue to claim sovereign rights to segments of the orbit above their territories; other Third

\footnotetext{
${ }^{33}$ International Telecommunication Convention, ch. III, Art. 33, Rational Use of the Radio Frequency Spectrum and of the Geostationary Satellite Orbit, paragraphs 130 and 131. Treaty and International Agreements Series (TIAS); also in Space Law, op. cit. (reference 15), pp. 86-87.

${ }^{34}$ Proceedings of the International Institute of Space Law, 23d Col loquium, Tokyo, Japan, September 1980: M. A. Rothblatt, International Cooperation in Regulating $12 \mathrm{GHz}$ Band Geostationary Satellite Communications Technology, Geopolitics and the Common Heritage of Mankind, pp. 189-195. Also, Ronald F. Stowe Implications of the 1979 WARC for $12 \mathrm{GHz}$ Satellite Services in Region 2, pp. 93-95. American Institute of Aeronautics and Astronautics, 1633 Broadway, New York, NY 10019.
} 
World countries are demanding orbit allocations even though they have no present plans for using the geostationary orbit (see ch. 6). Actions taken at this conference will affect INTELSAT, INMARSAT, U.S. domestic communications, and international space activities in general.

The U.S. national paper for UNISPACE '82, March 23, 1982, ${ }^{35}$ points out that the ITU's WARC 1979 proved that international consensus on regulating and managing the frequency spectrum and geostationary orbit is possible: the capacity for channels of the fixed, broadcast, and mobile satellite services was increased; remote sensing satellites were given new allocations; and small Earth terminals and two-way communications links were facilitated. However, the United States has stated that the WARC 1985-88 conference "may be crucial in determining whether a comprehensive international regulatory system can be maintained which will continue to facilitate the flow of the benefits of communications satellite technology to developing countries. "The United States has submitted to the ITU some options and criteria for technological adjustments to communication needs. In addition, the United States is directing research and development efforts toward improving the use of the limited resources of orbit and frequencies (see ch. 6 for discussion of issues the United States will face at WARC '85-'88).

\section{International Telecommunications Satellite Organization (INTELSAT) ${ }^{3}$,}

INTELSAT is a global commercial telecommunications satellite system owned by 109 member countries. it has a capital ceiling of $\$ 1.2$ billion.

5united States National paper, Second United Nations Conference on the Exploration and Peaceful Uses of Outer Space. For further details on WARC '79, see Radio frequency Use and Management: Impacts From the World Administrative Radio Conference of 1979 (Washington, DC: U.S. Congress, Office of Technology Assessment, OTA-CIT-163, January 1982).

${ }^{36}$ For further information on INTELSAT, see INTELSAT:1984 An nual Report, 490 L'Enfant Plaza, SW, Washington, DC 20024; INTELSAT: report describing the organization; Multilateral Intergovernmental Cooperation in Space Activities, Background Paper, Second United Nations Conference on the Exploration and Peaceful Uses of Outer Space, United Nations document A/CON F/101/BP/I O, Jan. 30, 1981, pp. 1 -27; and Current and Future State of Space Technology, Background Paper, Second United Nations Conference on the Exploration and Peaceful Uses of Outer Space, United Nations document A/CONF.1010/BP/2, Mar. 16, 1981, pp. 6-7.
The United States played a major part in establishing this intergovernmental organization. For the first 6 years of its operation, the Communications Satellite Corporation (COMSAT) managed INTELSAT under a contract from INTELSAT's Board of Governors. Since 1977, INTELSAT has been operated administratively and technically by an international secretariat.

INTELSAT is not an agency of the United Nations, but it has some cooperative agreements with the ITU, The organization has successfully combined both governmental and nongovernmental entities into a global commercial service. INTELSAT'S management structure provides a system within which to solve problems of national representation, investment shares, and equitable access to technology; these issues are resolved through technological solutions, seldom subject to current political rhetoric; furthermore, these practical solutions respond to the global demand for communications services, which has been constantly increasing and providing mounting profits.

INTELSAT's Operating Agreement provides in Article 6 that " . . . each signatory shall have an investment share equal to its percentage of all utilization of the INTELSAT space segment by all signatories.' The U.S. investment share (1984), which comes through COMSAT (as signatory for the United States), is 23.1 percent. The United Kingdom owns the next highest investment share, of 12.9 percent. $^{37}$

U.S. participation takes place within each of INTELSAT's four organizational units: 1 ) the Assembly of Parties is made up of governmental representatives who meet every 2 years to determine policies and long-term objectives; each member has one vote; 2) the Meeting of Signatories is comprised of either governmental or government-designated telecommunications entities that meet annually on such matters as capital investment and shares, approval of Earth stations for access to INTELSAT services, allotment of satellite capacity, and adjustment of charges; each signatory has one vote; COMSAT casts the

\footnotetext{
${ }^{37}$ See ch. 6 for a complete list of I NTELSAT members, signatories, and investment shares, and the INTELSAT Annual Report for investment shares of any given year.
} 
U.S. vote; 3) the Board of Governors is composed of signatory members who have an investment share (either individually or in groups) of not less than a specific amount which is determined each year by the signatories. INTELSAT seeks to have about 20 members on the Board and, in addition, "up to five groups composed of at least five signatories from within the same ITU region ... regardless of the size of their investment shares"; and 4) the Executive Organ is headquartered in Washington, DC, and has a staff of about 400 persons from about 40 different nations.

The purposes of INTELSAT's definitive multilateral agreement, which recognizes the 1967 Treaty on Outer Space, are to provide advanced technology, efficient and economic facilities for the benefit of all mankind "with the best and most equitable use of the radiofrequency spectrum and of orbital space. "The preamble provides that "satellite telecommunications should be organized in such a way as to permit all peoples to have access to the global satellite system"; and ITU members that invest in the system will participate in "the design, development, construction, including the provision of equipment, establishment, operation, maintenance and ownership of the system. "\#38

Nonmembers may use the INTELSAT system and are charged on the same basis as the 109 members; 145 nations use INTELSAT services, including the U.S.S.R. INTELSAT has a program for assistance and development which can be especially helpful to developing countries. The program includes feasibility studies for Earth segment stations, reports on financing and technical proposals, modernization and training, operation and maintenance, and coordinating frequencies in accordance with ITU regulations. In some areas "1 NTELSAT has enabled developing countries to leapfrog over generations of communications technology without having to invest a great deal of time and money in a telecommunications satellite system of their own . . . "39

\footnotetext{
${ }^{38}$ International Telecommunications Satellite Organization (I NTELSAT) Agreement with Annexes and also Operating Agreement Relating to the International Telecommunications Satellite Organization (I NTELSAT). In Space Law, op. cit. (see reference 15), pp. 173-304.

${ }^{39}$ Multilateral Intergovernmental Cooperation in Space Activities, op. cit. (see reference 36), p. 21.
}

\section{International Maritime Satellite Organization (I NMARSAT) ${ }^{40}$}

The impetus to create INMARSAT ${ }^{4} 1$ came from the commercialization of this technology by COMSAT during the 1970s and from a resolution of the Intergovernmental Maritime Consultative Organization (IMCO), a specialized agency of the United Nations, which in 1974 called for a conference to establish an international maritime satellite system. The conference was held in London in 1975-76, and concluded with two agreements patterned after those which established INTELSAT: a Convention on the International Maritime Satellite Organization and an Operating Agreement on INMARSAT. Both agreements entered into force on July 16, 1979. INMARSAT, as established, is not a U.N. organization but is comparable to INTELSAT.

INMARSAT developed technologically from the U.S. Marisat satellite system, which was started by COMSAT General Corp. in 1976. The international system, which is fully compatible with the Marisat system, has 43 member states; headquartered in London, it began operations in 1982.

INMARSAT's purposes are to improve maritime communications to handle situations involving distress and/or safety, through communication between ships and shore and among ships at sea. INMARSAT's high-speed satellite communications have improved search and rescue missions, medical assistance, warnings of weather conditions, and information to assist navigation. INMARSAT is exploring the feasibility of establishing a Future Global Maritime Distress and Safety System by the end of this decade, which would improve maritime distress and safety procedu res.

\footnotetext{
40 For more information on INMARSAT, see International Maritime Satellite Organization, INMARSAT, 40 Melton St., EustonSq., London NW1 2EQ, England; Satellite Communications for Shipping. INMARSAT, London, England. Investment shares as of August 1981, p. 15.

41 INMARSAT, established to facilitate maritime comm ${ }_{\mathrm{u}}$ nica'on across the world's shipping lanes, is important because it represents an area of European rather than American leadership in space activities and because it marks, for the first time, the participation of the Soviet Union in an international commercial space organization.
} 
INMARSAT is structured as follows:

1. An Assembly of member states meets at 2year intervals to consider policy, activities, and long-range objectives for recommendation to the Council.

2. The Council has 18 signatories (or groups of signatories) which have the largest shares of investment and, in addition, four representatives to ensure fair geographical representation and concern for developing countries; it is responsible for the space segment and its economic and efficient management; members vote according to the percentage of their investment shares.

3. The Directorate has a Director General and staff responsible for the actual operation of worldwide maritime communications.

The United States has the largest investment share (31 percent), followed by the United Kingdom (15 percent), Norway (12 percent), Japan (7 percent), and the U.S.S.R. (7 percent) .42 Voting shares are limited to a maximum of 25 percent. The United States designated COMSAT as the signatory for its representation .43

The space segment of the INMARSAT system is composed of satellites and tracking, telemetry, command, monitoring, etc. Capacity to perform maritime communications has been leased from COMSAT General (a wholly owned operating subsidiary of COMSAT). INMARSAT leases some transponders from the European Space Agencythe Maritime European Communications Satellites and some from INTELSAT (V-MCS). Future INMARSAT satellites will have greater capacity and higher in-orbit power than the transponders it now leases. IN MARSAT has recently signed a contract for purchase of second generation satellites from a consortium headed by British Aerospace. Hughes Aircraft Corp. is the prime subcontractor.

\footnotetext{
${ }^{42}$ See app. $6 \mathrm{C}$ for a complete table of I NMARSAT members and Investment shares,

${ }^{43}$ International Cooperation in Outer Space: A Symposium, edited by Eilene Galloway for the Senate Committee on Aeronautical and Space Sciences. Senate document No. 92-57, 92d Cong., 1st sess., Dec. 9, 1971 (see pp. 331-363).
}

\section{World Meteorological Organization (WMO)}

The origins of the WMO can be traced back to 1853, when the first International Meteorological Conference was held in Belgium. Participants recognized the importance of sharing meteorological research and data. In 1873, the international Meteorological Organization (IMO) was organized. IMO became a specialized agency of the United Nations in 1947 and began functioning as the WMO in 1951. All sovereign states and territories with weather services may become members. WMO is not an international operational organization, but rather a planning and coordinating body with basic programs to assist all nations. It is a specialized agency with specific weather-related tasks that are planned with due regard for operating efficiency to produce needed information from global sources and for worldwide distribution. The WMO has been highly successful in eliciting cooperation among nations.

The United States launched the first meteorological satellite on April 1, 1960. When the U.N. General Assembly passed resolution 1721 (XVI) on December 20,1961, on the peaceful uses of outer space, it recommended that the WMO make an early and comprehensive study:

(a) to advance the state of atmospheric science and technology so as to provide greater knowledge of basic physical forces affecting climate and the possibility of large-scale weather modification; and

(b) to develop existing weather forecasting capabilities and to help member states make effective use of such capabilities through regional meteorological centers ...,

WMO was requested to consult with others and submit a report to its members and the Economic and Social Council (ECOSOC) "regarding appropriate organizational and financial arrangements to achieve those ends, with a view to their further consideration by the General Assembly. " In addition, the General Assembly requested COPUOS to review the WMO report and submit comments to ECOSOC and the General Assembly. These U. N.-initiated WMO studies led 
to plans for the World Weather Watch (WWW), which was organized to use the new satellite technology to improve meteorological services:

Such improvements will have a profound impact on the agriculture, commerce, and industry of all nations and will permit more accurate and timely warnings of severe storms and other weather hazards for the protection of life and property. It will further the safety and efficiency of international air traffic and transportation and provide essential support to nations in the management of weather resources and food production. ${ }^{44}$

An additional U.N. resolution in 1967 led to the organization of the Global Atmospheric Research Program (GARP), a joint project of the WMO and the International Council of Scientific Unions (Icsu).

WMO organizes symposia, workshops, seminars, and provides training courses and fellowships in atmospheric science and meteorology. WMO's Voluntary Assistance Program assists developing countries purchase satellite data receiving stations. The weather services of all countries now depend on information from satellites. Through WMO, global, regional, and national environmental data are collected from the satellites of Europe, Japan, the United States, and the U. S. S. R., and distributed among all nations.

\footnotetext{
${ }^{44}$ U.N. General Assembly Resolution 1721 (XVI) Dec. 20,1961.
}

WMO projections for the future emphasize that more international cooperation will be required, especially for the planned World Climate Program. In 1978, WMO requested a U.S. and a Soviet expert to evaluate the future need for environmental satellites, including those for meteorology. ${ }^{45}$

In discussions of the Legal Subcommittee of COPUOS, the United States has, for many years, been extremely careful not to commingle meteorological satellites of the NOAA/WMO type with land remote sensing. However, some delegates from other nations have discussed rules and regulations for all remote sensing satellites-civilian and military, meteorological, and general use as represented by the Landsat system.

For more than a decade, COPUOS, within its two operating subcommittees, the Legal Subcommittee and the Science and Technology Subcommittee, has discussed the formulation of principles which are subject to political differences such as the issue of prior consent to distribute data sensed from space. Prior consent has not been made an impediment to WMO/NOAA weather agreements or those of any other nation. However, the situation is now further complicated by U.S. national actions to turn the Landsat system over to the private sector (see ch. 7).

45"The Role of Satellites in WMO Programmed in the 1980s," World Weather Watch Report No. 36, Annex III.

\section{ISSUES IN COOPERATION}

The changing role of industrialized countries in space, and the aspirations of the developing countries, coupled with a relatively static U.S. approach to cooperation in space, have raised several important issues for the United States:

- How can the United States use its participation in international multilateral organizations and meetings on space to promote U.S. interests? The conduct and outcome of recent international meetings on space has not always been favorable to U.S. interests. In part, this has come about as a result of
U.S. attempts over the last few years to limit potential damage to its positions, while at the same time posturing itself to reduce its activities within the various organs of the United Nations that deal with communications, treaty, and regulatory matters.

- How can the United States cooperate most effectively with the developing countries? Developing and newly industrialized nations are demanding a greater voice in the use of the assets of outer space (e.g., apportionment of the geosynchronous orbit-see ch. $6)$, and a larger share of the perceived social 
and economic benefits. Their demands have taken the form of intense political pressure at the United Nations and elsewhere.

- On what terms might the United States most profitably cooperate with other industrialized nations? Greater competitiveness, both among governments and the private sectors of different countries, alters the context for cooperation and may make it more difficult to establish cooperative programs.

\section{Cooperating in International Organizations}

Space is by nature and treaty an international realm about which cooperation between nations on some level is essential, if only to avoid potential conflict over its resources. The United Nations and other multilateral organizations serve as the forums for countries to discuss their needs and resolve their differences, The various treaties that provide the framework for the international use of space were forged in the U.N. COPUOS.

When arranging the terms of cooperative technical agreements, the United States has preferred to cooperate bilaterally rather than multilaterally. Nonetheless it has actively participated in COPUOS and the International Telecommunication Union (ITU), and during the 1960s and 1970s it provided leadership in forging the five ratified space treaties and agreements. Today, however, the U.S. approach to international organizations in general, and to the United Nations i n particular, is exemplified by its behavior at the United Nations Conference on the Peaceful Uses of Outer Space (UNISPACE '82) and the ITU Plenipotentiary in Nairobi in October 1982, "The United States has been generally reluctant to concede that its interests can be promoted or seriously jeopardized at such conferences (i. e., UNISPACE '82). It approached UN I SPACE ' 82 warily and attended primarily to "limit the damage" that UN I SPACE '82 could cause to U.S. interests. "A6 Although the United States was effective at UNISPACE '82 in preventing wording inimical to U.S. interests from appearing in the final UNISPACE ' 82 conference report, it was less effective in using the confer-

${ }^{46}$ UNISPACE'82: A Context for Cooperation and Competition, op. Cit., p. 4. ence to promote and explain U.S. positions on outer space.

U.S. actions at recent conferences indicate that the United States has adopted a "damage limitation" approach to participating in multinational organizations. It has also threatened to withdraw on several occasions, Such a stance, if maintained, will leave the United States in the position of having to "go it alone," while others, both friends and potential adversaries, continue to operate in coalitions.

\section{The United Nations}

The United States played a leading role in the formation and development of the U.N. Committee on the Peaceful Uses of Outer Space. It encouraged cooperative programs with NASA and transfer of some space technology to industrialized and developing countries. U.S. programs have consequently helped them realize some of the benefits of space technology. Because of these efforts by the United States, and the rapid evolution of space industry, applications of space technology have become an integral part of the operations of several U.N. committees and U.N. specialized agencies such as the ITU, the Food and Agricultural Organization (FAO), the World Meteorological Organization (WMO), and the international Maritime Commission (IMCO).

Developing countries see the U.N. as their preferred agent for deliberation and guidance for space affairs as well as a forum in which to express their political views. Specifically, the U.N. Special Political Committee, under whose administrative management the Committee on the Peaceful Uses of Outer Space (COPUOS) functions (fig. 3-2), is the focus of their hopes and aspirations, fears and concerns with respect to space. It provides the major forum for space-related issues-new regulations, proposed restrictive regimes, and challenges to Western world policies, politics, and business practices. If COPUOS, which operates by means of consensus, fails to reach agreement on a given course of action, the Special Political Committee, which is dominated by the developing countries, may refer matters to the General Assembly for action. 
Figure 3-2.-U.N. Bodies

(A)

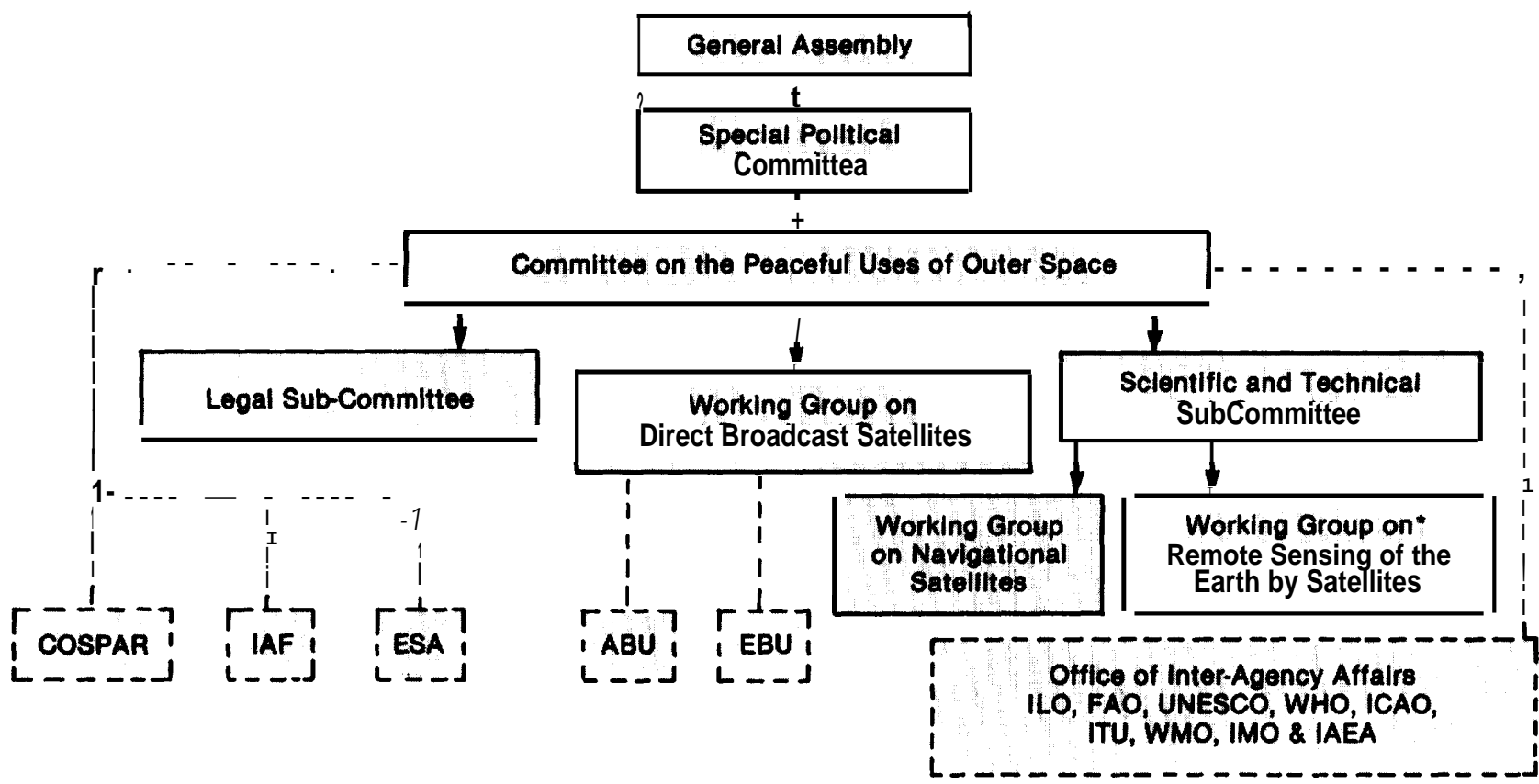

(B)

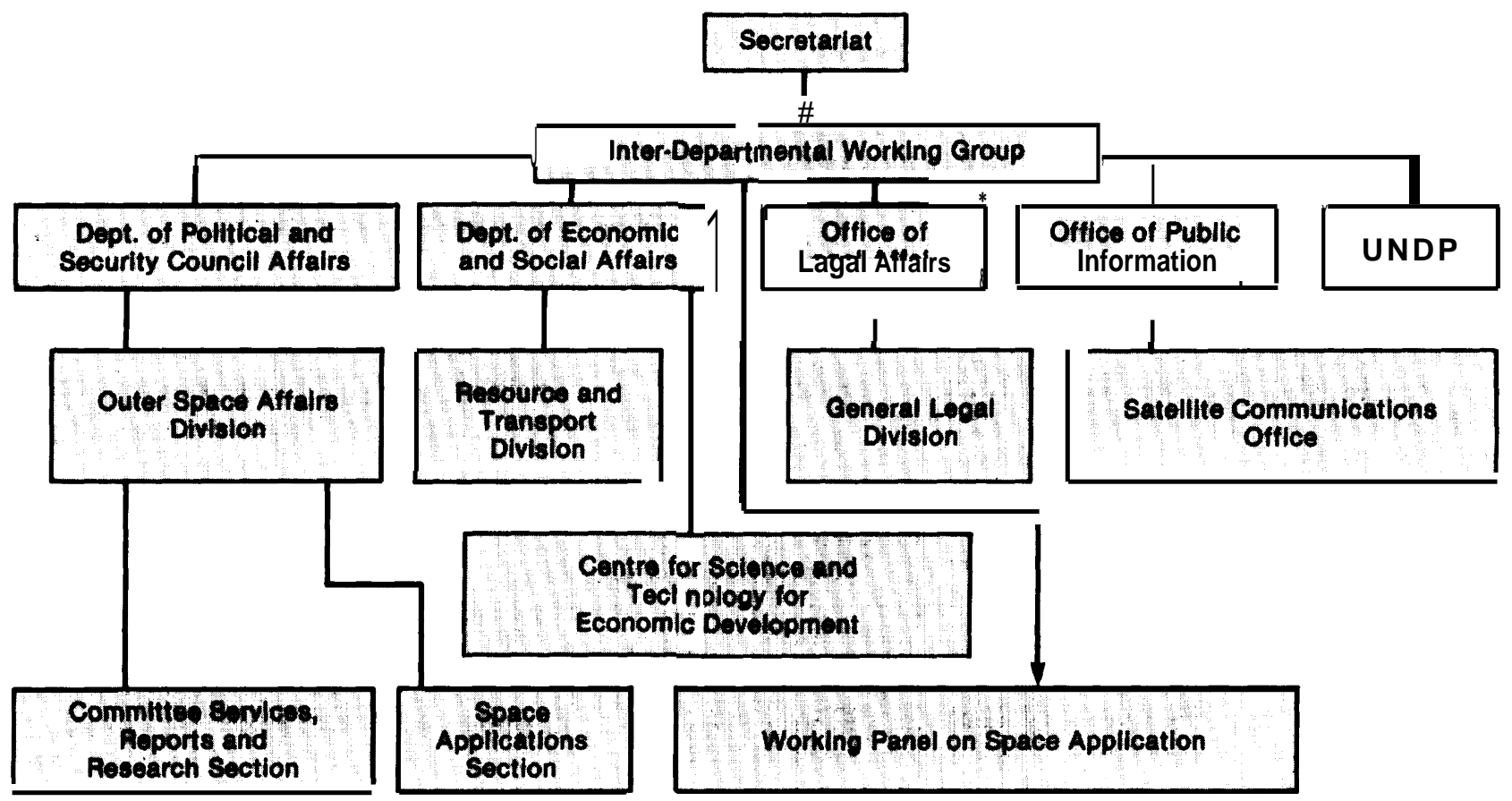


For example, one issue which COPUOS has deliberated for 10 years is that of direct broadcast satellites (DBS). The United States wants no restrictions imposed on the right to broadcast or otherwise to transfer information across national borders. Until 1982 it had been successful in preventing a restrictive set of principles on DBS from being adopted. However, in November of that year the developing countries, led by the G-77, demonstrated their willingness to take this unresolved issue directly to the General Assembly. The Special Political Committee, despite the objections of the United States and a few Western allies, removed the DBS issue from COPUOS and referred it to the General Assembly. The latter passed the resolution by a large majority and adopted a set of nonbinding principles governing the use of direct broadcast satellites. d' These principles endorse the right to "prior consent" to the nations receiving such broadcasts. Although nonbinding, the principles foster a disturbing trend of bringing political pressure on the United States and other industrialized countries at the expense of the consensus process.

Championed by the G-77, the use of majority voting rather than consensus may also be used to influence the outcome of other long-term issues of international debate, such as remote sensing and equitable sharing of the geostationary orbit. Members of the G-77 see the control of new technologies as necessary in order to change their societies in the directions in which they wish to move.

Currently, the U.S. response to the well-organized political pressure from the developing countries is to threaten to withdraw or curtail its

\footnotetext{
${ }^{47} \mathrm{~A} / \mathrm{SPC} / 37 / L$. 5/Rev, 1; nov . 19， 1982. Preparation of an International Convention on Principles Governing the Use by States of Artificial Earth Satellites for Direct Television Broadcasting (Argentina, Bolivia, Brazil, Chile, Colombia, Ecuador, Egypt, India, Indonesia, Iraq, Kenya, Mexico, Niger, Nigeria, Peru, Philippines, Romania, Uruguary, and Venezuela; revised draft resolution).

The relevant section reads:

Consultations and agreements between States.

A State which Intends to establish or authorize the establishment of an International direct television broadcasting satellite service shall without delay notify the proposed receiving State or States of such intention and shall promptly enter into consultation with any of those States which so requests.

An International direct television satellite service shall only be established after the conditions set forth in paragraph 1 above have been met and on the basis of agreements and/or arrangements in conformity with the relevant Instruments of the International Tele communication Union shall be exclusively applicable.
}

support for the organization in question. The United States has withdrawn from UNESCO and raised this possibility in the ITU, COPUOS, and the United Nations Conference on Trade and Development (U NCTAD). Each of the above organizations serve different purposes and the usefulness of U.S. participation in them may differ. The question of U.S. participation in one should be analyzed independently of participation in others. Although threat of withdrawal may appear to be an effective short-term tactic in some circumstances, its potential long-term cost in political, social, diplomatic, and economic terms may be too large a price to pay. Stressing, as the Administration does, that the U.N. has changed dramatically since the emergence of space technology, but refusing to change with it, is to circumvent the critical question of our political effectiveness within the U.N. Withdrawing from a given committee or specialized agency simply further reduces our effectiveness in working within multilateral forums on substantial issues that affect our interests i $n$ space .48

In the U.N. Secretariat, the office within which space issues are administered is the Outer Space Affairs Division (OSAD). Currently the United States has no high-level representation in OSAD, * although the Soviet bloc is well represented. Because allU.N. employees are international civil servants, countries cannot intervene directly in the personnel actions of the Secretariat. However, they can further their own interests by recommending the selection of citizens for the OSAD staff. The United States has not been as active as it could be in promoting U.S. interests in OSAD. ${ }^{*}$ * If the United States desires to increase its effectiveness in the United Nations, it should be alert to potential openings and plan in advance to recommend the appointment of qualified personnel. To such end, advance discussion with incumbents, U.S. departments and agencies, and foreign government and U.N. officials as appropriate, should be undertaken in timely fashion.

\footnotetext{
${ }^{48}$ UNISPACE '82. A Context for Cooperation and Competition, op. cit., p. $8,9$.

*See Unispace '82: A Context for International Cooperation and Competition, op cit., pp. 32-33, for an account of the selection of the Chief of OSAD prior to UNISPACE ' 82 , and how countries may become involved in the selection of U.N. personnel.

${ }^{* *}$ Ibid.
} 
In 1984, the United States drastically reduced its participation in the deliberations of COPUOS, which is the chief forum for international rules of outer space. The full Committee of COPUOS (composed of 53 member nations) is essentially a plenary session of its member nations to consider items on the agenda it adopts at the opening meeting of each session. Subjects assigned to its two subcommittees are routinely included and form a major part of its agenda. It is within these subcommittees that the United States over the years has been able to gain support of other nations for its positions in the full Committee and U.N. General Assembly sessions. The reports of the COPUOS subcommittees are also routinely included in the annual report COPUOS submits to the General Assembly. The General Assembly, after consideration of the COPUOS report, by resolution assigns the items for deliberation of the subcommittees at its next session. Although in the past the United States has maintained a leading presence in COPUOS and its subcommittees, and generally sends several delegates with a variety of expertise in space-related matters, it sent only one delegate to the February 1984 meeting of the Scientific and Technical Subcommittee of COPUOS. ${ }^{49}$ In 1985, the United States, by sending several experts to the COPUOS subcommittees, participated more fully in the ongoing work of the Com$\mathrm{m}$ ittee.

The uncertain stance of the United States toward COPUOS, arising from controversy within the Administration concerning the usefulness of COPUOS, has already had an adverse effect on how other countries perceive U.S. participation. A long-term drastic reduction in U.S. participation in COPUOS could send a message to the de-

\footnotetext{
${ }^{49} \mathrm{His}$ statement to that group reflects one point of view about the usefulness of U.S. participation in COPUOS:

Finally, Mr. Chairman, my delegation wishes to underscore that our doubts about the future usefulness of the committee have not in any way dissuaded the United States of the importance of international cooperation in the use of outer space. . Delegations can be sure that our many existing cooperate programs with other nations in space science and applications will continue to grow in the future. Nonetheless, we find it quite regrettable that the Committee on the Peaceful Uses of Outer Space now threatens to join the growing number of U.N. bodies that have grown increasingly impotent and irrelevant as a result of confrontation, politicization and rhetorical excesses.

Statement by Ambassador Jose S. Sorzano, U.S. Deputy Permanent Representative to the United Nations, to the Scientific and Technical Subcommittee of the Committee on the Peaceful Uses of Outer Space, Feb. 15, 1984.
}

veloping countries that the United States lacked interest in working with them in the peaceful application of space technology.

The importance of COPUOS to the world space community should not be underestimated. it is the one place where all countries, developing and industrialized alike, can discuss legal, scientific and technical issues related to space on a continuing basis. Attendees at both COPUOS subcommittees (the Legal Subcommittee and the Scientific and Technical Subcommittee) tend to have strong technical or legal backgrounds, and their discussions focus on legal and technical issues. To a large extent the discussions of these subcommittees are protected from overt political rhetoric.

Legal problems currently being discussed within the Legal Subcommittee include:

- the definition and/or delimitation of outer space;

- matters relating to the character and utilization of the geostationary orbit;

- legal implications of remote sensing of the Earth from space, with the aim of formulating draft principles; and

- the possibility of supplementing the norms of international law relevant to the use of nuclear power sources in outer space,

The Scientific and Technical Subcommittee has over the years discussed such issues as:

- Exchange of Information:

-National, regional and international programs.

-Governmental and nongovernmental space organizations.

-Manuals on technical requirements.

-World Data Centers.

-SPACEWARN communications networks.

- Encouragement of International Programs:

-International Year of the Quiet Sun,

-World Magnetic Survey.

-Synoptic rocket experiments,

- Polar cap experiments.

-Space communications.

- Satellite meteorology.

-Scientific and technological assistance, education and training. 
- International Equatorial Sounding Rocket Launching Facilities:

-Scientific value.

-Usefu Iness.

-Basic facilities.

Given the importance of the subcommittees to the work of COPUOS, it may not be possible to protect U.S. interests fully by cutting back drastically on U.S. participation either there or in the plenary sessions of COPUOS. Often, points of view at variance with the democratic principles of a free and open society could be debated, tempered, and sometimes changed within these subcommittees.

Although in the short run, the threat of cutting back drastically on U.S. participation at COPUOS may serve a useful political purpose in countering the perceived trend toward politicization of COPUOS, in the long term, reduced U.S. participation will lessen U.S. influence in international decisions on space activities. When the United States and the Soviet Union were the only two players in space, such a stance would have been more plausible than today, when all the major industrialized nations and several newly industrialized nations have increasingly strong space programs. In particular, as the U.S. private sector increases its investment in space technologies, it will need the support and encouragement of its Government in international forums such as COPUOS, where the private sector point of view is often misunderstood. By sending only one delegate to the Scientific and Technical Subcommittee in 1984, and one with relatively little technical or scientific expertise, the United States ran the risk of being perceived to be uninterested in the matters being discussed therein, and of itself contributing to the politicization of COPUOS. As noted, the United States sent more delegates to the Subcommittee meetings in 1985.

The International Telecommunication Union (ITU). Cooperation with other countries within the ITU has been crucial to maintaining access to frequencies the United States needs in order to support its Armed Forces, the Intelligence Community, its diplomatic missions, the Voice of America, and Radio Free Europe and indeed for everyone who wishes to use the electromagnetic spectrum. Similar cooperation will be necessary in the future if U.S. industry is to expand its sales of telecommunications equipment and services. Inherent in any multilateral undertaking is cooperation and compromise on the sometimes conflicting interests of parties to the process. This is generally attainable when technical managers apply their knowledge and understanding of the limitations of the usable spectrum to maximize its use for the maximum public good.

However, the technical experts must also work in the context of the political and economic interests of the countries they represent. This is why in the ITU the West faces strong political pressures from the group of nonaligned nations which function as the Group of 77 (G-77). The G-77 is committed to using international multilateral organizations to gain economic and political power. For example, at the ITU Plenipotentiary in Nairobi in 1982, the G-77 garnered strong support for a resolution condemning Israel for its invasion of Lebanon. After long and heated discussion, the United States, citing dangers to the international management of the electromagnetic spectrum if such strictly political issues were allowed to disrupt the workings of a technical group, threatened to pull out of the ITU if the vote carried.

The resolution condemning Israel failed by a scant four votes, demonstrating the power of the G-77. However, the United States cannot use the threat of a pullout in every instance of political concern. It is certain that the United States and its allies will face similar situations more often at the series of ITU meetings to be held over the next 5 years-all of which will address issues of great importance to the United States.

How the United States presents itself, or is perceived by others to present itself, to the rest of the world at multilateral conferences is a 
source of some concern to Congress. ${ }^{50}$ Yet, the question is not whether multinational organizations present the optimum means for the United States to pursue its cooperative programs, but, rather, whether the United States can use its participation in the ITU and other international organizations as opportunities for exerting leadership that would benefit the United States, including its space-related private sector industries.

Two critical issues, requiring global cooperative support, must be kept in the diplomatic forefront during this period of criticism of the U. N.: first, the White House commitment to the Space Station program and, second, the expansion of the U.S. private sector into U.N. member nations' markets for telecommunication goods and services. Those nations under criticism are now and will be in the future, in part, the same countries that NASA will eventually turn to for support and that the private sector will be asked to do business within an effort to reduce U.S. trade imbalances.

Attitudes established and policies created in one U.N. organization do carry over to others. As UN ISPACE ' 82 and the 1982 ITU Plenipotentiary in Nairobi clearly demonstrated, wherever possible the G-77 pursues its strategy of using U.N. and global conferences to demand changes in global resource allocation and technology t ransfer. ${ }^{51}$

Space Technology as a Tool for Development

Space technology has become increasingly important to some developing and newly industrialized nations because they have come to see it as a way to bypass intermediate stages of development and to become more independent of the industrialized countries. Cooperative space ventures can assist developing countries in this development process. For example, as chapter 7 points out, land remote sensing data have aided

\footnotetext{
50See hearing before the Subcommittee on Space Science and Applications of U.S. House Committee on Science and Technology, 97th Cong., July 14, 1982; hearing before the Subcommittee on International Operations of U.S. House Committee on Foreign Affairs, 98th Congress, Feb. 22, 1983.

5) UNISPACE '82: A Context for Cooperation and Competition, op. cit., p. 49.
}

both industrialized and developing countries to achieve better control over their agricultural and forestry planning. These data have also served as a powerful tool for locating needed nonrenewable resources.

As the SITE experiment in India demonstrated, satellite communication can help countries to "leapfrog" certain older technological developments and allow countries with inadequate terrestrial communications to build a strong educational and telecommunications network.

Space technology can be a powerful tool to accelerate national development: it provides a way of leap-frogging over obsolete technologies and getting away from percolation and trickle-down models of development for which developing countries do not have the time. It could effectively deal with the problems of illiteracy, isolation and lack of information afflicting the development process. Depending on each country's unique social, economic, cultural and resource context, and taking account of other alternative technologies, space could play an important role in specific areas of development.sz

Developing countries face four major difficulties in joining the "space club" in any significant way: 1 ) lack of capital; 2) few technically skilled

\footnotetext{
52 Report of the SecondUnited Nations Conference on the Exploration and Peaceful Uses of Outer Space, Vienna, Aug. 9-21, 1982, U.N. A/CON F.101/1 O; paragraph 11.
}

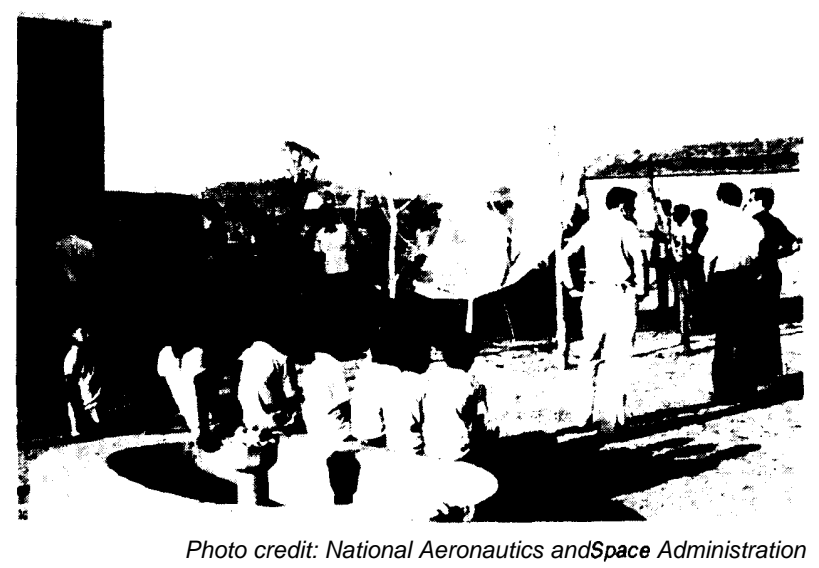

A Satellite Instructional Television Experiment (SITE) Direct Receive Antenna installed in the village of Kerelli, about 100 kilometers west of Hyderabad, in 1975 . 
personnel; 3) small scientific support base (computers, facilities, etc.); and 4) the need for stable government and policymaking apparatus committed to the long-term political and financial support of space. In addition, because of these impediments to using space technology, developing countries also have difficulties in forming and participating in stable multinational associations for using space.

One of the trickiest political issues for developing countries relates to the difficulty of relying on foreign assistance without becoming overly dependent on, or influenced by, the donor country. India, for example, has judiciously employed the assistance of both East and West over the past 15 years, while working toward an independent space capability. The People's Republic of China has attempted to do the same, though its unstable internal politics has prevented China from taking full advantage of all the external aid it might have received in developing indigenous space capabilities.

Developing countries have shared in the benefits of space technology by using satellite communications for international telecommunications (primarily via INTELSAT-see ch. 6) and tracking weather patterns using meteorological satellite data (see ch. 7). Some have also begun to make limited use of Landsat data. Most developing countries depend heavily on foreign aid to support applications of both the Metsat and Landsat data.

Major cooperative options available for developing nations are likely to continue to fall between those offered by the United States and the U.S.S.R. ESA, as a multinational coordinating body, has no mechanism for funding foreign aid to developing countries, nor does it solicit foreign proposals (other than from the United States or the Soviet Union and Japan) for cooperative missions. Individual European nations do carry on cooperative activities in space on a bilateral basis with developing countries, especially with former colonies, and though these are often of significant value to the recipient country, the overall amount of assistance is small compared to that offered by the United States or the Soviet Union. Japan is not likely to seek a wide variety of coop- erative bilateral agreements with less capable nations, as its tightly defined program is highly national in character and Japan engages in cooperative programs only for clear, pragmatic returns. However, it has engaged in a limited number of multinational projects. It is most likely to cooperate with other nations in the Western Pacific Rim.

India, with its highly successful, if small, indigenous space program, and its influence in the G77 , is an obvious potential partner for cooperative activities with smaller countries. However, lack of available capital limits what it can do. China, which has offered to cooperate in launching other Third World satellites and in developing joint space systems when its own abilities have matured, could be a major force in cooperative activities in a decade or two.

Developing countries need general education in mathematics, science, and technology; direct training with space technology; and funding for equipment in order to overcome their deficiencies in being able to put space technology to work in their economies, Though they have used a variety of multilateral platforms within and without the United Nations to press their case for greater assistance from the industrialized nations, they have made little headway in obtaining support for broad multilateral help from the United States, From the U.S. standpoint, bilateral and limited multilateral cooperation are preferable to blanket extensions of technology sharing to a wide variety of parties because the former two modes allow for greater specificity in meeting the needs of both the donor and recipient.

The United States has less to gain from broad multilateral cooperation because the direct political and economic benefits to the United States are less clear. Nevertheless, the developing countries are pressing for greater multilateral cooperation. The United States might gain political and economic benefits by offering to fund more multilateral educational programs, supported in part by private industry. The U.S. Telecommunications Training Institute (USTTI) is one example of the sort of training that might be offered. In the USTTI, expenses are shared by the U.S. Government and the telecommunications companies that participate in the program. 
This issue is tied directly to the question of how the United States should participate in the United Nations. U.N. assistance in technology development is necessarily multilateral. Yet, in contributing to development programs, the United States loses much of the control over the funding and nearly all of the credit for having provided the funding. Thus, it is loath to contribute to development programs within the U.N. structure, particularly if the funding is used on projects the United States would not otherwise agree to or to support the U.N. bureaucracy. If the United States were to contribute more heavily to multilateral assistance, it would certainly wish to do so in circumstances in which it could exercise more control over funded projects.

\section{Cooperation in the Face of Competition}

Cooperative agreements with other industrialized countries have always been undertaken for a different set of reasons and under a different set of guidelines than those with developing countries; in addition to the considerable political benefits accruing from cooperating with our allies, considerations of saving U.S. costs and of exchanging engineering know-how have been important. However, in recent years those industrialized countries with whom we cooperate have also become commercial and scientific competitors. Thus, as noted elsewhere in this report, the terms on which we might wish to cooperate with the industrialized, space-capable nations have altered. Because of their increased capability in space our new competitors have something to teach us, The possibility for costsaving and sharing engineering and scientific know-how have become more important than they once were.

Although by cooperating with other spacecapable nations the United States can accomplish important technological goals, it also runs the risk of transferring certain technology to potential economic competitors. Yet the United States cannot hope to lead in all space technologies without enormous expenditures. Cooperation continues to be in the long-term economic interest of the United States. As the technology chapters discuss, precisely what policy to follow will depend on the particular technology under consideration.
The competitive risks of technology transfer are high in some and lower in others. In general, however, the potential for technology transfer to the United States, or cost sharing, requires a reexamination of the terms of cooperation with the industrialized nations.

In some respects, the United States must cooperate with the western industrialized nations in order to demonstrate leadership in space. As chapter 4 emphasizes, the terms of such competition in the political realm extend not only to the western industrialized nations, but also to the Soviet Union. For example, the Soviet Union has cooperated with France in space science and in the manned space program by bringing a French cosmonaut aboard the Salyut space station. The United States has flown a German payload specialist aboard the Shuttle and will, in the future, fly French and Arab payload specialists as well as other foreign nationals.

Cooperation among competitors is well illustrated in the commercial satellite communications industry, where competitors sometimes team up for commercial reasons. For example, in the competition for supplying Arabsat, for political reasons U.S. companies were at a strong disadvantage. However, by teaming with the French firm Aerospatiale, the U.S. firm Ford Aerospace was able to capture the majority share of the contract to build Arabsat. ${ }^{53}$

If the United States is able to establish the private sector in the land remote sensing business (see ch. 7), the French-built SPOT remote sensing satellite will in one sense be in direct competition with a U.S. firm for high resolution data. Yet, data from the U.S. system will not have spatial resolution comparable to the SPOT data for several years. On the other hand, the U.S. system will have greater spectral capabilities. Consequently, because the competing systems serve somewhat different aspects of the overall market, it is in the interest of both to cooperate, at least, in setting data format, satellite passage, and perhaps in using the same receiving stations. The United States could promote the interests of the

\footnotetext{
${ }^{53}$ Seech.6. Aerospatiale became the prime contractor and Ford Aerospace the chief subcontractor. Ford Aerospace has actually built the satellite.
} 
U.S. data sellers and data users by encouraging cooperation between the two countries. Mechanisms already exist for such cooperation, and these could be continued and perhaps extended in some form if transfer of U.S. land remote sensing to the private sector is accomplished. As offered as an option in chapter 7, it maybe appropriate to consider establishing an international remote sensing corporation.

Because cooperation for scientific purposes can benefit all participants, it may be appropriate for the United States to seek cooperative ventures in studying materials processing in space. It might be possible to provide facilities, etc., on a cooperative basis. However, in this area, technology transfer at the production stage is a serious concern, because the potential for using U.S. technology in competition with U.S. private sector is higher. In some areas of materials processing, because of European experience, the United States could be in a position to gain technology from the Europeans. in activities such as meteorological or ocean remote sensing where the public interest is paramount, interdependence and cooperative arrangements are and will remain highly productive. For example, the United States is now attempting to develop a cooperative meteorological polar orbiter system with the Western industrialized countries (see ch. 7). This is a form of cooperation that would not have been possible before the Europeans and the Japanese developed the ability to compete with us in designing and building space systems.

As noted in chapter 9, space science has also become an arena for competition among nations. However, space science remains the most active area for government-to-govern ment cooperation, for the purpose of saving costs as well as for increasing understanding among nations and furthering scientific knowledge. Chapter 9 details the many cooperative ventures in space science that the United States has carried out or has planned with other nations. 
Chapter 4

COMPETITION 


\section{Contents}

The Space Powers . . . . . . . . . . . . . . . . . . . . . . . . . 65

Dominant Role of Governments . . . . . . . . . . . . . . . . . . . 65

Comparison of National Space Efforts . . . . . . . . . . . . . . . . . . . 65

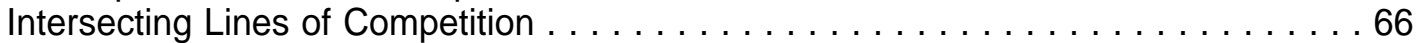

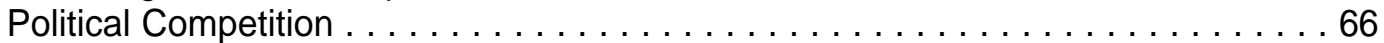

Military Competition . . . . . . . . . . . . . . . . . . . . . . . . . . . 68

Economic Competition . . . . . . . . . . . . . . . . . . . . 68

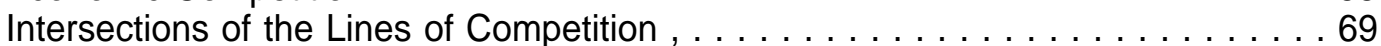

National Programs and Strategies . . . . . . . . . . . . . . . . . . . . . . . 70

Economic Motives for National Space Programs . . . . . . . . . . . . . . . . 70

The Programs . . . . . . . . . . . . . . . . . . . . . . . . . . . . 70

The Workability of Competition in Space-Related Markets.. . . . . . . . . . . . . 83

International Commercial Competition in Space-Related Markets . . . . . . . . . 83

Competitive Analysis of international Space-Related Service and

Equipment Industries . . . . . . . . . . . . . . . . . . 86

The Transition From Political to Economic Competition . . . . . . . . . . . . . . 95

Appendix 4A: The Main International Trading Rules of Relevance to

International Competition in Civilian Space Activities . . . . . . . . . . . . . . 96

\section{List of Tables}

Table No. Page

4-1. Space Expenditure. , . . . . . . . . . . . . . . . . . . . . . . .66

4-2. National Shares of European Space Agency Projects, $1983 \ldots \ldots \ldots \ldots \ldots$. . . 71

4-3. French Space Programs . . . . . . . . . . . . . . . . . . . . . . . . 74

4-4. Turnover of Major French Space Firms . . . . . . . . . . . . . . . . 76

4-5. Turnover in the Largest German Space Firms, $1981 \ldots \ldots \ldots \ldots \ldots$

\section{List of Figures}

Figure No.

4-1. National Space Budgets Compared-1984 . . . . . . . . . . . . . . . . 65

4-2. U.S, Civilian and Military Space Budgets, $1977-84 \ldots \ldots \ldots \ldots$. . . . . . . . 68

4-3. CNES and NASA Budgets Compared . . . . . . . . . . . . . . . . . . . 75

4-4. Funding Organization of German Space Activities ...,... . . . . . . . . . . . 76

4-5. Schematic Chart of Organization for Space Activities . . . . . . . . . . . . 79

4-6. Japanese Space Budget . . . . . . . . . . . . . . . . . . . . . . . . 82 


\section{Chapter 4 \\ COMPETITION}

\section{THE SPACE POWERS}

\section{Dominant Role of Governments}

Space activities today are primarily governmental: governments finance the research and development of space technology. They launch and operate satellites. Even though private sector interest in space has increased, governments still constitute the major markets for space-related goods and services. (Civilian satellite telecommunications services in the United States are an exception to this rule, but in most countries outside the United States the telecommunications service industry is owned and managed by the govern merit.)

Given this governmental domination of space activities, competition in space-related goods and services is often not conducted in a free-market environment. For instance, private firms supplying space-related goods and services have often acted as contractors to government agencies, rather than suppliers in a market of many buyers. The role of the private sector in some space-related industries has grown more substantially. In the case of ground equipment for satellite communications, for example, domestic and international firms compete internationally for the business of many buyers. Should materials processing in space prove profitable, private commercial activity may be expected. In the areas of remote sensing and space transportation, though, government involvement is likely to remain large, even though the role of the private sector is expected to expand. Space commerce occurs-and will continue to occur-in a context shaped primarily by the political, military, and economic interests and actions of national governments.

\section{Comparison of National Space Efforts}

Globally, the constellation of space powers closely resembles the constellation of politicalmilitary powers. The superpowers of space are the United States and the Soviet Union, followed somewhat distantly by Western Europe (with a partially unified space program under the European Space Agency (ESA)I and Japan.

When national space budgets are compared (fig. 4-1 ), the space programs of the United States

\footnotetext{
'Just as the Western European Community is not fully integrated, neither are the space programs of the European Space Agency members. About half of the West German space budget goes into ESA projects. Less than half the French space budget goes to ESA. Most of the smaller British, Italian, Dutch, and Spanish space budgets go to ESA.
}

Figure 4.1.-National Space Budgets Compared-1984 (billion U.S. dollars)

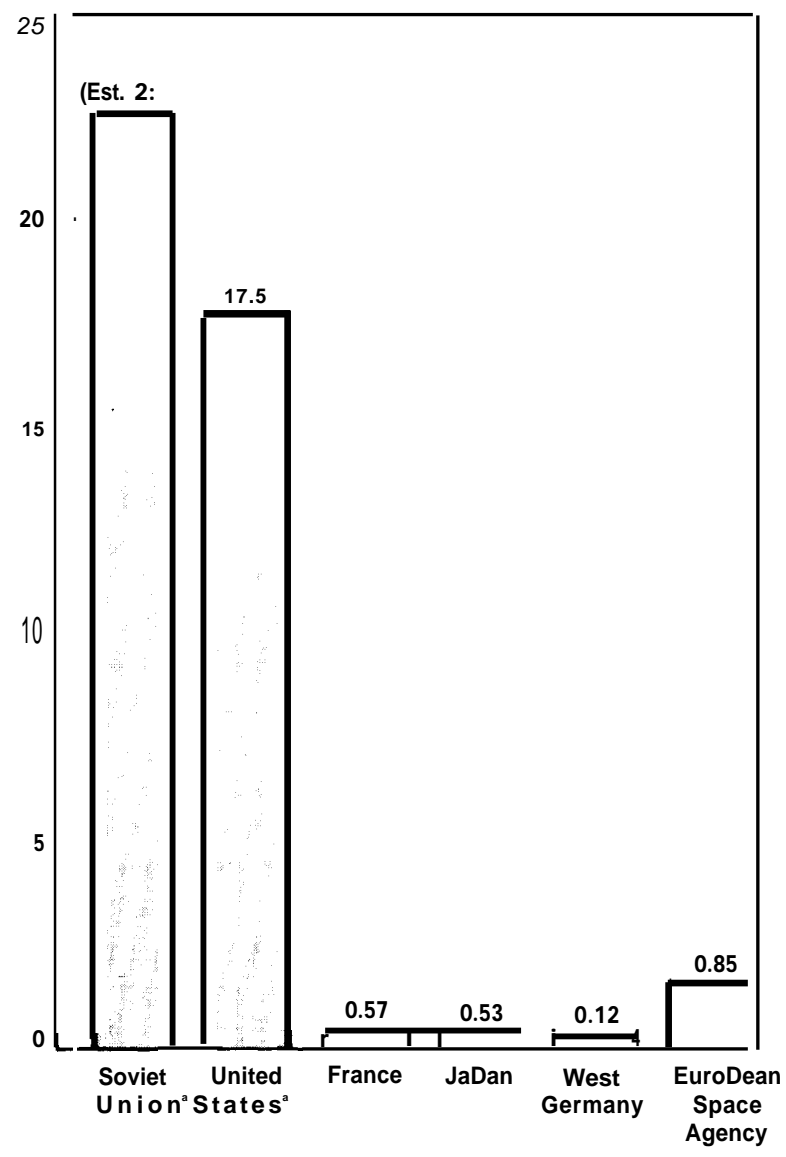

a Includes military space budget, but excludes classified military and intelli-

bestimated cost the United States would incur to duplicate Soviet effort.

SOURCE: Office of Technology Assessment. 
and the Soviet Union are by far the largest both absolutely and relatively. Recent estimates mark the overall Soviet space effort as substantially greater than its U.S. counterpart.z ${ }^{3}$ Some 600,000 people are thought to be employed in the Soviet space programs, civilian and military (as much as four times the total in the United States). Soviet expenditures on space in 1985 are estimated to be some $\$ 23$ billion, representing from 1.5 to 2.0 percent of Soviet gross national product (GNP); total U.S. space expenditures are estimated to represent only about 0.5 percent of U.S. GNP.

In contrast, the French, the West German, and the Japanese space budgets are each only about 3 percent that of the United States (civilian plus military). When percentages of GNP devoted to space budgets are taken as indices of national ef-

\footnotetext{
2Alain Dupas, "Un Programme Spatial En Plein Remouveau, " La Recherche, November 1984, vol. 15, pp. 1420-1427.

${ }^{3}$ Nicholas Johnson, "The Soviet Space-Current Plans and Programs-Future Direction, "Space: The Next Ten Years, TMSA Proceedings, 1984, p. 94 .
}

fort devoted to space, the level of U.S. space effort is approximately 6 times that of France, 11 times that of West Germany, and 11 times that of Japan. Although the governments of France, West Germany, and several other European countries (plus Canada) aggregate parts of their space budgets in the European Space Agency, the U.S. space budget is still eight times that of ESA. In short, in terms of spending the United States is by far the leading space power of the non-Communist world, whether the measure of effort is absolute or relative.

Table 4-1._Space Expenditure

\begin{tabular}{|c|c|}
\hline Country & $\begin{array}{c}\text { As a percent } \\
\text { of "GNP }\end{array}$ \\
\hline United States. . . . . . . . . . . . . . . . . & 0.47 \\
\hline France. . . . . . . . . . . . . . . . & 0.08 \\
\hline $\begin{array}{l}\text { Federal Republic of Germany } \ldots \ldots \ldots \ldots \\
\text { Japan } \ldots \ldots \ldots \ldots \ldots\end{array}$ & 0.04 \\
\hline Italy . . . . . . . . . . . . . . . . & 0.03 \\
\hline United Kingdom . . . . . . . . . . . . . . . & 0.03 \\
\hline
\end{tabular}

SOURCE: SEST/Euroconsult 1964-M.

\section{INTERSECTING LINES OF COMPETITION}

\section{Political Competition}

International competition in space began as a highly political duel between the United States and the Soviet Union. The Soviet Union scored a propaganda coup against the United States when it launched the first artificial Earth satellite, Sputnik 1, in 1957. When the U.S. Navy team, having started essentially from scratch, failed to get a Vanguard satellite into orbit, the Army's rocket team under Wernher von Braun, relying on a great deal of accumulated experience dating from the German V2 program in World War 11, managed to launch Explorer 1. An informal race then began to get the first man into orbit. The United States started work on Project Mercury late in 1958, but in 1961 the Soviet Union won that sprint with Yuri Gagarin in Vostok 1. Six weeks later President Kennedy announced his goal of placing Americans on the Moon by the end of the decade. The United States won that long-distance race in $1969 .{ }^{4}$ Both sides proclaimed their interest in exploring space for the benefit of mankind, but political motives clearly ranked high in the decisions to race for space.

The Soviet Union, generally inferior to the United States in economic and technological performance, was able to prove superiority in at least some areas. The United States, particularly in the early years, felt a strong need to "catch up" with the Soviet Union. Both sides found in space successes a source of national pride and self-respect. At the same time, they demonstrated to the rest of the world that their respective (and competing) political and social systems were powerful and

\footnotetext{
${ }^{4}$ For discussions of the evidence as to whether the Soviets were seriously committed to the moon race, see Marcia Smith, "Program Details of Man-Related Flights" in U.S. Congress, Senate, Soviet Space Programs, 1971-75, Vol.I, Staff Report Prepared for the Use of the Committee on Aeronautical and Space Sciences, U.S. Senate, 1976, pp. 218-221; see also Charles S. Sheldon, II, "Projections of Soviet Space Plans," ibid., pp. 502-515.
} 
effective. Moreover, each hoped that recognition as an advanced technical power would enhance its attractiveness as a political and trading partner.

After the United States reached the Moon, the contest became less direct (at least in civilian space activities) between the two great space powers, but the element of political competition remained. By then, several new entrants had entered the field. The European Space Research Organization (a precursor of ESA) seems to have originated in a December 1960 discussion among a group of European scientists about the impact of space technology on science and:

the then-hot issue of the "brain drain" [owing] to the explosive development of science and technology in the United States. S

Although in its first years-between 1966 and 1970 - the European Space Research Organization concentrated on scientific research:

The stated objectives of space collaboration in Europe .... were constantly presented in a way that obscured the most fundarnenta/ reason for cooperation, which was to help European industry develop its know-how and potential.G

Here is how the Director of Programs of the French national space agency has described French space policy:

For twenty years France has had the constant will to develop a European capacity in the domain of space and to prove that our country and Europe are in a position, as much in the domain of launchers as in that of satellites and associated ground equipment, to play a role on the world level. This will, which is affirmed equally in the national program and in the European cases, has permitted us to acquire, step by step, the autonomy indispensable for satisfying national and European needs and for developing a dynamic and exporting space industry.'

There is not much doubt that the "autonomy" mentioned here means autonomy from the United States, During that same 20 years France has consistently striven for military, political, and

\footnotetext{
${ }^{5} \mathrm{~A}$. Dattner, "Reflections on Europe in Space-The First Two Decades and Beyond," ESA BR-10 (Paris: European Space Agency, March 1982), p. 5.

6 lbid., p. 7.

JJean-Marie Luton, "La politique spatiale franchise," LesCahiers Francais, No. 206-207, May-September 1982, p. 89.
}

economic independence from the United States. It has also encouraged its European partners to do likewise-preferably asserting European independence under French leadership.

The transformation of the French Diamant launch vehicle program into the ESA Ariane program was consistent with this broader French European policy. The French argued in the 1960s and early 1970s that Europe needed its own launch capabilities, independent of the United States, so that a European satellite industry could develop. They expressed fear that although the United States had said it would always make launch services available to the Europeans, it might not actually do so if the Europeans chose to build satellites in competition with American products.

Offering to lead the development of a European launcher within ESA, the French used a cooperative space project for competitive purposes. The French launch vehicle program was brought to bear in the French effort to compete with the United States for leadership in Europe. In addition, European pooling of resources on the Ariane has permitted ESA to raise a challenge to U.S. domination of the market for launch services. Other ESA projects-weather observation satellites and communications satellites-appear designed to reduce European dependence on American suppliers.

Most of the space powers, major and minor, have sought to use their space assets as political instruments for cementing ties with friends and allies and for winning friends and influence in the less developed countries. (See ch. 3 for more details.) The Soviet Union has encouraged the French in their assertions of independence from the United States by offering themselves as an alternative partner in space cooperation. ${ }^{8}$ The Soviets have used their Intercosmos and Intersputnik co-

\footnotetext{
${ }^{8}$ As a Congressional Research Service Analyst has put it, "Expanding space relations with France opened up potential opportunities for the Soviets to influence the French politically, particularly in seeking the much cherished Soviet foreign policy goal of dividing the West." Joseph Whelan, "Soviet Attitude Toward International Cooperation in Space, " ch. 3 of Soviet Space Programs: 1976 -80," op. cit., p. 290.

The French, for their part, have found it useful to counterbalance U.S. power by forming a closer relationship with the Soviets than the United States would like to see.
} 
operative space programs to strengthen ties with East European and other Communist countries. They have also given extensive assistance to the Indian space program. ${ }^{9}$

As emphasized in chapter 3 , the United States has a long record of international cooperative projects in space technology with both industrialized and non industrialized nations, with both allies and nonallies. Besides seeking the benefits of the international pooling of resources, the United States has also tried to use these cooperative projects to demonstrate: 1 ) the relative openness of American society, and, particularly, American science, in comparison with the closed nature of Soviet society; and 2) the advantages of association with the United States and its advanced technology.

In the arena of international organization politics, the competitive aspect of space cooperation comes to the fore.l" The United States and the Soviet Union have each tried to show in international forums that it was the more peaceable user of space technology and the nation whose activities were most in the interests of "mankind" or the international community. The Soviet Union has in recent years made much of its willingness to resume negotiations on space weapons, an offer made especially effective by the unwillingness of the United States to discuss the question of arms control measures for space.'

\section{Military Competition}

The space competition between the United States and the Soviet Union has long been military as well as political (fig. 4-2). Many Americans took the launch of Sputnik 1 to signify that the Soviets were about to deploy large numbers of Intercontinental Ballistic Missiles-a feat the Soviet Union did not achieve until several years after

\footnotetext{
9"In the case of India, space cooperation was to play ... . [the role ] . . . of an instrument for expanding Soviet political influence in this leading country of the Third World, and thus furthering its larger purpose of linking the Third World to the Soviet Union's expected global destiny." Whelan, op. cit., p. 290.

IoSee the technical memorandum which is part of this OTA study, UNISPACE '82: A Context for International Cooperation and Competition, OTA-TM-ISC-26 (Washington, DC: U.S. Congress, Office of Technology Assessment, March 1983).

"See ibid., "Appendix B: The Militarization Issue at UN ISPACE '82, " pp. 61-67.
}

Figure 4-2.-U.S. Civilian and Miiitary Space Budgets, 1977.84 (millions of 1982 dollars)

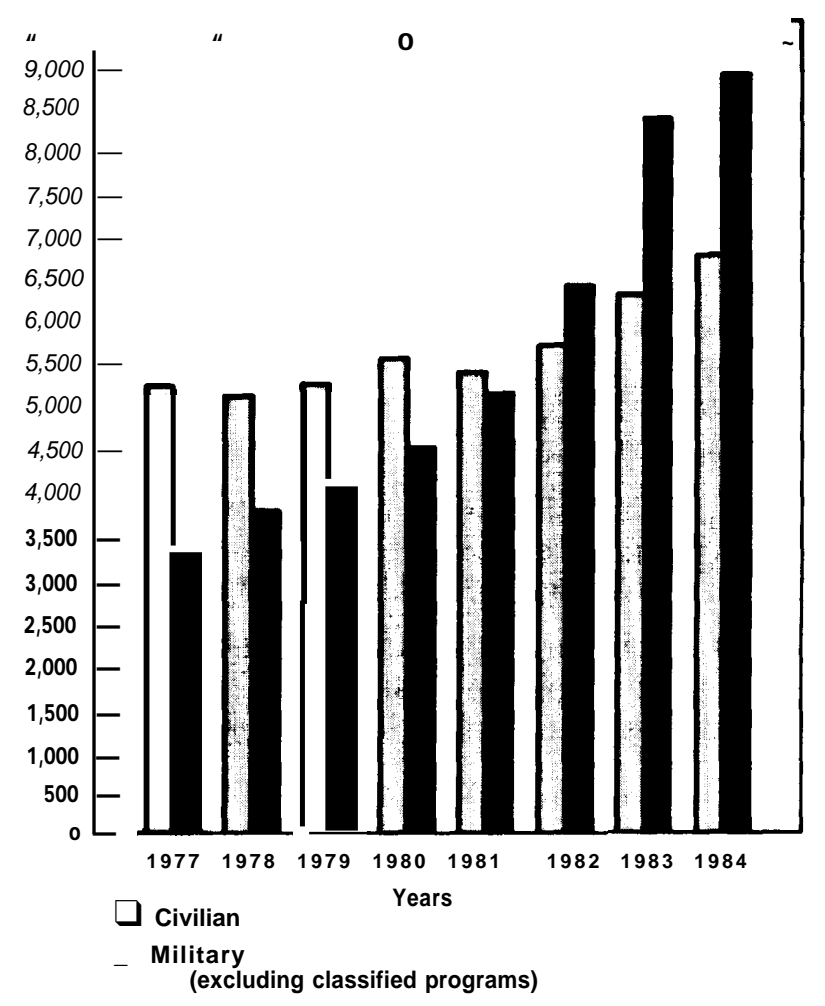

SOURCE: Office of Technology Assessment.

the United States had done so. Somewhat more quietly, the United States and the Soviet Union set about applying space technology to the enhancement of terrestrial military power. A discussion of the military space programs of the two nations is beyond the scope of this report. However, both sides now make extensive military use of space for purposes of geodesy, navigation, weather forecasting, reconnaissance, missilelaunch warning, and communications.

\section{Economic Competition}

The one line of space competition in which the U.S.-Soviet antagonistic relationship has not been central has been the economic. Indeed, for most of the Space Age there has been very little international economic competition at all. The Soviet Union has been the main supplier of space-related goods and services to the Communist world. But, except in France and India, it did not try to compete with the United States as the chief sup- 
plier to the rest of the world. Most non-Communist national space programs have been highly dependent on U.S. satellites, U.S. launch services, and U.S.-licensed space technology.

The U.S. space program remains the benchmark by which other non-Communist nations judge the progress of their own. At the same time, Japan and the Western European space powers (especially France) have been seeking greater independence from the United States as the major supplier of space technology and of spacerelated goods and services. These new space powers are beginning to offer some competition where before the United States held a virtual monopoly. Instead of relying substantially on U.S. suppliers, they are beginning to produce spacerelated goods and services domestically. Some are beginning to offer export competition as well.

Competition is greatest in the areas of launch services, satellite remote sensing services, and communications satellite equipment and services. Competition in the processing of materials in orbit is currently embryonic but may become significant in the future.

\section{Intersections of the Lines of Competition}

In part because space activities are so heavily governmental, the political, military, and economic lines of competition are not so divergent as the above analysis might indicate. In fact, they are sometimes difficult to separate.

1. Political-economic: For example, when a government undertakes to build a domestic launch vehicle industry (as have France and Japan), does it do so to conserve or earn additional foreign exchange, or does it do so to remove U.S. influence over the national space program? Economic dependence may seem inseparable from political dependence, and economic independence may be sought even when it is economically inefficient. Government efforts to subsidize exports of space goods or services in order to gain political influence over potential buyers may have "mercantilist" economic motives that reinforce the political competition.
2. Political-military: The U.S. military space program may have important effects on the political competition. For example, if the Soviets succeed in fostering the impression that the U.S. program is the main cause of the current 'militarization' of space, the United States may lose good will otherwise earned by its cooperative programs and its visible successes in space technology..$^{12}$ If the Space Shuttle or a future space station are seen as dominated by the military, that perception may reduce the willingness of the European Space Agency to cooperate in using the U.S. vehicle or platform. ${ }^{13}$ U.S. cooperative programs may also be hampered by attempts to limit the export of technology for "national security" reasons.

3. Military-economic: The same problem may affect the competitiveness of U.S. firms in the international space marketplace. Efforts to keep American technology out of Soviet hands may also keep it out of the hands of potential Western customers. ${ }^{14}$ If the process of controlling exports appears capricious, it could give the United States a reputation of being an unreliable supplier. Technology kept out of hands of the U.S. civilian space program (say, highresolution remote sensors) may weaken its ability to compete with foreign providers of remotely sensed images.

The impact of the U.S. military space program on U.S. competitiveness in space industries is complex and ambiguous. For example, billions of military dollars spent over many years have certainly helped to build the scientific and technological base, the manpower, and the plants which have made U.S. firms the competitors they are in international space markets.Is Potential competitors with the U.S. point to this subsidization as ample reason for

\footnotetext{
${ }_{12}^{2}$ UNISPACE '82, op. cit. $13 \mathrm{ESA}^{\prime} \mathrm{s}$ bylaws prevent cooperation in rnilitary-related activities. ${ }^{14}$ Technology and East-West Trade: An Update, OTA-IS C-209 (Washington, DC: U.S. Congress, Office of Technology Assessment, May 1983).

${ }^{5}$ For areport on how government work has benefited one supplier of space equipment, see James Cook, "A Paragon Called TRW," Forbes, July 18, 1983, pp. 102-114.
} 
their own government subsidies. On the other hand, it is also true that the increasing government expenditure on military space programs absorbs engineers, technicians, and specialized plants that might otherwise have participated more directly in the civilian competition.

\section{NATIONAL PROGRAMS AND STRATEGIES}

\section{Economic Motives for National Space Programs}

The economic motives for national space programs are more complex than the straightforward desire to compete for international markets in space goods and services. The space-faring countries commit national resources to space activities in part out of hopes or beliefs that:

- space research will contribute to the general advancement of national scientific development;

- efforts in space technology will contribute to building and maintaining a strong national technology base;

- applications of space technology such as remote sensing or satellite communications will contribute to national economic growth;

- useful products will spin off from space technology;

- leadership in space technology will benefit other industries in international competition by promoting perceptions of the nation as being at the forefront of modern technology in general;

- the space program will foster the development of space-related industries with competitively exportable products; and

- the export of space-related goods or services will help open up new markets for other high-technology exports.

The mix of economic motives varies from country to country. Degrees and kinds of governmental support for space activities therefore vary in turn with national conceptions of how those activities might contribute to economic growth and competitiveness.

\section{The Programs}

\section{European Space Agency}

The European Space Agency (ESA) is something more than an alliance of national space programs, but something less than a third space superpower. It is a mechanism for pooling the financial and industrial resources (table 4- I) of several European countries in cooperative space projects (see also ch. 3).

The French threatened in 1970 to quit the European Space Research Organization (ESRO) unless it reduced its purely scientific programs in favor of developing applications satellites. In 1971, the European Launch Development Organization (ELDO) abandoned its planned Europa series of launchers. Late in 1972, the French indicated a willingness to provide the majority of funding for a European launcher. In July 1973, the ESRO states accepted the French proposal. In the same year, the European Space Council (with members from both ESRO and ELDO states) arrived at a "package deal" in which they agreed to form the European Space Agency, combining the previous functions of ESRO and ELDO (the actual merger took place in 1975).

During the late 1960s, West Germany supported the French position on the importance of a European launch vehicle independent of the United States. In 1969, the United States offered the Europeans the opportunity to participate in the Space Shuttle program. The Germans were interested. More eager than the French to strengthen cooperative ties with the United States, they were more willing to rely on U.S. guarantees that the Shuttle would be fully available for European satellite launches. 
Table 4-2.-National Shares of European Space Agency Projects, 1983

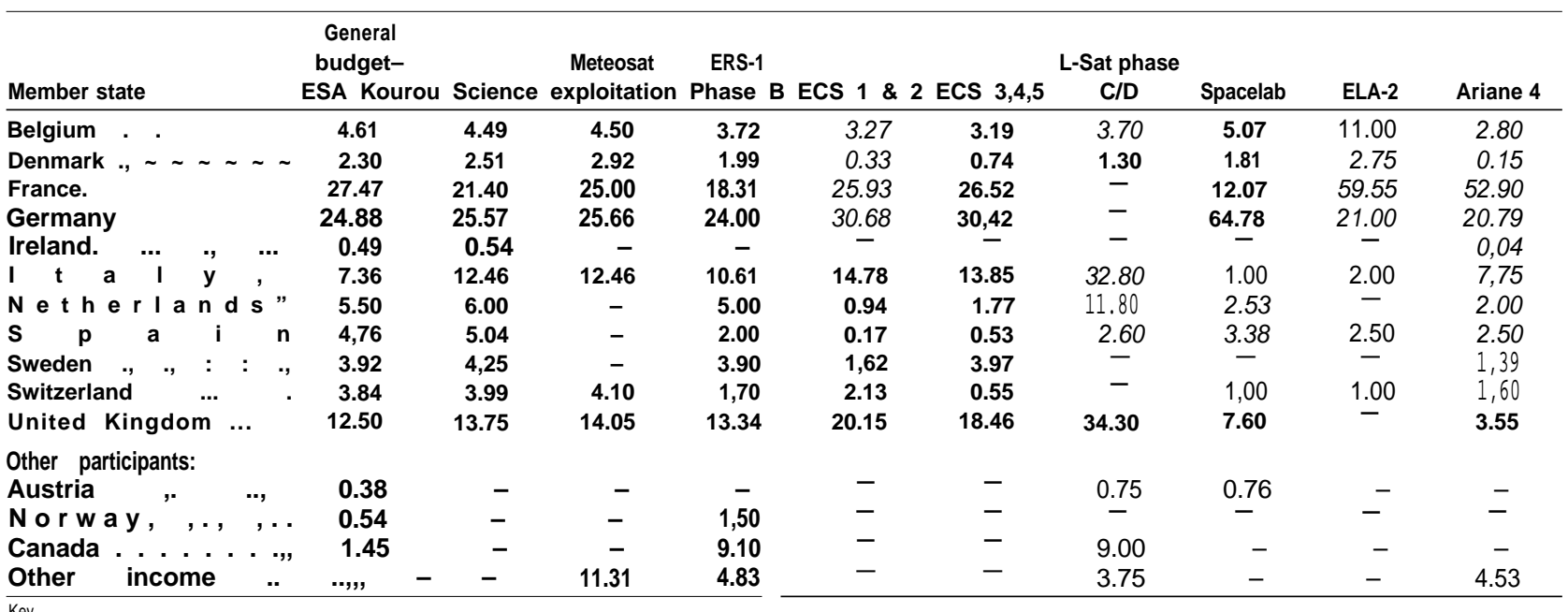

ESAKourou Launch facility In French Guana for the Ariane launcher Science includes Exosat-X-ray observatory satellite International Solar Polar Mission Hipparcos-Space astronomy satellite Giotto-probe of Comet Halley Participation m NASA Space Telescope

Meteosat Exploitation Use of data from the ESA geostationary weather observation satellites ERS-1A remote sensing satellite, with sensors for physical oceanography, glaciology, and climatatology To be launched in 1987

SOURCE European Space Agency

When the ELDO and ESRO members combined those organizations in the new ESA, they agreed on a division of labor among the three major participants. France would pay for $\mathbf{6 2 . 5}$ percent of the development of the ESA launch vehicle (Ariane). The United Kingdom would pay for most (56 percent) of the Marots maritime communications satellite (later "Marecs A" and "Marecs B"). Germany would take the lead in the Spacelab, a Space Shuttle project, paying for $\mathbf{5 2 . 5}$ percent of its developmental G Thus ESA'S largest single project, the Ariane launcher development under French leadership, was designed to deal competitively with the U.S. space program. The second largest project, the Spacelab under German leadership, was designed to increase cooperation with the United States.

The explicit rationale for ESA was to allow the member states to combine their resources for activities in a field-space technology-too costly for any single European nation to engage in alone. The Convention chartering ESA specifically

\footnotetext{
${ }^{16}$ Michiel Schwarz, "European Policies on Space Science and Technology, 1960-1978." Research Policy 8, 1979, pp. 204-243.
}

ECS 1,2,3,4, \& 5 Series of European Communication Satellites to operate 1984-1994 L-Sat Development of large, multi-purpose satellite for direct broadcasting, business communications, experimentation with $30 / 20 \mathrm{GHz}$ technology Spacelab: Modular laboratory designed for U S Space Shuttle cargo bay Ariane Development of vehicle to provide independent European launch services and to compete In the international launch services market

ELA-2 Constructlon of a second Ariane launch site at Kourou, French Guyana

charges the Agency with elaborating an "industrial policy" designed not only to "coordinate national space programmed in a cost-effective manner," but also to:

\section{... improve the worldwide competitiveness of} European industry by maintaining and developing space technology and by encouraging the rationalization and development of an industrial structure appropriate to market requirements, making use in the first place of the existing industrial potential of all Member States. ${ }^{17}$

Citing ESA accomplishments in space science, in satellite telecommunications, and in launch vehicles (the Ariane), an ESA official boasted in 1982:

[these are] . . cases where Europe can be described as a winning participant in the global world competition for space products, competing successfully with the superpowers, whose space potential is well known to everybody and whose monopoly one thought could not be menaced .18

\footnotetext{
17 "Convention for the Establishment of a European Space Agency, " Article V1.
}

16 Dattner, op. cit., p. 37. 
The members of ESA expect an economic return from their participation in its activities, and the Agency has tried to show that those expectations are being met. It commissioned a series of studies with the Theoretical and Applied Economics Bureau (BETA) of the Louis Pasteur University of Strasbourg aimed at showing the economic benefits of being in ESA. BETA asked a sample of 77 firms to identify the economic value of the benefits they derived from having received ESA contracts. The benefits were described as: "technological" - development of new products, diversification into new fields; "commercial"increased market penetration; "organization and methods" -knowledge and management techniques learned which improved internal operations; "work factor' '-vaiue of building skilled design and production teams.

The study concluded that the $\$ 1$ billion which ESA and its predecessors had granted in contracts from the early 1960s through 1975 had yielded another $\$ 2.7$ billion in benefits to some 550 contractors. In particular, additional exports of $\$ 622$ million were attributed to the "technological" and "commercial" categories of benefit:

This indicates the successes achieved by ESA'S contractors in penetrating difficult export markets such as the United States, where they have taken part in space programmed funded by NASA and INTELSAT. ${ }^{19}$

As one judges the validity of ESA claims about the economic value of its programs, one should of course realize that both ESA and its contractors have a vested interest in showing that national returns from the ESA subsidies are greater than the face value of the contracts. Moreover, despite the apparent successes of some European aerospace firms, ESA programs have not necessarily maximized European competitiveness in international markets. The European Space Agency to some extent reflects the continuing resistance of Western European nation-states to genuine integration into a larger political and economic unit.

\footnotetext{
19'Economic Benefits of ESA Contracts: Summary of a Study Conducted by the Theoretical\& Applied Economics Bureau of the Louis Pasteur University of Strasbourg for the European Space Agency," ESA BR-02 (Paris: European Space Agency, October 1979).
}

For example, the European Space Agency Convention provides that the industries of the member states should share "equitably" in the work of ESA-that the contracts granted should be in rough proportion to the contribution of each state's government to ESA. This has become known as the principle of "fair return" or juste retour. The principle of fair return means that ESA is not able to choose those firms that may offer the best combination of quality and cost, but instead must distribute its contracts geographically. Then, too, the necessary intermeshing of various national elements into a single project must impose additional costs on the manufacturers.

Other circumstances also deprive the European space-related industries from the benefits of competitive bidding. One problem is that expensive space projects become objects of political pressure. Most ESA contracts are currently negotiated directly rather than competitively. Another problem is that although three international consortia formerly competed for ESA contracts, those consortia are breaking down because of industrial mergers, the juste retour principle, and the lack of sufficient business to keep all of the consortia working at once. z"

Differences in national priorities have led to significant departures from another important principle, that of a single European "industrial structure." The communications satellite industry is especially fragmented. Although the Marecs maritime communications satellite is an ESA project, with the second, Marecs B, satellite, British participation went to 69 percent, while the next biggest share was only 13 percent, held by Germany. * The European Communications Satellites (ECS), for telephone and some television transmission, have more even participation: Germany 31 percent, France 26 percent, United Kingdom 20 percent, Italy 14 percent.

\footnotetext{
${ }^{20}$ See W. Thoma, "The Sophia Antipolis Workshop on the Relationship Between ESA and Industry," ESA Bulletin, May 1983, pp. 13-15.

* Marecs B failed to orbit because of a launch failure. Marecs B2 was successfully launched and deployed in November 1984.
} 
But in direct broadcast satellites, the intra-European competition seems to be growing. Within ESA, the British (34 percent) and the Italians (33 percent) are leading the development of the LSat entirely without French and German participation. Germany and France are sharing in the development of direct broadcast satellites (the TVSat/TDF 1) entirely outside the ESA framework. Meanwhile, the United Kingdom, despite the lack of an agreed European standard for satellite direct broadcasting, is proceeding with its own national direct broadcasting satellite.

\section{France}

In the 1960s, France identified certain industrial projects as "national champions' '-projects intended to bring France prestige and autonomy as well as economic benefit. One such project was the Concorde supersonic transport, a technical success but an economic failure. Another was the Plan Calcul, intended to give France a highly competitive computer industry (marginally successful at best). The French Government continues to try to guide the development of French industry through formal plans (the eighth such plan is now in effect), There is less emphasis on specific projects like the Concorde, but some space projects seem to have taken on the role of "national champions" pursued as much for prestige and independence as for economic reSults. ${ }^{211}$

French President Mitterand and his first Minister of Research and Industry called for increased research aimed at restructuring French industry to reduce imports and increase exports of hightechnology products. ${ }^{22}$ The Centre National

\footnotetext{
${ }_{21}$ For a summary description of recent French industrial policy, see "Appendix D: Foreign Industrial Policies" in U.S. Industrial Competitiveness: A Comparison of Steel, Electronics, and Automobiles, OTA-ISC-135 (Washington, DC: U.S. Congress, Office of Technology Assessment, July 1981), pp. 190-200.

${ }_{22, "}$ Mercantilism for the 21 st Century, "Business Week, Jan. 10, 1983 , p. 54. For a fuller report on French industrial policy, see the special report on 'France,': the same issue, pp. 45-74.

See also Jean-Pierre Chevenement, Minister of Research and Industry, "La Politique Industrielle," in Industrie \& EnergieFrancaise: Lettre d'information No. 101 (Paris: Ministry of Research and Industry, Sept. 7, 1982). In this speech, the Minister outlined his views on industrial policy to the heads of the French national research organizations and of the nationalized industrial enterprises.

For a description of French industrial research objectives, see $R e$ cherche et Technologie, No. 2 (monthly information letter of the
}

$d^{\prime}$ tudes Spatia/es (CNES) manages most of the French space program (table 4-2). CNES is an independent agency under the "tutelage" of the Ministry of Research and Industry. It disposes of an annual budget of around 3 billion francs (about \$325 million) (fig. 4-3). Much of that money is spent with the four largest aerospace firms of France: Aerospatiale, Matra, SEP, and Thomson-CSF-firms that are themselves owned by the French Government (table 4-3). ${ }^{23}$

CNES, like NASA, operates government research laboratories and oversees contractor work on satellites and launch vehicles. Unlike NASA, CNES itself is a key shareholder in important commercial ventures. Not only has CNES managed the development of ESA'S Ariane launcher, but it is the largest single shareholder (34 percent) in Arianespace, the company created to manage the marketing, production, and operation of the rocket. Similarly, CNES holds 34 percent of SPOT Image, S. A., the company which will sell the services of the French SPOT remote sensing satellite.

CNES formulated the French space policy adopted by the French Government in October 1981. According to the Director of Programs of CNES, the objectives of French space policy include:

To consolidate our position in the principal domains of application (telecommunications, television, Earth observation), to construct a solid space industry and enlarge our penetration of the international market for launchers, satellites, and associated services and ground equipment. ${ }^{24}$

In addition, the French space program is to carry out basic engineering and scientific research to prepare for changes in space systems of the

\footnotetext{
Ministry of Research and Technology), September 1982. See also JoelStratte-McClure, "French Technology: Preparing for the 21st Century, "Special Advertising Supplement to Scientific American, November 1982, pp. F1-F30.

${ }^{23}$ One firm, the Société Européene de Propulsion (S. E. P.) nicely illustrates the French competitive attitude. The French Government created the firm in $\mathbf{1 9 6 9}$ to develop solid rocket motors for the French nuclear missile force. In 1971, the Ballistics and Aeronautics Laboratory (L. R. B.A.) was folded into S.E.P. to “ . . create a unit competitive with the American companies in the domain of large liquid-fueled motors for satellite launchers. "Pierre Soufflet, president and director general of S. E. P., "La S. E.P.," in "Les quatres grands de l'industrie spatiale francaise" in Les Cahiers Francais, No. 206-207, May-September 1982, p. 11.

${ }^{24}$ Luton, “ op. cit., p. 94.
} 
Table 4-3.-French Space Programs

\begin{tabular}{|c|c|c|c|}
\hline Project & Mission & Year & Comment \\
\hline \multicolumn{4}{|l|}{ National programs } \\
\hline & $\begin{array}{l}\text { Business telecommunications; TV; } \\
\text { telephone; overseas connections }\end{array}$ & 1983 & $\begin{array}{l}\text { Telecom satellites } 1 \mathrm{~A} \text { and } 1 \mathrm{~B} \text {; Ariane } \\
\text { launcher }\end{array}$ \\
\hline SPOT $\ldots \ldots \ldots \ldots$ & $\begin{array}{l}\text { Inventory of terrestrial resources by } \\
\text { satellite remote sensing }\end{array}$ & 1985 & SPOT 1 satellite; Ariane launcher \\
\hline \multicolumn{4}{|l|}{ Biiaterai programs } \\
\hline ARGOS .......... & $\begin{array}{l}\text { Operational service of location and } \\
\text { collection of meteorological and } \\
\text { oceanographic data }\end{array}$ & 1978-1989 & $\begin{array}{l}\text { French system aboard } 10 \text { U.S. NOAA } \\
\text { satellites }\end{array}$ \\
\hline ARCAD $3 \ldots \ldots \ldots$ & Study of the magnetosphere & 1981 & $\begin{array}{l}\text { Soviet Arcad satellite; French computer } \\
\text { and experiments }\end{array}$ \\
\hline SARGOS & $\begin{array}{l}\text { Search and rescue of ships and planes in } \\
\text { distress }\end{array}$ & From 1982 & $\begin{array}{l}\text { French system aboard } 6 \text { U.S. NOAA } \\
\text { satellites }\end{array}$ \\
\hline First manned flight & $\begin{array}{l}\text { Studies of materials, astronomy, } \\
\text { medicine, biology aboard a Soviet space } \\
\text { station }\end{array}$ & 1982 & $\begin{array}{l}\text { French experiments conducted with } \\
\text { French-Soviet equipment }\end{array}$ \\
\hline \multicolumn{4}{|c|}{ Venera-Halley . . . . . . . Study of Venus in 1985 and Halley's } \\
\hline TDF 1 & $\begin{array}{l}\text { Comet in } 1986 \\
\text { Direct Broadcast Television satellite with } \\
\text { two France networks }\end{array}$ & $\begin{array}{l}1984 \\
1985\end{array}$ & $\begin{array}{l}\text { French experiments on two Soviet probes } \\
\text { Cooperative program with West Germany; } \\
1 \text { French TDF } 1 \text { satellite, } 1 \text { German } \\
\text { TV-sat }\end{array}$ \\
\hline $\begin{array}{l}\text { Projects with European } \\
\text { Ariane } 1,2,3,4 \ldots \ldots\end{array}$ & $\begin{array}{l}\text { Space Agency (degree of French participatic } \\
\text { European heavy launcher developed under } \\
\text { supervision of CNES }\end{array}$ & $\begin{array}{l}\text { ion varfes) } \\
1979-1986\end{array}$ & $\begin{array}{l}\text { Ariane } 1 \text { qualified } 1981 \text {; Ariane } 2-3 \text { two } \\
\text { flights in 1984; Ariane } 4 \text { available 1986; } \\
\text { Financing mostly French }\end{array}$ \\
\hline Meteosat . & $\begin{array}{l}\text { Imaging, broadcast and collection of } \\
\text { meteorological data }\end{array}$ & 1982 & $\begin{array}{l}1 \text { European Meteosat satellite: Ariane } \\
\text { launcher }\end{array}$ \\
\hline MARECS . & Maritime communications & 1982 & $\begin{array}{l}\text { Marecs A lost in Ariane launch failure; } \\
\text { Financing mostly British }\end{array}$ \\
\hline EXOSAT . & X-ray astronomy & 1982 & $\begin{array}{l}\text { Satellite planned for Ariane launch but } \\
\text { switched to U.S. Delta launcher }\end{array}$ \\
\hline & $\begin{array}{l}\text { European Communications Satellite; intra- } \\
\text { European telephone and telegraph }\end{array}$ & $1982-1990$ & 5 satellites; Ariane launcher \\
\hline & $\begin{array}{l}\text { Orbiting laboratory integrated with U.S. } \\
\text { space shuttle }\end{array}$ & 1983-1986 & Financing predominantly German \\
\hline Giotto. ... & Study of Halley's Comet & 1985 & $\begin{array}{l}\text { Planetary probe to be launched in July } \\
\text { 1985; Overflight of Mars in 1986; Ariane } \\
\text { launcher }\end{array}$ \\
\hline $\begin{array}{l}\text { Hipparcos ............ } \\
\text { international programs }\end{array}$ & & & Satellite to be launched by Ariane \\
\hline !ntelsat V & International telecommunications & Since 1980 & $\begin{array}{l}12 \text { satellites plus } 3 \text { options on Intelsat } \\
\text { network; Launchers: Ariane and Atlas } \\
\text { Centaur }\end{array}$ \\
\hline
\end{tabular}

1990s, to participate in international research, and to maintain European solidarity and cooperation.

CNES is to work closely with other French Government agencies to respond to their special needs in such areas as meteorology, telecommunications, broadcasting, and national defense. At the same time its mission also includes "the encouragement of French industry to get full value, particularly in international markets, from the competence and methods acquired over 15 years." ${ }^{25}$

Although the French space program is generally justified in terms of its contribution to industrial competitiveness, two projects in particular have the flavor of the "national champion" appreach: they may be pursued as much for their

\footnotetext{
${ }^{25}$ Jean-Marie Luton, “Le C. N. E.S.," Ibid., p. 96.
} 
Figure 4.3.-CNES and NASA Budgets Compared

France: CNES

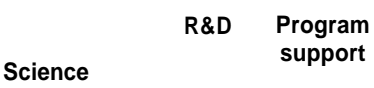

Applications

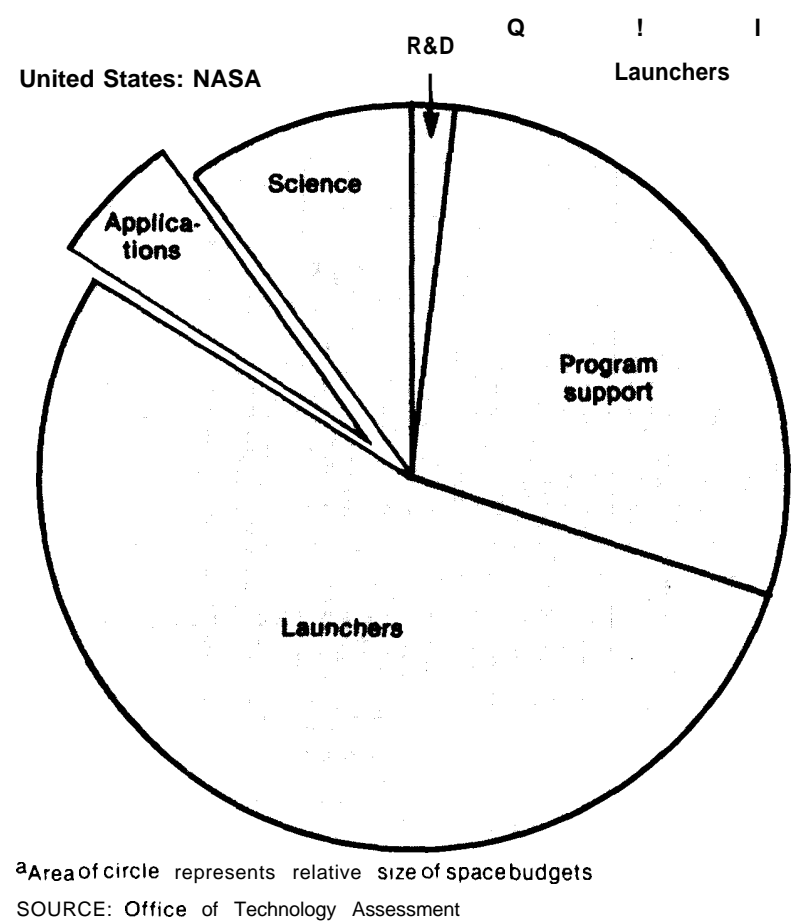

contributions to visibility and prestige as for their promise of economic return. One project is the Ariane rocket, formally an ESA program, but predominantly a French one. The other is the SPOT land remote sensing satellite, which France proceeded with independently when it was not accepted as an ESA project (see chs. 5 and 7).

\section{West Germany}

Unlike France, which seems determined to establish and promote particular space businesses (launch services and remote sensing) in the world market, West Germany seems more inclined to support space activities for more general purposes: to invest in basic scientific research, to enhance the overall technological capabilities of
German industry, to be a cooperative trading partner and ally (e.g., Ariane and spacelab), and, in the case of communications satellites, to realize some of the benefits of space applications.

The German space budget of about $\$ 350$ million a year is administered by the Ministry of Research and Technology (BMFT) (fig. 4-4). An official BMFT document describes the purposes of the space program this way:

1. Advancement of basic research as a cultural contribution and basis of a longer run security and productivity of our economy. Germany belongs to the small circle of countries which have traditionally advanced fundamental research. These countries are the same that today possess the strongest economic power in the world and have reached the highest standard of living. Thanks to the advancement so far, the employment of space technology has become a firm component of the methods of basic research in the Federal Republic of Germany (FRG). This component should be secured and further developed.

2. Innovation through the application of space technology above all for public services, where satellite communication and Earth observation stand in the foreground. Further, with its extreme demands on scientific and technical creativity, the space program should stimulate motivation and productive readiness in all areas of science and economy.

3. Strengthening of the competitiveness of industry through direct commercial utilization of space technology. The industry should reach a level of accomplishment that allows it to achieve a share of the world market for space-technological products (table 4-4). Our own use of these products for public services will advance competitiveness in the world market, ${ }^{26}$

\footnotetext{
${ }^{26}$ Der Bundesminister fur Forschung und Technologies, Viertes Weltraumprogramm, Bundesrepublik Deutschland (Federal Republic of Germany: Ministry of Research and Technology, 1982) (OTA translation of quotation).
} 
Table 4-4.-Turnover of Major French Space Firms (millions of French francs)

\begin{tabular}{|c|c|c|c|c|}
\hline & 1978 & 1979 & 1980 & 1981 \\
\hline \multicolumn{5}{|l|}{ Aerospatiale } \\
\hline Subtotal space and missiles . . . . . . . . . . & 1,781 & 2,543 & 2,642 & 2,845 \\
\hline Total $\ldots \ldots \ldots \ldots \ldots \ldots \ldots$ & 9,500 & 11,400 & 13,200 & 16,500 \\
\hline $\begin{array}{l}\text { Percent space and missiles . . . . . . . . . } \\
\text { Matra }\end{array}$ & 19 & 22 & 20 & 17 \\
\hline Satellites . . . . . . . . . . . . . & 172 & 169 & 285 & 499 \\
\hline Launchers . . . . . . . . . . . . . . &. .67 & 85 & 55 & 152 \\
\hline Other $\ldots \ldots \ldots \ldots \ldots \ldots \ldots \ldots$ & & & & 51 \\
\hline Total space . . . . . . . . . . . . . . . . . . . . & 239 & 254 & 340 & 702 \\
\hline Total . . . . . . . . . . . . . . . . . . & 2,249 & 2,939 & 2,903 & 4,501 \\
\hline $\begin{array}{l}\text { Percent space } \ldots \ldots \ldots \ldots \ldots \ldots \ldots \ldots \ldots \ldots \\
\text { SEP }\end{array}$ & 11 & 9 & 12 & 16 \\
\hline Satellites & 7 & 6 & 33 & 62 \\
\hline Launchers . . . . . . . . . . . . . . . . . . . & 344 & 291 & 244 & 342 \\
\hline Subtotal space . . . . . . . . . . . . . . . & 351 & 297 & 277 & 404 \\
\hline Total $\ldots \ldots \ldots \ldots \ldots \ldots$ & 854 & 773 & 908 & 1,055 \\
\hline $\begin{array}{l}\text { Percent space } \ldots \ldots \ldots \ldots \ldots \ldots \ldots \ldots \ldots \\
\text { Thomson-CSF }\end{array}$ &. .41 & 38 & 31 & 38 \\
\hline Satellites . . . . . . . . . . . . & .53 & 53 & 13 & 250 \\
\hline Ground Equipment . . . . . . . . . . . . . . . . & 219 & 275 & 421 & NA \\
\hline Space ................... & 272 & 328 & 560 & NA \\
\hline Total . . . . . . . . . . . . . . . . . . . & 6,955 & 9,440 & 12,794 & NA \\
\hline Percent space ................... & 4 & 3 & 4 & \\
\hline
\end{tabular}

SOURCE: S.ES.T ${ }_{v}{ }^{\prime L}$ 'Industire Spatiale DansLe Monde," vol. 1, Paris.

Figure 4-4.-Funding Organization of German Space Activities

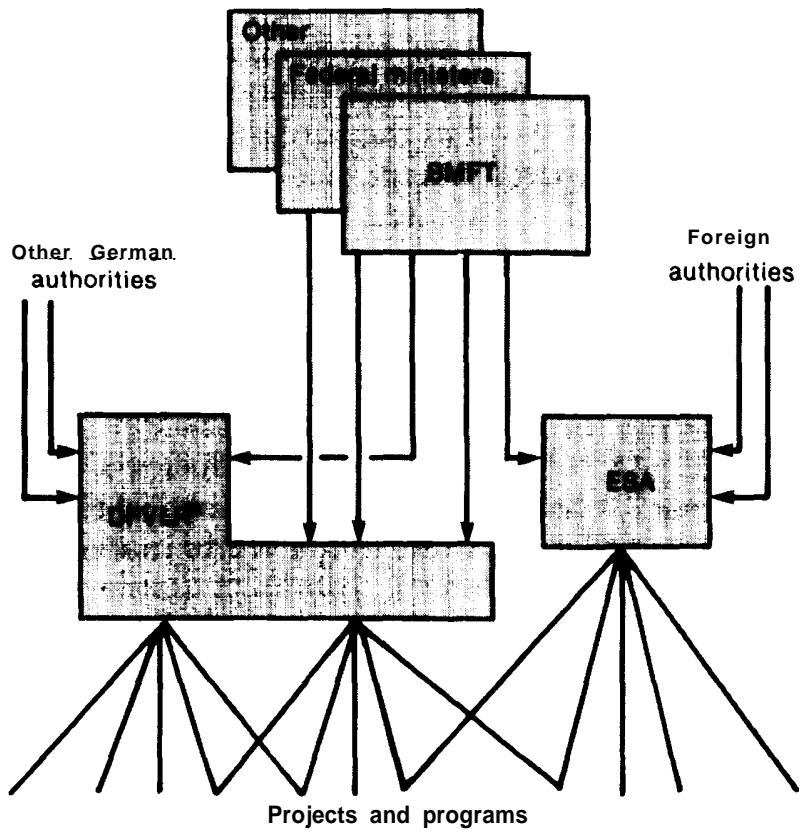

aGerman aerospace research establishment. SOURCE: DFVLR.
Table 4-5.-Turnover in the Largest German Space Firms, 1981

\begin{tabular}{|c|c|c|}
\hline Company & $\begin{array}{l}\text { Personnel } \\
\text { (space } \\
\text { activities) }\end{array}$ & $\begin{array}{c}\text { Turnover } \\
\text { (million } \\
\text { dollars) }\end{array}$ \\
\hline $\begin{array}{l}\text { Messerschmitt-Boelkow- } \\
\quad \text { Blohm/ERNO } \ldots \ldots \ldots \ldots \\
\text { Dornier } \ldots \ldots \ldots \ldots \ldots \\
\text { AEG-Telefunken } \ldots \ldots \ldots \ldots \\
\end{array}$ & $\begin{array}{r}1,200 \\
\text { NA } \\
600 \\
\end{array}$ & $\begin{array}{r}177.60 \\
88.80 \\
39.96 \\
\end{array}$ \\
\hline
\end{tabular}

Given the ability of the Spacelab to support manned experiments in orbit, materials processing in space is a logical field of interest for German research. ${ }^{27}$ (See ch. 8, "Materials Processingin Space.) The FRG contributes well over 25 percent of the ESA microgravity research program, its share for 1984 being some $\$ 12$ million.

2The German reason for building the Spacelab had moretodo with wanting toacceptthe partnership in advanced technology offered by the United States than it did with anya priori beliefin the usefulness of the Spacelab in developing a materials processing industry. 
Recently, ESA approved Phase II of this program; it will run from 1985 to 1989 with a total budget envelope of some $\$ 170$ million. Of this, the FRG has agreed to contribute 40 percent. Total FRG spending for MPS research totaled $\$ 28$ million in 1984, a sum rivaled only by NASA's 1984 expenditure of about $\$ 25.6$ million.

\section{Japan}

Over the past several decades, Japan has evolved a variety of mechanisms by which the government-particularly through the Ministry of international Trade and Industry (MITI)-influences private businesses so as to try to shape the national economy along planned lines. These mechanisms have included:

... selective access to governmental or government-guaranteed financing, targeted tax breaks, government-supervised investment coordination in order to keep all participants profitable, the equitable allocation by the state of burdens during times of adversity , . , governmental assistance in the commercialization and sale of products, and governmental assistance when an industry as a whole begins to decline, ${ }^{20}$

There is considerable debate about whether MITI has enforced a strategic "industrial policy" which successfully picks and promotes "winners" in international economic competition. ${ }^{29}$ Whatever the actual effectiveness of MITI, its economic planners did design a new strategy they hoped would adapt the Japanese economy to the new conditions encountered in the 1970s and expected in the 1980s.

The current Japanese declaratory strategy stresses growth of "knowledge-based" industries and the development of Japan as a "high-technology" society, one less dependent on the import of raw materials for re-export as manufac-

\footnotetext{
${ }^{28}$ Chalmers Johnson, MITI and the Japanese Miracle: the Growth of Industrial Policy, 1925-1975 (Stanford, CA: Stanford University Press, 1982), p. 311

${ }^{29} \mathrm{Cf}$.Roberts, Op. cit.; Philip Trezise, "Industrial Policy Not the Major Reason for Japan's Success, " The Brookings Review, spring 1983, pp. 13-18; Gary Saxonhouse, "Japanese High Technology, Government Policy, and Evolving Comparative Advantage in Goods and Services" (University of Michigan, Department of Economics: photocopy, Apr. 1, 1982.); Jimmy Wheeler, Merit E. Janow, and Thomas Pepper, Japanese Industrial Development Policies in the 1980s: Implications for U.S. Trade and Investment (Croton-on-Hudson, NY: The Hudson Institute, 1982), p. 138.
}

tured goods and more dependent on the export information and technology produced in Japan. Consistent with this approach is an emphasis on strengthening Japanese science and technology.

\section{JAPANESE SCIENCE AND TECHNOLOGY POLICY}

The Japanese are fully aware of their national weaknesses in science and technology (compared with, for example, the United States). Their government has outlined policies to build on Japanese strengths and remedy their weaknesses. Japanese research expenditures account for about 10 percent of the world's total, as does the Japanese GNP. Japan also possesses about 12 percent of the world's researchers ${ }^{30}$ It exports about 12 percent of the world's technology-intensive products. Using a mix of indexes of technological "power," the Japanese Science and Technology Agency found Japan to be relatively high in current technological capability, but lower than desirable in the potential for developing new technology. In terms of royalties paid for the licensed use of foreign technology, Japan is still a net importer of technology. Even so, when new annual licensing only is measured, Japan has already begun to export more technology than it imports.

The Japanese Government wants to reinforce this trend. It has concluded that in order to do so it will have to increase government support of the basic research that can lead to new technology in the longer run. As other observers have noted:

... there is a distinct bias in Japan's overall research expenditures toward applied research and prototype development-a bias reflected both in government-supported R\&D and private sector research expenditure. ${ }^{31}$

In the latter months of 1980 , the ministers whose tasks related to science and technology met and agreed on a set of policies intended to "make Japan into a so-called science and technology-oriented country," The first measure in this new set of policies was to increase govern-

\footnotetext{
${ }^{30}$ Much of the following taken from "Science \& Technology White Paper '81 Released," Science \& Technology in Japan, January 1982, pp. 6-14.

${ }^{31}$ Wheeler, Janow, and Pepper, op.cit.
} 
ment investment in research and development $(R \& D),{ }^{32}$ and thereby increase the proportion of national income devoted to $R \& D$ to 2.5 percent and eventually to 3 percent. ${ }^{33}$ The government undertook to improve the coordination of national R\&D policy among several ministries and agencies. In fiscal year 1981 it appropriated a special "Science and Technology Promotion Coordination Fund" to be managed by the national Council for Science and Technology. (This fund went from about $\$ 14$ million in fiscal year 1981 to about \$25 million in fiscal year 1982.)

Although the Japanese Government has recognized the need to increase basic research, it has also selected some specific areas of applied research that it thinks will help advance the goal of becoming a "technology-oriented country. " One such area, a highly visible one, has been that of industrial robotics. Japan has already assumed world leadership both in the use and the export of computer-controlled machines in manufacturing ${ }^{34}$ Another well-known project is the "Fifth Generation Computer Project," a research effort on which Japanese Government and industry will spend about $\$ 500$ million over 10 years.

\section{THE JAPANESE SPACE PROGRAM}

The Japanese space program, although not explicitly a part of this "high-tech" emphasis, seems to be consistent with it. About 16 percent of all Japanese Government research and development expenditures is space-related. In 1968 Japan formed a Space Activities Commission (SAC) to formulate space policy (fig. 4-5). The chairman of this five-man Commission is the Minister of the Science and Technology Agency; the STA pro-

\footnotetext{
32," Science \& Technology White Paper '81 Released," op cit., p. 11.

The other elements of the policy for promoting science and technology were as follows:

- Expansion and improvement of evaluation systems;

- Establishment of an organic system for coordinating activities among

academic, industrial and government circles;

. Promotion of original scientific and technological development;

- Recruitment and training of science and technology personnel;

- Promotion of international cooperation' in science and technology.

${ }^{33}$ The United States already was spending about 2.5 percent, but about a quarter of that went to military research, while much less Japanese research is military.

${ }^{34}$ See, for example, Computerized Manufacturing Automation: Employment, Education, and the Workplace, OTA-CIT-235 (Washington, DC: U.S. Congress, Office of Technology Assessment, April 1984).
}

vides the Commission staff. In October 1969, the SAC put together the first "Space Development Program, " a plan it reviews annually. 35

In 1978 the SAC issued an "Outline of Japan's Space Development Policy," enunciating "principles" and "priorities" for the long term. Although the policy statement holds as a priority goal "keeping Japan's level of science abreast with international standards, " the key words are probably "... promoting the development of science and its application in ways suitable to Japan."

- Space science: Japan has launched several scientific satellites for observing astronomical, near-Earth space, ionospheric, and atmospheric phenomena. They will send their first interplanetary satellite, PLANET A, to study Halley's Comet this year. They built hardware for the joint U.S.-Japan Space Experiments with Particle Accelerators aboard the Space Shuttle's first spacelab mission in 1983. Pursuing space science is consistent with the Japanese goals of promoting basic research in Japan and partaking of the benefits of international scientific cooperation.

- Meteorological satellites: In 1984, Japan launched its third geostationary meteorological satellite. (It should be noted that Japanese meteorological satellites have relied heavily on American suppliers of key technology.) The weather information provided to Japan is obviously of benefit to the Japanese economy, particularly because Japan is so fully a maritime nation. But by beaming its images to 13 other Asian and Pacific nations, the satellite also reinforces Japan's efforts in international cooperation.

The program contributes to Japanese international policy in other ways as well. The first Japanese weather satellite, launched in 1977, was a part of the World Weather Watch program of the First GARP (Global Atmospheric Research Program) Global Experiment. In 1978, Japan held a Joint U.N./WMO Training Seminar on the Interpretation and Analysis and Use of Meteorological Satellite Data for Asia

\footnotetext{
${ }^{35}$ Masao Yoshiki, "Japan's Space Programs, "International Aerospace Symposium, Paris, June 2-3, 1981, p. 1.
} 
Figure 4-5.-Schematic Chart of Organization for Space Activities

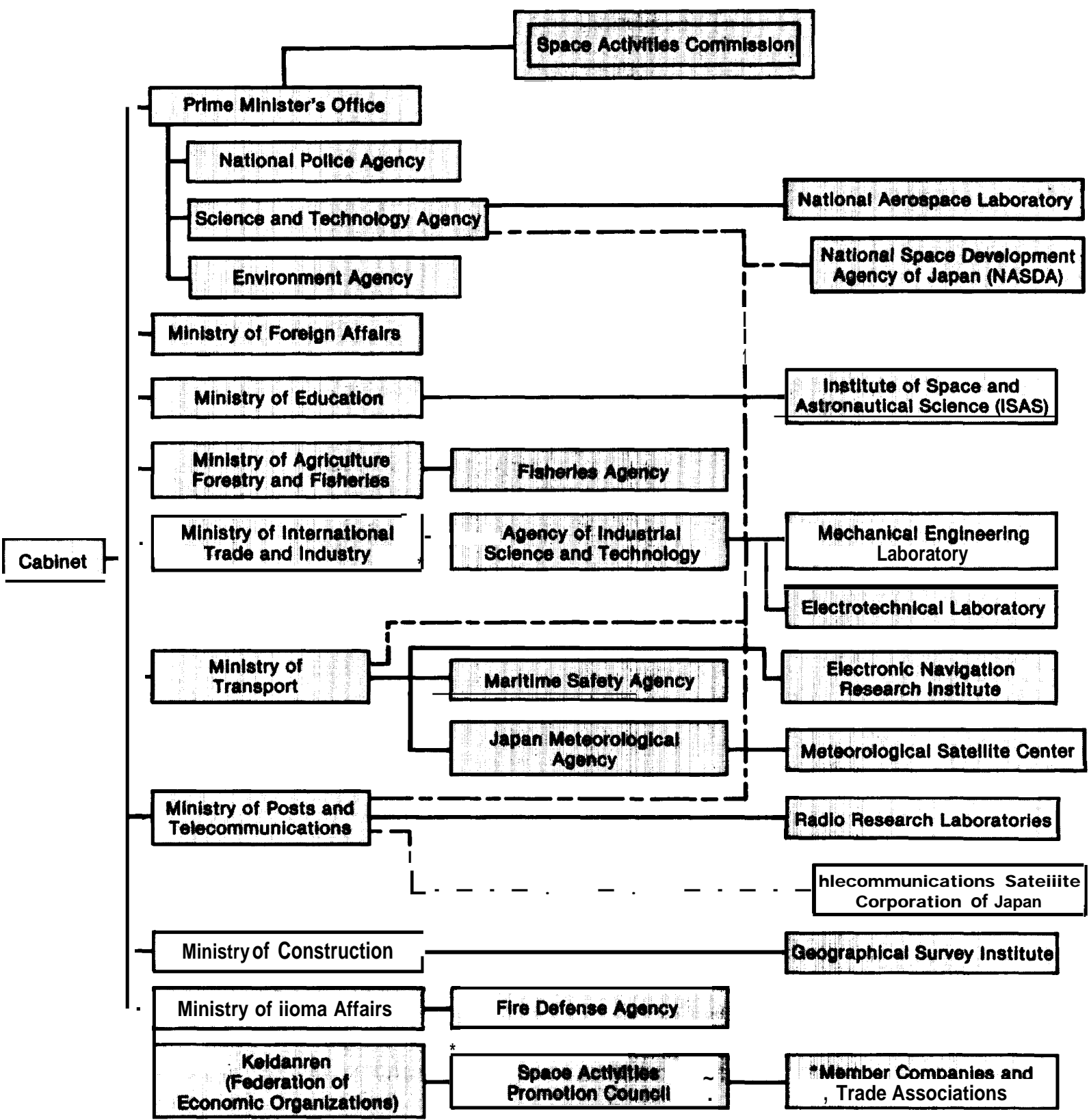

- Member companies and trade associations include: C. Itoh \& Co. Ltd./Daicel Chemical Industries, Ltd./Daido Oxygen Co., Ltd./The Dai-Ichi Kangyo Bank, Ltd./The Fuji Bank, Ltd./Fujitsu Limited./Hitachi, Ltd./Ishikawajima-Harima Heavy Industries Co., Ltd./Iwatsu Electric Co., Ltd/Japan Aircraft Mfg. Co., Ltd//Japan Aviation Electronics Industry, Ltd./Japan Broadcasting Corporation/Japan Propellent Industry Co., Ltd./Japan Radio Company Ltd./Kawasaki Heavy Industries, Ltd./KokusaiDen. shin Denwa Co., Ltd./Kokusai Electric Co., Ltd./Kyokuto BoekiKaisha, Ltd./The Kyowa Bank, LTD./Kyushu Electrical Construction, Ltd./The Long-Term Credit Bank of Japan, LId/Maruen Mitsubishi Heavy Industries, Ltd./Mitsubishi Precision Company, Ltd./Mitsubishi Space Software Co., Ltd./Mitsui \& Co., Lto./MitsuiEngineering \& Shipbuilding Co., Ltd./NAC Incorporated/NEC-Honeywell Space Systems, Ltd./Nippon Electronics Development Co., Ltd./Nippon Electric Company, Limited (N EC)/Nippon Oil \& Fats Co., Ltd./Nippon Sanso K,K./NIppon Steel Corporation/Nippon Telegraph and Telephone Public Corporation/Nissan Motor Co., Ltd./NissholwaiCorporation/Oki Electric Industry Company, Ltd./Okura and Company, Ltd./Remote Sensing Technology Center of Japan/The Sanwa Bank Ltd./Sharp Corporation/The Society of Japanese Aerospace Companies, Inc./Sumitomo Corporation/Sumitomo Precision Products Co., Ltd./System Development Corporation of Japan, Ltd. ITEISANK. K.ITokyo Aircraft Instrument Co., Ltd.Toray Industries Inc./Toshiba Corporation/Tokyo Communication Equipment Co., Ltd.IThe Yokohama Rubber Co., Ltd.

SOURCE: National Space Development Agency of Japan. 


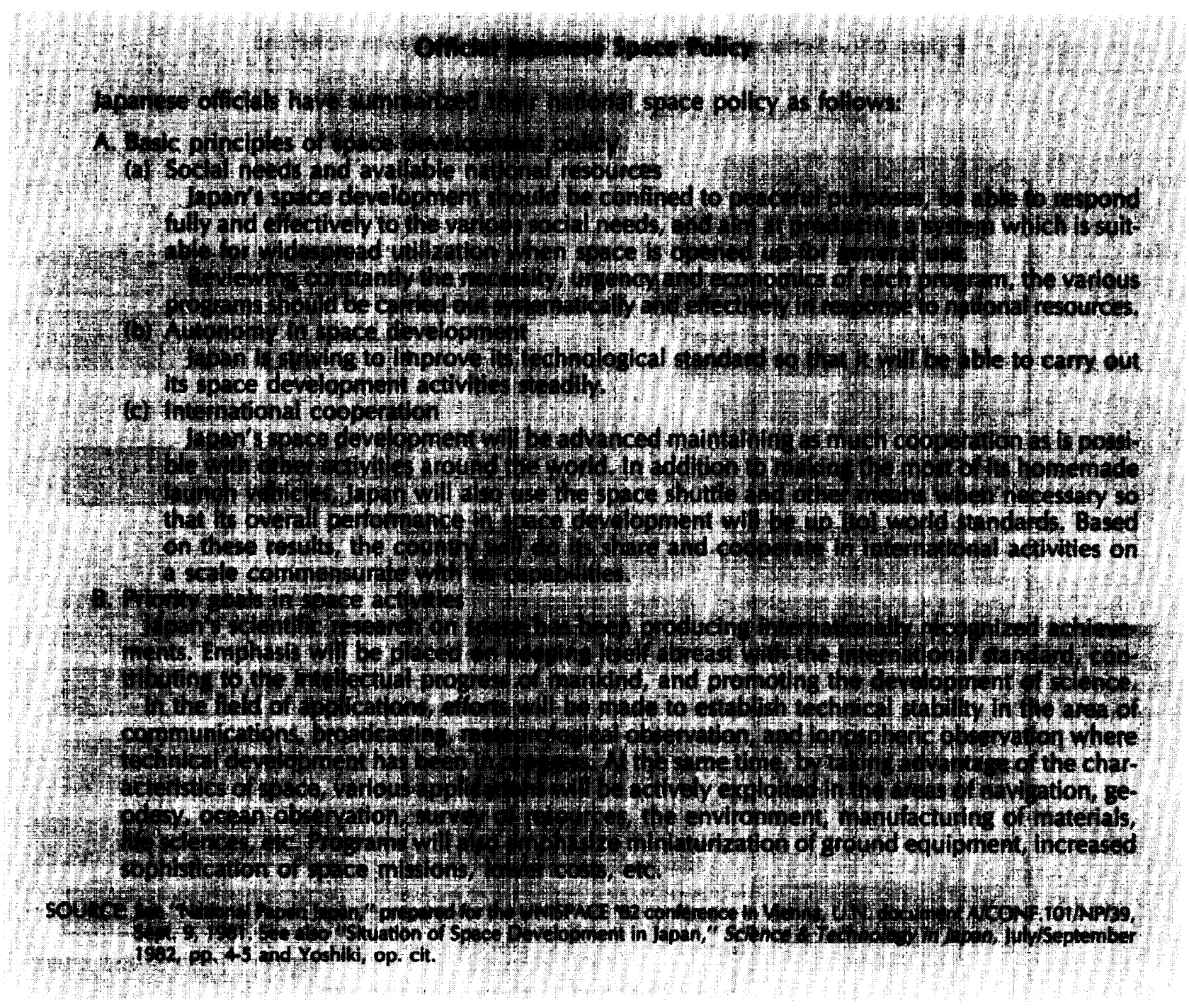

and the West Pacific, bringing together 32 representatives of 19 countries.

- Launch vehicles: Building on American technology (licenses to make the McDonnell Douglas Delta), Japan is developing its own stable of launch vehicles, to culminate in the $\mathrm{H}-1$ and $\mathrm{H}-11$. The former will be capable of delivering 550 kilograms of payload to geosynchronous orbit. (See ch. 5 for more details.) The Japanese launch vehicle program is consistent with the principle of "autonomy." It also opens up the possibility that someday Japan will enter

36"National Paper: Japan, " op. cit., p. 25. the international competition in launch vehicle services. But that day is not on the immediate horizon: the modest payloads deliverable by the $\mathrm{H}-1$ will not match the capabilities of the Ariane series, let alone that of the Space Shuttle. Indeed, a major communications satellite planned for the late 1980 s by Nippon Telegraph \& Telephone (NTT) will be far too heavy for the Japanese launcher.

- Satellite communications: Satellite communications has offered one promising avenue along which Japan can pursue its goal of developing a high-technology, information-based economy. NEC-with technical assistance from 
Hughes Aircraft Corp.-has become the leading manufacturer of INTELSAT satellite transponders and ground terminals. ${ }^{37}$

In February 1983, Japan launched the world's first operational Ka-band $(30 / 20 \mathrm{GHz})$ communications satellite. Japan plans a series of direct broadcast satellites and is conducting research on mobile satellite communications. They reportedly intend to begin launching multi-beam communications satellites in 1988, as a part of NTT's "Information Network Systern. "38

Satellite communications will allow Japan to improve its domestic communications networks and no doubt contribute in that way to the advancement of Japanese technology. But presumably the industry will also more directly draw on and stimulate Japanese strengths in electronics technology. As the first, or close to the first, operators of a Ka-band satellite communications system, Japanese firms may be in a position to compete more fully in any international satellite market that develops for advanced satellites of this type.

Remote sensing: In 1975, the Science and Technology Agency formed the Japan Remote Sensing Technology Center (RESTEC). Since 1979, Japan has had an operational Landsat receiving station, In 1981, the Machinery and information Industry Bureau of MITI created a public nonprofit corporation (with funds from 27 firms), the Earth Resources Satellite Data Analysis Center. One objective of the ERS-DAC is to help locate mineral resources (the President of ERS-DAC is Director of the Japan Petroleum Exploration Co.). Another seems to be to lay the groundwork for marketing remote sensing services. ${ }^{39}$

\footnotetext{
${ }^{37}$ See U.S. Congress, House Committee on Science and Technology, Science, Technology, and Energy: Report of a Congressional Study Mission, 97th Cong., 1st. sess., Serial Q, May 1981, p. 19. See also Neil Davis, "First Japanese Mass Production Satellite Plant Completed," Space World, January 1983, p. 33.

38)apnnt-tLaunchaMulti-Beam Communications Satellite," Aerospace Daily, Aug . 24, 1980, m. 301.

${ }^{39}$ ERS-DAC activitiesinclude the following: contracting for research and development in computer image processing and analysis software; contracting for research and development on the geologic applications of remote sensing for finding nonrenewable resources; engaging in foreign market research on user needs and the technical state of the art; exploring foreign technology transfer and liaison with foreign remote sensing organizations; sponsoring symposia and publishing documents for internal dissemination of
}

The Japanese National Aeronautics and Space Development Agency (NASDA) plans to launch the first of a series of ocean and land remote sensing satellites in 1986 (see ch. 7), Meanwhile, remote sensing is one of a handful of fields selected by the Council for Science and Technology as a "new vital research theme" to receive support from the Science and Technology Promotion Coordination Fund. ${ }^{40}$ One reason for Japanese Government support of supercomputer technology is the large-scale computing capacity useful for remotely sensed image processing.

The Japanese Government has not stated an intention to make Japan an active competitor in the international remote sensing market. Even so, the Japanese program could put Japan in a position to:

- satisfy future Japanese remote sensing needs without dependence on foreign satellites or image processing facilities;

-enter the market for image-processing equipment and software;

-enter the market for remotely sensed data, image processing, and image analysis; and

-offer remote sensing services to less developed countries in exchange for special consideration in supplying nonrenewable resources.

As an especially knowledge-intensive, hightechnology industry, remote sensing seems to be a natural choice as a small element in the stated Japanese industrial strategy for the 1980s and 1990s.

In sum, the Japanese have been making steady progress in space, but their program has, for the past several years, maintained a level budget (fig. 4-6), which means that their real effort has declined after inflation. ${ }^{42}$ Like the other space

\footnotetext{
remote sensing analysis techniques. Source: 1982 ERS-DAC brochure.

${ }^{40}$, New Fund for Coordination and Promotion of Science and Technology Policies, "Science \& Technology in Japan, January 1982, p. 21.

Al See Buzbee, et al., op. cit., p. 1189.

${ }^{42}$ Takashi Yamada, "Japan's National Space Program-Current Programs and New Directions," Space: The Next Ten Years, TMSA Symposium Proceedings, 1984, p. 324.
} 


\section{Figure 4-6. - Japanese Space Budget}

Budget for Japan's space activities

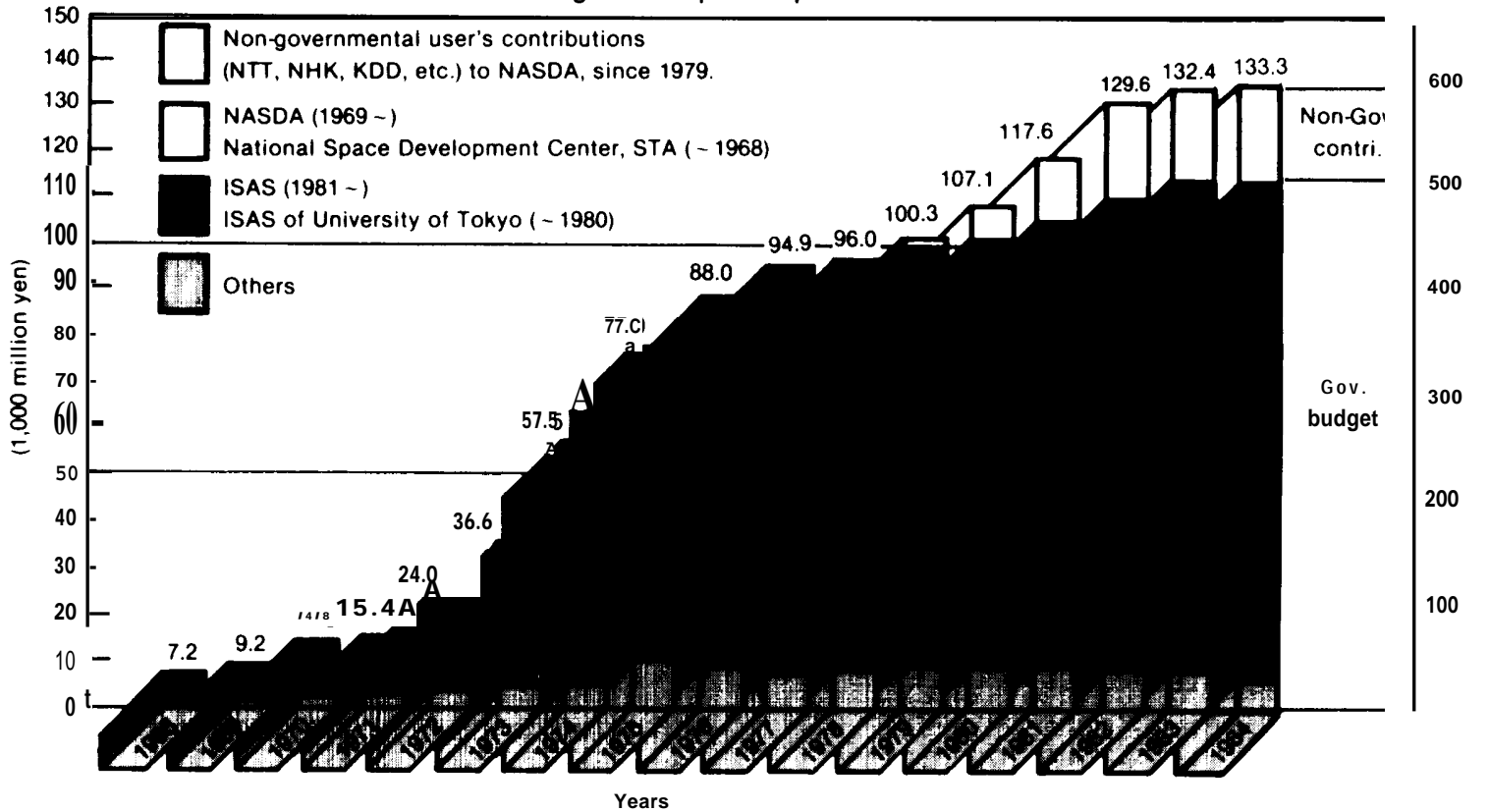

NOTE: Since 1981, the proportion of GNP and the national budget devoted to space developments has remained constant at $0.2 \%$ and $0.040 /$ respectively.

Growth of NASDA'S budget

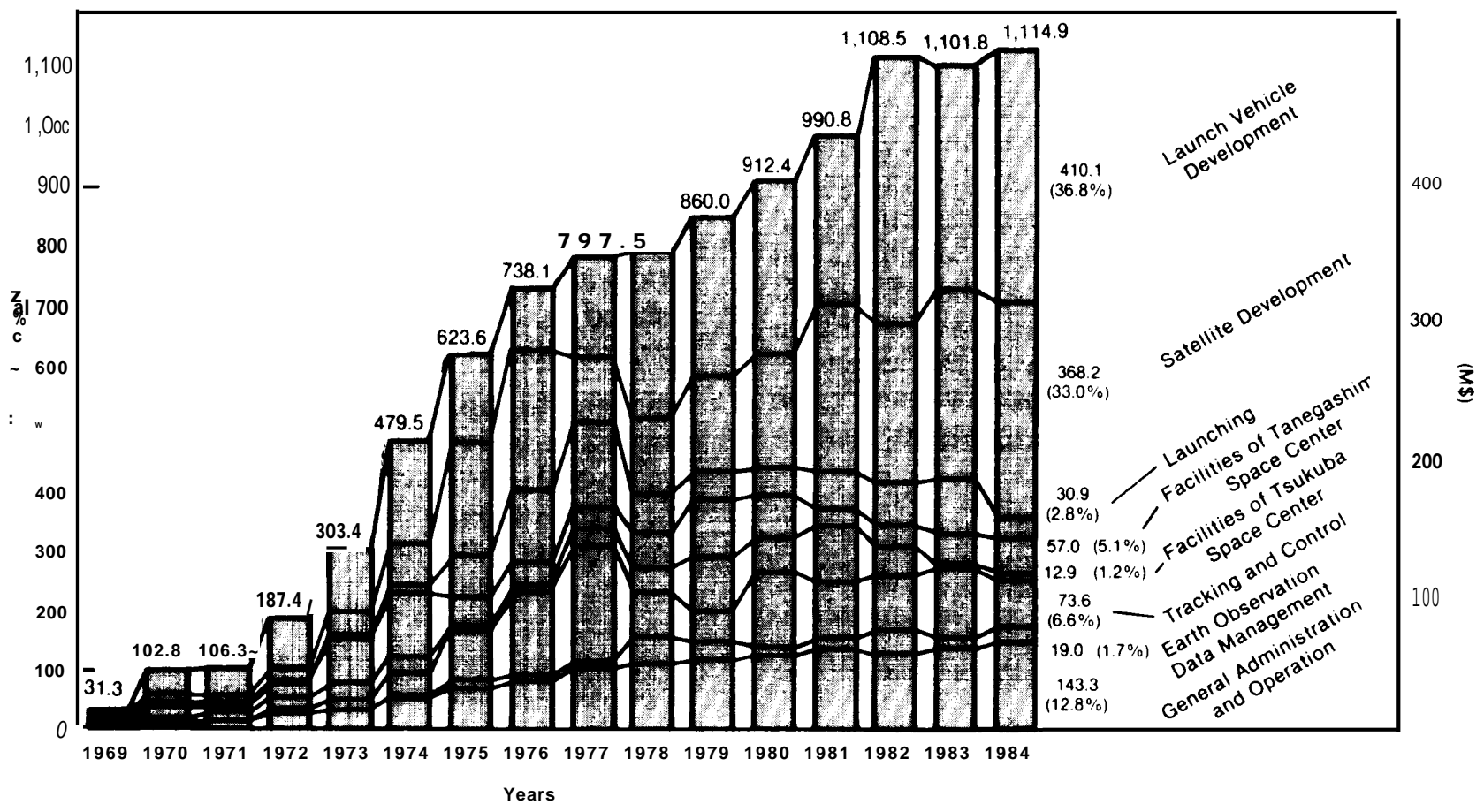

NOTE: The figures in parenthesis are the percentages of the total budget.

- Dollar figures calculated, for Information only, at rate of $\mathbf{2 4 0}$ yen to the dollar (U.S.).

SOURCE: National Space Development Agency of Japan. 
powers, Japan has accepted the assumption that a government space program will ultimately contribute to national economic well-being. Japan has not specifically identified space industries as "targeted" for special emphasis in export competition. The Japanese space program instead seems aimed at developing space technology- and doing so with increasing independence from U.S. technology and equipment. Whether they are to become major competitors in the international markets for space-related equipment (beyond the electronic components and ground stations they now sell) and for services will probably not be apparent until the 1990s.

\section{THE WORKABILITY OF COMPETITION IN SPACE-RELATED MARKETS}

As space applications become more commercial, questions of industrial organ ization-competition, monopoly, regulation-and of international trade assume a greater role in discussions of space policy, At the same time, debates over competition and protection are staples of public policy in many other areas of the general economy; much of this wider debate is relevant to the emerging space industries. Moreover, some policies in the space arena may be determined by broad existing U.S. policies governing competition and international trade in the general economy.

Space transportation and satellite communications are two technology sectors that provide examples of this shift of focus of the space policy discussion onto questions of industrial organization and international trade. As private sector and foreign space transportation firms challenge the position of NASA as the U.S. Government space transportation "firm," the question of whether or not the industry can be organized competitively-or should be-revolves around the questions of Shuttle pricing, government procurement, and U.S. and foreign government subsidization.
In international satellite communications, which has traditionally been organized noncompetitively, technological changes, the newly competitive long-distance telephone industry in the United States, and the Government's drive for a broad agreement on international trade in services are among the elements forcing the focus of the space policy debate to change.

\section{International Commerical Competition in Space-Related Markets}

As the earlier part of this chapter has demonstrated, the space arena has been and continues to be the scene of political competition among space powers. It is also the scene of growing commercial competition in most space-related sectors. The competing enterprises may be private firms or governmental organizations. They are subject to greater or lesser coverage of general international trading rules that govern commerce among nations in today's world..$^{43}$ In certain in-

\footnotetext{
${ }^{43}$ App. 4A surveys the international trading rules applicable to space commerce.
}

\section{Competition and Regulation in the whylyon Economy}

The competitive organization of industry is well entrenched the United States as the normal mode of industrial organization, even though this has not been the fa 4 in space industries. Most U.S. industries are considered to be workably competitive, in the sense og whatever the cepartures from perfect competition, we rely on competition to keep the firms in whese nd ussiles from eaming significant monopoly profits and thus misallocating society's resources. The ratomale for this reliance is that competitive firms will bid for customers by reducing prices and in the long run will earn only normal profits over the course of the business cycle.*

\footnotetext{
* "Over the business cycle" is an average concept. There's no expectation that prices will ever be such that normal profits will be earned at any one time. When there is overcapacity, competitive firms may reduce prices below long run average cost until the overcapacity is worked off, and when there is a shortage of capacity, prices may be above long-run average cost until capacity increases.
} 


\section{[Page Omitted]}

This page was originally printed on a gray background.

The scanned version of the page is almost entirely black and is unusable.

It has been intentionally omitted.

If a replacement page image of higher quality

becomes available, it will be posted

within the copy of this report

found on one of the OTA websites. 
stances they are also governed by domestic and international regulation.

The International Trading Regime in Space-Related Equipment

The current structure of international trading rules is primarily designed to regulate trade in commodities rather than services. Although the multilateral rules and understandings that have been negotiated through GATT $^{44}$ and $\mathrm{OECD}^{45}$ do have a significant effect on international trade in equipment in general, especially when the stakes are relatively small, the many exceptions, exclusions, escape possibilities, etc., that have been built into the rules can be used by sovereign governments to avoid effective trade discipline when the stakes are large or when political considerations dominate.

Since France and Japan, and to a lesser extent other industrial countries, have made the decision to join the United States as space powers, it would be wishful thinking to believe that they will fully abide by the trade rules i $\mathrm{n}$ competition for sales of space-related equipment. In most areas they would probably lose out to U.S. suppliers in open competition, as a result of the pricequality dominance of the latter.

From the point of view of U.S. space-related equipment suppliers, perhaps the most damaging exclusion in the trade rules is the exclusion of the major non-American buyers of satellite communications equipment from the list of government organizations covered by the GATT Government Procurement Code. These organizations are the European and Japanese PTTs (post, telephone, and telegraph organizations) that have communications monopolies (or near monopolies) in their respective countries. The code document, which has been signed by most of the industrial countries, specifies which government agencies in each country are covered,

\footnotetext{
${ }^{44}$ Ceneral Agreement on Tariffs and Trade. The name refers both to a treaty adhered to de jure and de facto by 117 countries and to an organization, which has a permanent staff, the GATT Secretariat.

${ }^{45}$ Organization for Economic Cooperation and Development. Membership includes the United States, Canada, Japan, Australia, New Zealand, and the governments of all Western European industrial market economies.
}

and the European countries and Japan have specifically excluded their PTTs from coverage. Because the PITs largely follow "buy-national" procurement policies, American aerospace and telecommunications equipment firms are systematically excluded from a significant share of the international trade in satellites and ground-segment equipment.

Under considerable pressure from the United States, Japan agreed in a 1981 bilateral agreement to open up government procurement for the NIT to American equipment suppliers. ${ }^{46}$ This agreement was also extended to the suppliers of all other countries and in 1984 was extended to December 31 , 1986. U.S. observers currently disagree about whether enough progress in opening up NTT procurement occurred to justify renewing the agreement or not. No important progress has taken place in opening up European telecommunications equipment markets.

In third-country markets, the GATT Subsidies Code, a second major multilateral trade agreement, in theory, limits all kinds of subsidized export competition. In practice, however, it has not been used to cover the important types of subsidies in space-related equipment exports, such as $R \& D$ subsidies and the subsidized operation of government space organizations. Although these types of subsidies affect export competition, they also have justifications unrelated to international trade that are within the sovereign powers of individual nations. Separating the effects of these subsidies on trade from other effects has not yet been attempted to any extent in the case of $R \& D$ subsidies.

The OECD Arrangement on Officially Supported Export Credit, a third major multilateral trade agreement among the industrial countries, is designed to eliminate one particular type of export subsidy - subsidized credit. It applies to sales by both private and governmental organizations and is effective to a degree in preventing competition for third-country markets using subsidized export finance. Perhaps the heart of the arrangement lies in the elimination of credit subsidies that are relatively small. In instances where exporter govern-

\footnotetext{
${ }^{46}$ "NTT Pact Extended for Three Years, Abe Holds Trade Talks With U.S. Official," U.S. Export Week/y, Jan.31, 1984, pp. 580-581.
} 
ments do not choose to make large credit subsidies, the arrangement now keeps them and their competitors from offering interest rates substantially below commercial interest rates and in this way lessens "unfair" competition .47 A special OECD arrangement exists for satellite ground stations; among other things, it limits the duration of export credit for ground stations to 8 years. ${ }^{48}$

There are limits, in practice, to this discipline in the use of export credit. Despite the arrangement, governments find ways to subsidize largeticket, high-technology sales to less developed countries, both for political reasons and to promote exports. No existing multilateral agreement disallows credit subsidies with a large grant element in sales to less developed countries; they are simply given the label of "official development assistance" when the credit subsidy exceeds a ${ }_{25}$ percent grant element.

Space-related transactions-e.g., the sale of a satellite communications system-are often large and politically significant to exporter countries. Hence, large credit subsidies appear to be the norm rather than the exception in sales of spacerelated equipment to less developed countries. The other industrial countries have justified the trade restrictions they have erected for space-related equipment and services and for subsidizing competition in third-world markets by arguing that they are simply countervailing against the strong subsidy and industrial-policy support the United States gives to its aerospace industry through the defense budget.

\section{International Trading Regimes in Space-Related Services}

General international trading rules do not as yet exist for trade in services of any kind (with the one important exception that export credit for services is covered by the OECD arrangement). Thus, different international trading regimes exist for each different service industry. in the four space-related service industries discussed in this report-space transportation, remote sens-

\footnotetext{
${ }^{47}$ For an extensive treatment of the subsidy issue see Gary Clyde Hufbauer and Joanna Shelton Erb, Subsidies in International Trade (Cambridge, MA: MIT Press, 1984).

${ }^{48}$ Unpublished document, supplied by the U.S. Treasury.
}

ing, materials processing, and satellite communications-only the latter has a well-defined international trading and regulatory regime. Space transportation and remote sensing have only begun to glimpse real commercial competition and international trading regimes have not been developed for these industries. The materials processing industry (as well as its international trading regime) does not yet exist.

The questions of industrial organization and international trading regime are discussed in the following section in the context of each of the service industries, but we note here that the international trading regime in international satellite communications has largely eliminated international competition in both the sale of services and the ownership of facilities. International trading regimes in finance and other auxiliary services important for international trade in large, risky, and long-lived space-related ventures, are also highly anticompetitive in many countries because of restrictive national regulation and constitute an important non-tariff barrier to the sale of U.S. space-related services and equipment in these countries. ${ }^{49}$

\section{Competitive Analysis of International Space-Related Service and Equipment Industries}

\section{Space Transportation Services}

The space transportation services industry has recently passed from infant industry status, where to all intents and purposes there was only one

\footnotetext{
${ }^{49} \mathrm{By}^{\prime \prime}$ anticompetitive" trading regimes, we mean that in the markets involved, firms (particularly foreign firms) are significantly restricted in entering the market, in offering products or services at their discretion, in pricing these products and services, and in investing in facilities. The International Banking Act of 1978 established a U.S. Federal regulatory framework giving "national treatment" to foreign banks (i.e., nondiscriminatory treatment of foreign banks vis-a-vis U.S. banks). U.S. banks and other financial institutions, however, are not accorded national treatment in many other countries. In a recent survey for the Senate Committee on Banking, Housing, and Urban Affairs, the Controller of the Currency found that significant progress had been made since an earlier 1979 survey in securing national treatment for U.S. banks in six of the seven OECD countries surveyed (Canada, Finland, Norway, Portugal, Spain, and Sweden, but not Australia); Department of the Treasury, "Report to Congress on Foreign Government Treatment of U.S. Commercial Banking Organizations, 1984 Update, " submitted July 5, 1984.
} 
producer carrying commerical payloads, to a more complex competitive status. NASA is still the dominant producer and still receives annual congressional appropriations for space transportation, but there are now four additional actual or potential major competitive carriers, Arianespace [Ariane], Transpace Carriers, Inc. [Delta], General Dynamics IAtlas-Centau r], and Martin Marietta Titan].

In addition to these major carriers or potential carriers, several specialty carriers now offer or may soon offer minor or specialized services, such as low-earth-orbit and sub-orbital space transportation. Identified in this report are Space Services, Inc., Starstruck, Inc., Orbital Sciences Corp., OTRAG (Germany), and Bristol Aerospace, Ltd. (Canada), but other firms are likely to enter this specialty market in the future.

Two classes of potential competitors are government launch agencies (in the U. S. S. R. ${ }^{50} \mathrm{In}-$ dia, China, ${ }^{51}$ Brazil, and Japan), which so far have not indicated a commercially important desire to compete in the general international space transportation market, and the large U.S. aerospace firms that do not currently maintain launch capability but are well entrenched in one or another aspect of space (e.g., Hughes Aircraft Co. or British Aerospace).

Whether or not the fringe of the space transportation services industry develops or aerospace firms enter the market will depend primarily on future demand for space transportation and the pricing of services by established subsidized providers like NASA and Arianespace.

By far the largest current demand for commercial space transportation comes from the communications industry. This demand for placing communications satellites in orbit is relatively well known for the next 5 years, but becomes highly uncertain thereafter. ${ }^{52}$ This uncertainty arises because satellite and fiber-optic cable technologies will be active technological alternatives in vol-

\footnotetext{
50TheU.S.S. R. has offered its Proton launcher to INMARSAT in what may be called international competitive behavior.

${ }^{51} \mathrm{Ch}_{\mathrm{na}}$ has recently offered to sell lau nch services to other nations. See "China Offering Launch Services to International Users," Aviation Week and Space Technology, Apr. 8, 1985, pp. 25-26.

'See chs. 5 and 6.
}

ume long-distance communications in the 1990s. With the greater integration of space-related commerce into the economy, economic events far from space will strongly influence the market for space transportation.

Other civilian demand for space transportation-for materials processing, remote sensing, space station activities, space science and space R\&D-is even more uncertain. Complicating everything will be military demand for both NASA Shuttle bay capacity and, perhaps, for expendable launch vehicles (E LVs). ${ }^{53}$

Under continuing high demand, the space transportation industry could mature rapidly in the late 1980 s and early 1990s. NASA, or private sector descendants, would be providing Shuttle services to space stations and to firms parking free- flyers in space or sending communications satellites on "upper stage" rockets to geostationary orbit. ELV operators, Arianespace and a number of U.S. firms, would probably be providing an array of tailored services primarily to the communications industry. Firms providing specialty services might be competing for a variety of lowmass communications and materials processing payloads. The space transportation industry could develop vigorously in the normal competitive mode.

Under low demand, however, the industry structure would be far different. There might be an excess supply of Shuttle services. Arianespace might be the only ELV operator, with most or all U.S. aerospace firms either definitively discarding plans to offer ELV services on current-generation vehicles or simply continuing to hold back. Some specialty firms might die out. NASA and Arianespace might continue to provide commercial launches in protected home markets and engage in subsidized export competition in international markets.

Of several key decisions that will affect competition in space transportation, the first concerns whether competition can be the preferred industrial organization in this industry, as it is in American industry in general, or whether there are special characteristics in the industry that make an

\footnotetext{
53 See ch. 5 for a more extensive discussion of space transportation.
} 
organization based on regulation necessary. Recently, the theory that transportation industries, absent special circumstances, operate more efficiently under competitive conditions has been widely put into practice. In the face of this general practice, proponents of regulating space transportation would have to argue that special circumstances do indeed obtain .54 Their argument might emphasize the political and military aspects of space, the large investments often necessary and the need for special institutions to accomplish national objectives.

The essence of competitive organization in any industry is freedom of pricing and entry. ${ }^{55}$ in space transportation, pricing freedom would apply to both private and government entities. In the United States, space transportation is far from being a perfectly competitive industry. Firms are free to enter, but may face subsidized price competition from Government-owned systems (e.g., the Shuttle). But attempting to make it more competitive by establishing price controls, allowing price fixing, or maintaining entry restrictions would be contradictory. Workable competition depends on firms having sufficient freedom of both entry and pricing that customers will have full freedom of choice. In this, as in many other industries, regulating imperfect competition in order to improve it may prove to be counterproductive. ${ }^{5 \mathrm{G}}$

\footnotetext{
54The Department of Transportation (DOT), with the demise of the Civil Aeronautics Board at the end of 1984, now has full responsibility for both economic and safety regulation of the airline industry; it also has recently been given the lead responsibility for regulating the space transportation industry. The recent history of regulation of the airline industry may offer some guidance to what form regulation of space transportation may take; in recent years, economic regulation of entry, price, and capacity for both passenger and cargo has largely been removed for domestic but not for international air transportation.

s5/t also needs to be specified that in space transportation or any other market where the buyers may be government entities, "free entry" has to mean more than just the freedom for sellers to offer price-service combinations at their discretion. There must also be buyers willing to purchase the best price-service offering, rather than be constrained to purchase only from certain sellers because of political directions.

56Mixed public/private industries are a' particular casein point. Aside from advantages in government procurement, public firms are likely to have an advantage in their cost of capital and in their de facto insurance against bankruptcy due to losses. Conversely, they are likely to suffer from the disadvantage of being used as an employment utility and, generally, from political interference. Thus, there is usually no shortage of imperfections in competition involving such firms. Nevertheless, the use of regulation to cure such con-
}

A second important decision affecting competition in space transportation concerns the amount of subsidy that will be provided to NASA in the future to provide commercial space transportation services. If it is not Congress' intention to subsidize these services, NASA would have to earn a market return on its investment in facilities to provide them. Measurement of NASA's rate of return on investment in these facilities is not a trivial exercise, and key accounting determinations would need to be made (beyond those now provided by NASA) as to what facilities should be counted and how much of their services should be ascribed to civilian launches.

Large new investments (e.g., the purchase of additional orbiters) in a program to carry commercial cargoes would make the subsidy question salient. Under these circumstances, Shuttle prices that did not take account of capital costs related directly to commercial cargoes and did not reasonably allocate costs of all kinds between commercial and government business, would constitute the subsidization of one competitor (NASA) in a mixed public-private international industry. ${ }^{57}$

A third important decision affecting competition will be what stance the United States should take toward international competition. It should be clear that, in addition to developing other space-related industries, France, Japan, and other countries are convinced that they must have a space transportation capability. This commitment has been based on various theories about leadingsector industries, but it is undoubtedly also grounded in straightforward considerations of national pride.

Given their commitment to developing launch capability, it appears inevitable that they will also practice restrictive procurement when their space-related industries might not otherwise develop the minimum level of sales to justify operations. Open access of U.S. producers to these

\footnotetext{
ditions may often be a cure worse than the disease, if imperfect competition is replaced by a government-managed cartel.

${ }^{57}$ Similar questions concern Arianespace, but since an important current subsidy of international launches comes from discriminatory pricing in favor of non-European cargoes, a more conventional international trade approach against "dumping" is possible if services should come to be covered by U.S. antidumping statutes.
} 
markets and full coverage of their space industries by liberal international trade principles do not, therefore, appear to be possible in the near future. Rather than attempting to prevent trade restrictions in the international market for launch services, the United States could try to minimize their impact and scope.

Continued efforts to get a multilateral code on trade in services, ${ }^{58 t} 0$ make general progress on government procurement and subsidies, to achieve an agreement on mixed credits in trade with developing countries, and to make sure that space industries are not systematically removed from coverage would probably help to achieve this objective. In addition to multilateral trading rules, bilateral negotiations and reciprocity legislation have also been advocated as mechanisms for securing access of U.S. firms to foreign markets.

How open the U.S. market should be to space transportation firms from countries that exclude U.S. firms and how to counteract subsidized competition in the U.S. market and in thirdcountry markets are related questions. The use of U.S. trade law and administrative procedures to impose countervailing penalties has been the traditional U.S. method of ensuring that competition is fair in the U.S. market. Transpace Carriers, the U.S. space transportation company offering the Delta launcher, has attempted to use them and has asked the Administration to penalize Arianespace and the European governments subsidizing it, if negotiations fail to ameliorate any unfair competitive practices in space transpoftation. ${ }^{59}$

\footnotetext{
${ }^{58}$ In the case of services (space transportation included), the only multilateral agreement of any substance that currently applies is the OECD Arrangement on Officially Supported Export Credit, but the United States is leading a campaign to start multilateral negotiations for a GATT code on services.

${ }^{59}$ In its June 1984 petition, filed with the U.S. Trade Representative's Office, Transpace Carriers, Inc., charged European Space Agency member states (particularly France) with subsidizing Arianespace in its provision of expendable launch services. The Transpace complaint objected to Arianespace's two-tiered pricing structure (lower for non-European buyers); the subsidized provision of launch and range facilities, services, and personnel; the subsidized provision of Centre National d' Études Spatiale personnel; and the subsidization of mission insurance rates for Arianespace customers. The complaint asks the President to negotiate for an end to such practices, in the meantime to bar Arianespace from marketing its services in the United States, and to impose economic penalties against ESA-country imports under Sec. 301 of the Trade Act of 1974. (U.S. Export Week/y, June 12, 1984.)
}

\section{Satellite Communications Services}

The satellite communications industry is the most mature of all the space-related industries and has been big business since the late 1960s. If we define the international satellite communications industry to be the firms that sell international communications services using communications satellites, the major U.S. industry participants are AT\&T, Western Union, RCA, IBM (through SBS), ITT, GTE, MCl, McDonnell Douglas, United Brands, and COMSAT. These are the large, basic U.S. long-distance telecommunications firms. ${ }^{61}$

After a decade of deregulatory action in longdistance domestic communications, culminating with the AT\&T divestiture, these firms are now vigorously competing in the various domestic communications/basic communications submarkets. In addition, other U.S. firms specialize in various types of enhanced communications and distribute them over circuits leased from the basic communications carriers. A number of such firms are those whose business has primarily been in the information industry but which, because of the merging of the data processing and telecommunications industries, are now offering satellite communications services of various sorts in competition with traditional communications firms. Private corporate networks are also a significant element in the domestic market, since they provide excess communications capacity from their private communications networks for resale. Hence the U.S. domestic market is now vigorously competitive. ${ }^{\mathrm{G} 2}$

\footnotetext{
60The involvement of these firms in international telecommunications is not well known. McDonnell Douglas participates through its FTC Communications, Inc., Tymshare, Inc., and Tymnet, Inc. subsidiaries. United Brands participates through its TRT Telecommunications Corp. subsidiary, and its ownership interest in International Satellite, Inc.

${ }_{61}$ For a more complete list of firms that sell or intend to sell basic international communications services, see ch. 6.

${ }_{62} \mathrm{n}$ recent yearsboththe information and communications industries have seen substantial technological changes that make it impossible to draw a clear boundary between them. Digital and other communications transmissions in communications networks can be made more efficient with computer processing (e. g., packet switching), and computer networks also require special communications facilities and software to optimize their use. Particular users, such as banks, may benefit when their computer and communications hardware and software are designed as an integrated system. The manufacture of specialty components for such communications/com putation systems is now a major economic activ-
} 
Overseas, most countries have governmental communications monopolies, for instance the post, telephone, and telegraph organizations (PTTs) of Germany and France, and these are often very large firms. As regulated monopolies, they typically handle all the telecommunications of their countries-satellite and terrestrial, domestic and international. Although this is the dominant pattern, there is some institutional variation. In Britain, the government monopoly, British Telecom, has recently given way to an industry with two major firms, and both have now been privatized. In Japan and Canada, the international satellite communications firms are regulated private rather than public monopolies.

In all industrialized countries, regulatory authorities have been and will increasingly be facing the need to decide: 1 ) where the regulated domestic "network" (carrier-owned equipment) ends and what customer-owned equipment can be connected to it; and 2) where the precise dividing line between regulated communications and unregulated data processing is. The need to make and revise these determinations has already brought large regulatory changes in U.S. domestic communications and will almost certainly do so in other countries. At a minimum, competition will develop in the equipment and enhanced services industries at the fringes of the governmental telecommunications monopoly. The new fringe competitors, along with firms from other countries, will, in turn, seek entry into international communications and create pressure for regulatory changes there as well. The countries that are experimenting with or about to experiment with competition in long-distance domestic communications will also be adding potential competitors and stimuli to change to the international communications industry.

This is a process that is only beginning. Competition among carriers in international communications is still highly constrained by regu lation. The carrier selected by a consumer to initiate a

ity. The communications service and equipment firms are entering various information lines, and computer firms are entering various communications service and equipment lines. The recent AT\&T divestiture decision was predicated, among other things, on the idea that it is no longer possible to draw a definitive line between the two industries. communication is almost never able to deliver it internationally over its own facilities or more generally to optimize an international network for the use of its customers. Instead, because of U. S., foreign, and international organization regulatory restrictions, it must hand off the communications to other entities at some point in its journey with the result that linkage through a whole chain of entities is typical of international communications transmissions,

Little competition takes place between the entities in this chain. In all major countries, entry, prices, service offerings, and facilities in the international satellite communications industry are highly controlled. International competition between service sellers from different countries does not yet exist to any extent. Even connection rights to other countries' networks currently are severely limited for all but a handful of traditional U.S. carriers.

Despite the complexity of international interconnection, a number of large multinational firms, such as Citicorp (connecting 1,400 offices in 93 countries), Merrill Lynch, Texas Instruments, General Electric, Shell Oil, etc., have developed their own private international communications networks.$^{63}$ At the present time, these networks are the closest that international communications come to being handled by a single entity. Facilities outside their premises are typically not owned by the communicating firm, but the network is functionally controlled by it from initiation to completion of communication. These corporate networks are beginning to constitute a challenge to the international regulatory regime as it is now constituted, because excess capacity on these networks (including that on U.S. domestic satellites) is potentially resalable to those who now use international common carrier facilities. If large-scale competition among resellers were permitted internationally as it is within the United States, the competitive situation in international communications services would be very different. Hence, the issue of resale of capacity reaches to

\footnotetext{
${ }^{63}$ U.S. Department of Commerce, U.S. Industrial Outlook 1984 pp. 46-48; "Multilevel Network Connects Worldwide Workstations," Telecommunications, North American Edition, August 1984, pp. 41-45.
} 
the heart of the current international regulatory regime.

To date, INTELSAT, an international satellite consortium owned by the PITs (or other telecommunications organizations designated by its 109 member governments), provides most of the transponders used in intercontinental civilian communications. ${ }^{\text {b4 }}$ However, competitive pressures may change this situation in the next few years.

Technological developments and market growth have created competitive pressures that are likely to reduce the dominance of INTELSAT in coming years. First, a number of regional international systems have come into existence in recent years. Second, since the AT\&T divestiture and the privatization of the British telecommunications industry, a number of private U.S. and British firms are poised to construct satellite or fiber-optic undersea cable facilities in competition with INTELSAT and the traditional cable consortia, which have been dominated by AT\&T and the European PTTs.

Under stringent limitations to safeguard INTELSAT'S revenue base, the Reagan Administration at the end of 1984 urged the Federal Communications Commission to process favorably the applications of five U.S. corporations wishing to launch satellites for transatlantic communications. ${ }^{b 5}$ The FCC, for its part, in early 1985 recommended that the State Department approve the application of a British carrier's U.S. partner

\footnotetext{
${ }^{64} \mathrm{COMSAT}$, a Private firm, which functions as an intermediary in virtually all U.S. intercontinental civilian satellite communications, is the U.S. representative.

${ }_{65}$ Intersputnik, aninternational satellite organization with mostly East bloc countries as members, INMARSAT, an international satellite organization of which the United States is a member handling marine communications, and the "domestic" satellites of countries that send communications to territories on other continents (e.g., France's Telecom I or U.S. COMSAT satellites transmitting to Pacific territories), are the other elements in intercontinental com$m$ unications at the present time. See ch. 6 for further information.

${ }^{65}$ Other systems from the United States and other countries would seem to be in the wings, as well, if the applications of the first five are affirmatively acted on. For instance, France's Telecom 1, designed for satellite communications with its overseas territories in the Americas, has a reception "footprint" that covers large parts of the United States and could be used for transatlantic communications to the United States.
}

to land a high capacity U. S.-U. K. undersea fiberoptic cable. ${ }^{66}$

If some or all of the alternative satellite and cable systems come into being, as now seems likely, both the operations of INTELSAT and the international communications regime will be altered significantly. At present, it is not clear how the foreign satellite link will be arranged. The alternative satellite proposals are not definitive on the terms of interconnection with the very same foreign telecommunications entities that are the part owners of INTELSAT with whose facilities theirs would be competing.

As it attempts to allow greater competition generally in international telecommunications, the FCC should analyze whether the incentives U.S. and foreign carriers will operate under will result in overcapacity in U.S. international telecommunications. One element in this determination involves the amount of capacity to be provided by the potential new satellite firms. Another involves the planned capacity of INTELSAT'S VI and VII series satellites. A third involves the capacity to be provided by the proposed transatlantic fiber-optic cables and the similar cables that have been proposed for transpacific communications. If open facilities competition should lead to overcapacity in international communications that resulted in higher rather than lower rates through service regulation, continued facilities regulation to avoid the overcapacity might be justified even in a partially deregulated market. (See ch. ${ }_{6}$ for a discussion of competition between satellites and fiber-optic cables.)

The FCC has regulatory authority over both the construction and use of U.S. international telecommunications facilities. The prevailing pattern of FCC facilities approvals in international (but not in domestic) communications has been to approve the investment of U.S. carriers in international facilities owned by consortiums of carriers-COMSAT in INTELSAT for satellites and AT\&T and the other international service carriers in cable consortiums with European PTTs. The

\footnotetext{
${ }^{66}$ FCC News, "Preliminary Action on Tel-Optic and SLC (Submarine Lightwave Cable Co. ) Cable Landing Applications, Report No. 30992, Mar. 4, 1985.
} 
current exceptions to this involve North American regional use of U.S. domestic satellites owned by single carriers in communications with certain Western Hemisphere destinations. The Commission has also in the past regulated the relative use of existing satellite and cable facilities for transatlantic service and is investigating what its policy toward facilities competition should be in the North Atlantic during the 1986-91 period.

The market for international satellite communications services is part of the total market for international telecommunications, which has been growing rapidly since 1970 and will probably continue to do so. The fraction of this growing total that will be carried by satellite (and consequently the demand for satellites for this purpose) is difficult to predict. Among other factors, it will depend on the relative cost of satellite and fiber-optic cable capacity, which remains uncertain because technological developments are extremely difficult to predict. The decisive factor, however, is likely to be the facilities regulation policies of the FCC and other governments.

In formulating U.S. policy regarding competition in international communications, policymakers should realize how much the market would have to be liberalized before it could be regarded as competitive, A not very likely competitive scenario can be specified as a standard for comparison to make this point. In a fully competitive industry, hundreds or thousands of communications firms from many countries would offer various kinds of international voice, data, and TV services to individual consumers and businesses around the globe. Unrestricted leased circuits and lines would be freely available from a variety of large and small satellite and cable owners. In most places local telephone service would still be provided by regulated common-carrier monopolies, but access by long-distance communications firms would be on a nondiscriminatory basis, regardless of their nationality and the destination of the communication. Regulatory problems would be transmuted into problems of trade-in-services, with governments negotiating about subsidies, nontariff barriers, and discrimination in government's procurement of communications services, rather than regulating the prices, entry, and investment of carriers.
This portrait of a fully competitive telecommunications industry is probably unrealizable in the next decade, because the current structures of international telecommunications regulation are firmly entrenched in many countries, and the United States cannot unilaterally alter them even if it would like to. The policy questions that arise, therefore, will most usefully be cast in terms not of the general wisdom of competition vs. regulation, but rather whether the particular partial moves toward deregulation under consideration will produce economically and/or politically effective outcomes within the time-frame envisaged. This stance is particularly useful since many of the proposed future actions in U.S. international communications are likely to be reactions to developments in technology or in domestic telecommunications markets, and the issue will be how most effectively to secure their benefits in international communications in the context of continuing restrictions.

\section{Remote Sensing Services}

Remote sensing from space provides data relating to the Earth's atmosphere, land masses, and oceans. In all three cases, these data have "public-good" characteristics. ${ }^{67}$ Different governmental responses to their public good aspects, depending on whether they originate from meteorological, land, or oceans remote sensing systems, have resulted in different industry structures and different competitive patterns from those characterizing the other space applications technology sectors.

\footnotetext{
67"Public good" is used here in the technical sense used in formal economic theory to refer to those goods or services like national defense, city parks, and public health services, where the cost of servicing an additional consumer (marginal cost) is negligible and where it is often impossible or undesirable to charge consumers for the service they consume. The general principle that economic efficiency is served when consumers pay just the extra cost of servicing them is only approximately honored in most industries, but in the case of industries producing public goods, it is either impossible, infeasible, or undesirable even to approximate it. Hence, alternative arrangements are common in the provision of "public goods," often involving government subsidy and production. Although consumers who do not pay for the data may be excludable from consumption (e.g., by coded signals), the transactions costs of excluding them may be large compared with marginal cost of servicing them. See app. $4 \mathrm{~A}$, for a fuller treatment of public goods.
} 
In the United States and other countries, the public benefits of having a meteorological remote sensing capability have been considered large enough to justify subsidized Government production. Accordingly, industry participants in the United States and elsewhere have been governmental organizations producing meteorological data and distributing them free or at the cost of reproduction. ${ }^{68}$ Currently, both the geostationary and the polar-orbiting meteorological satellite systems are operated by the National Oceanic and Atmospheric Administration. NOAA provides free direct data transmission to Earth receivers around the globe and a variety of data products which can be purchased for the cost of reproduction.

Commercial operation of the meteorological remote sensing system might be both possible and profitable for private firms, but because of the public good aspects of the industry, the level of operation and the pattern of distribution of benefits that would result would not be economically efficient. Congress, in fact, acted in 1983 to prevent transfer of the U.S.-owned meteorological satellites to the private sector (Public Law 98166) for this and other reasons.

Land remote sensing shares some of the public good characteristics of meteorological remote sensing ${ }^{69}$ but there are two important differences in how the government and the public at large regard it. First, the public interest in assuring that the land remote sensing industry operates efficiently (in the sense that additional users pay only the extra cost of servicing them) is not as great as in weather remote sensing where universal access to the data is an important public goal. Second, fewer citizens benefit directly from land remote sensing data than from meteorological data.

\footnotetext{
${ }^{68} \mathrm{Although}$ it would bepossible to charge for weather-related satellite data, the costs of doing so are disproportionately large. First of all, the cost to NOAA of supplying data transmission to one more receiving station is zero. Society would also suffer an extra cost if data leading to weather forecasts were subject to user charges. If the general public were not informed about weather dangers, society as a whole would suffer avoidable costs from weather disasters.

${ }^{69}$ Oceanremote sensing also shares public good characteristics but will not be discussed here. The United States is planning an ocean remote sensing system to be operated by the Navy; the Navy Remote Ocean Satellite System (N ROSS) is scheduled for deployment in 1987. NOAA is planning to distribute data from NROSS to civilian users.
}

Moreover, the few users there are can sometimes use alternative aerial-photogram metric and groundobservation data sources. Hence, U.S. policymakers have chosen to attempt to transfer the Government's Landsat system to the private sector (Public Law 98-365).

The difficulties in implementing this policy stem primarily from the fact that the market for land remote-sensed data is not currently large enough to sustain a single, unsubsidized, self-sustaining private enterprise, let alone a competitive industry. Only small amounts of land remote-sensed data have actually been sold to private sector buyers in either raw or analyzed form. At present most of the consumers of land remote-sensed data are governmental agencies.

Private sector users are either firms that process the data for their own use, principally petroleum or other minerals firms, or "value-added firms," such as Earthsat Corp. and ERIM, Inc., which purchase raw data from the U.S. Government, analyze them and convert them to information suitable for clients. These companies are essentially in the information business. Such firms, for example, offer enhanced data for sale to agribusiness, forestry, and mineral-exploration companies.

Much of the potential demand for satellite remote sensing that has been identified is price sensitive and will not materialize at high prices. 'o Data consumers will continue to use photogrammetric data when they are inexpensive enough, or do without.

Despite the current meager prospects for commercialization, international competition has nevertheless emerged. SPOT IMAGE, S. A., a French Government-owned remote sensing company, will soon begin offering remotely sensed data to customers in the United States and elsewhere in the world.

Because of the characteristics of the two systems, data from SPOT and from the Landsat system are not perfect substitutes. The SPOT system,

\footnotetext{
${ }^{70}$ The steep decline in sales of multispectral data after the Price increased in October 1982 is evidence of such price sensitivity. The availability of aerial photogrammetry and ground observation are one reason for this price sensitivity. See Remote Sensing and the Private Sector: Issues for Discussion, op. cit., ch. 5.
} 
for instance, provides relatively high resolution data (20 meters) in three color bands (or 10 meter resolution in black and white). It also provides quasi-stereo, an important feature for mineral exploration and mapmaking. The U.S. Landsat system has two instruments providing data: relatively low resolution data ( 80 meters) in four wavelength bands; and higher resolution data (30 meters) in six wavelength bands. Given these factors, and the current uncertain state of private sector entry into land remote sensing in the United States, exactly how the competition will develop is a matter of conjecture. SPOT IMAGE, nevertheless, has already embarked on an aggressive data marketing effort in the United States.

The present inadequate size of the market leads to the question of how much subsidy, if any, is desirable for this infant industry and how long it should be maintained. Both the United States and France will have to answer this question on a continuing basis; both currently are providing significant subsidies to establish the firms. The inadequate size of the market and other considerations also lead to the question of how much regulation should be imposed on the U.S. private satellite operator or operators. ${ }^{71}$ (See ch. 7 for a fuller discussion of these issues.)

\section{Materials Processing Services}

Whether or not an industry processing materials in space will come to exist for any substantial volume or value of materials processed is still highly uncertain. The industry analyzed in this section, therefore, should be thought of as a potential industry rather than an actual one.

The set of firms likely to be processing materials in space is potentially a diverse one. Two main groups of firms will probably be, first, large pharmaceutical, metallurgical, electronics, or ceramics firms processing materials for themselves; and, secondly, specialized firms selling materials processing services, such as unmanned orbital processing units ("free-flyers"), special metallurgical furnace services, or microgravity processing facilities. The large cost of establishing a credible space processing facility will limit

\footnotetext{
${ }^{71}$ The Department of Commerce currently has regulatoryresponsibility.
}

entry to existing firms or entrepreneurial groups that can marshall substantial resources. Joint ventures, like the one already in existence between McDonnell Douglas, Ortho Pharmaceutical, and NASA might be common as the industry gets underway. Although the cost of entry may be high, there appear to be a large number of firms in materials-using industries and aerospace firms able to deploy sufficient resources, particularly if NASA offers subsidized shuttle services to them.

It is uncertain whether the relatively high expense of processing materials in space will substantially deter their marketability. Even if a material were produced in space, and marketed in sufficient volume, there would always remain the possibility that the space-based operation could be undercut by terrestrial production of an adequate and less costly substitute.

The industry, it should nevertheless be emphasized, is poised for rapid development if the risks are reduced and if a high value material is found that can be produced most efficiently in space. For example, if the McDonnell Douglas electrophoresis process should efficiently produce highpurity interferon in space and if interferon should prove to be the wonder drug of the decade, a number of pharmaceutical firms and aerospace firms catering to the pharmaceutical industry would be able to enter rather quickly. Such a development would also produce increased demand for space transportation and materials processing capacity.

Among U.S. pharmaceutical, metallurgical, and other manufacturing firms which might manufacture materials in space for their own use, competition is now the organizing principle in most cases and would undoubtedly continue to be, as long as firms were allowed nondiscriminatory access to space processing facilities. Competition will probably also be the organizing principle of the processing services industry. However, if as seems likely, the market for processing is both small and broken up into specialized segments, society will have to rely on potential rather than actual new entrants to contest the several little monopoly markets and keep prices down.

There would probably be few barriers to international competition in the materials processing 
industry. Materials processed by a French firm, for example, and brought down from space in France could be imported into the United States, subject, presumably, to whatever tariffs were applicable. The principal, and probably the only important, barrier to free international competition in materials processing, will be the question of foreign access to the NASA Shuttle, as it is currently the most practical way to retrieve processed materials from orbit.

\section{The Transition From Political to Economic Competition}

In this chapter we have looked at the various political and economic aspects of international competition in civilian space activities. With the increasing commercialization of space, a number of space-related activities are caught between the political competition of "national space programs" and the economic competition of international commerce.

Prior to the development of vigorous commercial civilian space activities, the arguments in favor of continued support of space activities are usually scientific and political, although they usually also include subsidiary industrial-policy reasoning. Congress supports the national space program both for national pride and also for technological development that may lead to later economic growth and exports.

As commercial activities develop, however, the arguments used to justify government space activities begin to be measured against general concepts of international trade. Previously unfettered national space policy-in its competitive aspects-becomes challenged as to its fairness and consistency with general international trading rules. Appropriations for the national space program in areas of commercial activity are now characterized by some as subsidies against which countervailing duties can in principle be assessed or against which other retaliatory measures can be taken. The government space agency now becomes a government entity covered or potentially covered by the GATT government-procurement agreement. Assistance to developing countries in satellite communications or launch services, previously seen as an essential part of bringing the benefits of space technology to all mankind, now becomes the subject of international negotiations on export credit subsidies. And trade negotiators have to deal with whether or not space-related services should be included among those to be covered by potential future agreements on international trade in services.

This process is actually the natural outgrowth of successful commercialization and the beginnings of healthy international trade, rather than a threat to them. In space-related equipment the process has been clearly underway for some time. Trade restrictions and subsidies in space-related equipment manufacturing industries are increasingly seen as part of industrial policy in these industries and referred to as "targeting." As in other industrial contexts, government-supported R\&D in early phases of an industry are difficult to deal with under the international trading rules, but insofar as the targeting takes the form of large current subsidies or trade restrictions, it becomes the subject of trade negotiations, like those, for instance, that have taken place with Japan on spacesegment satellite communications equipment.

In space-related services, the process is less clear, mainly because general international trading rules on services have not yet been agreed on even within the industrialized countries, and each trade sector currently has its own rules. international satellite communications services, for instance, are subject to the unique regulatory regime that governs international telecommunications services generally.

What this implies for an understanding of competition in international civilian space activities is that as each space sector matures commercially, it becomes subject not only to the international politics of space but also to the broader and more complex politics of international trade and regulation. A national political commitment to space-and to competition for leadership in space activities-may come into conflict with another national commitment to fair competition within an open world trading system. 


\section{APPENDIX 4A.-THE MAIN INTERNATIONAL TRADING RULES OF RELEVANCE TO INTERNATIONAL COMPETITION IN CIVILIAN SPACE ACTIVITIES}

The general international trading rules have been the subject of extensive negotiation in recent years. Trade specialists generally agree that the rules are having a significant effect on the sales of equipment, but that this effect is somewhat hard to quantify. With respect to services, general international trading rules do not yet exist to any extent, although informal negotiations are currently underway to explore the possibility of a services code.

Three major trading rules affect "unfair" competitive practices in international trade in equipment, in addition to the general GATT principles of equal access and equal treatment:

1. the OECD Arrangement on officially supported export credits,

2. the GATT code on subsidies, and

3. the GATT code on government procurement. These three codes fill gaps in the GATT treaty but do not have universal coverage. They are largely restricted to the industrial countries, but a few developing countries are signatories.

in their present form they are quite new. Although the OECD Arrangement has existed since the early 1970s, the minimum interest rate levels allowed for official export finance had until recently been so much lower than commercial interest rates that a large subsidy element remained. However, starting in 1982, the minimum rates have been close to commercial rates. When they are adhered to, these minimum rates now serve effectively to discipline export finance subsidies in equipment sales. The new GAIT codes on subsidies and government procurement are also quite recent; they entered into effect only in 1980 and 1981, respectively, and experience with them is still limited.

in addition, because of incomplete country coverage, specific exclusions, ease of escape, differences in interpretation, and ineffective enforcement, the trading rules are observed, when they are observed, through a combination of deterrence and negotiation. Essentially they set a standard that can be followed voluntarily or against which deviations can be measured.

The deterrence effect probably constitutes the major effect of the rules. Governments comply voluntarily with the rules because they want to avoid being confronted by other governments asserting that they have violated agreed trade rules and threatening retaliation.

The trade rules also set the standard for negotiation, which is the predominant way that they are "en- forced." Although the term is used, enforcement is clearly the wrong concept. The conciliation and negotiation activity referred to as "enforcement" does not even approximately resemble an adjudicatory proceeding. It is primarily carried out on a bilateral basis but also takes place, on occasion, in the GATT multilateral framework, Bilateral negotiation (or negotiation among small groups of countries) may concern questions of compliance with the general trade rules, but often these negotiations will be sector-specific, e.g., for aircraft or satellite ground stations. Frequently, the participants in such negotiations hammer out sectorspecific arrangements that may conflict significantly with the principles embodied in the general rules.

GATT dispute settlement panels complement bilateral negotiations in "enforcing" the trade rules in several ways. First, a GATT panel may award the right to take retaliatory action as "compensation" for a trade rule violation after conciliation has failed. Legitimizing retaliatory action in this way reduces the possibility that a generalized trade feud will result from retaliation against retaliation. Secondly, the possibility that a retaliatory action taken on the basis of a country's domestic law might subsequently be found by a GAIT panel to be itself a trade rule violation tends to lessen the incompatibility of these actions with the rules. The major limitation on the usefulness of the GATT panels is that panels in the past have typically decided cases on the narrowest of grounds.

The actual workings of the trade codes have not always been transparent. Only narrow specialists, in government agencies and in specialized private law firms, are fully aware of all the relevant provisions of the various agreements and statutes bearing on a particular problem area and how they work together. In a given case, these complexities may result in a determination quite different from what a nonspecialist might expect from a straightforward reading of the documents.

One topical example of the complexity of trade codes and laws is the question of how to classify a launched satellite under U.S. trade law. Suppose a French company offered to sell a satellite with subsidized financing to an American buyer delivered CIF space. Would imposition of a countervailing duty under section 301 of the Trade Law of 1974 be available as retaliation against such an unfair trade practice as it would be in the cases of other subsidized sales of equipment imported into the U.S. market? 
Under U.S. trade laws, the satellite would be classified as an export from France but it could not be classified as an import into the United States, since it had not physically entered through customs. Because it was not an import, countervailing duties or charges therefore could not be levied under section 301. However, under section 1912 of the Export-Import Bank statute, the Secretary of the Treasury may direct the Em-Im Bank to subsidize the sale of an American product in the U.S. market in retaliation, if that product is competing with a subsidized foreign product. This action is available even when the equipment has not passed through customs.

It appears to be the consensus of the trade experts that the trading rules should be seen as "working" in the general international trade in equipment, primarily by their deterrence effect but also through negotiation. This is particularly true when the stakes are relatively small. When the stakes are large, however, the many exceptions, exclusions, and escape possibilities that have been built into the rules, can be used by sovereign governments to avoid effective trade discipline. Roughly speaking, where international trade per annum in a sector on the order of $\$ 1$ billion or more is involved, the trade rules are likely to be seriously breached by governments.

\section{Exclusions and Exceptions Keep Space-Related Equipment From Being Effectively Covered by the International Trading Rules}

None of the three major codes referred to above effectively constrain "unfair" competition in spacerelated equipment because of exclusions and exceptions. Perhaps the most damaging exclusion involving space-related equipment is the exclusion of the major non-American buyers of satellite packages (satellites transported into space and insured) from the list of government organizations covered by the GATT government procurement code. These organizations are the PTTs (post, telephone, and telegraph organizations) that have communications monopolies in their respective countries. ${ }^{1}$ The code document specifies which government agencies in each country are covered, and the European countries and Japan specifically excluded their PTTs. (Because of this refusal to include the PTTs, the United States, in retaliation, excluded the Corps of Engineers from its list. NASA, however, is included.) Because the PTTs do largely

\footnotetext{
' See ch. 6 for discussion of recent events concerning transfer of some PTI ownership to the private sector and the introduction of limited competition intelecommunications in the United Kingdom and Japan.
}

follow "buy-national" procurement policies, American firms are systematically excluded from a share of the international trade in satellites and communications equipment.

In practice, the subsidies code does not effectively cover the types of subsidies that are important in international sales of space-related equipment. Although the code contains broad language prohibiting unfair subsidies that affect international trade, it illustrates what a subsidy is only by a short list of examples, all of which relate directly to international trade except for a general "any other subsidy" category. Not by accident, none of the examples relates to research and development expenditures or generally to the subtle types of assistance included under the rubric of "industrial policy."

Whether or not the subsidies code will be of any use in disciplining international trade in space-related equipment is problematic, because $R \& D$ and industrial-policy subsidies frequently occur in the space sector, and they will be the hardest to bring effectively under the subsidies code. To be sure, the category including "any other subsidy," defined as "any subsidy ... which operates directly or indirectly to increase exports of any product from, or to reduce imports of any product into, [the] territory" of a contracting party, is a very broad one which could easily be interpreted to cover R\&D and industrial policy in general. It has not been effectively tested, however. The general impression among trade specialists is that it will be difficult to apply the subsidies code to those subsidies, whose focus is primarily domestic, even if their impact on international trade is substantial.

The United States has plainly been the country that has most heavily used R\&D and other industrial-policy subsidies in the aerospace industry. This has not escaped the attention of other industrial countries and has been a point of contention in recent trade negotiations. It should also be noted that the process of countervailing against industrial policy measures is not a trivial technical problem; such things as "reasonable price," subsidy margin, and injury would be difficult to determine in a satisfactory way in order that an appropriate countervailing duty or other measured retaliation could be imposed.

The OECD Arrangement on export credits applies universally to the official export finance of 22 OECD signatories (excluding Turkey and Iceland), whether or not the exports are undertaken by a government entity or a private firm. Nevertheless, it has a big exception in it where sales to developing countries are concerned. Soft terms can still be offered on big-ticket items to developing countries with relative impunity, as long as they are called "official development assistance" (ODA) rather than "officially supported export 
credits. "There has to be a "grant element" of greater than 25 percent in order to escape into the ODA category and be free of the strictures of the export credit agreement. $^{2}$

A separate OECD Arrangement on Mixed Credits has recently been discussed within a working group of the Development Assistance Committee of the OECD (as opposed to the Export Credit Committee), and it would supposedly further discipline the use of mixed credits (i.e., development assistance mixed with export credits). Disentangling true development assistance from commercially motivated sales would be desirable and is probably manageable in practice. How much success any ODA arrangement would have, though, is in doubt in the light of the demonstrated desires of some of the negotiating governments to subsidize exports to developing countries by granting aid. Subsidized credit to developing countries will therefore probably continue to be substantially undisciplined in high-cost items such as the sales of satellite packages and other space-related equipment. On the other hand, smaller sales of instruments and other equipment may well generally take place in conformance with the OECD guidelines and not be the occasion for heavy-handed official competitive jockeying.

To summarize this section on exclusions and exceptions, each of the three major trading rules has an important exclusion or exception that removes a large part of international trade in space-related equipment from its coverage.

\section{International Trading Rules for Services}

In the area of services, there have been indications, starting at the GATT ministerial talks in 1973 and extending to Economic Summit meetings since that time, that the major industrial countries might be willing to consider a code on services.

There are a number of barriers to an agreement on international trade in services, however. Europeans do not regard services as trade in the classic sense, are worried about cultural imperialism from the United States, and have service industries that are heavily regulated and not very entrepreneurial. In the area of telecommunications services, for instance, a complicating factor is the fact that revenues from the PITs often subsidize unrelated activities, including bus service. In this context it is unlikely that much will be

'Grant element is defined as one minus the ratio of the present value of the stream of payments that are proposed divided by the present value of the stream that would occur if the Arrangement terms governed, both discounted at the appropriate Arrangement rate. Deals, with financing still labeled as officially supported export credits, with grant element between 20 and 25 percent are permitted, but there must be advance notification to the member governments adhering to the Arrangement. accomplished for telecommunications services in multilateral negotiations.

What can be accomplished in the relatively near future, however, would nonetheless be useful. Removal of the nontariff barriers to the movement of commodities, such as insurance and banking industry restrictions, might be one accomplishment. Another would be to develop rules regarding competition with stateowned monopolies. A third would be to develop guidelines on the cost of capital that state-owned or regulated service enterprises must be charged.

\section{Sovereignty Considerations Largely Dominate the General Trading Rules When They Are Applied to Space-Related Equipment}

The international trading rules are not strong enough to restrain sovereign governments from taking action they deemed to be of substantial importance to sovereignty and defense, including certain actions in space with respect to goods and services. The escape clauses, exclusions and fuzzy areas built into the trade rules provide governments with plenty of opportunity, in cases of particular importance to them, to elude the bite of the trade rules. Because France and Japan, and to a lesser extent other industrial countries, have made the decision to develop wide-ranging space programs, it would be wishful thinking to believe that they would fully abide by the trade rules in competition for sales of space-related equipment or space transportation services, because for some time at least, they would probably lose out in open competition with American suppliers such as Hughes Aircraft.

However, the debate is not all one-sided. One justification other industrial countries have offered for the trade restrictions they have erected in the space area is that they are simply countervailing against the strong subsidy and industrial-policy support the United States gives to its aerospace industry.

\section{How International Trading Rules Actually Affect Competition for U.S. Exporters of Space-Related Goods and Services}

The question of whether or not the international trading rules affect competition at the level of the actual marketplace, of course, goes beyond the question of whether or not the general trading rules do or do not have effect. For one thing the recent exchange rate divergence of the dollar and other foreign cur- 
rencies, has had a more damaging effect on the overall position of U,S. equipment exporters than all existing tariffs and quotas combined.

From the business point of view, the government decision to take complaints to bilateral negotiation or to GATT panels rests on a prior business decision "to fight this thing out through government channels," Considering that victories "through government channels" may be pyrrhic or much delayed or not valuable, the reality of engaging in competition in international markets is that competition takes place on many fronts, including price, quality, service, political connections, and regulatory action. Some markets will simply be off bounds to U.S. exporters no matter what general or special agreements exist. Others may, in fact, be penetrable despite supposedly formidable barriers.

One tactic that has been used by American equipment manufacturers, in the defense area and also in other equipment areas, is to develop non-U. S. component suppliers with the conscious purpose of obtaining political support for entering the market in the component supplier's country. In pursuit of this goal, the seller may acquiesce in or seek out offset arrangements that it would not otherwise consider. Formal international trading rules would have difficulty under the best of circumstances in countering such subtle trade restrictions. 
Chapter 5

\section{SPACE TRANSPORTATION}




\section{Contents}

Page

Introduction. . . . . . . . . . . . . . . . . . . . . . . . ...........103

The Space Transportation Industry . . . . . . . . . . . . . . . . . .................103

The providers of Space Transportation Services . . . . . . . . . . . . . . . . ...103

Buyers of Space Transportation Services . . . . . . . . . . . . . . . ...............122

Competition in Space Transportation . . . . . . . . . . . . . . . . . . . . . . . . . . . . 125

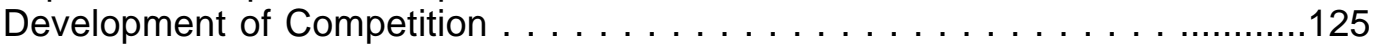

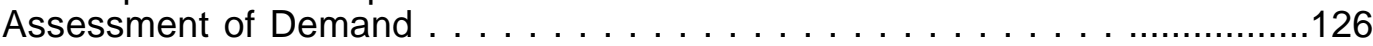

Nature of Competition . . . . . . . . . . . . . . . . . . . . . . . . . . . . . . . . . . . . . . . . . . . . . . . . . . . . . . . . . . . . . . . .

Effects of Competition . . . . . . . . . . . . . . . . . . . . . . . . . . ....134

Cooperation in Space Transportation . . . . . . . . . . . . . . . . . ...........137

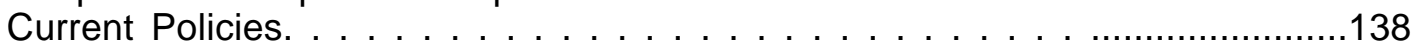

Future Policy Options.. . . . . . . . . . . . . . . . . . . . . . . . . . . . . . . . . . . . . . . . . 140

\section{List of Tables}

Table No.

5-1. Ariane Flights . . . . . . . . . . . . . . . . . . . . . . . .......115

5-2. Transportation Costs to Geosynchronous Orbit . ..................132

5-3. NASA vs. Arianespace Financing . . . . . . . . . . . . . . . . . ...........133

5-4. Companies That Contribute to Manufacturing Japanese Launch Vehicles ..139

\section{List of Figures}

Figure No. $\quad$ Page

5-1. U.S. Launch vehicles . . . . . . . . . . . . . . . . . . . . . . .............104

5-2.The Hermes Spaceplane . . . . . . . . . . . . . . . . . . . ................116

5-3. Foreign National Comparative Launch Vehicle Development. . .........118

5-4. Projection of Future Space Shuttle Demand Rockwell International. . . . ...127

5-5. Outside Users Payload Model Battelle's Columbus Laboratories . ......, 128

5-6. Low Model Market Share by Launch Vehicle . . . . . . . . . . ...............129

5-7. High Model Market Share by Launch Vehicle . ...................130

5-8. Arianespace Financing . . . . . . . . . . . . . . . . . . . . . . . . . . . . . ..133

5-9. Rockwell International Estimates That the Shuttle is Most Economical Over ELVs at High-Volume Operations. 


\section{INTRODUCTION}

Space transportation is an industry in which the U.S. Government has acted both as the primary seller and the primary buyer. But over the last 10 years the European Space Agency (ESA) has developed the Ariane launcher, and in 1980 the corporation Arianespace was formed to market Ariane launch services. Taken together, these events have ended the U.S. monopoly in commercial launches. Now that the Space Shuttle has been certified "operational" and the U.S. Government has, for the most part, terminated its use of the present fleet of expendable launch vehicles (at least for civilian launches), private U.S. firms may take over their operation. In addition, recent activities of some small U.S. firms suggest that a new generation of low-cost, low-capacity ELVS could soon be competing in the launch vehicle market. Thus, the National Aeronautics and Space Administration (NASA) monopoly in U.S. commercial launches may be ending as well.

Although NASA and Arianespace compete for launch customers, neither has had much difficulty filling current flight manifests. However, the entry of additional launch service providers over the next 5 years could lead to a situation where launch service capacity exceeds demand. In the past, space transportation policy in the United States has focused on development of new technology. The emergence of foreign competition and the interest of the U.S. private sector in providing launch services require a reassessment of the Government's role as space transportation service provider.

This chapter assesses the challenges of international competition and the opportunities for future cooperation in the international space transportation industry. It gives additional consideration to the role the private sector may play in developing a space transportation industry based on the principles of competition and open entry.

\section{THE SPACE TRANSPORTATION INDUSTRY}

The Providers of Space

Transportation Services

National Aeronautics and

Space Administration

When NASA was established in 1958 it was charged with responsibility for the "... development and operation of vehicles capable of carrying instruments, equipment, supplies, and living organisms through space."' The launch vehicles that NASA developed (through contracts with private manufacturers) created the opportunity for commercial space endeavors. Until the establishment of Arianespace, NASA was the only seller

\footnotetext{
' National Aeronautics and Space Act of 1958, sec. 102(c)(3), 42 U.S.C. 2451
}

of commercial launch services. The U.S. manufacturers of expendable launch vehicles (ELVs)although they are "commercial companies"have not sold vehicles except through NASA.

In a typical pre-Shuttle commercial transaction, the buyer would contract with NASA to launch a payload-generally a communications satellite. NASA would then contract with one of the launch vehicle manufacturers for delivery of a launch vehicle; when it was complete, NASA would integrate the payload into the launch vehicle and supervise both launch and insertion of the payload into orbit. With a fully operational Shuttle, NASA no longer needs to order individual vehicles for each of its launches; its responsibilities for launch services have otherwise remained the same. 
NASA entered into its first launch services agreement in July 1961, with American Telephone\&Telegraph (AT\&T) for the experimental Telstar communication satellites. ${ }^{2}$ Under this agreement AT\&T financed, designed, and built the satellites and reimbursed NASA for the costs it incurred for the launch. NASA's policy then was to recover incremental, "out-of-pocket" costs associated with the launch and not the "sunk" costs associated with the development of the vehicle or of the terrestrial support facilities. Since that time, NASA has continued to provide launch services on expendable vehicles for its own missions and, on a "reimbursable basis, " for other U.S. Government users, foreign governments, and private entities. ${ }^{3}$ The cur-

\footnotetext{
2The Space Industrialization Act of 1979: hearings on H.R. 2337 before the Subcommittee on Space Science and Applications of the House Committee on Science and Technology, 96th Cong. Ist sess. p. 85 (1979) (Statement of Dr. Robert A. Frosch).

'Although it was NASA's policy to recover incremental, "out-ofpocket" costs in 1961, this later was changed to recovering "all reasonable costs." Launch services provided on a "reimbursable basis" implies, then, a recovery of "all reasonable costs."
}

rent pricing policy for the Shuttle-although similar to the policy for ELVs-raises a number of specific problems which are discussed in detail below.

Provision of a reliable vehicle is only one element of a launch service. Launch pads must be built and special facilities must be provided for integrating the payload and the launch vehicle. Equipment and personnel must be available for tracking and control of the vehicle after launch, and pre- and postlaunch safety procedures must be developed and implemented. The complex technical nature of launch services, the need for elaborate terrestrial facilities, and the high cost of operations have, until 1982, prevented any challenge to NASA's monopoly in free world space transportation services.

NASA has used the following vehicles to launch commercial payloads (fig. 5-1):

Delta: When NASA modified the Thor IRBM in 19s9 to produce the Delta it was thought to be only an interim launch vehicle. However, with 177 launches to date-94 percent of which have

Figure 5:1.-U.S. Launch Vehicles

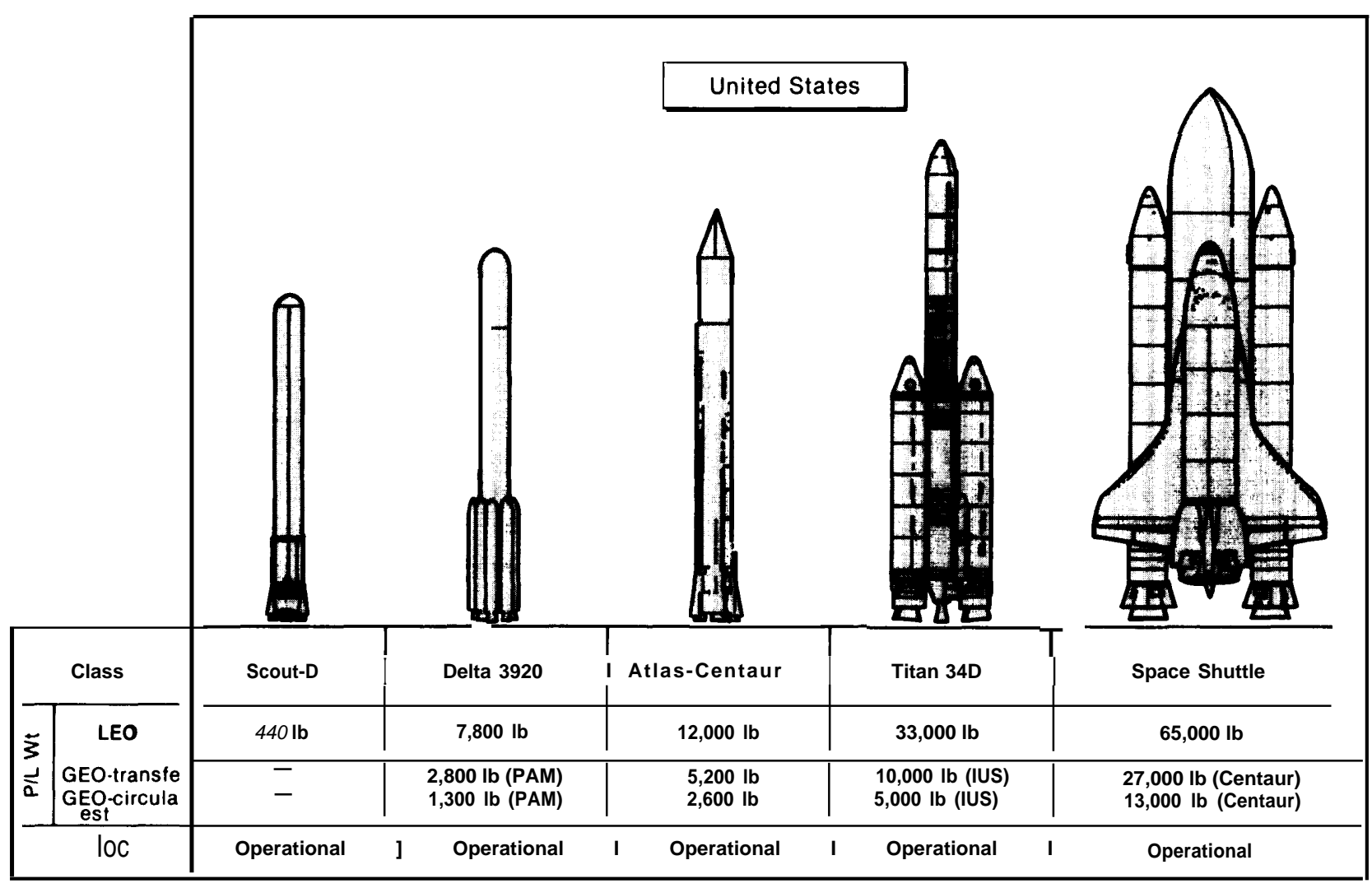


been successful-the Delta has become the mostused U.S. launch vehicle. The Delta has been constantly upgraded by its manufacturer, McDonnell Douglas, during its 25-year history and presently performs at nearly 30 times its original payload capacity. The Delta 3920/PAM-D, which began service in 1982, is capable of launching payloads of 2,800 pounds to geostationary transfer orbit. ${ }^{4}$

The Delta can be used with a two- or threestage configuration. The first stage, or booster, is an elongated Thor missile with Castor IV solid strap-on motors. The second stage (the Delta stage) is a liquid stage with restart capability. Firstand second-stage guidance is accomplished by an inertial guidance system mounted in the second stage. The Delta third stage can be a solid rocket motor with spin stabilization, or the Shuttle-compatible payload assist module (PAM) (discussed below). This interchangeability made the Delta the obvious choice as backup vehicle during the early Shuttle program. NASA no longer books satellites on the Delta, either as primary or backup vehicles. As of January 1985, there were four Delta launches left on NASA's books.

Atlas-Centaur: The Atlas-Centaur is a 2.5-stage vehicle which uses liquid oxygen and kerosene as propellants in the Atlas booster and liquid oxygen and liquid hydrogen in the Centaur upper stage. ${ }^{5}$ Based on the Atlas ballistic missile, the Atlas rocket was first used as a space booster in 1958. NASA first used the present Atlas-Centaur configuration in 1966, to launch the Surveyor lunar-landing spacecraft. Since this time, the Atlas-Centaur has been used for low-Earth-orbit (LEO), lunar, planetary, and synchronous trans-

\footnotetext{
${ }^{4}$ The Delta and Titan ELVs and the shuttle-PAM and shuttle-TOS combinations all require apogee kick motors; therefore in this report their capabilities are given as pounds to geostationary transfer orbit. These upper stages place about twice as much weight into geostationary transfer orbit as eventually reaches geostationary orbit. For example, the PAM-D can place about 2,800 pounds into geostationary transfer orbit, but only 1,350 pounds into geostationary orbit. The Centaur stage of the Atlas-Centaur ELV, the ShuttleCentaur, or Shuttle/TOS-AMS, and the Shuttle-I US do not require separate apogee kick motors; the capabilities of these vehicles are given as pounds to geostationary orbit.

${ }^{5}$ The Atlas is referred to as a one-stage booster because it shuts down and jettisons two of its three engines during its flight. See: R. Teeter, "U.S. Capability for Commercial Launches," AIAA Space Systems Conference, Oct. 18-20, 1982, Washington, DC, AIAA-821789, p. 1.
}

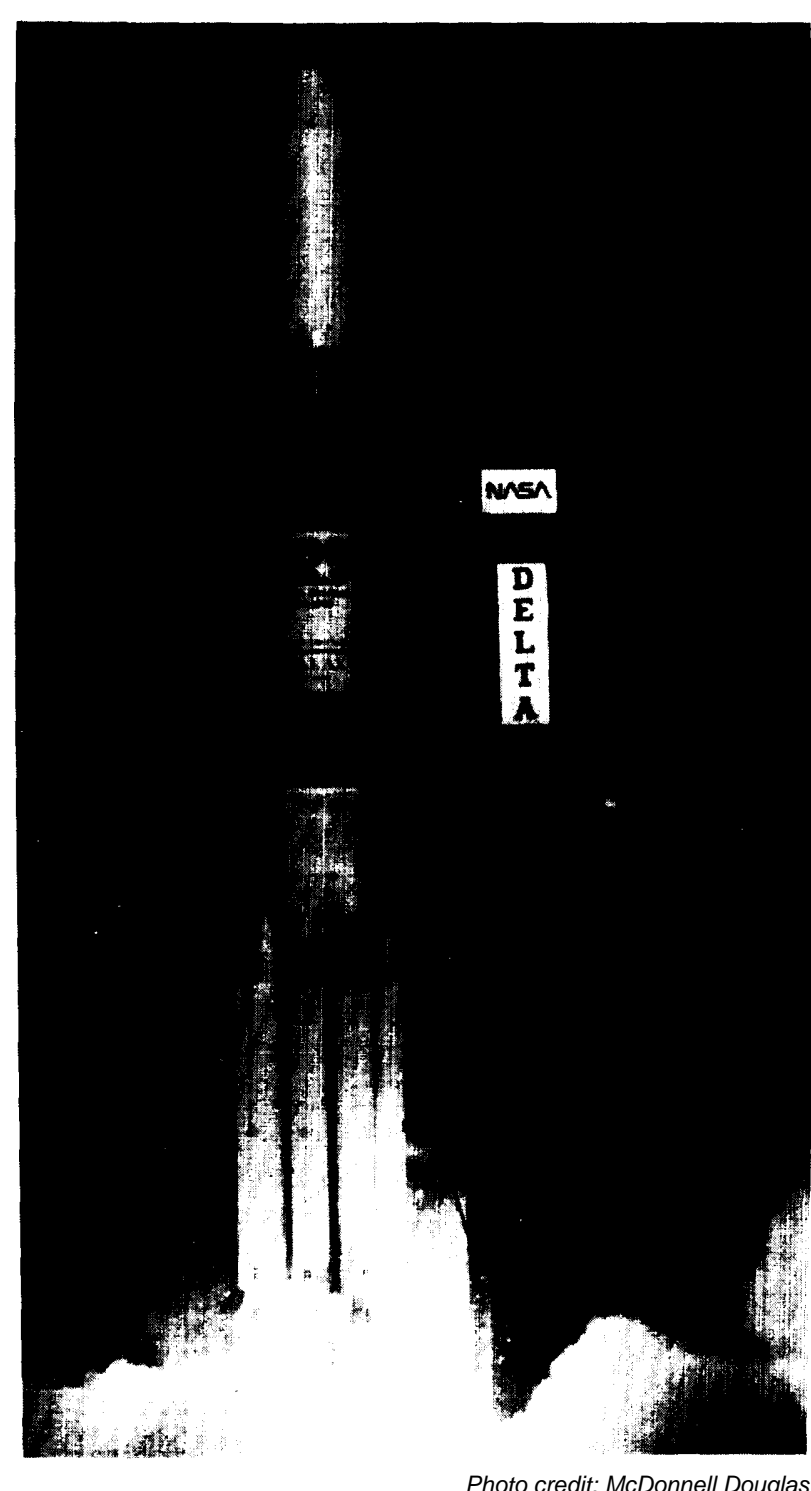

Delta Launch Vehicle

fer orbit missions. This vehicle can launch 2,600 pounds to geostationary orbit (about 5,000 pounds to geostationary transfer orbit; see footnote 4) and has a 91 percent success rate with 53 launches.

Atlas-Centaur performance was improved in 1982 to enable it to launch the INTELSAT V satellites. General Dynamics' Convair Division, the manufacturer of the Atlas-Centaur, had planned to add strap-on boosters like those used on the Delta to increase performance. In order to com- 
pete for smaller payloads, General Dynamics also considered developing a tandem adapter and a stretched payload shroud to allow the Atlas-Centaur to carry two Delta-class satellites or one PAM-DII or Ariane-4 class satellite. As a result of NASA discontinuation of Atlas-Centaur bookings, such modifications may depend on General Dynamics' success at marketing this vehicle commercially. As of January 1985, there were six Government-contracted Atlas-Centaur launches left. ${ }^{G}$

Titan: Designed by the Air Force to meet its own needs, the Titan has not, to date, been used as a commercial launch vehicle, although several firms have expressed interest in offering a "commercial" Titan launch service. The Titan has been configured in several different ways since the vehicle was first manufactured under contract by Martin Marietta in 1955. One of its current configurations, the Titan IIIC, is a three-stage solid-and-liquid-propellant launch vehicle. Its central core is composed of two liquid stages. Two 120-inch-diameter, solid-propellant motors are added as an "O stage. " The final or third stage, called the transtage, contains an inertial guidance system and altitude control system. The transtage has a multistart capability and provides the propulsive maneuvers for achieving a variety of circular and elliptical orbits. Titan IIIC can launch multiple payloads to the same or different orbits on the same launch and can place about 6,000 pounds into geosynchronous transfer orbit.

The Titan IIID is a two-stage solid-and-liquidpropellant launch vehicle. it is essentially a Titan IIIC with the transtage removed. This vehicle was designed to launch heavy, low-altitude payloads for the military. It can place about 30,000 pounds into LEO.

The Titan 34D, (considered for possible commercial use) is similar to the Titan IIIC and can use the transtage, the Boeing inertial upper stage (IUS, discussed below), the Centaur, or the TOS/AMS upper stages (discussed below). As a result, the Titan 34D can be used as a backup vehicle for Shuttle upper stage payloads. It is ca-

61 bid. Of the six satellites manifested on Atlas-Centaur, three are U.S. Navy Fltsatcoms and three are INTELSAT VA communication satellites. pable of launching about 4,000 pounds into geostationary orbit.

ELV Derivations: The Air Force has announced plans to purchase a fleet of 10 ELVs as a backup and/or complement to the Shuttle fleet. ${ }^{7}$ General Dynamics and Martin Marietta each received contracts to study a larger launcher based, respectively, on the Atlas and the Titan. The Air Force declared the Titan-derivative the victor in this initial competition; in a second round, undertaken at the insistence of NASA, the Air Force recommended the Titan-derivative over the proposed SRB$X$, an ELV based on Shuttle hardware. ${ }^{8}$ These possible derivations are mentioned because, when developed, a commercial version could very well emerge.

Shuttle? The Shuttle is the world's first partially reusable, manned, launch vehicle. The prime contractor is Rockwell International. The Shuttle system consists of an orbiter with 3 liquid-fuel engines, two solid rocket boosters and a large external fuel tank (ET). The orbiter is about the size of a DC-9 jet and carries both the crew and payload, When fully developed it will be able to place 65,000 pounds into low-Earth orbit (LEO) and return payloads up to 32,000 pounds,

The Shuttle is launched by the combined firing of the liquid fuel engines on the orbiter (which are fed by the ET) and the solid rocket engines. The solid rocket casings are parachuted back to Earth and land in the ocean to be recovered and reused. On all Shuttle flights to date or planned, the ET, when nearly empty, is released just before orbital insertion so as to be destroyed on its reentry trajectory by atmospheric friction. However, one or more ETs may eventually be orbited as components of (or raw materials for) permanent LEO infrastructure. ${ }^{10}$

\footnotetext{
7"CommercialELV Competition Planned by Air Force, "Aerospace Daily, Feb. 22, 1984, p. 289.

${ }^{8}$ Space Business News, Jan. 14, 1985, p. 1; see also' 'presidential Directive Expands U.S. Space Launches Spectrum, " Aviation Week and Space Technology, Mar. 4, 1985, pp. 18-20.

'See generally: H. Allaway, "The Space Shuttle At Work," NASA, Washington, DC, 1979, NASA SP-432.

${ }^{10} \mathrm{C}$ ivilian Space Stations and the U.S. Future in Space (Washington, DC: U.S. Congress, Office of Technology Assessment, OTA. STI-242, November 1984), pp. 77-82.
} 
Multiple payloads-e.g., communication satellites, the ESA-developed Spacelab, or various experimental pallets-can be carried in the Shuttle's $15 \times$ 60-foot cargo bay. "When in orbit, payloads can be lifted out of or hauled into the cargo bay by the remote manipulator. This 50 foot robot arm was designed and built by Spar Aerospace under contract to the National Research Council of Canada.

Shuttle Upper Stages: The Shuttle carries its payloads only to low-Earth-orbit; to reach the higher orbits in which most communication satellites are placed an additional upper stage must be used. McDonnell Douglas manufactures one upper stage family called the payload assist module (PAM). ${ }^{12}$ There are currently two versions of this stage designed to place payloads into geostationary transfer orbit; PAM-D, which has a capacity of $2,800 \mathrm{lbs}$, and PAM-DI 1 , which has a capacity of $4,000 \mathrm{lbs}$.

The PAM-DII is used only with the Shuttle, while the PAM-D can be employed either with the Shuttle or as the final stage of a Delta. ${ }^{13}$ For Shuttle use, each system has an expendable stage consisting of a spin-stabilized solid rocket motor, spacecraft fittings, and the necessary timing, sequencing, power, and control assemblies. Also required is a spin system to provide stabilizing rotation, a separation system to release and deploy the stage and spacecraft, and the necessary avionics to control, monitor, and power the system. A cradle structure is also necessary to hold the PAM and its spacecraft in the Shuttle bay.

The cost of a PAM-D upper stage system is approximately $\$ 7$ million to $\$ 8$ million (1984 dollars) for a launch in $1987 .{ }^{14}$ Costs may vary depending on whether it is a first or a repeat launch for

\footnotetext{
1 I The Shuttle is large and powerful enough to hold five Deltaclass satellites. However, due to center-of-gravity problems, and limitations imposed by tracking facilities and the insurance market, it is unlikely that the Shuttle will carry more than three or four satellites at one time.

${ }^{12} \mathrm{~A} /$ so referred to as the spinning solid upper stage or SSUS. See generally, "Using the Space Shuttle," Rockwell International, 1982, p. 12.

${ }^{13}$ E.H.Petersonand R. J. Thiele, "PAM Commercial Upper Stages for Space Access," (Huntington Beach, CA: McDonnell Douglas Astronautics Co., August 1982), MDAC Paper G8920, p. 1-2.

14 "McDonnell Douglas Sees 50 PAM-Ds Sold by 1990," Aviation Week and Space Technology, June 25, 1984, pp. 169-171.
}

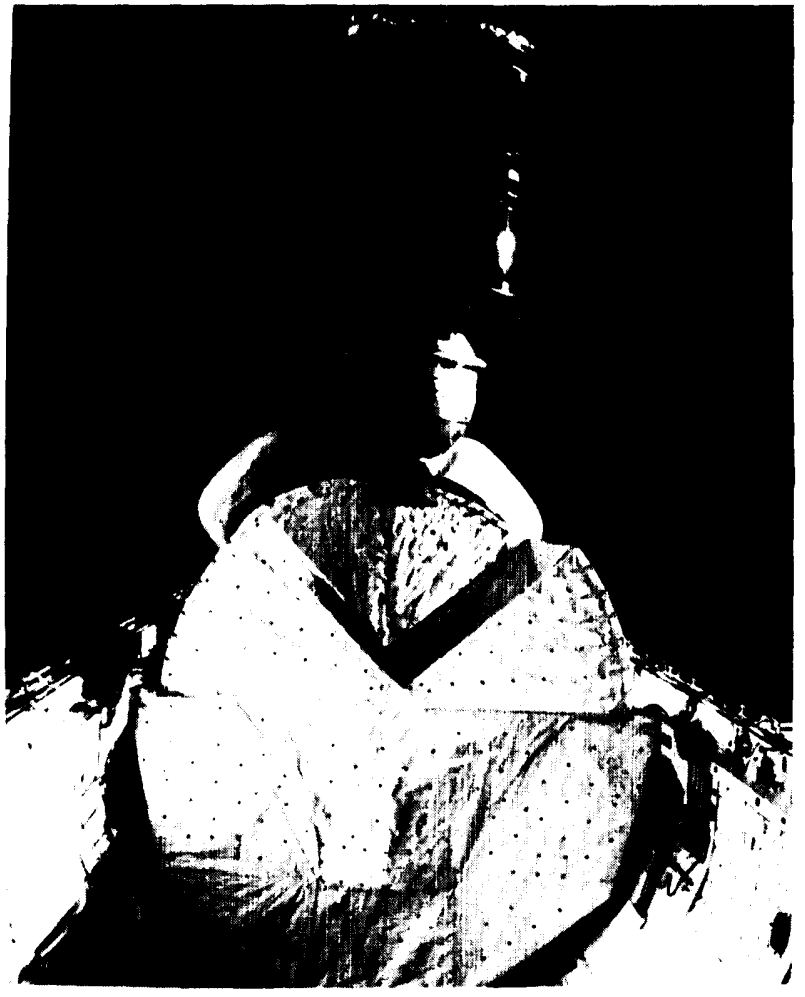

Photo credit: National Aeronautics and Space Administration

Shuttle launching Satellite Business Systems communication satellite. PAM upper stage is attached below satellite.

a customer, because initial launches require additional preparation such as structural analysis. As of January 1985, a total of 26 PAM upper stages have been launched. With the exception of the 17th and 18th launches, all were successful.Is

Another upper stage, the inertial upper stage (I US), was developed by Boeing, primarily for the Air Force. ${ }^{16}$ The I US, when used with the Shuttle, should be able to place about 5,000 pounds into geostationary orbit. It is a two-stage solid-propellant, three-axis-controlled, inertially navigated upper stage. The I US was designed originally as an interim vehicle that would bridge the gap between existing expendable upper stages and the reusable space tug desired by NASA. When it became apparent that the space tug would not be developed in the foreseeable future, the "interim

\footnotetext{
${ }^{15}$ |bid.

${ }^{16} \mathrm{E}$. L. Bangsund, "IUS Status and Growth Potential," Boeing Aerospace, Headquarters Space Division, 1982, IAF-82-05.
} 


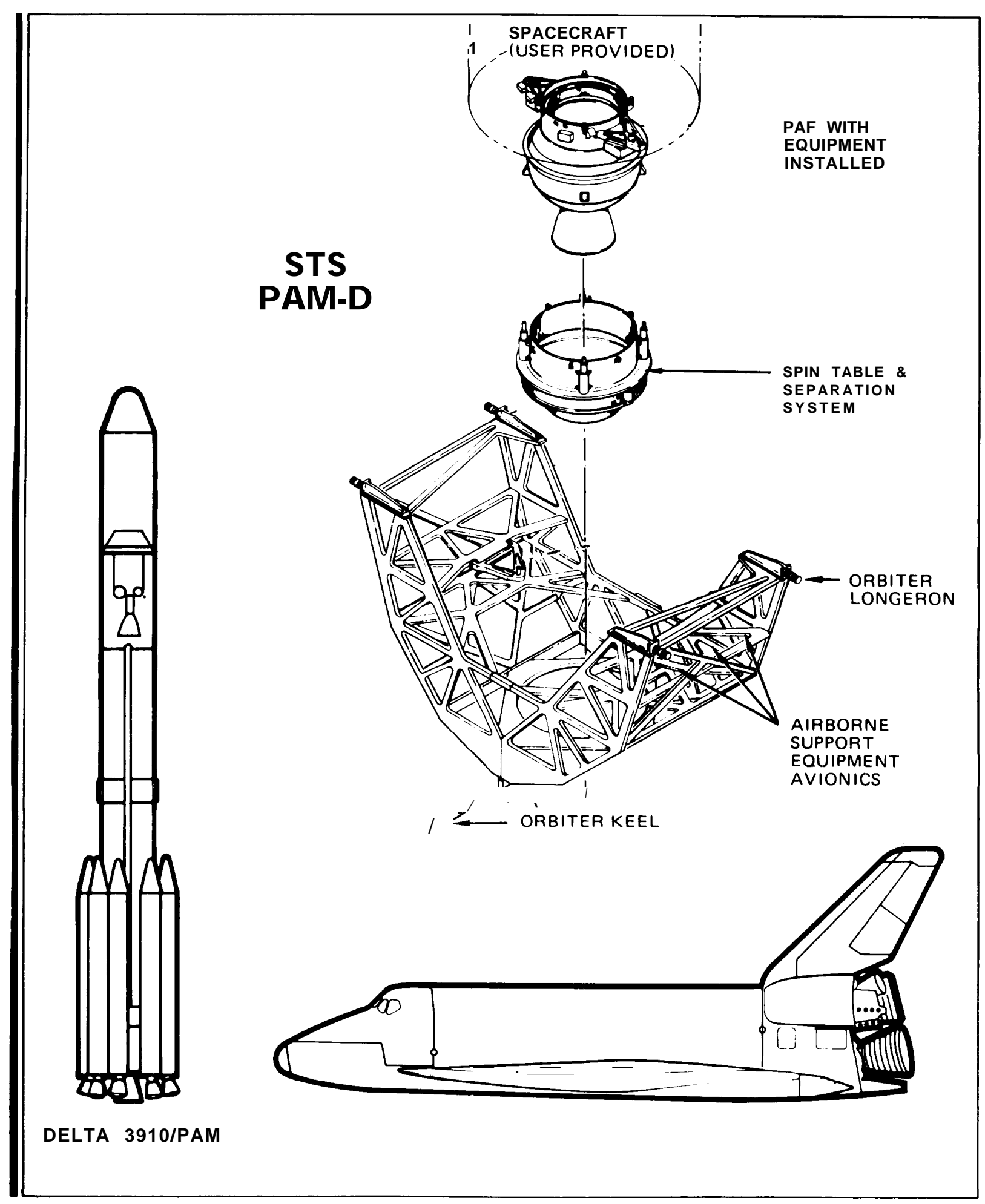

Photo credit: National Aeronautics and SpacEAdministration

The PAM-D was designed to be compatible with both the Shuttle and the Delta in order to provide a backup capability for early Shuttle missions. 
upper stage" gradually evolved into the present "inertial upper stage." The I US can be used on the Shuttle or the final stage of the Titan 34D. NASA plans to use the I US only to launch the Tracking and Data Relay Satellite System (TDRSS) satellites, after which it will rely on the Centaur upper stage. The Air Force will continue to use the I US for its launches at an estimated cost of $\$ 60$ million per flight.

The Centaur $\mathrm{G}$ and $\mathrm{G}$-prime upper stages are wide-body derivatives of the upper stage of the expendable launch vehicle, the Atlas-Centau r. ${ }^{17}$ These upper stages are under development by General Dynamics for NASA and the Air Force. The Centaur $\mathrm{G}$ will be capable of placing about 10,000 pounds into geostationary orbit from the Shuttle. The Centaur G-prime is to be used on the International Solar Polar Mission, and for the Galileo Jupiter probe, both planned for 1986. This stage will be capable of placing about 14,000 pounds into geostationary orbit.

Believing that the I US would be too expensive for commercial users and that the PAM-D and DII are too small for the large communication satellites of the late 1980s, a private corporation, Orbital Sciences Corp., is working on an upper stage called the Transfer Orbit Stage (TOS). ${ }^{18}$ The TOS would be able to place about 13,000 pounds into geostationary transfer orbit and is less expensive than the I US. The prime contractor for the TOS is Martin Marietta.

Orbital Sciences Corp. also plans to offer an Apogee and Maneuvering Stage (AMS); a bipropellant propulsion module which, depending on the weight of the payload and the desired orbit, will operate independently of, or with, the TOS. OSC intends to charge about $\$ 30$ million to launch IUS-class payloads. ${ }^{20}$

\footnotetext{
${ }^{17}$ E. H. Kolcum, "NASA Weighs Greater Role for Centaur, " Aviation Week and Space Technology, July 25, 1983, p. 60.

${ }^{18}$ D. Dooling, "Business Graduates Plan New Shuttle Stage," Space World, March 1983, p. 29.

19 The TOS was full financed by a $\$ 50$-million $R \& D$ limited partnership, the largest private financing of any commercial space endeavor to date.

${ }^{20}$ "Orbital Sciences Offers Upper Stages, "Aviation Week and Space Technology, June 25, 1984, pp. 108-113.
}

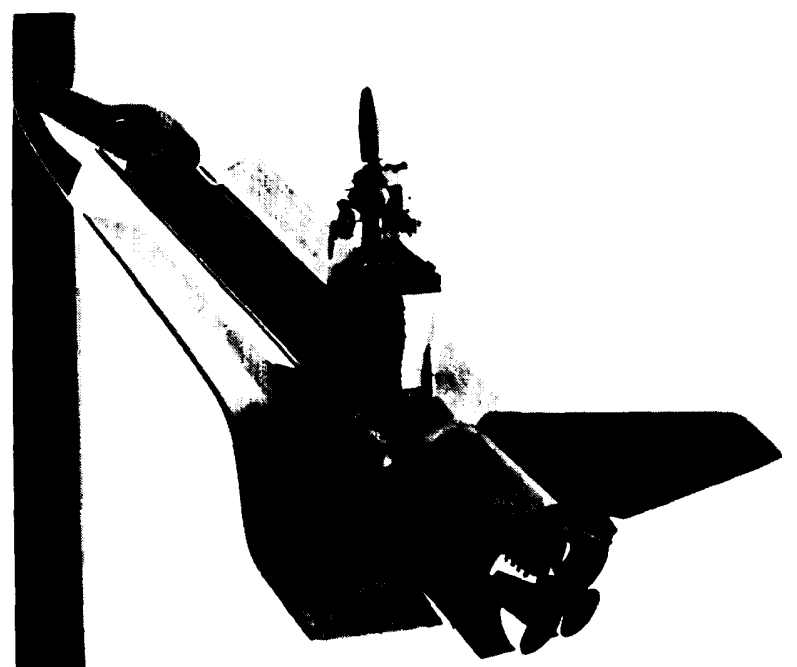

Photo credit: National Aeronautics and Space Administration

Artist's conception of the proposed Shuttle launched Centaur Inertial Upper Stage

Aerojet Tech Systems is also undertaking development, with in-house funds, of a high-performance, all-liquid upper stage, called the Liquid Propulsion Module (1PM). The basic model is tailored for launching up to 3,500 pounds to geostationary orbit; by using tandem stages it would be capable of launching up to 8,500 pounds to geostationary orbit. Aerojet's goal is to offer this stage commercially by 1987 for $\$ 10$ million. Its engine is derived from the Shuttle Orbit Maneuvering System Engine.

Astrotech Space Operations is another firm interested in entering the IUS-class upper stage market for commercial and military payloads. Astrotech and its prime contractor, McDonnell Douglas, hope to develop a liquid-propellant upper stage (Delta Transfer Stage) capable of placing as much as 7,500 pounds into geosynchronous orbit or 20,000 pounds into geosynchronous transfer orbit. The Delta stage, as currently envisioned, would be Shuttle- and Titan-compatible and would cost in excess of $\$ 30$ million. ${ }^{21}$

\footnotetext{
${ }^{2}$ "Astrotech Sees Military Uses for Stage, "Aviation Week and Space Technology, June 25, 1984, p. 158.
} 


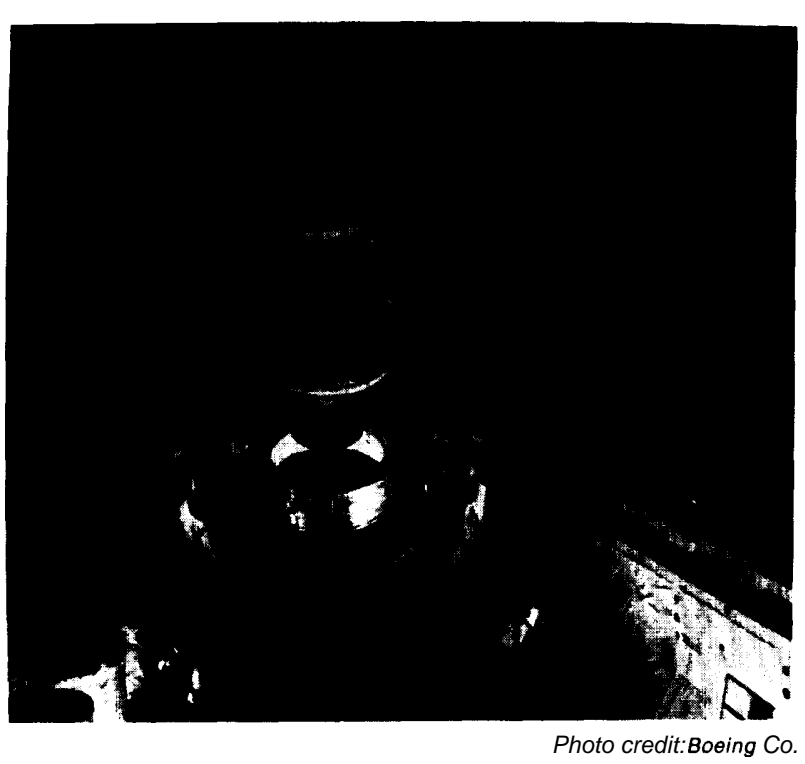

IUS and attached tracking and data relay communications satellite being launched from the Shuttle.

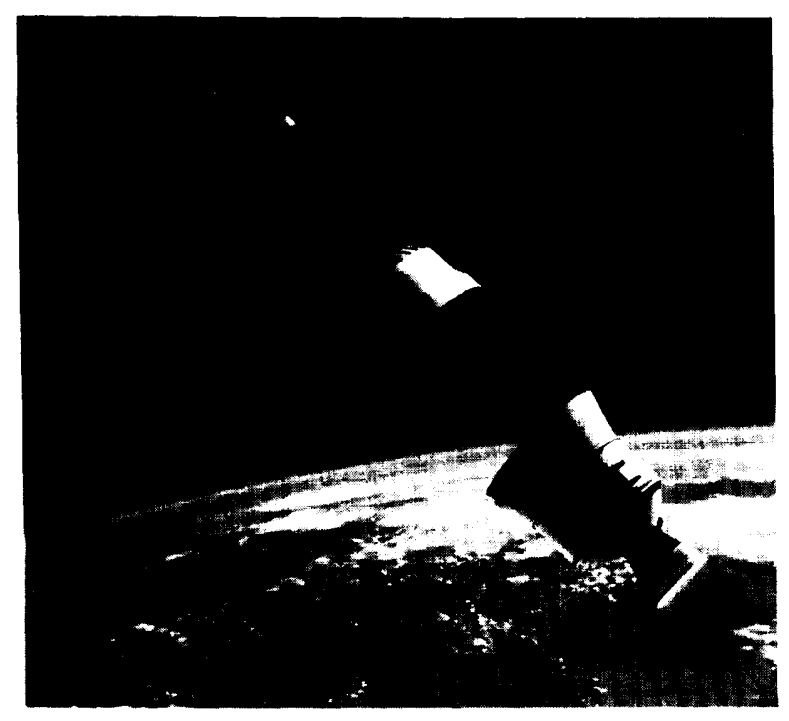

A

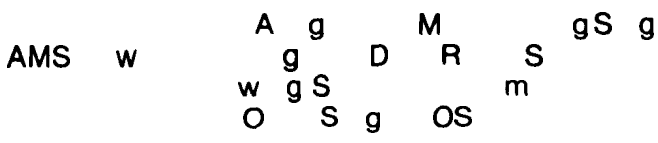

\section{Arianespace}

Since the early 1960s, Europe has attempted to mount a coordinated space program to ensure European participation in the economic, scien- tific, and political benefits of space activities and to compete with the United States and the Soviet Union. The latest and most successful organization is the European Space Agency (ESA), which was founded in $1975 .{ }^{22}$ ESA inherited the programs and facilities of its predecessor organizations, the European Space Research Organization (ESRO), the European Launcher Development Organization (ELDO), and the European Space Conference (ESC). ${ }^{23}$ ESA'S most important launch program to date has been development of the Ariane vehicle.

Ariane 1 is a three-stage ELV with an advanced liquid-oxygen/liquid-hydrogen third stage. This vehicle was only the first in a series of as many as five models; successive designs will improve payload capacity and performance through the 1980s. With Ariane 2 and 3 already operational, the ESA member states have approved a program to develop Ariane 4 as well as the HM-60 engine, an essential component of the Ariane $5 .{ }^{24}$ Ariane 1 is capable of placing about 3,800 pounds into geostationary transfer orbit, Ariane 2 , about 4,400 pounds, Ariane 3 , about 5,200 pounds, and Ariane 4, about 9,200 pounds. With the successful launch of an Ariane 1 on May 23, 1984, the Ariane vehicle entered into commercial service (see table s- I). Previous flights had been developmental (LO1 -L04) and promotional (L5-V8). The first Ariane 3 was successfully launched on August 4, 1984. The first flight of Ariane 4 is expected in 1986. A variety of designs for Ariane 5 are being debated, including a manned Shuttletype system called "Hermes" (fig. 5-2).

Using a dual launch system, the Ariane is capable of carrying two payloads on each flight. Launches are made from the French-owned, ESAfunded Kourou spaceport in French Guiana, South America. Currently, the one pad at Kourou will allow only five or six flights a year; a new

\footnotetext{
22ESA has 17 full members-Belgium, Denmark, France, West Germany, Ireland, Italy, the Netherlands, Spain, Sweden, Switzerland, and the United Kingdom-and three associate members-Austria, Canada, and Norway. (See ch. 3 for a discussion of ESA.) 23 For a description of European space activities prior to and following the formation of ESA, see: Civilian Space Policy and Applications (Washington, DC: U.S. Congress, Office of Technology Assessment, OTA-STI-177, June 1982).

${ }^{24}$ Gibson, Roy, "Europe-Towards a New Long-Term Programme," Space Policy (1: 1), February 1985, p. 5.
} 


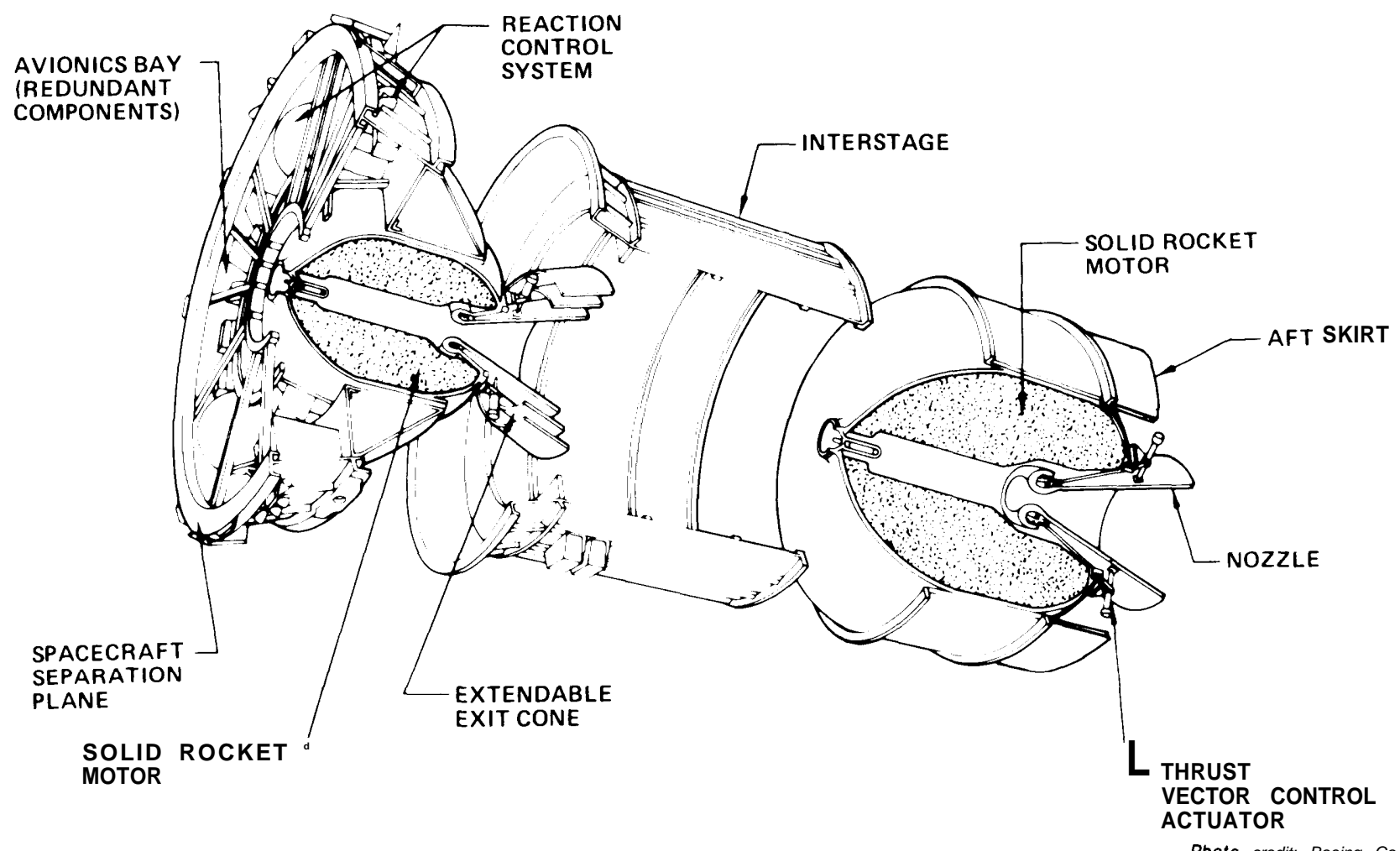

Inertial Upper Stage

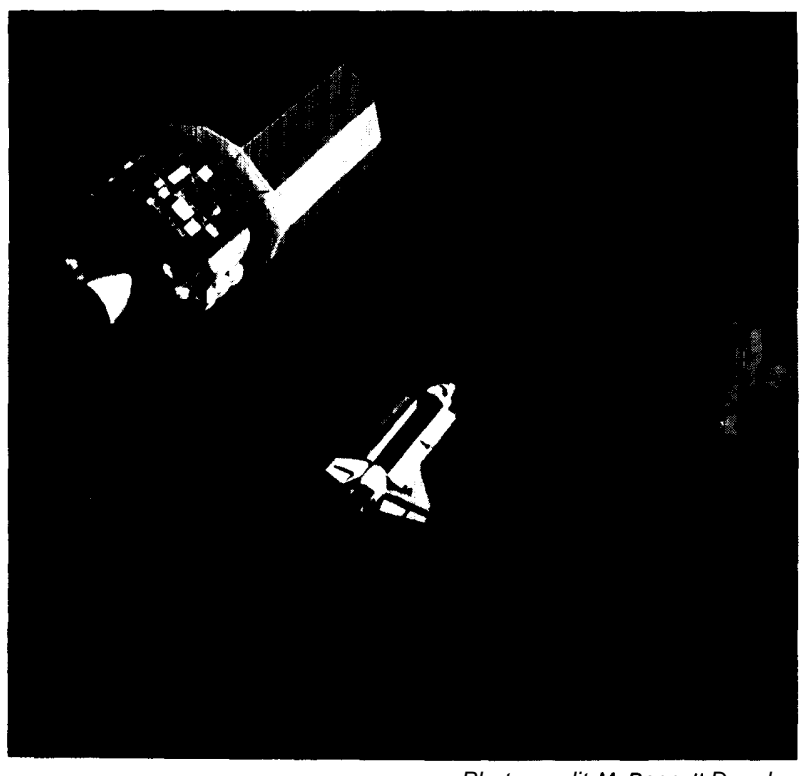

Photo credit:McDonnell Douglas Artist's conception of Delta Transfer Stage pad in 1985 will allow about 10 annual au riches. As of January 1985, there have been 1 Ariane launches, of which two have been fain res (table 5-1).

Realizing that commercial operations would be difficult if the 11 ESA nations had to agree unanimously to every business decision, ESA and CNES (the French national space program) established a quasi-private corporation called Arianespace to produce, finance, market, and launch Ariane vehicles. ESA and CNES remain responsible for development of future Ariane vehicles and for operation of the Guiana spaceport. Arianespace S.A. is incorporated in France (March 1980) and owned by firms from the states that funded Ariane's development, by CNES, and by European banks. French investors (including CNES, which is the largest single shareholder with 34 percent) own 60 percent; West German investors own 20 percent; and the remainder is split 


\section{[Page Omitted]}

This page was originally printed on a gray background.

The scanned version of the page is almost entirely black and is unusable.

It has been intentionally omitted.

If a replacement page image of higher quality

becomes available, it will be posted

within the copy of this report

found on one of the OTA websites. 


\section{[Page Omitted]}

This page was originally printed on a gray background.

The scanned version of the page is almost entirely black and is unusable.

It has been intentionally omitted.

If a replacement page image of higher quality

becomes available, it will be posted

within the copy of this report

found on one of the OTA websites. 


\section{[Page Omitted]}

This page was originally printed on a gray background.

The scanned version of the page is almost entirely black and is unusable.

It has been intentionally omitted.

If a replacement page image of higher quality

becomes available, it will be posted

within the copy of this report

found on one of the OTA websites. 


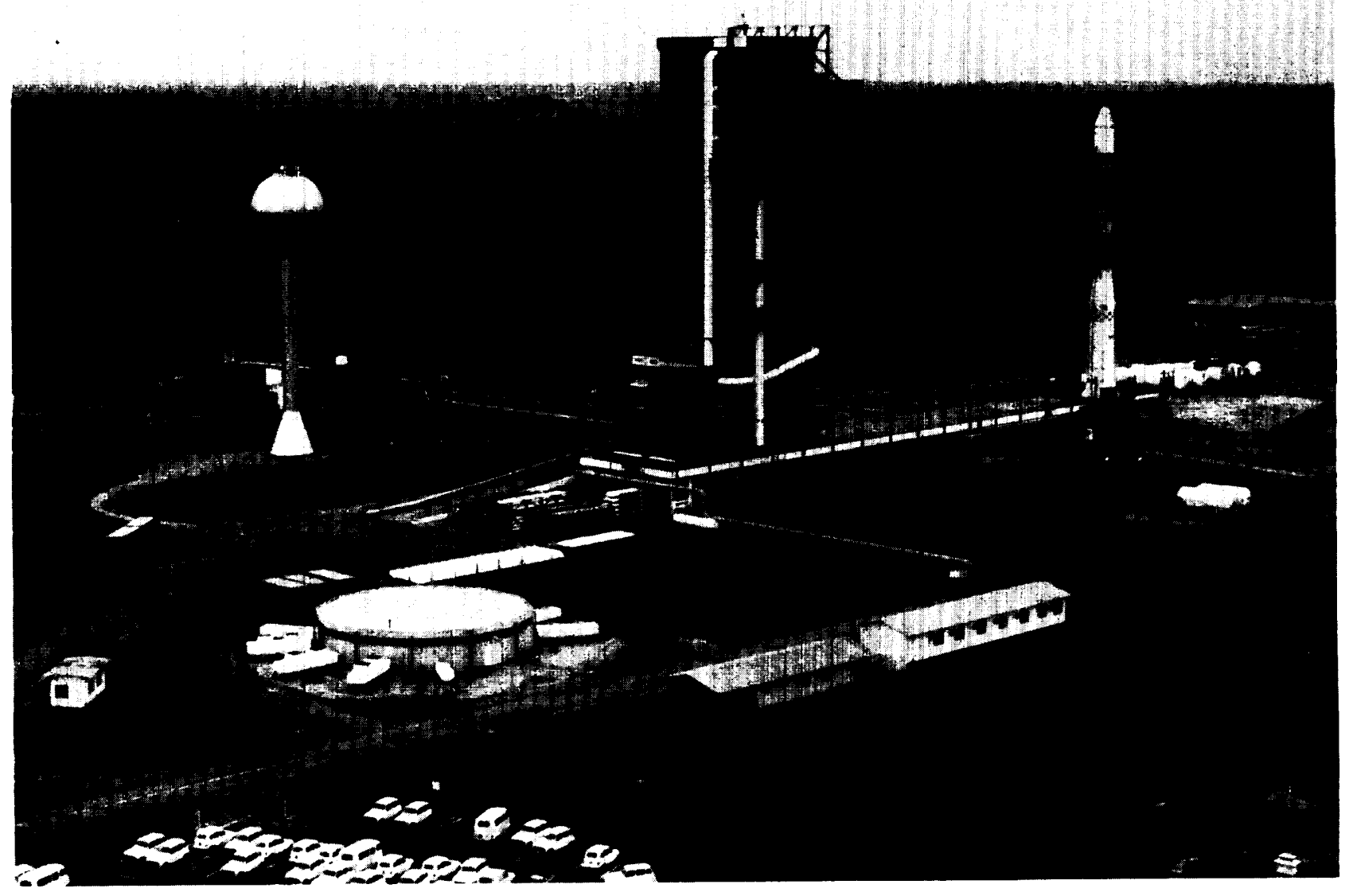

Photo credit: European Space Agency

Ariane L1 on ELA1

Table 5-1.-Ariane Flights

\begin{tabular}{|c|c|c|c|}
\hline Flight reference & Launcher & Payload & Comments \\
\hline $\begin{array}{l}\text { Development flights: } \\
\text { LO1. } \ldots \ldots \ldots \ldots \ldots \ldots \ldots \ldots \ldots \text { Dec. 24, } 1979 \\
\text { L02 . } \ldots \ldots \ldots \ldots \ldots \ldots \ldots \text { May 23, } 1980\end{array}$ & $\begin{array}{l}\text { AR } 1 \\
\text { AR } 1\end{array}$ & $\begin{array}{l}\text { Technological Capsule (CAT) } \\
\text { AMSAT-FIREWHEEL }\end{array}$ & $\begin{array}{l}\text { Success } \\
\text { Failure } \\
\quad \text { (Viking engine } \\
\quad \text { instability) }\end{array}$ \\
\hline $\begin{array}{l}\text { LO.. . . . . . . . . . . . . . . . June 19, } 1981 \\
\text { LO.. . . . . . . . . . . . . Dec.20, } 1981 \\
\text { Promotion flights: }\end{array}$ & $\begin{array}{l}\text { AR } 1 \\
\text { AR } 1\end{array}$ & $\begin{array}{l}\text { CAT + APPLE + METEOSAT } \\
\text { CAT + MARECSA }\end{array}$ & $\begin{array}{l}\text { Success } \\
\text { Success }\end{array}$ \\
\hline Lo. . . . . . . . . . . . . . . . . Sept 10, 1982 & AR1 (SYLDA) & MARECSB/SIRIO & $\begin{array}{l}\text { Failure } \\
\text { (third-stage Turbo } \\
\text { pump) }\end{array}$ \\
\hline $\begin{array}{l}\text { Lo. . . . . . . . . . . . . . ... .June 16, } 1983 \\
\text { L7. . . . . . . . . . . . . . . . . Mar. 19, } 1983 \\
\text { V8 . . . . . . . . . . . . . Ma . } 1984 \\
\text { Arianespace commercial flights: }\end{array}$ & $\begin{array}{l}\text { AR1 (SYLDA) } \\
\text { AR } 1 \\
\text { A R } 1\end{array}$ & $\begin{array}{l}\text { ECS-1/OSCAR } \\
\text { INTELSATV-F7 } \\
\text { INTELSATV-F8 }\end{array}$ & $\begin{array}{l}\text { Success } \\
\text { Success } \\
\text { Success }\end{array}$ \\
\hline 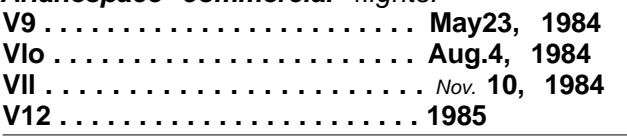 & $\begin{array}{l}\text { AR1 } \\
\text { AR3(SYLDA) } \\
\text { AR3 } \\
\text { AR3(SYLDA) }\end{array}$ & $\begin{array}{l}\text { SPACENET1 } \\
\text { ECS-2/TELECOM 1A } \\
\text { SPACENETF21MARECS } 62 \\
\text { ARABSAT/SBTS-I }\end{array}$ & $\begin{array}{l}\text { Success } \\
\text { Success } \\
\text { Success }\end{array}$ \\
\hline
\end{tabular}

SOURCE" Arianespace, Inc 
Figure 5=2.-The Hermes Spaceplane (conceptual design)
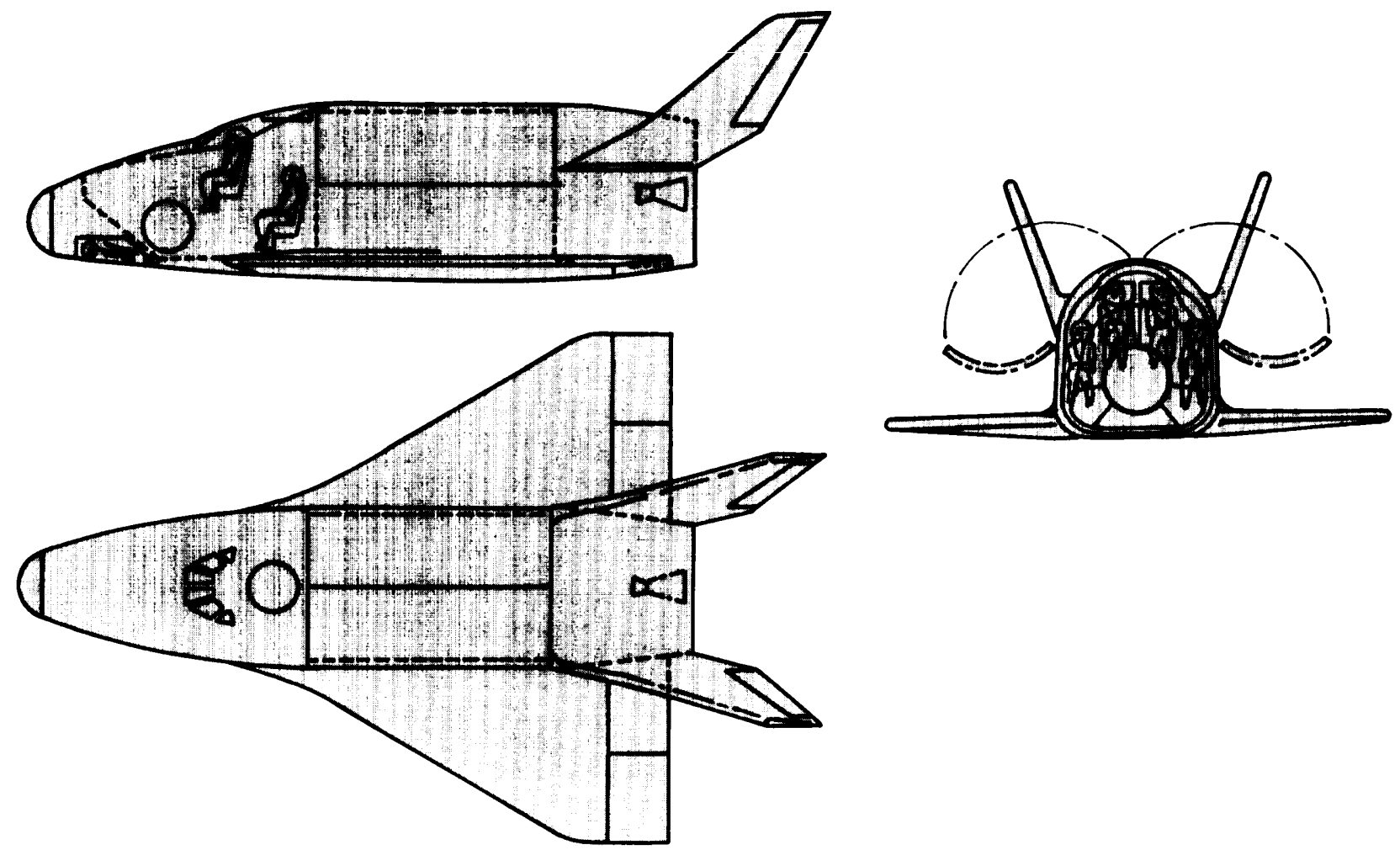

SOURCE: CNES

among the other ESA nations, A U.S. subsidiary (Arianespace, Inc.) was chartered in November 1982.

\section{Potential Government Sellers}

A number of countries have, or are developing, launch vehicles which would enable them to enter the launch vehicles market (figs. 5-3a and $5-3$ b):

\section{SOVIET VEHICLES ${ }^{25}$}

The Soviets have developed a number of expendable launch vehicles; the most commonly used is the Sapwood-A launcher, a derivative of an ICBM design dating back to the mid-1950s.

\footnotetext{
25The Soviet Union does not name or identify its launch vehicles. Soviet surface-to-surface missiles are assigned numbers with the prefix SS by the U.S. military. When such missiles are seen often enough to be identified by military branches of the NATO powers, code names such as Sandal, Skean, or Sapwood are assigned. (The Proton, not having been developed as a missile, does not have an SS or code-S designator. ) In order to convey more information about the Soviet vehicle and its various stages, TRW developed the sys-
}

As presently modified, the Sapwood-A can launch Soyuz manned vehicles of about 15,000 pounds to low-Earth-orbit. The larger Proton-D launcher can carry about 44,000 pounds to lowEarth-orbit and has been used to launch the Salyut space stations. Recent reports indicate that the Soviets are developing both a Saturn-class vehicle capable of placing 300,000 pounds into low-Earth-orbit and a reusable space vehicle similar to the Shuttle. ${ }^{26}$

Although the Soviets have long had a reliable fleet of launch vehicles they have only recently

tern of using capital letters for the first stage, numbers for the upper stages and small letters for the final stage. Both the letter and code designators are used here. For a detailed discussion of Soviet launch activities, see: Soviet Space Programs, 1971-1975, Staff Report for Senate Committee on Aeronautics and Space Sciences, Congressional Research Service, August 1976.

"b"' Soviets Said to Remove Camouflage Nets From New Launch Vehicles," Aerospace Daily, Dec. 14, 1983, p. 227; See also: D. Doder, "Soviets Say They Plan to Build Space Shuttle," The Washington Post, Dec. 13, 1983, p. A 10, c. 1; See also, "Soviets Ready New Boosters at Tyuratam," Aviation Week and Space Technology, Aug. 27, 1984, pp. 18-21. 


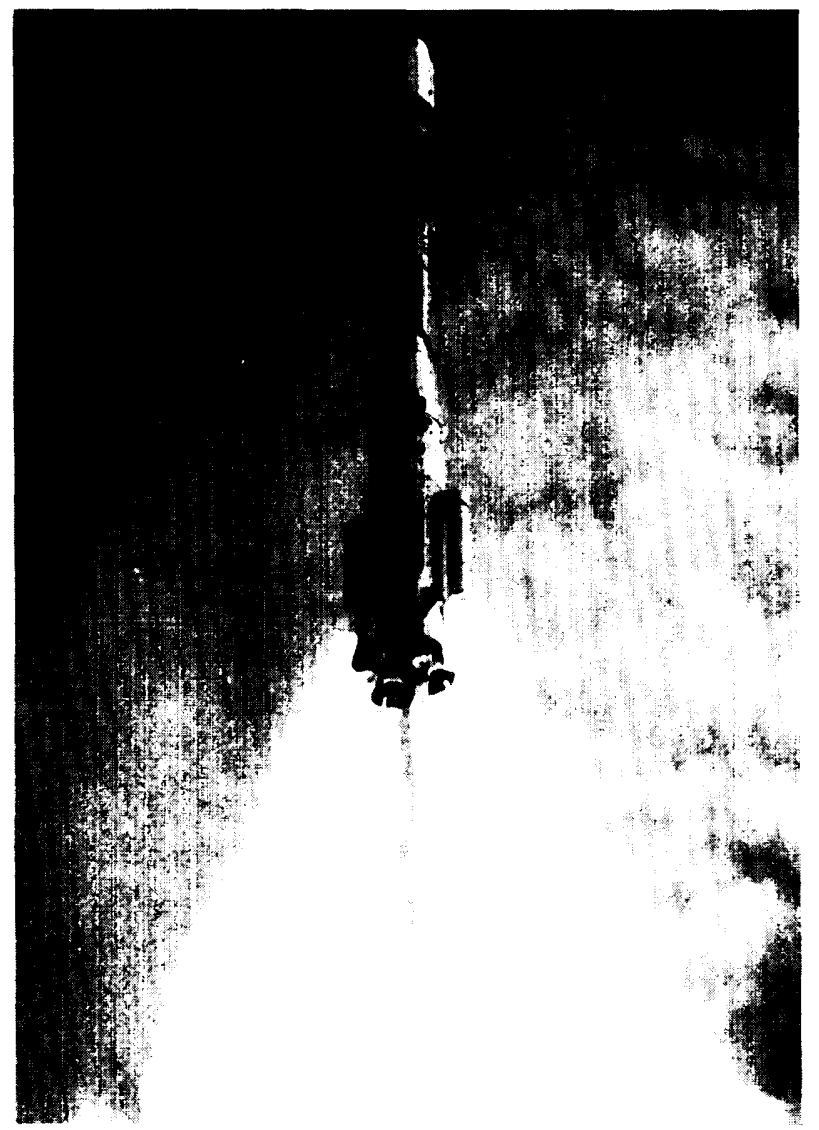

Photo credit: Ariane

Kourou, French Guiana V10 launch, August 4, 1984. Arianespace/ECS-2 Telecom 1-A

made an attempt to enter the international launch services market. In June 1983, the Soviets requested that their Proton launcher be considered as a candidate to orbit INMARSAT's second-generation communication satellites. ${ }^{27}$ At the time of the Soviet announcement, the other candidate launch vehicles were the Shuttle, Ariane, AtlasCentaur, Delta, and Titan. The INMARSAT council accepted the Soviet request and informed its satellite contract bidders that they must design their spacecraft for compatibility with at least two of the six launchers and that one of their selections had to be the Proton, Shuttle, or Ariane. ${ }^{28}$

\footnotetext{
${ }^{27}$ J. M. Lenorovitz, "IN NMARSAT Adds Proton to Booster List," Aviation Week and Space Technology, Aug. 1, 1983, p. 16; see also, "Soviets Provide Data to Guide INMARSAT in Launcher Decision," Aviation Week and Space Technology, Aug. 8, 1983. p 22. It should be noted that the Soviet Union is a member of INMARSAT (see chs. 3 and 6).

${ }^{28}$ Aviation Week and Space Technology, Aug. 1,1983, p.17
}

The Soviets have quoted a launch price of approximately $\$ 24$ million (current year dollars) for the Proton; this is less than the price of either the Space Shuttle or the Ariane.

Soviet willingness to specify the launch site (Tyuratam) and to provide technical data concerning the Proton suggests that they are serious about the INMARSAT offer. It seems unlikely that a more general entry into international launch vehicle competition will be forthcoming. Although the Soviets possess the technology to compete with NASA and Arianespace or with U.S. commercial firms, they will probably never become an important provider of commercial launch services: first, the Soviets would have to allow Western scientists and businessmen to supervise the assembly, testing, integration, and launch of their satellites; second, it is unlikely that the United States, or any Western government, would allow sophisticated communication satellites to be exported to the Soviet Union; and third, it is unclear whether financing and insurance could be obtained for a Soviet launch.

\section{JAPANESE LAUNCH VEHICLES}

Beginning in the late 1950s and through the 1960s, the Institute of Space and Aeronautical Sciences (ISAS), developed the Kappa and Lambda series of solid-fuel sounding rockets, which were used for Japanese scientific and applications experiments. The difficulties of rocket development were exacerbated by inadequate guidance and stabilization technology, the result in part of a self-imposed reluctance to fund technologies that might be perceived as having military applications. ISAS went on to develop orbital rockets; the first successful 50-pound test satellite was launched by an advanced Lambda in February 1970. The Mu-class orbital launcher achieved its first success in 1971 and continues to be operated by ISAS from its Kagoshima test range. Nissan Motors is currently designing an advanced version of the Mu, the M-3-kai-I, which will be used for Japan's first planetary exploration missions in the mid-1980s, including a planned Halley/Venus mission in 1985.

In 1969, the National Space Development Agency (NASDA), assumed primary responsibility for launcher development for applications satel- 
Figure 5-3.-Foreign National Comparative Launch Vehicle Development
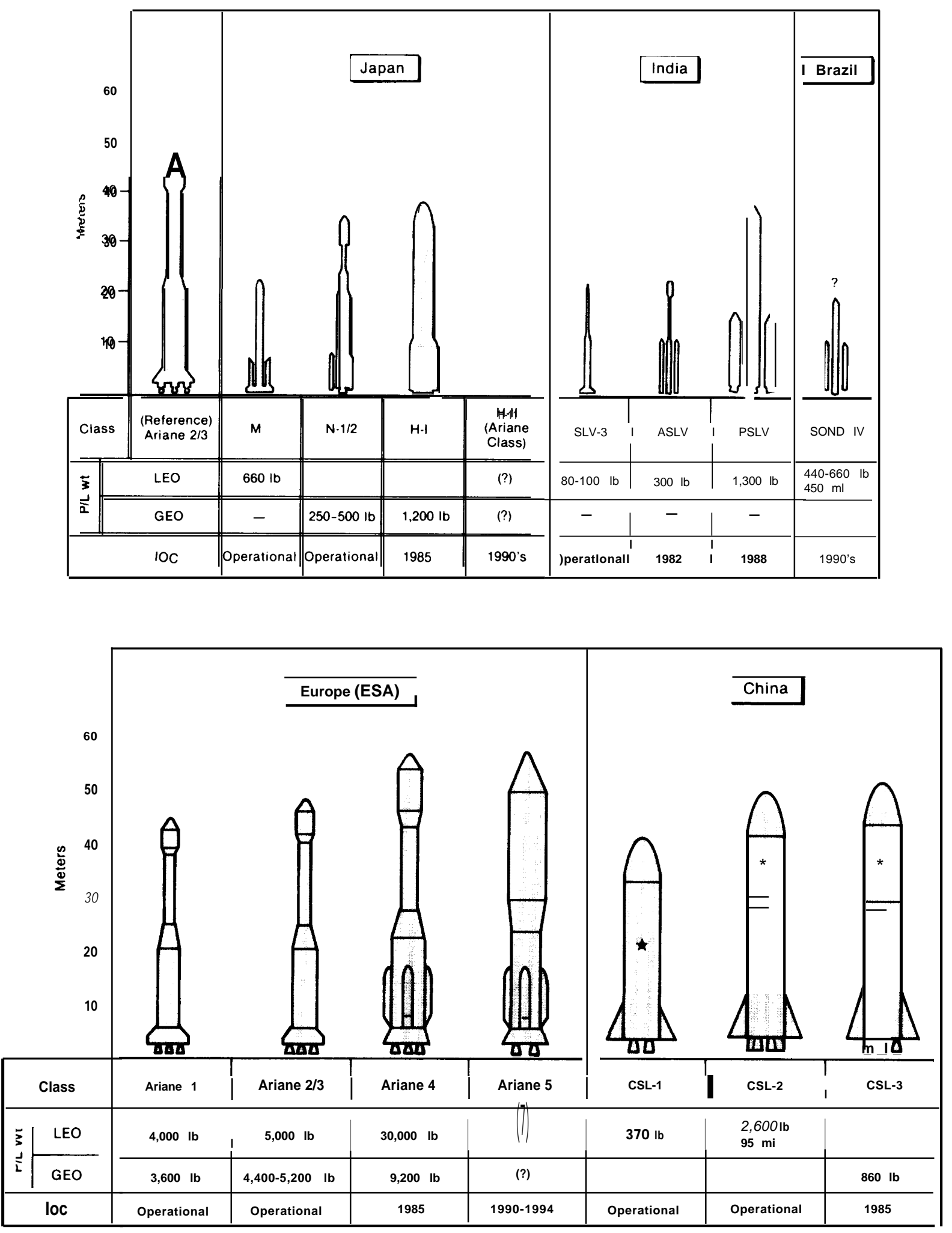


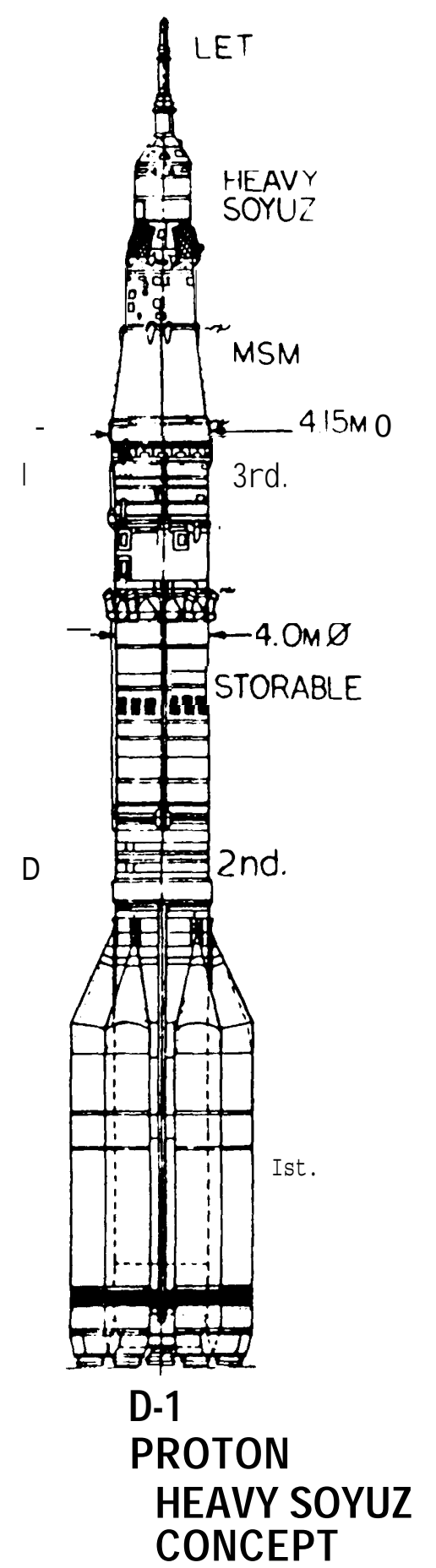

Photo credit: C. P. Vick@

Soviet launcher lites. Instead of attempting to develop further versions of the Mu launcher, NASDA decided to purchase U.S. Delta launcher technology. The U. S.Japanese Agreement on Space Activities, signed on July 31, 1969, gave Japan access to this technology (subject to certain limitations, which are discussed below). As a result, Japan developed the $\mathrm{N}-1$ launcher, which is capable of lifting over 500 pounds into geostationary transfer orbit. The $\mathrm{N}-1$ consists of a Thor first stage, built in Japan by Mitsubishi Industries under license to McDonnell Douglas, a Japanese-developed liquid-fuel second stage, and a U.S. Thiokol third stage. Approximately 67 percent of the $\mathrm{N}-1$ is supplied by Japanese firms.

A more powerful version, the $\mathrm{N}-11$, had its first successful test flight in February 1981, and is capable of lifting about 1,500 pounds into geostationary transfer orbit. The major differences from the $\mathrm{N}-1$ are use of additional solid-fuel strap-on boosters and replacement of the Japanese-designed second stage by an improved version of the Aerojet-General (U. S.) second stage used on the Delta. As a result the Japanese contribution to the $\mathrm{N}-11$ is only 56 percent. For the late 1980 s and the 1990s, the Japanese have a new booster, the $\mathrm{H}-1$, under development. The major innovation is a planned liquid oxygen-liquid hydrogen second stage to be built by Mitsubishi. The initial version of the $\mathrm{H}-1$ will be able to place about 2,400 pounds into geostationary transfer orbit; a recently funded follow-on version, the $\mathrm{H}-11$, will have even greater capacity (in the early 1990s).2'3 The $\mathrm{H}-1$ will use an inertial guidance system instead of the radio guidance of the $\mathrm{N}-1$ series.

The Japanese have not announced plans to offer commercial launch services. At present, Japanese launch capabilities are restricted not only by technology, but also by agreements with the Japanese fishing industry which allow missiles to be fired only at two times of the year, JanuaryFebruary and August-September. In addition, the U.S.-Japanese agreements which cover the transfer of Delta technology prevent its transfer to third

\footnotetext{
29"Japan Funds Launcher, Satellite Development," AviationWeek and Space Technology, Feb. 13, 1984, p. 125.
} 
countries or its use for launching third-country payloads. The $\mathrm{H}-11$ launch vehicle, which will be designed and built entirely with Japanese technology, will not be similarly restricted.

\section{CHINESE VEHICLES}

The Peoples Republic of China's (PRC) launch technology has been derived from the Soviet Union, primarily the SS-4 (Sandal) medium-range liquid-fueled missile. The design for these missiles was given to the Chinese in the late 1950s before relations between the two countries deteriorated.

The Chinese launched their first satellite, the 380-pound China 1, in April 1970, with a CSL-I (Long March 1) launcher. Starting with China 3 in 1975, launches were made with the FB-I (Storm) vehicles, a version of the CSS-X-4 ICBM, which is equivalent in size to the U.S. Atlas. The FB-1 can launch about 2,600 pounds into lowEarth-orbit.

The Chinese are known to be working on a new launcher, the Long March 3, that would use the two stages of the FB-1 plus a liquid oxygenliquid hydrogen upper stage. If successful, this would make them third in the world, after the United States and ESA, to use high-energy cryogenic fuels. The Long March 3 would be capable of launching about 3,080 pounds into geostationary transfer orbit.

China is planning to accelerate its international cooperative efforts in space, and it has announced that it is ready to discuss Long March launch services with interested customers .30

\section{INDIAN LAUNCH VEHICLES}

India began to work on its first launch vehicle, the SLV-3, in 1973. It is is a four-stage, inertially guided, solid-propellant rocket designed to lift 80 to 100 pounds to low-Earth-orbit. The SLV-3 successfully launched a 75-pound RS-1 technology demonstration satellite in July 1980.

The Indians are developing the ASLV, which will be able to lift about 300 pounds into lowEarth-orbit. The first launch of the ASLV is

30"China Offering Space Launch Services to International Users," Aviation Week and Space Technology, Apr. 8, 1985, p. 25. planned for 1985 or 1986 . The ASLV will continue to use solid propellant for the main motors, as does the SLV, but will have two solid-propellant strap-on boosters. The PSLV, a vehicle planned for development in the late 1980s or early 1990s, will be similar to the ASLV but may use the Viking engine (currently used on the Ariane) as its second stage and will be able to launch 1,300 pounds into low-Earth-orbit. Longterm plans call for development of a SPSLV capable of low-Earth-orbit launches of 7,500 pounds. It is unlikely that India will be able to compete with NASA or Arianespace in the next two decades.

\section{BRAZILIAN VEHICLES}

Brazil has developed a family of solid-propellant sounding rockets called the Sonda; the latest of these-the Sonda III-is a two-stage rocket which can carry payloads of about 130 pounds to altitudes of 380 miles. Several variants of the Sonda are now operational and regularly used for meteorological observation and atmospheric testing. Although these rockets lack the power to place a satellite into orbit, current plans call for development of more powerful boosters.

\section{Potential Non-Government Sellers \\ U.S. PRIVATE SECTOR ACTIVITIES}

Three types of private sector launch activities are currently under way in the United States: firms which want to market one of the existing ELVS (Delta, Atlas-Centaur, or Titan), firms which want to develop new, low-cost expendable launch vehicles, and those marketing upper stages for use with the Shuttle.

When NASA announced in 1983 that it was seeking private sector operators for the Delta and the Atlas-Centaur, five firms expressed interest in marketing these vehicles. ${ }^{31}$ However, when NASA published its official solicitation for proposals, only two companies responded with firm offers. General Dynamics' Convair Division, the current manufacturer of the Atlas-Centaur, was the only company to express interest in that vehicle. Transpace Carriers, inc., was the only company to re-

\footnotetext{
J' "Five Firms Seek NASA ELVs," Space Business News, July 18,
} 1983. 
quest the right to operate the Delta line. McDonnell Douglas Astronautics, the manufacturer of the Delta, did not bid on this vehicle.

The Titan was not included in the NASA solicitation because it is an Air Force vehicle. Prime contractor Martin Marietta has expressed interest in marketing the Titan as a military backup for the Shuttle.

Several private U.S. companies are developing small expendable launch vehicles. Most notable are Space Services Inc. (SS1) of Houston, TX, and Starstruck, Inc. (formerly Arc Technologies) of Redwood City, CA.

[n September 1982, SS1 flew a successful suborbital flight of its Conestoga 1 vehicle, demonstrating payload spin-up and separation capabilities. This vehicle was an adaptation of the Minuteman 1 second-stage motor and did not have the ability to achieve orbit. The Conestoga II being developed by SS1 will be able to place small payloads into low-Earth-orbit. The Conestoga II will be a multistage vehicle based on the Thiokol solidrocket motors presently used as strap-ens for the Delta. ${ }^{32} 33$

Starstruck is presently developing a hybrid solid/liquid-fueled rocket engine for its Dolphin launch vehicle, which may be launched from the open seas. ${ }^{34}$ In June 1983, Starstruck successfully tested key propulsion and electronic systems, and in August 1984 conducted a successful test launch. Eventually, Starstruck hopes to in the market for geosynchronous payloads 1,300 to 1,500 pounds. ${ }^{35}$ However, the company has had major financial, technical, and organizational problems recently and it is not clear that it will remain in business. ${ }^{36}$

As discussed above, there are five families of Shuttle upper stages either existing or under de-

${ }^{32}$ Space Services Inc., press release, Sept. 8, 1983. See also, "SSI Selling Conestoga 1-6, "Space Business News, Aug. 13, 1984

${ }^{3} 3 \mathrm{SS}$ has a contract to launch the cremated remains of humans into orbit in an orbiting mausoleum. The firm awaits DOT approval to do so. See "SS1 Awaits DOT Mission Approval," Space Business News, Jan. 28, 1985, p. 1

${ }^{34}$ J.Levine, "Shooting for Outer Space, "Venture, October 1983, pp. 116-117.

35"Arc/Starstruck Plans Three Tests In '83," Space Business News, July 18,1983, p. 6.

${ }^{36}$ See, for example, "Reorganization Gives New Life to Starstruck," Space Business News, Oct. 22, 1984, pp. 2-3.

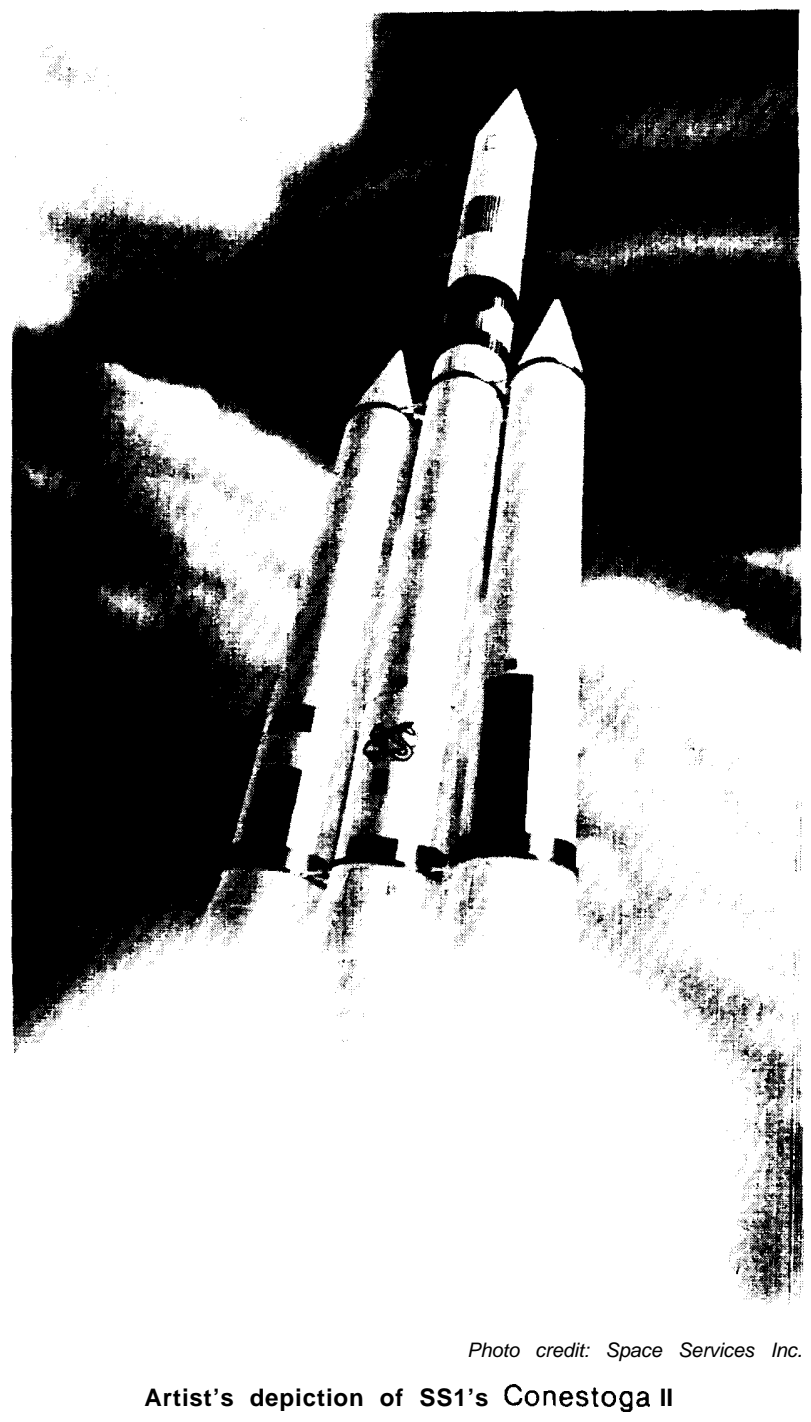

velopment in the United States-PAM, I US, Centaur (under development), TOS (under development), and the Delta Transfer Stage. Although it is possible that any of these might be sold commercially, only the PAM (McDonnell Douglas), the TOS (Orbital Sciences Corp./Martin Marietta), and the Delta Transfer Stage (Astrotech, McDonnell Douglas) were developed as private initiatives. The I US was developed for the Air Force by Boeing, and the Centaur is being developed under a joint NASA-Air Force contract by General Dynamics. There might be little competition between these upper stages because they are designed to serve different weight classes of satel- 
lites. Their approximate capacities to geostationary orbit are: PAM-D-1,400 pounds, IUS $-5,000$ pounds, TOS $-5,000$ pounds, Delta Transfer Stage-7,500 pounds, Centaur-10,000 to 14,000 pounds. Although the I US and TOS/AMS are in the same weight class, the currently planned TOS should cost substantially less than the IUS. ${ }^{37}$

The only potential foreign participation in the Shuttle upper stage market is the Italian Research Interim Stage (I RIS).SB The IRIS is being developed by the Italian Government and aerospace industries and should be able to launch 1,900 pounds to geostationary transfer orbit or about 900 pounds to geostationary orbit. The limited capacity of the IRIS will prevent it from launching even small Delta-class communication satellites; however, it may be ideal for scientific satellites and small commercial satellites should a market develop for these. The first flight of the IRIS is planned for November 1986.

\section{FOREIGN PRIVATE SECTOR}

In the late 1970s, a private West German firm, OTRAG (Orbital Transport-und-Raketen Aktiengesellschaft), announced its plans to offer private launch services. However, political complications with the West German Government, combined with the company's inability to find a permanent location for its launch pad, have so far prevented OTRAG'S success. OTRAG plans to create a family of vehicles using clusters of identical liquid propulsion units; such units would be added or subtracted to match the payload weight. Their smallest model would be capable of launching a 440-pound payload to an altitude of 31 miles and their largest vehicles would be able to carry a 1,100-pound payload to 174 miles. OTRAG successfully tested a two-unit rocket in 1977 and a four-unit rocket in 1978. Eventually, OTRAG hopes to create a vehicle in the Ariane class; however, its present activities are limited to launching sounding rocket-class vehicles from Sweden's Kiruna launch site. ${ }^{39}$

\footnotetext{
37PAM and TOS upper stages only go to geostationary transfer orbit. Figures given here assume an appropriate apogee motor.

${ }^{38} \mathrm{E}$. Vallerani, F. Veresio, and L. Bussolino, "IRIS-A New Italian Upper Stage System, " 34th Congress of the International Astronautical Federation, Oct. 10-15, 1983.

${ }^{39}$ J.Lenorovitz, "Otrag Prepares for Full Launch Service, " Aviation Week and Space Technology, Sept. 12, 1983, pp. 77-78.
}

Bristol Aerospace, Ltd., of Canada, has also announced plans to offer a low-cost commercial launch vehicle. ${ }^{40}$ Bristol currently manufactures the Black Brant sounding rocket, which has been used for research by several space agencies including NASA and ESA. Bristol plans to develop a solid-propellant vehicle capable of placing 500to 1,700-pound payloads into low-Earth-orbit and payloads of up to 800 pounds into geosynchronous orbit. The company hopes to conduct flight tests in 1988 and to begin commercial launch activities by 1990 .

\section{Buyers of Space Transportation Services}

At present, the three primary purchasers of space transportation services are the military, national and cooperative space programs, and communication satellite service providers. Activities of the military and of the various national and cooperative space programs will account for over 75 percent of the total demand for launch services over the next decade. Although these activities are numerically the largest, they raise few international competitive issues. In the United States, most NASA and Department of Defense (DOD) payloads will fly on the Shuttle. A number of DOD payloads will fly on an ELV designated as a Shuttle backup. The payloads of ESA and the ESA member states will most likely fly on Ariane unless-as in the case of Spacelabthe unique capabilities of the Shuttle are necessary. International commercial competition in space transportation will take place primarily with regard to large communication satellites launched to geostationary orbit.

Outside the Soviet bloc, the buyers of civilian communication satellites can be divided into three submarkets: U.S. communications carriers, global international satellite organizations, and considered together, foreign national and regional satellite systems.

\section{U.S. Communications Firms}

Of these submarkets, that of U.S. communications carriers is by far the largest. U.S. commu-

\footnotetext{
40"Expendable Launch Vehicle," Bristol Aerospace Ltd., 1983.
} 
nications and satellite manufacturing firms such as AT\&T, RCA, Western Union, ITT, Satellite Business Systems, American Satellite, Ford Aerospace, and Hughes now own 21 geosynchronous communication satellites, used primarily for domestic U.S. communications. In limited but growing numbers, they are also used for transborder communications between the United States and North and South America and the Caribbean.

Up to the present, forecasters have been optimistic regarding the continuing need for launch services to put U.S. communications satellites in orbit. One indication supporting this prospect are the $\mathbf{8 1}$ pending and approved applications filed with the Federal Communications Commission (FCC) to construct and launch satellites, and to receive orbital locations. Two studies done for NASA have also concluded that the demand for launch services for communications satellites would remain strong. ${ }^{41}$ One estimated that $\mathbf{6 1}$ U.S. communications satellites would be launched during the 1986-89 period, with 68 more launched before 2000; the other that between 97 and 163 U.S. domestic communications payloads would be launched between 1984 and 1999.

Recent events, however, put these optimistic projections in doubt. First, the expected surge in demand for direct broadcasting satellites has failed to materialize. Second, current substantial excess satellite capacity (see ch. 6) may delay or deter firms from proceeding with announced plans. Third, in the late 1980s and 1990s, communications carriers are expected to have large fiber optic networks in place that will compete with satellite communications in virtually all applications except point-to-multipoint, sparse area, and some mobile communications. While the outcome of this technological competition cannot now be clearly foreseen, fiber optic cables and other terrestrial modes linked to fiber optic local area networks will almost certainly carry some traffic that satellites heretofore had been expected to carry. Optimistic projections of the number of communications satellite launches,

\footnotetext{
${ }^{41}$ Outside Users Payload Mode/, Battelle's Columbus Laboratories, NASA contract NASW-338; June 1983. For a more complete discussion of the demand for communication satellites see ch. 6 .
}

therefore, should be treated with considerable skepticism.

included in the forecasts is launch demand generated by satellite replacement. Because communications satellites typically have design lives of less than 10 years, most of the satellites that are expected to be in orbit or launched before the end of 1985 will therefore cease operation before 1995 and, if replaced, will generate demand for launch services.

The Shuttle, Ariane, Delta, Atlas-Centaur, and Titan launch vehicles could all meet the needs of U.S. communication satellite system operators. The Shuttle, although more sophisticated than its competitors, has no special advantage in launching satellites to geostationary orbit, If all these vehicles are equally reliable, the choice of launcher will be based primarily on: 1 ) the price of the vehicle, 2) the reliability of the launch schedules, 3) the relative simplicity of planning, documenting, and processing their payloads.

\section{INTELSAT and INMARSAT}

The International Telecommunications Satellite Organization (INTELSAT) and the international Maritime Satellite Organization (INMARSAT) maintain global communications systems. INTELSAT, which also provides space segment capacity for many countries that do not have national systems, currently has 15 satellites in orbit, 8 of them large INTELSAT V satellites, which were launched by Atlas-Centaur and Ariane from 1980 through 1984. Current plans are for INTELSAT to launch 13 satellites in the 1985-87 period. If all are launched as planned, six of them will be INTELSAT $V$ satellites, and seven will be INTELSAT VIs. The latter series of satellites are very large and will be able to carry approximately 40,000 separate simultaneous telephone conversations. Still on the drawing board is an INTELSAT VII series.

Whether all the INTELSAT VIs will be launched as planned is in some doubt. INTELSAT transatlantic and transpacific satellites will compete with undersea fiber optic cables, several of which are

\footnotetext{
${ }^{42}$ NASAAdvisoryCouncilStudy of Effective Shuttle Utilization, NAC Task Force for the Study of Effective Shuttle Utilization, Nov. 17, 1983,
} 
planned for the late 1980s and early 1990s. In addition, some competition from private U.S. satellite systems is likely to emerge. Although INMARSAT is purchasing its own system of satellites, it currently leases capacity from INTELSAT and other systems.

Satellites of the INTELSAT 1, 11, and 111 series were launched on the Delta; satellites of the INTELSAT IV and V series were launched on the Atlas-Centaur. To satisfy political pressures that have arisen since the development of Ariane, INTELSAT now intends to distribute its business between U.S. and European vehicles, The Ariane has been used to launch an INTELSAT V, and the Shuttle will be used for the initial INTELSAT VI launch.

As a result of the projected size of the next generation of INTELSAT satellites (I NTELSAT VI will weigh ${ }_{4,800}$ pounds in orbit) the only vehicles that could launch them are the Shuttle, Ariane4 (under development), Atlas (improved version not developed), and Titan.

\section{Foreign Satellite Systems}

This category includes both the satellites of individual foreign countries (private or government owned) and organizations established to provide services to regional groups of countries. In addition to voice communication, such systems provide TV distribution, maritime communication, data transfer, and direct broadcast TV,

At present, Canada, France, Great Britain, Indonesia, Japan, the Middle East countries (Arabsat), and NATO all have operational systems. Other planned but not yet operational systems include: ITALSAT (Italy), MORELES (Mexico), SBTS (Brazil), AUSSAT (Australia), ECS (Eutelsat), LUXSAT (Luxembourg), and STW (China). Current users of the INTELSAT system may convert to national or regional satellite systems if they experience a dramatic increase in traffic volume or it becomes politically or economically desirable to exercise greater control over their communications network (see ch. 6).

Battelle has estimated that between 1983 and 1998 anywhere from 110 to 176 satellites will be launched for foreign national or regional com- munications. ${ }^{43}$ Countries that have the ability to place large payloads into geostationary orbit will presumably use their own launch vehicles, For example, the Europeans will favor the Ariane rocket. Countries such as Japan and China, which have at present only a limited launch capability, will within 10 years probably be able to launch large communication satellites to geostationary orbit.

Countries which do not possess an independent launch capability will, like the U.S. domestic communications suppliers, be concerned with the price, schedule, reliability, and processing simplicity of individual launchers. The availability of favorable financing and/or trade offsets (particularly for developing countries) may also be an important consideration .44

In addition to communication satellites, other space activities such as remote sensing (ch. 7), materials processing (ch. 8), and navigational satellites (app. C) may require commercial launch services. Many activities conducted in low-Earthorbit might be launched not only with the Shuttle, Ariane, Delta, Titan, and Atlas, but also with the new generation of low-cost privately developed launch vehicles and with the vehicles of Japan, China, and perhaps Brazil and India. Current demand for such activities is limited; however, together they constitute a significant uncertainty in future launcher demand estimates.

The Shuttle, because it allows human interaction with and retrieval of payloads, has a decided advantage over other launch systems for manufacturing in space. Unless the Ariane is substantially modified-a subject which has been discussed within ESA - it cannot compete with the Shuttle for MPS and other payloads that require human interaction. Other ELVS are equally disadvantaged in comparison to the Shuttle.

\footnotetext{
${ }^{43}$ Battelle, op. cit., note 41 .

${ }^{44}$ Rainbow Satellite Inc. 's decision to launch two communication satellites on the General Dynamics Atlas-Centaur is a good example of the value of creative financing. In order to insure that Rainbow's launch business did not go to either NASA or Arianespace, General Dynamics agreed to provide $\$ 200$ million in financing for Rainbow and to give "a back-up commitment for all of the capacity" of one of the satellites. See: Space Business News, July 16, 1984, p. 1.
} 


\section{COMPETITION IN SPACE TRANSPORTATION}

The entrance of ESA's Ariane rocket into the international marketplace brought an end to NASA's monopoly in commercial space transportation services. This fact, combined with the development of the Shuttle and the potential entry of other new launch vehicles, has created a situation where, for the first time, supply cou/d significantly exceed demand in the space transportation service market. Prior to these two occurrences, vehicles were manufactured and consumed as they were needed; therefore, the supply of launch services was always roughly equivalent to the demand for that service. Depending on the size of demand for satellites, NASA and the other launch service suppliers may find themselves in a situation where they must compete for a limited number of payloads.

\section{Development of Competition}

Access to space via a capable and reliable launch vehicle is important to the technological and commercial goals of all nations that may wish to orbit satellites. The desire of some nations to develop an indigenous launch capability derives from three considerations: first, a lack of confidence that launch services would be available when needed and without restriction from the United States or the Soviet Union; second, an interest in enhancing national prestige by demonstrating the technical virtuosity required to maintain an independent launch service; and third, an intention to participate in any economic gain to be derived from a wide range of commercial space services. Some newly industrialized countries, may also desire to acquire launch vehicle and precision guidance and control technologies for use in military ballistic missile systems.

Some European countries-particularly Francehave always been reluctant to concede to the United States a monopoly in launch vehicles. Consequently, U.S. hesitation before launching the French-German Symphonic communications satellite in 1971 strengthened European determination to develop an autonomous launch capability. ${ }^{45}$ The decision to build the Ariane launch

\footnotetext{
${ }^{45}$ Civilian space Policy and Applications, op. cit., p. 363.
}

vehicle was a declaration of political and technological independence from the United States.

In Japan, space technology has been identified as an area of future economic significance. A 1981 report by the Ministry of International Trade and Investment (MITI), emphasized the export potential of space technology and concluded that an indigenous space industry is vital because:

As unilateral introduction of technologies from foreign countries is getting more difficult, it is necessary to strengthen Japan's own bargaining power through accumulation of necessary technological know-how. ${ }^{46}$

With a smaller economic and technical base to draw from than either the United States or Europe, and lacking the major military program to ensure political and financial support, the Japanese launcher program has relied on close cooperation with the United States.

Brazil, India, and China are also developing their own launch capabilities-for many of the reasons mentioned above. All three countries possess a strong desire to be technologically independent from the developed world, to gain any economic benefits that derive from the application of space technology, and to be regarded as belonging to the prestigious club of "space powers." Although the launch vehicles being developed in these countries are at present somewhat limited, their political importance will probably assure their continued existence. In some respects, national launch vehicle programs can be compared to national airlines-some are conducted primarily for profit, others play the role of enhancing "prestige" and "national self-image."

To date, competition in launch vehicles has been limited to those developed by governments. The fact that private or semi-private launch services will soon be available introduces a different kind of competition into this market. On May 16, 1983, the president announced that the U.S. Government fully endorsed and would facilitate the commercial operation of expendable launch ve-

\footnotetext{
${ }^{46}$ Report of the Deliberation Council on Basic problems in the Space Industry, MITI, Apr. 20, 1981.
} 
hicles (ELVs) by the private sector. ${ }^{47} \mathrm{He}$ assigned the Department of Transportation the task of assisting commercial ELV operations and recommending necessary regulatory, policy, and treaty changes. Subsequent legislation (Public Law 98575), signed into law on October 30, 1984, confirmed and strengthened the previous Executive Order. Whether such private sector participants can compete with Government-supported launch vehicles and services has yet to be demonstrated.

\section{Assessment of Demand}

Because U.S. space transportation policy will significantly affect the supply of launch vehicles, it is important to give some consideration to the worldwide demand for launch services. NASA hopes that the four-orbiter Shuttle fleet will be able to provide $\mathbf{2 4}$ launches per year by 1988 , and Arianespace hopes to be able to launch 10 Arianes per year by that time. Experts disagree about whether the demand for launch vehicles will exceed the supply. They further disagree about what, if any, public policies to pursue to affect supply and demand. ${ }^{48}$ Estimates of demand must be viewed with caution since they are, at bottom, only "best guesses." Such estimates will be affected by changes in:

- U.S. and foreign government space activities-Building a space station, pursuing planetary exploration, or pursuing additional military activities in space will increase the demand for launch services.

- Space policy-Encouraging or subsidizing commercial activities such as remote sensing or materials processing in space could increase demand.

- Space technology-Satellites with longer lives could reduce the need for new satellite launches; new technologies such as DBS may increase the demand for new launches.

- Terrestrial technologies-Use of fiber optics may reduce the demand for communication satellites; technologies such as genetic engineering might reduce the desirability of conducting biological and materials research in space.

\footnotetext{
${ }^{47}$ White House press release, May 16, 1983.

${ }^{48}$ The question of whether or not NASA should be competing for commercial launches is discussed in the policy options.
}

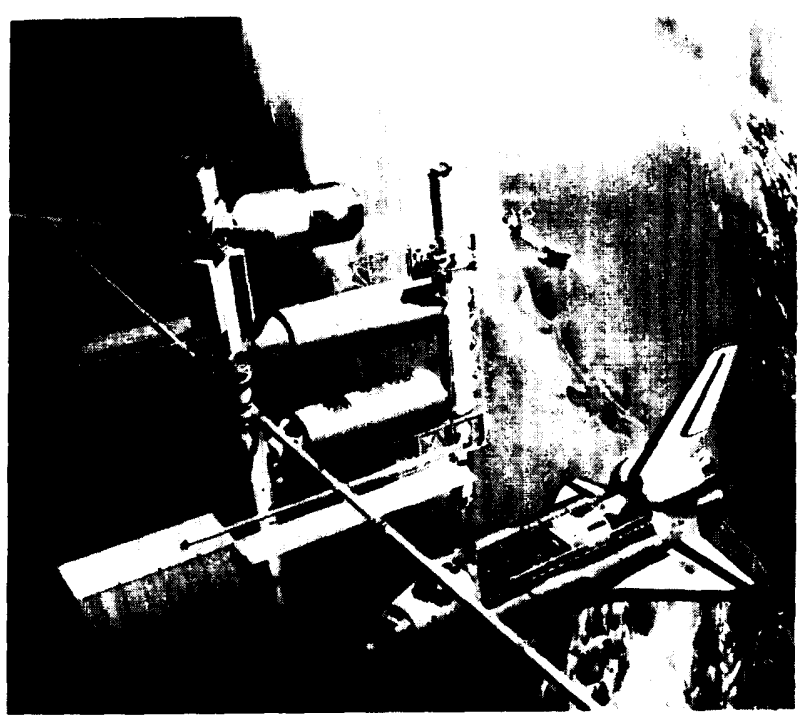

Photo credit: National Aeronautics and Space Administration

Artist's depiction of a Shuttle paying a visit to a Space Operations Center (SOC) in Earth orbit.

The results of the Rockwell International (fig. 5-4) and the Battelle (fig. 5-5) assessments of future launcher demand are presented below to illustrate the connection between the demand for launch vehicles and U.S. space policy .49 OTA has not conducted an independent appraisal of either of these studies; and therefore offers no opinion as to their validity. They are included here to provide a rough quantitative dimension to this discussion. ${ }^{\text {so }}$

-Result 1: If the Shuttle fleet can provide 24 flights per year and the Ariane 10 flights per year, and the Rockwell projection of total demand is correct or low, then by 1988 additional launch capacity will be needed. This could be supplied by U.S. commercial or foreign ELVS or additional orbiters.

${ }^{49}$ See also: Projection of Non-Federal Demand for Space Transportation Services Through 2000: An AlAA Assessment for the Office of Science and Technology Policy of the White House, American Institute of Aeronautics and Astronautics, Jan. 19, 1981; Systems Analysis of National Space Launch Possibilities, The Aerospace Corp., March 1983; "United States Commercial Expendable Launch Vehicles, "General Dynamics, 1982; Assessment of Constraints on Space Shuttle Launch Rates, National Research Council, Committee on NASA Scientific and Technological Program Reviews, April 1983.

50These analyses $a_{e}$ based on the Shuttle reaching 24 flights Per year and Ariane reaching $\mathbf{1 0}$ flights per year, assumptions that remain to be proven by experience. Some analysts doubt that NASA will be able to reach that level of flights before 1990 . 
Figure 5-4.-Projection of Future Space Shuttle Demand Rockwell International

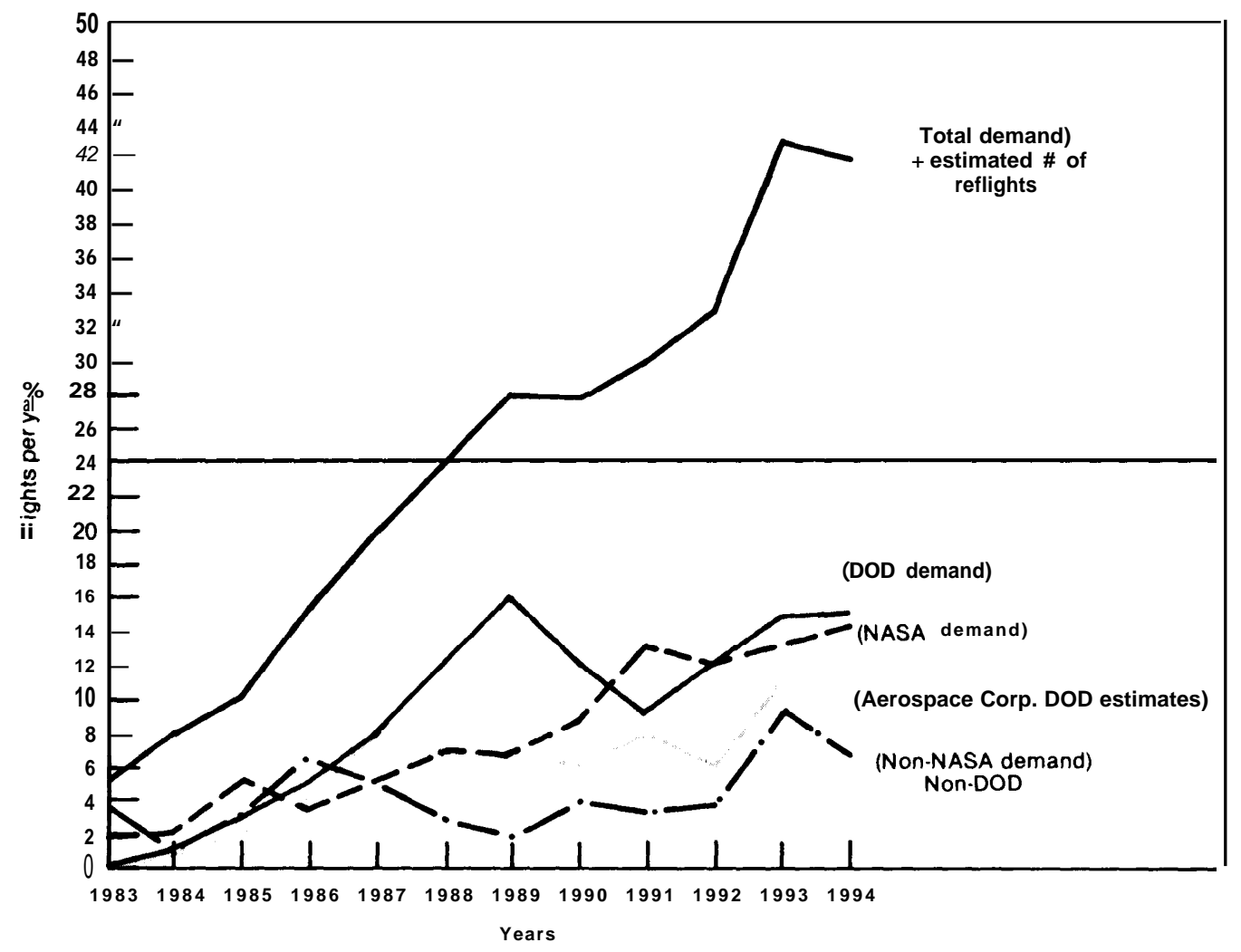

Rockwell International's Projection of Future Space Shuttle Traffic Demand, (July 1963).

Time period: 1963-1994 (shown here 1964-1994).

Scope: All NASA, DOD, commercial and foreign (non-Soviet) space transportation demand.

Key assumptions: Payloads booked on U.S. ELVs would fly on them

- Payloads for Japan and China would fly on their own national vehicles unless specifically

booked elsewhere

-The Ariane will fly full. (5 launch 19S4-5; 10 launches 1986-1994)

- Model includes funded, extensions or follow-ons and potential new missions.

"Equivalent Shuttie Flights:" All payloads characterized in terms of equivalent Shuttle payloads.

- Result 2: Starting with the assumptions listed in Result 1, if the Rockwell projection for DOD demand is overstated (as has been suggested by an Aerospace Corp. study), ${ }^{5 t}$ and/or, some DOD payloads continue to fly on ELVS, then the Shuttle and Ariane could probably meet the total launch demand through 1994.

- Result 3: If the Rockwell and Battelle estimates of non-NASA, non-DOD demand are accurate, but Rockwell's NASA and DOD estimates are both overstated, then the Shuttle and Ariane will create a surplus of launch capacity through 1994. Neither U.S. com-

\footnotetext{
${ }^{5}$ 'Systems Analysis of National Space Launch possibilities, op. cit.
}

mercial nor other foreign ELVS would be necessary to satisfy total launch demand,

If the demand for launch services were unlimited the United States would be well-advised to pursue a policy of encouraging both Shuttle use and the commercialization of ELVS. With the demand for launch services uncertain, the questions become more complex. Should the Shuttle be allowed to compete with private firms for a limited number of commercial launches? If the demand for launch services exceeds the Shuttle's capacity, should additional orbiters be purchased, or should ELVS be used to fill the gap? If the Shuttle fleet is diminished by a catastrophic accident or unforeseen technical problems, how is the de- 
Figure 5-5.-Outside Users Payload Model Battelle's Columbus Laboratories (nominal non.NASA, non.DOD demand)

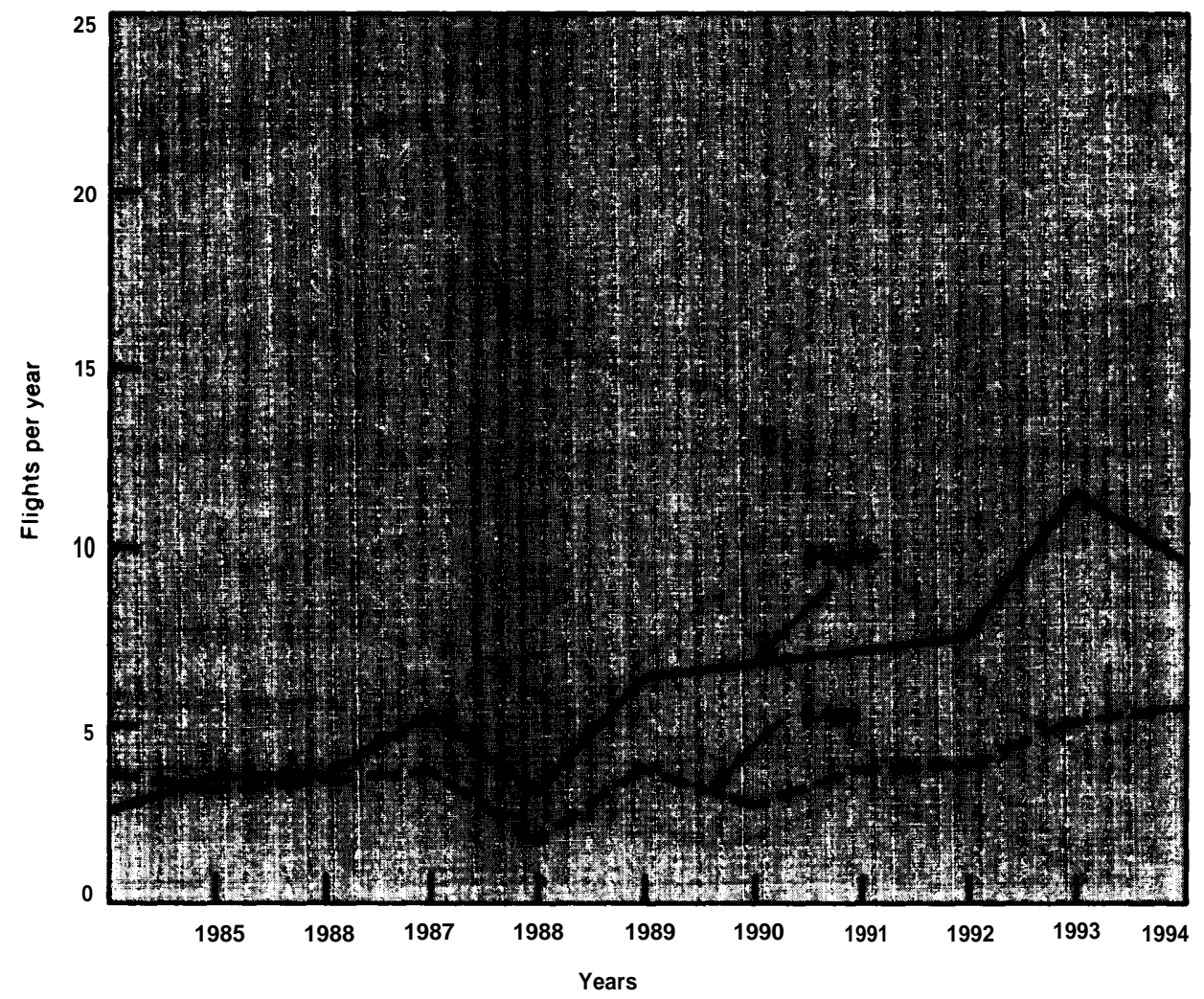

Battelle's Outside Users Payload Model (June 19S3).

Time period: 1983-1988 (shown here 19S4-1904).

Scope: All known non-NASA, non-DOD reimbursable payloads scheduled to be flown by non-soviet-bloc countries.

Key assumptions: $\bullet$ Shuttle and Ariane successful and price competitive

-U.S. commercial ELVs not considered

- Space station not considered

- No revolutionary technical, economic or social developments

"Equivalent Shuttle Flights:" All payloads characterized in terms of equivalent Shuttle payloads.

mand for launch services to be met? In the long run, will private ELVs or the Shuttle prove to be the more cost-effective way to meet the additional demand? Unless additional orbiters or ELVs are ordered, will the production lines for either remain open? Given the U.S. Government's commitment to the space station and other space goals, is cost effectiveness an important shortterm consideration?

The primary focus of this study is international competition and cooperation; therefore, many of these questions are beyond the scope of this report. Those that pertain directly to international competition are discussed in greater detail in the policy options that follow.

\section{Nature of Competition}

Although there are a number of potential entrants, current competition in space transportation is predominantly between the U.S. Government-supported Shuttle and the European government-supported Ariane.$^{52}$ The Shuttle and Ariane are competing primarily for the launch of large geosynchronous communication satellites. A recent study conducted for NASA estimated that from 1983 to 1998 there will be between 103 and 163 non-NASA, non-DOD payloads for which NASA and Arianespace are in direct competiCompetition ${ }_{n}$ between U.S. upper stage manufacturers is to a great extent dependent on, and subsidiary to, the Shuttle successfully competing with other launch vehicles. 
tion. ${ }^{53}$ (See figs. 5-6 and 5-7.) Of this number, the study estimated that between 29 and 72 payloads would go to Arianespace. ${ }^{54}$ That is a loss of between one and two dedicated Shuttle flights per year over a period of 15 years.

The primary advantages of the Shuttle are that it is manned, reusable, and able to retrieve and deploy large objects in low-Earth-orbit. Normally, none of these advantages is important when communication satellites are launched to geosynchronous orbit. * Its primary disadvantages are that schedules have slipped about 1s percent each year, raising questions of reliability and planning, and that documentation and integration are more complex and expensive than those of Ariane.

\footnotetext{
${ }^{53}$ Outside Users payload Model, op. cit.

${ }^{54}$ In 1984, Ariane and the Shuttle each took about half of the commercial space transportation market.

${ }^{*}$ However, when certain types of malfunctions occur, in either the satellite or its upper stage, astronauts or payload specialists may be able to repair the malfunction or retrieve a satellite that has gone into an anomalous orbit. An example was the recent retrieval of the Westar and Palapa spacecraft after their PAM-D stages failed. See "Astronauts Deploy, Retrieve Satellites, "Aviation Week and Space Technology, Nov. 26, 1984, pp. 20-23.
}

These particular disadvantages are quite important to commercial launch customers. As a result, the Ariane launch vehicle, which is less sophisticated than the Shuttle, is capable of competing with the Shuttle for payloads. (In addition, Ariane competes well with the Shuttle on the basis of price.) For the same reasons, private U.S. ELVs, which are technically comparable to Ariane, can also compete with the Shuttle.

The technical comparability of the Shuttle and Ariane with respect to launching communication satellites has focused competition primarily on launch price and financing. ${ }^{55}$

Current pricing policies have occasioned complaints of unfair competition on both sides of the Atlantic and generated considerable unrest among private U.S. ELV manufacturers. In a state-

\footnotetext{
${ }^{55}$ ShouldaU.S. commitment to a space Stati On or an increase in military space activities reduce the number of commercial Shuttle flights, or should a catastrophic failure reduce or ground the Shuttle fleet, availability would become a more important factor than price or financing.
}

Figure 5-6.-Low Model Market Share by Launch Vehicle

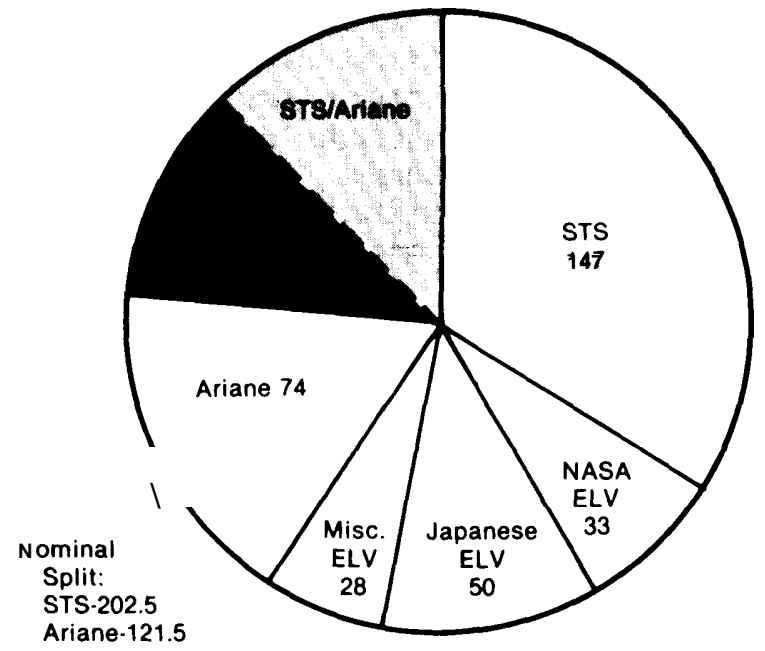

435 payloads

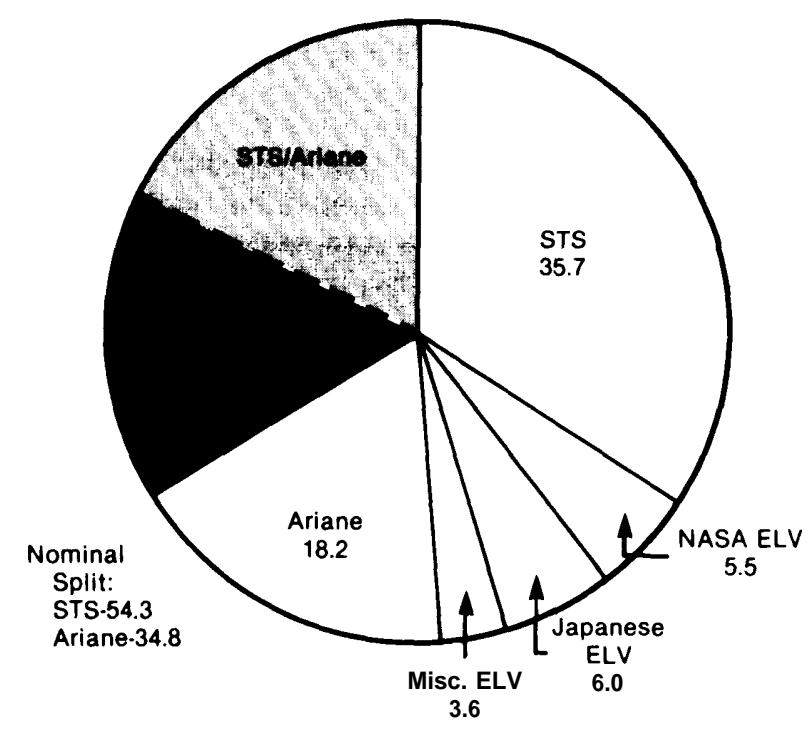

104 equivalent Shuttle flights

Assumes $75 \%$ average Shuttle load factor

SOURCE: Outside Users Payload Model Battelle Columbus Laboratories (NASA contract NASW.338), June 1963. 
Figure 5“7.-High Model Market Share by Launch Vehicle

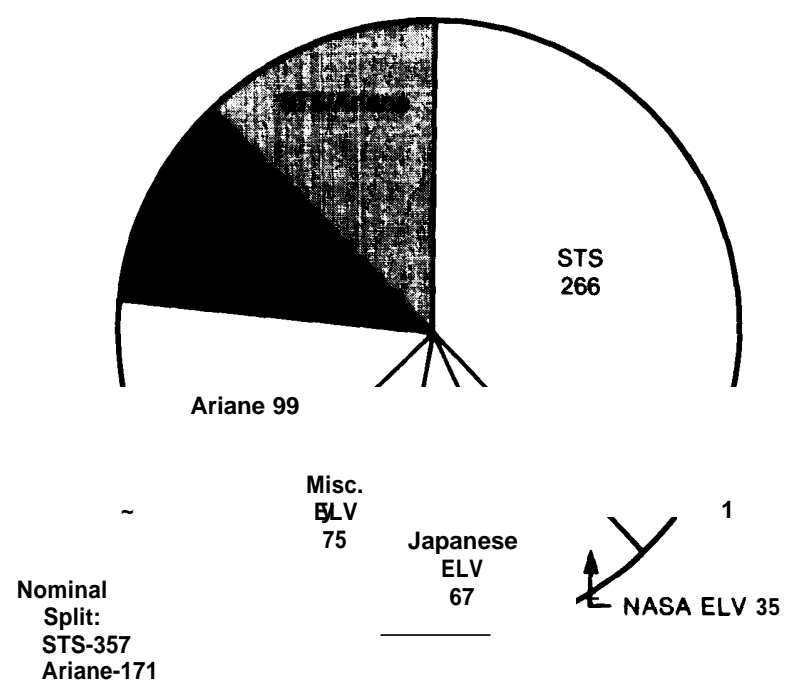

705 payloads

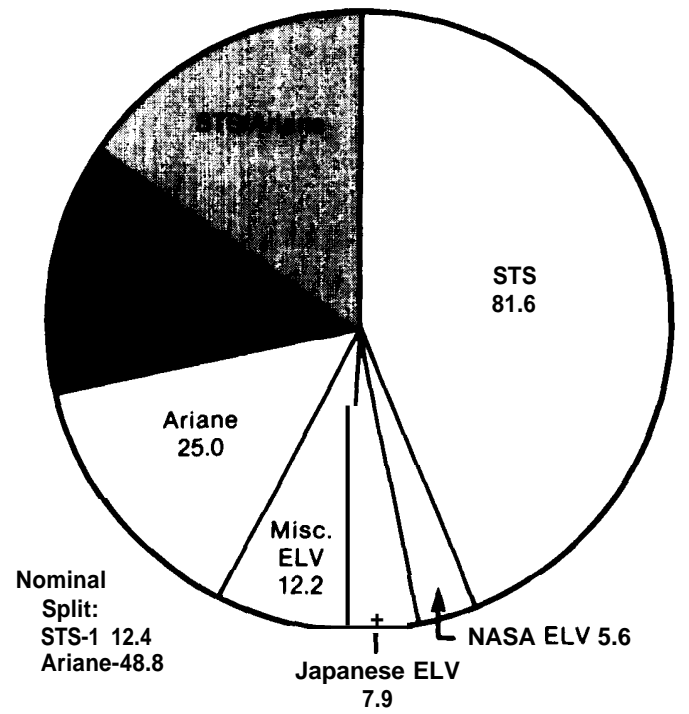

187 equivalent Shuttle flights

Assumes $75 ? 40$ average Shuttle load factor

SOURCE: Outside Users Payload Model Battelle Columbus Laboratories (NASA contract NASW-338), June 19S3.

ment before the Senate Commerce Committee, NASA Administrator James Beggs cautioned: ${ }^{56}$

The French are pricing their service very, very competitively. As a matter of fact, they have set the price very close to Shuttle-type pricing. They are, without any question, subsidizing that, because their costs are not down. With respect to the cost per launch and the financial terms ... they are more than competitive with us

.. (T)hey are formidable competition, and we are not taking them lightly.

The Europeans take exception to suggestions that the Ariane is unfairly being subsidized. Frederic D'Allest, President of Arianespace, testified before a Senate subcommittee: $:^{57}$

There is no transfer of money between Arianespace and ESA and the other European organizations other than the payments due to Arianespace within the framework of the launch services contracts ...

56NASA Authorization for Fiscal Year 1983: Hearings before the Subcommittee on Science, Technology, and Space of the Senate Committee on Commerce, Science, and Transportation, 97th Cong., 2d sess., February 1982, Statement of Hon. James A. Beggs, p. 41. s'lbid., p. 170, statement of Frederic D'Allest.
When establishing Arianespace, we succeeded in convincing ESA and its member States that the STS (Space Transportation System) pricing policy during the first 3 years of its operations involved a huge subsidy, thus creating an unfair competition. In response, it was agreed that for the European payloads launched before mid-1 986, the standard price negotiated with ESA... would include a 25-percent extra charge to support the company.

We consider, and hope you will consider, that these practices are not very sound, as they charge the research and development programs on both sides of the Atlantic, instead of charging the users who reportedly look to gain great financial profit from their commercial applications.

As long as the STS production and operation costs do not reflect realistically the STS pricing policy, we shall claim some support through the European payloads launch prices, to ESA and its member States.

The principal complaint of the Europeans has been that the Shuttle price-unlike the price charged for U.S. expendable vehicles, which was based on the recovery of "all reasonable costs' '-bears little relationship to the cost of 
operating the Shuttle. The price currently charged by NASA for a Shuttle launch was developed in 1975 and was designed, in part, "to effect early transition from expendable launch vehicles. At the time, NASA felt that Shuttle costs would fall as they gained more experience with the system and the flight rate increased. It was assumed that there would be a tendency among users to delay Shuttle use in order to take advantage of the lower prices in later years. ${ }^{59}$

In order to overcome this tendency, NASA based the Shuttle price on the estimated 12-year average cost of the program. As a result, cost of launching a Delta-class payload to geosynchronous orbit on the Shuttle was about one-half of what it would have cost to use an expendable Delta. ${ }^{60}$ The initial price for a dedicated Shuttle bay was $\$ 18$ million in 1975 dollars or about $\$ 40$ million in 1984 dollars. ${ }^{61}$ Although exact, per flight, Shuttle costs (recurring costs per flight, refurbishment, support facilities, and personnel) are difficult to calculate, it has been estimated that each of the five Shuttle flights in 1983 cost \$375 million ${ }_{0}^{\text {b2 }}$

In 1981-82, when NASA began to reassess its pricing policy, several U.S. customers had already switched from the Shuttle to Ariane. NASA felt that a pricing policy based on current Shuttle costs would lead to "an unacceptable commercial and foreign users price. ${ }^{63} \mathrm{NASA}$ does plan to raise the price for a dedicated Shuttle launch in 1985 to $\$ 38$ million 1975 dollars (about $\$ 80$ million in 1984 dollars). President Reagan's policy statement of May 16, 1983, declared that after 1988 NASA should charge a "full cost recovery" price $^{64}$. If prices continue to fall as experiencxe is

gained with Shuttle operations, the 1988 price could still be as high as $\$ 100$ million to $\$ 150$ million in 1984 dollars.

\footnotetext{
${ }^{58}$ C. M. Lee and B. Stone, "STS Pricing Policy," AIAA Space Systems Conference, Oct. 18-20, 1982, Washington, DC, p. 1.

s9lbid., p. 2.

$60 l$ bid.

6) Based $o_{n}$ an escalation rate of 2.192 from 1975 to 1984. Note that this is the price for a "dedicated payload bay"; a Delta-class satellite would only take up about 25 percent of the bay, and therefore the price to launch this payload would be about 25 percent of the "dedicated payload bay" price.

${ }_{62}$ James Abrahamson, testimony before the Subcommittee on

Space Science and Technology, February/March 1984, p. 584.

${ }^{63}$ Lee and Stone, Op. Cit.

${ }^{64}$ White House Press Release, May 16,1983.
}

As described above in Frederic D'Allest's statement, the ESA nations also felt that the early success of Ariane could not be assured if the price were based entirely on launch costs. An Organization for Economic Cooperation and Development (OECD) study has estimated that the Ariane is priced at about two-thirds of its cost. ${ }^{\text {bs }}$ The commercial Ariane price is approximately $\$ 54$ million, or $\$ 25$ million to $\$ 30$ million per customer for dual launch. This is purportedly a temporary promotional price to be followed by a "more normal cost coverage basis. "ESA States pay a 25 percent additional charge to support the Ariane program.

Price competition between Shuttle and Ariane has made it difficult for private sector ELVS to enter the market. In an attempt to alter the current situation, Transpace Carriers, Inc., seller of the commercial Delta launch vehicle, filed a complaint with the Office of the U.S. Trade Representative charging that Aria nespace was engaged in predatory pricing. The complaint, filed under Section 301 of the U.S. Trade Act of 1974, stated that Arianespace charged prices to U.S. firms that were 25 to 33 percent lower than those charged to ESA members, and that as a result of this practice $\mathrm{TCl}$ had lost sales to Arianespace. ${ }^{\mathrm{bb}}$

In its petition, $\mathrm{TCl}$ asked that the President seek the immediate discontinuance of the two-tiered pricing policy; the elimination of the cost-free or below-cost support in facilities, services, and personnel; and the subsidization of mission insurance rates. Pending the cessation of these practices, the complaint requested the President to retaliate by prohibiting Arianespace from advertising and marketing its services in the United States and by imposing economic sanctions against the goods and services of the Member States of ESA.

\footnotetext{
${ }^{65}$ OECD, Trade in High-Technology Products, The Space Products Industry, Paris, 1985.

"See"U.S.Space Launch Services Company Brings Unprecedented Complaint Against Europeans," U.S. Import Week/y, vol. 9, June 6, 1984, p. 1088. The complaint stated:

As a beneficiary of such subsidy practices Arianespace has been able to offer launch services to U.S. companies and third country customers at rates which are substantially less than those charged to Member States of ESA and substantially below those prices that Arianespace would be able to charge in the absence of subsidization. This unfair competitive advantage has resulted in lost sales to petitioner and price suppression, if not depression, of bid prices. Furthermore, it poses a serious threat to the establishment of a United States commercial launch services industry.
} 
Responding to the TCl complaint, Erik Quistgaard, ESA Director General, announced that his agency was willing to talk to the U.S. Government in an attempt to "create conditions for healthy competition " in launch services. ${ }^{67}$

To summarize, the price for an Ariane launch has been set so as to compete effectively with the Shuttle. The ESA nations, in order to assist in this goal, pay more for a flight than would the purchaser of a commercial launch.

The Shuttle price rests heavily on the following reasoning. First, in the absence of commercial payloads the Shuttle would fly anyway. As a consequence, NASA charges customers only for the amount that their payload adds to the cost of flying all Government payloads for a given period and not for a portion of the total cost of an individual flight. Second, the cost of flying the Shuttle will decrease substantially as experience is gained. By spreading the average cost over a number of years and projecting a rapid decline in Shuttle launch prices, the near-term average cost can be kept low. As a result of current NASA/ ESA price competition, launch service purchasers (largely satellite communication service providers) are benefiting - at least in the early years of Shuttle operations-from substantial government subsidies for each launch.

Given the commitment of the United States and the European nations to the success of their respective vehicles, these pricing structures are defensible; they do, however, raise substantial

67"ESA Replies to Charges on Arianespace Pricing," Aviation Week and Space Technology, July 2, 1984, pp. 22-23. barriers to the commercial success of any private ELVS. Assuming a 65,000-pound capacity and an $\$ 80$ million (1984 dollars) price per launch, the Shuttle can place a Delta-class payload into low-Earth-orbit for about $\$ 1,200$ per pound. However, because the full payload capacity is rarely used and in order to reach geosynchronous orbit communication satellites require the additional weight of upper stages and cradle structures, the Shuttle cost of placing a payload into orbit is about $\$ 10,000$ to $\$ 20,000$ per pound depending on the upper stage (see table 5-2). This is compared to the approximate per pound cost of a Delta $(\$ 24,000)$, an Atlas-Centaur $(\$ 25,000)$, or the Ariane $3(\$ 20,000)$.

At current prices, the Shuttle is less expensive than any of the ELV alternatives; however, this advantage will be lost as Shuttle prices increase. At $\$ 125$ million per dedicated launch, the Shuttle is competitive though not preferable to the ELVS; at \$150 million per launch the Shuttle ceases to be financially attractive for payloads not requiring human interaction. ${ }^{68}$

NASA has expressed concern that it cannot effectively compete with the Ariane because of the favorable financing that Arianespace has been

\footnotetext{
${ }^{68}$ Prices givenhere are approximations, supplied to illustrate the Shuttle's competitive position vis-a-visELVs. Such estimates do not reflect the dynamic nature of the launch vehicle industry. NASA maintains that Shuttle prices will fall substantially as experience is gained. It is also possible that less expensive upper stages or orbital transfer vehicles will be developed, thereby reducing the cost to geostationary orbit. Both General Dynamics (Atlas-Centaur) and Transpace Carriers Inc. (Delta) have stated that commercial competition and private sector efficiencies will reduce the cost of ELV launches.
}

Table 5-2.-Transportation Costs to Geosynchronous Orbit (approximate)

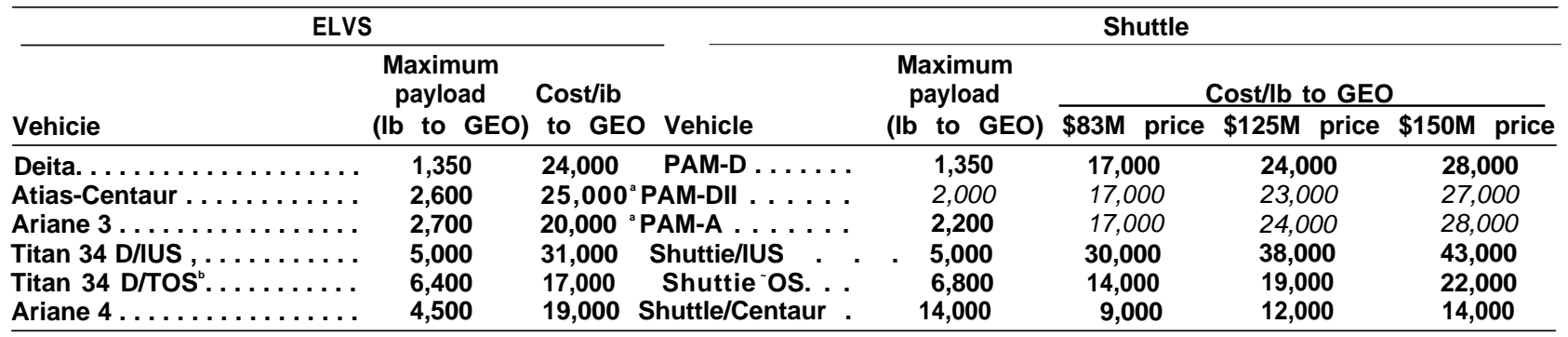

eoTa figures.

\%ransfer Orbit Stage.

SOURCE: M. C. Simon and O. Steinbroun, "The Economics of Space Development," General Dynamics, Convair Division, October 1983, p. 3. 
able to offer its customers. The Ariane payment schedule requires that a company pay 20 percent of the cost $\mathbf{3 0}$ months prior to launch; the balance is spread over 5 years at low interest rates while the satellites are in orbit earning revenue (table 5-3 and fig. 5-8). Typically, Arianespace will finance 80 percent of the cost, of which 80 percent of the debt will be at a subsidized rate. ${ }^{69}$ The remaining ${ }_{20}$ percent of the 80 percent financing would be at market rates.

Although NASA cannot provide financing and requires that the entire cost be paid prior to launch, it can, with the help of the U.S. ExportImport Bank (Ex-Im), offer financing similar to that of Arianespace in foreign, non-EEC (European Economic Community) countries. ${ }^{70}$ Recently, the Ex-Im Bank agreed to guarantee 85 percent of costs to be incurred by Mexico for a Shuttle launch; this allowed the Private Export Funding Corp. (PEFCO) to provide the funding for this

\footnotetext{
${ }^{69} \mathrm{In}$ One example, 64 percent of the subsidized debt was at 9.5 percent (from Compagnie Francaise d'Assurance Pour Le Commerce Exterieur) and the remaining 16 percent was at 10.5 percent; this resulted in a blended subsidized rate of 9.75 percent. See NASA Advisory Council Study of Effective Shuttle Utilization, Nov. 17, 1983, p. 30.

7olbid., p. 30 .
}

Table 5-3.-NASA vs. Arianespace Financing (1982 \$M) (FY 1982-85 pricing)

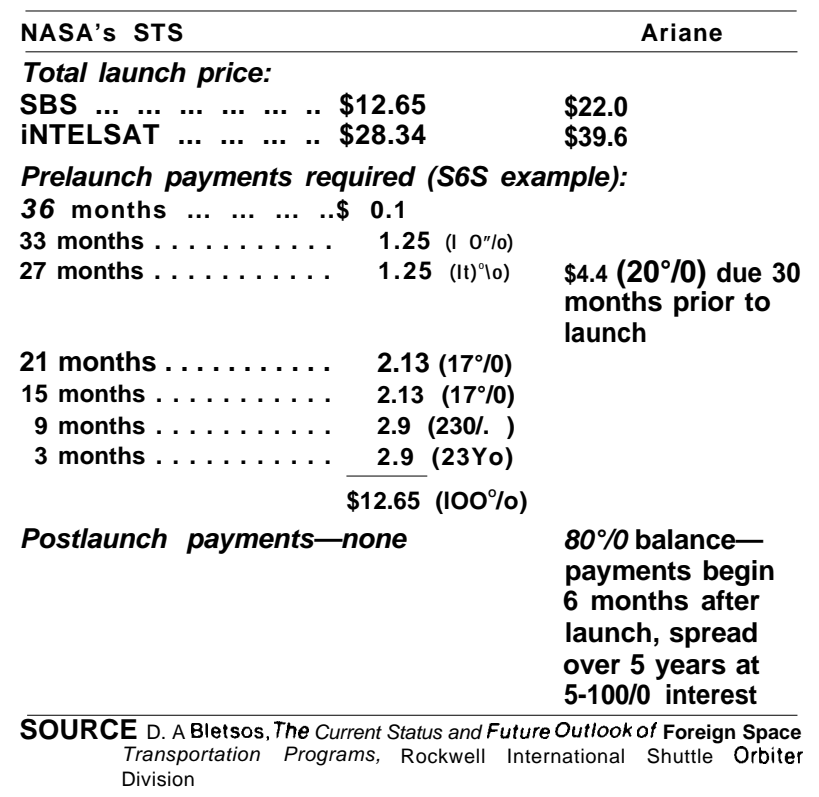

Figure 5-8.-Arianespace Financing

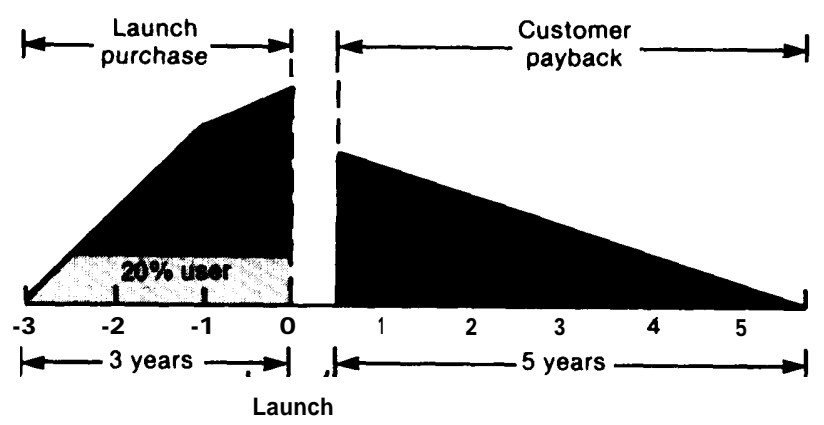

. Arianespace gets paid up front

- Financing by FrenchlGerman banks

- Rates negotiable (typically 9-10\%)

. Payback out of revenues - starts 6 months after launch

transaction. ${ }^{71}$ Similar NASA/Ex-Im packages have been proposed for Australian and Colombian payloads. A recent report by the NASA Advisory Council stated: $:^{72}$

In virtually all cases the difference between Shuttle and Arianespace rates and terms were not significant. Except for the loss of a Brazilian launch due to a development loan and offsets, NASA has not lost any launch business due to more competitive financing.Based on recent discussions with senior officers of the Ex-Im Bank, there is every indication that the Ex-Im will be responsive to export financing for non-EEC countries, particularly when there is competitive European export financing involved (emphasis added).

When dealing with EEC countries, neither NASA nor Arianespace can employ subsidized financing. EEC export agencies will not provide subsidized financing to other EEC members, and, in the absence of such subsidized financing, the ExIm bank will not become involved. In any case, since European nations will almost certainly choose to support the Ariane program, there will probably be no significant number of Shuttle sales to EEC countries. ${ }^{73}$

${ }_{71}$ PEFCO is owned by 52 U.S. banks and manufacturers. Its function is to provide funding against Ex-Im-guaranteed paper. Its rates are essentially the prevailing market rate for U.S. Government-guaranteed obligations plus a commitment fee and arrangement fee. 72 lbid.

${ }^{73}$ Special Circumstances ma make possible a limited number of sales of Shuttle services to EEC members. For example, British Skynet military satellite will fly on the Shuttle in 1986. 
Arianespace has its strongest potential advantage in U.S. domestic markets. Here, it can provide 80 percent financing at a subsidized rate (currently 12.4 percent), and the Ex-Im Bank will not step in because the customers are U.S. nationals. In examining this issue, the NAC report acknowledged that it was a potential problem, but noted that:

... Arianespace financing up to this point did not present a big enough discount off the advertised Arianespace price to affect significantly and adversely NASA's marketing of the shuttle.

However, this could become a serious competitive disadvantage in the future if prices equalized. ' 4

In summation, current international launch vehicle competition has been between government-supported vehicles and has focused almost exclusively on price. To date, sales have been sought to ensure maximum use of the Ariane and the Shuttle and there has been little opportunity for profit taking. ${ }^{75}$ In this environment, the successful entry of commercial, nongovernmentsupported launch vehicles seems unlikely.

\section{Effects of Competition}

Foreign launch vehicles can reduce the demand for U.S. Government and private sector launch vehicles in two important ways: 1) by flying their own and regional payloads, and 2) by marketing their services internationally. Reductions in demand caused by the former will be difficult, if not impossible, to offset by altering present U.S. practices or policies. Other governments willing to expend the human and economic resources to develop their own launch capabilities can, of course, work toward satisfying all of their indigenous launch needs and may capture some portion of the overall world demand for space transportation services. However, the resulting losses to the United States are likely to be small, because the vast majority of nations will continue to be launch service consumers rather than producers.

\footnotetext{
${ }^{74}$ Ibid.

${ }^{75}$ Arianespace claims that in $\mathbf{1 9 8 5}$ it made a profit on its commercial launch activities. See Space Commerce Bulletin, vol. II, No. 1, Jan. 18, 1985, p. 3.
}

There is substantial difference of opinion regarding the effect that the marketing of foreign launch systems may have on U.S. space transportation services. Under these circumstances, perhaps the most useful approach is to lay out possible effects that international competition in space transportation may have, with a view to setting boundary conditions for an appropriate policy response. Possible effects are:

Reduced demand for the Shuttle: A substantial reduction in demand would occur only if an international provider were to offer equivalent services to users at significantly lower prices. Now it is already the case that the prices charged to users do not recover the Shuttle's operating and maintenance (O\&M) costs, and Rockwell International, the manufacturer of the Shuttle, has argued that, with only four orbiters and a low annual flight rate, these costs probably cannot be significantly reduced (fig. 5-9). ${ }^{76}$ With Shuttle prices set to rise over the next few years in order to more closely approximate average operating costs, there is every likelihood that international providers may capture an increasing share of the market for users whose spacecraft do not require hum.. intervention in orbit. However, this result, in itself, is not a simple economic negative, for the prices charged for an all-commercial flight do not recoup the costs of making the flight.

With these new facts in view, the Office of Management and Budget (OMB) has stated that the Shuttle's primary goal is to meet U.S. Government needs, not those of foreign governments or the private sector. Therefore, the price charged to non-U.S. Government users should reflect the true "additive costs" of flying them on the Shuttle and should serve to "minimize the overall cost to the Federal Government of meeting its own needs."' In a letter to NASA

\footnotetext{
${ }^{76}$ 'Economic $\mathrm{Co}_{\text {mpar }}$ i $\mathrm{s}_{\text {on: }}$ Shuttle-only Fleet vs. Shuttle/Commercial ELV Mixed Fleet, " Rockwell International Space Transportation \& Systems Group, May 17, 1983.

77 Letter from David A. Stockman, Director, OMB, to James M. Beggs, NASA Administrator, June 14, 1982; See also C. Covault, "Shuttle Fund Policy Stirs Concern at NASA," Aviation Week and Space Technology, Oct. 18, 1982.
} 
Figure 5-9.-Rockwell International Estimates That the Shuttle is Most Economical Over ELVS at High-Volume Operations

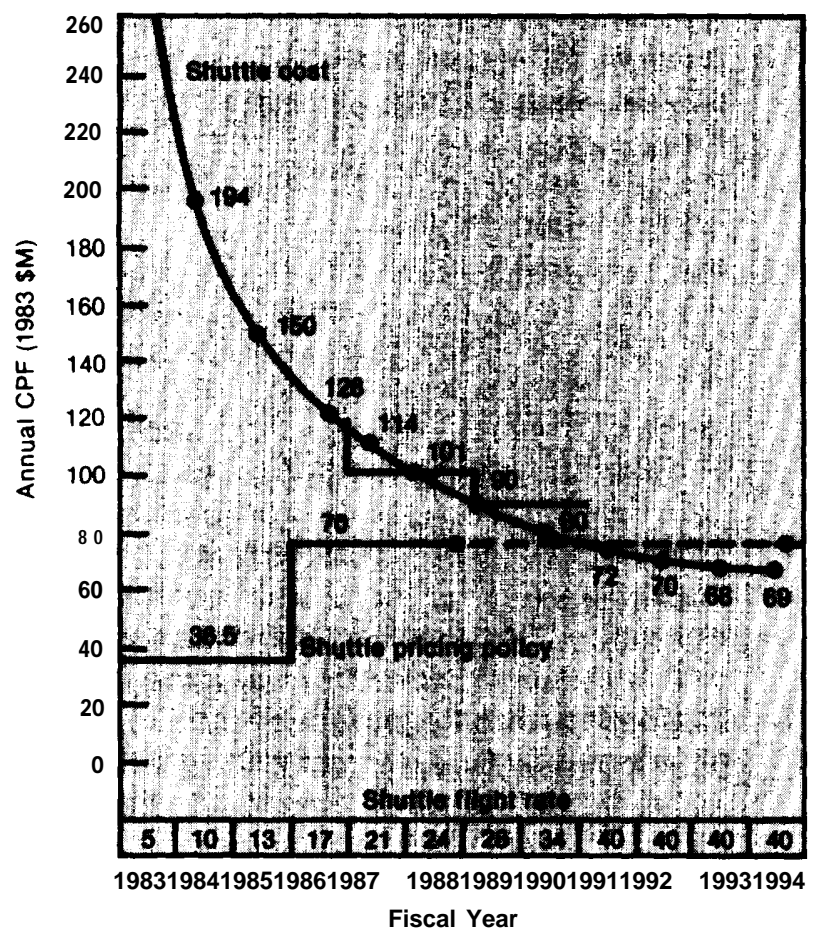

(Shuttle cost data from NASA independent assessment, April 1982)

SOURCE: "Economic Comparison: Shuttle-Only Fleet vs Shuttle/Commercial ELV Mixed Fleet," Rockwell International Space Transportation and Systems Group, May 17, 1983.

Administrator James M. Beggs, OMB Director David Stockman stated :78

... (T)he appropriate price for excess Shuttle launch capacity after 1985 would appear to be one that:

- Is the highest price at which sufficient users will be available to utilize the excess capacity of the Shuttle system after USG [U.S. Government] user needs are met.

- At least covers the additive costs of the USG to operate the Shuttle system for nonU.S. Government users.

- Does not in itself lead to the demand for funding of additional capacity by the USG (e.g., additional orbiters, ground support systems).

According to OMB'S view, a reduction in non-U.S. Government demand for Shuttle services resulting from foreign competition would require no policy change. Indeed, the Stockman letter implies that if Shuttle launch costs were to rise as a result of a reduction in demand, then the price charged to nonU.S. Government users should also be increased.

On the other hand, it should be pointed out that such a price increase might lead to a further reduction in demand, thus setting up a vicious cycle. In economic terms, this result might make sense, but there is a political price to be paid, namely that the commercial market may come to see the Shuttle as vehicle of last resort, rather than vehicle of choice. [n that case, the Shuttle might be perceived as increasingly irrelevant to the commercial development of space.

- Loss of revenue: A 1982 NASA report stated that: "The present projection of capital lost to Ariane is estimated to be approximately $\$ 3$ billion total through 1984, if every compatible U.S. customer used Ariane." ${ }^{.79}$ There is considerable question as to the significance of this finding. It should be noted that this is a potential loss of income, not a real loss to NASA, since none of the "out-ofpocket" costs associated with each additional commercial flight would be incurred. Therefore, the actual "loss" to NASA would be limited to the amount of "revenue" which would have been derived from each Shuttle launch and the potential costs of a lessthan-optimal use of the Shuttle fleet. Since the cost of an additional Shuttle flight still exceeds the revenue produced by that flight, the marginal value of additional flights is debatable. In addition, there is no reason to believe that Ariane will capture "every compatible customer." Current Shuttle manifests do not reflect an exodus to Ariane; it will probably be the early 1990s before Arianespace can handle more than 10 flights per year. Therefore loss of revenue does not seem to be a major problem requiring immediate policy attention. 
- Loss of technological leadership: A recent $\mathrm{Na}$ tional Academy of Public Administration report warned that the loss of U.S. leadership in space technology "would be felt acutely on the economic front. ${ }^{80}$ The report compared space to the electronics and communications fields where the United States once held a dominant position and cautioned that foreign competitors have "increased their public expenditures for space programs in recognition of the benefits of such endeavors to the strengthening of their national economies." Broadly taken, this is sound advice. However, with specific reference to space transportation it loses some of its urgency. The Shuttle is, and will be for some time, the most sophisticated and capable space vehicle flying. Ariane, Shuttle's main competitor, challenges the Shuttle in only one important area-the placement of satellites into geostationary orbit.

- Loss of prestige: The perception that the United States is first among space powers is an important advantage, albeit difficult to define. The United States has had enormous influence on the international application of space technology. This is particularly true with regard to satellite communications and remote sensing, where the United States not only developed most of the technology but also played a major role in establishing the institutions by which it was shared.

Some diminution of the world's regard for U.S. technological prowess is certain to occur as alternatives to U.S. launch vehicles begin to appear. However, the United States may offset such changes by taking a leadership role in defining the organizational structure of the future space transportation industry. Major questions regarding the roles that governments and the private sector will play in this industry, the need for international regulation, and the usefulness of competition have yet to be answered. Space transportation is an infant industry; the United States, as its most important actor, still exerts considerable influence. It is appropriate that the United States exercise its leadership to ensure that this industry matures in a man-

\footnotetext{
${ }^{80}$ Encouraging Business Ventures in Space Technologies, National Academy of Public Administration, May 1983, p. 6.
}

ner consistent with long-term U.S. trade objectives.

- Hindrance of private sector entry: The current Shuttle pricing policy, not foreign competition, is the most important barrier to U.S. private sector entry. Though the private firms-using current ELVs-should be able to compete on technical grounds with Government-backed launch services, they are not now financially competitive. Although the price for a Shuttle launch will be raised by NASA in 1985 and probably again in 1988, private operators may not be able to keep current ELV production lines open. Should the Air Force decide to purchase private launch vehicles to complement the Shuttle, the chosen company would be in a good position for successful "commercial" operation. Firms such as Starstruck and SS1, which do not compete for the same class of payloads as Ariane and the Shuttle, may not be affected by Government pricing policies. ${ }^{81}$

- Secondary effects (e.g., loss of satellite sales, etc.): Although foreign competition may not cause serious disruption of the Shuttle program, it may have indirect effects on other U.S. industries. A 1982 NASA policy report cautioned: $:^{22}$

The loss of launch operations to foreign competition can have important secondary effects. Foreign candidates for launch services are candidates for U.S. development of their satellite and of any related ground stations. When the direct effects are totaled, the estimate of the direct losses to the U.S. econo$\mathrm{my}$ is very close to $\$ 4$ billion over (a 12-year period).

Although it is possible that Arianespace, or some other foreign organization, might eventually offer an attractive "package deal" including both satellite and launch vehicle, current buying practices do not indicate a cause for concern. Recent examples of satellite double-booking on both the Shuttle and Ariane and the successful entry of Japan into the ground station market indicate that price and product quality remain the primary concern of the buyer.

\footnotetext{
81 It should be noted, however, that Ariane and Shuttle can both carry small payloads along with larger ones. Their prices for such services could be substantially lower than the private operators could afford to charge.

${ }^{82}$ Analysis of Policy Issues, op. cit.
} 


\section{COOPERATION IN SPACE TRANSPORTATION}

In the heyday of the Apollo program, President Nixon in 1968 impaneled a Space Task Group to develop future goals for the U.S. space program, One of the recommendations of the Space Task Group (STG) was that the United States: ${ }^{.3}$

(U)se (its) space capability not only to extend the benefits of space to the rest of the world, but also to increase direct participation by the world community in both manned and unmanned exploration and use of space.

More specifically, the STG advocated a national commitment to what would eventually become the Space Shuttle. ${ }^{84}$ As conceived by the STG, the Shuttle program would be an international cooperative effort with possible European design and construction of major subsystems. In 1970 and 1971, NASA discussed the possibility of a European contribution to a variety of cooperative ventures including the space transportation system. While Shuttle design options were proliferating and tradeoffs were being made internally among NASA, OMB, and Congress, NASA tried to include the Europeans in the program. However, in view of the difficulty of resolving emerging conflicts within U.S. agencies, simultaneous negotiations with a multinational European group seemed out of the question.

To prevent the total exclusion of the Europeans from Shuttle activities, NASA suggested that they might develop the "space tug." This potential role was the subject of extensive discussions lasting almost 2 years. As the final design approach to the Shuttle became fixed in the spring and summer of 1972, the role of DOD in supporting Shuttle development became more important. When the Space Task Group had identified the Shuttle as the next major technological develop-

\footnotetext{
83," The Post-Apollo Space Program: Directions for the Future, " Space Task Group Report to the President, September 1969, p. 10. ${ }^{84}$ The "space shuttle" endorsed by the STG was a concept rather than a specific design. It was merely one part of a set of space activities which included a space station, an integrated transportation system and a vigorous program of advanced technology development. The integrated transportation system included the basic shuttle, an orbital transfer vehicle, and a reusable nuclear stage for larger, manned systems and for follow-on lunar or planetary missions. All of these systems were to satisfy three basic characteristics- "cornmonality, reusability, and economy. "
}

ment in space, DOD had not been an enthusiastic supporter. It was only with the aid of policy guidance from the President (i. e., that the Shuttle was a "national" system that would serve both DOD and civilian payloads) that DOD requirements were brought into the design process. Although NASA had primary responsibility for Shuttle development, the President decided that for political and economic reasons visible DOD interest and contribution to the Shuttle would be desirable.

DOD involvement in Shuttle design resulted in a further reduction of the European role. Some DOD missions would require the addition of an upper stage to place payloads into their desired orbits. The European space tug was originally intended to serve this function. But, because of the sensitive nature of certain of these payloads, DOD decided to take responsibility for the upper stage development. As a result, the United States discouraged European development of a tug and urged them to redirect their efforts toward what was to become the Spacelab.

Thus, in 2 years, the United States went from its initial encouragement of substantial international cooperation in space transportation system development to a position in which only payloads were being discussed. This change in position left segments of the European space community suspicious of U.S. intentions and disturbed by its peremptory behavior.

Against this background, future cooperative activities in space transportation must overcome major economic and political hurdles. First, the military security sensitivities which prevented the Europeans from building the space tug still exist and would presumably inhibit other types of cooperation. Second, both Europe and Japan foresee possible constraints on their full development of competitive commercial spacecraft and services (e.g., communication and remotesensing satellites) if they do not also have control of an independent launch capability for such spacecraft. Both Europe and Japan have active aerospace industries increasingly capable of competing in the world markets. Finally, the Europeans are particularly sensitive to the prospect 
that any cooperative launching enterprise with the United States would depend on budget support that cannot be guaranteed.

The ability to reduce costs significantly is one reason why nations might wish to cooperate on the development and/or operation of launch vehicles. It is expensive to develop and maintain an efficient, low-failure-rate launching service to geostationary orbit. Subsidized and inefficient launch vehicles may keep aerospace employment high and help to support production costs, but are a drain on the economy.

Despite the pull of potential cost savings, the future of cooperative space transportation research will be further limited if the private sector can successfully offer launch services. international cooperation would most certainly involve government activities that would provide competition to private firms. It is unlikely that the United States will find reason to engage in international development programs in space transportation.
The U.S./Japanese agreements of 1969, 1975, and 1980 provide a different example of international cooperation. ${ }^{85}$ Under these agreements the United States allowed U.S. firms to provide the Japanese Government-or firms working under contract to the Japanese Government-with launch vehicle equipment and technology. Although the individual agreements differ slightly, taken as a whole, Japan agreed: 1) to use the technology for peaceful purposes, 2) not to transfer the technology to third countries, 3) to use the technology exclusively for the launch of satellites for the Japanese National Space Development Agency, and 4) not to launch projects for third countries. As a result of these agreements, U.S. firms have played and will continue to play an important role in Japanese launch vehicle technology (see table 5-4). This type of cooperation might be used successfully as other nations begin to develop indigenous launch vehicles.

\footnotetext{
${ }^{85}$ See generally, "Space Cooperation: Agreement Between the United States of America and Japan," July 31, 1969, T. I.A.S. 6735.
}

\section{CURRENT POLICIES}

As a corollary to the development of the Shuttle, NASA had planned to phase down and eventually terminate ELV programs; this plan was endorsed in the President's July 4, 1982, policy statement. ${ }^{86}$ As a result of early Shuttle successes, NASA declined to order new Delta or Atlas-Centaur vehicles after 1982. Early in 1983, the Department of Defense also announced that it was stopping production of the Titan vehicle.*'

When it appeared that NASA and DOD would no longer fund ELV procurement, several private firms expressed interest in providing this service on a commercial basis. They encouraged the

\footnotetext{
${ }^{86}$ White House Fact Sheet: National SpacePolicy, July4,1982.

${ }^{87}$ The DOD decision to launch all payloads on the Shuttle is being reconsidered. The Air Force recently asked Congress to approve procurement of 10 upgraded Titan or Atlas-Centaur vehicles to be launched two each year for 5 years. Although claiming strongly to support the Shuttle, the Air Force has stated that ELVs are necessary to provide "assured access to space." See: Aviation Week and Space Technology: Mar. 5, 1984, p. 19; Apr. 16, 1984, p. 17; Apr. 30, 1984, p. 25; Aerospace Daily, Mar. 23, 1984, p. 129; Defense Daily, Feb. 28, 1984, p. 317.
}

White House to develop a policy in support of their efforts. On May 16, 1983, the Reagan Administration announced that "the U.S. Government fully endorses and will facilitate commercial operations of Expendable Launch Vehicles (ELVS) by the U.S. private sector." One of the basic goals of the President's ELV policy was to "ensure a flexible and robust U.S. launch posture to maintain space transportation leadership." Although not cited as one of its major goals, the President's statement did observe that: "Each commercial launch conducted in the United States, rather than by foreign competitors, would strengthen our economy and improve our international balance of payments. "

The ELV policy further emphasized that the Shuttle is the "primary launch vehicle for the U.S. Government" and that it would also continue to be available for domestic and foreign commercial users. NASA has interpreted this to mean that the Government will not only take care of its own needs, but also participate actively as a compet- 
Table 5-4.-Companies That Contribute to Manufacturing Japanese Launch Vehicies (U.S. corporations are given in parentheses)

\begin{tabular}{|c|c|c|c|}
\hline \multirow[b]{2}{*}{ Covered work } & \multicolumn{3}{|c|}{ Vehicle } \\
\hline & $\overline{\mathrm{N}-1}$ & $\mathrm{~N}-11$ & $\mathrm{H}-1$ \\
\hline \multicolumn{2}{|c|}{ Vehicle integration $\ldots \ldots \ldots \ldots \ldots \ldots \ldots \ldots$ MHI (M DC) } & MHI (MDC) & MHI \\
\hline \multicolumn{2}{|c|}{ First stage: } & & \\
\hline Airframe..$\ldots \ldots \ldots \ldots \ldots \ldots \ldots \ldots$ & MHI (MDC) & $\mathrm{MHI}(\mathrm{MDC})$ & MHI (MDC) \\
\hline Main engine.$\ldots \ldots \ldots \ldots \ldots \ldots \ldots \ldots \ldots \ldots$ & MH1/IHI (RIC) & MH1/IHI(RIC) & MHUIHI(RIC) \\
\hline Vernier engine $, \ldots, \ldots \ldots \ldots \ldots \ldots \ldots$ & IHI (RIC) & IHI (RIC) & IHI (RIC) \\
\hline Strap-on booster . . . . . . . . . . . . . . & NM (TC) & NM (TC) & NM (TC) \\
\hline \multicolumn{4}{|c|}{ Second stage: } \\
\hline Airframe,... & MHI (MDC) & MHI (MDC) & $\mathrm{MHI}$ \\
\hline Engine ...... & MHI (RIC) & IHI (ATC) & MHI, IHI \\
\hline Reaction control system . . . . . . . . . & IHI (TRW) & IHI (ATC) & IHI (TRW) \\
\hline \multicolumn{4}{|l|}{ Third stage: } \\
\hline Airframe .... & MHI(MDC) & MHI(MDC) & $\mathbf{M} \mathbf{H} \backslash \mathbf{N} \mathbf{M}$ \\
\hline Motor $\ldots \ldots \ldots \ldots \ldots \ldots \ldots \ldots$ & NM(TC) & $\mathrm{NM}(\mathrm{TC})$ & NM \\
\hline Satellite fairing . . . . . . & . MHI(MDC) & MHI(MDC) & MHI(MDC) \\
\hline \multicolumn{4}{|l|}{ Onboard equipment: } \\
\hline Guidance and control equipment . . . . . . & $\begin{array}{l}\text { NEC(HONEYWELL JAE,MHI } \\
\text { (MDC) }\end{array}$ & MHI(MDC) & JAE, NEC, MH MPC, MSS \\
\hline \multicolumn{2}{|c|}{$\begin{array}{l}\text { First/third-stage telemeter } \ldots \ldots \ldots \ldots \ldots \ldots \text { MELCO } \\
\text { Command destruct receiver } \ldots \ldots \ldots \ldots \ldots \text { NEC(MMAE) } \\
\text { Second-stage telemeter and }\end{array}$} & $\begin{array}{l}\text { MELCO } \\
\text { NEC(MMAE) }\end{array}$ & $\begin{array}{l}\text { MELCO } \\
\text { NEC(MMAE) }\end{array}$ \\
\hline \multicolumn{2}{|c|}{ pulse transponder.............. NEC(MMAE) } & NEC(MMAE) & NEC \\
\hline $\begin{array}{l}\text { Abbreviations: } \\
\text { ATC:Aeroject Techsystems Co. } \\
\text { HONEYWEL: Honeywell Inc. } \\
\text { IMI:Ishikawajima-Harima Heavy Industries Co. Ltd. } \\
\text { JAE: Japan Aviation Electronics Industries Co. Ltd. } \\
\text { MDC: McDonnell Douglas Corp. } \\
\text { MELCO: Mitsubishi Electric Corp. } \\
\text { MHI: Mitsubishi Heavy Industries, Ltd. } \\
\text { MMAE:Motorola Military and Aerospace Electronics Inc. }\end{array}$ & $\begin{array}{l}\text { MPC: Mitsubishi Precision Co. Ltd. } \\
\text { MSS: Mitsubishi Space Software Co. Ltd } \\
\text { NEC: NEC Corp. } \\
\text { NM: Nissan Motor Co. Ltd. } \\
\text { RIC: Rockwell International Corp. } \\
\text { TRW: TRW Inc. } \\
\text { TC: Thiokol Corp. }\end{array}$ & & \\
\hline
\end{tabular}
SOURCE: National Space Development Agency.

itor in the overall launch market. The President's policy encourages "free market competition among the various systems and concepts within the U.S. private sector," yet the policy fails to recognize that the Government-owned Shuttle is one of the main competitors for private sector ELV activities. Therefore, "free market competition" between private ELV suppliers may be meaningless if ELVs are noncompetitive vis-a-vis the Shuttle.

Notwithstanding its support for ELVS, the policy stated that the price for Shuttle flights "will be maintained in accordance with the currently established NASA pricing policies" through 1988. After this time, " . . . it is the U.S. Government's intent to establish a full cost recovery policy for commercial and foreign STS flight operations." If the price of a Shuttle launch were increased before 1988 to reflect actual costs, including depreciation, current ELVs might have a better chance of competing for a share of the commercial market. Such a price increase might be dam- aging to Shuttle-related commercial activities such as privately developed upper stages and various MPS-related activities.

his unclear what effect such an increase would have on the demand for Ariane launches. It is possible that an increase in Shuttle prices would drive some customers to U.S. ELVs or to Ariane,

If, as has been suggested by some analysts, the Ariane price was chosen to be competitive with the Shuttle, an increase in Shuttle price might result in a like increase in the price of an Ariane. In any case, since "full cost recovery" will not be the Shuttle pricing policy until 1988, it is uncertain whether the Titan, Atlas-Centaur, and Delta launch vehicles will be able to sustain launch activity to see them through to this time. Therefore, commercial U.S. ELVS may not be an important participant in the global competition for launch services. 


\section{FUTURE POLICY OPTIONS}

The United States does not lack the "means" by which to engage in successful private or government-supported international competition in space transportation; what it lacks is a national consensus concerning the "ends" of such competition. The development of foreign space transportation systems has caused considerable-and often unwarranted-concern in the United States. It is true that foreign competition will reduce the demand for Shuttle launches and for private ELVs; whether this requires an immediate policy response depends entirely on the constraints that the Government imposes on NASA and the incentives it offers the private sector. The following discussion analyzes several different policy options that have been proposed for the U.S. space transportation system.

\section{Option 1: \\ Use the Shuttle primarily for launching Government payloads}

Should the U.S. Government compete in the intemational launch service market? The United States could adopt the policy that the primary role of the Shuttle is to launch U.S. Government payloads. Such a position might rest on the ideological conviction that, except in rare instances, the Government should not undertake activities that compete with the private sector. Alternatively, since commercial payloads launched on the Shuttle involve some degree of Government subsidy, such a policy might flow from a desire to reduce the cost to the taxpayer of operating the space program. OMB has indicated its support for such a policy : ${ }^{88}$

Generally speaking, when circumstances justify the funding and management of an operational system by the U.S. Government that is also sought by nongovernment entities, the U.S. Government should limit its role to making available system capacities which exceed its own needs.

Under the OMB approach, NASA would not regard itself as being in competition with foreign or domestic launch services. To the extent that

\footnotetext{
${ }^{8 B S t o c k m a n}$ Letter, Op. cit.
}

excess capacity existed, it would be sold "so as to minimize the overall cost to the federal government of meeting its own needs in the long run." The existence of foreign and private U.S. vehicles would be important only insofar as they affected the price at which this excess capacity could be sold. OMB suggested that an appropriate price would be "the highest price at which sufficient users will be available to utilize the excess capacity." Limited competition from foreign and private U.S. suppliers would allow NASA to charge a high price for launch services; aggressive competition would limit the price that NASA could charge and still sell all of its excess capacity.

Under a policy of noncompetition, an increase in Government launch activities could significantly reduce commercial Shuttle operations. For example, the decision to build a space station or to increase military activities in space might limit the space available on the Shuttle for commercial launches. OMB suggested that the Shuttle price should not "in itself lead to the demand for funding of additional capacity by the U.S. Government." This would indicate that, with a very limited capacity, NASA would discourage commercial Shuttle use by charging higher prices. The $\mathrm{OMB}$ position does not consider the possibility that an increased Shuttle flight rate might increase efficiency and reduce costs for all users.

To summarize, a policy that restricted the Shuttle primarily to Government payloads would likely have the following results:

- eliminate NASA as a major supplier of commercial launch services;

- reduce the likelihood that additional orbiters will be needed in this decade;

- increase the likelihood that the U.S. private sector could make an early and successful entry into the launch service market;

- potentially reduce the cost of operating the overall Shuttle program by requiring fewer flights; and

- increase the demand for, and potential commercial success of, the Ariane launch vehicle. 


\section{Option 2:}

Capture a high percentage of commercial launches with the Shuttle

This would appear to be the current U.S. policy. Two reasons are often stated for a strong U.S. competitive posture: to maintain its leadership role in the development and application of space technology, and to ensure foreign technical and financial support for future U.S. space activities. In addition, being regarded as first among the Free World space powers carries important international political and psychological advantages.

A recent NASA Advisory Council report on the Shuttle found that: ${ }^{89}$

The overwhelming positive appeal of the Shuttle lies in current NASA pricing policy, designed to make the Shuttle competitive to currently available expendable boosters. Commercial success of STS hinges on continuation of this margin.

In accordance with the Council's report, a policy decision has been made to pursue international launch opportunities aggressively. This decision entails a commitment to continue the current practice of subsidizing the Shuttle's commercial payloads, as well as a requirement that greater attention be paid to Shuttle marketing. The NASA Advisory Council report stated:

There was general agreement in the Task Force that an intensive high level marketing effort on behalf of Shuttle utilization is warranted. In this context, marketing means to develop and implement a broad scale and long range plan to involve increasing numbers of users in the exploration of the STS capabilities. It thus involves market analysis, planning, advertising, customer service, financing, and insurance, to name a few areas. It must be a high level, strongly led effort, with the active participation of NASA top management to the Administrator level.

The NASA Advisory Council report identified "the emergence of increased competition" as one of the primary reasons for pursuing a bold marketing strategy.

\footnotetext{
89"Study of Effective Shuttle Utilization, " report of the NASA Advisory Council Task Force, Nov. 17, 1983.
}

To summarize, current policy encouraging the Shuttle to capture a high percentage of commercial launches, will likely have the following results:

- increase the demand for Shuttle services;

- create a need for additional orbiters in this decade;

- potentially increase the cost of operating the overall Shuttle program; ${ }^{90}$

- decrease the likelihood that the U.S. private sector could make an early and successful entry into the launch services market; and

- reduce the demand for, and the potential for commercial success of, the Ariane launch vehicle.

\section{Option 3:}

Encourage private launch activities

When the National Aeronautics and Space Act was written in 1958, it was assumed that the Government would be the prime launch authority. The NAS Act stated: ${ }^{91}$

The Congress further declares that such (aeronautical and space) activities shall be the responsibility of, and shall be directed by, a civilian agency (NASA) exercising control over aeronautical and space activities sponsored by the United States."

The NAS Act refers to the private sector as potential NASA contractors but does not mention their independent participation in space activities. ${ }^{92}$ It may be assumed from the historic U.S. dependence on a private sector economy that expectations of private launch services were implicit in U.S. space policy, subject only to satisfying the applicable health and safety regulations. More recently, statements of national space policy by both the Carter and Reagan Administrations have highlighted the importance of private sector space activities. For example, President Reagan's Statement on Space Policy of July 4, 1982, declared:

\footnotetext{
gosome analysts believe that an increase in Shuttle flights will, through a combination of learning curve efficiencies and economies of scale, actually reduce the cost of operating the Shuttle.

${ }_{1}$ NationalAeronautics and Space Act of 1958, sec. 102 (b), 42 U.S.C. 2451.

${ }^{9}$ Ibid., sec. 203(5).
} 
The U.S. Government will provide a climate conducive to expand private sector investment and involvement in space activities ...

Can the U.S. private sector, encouraged by the U.S. Government, be competitive with foreign, government-supported launch systems? This is a point on which there is significant disagreement both in the U.S. Congress and in the private sector. In the U.S. air transportation industry, however, private U.S. firms have successfully competed with foreign government-owned, often subsidized, firms. Private U.S. firms, using current ELV technology, could probably compete successfully against foreign launch vehicles such as the Ariane.

It is uncertain whether U.S. firms will be able to compete against both foreign ELVs and the U.S. Government's Shuttle. A decision to support private launch activities aggressively would most certainly require either limiting the number of commercial payloads carried on the Shuttle or raising the Shuttle launch price. On this subject, the NASA Advisory Council report stated: ${ }^{93}$

The potential for the successful privatization of ELVs was considered fairly low by the Task Force. It seems probable that following divestiture by NASA of an ELV to an entrepreneurial company, that company would exert every effort to cause the Shuttle pricing to be revised upward in order to make the ELV more competitive. This would run counter to the Shuttle pricing policy and its objectives.

It is possible to argue by analogy to the postal service that the Government and the private sector might coexist as launch service providers. The majority of the mail in the United States, by law, can be handled only by the U.S. Postal Service; however, private firms are allowed to provide numerous specialty services. If NASA continues to pursue commercial payloads aggressively, it is conceivable that some private sector firms might be able to market expendable launch vehicles to customers who needed unique services such as rapid launches or payload delivery to non-Shuttle orbits. It is doubtful, however, that the near-term demand for such "specialty services" will be sufficient to sustain even a single private firm.

\footnotetext{
93" Study of Effective Shuttle Utilization," op. cit.
}

At present, the United States is attempting to pursue policies that simultaneously seek to encourage the entry of the private sector into the launch services market and to maximize the use of the Shuttle for commercial launches. If the demand for launch services were to increase dramatically, it might be possible to maintain both positions; since this is unlikely in this decade, the United States must choose which of these two courses it intends to follow.

To summarize, a policy that encouraged the participation of the Private sector with expendable launch vehicles would likely have the following results:

- encourage the formation of an internationally competitive U.S. space transportation industry;

- reduce NASA's role in space transportation and the demand for Shuttle launches;

- reduce the likelihood that additional orbiters will be needed in this decade;

- potentially reduce the cost of operating the Shuttle program; and

- increase the demand for, and the potential commercial success of, the Ariane launch vehicle.

Option 4:

Use the Shuttle to meet all current and future U.S. space objectives

The Shuttle is not "just another launch vehicle." It is a unique tool for conducting manned activities in space that until now were not possible. It is also a technology in which this Nation has invested over \$15 billion. The NASA Advisory Council recently expressed their concern that the U.S. commitment to the Shuttle might be wavering: ${ }^{94}$

We sensed a great pressure within the government to find some way to make the STS "pay its way" ... We are concerned that preoccupation with this thrust may distort our national priorities in space. In our view the Shuttle is a great national asset in its own right, and is essential to pursuit of civil and military objectives in space.

\footnotetext{
${ }^{94}$ lbid.
} 
It is possible to conceive of a space transportation policy built around the expansion of space activities through the Shuttle, Having recently made the decision to encourage Shuttle-related commercial activities, to build a space station, and to use the Shuttle for military space activities, this Nation has already made a substantial commitment to Shuttle operations. It is reasonable to argue, as NASA has often done, that commercial space operation should be coordinated so as to contribute to overall national space goals, including in this case the success of the Shuttle program. If current Shuttle-use policies were combined with a more vigorous attempt to enlist commercial communication satellites (perhaps at the expense of developing a reusable orbital transfer vehicle for payload delivery to geostationary orbit) and an increased level of effort (and of expenditure) for scientific and new commercial payloads such as materials processing, Shuttle utilization might remain the most important single element in future space policy decisions.

Under such a policy NASA would not be limited to flying Government payloads, since it would be desirable to direct the energies of the private sector into Shuttle-related activities. However, capturing a large number of communication satellite launches with the Shuttle would not be the only purpose of such a policy; it would also require a commitment to NASA programs and research activities that would create new sources of demand for Shuttle services. Such a policy would rest on the belief that, if the benefits of "space industrialization" are to be realized, the Shuttle, is indispensable.

Competing with foreign launch vehicles would not be the primary reason for such a policy. Capturing a large number of commercial payloads might be useful if it created pressure to "Shuttleoptimize" satellites and other cargo. Conceivably, a strong movement in this direction could, as NASA had hoped in the past, render ELVs obsolete.
A policy that sought to maximize Shuttle use would have to overcome a number of important domestic and international barriers. Domestically, there is considerable support for a policy to encourage a private ELV industry. There are some compelling arguments in support of this position. There is also substantial national interest in reducing the Federal deficit and, therefore, Government expenditure; this includes expenditures for the space program. Though NASA argues that revenue from commerical flights will eventually reduce the cost of operating the Shuttle, critics charge that, for the foreseeable future, such activities only add to the cost of the space program.

Even though the Shuttle is technologically superior to the Ariane and other potential foreign competitors, as long as these competitors can launch payloads at a price that bears a reasonable relationship to the cost, they will continue to do so. For this reason, it is unlikely that foreign equipment manufacturers will "Shuttle-optimize" future satellites and other space cargo; likewise, U.S. equipment manufacturers are unlikely to build "Shuttle-only" equipment as long as the space transportation market includes both the Shuttle and ELVS.

To summarize, a policy that encouraged the maximum use of the Shuttle for all types of missions would likely have the following results:

- increase the likelihood that the Shuttle will play a major role in the successful exploitation of outer space;

- create a need for additional orbiters in this decade;

- decrease the likelihood that the U.S. private sector could make a successful entry into the launch service market;

- greatly increase the cost of operating the Shuttle program (as well as other NASA programs); and

- reduce the demand for, and the potential commercial success of, the Ariane launch vehicle. 


\section{Chapter 6 SATELLITE COMMUNICATIONS}

\section{Contents}

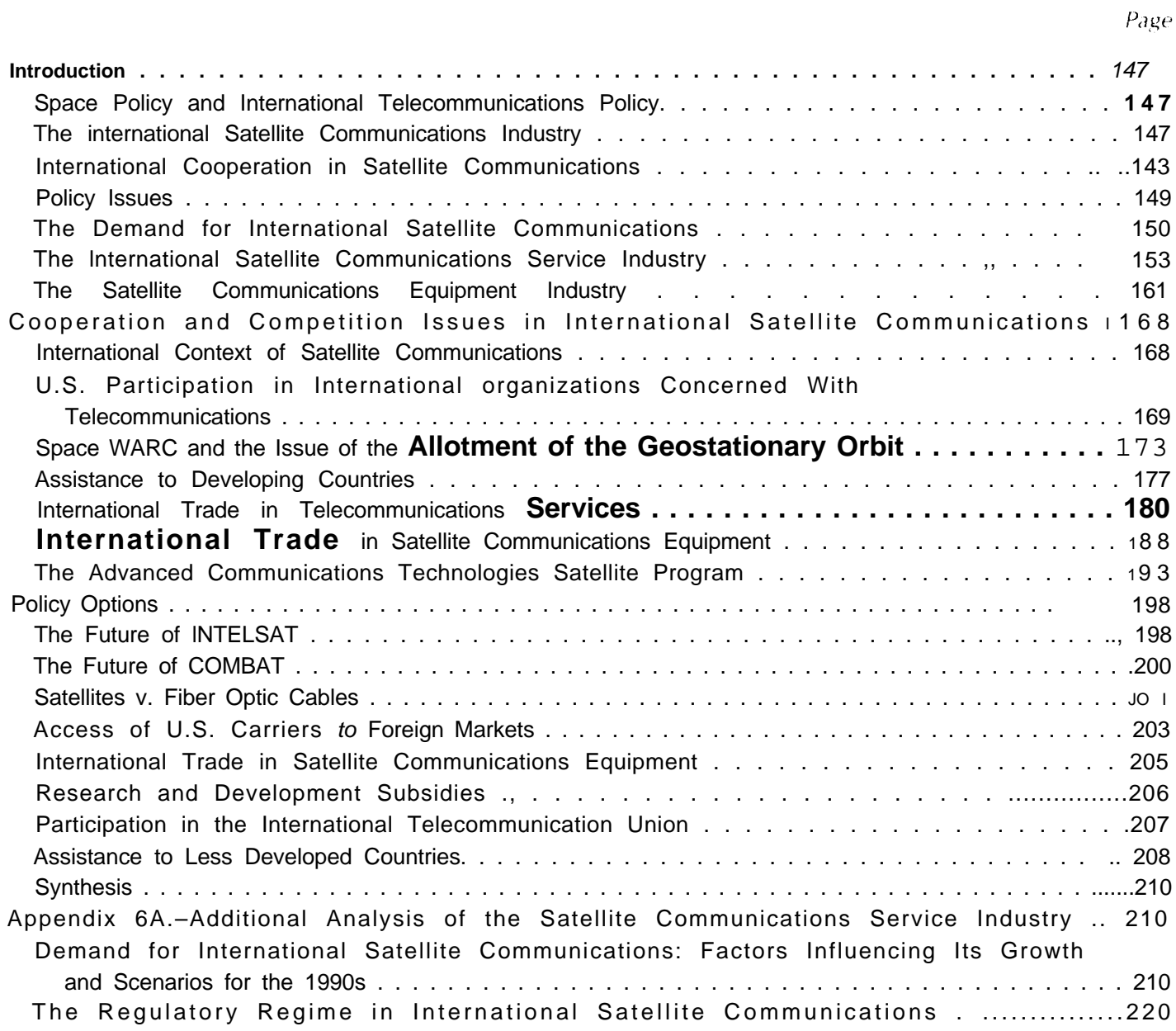


Appendix 6B: The Communications Satellite Equipment Market. . ..................226

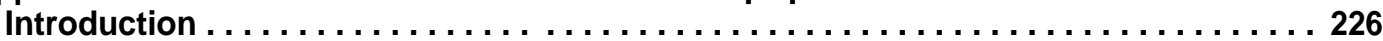

Satellite Markets . . . . . . . . . . . . . . . . . . . . . . . . ...................226

Satellite Suppliers . . . . . . . . . . . . . . . . . . . . . . . . . . ...............237

International Competitive Factors in the Wodd Satellite Market . ................,238

Earth Station Equipment Suppliers . . . . . . . . . . . . . . . . . . .......238

Appendix 6C: INTELSAT and INMARSAT Members: Signatories and

Investment Shares . . . . . . . . . . . . . . . . . . . . . . ....................244

Appendix 6D:Article XIV and Other Excerpts From the INTELSAT Agreement

Relating to Space Segment "Facilitie separate From INTELSAT"

List of Tables

Table No.

6-1. U.S. International Telephone and Telegraph Service Revenues, 1972-85 Page

6-2 U.S. International Common Carrier Telecommunications Traffic by

World Region, $1982 \ldots \ldots \ldots \ldots \ldots \ldots \ldots \ldots \ldots \ldots \ldots \ldots . . .151$

6-3, Scenarios for Satellite Communications Demand in the 1990s ... ... .........153

6-4, U.S. Telecommunications Firms Providing International Satellite

Communications Services . . . . . . . . . . . . . . . . . . . . . . . . . .......156

6-5. Members of INTELSAT: The Major Non-U.S. Telecommunications Providersof

International Satellite Communications Services. . . . . . . . . . . . . . . ....159

6-6. U.S. Market Share of Commercial Satellite Prime Contracts . ..................162

6-7. Prime Contractors for Commercial Communications Satellites . ..............164

6-8. Earth Station Market Shares, By Country of Supplier For the Period 1965-82....165

6-9. U.S. international Telephone and Telegraph Equipment Trade, 1978-85........189

6A-1. U.S.-Europe Telecommunications Forecast 1985-95 ......................211

6A-2. Representative Transatlantic Facilities Plans for U.S.-Europe Telecommunications, $1985-95 \ldots \ldots \ldots \ldots \ldots \ldots \ldots \ldots \ldots \ldots \ldots \ldots \ldots \ldots \ldots \ldots \ldots \ldots \ldots \ldots \ldots . .212$

6A-3. Satellite Share of international Communications Capacity CEPT Master Plan Projections . . . . . . . . . . . . . . . . . . . . . . ................213

66-1. international Communications and Direct-Broadcast Satellite Series . . . . . . . .228

66-2. Estimated New and Replacement Communications Satellites

Scheduled for Launch During 1984-2000 . . . . . . . . . . . . . . . . . . .236

68-3. INTELSAT VI: Subcontracts Let by the Prime Contractor Hughes Aircraft . ......237

66-4. Satellite Earth Station Market Forecast . . . . . . . . . .............................238

6B-5. INTELSAT Earth Station Standards . . . . . . . . . . . . . . . . . ......239

66-6. Major Worldwide Suppliers of Satellite Earth Stations ., . ......................239

66-7. Major Satellite Earth Station Suppliers-Company Profiles, . . . . . . . . .......241

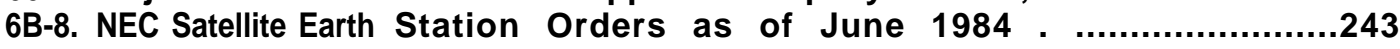

List of Figures

Figure No.

6-1. Texas Instruments' Worldwide Data Communications Network . ............157
6-2. Texas Instruments' information Network Concept . .....................158

6-3. Radio Signal Attenuation . . . . . . . . . . . . . . . . . . . . . . . ...............194

6A-1. Cost of Satellite vs. Cable Transmission: Conceptual Diagram . ................214

6B-I. Estimated Worldwide Investment in Commercial Communications Satellites,

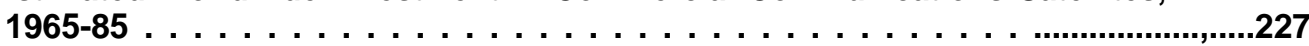

6B-2. Estimated Worldwide investment uncommercial Communications Satellites, $1985-89 \ldots \ldots \ldots \ldots \ldots \ldots \ldots \ldots . . .233$

6B-3. Locations of Commercial Communications Satellites in Geosynchronous Orbit as of June $25,1984 \ldots \ldots \ldots \ldots \ldots \ldots \ldots \ldots \ldots \ldots \ldots \ldots \ldots \ldots . . .234$

6B-4. Locations of Commercial Communications Satellites in Geosynchronous Orbit

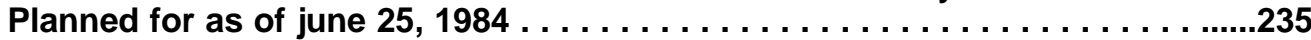

6B-5. Typical Ground Station Costs for Differing Antenna Sizes . . . . . . . . ........240

613-6. INTELSAT Satellite Earth Station Suppliers . . . . . . . . ....................243 


\section{SATELLITE COMMUNICATIONS}

\section{INTRODUCTION}

\section{Space Policy and International Telecommunications Policy}

Satellite communications is the only substantial commercial exploitation of space. As communication satellites came into commercial use, many people concerned with international satellite communications policy assumed that most of the important issues in the satellite arena could be analyzed apart from the regulatory issues of the wider telecommunications industry. The policy they made, embodied initially in the Communications Satellite Act of 1962 and the INTELSAT Agreement of 1973, evolved with its own momentum, its own objectives, and its own "space" constituencies. The Federal Communications Commission (FCC) then molded the regulatory framework to accommodate the policy framework.

Recently, the regulatory framework that the FCC put in place to reconcile U.S. international satellite communications policy with commercial reality has come $u$ rider new challenge in a number of different contexts and must adapt in fundamental ways. Technological, economical, and regulatory changes have resulted in a situation where almost no aspect of international satellite communications can any longer be analyzed apart from the international telecommunications industry-terrestrial and satellite-as a whole. At the same time, most of the major issues in international satellite communications have also become issues of telecommunications regulation rather than space policy.

International competition in satellite communications equipment has also taken on a new dimension now that the U.S. market has opened up because of domestic deregulation. Foreign suppliers, who had hitherto largely sold in protected markets or according to the allocation formulas of international agencies, are free to sell in the United States, but U.S. suppliers are seriously restricted in Europe and Japan.

\section{The International Satellite Communications Industry}

These shifts in policy emphasis are taking place at a time when satellites provide the dominant transmission technology in international telecommunications. Approximately two-thirds of transoceanic international telecommunications now pass through satellites; the remainder is carried via undersea cables. The information transmitted includes not only telephone conversations, telex messages, and television programs, but increasing amounts of computer-processed data. In the future, videoconferencing may become a large service. Multinational corporations now send large quantities of data around the world within private line networks. In the general international economy, the exchange of goods and services among nations is paralleled by streams of related information and electronic financial transfers.

More and more, the same firms that carry data from one point to another also process the data. This merger of two formerly separate activitiestelecommunications and data processing-already has led to substantial regulatory changes in both the domestic and international telecommunications of the United States, a process that is beginning to occur in several other countries as well. The 1984 breakup of AT\&T in an antitrust consent decree is the most spectacular, but only one, result of the pressure that technical changes are placing on regulatory structures. ${ }^{2}$

Within the United States, several of the largest U.S. corporations now offer both domestic and international satellite communications services. AT\&T, Western Union, IBM, RCA, ITT, and GTE

\footnotetext{
' Departments of State and Commerce, "A White Paper on New International Satellite Systems," February 1985, p. 7.

$2_{u}$. S. Congress, Office of Technology Assessment, Effects of information Technology on Financial Services Systems, OTA-CIT-202 (Washington, DC:U.S.Government Printing Office, September 1984), ch. 6.
} 
are important examples. ${ }^{*}$ Each of the three largest communications satellite makers-Hughes, Ford, and RCA - also offers, or is about to offer, satellite communications services. In addition to these firms, which offer services for sale, a number of large U.S. firms, e.g., Citicorp and General Electric, have sizable private communications networks.

Abroad, the picture is much different: except in a few countries, telecommunications is a government monopoly (the so-called "PTT" or post, telegraph, and telephone entity). ${ }^{3}$ Internationally, the International Telecommunications Satellite Organization (INTELSAT), a consortium with more than 100 member countries, is the monopoly provider of intercontinental satellite facilities. ${ }^{4}$ INTELSAT was established under U.S. leadership pursuant to the Communications Satellite Act of 1962, which also authorized the charter of the Communications Satellite Corp. (COMSAT) as a private company. COMSAT is a carriers' carrier (all U.S. carriers sending international satellite communications via the INTELSAT system must pay COMSAT's tariff) and represents the United States in the INTELSAT Board of Governors. It currently has an investment share in INTELSAT of 23 percent. Other countries are typically represented on the INTELSAT Board of Governors by their PTTs.

Both INTELSAT and the PTTs in the industrial countries are beginning to feel pressures for increased openness to competition-pressures from

\footnotetext{
*Several of these firms use their own satellite systems for domestic satellite services; the others lease transponders from satellite providers. For reasons discussed below, virtually all International satellite communications are sent via leased transponders.

${ }^{3}$ The divestiture decisions contained in the AT\&T consent decree are, of course, just one of the possible ways in which industry structures could be reformed to take account of the new technological realities. Other countries, notably the United Kingdom, Japan, and France, responding to these same technological realities by altering industry structures in other ways.

Some traffic is now or will shortly be carried on regional systems in the Western Hemisphere, Southeast Asia, Europe, and the Middle East, on INTERSPUTNIK, a Communist bloc satellite system, and on INMARSAT, an international system for marine communications. The Western Hemisphere regional system is often omitted from the list of regional systems, perhaps because it is made up of unrelated private carriers rather than operated by an intergovernmental organization, and is usually referred to as "transborder services. "Currently, U.S. domestic satellite operators are authorized to carry international traffic to Canada, Mexico, Bermuda, and many locations in the Caribbean.
}

the continued growth of demand for telecommunications services, from the new information and telecommunications technologies, and from the new competitors in the U.S. markets They fear that unilateral moves by the United States will cause changes in the current international regulatory regime that will make them change valued modes of operation and, in the case of INTELSAT, threaten its economic viability. ${ }^{\mathrm{b}}$ At the same time, some developing countries are demanding changes in the ways in which the international community assigns the radio frequencies and geosynchronous orbital positions.

\section{International Cooperation in Satellite Communications}

The United States cooperates extensively in international satellite communications and, in addition to its membership in INTELSAT, participates in several other international organizations concerned with it. U.S. concerns in these cooperative processes are not only related to the welfare of U.S. producers and consumers of telecommunications services and equipment. They also are concerned with linkages to wider foreign policy concerns-e.g., relations with other industrial countries and with the developing world, global national security communications capabilities, the effectiveness of international institutions, and the general international trading system.

\footnotetext{
${ }^{5}$ EliM. Noam, "Telecommunications Policy on the Two Sides Of the Atlantic: Divergence and Outlook, "Columbia University, Research Program in Telecommunications and Information Policy, New York, Aug. 15, 1984. See also testimony and statements in "international Satellite Issues," U.S. Congress, House Committee on Energy and Commerce, Subcommittee on Telecommunications, Consumer Protection, and Finance, Hearings, June 13, July 25 and 26, 1984, Washington, DC, 1985,

"We use the term "international regulatory regime" (Or "international communications regime") broadly to include all governmental and intergovernmental actions affecting the operations of the international communications carriers. These include treaties and other formal and informal intergovernmental agreements in the area of telecommunications, other elements of international law affecting telecommunications, the actions of international organizations such as the ITU or INTELSAT, and the actions of national governments that affect the international telecommunications industry.
} 


\section{Policy Issues}

These pressures for change pose issues for U.S. international communications policy that involve both international competition and international cooperation. Important current policy issues of relevance to international satellite communications are mentioned below.

\section{Competition for INTELSAT}

Should the United States attempt to foster greater competition in the provision of international satellite communications facilities? If so, would the United States serve this objective, and wider U.S. foreign policy concerns, by allowing private U.S. firms to construct satellite facilities for use in whichever country markets they can gain entry, in possible competition with INTELSAT?

\section{Competition for COMSAT}

Should other U.S. telecommunications carriers be allowed access to INTELSAT on the same basis as COMSAT? If COMSAT continues as the sole U.S. investor in INTELSAT and as the sole U.S. "wholesaler" of international satellite communications, should COMSAT be required to divest itself of its other activities or could they be carried out in separate subsidiaries, as at present, with accounting controls to guard against its monopoly activities cross-subsidizing its competitive ones?

\section{Satellites v. Cables: Facilities Regulation}

How will the international facilities regulation of the FCC affect the future of satellite communications? The future distribution of traffic in international communications between satellites and undersea cables is partly dependent on the cost and performance characteristics of the two technologies, but it also depends on whether the Government regulates investment in new satellite and cable facilities and whether it mandates the shares of the traffic that U.S. service carriers must send over the two media. Should the current regulatory regime be maintained or can competition be relied on to determine investment in long-distance international facilities in the same manner that it does in the substantially deregu- lated U.S. domestic telecommunications industry?

Access of U.S. Carriers to Foreign Telecommunications Service Markets

Now that several dozen large U.S. corporations are active in U.S. domestic satellite communications, as basic, enhanced, or private communications providers, how can the United States endeavor to assist them in gaining access to foreign telecommunications service markets (principally in the industrial countries)? Should the United States adopt a demanding posture at the risk of straining relationships with our principal trading partners?

International Trade in Satellite Communications Equipment

What additional action should the Government take to try to assure fair international competition in both space- and ground-segment equipment? Can foreign governments be persuaded to end their PTTs' discriminatory procurement policies by agreeing to apply the GATT agreement on government procurement (or a similar principle) to PIT procurement of telecommunications equipment? Would reciprocity legislation help? How disadvantaged are U.S. satellite communications equipment makers likely to be in the availability of and interest rates charged for official export finance for sales to less developed countries? Would a new international agreement help?

\section{NASA Satellite R\&D}

How much should the Government spend on research and development to help keep the U.S. satellite manufacturing industry technologically vital and ahead of potential foreign competitors? In particular, is the NASA Advanced Communications Technologies Satellite (ACTS) program a desirable program that the private sector is not financially capable of mounting? Or should the private sector be relied on to do its own R\&D? Should the U.S. Government match foreign civilian R\&D programs in satellite communications or would the ACTS program actually engender greater foreign efforts to surmount U.S. domi- 
nance in communications satellites? Finally, how much success is a government-conducted R\&D program likely to have in developing marketable technology?

\section{Space WARC}

What should be the U.S. approach to cooperation with other countries in international telecommunications organizations? In particular, how should the United States approach the international Telecommunication Union's (ITU)upcoming World Administrative Radio Conferences on space services ("Space WARC"), so as to protect U.S. access to the geosynchronous orbit and the radio frequency spectrum? Should temporary or permanent withdrawal from ITU' (and other international organizations concerned with satellite communications, such as the U.N. Committee on the Peaceful Uses of Outer Space (COPUOS) be considered as active contingencies in the wake of U.S. withdrawal from the U.N. Educational, Scientific, and Cultural Organization (UNESCO)?

\section{Aid to Developing Countries}

Should Congress attempt to direct more U.S. development-assistance resources into telecommunications? Should the United States encourage multilateral assistance to developing countries through the World Bank or specialized international telecommunications institutions, such as INTELSAT (cross subsidies) and the ITU (development assistance), or are bilateral programs, such as those that might be carried out by the U.S. Agency for International Development (AID), more effective in achieving U.S. objectives? Can mixed credit programs $f \sim r$ buyers in developing countries assist U.S. telecommunications exports?

\section{The Demand for International Satellite Communications}

The Importance of the Demand Factor

The demand for satellite communications, its size and rate of growth in this decade and in the

\footnotetext{
Thether significant cross subsidies are created by INTELSAT pricing is in dispute (see below).
}

$1990 \mathrm{~s}$, will be one of the fundamental variables affecting issues of importance to the United States in international space and telecommunications policy. ${ }^{8}$ The prospect of high demand for satellite communications over the North Atlantic would make it easier for the United States and other governments to allow the entry of private satellite communications firms in competition with INTELSAT. High demand for satellite communications services would also result in higher derived demand for space transportation services and for satellite equipment and would affect international competition in both areas. One effect of high demand would not be favorable, however. High demand would tend to exacerbate any situation of crowding in the geostationary orbit. ${ }^{9}$

\section{Growth of International}

Telecommunications as a Whole

U.S. international communications has been growing rapidly since high-quality voice service was inaugurated in transatlantic service via undersea cable in 1956. U.S. carriers' international real revenues grew at an annual average rate of approximately 13 percent during the $1972-84$ period (table 6-I). For 1985, the Department of Commerce projects a growth rate of 14 percent.

\footnotetext{
${ }^{8}$ Care should be taken with the concept of "demand for international satellite communications," since satellite communications and terrestrial communications are extremely close substitutes in telephony and most other international volume applications. It should probably be thought of as a demand derived from total international telecommunications demand that is determined by the institutional and regulatory structures of both cables and satellites and also by the relatively small differences in the characteristics of the services provided. The general conclusion that satellite and cable transmission modes are close substitutes is not changed by the existence of certain uses, such as point-to-point television or certain high-speed interactive data communications, where the two modes are not close substitutes. At present these uses are relatively low-volume uses in international satellite communications.

${ }^{9}$ Crowding (or congestion) in the geostationary orbit is said to occur when preferred or substitutable orbital slots in a desired frequency band are not available to an applicant. This may be because they are occupied by another satellite or reserved for future use by another user. Thus, the applicant experiences the economic costs of changing desired services. Crowding can be local or can occur in an entire region of the geostationary orbit, such as the Western Hemisphere. Certain observers eschew the term as misleading, since no physical crowding occurs, and the spacing is fixed by regulatory decision. At 2 deg. orbital spacing, for instance, satellites would be approximately 500 miles apart. The volume of two-way communications that can be handled in a given slot also depends on the technology in use by the satellite.
} 
Table 6.1 -U.S. International Telephone and Telegraph Service Revenues, 1972-85

\begin{tabular}{|c|c|c|}
\hline \multirow[b]{2}{*}{ Year } & $\begin{array}{l}\text { International } \\
\text { revenues }\end{array}$ & \multirow{2}{*}{$\begin{array}{c}\text { Growth } \\
\text { rate }^{\mathrm{a}} \\
\text { (percent) }\end{array}$} \\
\hline & (1972\$ millions) & \\
\hline $1972 \ldots \ldots \ldots \ldots$ & 663 & - \\
\hline $1977 \ldots \ldots \ldots \ldots$ & 1,339 & $15.1(1972-77)$ \\
\hline $1978 \ldots \ldots \ldots \ldots \ldots$ & 1,607 & 5.7 \\
\hline $1979 \ldots \ldots \ldots \ldots$ & 1,906 & 18.6 \\
\hline $1980 \ldots \ldots \ldots \ldots$ & 2,082 & 9.2 \\
\hline $1981 \ldots \ldots \ldots \ldots$ & 2,250 & 8.1 \\
\hline $1982 \ldots \ldots \ldots \ldots \ldots$ & 2,325 & 3.3 \\
\hline $1983 \ldots \ldots \ldots \ldots \ldots$ & 2,500 & 7.5 \\
\hline 1984 e . . & 2,800 & 12.0 \\
\hline \multicolumn{2}{|l|}{ Average twelve-year period } & $12.8(1972-84)$ \\
\hline $1985 p \ldots \ldots \ldots \ldots$ & 3,200 & 14.3 \\
\hline
\end{tabular}

KAYYO = estimated; $P$ O $=$ projected. ods of over 1 year, SOURCE: U.S. Department of Commerce, U.S. Industrial Outlook 1985, pp. 31-7,

U.S. carriers expect rapid growth of international communications to continue. In forecasts prepared for a working group meeting in connection with the FCC's facilities planning process, the U.S. international service carriers ${ }^{10}$ projected the demand for U.S.-Europe common carrier commu nications (including new services) to increase at an average annual rate of 16.3 percent during

\footnotetext{
10 In 1983, themajor U.S. companies involved in the planning process were AT\&T, RCA, Western Union, GTE, MCI, and ITT and COMSAT.
}

the period 1985-95. They foresee demand for capacity of 82,000 voice-equivalent circuits in 1995.11

Table 6-2 shows the distribution of two-way telephone and telex services between the United States and various world regions in 1982. In that year, 86 percent of telephone and 80 percent of telex minutes were transmitted along high-volume corridors to Europe, North Asia, and the Americas. ${ }^{12}$ Transatlantic traffic to Europe alone accounted for about 50 percent of total minutes.

\section{Demand Forecasts Subject to Substantial Uncertainty}

Forecasts of demand a decade ahead are, of course, subject to wide forecast error, because the assumptions regarding price, economic growth, technology, market development, and consumer response on which they are implicitly or explicitly based are themselves subject to great uncertainty.

One assumption behind the U.S. carriers' forecast stands out as particularly uncertain-their

I I This growth rate refers to the forecast of November 1984. Table 6A-1 in app. 6A presents these November 1984 overall forecasts. It also presents 1983 forecasts (which were significantly higher) by carrier and by major destination country.

${ }_{12}$ Not including Canada and Mexico. These percentages are taken from table 6-2.

Table 6-2. -U.S. International Common Carrier Telecommunications Traffic by World Region (Voice and Telex), $1982^{\mathrm{a}}$

\begin{tabular}{|c|c|c|c|c|}
\hline & \multicolumn{2}{|c|}{ Voice } & \multicolumn{2}{|c|}{ Telex } \\
\hline & $\begin{array}{l}\text { (million } \\
\text { minutes) }\end{array}$ & (percent) & $\begin{array}{l}\text { (million } \\
\text { minutes) }\end{array}$ & (percent) \\
\hline 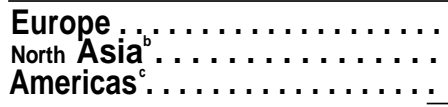 & $\begin{array}{r}1,003 \\
209 \\
525 \\
\end{array}$ & $\begin{array}{l}49.7 \\
10.3 \\
26.0 \\
\end{array}$ & $\begin{array}{r}152 \\
59 \\
58 \\
\end{array}$ & $\begin{array}{l}45.2 \\
17.6 \\
17.2 \\
\end{array}$ \\
\hline Subtotal $\ldots \ldots \ldots \ldots \ldots$ & 1,737 & 86.0 & 269 & 80.0 \\
\hline $\begin{array}{l}\text { Near East } ., \ldots \ldots \ldots \ldots \ldots \ldots \\
\text { Other Asia/Pacific }{ }^{\prime} \ldots \ldots \ldots \ldots \\
\text { Africa } \ldots \ldots \ldots \ldots \ldots \ldots \ldots\end{array}$ & $\begin{array}{r}148 \\
87 \\
46 \\
\end{array}$ & $\begin{array}{l}7.4 \\
4.3 \\
2.3 \\
\end{array}$ & $\begin{array}{l}19 \\
33 \\
14 \\
\end{array}$ & $\begin{array}{l}5.7 \\
9.9 \\
4.3 \\
\end{array}$ \\
\hline Total . . & 2,019 & 100.0 & 336 & 100.0 \\
\hline
\end{tabular}

$\mathrm{al}_{n e} \mathrm{l}_{u} \mathrm{~d}_{\mathrm{e}} \mathrm{s}$ only telephone and telex traffic. In addition to telex, which was reported by region and by minutes and which accounted for 70 percent of their revenues, the (former) international record carriers derived $\mathbf{3 0}$ percent of their revenues from teleqraph messages and private lines.

bJapan, Republic of Korea, China, Hong Kong, Taiwan, Philippines.

${ }^{C}$ Excluding Canada, Mexico, and u.s. territories. Canada and Mexico are not included in the source FCC data on international telephone carriers. Mexico is included in the data on telex, but for consistency, we have excluded it from this analysis. Excluding Hawaii and Guam.

SOURCE: Derived from Federal Communications Commission, Statist/es of Common carders, year ended Dec. 31, 1982, pub. lished in 1984. 
assumption that new services, especially videoconferencing, will not grow to be a large fraction of total demand..$^{13}$ A study prepared for NASA in 1980 comes to a different conclusion as do recent statements by other observers. (See app. 6A of this chapter for further discussion.) If a large demand for videconferencing should materialize, perhaps stimulated by new satellite and cable competitors, demand for international communications could grow even more rapidly than the carriers' forecast.

The Satellite Communications Component

Will international satellite communications share in this rapid growth? Will it grow as rapidly as international telecommunications as a whole? The growth prospects for satellite communications are even more uncertain than those of the total industry. It is even possible that the growth of international satellite communications could level out in the 1990s at the same time as total international telecommunications was continuing to expand rapidly. This could occur if undersea cables, using advanced fiber optic technology, are used relatively more in the future than satellites.

Although international satellite communications can be expected to continue to grow rapidly in the 1980s,14 the prospects for the 1990s are much less certain. The s-hare of satellites in the 1990s will depend on:

- the growth in the total demand for international telecommunications services;

- the price advantage/market preference, if any, of fiber optic over satellite transmission for high-volume applications; ${ }^{15}$

\footnotetext{
${ }^{13}$ Videoconferencing and audioconferencing (no video element) together comprise teleconferencing. Full-motion videoconferencing requires broadband telecommunications capability, but slowscan videoconferencing (as well as audioconferencing) can be sent over standard telephone circuits.

${ }^{14}$ At least through 1\%8, when the transatlantic TAT-8 and transpacific Transpac 3 fiber optic cables are scheduled to be operational.

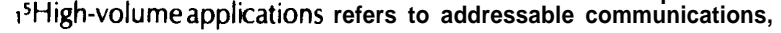
mostly telephone conversations, that are transmitted point-to-point, with international transit along major cable or satellite trunk routes. The growth of demand for services for which satellites are particularly suited-point-to-mu Iti-point receive-only television transmission and low-density communications-will also be a factor, but
}

- the strength of industry-structure and other incentives for carriers to invest in fiber optic undersea cables and use them in preference to satellites; and

- the actual growth of undersea cable capacity and the presence or absence of regulatory restrictions on its use.

Because all of these factors are uncertain, we organize the discussion of the demand for satellite communications in the 1990s in terms of three plausible scenarios:

1: Rapid growth throughout the 1990s.

li: Slow growth throughout the 1990s.

III: A no-growth plateau in the 1990s.

Essentially the three scenarios represent different outcomes of the modal competition between fiber optic undersea cables and communication satellites for international communications in high volume uses. If users and carriers have significant preferences in favor of fiber optic transmission, and if these preferences are not blunted by regulatory decisions to limit the construction or use of undersea cables, the employment of satellites on major trunk routes could decline significantly in the 1990s, and total satellite communications use could level off. This would be more likely to occur if international telecommunications as a whole did not grow as rapidly as the videoconferencing optimists expect. This is the no-growth scenario for satellite communications in the 1990s.

On the other hand, less preference for cables or more stringent regulation requiring carriers to use satellites could keep satellite communications carrying roughly the same 50 percent share of the growing transatlantic market as it does now. This would be the rapid growth scenario.

A slow growth scenario represents a trend midway between the other two scenarios.

Table 6-3 lists the key variables that are uncertain and the assumptions about them that would affect demand according to the three scenarios. a relatively unimportant one in international satellite communica-
tions than the growth of high-volume point-to-point applications
because of the low total communications volume of the former. 
Table 6-3.-Scenarios for Satellite Communications Demand in the 1990s

\begin{tabular}{lccc}
\hline Key uncertain variables & $\begin{array}{c}\text { Scenario I } \\
\text { Rapid } \\
\text { growth }\end{array}$ & $\begin{array}{c}\text { Scenario II } \\
\text { slow } \\
\text { growth }\end{array}$ & $\begin{array}{c}\text { Scenario III } \\
\text { No growth } \\
\text { plateau }\end{array}$ \\
\hline $\begin{array}{l}\text { Cost/price advantage/consumer } \\
\text { preference for fiber optic } \\
\text { transmission for high } \\
\text { volume uses }\end{array}$ & SMALL & MODERATE & LARGE \\
$\begin{array}{l}\text { Industry-structure incentives to } \\
\text { adoption of fiber-optic cable } \\
\text { transmission }\end{array}$ & OR & OR & OR \\
$\begin{array}{l}\text { Growth in actual cable capacity } \\
\text { or in capacity available } \\
\text { under loading restrictions }\end{array}$ & SLOW-TO-MODERATE & MODERATE & HIGH \\
$\begin{array}{l}\text { Note: These scenarios and assumptions are discussed in app. 6A of this chapter. This chart emphasizes the factors affecting } \\
\text { the share of satellite communications. Slow growth In total international telecommunications demand would reduce } \\
\text { the growth of satellite communications in all scenarios and make the growth plateau more likely. }\end{array}$
\end{tabular}

The scenarios and the assumptions behind them are discussed in greater detail in appendix 6A of this chapter.

\section{The International Satellite Communications Service Industry}

A number of important issues in U.S. international space and satellite communications policy are embedded in the structure of the world telecommunications service industry. (Structure here refers to the prevailing modes of operation, ownership, and regulation in the industry.) The world industry and its structure are increasingly affected by the same technological developments-the merging of the data processing and telecommunications industries based on inexpensive computing power, digital communications, satellite networks, and other technical innovations-that contributed to the break-up of the regulated-monopoly structure in U.S. long-distance communications. ${ }^{16}$ These developments are now affecting the telecommunications economies of a number of other industrial countries and are beginning to force structural change to occur there as well. ${ }^{17}$

\footnotetext{
${ }^{16}$ See Richard!.Kirkland, "Ma Blue: IBM's Move Into Commu. nications," Fortune, vol. 110, Oct. 15, 1984, pp. 52-54,58,62. Also see Dante B. Fascell and Virginia M. Schlundt, "United States International Communications and Information Policy: A Crisis in the Making?" Northwestern journal of International Law and Business, vol. 5, fall 1983, pp. 486-509.

${ }_{1}$ FFor a discussion of technological change as the leading edge of change in telecommunications regulation in the United States and other countries, see unpublished paper by Alan Baughcum,
}

Since the pace of change is greatest in U.S. telecommunications markets, conflicts with other countries in international satellite communications policy have been growing out of the conflicting desires and actions of U.S. and foreign telecommunications producers and consumersboth in the United States and other countriesas they respond to technology-driven changes in telecommunications markets. These market developments, rather than the initiatives of the U.S. or foreign governments, are the primary impetus behind current policy discussions in satellite communications.18

The Emerging Industry Structure in U.S. International Communications

Even though the United States has deregulated much of its domestic telecommunications, the old regulatory structures affecting U.S. interna-tional communications remain largely in place. ${ }^{19}$ While the FCC has relaxed the distinctions between international and domestic and voice and record carriers, ${ }^{20}$ this as yet has had little impact

presented at the Research Workshop on Economics of Telecommunications, Information and Media Activities in Industrial Countries, National Science Foundation, Apr. 30-May 2, 1984, Washington, DC (forthcoming, North-Holland Publishing Co., 1985). Also see "America calling," Economist, Nov. 24, 7984, pp. 97-98.

${ }^{18}$ For ageneral treatment of the problem of international conflicts of jurisdiction, see George Shultz, "Trade, Interdependence, and Conflicts of Jurisdiction," Current Policy No. 573, May 5, 1984.

${ }^{19}$ See app. 6A for further discussion of how the international regulatory regime has changed in recent years.

“"” Record" communications-telegraph, telex, and data-are conventionally distinguished from "voice' '-telephone-and from television transmissions. 
on which firms carry what traffic and on how they do business internationally. AT\&T Communications still carries almost all U.S. international telephone communications; the international record carriers, formerly restricted to record communications, still handle most of the record traffic; INTELSAT and COMSAT still have a virtual monopoly on U.S. intercontinental space-segment communications; and the FCC still oversees a process in which approved carrier consort a plan facilities years ahead.

Nevertheless, pressed by regulatory and technological changes, the large firms, such as AT\&T, IBM, GTE, ITT, RCA, Western Union, and COMSAT, have all started to penetrate each other's former preserves (or are contemplating it). New entrants have also been able to enter the international markets for both basic and enhanced telecommunications services. ${ }^{21}$

Several notable events have recently set the stage for the large telecommunications firms to start moving toward an undifferentiated international industry on the U.S. side:

- The Orion Satellite Corp., RCA, and other applications to the FCC in 1983, 1984, and 1985 to construct private transatlantic satellite facilities to be owned by individual firms.

- The FCC decisions to allow COMSAT to provide retail service and other carriers to independently own Earth stations transmitting to and receiving from INTELSAT satellites. ${ }^{22}$

\footnotetext{
21 In early 1985 , the FCC was moving toward making entry even easier by relaxing the procedural requirements for all but "dominant" carriers (those having significant market power). In the course of this process, it has tentatively concluded that, except for the local telephone carriers in Alaska, Hawaii, and Puerto Rico, only AT\&T (in message telephone service) and COMSAT are dominant carriers and therefore have to be closely regulated. (FCC, "In the Matter of International Competitive Carrier Policies, " File No. 85-177, released Apr. 19, 1985.)

22TheFCC authorized COMSAT to compete directly with other carriers for customers' business in 1982, but the U.S. Court of Appeals for the District of Columbia suspended action until the FCC resolved other matters, including the issue of Earth stations and direct ownership-type access to the INTELSAT system by carriers other than COMSAT. (U.S. General Accounting Office, FCC Needs to Monitor a Changing International Telecommunications Market, RCED-83-92, Mar. 14, 1983.) In a series of decisions culminating in an order released in January 1985 , the FCC reaffirmed its policy to allow COMSAT to provide retail service (through a subsidiary separate from the monopoly World Systems Division), denied carriers ownership-type access to INTELSAT, but allowed them and other users to own their own Earth stations communicating directly
}

- The success of Western Union Telegraph co. $^{3}$ in penetrating the international record market and the moderate success of $\mathrm{MCl}$ and GTE in penetrating the international telephone market.

- The emergence of a Western Hemisphere regional system based on the satellites owned individually by U.S. private domestic satellite providers and by Telesat Canada.

- Finally, the plans announced in 1984 by: 1) Cable'\& Wireless, Ltd., a British firm, and its U.S. partners; ${ }^{24}$ and 2) Submarine Lightwave Cable Co. (SLC), ${ }^{25}$ a U.S. entrepreneurial group, to install new very high-capacity, transatlantic fiber optic cables. ${ }^{26}$

Because data processing and telecommunications firms can no longer easily be separated into different industries, and telecommunications providers themselves are no longer segmented into the traditional rigid regulatory categories, the in-

with INTELSAT satellites (FCC, "Second Report and Order in the Matter of Proposed Modification of the Commission's Authorized User Policy Concerning Access to the International Satellite Services of the Communications Satellite Corporation," released Jan. 11, 1985).

${ }^{23}$ Western Union Telegraph Co., formerly the de facto monopoly domestic record carrier, should not be confused with Western Union International, a separate firm, one of the traditional record carriers and now a wholly owned subsidiary of $\mathrm{MCl}$ Corp.

${ }^{24}$ Application of Tel-Optik Ltd. (Cable \& Wireless' U.S. partner) for a license to land and operate in the United States a submarine cable extending between the United States and the United Kingdom, FCC File No. S-C-L-84-002, Sept. 28, 1984.

${ }^{25}$ Application of submarine Lightwave Cable Co., FCC file No. SCL-85-001, Oct. 16, 1984. Submarine Lightwave's FCC filing says that the cable would provide 250,0 (X voice circuits for telephony or 72 broadcast-quality video channels, if used entirely for those purposes; it would cost $\$ 450$ million, and would be installed in 1989. The application also states that the cable may in its final design result in even more usable capacity, since "current technology is developing extremely rapidly" (p. 2).

26/n March 1985, the FCC informed the Secretary of State of its conclusions that the Tel-Optik application "meets the threshold reciprocity showing of the Cable Landing License Act and otherwise appears to be consistent with U.S. interests under the Act." The SLC application was not acted on pending the receipt of additional information. (FCC News, Report No. 3092, Mar. 4, 1985). In May 1985 (based on an April refiling by SLC), the FCC recommended to the State Department that it also approve the SLC cable landing license (letter from Mark S. Fowler to William Schneider, Jr., May 16, 1985). The Tel-Optik cable landing license was approved • by the FCC on May 16, 1985, subject to conditions that it is revocable after due notice of hearing and that it is subject to future modification by the Secretary of State "to protect U.S. interests as a result of the sale or lease of capacity to particular foreign or domestic entities" ("In the Matter of Tel-Optik Ltd. Cable Landing License, " FCC Mimeo 4618 ). 
ternational telecommunications industry is described broadly in this report and the formerly important distinctions between telephone and telegraph, terrestrial and satellite, enhanced and basic, international and domestic, and international and transborder are not emphasized.

Participants in the U.S. International Satellite Communications Market

Of all the U.S. firms participating in international communications, AT\&T is still the largest with $\$ 38.7$ billion in (postdivestiture) total assets in 1984. IBM, GTE, ITT, MCI, RCA, McDonnell Douglas, Western Union, Continental Telephone, United Brands, and COMSAT are also among the largest U.S. firms. Not all of them (e.g., McDonnell Douglas, Continental Telephone, and United Brands) currently have a large participation in international telecommunications, but each is in a competitive position to expand their already significant activities should they so choose. (See table 6-4 for a listing of U.S. international communications firms.)

In addition to these firms, the list of potential new entrants into international satellite communications is large and growing. It includes both other owners of satellites used in U.S. domestic communications (e.g., Hughes Aircraft $\mathrm{C}_{0}{ }^{27}$ and Ford Motor $\mathrm{CO}^{28}$ and those that lease or buy transponders from them. Several potential entrants are new corporations organized to provide international satellite capacity.

In addition to firms that sell or plan to sell telecommunications services, a growing number of other large U.S. multinational firms have put together very large private international communications networks, notably Citicorp (connecting 1,400 offices in 93 countries), General Electric, Merrill Lynch, Shell Oil, and Texas Instruments, that use the private-line and public services of authorized telecommunications carriers (see figs. 61 and $6-2) \cdot{ }^{29}$ Through resale of excess capacity, many of them have become telecommunications

\footnotetext{
${ }^{2}$ Through its Hughes Communications, Inc., and Hughes Communications Galaxy, Inc., subsidiaries.

28Through its Ford Aerospace \& Communications Corp. andFord Aerospace Satellite Services Corp. subsidiaries.

${ }^{29}$ Department of Commerce, U.S. Industrial Outlook1984, pp. 46-48.
}

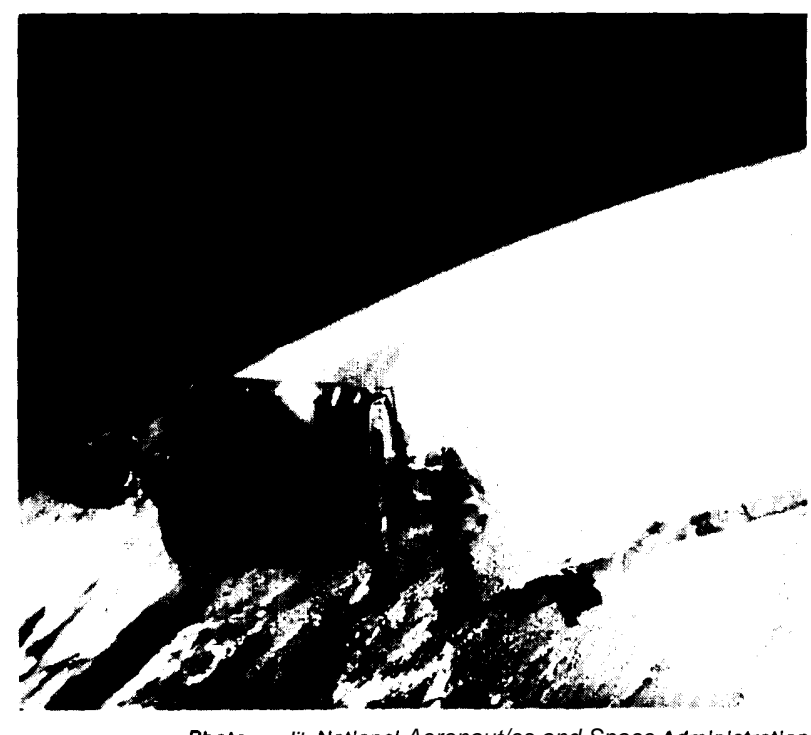

Photo credit: National Aeronaut/es and Space Administration

Westar VI, communications satellite built by Hughes Aircraft Co., being retrieved by Shuttle astronauts on mission 51-A after it failed to achieve geostationary orbit. The astronauts are to the left and right of the satellite. An astronaut on board controls the remote manipulator arm to bring the satellite into the Shuttle bay.

providers in the U.S. domestic market, and if permitted, could participate in the international market as well.

As the international regulatory regime ${ }^{30}$ for telecommunications is currently structured, U.S. international service carriers must hand off communications traffic to foreign telecommunications carriers for entry into other countries. Table 6-5 presents a list of the major carriers of satellite communications outside the East European bloc; these are the officially designated representatives of their countries ("signatories") to INTELSAT. The PTTs of Germany and France are both large entities, as are the PTTs of a number of other countries. They own most of the telecommu-

\footnotetext{
30We use the term "international regu latory regime' (or "international communications regime") broadly to include all governmental and intergovernmental actions affecting the operations of the international communications carriers. These include treaties and other formal and informal intergovernmental agreements in the area of telecommunications, other elements of international law affecting telecommunications, the actions of international organizations such as the ITU or INTELSAT, and the actions of national governments that affect the international telecommunications industry.
} 
Table 6.4.-U.S. Telecommunications Firms Providing international Satellite Communications Services

\begin{tabular}{|c|c|}
\hline $\begin{array}{l}\text { Salected major U.S. corporations currently authorized to } \\
\text { provide International service to consumers, } \\
\text { directly or through one or more subsldlarie }\end{array}$ & $\begin{array}{l}\text { Assets } \\
\text { Dec. } 31,1984 \\
\text { (\$ millilon) } \\
\end{array}$ \\
\hline International Business Machines Corp. (Satellite Business Systems) ${ }^{\text {bc de }} \ldots$ & 4 \\
\hline $\begin{array}{l}\text { American Telephone and Telegraph Co. (post-divestiture) }{ }^{\text {cd }} \ldots . . . . . . . \\
\text { GTE Corp. (GTE Sprint Communications GTE Spacenet Corp., Hawaiian }\end{array}$ & \\
\hline Telephone Co., GTE Telenet Corp ${ }^{c d e} \ldots \ldots \ldots \ldots \ldots \ldots \ldots \ldots \ldots$ & 26,364 \\
\hline $\begin{array}{l}\text { IIT Corp. (ITT Worldcom, U.S. Transmissions Systems, Inc. })^{\text {dt }} \ldots \\
\text { RCA Corp. (RCA Globcom, RCA Americom)............... }\end{array}$ & $\begin{array}{r}13,277 \\
8,221\end{array}$ \\
\hline McDonnell Douglas, Inc. (FTC Communications, Inc., FTC Satellite & \\
\hline & 6,191 \\
\hline Continental Telecom, Inc. (American Satellite and Space Communications & \\
\hline Co., joint venture with Fairchild Industries ${ }^{\text {cd }}$. & 4,557 \\
\hline $\begin{array}{l}\mathrm{MCl} \text { Communications Corp. (Western Union International, Inc. })^{t} \\
\text { Hughes Aircraft Co. (Hughes Communications, Inc., Hughes }\end{array}$ & 3,894 \\
\hline & $10^{\prime}$ \\
\hline n Corp. ${ }^{\text {et }}$. & 59 \\
\hline Federal Express Corp. (Fedex international Transmission & 6 \\
\hline $\begin{array}{l}\text { Communications Satellite Corp. (COMSAT International Communications, } \\
\text { COMSAT General Telematics, Inc. })^{\mathrm{d}} \ldots \ldots \ldots \ldots \ldots \ldots \ldots \ldots \ldots \ldots\end{array}$ & 1,166 \\
\hline 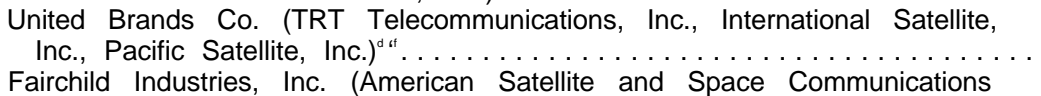 & 1,024 \\
\hline Co., joint venture with Continental Telecom ${ }^{\text {dd }} \ldots \ldots \ldots \ldots \ldots \ldots \ldots$ & 948 \\
\hline \multicolumn{2}{|c|}{ 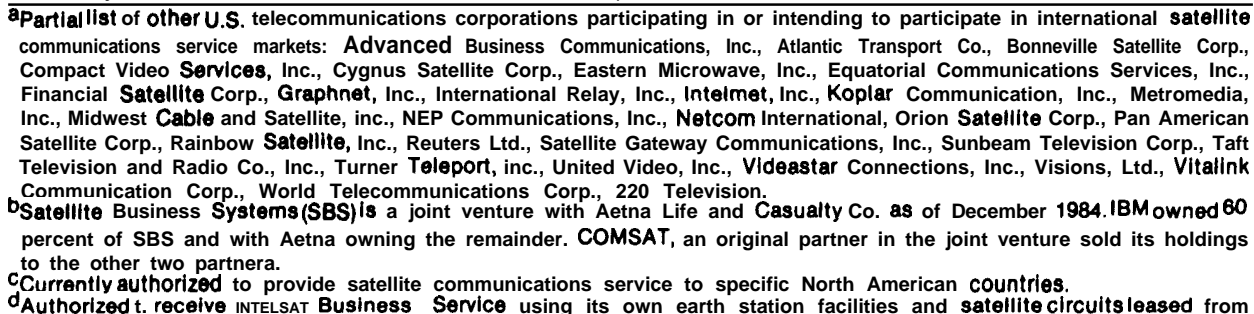 } \\
\hline \multirow{2}{*}{\multicolumn{2}{|c|}{$\begin{array}{l}\text { COMSAT. } \\
\text { OApplication to provide capacity for specific transatlantic, transpacific or Western Hemisphere satellite Services pending at } \\
\text { the FCC. } \\
\text { 'Established U.S. International Service Carrier. } \\
\text { OApplication to provide speciflc North and South American international services conditionally approved by the FCC pending } \\
\text { INTELSAT coordination procedure. } \\
\text { nFTC, Communications, Inc., is } 20 \text { percent owned by the French Government, } 80 \text { percent owned by McDonnell Douglas. } \\
\text { "This flgure is the mid-point of the range of estimated market value by "Wall Street sources" of this privatelyheld corporation }\end{array}$}} \\
\hline & \\
\hline smiss & \\
\hline
\end{tabular}

nications assets of their countries. ${ }^{31}$ British Telecom, slightly more than half of which was sold to private stockholders in November 1984, remains the preponderant British domestic and international carrier and is the U.K. INTELSAT signatory. Kokusai Denshin Denwa (KDD), Japan's officially designated international monopoly carrier, is both a regulated private firm and the INTELSAT signatory for Japan.

\footnotetext{
${ }^{31}$ For instance, thePTT of France, Direction General des Telecommunications, had year-end 1983 assets of FF 164 billion, about $\$ 20$ billion (source: telephone conversation with France Telecom, Inc. (New York), October 1984).
}

INTELSAT is the final element in the international industry. At the end of 1983, it had assets of $\$ 1.6$ billion .32 Like most of the participants in the international telecommunications service industry, INTELSAT provides communications services (in this case, space-segment capacity) in both international and domestic markets. ${ }^{33}$ INTELSAT

\footnotetext{
32] NTELSAT Financial Statements, Contribution of th ${ }_{\mathrm{e}}$ Director General to the Board of Governors Meeting, BG-58-70E W/3/84, Feb. 10, 1984.

MINTELSAT participates in the domestic markets of a number of countries by leasing transponders for domestic service to telecommunications entities, usually its signatory-owners. It also provides a small fraction of its space-segment capacity to non-owner gov-
} 
Figure 6-1 .-Texas Instruments' Worldwide Data Communications Network

Information systems and services

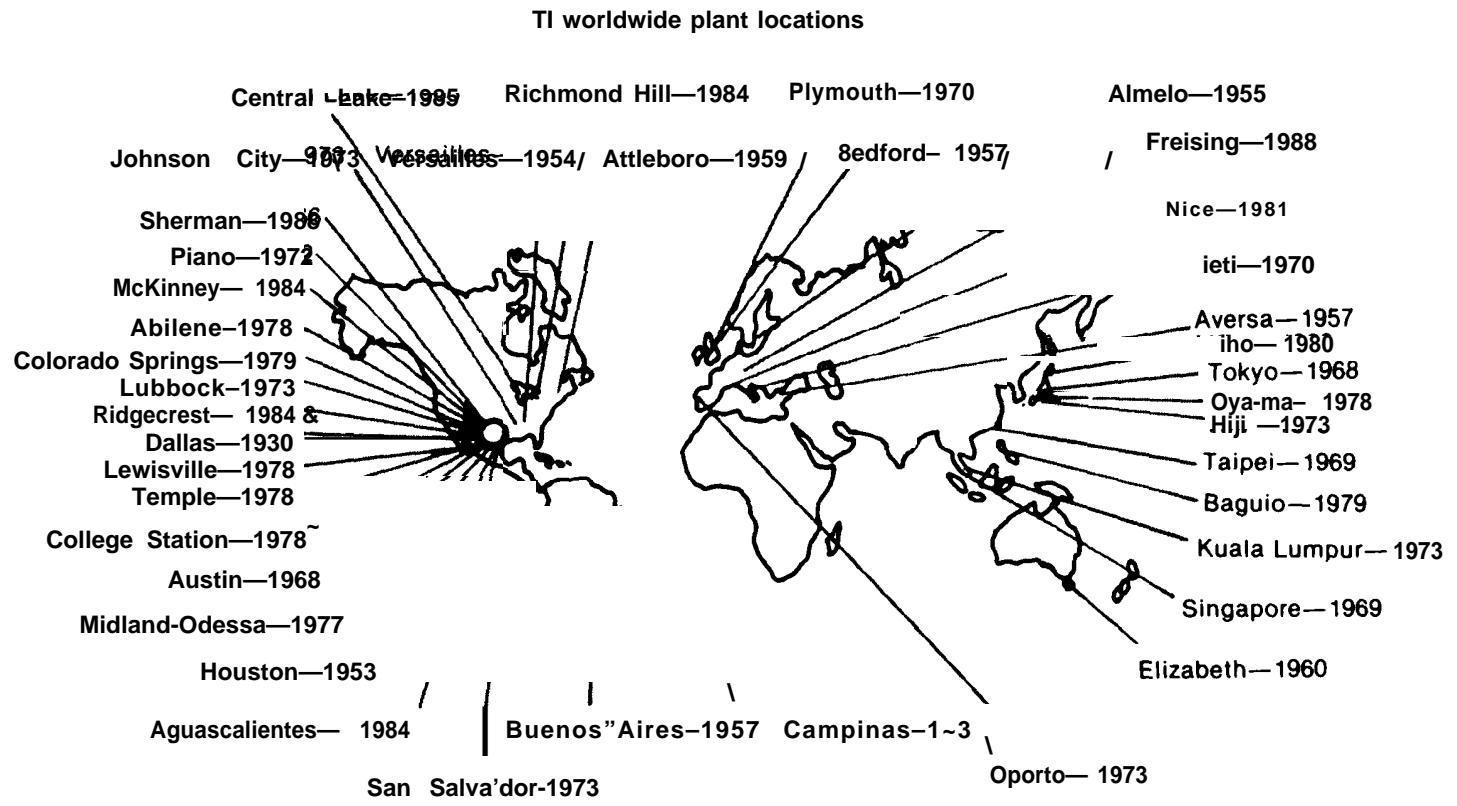

- Location and date connected

Texas Instruments' worldwide data communications and electronic mail network is an illustration of the current possibilities for multinational communications networks. It grew to its present configuration over three-decades, as domestic and overseas locations were linked by telecommunications. This shows Tl's overseas plant locations and the dates they were linked to the TI corporate network. Exchange of detailed production, engineering and financial data is routine and allows the corporation to effectively coordinate worldwide manufacturing operations. Computer-assisted design capabilities in the system also allow engineers and managers at any location to use the firm's extensive computer capabilities in the United States

SOURCE: Texas Instruments.

serves as both a communications enterprise with commercial goals and an international organization with important noncommercial goals.

ernments, such as the Soviet Union. How to characterize INTELSAT has become an element in the policy debates involving INTELSAT and COMSAT. INTELSAT and COMSAT and those supporting their positions often denote INTELSAT as a "cooperative" of owner-members. Others, in opposition to these positions, who wish to emphasize the price-and capacity-setting aspects of the organization, often characterize it as a "monopoly" or a "cartel" composed of COMSAT and the PTTs. To attempt neutral terminology in this report, we refer to it as a "consortium" or an "international organization" as appropriate.

\section{Competition in the United States Among International Communications Firms}

The major U.S. participants in international satellite communications are the same firms that dominate the massive U.S. domestic telecommunications industry. As we have noted, other large corporations would also be able to compete in all segments of a deregulated international market, should they choose to or be allowed to enter. ${ }^{34}$

Entry is likely to take place in those areas with the highest profit rates. This applies to both domestic and international markets. Although most domestic market segments are now contestable, in the sense that firms are free to enter, firms will pick and choose carefully for actual entry among the richly differentiated opportunities in the communications and information industries that are available. 
Figure 6-2.-Texas Instruments' Information Network Concept

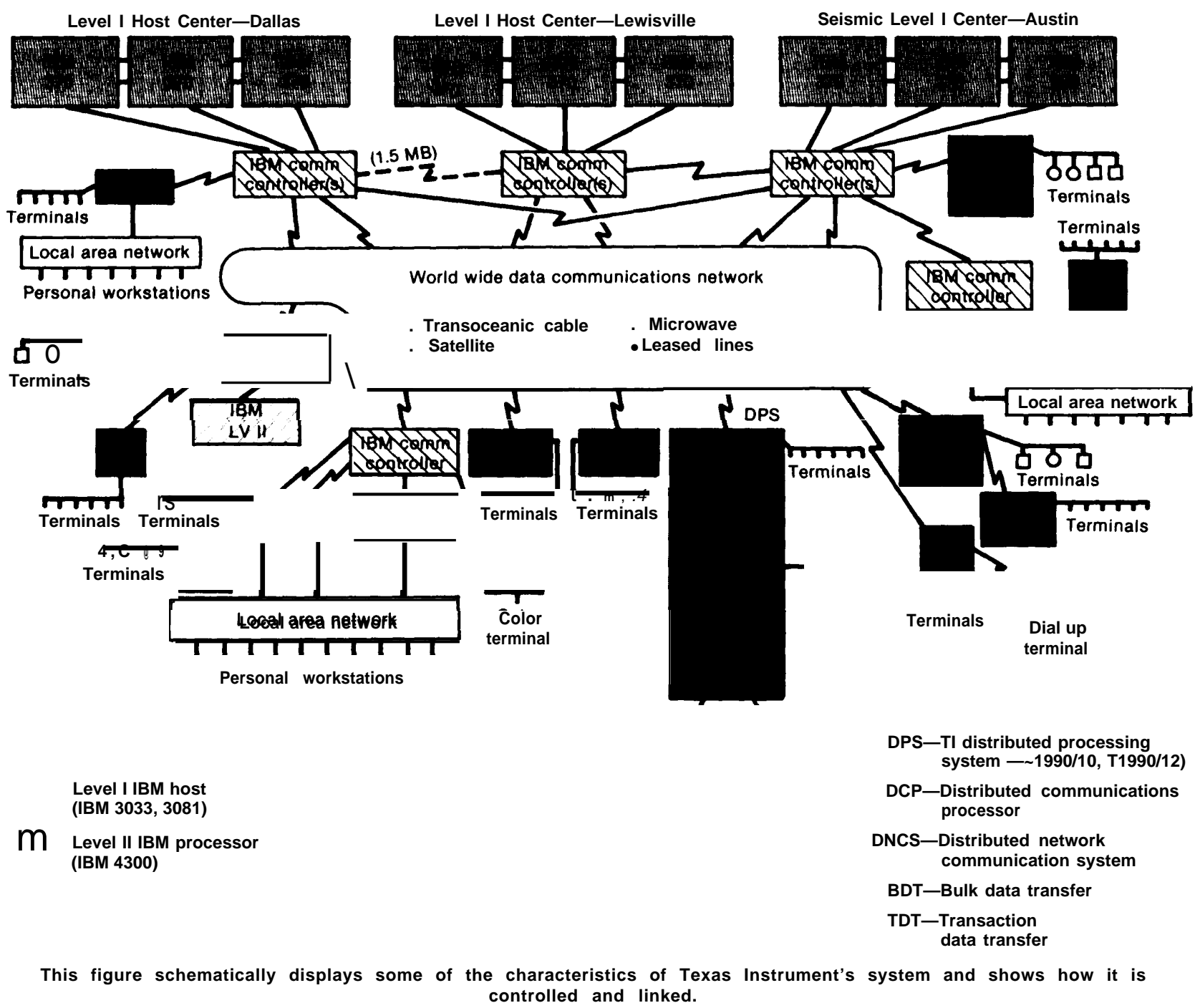

SOURCE: Texas Instruments.

An important point to make is that competition among U.S. firms takes place not only in the services and facilities markets but also in the financial markets. Firms that are successful in attracting funds are able to expand more rapidly into opportunities that become available than firms that attempt to deter entry into their traditional preserves through a strategy of keeping their prices and profits low. This second dynamic (competition in financial markets) will affect the 
Table 6-5.-Members of INTELSAT: The Major Non-U.S. Telecommunications Providers of International Satellite Communications Services

\begin{tabular}{|c|c|c|}
\hline Country & Signatory & $\begin{array}{c}\text { Investment share } \\
\text { (percent) }\end{array}$ \\
\hline Total nine countries with 3 percent or more: & & 60.7 \\
\hline United States of America $\ldots \ldots \ldots \ldots \ldots \ldots$ & Communications Satellite Corp. & 23.1 \\
\hline United Kingdom $\ldots \ldots \ldots \ldots \ldots \ldots \ldots \ldots$ & British Telecommunications & 12.9 \\
\hline France. . & Government of France & 5.6 \\
\hline Japan . . & Kokusai Denshin Denwa Co. Ltd. & 3.3 \\
\hline Germany, Federal Republic of & Ministry for Post and Telecommunication & 3.3 \\
\hline Australia. $\ldots \ldots \ldots \ldots \ldots$ & Overseas Telecommunications Commission & 3.2 \\
\hline Saudi Arabia $\ldots \ldots \ldots \ldots \ldots \ldots \ldots$ & Government of Saudi Arabia & 3.1 \\
\hline Brazil . . . . . . . . & Empresa Brasileira de Telecomunicacoes S.A. & 3.0 \\
\hline $\begin{array}{c}\text { Canada } \ldots \ldots \ldots \ldots \ldots \ldots \\
\text { The Other } 99 \text { INTELSATMembers: }\end{array}$ & Teleglobe Canada & $\begin{array}{r}3.0 \\
39.3\end{array}$ \\
\hline
\end{tabular}

'Asof Mar 1, 1964.

SOURCE: INTELSAT. See app. 6C, for a complete listing of the members of INTELSAT and their investment shares.

speed with which the old specialist structures remaining from the era of tight regulation break down and new specializations based on competitive advantage emerge.

Foreign competition in U.S. long-distance telecommunications (in both domestic and international market segments) is also a possibility now that the U.S. market is substantially deregulated. At least one foreign firm is currently seeking to enter in a substantial way. Cable \& Wireless, a British firm with some U.K. Government ownership, is reputed to be planning to enter the U.S. domestic long-distance telecommunications market by constructing an extensive fiber optic cable network laid on railroad rights of way. ${ }^{35}$ It is quite possible that telecommunications firms from other countries will also enter in the future. Cable \& Wireless, in joint venture with U.S. investors, has also applied for and received a cable landing license for a high-capacity transatlantic fiber optic cable facility (six fiber pairs) between the United States and the United Kingdom. ${ }^{3 b}$ A Cable

\footnotetext{
${ }^{35}$ Cable \& Wireless has discussed the possibility with a number of U.S. railways. (Department of Commerce, U.S. IndustrialOutlook 1984, pp. 46-51). Rights of way along highways, gas or oil pipelines, and electric utility transmission lines may also be usable ("Golden Opportunity, Can Utilities Move Fast Enough to Cash in On the Telecommunications Boom?" The Energy Daily, Nov. 16, 1984.) Mercury Communications, the new entrant in U.K. domestic telecommunications, is a wholly owned subsidiary of Cable \& Wireless, Ltd.

36 Application of Tel-Optik Ltd. (Cable \& Wireless' U.S. Partner) for a license to land and operate in the United States a submarine cable extending between the United States and the United Kingdom, op. cit.
}

\& Wireless subsidiary has already established service between the United States and Canada. s'

It may be somewhat difficult for European government-owned PTTs to compete directly in the U.S. market (selling domestic and international communications services directly to U.S. consumers) without undercutting the diplomatic justifications they make for preserving their monopolies at home. ${ }^{3 e}$ Nevertheless, the French PIT has designed its transatlantic satellites Telecom I and Videosat III with footprints (transmission area) that include the Eastern United States. (Any intent to use them for transatlantic international communications other than to reach French territories is denied by French telecommunications officials. ${ }^{39}$ Self-imposed restraints may not be as binding for certain foreign private telecommuni-

${ }^{38}$ This reticence may not be as strong in enhanced (computerprocessed) communications services, and entry via INTELSAT Business Services will be easy (Eli M. Noam, "Telecommunications Policy on the Two Sides of the Atlantic: Divergence and Outlook," op. cit., p. 16).

${ }^{39}$ The stated justification for the Telecom I satellite is to Com municate with a French island territory in the Atlantic off of Canada and French territories in the Caribbean, but there would be no technical reason why it or the successor satellite Telecom I B, scheduled to be launched in March 1985, could not be repositioned to offer competition to INTEL5AT or entry into the U.S. market (source: telephone conversation with France Telecom, Inc., October 1984). See also "French PTT Chief, COMSAT Deny Telecom 1 Will Compete With INTELSAT," Satellite News, Nov. 5, 1984. There has also been a January 1985 French filing with the IFRB for the Videosat satellite, whose footprint will include most of the Eastern United
} States. 
cations firms like KDD, ${ }^{@}$ Japan's international carrier, however, since they are not government corporations. Cable \& Wireless has led the way, but now that British Telecom has been taken private, it may also become more aggressive. Similarly, Britain's Unisat satellite (launch date 1986), which like the French satellites has a footprint covering parts of North America, ${ }^{41}$ may not be constrained from competing for U.S. business by its minority government ownership.

In sum, in the highly competitive, new U.S. telecommunications industry, very large U.S. domestic telecommunications and data processing firms, as well as a full range of large, small, and foreign new entrants, are in actual or potential competition with each other for both domestic and international communications opportunities. AT\&T may be able to keep its present dominance in domestic long-distance telephony in the new domestic market, but it will do so only by competitive success. In the long run, technological and economic forces, which are affecting regulatory structures in the national markets of other countries, as well as in the United States, appear likely also significantly to expand opportunities for firms other than AT\&T in international communications service markets. ${ }^{43}$ For the present, however, powerful barriers to change in foreign countries are still limiting these opportunities.

\footnotetext{
${ }^{40} \mathrm{KDD}$ is formally a private stock company traded on the Tokyo Stock Exchange. The private status of KDD can be overemphasized, however. Very strong Japanese Government influence enters not only through regulatory channels, but also because large blocks of stock are owned by government employee pension funds and other government employee organizations.

41 Departments of State and Commerce, "A White Paper on New International Satellite Systems," op. cit., p. 25.

${ }^{42}$ British Telecom, which had previously been separated from the postal administration, underwent majority privatization Nov. 28, 1984, and is facing limited domestic competition from Cable\& Wireless' domestic subsidiary (Mercury Communications) and from enhanced service providers. The expectation that the European PTTs will not enter the domestic U.S. telecommunications market is also subject to some question. Several European state-owned enterprises have entered the U.S. market in other industries. For instance, Renault, a French state-owned auto company has a relationship with American Motors, various European state-owned airlines have effectively competed for U.S.-origin airline passengers, and several state-owned banks have established active branches in the United States.

${ }^{43}$ One such technological force impelling change concerns telecommunications equipment. Developments in customer-premises communications equipment and in computers have undercut regulatory rules that require customers to acquire such equipment only by leasing or purchasing it from their telecommunications carrier.
}

Competition in Foreign

Telecommunications Service Markets

In "basic" telecommunications services, ${ }^{44}$ international competition in foreign markets is practically nonexistent. Most countries outside the United States do not allow competition even in domestic long-distance telecommunications; a telecommunications monopoly, owned by the government (or, alternatively, in some cases a private monopoly regulated by the government) is the prevailing mode of industry organization around the world. While a few countries, notably the United Kingdom, Japan, and Canada, are moving toward privatization and limited domestic competition, they do not as yet envisage competition from foreign (including U. S.) firms. Foreign carriers must transfer control of communications passing into (or through) the country to the PTT at the international border or to an intermediate cable or satellite consortium that subsequently passes control to the PTT.

In contrast, at the information services end of the information/communications continuum, U.S. and foreign firms, which provide interactive data processing services, compete in many national markets. For regulation to have practical effect, a boundary has to be drawn somewhere between the regulated basic communications industry and the unregulated data processing industry, since they merge into each other. Unlike the present situation in the United States, in most countries, the telecommunications entities attempt to monopolize enhanced communications and value-added network (VAN) services, which increase the efficiency of communications in private networks. (This latter technique uses computer processing to group communications into packets going to common destinations.) In a few countries, private firms, including U.S. ones, are allowed to compete freely in providing these serv-

\footnotetext{
Private purchase and interconnection of telecommunications equipment to the public network have been permitted in the United States since the 1970s and are now allowed in a variety of other countries. (See Del Meyers, Janice Drummond, and Czatdana Inan, "World Telecom Spending to Reach $\$ 78.5$ Billion This Year," Telephony, Feb. 28, 1983, p. 43.)

44) e., ordinary voice, record, data, and television transmission, where computers are not used to process the communications flow.
} 
ices. (See app. 6A for a discussion of the international regulatory regime.)

\section{International Facilities Competition}

Control of international communications sent between adjacent countries by land cable, undersea cable, or terrestrial microwave passes bilaterally at the border from one country's carrier to the other country 's. In certain cases, however, governments and carriers have devised mukilateral mechanisms of joint ownership for international satellites and transoceanic cables (described further in app. 6A). INTELSAT and INMARSAT are two such consortiums of international carriers, and there are transatlantic and transpacific cable consortiums that are jointly owned by U.S. and Canadian carriers, on the one hand, and European or Asian carriers, on the other. ${ }^{45}$

As in the provision of basic international telecommunications services, competition among firms in the provision of international transmission facilities is also almost universally not allowed. The closest thing to competition in international facilities in the current regulatory regime is the competition between INTELSAT and the various transatlantic cable consortia. Even this competition is largely managed by overlapping PTT representation in INTELSAT and the consortia, by U.S. regulatory policies encouraging the "balanced" use of both kinds of facilities, and by facilities planning processes overseen by the FCC and other regulatory authorities. ${ }^{46}$

${ }^{45}$ U.S. carrier participation in INTELSAT and INMARSAT is through COMSAT alone, in its role as a carriers' carrier, in contrast to the cable consortiums to which most U.S. service carriers belong.

46 "Balanced use," as used in this report, means the substantial use of both satellites and cables, without specifying exactly how this is to come about. At various times in the past, the FCC has used several formulas to balance the use of satellites and cables through regulation, including "proportional fill," "50-50," and "balanced loading. "The loading methodology currently in use was negotiated among AT\&T, COMSAT, and the European PTTs on a country-by-country basis and approved by the FCC. It is generally "in accordance with what is known as the 'balanced loading' methodology," defined by the FCC as the "distribution of circuits among
Recently, these arrangements have been challenged by the would-be private transatlantic and Western Hemisphere satellite and cable operators referred to above. These potential entrants have received qualified official encouragement from either the FCC, the executive branch, or both. As we discuss below and in appendix 6A, the capacity additions specified in these applications, together with INTELSAT's planned additions and the cable facilities discussed within the official planning process, are far in excess of the 1995 communications demand projected by the U.S. international service carriers and their European counterparts. ${ }^{47}$ This would appear to call into serious question the FCC planning process and/or the demand projections of the carriers.

\section{The Satellite Communications Equipment Industry}

The large-scale development of the world satellite communications service industry has been made possible by the development of a large satellite communications equipment industry, particularly in the United States. Despite severe trade restrictions and growing industrial policy chal-

\footnotetext{
facilities with unused capacity in a manner which, to the extent possible, seeks to place equal numbers of circuits on all transmission systems" [emphasis added] (Federal Communications Commission, "Second Notice of Proposed Rulemaking in the Matter of ... Authorization of Common Carrier Facilities to Meet North Atlantic Telecommunications Needs During the 1985-1995 Period," FCC 85-176, released Apr. 22, 1985, p. 3). See below and app. 6A for further discussion of facilities regulation.

${ }^{4}$ For transatlantic communications the FCC has received applications to install satellite capacity of about 120,000 circuits and fiber optic cable capacity of about 330,000 circuits in addition to the proposed capacity additions of the traditional consortia listed in table 6-A2 in app. 6A. See also discussion of alternative satellite providers below and in app. 6A. The additional 330,000 circuits of cable capacity, for which cable landing licenses have been applied, are in the cable projects of Cable \& Wireless and its U.S. partners (Tel-Optik) and Submarine Lightwave Cable Co., which

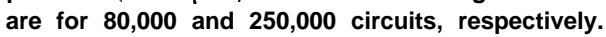


lenges from Japan and Europe, U.S. manufacturers continue to dominate world sales of communication satellites. U.S. ground equipment manufacturers, however, no longer dominate the world market for large standardized Earth stations, and though they still lead in the market for small Earth stations designed for customer premises, they are beginning to receive strong foreign competition there as well, ${ }^{48}$

\section{World Satellite Markets}

For the satellite manufacturing industry, the non-Communist world market can be conveniently divided into five parts: the United States, INTELSAT, Canada, Europe and Japan considered together, and the rest of the world. During the 1965-83 period, INTELSAT was the largest of these markets, with 35 satellites launched, followed by the United States with 26 (as shown in table 6-6). U.S. prime contractors manufactured all 72 of the commercial communication satellites sold outside of Europe and Japan during the 1965-83 period. In contrast, European and Japa-

\footnotetext{
${ }^{48}$ Customer premises Earth stations can be defined as stations which are located at the point of use.
}

nese contractors produced only the eight satellites launched for European and Japanese buyers during the same period and sold none outside of these reserved markets. In the case of the Japanese satellites placed in orbit, a U.S. company provided many of the components and provided technical assistance.

In the 1984-89 period, for satellites whose prime contractors have already been announced, the pattern is similar, with the one important exception that the United States is expected to be by far the largest single market, with 53 percent of the scheduled satellites during this period (see table 6-6). U.S. satellite buyers are of several types: private communications firms such as AT\&T, Western Union, COMSAT, GTE, Federal Express, and IBM's Satellite Business Systems (SBS) subsidiary, direct broadcasters (e.g., Dominion Video Satellite Corp.), and several smaller and newer firms that provide specialized satellite facilities to business and media customers (e.g., American Satellite). The three major U.S. satellite manufacturers-Ford, RCA, and Hugheshave also launched, or plan to launch, their own satellites for lease or self-use. RCA plans to use its satellites in its own common carrier operations,

Table 6-6.-U.S. Market Share of Commercial Satellite Prime Contracts

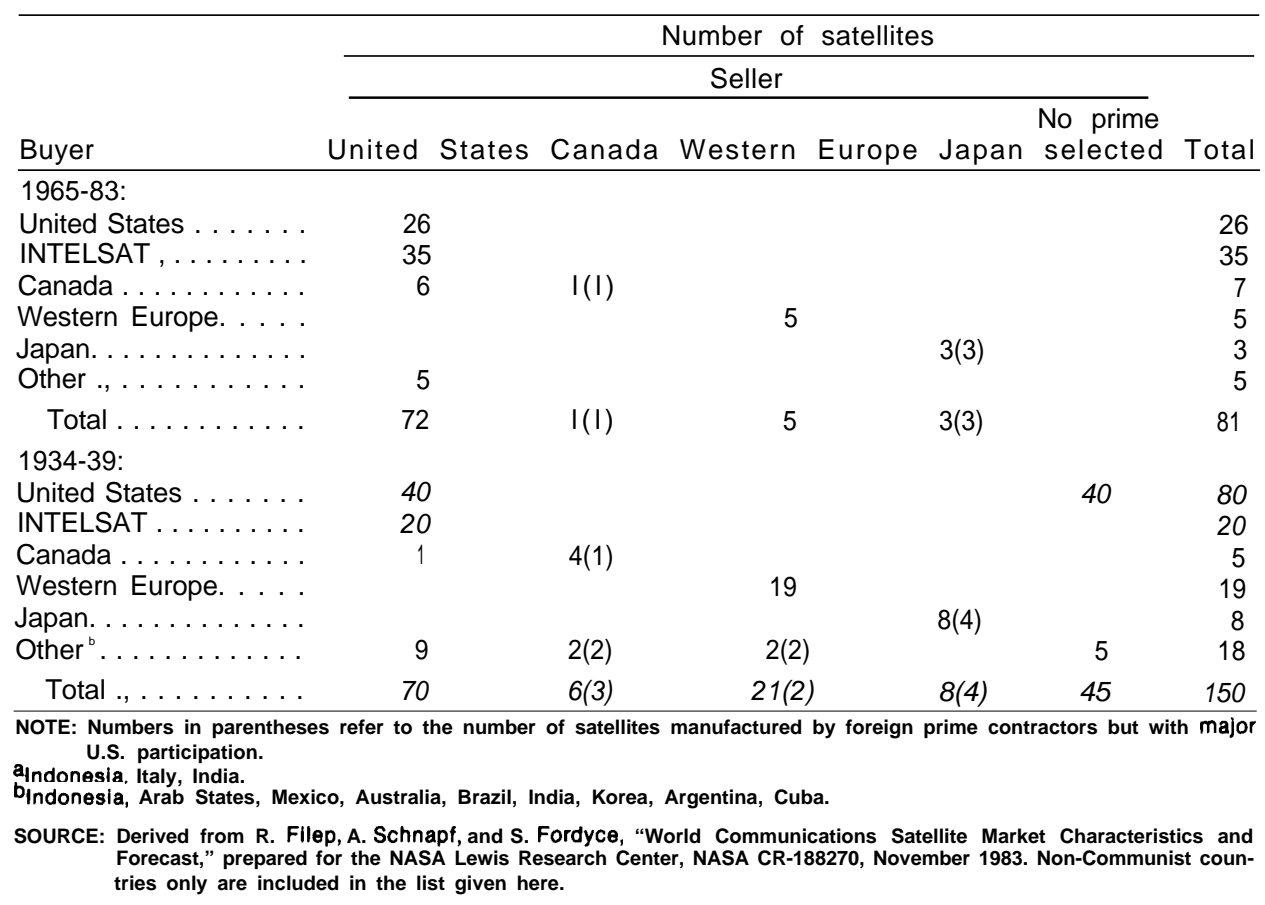




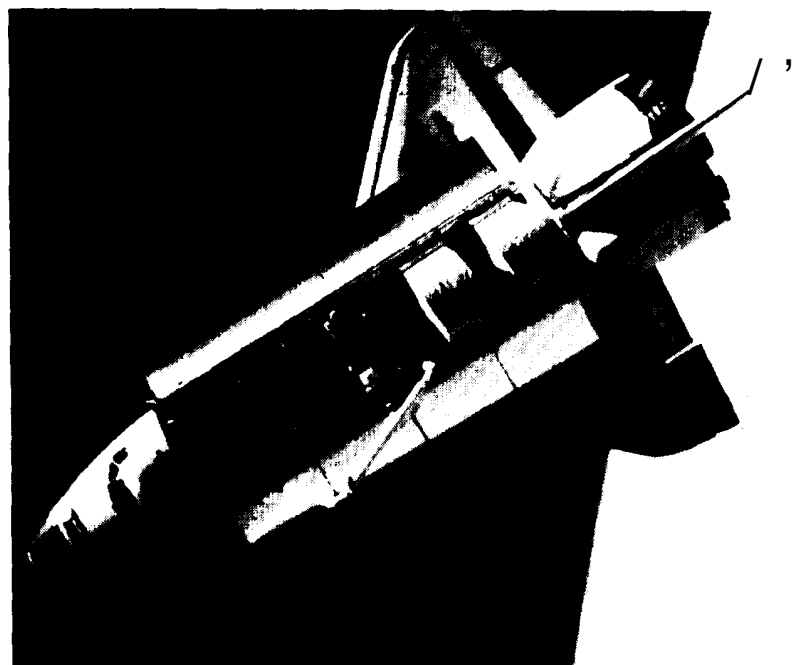

S B B $\stackrel{S}{W}$

both domestically and internationally, and all three either lease facilities to other firms now, or plan to.

In the rest of the world, the buyers are almost always governmental entities such as the Indonesian and other ASEAN ${ }^{49}$ PTTs, for the Palapa series, or the Arab League consortium of PTTs for Arabsat.

For the period 1984-89, all sales of communications satellites to U.S. buyers and to INTELSAT (where prime contractors are known) have gone to U.S. prime contractors. ${ }^{\text {so }}$ All 19 of the European contracts went to European contractors, and all 8 of the Japanese contracts went to Japanese contractors (see table 6-7). U.S. satellite manufacturers will still participate in major ways in four of the eight Japanese satellites to be launched during this period, but the other four will be manufactured by Japanese firms without the formal association of an American satellite manufacturer and will use key components of

\footnotetext{
${ }^{49}$ Association of Southeast Asian Nations.

${ }^{50}$ Contractors had been selected, however, for only 40 of the 80 announced US. satellites. Whether they will all be built will depend on whether sufficient demand for U.S. domestic satellite communications services develops.
}

Japanese design. ${ }^{51} n$ the rest of the world in the 1985-89 period, U.S. manufacturers are the prime contractors for, or have major involvement in, all but three of the satellites with announced contractors. These three satellites are being built by a Canadian prime contractor (Spar) for Canadian buyers.

Although the United States continues to dominate markets where competition is allowed, it should be noted that Canadian, European, and Japanese manufacturers are now able to build significant numbers of satellites without major U.S. involvement, albeit within the confines of protected markets. European and Japanese capabilities have grown even more at the component level, U.S. manufacturers were awarded the prime contracts for the current (INTELSAT $V$ and $\mathrm{V}-\mathrm{A}$ ) and the next (INTELSAT VI) generation of INTELSAT satellites, but non-U.S. subcontractors received contracts for 23 and 21 percent, respectively, of the contract value of the two satellite series .52

\section{Satellite $R \& D$}

Even though NASA funded relatively little communication satellite research and development during the 1973-83 period, U.S. market dominance persisted. U.S. industry was relied upon to finance its own R\&D efforts. During the same period, however, foreign government-funded satellite communications $R \& D$ increased substantially. At present, the governments of Japan, Canada, United Kingdom, France, Germany, and Italy; the European Space Agency; and INTELSAT are all funding significant satellite communications research programs. ${ }^{53}$ This imbalance in government $R \& D$ support led to concern in the United

51 R. Filep, A. Schnapf, and S. Fordyce, "World Communications Satellite Market Characteristics and Forecast, " prepared by Communications 21 Corp., Redondo Beach, CA, for the NASA-Lewis Research Center, Cleveland, OH, NASA CR-1 68270, November 1983.

${ }^{52}$ Filep, et al., op. cit., p. 101

53SeeR'. Filep, A. Schnapf, and S. Fordyce, "Japanese and Western European Space Research and Development, " unpublished paper prepared for NASA Lewis Research Center, Feb. 1, 1984. See also U.S. Congress, Office of Technology Assessment, Information Technology R\&D: Critical Trends and Issues, OTA-CIT-268 (Washington, DC: U.S. Government Printing Office, February 1985), ch.7. 
Table 6-7.-Prime Contractors for Commercial Communications Satellites (by launch period)

\begin{tabular}{|c|c|c|c|}
\hline Company & Country & $\begin{array}{l}\text { Actual } \\
1985-83\end{array}$ & $\begin{array}{r}\text { Planned } \\
1984-89 \\
\end{array}$ \\
\hline \multicolumn{4}{|l|}{$\begin{array}{l}\text { Prime contractor: } \\
\text { [First launch } 1983 \text { or before] }\end{array}$} \\
\hline Hughes Aircraft . . . . . . . . . & United States & 45 & 33 \\
\hline Ford Aerospace . . . . . . . & United States & 10 & 10 \\
\hline RCA Astro-Electronics. & United States & 9 & 27 \\
\hline TRW Defense and Space Systems. & United States & 8 & 0 \\
\hline British Aerospace Dynamics & United Kingdom & 4 & 9 \\
\hline Melco/Ford Aerospace . . . . . & Japan/United States & 3 & 1 \\
\hline C.N,S. . . . $\ldots \ldots \ldots \ldots$ & Italy & 1 & \\
\hline Spar Aerospace/Hughes Aircraft. & CanadaWnited States & 1 & : \\
\hline Total . & & 81 & 84 \\
\hline \multicolumn{4}{|l|}{$\begin{array}{l}\text { Additional prime contractors: } \\
\text { [First launch } 1984 \text { or later] }\end{array}$} \\
\hline Eurosatellite . . . . . . . . & West European Consortium & & 5 \\
\hline Melco (Mitsubishi Electric Co.). & Japan & & 4 \\
\hline Toshiba/GE . . . . . . . . . . . & Japan/United States & & 3 \\
\hline Spar Aerospace. & Canada & & 3 \\
\hline Matra Space. & France & & 2 \\
\hline Aerospatiale (with Ford Aerospace) & France/United States & & 2 \\
\hline Siemens/MBB/ERNO/AEG/ANT . & West European Consortium & & 2 \\
\hline Total $\ldots \ldots \ldots \ldots \ldots \ldots$ & & & 21 \\
\hline $\mathrm{Pr} / \mathrm{rne}$ contractor not yet selected: & & & 45 \\
\hline Grand total . & & 81 & 150 \\
\hline \multicolumn{4}{|c|}{$\begin{array}{l}\text { aFo, the period "Beginning of } 1990 \text { " Through "The End of } 1999, " 18 \text { prime contractors have been selected (Of which } 11 \text { are } \\
\text { U. S.) for specific satellites. During this same period, } 149 \text { satellite projects as yet have no prime contractor selected. }\end{array}$} \\
\hline \multicolumn{4}{|c|}{$\begin{array}{l}\text { SOURCE: Derived from R. Filep, A. Schnapf, and S. Fordyce, "World Communications Satellite Market Characteristics and } \\
\text { Forecast," prepared for the NASA Lewis Research Center, NASA CR-188270, November 1983. Non-Communist coun. } \\
\text { tries only are included In the list given here. }\end{array}$} \\
\hline
\end{tabular}

States that the United States could be behind in the technology of the next generation of communications satellites and was a prime motivation for Congress funding NASA's Advanced Communication Technology Satellite (ACTS) program at higher levels in fiscal year 1985 than previously. ${ }^{54}$ (See below for further discussion of the ACTS program.)

\section{Competitive Factors in International Satellite Markets}

The price/quality dominance of U.S. manufacturers has been the most important competitive factor in both the U.S. domestic market and in INTELSAT contracts. Even the strong dollar has not hampered their recent successes. Other competitive factors helping U.S. firms are their wellknown experience and the operational reliability of their satellites.

\footnotetext{
${ }^{54}$ Chris Bulloch, "Advancing the Art of Satellite CommunicationsForeign Competition Spurs NASA Satcom Research," Interavia, January 1985 , pp. $25-28$.
}

Protection and discriminatory government procurement are major factors segmenting world satellite markets and are the major factors determining sales of satellites in Europe and Japan. European and Japanese space development policies have included restrictions on procurement of complete satellites in order to favor national development of space technology. ${ }^{55}$ Recent policy changes, however, may make possible the sale of U.S. communications satellites in Japan. ${ }^{5 b}$

\section{World Earth Station Markets}

In contrast to the relatively small number of satellite manufacturers, more than 25 sizable firms

\footnotetext{
55"Japan's Satellite Development Program," Japan Economic Institute Report, Washington, DC, No. 11A, Mar. 16, 1984 and "Aerospace in Japan: Competition Through Partnership," Aerospace America, March 1985, pp. 68-70. See also Neil Davis, “Japan Broadens Domestic Role in Satellite Development, "Aerospace America, February 1985, p. 27.

${ }^{56}$ See "New Trade Policy May Boost Japanese Imports of Satellites," Aviation Week and Space Technology, May 7, 1984, p. 16; and William Chapman, "Japanese Trade Plan Seems to Open Door for U.S. Satellite Sales," The Washington Post, Apr. 28, 1984, p. A20.
} 
in 7 countries manufacture Earth station equipment (see app. 6B). The equipment for an Earth station is diverse and includes antennas, tracking systems, amplifiers, ground communication equipment, multiplex equipment, and, for larger installations, support buildings and equipment (for air-conditioning, controls, power, etc.) .57 Earth stations vary considerably in size, from large stations, such as the INTELSAT Standard A stations that send and receive most international trunk communications, which have 30-meter antennas, to receive-only equipment whose antennas are less than 1 meter in diameter. INTELSAT Standard A stations cost $\$ 5$ million to $\$ 9$ million each (higher-density INTELSAT $C$ stations can cost up to $\$ 15$ million), compared to 5 -meter and smaller transmit and receive stations that might cost $\$ 200,000$ to $\$ 300,000$. $^{58}$ Small receive-only stations, such as those used for CATV or home reception, can cost as little as $\$ 2,000 .^{59}$

The larger stations are purchased mainly by common carrier communications firms, which carry domestic and international switched voice and message traffic and television. Common carriers also use medium-sized stations in locations with smaller traffic volumes. Specialized data and television carriers and firms operating private communications networks use medium-sized Earth stations located on "customer premises." Receive-only stations on customer premises are typically small and are used only for television and data reception. They may be purchased by businesses for point-to-multi-point teleconferencing networks or data transmission (when it can be carried out at slow speeds) and by home consumers for television reception.

Nippon Electric Co. (NEC), a Japanese firm, is the largest manufacturer of large nonmilitary Earth stations, having manufactured approximately one-third of all such stations around the world .61 The cumulative market shares, by coun-

\footnotetext{
${ }^{57}$ Eloise Jensen, Tracey Harbaugh, Kenneth Telesca, and James Mahoney, "Sector Study-Satellite Earth Stations, "The ExportImport Bank, Washington, DC, June 1984.

${ }^{58} 1$ ndustry sources.

${ }^{59}$ Unpublished memorandum, Ford Aerospace \& Communications, 1981.

${ }^{60} \mathrm{Chris}$ Bulloch and Paul Rubin, "Satellite TelecommunicationsThe Ground Segment Grows, "Interavia, November 1984, pp. 1231-1235.

b'ibid., p. 1233.
}

try, for major suppliers from various countries for INTELSAT standard A and $B$ stations are shown in table 6-8. Over the whole period, U.S. major firms had the largest share-39 v. 37 percent for Japanese firms-but this larger share of U.S. firms reflects their early dominance. Japanese firms now dominate new orders.

In addition to leading in sales of standard INTELSAT Earth stations, NEC also leads in large and medium-sized domestic-system Earth stations. It sold in excess of 500 Earth stations in 15 countries prior to 1984 and is particularly strong in total equipment technology.

Despite its worldwide preeminence, up to the present, NEC has rarely been seen as a major competitor in U.S. Earth station sales. Nevertheless, it recently penetrated the U.S. market in a significant way, with the sale of $130 \mathrm{RF}$ terminals (antennas and radio-frequency electronics) to IBM's Satellite Business Systems network. (IBM provided its own digital baseband equipment.)

in Europe, Alcatel-Thompson/Telspace is the largest manufacturer of Earth stations, with approximately 580 systems of all types operating, under installation, or on order. It has supplied 30 INTELSAT Standard A terminals plus another 30 Standard B and C stations for international traffic and 21 for domestic leased-capacity traffic. It is also supplying 467 stations for France's Telecom 1 network. Of these, 350 will be the 2.0 to 2.3 meter video receive-only type and 116 will be 3.5 meter business data transmit/receive terminals.

\footnotetext{
62lbid., P. 1234; Richard Shaffer, "Japanese Now Target Communications Gear as a Growth Industry, "The Wall Street fournal, Jan. 13, 1983, p. 1.

Table 6-8.-Earth Station Market Shares, By Country of Supplier, For the Period 1965-82

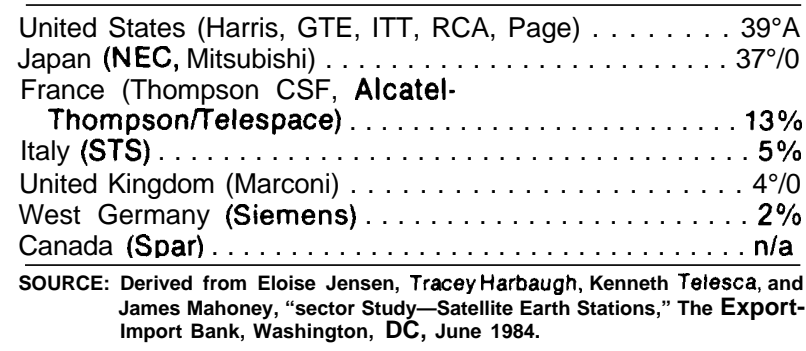
James Mahoney, "sector Study-Satellite Earth Stations," The ExportImport Bank, Washington, DC, June 1984. 
Although U.S. manufacturers are no longer the dominant suppliers of large Earth stations as they were in the beginning phase of satellite communications, they continue to win contracts for INTELSAT A and B stations and are particularly competitive in specialized, medium-sized Earth stations for domestic satellite systems, which are a growing part of world demand, and in digital subsystems associated with large station networks. ${ }^{63}$ This has resulted in U.S. companies such as Scientific Atlanta, Harris, GTE, and M/A Corn increasing their relative share of U.S. exports of Earth stations or associated equipment. ITT, RCA, and Page have seen their exports decline. California Microwave is an important additional participant in the U.S. domestic Earth station market.

Customer-premises Earth stations include small to medium-sized transmit/receive Earth stations as well as television and data receive-only equipment. Although reliable sales data is not available for sales of customer-premises Earth station equipment, because satellite ground equipment is not broken out of the more inclusive data category for telecommunications equipment as a whole, it appears that, worldwide, most such stations are manufactured by U.S. firms and sold in the United States. ${ }^{b 4}$ The direction of technological change is toward higher-power, more sophisticated satellites making possible smaller, less expensive, but technically advanced Earth stations that can be used for corporate data transmission and videoconferencing. U.S. firms, represented by Scientific Atlanta, M/A Corn, and numerous smaller firms, are still dominant at this end of the market, and appear to have the technical edge, particularly in equipment for digital transmission. ${ }^{\text {bs }}$

Television receive-only Earth stations (TVROS), which are primarily used to feed large or small television cable networks, are already a large part of the total demand for Earth stations in the United States and are becoming so in Europe, where a major proportion of Eutelsat's ECS system capacity is devoted to TV distribution. Whether the market for TVROS will continue to

\footnotetext{
${ }^{63}$ Jensen, et al., op. cit., p. 10.

@private communication, International Association of Satellite Users and Suppliers, March 1985

${ }^{65}$ Jensen, et al., op. cit., June 1984.
}

grow will depend on the ultimate popularity of high-power direct broadcasting systems (DBS) designed to feed very small home TVROS. Scientific Atlanta has supplied over 10,000 Ku-band TVRO Earth stations to individual cable systems. The company has also supplied video uplink stations to over 350 U.S. television stations. Harris Corp., another major U.S. supplier of cable TVRO stations, is the contractor for 180 ground stations for NBC television affiliates. DBS receiving dishes, if a mass residential market develops, will undoubtedly be sold through consumer electronics channels. Somewhat larger and more expensive TVRO dishes, capable of tapping directly into existing cable distribution systems, are already being marketed in this way (see app. 66 of this chapter).$^{66}$

A significant and growing number of mediumsize and small Earth stations, ranging from oneway data to full two-way voice and data, are being used in corporate networks and in shared tenant systems operated by office building management firms. These networks, using small send/ receive Earth stations, are now very competitive in cost with established local and long-distance telephone companies for two-way voice communication. This has been called the "bypass problem"; the equipment itself is said to embody "bypass technology."

A U.S. firm, Equatorial Communications Co., has been very successful in marketing very small, receive-only dishes, only 2 feet in diameter, that permit reception of computer data at relatively slow speed but at a cost only about 60 percent of AT\&T's charges for functionally equivalent private-line service. Major corporations, such as the Associated Press, Reuters, Dow Jones, and E.F. Hutton, concentrated in the media and financial sectors, have collectively purchased 20,000 of these $\$ 2,500$ one-way dishes in the last 3 years. In 1984, Equatorial began to sell a new line of 4-ft send/receive digital Earth stations for lowspeed data transmission. ${ }^{67}$

The most rapid growth in demand for satellite services (primarily domestic), and in ground equipment, will probably occur in the data, tele-

\footnotetext{
${ }^{66}$ Bullock and Rubin, op. cit., November 1984, p. 1232.

67"Tiny Satellite Dishes Are Serving Up a Hot New Market, "Business Week, Mar. 11, 1985, pp. 102, 106.
} 
vision distribution, and videoconferencing areas. Business data services are projected to be the largest growing segment of the satellite communications market. Internationally, INTELSAT has developed new E- and F-Standard stations for its INTELSAT Business Service. California Microwave, Fairchild, and GTE are the primary competitors in this field, and Scientific Atlanta has developed an Integrated Business Terminal that is roof-mounted, fully remote controlled, and requires no air-conditioning. Rural thin-route telephony and mobile services, while not a large element in total sales, may require a large number of Earth receiving units.

\section{Competitive Factors in International Earth Station Markets}

The competitive factors influencing sales of Earth station equipment are different in the three market segments: 1 ) INTELSAT and other large standardized Earth stations, 2) medium-sized, "domestic" Earth stations, and 3) television and data receive-only equipment.

In the world market for large Earth stations, where typical contracts are in the $\$ 5$ million to $\$ 15$ million range, procurement restrictions and price (including the cost of financing) appear to be the principal competitive factors affecting international market shares. The Japanese, French,

German, and Italian markets are essentially closed to U.S. manufacturers of INTELSAT and domestic-satellite Earth stations because of government procurement restrictions. The markets of other European countries, though, are not fully closed. In recent years there have been sales by Japanese companies in the United Kingdom, Sweden, and Turkey. But these markets are not fully open either. The problem is that the buyers of large Earth stations are usually PTTs, which are not covered by the GATT Government Procurement Code, and they typically discriminate in favor of local manufacturers or make other discriminatory purchases. In the case of Japan, even if the telecommunications sector should be opened generally to foreign telecommunications equipment, NEC would probably still dominate the market for large Earth stations for the same reasons of low price and high quality that have led to its current dominance in other world markets outside of Europe.
In the rest of the world-the United States, the smaller industrial countries outside the EEC, and the developing world-price appears to be the principal competitive factor in the sale of large Earth stations. Subsidized financing through the use of mixed credits has been a determining factor in a some sales to developing countries. ${ }^{68}$ Other competitive elements in sales to developing countries have been political factors (Frenchspeaking West Africa) and the willingness of suppliers to meet local content thresholds (Brazil). ${ }^{\text {bg }}$ For large Earth stations, superior technical features appear as a competitive factor only in the digital subsystems. NEC (particularly outside the United States) and U.S. manufacturers like M/A Corn, COMSAT, Comtech, and Fairchild appear to have a competitive advantage in these subsystems.

Technical features are a more important competitive element for medium-size customer premises Earth stations than in large ones, because technical change is faster and customer needs are more differentiated. For this reason, restrictive telecommunications standards join restrictive procurement practices as trade barriers to U.S. exports to Europe and Japan .70 Industry sources in the United States believe that both the Japanese and EEC markets are effectively closed to U.S. manufacturers of customer premises and domestic-system Earth stations at the present time." Exporting to these markets, however, is likely to be more possible in the future, as businesses in foreign countries increasingly come to use customer premises equipment in corporate information/communications networks and seek to control it through ownership, rather than lease it from

\footnotetext{
${ }^{68}$ Jensen, et al., op. cit., app. 11. Also Robin Day Glenn, "Financing of United States Exports of Telecommunications Equipment, " International Law Institute, Georgetown University, Washington, DC, 1982, pp. 34-39.

${ }^{69}$ Jensen, et al., Op. cit., p. 9.

70As a ControlData executive put it, "If you' re trying to bring in a competing product, a written request may gather dust for four years before it's certified by the PIT, " quoted in Gary Stix, "PTTs Make Life Rough Overseas," Computer Decisions, Apr. 9, 1985.

71 "Europe's Technology Gap, " The Economist, Nov. 24, 1984, pp. 93-98. Shaffer,op. cit.; U.S. Department of Commerce International Trade Administration, Country Market Survey- Telecommunications Equipment: Japan, CMS/TCE/558/83, April 1983; John Burgess, "Japan's Phone Shake-Up May Profit U.S. Firms," The Washington Post, Nov. 18, 1984, p. 51; and "Phone Market: Japan Keeps Hanging Up on the U.S., "Business Week, Mar. 11, 1985, p. 67.
} 
the PIT. In the case of Japan, while domestic telecommunications privatization and competition and trade understandings with the United States may succeed in opening up some sectors of Japan's telecommunications market to foreign competition, industry sources are skeptical that it will have measurable impact in the Earth station market.

In any case, by far the largest portion of the world market for customer premises Earth stations is currently in the United States. In this market, dozens of established and new firms compete for the business of corporate networks and sharedtenant systems in office buildings. Because technical change has been rapid in the customer premises segment, the ability to assist customers with technical sales support activities is an important competitive factor in addition to price.

At the low end of the market, the receive-only segment, the world market is again principally concentrated in the United States. When the product sold is simply the equipment, the principal competitive factor is price. When the prod- uct is sold as part of a data-transmission service package, however, the price of the equipment has not been the major factor. The large numbers of small receive-only dishes sold (or leased) by Equatorial Communications, for instance, are not in competition with other small Earth stations. Rather as a required component of Equatorial's spread-spectrum service, they compete with terrestrial alternatives such as packet-switching services. price competition may become more intense as new firms enter the market for small-dish satellite data transmission services, however.

One indication that this may happen in the near future is that a significant number of firms are now in bidding competition to provide approximately 50,000 small transmit/receive Earth stations for Federal Express's Zap Mail service. Besides Equatorial, the main contenders are NEC, Mitsubishi/ COMSAT, Fujitsu, and Matsushita (in collaboration with Harris and Scientific Atlanta). The bidders on this huge contract ( $\$ 500$ million to $\$ 750$ million) may be in a position to challenge Equatorial's dominance in other sectors of the market for small data-oriented Earth stations.

\section{COOPERATION AND COMPETITION ISSUES IN INTERNATIONAL SATELLITE COMMUNICATIONS}

\section{International Context of Satellite Communications}

By its nature, the world satellite communications network is an important arena for international cooperation. The United States participates with other nations in a number of specialized international institutions producing satellite communications services and dealing with the regulation of international telecommunication services. Because of the politics of these organizations, U.S. telecommunications interests are frequently linked to wider foreign policy concerns, and conflict originating in diverse contexts can spill over into telecommunications matters. *

\footnotetext{
*See ch. 3 for an in-depth discussion of issues relating to the U.S. role in international organizations. See also Unispace '82: A Context for Cooperation and Competition, op. cit.
}

In recent years the reverse process also appears to be occurring. Conflicts originating in the satellite communications area now affect broader U.S. foreign policy interests. These conflicts, in turn, have grown out of two fundamental trends in satellite communications:

1. The expansion of the world's satellite communications industry is producing potential crowding in the geostationary orbit. ${ }^{72}$ This has resulted in conflict with developing countries in international organizations. ${ }^{73}$

2. Technology-driven change in satellite networks, data processing, and telecommunica-

\footnotetext{
${ }^{72}$ See box, p. 174 for a description of the use of the geostationary orbit for communication satellites.

${ }^{73}$ Certain industrialized countries, notably Canada, may also have interests that potentially conflict with those of the United States with regard to the geostationary orbit.
} 
tions generally is upsetting the current international regulatory regime and the existing cooperative arrangements in satellite communications. ${ }^{74}$ It has resulted in conflict between the United States and other industrial countries.

The expansion of the world's satellite communications industry has made access to the geostationary orbit an issue. It is basically a "NorthSouth" issue between the industrial countries of the "North" and the developing countries of the "South." The crowding that is currently developing in that portion of the geostationary orbit that serves the Western Hemisphere, mostly for satellites broadcasting in the $\mathrm{C}$ band, is the result of the continuing expansion of U.S. domestic satellite systems. A World Administrative Radio Conference of the International Telecommunication Union scheduled to convene in August 1985 will attempt to develop new international mechanisms to deal with the issue.

Prospective moves by the United States to alter the international regulatory regime in satellite communications (discussed above and in app. 6A) constitute a second major satellite communications issue..$^{75}$ It is primarily a "North-North" issue between the United States and other industrial countries but has an important "North-South" dimension as well. ${ }^{7 b}$ The general issue is whether the United States should attempt to derive the benefits of the free market in international telecommunications, as it does in most other industries, even if other countries are opposed to competition.

The most contentious specific issue at present is whether the United States should allow the entry of U.S. firms into transatlantic satellite communications in full or partial competition with the International Telecommunications Satellite Orga-

\footnotetext{
${ }^{74, '}$ 'International regulatory regime" is defined in note 6 above in this chapter.

${ }_{75}$ For a treatment of how certain aspects of the international regulatory regime affecting frequency allocations evolved, see David M. Leive, International Telecommunications and International Law: The Regulation of the Radio Spectrum, Oceana Publications, 1970. ${ }^{76} \mathrm{~A}$ currently controversial issue within I NTELSAT is the concern that less developed countries have about the impact of competition in the North Atlantic on the present global averaging of the INTELSAT unit charge.
}

nization (INTELSAT). As described below, an initial move was made in this direction in November 1984, when the Reagan Administration found that private satellite systems were "required in the national interest. ${ }^{77}$ The decision to allow U.S. firms to launch private satellite communications facilities in competition with INTELSAT has the potential for causing difficulties with other governments that actively seek to limit competition in telecommunications. Beyond the INTELSAT issue, the United States must also face the broader question of how much conflict to allow into the necessarily cooperative regulation of international communications.

A second highly contentious competition issuethe issue of access for U.S. telecommunications equipment manufacturers into other industrial country markets-also arises because the United States wishes to derive the benefits of free markets in telecommunications equipment, both within the United States and in international trade. The open market for telecommunications equipment within the United States has brought into sharp relief the restrictionist policies of other industrial countries toward trade in satellite and other communications equipment.

These conflicts with other countries in international satellite communications can best be understood in the organizational context in which the United States participates with other countries in operating and regulating the international satellite communications system.

\section{U.S. Participation in International Organizations Concerned With Telecommunications}

In international satellite communications, the United States interacts with other nations both through bilateral diplomacy and within international institutions. Outside of North America, formal bilateral telecommunications service agreements of any substance between the United States and other governments are rare, but bi-

\footnotetext{
77Presidential Determination No. 85-2, Nov. 28, 1984. This has been elaborated in Departments of State and Commerce, "A White Paper on New International Satellite Systems, " op. cit.
} 
lateral activity takes place short of formal agreements. In addition to according representation to U.S. commercial interests, the Government is diplomatically active in connection with its participation in the activities and meetings of international organizations.

Such organizations include:

1. International Telecommunication Union (ITU):

-Consultative Committee on Radio (CCIR) -Consultative Committee on Telephone and Telegraph (CCITT)

-World Administrative Radio Conferences (WARC)

-Regional Administrative Radio Conferences (RARC)

- International Frequency Registration Board (IFRB)

2. United Nations Committee on the Peaceful Uses of Outer Space (COPUOS)/United Nations General Assembly

3. United Nations Educational, Scientific and Cultural Organization (UNESCO) [United States withdrew at the end of 1984]:

-International Program for the Development of Communication (IPDC)

4. Universal Postal Union

5. International Telecommunications Satellite Organization (INTELSAT)

6. International Maritime Satellite Organization (INMARSAT)

7. Organization for Economic Cooperation and Development (OECD):

-Committee on Information, Computer, and Communications Policy (ICCP)

8. North Atlantic Consultative Process (NACP): ${ }^{78}$

-European Conference for Post and Telecommunications (CEPT)

9. Organization of American States (OAS):

- La Conferencia Interamericana de Telecomunicaciones (CITEL)

\footnotetext{
78While not a formal organization', the North Atlantic Consultative Process is an organized effort involving the European PTTS, U.S. International Service Carriers, the Federal Communications Commission and other U.S. and foreign governmental entities in ongoing facilities planning activities. There is an even more informal $\mathrm{Pa}$ cific Planning Process.
}

The ITU and Other Specialized United Nations Agencies

The first four organizations in the above list are within the United Nations group of organizations and, if voting takes place, operate within the rules of one-nation-one-vote typical of such organizations. They perform the international regulatory functions of setting the legal framework for the use of space, setting telecommunications standards, allocating radio frequencies, and allotting positions in the geostationary orbit. The dominant politics of such organizations is the general politics of "North-South" relations between the industrialized and the developing nations.

Superimposed on the North-South politics are the East-West politics of Soviet-U. S. confrontation and the "North-North" alliance-cum-competition politics of the industrial countries. ${ }^{79}$ When substantive regulatory decisions are taken in regular or special meetings of the ITU or other specialized U.N. bodies, the general practice of the past has been to develop as much consensus as possible on conventions to be submitted to governments for ratification .80

At ITU meetings, many votes are taken, but to preserve the consensus on basic issues, delegates usually agree to reschedule unresolved major issues for later resolution. Certain significant issues dealing with the allotment of the geostationary orbit, for instance, were not dealt with at the 1979 World Administrative Radio Conference (WARC) of the ITU because of their controversiality. instead, the issues were put off for future consideration. ${ }^{81}$ After limited discussion at WARC '79,

\footnotetext{
${ }^{79}$ Within the industrialized country group, the CEPT countries often constitute a European regional bloc in telecommunications matters.

${ }^{80}$ In COPUOS, consensus operation is taken to the extreme in that voting, even unanimous voting, is not a practice. Unresolved issues either stay unresolved or are passed on to the Special Political Committee and the General Assembly. This does not always guarantee a lack of contentiousness; the United States in 1984, for instance, walked out of a COPUOS debate on the militarization of space on the grounds that it was the wrong forum and the U.S. delegate indicated that it was considering quitting the committee over the issue (Washington Post, June 15, 1984, p. A28).

${ }^{81}$ The issue of planning the geostationary orbit was also aired at the UN ISPACE ' 82 conference, without being resolved. (Unispace '82: A Context for Cooperation and Competition, op. cit.)
} 
where the contentiousness of the issues became apparent, the delegates decided to schedule a special WARC to consider them (see below).

In recent years, a trend toward the politicization of the specialized United Nations agencies, including those that deal with international satellite communications, has emerged to threaten the consensus mode of operation, For instance, at the ITU plenipotentiary in Nairobi in 1982, after a maximum worldwide diplomatic effort by the United States and its allies and an explicit U.S. threat to withdraw from the ITU, a key procedural question bearing on the attempted expulsion of Israel nevertheless almost attracted a majority and failed by a scant four votes. ${ }^{82}$ In UNESCO, another forum in which telecommunications issues are discussed, politicization was one issue cited by the United States when it withdrew at the end of $1984,{ }^{83}$

Both the politicization of international for a and the countervailing threats of the United States to withdraw threaten the cooperative operation of international organizations, including the ITU and other organizations dealing with satellite communications. In addition to this general politicization and the U.S. reaction to it, certain factions composed of developing countries may be increasingly willing to violate the consensus-building mode of operation strictly on telecommunications issues. For both these reasons, the United States may, therefore, face difficult decisions in the coming decade if it should find itself on the losing side in votes taken on contentious telecommunications issues.

The basic calculation implicit in U.S. participation is whether the net benefits are positive (when all the linkages with other issues and negotiations are considered). Economic costs-higher than necessary communications costs for U.S. residents and less of an array of services-may result from the regulatory arrangements of an

\footnotetext{
${ }^{82}$ As of December 1984, the ITU had 158 members (source: U.S. State Department, Office of International Communications Policy). ${ }^{83}$ For a discussion of various U.S. and foreign points of view on the withdrawal see "World Forum: the U.S. decision to withdraw from UN ESCO," Journal of Communication, vol. 34, autumn 1984, pp. 81-1 79; and Lois McHugh, U.S. Withdrawal From the International Labor Organization: Successful Precedent for UNESCO?" Congressional Research Service Report No. 84-202, Nov. 8, 1984.
}

achievable consensus. But there may also be the economic benefits of continued orderly communications that could not otherwise be ensured.

Looked at from another angle, the United States might have to shoulder significant political costs in order to persuade reluctant delegates to adhere to a consensus that benefits the United States. Thus, there could be significant costs to a policy of building and adhering to consensus within the ITU and other international organizations. On the other hand, confrontation in these for a, or withdrawal from them, could also have large economic and political costs.

Effectively balancing these costs has been a difficult assignment for the diffuse and frequently ad hoc U.S. policymaking apparatus in international telecommunications. on the one hand, policy makers must have effective knowledge about the telecommunications and space sectors and the importance of substantive matters. On the other, they must also have knowledge of the full international economic context of the United States, the connections of telecommunications negotiations to this context, and the diplomatic costs of accommodation or confrontation. U.S. diplomacy, however, has often not been informed by all these requisite skills. ${ }^{84}$

Regional Organizations or Suborganizations in the Americas Dealing With Satellite Communications

Two entities deal solely with Western Hemisphere communications matters: CITEL (affiliated with the Organization of American States) and the ITU Region 2 Regional Administrative Radio Conferences, which are held periodically. Given their framework of one-nation-one-vote, they exhibit similar characteristics to those of the full ITU and other international for a that are similarly organized.

\footnotetext{
${ }^{84}$ See U.S. Congress, Office of Technology Assessment, Radiofrequency Use and Management: Impacts From the World Administrative Radio Conference of 1979 (Washington, DC: U.S. Government Printing Office, January 1982); and UN/SPACE '82: A Context for International Cooperation and Competition, op. cit. See also Simon Jenkins, "A Diplomat Now Needs Expertise Rather Than Experience," Listener, vol. 111, Mar. 22, 1984, pp. 2-4 for a discussion of the diplomacy needed in modern foreign relations.
} 


\section{Weighted Voting Institutions}

Two international institutions in the satellite communications area-INTELSAT and INMARSAT ${ }^{95}$ are controlled through a process of weighted voting and hence exhibit different institutional characteristics from the U.N. or regional organ izations. ${ }^{86}$

While INTELSAT is an operating organization that provides almost all of the world's international satellite communications capacity, it can also be viewed as an intergovernmental organization whose board of governors establishes policies affecting the two-thirds of intercontinental communications that pass through its transponders. In this limited sense, INTELSAT is one of the key elements in the regulation of international communications. In INTELSAT'S board of governors, a country's voting power is determined by its volume of communications on the INTELSAT system. Because they are the big users, a small coalition of the United States and a few industrial countries can muster a majority of votes (see table 6-5, above, and app. 6C of this chapter). Nevertheless, non-unanimous votes are rare. Consensus is still the norm in INTELSAT. The consensuses the United States adheres to in INTELSAT,

\footnotetext{
${ }^{85}$ In the Communications Satellite Act of $1 \% 2$, Congress set basic goals for international satellite communications and of U.S. participation in it. COMSAT, a private corporation, was subsequently chartered and designated to represent the United States in INTELSAT and INMARSAT. Most countries are represented in INTELSAT by their post, telephone, and telegraph (PTT) administrations.

${ }^{86}$ The reality of INTELSAT's operation has been that of a weighted voting institution, but the actual legal structure of the organization is somewhat complicated. The 1973 INTELSAT Agreement provides for two one-nation-one-vote bodies formally superior to the weighted-voting Board of Governors. These are the Assembly of Parties (governments), which usually meets every two years, and the Meeting of Signatories (telecommunications entities), which meets every year. With a few exceptions, the powers of these bodies are not clearly specified in the INTELSAT Definitive Agreements. See Richard R. Colino, "The INTELSAT Definitive Arrangements: Ushering in a New Era in Satellite Telecommunications," European Broadcasting Union, Geneva, 1973. Both bodies were characterized in one critical review of INTELSAT (Michael E. Kinsley, Outer Space and Inner Sanctums (New York: Wiley, 1976), p. 128) as "impotent. " Nevertheless, the INTELSAT 1982 Annual Report indicates that the Meeting of Signatories "accepted the recommendation of the Board of Governors to increase INTELSAT's capital, " a rather important function, if the ability to "not accept" would have any substantive effect. The Assembly of Parties specifically has the formal power of decision in the INTELSAT procedure of coordinating with separate satellite systems, a power that has recently taken on importance. It may be that, in future years, the character of INTELSAT could take on more of the characteristics of one-nationone-vote organizations, if the Assembly of Parties or the Meeting of Signatories become more influential.
}

however, are influenced by its juridical voting power and not just by its diplomatic efforts.

It would therefore be expected that NorthSouth issues would be muted in INTELSAT, and this is usually the case. For this reason and because they must manage INTELSAT as a functioning commercial entity, developing-country members have incentives to keep politicization to a minimum. Nevertheless, because INTELSAT is increasingly likely to be a locus of "North-North" deregulatory and trade controversies among the industrial countries, and because developing countries may be receiving benefits from cross subsidization (through a process called "global averaging8), the future of INTELSAT is likely to become a North-North and North-South question at the same time.

INMARSAT, a second international satellite organization, which was established in 1976 and commenced service in 1982, aims to increase the efficiency and safety of marine transportation by providing effective communications. ${ }^{88}$ Unlike INTELSAT, INMARSAT does not currently own its own satellites; instead, it leases or is committed to lease capacity from MARISAT (a joint venture of U.S. communications carriers), ESA and INTELSAT. ${ }^{89}$ To date, it has not been an important arena for international controversy, except for subtle jockeying among the major industrialized-country members for shares in procurement, but East-West and North-South politics could become more important in INMARSAT in the future. Politicization of the organization along the lines of the U.N. Specialized Agencies, is unlikely,

\footnotetext{
${ }^{87}$ See, e.8., Testimony of Richard R. Colino, Hearings Before the Subcommittee on Arms Control, Oceans, International Operations, and Environment, Senate Foreign Relations, 98th Cong., Oct. 19 and 31,1983, p. 152.

${ }^{88}$ As of early 1985, INMARSAT had 43 members (see app.6C of this chapter for a list of the members and their voting shares). The INMARSAT Council, modeled on the INTELSAT Board of Governors, is made up of the largest 18 shareholders plus four additional country representatives to insure geographical balance. Voting is weighted according to ownership shares, except that no country can have a weight greater than 25 percent. The ownership shares of the six largest country owners were as follows: United States (30.9 percent), United Kingdom (14.6 percent), Norway (1 1.6 percent), Japan (7.0 percent), USSR (6.9 percent), and Canada (3.9 percent) [source: COMSAT]. COMSAT represents the United States in INMARSAT, as well as in INTELSAT.

${ }^{89}$ David W. Lipke, "IN NMARSAT Plans for New Satellites, " Marifacts, March 1983.
} 
however, because the major maritime countries are also the major actors, as a result of its weighted voting mode of governance (see app. $6 \mathrm{C})$. The commercial goals of the organization also militate against politicization.

Nevertheless, the presence of the Soviet Union within the organization has resulted in technology transfer controversy with the U.S. Government. COMSAT, which holds the management contract for INMARSAT, was prevented by the U.S. Government (through delay of an export license) from providing the results of several small study contracts to other members of INMARSAT. ${ }^{90}$

In March 1985, it was reported that INTELSAT and the U.S.S.R. might sign an information exchange agreement. ${ }^{91}$ Although it would be premature to assume that such an agreement would lead to U.S.S.R. membership in INTELSAT, such membership might intensify U.S. concern about issues of technology transfer. The People's Republic of China is already a member, as are Vietnam and Afghanistan.

\section{Industrial Country Organizations}

In addition to INTELSAT and INMARSAT, the United States participates in two other organized groups that are ordinarily concerned with international telecommunications between the industrial countries, the Organization for Economic Cooperation and Development (OECD) and the North Atlantic Consultative Process (NACP).

The OECD ${ }^{92}$ provides a setting where industrial countries can reach understandings on satellite communications (as well as many other) issues and also can develop coordinated positions on North-South issues. A special arrangement concerned with the terms of export finance in satellite ground segment equipment, for instance, has been reached under the aegis of the OECD. In the NACP (in coordination with similar planning

\footnotetext{
'Conversations with industry sources in 1983. See below, p. 192. 91 "U.S.S.R, May JoinINTELSAT Consortium Within 2 Yearsr" Washington Post, Mar. 13, 1985, p. 1; "Fingerprints on the SelfDestruct Button, "Chronicle of International Communication, March 1985, p. 1.

${ }^{92}$ Membership includes the United States, Canada, Japan, Australia, New Zealand, and the governments of all European industrial market economies.
}

within INTELSAT), an ad hoc group of representatives of U.S. and European governments and/or their communications carriers discuss communications facilities planning for transatlantic communications. While not a formal organization, per se, because it has no charter or secretariat, the NACP and its working groups (NACPWG) constitute one of the most important elements in the international regulatory regime ${ }^{93}$ affecting U.S. international communications.

U.S.-Europe controversy over liberalization in international communications has recently increased as the newly deregulated long-distance communications industry in the United States has attempted to deal with the European industry, with its general preference for restrictions on entry and trade in both international telecommunications services and equipment. It finds a locus in INTELSAT, INMARSAT, OECD and the NACP, as well as in relations between carriers and governments. There is a good possibility that differences among the industrial countries over how to structure international telecommunications will make it difficult for the North to take a unified position in some North-South disputes, and it may result in a position of isolation for the United States on certain telecommunications issues in international organizations and meetings.

\section{Space WARC and the Issue of the Allotment of the Geostationary Orbit}

"Space WARC," whose first session "ORB-85" will convene in August 1985, is one of the ITU World Administrative Radio Conferences that regulate international satellite communications. ORB-85 will attempt to resolve the issue of equitable access for all countries to the geostationary orbit by devising mutually acceptable changes in the arrangements by which radio frequencies and orbital locations are assigned. Three years later, the second session-ORB-88-is designed as a follow-on and implementing conference and will provide an opportunity to fine-tune decisions reached at ORB-85..$^{94}$

\footnotetext{
gl'International Regulatory Regime" is defined in note 30 above in this chapter.

${ }^{94}$ See A. M. Rutkowski, "The Space WARC," Telecommunications, January 1984 and "Space WARC Momentum Builds," Chronicle of International Communication, October 1984, vol. 5, No. 8.
} 
The conference is being taken seriously by the U.S. Government. ${ }^{95}$ The United States not only has important specific satellite communications interests relating to the geostationary orbit, but, since ITU decisions on how frequencies are allocated affect the full range of U.S. civilian and military communications, the United States also has an important general interest in the successful operation of the conference and of the ITU generally. Alternatives to even a poorly functioning ITU all have serious disadvantages from the U.S. point of view. ${ }^{9 b}$

\section{Potential Western Hemisphere Crowding Important to U.S. Satellite Communications Operators}

In the geostationary arc above the Western Hemisphere, the problem of actual scarcity may arise at the end of this decade, depending principally on the demand for U.S. domestic satellite communications. In the preferred $\mathrm{C}$ and $\mathrm{Ku}$ bands, many of the most desirable slots for U.S. communications satellites are already taken. As of January 1984, there were 44 satellites in orbit or assigned orbital locations by the Federal Communications Commission for launch prior to 1988.97

There may come a time in the not too distant future, depending on how rapidly U.S. domestic satellite communications expands, when close substitutes for desired $\mathrm{C}(6 / 4 \mathrm{GHz})$ and $\mathrm{Ku}(14 / 12$ $\mathrm{GHz}$ ) band slots will not be obtainable unless a satellite currently in orbit is deactivated. A study done recently for NASA by Western Union Telegraph $C o$. concluded that crowding in the $C$ and $\mathrm{Ku}$ bands will be such that slots in the higher frequency $\mathrm{Ka}$ band $(30 / 20 \mathrm{GHz})$ will be needed for U.S. domestic communications starting in the early $1990 \mathrm{~s} .{ }^{98}$ The conclusions were based on rapidly expanding demand for domestic satellite communications. If it does not materialize, the ${ }^{95}$ See, e.g., FCC First Report and Order in the matter of ORB85], FCC 85-94, released Mar. 1, 1985.

For ational discussion of policy options regarding U.S. participation in the ITU, see ibid. and Leslie Milk and Allen Weinstein, "United States Participation in the International Telecommunication Union: A Study of Policy Alternatives, " paper prepared for the Department of State as part of its external research program, undated.

97FCC, "United States Domestic Satellite Summary, " unpublished table, Jan. 11, 1984.

${ }^{98}$ WesternUnion Telegraph Co., Government Systems Division, "Satellite Provided Fixed Communications Services: A Forecast of Potential Domestic Demand Through the Year 2000," Final Re-

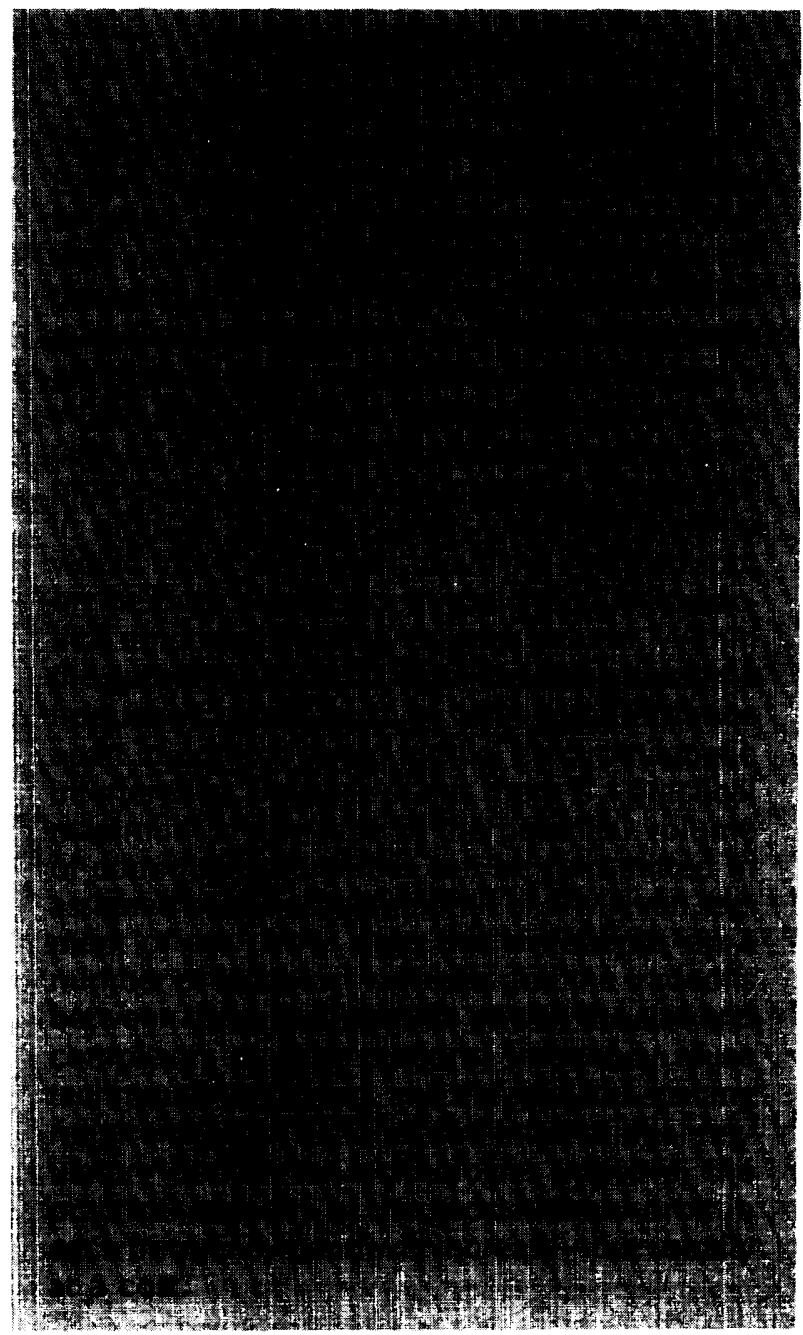

crowning would be less or, with low demand, might not occur at all.

The issue for the United States at Space WARC is that crowding in the $\mathrm{C}$ and $\mathrm{Ku}$ bands would occur sooner under an institutional arrangement favored by many less developed countries in and out of the Americas. In various versions this would essentially assign future rights to the geostationary orbit to individual countries, utilizing an a priori planning process to do so. The availability of geostationary arc locations for the United States for $\mathrm{C}$ and $\mathrm{Ku}$ band transmission could be reduced, under such a scheme, because particular slots would be reserved prior to use and might

port-Executive Summary, NASA Contractor Report 168145, August 1983 , p. $4-1$. Ka band $(30 / 20 \mathrm{GHz})$ commercial satellites are not yet in service in the United States, although several are proposed for launch in the late 1980s. Because of its size and current nonutilization, the possibility of crowding in the $\mathrm{Ka}$ band is distant. 
be unused for lengthy periods of time. ${ }^{99}$ nder the current system of registration and coordination, slots are not reserved but are made available on a first-come-first-served basis.

It is, of course, possible that under an a priori scheme slots could be made available to U.S. satellite operators by the countries to which they were allotted, on a rental basis or under an arrangement whereby capacity on U.S. satellites was exchanged for the right to use the slots, These arrangements, even if they could be made, would undoubtedly have direct financial costs and also indirect costs whenever the arrangements resulted in decreased flexibility.

Thus, whether reserved slots would be made available to U.S. satellite operators under rental or other arrangements or not, the economic issue for the United States in Space WARC is still the possibility of both an increase in the cost and a reduction in the effectiveness of its use of the geostationary orbit in the $\mathrm{C}$ and $\mathrm{Ku}$ bands.

A somewhat different consideration is that if some a priori arrangement did come into force in the 1990s for the C and Ku bands, the United States would have a stake in trying to assure that the ground equipment associated with retired satellites would not be made artificially obsolete. This could happen if no appropriate slots would be assigned for replacement satellites to utilize it. Under current ITU [International Frequency Registration Board] rules, the problem would not arise in most circumstances, since a replacement satellite with the same technical characteristics as a defunct one can be placed in the same slot without a need to go through the complete IFRB registration process.

Access to the Lower Frequency

Satellite Transmission Bands Important to Developing Countries

The United States argued at the UNISPACE '82 conference that technological advances that allow more intensive use of the geostationary or-

\footnotetext{
${ }^{99}$ Suchanapriori allotment scheme was actually incorporated in the 1977 Broadcasting-Satellite Plan for ITU Regions 1 and 3. It arbitrarily allotted a minimum of four or five transmission links to every country irrespective of any requirements (FCC, op. cit., Mar. 1, 1985, p. 43, note 127).
}

bit for $\mathrm{C}$ and $\mathrm{Ku}$ band transmissions, such as frequency reuse, better station keeping, shaped beams, scanning spot beams, superior ground equipment, and closer spacing are likely to put off the day of scarcity in these bands for the foreseeable future. ${ }^{100}$ (This is contradicted by the Western Union study, which states that such scarcity may arrive in the early 1990s.) Furthermore, the United States has argued, the availability of the very high capacity $\mathrm{Ka}$ band $(30 / 20 \mathrm{GHz})$ for satellite transmission reduces the importance of potential crowding in the lower frequency bands. When scarcity does arrive for the $C$ and $\mathrm{Ku}$ bands, satellite communications can begin to be transmitted in the higher frequencies of the Ka band.

Representatives from developing countries have pointed out, however, that satellite systems transmitting in the lower frequency $\mathrm{C}$ and $\mathrm{Ku}$ bands are less costly at given satellite power levels and less technically demanding than satellite systems transmitting and receiving at higher frequencies. The space segment technology for transmission in these bands (particularly the $C$ band technology) is now widely known and ground stations to receive this transmission are less costly than those designed for receiving transmissions at higher frequencies. As such they are more suitable for the rural and remote area communications that are thought to be an important satellite communications contribution to rural development in developing countries.

Developing country representatives have also stated that the present first-come-first-served system allows the industrial countries to exploit a scarce global resource that is the "common heritage of mankind" and, this being the case, developing countries should also benefit from the common heritage by using it or profiting from its use..$^{101}$ They fear that if first-come-first-served assignment of orbital slots continues in the $C$ and $\mathrm{Ku}$ bands, the industrial countries will have made

\footnotetext{
100See Unispace '82: A Context for International Cooperation and Competition, op. cit.

101Taking a different approach, certain equatorial countries have claimed (without much international support) that the geostationary orbit above their territories is within their national jurisdictions. In 1976, seven equatorial states, including Colombia, Ecuador, and Indonesia signed the Bogota Declaration claiming sovereignty over portions of the geostationary arc.
} 
substantial further investments in ground equipment appropriate to those bands. The existence of this investment will then constitute an argument for renewing the supposedly temporary assignments, and the developing countries will have lost out permanently. ${ }^{102}$ The developingcountry proposals for a system of a priori allotment of orbital slots are based on these ideas of common heritage and equitable access.

A Priori Planning Would Tend to Increase Crowding in the Geostationary Orbit

The United States has an important stake in Space WARC. Any a priori planning system to assign the remaining orbital slots in these bands (plus previously occupied slots that become vacant) would tend to increase the crowding already experienced by U.S. communications carriers in the $\mathrm{C}$ and $\mathrm{Ku}$ bands, if it should place a significant number of slots out of their reach. (It should be noted that any allotment scheme decided on by ORB- 85 and implemented in detail in ORB-88 would not take affect until 1989 at the earliest.) By then almost all of the slots above the Western Hemisphere that are desirable for U.S. domestic communications may well have already been occupied (mainly by U.S. domestic satellites).

If both U.S. launch schedules and the Space WARC schedule are maintained, the question of greatest economic importance to the United States would seem to be whether slots then occupied by U.S. satellites would be reassigned to other countries when U.S. satellites are decommissioned. Other countries will, of course, be aware of the possibility that U.S. satellites may occupy most of the desirable slots before a planning scheme could go into effect under the present conference timetable. Their ORB-85 positions may, therefore, include proposals for early implementation of any planning scheme adopted and rigid safeguards to stop first-come-first-served occupation of geostationary slots by U.S. satellites in the late 1980s.

\footnotetext{
${ }^{102}$ This argument, in fact, is made explicitly in an FCC ORB-85 preparatory document (FCC, op. cit., Mar. 1, 1985, app. B, p. 8).
}

Close Substitutes to $\mathrm{C}$ and $\mathrm{Ku}$ Band Satellite Transmission Set Limits on the Economic Cost of Crowding

Fortuitously, at the same time that potential crowding in the geostationary orbit has appeared, it has also become apparent that that the United States can expect to have two important close substitutes for satellite capacity in the $\mathrm{C}$ and $\mathrm{Ku}$ bands in the 1990s:

1. satellites transmitting in the large Ka band (30/20 GHz), which, however, requires more sophisticated satellites and ground-segment equipment; ${ }^{103}$ and

2. the developing domestic and international fiber optic cable network. ${ }^{104}$

The existence of these two substitutes clearly limits the potential economic damage to the United States of losing $\mathrm{C}$ and Ku band capacity. Ka band capacity, which has yet to be fully developed, will probably be somewhat more costly than that in the $\mathrm{C}$ and Ku bands, since, for many applications, more sophisticated satellites and Earth stations will be required to avoid significant effects from the rain attenuation of satellite signals. For certain high-volume uses, there is a possibility that Ka band technology, when it has been developed sufficiently, may be more cost effective than $\mathrm{C}$ or $\mathrm{Ku}$ band technology, or that the penalty will be very slight, but there seems to be general agreement that there will be some cost penalty in most cases for U.S. carriers to substitute $\mathrm{Ka}$ band transmission for that in the $\mathbf{C}$ and Ku bands.

There also is general agreement that the emerging fiber optic domestic and international cable networks will be fully competitive with satellites using $\mathrm{C}$ and $\mathrm{Ku}$ band technology and may in fact be technologically preferred (see discussion above and in app. 6A). A relative shift toward fi-

\footnotetext{
${ }^{103}$ See the discussion below in this chapter of the NASA ACTS program.

${ }^{104}$ While terrestrial networks are a close substitute for satellites for point-to-point communications, and technically could distribute point-to-m ultipoint communications, they would generally not be used for the latter, unless there were excess network capacity, because of the long-run cost advantage satellites have for pointto-multi-point applications.
} 
ber optic cable transmission for new domestic and international telecommunications capacity is expected to take place in any case. Less availability of $\mathrm{C}$ and $\mathrm{Ku}$ band capacity might simply make this shift take place sooner or take place to a greater extent than otherwise. Furthermore, because of fiber optic efficiencies, there may not be a cost or service penalty for the shift. Again, this is uncertain, because fiber optic technology is still evolving too rapidly to allow reliable cost projections for the period beyond 1990, when any arrangements determined in Space WARC would come into force.

It should be emphasized that the need for substitutes for $\mathrm{C}$ and Ku band capacity and any cost to the United States of using them would only occur if serious crowding, in fact, did materialize in the two bands. Crowding might not materialize if there were a major shift toward fiber optic and other terrestrial transmission modes for the types of U.S. domestic communications now carried by satellite and if earlier projections of direct broadcasting demand prove high. ${ }^{105}$

\section{Foreign Policy Linkage}

On the other side of the ledger, the foreign policy cost that the United States would have to pay for an isolated, combative stance at Space WARC against a priori planning of the geostationary orbit must also be considered. Just as the U.S. influence in any Space WARC consensus will depend on the wider influence that it exercises in North-South politics, so will a break in consensus politics of Space WARC affect the ability of the United States to further its general foreign policy objectives. ${ }^{106}$

The U.S. stance at Space WARC also involves a link with U.S. national defense communications requirements. Any breakdown in the current in-

\footnotetext{
${ }^{105}$ Directbroadcasting ventures have been holding back because of competition from cable television and video cassettes, and the part of the spectrum reserved for this use maybe available for other uses. See "FCC Asked to Delay Radio Spectrum Shift," Washington Post, Apr. 9, 1985, p. D3.

${ }^{106}$ One close-by linkage that may play a role in the outcome of the Space WARC sessions is the linkage with INTELSAT politics. One study suggests a U.S. negotiating strategy that would utilize that linkage. See Wilson P. Dizard, "Space WARC and the Role of International Satellite Networks," Georgetown University Center for Strategic and International Studies, Washington, DC, August 1984.
}

ternational arrangement on frequency assignments or orbital slots might bring into question the availability of frequencies for military communications. Consequently, there is understandable concern in the U.S. military establishment about anything that might upset the international consensus on arrangements for frequency use.

The problem facing the U.S. delegation and the Administration behind it will be to weigh the various aspects of this issue against each other. The Congress, in its oversight capacity and also because (in the Senate) it will have to decide whether or not to ratify any WARC agreement the United States has signed, will also have to weigh the consequences of various courses of action in Space WARC.

\section{Assistance to Developing Countries}

The issues involved in assistance to developing countries in the area of satellite communications are complex and intertwined with general development assistance issues. Should the United States use international institutions, such as INTELSAT, the ITU, and the World Bank, as mechanisms for development assistance or would bilateral U.S. Agency for International Development (AID) programs be more effective in achieving U.S. objectives? Should Congress direct more U.S. development-assistance resources into telecommunications or leave such decisions to AID and other agencies?

\section{Assistance Through INTELSAT'S Operations}

The Communications Satellite Act of 1962 directed:

$$
\begin{aligned}
& \text {... sare and attention ... toward providing } \\
& \text { [satellite communications] services to economi- } \\
& \text { cally less developed countries and areas as well } \\
& \text { as those more highly developed ... } .^{107}
\end{aligned}
$$

The INTELSAT Agreement speaks of extending services to all peoples and to all areas of the world, and INTELSAT has brought many cities in the developing nations into the global satellite network. ${ }^{108}$ Developing countries with INTELSAT

\footnotetext{
${ }^{107}$ Communications Satellite Act of 1962, Sec. 102(b).

${ }^{108}$ See Preamble to the Agreement, app. 60 of this chapter.
} 
Earth stations now no longer need to pay extra tariffs to route their international communications to other developing countries through cable systems that pass through the industrialized countries. They also have the opportunity to lease spare INTELSAT capacity for domestic communications when terrestrial communications or satellite ownership are impractical. ${ }^{109}$

While the INTELSAT network has brought modern communications to major cities in the developing world, it has not met the needs of dispersed populations in rural areas or island territories, for example, in the pacific, where small populations live in widely dispersed settlements in a dozen sovereign nations and territories. INTELSAT Earth stations of current design are too expensive for use in these contexts. Such expensive Earth stations are required because transponders of higher power than INTELSAT has deployed on its satellites are necessary to make possible small, inexpensive ground terminals to handle one or two telephone channels.

The current smallest Earth terminals for INTELSAT connection are expensive: the type (Std B) installed in Micronesia in 1982 cost \$1.6 million. In an effort to make satellite communications more widely available, the INTELSAT Board of Governors approved in 1983a new (Std D) class of small terminal for isolated areas. In one estimate, this terminal alone will still cost about $\$ 60,000$ initially. ${ }^{110}$ Even with significant cost reductions when mass-produced, Earth station costs of this magnitude, together with the cost of site preparation and other associated terrestrial facilities, would continue to put satellite communications via INTELSAT satellites out of the reach of most developing-country villages and towns. ${ }^{11}$ Because of this, INTELSAT, in collabora-

\footnotetext{
109 |NTELSAT also provides capacity for a number of developing countries' domestic satellite systems. As of 1983, some 30 developing or newly industrialized countries were leasing (or planning to lease by 1986) space segment capacity from INTELSAT. (j. N. Pelton, "INTELSAT: Making the Future Happen," Space Communications and Broadcasting, vol. 1, No. 1, April 1983.)

$1^{10}$ Aviation Week and Space Technology, Jan. 16, 1984, P. 203

111 In any case, INTELSAT's new low-density services will be useful in certain commercial applications. For instance, a low-density INTELSAT Vista system, also using Std D-1 5-meter antennas, will be used by a U.S. multinational oil company for communication with its drill sites starting in 1985 (Thomas A. Mclntyre and Robert H. Emberley, "The Vista Link From Madagascar to Houston," Telecommunications, April 1985, pp. 66g-66q).
}

tion with other organizations, has proposed a 16month satellite test and demonstration program to experiment with health and education programs for populations in remote areas. INTELSAT would provide technical advice and free satellite transmission time using spare capacity. ${ }^{112}$

\section{Assistance Through the ITU}

The International Telecommunication Union (ITU) is considering forming a Center for Telecommunications Development to assist developing countries. Such a center has been proposed in the report of the Independent Commission for Worldwide Telecommunications Development (informally known as the Maitland Commission), which has been financially supported by the United States, other governments, and U.S. private firms.' The center would offer both general advice and analysis on telecommunications development and assistance in detailed project planning with the aim of "bringing all mankind within easy reach of a telephone by the early part of next century."' 114

While not opposing multilateral communications programs in general (e.g. World Communications Year '83 and the Maitland Commission itself), the Reagan Administration has opposed channeling U.S. Government development assistance funds to any significant extent through such programs. ${ }^{115}$ Thus, it is not expected to budget more than minimal funding for the Center and certainly does not favor funding it through a tax on international telecommunications traffic.

\footnotetext{
112 Satellite News, Aug. 20, 1984.

113 Independent Commission for World Wide Telecommunications Development, "The Missing Link," International Telecommunication Union, December 1984. See also Chronic/e of International Communications, August 1984, pp. 1-2, September 1984, pp. 1-3, and December 1984, p. 5.

${ }_{1}^{14} /$ ndependent Commission for World Wide Telecommunications Development, op. cit., p. 5.

"5"Cancelled Ticket to Arusha," Chronic/e of International Communication, March 1985, p. 1.
} 


\section{Assistance Through Multilateral Lending Institutions}

Developing countries spend approximately $\$ 8$ billion per year on public telecommunications plant (1983 figure cited in the Maitland Report ${ }^{116}$ ). Most of the external finance for this expenditure comes from commercial sources, augmented by officially supported export credit from exporter countries. Only about $\$ 200$ million per annum comes from the World Bank; other regional lending institutions, such as the Inter-American Development Bank or the Asian Development Bank, are also not active in financing telecommunications projects. ${ }^{117}$

Using U.S. influence to encourage international lending institutions to give more emphasis to telecommunications lending is a multilateral akernative to the proposed ITU center. Particularly in the case of the World Bank, it would have the advantage of keeping telecommunications lending in the context of the Bank's ongoing country development assistance programs. ${ }^{118}$ It would also make use of its project analysis capabilities, its influential status with both developing country governments and industrial country lenders, and its relative freedom from politicization,

\section{Bilateral Assistance}

How to help bring the benefits of satellite communications technology to more people in developing nations is also a policy issue for U.S. bilateral assistance programs. ${ }^{119}$

In the 1970s, the United States used its Applications Technology Satellite series (particularly the highly capable ATS-6) and other programs to demonstrate some of the applications of communications satellites in health, education, and agriculture. After year-long experiments in the United States (Health, Education, Telecommunications

\footnotetext{
116 ndependent Commission for World Wide Telecommunications Development, op. cjt., p. 57.

11 'lbid., app, VII, p.121.

${ }^{18}$ See Robert J. Saunders, Jeremy J. Warford, and Bjorn Wellenius, Telecommunications and Economic Development, World Bank Publication, Johns Hopkins Press, Baltimore, 1983 for an examination of the issues involved in World Bank lending for telecommunications.

${ }_{119} \mathrm{~A}$ discussion of these benefits can $\mathbf{b}_{\mathrm{e}}$ found $\mathbf{i}_{\mathbf{n}}$ ibid. andin "Development Communications," Policy Determination PD 10, U.S. Agency for International Development, Feb. 17, 1984.
}

Experiments) and in India (the Joint U.S.-India Experiment in Educational Broadcasting), the ATS6 was used in a 3-month project (AIDSAT) by NASA and AID to show a number of other countries (27, in all) what was possible. The United States and Canada later cooperated in the Kuband Communications Technology Satellite program to demonstrate applications in education, health, and specialized community services. These programs were phased out beginning in 1973 after the Nixon Administration decided that the Federal Government would no longer undertake advanced technology development for communications satellites or satellite demonstration programs. Some funding for Earth station demonstration projects continues. ${ }^{120}$

In 1982, the United States established the U.S. Telecommunications Training Institute (USJTI) to train developing country nationals in basic and advanced telecommunications technologies and management. USTTI is a nonprofit independent corporation administered by a board of directors representing both industry and govern merit.' ${ }^{121}$ Expenses of the training program, including travel and living expenses, are shared among the Government and the telecommunications companies on whose premises the training takes place. ${ }^{*}$ The program is supported by such corporations as AT\&T, IBM, GTE, Western Union, $\mathrm{MCl}$, and COMSAT. Some 400 people from 65 developing countries were trained in 1983 and 1984, the first 2 years of operation. As a result of the program, graduates will be better informed about U.S. telecommunications products, and some may be in a position to influence procurement decisions. ' 122

120 U.S. development assistance efforts in telecommunications in fiscal years 1983 and 1984 were estimated by the Academy of Educational Development to exceed $\$ 422$ million in loans and grants. These efforts, in addition to financing the purchase of U.S.-produced equipment, trained 1,153 LDC participants, arranged at least 63 distinct technical assistance and training programs, and served over 100 countries. Twenty-five U.S. agencies had such activities, but only the Export-import Bank, Overseas Private Investment Corp., Agency for International Development, and U.S. Information Agency made monetary estimates and these are included in the total. (Chronic/e of International Communication, September 1984, p. 7). 121 U.S. Telecommunications Training Institute, Course Catalog, 1983-84.

*Travel and living expenses of participants are financed by a variety of sources, including AID, international institutions, and private firms. Participants from some high-income oil exporting countries receive support from sources in their own countries.

122The president's Task Force on International private Enterprise, Report to the President, December 1984, p. 114. 
The program is, in part, a response to telecommunications training programs conducted by training centers in France and Japan, which also combine development assistance with export promotion. ${ }^{123}$

While AID anticipates substantial increase in support for communications activities, aside from the USTTI program and limited investment in communications infrastructure, it "does not expect to support communications as a distinct program sector. "124 It plans to focus its spending on specific cost-effective communications applications on a bilateral basis within projects in its principal development sectors, agriculture, education, health, nutrition, and population.

With respect to developing country investment in communications infrastructure, AI D plans primarily to concentrate on providing technical assistance and training that will help countries: 1) assess their technology needs both for specific sectors or functions and for entire communications systems; 2) plan for infrastructure expansion; and 3) develop operational and maintenance skills for existing as well as new infrastructure, rather than to provide support for the acquisition of such equipment as telephone switching systems, radio or television broadcasting facilities, or communications satellites and ground stations. It takes this position because "other financing mechanisms (both conventional and confessional) exist for communications infrastructure." The door is not closed to "add-ens" of specialized equipment, such as satellite ground stations, though, which would extend the country's communications systems in ways that would accomplish development objectives.

AID also does not intend to finance substantial multilateral development activities in communications and will avoid financing host country participation fees or membership contributions in international organizations or regional/international communications infrastructure.

\footnotetext{
${ }^{123}$ Eli M. Noam, "Telecommunications Policy on the Two Sides of the Atlantic: Divergence and Outlook, " op. cit., pp. 4-5.

$1^{24,}$ Development Communications," Policy Determination P D 10, op. cit., p. 5.
}

\section{International Trade in Telecommunications Services}

The principal issues in the regulation of international satellite communications services involve how much competition the United States should seek and how aggressively it is prepared to seek it. Despite important deregulatory moves affecting the international arena, which have mostly been offshoots of deregulatory actions in the newly competitive domestic market, the FCC and the Reagan Administration have been rather cautious in extending deregulation directly into international communications. For the most part, the foundations of the international communications regime described above and in app. $6 \mathrm{~A}$, in which competition is severely limited, have hardly been touched. As this discussion and that in app. 6A indicate, however, harbingers of change are appearing in virtually every aspect of international satellite communications, as technological and market forces begin to chip away at aging regulatory structures.

\section{Competition for INTELSAT}

Competition for INTELSAT is a partial exception to this generalization. Currently INTELSAT has a near monopoly on intercontinental satellite communications facilities, and the recent executive branch decision to sponsor the entry of private U.S. satellite systems in competition with it is a purely international regulatory decision that did not grow out of domestic deregulation.

In the Preamble of the INTELSAT Agreement the contracting parties state that in establishing INTELSAT their intention was:

... to continue the development of this telecommunications satellite system with the aim of achieving a single global commercial telecommunications satellite system as part of an improved global telecommunications network which will provide expanded telecommunications services to all areas of the world and which will contribute to world peace and understanding . . . ${ }^{125}$

\footnotetext{
125That goal was achieved the original 1965 satellite with one Earth station in the United States, another in Canada and a few in Europe had led to a system of 15 satellites in 1984, covering three ocean regions with 981 operating or approved Earth stations in 172
} 
The term "single global commercial" system implies to some that INTELSAT is to have a permanent monopoly over virtually all international communications carried by satellite, while others see INTELSAT as only one element, a major one to be sure, but only one, in the developing international telecommunications industry, where competition will also be an increasingly important principle.

INTELSAT argues that it receives sufficient competition from transoceanic cables and that this competition between transmission media will intensify in the future as the TAT- 8 and other fiber optic cables come into operation in the period just before and after $1990 .{ }^{126}$ Any more competition from private satellite companies, in the INTELSAT view, would further reduce the scale of INTELSAT'S operations and raise the price of INTELSAT'S services, since its costs would be recovered over a smaller volume of traffic. This judgment of higher prices, of course, would not hold true if a competitive market developed in which competition forced all satellite prices down, including INTELSAT'S.

INTELSAT officials fear that growing numbers of competitors to INTELSAT might result in the decline of the system and its eventual replacement by poorly connected regional systems. Several regional international satellite systems, described earlier in this chapter and in app. A, have recently emerged. All have been through or are going through a process called the "INTELSAT coordination process, " in which proposed new international satellite services are presented to INTELSAT for a finding of whether they are technically compatible or in the case of "international public telecommunications services" whether they will cause it "significant economic harm." Parties to the INTELSAT Agreement, including the United States, have bound themselves to go through the somewhat cumbersome consultation

countries or territories. The number of telephone channels went from 150 to 60,000 , while the annual tariff per voice half-circuit went from $\$ 93,000$ to $\$ 4,680$ [in 1983 dollars] (I NTELSAT Annual Report, 1983; converted to 1983 dollars using the U.S. GNP deflator).

${ }_{126}$ Testimony of Richard R. Colino, Hearings Before the Subcommittee on Arms Control, Oceans, International Operations, and Environment, Senate Foreign Relations, 98th Cong., Oct. 19 and 31, 1983, p. 25. process in Article XIV(d) of the agreement with respect to proposed systems offering separate public international services, but are not obligated by the agreement to do more than that (see app. 6D of this chapter for the text of Article XIV and related parts of the INTELSAT Agreement) .127

The INTELSAT Assembly of Parties, a one-nation-one-vote body, which ordinarily meets biennially, is charged by Article XIV with making INTELSAT'S recommendations to the parties (governments) proposing to establish satellite systems separate from INTELSAT as to whether, in its opinion, they will or will not cause significant economic harm to INTELSAT. ${ }^{128}$ To date INTELSAT has approved at least some of the services to be offered by the four regional systems, usually on the grounds that the communications services to be carried would not to any significant extent have been carried on INTELSAT, because they would have been carried on terrestrial media instead, or not sent at all. The Palapa, Eutelsat, and Arabsat systems have been approved for this reason, even though they carry international message telephone service and other communications of the type INTELSAT typically carries.

The development of a Western Hemisphere regional system composed of satellites and Earth stations owned by a diverse set of mostly private entities rather than by a regional organization of governments, however, has been delayed for several years because of INTELSAT coordination difficulties. By March 1984, the FCC had conditionally approved a total of 114 applications for regional international service in the Americas involving U.S. and Canadian domestic satellites, but

\footnotetext{
${ }^{127}$ ArecentAdministration policy paper, however, asserts that the "United States is committed to ensuring that non-I NTELSAT satellite systems are technically compatible with existing and planned INTELSAT satellites and to avoiding significant economic harm to the global INTELSAT system (Departments of State and Commerce, "A White Paper on New International Satellite Systems," op. cit., p. 17.

${ }^{28}$ The INTELSAT coordination procedures and criteria of economic harm have not been fully developed, and guidelines are now under consideration within INTELSAT. If the proposed services are international but not public, they fall under Article $X I V(e)$; if they are public but domestic they are coordinated under Article XIV(C), The Assembly of Parties has as yet not adopted an official definition of "significant economic harm," the number of cases decided have been few, and the findings to date have in almost all cases been in favor of the proposed systems.
} 


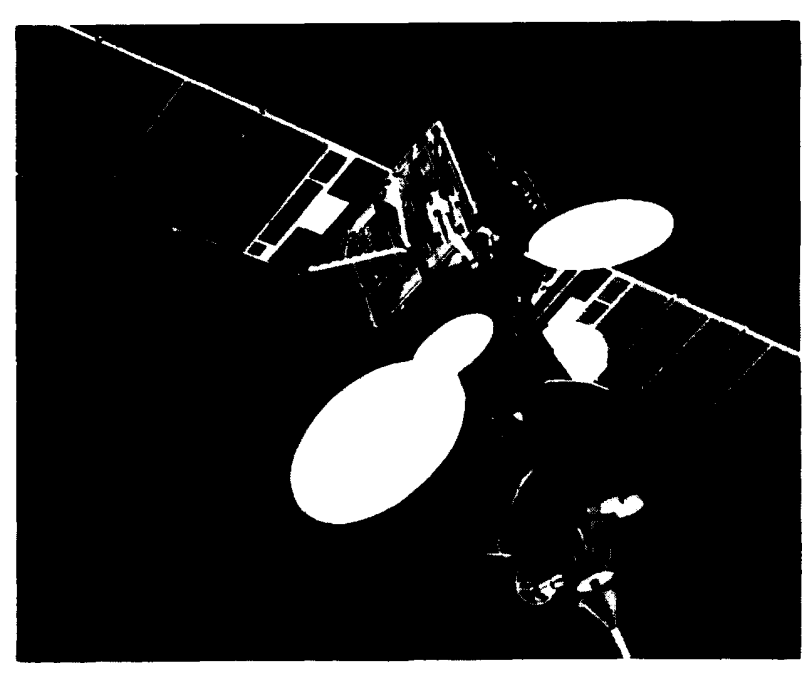

Photo credit: National Aeronautics and Space Administration

Artist's conception of INTELSAT V, for which the U.S. company Ford Aerospace was the prime contractor.

many of these were on hold awaiting State Department, foreign government, or INTELSAT action. As of March 31, 1985, the FCC had given final approval to 46 applications for services to Canada, Mexico, Central America, and the Caribbean. Although final approval has been given for extended data and television services between the United States and Canada, the only services that have been approved for most of the other destinations are television receive-only transmissions. ${ }^{129}$ Thus, only part of the potentially large Western Hemisphere system is currently in place. In the future, this system could compete with INTELSAT.

Whether the INTELSAT coordination process for the other conditionally approved television and data services will go smoothly and whether telephony will ever be a service carried on the

\footnotetext{
${ }^{129}$ Coordination of even this limited competition represented a significant departure from the previous situation. Until the meeting of the INTELSAT Assembly of Parties in January 1985, only 13 services had been given final approval by the FCC on the basis of INTELSAT coordination and only to Canada, Bermuda, and the Cayman Islands. At the January meeting, 19 U.S. and 6 Canadian satellite systems were coordinated, involving data transmission to and from Canada and television receive-only transmission to Mexico, Bermuda, Bahamas and 17 Caribbean and Central American countries and territories. Television services coordinated between Canada and the U. S., U.S. and Canada, and Mexico and the U.S. were point-to-point and point-to-multi-point in some cases.
}

Western Hemisphere system is unclear at present. All the current applications that the FCC has conditionally approved have been approved on the grounds that they will not divert traffic from INTELSAT or that using INTELSAT would be economically wasteful.

At the present time, the U.S. Government (FCC and State Department) is taking the lead in overseeing the development of the Western Hemisphere regional system in response to market pressures, by: 1) approving applications of U.S. providers domestic satellite communications to provide "transborder" services; 2) establishing that the governments in the countries involved approve; and 3) carrying the bilaterally approved applications through the INTELSAT coordination process.

The key U.S. decisions about its policy toward INTELSAT will probably not be initially made on issues involving the Western Hemisphere, but rather on issues that concern what could potentially develop into a North Atlantic regional system, if any of its components come into existence. As described above, six private U.S. companies have applied for permission to construct and operate transatlantic communications satellites. Two of these are large corporations with communications interests-RCA (through its RCA Americom subsidiary) and United Brands (through its International Satellite, Inc. [ISI] subsidiary); four smaller firms-Orion, Cygnus, Pan American Satellite, and Financial Satellite-have also applied. ${ }^{130}$ In response to this potential entry, INTELSAT has argued that open competition in transatlantic satellite communications facilities could mean the breakup of the INTELSAT system,

\footnotetext{
${ }^{30}$ Orion, PanAmSat, and Finansat do not plan to offer any common carrier services, but the other three applicants (RCA, United Brands' ISI, and Cygnus) have stated their desire to use some capacity for common carrier service, in addition to business and media services, which they state to be their primary offering. The satellites of other countries, including those owned by noncitizens (analogous to flags of convenience in ocean shipping), are also potential entrants in transatlantic satellite communications. France and the United Kingdom are constructing satellite systems that will be capable of serving both sides of the Atlantic (the first French satellite has already been placed in orbit) to connect them to their North American and Caribbean territories. They have stated that they do not intend to compete with INTELSAT.
} 
which U.S. diplomacy worked long and hard to put together in the first place.

After many months delay, President Reagan in November 1984 determined that separate international satellite systems "are required in the national interest. " ${ }^{132}$ However, in an attempt to reduce the challenge to INTELSAT, the Administration set two criteria for the FCC to use in acting on the existing transatlantic satellite applications.

... to assure that the United States meets its obligations as a Party to the Agreement Establishing the International Telecommunications Satellite Organization (INTELSAT):

1. each system is to be restricted to providing services through the sale or long-term lease of transponders or space segment capacity for communications not interconnected with public-switched message networks (except for emergency restoration service); and,

2. one or more foreign authorities are to authorize use of each system and enter into consultation procedures with the U.S. party under Article XIV(d) of the INTELSAT Agreement to ensure technical compatibility and to avoid significant economic harm. ${ }^{13}$

As of this writing, neither the Administration's nor the FCC's policy is clear concerning how many transatlantic systems will be authorized, how much capacity will be allowed, and, despite the interconnection prohibition, what the conditions on resale will be. Even if stringent connection and resale conditions were enforced, users of these systems would undoubtedly withdraw a nontrivial amount of transatlantic traffic from INTELSAT and send it via their own transponders (what they carry would not all be new demand). Hence, it is not clear that any of the systems would satisfy the as yet ill-defined criterion of avoiding significant harm to INTELSAT. '34

\footnotetext{
${ }^{131}$ Seewritten testimony (dated Nov. 14, 1983) of Richard D.Colino, Director-General of INTELSAT, before the Subcommittee on Arms Control, Oceans, International Operations, and Environment, Senate Foreign Relations Committee, Oct. 19, 1983.

${ }_{132}$ Presidential Determination No. 85-2, Nov. 28, 1984.

${ }^{33}$ Letter of the Secretaries of Commerce and State to the Chairman of the Federal Communications Commission, Nov. 28, 1984. $1^{34}$ The FCC inquiry will evaluate what economic effects the new systems would have on INTELSAT. (Mark S. Fowler, statement on New International Communications Satellite Systems at Hearings Before, U.S. Congress, House, Hearings on International Satellite Issues before the Subcommittee on Telecommunications, Consumer Protection, and Finance, Apr. 3, 1985.)
}

If the United States should take the applications for private transatlantic satellite systems through the INTELSAT coordination process in collaboration with one or more other governments, as the executive branch now plans (providing the FCC conditionally approves the applications), and if they were rejected by INTELSAT for coordination, the stage would be set for one of the following five processes:

- U.S. denial of operating authority to all of the proposed systems.

- Unilateral U.S. conditional approval of operating authority to some or all of them, (They would then need to secure foreign connection rights from foreign regulatory authorities, with or without the good offices of the U.S. Government.)

- Bilateral governmental negotiations with one or more communications partners with the object of establishing bilateral regulatory regimes that would allow the operation of some or all of the systems, as well as systems proposed by these partners.

- Multilateral governmental negotiations outside of INTELSAT with the object of establishing a regional international regulatory regime for North Atlantic satellite communications that would also allow the operation of some or all of the systems as well as systems proposed by parties to the negotiations.

- Multilateral negotiations within INTELSAT to amend Article-XIV(d) so as to permit certain alternative satellite systems even though the permitted services might cause some degree of "economic harm."

Because the applications to provide international satellite communications involve facilities competition and, in the case of transborder and transatlantic business services, the possibility of single-vendor, dish-to-dish service, they provide a strong challenge to the current international regulatory order ${ }^{135}$ Free markets in telecommunica-

\footnotetext{
$1{ }^{35}$ The uniqueness of international communications arrangements is not always appreciated. "Single-vendor service" is now the norm in U.S. domestic long-distance communications and always has been in virtually all other markets in the U.S. economy, and even in most other international service markets, Single-vendor service, however, is not the norm in international telecommunications service markets. U.S. basic telecommunications providers (and those
} 
tions are not considered desirable by most telecommunications partners of the United States. Consequently, U.S. moves that attempt to increase competition in the provision of international facilities are likely to engender conflict with some of our telecommunications partners in Europe, Japan, and elsewhere. ${ }^{136}$

In transatlantic telecommunications, U.S. approval of the six satellite applications, without prior agreement by all its major European communications partners, would amount to a major modification in the multilateral mechanismsthe North Atlantic Consultative Process and INTELSAT-that have been used in recent years to coordinate facilities decisions in that geographical sector. (The Administration's recently adopted policy requires only that "one or more" foreign authorities authorize new systems and be involved in the INTELSAT coordination procedures. ${ }^{137}$ Approval of the private cable applications would have a similar effect. If any U.S. moves to increase facilities competition should successfully obtain the collaboration of one or more U.S. communications partners, major changes in INTELSAT operations, as the consortium attempted to adapt to the new competitive environment, might be required. The principles that are employed in taking action in the case of the transatlantic applications will also set a precedent for similar Western Hemisphere and transpacific facilities.

If INTELSAT were in fact significantly damaged, then the United States would be blamed, justifiably or not, for helping to ruin the cooperative mechanism it had been instrumental in creating. U.S. telecommunications users might also lose from higher rates and poorer service, if the successor system performed poorly.

of other countries) are not free to offer single-vendor service in most international markets (i.e., to offer end-to-end communications service over their own owned or leased networks).

136 See National Telecommunications and Information Administration, Telecommunications Policies in Seventeen Countries: Prospects for Future Competitive Access, May 1983 for a survey of country policies. Also Eli M. Noam, "Telecommunications Policy on the Two Sides of the Atlantic: Divergence and Outlook," op. cit.

${ }_{1}{ }^{37}$ Letter of the Secretaries of Commerce and State to the Chairman of the Federal Communications Commission, Nov. 28, 1984.
INTELSAT officials also maintain that INTELSAT now significantly subsidizes satellite communications for developing countries by means of averaged rates, but this is contradicted by analyses sponsored by the Orion Satellite Corp. ${ }^{138}$ If there is a substantial cross-subsidy, then INTELSAT'S loss of revenues to competitors could lead it to raise rates for developing countries. Developing countries' displeasure over this, in turn, might then affect U.S. foreign policy interests.

A representative of one of the would-be new entrants suggested in testimony to Congress that consumers, in fact, would gain a number of benefits from competition to INTELSAT: advancing the general U.S. policy of favoring competitive markets, creating new markets, introducing new and more flexible services, lowering prices, and stimulating new technology. ${ }^{139}$ The argument about the stimulative effects of competition (from alternative satellite or cable providers) is plausibly supported (at least prima facie) by INTELSAT'S announcement in October 1983 that it would accelerate the introduction of its "INTELSAT Business Service," offering firms facilities for dedicated international satellite telecommunications networks. ${ }^{140}$

\section{Facilities Planning}

Beyond the issue of satellite competition to INTELSAT from private U.S. satellite systems,

\footnotetext{
${ }_{1}^{38}$ The existence and importance of a cross-subsidy to developing countries through the INTELSAT system is a complex issue that has been addressed in testimony before Congress by witnesses presenting material developed for INTELSAT and Orion Satellite Corp. See, e.g., Kenneth R. Dunmore, Hatfield Associates, "An Analysis of the INTELSAT Subsidy Issue," August 1983 and "Issues in International Telecommunications Pricing and Demand," Nov. 27, 1984, both prepared for Orion Satellite Corp.; Walter Hinchman Associates, Inc., "The Economics of International Satellite Communications," May 18, 1984, prepared for INTELSAT. The principal analytical questions revolve around what satellite capital cost should be assigned to different world regions, considering that satellites are movable, and the efficiency of transponder use when a single transponder is used by more than one country.

${ }^{139}$ Testimony of WilliamL. Fishman (International Satellite, Inc.), International Communication and Information Policy, op. cit., p. 280.

${ }^{140}$ See $\mathbf{C}_{\text {onnect }} \mathbf{i}_{\text {on }} \mathbf{s}$. World Communications Report, published by The Economist and Television Digest, Oct. 27, 1983, p. 2 and Broadcasting, July 4, 1983, p. 67. This conclusion was also reached in the Departments of State and Commerce, "A White Paper on New International Satellite Systems, ” op. cit., p. 51.
} 
there are two broader issues in facilities regulation:

1. Does the United States need to develop new international regulatory mechanisms to balance the use and/or construction of satellite and cable facilities?

2. Should U.S. regulatory authorities be concerned with the possibility of overcapacity in transatlantic telecommunications facilities?

Restrictions on facilities construction, ownership, and use are key elements in the present international communications regulatory structure and are the elements currently most under challenge. Carriers or other firms wishing to construct, purchase, or operate international communications facilities are not free simply to do so. They must apply to the FCC for authority, and the Commission has often used its power to delay or deny such applications on a variety of grounds. For instance, in 1984 the Commission decided not to allow firms to gain direct ownership access to INTELSAT, and private U.S. firms have not yet been allowed to own satellites for use in international communications, except within the limited Western Hemisphere regional system. (See app. $6 \mathrm{~A}$ for further discussion of the issues in this section.)

The FCC also restricts the U.S. international service carriers in their use of communications facilities. In practice, this has meant that AT\&T and other carriers have been required or induced to divide their transatlantic traffic between cables and satellites in approximately equal parts. Although the Communications Satellite Act of 1962 and the INTELSAT Agreement of 1973 endeavored to promote the use of satellites, incentives set up by the Act and the Agreement and by regulations based on them have had just the opposite effect.

This paradoxical outcome occured because, under U.S. regulation, carriers have an incentive to invest in and use their own cables in preference to satellite circuits leased from COMSAT, particularly at times of day and during seasons and periods when there is surplus cable capacity. These reasons involve the impacts of returnon-rate-base regulation, the tax code, and the fact that COMSAT'S tariff is greater than the variable costs of using cables. Once the distortion of incentives became apparent, the FCC decided to ameliorate the situation through additional regulation to limit the cable capacity of carriers and to secure the balanced use of the satellite and cable facilities in existence.

The FCC is currently considering what circuit distribution and facilities planning policies to implement in the 1985-95 period and has tentatively concluded that only AT\&T's message telephone traffic should be forced to conform to a circuit distribution scheme during the period (all other carriers and AT\&T's record traffic would be exempt). ${ }^{141}$ It also tentatively concluded that AT\&T should be gradually allowed to raise the proportion of its message telephone traffic transmitted by cable to 60 percent by 1991 (up from 48 percent in 1984). Based on AT\&T projections, the FCC analysis is that this would allow AT\&T to send 72 percent of its 1991 traffic growth by cable and would reduce INTELSAT'S revenues by $\$ 33$ million in the same year. ${ }^{142}$

The FCC has also recently altered the regulatory structure to change COMSAT'S special role in the ownership of INTELSAT Earth stations. Previously, the U.S. international service carriers had been locked in a mandated Earth Station Ownership Committee Consortium with COMSAT. COMSAT owned 50 percent of the Earth stations and the carriers owned the rest. Now there is a COMSAT tariff purely for space segment services, and the carriers (and other users) are free, as they see fit, to own their own Earth station facilities and incorporate them in their rate bases or, akernatively, to lease Earth station capacity from COMSAT or other owners. One effect of the new FCC Earth station policy is to reduce (in only a moderate way, however) the bias of U.S. carriers toward cables.

Because the would-be satellite entrants arrived on the scene first, and because an intergovern-

\footnotetext{
1-11 FCC, "Second Notice of proposed Rulemaking In the Matter of ... A A thorization of Common Carrier Facilities to Meet North Atlantic Telecommunications Needs During the 1985-1995 Period," op. cit., pp. 20-32.

${ }^{142}$ Derived from i bid., table following $p$. 34 . The reduction in INTELSAT's revenues is in comparison with the "balanced loading" circuit distribution scheme used by the FCC at times in the past (see note 46, p. 161 , for a definition of balanced loading).
} 
mental organization (and its financial health) are involved, much of the public discussion has centered around satellite entry in competition with INTELSAT. In late 1984, however, the FCC received two transatlantic cable landing applications that may pose an even greater threat to the current regulatory regime and, consequently, to INTELSAT. They propose to add an estimated total of 330,000 voice-equivalent circuits in private fiber optic cables by 1990 , four times the estimated 80,000 combined capacity of the TAT- 8 and TAT-9 cables that the consortium of the North Atlantic carriers has discussed in the North Atlantic Consultative Process. By itself, the capacity proposed by the two new cable applicants is approximately four times the carrier demand forecasts for 1995.'43

Such major capacity additions obviously raise the possibility of substantial overcapacity (discussed below), and they also threaten both the cable-consortium mechanism, which has heretofore built all transatlantic cables, and an international "institution," the North Atlantic Consultative Process. Once again, the challenge comes ostensibly in business communications, although the organizers of Submarine Lightwave Cable Co. do not exclude sales of capacity to common carriers like $\mathrm{MCl}$. One of the two cable facilities is proposed by a major foreign carrier, Cable \& Wireless Ltd. (with U.S. venture capital partners) and therefore also raises questions of international service competition in the United States.

These large proposed capacity additions-far in excess of demand projections-pose the question of whether there is a built-in tendency in the

\footnotetext{
${ }^{143}$ The TAT-8 8 cable (owned jointly by AT\&T, other U.S. international service carriers, and European PTTs) was approved by the FCC in 1984. A similar TAT-9 cable is proposed by the consortium for 1992. The new cable applicants are: 1) Tel-Optik Ltd. (the U.S. venture capital partner of Cable \& Wireless, Ltd., a British telecommunications carrier), which has applied to build two fiber optic undersea cables with capacity of 80,000 voice-equivalent circuits (FCC, File No. S-C-L-84-002, Sept. 28, 1984); and 2) Submarine Lightwave Cable Co., a U.S. venture capital group, which has applied to build a second cable facility with capacity of 250,000 voiceequivalent circuits (FCC File No. SCL-85-001, Oct. 16, 1984). In March 1985, the FCC informed the Secretary of State of its conclusions that the Tel-Optik application "meets the threshold reciprocity showing of the Cable Landing License Act and otherwise appears to be consistent with U.S. interests under the Act. " The SLC application was not acted on pending the receipt of additional information but no prejudicial finding was made. (FCC News, Report No. 3092, Mar. 4, 1985).
}

imperfectly competitive transatlantic telecommunications market for unrestricted freedom to invest to result in chronic overcapacity. A case could be made for facilities regulation, if consumers, rather than investors, would suffer the consequences of over-investment by having to pay higher prices. This could occur if investing carriers would be able to recoup losses from any "white elephants" by persuading regulators to allow high prices and restrict the capacity in use. Regulation of price and of the use of capacity creates an effective cartel, and facilities owners might be able to avoid the competitive consequences of over capacity investment and still earn high returns (supposing that demand responsiveness would not prevent it). The primary justification for facilities regulation, thus, is that price and capacity-use regulation can be even worse. U.S. use of facilities regulation can also be justified if price and capacity-use regulation is imposed by foreign authorities.

Considering the announced plans and the nature of the actual participants in the transatlantic service market, there is some realistic possibility that the supply of transatlantic capacity, in the absence of controls on construction, could far exceed the demand for it in the 1990s. if all the proposed capacity additions were actually constructed, capacity in 1992 would amount to about 650,000 voice-equivalent circuits, ${ }^{144} \mathrm{com}$ pared to current expected demand (about 20,000 circuits in 1985) and the transatlantic demand forecasts of the U.S. international service carriers (USISCS) and the European CEPT carriers for 1995. Both of these 1995 forecasts are for approximately 82,000 voice-equivalent circuits (tables 6A-1 and 6A-3, app. 6A). Taking all estimates at face value, the construction of the proposed facilities would result in a very large excess supply.

\footnotetext{
$1^{44}$ This should be regarded as only a rough estimate of the circuit capacity of proposed facilities, since both the magnitude of circuit multiplication that will be possible for voice conversations (this estimate is based on a multiplication factor of 5), and the proportion of voice to other uses that do not use multiplication techniques, are uncertain. It is arrived at by adding the following rough estimates: Currently existing cables in service at that time $(10,000)$, TAT-8 and TAT-9 (80,000), Tel-Optik cable (Cable \& Wireless) $(80,000)$, Submarine Lightwave Cable $(250,000)$, separate satellite systems (RCA, Orion, et al.) $(120,000)$, and INTELSAT $(100,000+)$.
} 
If the USISC or CEPT forecasts are even remotely realistic, much of the excess supply can be expected not to materialize as plans are reevaluated. Nevertheless, even if all the venture-capital groups drop out, just the announced plans of INTELSAT, the cable consortia (principally AT\&T and the European PTTs), Cable \& Wireless, and RCA would together still equal more than 300,000 voice-equivalent circuits. It is not at all clear that any of these large firms or consortia would drop out or scale their plans far enough back to reach the neighborhood of the demand projections, even if they could forecast demand (at the level of the USISC projection) with certainty. They might fear that scaling back, without the certainty that the other major players would also scale back, would expose them to an unacceptable loss of market share. Such behavior might occur $\mathrm{u}$ rider the existing conditions of imperfect competition if firms had full freedom to invest in facilities, especially if they could expect to recover the costs of the capacity from consumers via higher prices enforced by regulation.

The competitive solution would be to liberalize the entire market, allowing free entry in both the service and facilities markets. Overinvestment that resulted in lower rates of return would deter additional investment. In the long run, society's resources would be allocated optimally. ${ }^{145}$ One advantage of the competitive solution, if it could actually be implemented, is that consumers would determine the types of facilities that would be utilized and the types of services that would be provided. They would also determine the mix of private and public (common carrier) networks.

Facilities regulation would be an alternative solution, using the methodology that the FCC currently uses or another that involves INTELSAT more formally in the process. Facilities regulation

\footnotetext{
${ }^{145}$ This might not be true of imperfect competition. Regulatedfirms would have a tendency to overinvest, if they did not have to pay for their investment mistakes. A number of the participants in international communications are likely to act differently from competitive firms. AT\&T, whatever its regulatory status, is likely to retain significant market power and might invest for strategic reasons, particularl ${ }_{y}$ if there are important fiber optic economies to scale. Foreign PTTs, being for the most part government owned, might also have a tendency to overinvest in facilities for defensive reasons, if they had reason to expect a financial bailout in the case of loss and had monopoly power over rates, INTELSAT might have an incentive to overinvest for the same reasons as its PTT owners.
}

would have symmetrical disadvantages compared to the competitive model; there would likely be some level of regulation-induced inefficiency in the facilities mix, in the service mix, and in the mix between public and private networks. A second disadvantage is that facilities regulation might be used to maintain an uncompetitive, highpriced services market, if facilities regulation were used to make entry difficult for new service providers. Despite these potential defects, facilities regulation might still be justified if the possible excess supply of facilities suggested by the current facilities plans were considered to reflect a tendency towards either chronic overcapacity or chronic instability.

This brief discussion suggests that a clear prima facie case cannot be made either for unrestricted transatlantic facilities competition (in the current institutional context) or for facilities regulation. Much depends on the particular technical, market, and institutional characteristics of the transatlantic communications market involved: the size of the demand, the seriousness of any tend ency by the institutions involved to overinvest, the actual magnitude of fiber optic economies to scale, and the cost effectiveness of alternative methods of communication security.

\section{Entry for U.S. Service Providers in International Markets}

The United States must also choose how aggressively to pursue liberalization in the general area of entry into international telecommunications service markets. The issue is: how can the United States assist the several dozen large and small U.S. corporations active in U.S. international satellite communications, plus those currently only in domestic satellite communications, to gain access to foreign telecommunications service markets? Should the United States adopt an aggressive posture at the risk of straining relationships with our principal trading partners?

Because basic telecommunications providers are not free to offer single-vendor service in most international markets (i.e., to offer end-to-end communications service over their own owned or leased networks), they can only gain entry to the U.S.-Country X market, if the PTT of Coun- 
try $\mathrm{X}$ will allow them to connect. Even if they were able to enter, they would have to tailor the service they offer to the facilities and practices of the PTT.

Full liberalization in international telecommunications service would require single-vendor service, pricing freedom, and open entry for common carriers and private firms alike in both U.S. and foreign markets. ${ }^{146}$ While full liberalization is very unlikely in the short run, the United States could pursue certain short- to medium-term liberalization objectives in order to increase efficiency in U.S. international telecommunications markets and also increase the access of U.S. carriers. It could attempt to:

- establish a right of connection for all U.S. common carriers to connect to foreign public networks on a nondiscriminatory basis;

- retain country-of-origin pricing;

- prevent deterioration in the ability of U.S. firms to lease international private lines overseas under flexible conditions and with prices related to facilities cost;

- develop beachhead rights for the two-way handling of international communications to and from foreign satellite ground stations by both U.S. common carriers and private firms ${ }^{147}$ and

- secure the right of entry for U.S. value-added and data processing firms into foreign domestic markets.

One possible outcome of the current attempts by U.S. corporations to enter transatlantic satellite markets could be that even if private competition were permitted, it could be narrowly restricted to business communications that do not enter public-switched networks and effectively circumscribed on the ground in Europe. In this case the current international system would probably largely remain in place. ${ }^{148}$

\footnotetext{
${ }^{146}$ Single-vendor senice can coexist with monopoly provision of local service under an access-charge arrangement.

${ }_{14 T}$ The import of this would be that a U.S. carrier or firm could use its own equipment or lease whole, not half circuits from INTELSAT or other satellite facilities providers.

${ }^{148}$ Eli M. Noam, "Telecommunications Policy on the Two Sides ofthe Atlantic: Divergence and Outlook," op. cit., pp. 13-14.
}

Another possible outcome is that the data processing revolution, and the business communications involved in it, will simply overwhelm regulatory defenses and bring not only international liberalization but also substantial domestic deregulation in most industrial countries within the next 15 years.

A third possible outcome could be that great resistance will develop to change, in Europe in particular, and that deregulatory pressures from the U.S. side-from consumers, excluded carriers, and the U.S. Government-will mount. For instance, large consumers abroad might attempt (with U.S. Government toleration) to circumvent national regulation and high prices in certain countries, by routing a greater flow of communications to the United States via cheaper neighboring countries than they do now. This could force unwilling PTTs to lower their international rates to meet the competitive threat. ${ }^{149}$ The conflict that could result from such a situation might so sour communications relationships that the United States could find itself with few allies within international organizations on matters of telecommunications.

\section{International Trade in Satellite Communications Equipment}

The issue in this area is what action the Government should take to try to assure fair international competition in trade in both space- and ground-segment equipment.

The United States is both a leading importer and a leading exporter of telecommunications equipment. It used to have a large overall positive balance of trade in telecommunications equipment, but the balance suddenly shifted to negative in 1983. Table 6-9 shows this deterioration for the whole category "telephone and telegraph equipment," data being unavailable for satellite communications equipment separately. A surplus of over $\$ 200$ million as recently as 1982 has turned into an estimated deficit of $\$ 945$ million in 1984 and a projected deficit of $\$ 1.7$ bil-

\footnotetext{
${ }^{149}$ Data Communications, "Users May Reap Benefitsof Transatlantic Competition, " March 1985; Gary Stix, "PTTs Make Life Rough Overseas," Computer Decisions, Apr. 9, 1985.
} 
Table 6-9.-U.S. International Telephone and Telegraph Equipment Trade, 1978-85 (\$ millions)

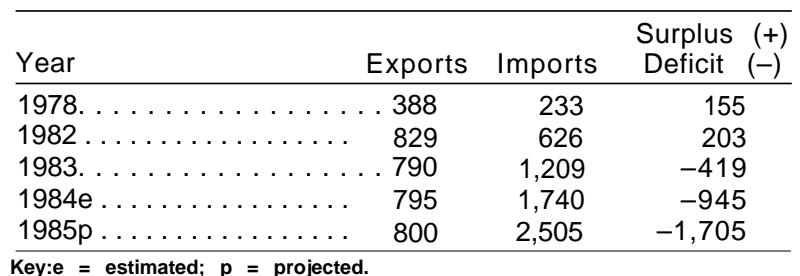

Key:e = estimated; $P$ = projected.

SOURCE: Derived from Departmentof Commerce, U.S. /ndustria/Ouf/ook 1985, pp. $30-1,30-5$,

lion for 1985. The International Trade Commission has forecast that the deficit will continue to increase and will reach $\$ 3$ billion by $1993 .{ }^{150}$ Large exports to developing countries used to more than make up for a trade deficit in telecommunications equipment with other OECD countries. Recently, however, a number of changes in international trade patterns-the deregulation of the U.S. long-distance communications market and the elevated value of the dollar among them, together with continuing barriers to U.S. telecommunications exports in the other industrial countries-have resulted in both a disappearing surplus in trade with less developed countries and a much greater deficit with other industrial count ries. 151

Turning to satellite communications equipment, in particular, it seems clear that, absent trade barriers, the United States still enjoys strong comparative advantage in communication satellites. This also appears to be true in customer-premises Earth stations, except that the advantage of U.S. firms over Japanese ones in this area may be ephemeral. In standard INTELSAT Earth station components, DBS equipment and standard telecommunications equipment, comparative advantage in high-volume manufacturing operations appears to have been shifting away from the

\footnotetext{
$1^{\text {so }}$ Statement of Paula Stern, Chairwoman of the ITC, in U.S. Senate, 98th Cong., Committee on Finance, Subcommittee on International Trade, Hearing, Telecommunications Trade, June 26, 1984, p. 9.

${ }_{15}$ SeeRobertEckelman, "A Stud of the International Competitive Position of the U.S. Telecommunications Equipment Industry" in U.S. Department of Commerce, International Trade Administration, The Telecommunications Industry (High Technology Industries: Profiles and Outlooks), April 1983 and International Trade Commission, "Changes in the U.S. Telecommunications Industry and the Impact on U.S. Telecommunications Trade, "Investigation No. 332-172, 1984,
}

United States, first to Japan, and now to Hong Kong, Taiwan, and South Korea. The latter advanced developing countries all had large telecommunications equipment deficits in 1978, but in 1983 had substantial telecommunications trade surpluses. 152

While fundamentals may govern the movement of certain components of the telecommunications equipment industry into less developed countries, particular factors have contributed to the decline of both the U.S. export share in telecommunications exports and to the vastly greater imports of telecommunications equipment into the United States from the other industrial countries.

\section{Strength of the Dollar}

The high value of the dollar (typically described as over-valuation) tends to make all U.S. exports, including telecommunications exports, less competitive in price. The dollar rose by 58 percent between 1980 and 1984 relative to other currencies $^{153}$ and a shift of this magnitude, seemingly unrelated to changes in U.S. comparative advantage, is large enough to overwhelm it in many sectors.

\section{Unequal Access to Industrial Country Markets}

Following the AT\&T breakup at the beginning of 1984, which separated Western Electric (now AT\&T Technologies) from its special corporate relationship with the Bell Operating Companies, foreign telecommunications equipment sellers are now able to compete in the U.S. civilian market on substantially equal terms with U.S. producers. This market has supported explosive growth of imports for several reasons-because of strong U.S, economic growth, because of the elevation of the dollar, and because of some shift in comparative advantage. Imports grew 93 per-

\footnotetext{
152Department of Commerce, U.S. Industrial Outlook1985, p. 30-5. See Raymond F. Mikesell and Mark G. Farah, U.S. Export Com petitiveness in Manufactures in Third World Markets (Washington, DC: Center for Strategic and International Studies, Georgetown University, 1980), p. 106ff for an analysis of comparative advantage patterns, which concludes that the United States continues to have comparative advantage in technology-intensive products. ${ }^{153} \mathrm{U}$,s, president, Economic Report of the President, February 1985, table B-104, p. 351.
} 
cent in 1983, are estimated to have grown 44 percent in 1984, and are projected to grow another 44 percent in 1985.

The same is not true for U.S. manufacturers in most other industrial countries. The PITs of most such countries usually purchase telecommunications equipment from national firms. Sometimes they engage in extensive $R \& D$, which is provided to national supplier firms without cost. The GAIT Government Procurement Code covers only those government entities that individual countries specify as being under its coverage. As discussed in chapter 4 , most governments have elected not to place their PTTs under its coverage and the European Space Agency is not a party to it, so there is no question of, for example, accusing the Bundespost monopoly, of breaking international trading agreements by proposing to launch a German-made communications satellite without allowing U.S. manufacturers to bid on the project. In another example, the French Telecom 1 satellite system has been developed directly by the D.G.T (Direction General des Telecommunications), the French telecommunications monopoly. The radio and television broadcasting companies of most foreign countries are also government organizations, and, where possible, buy direct broadcasting satellites from their own national or regional manufacturers.

Despite the desire by foreign governments to buy locally, U.S. firms have nevertheless had important participation in foreign satellite projects. The current Japanese communications satellites, CS-2A and CS-2B, for example, were built by Mitsubishi Electric with the active participation of Ford Aerospace \& Communications. ${ }^{154}$ Although the French firm Aerospatiale is the prime contractor for the Arabsat regional system, Ford is doing 59 percent of the work. ${ }^{155}$ Brazil has contracted with SPAR Aerospace of Canada to supply the Brasilsat satellite, but Hughes will actually build it. A primary objective of foreign national space programs has been to reduce dependence on U.S. suppliers, and although U.S. satellite suppliers may continue to supply major components

\footnotetext{
${ }^{154}$ Aviation Week and Space Technology, Feb. 4,1985.

${ }_{155} \mathrm{U}$.S. Congress, Office of Technology Assessment, Technology Transfer to the Middle East, OTA-ISC-173 (Washington, DC: U.S. Government Printing Office, September 1984), p. 210.
}

or technical services, foreign programs will continue to try to do more on their own.

There are signs that some PTTs may in the future permit some competition in equipment purchases, but these signs are far from suggesting a wave of the future. ${ }^{156}$ In 1980 the U.S. and Japanese Governments signed an agreement to open the Japanese equipment market to U.S. firms. This agreement has not so far resulted in substantial U.S. telecommunications equipment sales in Japan, and it does not cover imports of satellites themselves. ${ }^{1} 57$

Just prior to when the partial privatization of the Nippon Telephone \& Telegraph Co. (NTT) and removal of its monopoly status took effect in April 1985, the Ministry of Posts and Telecommunications proposed regulations that, in effect, would give Japanese manufacturers almost veto power over which foreign telecommunications products could be introduced into the Japanese market. Furthermore, the restructured NTT would be given special competitive advantages.

Major changes in these regulations, which U.S. diplomacy (and certain Japanese industry groups) have been seeking from the Japanese Government and have obtained in principle, are:

1 that U.S. manufacturers be allowed to certify that their products meet Japan's standards, instead of having to submit individual products for inspection by a Japanese Government agency;

2. that trade secrets should not have to be submitted to a group containing representatives of their Japanese competitors; and

3. that a single agency would be set up to approve telecommunications products for sale in Japan, rather than the four specified in the draft regulations. ${ }^{158}$

In this instance, as in previous trade disputes between the United States and Japan, political maneuvering within the Japanese Government and bureaucracy has made implementation far from certain, despite the strong support the U.S.

\footnotetext{
156See Dan Schiller, "The Storming of the PTTs," Datamation, May 1983, pp. 155-158.

157U.S.Export Weekly, Jan. 31, 1984, pp. 580-581.

${ }^{158}$ Washington Post, op. cit., Mar. 19,1985, p. D1.
} 
position has received from the Prime Minister. In Japan, as in other industrial countries, the old PTT structure does not easily accommodate international competition, even when it is altered.

In satellite communications equipment, the opening of the telecommunications market, if it should materialize, would primarily affect Earth station equipment and some satellite components. Even an open market would not guarantee success in the Earth station market, however; in this market U.S. firms face a formidable competitor in NEC, the leading ground station supplier internationally as well as in Japan. Japan's response to U.S. pressure to open its satellite procurement market was to give NTT the option to buy foreign communications satellites if it should wish to do so, but U.S. "officials would not venture to guess the extent to which it would result in foreign purchases." ${ }^{159}$ Under the terms of the restructuring of the telecommunications service industry, new entrants will also be allowed to purchase foreign satellites, and U.S. satellite makers appear to be actively seeking sales. ${ }^{160}$

Questions of the openness of the Japanese market are likely to persist, given the history of the bilateral negotiations over the $1980-85$ period, but there is at least some movement there. ${ }^{161}$ Elsewhere in the industrial world, the European markets remain tightly closed to imports of satellites and much telecommunications equipment. In these circumstances, some U.S. firms have found joint ventures with European firms to be a partial substitute. ${ }^{162}$

\section{Trade Barriers in Developing Countries}

Given the barriers to equipment market entry in the industrialized countries, the major new markets outside the United States seem to be in

\footnotetext{
$1^{59}$ Washington Post, Apr. 28, 1984, p. A20.

160 "Hughes Pushes Japanese Ku-Band Allocation, "Aviation Week and Space Technology, Feb. 4, 1985, p. 72.

${ }^{161}$ Lee Smith, "What the U.S. Can Sell to Japan," Fortune, May 13, 1985.

${ }^{162}$ For example, Fairchild Industries has entered into a complicated joint venture agreement with Thompson Alcatel of France that involves each partner as a minority shareholder in subsidiaries of the other. The four jointly owned subsidiaries, two in the United States and two in France, will market pooled lines of satellite and terrestrial communications products and services (Washington Post, Washington Business Section, Mar. 11, 1985, p. 3).
}

the developing world and in smaller industrial countries that do not produce satellites or ground equipment. U.S. satellite manufacturers are in a particularly good competitive position to sell in those markets due to their technological dominance. In Earth station sales, U.S. firms are more on a par with firms from other industrial countries, particularly Japan. In the developing world, it should be noted, there are a variety of nontariff barriers to trade that U.S. manufacturers must cope with. These include adherence to equipment standards set by former colonial powers and the fact that the PTT buyers of satellites and satellite equipment, by dint of their governmental status, may make purchasing decisions not entirely on economic grounds. ${ }^{163}$

\section{Foreign Government Export Support}

Some U.S. firms also believe that other OECD governments offer better export financing for their firms than does the U.S. Export-Import Bank does for U.S. firms, despite the fact that the OECD Arrangement on officially supported export credit has reduced credit subsidies in regular export financing. ${ }^{164}$ For some kinds of exports to developing countries, industrial countries combine foreign assistance credits with commercial export credits, i.e., "mixed credits, " an allowable practice under the current OECD arrangement on official export financing as long as the assistance meets certain criteria (see ch. 4), but one that the U.S. Government believes is being abused by France and Japan. ${ }^{165}$ To counter an earlier use of subsidized credit by Japan in sales of Earth stations to less developed countries (in this case, an over-generous repayment period), the United States negotiated a special OECD Understanding on Export Credits for Ground Satellite Communication Stations. it provides for a maximum repayment term of 8 years in this case. ${ }^{166}$

\footnotetext{
${ }^{163}$ See discussion above and also Technology Transfer to the Midd/e East, op. cit.

${ }^{164} \mathrm{John}$ N. Lemasters, op. cit., pp. 66-69. For a general d iscussion of the OECD Arrangement and the reprint of an unofficial version of its text, see Gary Hufbauer and Joanna Shelton Erb, subsidies in International Trade, Institute for International Economics, Washington DC, 1984, ch. 3 and app. G, respectively.

165"U.S. Warns France on Trade Issue, "Washington Post, Nov. 28, 1984.

166 Hufbauer and Shelton Erb, op. cit., app. G,p. 224.
} 
Currently, the United States is attempting to ob tain a significant tightening of the criteria for mixed credits and is threatening to retaliate with higher funding for U.S. mixed credits, if negotiations fail to produce the sought-after tighten ing. ${ }^{167}$ An earlier example, where the United States matched foreign subsidized credit in satellite communications, occurred when ITT, a U.S. company, was attempting to sell an INTELSAT Earth station package to Cyprus in competition with a French company. Eximbank offered 85 percent financing at 6 percent, and the sale went to ITT. ${ }^{168}$

Other potential governmental means of supporting satellite communications equipment sales include: offering specially discounted combination packages of satellite and government-subsidized launch services (see ch. 4) or making countertrade arrangements in which satellite or ground equipment sales at ostensibly unsubsidized prices are tied to the purchase of commodities from the buyer at higher-than-market prices. ${ }^{169}$

\section{U.S. Government Policy \\ on Export Controls}

In recent years there has been increased Government concern over the risk that exported hightechnology equipment may fall into Communist, particularly Soviet, hands where it might be used for military purposes. One result has been increased vigilance over items which might be on the Department of Defense list of militarily critical technologies. At the same time, the United States has used export controls for political purposes-the most dramatic use being the withholding of technology and equipment that might be used to build the Soviet natural gas pipeline to bring gas to Western Europe. ${ }^{170}$ These restraints on exports, whatever other purposes they may

\footnotetext{
${ }^{167 N e w s}$ conference of the vice chairman of the U.S. ExportImport Bank, Paris, Nov. 27, 1984.

${ }^{168}$ Robin Day Glenn, Financing of United States Exports of Telecommunications Equipment, International Law Institute, Georgetown University, Washington DC, 1982, p. 39.

${ }^{169}$ Douglas L. Addkins, "Countertrade, Clearing Arrangements, Reciprocity and Other Instruments of the New Bilateralism in International Trade, " unpublished paper presented at the Allied Social Sciences Association meetings, San Francisco, Dec. 29, 1983.

$1^{70}$ U.S. Congress, office of Technology Assessment, Technology and East-West Trade: An Update, OTA-ISC-209 (Washington, DC: U.S. Government Printing Office, May 1983).
}

serve, affect the competitiveness of U.S. telecommunications equipment suppliers in international markets.

One case of note in satellite communications illustrates the problem. In late 1981 and early 1982, INMARSAT signed four contracts with U.S. companies (three with COMSAT and one with Digital Communications Corp.) in connection with the INMARSAT research program on the next generation of maritime communications satellites. Because the Soviet Union is a member state of INMARSAT and contract studies are available to all members, the U.S. Government delayed delivery of these studies to INMARSAT. Three of the studies were eventually delivered, but well beyond the contractual due dates, and one was completely canceled by INMARSAT.

INMARSAT officials expressed surprise at the export blockages, particularly since critical technical details did not have to be disclosed. INMARSAT required only enough information on the workings of the satellites to be sure they met performance specifications. With respect to the prospective delivery of actual U.S. satellites, no actual satellite equipment would ever actually be in the possession of INMARSAT, because the satellites would be launched directly from the United States or from French Guiana by the U.S. contractor. Responding to the U.S. action in this case, INMARSAT has decided not to accept bids on future contracts unless a firm can show that it has its government's permission to deliver the goods or services offered. ${ }^{171}$

Some U.S. firms see the application of export controls as putting them at a potential competitive disadvantage. As the vice-president of a firm manufacturing satellite Earth stations and other products put it:

Too much time and effort is wasted in the U.S. on the so-called control of mature products which are already commercially available throughout the world. Control of technology must take place prior to the commercial introduction of a new product. ${ }^{172}$

\footnotetext{
171 See "inNMARSAT Adds Contract Stipulations, " Aviation Week and Space Technology, Nov. 15, 1982, p. 25.

${ }^{172}$ John N. Lemasters, op. cit., p. 68. Mr. Lemasters is Senior Vice President, Communications Sector, Harris Corp.
} 
The same official argued that export restrictions for foreign policy, rather than military, reasons was "the single most damaging U.S. action affecting U.S. exports, particularly to lesser-developed countries." He called the practice particularly harmful to the U.S. telecommunications industry, saying that customers would not buy from a country whose government might arbitrarily step in to restrict the flow of spare parts and maintenance services.

As OTA has previously suggested, the national security and foreign policy benefits of export controls need to be weighed against the loss in export competitiveness to which they may sometimes lead. ${ }^{173}$

\section{The Advanced Communications Technologies Satellite Program}

The key issues for Congress concerning the NASA Advanced Communications Technologies Satellite (ACTS) program are:

1. how much should the Government spend on research and development to help keep the U.S. satellite manufacturing industry technologically vital and ahead of potential foreign competitors? and

2. will the ACTS program do this?

In 1973 the Office of Management and Budget directed NASA to cut back research on civilian communication satellite technology on the grounds that the industry had matured to the point where it could provide its own research and development funds. In 1978 the NASA communication satellite program picked up again and conducted a proof of concept program on advanced satellite communications technology. Authority for elements of a demonstration satellite program (including a flight testing program) were included in 1984 appropriations. ${ }^{174}$ The Administration proposed cutting back the program considerably for the 1985 budget, eliminating funds for the flight testing program, but interest in both the House and Senate in retaining the full ACTS

\footnotetext{
${ }^{173}$ Technology and East- West Trade: An Update, op.cit.

17 Marcia Smith, "NASA's Advanced Communications Technology Satellite (ACTS) Program in Light of the Hughes Filing, " Congressional Research Service report LTR84-158, Mar. 2, 1984 (Washington, DC: Library of Congress).
}

flight test program has resulted in Congress funding the $\$ 354$ million program with a $\$ 45$ million budget in fiscal year $1985 .{ }^{175} \mathrm{RCA}$ is the prime contractor for the $\$ 260$ million outside contract, and TRW and COMSAT are co-contractors;' ${ }^{176}$ Motorola, Electromagnetic Services, and Hughes are the major subcontractors.' 77 NASA estimates that the contractors and other experimenters will spend an additional $\$ 100$ million of their own funds on $R \& D$ that uses the test satellite facility or is otherwise closely related to the program.

ACTS will develop technology for $\mathrm{Ka}$ band $(30 / 20 \mathrm{GHz})$ satellite systems and will a!so explore techniques for increasing satellite capacity that may have application in the $\mathrm{C}$ and $\mathrm{Ku}$ bands as well as the Ka band. ' ${ }^{178}$ Operational satellites in the $\mathrm{Ka}$ band could be used to relieve crowding in the $\mathrm{C}$ and $\mathrm{Ku}$ bands. There is $2,500 \mathrm{MHz}$ of frequency spectrum allocated for communication satellite use in the Ka band, compared to a total of $500 \mathrm{MHz}$ in both the $\mathrm{C}$ and Ku bands. ' $79 \mathrm{Be}-$ cause of greater rain attenuation of signal in the $\mathrm{Ka}$ band (see fig. 6-3), however, special techniques, such as variable power level control to amplify the signal in compensation for the rain effects, forward error correction, involving signal redundancy, or alternative Earth station routings are necessary to use the band effectively.

\footnotetext{
${ }^{175}$ Aviation Week and Space Technology, Aug. 6, 1984, Pp. 2425. The fiscal year 1985 program will continue ACTS technology development and activities leading to the flight program. Much of the $\$ 9$ million appropriation for Communications Program research and analysis will be used for in-house research related to the ACTS program. U.S. House of Representatives, 98th Cong., 2d sess., Report 98-629, Committee on Science and Technology, "Authorizing Appropriations to the National Aeronautic and Space Administration for Fiscal Year 1985, Mar. 21, 1984, pp. 97-102.

176 The NASA program cost estimate was based on a 1988 launch, but this has now been moved into 1989 (Aviation Week and Space Technology, Aug. 6, 1984, pp. 24-25).

,77Smith, CRSReportLTR84-1 58, Op. Cit., p. 11

${ }_{18}^{78}$ This discussion draws on a number of sources, especially Smith, CRS Report LTR84-158, op. cit. NASA, Office of Space Science and Applications, "ACTS: Advanced Communications Technology Satellite Program" [undated pamphlet]; Chris Bulloch, "Advancing the Art of Satellite Communications," Interavia, January 1985, pp. 2528; and C. Richard Whelan, "Communications Satellites Move to Higher Frequencies, " High Technology, November 1984, pp. 49-53.

${ }^{79} \mathrm{An}$ advantage of the Ka band, minimal orbital spacing (poten tially 1 rather than the 2 or 3 degree spacing in the lower bands), is of little economic value unless there were also crowding in the $\mathrm{Ka}$ band, a possibility that is unlikely in any but the distant future (Whelan, op. cit., p. 49).
} 
Figure 6-3.-Radio Signal Attenuation

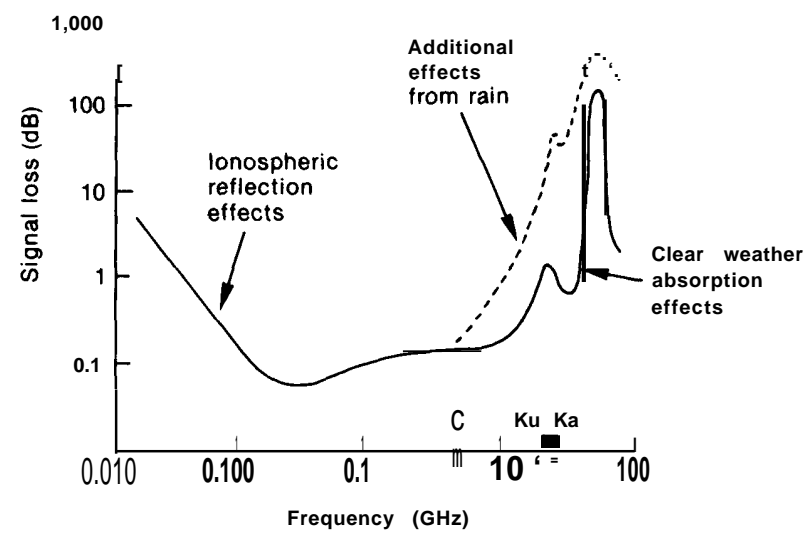

SOURCE: National Aeronautics and Space Administration

Among the techniques that increase satellite capacity are those designed to increase the communications capability of individual satellites in given geosynchronous slots, called "frequency reuse" techniques. One such technique that the program would investigate is the use of spot beams, allowing the satellite to use the same frequencies simultaneously to transmit and receive different signals to and from geographically separate ground stations. On the ACTS test satellite, some of these beams would be scanning, sweeping back and forth from ground station to ground station. The scanning spot beams would further increase the total message capacity of the satellite by permitting fewer separate beams with higher power in each transmission. This scanning technique also would allow the satellite to redistribute its capacity continuously, following variations in service demand, to different areas of the country. Higher satellite power in beams would by itself allow the use of less expensive Earth station equipment, but a firm opposing the program contended that Earth stations required for the ACTS scanning-spot-beam technology would be more expensive than Earth stations required by satellites employing fixed spot beams. ${ }^{180}$

The program would also study increasing satellite capacity by a message processing procedure called "satellite switched time division multiple access" (SSTDMA). ${ }^{181}$ SSTDMA is a technique of

\footnotetext{
${ }^{180}$ Smith, CRS Report LTR84-1 58, Op. cit.

181 "By dividing the satellite communications signals into short, compressed bursts of information, several users may transmit and
}

beam-to-beam digital switching within the satellite, which, though potentially useful with fixed spot beams, would be essential for scanning spot beams. An onboard computer, called a "baseband processor," would control scanning, switching, and other functions within the spacecraft.

During the period of low NASA effort in satellite communications research, individual European countries and Japan were all providing government funds for research in satellite communications technology and for the development of operational satellites in an effort to catch up with U.S. technology. One NASA study showed that, at $\$ 55$ million in 1982, European expenditures were 2.5 times those of NASA, while, at $\$ 190$ million, Japan's were 11 times NASA's. ${ }^{182}$ Another estimate placed combined Japanese Government and private communications satellite R\&D expenditures in 1983 at nearly $\$ 400$ million. ${ }^{183}$ Japan's current and planned satellites include fixed spot beams in the Ka band, as does Italy's Italsat, planned for launch in 1987. Satellites proposed by the European Space Agency, and by France and Germany separately, would also use the Ka band. None of the current foreign programs appear to contemplate movable or scanning spot beams, but Japan is considering a next-generation operational satellite system (cs-4) using scanning spot beams and onboard signal processing. ${ }^{184}$

U.S. firms have also carried out large corporate $R \& D$ efforts in satellite communications. ${ }^{185}$ Nevertheless, industry and NASA officials have repeatedly told Congress that no private firm would be willing to bear the risk, expense, and delayed payoff of launching its own Ka band satellite incor-

receive at the same frequencies by taking turns or time sharing. The time slot allocated to a given Earth station can be lengthened or shortened to accommodate a varying amount of communications needs." NASA, op. cit., p. 9.

${ }^{182}$ Aviation Week and Space Technology, Sept. 6, 1982, p. 241.

${ }^{183}$ R. Filep, A.Schnapf, and S. Fordyce, "Japanese and Western European Space Research and Development With a Focus on Communications Satellites, " paper prepared for NASA Lewis Research Center, Feb. 1, 1984.

${ }^{184}$ Bulloch, op. cit., p. 462-63.

185These effortsmay have been stimulated by research for, or in anticipation of, military and INTELSAT contracts. Hughes, in particular, has developed advanced technology for the Department of Defense's MI LSTAR series of military communication satellites and for the INTELSAT VI series. Smith, CRS Report LTR84-158, op. cit., p. 13. 


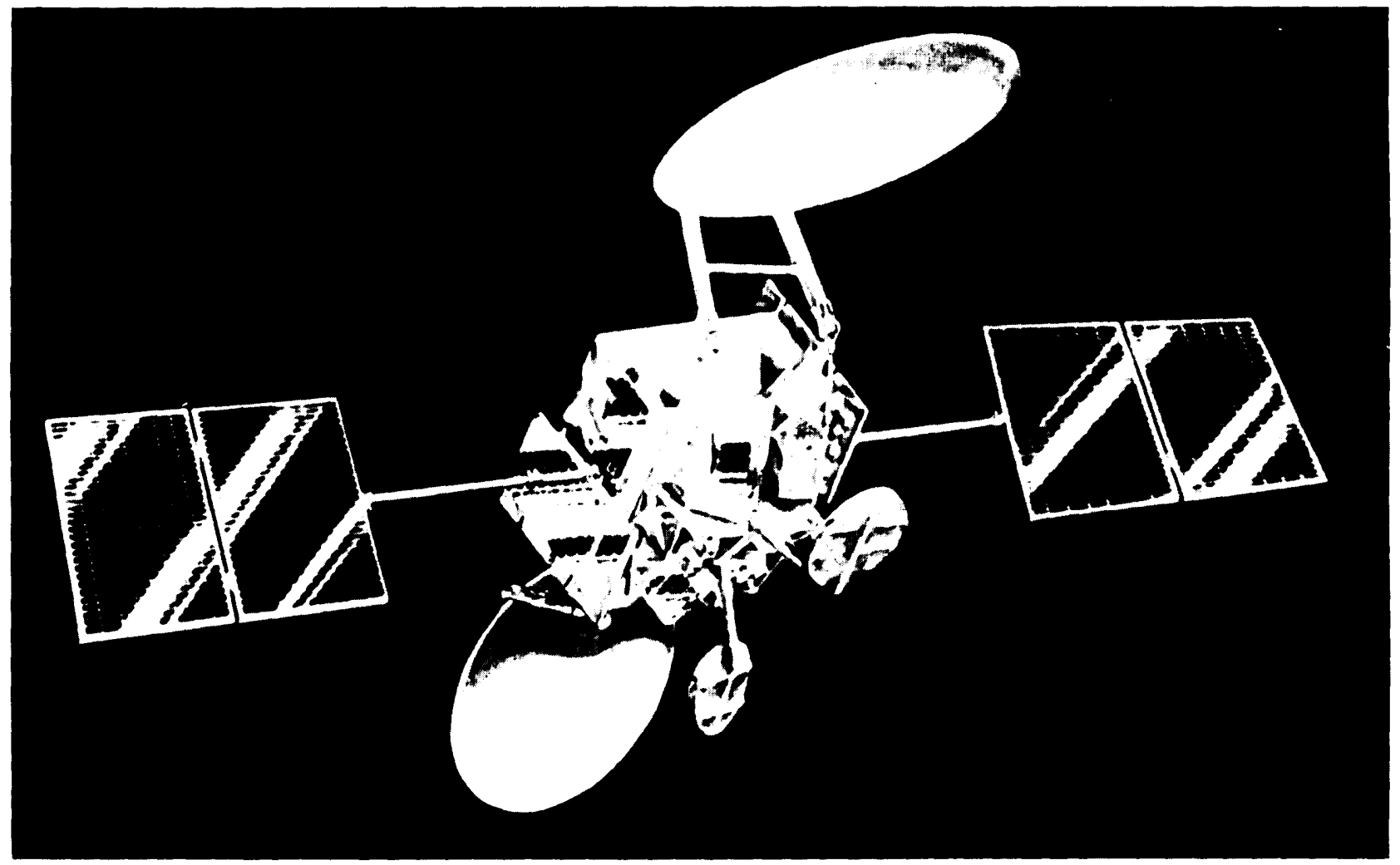

Photo credit: National Aeronautics and Space Administration

Artist's conception of the NASA Advanced Communication Technology Satellite (ACTS). The solar panels that provide the power are deployed on the left and right of the drawing. The reflectors for the $30 \mathrm{MHz}$ and $20 \mathrm{MHz}$ frequency antennas are shown above and below the satellite.

porating advanced technology. Were NASA not to test such a satellite first, their argument has been, the United States would lose its "preeminence" in satellite communications technology.

In 1984, however, Hughes Communications Galaxy, Inc., filed with the FCC for permission to construct, launch, and operate two Ka band satellites with its own funds in 1988 and 1989. The proposed Hughes satellites would have 16 spot beams, thus allowing multiple re-use of the same frequencies. The on board signal processing techniques would not include the SSTDMA planned for the ACTS satellite. The spot beams would all be fixed rather than scanning. According to Hughes, the simpler onboard system would allow the use of less expensive ground stations than those that would be required for the ACTS satellite. ${ }^{186}$ On board switching circuitry would interconnect all 16 spot beams. The system in orbit was expected to cost about $\$ 450$ million, to be financed with private capital.

Hughes officials argued scanning spot beam technology would probably never be economical for commercial satellites; there was thus no commercial reason for NASA to invest in that technology. ${ }^{187}$ As for the advanced signal proc-

\footnotetext{
${ }^{186}$ It appears that Hughes also has the ability to install movable spot beams in commercial satellites, at least at lower frequencies. The recent application by Pan American Satellite Corp. to provide international communications satellite service proposes to launch a hybrid system based on the Hughes HS-393 satellite with one "movable spot beam" and several fixed beams in 1987. The movable spot beam is designed to transmit in C band. ("Application of Pan American Satellite Corp. for a Subregional Western Hemisphere Satellite System," May 31, 1984, before the FCC, pp. 15-18).

$1{ }^{87}$ See Jay C. Lowndes, "Hughes Plan May Spark Round of Ka band Filings," Aviation Week and Space Technology, Dec. 19, 1983, pp. 28-29.
} 
essing (called "baseband processing" to be explored in the ACTS), Hughes argued that NASA could do that research on the ground. ${ }^{188}$

The decision on whether the U.S. Government should fund the space testing of advanced satellite communications technologies depends on two classic arguments for government R\&D as an element in the commercialization of advanced technology and on one argument unique to satellite communications:

1. The Government needs to protect U.S. industry's market share (jobs, exports, etc.) from the R\&D subsidies of other countries by funding R\&D of its own.

2. The Government should fund and possibly conduct advanced R\&D in many advanced technology industries, such as aircraft, computers, telecommunications, etc., because the private sector systematically underfunds research that has two types of risks: the risk that the technology will not work or be saleable and the risk that competitors will be able to gain access to their expensive research as free riders. Industry therefore stays with proven, if older, technology.

3. In satellite communications in particular, only Government has the incentive to do research to guard against the misuse of a resource that is in the public domain, the geostationary orbit.

In satellite communications, as in other R\&D contexts, evaluating the strength of these arguments is difficult because the chains of reasoning involved are complex and key facts and cause-effect relationships are highly uncertain. In satellite communications, there is no issue of the narrowness of the groups that would benefit from Government funding, assuming that the benefits were real. Every member of the public is a communications user.

How strong is the argument that unless the U.S. Government funds satellite research, the U.S. communication satellite manufacturers will fall behind their government-subsidized international rivals? In particular, determining whether the costly flight testing aspect of the ACTS program

\footnotetext{
${ }^{188}$ Smith,CRS Report LTR84-1 58, Op. cit., p. 4.
}

will be needed and effective in keeping U.S. firms competitive with foreign firms will have to deal with the following question:

-Will there be enough of a world market for $\mathrm{Ka}$ band satellites to justify a sizable research program of any kind on Ka band satellites?

A large market for $\mathrm{Ka}$ band satellites would exist only if there were substantial crowding in the geostationary orbit in the $\mathrm{C}$ and $\mathrm{Ku}$ bands, which in turn would occur in the 1990s only if the demand for U.S. domestic satellite communications expands very rapidly ${ }^{189}$ The current glut in U.S. domestic satellites, the failure, as yet, of direct broadcasting satellites (DBS) to prove a market, ${ }^{190}$ and the almost certain existence of an extensive U.S. fiber optic cable network in the 1990s, all make the existence of a Ka band market highly uncertain.

- Assuming that there will be a sizable Ka band satellite market, is the U.S. satellite manufacturing industry already competitive in $\mathrm{Ka}$ band satellites? At least one U.S. satellite manufacturer (Hughes Aircraft) asserts that it has the capability to build and market fairly sophisticated Ka band satellites, with technology as advanced or more advanced than the satellites in many of the foreign experimental programs.

- Will there be enough of a world market for satellites with scanning spot beams to justify a sizable research program on the necessary advanced techniques?

Depending on their cost, satellites with scanning spot beams might be purchased by satellite buyers so that they could increase the capacity of satellites in given orbital locations by more efficiently handling the communications of smaller cities outside of metropolitan areas and of rural areas. The actual cost and characteristics would be important, since other techniques of increasing the capacity of given orbital locations will be available, including the use of less sophisticated and less costly versions of Ka band technology.

\footnotetext{
${ }^{189}$ See th ${ }_{e}$ discussion of the satellite equipment market above in this chapter.

190 "FCC Asked to Delay Radio Spectrum Shift, "Washington Post, Apr. 9, 1985, op. cit., p. D3.
} 
- Assuming that there are significant markets for satellites with $\mathrm{Ka}$ band and scanning spot beam features in the 1990s, will U.S. firms gain an advantage over foreign firms from the ACTS program or at least not lose the advantage they now have in commercial satellites? in part this depends on the usefulness of the results; can NASA's ACTS program, with the advice and significant financial participation of the private sector, "pick winners"? Whether U.S. firms would gain a competitive advantage also depends on whether foreign governments match NASA's research program with programs of their own intended to accomplish the same commercial objectives. Such induced programs might cancel or partly cancel the effects of the ACTS program on U.S. competitiveness. There is also the problem of NASA transferring the technology to U.S. firms and simultaneously preventing foreign firms from gaining access to it.

Turning from foreign competition to the basic role of government in advanced technology R\&D, how strong is the argument that the private sector would not perform the socially optimum level of $R \& D$ in satellite communications, if there were no ACTS program? There is general agreement that the Government has a role in funding basic research, since the private sector has insufficient incentive to invest in it. Because an investing firm would not be able to keep its competitors from gaining substantial access to the research results, such an investment would usually not be profitable. If the basic research results are available to other firms through scientific publications or personnel transfer, they need not recover the costs of the basic research to stay in business and, in a competitive market, will tend to set their prices too low for the investing firm to recover its costs. The best way for a firm to avoid this situation is not to do the basic research. Private firms may also be too risk averse or too small to perform the basic research function. Consequently, government (and certain other research institutions) typically must do socially useful basic research, if it is to be done at all.

At the other end of the basic/applied research spectrum, firms are much more able to keep the results of applied process, product, and market research from their competitors and, thus, earn sufficient revenues from them to finance the research and earn profits. They can keep their research results secret as proprietary information, protect it with patents, incorporate it in engineering drawings and prototypes, and, finally, embed it in organizational practices. Much applied research and development is so intimately involved with the operations of firms and the characteristics of markets that only firms have the proper incentives to perform it well. Government organizations that try to perform highly applied research may end up with commercially irrelevant results.

To determine how much of the ACTS-type research private industry would do and what part the Government should fund, answers to the following questions should be sought:

- What kind of R\&D have U.S. satellite manufacturers been doing by themselves? In connection with the ACTS program, what kinds of coordinated research have the private participants been willing to finance from their own funds or in joint venture with other large aerospace, communications and information corporations? Using this evidence, what kinds of research would the industry be likely to do on its own? Considering that each of the three largest satellite prime contractors (Hughes, Ford, and RCA) own or expect to own satellite capacity for sale or lease to customers, should they be expected to flightiest innovative components on their own spacecraft? (The Hughes application promises to do just that.)

- How important, within the overall U.S. Government program of $R \& D$ in advanced technology, are those components of the ACTS program that only the government appears likely to perform? Which particular markets are they relevant to? The market for less sophisticated Ka band satellites or the market for satellites equipped with scanning spot beams and other sophisticated technology? Are either of these markets likely to be large enough to justify the cost of the ACTS program?

Finally, the unique argument in support of satellite communications R\&D, which does not have 
a counterpart in the debates over other types of government-supported advanced R\&D, is its relevance to potential crowding in the geostationary orbit. Certain questions need to be answered in order to evaluate the strength of the argument that Ka band satellites will be needed due to the crowding in the geostationary orbit:

- How likely is crowding in the geostationary orbit in C and Ku bands in the 1990s, considering the current satellite glut and the emerging domestic and international fiber optic networks? How damaging to the public interest would any crowding be that developed in the $\mathrm{C}$ and $\mathrm{Ku}$ bands, considering the existence of transmission alternatives.

- How much of the private sector's response to any crowding in the two lower bands would use existing frequency reuse techniques or less sophisticated Ka band satellites of the Hughes type, rather than sophisticated techniques, such as the ACTS scanning spot beams?

- How would crowding and technological responses to it be affected by any planning mechanisms decided on in the upcoming ITU Space WARC conferences?

- Is there a role for an auction techniaue to allocate the geostationary arc available 'to the United States in providing incentives to satellite manufacturers to develop arc-conserving technologies?

\section{POLICY OPTIONS}

This chapter has discussed and analyzed a number of elements in the U.S. international satellite communications sector. Implicit were various policy options. This section draws them out explicitly.

\section{The Future of INTELSAT}

The United States has three principal longrange options for dealing with the future of the international satellite communications system (INTELSAT augmented, as it currently is, by a number of coordinated regional systems):

1. It could attempt to preserve the current system, with INTELSAT continuing to carry the preponderant amount of intercontinental traffic and carefully controlled regional systems handling some intra-regional communications. Denial of the applications of private U.S. satellite firms to undertake largevolume transmit/receive operations across the Atlantic or within the Western Hemisphere would be consistent with this goal.

2. It might assert the freedom of U.S. satellite firms to offer substantial but not unlimited intercontinental transatlantic and Western Hemisphere satellite services, particularly in business and television communications, if it is satisfied that moderate competition in these areas would not jeopardize INTELSAT's financial performance. This objective could be pursued with the following short-run policy options:

a. attempt to negotiate a regulatory regime with one or more major U.S. communications partners that would permit these services before licensing U.S. satellite firms to provide them, or

$b$, license U.S. firms first, then negotiate the regulatory framework with communications partners later (or let the firms do it).

3. It could opt to abandon special support of INTELSAT; allowing U.S. firms to offer competitively as much and as many different kinds of international satellite and cable service as they wish (and can find interconnections for), and expect INTELSAT to adjust, with its survival a matter of its competitive success $^{191}$ (I NTELSAT would, of course, continue to benefit from its monopoly position in non-competitive world regions.)

The question of competition to INTELSAT involves two conflicting objectives: 1 ) preservation of the "single global system" for foreign policy

\footnotetext{
${ }^{191}$ This option is not under active consideration by any of thepolicymaking bodies in the U.S. Government, but is included for completeness.
} 
reasons and for its economic benefits, and 2) maximum competitive access for U.S. telecommunications carriers on grounds of fairness and the economic benefits that flow from competition. There is general agreement that U.S. policy toward INTELSAT in its formative stages engendered international goodwill and therefore furthered general U.S. foreign policy objectives.

In the United States, at least, there is support for the general ideas of increased competitive access for U.S. firms and fair international competition. ${ }^{192}$ As discussed in chapter 4 , competitive organization is the recognized normal form of industrial organization relied on by the United States in most domestic and international markets. In the specific case of international telecommunications, however, the U.S. consensus that competition promotes economic efficiency has been tempered by the fact that the United States simply does not have the power to create fully competitive conditions either by unilateral action or by entering into good-faith negotiations with communications partners. Competition in international telecommunications is not something that the United States can impose or that will happen if negotiations fail. Other nations have the unilateral power to disallow competitive arrangements when their territories are directly involved.

In the case of transatlantic entry, any U.S. satellite firms wishing to compete with INTELSAT will need the permission of one or more foreign governments to legally transmit into their territory. In cases where the public network is involved, it will also mean that the PTT will have to be willing to interconnect. ${ }^{193}$ Even when the PIT is wholly government owned, formal permission by the regulatory authorities may not easily translate into actual connection by the PIT; when the PTT is partly or wholly private, resistance by an unwilling PTT may be even more of a prob-

\footnotetext{
${ }^{192}$ This consensus does not generally extend beyond U.S. borders, however, where the idea of competitive provision of "basic public services" by lightly regulated private companies is often severely criticized.

${ }^{193}$ Intercon nection, however, does not mean nondiscriminatory treatment. For this to occur, the PTT would have to agree to send communications it originates via each of the U.S. carriers' satellite facilities (according to some formula) in competition with the INTELSAT facilities of which it is part owner.
}

lem. Reciprocal access of communications carried via foreign-owned satellites into the United States could be a condition for the entry of U. S.owned satellite operations into foreign countries in many cases; foreign countries might alternatively insist on joint ownership as a condition for operation.

The three options listed above should be seen as different tradeoffs between the U.S. foreign policy objective of friendly relations with other countries and the economic interests of U.S. telecommunications producers. Where the interests of consumers lie is subject to debate and depends on how much competition would actually be established. ${ }^{194}$

Option 1 would attempt to prevent private competition to I NTELSAT in any but minor ways. Option 2 would move toward increased competition, while keeping INTELSAT viable. Option 3 would disregard any special consideration for INTELSAT and would move toward a competitive system if at least a small number of U.S. communications partners would let it.

In option 2, there is a significant range of tactical options between the extremes of "license first then negotiate" and "negotiate first for as good a deal as possible and then license in conformity with it." Because the United States does not have the power to remake the international regulatory regime unilaterally, if it decides to promote greater competition in international telecommunications, it should choose tactics that will help gain the agreement of the relevant foreign countries (and not harm general U.S. interests). Cases can be made for both of the tactical options listed or for something in between. ${ }^{195}$

For instance, would-be satellite providers could be given permission to construct (but not launch) their satellites, prior to the completion of the

\footnotetext{
${ }^{194}$ One argument in favor of option 2 is that it would allow some measurement of the performance of competitive satellite operations and thereby allow a better estimate of the costs or benefits to U.S. consumers, and to those in developing countries, of maintaining INTELSAT as a viable entity.

${ }^{195}$ See Bert W. Rein, et al., "Implementation of a U.S. 'Free Entry' Initiative for Transatlantic Satellite Facilities: Problems, Pitfalls and Possibilities" (Washington, DC: Wiley, Johnson \& Rein, July 3, 1984); and Daniel P. Kaplan, "Buying and Selling International Airline Deregulation, " paper presented at the Allied Social Science Associations Meetings, Dallas, TX, Dec. 28, 1984.
} 
INTELSAT coordination process. Construction took place in the Eutelsat and Arabsat cases prior to coordination. Alternatively, permission both to construct and launch satellites could be given but made contingent on completing the coordination process. In any case, there will be a mix of the unilateral exercise of sovereign power and of negotiations with communications partners over bilateral or mu Itilateral communications arrangements.

The President has decided on option 2, in finding that alternative satellite systems (not connected to public networks) are "required" in the national interest, but has not indicated his tactical decisions. ${ }^{196}$ To date the United States has conditionally approved applications by U.S. domestic satellite providers in the Western Hemisphere and may proceed to do the same for the prospective transatlantic satellite providers. What action the United States should take if INTELSAT refuses to coordinate some or all of the conditionally approved services is another important tactical issue yet to be joined.

In option 3 the tactical issues would not be so varied. For instance, because this option, to abandon special support of INTELSAT, would be the most disruptive of the current system, the United States' ability to negotiate it with most of its major communications partners in advance would be in great doubt. Hence, the license-first tactic is probably implicit in it. This, of course, would not rule out the ordinary type of diplomatic interaction by which the Government keeps its allies and trading partners informed of what it is about to do.

\section{The Future of COMSAT}

A separate set of policy options apply to COMSAT. Congress could:

1. Continue current legislative policy toward COMSAT, except with greater legislative oversight of the FCC's surveillance of COMSAT'S rate-of-return and its separation of regulated from unregulated activities. In this option,

\footnotetext{
196 Seepreviousdiscussion in this chapter of the Reagan Administration's 1984 decision to support limited operations by new satellite entrants.
}

COMSAT would continue its monopoly status as the sole U.S. owner of INTELSAT investment shares and thereby as an intermediary in both traditional services and the new INTELSAT Business Service (IBS).

2. Mandate a rapid evolution of COMSAT into a fully competitive, general communications carrier, ending its special status at some specified future date by allowing other carriers direct ownership of or "direct access" to INTELSAT space segment facilities. ${ }^{197}$

3. Retain COMSAT'S monopoly as the sole conduit to INTELSAT, but restrict this role to the minimum and force divestiture of all other activities.

The fact that COMSAT is an ongoing, regulated enterprise that has managed the international satellite communications of the United States with technical effectiveness at declining prices to the carriers it serves and, as the U.S. signatory, has maintained good relations with U.S. communications partners is an argument in favor of option 1 , to continue the status quo.

As the FCC sees it, this is an evolving status quo. For instance, several other communications firms are now allowed direct technical access to INTELSAT space segment facilities for I NTELSAT Business Service (IBS), although they still must pay COMSAT'S tariff for their use.$^{198}$ Its Earth station decision also now allows carriers to own Earth INTELSAT stations. ${ }^{199}$ The FCC also allows COMSAT to participate in other regulated and unregulated

\footnotetext{
'97," Direct access" is the term used by the FCC to refer to various mechanisms whereby the other carriers could bypass COMSAT without actual ownership of an investment share in INTELSAT. Among the proposals the Commission considered (and denied) in its direct access decision were: 1 ) a capitalized lease option whereby the carriers would include in their rate bases the amounts they now pay COMSAT for circuit leases, and 2) an IRU (indefeasible right of user) mechanism similar to that used for cable facilites whereby the carriers would invest in INTELSAT circuits directly by paying COMSAT a prorata share of its investment in INTELSAT. The Commission also did not foreclose the possibility that it might revisit the direct access question in the future. (FCC, "Second Report and Order ....," op. cit., Jan. 11, 1985, pp. 8-9).

${ }^{198}$ The executive branch has recommended that "cost-based carrier and user access to INTELSAT with respect of customized services" be ordered by the FCC but has not yet specified whether this is compatible with current IBS arrangements (Departments of State and Commerce, "A White Paper on New International Satellite Systerns," op. cit. p. 33 .

${ }^{199}$ FCC, "SecondReport and Order . . .," op. cit., Jan. 11, 1985, p. 10.
} 
communications markets, with strict separation of accounts and of elements of the corporate structure. In accord with FCC policy, COMSAT will now also be allowed to offer 1NTELSAT services to customers other than the international service carriers.

Options 2 and 3 would both make major changes in COMSAT's position. They might be attractive to those who have argued that, no matter how carefully COMSAT and its regulators attempt to insulate COMSAT's special role as the sole U.S. intermediary to INTELSAT from its other roles as a basic and enhanced communications carrier and equipment manufacturer, it cannot be effectively done. Thus, in this view, COMSAT would always be able to gain unfair competitive advantage from its special position. ${ }^{200}$ The solution of option 2 is to end COMSAT'S special role, and that of option 3 is to restrict it only to that special role.

Option 2, to end COMSAT'S special role by allowing other U.S. businesses direct ownership of INTELSAT space segment facilities on the same basis as COMSAT could be difficult to implement, if it would require the agreement of the Board of Governors of INTELSAT or other INTELSAT bodies. Such agreement might not be forthcoming or might not be forthcoming on terms the U.S. would find acceptable. ${ }^{201}$ Various direct access plans, which have been proposed to the FCC would allow the carriers to acquire ownership of assets from COMSAT, but depending on the arrangement, COMSAT might end up with a "ministerial role" in which it had large responsibility but little financial stake. If it did retain substan-

\footnotetext{
200 The fear that COMSAT would be able to subsidize its competitive activities with revenues as monopoly provider of INTELSAT space segment services is one aspect, but information access is also cited. For instance, International Relay, Inc., stated in congressional hearings that the fact that COMSAT receives information prior to INTELSAT meetings that IRI receives only after decisions have been taken at those meetings is "critical to the future course of IRI's business plans, and those of others who are dependent on the INTELSAT system." (Statement of Steven A. Levy, U.S. Congress, House, Hearings on International Satellite Issues before the Subcommittee on Telecommunications, Consumer Protection, and Finance, June 13, July 25-26, 1984, pp. 156-185)

201 The substitution of a new entity, perhaps governmental, to represent the United States so as to avoid the need to involve INTELSAT in the decision can best be seen as a version of option 3 to restrict COMSAT (or the new entity) to the role of owner of and intermediary to INTELSAT or as a separate option. See the following discussion of option 3 .
}

tial financial stake (perhaps because the other carriers did not choose to or were not allowed to acquire assets proportional to their use of INTELSAT) the situation would be little different from the current arrangement. ${ }^{202}$

Option 3, which would restrict COMSAT (or a successor, perhaps governmental, entity) to its special, highly regulated role as the owner of and intermediary to I NTELSAT, would also remove the possibility that COMSAT'S special position in INTELSAT could be used to give it a competitive advantage in other activities, since it would not then have any other activities. This option could take diverse forms with diverse effects on market structure, however, depending on ownership and other restrictions that might be placed on the restructured COMSAT and on other changes i $n$ the regulatory regime in international communications. For instance, if U.S. international carriers could gain ownership rights in the stripped-down COMSAT, such an arrangement could constitute a capacity carte ${ }^{203}$ and could make the current regime even less competitive than it is now.

Full assessment of the regulatory requirements under options 2 and 3 would require further analysis, but this brief treatment indicates that solutions designed to mitigate the competition problems caused at the domestic interface with INTELSAT are themselves likely to engender other, knotty problems of competition and regulation.

\section{Satellites v. Fiber Optic Cables}

The demand for international satellite communications services will undoubtedly continue to grow rapidly at least until the early 1990s, but between then and the end of the century, it may or may not continue to grow. The pace of that

\footnotetext{
${ }^{202}$ It should be noted that even if the carriers were allowed to gain ownership rights in INTELSAT, this would reduce but not eliminate their extra incentive to use cables rather than satellite transponders. Their traffic-sensitive satellite costs, which, depending on the exact arrangements, might be reduced from the COMSAT tariff to something closer to the INTELSAT unit charge, would still be greater than the minimal traffic-sensitive costs of using the cables they own.

${ }^{203}$ The term cartel is used here and elsewhere in this assessment descriptively to mean a group of firms that openly communicate with each other and reach joint decisions on such things as price, capacity, product offerings, market participation, etc. We do not use it to judge whether firms are in violation of the antitrust laws.
} 
growth will be conditioned not just by technology developments but also by choices that government will make with respect to facilities regulation, Options for the U.S. Government include:

1. Continue to control the amounts of transatlantic cable and satellite capacity available by approving or disapproving the facilities plans of cartels of U.S. and foreign carriers or of individual firms, and to oversee the loading of traffic on satellites and cables so that some form of balanced use of cables and satellites is maintained. Primary U.S. responsibility for international facilities regulation would remain with the FCC.

2. Same as above, except that no systematic policy of facilities balance would be followed. Technological competition between cables and satellites would be allowed. Action might be taken to reduce carrier bias toward cables, but other than this, the market, the carriers, and foreign regulation would be the primary determinants of the relative use of satellites and cables.

3. Leave U.S. telecommunications firms competitively free to invest in international cable or satellite facilities as they see fit and secure international connection rights as they are able. Reciprocal access for carriers using foreign-owned facilities is likely to be a condition for such connection. When entry to foreign service markets is limited, regulate the country-pair cartels that may arise to prevent high rates and the whipsawing of U.S. carriers. ${ }^{204}$ Primary responsibility for overseeing the process would probably remain with the FCC.

4. Change to a more activist international-facilities policy involving a greater emphasis on bilateral government-to-government agreements on telecommunications facilities. Under

\footnotetext{
${ }^{204}$ Whipsawing refers to a feared practice on the part of foreign monopoly PTTs in the negotiation of settlement rates with U.S. competitive carriers whereby the privilege of connection is awarded to the single U.S. carrier offering the highest accounting rate (or is awarded to each of a number of carriers based on what their offers are). Competition among the U.S. carriers could reduce their revenues, but the price of the end-to-end message could still be kept high if the favored U.S. carrier or carriers had to pay out monopoly profits to the PTT. See Evan Kwerel, "Promoting Competition Piecemeal in International Telecommunications," working paper, Office of Plans and Policy, FCC, December 1984.
}

this option, the United States would undoubtedly seek bilateral telecommunications collaboration with countries like the United Kingdom or Japan that are favorably disposed toward deregulation. In such a strategy there could also be room for multilateral communications agreements and for more general multilateral agreements on trade in services. This strategy would require more negotiation than the current regulatory regime and would be similar to the U.S. a: preach to international airline regulation. The executive branch (National Telecommunications and Information Administration, the State Department and/or the U.S. Trade Representative) would be likely to take over the leadership in international facilities regulation from the FCC.

Option 1, to continue the present policy of controlling transatlantic communications capacity and its division between satellites and cables, has the attractive feature that it is a well-established policy in which flexibility can be obtained through ad hoc actions of the FCC. In support of current policy, INTELSAT and others have expressed the concern that unrestricted facilities competition between cables and satellites, in a still restricted international market, might result in:

1. excess capacity that consumers might have to pay for through higher-than-necessary prices, and

2. serious difficulty for INTELSAT with attendant political problems.

Nevertheless, a policy of balance-balanced construction and/or balanced use-could entail a large economic cost to U.S. consumers if the cost advantage of cables (or satellites) should prove to be substantial and if it required carriers and consumers to use facilities they would otherwise not choose to use. ${ }^{205} \mathrm{~A}$ second question

\footnotetext{
${ }^{205}$ Under a balance policy, a desired distribution of traffic between cables and satellites could result from either controls on construction or on use. If a carrier, carrier pair, or carrier consortium were convinced that the FCC would enforce a balanced use policy (e.g., 50-50 or "balanced loading" - see note 46, p. 161 for the FCC's definition of "balanced loading" between cable and satellite facilities), they would be unlikely to invest disproportionately in facilities they would not be allowed to use.
} 
relating to balance is whether the existence of satellites should be guaranteed by government regulation so as to provide security against communications interruption or whether this function can be provided by redundant cable capacity.

Any large shift to cables would have important effects on INTELSAT and make it more likely that INTELSAT could become seriously unprofitable, so the issues of facilities planning and competition for INTELSAT are closely linked. The recent FCC recommendations of approval for approximately 330,000 voice-equivalent, transatlantic circuits in new private fiber optic cables, without much attention to its planning process, indicate that the Commission is acting without much regard for this link.

Option 2, to avoid any policy of balance but to continue to attempt control of total capacity, would leave the present regulatory regime in international communications largely intact, with the important exception that, if carriers were free to construct cables and did so, INTELSAT's share of transatlantic communications (and that of other satellite providers) would probably decline. This would represent a substantial change in policy toward both INTELSAT and COMSAT (see discussion of policy options on competition to INTELSAT, above.) It would have the advantage of partially meeting the long-standing objections of European PTTs to unilateral U.S. Government intervention in facilities decisions. (The favorable actions by the FCC and the State Department on cable landing licenses for large capacity private fiber optic cables, however, may have removed option 2 as a possibility.)

Options 3 and 4 would represent the abandonment by the United States of the North Atlantic Consultative Process as it is now structured and of INTELSAT'S position as the monopoly transcontinental satellite provider. They would also give freer rein to technological experimentation as individual cable and satellite operators (including INTELSAT) attempted to provide specialized facilities to meet differentiated market demands, Option 3, where the FCC would oversee the process of facilities decontrol, might have a number of outcomes depending on the reactions of foreign governments and the ability of consumers to circumvent restrictive regimes.
Option 4, the activist strategy of bilateral negotiation, however, would almost certainly move the international communications industry away from its present facilities structure, which on the U.S. side has till now meant the dominance of AT\&T and COMSAT in the cable and satellite consortiums, respectively, along with the PTTs. Again, outcomes are difficult to forecast, but, for instance, the fortunes of the U .S, transatlantic satellite applicants and the U.K.-led fiber optic cable group could very well be the subject of a bilateral U.S.-U.K. communications agreement that would regulate the conditions of facilities competition. Such a bilateral agreement would be likely to include restrictive features; nevertheless, the United States might be able to secure enough facilities decontrol that there would be a large increase in competition in U.S,-U. K. telecommunications. Competitive effects, such as pressure on prices, might also extend to the wider market in other countries whose communications can reach the United States by transiting the United Kingdom.

\section{Access of U.S. Carriers to Foreign Markets}

The essence of the current regime in international communications is that U.S. carriers are barred from competing freely for the international communications business of either U.S. or foreign residents. With deregulation firmly entrenched as its domestic communications policy, the United States is now led to a number of specific objectives in international communications policy. In light of the fact that pursuit of these objectives might engender conflict with important countries, they can be analyzed according to the following options:

1. Give regulatory support and diplomatic representation to: a) carriers desiring to make voice and other connections with foreign carriers, b) data processing and enhanced telecommunications service providers wishing to service the needs of U.S. and foreign businesses, and c) U.S. multinational firms desiring to establish private communications networks. In this option the FCC and the Departments of State and Commerce would do 
little more than facilitate carriers' efforts to gain market access.

2. Formulate an activist policy of bilateral negotiations to secure interconnection (particularly, message-telephone) rights in foreign countries for U.S. carriers. Where possible, attempt to stimulate competition in all aspects of international communications by negotiating direct access for U.S. firms to foreign consumers. The United States would likely be called on to extend equivalent access to foreign firms in the United States.

3. Seek to accomplish the same objectives on a multilateral basis through an effective GATT agreement on international trade in services.

Option 1 is essentially to continue present policy, with increased diplomatic representation for U.S. telecommunications service firms seeking access to foreign markets. Such a policy is feasible and desirable, as far as it goes, but it is doubtful that it would, in fact, result in market access in many countries in the face of continued foreign opposition. Only if domestic deregulation in our communications partners' home markets should proceed very rapidly, would effective access for U.S. firms be secured in this way without conflict. Even then, while domestic deregulation may be a necessary condition for access, it is not a sufficient one, since U.S. firms could still be excluded. ${ }^{206}$

Option 2, the activist policy of bilateral negotiations is probably the option that would achieve the greatest gains in market access for U.S. telecommunications service firms. In this option, substantial bilateral and multilateral conflict, engendered by U.S. efforts to export its deregulation policies into the international market, might entail substantial foreign policy costs in our relations

\footnotetext{
206 That this will happen is the conclusion of one knowledgeable European observer (Guy de Jonquieres of the Financial Times). He notes that, while the PTT ministers of the EEC have agreed to open a small percent of PTT procurement to competitive bidding, it is only for the benefit of bidders from European countries. He specifically expects most European, governments to continue to restrict the opportunity for U.S. firms, in particular IBM, to enter telecommunications markets unrestrictedly. (Text of speech to the USTSA, Washington DC, Apr. 17, 1985, pp. 41, 45.)
}

with our principal communications partners, who, after all, are also our principal allies. The advantage of this option is that both the source of the conflict and effective negotiating strategies could be determined on a country-by-country basis. This option of bilateral negotiation would also allow the agreements reached with one communications partner to put liberalizing pressure on negotiations with another, since consumers might be able to circumvent the high prices of the latter country by routing their U.S.-bound communications via the former. This aspect of bilateralism might engender the greatest amount of conflict but also the greatest deregulation.

Option 3 (the multilateral option) would not appear to be any more likely to succeed than option 1 (the status quo) for telecommunications services as a whole, because any GATT agreement on trade in services would have to take account of the desires of the most restrictive countries. If and when domestic telecommunications is liberalized in all major OECD countries, significant gains in access for service firms could probably be made through multilateral understandings, but not before then. Nevertheless, a near-term multilateral agreement on trade-in services should be pursued in any case in the telecommunications area for the benefit of data processing and information firms.

The differences between options 1 and 2 are matters essentially of degree. They are distinguished by judgments about how much diplomatic capital to spend on attempting to gain access for U.S. telecommunications service firms in individual countries, particularly when the attempt engenders conflict. If a significant effort (option 2) is chosen, the fact that there are many U.S. actors on the international telecommunications scene who officially or unofficially negotiate with foreign government entities-notably the FCC, the State Department, NTIA, COMSAT, $A T \& T$, the other international service carriers, and, now, the would-be satellite and cable providers-raises the question of whether effective negotiations to serve the national interest can take place outside the framework of formal bilateral communications agreements. 


\section{International Trade in Satellite Communications Equipment}

Freer trade in telecommunications equipment would help two important sectors in the United States-consumers of telecommunications services, who benefit from using whatever cheaper or better imported equipment might be available, and the satellite communications equipment industries, which would like to export more to currently restricted markets. U.S. options for reducing barriers to international trade in telecommunications equipment include:

1. Continue to follow a quasi-multilateral approach through the GAIT process of opening access to government procurement and the OECD process of controlling the terms of export finance. This involves bilateral negotiations to persuade other governments to put their PTTs under the government procurement code (or an equivalent agreement) and to regularize their use of mixed credits. Major departures from most-favored-nation treatment of U.S. trading partners would be avoided in this option.

2. Aggressively enforce more trading reciprocity by political persuasion, threats of retaliation, and bilateral negotiations. Take more positive government action to promote U.S. exports through subsidized export credits and industrial policy. If reciprocal market access can not be brought about, take steps selectively to close the U.S. market to countries that restrict U.S. exports.

Opinion appears to be divided over whether the current policy, option 1, will actually be effective in opening the Japanese market to U.S. satellite equipment exports. (It is not expected to do so in the immediate future..$^{207}$ ) It clearly has not opened up European markets, although these markets, particularly for specialized telecommunications and data processing equipment and 207 telecommunication equipment as a whole in 1983 the Department of Commerce forecasted that Japan would import only $\$ 210$ million in 1986 from all countries, compared to a total Japan market of $\$ 6.5$ billion and Japanese exports of $\$ 2.6$ billion. (International Trade Administration, "Country Market Survey: Telecommunications Equipment, Japan," April 1983. Nevertheless, Japan appears to be making an unprecedented effort to encourage imports (Susan Chira, "Japan Urges Companies to Buy Foreign Goods," New York Times, Apr. 23, 1985). components of satellites and Earth stations, are not completely closed. ${ }^{208}$ Despite the U.S. success in negotiating the bilateral agreements to open the wider Japanese telecommunications market to U.S. suppliers, the Japanese satellite market was specifically placed off bounds to foreign suppliers in 1984, even though Japan is in the special position of having an embarrassingly large trade surplus with the United States, The United States later succeeded in having this restriction partially removed, but how much actual effect on sales this will have is uncertain.

Were the United States to single out satellite communications equipment as a special target for reducing trade barriers in European producer countries, it would be an especially difficult task. On the one hand, many European countries, rightly or wrongly, see U.S. satellite equipment makers as heavily subsidized-earlier in their development by NASA, more recently by DOD. Those countries which potentially offer competition to U.S. satellite manufacturers have devoted large government resources to try to reduce their national dependence on U.S. suppliers. While they have been willing to purchase U.S. technology where necessary, including satellite subsystems, they are not eager to see their fledgling industries outcompeted by technologically more capable U.S. competitors.

Option 2 would take more aggressive government action to promote exports and secure reciprocal market access. It is an alternative to striving for a more open international trading environment in satellite communications equipment. Exports might be supported by making Government-subsidized export credits available, by attempting to use political influence to promote foreign sales, or by using foreign aid programs to subsidize sales to developing countries through mixed credits. Government subsidy of export activities involves distortions in the operation of the market system. Insofar as other countries seem to be engaging in these practices, the United States may decide that in defense of its own firms it can do no less.

\footnotetext{
${ }^{208}$ Severalu. S. telecommu nications equipment firms have also formed joint ventures with European firms with the object of thereby gaining some access to their markets, among other reasons (e.g., AT\&T with Olivetti and Fairchild with Alcatel-Thompson).
} 
Imposing retaliatory trade barriers in the U.S. market in order to secure the opening of foreign markets might succeed, or it might engender further retaliatory measures by the countries targeted. ${ }^{209}$ Because they involve breaching the most-favored-nation principle, engaging in such practices in many sectors runs the risk of inducing escalator responses from other governments, ultimately restricting international trade as a whole and leaving everyone worse off. ${ }^{210}$ Judicious use in individual sectors, such as telecommunications equipment, could serve the purpose of indicating the seriousness with which the U.S. regards the barriers in those sectors and could serve as a bargaining chip. ${ }^{211}$ Even if the Government should decide to use public resources to support particular industries, whether satellite communications should be singled out in the competition for such government resources would remain to be determined. There are, of course, many other national demands for government budgetary resources in addition to export subsidies, a fact that has led the Reagan Administration to propose the curtailment of Export-import Bank funding in the 1986 budget.

\section{Research and Development Subsidies}

Another way of attempting to improve the international competitive position of the U.S. satellite equipment industry would be for the Government to carry out research and development in advanced communications technology that private manufacturers seem unwilling or unable to finance with their own resources. This is just what

\footnotetext{
${ }^{209}$ Occasioned $b_{y}$ the $\$ 37$ billion 1983 bilateral trade deficit with Japan, a number of legislative proposals have been directed at the overall trade deficit and at the telecommunications equipment trade deficit in particular, among them a 20 percent surcharge on all imports from Japan for 3 years and a boycott of Japanese telecommunications equipment until the Japanese telecommunications market is fully open (Washington Post, Jan. 27, 1985, p. D1). See also U.S. Congress, Senate, Committee on Finance, Hearings on the Telecommunications Trade Act of 1984(S.2618) Before the Subcommittee on International Trade, Sept. 12, 1984.

210 U.S Congress, Joint Economic Committee, "1985 JointEconomic Report," Washington DC, Apr. 18, 1985, ch. 6.

${ }_{21}$ I congressional statements also have an impact, Such statements at a March congressional hearing were reputed to have "shocked the Japanese and may have contributed to their willingness" to alter complex proposed telecommunications products regulations that would disadvantage U.S. suppliers (Washington Post, "Japan Softens Stance in Trade Talks, "Mar. 19, 1985, p. D1).
}

is being done in the NASA Advanced Communications Technologies Satellite (ACTS) program.

Since Congress provided funding for the ACTS program in the current budget, the following options relate to the scale of the program in future years:

1. Fund the full ACTS program, in one of its existing versions, including the flight test of the experimental satellite.

2. Continue to fund the research programs on the ground but postpone from year to year a decision on construction and flight testing of the spacecraft until clearer support for one or more of the three supporting arguments discussed earlier occurs. For example, the United States might want to postpone commitment to a space test until a sizable market for satellites with scanning spot beams emerges and potentially competitive government programs abroad have committed funds to space testing of similar technology.

3. Continue funding only for those research programs that can be developed on the ground (e.g., the baseband processor for onboard message switching), but make a decision to leave flight testing and its funding to the private sector, at its option.

4. Return NASA satellite communications research to the very low levels of previous years, leaving responsibility for maintaining U.S. competitiveness in communications satellites to the private sector.

Budgetary and foreign response considerations will clearly continue to weigh heavily in future decisions on the ACTS program as they have in the past. There are significant arguments in favor of the program-promoting the international competitiveness of U.S. satellite manufacturers, the economic efficiency of the U.S. economy, and the danger of orbital crowding (see discussion of these arguments above). If none of these arguments in favor of the program are deemed to be strong enough, the U.S. Government would certainly be able to apply the significant resources of option 1 to other NASA projects, to other Government purposes, or to deficit reduction. A lot depends on whether sizable markets for either $\mathrm{Ka}$ band satellites of any kind or for ones incor- 
porating ACTS-type sophisticated scanning spot beams can be realistically forecasted.

Options 2 and 3 are ways of hedging the Government's position by limiting it to the relatively less expensive, but arguably critical research that can be done on the ground. Option 2 would give the U.S. Government a way of waiting to see if foreign governments are first attempting tradeimpacting R\&D before it does the same. At the present time foreign governments have not yet committed significant funds to flight test programs for satellites with such advanced features as scanning spot beams. Congress could take the waitand-see attitude implied by option 2, with the risk that the time lags involved could give foreign manufacturers a significant, avoidable advantage. It would open the possibility that the executive branch could reach an understanding with specific foreign governments about the level and type of their export-relevant R\&D subsidies for communication satellites. The funding level and nature of the ACTS program could be the U.S. bargaining chip in such discussions.

The case can be made here (as in other $R \& D$ contexts) that the Government's best contribution is at the research rather than at the development stage. The more general the research, the less danger that the Government, in attempting to pick the specific configurations of ideas that the rapidly changing satellite market will adopt, will pick commercially nonviable ideas. Option 3 would take the Government out of the expensive and risky development end of the business. $\mathrm{h}$ would also preclude the research planned by the private sector from its own funds using the experimental ACTS satellite. Of course, the absence of a government development program might in the longer run stimulate private sector development efforts.

The Government could also use either option 2 or 3 to wait until the outcome of technological competition between fiber optic networks and satellites in U.S. domestic communications-and thus the demand for communication satellitesbecomes clearer. There is a clear possibility that both domestic and international fiber optic networks will have sufficient capacity and coverage by the mid-1990s that new communication sat- ellites will be priced out of the market for volume communications. In that event the eventual market for the ACTS innovations could be too small to justify a large program.

Option 4, essentially the abandonment of an ongoing program funded by Congress, would be an extreme measure (perhaps justified by the general budgetary situation), because much of the potential future benefit from the current research effort would undoubtedly be lost.

\section{Participation in the International Telecommunication Union}

In the face of growing "politicization" of ITU conferences and technical committees, the United States seems to have three broad options. It could:

1. stay in the ITU but take an increasingly confrontational posture, using the threat of withdrawal from the organization to attempt to prevent votes against the maintenance of principles important to the United States;

2. reduce or end U.S. participation in the ITU and establish U.S.-led, ad hoc international arrangements for sharing the radio frequency spectrum; ${ }^{2} 12$

3. attempt a more flexible approach in which a broad range of telecommunications and other issues, negotiated in the ITU and elsewhere, are treated as "linked. " The emphasis here would be on a centralized bargaining strategy with developing countries intended to maximize U.S. interests across the board. In this option, U.S. delegations to conferences and committees would need to have very high levels of both telecommunications industry and foreign policy knowledge.

The United States faces a dilemma here. On the one hand, the international regulation of telecommunications seems to some observers to be in danger of further politicization and of bloc voting to the detriment of U.S. telecommunications and other interests. Option 1, a confronta-

\footnotetext{
${ }_{21}^{2}$ For a fuller discussion of these options and the middle course of participating fully in the ITU but adhering only selectively to its agreements, see National Telecommunications and Information Administration, op. cit., pp. 35-55.
} 
tional approach within the organization to meet this, has been been discussed within the Administration as a means to minimize the damage to U.S. telecommunications interests (e.g., in the allocation of the geostationary orbit) without inducing the breakdown of the international telecommunications system.

In option 2, withdrawal from the ITU, the United States faces a significant risk of a breakdown in the international system of assigning radio frequencies and developing international standards for telecommunications equipment. The United States also runs the risk that if the international system continued to operate without U.S. participation, it might act with increasing disregard for U.S. interests. Either a proliferation of inconsistent national regulations or a coherent international regime that was injurious to the United States could develop and damage both U.S. economic and national security interests. It is not clear that U.S. technical leadership and economic power would suffice to induce the international community to follow U.S. telecommunications preferences in the absence of our participation in the ITU.

Option 3 is the diplomatic option, where the avoidance of conflict continues to be an important value in U.S. foreign policy. It might lead to the United States being induced to accept a spectrum-and-orbit regulatory regime that we would otherwise oppose. The attractiveness of this option depends on how important the linkages to other foreign policy objectives are and on how deleterious the ITU actions opposed by the United States might be. Because important U.S. economic and military interests are dealt with by international bodies that regulate the spectrum and orbit, as is rarely the case in other individual international fora where the United States can be outvoted by developing countries, the United States is likely to prevail in the ITU in the face of significant opposition only if it is willing to make a large investment of political and economic resources in a variety of bilateral and multilateral contexts. For this reason, options 1 and 2, where the United States would attempt to live with significant defeats in the ITU and would thereby save the investment of resources that it might have to make under option 3 , could be more attractive budgetarily.

\section{Assistance to Less Developed Countries}

Assistance in satellite communications is one among many potential elements in U.S. aid programs. Because of the large number and complexity of individual country programs, because program elements are interrelated, and because host-country government officials are actively involved, Congress necessarily leaves detailed planning of such programs to program officials. For example, the role of receive-only rural satellite transmission, through which educational television programs can be made available to villagers, is viewed by Al D in the context of the actual agricultural and social development activities to which the information is related and in comparison to alternative means of accomplishing the educational objectives. The role of satellite communications in national systems of addressable telecommunications-telephone, telegraph, and telex-can also only be assessed effectively in the context of the country involved, its existing and planned national telecommunications system, its existing and planned domestic regional telecommunications systems and its development program.

Satellite communications options, like those concerning other aid program elements, are typically formulated at the program level, even if higher levels in the U.S. Government may ultimately become involved in program and funding decisions. This country-specific nature of assistance programs makes it difficult to formulate general options for satellite communications assistance, ones that would have worldwide applicability, and the more detailed country-program options that might be formulated for given countries' use of satellite communications are outside the scope of this assessment. Consequently, we do not set out options for development assistance in satellite communications here. Rather we highlight a number of issues in which satellite communications figures prominently, which Congress 
may find it useful to explore with relevant officials in its oversight of country development assistance programs and the export credit program.

Country-specific considerations for satellite communications include:

- the goals of U.S. assistance in the country (i.e., the relative emphasis given to rural development, regional development, industrial development, social and institutional development, general support of the regime, the support of particular power centers and institutions within the country, etc.);

- the extent of U.S. and other industrial-country use of mixed credits for financing equipment exports to the country;

- the volume of assistance the United States gives to the country through bilateral v. multilateral channels;

- the philosophies toward development policy of the country's government and the various donor agencies and organizations through which the United States gives assistance (e.g., AID and the World Bank);

- the presence or absence of special country characteristics enhancing the usefulness of satellite communications, such as large geographical size or insularity and other factors that limit the feasibility of terrestrial transmission modes; and

- the difficulties that the country has had or is likely to have with technology transfer in advanced technology systems-particularly in training and maintenance.

This variety of country-specific considerations demonstrates the difficulty of formulating general policy options toward satellite communications assistance. Often the issues that are relevant to satellite communications are either country- or program-specific or they are embedded in issues whose scope reaches far beyond the relevant satellite communications aspects. Nevertheless, several issues in which satellite communications figures prominently can be highlighted:

1. How much emphasis, financial and otherwise, should U.S. development assistance programs give to the development of a country's general telephone/telegraph/telex infrastructure, as opposed to the communica- tions components embedded in particular agricultural, health, education, industrial, and regional development projects. ${ }^{213}$ Current AID policy prefers the embedded component approach. ${ }^{214}$

2. Are there development assistance programs for specific countries that Congress can identify as underinvesting in satellite communications technologies for rural and remote area residents? New technologies allowing much smaller and less expensive receiving dishes and other advances are important reasons to make this examination.

3. Should Congress finance more satellite communications R\&D directed specifically at the needs of developing countries?

4. Given the differing goals of U.S. programs in various countries, can countries be identified in which U.S. mixed credit financing of satellite communications systems is indicated on important development assistance or political grounds (in addition to its usefulness in financing exports of U.S. satellites and ground equipment or protecting against the mixed credit programs of other countries)?

5 What are the relative political advantages for the United States of multilateral v. bilateral telecommunications assistance programs compared to the general thrust of the U.S. aid program? Considering U.S. need to deal with developing nations within international telecommunications organizations, does telecommunications constitute a special case for directing relatively more (or relatively less) assistance through multilateral channels (e.g., the Center for Telecommunications proposed by the Maitland Commission or the World Bank)?

\footnotetext{
$21^{3}$ nnearly 1985 the Senior Interagency Group on International Communications and Information Policy recommended to the $\mathrm{Na}$ tional Security Council that the telecommunications development be given strategic priority on the U.S. foreign policy agenda because of the desirability of promoting the free flow of information, U.S. exports, and economic development ("U.S. Development Communications Assistance Programs, " Feb. 1, 1985).

${ }_{214}$ See Policy Determination PD-1 O, U.S. Agency for International Development, op. cit., Feb. 17, 1984.
} 


\section{Synthesis}

A theme that runs through this discussion of specific policy areas is that there is frequently a tension between international competition and cooperation as means to further the U.S. national interest. Avoiding excessive conflict with other countries through international mechanisms (cooperation) is an important value in itself. But so is the furtherance of the legitimate objectives that the United States has in support of its consumers and producers. These objectives may often require the furtherance of competition, which, in turn, may engender conflict. A broad judgment about how the United States should most effectively make its way in the general world of cooperation and competition, then, is one of the key factors in choosing among the various options presented for specific satellite communications policies and is an important link with the Government's broader international economic policies.

\section{APPENDIX 6A.-ADDITIONAL ANALYSIS OF THE SATELLITE COMMUNICATIONS SERVICE INDUSTRY}

\section{Demand for International Satellite Communications: Factors Influencing Its Growth and Scenarios for the 1990s}

\section{Policy Issues and Demand}

As the discussion in chapter 6 has demonstrated, the future growth of satellite communications is a key parameter that will affect virtually all important U.S. international space and telecommunications policy issues during the remainder of this century. While the impacts of high or low demand for satellite communications services are reasonably clear, our ability to forecast what demand will be is limited. This is because satellite communications demand is not only the result of overall economic activity and the price of the satellite services, difficult in themselves to predict, but is also strongly affected by the availability and the price of closely substitutable terrestrial communications modes. Most important of all, the demand for satellite communications is tremendously affected by the institutional and regulatory structures governing both cables and satellites.

This section discusses in detail the factors influencing the demand for international satellite communications and shows how different scenarios for its growth can be the result of different outcomes for these factors. 1

'A similar treatment of the demand for U.S. domestic communications is beyond the scope of this assessment, but it is treated in less detail in ch. 6 and app. 66, in connection with the NASA ACTS program and with satellite communications equipment issues.
Demand for International

Telecommunications as a Whole

Historically, U.S. international telecommunications has grown at an impressive rate. During the 1972-84 period, U.S. carriers' international real revenues grew at an annual average rate of approximately 13 percent (see table 6-I). Growth between 1980 and 1983 was temporarily slowed by recessionary conditions, but even during this period, when other sectors of world trade experienced declines, real U.S. international telecommunications revenues grew at rates of about 8 percent per annum (except in 1982, when large cuts in AT\&T's international telephone rates reduced revenues more than they stimulated demand).

Estimates of the future growth of international telecommunications are available from several sources. For 1985, the Department of Commerce projects a growth rate of 14 percent. U.S. telecommunications carriers also expect rapid growth of international communications to continue. In November 1984 forecasts prepared for a working group meeting in connection with the North Atlantic Consultative Process, the U.S. international service carriers (USISC)Z projected the demand for U.S.-Europe common carrier communications (including new services) to increase at an average annual rate of 16.3 percent during the period 1985-95. They foresee demand for telecommunications capacity of 82,000 voice-equivalent circuits in 1995 (table 6A-1, last line).J

\footnotetext{
ZIn 1983, the major U.S. companies involved in the planning process were AT\&T, RCA, Western Union, GTE, MCI, and ITT and COMSAT.

${ }^{3}$ This growth rate refers to the forecast of November 1984. Table 6A-1 also presents 1983 forecasts (which forecasted a significantly higher growth rate of $\mathbf{1 7 . 5}$ percent) by carrier and by major destination country. The U.S. carriers' European counterparts did not expect as rapid growth in overall transatlantic telecommunications demand in 1983 as did the U.S. carriers, Both
} 
Table 6A-1 -U.S..Europe Telecommunications Forecasts, 1985 "95 (equivalent voice quality circuits)

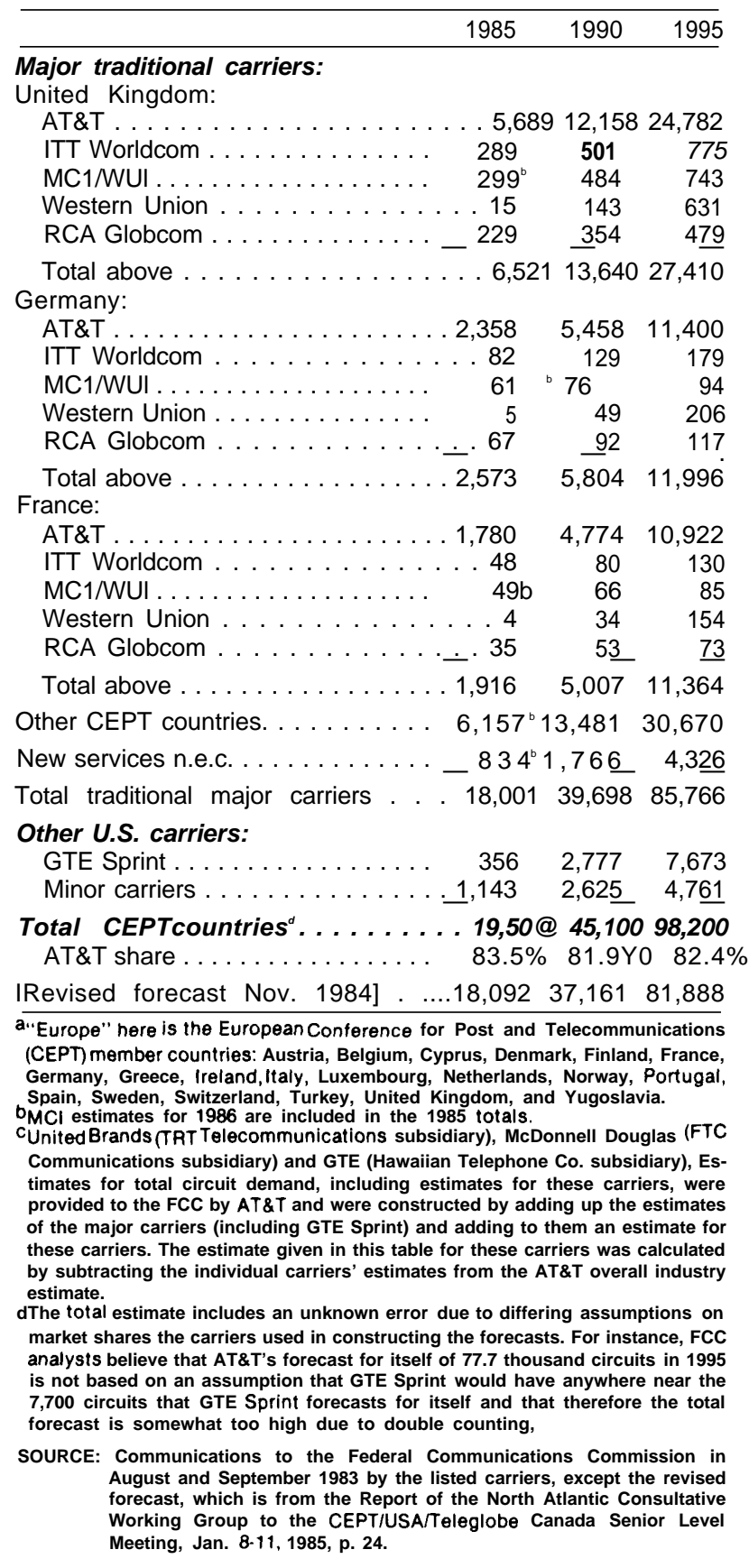

一....

(footnote continued)

groups revised their forecasts in November 1984, and the revised forecasts are relatively close. See table $6 \mathrm{~A}-3$ for the European carriers' forecasts. Carrier forecasts are also incorporated in the INTELSAT Traffic Data Base; see below note 11 .
This rapid growth is expected in all sectors except TV transmission by satellite. COMSAT'S 1983 forecast projects total half-channel hours of occasional-use television to increase from $\mathbf{2 , 1 8 0}$ in 1985 to 2,240 in 1995, and the number of $40-\mathrm{MHz}$ transponders for fullperiod television to increase from three in 1985 to four in 1995. In both cases, this is less than a 3 percent annual growth rate. ${ }^{4}$

The U.S. international service carriers forecast that "new services," including videoconferencing, facsimile, electronic mail, and computer traffic, while growing rapidly from a small base, will account for onlys percent of total demand by 1995 (table 6A-1 ).5 That new services will be a small fraction of total demand is in considerable dispute. A 1980 NASA study, for instance, projects very large worldwide videoconferencing demand in the 1990s, Videoconferencing alone is forecasted to constitute approximately onethird of total world telecommunications demand in the year $2000 .{ }^{6}$ Several of the recent applicants for permission to construct transatlantic satellite and cable facilities have also stated in their applications to the Federal Communications Commission (FCC) that they expect videoconferencing demand to be substantial but have not given quantitative estimates of the growth; RCA in its application, for instance, stated that "teleconferencing should increase dramatically."

\section{The Supply of Capacity in International Communications}

Despite rapidly expanding demand, the discussion of facilities planning at the FCC has been concerned with excess capacity, rather than shortage. ${ }^{7}$ Some ex-

\footnotetext{
4These numbers do not refer to videoconferencing, which is included in new services.

${ }^{5} A T \& T$, the principal contributor to the USISC forecast, nevertheless, intends to participate fully in any expanding market for videoconferencing that materializes, It recently introduced a U.S.-U .K. videoconferencing tariff. It has also signed an agreement with the French PTT to prowde transatlantic videoconferencing for multinational firms, using a system of INTELSAT satellites for transatlantic transmission and Telecom 1 for European transmission (Satellite News, Oct. 15, 1984, p. 4). And it has now introduced a new domestic C-band satellite videoconferencing service named Skynet Digital Service (Ibid., Oct. 22, 1984, p. 8)

${ }^{6}$ Future Systems, Inc., "Cross-Impact of Foreign Satellite Communications on NASA's 30/20 GHz Program," NASA Lewis Research Center, August 1980, FSI Report No. 251, It contains a detailed world satellite communications demand forecast, by type of service, pp. 24-85, Including extensive quantitative demand estimates for videoconferencing. Since the authors give a detailed analysis only for satellite transmission, it required minor calculation to relate their videoconferencing projection to total telecommunications demand. (To make these calculations, we used their assumption that 5 to 8 percent of nonvideoconferencing long-distance demand will be carried on satellites in North America, Europe, and Japan (higher in other world regions.) Future Systems, Inc., ibid., table 3-25, p. 60.

'For instance, see Federal Communications Commission, 'Notice of Proposed Rule Making," released Nov. 7, 1980, in CC Docket No. 79-184, "Inquiry Into the Policies To Be Followed in the Authorization of Common Carrier Facilities To Meet North Atlantic Telecommunications Needs During the 1985-1995 Period,"
} 
cess capacity is, of course, required to maintain service quality in the event of a facilities outage ${ }^{8}$ and to guard against greater-than-expected demand on the system. When capacity is added in large increments every few years, such as in the TAT-8 and TRANSPAC3 transoceanic cables or in INTELSAT VI facilities, excess capacity in the early years is inevitable if shortages are to be avoided before the next capacity addition. But other reasons relating to the industry structure of regulated industries, which we discuss below, may also be involved.

As part of the FCC's formal facilities planning process, various facilities plans have been proposed' by communications carriers or groups of carriers to meet projected transatlantic telecommunications demand. Table 6A-2 lists the plans proposed in 1980 by the U.S. international service carriers as a group (USISC), plus COMSAT, as well as a reference plan the FCC constructed for analytical purposes to determine when capacity would equal demand. Some of the features of these three plans are:

They differ principally in when they schedule the transatlantic cables.

${ }^{8}$ Restoration of service of different given qualities after a faci lities outage requires different types of backup facilities. The new competition developing on the North Atlantic among carriers who may desire different qualities of restoration, the large size of the individual TAT-8 and INTELSAT VI facilities, and the new network management techniques that allow carriers to make optimal use of facilities, has made the discussion more complex in recent years. (U.S. International Service Carriers submission to the North Atlantic Consultative Working Group meeting, Jan. 31-Feb. 2, 1984, Pans, France, p. 29.)
- They cover a range from 106,000 to 145,000 U. S.Europe circuits in 1995.

- They do not include satellite or fiber optic cable capacity supplied by private U.S. or foreign communications firms.

- A single cable or large satellite, such as the TAT9 cable (included in the USISC plan but not in the COMSAT or FCC plans), can by itself produce a large excess supply of capacity.

The amount of transatlantic cable capacity is potentially even more uncertain than indicated in the plans. Fiber optic technology is evolving rapidly and becoming more efficient in the sense that improved digital multiplication techniques are increasing the number of telephone circuits that can be carried on a given cable. Furthermore, large additional cable capacity can be provided in cables by straightforward design changes (e.g., three working fiber pairs rather than two). What is holding down the size of cables (particularly the USISC planned facilities) is not the limitations of the technology but the size of the demand and the regulatory policy requiring a balance between satellite and cable facilities. $g$

\footnotetext{
${ }^{9} \mathrm{~A}$ case in point is that TAT-8 was originally designed by AT\&T to have 12,000 basic circuits. With an assumed 3-to-1 multiplication factor, the cable was then rated as capable of carrying 36,000 simultaneous telephone conversations (or some lesser number of telephone, record, data, and video circuits, since the 3-to-1 multiplication factor does not apply to the latter types of service). It is now expected to have a 5-to-1 multiplication factor. (U.S. Carriers' submission to the North Atlantic Consultative Working Group meeting, Jan. 31 -Feb. 2, 1984, Paris, France, pp. 15-1 6.) To compensate for the improved performance of the cable-a 5-to-1 multiplication would re-
}

Table 6A-2.-Representative Transatlantic Facilities Plans for U.S.-Europe Telecommunications, 1985-95

\begin{tabular}{|c|c|c|c|c|c|c|c|}
\hline \multirow[b]{2}{*}{ Year } & \multirow{2}{*}{$\begin{array}{c}\text { USISC }^{\mathrm{a}} 1983 \text { demand } \\
\text { Forecast }\end{array}$} & \multicolumn{2}{|c|}{ USISC Plan 1} & \multicolumn{2}{|c|}{ COMSAT Plan 1} & \multicolumn{2}{|c|}{ FCC reference plan } \\
\hline & & Type & Capacity $^{\mathrm{b}}$ & Type & Capacity $^{\mathrm{b}}$ & Type & Capacity ${ }^{b}$ \\
\hline 1985 & 19.5 & & 34.0 & & 34.0 & & 34.0 \\
\hline 1986 & 23.0 & $1-\mathrm{VI} P P$ & 45.9 & $1-V I P P$ & 45.9 & $\mathrm{I}-\mathrm{VI} P \mathrm{PP}$ & 43.6 \\
\hline 1987 & 27.1 & $1-\mathrm{VI}$ & 45.9 & I-VI Spare & 45.9 & I-VI Spare & 43.6 \\
\hline $1988 \ldots \ldots \ldots \ldots$ & 33.0 & $\begin{array}{c}\text { TAT-8 } \\
\text { I-VI MP1 }\end{array}$ & 81.2 & $\begin{array}{c}\text { TAT-8 } \\
\text { I-VI MP1 }\end{array}$ & 81.2 & I-VI MP1 & 49.4 \\
\hline $\begin{array}{l}1989 \ldots \ldots \ldots \ldots \ldots \\
1990 \ldots \ldots \ldots \ldots \ldots\end{array}$ & $\begin{array}{l}38.6 \\
45.1\end{array}$ & I-VI MP2 & $\begin{array}{l}88.4 \\
88.4\end{array}$ & I-VI MP2 & $\begin{array}{l}88.4 \\
88.4\end{array}$ & $\begin{array}{l}\mathrm{I}-\mathrm{VI} \text { MP2 } \\
54.3\end{array}$ & 54,3 \\
\hline $1991 \ldots \ldots \ldots \ldots$ & 52.6 & & 88.4 & & 88.4 & TAT-8 & 81.1 \\
\hline 1992 & 62.5 & TAT-9 & 115.6 & & 88.4 & 81.1 & \\
\hline 1993. & 72.7 & $\begin{array}{c}\text { 1-VI PP } \\
\text { I-VI Spare }\end{array}$ & 129.8 & $\begin{array}{c}\text { 1-VI PP } \\
\text { I-VI Spare }\end{array}$ & 102.6 & $\begin{array}{r}\text { 1-VI PP } \\
\text { I-VI Spare }\end{array}$ & 93.0 \\
\hline $1994 \ldots \ldots \ldots \ldots$ & 84.5 & & 129.8 & & 102.6 & 93.0 & \\
\hline $1995 \ldots \ldots \ldots \ldots$ & 98.2 & I-VII MP1 & 145,1 & I-VII MP1 & 117.9 & I-VII MP1 & $106.0^{c}$ \\
\hline
\end{tabular}

KEY: Fiber optic cables-TAT-8 and TAT-9

$\begin{array}{ll}\text { Satellites-INTELSAT VI Prtmary Path } & 1-\text { VI PP } \\ \text { INTELSAT VI Primary Path Spare I-VI Spare } \\ \text { INTELSAT VI Major Path } 1 & \text { I-VI MP1 } \\ \text { INTELSAT VI Major Path 2 } & \text { I-VI MP2 } \\ \text { INTELSAT VII Major Path 1 } & \text { I-VII MP1 }\end{array}$

Satellite designs identical except for FCC satellites, which are lower capacity $L$ designs.

auslsC $=1$ J.S. International Service Carriersthe principal ones are listed in table $6 \mathrm{~A}-1$.
bThousands of voice grade circuits.

CThe FCC reference plan eliminated excess capacity in 1995 when compared with the then-current 104,516-circuit USISC 1995 forecast.

SOURCE: Demand forecast: 1963 forecast from table 6-Al. Facilities: Federal Communications Commission, "Notice of Proposed Rule Making," released Nov. 7, 1960, in CC Docket No. 79-164, "Inquiry into the Policies to be Followed in the Authorization of Common Carrier Facilities to Meet North Atlantic Telecommunications Needs During the 1985-1995 Period," pp. 20-35. 
By early 1985, the FCC had received applications to install satellite capacity of about 120,000 circuits and fiber optic cable capacity of about 330,000 circuits for transatlantic communications, in addition to the capacity additions listed in table $6 \mathrm{~A}-2.1^{\circ}$ These large proposed capacity additions call into question the FCC planning process, the demand projections of the USISC carriers and their European counterparts or both.

\section{Satellite Communications' Share}

European communications carriers (CEPT) expect that satellites will maintain their share of transatlantic telecommunications at least through 1995, according to projections submitted in connection with the North Atlantic Consultative Process (table 6-A3) .11 In all

suit in a capacity of 60,000 circuits-the originally contemplated three-fiberpair cable was replaced by a two-fiber-pair cable (ibid., p. 12) with only 8,000 basic circuits, which would have a capacity of approximately 40,000 circuits. These data indicate that capacity estimates for the transatlantic cables may be alterable by design changes, by improved multiplication techniques, and by Investment inmultiplication equipment embodying these techniques.

${ }^{1}$ Seealso th discussion of alternative satellite providers in ch. 6 . The additional 330,000 circuits of cable capacity are in the cable projects of Cable \& Wireless and its U.S. partners (TelOptic) (license granted) and Submarine Lightwave Cable Co. (license recommended by the FCC), of 80,000 and 250,000 circuits, respectively.

1 I The USISC forecasts for circuit demand presented to the North Atlantic Consultative Process (table 6A- I above) are not broken down by the shares for satellites and cables. Data submitted to the !NTELSAT Traffic Data Base, which Includes a U.S. submission based on data from U.S. carriers, however, is roughly consistent with the CEPT forecast. For instance, satellites are projected to have 1995 demand for 11,312 4khz-equivalent satellite circuits between the United States and the United Kingdom. (INTELSAT, Contribution of the Director General BG-56-1OE W/9/83, Aug. 2, 1983.) Although not strictly comparable this may be compared to the major USISC carriers' $U$.S.U.K. projection in table $6-3$ of 27,410 circuits to get a rough idea of the satellite share.

\section{Table 6A.3.-Satellite Share of International Communications Capacity CEPT Master Plan Projections ${ }^{a}$}

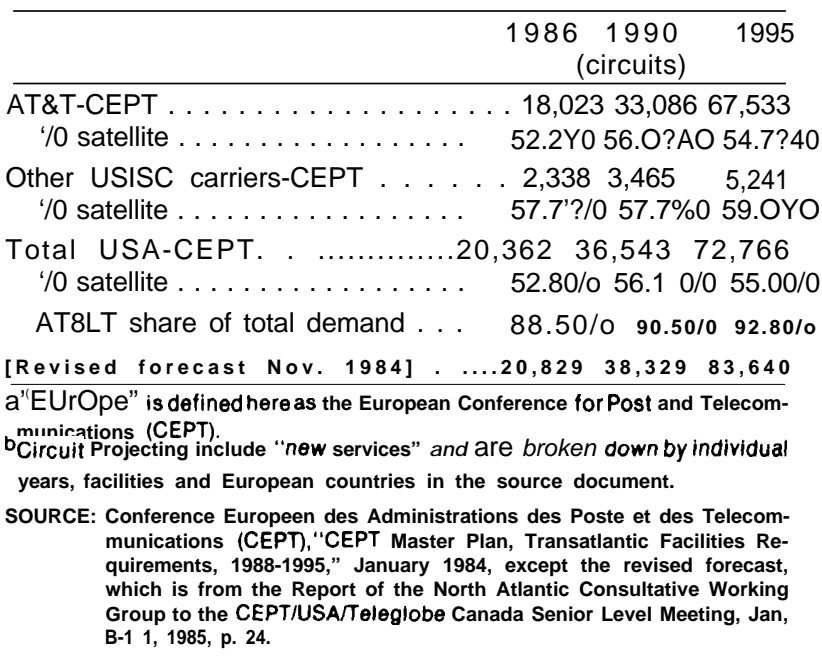

years, and for AT\&T and other U.S. carriers independently, the CEPT forecast has the satellite share remaining at over 50 percent.

\section{DEMAND FOR INTERNATIONAL SATELLITE COMMUNICATIONS IN THE 1980s}

The demand for international satellite communications can be expected to continue to grow rapidly in the 1980s, because major capacity on the expected competing transmission mode, fiber optic undersea cables, will not be in place until 1988, when the TAT-8 cable is scheduled to be operational. Other cable landing applications, which have been filed with the FCC, are for cables to be constructed in the 1988-92 period, as well.

\section{DEMAND FOR INTERNATIONAL SATELLITE COMMUNICATIONS IN THE 1990s}

Whether international satellite communications will continue to grow as rapidly in the 1990s as international communications as a whole is highly uncertain, however, and will depend on the following factors:

- The price advantage/market preference, if any, of fiber optic over satellite transmission for highvolume applications.

- The strength of industry-structure and other incentives to the adoption of fiber optic technology.

- The growth of undersea cable capacity and the presence or absence of regulatory restrictions on its use.

\section{Discussion of Uncertainties in Factors Affecting the Demand for Satellite Communications}

\section{EXTENT OF PRICE ADVANTAGE OF OR CONSUMER PREFERENCE FOR FIBER OPTIC UNDERSEA CABLES}

Any basic advantage that fiber optic cable technology will have over satellite technology for use in U.S. long-distance international communications in the 1990s will probably depend more on technical features than on cost, ${ }^{12}$ because the difference in cost

\footnotetext{
$\mathrm{I}^{2} \mathrm{By}$ "cost," we refer to the investment cost of the communications and maintenance faci lities and the cost of operating them, per unit of communıcations. Since the investment cost is the most important cost component, cost estimates are sensitive to the depreciation periods assumed for cables and satellites and to the discount factor used in calculating present values. An economic evaluation of cost will usually be different from an accounting evaluation and both cost concepts should be distinguished from price. Both average and marginal cost concepts are used in the discussion.
} 
is not likely to be large for long-distance communications, such as transatlantic or transpacific communications. In any case, the prices charged users of the alternative satellite and cable facilities may not bear a close relation to cost.

Cost.-Not long ago it seemed that advanced satellites would have a large cost advantage over fiber optic cables. ${ }^{13}$ Rapid advances in fiber optic technology have now convinced many experts that fiber op,tic cables will eventually be less costly than satellites over substantial distances. ${ }^{14}$ At very long distances however, satellites are expected to retain some cost advantage because transmission cost by satellite is nearly invariant with distance, while transmission cost by cable is not. ${ }^{15}$ Figure $6 \mathrm{~A}-1$ is a conceptual diagram that illustrates how these characteristics result in a breakeven point that may affect the choice of mode in international communications investment. Technological forecasting, difficult enough for all technologies, is especially difficult in telecommunications due to the rapidity of fundamental change and the flow of innovations. Nevertheless, in OTA'S judgment, fiber optic technology will probably experience greater cost reduction than satellite technology. This judgment is based on the premise that satellite technology is now more mature than fiber optic technology and that considerable "learning economies" are still available for the latter. ${ }^{16}$ Both technologies have further room for fundamental innovation, and substantial R\&D is being done in both. However, because light wave-guide technology is farther below its theoretical information capacity limit than microwave transmission from satellites, and because the latter is constrained by practical interference problems, fiber optics appear to have

\footnotetext{
$1^{3}$ For instance, see Future Systems, Inc., "Transmission Cost Comparison for Satellite, Fiber Optics, and Microwave Radio Communications," FSI Report No. 107, Gaithersburg, MD, May 1980. Since facilities cost is most of the cost of transmission, the cost concept referred to is long-run average cost. 14 Industry sources surveyed by telephone in 1984 estimated that the breakeven distance will be in the 800 to 1,000 -mile range in the late 1980s. It is expected to increase in the 1990 s.

isAll current commercial satellite transmissions travel roughly 44,600 miles roundtrip to the geostationary orbit and back, regardless of the terrestrial distance between the sending and receiving points. The transmission cost is thus the same regardless of distance (for one-hop transmissions). Conversely, since longer cables cost more to lay than shorter ones, cable transmission cost varies with distance. Two-hop satellite transmission is approximately twice as costly as one-hop transmission, it should be noted, however.

${ }^{16}$ See, e.g., J. Shubert, "Progress in Optical Communication Technology," Telecommunications, July 1983, Global Edition, vol. 17, No. 7, p. 35-1. In a 1984 press report, AT\&T Bell Laboratories announced the development of an improved fiber over which signals can be transmitted with 10 times as much strength after 125 miles, without boosting, as any previous fiber, a feature important for undersea cables (New York Times, 1984). NASA believes that zero-gravity, containerless manufacturing of very pure glass in space may increase fiber optic efficiency. (Space Enterprise Today, September 1984 , p. 5 .)
}

Figure 6A-1 - Cost of Satellite vs. Cable Transmission (Addressable Communications): Conceptual Diagram

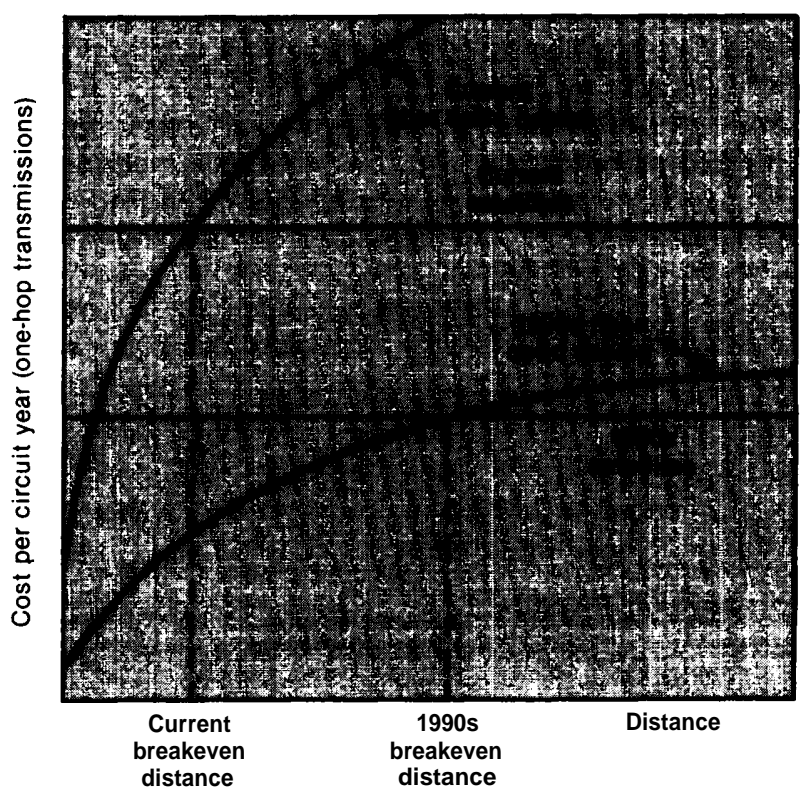

The horizontal lines for satellites indicate that average satellite transmission cost per circuit-year does not vary by distance for current and future generation models and that future cost is lower than current cost. The rising curved lines for fiber optic cables indicate that average cost for both current and future generation technology does vary with distance, but that the cost increase per mile declines as distance increases.

NOTE: Diagram is constructed to illustrate the situation where breakeven distance increases markedly for 1990's technology.

the better chance of experiencing innovations that would significantly reduce costs. Thus, while the breakeven distance in the 1990s should be regarded as highly uncertain, it is likely to increase.

One further important aspect of the technological competition between cables and satellites in longdistance international communications is also illustrated in the diagram. For the long distances typical of transatlantic and transpacific communications and of communications to and from South America, satellites and cables may not differ very much in transmission cost, even if satellites are less costly than cables. ${ }^{17}$ This is because, while the transmission cost for cables will increase with distance, it will not increase

${ }_{1}$ Below the breakeven distance, fiber optic cables are expected to have a substantial cost advantage. Within the United States, therefore, it is likely that carriers will use fiber optic cables for dense trunk routes. At a 1984 conference on satellites $v$. fiber optic cables, the president of IBM's subsidiary, Satellite Business Systems, stated that even SBS plans to develop a fiber optic network for high-traffic trunk routes to complement its current primarily satellite network, because [within the United States] "it is highly efficient for point-to-point trunking" ("Fiber Optics, Satellite Technologies Confront Each Other: Merging Expected," Satellite News, Nov, 19, 1984, p. 8). 
proportionally for longer cables. ${ }^{18}$ Thus, even at distances far above the breakeven point, satellites may not have much of an advantage in transmission cost. Considering that nontransmission costs do not differ by mode, this advantage would be even less as a proportion of total message cost.

Price.-The implicit implication of many discussions of the relative cost of cables and satellites is that telecommunications service markets will react to cost differentials in much the same way they would react to price differentials. This is clearly not the case in international telecommunications. In some industries, cost can be used as a proxy for price, because price and cost are of similar magnitude in these industries. In international telecommunications, however, there can be very wide divergence between cost and price.

This is not to say that cost competition between satellites and cables is not an important long-run factor i $n$ determining the supply of various kinds of i nternational telecommunications facilities, since if cost differentials are large, they would affect carrier incentives to invest in various types of capacity. But in the telecommunications service markets themselves, it is prices that buyers pay, and to which they react, not the costs of suppliers.

The significance of this is twofold: 1 ) even if costs differ for satellites and cables, the prices could and would probably be closely similar and 2) under conditions of overcapacity, international telecommunications prices could drop far below calculated full costs, as carriers responded to market pressures,

Prices would be similar for telecommunications services using the two transmission media (if markets were unrestricted) because they deliver similar services, This would occur regardless of what the facilities cost to install when they were new or what new facilities would cost. If prices started to diverge, consumers would move toward the cheaper medium, and sellers of the expensive one would have to lower their prices to stay competitive.

International telecommunications prices (similar for both media) could also drop far below the full costs of both satellites and cables. Telecommunications service markets contrast with many other markets in this regard because of one key factor; the telecommunications service industry (using either satellites or cables) is highly capital intensive. Capital intensity means that most costs are incurred when the facilities are installed and that variable costs for labor, materials,

\footnotetext{
${ }^{19}$ These economies to scale are Illustrated infig. $6 \mathrm{~A}-1$ by the curvature of the cable cost curve.
}

power, etc. are small relative to total cost. Because of this, revenues from the sale of services are usually used mainly to cover payments of principal and interest on debt incurred in acquiring the facilities, rather than for meeting payrolls and paying suppliers.

If the market becomes highly price-competitive because of excess capacity, carriers may have to reduce their prices markedly to sell anything at all. The paradoxical aspect of this is that even if overcapacity should cause prices to drop to very low levels, individual carriers would not have an incentive to reduce the capacity offered for sale and thereby counteract the overcapacity. In fact, the prime motivation for dropping prices would be to keep capacity in operation and earn as much cash flow as possible, for even at very low prices, carriers would still generate cash flow as long as they covered the low variable cash costs of running the operation. If they tried to charge higher prices to cover full costs, there would be few or no sales, little or no revenue and thus little if any cash flow from operations. For these twin reasons, the existence of net revenue possibilities even at low prices and the inability to sell much except at the competitive price, individual firms have a strong incentive to keep the facilities in operation.

Even bankruptcy would not serve to inspire them to remove the facilities from service. If a court gives protection from creditors, the firm could continue to use the net cash flow from operating the facilities to make partial payments to creditors and for other uses. If the assets had to be sold at realistic prices consistent with the reduced earning potential of the facilities, the new owners would also have incentives to operate them. These would be the usual investment incentives of cash flow and profits. Thus, while very low prices might constitute a severe financial problem for carriers with high fixed obligations, their financial problems would be unlikely to induce them to take their capacity off the market.

Overcapacity does not last forever, however. It is a so-called "short-run" phenomenon, in the sense that in normal competitive markets, it would ultimately be worked away as plans for new investment are reduced and existing equipment depreciates. Yet in telecommunications, overcapacity, with low prices could persist for many years. The low prices that have persisted for years in the markets for certain long-lived capital items (and for the services rendered by them) - e.g., supertankers and widebody jets-are instructive on this point.lg

\footnotetext{
${ }^{19} \mathrm{Although}$ this discussion concentrates on overcapacity, shortages of $\mathrm{n}$ ternationaltelecommunications capacity could also occur and result inprices considerably higher than costs.
} 
In a situation of overcapacity, the gradual working off of surplus capacity and the restoration of prices that cover full costs, of course, assumes a relatively normal investment market. Such a market exists in U.S. domestic satellite communications. In a situation of overcapacity, sources of financial capital become less willing to invest in more capacity. An adjustment process then takes place. Rapidly expanding demand or rapid physical deterioration of the capacity speeds this adjustment process. In the case of international satellite communications, however, the investment market is far from normal, Governmental, intergovernmental and regulated institutions-INTELSAT and its mostly PTT owners are currently the principal investors in international satellite facilities-may not respond to market signals as quickly as private firms might,

Much of this analysis applies to carriers making decisions singly. If carriers should make coordinated decisions on prices (in many circumstances illegal under the antitrust laws) or if governments should impose capacity-use regulation on the industry, capacity could be withdrawn from the market, and prices could be higher. Even in this circumstance, however, if consumers responded to low prices by substantially increasing their purchases, prices designed to maximize carrier net revenues would still probably be way below full cost.

One further aspect of capacity in international communications should be considered. Since all satellites have on-board propulsion capabilities that allow them to be moved occasionally from one world region to another, the locations of particular satellites and, therefore, of excess satellite capacity, will also respond to market forces. ${ }^{21}$ At present, there is a regulationenforced separation between domestic and international facilities, but if private satellite firms from the United States and other countries are allowed to enter international facilities markets, domestic and international capacity may ultimately become interchangeable, and world overcapacity (or shortage) would affect both international and domestic prices.

\footnotetext{
${ }_{20} 0$ should not be concluded, however, that govern mental entities operating in substantially competitive international markets will not make rational commercial decisions. Evidence from the international airline industry in the period 1976-80 indicates that European state-owned carriers had approximately the same rates of return as U.S. private carriers and that, in response to changes in demand, they adjusted capacity similarly in individual North Atlantic city-pair routes (Douglas L. Adkins, Martha J. Langelan, and Joseph M. Trojanowski, "IS Competition Workable in North Atlantic Airline Markets?" Civil Aeronautics Board, March 1982).

21 Because of limited on-board propulsion fuel, changing orbital position can only be done infrequently as a practical matter. If permitted by regulation, satellites would be sufficiently mobile, however, to allow transponder sale and lease prices to be determined by world rather than national conditions of supply and demand, just as the prices of super tankers or wide-body jets now are.
}

Technical Features.-Fiber optic cables appear to have three technical advantages over satellite transponders that are moderately to highly important in certain applications in international communicationsfreedom from external and environmental sources of interference, greater communication security, and relatively short signal delay. None of these advantages is decisive in volume uses of international telecommunications, however.

For instance, despite the greater vulnerability to interference, error rates for satellite communications can be designed to the same minimum technical specifications in most cases as fiber optic cable systems, but the extra design features can be costly.

The greater signal delay in satellite transmission adds to the total of all the delays in terrestrial switching and in the facilities through which it must pass and, thus, typically consumes between one-fourth and one-third of a second. innovations in satellite transmission of ordinary voice and videoconferencing are likely to continue to improve the techniques that now reduce the disadvantages of satellites that arise from signal delay in those uses and in interactive data transmission as well.

In communication security, the absence of an electromagnetic field around a fiber optic cable means that, to intercept the information, the cable itself has to be tapped, an act that can be detected by sensitive monitoring devices. In contrast, microwave radiation that satellites use to transmit information is usually easily accessible by the public and certainly by those who would intercept it. Encryption possibilities, however, can give satellite microwave transmission substantial protection against all but the most sophisticated interception attempts. Once again, there may bean extra cost penalty for various levels of security for satellite v. fiber optic transmission.

Taken together, the disadvantages of satellite transmission result in a product that is currently perceived by users to be somewhat technically inferior to the product of cable in certain point-to-point applications, particularly voice, certain computer applications, and secure communications. If there should be carriers who specialize in a single mode of transmission, as several of the new firms applying for permission to construct satellite or cable facilities are planning to do, or if carriers using both modes should offer consumers the opportunity to choose mode, the preferences of the marketplace would govern. What seems a trivial disadvantage to satellite proponents might loom large in consumer choices. ${ }^{22}$

\footnotetext{
22Speakers at the Fourth Annual Satellite Communications Conference, Washington DC, Apr. 10-11, 1984, who were involved in satellite communications as producers or consultants uniformly stated that when the echo
} 
When there are domestic communications legs on either side of the international leg, undersea cables may sometimes have an advantage over satellites in international transmission. Because of the total delay, CCITT recommendations and consumer preferences discourage the use of more than one satellite hop in end-to-end service. Mixed satellite/cable transmission is the means employed to keep the satellite segment to one-hop, of course. In international communications, this may result in a preference for cable transmission in certain situations. If domestic transmission by satellite has been decided on for the U.S. leg, for instance, because a business user would like to bypass the local phone company, keeping the satellite link to one-hop would induce such a user (or his carrier) to arrange cable transmission for the international link. If the domestic link was cable, however, there would be no parallel incentive to use a satellite for the international link.

International satellite transmission currently has two important advantages over cable transmission-broadband capability and certain networking advantages. Broadband capability refers to the ability to send large amounts of related information simultaneously and is important $\mathrm{i} \mathrm{n}$ television and certain data applications. Large capacity coaxial copper cables, terrestrial microwave, and fiber optic cables all have this capability, as do satellite transponders, but for the broadband communication to take place, the capability must be in place end to end, This is straightforward for most all-satellite systems, but for terrestrial networks, all legs and switching facilities must have broadband capability. Currently, it is often necessary to have a satellite link in order to have broadband communication at all. As international and domestic fiber optic networks become widespread in the 1990s, this advantage of satellites will diminish and will probably not continue to be quantitatively very important.

Satellites have a more enduring advantage in certain networking applications. For instance, point-tomulti point transmissions are trivially simple using a satellite. The single transmission can simply be picked up by even thousands of individual satellite Earth stations. To do the same thing in cable networks would require vast amounts of switching, something which would not usually be done terrestrially if the number of destinations were at all large. In general, whenever the alternative terrestrial network becomes cumbersome or expensive or lacking in certain capabilities,

equipment was tuned properly, the delay problem for one-hop satellite transmission was trivial. On the other hand, representatives of a large bank and a large developer stated that there is currently a prejudice among consumers agaınst satellite transmission on the basis of quality. satellites can be employed to bypass the difficulties and transmit directly from one Earth station to another.

These special networking capabilities of satellites will ensure a market for communication satellites. Only if nationwide and worldwide fiber optic networks should have large excess capacity in the future would they be used for the point-to-multipoint (or multipoint-to-multipoint) communications that satellites have a cost natural advantage in. Nevertheless, this advantage is important in only a small proportion of the international communications volume sent by satellites at present. It is likely to grow rapidly if international videoconferencing does, but will become a large fraction of international satellite communications only if satellites lose out to fiber optic cables in the telephone, record, and data uses that now constitute the major uses of international satellite transmission.

\section{Industry-Structure Incentives to Adoption of Fiber Optic Technology}

The second important uncertainty affecting the demand for international satellite communications in the 1990s is whether the structure of the communications industry will continue to provide incentives to invest in and use cable technology that are independent of the cost and technical features of fiber optic cables. Three such incentives have been suggested in analyses of telecommunications industry structure .23

First, U.S. regulated international telecommunications carriers are said to have a bias in favor of investment in undersea cables that they own and which therefore constitute part of their rate base, in preference to the alternative of leasing INTELSAT/COMSAT satellite transponders, which are not in their rate bases. This incentive (to buy cable capacity rather than lease capacity on satellites) allegedly operated in the past even when transatlantic transmission by satellite had a substantial underlying cost advantage over coaxial copper cable. It and other reasons have been cited to explain why the FCC ordered the balanced use of satellite and cable capacity in transatlantic service.

The putative industry bias toward investment in cables, which has existed during the period when cable technology had a cost disadvantage, would undoubtedly reinforce any desire of the carriers to use cable technology for other reasons. It might be mitigated if the carriers should come to own satellite facilities. RCA, for instance, has proposed to use a satellite for transatlantic communications that it had

\footnotetext{
${ }^{23}$ See, e.g., Bruce M. Owen and Ronald Braeutigam, The Regulation Game (Cambridge, MA:Ballinger,1978), ch. 2-"'Regulatton of Oligopoly: Interna tional Communication;" and Michael E. Kinsley, Outer Space and Inner Sanctums: Government, Business and Satellite Communication (New York: Wiley, 1976).
} 
originally proposed solely for domestic use. It would, of course, be able to include this satellite in its rate base. ${ }^{24}$

It should be noted that the preference for facilities that can be put in the rate base is a long-run decision factor in the purchase of facilities, with the comparison being between installing new cable capacity in preference to an alternate program of leasing satellite capacity during the life of the cable. Besides this longrun factor, there is also a powerful short-run incentive for U.S. international service carriers to use cables. Once a cable and associated maintenance capability is owned but not fully utilized, the variable cost of using it approaches zero and is, of course, much smaller than COMSAT'S circuit lease price. ${ }^{25}$ This powerful incentive to use owned cable facilities up to their capacity before leasing more expensive INTELSAT/COMSAT satellite capacity operates strongly during the early life of a new cable facility before it approaches capacity use. if carriers owned under-utilized satellites as well as cable facilities, this incentive would also cease to operate.

Finally, some carriers, such as AT\&T, KDD, and Cable \& Wireless, are also producers and servicers of cables; they may favor using what they themselves manufacture and maintain. Carriers manufacturing satellites, such as RCA, might find a similar reason to favor satellites.

Some of the major European PTTs are also said to favor using cable facilities over satellites for much the same reasons as U.S. carriers. ${ }^{26}$ The incentive to use unused cable capacity before INTELSAT probably also applies to them as well as to the U.S. private carriers, but because of the different regulatory structure, the impact is less powerful. In the first place, they pay the lower INTELSAT utilization charge rather the higher tariff of an intermediary such as COMSAT. Secondly, as signatories, they make investment payments and

\footnotetext{
${ }^{24}$ In fact the incentive couldsh ift $\mathrm{i} n$ favor of owning satellites if satellite capacity were relatively inexpensive due to glut conditions, such as now may be occurring in U.S. domestic communications. A 1984 survey by the FCC found that there only 143 out of 312 transponders were in use on 14 satellites on a weekday afternoon. ("Satellites Outpace Customers," New York Times, Apr. 10, 1984, First Business Page.)

${ }^{25}$ The Variable transmission cost of using the cables they own is primarily the cost of the electrical current and of the cable repairs, and this is relatively small compared to the fixed cost of building the cable, providing it with auxiliary communications equipment, and providing maintenance vessels and facilities. In the case of underutilized INTELSAT satellite facilities, however, the variable cost to AT\&T, for instance, is still the COMSAT tariff. This tariff Includes a capital recovery factor and is thus considerably higher than the small variable satellite transmission cost. COMSAT's prices for satellite circuits may also have been higher than they need be, due to a higher than normal rate of return and the existence of substanital I NTELSAT excess capacity which the FCC allows COMSAT to earn a rate of return on.

${ }^{26}$ Bruce M. Owen and Ronald Braeutigam, op. Cit., p. 61.
}

receive returns on that investment that vary with their usage of the INTELSAT system. Nevertheless, the variable cost to most PTTs of increased INTELSAT use is probably greater than the variable cost of cable use. ${ }^{27}$ They would not have the same incentive to create excess cable capacity as U.S. carriers, however, unless they were also subject to regulation similar to U.S. return-on-rate-base regulation. ${ }^{28}$

\section{CABLE CAPACITY GROWTH}

The third key uncertainty that will affect the demand for satellite communications in the 1990s is the growth of usable undersea cable capacity vis-a-vis the demand for telecommunications service.

Transoceanic cables often require lengthy periods between conception and installation for planning, regulatory action, and construction. The official planning process for a transpacific fiber optic cable, for instance, was only just beginning in 1984 (following extensive planning work by individual carriers), and it is possible that the TRANSPAC-3 cable will be delayed beyond its proposed year-end 1988 service date. ${ }^{29}$ Considering the TAT- 8 transatlantic cable and the other proposed transatlantic cables, 5 years or more could be regarded as the norm.

If telecommunications demand should outstrip the cable capacity available in a geographical sector for any reason, satellites, if available, could and would be repositioned to serve it. More rapid growth in demand than expected, or regulatory restrictions on cable installation, could be important reasons why total telecommunications demand might outstrip cable capacity.

If, on the other hand, there should be excess cable capacity (the more likely case in the Atlantic region), the question remains as to whether it would be used in preference to satellite capacity. It would appear, according to the discussion above, that U.S. international carriers have a significant incentive to invest in and use their own transatlantic facilities (which happen to be cables because of the industry structure imposed by regulation) rather than facilities owned by other entities (which happen to be satellites). By 1985

\footnotetext{
27For PTTs subject to significant transit charges, however, cable variable costs may be significant, and their incentive to use cables would be less or nonexistent.

${ }^{28} \mid \mathrm{t}$ should be noted that a PTT's bias in favor of using fiber optic cables for communication trunks does not necessarily mean that they can handle large volume and/or broadband communications in their local cable networks, Until appropriate switching and broadband transmission facilities have been installed at the local exchange level, premises-to-premises satellite transmission may be the only practical way to handle business communications that that require these Tragilities.

${ }^{29}$ According to a $A T \& \mid$ press release, Jan. 23, 1985, Hawaii 4/TRANSpAC3 will have two working fiber pairs, will run 7,200 nautical miles across the Pacific, will have approximately 250 undersea generators, and would be able to transmit 37,400 simultaneous telephone conversations,
} 
the FCC had granted or recommended cable landing licenses for fiber optic capacity of approximately $\mathbf{3 7 0 , 0 0 0}$ voice circuits to be installed in 1988 or 1989 , compared to the 1990 USISC forecast (above, table $6 \mathrm{~A}-1$ of 45,000 equivalent voice circuits. ${ }^{30}$

Hence, unless regulation or other nonmarket forces impell carriers to use satellites in a situation of plentiful carrier-owned cable facilities or unless carriers come to own satellites, they would be likely to use available cable facilities in preference to satellites, even if, to a certain extent, satellites were less expensive.

\section{Scenarios for Growth of Satellite Communications Demand in the 1990s}

Depending on what assumptions are used for the uncertain factors that we have just discussed, projections of the demand for international satellite communications would vary. Since all of the factors are highly uncertain, the discussion is organized into three credible scenarios that use different assumptions that result in rapidly growing demand, slow growing demand and plateauing demand, respectively.

\section{SCENARIO 1: RAPID GROWTH OF SATELLITE COMMUNICATIONS IN THE 1990s}

The North Atlantic communications carriers, both the U.S. international service carriers and the European CEPT carriers, expect Scenario I-continued rapid growth of satellite communications-at least through 1995, as indicated by the projections provided for the North Atlantic Consultative Process. These projections were discussed above in this appendix and are presented in tables $6 \mathrm{~A}-1$ and $6 \mathrm{~A}-3 .^{31}$

Implicit in the carriers' facilities demand forecast for the North Atlantic are assumptions about a number of factors that would lead to rapid growth in satellite communications in the 1990s. This could result from fiber optic cables having little or no cost/price advantage or consumer preference, from the absence of special carrier incentives to use cable transmission, or from limited actual cable capacity in place or in use.

\footnotetext{
${ }^{30}$ This estimate includes 40,000 for the approved TAT- 8 cable, and 80,000 and 250,000, respectively, for the proposed Cable \& Wireless (TelOptic) and Submarine Lightwave Cable Co. cables, making a total of 370,000 volceequivalentcircults. These estimates must be regarded as order of magnitude only, since estimates of multiplication factors for voice conversations are likely to change considerably.

31 Data submitted to the INTELSAT Traffic Data Base reflecting the projections of the U.S. International service carriers tends to reinforce this expec tatıon of rapidly growing transatlantic satellite communications demand through 1997. (I NTELSAT Contribution of the Director General, BG-56-10E W/9/83, Aug 2, 1983.) See note 11.
}

\section{SCENARIOS II AND III: MODERATE OR ZERO GROWTH OF INTERNATIONAL SATELLITE COMMUNICATIONS IN THE 1990s}

Four elements, none of them improbable, could cause a slowdown in satellite communications growth as a result of the substitution of fiber optic cable for satellite transmission. First, various decision makers could perceive fiber optic technology to be superior for reasons of its technical features or cost/price advantage. Second, the price (or other advantage) would be available to them in such a way that they would actually have the incentive to use cable transmission. Thirdly, actual cable capacity would be great enough to service most of the growth in total telecommunications demand. And last, but not least, there would be a noninhibiting U.S. and international regulatory framework that would allow greater relative cable use.

Scenario II Slow Growth.-Even if consumers or carriers came to prefer fiber optic cables for transatlantic and other long-distance international communications in the late 1980s, their preference might not be particularly intense. They therefore might not make the switch very rapidly. Whether or not their preference is intense, regulatory barriers in any case could delay the adoption of cable transmission. For all of these reasons, satellite usage in high-volume trunking applications might continue to grow, if only moderately, through the end of the century.

Scenario III: No-Growth Plateau.-In this scenario, cable transmission would be adopted relatively quickly because of strong carrier or consumer preference, or for other reasons, and would be used for most highvolume point-to-point international communications. Cable capacity for this expansion would be in place by the early 1990s in the form of the TAT-8, TAT-9, and TRANSPAC- 3 cables to be constructed and owned by cable consortia and/or those proposed by individual firms. Satellites would still perform an essential role in long-haul international communications, however, particularly on low-volume routes to smaller or less developed countries and to remote areas. Satellites could also fill in where cables had not been constructed or could not handle broadband communications because of networking problems. Essentially, satellite transmission in this scenario would serve as the backup technology for cable transmission.

Satellites would also continue to be used where they have a competitive edge over cables in technical features or cost: to service the growing expected demands for point-to-m ultipoint or multi point-to-m ul- 
tipoint communications, for certain mobile communications, and for broadband communications where local broadband fiber optic or microwave distribution capacity was not in place. This scenario posits a leveling off of satellite communications in the 1990s, rather than a decrease. The latter would result if these specialized uses did not grow sufficiently to offset the relinquishment of high-volume, long-haul traffic to cable

\section{The Regulatory Regime in International Satellite Communications $^{33}$}

\section{The Traditional Regulatory Regime in U.S. International Telecommunications}

Ten years ago, both the domestic and international segments of the U.S. telecommunications industry were tightly controlled by government regulation. Consumers of international telecommunications services were not allowed to choose among carriers on the basis of price and service offerings. ${ }^{34}$ The carriers of the countries between which the communications moved were almost always organized into a monopoly or close-to-a-monopoly structure and thus did not have to respond closely to consumer needs.

On the U.S. side, as a rule, each country-pair market was segmented into a number of nearly air-tight compartments. There was a telephone ("voice") monopolist (usually AT\&T). Terrestrial and satellite record (telegraph/telex) communications for the most part had to pass through a small, regulated cartel of U.S. "international record carriers," principally ITT, RCA, and WUI, ${ }^{35}$ prior to being interconnected with West-

\footnotetext{
3Zif the component of International telecommunications where satell ites have a technical or cost advantage is one-fourth of the total and is growing at the same rate as transatlantic telecommunications as a whole (1 6.2 percent per annum in the USISC forecast for the North Atlantic), it alone would equal the total current international telecommunications volume in 9 years

${ }^{33}$ We us the term "international regulatory regime" (or "international communications regime") broadly to include all governmental and intergovernmental actions affecting the operations of the international communications carriers, These include treaties and other formal and informal intergovernmental agreements in the area of telecommunications, other elements of international law affecting telecommunications, the actions of international organizations such as the ITU or INTELSAT, and the actions of national governments that affect the International telecommunications industry.

${ }^{34}$ The uniqueness of international communications arrangements is not always appreciated. "Single-vendor service" is now the norm in U.S. domestic long-distance communications and always has been in virtually all other markets in the U.S. economy, and even in most other international service markets. U.S. basic telecommunications providers (and those of other countries), however, are not free to offer single-vendor service in most international markets (i .e., to offer end-to-end communications service over their own owned or leased networks)

"Western Union International, inc., was separated from Western Union Telegraph Co., the former domestic record monopoly, in a divestiture that took place in 1963. (General Accounting Office, FCC Needs to Monitor a Changing International Telecommunications Market, RCED-83-92, Mar. 14, 1983, p. 22.) In 1982 WUI was acquired by $\mathrm{MCl}$ Corp. as a wholly owned subsidiary.
}

ern Union, the de facto monopoly domestic telex/telegraph company .36 On the foreign side, the operator of both voice and record facilities was usually a single government post, telephone, and telegraph firm or ministry (PTT). Usually, the PTT controlled virtually all civilian telecommunications-voice and record, satellite and terrestrial, international and domestic.

In cable transmission, the cartel arrangements were cemented further by joint ownership of oceanic cables. For private, regulated U.S. carriers, ownership in cables is counted among the assets of their rate bases. The size of a carrier's rate base, in turn, along with the allowed rate of return, determines the maximum allowable profit in regulated activities.

The situation has been somewhat different in satellite communications, principally because there are intermediaries (INTELSAT and COMSAT) whose tariffs must be paid. All U.S. intercontinental satellite communications are currently routed through COMSAT and INTELSAT. U.S. international service carriers pay COMSAT'S tariff, and COMSAT, in turn, pays INTELSAT ciruit charges. ${ }^{37}$ This differs from the cable situation in that once the cable is in place, only minor payments are made by the owner-users for cable use and maintenance, and usage sensitive costs are practically nil. ${ }^{38}$ In the satellite situation, carriers have to pay the COMSAT or INTELSAT charges in proportion to their use of INTELSAT capacity .39 In the case of U.S. international carriers, the charges for leasing COMSAT circuits are current costs and can, of course, be recovered from their customers, but the satellite charges are not capitalizable and therefore do not enter the carriers' rate bases.

36 If a customer was sited at one of the five "gateway cities" or at several other domestic "points of operation," he or she was able to deal directly with one of the international record carriers without having to go through Western Union (General Accounting Office, FCC Needs to Monitor a Changing International Telecommunications Market, GAO/RCED-83-92, Mar. 14, 1983 , p. 22). Western Union's monopoly status was never formally conferred by the FCC. How it used the regulatory process to preserve this status is a complex question (see Bruce M. Owen and Ronald Braeutigam, The Regulation Game (Cambridge, MA: Ballinger, 1978), ch. 1.

${ }^{37}$ COMSAT is part owner of INTELSAT, and receives offsetting return on its investment. Foreign international carriers from countries that do not belong to INTELSAT are able to use the system by paying the circuit charge.

${ }^{38}$ These should be distinguished from payments at the "accountl ng rate" which are calculated on the volume of telecommunications regardless of the transmission medium used. The country-pair partner that originates the greater volume of traffic compensates the other partner for its greater use, at the agreed-on accounting rate.

${ }^{39}$ The foreign PTTs and CC) MSAT, of course, collectively determine the INTELSAT unit charge through their weighted votes on the Board of Governors of INTELSAT. Table 6-5 and app. C give the voting weights of INTELSAT signatories.

${ }^{40} \mathrm{~A}$ number of U.S. international service carriers do have part ownership in the INTELSAT Earth stations (prior to recent changes COMSAT owned the other half and can add the value of these facilities into their rate base. 1984 ownership shares were as follows: contiguous United States: COMSAT 50 percent, AT\&T 35.5 percent, RCA 10.5 percent, MCI (WUI subsidiary) 4.0 percent; Hawaii: Comsat 50 percent, GTE (Hawaiian subsidiary) 30 percent, RCA 11 percent, ITT 6 percent, MCI(WUI) 3 percent; Guam: COMSAT 50 percent, RCA 48.9 percent, MCI(WUI) 1.1 percent (Satellite News, Dec 10 and 24,1984 ). 
Under the traditional regulatory regime, U.S. international carriers and satellite intermediaries were usually not allowed to penetrate very far into each other's markets. With only minor exceptions, the entry of new firms was also not allowed. Even when new firms were allowed in the United States, most foreign countries continued as they had in the past to allow only the traditional U.S. international service carriers (in voice only AT\&T) to connect to their networks. For the international record carriers and COMSAT, U.S. international communications prices were regulated by the Federal Communications Commission under loose "rate of return on rate base" procedures. ${ }^{41}$ For AT\&T, no international rate base was separated; the firm retained greater discretion over international rates and could engage in price discrimination to the disadvantage of consumers of international communications.

Investment by the carriers in new facilities was also restricted-only cable or satellite facilities approved by the FCC and foreign governments were allowed. Investment by consumers was also restricted; only certain types of equipment, usually owned, manufactured, or supplied by carriers could be connected to their networks. Both of these restrictions constituted a severe barrier to international (and domestic) trade in telecommunications equipment and services and may have inhibited the full development of communications technology.

\section{The Deregulated U.S. Industry:}

\section{A New Element}

Since the breakup of AT\&Tat the beginning of 1984 , a new more competitive U.S. telecommunications service industry has clearly emerged, with some of the largest U.S. corporation entering into what had been regulation-protected preserves. The formerly distinct industry compartments-voice and record, satellite and terrestrial, basic and enhanced, and domestic and international-have all been breached by large firms and smaller entrants, and each is now a competitive arena.

This vigorous new U.S. industry is also placing immense pressure on the international regulatory regime. Institutional and regulatory barriers to competition have allowed firms to earn high profits in international communications. Lured by these profits, many large firms in U.S. domestic telecommunications are seeking to expand their international activities (e.g., $\mathrm{MCl}$, Western Union, and GTE). The list of potential new entrants into international satellite communications is

41 General Accountıng Off Ice, FCC Needs to Men/for a ChangingInterna tional Telecommunications Market, RCED-83-92, Mar. 14, 1983. large and growing (see table 6-4 for a partial listing of U.S. international communications firms).

Even though considerable domestic telecommunications deregulation has occurred in the United States, the old regulatory structures affecting U.S. international/ communications remain largely in place. While the FCC has relaxed the distinctions between international and domestic, satellite and cable, and voice and record carriers, this as yet has had little impact on which firms carry the bulk of each type of traffic and on how they do business internationally. AT\&T Communications still carries almost all U.S. international telephone communications; the former international record carriers still handle most of the record traffic; INTELSAT and COMSAT still have a virtual monopoly on U.S. intercontinental space-segment communications; and the FCC still oversees a process in which approved carrier consortia plan facilities years ahead.

\section{Competition in Foreign}

\section{Telecommunications Service Markets}

In "basic" telecommunications services, ${ }^{42}$ international competition in foreign markets is practically nonexistent. While a few countries, notably the United Kingdom, Japan, and Canada, are moving toward privatization and limited domestic competition, most countries outside of the United States do not allow competition even in domestic long-distance telecommunications. A telecommunications monopoly, owned by the government (or, alternatively, in some cases a private monopoly regulated by the government) is the prevailing mode of industry organization around the world. Competition from foreign (including U.S. firms) is not yet envisaged even in countries allowing limited domestic competition .43 Foreign carriers must transfer control of communications passing into (or through the country) to the PTT at the international border or to an intermediate cable or satellite consortium that subsequently passes control to the PTT.

For regulation to have practical effect, a boundary has to be drawn somewhere between the regulated basic communications industry and the unregulated data processing industry, since they now merge into each other. [n contrast to the present situation in the United States, in most countries, the telecommunications administrations still attempt to draw this boundary so as to keep computer-enhanced communications services, such as "packet switching," which

\footnotetext{
${ }^{42} !$ e., ordinary voice, record, data, and television transmissions, as opposed to "enhanced" or "value-added" communications, to produce which the provider uses computers to process or package them.

${ }^{4}$ Except that Japan's new domestic telecommunications lawseems to permit U.S. firms to operate some types of value-added networks within Japan.
} 
increase the efficiency of communications in private networks, on the PTT monopoly side of the boundary. ${ }^{44}$ In only a few countries are private firms, including U.S. corporations, allowed to compete freely in providing computer-enhanced communications service.

Further in the direction of information services are the value added networks (VANS). These are networks of computers that interact with each other in "real time, " that is, with little delay. For instance, users at keyboards in New York and other cities may wish simultaneously to query an industry data base in Philadelphia and use some of its software. The VAN operator buys communications capacity in bulk and uses its computers to make this communications network most efficient. In the United States these services have been fully deregulated since $1980 .{ }^{45}$ The situation abroad is variable; in many countries, the PTTs still do not allow private firms to construct VANS, and the only VAN services available are those provided by the PTTs. In countries, such as Canada, United Kingdom, and Japan, that are experiencing a measure of domestic liberalization, competition is now allowed in the provision of VANS.

Control of international communications sent between adjacent countries-usually by land cable, undersea cable or terrestrial microwave-passes bilaterally at the border from one country's carrier to the carrier of the other country. In certain cases, however, governments and carriers have devised multilateral mechanisms of joint ownership for international satellites and transoceanic cables. ${ }^{4 \mathrm{G}}$

As in the provision of basic international telecommunications services, competition between firms in the provision of international transmission facilities (with or without joint-venture affiliation) is also almost universally not allowed. The closest thing to competition in international facilities in the current regulatory regime is the competition between INTELSAT and the various transatlantic cable consortia. Even this competition is largely managed by overlapping PTT representation in INTELSAT and the cable consortia, by U.S. regulatory policies encouraging the "balanced" use of both kinds of facilities, and by facilities planning processes overseen by the FCC and other regulatory authorities.

\footnotetext{
${ }^{44}$ Packet switching uses computer processing to group communications into packets going to common destinations.

${ }^{45} \mathrm{FCC}$, "In the Matter of Amendment of Section 64.702 of the Commission's Rules and Regulations [Second Computer Inquiry]," FCC-80-1 89, final decisions, released May 1980.

${ }^{46}$ See ch. 6 for descriptions of the INTELSAT, I NMARSAT, and the transatlantic cable consortium.
}

Although in recent years the Commission has tried to back away from explicit satellite/cable use rules on the grounds that competition between the transmission modes should be allowed so that consumers would benefit, its 1982 "Authorized User" decision stated that the FCC would "continue to monitor the carriers' use of facilities to insure [that] both cable and satellite facilities are reasonably used ${ }^{47}$ Using monthly circuit status reports, the FCC notes that "the existing policy has produced a satellite-cable facility usage ratio in the North Atlantic region of approximately 5050 (specifically 48 percent cable, 52 percent satellite).$^{48}$

The FCC is currently considering what transatlantic circuit distribution policy to follow in the 1985-95 period, since the current negotiated plan expires in $1985 .{ }^{49}$ It is considering as alternatives: 1) continued use of "balanced loading, ${ }^{50} 2$ ) other distribution schemes, and 3) no FCC prescription of circuit distribution. The Commission recently tentatively concluded that transatlantic balanced use restrictions will still be necessary in the $1986-91$ period. ${ }^{51}$ Although no hint to the effect is given in the relevant FCC documents, ${ }^{52}$ these distribution alternatives must be considered in the context of the large transatlantic capacity in the proposed new private satellite and fiber optic cable systems that may come to exist alongside the facilities of the cable consortia and INTELSAT. It must also take into account the growing private transborder regional system in the Americas.

The option of having no FCC circuit distribution prescription would not necessarily mean a significant change in the regulatory regime, however. The FCC could continue to approve the coordinated planning of new facilities within the North Atlantic Consultative Process by groups of U.S. and foreign carriers, who, as part of the process, would be likely to negotiate circuit loading rules. As long as facilities construction is regulated and individually owned facilities are not allowed, some formal or informal circuit loading rules are likely to be followed in any case. What is not clear, however, is how any but the most stringent circuit distribution requirements can protect the revenues of COMSAT/INTELSAT, if large alternative satellite and cable capacity comes into existence.

\footnotetext{
qpGeneral Accounting Office, Op. Cit., p. 43.

${ }^{48} \mathrm{NOI}$, op. cit., p. 9.

${ }^{49}$ The u.S. international carriers have also stated that they wouldl ike to see a reevaluation of the circuit loading policy ("Contribution of the U.S. Delegation to the North Atlantic Consultative Working Group, Paris, France, Jan. 31-Feb. 2, 1984, unpublished, p. 41).

${ }^{50}$ Balanced loading is defined in note 46, P. 161.

51FCC, 'Second Notice of Proposed Rulemaking I $n$ the Matter of . . Authorization of Common Carrier Facilities to Meet North Atlantic Telecommunications Needs During the 1985-1995 Period," FCC 85-176, released Apr. 22, 1985.

52/bid., and NOI, OP. cit.
} 


\section{Pricing}

The pricing of international telecommunications to consumers is in most cases determined solely by the carrier and/or regulatory authority of the originating country. Rates for calls originating in (or collect to) a country can therefore differ tremendously from rates of calls going the other way, frequently by a factor of more than 2. In most cases, U.S. rates are significantly lower than the rates of other countries (even with the strong dollar), but nevertheless, as a recent executive branch white paper states, "International service, in short, costs between two and three times comparable U.S. domestic service. ${ }^{53}$

In virtually all countries, international telecommunications profits cross-subsidize various unrelated activities. The surplus from international operations is transferred by administrative or regulatory action to such other activities as local or domestic long-distance phone service (e.g., the United States), the postal service (Germany), or even bus service (Switzerland). At stake in current telecommunications regulation, therefore, are the interests of the subsidy recipients as well as the carriers and buyers of international telecommunications services,

\section{Deregulatory Moves in International Telecommunications}

To date most of the actions taken to liberalize international telecommunications have been in the United States, although some moves in this direction have taken place in $\mathrm{Canada}^{54}$ and the United Kingdom. ${ }^{55}$ Even though domestic deregulatory actions have not been taken to any great extent in most other industrial countries, all are wrestling with the need to erect a practical perimeter around the regulated or state-owned sector that can effectively differentiate it from the growing array of computer-enhanced communications applications outside the perimeter without stunting their development. ${ }^{56}$

\footnotetext{
${ }^{53}$ Departments of State and Commerce, "A White Paper on Newinternational Satellite Systems, " op.cit., p. 42.

${ }^{54}$ See Josephs. Schmidt and Ruth M. Corbin, "Telecommunications in Can ada: The Regulatory Crisis, "Telecommunications Policy, vol. 7, September 1983, pp. 215-227.

55 See Andrew C. Brown, "For Sale: Pieces of the Public Sector, " Fortune, vol. 108 , Oct. 31,1983 , pp. $78-84$, for a discussion of the privatization of British Telecom. Also "Evaluating Telecom's Outlook," New York Times, p. D1. Actual sale of $\mathbf{5 0 . 8}$ percent of the stock to the public took place on Nov. 28, 1984. A second domesticinterexchange carrier has also emerged: Cable \& Wireless' wholly owned subsidiary, Mercury Communications. See also Eli M. Noam, "Telecommunications Policy on the Two Sides of the Atlan IIC: Divergence and Outlook, " op. cit.

56See Marcellus S. Snow, "Telecommunications Deregulation in the Federal Republic of Germany," Columbia Journal of World Business, vol. 18, No. 1, spring 1983; and Dan Schiller, "The Storming of the PTTs," Datamatıon, May 1983, pp. 155-158.
}

The deregulatory moves the United States has taken in international telecommunications can be explained mostly as the straightforward result of domestic deregulatory actions that have, insofar as possible, removed the regulatory distinctions between firms. For instance, the dropping of the distinction among voice and record carriers could not easily be maintained by the FCC in international communications after it had abandoned it in domestic communications. As a practical matter, it would also be difficult for the FCC to discriminate in international communications among the major U.S. corporations that are now the vigorous new competitions in domestic markets. In theory at least, discrimination is now left to foreign governments beyond the control of the FCC and to the market. $^{57}$

COMSAT'S special status as the monopoly wholesaler of INTELSAT services is an exception to this. By law and regulatory action, COMSAT has the special status of a carrier's carrier with monopoly access to INTELSAT space segment facilities. The FCC would like to control and dilute this special status, however, and see COMSAT evolve primarily into a general communications carrier. ${ }^{58}$ The FCC's 1982 decision to allow COMSAT to sell to consumers directly was to be a step in this direction, but it was suspended until 198 s by court decision and may continue to accrue court challenges. ${ }^{53}$ In 1984, the FCC first allowed communications firms to own limited-use INTELSAT Earth stations. Traditional INTELSAT Earth stations have been owned 50 percent by COMSAT and 50 percent by the international carriers using them. The FCC altered this policy by approving the applications of several carriers to construct and operate special Earth stations in Chicago, New York, Washington, and other cities for INTELSAT Business Service (IBS) (primarily data and videoconferencing) and expects to approve other similar applications in the future ${ }^{60}$ It then fol-

\footnotetext{
5The FCC provisionally still regulates $A I \& \mid$ as the dominant carrier both domestically and internationally and also the other international carriers in most international markets, since competition at present is Insufficient to eliminate market power. Legislation, such as the Record Carrier Competition Act of 1981, guides the FCC in making the transition and in residual regulation of nondominant carriers.

${ }^{58}$ See main ch. 6 for a discussion of other alternative means of dealing with COMSAT's future status.

${ }^{59} \mid t$ has already come under fire. A number of US carriers petitioned the FCC to be allowed to acquire capacity in the INTELSAT system parallel to COMSAT, in much the same way that they now own capacity in transatlantic cables. The FCC recently turned them down and closed the issue for the time being, but it will undoubtedly be raised again at some time in the future, perhaps as an alternative to private satellite ownership (Satellite News, Apr. 2, 1984, p. 2)

@As of January 1985, besides that of COMSAT, the FCC had approved applications of the following firms or their subsidiaries to distribute INTELSAT Business Service: International Relay, Inc., ITT Corp., United Brands Co. (subsidiary: TRT Telecommunications, Inc.), IBM Corp. (joint venture subsidiary: Satellite Business Systems), Satellite Gateway Communications, Inc., Vital Ink International Communications, Inc., McDonnell Douglas (subsidiary: FTC Satellite Systems, Inc.), and United Video, Inc.
} 
lowed this by removing the requirement that COMSAT must own a half share of the general-purpose INTELSAT Earth stations. ${ }^{64}$

In the view of some, this evolution is too slow. In their view, it may allow COMSAT to take advantage of its special position in international communications to unfairly cross subsidize its competitive domestic activities, despite the special accounting rules devised by the FCC to minimize the possibility.

The FCC's abandonment of the distinctions between international voice and record carriers and international and domestic carriers, together with its moves to end the special position of COMSAT, already make a significant difference in the way the U.S. industry faces the world. What the changes mean collectively is that all U.S. communications carriers (except COMSAT, for the present) will be allowed to operate in international communications markets in the nearly same way as far as the U.S. Government is concerned.

What this will mean in terms of actual competition in the intermediate-range future is in doubt, however. First, AT\&T currently has a dominant position in international service markets: at the end of 1983, AT\&T alone was using approximately 88 percent of all cable and satellite circuits in service between the United States and Europe just for message telephone service. ${ }^{62}$

Despite its important domestic deregulatory moves, the FCC has been rather cautious in extending deregulation directly into international communications. For the most part, the foundations of the international communications regime, in which competition is severely limited, have not been touched.

Restrictions on facilities construction, ownership, and use, for instance, are one of the key elements in the current international communications regulatory structure. Up to 1985 the FCC continued to approve carrier facilities agreements and implicit or explicit balance criteria. The proposed transatlantic TAT-8 cable, for instance, which received FCC approval in 1984, will be jointly owned by the traditional U.S. international service carriers, together with foreign PTTs and governments. Likewise, INTELSAT, among other things, is a satellite cartel, and the FCC has been a strong supporter of INTELSAT. The pending applications for private "international" and "transborder" facilities, however, are forcing the FCC to reevaluate its position on facilities. The reevaluation also appears to be underway in the current inquiry on facilities loading. Whether this reevaluation will result in important U.S. deregulatory moves in international communications is not clear.

\footnotetext{
6IFCC, "Second Report ., .," op. cit., Jan. 1 1, 1985

${ }_{62} \mathrm{NOI}$, op. cit., p. 12.
}

The changes that have already taken place in the international regulatory regime mean that the international communications game will now be played by a greater number of potential U.S. players. This introduces one new element, the increased ability of the PTTs to use their monopoly power at the expense of competitive U.S. carriers (and consumers) by favoring those U.S. carriers which offer the most advantageous terms ${ }^{63}$ In the extreme, this would mean selling the right to interconnect to the single highest bidder. In this way, PTT could get most of the excess profit obtainable from the monopoly structure.

Care needs to be taken in interpreting the prices ("accounting rates") paid by international carriers to their country-pair partners ("correspondents") in other countries. With certain exceptions, notably private lines, carriers derive revenues only from customers sending outbound communications and do not charge for inbound ones. Since country-pair traffic flows are usually unbalanced, sometimes with heavy net flow in one direction, there is a need for the carrier with the heavier flow (and heavier collection of tariff revenue from customers) to compensate the carrier that is the net communications recipient for the uneven use of jointly provided facilities.

It is a two-step procedure. First, there is a barter mechanism, whereby minutes in one direction are traded one-for-one for minutes in the other direction, up to the level of the smaller directional flow. The country-pair partners then complete the settlement by negotiating a price for the excess minutes, the "accounting rate." This is than multiplied by the number of excess minutes to determine the amount to be paid to the net recipient. These payments are made regardless of which transmission mode is used and, therefore, cover communications sent both by cable and satellite, ${ }^{64}$

For voice service, there is a net communications outflow from the United States, and U.S. carriers therefore typically make payments to the PTTs. Any increase in the accounting rate that a foreign PTT could negotiate with U.S. voice carriers would therefore typically increase the operating expenses and decrease the net revenues of the U.S. carriers. For record service, the reverse movement in the accounting rate would disadvantage U.S. carriers. While there is some variation in directional flow among individual U.S. record carriers, the record carriers as a group have more traffic flowing into the United States than

\footnotetext{
${ }^{63}$ According to GAO, op. cit., p. 18, the PTTs or groupings of PTTs representing Belgium, Luxembourg, the Netherlands, Denmark, Finland, Iceland, Norway, and Sweden invited potential suppliers of data communication services to make accounting rate bids on existing and new services.

${ }^{64}$ The partners also negotiate an exchange rate, the "settlement rate, " so the payment can be made in the appropriate currency.
} 
out. Here PTTs typically gain by pressuring U.S. record carriers to decrease the accounting rate, which, decreases the revenues of U.S. carriers.

To combat the use of PTT monopoly power to disadvantage competitive U.S. carriers, the FCC has mandated that all potential U.S. connectors agree on a single accounting rate. Ironically, this discourages competition among the U.S. carriers, and, in particular, does not allow new entrants to compete on the basis of price. It thereby lessens the benefits that consumers derive from increasing international competi tion. ${ }^{65}$ It also illustrates the broader principle that halfway liberalization of markets may have unintended consequences.

\section{Entry Into U.S. International Satellite Communications Markets}

In most foreign countries, when there is more than one potentially connecting U.S. firm, each country determines which carrier or carriers it will interconnect with and which it will exclude in each market segment. ${ }^{66}$ The arrangement is facilitated by joint owner-

\footnotetext{
${ }^{65}$ This Point is made in an unpublished paper by Eli Noam presented at the Research Workshop on Economics of Telecommunications, Information and Media Activities in Industrial Countries, National Science Foundation, Apr. 30-May 2, 1984, Washington DC.

${ }_{66}$ In the u nited States, the Federal Communications Commission has required Interconnectlon. Nevertheless, since usually there was only one forelgn carrier to connect with in each market, the market structure in countrypair markets remained noncompetitive.
}

ship of oceanic cables. For instance, the planned TAT8 and TAT-9 fiber optic cables are to be owned jointly by a consortium of AT\&T, seven other U.S. international carriers, British Telecom, French Telecom, and virtually every PIT in Europe. The Hawaii 4/TRANSPAC-3 cable that is to link the U.S. mainland to Japan and several other Asian countries in 1988 or 1989 will be also jointly owned by numerous telecommunications entities (22 in all from North America, the Pacific region, and Europe).

In both the North Atlantic and Western Hemisphere satellite arenas, deregulatory pressures from the U.S. private sector have recently become intense. They are currently manifesting themselves mainly in attempts to enter communications markets with private facilities. The traditional U.S. international service carriers, augmented by Western Union Telegraph $\mathrm{Co}$., $\mathrm{MCl}$ international, and GTE Sprint, require correspondent relationships with the PTTs of the destination countries, and while some entry is taking place in these markets, they are not the scene of the most active entry. Western Union's ability to enter many international record markets, since being allowed to by the FCC, and $\mathrm{MCl}$ International's entry into the United Kingdom, Belgium, Brazil, and other voice markets in late 1984/early 1985 are the most notable events. The most active entry is currently being attempted in transatlantic and Western Hemisphere satellite facilities markets (as described above, in ch. 6) and in markets for business communications facilities, such as INTELSAT Business service. 


\section{APPENDIX 6B.-THE COMMUNICATIONS SATELLITE EQUIPMENT MARKET}

\section{Introduction}

The large-scale development of the satellite communications service industry has been paralleled by the requisite development of a large satellite equipment industry. Estimated worldwide investment in commercial communications satellites from 1965 to 1985 (not including the Soviet Union) will have been $\$ 4.8$ billion with 132 launches.' This is shown in figure 66-1, which breaks out this investment for various countries, organizations, and regions.

Some analysts foresee continued expansion in communication satellite systems. In one recent optimistic forecast, for instance, the world market for satellite communications equipment in the 1980-2000 period is projected to be $\$ 30$ billion to $\$ 50$ billion. z Expansion and periodic replacement of the world's satellite communications systems, which will require continuing future investment in satellites and ground segment equipment, is included in this projection,

While this is consistent with one of the possible futures for satellite communications, previous analysis in chapter 6 concluded that the demand for international satellite communications services on which the demand for satellite equipment depends, is highly uncertain, particularly in the 1990s. Although the domestic markets for satellite communications in the United States and other countries are not analyzed in this assessment, it is clear that demand for domestic, as well as international, satellite services and for equipment to provide them is also highly uncertain. ${ }^{3}$ Consequent-

'R. Filep, A. Schnapf, and S.Fordyce, "World Communications Satellite Market Characteristics and Forecast," prepared by Communications 21 Corp., Redondo Beach, CA, for the NASA-Lewis Research Center, Cleveland, OH, NASA CR-168270, November 1983.

"See Ted Lanpher, "ACTS: The Case for U.S. Investment in $30 / 20 \mathrm{GHz}$," Satellite Communications, May 1983. A second projection for the world equipment market between 1983 and 1990 in just the $14 / 12 \mathrm{GHz} \mathrm{Ku}$ band is $\$ 25$ billion, peaking in 1988-89. Interview with Dennis Fraser, Corporate Vice President and General Manager, NEC America Broadcasting Equipment Division and Executive Vice President Alcoa-NEC Communications Corp. as quoted in Satellite Week, Mar. 28, 1983, p. 7.

${ }^{3}$ For a recent forecast of the demand for U.S. satellite and terrestrial telecommunications capacity, see S. Stevenson, W. Poley, J. Lekan, and J.Salzman, "Demand for Satellite-Provided Domestic Communications Services to the Year 2000, "Technical Memorandum 86894, NASA, Lewis Research Center, Cleveland, OH, November 1984, For the decades of the 1980s and 1990s, the authors forecast the average annual demand for long-haul communications capacity in the United States to grow at 1.6 and 3.8 percent respectively, but that the demand for satellite capacity will grow at 10.4 and 7.5 percent, respectively. In their projection, the ratio of total satellite demand to total long-haul demand increased rapidly from 0.15 in 1980 , to 0.35 in 1990 and $0.51 \mathrm{i} \mathrm{n} \mathrm{2000.} \mathrm{The} \mathrm{authors} \mathrm{project} \mathrm{an} \mathrm{even} \mathrm{more} \mathrm{dramatic} \mathrm{in-}$ crease in the ratio of business services demand for satellite capacity (data and video [mostly videoconferencing]) to demand for total long-haul capac- ly, considerable skepticism of both U.S. and worldwide projections of satellite communications equipment demand is warranted.

\section{Satellite Markets}

The bulk of satellite communications services (outside the Soviet bloc) in the 1980s and 1990s will be provided by INTELSAT and other global systems, ${ }^{4} \mathrm{re}$ gional systems such as ARABSAT, PALAPA, EUTELSAT, and the potential private Western Hemisphere and transatlantic systems; and national systems, particularly those of the United States, Canada, Mexico, Brazil, Japan, India, China, and Australia. The latter are starting to provide increasing amounts of transborder service to neighboring nations; consequently, the distinction between national and regional will become less clear. Information on major international communications and direct broadcast satellites (DBS) which are in use already or reasonably certain to be orbited soon are listed in table 66-1.

The United States is the world's largest single market for satellite communications equipment. One estimate places U.S. investment in commercial communications satellites at $\$ 1.63$ billion between 1965 and 1985 as shown in figure $66-1$ and $\$ 3.19$ billion between 1986 and 1989 as shown in figure 6B-2. In April 1983, the Federal Communications Commission (FCC) authorized 19 new communications satellites for launch by 1987-more than are to be launched by the rest of the non-Communist world combined. $s$ Pending before the FCC are applications for over 50 more communications satellites (represented by 22 differ-

Ity for these services: 0.11 (1 980), 0.56 (1 990) and 0.87 (2000). This, therefore, presents one view of the outcome of technological competition between satellites and fiber optic cables. In addition, commercialization of space ventures such as launch vehicles and materials processing may divert invest ment capital from communications satellites. See Jay C. Lowndes, "Increased Space Commercialization May Tighten Investment Capital," Aviation Week and Space Technology, Apr. 29, 1985, pp. 123-128.

'E.g., INMARSAT

SPersonal communication, FCC, May 1985. No more have been authorized since April 1983. In addition, the authorizations granted in April 1983 to Advanced Business Communications, Inc., Rainbow Satellite, Inc., and United States Satellite Systems, Inc., all In Ku-band, have since been declared null and void. The FCC hopes to have the pending applications settled by August 1985, prior to ORB-85.

'including spares, but not including previously built replacement satellites. Much of this capacity is for private business networks which bypass the local terrestrial telephone networks. Reasons why businesses have invested in such private bypass facilities are that they can avoid cross subsidizing res idential phone service, they may be able to gain types of service not available over the public network, and large users might find their own networks to be economic since they can design them without provision for redundancy. (For a discussion of these issues, see House of Representatives, 98th 


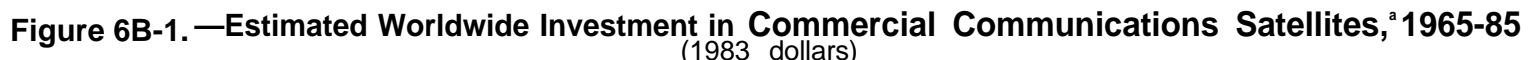

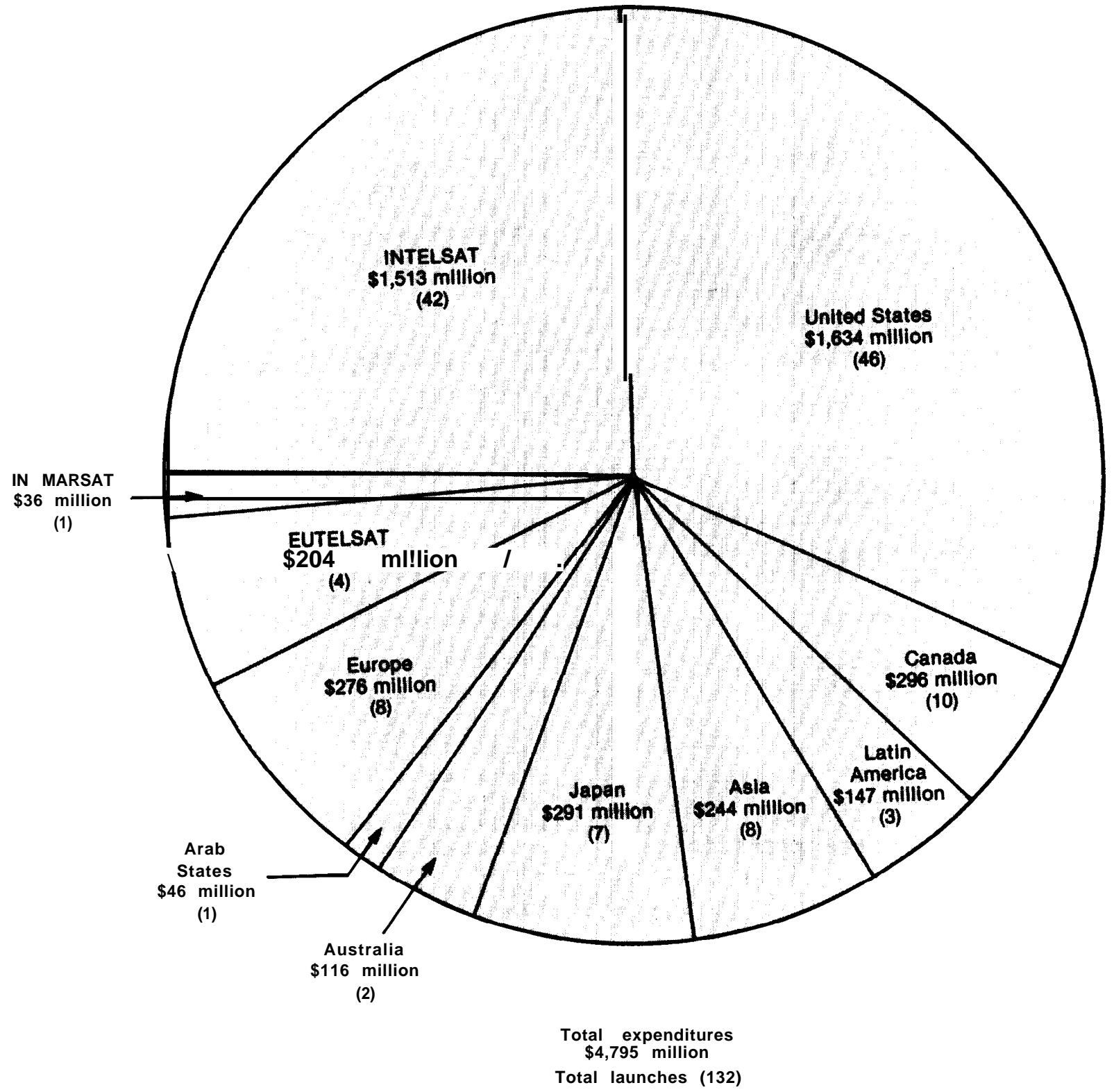

${ }^{a_{\text {Does }}}$ not include the Soviet Union.

SOURCE: Data from: R.Filep.A.Schnapf, and S. Fordyce,

"World Communications Satellite Market-characteristics and Forecast,"

,prepared for NASA by Communications 21 Corp., NASA CR-168270, November 1983, p. 12

Congress, Committee on Energy and Commerce, Report on HR 4102, Universal Telephone Service Preservation Act of 1983, Report No. 98-479, No v. 3, 1983; "FCC Needs to Monitor a Changing International Telecommunications Market, "General Accounting Office, Washington, DC, Report RCED83-92, Mar 14, 1983; "Efficiency vs Comity In U.S. International Telecommunications Regulation," by Douglas L. Adkins, paper presented at the Soc iety of Government Economists' Session on International Regulation, ASSA Meetings, Dallas, TX, Dec 28, 1984; and "Breaking Up AT\&T" by Mary H Cooper, Editorial Research Reports, vol. 11, No.23,Dec 16, 1983. ent companies) and about 18 direct-broadcast satellites. ${ }^{7}$ Not all of these satellites will be built, partly because a number of the firms are requesting the same

'See "FCC Approves 4 Firms for Satellite TV, Aviatıon Week and Space Technology, Oct. 15, 1984, p. 22; and "Four Firms Win Approval of FCC for TV Satellites, "Aviation Week and Space Technology, Dec. 17, 1984, p, 18 
Table B=I.-International Communications and Direct Broadcast Satellite Series

\begin{tabular}{|c|c|c|c|c|}
\hline Name & Date & Owner & Manufacturer & Technical characteristics \\
\hline AM ERSAT & 1985,86 & $\begin{array}{l}\text { American Satellite (jointly } \\
\text { owned by Fairchild } \\
\text { Industries and } \\
\text { Continental Telephone) }\end{array}$ & RCA Astro-Electronics & $\begin{array}{l}\text { Six } \mathrm{Ku} \text {-band }(14 / 12 \mathrm{GHz}) \\
\text { transponders plus } 12 \mathrm{C} \text { - } \\
\text { band }(6 / 4 \mathrm{GHz}) \\
\text { transponders }\end{array}$ \\
\hline ARABSAT & 1985,86 & Arab Satellite Organization & $\begin{array}{c}\text { Aerospatiale/Ford } \\
\text { Aerospace }\end{array}$ & $\begin{array}{l}25 \text { C-band transponders plus } \\
1 \text { S-band transponder }\end{array}$ \\
\hline Anik & $1978,82,84$ & Telesat Canada & $\begin{array}{l}\text { Anik B-RCA Astro- } \\
\text { Electronics, Anik C- } \\
\text { Hughes Aircraft, Anik D- } \\
\text { Spar Aerospace/Hughes }\end{array}$ & $\begin{array}{l}\text { Anik B, } 18 \text { transponders; Anik } \\
\text { C, } 16 \text { transponders; Anik D, } \\
24 \text { transponders. All Ku or } \\
\text { C-band or combination }\end{array}$ \\
\hline BS 2 & 1984,85 & NASDA & ToshibalGeneral Electric & $\begin{array}{l}2 \mathrm{Ku} \text { transponders covering } \\
\text { all Japanese territory }\end{array}$ \\
\hline$\underline{B S E}$ & 1978 & NASDA & & \\
\hline Comstar & $1976,78,81$ & COMSAT Corp. & Hughes Aircraft & 24 transponders at $6 / 4 \mathrm{GHz}$ \\
\hline Cs 2 & 1983 & NASDA & $\begin{array}{l}\text { Mitsubishi Electric/Ford } \\
\text { Aerospace }\end{array}$ & $\begin{array}{l}\text { Six Ka-band }(30 / 20 \mathrm{GHz}) \text { plus } \\
2 \text { C-band transponders }\end{array}$ \\
\hline ECS & 1984,85 & EUTELSAT & $\begin{array}{l}\text { British Aerospace Dynam. } \\
\text { leading Mesh consort. }\end{array}$ & $12 \mathrm{Ku}$ transponders \\
\hline Galaxy & 1983 & Hughes Communications & Hughes Aircraft & 24 transponders at $6 / 4 \mathrm{GHz}$ \\
\hline Gstar & 1984,85 & GTE Satellite & RCA Astro-Electronics & 16 transponders at $14 / 12 \mathrm{GHz}$ \\
\hline Morelos & 1985,86 & Mexican Government & Hughes Aircraft & $\begin{array}{l}22 \text { transponders (mix of } \mathrm{Ku} \\
\text { and C-band) }\end{array}$ \\
\hline INTELSAT IV & $\begin{array}{r}1974,75 \\
76,77\end{array}$ & INTELSAT & $\begin{array}{c}\text { Hughes Aircraft including } \\
\text { participation by British } \\
\text { Aerospace Dynamics, } \\
\text { Thomson-CSF, AEG- } \\
\text { Telefunken, Selenia, NEC }\end{array}$ & 12 C-band transponders \\
\hline INTELSAT V & $1978-84$ & INTELSAT & $\begin{array}{l}\text { Ford Aerospace leads a } \\
\text { team that includes } \\
\text { Aerospatiale, MSDS, } \\
\text { MBB, Mitsubishi, } \\
\text { Selenia, and } \\
\text { Thomson-CSF } \\
\end{array}$ & $\begin{array}{l}21 \text { transponders at } 6 / 4 \mathrm{GHz} \\
\text { plus } 6 \text { at } 14 / 11 \mathrm{GHz}\end{array}$ \\
\hline INTELSAT VI & 1986- & INTELSAT & $\begin{array}{l}\text { Hughes Aircraft, including } \\
\text { shares by British } \\
\text { Aerospace Dynamics, } \\
\text { Spar Aerospace, } \\
\text { Thomson-CSF, Selenia, } \\
\text { NEC, MBB, Comdev, } \\
\text { and AEG-Telefunken }\end{array}$ & $\begin{array}{l}36 \text { transponders in C-band } \\
\text { plus } 10 \text { transponders in } \\
\text { Ku-band }\end{array}$ \\
\hline ITALSAT & 1987 & Italy (Telespazio) & Aeritalia and Selenia & 6 transponders in Ka-band \\
\hline $\begin{array}{l}\text { L-Sat } \\
\text { (Olympus) }\end{array}$ & 1986, 90 & ESA & $\begin{array}{l}\text { British Aerospace Dynam. } \\
\text { leads; team includes } \\
\text { Selenia, Marconi, BTM, } \\
\text { and Telespazio }\end{array}$ & $\begin{array}{l}2 \text { transponders for direct } \\
\text { broadcast TV; transponders } \\
\text { for business services plus } \\
30 / 20 \mathrm{GHz} \mathrm{Ka}\end{array}$ \\
\hline Marecs & $1981,82,84$ & $\begin{array}{l}\text { INMARSAT leases craft } \\
\text { from ESA }\end{array}$ & $\begin{array}{l}\text { British Aerospace } \\
\text { Dynamics (payload } \\
\text { made by Marconi Space } \\
\text { \& Defense Systems) }\end{array}$ & $\begin{array}{l}\text { Two transponders can relay } \\
30 \text { to } 50 \text { voice channels } \\
\text { simultaneously }\end{array}$ \\
\hline Marisat & 1976 & COMSAT Corp. & Hughes Aircraft & $\begin{array}{l}\text { Transponders in VHF, L-band, } \\
\text { and C-band }\end{array}$ \\
\hline
\end{tabular}

"This includes all major satellites currently in service in the Western world as well as new ventures with a firm go-ahead. Derived from "International Satellite Directory-Flight Data," Flight International, May 14,1983, pp. 1311.1330 and Satellite Communications Notebook, 1984. -'Retrieved November 19S4 after a previous failed mission.

NOTE: All satellites are geosynchronous. 
Table B-1 .—International Communications and Direct. Broadcast Satellite Series-Continued

\begin{tabular}{|c|c|c|}
\hline General information & Design life (years) & Launch \\
\hline Two satellites ordered so far by American Satellite & $\begin{array}{l}\text { AM ERSAT A, } 8.5 \text { yrs. } \\
\text { AM ERSAT B, } 10 \text { yrs. }\end{array}$ & Shuttle \\
\hline Will provide television, voice, and data links among Arab League countries & 7 & Ariane, Shuttle \\
\hline Used for Canada's domestic network of communications satellites & $\begin{array}{l}\text { Anik B, } 7 \text { yrs. Anik } \\
\text { C, } 8 \text { yrs. Anik D, } 9 \\
\text { yrs. }\end{array}$ & Delta, Shuttle \\
\hline $\begin{array}{l}\text { There will be two craft in orbit. Will bring television to Japanese islands } \\
\text { and mountainous regions }\end{array}$ & 5 & $\mathrm{~N}-11$ \\
\hline Medium-scale broadcasting satellite for experimental purposes & NIA & Delta \\
\hline A series of four U.S. domestic communications craft, leased by AT\&T & 7 & Atlas-Centaur \\
\hline $\begin{array}{l}\text { Japan's first operational domestic communications satellites. The network } \\
\text { comprises two craft in orbit }\end{array}$ & 3 & $\mathrm{~N}-11$ \\
\hline $\begin{array}{l}\text { European Communications Satellite. Five ECS are being built, procured for } \\
\text { Eutelsat by ESA }\end{array}$ & 7 & Ariane \\
\hline A series of three craft which Hughes Comm. will own and operate & 9 & Delta \\
\hline The first domestic communications craft bought by GTE; they previously leased & 10 & Ariane \\
\hline $\begin{array}{l}\text { Mexico's first domestic communications satellite; will relay television, } \\
\text { telephone calls, and data }\end{array}$ & 9 & Shuttle \\
\hline
\end{tabular}
four INTELSAT IV As

The largest series of communications satellites in the world, providing two- 7 thirds of all international links

Atlas-Centaur Ariane

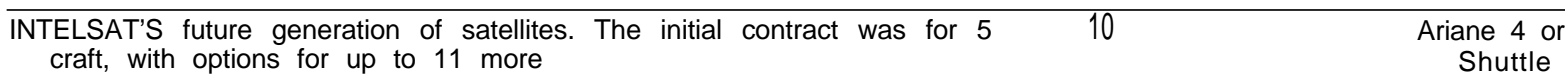

\begin{tabular}{lll}
\hline Italy's first domestic communications craft-intended as semi-operational & 10 & Ariane or Shuttle \\
\hline $\begin{array}{l}\text { Large Satellite (L-Sat) is Europes' entry into direct broadcast satellites and } \\
\text { business communications }\end{array}$ & $\begin{array}{l}\text { Olympus-1, } 5 \text { yrs. } \\
\text { Olympus-2, 10 yrs. }\end{array}$ & Ariane \\
\hline $\begin{array}{l}\text { Europe's first maritime communications satellite. Marecs A INMARSAT } \\
\text { debut was May 1, 1982 }\end{array}$ & 7 & Ariane \\
$\begin{array}{l}\text { Worlds first maritime communications satellite. Used by U.S. Navy and } \\
\text { IN MARSAT to provide ship-shore link }\end{array}$ & 8 & Delta
\end{tabular}

"This includes all major satellites currently in service in the Western world as well as new ventures with a firm go-ahead. Derived from "International Satellite DirectoryFlight Data," Flight Irrterrrational, May 14, 1983, pp. 1311-1330 and Satellite Communications Notebook, 1984.

- "Retrieved November 19S4 after a previous failed mission.

NOTE: All satellites are geosynchronous 
Table B-1.-International Communications and Direct-Broadcast Satellite Series-Continued

\begin{tabular}{|c|c|c|c|c|}
\hline Name & Date & Owner & Manufacturer & Technical characteristics \\
\hline PALAPA & $\begin{array}{l}1976,77 \\
84,{ }^{*} \cdot 85\end{array}$ & $\begin{array}{l}\text { Permutel (Indonesian } \\
\text { telecommunications } \\
\text { administration) }\end{array}$ & Hughes Aircraft & $\begin{array}{l}12 \text { transponders in C-band; } 1,2 \\
24 \text { transpond. in C-band; } 61,62\end{array}$ \\
\hline Postsat & 1986 or 87 & $\begin{array}{l}\text { German Ministry for Post } \\
\text { and Telecommu- } \\
\text { nications }\end{array}$ & $\begin{array}{l}\text { MBB/ERNO (as } \\
\text { subcontractor to } \\
\text { Siemens) }\end{array}$ & $\begin{array}{c}7 \text { transponders at } 14 / 12 \mathrm{GHz} \\
\text { plus } 3 \text { at } 14 / 11 \mathrm{GHz} \text { plus } 1 \\
\text { experimental } 30 / 20 \mathrm{GHz}\end{array}$ \\
\hline Satcom & $\begin{array}{c}1975,76 \\
81,82 \\
83,85 \\
\end{array}$ & $\begin{array}{l}\text { Satcom I and 11: RCA } \\
\text { American Comm., Satcom } \\
\text { III onward: Americom }\end{array}$ & RCA Astro-Electronics & 24 transponders at $6 / 4 \mathrm{GHz}$ \\
\hline$\overline{\text { SOS }}$ & $1980,81,82$ & $\begin{array}{l}\text { SBS was consortium of } \\
\text { Aetna Life \& Casualty, } \\
\text { COMSAT Corp. and } \\
\text { IBM. COMSAT recently } \\
\text { opted out }\end{array}$ & Hughes Aircraft & $\begin{array}{l}10 \text { active transponders at } \\
14 / 12 \mathrm{GHz} \text { (Ku-band) }\end{array}$ \\
\hline Spacenet & 1984, 85 & $\begin{array}{l}\text { Southern Pacific } \\
\text { Communications }\end{array}$ & RCA Astro-Electronics & $\begin{array}{l}12 \text { transponders in C-band } \\
\text { plus } 6 \text { in Ku-band }\end{array}$ \\
\hline TDRS & 1983,85 & $\begin{array}{l}\text { Spacecom (consortium of } \\
\text { Continental Telephone, } \\
\text { Fairchild Industries, and } \\
\text { Western Union) }\end{array}$ & $\begin{array}{l}\text { TRW Defense and Space } \\
\text { Systems }\end{array}$ & $\begin{array}{l}2 \text { S-band transponders, duplex } \\
\text { single access; } 2 \text { Ku-band, } \\
\text { duplex single access; IS- } \\
\text { band } 20 \text {-user mult. access } \\
\text { (RO), } 1 \text { timeshare multiple } \\
\text { access (TO); } 12 \text { C-band }\end{array}$ \\
\hline Telecom 1 & 1985 & $\begin{array}{l}\text { French Ministry of } \\
\text { Telecommunications/ } \\
\text { CNES }\end{array}$ & $\begin{array}{l}\text { Matra Space with } \\
\text { participation by } \\
\text { European industry }\end{array}$ & $\begin{array}{l}6 \text { transponders at } 14 / 12 \mathrm{GHz} \\
\text { covering France plus } 4 \text { at } \\
6 / 4 \mathrm{GHz} \text { covering Africa } \\
\text { and French Guiana plus } 2 \\
\text { at } 8 / 7 \mathrm{GHz} \text { for French govt. }\end{array}$ \\
\hline Telstar 3 & $1983,84,85$ & $\begin{array}{c}\text { American Telephone \& } \\
\text { Telegraph (AT\&T) }\end{array}$ & Hughes Aircraft & $\begin{array}{l}24 \text { transponders at } 6 / 4 \mathrm{GHz} \text {, in- } \\
\text { creasing to } 30 \text { in later series }\end{array}$ \\
\hline Unisat & 1986 & $\begin{array}{l}\text { United Satellites, a } \\
\text { consortium of British } \\
\text { Telecom, British } \\
\text { Aerospace Dynamics, } \\
\text { and Marconi Space \& } \\
\text { Defense Systems }\end{array}$ & $\begin{array}{l}\text { British Aerospace } \\
\text { Dynamics (payload by } \\
\text { Marconi) }\end{array}$ & $\begin{array}{l}2 \text { direct-broadcast television } \\
\text { channels plus } 4 \text { trans- } \\
\text { ponders for mixed } \\
\text { business use }\end{array}$ \\
\hline Westar & $\begin{array}{r}1974,79, \\
82,84^{*}\end{array}$ & $\begin{array}{l}8001_{0} \text { WesternUnion and } \\
\text { zoo/o American Satellite }\end{array}$ & Hughes Aircraft & $\begin{array}{c}\text { 1, } 11, \text { III: } 12 \text { transponders at } 6 / 4 \\
\text { GHz IV, V: } 24 \text { at } 6 / 4 \mathrm{GHz}\end{array}$ \\
\hline \multicolumn{5}{|c|}{ Direct-Broadcast: } \\
\hline AUSSAT & 1985 & Aussat & Hughes Aircraft & $\begin{array}{l}4 \text { transponders with } 30 \mathrm{~W} \\
\text { power plus } 11 \text { with } 12 \mathrm{~W} \\
\text { power. All are } 14 / 12 \mathrm{GHz}\end{array}$ \\
\hline STC & 1986 & $\begin{array}{l}\text { STC, a subsidiary of } \\
\text { COMSAT Corp. }\end{array}$ & RCA Astro-Electronics & 3 transponders at $14 / 12 \mathrm{GHz}$ \\
\hline Tele-X & 1986 & Swedish Space Corp. & $\begin{array}{l}\text { Aerospatiale as prime, plus } \\
\text { Saab-Scania, LM } \\
\text { Ericsson, and } \\
\text { Eurosatellite consort. }\end{array}$ & $\begin{array}{l}3 \text { direct-broadcast } \\
\text { transponders (12 GHz) plus } \\
\text { transponders for video and } \\
\text { data relay }\end{array}$ \\
\hline TDF 1 & 1986 & TDF & Eurosatellite & $\begin{array}{l}3 \text { active direct-broadcast } \mathrm{Ku} \\
\text { band plus } 2 \text { spares }\end{array}$ \\
\hline TV-Sat & 1985 & $\begin{array}{l}\text { German Ministrv for Post } \\
\text { and Telecom". }\end{array}$ & Eurosatellite & $\begin{array}{l}3 \text { active direct-broadcast } \\
\text { transponders olus } 2 \text { st)ares } \\
\end{array}$ \\
\hline
\end{tabular}


Table B-1 .-International Communications and Direct-Broadcast Satellite Series-Continued

\begin{tabular}{|c|c|c|}
\hline General information & Design life (years) & Launch \\
\hline $\begin{array}{l}\text { Indonesia's first generation of communications satellites, PALAPA I and } 2 \\
\text { are being replaced with PALAPA B1 and B2 }\end{array}$ & $\begin{array}{l}\text { PALAPA I and } 2,7 \\
\text { yrs., PALAPA } 61 \\
\text { and } 62,8 \text { vrs. }\end{array}$ & Delta, Shuttle \\
\hline $\begin{array}{l}\text { West Germany's first domestic communications satellite, also known as } \\
\text { DFS; three craft built, two to be orbited }\end{array}$ & 7 & Ariane 3 or 4 \\
\hline $\begin{array}{l}\text { Series of U.S. domestic communications satellites relaying cable television } \\
\text { and other services. Currently comprises six satellites }\end{array}$ & 7,10 & Delta \\
\hline $\begin{array}{l}\text { Satellite Business Systems (SBS) was first to provide a satellite network } \\
\text { aimed at business users. Provides links among companies within the } \\
\text { Us. }\end{array}$ & 7 & Delta, Shuttle \\
\hline Southern Pacific has ordered four craft for its first network & 8.5 & $\begin{array}{l}\text { Ariane 3, Ariane } \\
\text { or Shuttle for } \\
\text { \#3 and \#4 }\end{array}$ \\
\hline $\begin{array}{l}\text { NASA's tracking and data-relay satellite system (TDRSS) is designed to } \\
\text { provide a more comprehensive communications link between spacecraft } \\
\text { and the ground }\end{array}$ & 10 & Shuttle \\
\hline
\end{tabular}
France's first domestic communications satellite will relay telephone calls, 7 television, and data within France and provide link with French overseas departments

\begin{tabular}{l}
\hline $\begin{array}{l}\text { The first domestic communications satellites owned by AT\&T, which } \\
\text { previously leased capacity on Comstars owned by COMSAT }\end{array}$ \\
\hline Britain's first direct-broadcast television satellite, whose two channels have 7 to 10
\end{tabular}
been allocated to the BBC. Unisat is a private venture

The bulk of Western Union's traffic is now carried by Westars III, IV, and V 1, 11, III: 7 yrs. IV, V: $10 \mathrm{yrs}$ Shuttle

Australia's first domestic communications satellite. AUSSAT has two main 7 functions-direct broadcast TV and radio, and the relay of TV, telephone calls. data. etc.

Satellite Television Corp. was the first company to win approval for a direct 7 Shuttle, Ariane broadcast television network in the U.S. STC will eventually have a option network of four operational craft serving all 50 staks

First export application of the French-German TV-Sat/TDF 1 direct- $\quad 5 \quad$ Ariane broadcast television satellite

\begin{tabular}{l}
\hline $\begin{array}{l}\text { France's version of the direct-broadcast television satellite, being } \\
\text { develor)ed with West Germany }\end{array}$ \\
$\begin{array}{l}\text { West German version of a direct-broadcast satellite being developed jointly } 7.5 \\
\text { with France, outside the framework of ESA }\end{array}$
\end{tabular}

- This includes all major satellites currently in service in the Western world as well as new ventures with a firm go-ahead Derived from "International Satellite Directory. Flight Data," Flight International, May 14, 1983, pp. 1311.1330 and Satellite Communications Notebook, 1984

." Retrieved November 1984 after a previous failed mission

NOTE: All satellites are geosynchronous 
geosynchronous orbital slots in the $\mathrm{C}(6 \mathrm{GHz}$ uplnak/4 $\mathrm{GHz}$ downlink) and $\mathrm{Ku}(14 / 12 \mathrm{GHz})$ bands. ${ }^{8}$ Several of the proposed satellites will either have to be placed in less desirable slots, not launched, or redesigned to transmit in the higher frequency $\mathrm{Ka}(30 / 20 \mathrm{GHz})$ band. ${ }^{9}$ The present transponder oversupply or inroads made by fiber optic systems could also reduce the number launched. ${ }^{10}$ Geostationary commercial communications satellite locations, present and planned as of June 1984, are shown in figures 6B-3 and 6B-4.

The next largest civilian communications satellite market is INTELSAT, now operating 16 satellites with a network of 173 receiving and transmitting Earth sta-

一

${ }^{8}$ The geostationary orbit is becoming increasingly congested, as shown in figs. 6B-3 and 6B-4 and allocation of these slots will be a major issue in the upcoming Space WARC '85, Some technical solutions will help alleviate but not solve the seriousness of the congestion. See, for example, L. Pollack and H. Weiss, "Communications Satellites: Countdown for INTELSAT VI," Science, Feb. 10, 1984, pp. 553-559; and Walter L, Morgan, "Satellite Locations-1984," Proceedings of the IEEE, vol. 72, No. 11, November 1984, pp. 1434-1444.

9See for example: Chris Bulloch, "Space Communications Move Into the Millimetre-Wave Bands, "Interavia, May 1984, pp. 461 -463; "Advanced Technology Satellites in the Commercial Environment," vol. 2, final report, prepared by Future Systems Inc., Rockville, MD, for NASA-Lewis Research Center, Cleveland, OH, March 1984; and C. Richard Whelan, "Communications Satellites Move to Higher Frequencies, "High Technology, November 1984, pp. 48-53.

"OSeefor example: "satellites OutPace Customers-Gap Viewed as Cyclical," The New York Times, Apr. 10, 1984; or Stephen Shaw, "Business Outlook-Satellite Operators Bet on Demand Surge," High Technology, November 1984, p. 54 tions located in 146 countries, dependencies, and areas of other special sovereignty .11 In most cases, the Earth stations themselves are owned and operated by the international telecommunications organizations of the member countries in which they are located. INTELSAT has contracted for nine INTELSAT $V$ and V-A satellites to be launched between 1983 and 1986 and five of the new INTELSAT VI models for 1986-87 Iaunches. ${ }^{12}$ Options exist for an additional 11 INTELSAT VIs, which, if built, are projected for launch in 1988 and onward. Anticipated INTELSAT investment in commercial communications satellites between 1986 and 1989 at $\$ 1.2$ billion would be second only to that of the United States ( $\$ 3,19$ billion) as shown in figure 6B-2.

Several other satellite systems, for which the satellites have already been contracted, may later require replacement or follow-on satellites. These systems include that of the International Maritime Satellite Organization (I NMARSAT) and others listed in table 6B-1 such as ARABSAT, ANIK, ${ }^{13}$ PALAPA, and AU SSAT. Japan apparently plans a larger satellite series to follow its current series .14 France has not announced plans

IINTELSAT Annual Report, Washington, DC, 1983, p. 9.

12Personal Communication, INTELSAT, November 1984;Pollack and Weiss, op. Cit.

1 'See however, "Mature Market to Affect Next ANIK Generation," Aviation Week and Space Technology, Dec. 10, 1984, pp. 87-88.

${ }^{14}$ Filep, Schnapf, and Fordyce, op. cit., p. 89. 
Figure 6B"2.-Estimated Worldwide Investment in Commercial Communications Satellites, ${ }^{\mathrm{a}} 1985-89$ (1983 dollars)

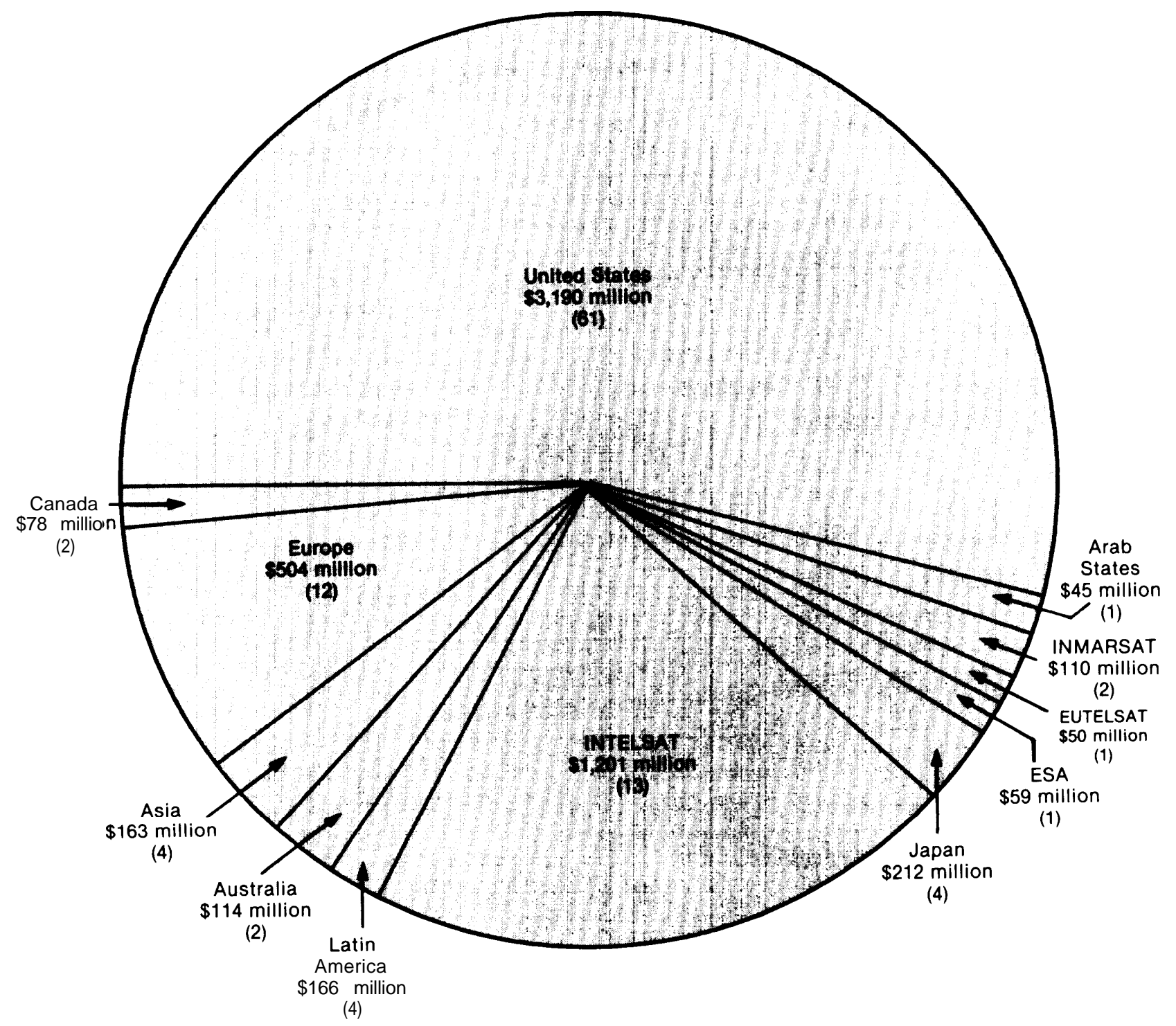

Total expenditures $\$ 5,892$ million Total launches (107)

aDoes not include the Soviet Union.

SOURCE: Data from: R. Filep, A. Schnapt, and S. Fordyce, "World Communications Satellite Market-Characteristics and Forecast," prepared for NASA by Communications 21 Corp., NASA CR-166270, November 1963, p. 36. 
Figure 6B-3.-Locations of Commercial Communications Satellites in Geosynchronous Orbit as of June 25, 1984
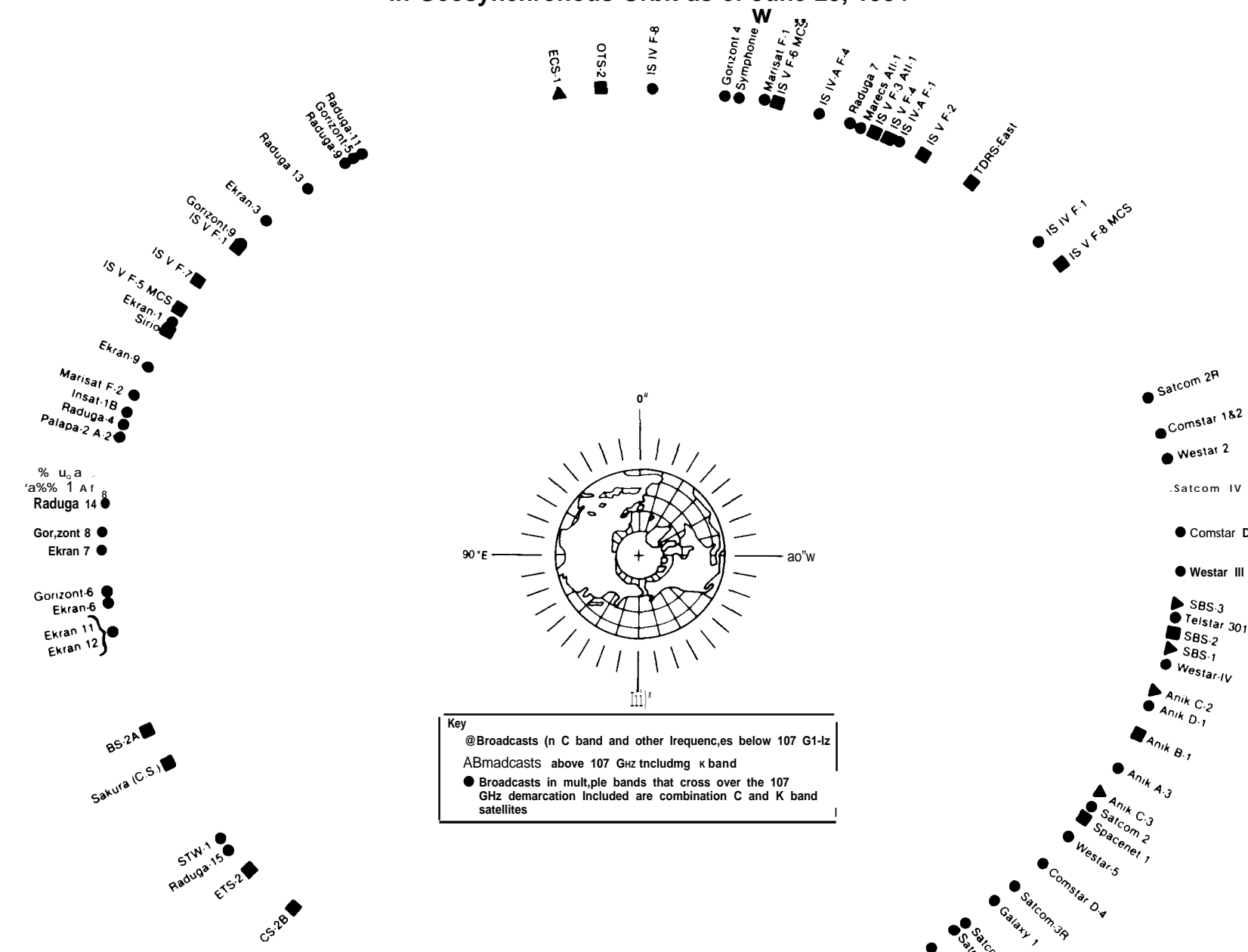

Broadcasts in mult,ple bands that cross over the 107 satellites
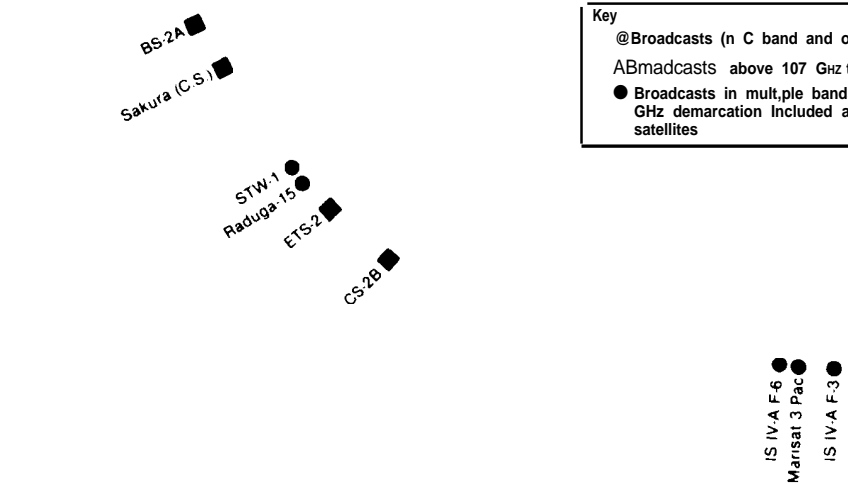

Satcom IV

- Comstar D III

- Westar III

ses.3

SBS.2

WEStar.1.

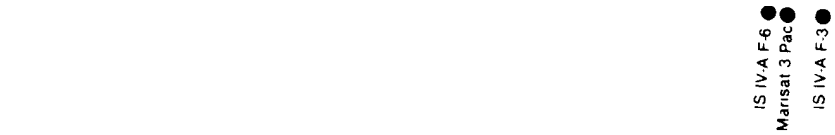

NOTE:

1. IS refers to INTELSAT satellites.

2. The following are USSR satellite series: CSDRN,Ekran,ESDRN,Gorizont, Loutch, Potok, Prognoz, Raduga, Statsionar, Volna, WSDRN.

SOURCE: COMSAT, Communications Satellite Corporation Magazine, Washington, DC., 1984. 
Figure 6B-4.-Locations of Commercial Communications Satellites in Geosynchronous Orbit Planned for as of June 25, 1984

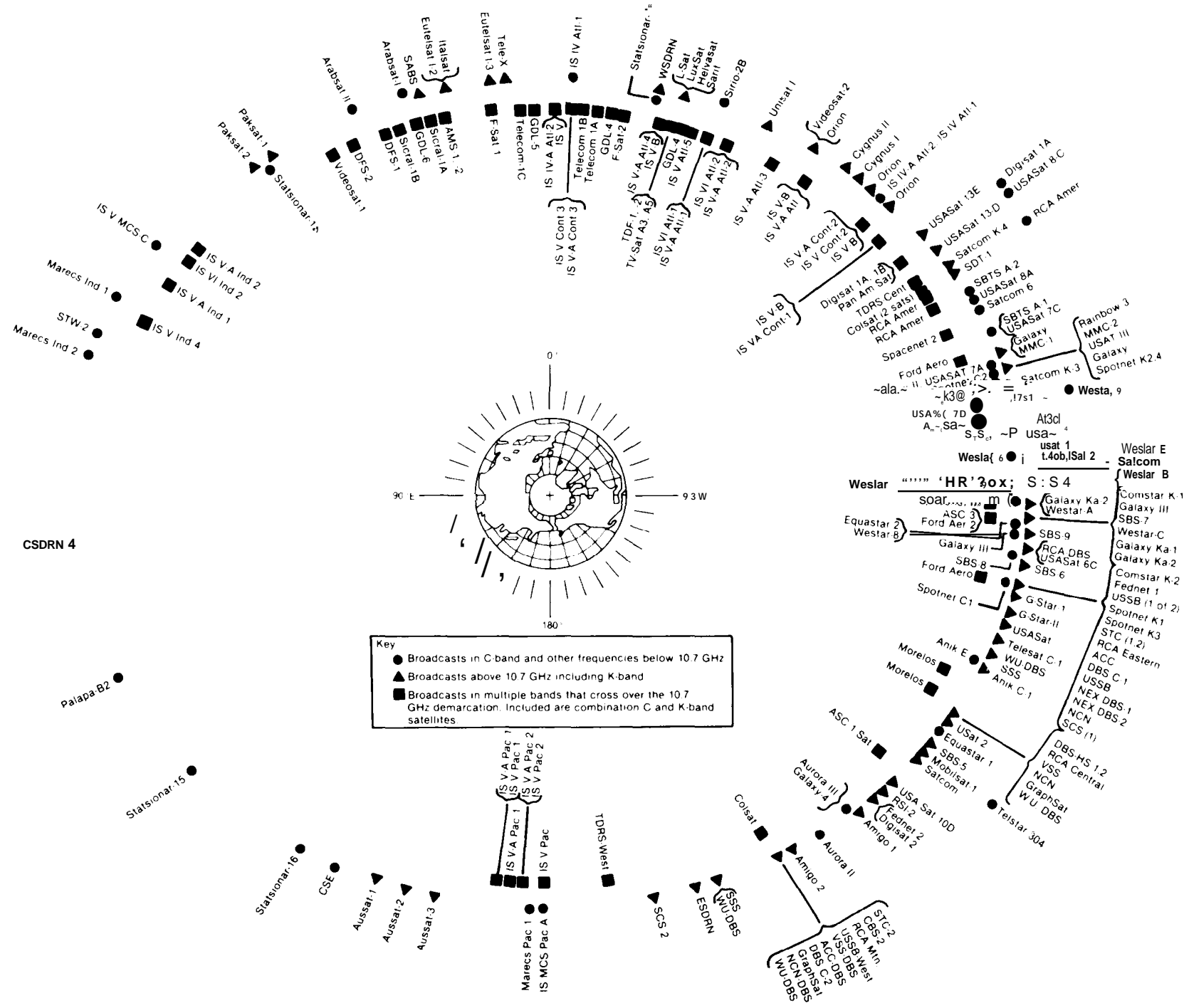

NOTE:

1. IS refers to INTELSAT satellites.

2. The following are USSR satellite serıes: CSDRN, Ekran, ESDRN, Gorizont, Loutch, Potok, Prognoz, Raduga, Statsionar, Volna, WSDRN

3. Multiple orbits are for legibility only. All geosynchronous satellites orbit at approximately 22,300 miles above the earth.

SOURCE: COMSAT, Communications Satellite Corporation Magazine, Washington, DC., 1984. 
to follow its current Telecom series, but there are likely to be follow-on launches. The planned German, French, and British DBS launches have been delayed. ${ }^{15}$

A 1983 market analysis ${ }^{16}$ also estimated that worldwide (excluding the Soviet Union), 107 commercial communications satellites, worth $\$ 5.9$ billion, might be launched between 1986 and 1989, as shown in figure 66-2. U.S. firms are likely prime contractors for at least three-quarters of these 1986-1989 launches (as shown previously in table 6-7). Also projected are 171 launches worth \$8.6 billion for the period 1990-2000. In another separate study for NASA, it is estimated that between 1983 and 1998, anywhere from 240 to 330 civilian communication satellites will be launched by the non-Communist world. ${ }^{17}$ Again, as mentioned previously, launch projections in the $1990 \mathrm{~s}$ are highly uncertain.

In the more predictable decade of the $1980 \mathrm{~s}$, it is observed when comparing figure 66-1 and figure 6B2 that investment in U.S. commercial communications satellites between 1986 and 1989 (\$3.19 billion) is projected nearly to double the investment (in constant 1983 dollars) during the previous cumulative 20 years (\$1 .63 billion). In addition, the U.S. share of this worldwide investment would actually increase from 34 percent in the $1965-85$ period to 54 percent in the 1986-89 period. The number of U.S. satellite transponders is expected to increase from 449 in December 1984 to as many as 883 by $1987 .^{18}$

After several years of relativel y tight capacity, there is now surplus capacity, known as "transponder glut" in the industry. ${ }^{19}$ This oversupply is likely to continue for the next 2 or 3 years at least because demand is expected to continue to lag supply as more satellites are launched in the near future. This may result in less launches actually taking place. According to a study by the FCC, carried out on a weekday afternoon in December 1983 , only 54 percent of capacity on U.S. communication satellites was in use. Of the 14 satellites studied, 143 of 312 transponders were idle..$^{20}$ INTELSAT also has stated that its overall "load factor"

\footnotetext{
"5" W Transmission Wave Tube] Problems Delay French, West German, DBS Programs," Safe//ire News, vol. 7, No. 43, Oct. 29, 1984, p. 5; "France Delays Launch of Direct Broadcast TDF-1Until 1986," Aviation Week and Space Technology, Jan. 28, 1985, p. 93; Chris Bulloch, "New Satellites at Telecom 83-Spacecraft Builders Chase a Growing Market, "Interavia, January 1984, p. 77 ,

16Filep, Schnapf, and Fordyce, op. cit.

'Outside Users payload Model, prepared by Battelle Columbus Laboratories for NASA, NASW-3381, June 1983.

${ }^{18}$ Shaw, op. cit., p. 54, Filep, Schnapf, and Fordyce, op. cit.

${ }^{9}$ The New york Times, Op. cit.

20lbid. See also "Quarterly Transponder Report of C-band and Ku-band Communication-Satellite Space Stations" by Charles C.Magin, Federal Communications Commission Field Operations Bureau, Sept. 28, 1984 and "FCC's Transponder Loading Report Continues to Show Wide Disparities in Usage," Satellite News, Washington, DC, vol. 7, No. 45, Nov. 12, 1984, p. 1.
}

has been only about 34 percent in recent years. ${ }^{21}$ industry executives assert that this situation is cyclical and expect the excess capacity to disappear as they claim that a drop in service prices will eventually result in a dramatic rise in demand. ${ }^{22}$ For several reasons, developing countries may also find it more feasible in the 1990s to rent INTELSAT or other satellite capacity than to install large complex terrestrial cable networks. ${ }^{23}$

The replacement market will continue to be a source of demand for satellites, even in the event of a slowdown in the demand for satellite communications, since satellite performance diminishes with age and satellites have typically been designed with lifetimes of 5 to 10 years $^{24}$ (see table 66-1, Design Life column). Table 66-2 lists estimated new and replacement commercial communications satellites scheduled for launch in the interval 1984 to the year 2000. The table demonstrates the significance of the replace-

\footnotetext{
21 Chris Bulloch, "INTELSATBuilds Its Defenses Against Competition, Interavia, October 1984.

${ }^{22}$ Some industry groups contend that by the end of the 1980s, the supply of transponders may not keep pace with demand. ITT forecasts 1,370 transponders will be needed in 1990 and 3,594 in 2000. Western Union independently arrived at the numbers 1,140 transponders required in 1990 and 2,779 by 2000 .

${ }^{23}$ Th is contrasts with the situation in developed countries which already have terrestrial networks of copper cable and microwave in place and also have many other available routes such as rail rights-of-way in which to lay fiber optic cable.

${ }_{24}$ mprovementsın solar cel 1, battery, stationkeeping, and microwave amplification technology have Increased satellitelifetimes from 1.5 to 10 years in several cases. (Pollack and Weiss, op. cit. )
}

\section{Table 6B-2.-Estimated New and Replacement Communications Satellites Scheduied for Launch During 1984-2000}

\begin{tabular}{|c|c|c|}
\hline Year & New & Replacement \\
\hline $1984 \ldots$ & 11 & 10 \\
\hline $1985 \ldots$ & 21 & 9 \\
\hline 1986 & 21 & 7 \\
\hline 1987. & .26 & 6 \\
\hline 1988 & .20 & 9 \\
\hline 1989 & 15 & 2 \\
\hline 1990 & . . 8 & 4 \\
\hline 1991 & . 10 & 17 \\
\hline 1992. & $\ldots 8$ & 13 \\
\hline 1993 & .16 & 6 \\
\hline 1994. & 10 & 10 \\
\hline 1995 & .15 & 9 \\
\hline 1996. & .13 & 4 \\
\hline $1997 \ldots$ & $\ldots 6$ & 11 \\
\hline 1998 . & $\ldots 8$ & 8 \\
\hline $1999 \ldots$ & $\ldots 3$ & 2 \\
\hline Total & .211 & 127 \\
\hline
\end{tabular}


ment market, which represents over one-third of total estimated launches during this period.

Satellite life and therefore replacement interval is, however, subject to substantial uncertainty, Current generation satellites typically have estimated lifetimes of about 7 years, but experience with satellites to date and recent advances have led to estimates of increased life for satellites. RCA American Communications, for instance, recently asked the FCC to approve design modifications on its Satcom VI satellite that would increase its design life from 10 to 12 years .25

\section{Satellite Suppliers}

\section{U.S. Firms}

U.S. firms have dominated the international satellite market, All U.S. communications satellites thus far have been U.S.-built, and few, if any, of those now planned are likely to be foreign-built. ${ }^{2 b}$ Table 6-7 previously listed the prime contractors for commercial satellites for the periods 1965-83 and 1984-89; U.S. dominance is evident, but foreign activity is increasing, The large U.S. market share in commercial satellite prime contracts was shown previously in table 6-6 with the United States capturing over 90 percent of the prime contracts from 1965 to 1983 . It should be noted that in the future (1 984 through 1989) prime contracts will increasingly reside with the purchaser. It was also seen in table 6-6 that U.S. firms have been the prime contractors on all INTELSAT satellites, though models IV, $\mathrm{V}$, and $\mathrm{VI}$ have had certain subsystems subcontracted to European and Japanese firms. For example, the INTELSAT VI contract, while going to Hughes Aircraft, involved subcontracts to non-U. S. firms totaling 21 percent of the contract value, as shown in table 6B-3.

The Indonesian, Australian, Indian, and Mexican national satellites have been or will be mostly or completely U.S.-built. Even where the U.S. firm is not the prime contractor, U.S. suppliers often play a key part-this is the case with the Brazilian, Arab League, and Japanese satellites.

Three U.S. firms dominate the civilian communication satellite market-Hughes Aircraft, Ford Aero-

25 The improvement hascomeprimarilyfrom the substitution of a new Upper stage, which will allow a larger amount of stationkeeping fuel (hydra zine) to be transported (Satellite News, Apr. 23, 1984, p. 1). Responsible adminıstratıons are moving their retired geosynchronous satellites intohigher orbits to avoid the possibility of an orbitcollision with an operating satellite. The orbital decay of these supergeosynchronous orbits is estimated at only 1 meter per year (Personal communication, Walter Morgan, Communicatıons Center, December 1984 )

${ }^{26}$ A possible exception cou Id be in the DES market, where $\mathbf{i} \mathbf{n}$ at least one case, a European consortium, Eurosatellite (led by Aerospatiale of France and MBB of West Germany) has teamed with General Electric of the United States to offer a satellite to that of one of the U.S. JBS firms. (See Chris Bul. loch, "Aerospatiale and MBB Found a New Satellite Dynasty," Interavia, May 1984, p. 465. )
Table 6B-3.-INTELSAT VI: Subcontracts Let by the Prime Contractor Hughes Aircraft

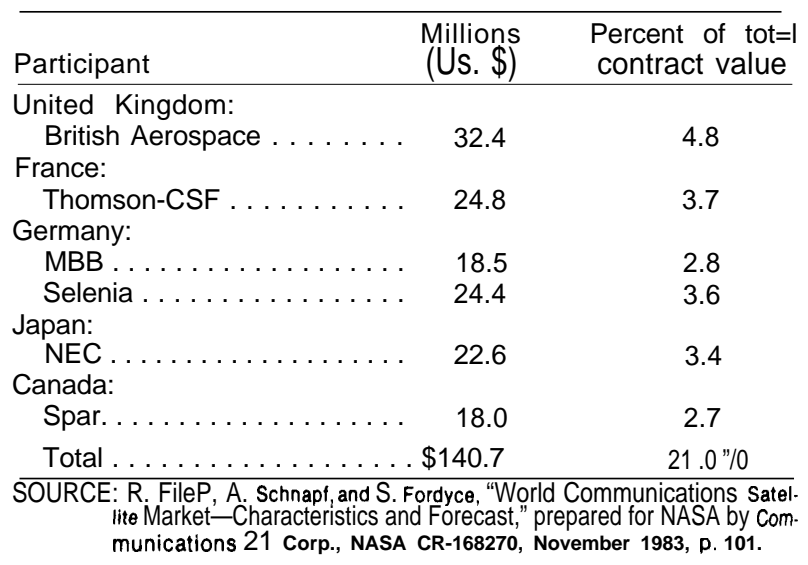

space, and RCA Astro-Electronics-as seen in table 67.27 $\mathrm{Th}_{\mathrm{e}}$ largest supplier is Hughes Aircrafi, Which ' $\mathrm{n}$ addition to providing satellites for several U.S. systems, has also sold satellites to Canada, Indonesia, Australia, and Mexico. Hughes won the INTELSAT contract to build at least the first five INTELSAT Vi-class satellites. That contract is worth $\$ 750$ million and could rise to $\$ 1.3$ billion. Estimated satellite sales (civilian and military) for 1983 were $\$ 1$ billion, up from $\$ 715$ million in 1982. The backlog of orders in 1983 was approximately $\$ 2$ billion, half of which was for civilian satellites. ${ }^{28}$ Approximately 8,000 Hughes employees work on space programs.

RCA Astro-Electronics estimated its satellite sales to be $\$ 240$ million in 1983, but this figure includes Government-purchased, noncom munications satellites. The firm projects annual sales of $\$ 400$ million by 1988 and has a current backlog of approximately $\$ 992$ million .29 RCA employs 800 people on space programs.

Ford Aerospace \& Communications has had contracts worth about $\$ 600$ million to build 15 INTELSAT $\mathrm{V}$ and $\mathrm{V}$-A satellites. The company's recent annual sales of civilian communications satellites has been in the range of $\$ 150$ million. Ford has joined its competitors, Hughes and RCA, in forming its own satellite communications service subsidiary to buy and operate some of its equipment. The Ford Aerospace Satellite Services Corp. has applied with the FCC to launch three large "Fordsat" satellites each with 24 C-band and 24 Ku-band transponders. ${ }^{30}$

\footnotetext{
2They are also large military satellite commu $\mathbf{n}$ ICatıons contractors. ${ }^{28}$ Chris Bulloch, "Communications Satellite Prospects: Competition Sharpens Between the 'Big Three' U .S Builders,' Interawa, vol. 38, October 1983, p. 1111-1113

29lbid.

${ }^{30} \mathrm{Bu}$ I loch, "New Satellites at Telecom '83," op. CIt
} 


\section{Foreign Firms}

The major foreign firms building communication satellites and subsystems were indicated in tables 6-7 and 6B-3. One possible competitor to the big three U.S. firms appears to be the Eurosatellite consortium, made up of Aerospatiale (France), Compagnie Generale d'Electricity (France), MBB/ERNO (West Germany), ANT-Nachtrichten (successor in the space flight field to West Germany's AEG), and ETCA (Belgium). This consortium is not only offering a DBS satellite to U.S. firms, but may attempt to sell a low-capacity C-band satellite to INTELSAT for "thin-route" use over the Indian and Pacific Oceans. Two satellite consortia, which include West European firms, have been active in bidding on the second-generation INMARSAT system-namely, British Aerospace Dynamics Group/ Hughes Aircraft Co,; and Marconi Space Systems Ltd./Ford Aerospace \& Communications Corp. /Aerospatiale. $^{31}$

The major communication satellite firms of Japan have been MELCO (Mitsubishi Electric Co.) andToshiba, With assistance from Ford Aerospace, MELCO built the current CS-2A and CS-2B satellites. With help from General Electric, Toshiba is building the BS-2A and BS-2B direct broadcast satellites. Although the CS$2 A$ is the world's first operational civilian communication satellite using the $\mathrm{Ka}$ band, it is a relatively small satellite with limited capacity: it is not likely to be offered for export. At some point in time, however, future generations of heavier Japanese satellites will probably be able to enter the export market.

\section{International Competitive Factors in the World Satellite Market}

In general, it seems likely that those countries or groups of countries that have invested substantial public resources in building industries capable of producing communication satellites will buy their satellites at home if they can, ${ }^{32}$ This has been the case previously as shown in table 6-6. In the general export market and in the U.S. domestic market (the world's largest), U.S. firms will probably continue to dominate, based on their performance to date, although there are no trade barriers to the import of civilian communications satellites.

Inroads into this U.S. dominance might occur if foreign governments continue their heavy subsidization of satellite communications research and develop-

\footnotetext{
I Space Business News, Apr. 23, 1984, p, 2; and Bulloch, "New Satellites at Telecom '83," op. cit.

32 This Commitment to their own prime contractors may nevertheless involve continued reliance on technical assistance or components from U.S. satellite manufacturers,
}

ment and neither the U.S. Government nor U.S. private firms develop technology desired by those who buy and operate satellites in the 1990s,

\section{Earth Station Equipment Suppliers}

The major equipment components which comprise Earth stations can be summarized by the following:

1. antenna and tracking system;

2. high power and low noise amplifiers;

3. ground communications equipment;

4. multiplex equipment (analog or digital); and

5. ancillary and support equipment (air-conditioning, power supplies, controls, etc, )33

Because U.S. Department of Commerce statistics do not permit easy identification of space-related telecommunications equipment, even the current size of this market is difficult to estimate. In 1981 it was estimated that between 1981 and 1985 the world market for Earth station equipment would total approximately $\$ 2.2$ billion (in 1984 dollars). ${ }^{34}$ The estimate for the period 1986-2000 was over $\$ 19$ billion (in 1984 dollars) as shown in table 6B-4 which disaggregates

\footnotetext{
"Eloise Jensen, Tracey Harbaugh, Kenneth Telesca, and lames Mahoney, "Sector Study-Satellite Earth Stat ions," The Export-Import Bank, Washing ton, DC, June 1984.

34. Task 11 Report Planning Assistance for the 30/20 GHz Program: Worldwide Satellite Market Demand Forecast, "Western Union, NASA Report No. 1-4-W-I -TH, June 19, 1981.
}

Table 6B-4.-Satellite Earth Station Market Forecast (millions of 1984 U.S. dollars)

\begin{tabular}{|c|c|c|}
\hline 1986.90 & $1991-2000$ & Total \\
\hline \multicolumn{3}{|l|}{ North America: } \\
\hline INTELSAT. . . & 46 & 57 \\
\hline Domestic . . . . . . . . . . . 1,414 & 5,696 & 7,110 \\
\hline \multicolumn{3}{|l|}{ South America: } \\
\hline INTELSAT ... & 469 & 592 \\
\hline Domestic . . . . . . . . . . . 14 & 121 & 135 \\
\hline \multicolumn{3}{|l|}{ Europe: } \\
\hline INTELSAT. & 276 & 354 \\
\hline Domestic & 2,511 & 3,192 \\
\hline \multicolumn{3}{|l|}{ Africa: } \\
\hline INTELSAT & 976 & 1,393 \\
\hline Domestic . & 36 & 40 \\
\hline \multicolumn{3}{|l|}{ Asia: } \\
\hline INTELSAT. & 690 & 874 \\
\hline Domestic . . . . . & 4,310 & 4,918 \\
\hline \multicolumn{3}{|l|}{ Oceania: } \\
\hline INTELSAT. . . & 129 & 164 \\
\hline Domestic . . . . . . . . . . . . 48 & 134 & 181 \\
\hline \multicolumn{3}{|l|}{ Totals: } \\
\hline INTELSAT . . . . & 2,586 & 3,433 \\
\hline Domestic . . . . . . . . . . . . 2,768 & 12,608 & 15,576 \\
\hline
\end{tabular}


by world region and INTELSAT versus domestic systems.

Several standards for Earth stations operating in conjunction with INTELSAT have been established with Standard A and Standard B being the most common. The features and differences of these INTELSAT station types are listed in table $6 \mathrm{~B}-5 .{ }^{35}$ Figure B- 5 shows how typical ground stations costs vary for hardware and technical expertise for differing sizes of antenna.

Unlike the satellite manufacturing industry, which is dominated by three U.S. firms, the ground station industry has many firms in the United States and several prominent foreign firms as well. The Earth station market is large and growing, there are many suppliers in the international arena, and competition among them is intense. Price, rather than any specific technological advantage, is often the deciding factor in contract awards. The principal worldwide suppliers of satellite Earth stations and the station types they specialize in are listed in table $6 \mathrm{~B}-6{ }^{36}$

Company profiles of some of the major satellite Earth station suppliers are given in table 6B-7. No one U.S. company produces all of the subsystems required for a significantly sized ground station; hence, numerous individual vendors may in fact be involved in a typical station project. Often the prime contractor will be a company with extensive background in microwave or antenna technology or $\mathrm{i} n$ the actual communications technology ${ }^{37}$ For examnple, TIW specializes

\footnotetext{
$\sim \sim \mathrm{e}$ a 50 lensen, et al, Op (It; a nd Corn mitteePrint $-U$ nited States Ci i ilianSpace Programs, vol I Applications Satellites Subcommittee on Space Science and Applications of the Committee on Science and Technology, U S. House' of Representatic es, May 1981, p. 35

$\mathrm{N}$, Note that, 'small" station, $\mathrm{n}$ this table refers to a Standard $Z$ station which carries a 5- to 11 -meter antenna The smallcom mere ial and "backyard' staIIoni in the 1-to 2-metersize range) cou ld thus be considered a very small, $\mathbf{m}$ ın 1 , or $\mathbf{m}$ icrostation The $\mathbf{n} \mathbf{u} \mathbf{m}$ ber ot su ppl ıers of these $\downarrow$ ery small stations issubstantial and increasing ra pidly and are thus not specifical ly I istedin the table

Thensen et a I, op c It
}

Table 6B-6.-Major Worldwide Suppliers of Satellite Earth Stations

\begin{tabular}{|c|c|c|}
\hline & \multicolumn{2}{|c|}{ Station type ${ }^{a}$} \\
\hline & Medium & Large \\
\hline \multicolumn{3}{|l|}{ United States: } \\
\hline $\begin{array}{l}\text { GTE International System Corp. . . . . X } \\
\text { ITT }\end{array}$ & $\mathbf{x}$ & $\mathbf{x}$ \\
\hline 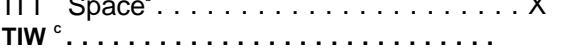 & $\hat{x}$ & $\begin{array}{l}x \\
x\end{array}$ \\
\hline Harris Corp. $\ldots \ldots \ldots{ }$ & $\hat{x}$ & $\hat{x}$ \\
\hline Scientific Atlanta. . . . . & $\mathbf{x}$ & $\mathbf{x}$ \\
\hline \multirow{3}{*}{\multicolumn{3}{|c|}{$\begin{array}{l}\mathrm{GE}{ }^{\mathrm{d}} \ldots \ldots \ldots \ldots \ldots \ldots \ldots \ldots \ldots \ldots \ldots \\
\text { M/A Communications Corp. } \ldots \ldots \ldots \ldots \ldots \ldots \ldots\end{array}$}} \\
\hline & & \\
\hline & & \\
\hline \multicolumn{3}{|l|}{ Satellite Transmission System, Inc. . X } \\
\hline Aydin $\ldots \ldots \ldots \ldots \ldots \ldots \ldots$ & $\mathbf{x}$ & \\
\hline \multicolumn{3}{|l|}{ Microdyne Corp. . . . . . . . . . X } \\
\hline \multicolumn{3}{|l|}{ Amplica $\ldots \ldots \ldots \ldots \ldots \ldots \ldots$} \\
\hline \multicolumn{3}{|l|}{ Satellite America $\ldots \ldots \ldots \ldots \ldots \ldots$ X } \\
\hline \multicolumn{3}{|l|}{ NETCOM-TES $\ldots \ldots \ldots \ldots \ldots \ldots \ldots$} \\
\hline \multicolumn{3}{|l|}{ Japan: } \\
\hline NEC (Nippon Electric Co.) . . . . . . . . X & $\mathbf{x}$ & $\mathbf{x}$ \\
\hline Mitsubishi $\ldots \ldots \ldots \ldots \ldots \ldots \ldots$ X & $\mathbf{x}$ & $\mathbf{x}$ \\
\hline \multicolumn{3}{|l|}{ France: } \\
\hline Alcatel Thon & $\mathbf{x}$ & $\mathbf{x}$ \\
\hline Thomson-CSF. . . . . . . . . . . . X & $\mathbf{x}$ & $\mathbf{x}$ \\
\hline \multicolumn{3}{|l|}{ United Kingdom: } \\
\hline Marconi & $\mathbf{x}$ & $\mathbf{x}$ \\
\hline \multicolumn{3}{|l|}{ West Germany: } \\
\hline Siemens & $\mathbf{x}$ & $\mathbf{x}$ \\
\hline ANT Telecommunications & $\mathbf{x}$ & $\mathbf{x}$ \\
\hline$\ldots \ldots \ldots x$ & $\mathbf{x}$ & $\mathbf{x}$ \\
\hline \multicolumn{3}{|l|}{ Italy: } \\
\hline STS $\ldots \ldots \ldots \ldots \ldots \ldots \ldots$ & $\mathbf{x}$ & $\mathbf{x}$ \\
\hline \multicolumn{3}{|c|}{$\begin{array}{l}\text { aTh, small, medium, and large station types are roughly similar to INTELSAT } \\
\text { standard type } Z \text {, B, and A size stations respectively. } \\
\mathrm{b}_{\text {ITT, an early competitor in the large Earth station market, is now withdrawing }} \\
\text { from this market } \\
\text { CTIW, previously a major supplier of Earth station antennas, is now penetrating } \\
\text { the main contractor market. } \\
\text { dGE supplies LANDSAT type earth stations only }\end{array}$} \\
\hline \multicolumn{3}{|c|}{$\begin{array}{l}\text { SOURCES: E. Jensen, et al , "Sector Study-Satellite Earth Stations," The Export. } \\
\text { Import Bank, Washington, DC, June 1984; and Chris Bulloch and Paul } \\
\text { W. Rubin, "Satellite Telecommunications-The Ground Segment } \\
\text { Grows," Interavia, November 1984, pp. 1231-1235 }\end{array}$} \\
\hline
\end{tabular}

Table 6B-5.-INTELSAT Earth Station Standards

\begin{tabular}{|c|c|c|c|}
\hline $\begin{array}{l}\text { Earth station } \\
\text { standard }\end{array}$ & $\begin{array}{l}\text { Antenna size } \\
\text { in meters }\end{array}$ & Types of service & $\begin{array}{c}\text { Frequency band }(\mathrm{G} \mathrm{Hz}) \\
\text { uplink/downlink }\end{array}$ \\
\hline & $26-32.5$ & International voice, data, TV, IBS & $6 / 4$ \\
\hline B & $10-13$ & International voice, data, TV, IBS & $6 / 4$ \\
\hline c & $17.4-38$ & International voice, data, TV, IBS & $14 / 11$ \\
\hline Dl" : : : : : : : : : & $: 5$ & VISTA (International or Domestic) & $6 / 4$ \\
\hline $\mathrm{D} 2 \ldots \ldots$ &. .11 & VISTA (International or Domestic) & $6 / 4$ \\
\hline $\begin{array}{l}\mathrm{El} \\
\mathrm{E} 2\end{array}$ & $\begin{array}{l}3.5-4.5 \\
5.5\end{array}$ & $\begin{array}{l}\text { IBS ( } \mathrm{K} \text { band) } \\
\text { IBS ( } \mathrm{K} \text { band) }\end{array}$ & $\begin{array}{l}14 / 11 \& \text { \&. } 14 / 12 \\
14 / 11 \& 14 / 12\end{array}$ \\
\hline E3 $\ldots \ldots \ldots$ & $. .8-10$ & IBS ( $\mathrm{K}$ band) & $14 / 11 \& 14 / 12$ \\
\hline F1 & $4.5-5$ & IBS ( $\mathrm{C}$ band) & 614 \\
\hline $\mathrm{F} 2 . \ldots \ldots \ldots$ & $7.5-8$ & IBS (C band) & $6 / 4$ \\
\hline$\ldots$. & $.9-10$ & IBS ( $\mathrm{C}$ band $)$ & $6 / 4$ \\
\hline G & $0.8-1$ & INTELNET, international TV, etc. & $6 / 4 \&$ \\
\hline & $4.5-18.3$ & Domestic voice, TV, data & $6 / 4 \& 14 / 11$ \\
\hline
\end{tabular}


Figure 6B-5. - Typical Ground Station Costs o D e ng An enna S zes
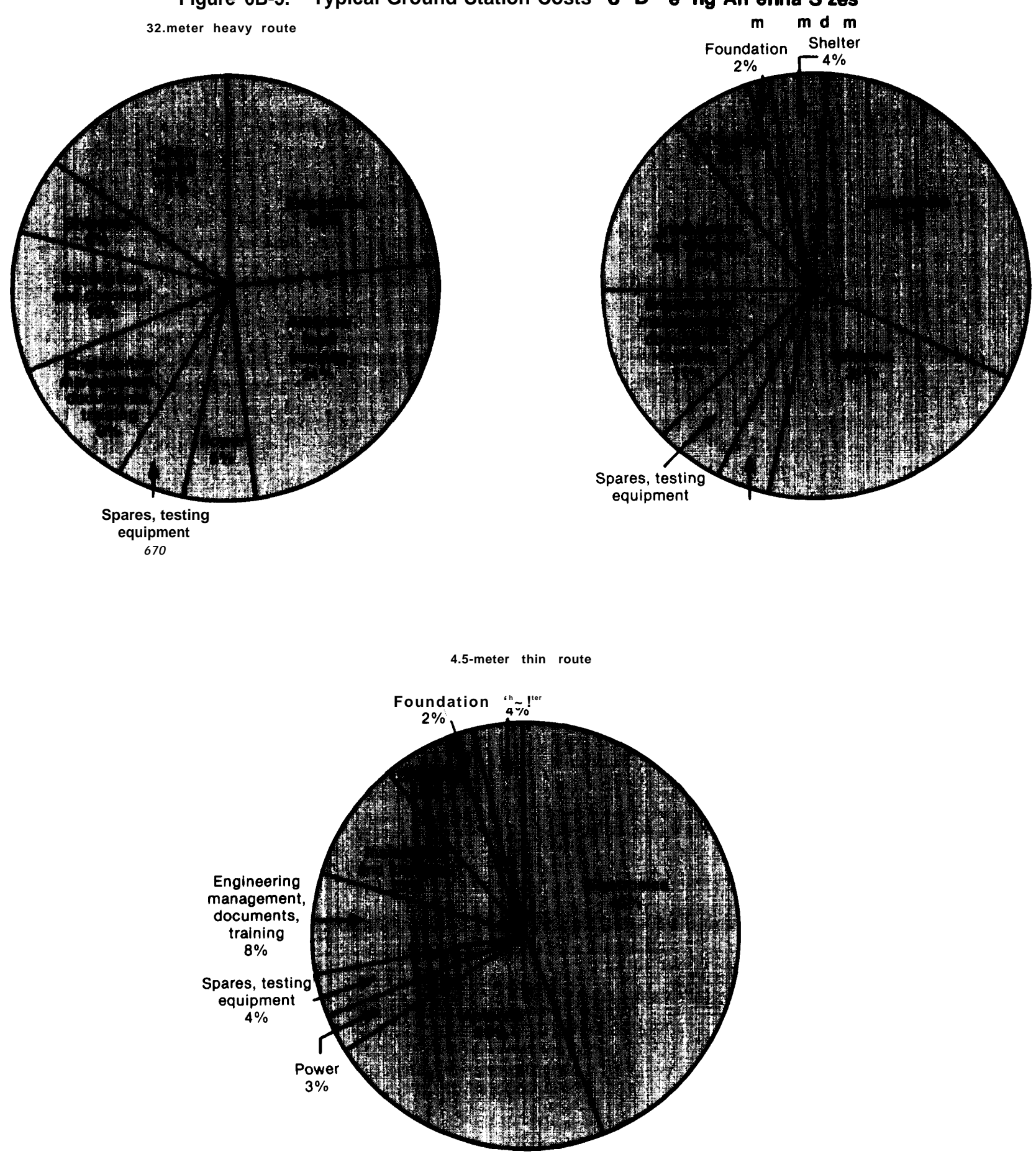

SOURCE: Ford Aerospace and Communications, 1981.

in microwave and radar antenna systems, whereas GTE specializes in communications technology. Earth station technology was pioneered by several U.S. firms. The maturing of the technology, however, has marked the emergence of non-U.S. S. competitors who have successfully penetrated the market.

Early dominance by U.S. suppliers of large Earth stations has shifted to dominance by Japanese suppliers. 
Table 6B-7.-Major Satellite Earth Station Suppliers-Company Profiles

\begin{tabular}{|c|c|c|c|c|c|}
\hline Company, country & Origin & Ownership & Major business (products) & Performance & Comments \\
\hline $\begin{array}{l}\text { 1, General Telephone \& } \\
\text { Electromcs Corp., } \\
\text { U.S.A. (GTE) }\end{array}$ & $\begin{array}{l}\text { Created as partnership in } \\
\text { 1918. Incorporated in } 1920 \text { as } \\
\text { Associated Telephone Utihties. } \\
\text { (Reorganized in } 1936 \text { as Gen- } \\
\text { eral Telephone Corp. ) }\end{array}$ & Private & $\begin{array}{l}\text { GTE is the parent company of more than } 60 \text { communications, } \\
\text { products, research, and serwce subsidiaries operating in } 39 \\
\text { States } \& 19 \text { foreign countries. Provides many types of com- } \\
\text { munications services \& the GTE products group produce prod- } \\
\text { ucts ranging from complete communications systems \& } \\
\text { telephone instruments to TV sets \& lighting products. }\end{array}$ & $\begin{array}{l}1982 \\
\text { Revenue \& sales, } 12,066 \mathrm{M} \$ \\
\text { Communications products, 1,614 M \$ } \\
\text { Net income, } 550 \mathrm{M} \$\end{array}$ & $\begin{array}{l}\text { Well-positioned in ground station } \\
\text { market as they are one of the few } \\
\text { full-line telecommunications com- } \\
\text { panies, }\end{array}$ \\
\hline 2. Harris, U.S.A. & Incorporated in 1926 & Private & $\begin{array}{l}\text { Information systems, communications equipment including two- } \\
\text { way radios, microwave \& lightwave transmission equipment, } \\
\text { Earth stations \& antennas for satellite communication, auxiliary } \\
\text { telephone products, \& turn-key telecommunications networks. }\end{array}$ & $\begin{array}{l}1983 \\
\text { Total sales, } 1,424 \mathrm{M} \$ \\
\text { Information systems, } 319 \mathrm{M} \$ \\
\text { Communications products, } 425 \mathrm{M} \mathrm{\$} \\
\text { Net income, } 27 \mathrm{M} \mathrm{\$}\end{array}$ & $\begin{array}{l}\text { Satellite-related revenues in } 1983 \\
\text { were about } \$ 350 \mathrm{M} \text {. It has a wide } \\
\text { breadth of products } \mathrm{m} \text { Its Earth sta- } \\
\text { tion line. }\end{array}$ \\
\hline 3. ITT, U.S.A. & & Private & $\begin{array}{l}\text { Diversified, principally in telecommunications-transmission } \\
\text { switching \& subscriber systems. Has } 45 \text { major R\&D \& } \\
\text { engineering centers in } 24 \text { countries. In } 1982 \text { ITT operated } \\
\text { plants \& performed business in about } 100 \text { countries. }\end{array}$ & $\begin{array}{l}1982 \\
\text { Total sales, } 15,958 \mathrm{M} \$ \\
\text { Telecommunications sales, } 6,375 \mathrm{M} \$ \\
\text { Net income, } 703 \mathrm{M} \$\end{array}$ & $\begin{array}{l}\text { Also involved in insurance/financial } \\
\text { services and natural resources. }\end{array}$ \\
\hline $\begin{array}{l}\text { 4. Scientific Atlanta, } \\
\text { U.S.A. }\end{array}$ & Organized in 1951. & Prwate & $\begin{array}{l}\text { Designs, manufactures, \& markets commercial electroruc } \\
\text { signal-generating and receiving equipment. Sales made directly } \\
\text { to foreign purchasers constituted from } 13 \text { to } 17 \% \text { of the com- } \\
\text { pany's total sales in recent years. }\end{array}$ & $\begin{array}{l}1983 \\
\text { Total sales, } 327 \mathrm{M} \$ \\
\text { Communications products, } 205 \mathrm{M} \mathrm{\$} \\
\text { Net income, } 0.37 \mathrm{M} \$\end{array}$ & $\begin{array}{l}\text { The formation of a European } \\
\text { marketing joint venture with } \\
\text { PLESSY should have given } \\
\text { Scientific-Atlanta better access to } \\
\text { the U.K. \& Common Market com- } \\
\text { munications markets-however, it } \\
\text { was ended in Nov. } 1984 .\end{array}$ \\
\hline 5 TIW, U .5A. & $\begin{array}{l}\text { Until July 1983, TIW Systems } \\
\text { Inc. was a wholly owned sub- } \\
\text { sidiary of TIW Systems Ltd. In } \\
\text { July 1983, Visionics Corp. ac- } \\
\text { quired the shares of TIW Sys- } \\
\text { tems Ltd. and effected a } \\
\text { reorganization resulting in two } \\
\text { subsidiaries wholly owned by } \\
\text { Visiomcs Corp. }\end{array}$ & Private & Design, fabrication, \& installation of large-diameter antennas & $\begin{array}{l}1983 \\
\text { Contract revenue, 9.8 M \$ } \\
\text { Net income, O } 38 \mathrm{M} \mathrm{\$}\end{array}$ & $\begin{array}{l}\text { A world leader in design and con- } \\
\text { struction of large steerable antenna } \\
\text { systems. TIW is now attempting to } \\
\text { penetrate the prime contractor mar- } \\
\text { ket for Earth stations }\end{array}$ \\
\hline
\end{tabular}


Table 6B-7.-Major Satellite Earth Station Suppliers-Company Profiles-Continued

\begin{tabular}{|c|c|c|c|c|c|}
\hline Company, country & Origin & Ownership & Maior business (Products) & Perf̣ņ̧̧̧2nro & Comments \\
\hline 6. NEC, Japan & $\begin{array}{l}\text { Began as a partnership in } \\
\text { 1848. Incorporated in Japan m } \\
1899\end{array}$ & Private & $\begin{array}{l}\text { Leading Japanese maker of telecommunications, electronic, \& } \\
\text { related equipment. In } 1982 \text { Government-owned NTT \& Govern- } \\
\text { ment agencies accounted tor } 18 \% 0 \text { of sales; Commercial } 49 \% \text {, } \\
\text { and overseas } 33 \% \text {. Company has } 42 \text { major plants in Japan \& } \\
18 \text { overseas plants, R\&D labs are located near Tokyo. }\end{array}$ & $\begin{array}{l}1982 \\
\text { Total sales, } 4,872 \mathrm{M} \$ \\
\text { Telecommunications sales, } 1,461 \mathrm{M} \$ \\
\text { Employees, } 69,000 \\
\text { Sales/employee, } \$ 70,546\end{array}$ & $\begin{array}{l}\text { Sales distribution by product line } \\
1982 \text { Elec. Computers \& Industrial Elec. } \\
\text { Equipment }(23 \%) \text {, Communications } \\
\text { equipment }(37 \text { 'Yo), Electron Devices } \\
(24 \%) \text {, Home Electronics }(12 \%) \text {, } \\
\text { Other }(4 \%) .\end{array}$ \\
\hline 7. Mitsubishi, Japan & $\begin{array}{l}\text { Founded in } 1870 \text { as a small } \\
\text { shippmg company. Later incor- } \\
\text { porated }\end{array}$ & Private & $\begin{array}{l}\text { Diversified, Fuels, metals, machinery, foods, chemicals, \& tex- } \\
\text { tiles. Its communications products exist in its machineries } \\
\text { group. Has a worldwide network of offices \& offers a variety of } \\
\text { products \& services. }\end{array}$ & $\begin{array}{l}1983 \\
\text { Total sales, } 65,346 \mathrm{M} \$ \\
\text { Net Income, } 109 \mathrm{M} \$ \\
\text { Machinery, } 13,893 \mathrm{M} \$ \\
\text { EXpOrtS, } 12,062 \mathrm{M} \$\end{array}$ & $\begin{array}{l}\text { Many of the company's overseas } \\
\text { projects are undertaken in partner- } \\
\text { ship with local interests }\end{array}$ \\
\hline $\begin{array}{l}8 \text { Siemens, A, G., } \\
\text { West Germany }\end{array}$ & $\begin{array}{l}\text { Founded In } 1847 \text { by Werner } \\
\text { Siemens. Reorganized as a } \\
\text { stock corporation in } 1897 .\end{array}$ & Private & $\begin{array}{l}\text { Diversified telecommunications: Data Systems, Electromc Com- } \\
\text { ponents, Safety \& Securty Systems, Electrical Installations. } \\
\text { Sales outside of Germany accounted for } 55 \% \text { of total sales in } \\
\text { 1982. Almost one-half of its international business is } \mathrm{m} \\
\text { Western Europe, }\end{array}$ & $\begin{array}{l}1982 \\
\text { Total sales, } 16,527 \mathrm{M} \$ \\
\text { Telecommunications sales, } 4,627 \mathrm{M} \$ \\
\text { Export sales, (all categories), } \\
4,938 \mathrm{M} \$ \\
\text { Net income, } 272.6 \mathrm{M} \$ \\
\text { Employees, } 324,000 \\
\text { Sales/employee, } \$ 51,009\end{array}$ & $\begin{array}{l}\text { Sir?mens \& ItS subsidiaries are the } \\
\text { largest electrical company in West } \\
\text { Germany }\end{array}$ \\
\hline $\begin{array}{l}\text { 9. The Thomson Group, } \\
\text { France (Thomson-CSF } \\
\text { and Thomson-Brandt) }\end{array}$ & $\begin{array}{l}\text { Group founded } m 1893 \text { as } \\
\text { Compagnie Francaise } \\
\text { Thomson-Houston, Thomson- } \\
\text { Brandt \& CSF merged in } \\
\text { 1968. Nationalized in early } \\
\text { 1982. }\end{array}$ & $\begin{array}{l}\text { French } \\
\text { Govern- } \\
\text { ment }\end{array}$ & $\begin{array}{l}\text { CSF-Dwerslfied Telecommumcatlons products: transmitters, } \\
\text { receivers, microwave, fiber optics, etc. Brandt-wire \& cables, } \\
\text { CSF is active in over } 100 \text { countries with manufacturing and/or } \\
\text { commercial subsidiaries \& representatwe offices. Thomson } \\
\text { Corp. of America \& seven other major subsidiaries are located } \\
\mathrm{m} \text { the U.S. }\end{array}$ & $\begin{array}{l}\text { CSF 1981 } \\
\text { Total sales, } 4,363 \mathrm{M} \$ \\
\text { Telecommunications sales, } 2,574 \mathrm{M} \$ \\
\text { Net income, } 12 \mathrm{M} \$ \\
\text { Employees, } 82,500 \\
\text { Sales/employee, } \$ 52,885\end{array}$ & $\begin{array}{l}\text { Thomson-CSF is a world leader in } \\
\text { electronic systems \& equipment. IS } \\
\text { a major subcontractor to Hughes } \\
\text { aircraft for supplying electronics } \\
\text { equipment for five INTELSAT VI } \\
\text { satellites. TELSPACE, CSF'S joint } \\
\text { venture with the CGE group, has } \\
\text { many larae Earth station contracts }\end{array}$ \\
\hline
\end{tabular}


For example, NEC of Japan is the single largest source of large (Standard A) INTELSAT Earth stations. Figure 6B-6 illustrates relative market shares of suppliers of INTELSAT Standard A and Standard B stations. Japanese companies supplied 41.4 percent of the A stations while U.S. companies supplied 29.0 percent. U.S. companies performed better with B stations, having a 46.7 percent share of the INTELSAT B stations while Japanese companies captured 37.1 percent. When considering all types of full-scale, nonmilitary Earth stations in the non-Communist world, NEC alone has 1,018 of the approximately 3,000 stations, or about a 34-percent share of the world market, as shown in table 6B-8.

Japanese Earth station suppliers are successful in a broad spectrum of enterprises. Satellite Business Systems (SBS) ordered Time Division Multiple Access (TDMA) modems from Fujitsu, Ltd., for its Earth stations. Japanese manufacturers have sold $130 \mathrm{RF}$ terminals to SBS. ${ }^{38}$ Satellite Television Corp., a subsidiary of COMSAT, selected Alcoa-NEC Communications Corp. and Toshiba Corp. as suppliers of home receivers for its planned direct broadcast service .39 Thus, de-

\footnotetext{
${ }^{38}$ Chris Bulloch andPaulW.Ru bin, "Satel I ite Telecommunications-The Ground Segment Grows, "Interavia, November 1984, pp. 1231-1235.

"q" FCC Evaluating 15 Proposals for Satellite TV Broadcasting, "Aviation Week and Space Technology, Mar. 12, 1984, p. 116. “
}

\section{Figure 6B-6. -INTELSAT Satellite Earth Station Suppliers ${ }^{a}$}

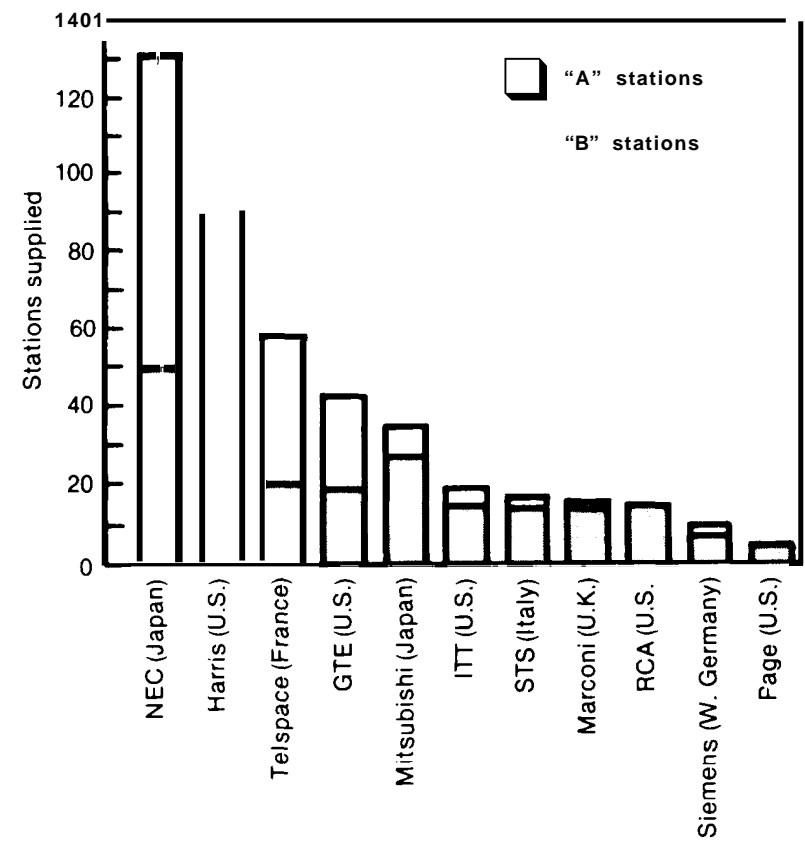

aAs of June 1982. From "Sector Studv-Satellite Earth Stations." bv E. Jensen. et al., The Export-Import Bank, Washington, DC, June 1984 and private communications with INTELSAT, Washington, DC, November 1984.

\section{Table B-8.-NEC Satellite Earth Station Orders as of June 1984}

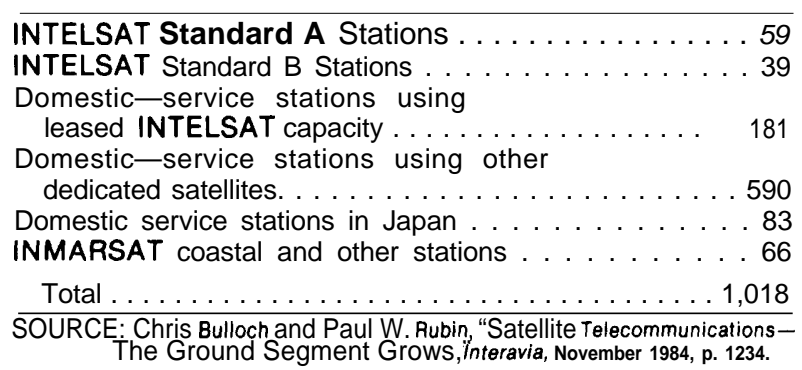

spite Japan's limited experience i $\mathrm{n}$ manufacturing sophisticated communications satellites, its ground equipment firms compete very well in international markets .40 Market trends indicate an increasing demand for smaller Earth stations and a smaller market for the larger Earth stations. As the demand for small, direct-broadcast receivers and antennas grows, Japanese firms may increase their penetration of the U.S. market. Whether Japanese companies will achieve in this sector of consumer electronics what it did with television sets and video recorders remains to be seen ${ }^{41}{ }_{1}$

Developing countries are increasingly important markets for Earth station suppliers, since country authorities are placing a high priority on building and modernizing communications systems. However, in certain countries, as the number of sales within a country increases and the country develops technologically, ground station suppliers will be required to use an increasing percentage of local content. ${ }^{42}$

\footnotetext{
${ }^{40}$ Bulloch, "Satellite Telecommunications-The Ground Segment Grows, ' op. cit.

${ }^{4}$ 'Sales of u s. ground station equipment in Japan, however, has so far been minimal. Telecommunications policy in Japan is now undergoing changes that may permit private companies to supply telecommunications services and own telecommunications facilities which theoretically could make possible the sale of U.S. communications satellites and ground statıon equipment inJapan in the future. See for example: "New Trade Policy May Boost Japanese Imports of Satellites, "Aviation Week and Space Technology, May 1984. "Hughes to Announce Extensive Joint Venture for Japanese DOMSAT System," Satellite News, Washington, DC, vol. 7, No. 37, Sept 17, 1984 p. 1; "Hughes to Study Japanese Telecommunications," Aviation Week and Space Technology, Sept. 24, 1984, p. 25; "Japan'sltoh Plans Hughes Satcom Buy," Aviation Week and Space Technology, Oct. 22, 1984, p. 30; "RCA Astro to Announce Japanese Satellite Venture With Sony; Ford Works With Mitsubishi," Sate//he News, Washington, DC, vol. 7, No. 49, Dec. 10, 1984, lohn Burgess, "Japan's Phone Shake-Up May Profit U.S. Firms," The Wash ington Post, Nov. 18, 1984, p F 1; Susan Chira, "Nippon Telegraph Sale to Public is Backed, "The New York Times, Dec. 14, 1984, p. D1

${ }^{42}$ Jensen, et al,op.cit and personal com mu $\mathbf{n}$ ications with Ha rris Corp. and Scientific Atlanta, December 1984 These requirements for technology transfer are becoming increasingly prevalent.
} 


\section{APPENDIX 6C.-INTELSAT AND INMARSAT MEMBERS: SIGNATORIES AND INVESTMENT SHARES}

\begin{tabular}{|c|c|c|}
\hline Country & Signatory & $\begin{array}{c}\text { Investment } \\
\text { share* }^{*} \\
\text { percent }\end{array}$ \\
\hline \multicolumn{3}{|l|}{ INTELSAT } \\
\hline United States & 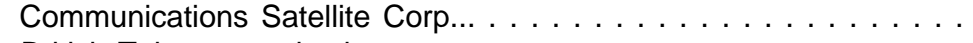 & 23.09 \\
\hline United Kingdom ., , . . . . . . & British Telecommunications & 12.93 \\
\hline France . & Governmentof France & 5.65 \\
\hline Japan ... & Kokusai Denshin Denwa Co. Ltd. & 3.33 \\
\hline \multicolumn{3}{|l|}{ Germany, Federal } \\
\hline Republic of & Ministry for Post and Telecommunication. & 3.30 \\
\hline Australia ., & Overseas Telecommunications Commission & 3.24 \\
\hline Saudi Arabia & Government ofSaudi Arabia . & 3.14 \\
\hline Brazil . . . . . . . . . . . & Empri\%a Brasileira de Telecomunica@es S.A. . & 3.04 \\
\hline Canada . & Teleglobe Canada $\ldots \ldots \ldots \ldots \ldots \ldots \ldots \ldots \ldots \ldots \ldots$ & 2.98 \\
\hline$\ldots$ & Societ3 Telespazio. . & 2.15 \\
\hline$\ldots \ldots$ & Compall Telef6nica Nacional de Espafia . . . . . . . . . . . . . & 2.00 \\
\hline Mexico . & Government of Mexico & 1.82 \\
\hline United Arab Emirates . . . . & Ministry of Communications & 1.74 \\
\hline Venezuela & Compah Anofiima Nacional TelFfonos de Venezuela & 1.42 \\
\hline$\ldots \ldots \ldots$ & Nigerian Extemal Telecommunications Ltd. . . . . . . . . . & 1.33 \\
\hline$\ldots \ldots \ldots$ & Telecommunication Authority of Singapore $\ldots \ldots \ldots \ldots \ldots$ & 1.30 \\
\hline \multirow[t]{2}{*}{ Switzerland } & Direction G<n ralede l'Entreprisedes Postes, TEl@phoneset & \\
\hline & T I\&graphes Suisses . . . . & 1.25 \\
\hline South Africa & Department of Posts and Telecommunications. . & 1.17 \\
\hline Argentina . & Empresa Nacional de Telecomunicaciones & 1.15 \\
\hline Netherlands & Government of the Kingdom of the Netherlands & 1.06 \\
\hline India & Ministry of Communications & 1.03 \\
\hline Iran, Islamic Republic of. & Telecommunication Co. oflran & 1.02 \\
\hline Kuwait . . . . . . . . & The Ministry of Communications . & 1.01 \\
\hline Colombia & Empresa Nacional de Telecomunicaciones & 1.00 \\
\hline$\ldots \ldots$ & Hellenic Telecommunications Organization S.A. . . . . . . . & 0.84 \\
\hline Korea, Republic of . . . . . . . & Korea Telecommunication Authority & 0.72 \\
\hline Belgium $\ldots, \ldots \ldots \ldots$ & $\mathrm{R} \sim$ giedes $\mathrm{T} 61 \sim$ graphes et des $\mathrm{T} 61<$ phones $\ldots \ldots \ldots \ldots \ldots$ & 0.72 \\
\hline Philippines . . . . . . . . . & Philippine Communications Satellite Corp. . . . . . . . . . . . . . . . & 0.65 \\
\hline Sweden & Swedish Telecommunications Administration & 0.64 \\
\hline Portugal & Companhia Portuguese RSdio Marconi & 0.63 \\
\hline$\ldots \ldots \ldots$ & Government of the Arab Republic of Egypt. & 0.62 \\
\hline Peru . & Empresa Nacionai de Telecomunicaciones del Peru. & 0.06 \\
\hline$\ldots \ldots \ldots$ & Empresa Nacional de Telecomunicaciones S.A. . . . . . . . . . . & 0.58 \\
\hline Israel . & Government of the State oflsrael $\ldots \ldots \ldots \ldots \ldots \ldots \ldots \ldots$ & 0.56 \\
\hline$\ldots \ldots \ldots$ & Sultanate of Oman . & 0.51 \\
\hline Thailand. & Government of Thailand & 0.49 \\
\hline Indonesia & Government of the Republic oflndonesia & 0.48 \\
\hline Denmark . & Generaldirektoratet for Post-og Telegrafvaesenet . . . . . . . . . . & 0.42 \\
\hline New Zealand.. . & Postmaster-General of New Zealand & 0.40 \\
\hline Jamaica & Jamaica International Telecommunications Ltd. & 0.04 \\
\hline & Government of the Republic oflraq & 0.04 \\
\hline
\end{tabular}


Country

Republic of. . . . . . . . .

Norway . . . . . . . . . . .

Algeria . . . . . . . . . . .

Kenya ..............

Pakistan . . . . . . . . . .

Qatar . . . . . . . . . . .

Ecuador . . . . . . . . . .

Sudan .............

Yugoslavia ...........

Morocco . . . . . . . . . . .

Austria . . . . . . . . . .

Jordan . . . . . . . . . .

Zaire ...............

Ivory Coast . . . . . . . .

Malaysia. . . . . . . . . .

Cameroon . . . . . . . . . . .

Turkey . . . . . . . . . . .

Yemen Arab Republic. ...

Haiti . . . . . . . . . . . .

Iceland .............

Libya . . . . . . . . . . .

Ireland ............

Cyprus . . . . . . . . . . .

Syria ..............

Paraguay . . . . . . . . .

Angola . . . . . . . . . . .

Zambia. . . . . . . . . . . .

Bangladesh . . . . . . . . . .

Lebanon. . . . . . . . . . . .

Ethiopia . . . . . . . . . .

Mali . . . . . . . . . . . .

Finland. . . . . . . . . . .

Bolivia . . . . . . . . . .

Afghanistan . . . . . . . .

Barbados ............

Burkina Faso . . . . . . . . . .

Central African Republic.

Chad . . . . . . . . . . . .

Congo . . . . . . . . . . .

Costa Rica . . . . . . . . . .

Dominican Republic . . . . .

El Salvador. . . . . . . . . . .

Fiji . . . . . . . . . .

Gabon ............. .

Ghana . . . . . . . . . . .

Guatemala ...........

Guinea .............

Honduras. . . . . . . . . . .

Liechtenstein . . . . . . . . .
Signatory

Investment

share*

percent

Ministry of Posts and Telecommunications . . . . . . . . . . 0.39

Norwegian Telecommunications Administration. . . . . . . . . . . . . 0.39

Government of Algeria . . . . . . . . . . . . . . . . . . . 0.39

Kenya Posts \& Telecommunications Corp. . . . . . . . . . . . . 0.38

Government of Islamic Republic of Pakistan . . . . . . . . . . . . 0.37

Government of the State of Qatar. . . . . . . . . . . . . . . 0.35

Instituto Ecuatoriano de Telecomunicaciones . . . . . . . . . . 0.35

Governmentof Democratic Republic of Sudan . . . . . . . . . . . 0.33

Yugoslav Posts, Telegraphs \&Telephones. . . . . . . . . . . 0.32

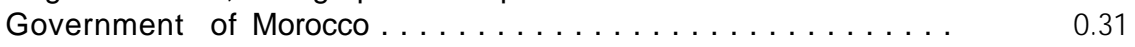

Governmentof Austria..................... 0.30

Governmentof the Hashemite Kingdom of)ordan . . . . . . . . 0.30

Office National des Posteset Telecommunications du Zaire.. $\quad 0.29$

Governmentof the Republic oflvory Coast . . . . . . . . . . . 0.29

Telecommunications Department, Malaysia . . . . . . . . . . 0.25

Socid\#des Td@communications Internationalesdu

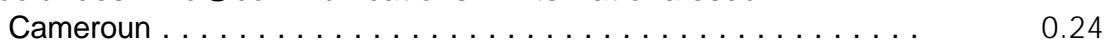

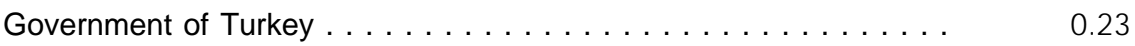

Government of Yemen Arab Republic . . . . . . . . . . . . 0.22

T61\{communications d'Haiti S.A. . . . . . . . . . . . . . 0.18

Government oflceland. . . . . . . . . . . . . . . . . . 0.18

Government of the Libyan Arab Republic . . . . . . . . . . . . . 0,15

Department of Posts and Telegraphs . . . . . . . . . . . . . 0.13

Cyprus Telecommunications Authority . . . . . . . . . . . . . 0.13

Government of the Syrian Arab Republic . . . . . . . . . . . . . . 0.13

Administration Nacional de Telecomunicaciones . . . . . . . . . . 0.12

Empr sa Ptiblica de Telecomunica@es . . . . . . . . . . . . . . 0.11

Government of the Republic of Zambia . . . . . . . . . . . . 0.11

Telegraph and Telephone Board of Bangladesh . . . . . . . . . . 0.10

Government of Lebanon . . . . . . . . . . . . . . . . . . . . . 0.10

Telecommunications Service

T61dcommunications Internationalesdu Mali . . . . . . . . . . . 0.09

General Directorate of Posts and Telecommunications . . . . . . 0.08

Empresa Nacional de Telecomunicaciones . . . . . . . . . . . . . 0.08

Ministry of Communications $\quad 0.05$

Cable and Wireless (West Indies) Ltd. . . . . . . . . . . . $\quad 0.05$

Officedes Postes et Td<communications de Burkina Faso 0.05

Government of the Central African Republic . . . . . . . . . . . . 0.05

Socid<des T61<communications Internationalesdu Tchad 0.05

Government of People's Republic of the Congo ........... 0.05

Instituto Costarricense de Electricidad . . . . . . . . . . . . . . . 0.05

Compa;fi Dominican de TelFfonos . . . . . . . . . . . . . . . . 0.05

Administration Nacional de Telecomunicaciones .......... 0.05

Fiji International Telecommunications Ltd. . . . . . . . . .... 0.05

Soci<td des T41<communications Internationales .......... 0.05

Ministry of Transport and Communications . . . . . . . . . . . 0.05

Empresa Guatemalteca de Telecomunicaciones ........... 0.05

Government of People's Revolutionary Republic of Guinea .. 0.05

Empresa Hondurefia de Telecomunicaciones . . . . . . . . . . . 0.05

Government of the Principalityof Liechtenstein. .......... 0.05 


\begin{tabular}{|c|c|c|}
\hline Luxembourg. . . . . . . . . . . & Government of Luxembourg . . . & 0.05 \\
\hline Madagascar . . . . . . . . . . & Societe des Telecommunications Internationales . . . . . . . . & 0.05 \\
\hline Mauritania . . . . . . . . . . & Government of Islamic Republic of Mauritania . . . . . . . . . . & 0.05 \\
\hline Monaco . . . . . . . . . . . . & Government of the Principality of Monaco. . . . . . . . . . . . . & 0.05 \\
\hline Nicaragua . . . . . . . . . . & Compania Nicaraguense de Télecomunicaciones por Satelite. & 0.05 \\
\hline Niger . . . . . . . . . . & Government of the Republic of Niger. . . . . . . . . . . . . & 0.05 \\
\hline Panama . . . . . . . . . & Intercontinental de Comunicaciones por Satelite, S.A. . . . . . & 0.05 \\
\hline Papua New Guinea. . . . . . & Post and Telecommunication Corp. of Papua New Guinea ,. & 0.05 \\
\hline Senegal. . . . . . . . . . . . & Government of the Republic of Senegal . . . . . . . . . . . . . . & 0.05 \\
\hline Somalia . . . . . . . . . . . & Ministry of Posts and Telecommunications . . . . . . . . . . . & 0.05 \\
\hline Sri Lanka . . . . . . . . . . & Government of Sri Lanka . . . . . . . . . . . . . . . . . . . . . & 0.05 \\
\hline Tanzania . . . . . . . . . . . & Tanzania Posts and Telecommunications Corp. . . . . . . . . . . . & 0.05 \\
\hline Trinidad and Tobago. . . . . & Trinidad and Tobago External Telecommunications Co. Ltd. & 0.05 \\
\hline Tunisia . . . . . . . . . . . & Administration for Post, Telegraph and Telephone & 0.05 \\
\hline Uganda . . . . . . . . . . & Ministry of Power, Posts, and Telecommunications & 0.05 \\
\hline Uruguay ..... . & Administration Nacional de Telecomunicaciones & 0.05 \\
\hline Vatican City State & Government of the Vatican City State . . . . . . . . . . . . & 0.05 \\
\hline Viet Nam ....... & Direction Generaledes Postes et Telecommunications . . . . & 0.05 \\
\hline
\end{tabular}

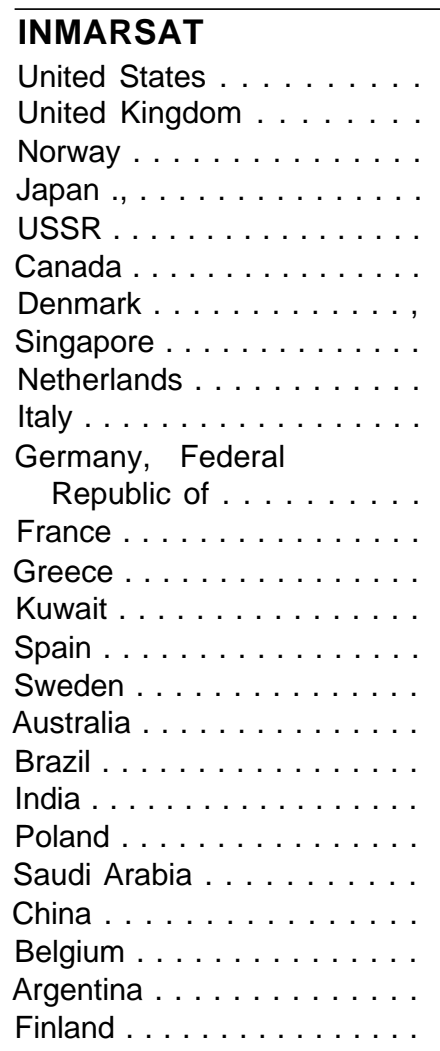

Communications Satellite Corp. . . . . . . . . . . . . . . .

British Telecommunications . . . . . . . . . . . . . . . .

Norwegian Telecommunications Administration . . . . . . . . . .

Kokusai Denshin Denwa Co., Ltd.. . . . . . . . . . . . . . . . .

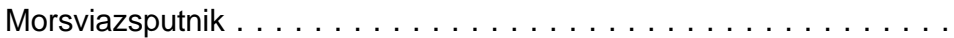

Teleglobe Canada . . . . . . . . . . . . . . . . . .

Post and Telegraph Administration . . . . . . . . . . . . .

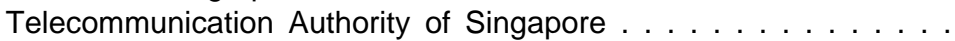

Netherlands PTT Administration . . . . . . . . . . . . . . . . . .

Telespazio . . . . . . . . . . . . . . . . . . .

Ministry for Port \& Telecommunication . . . . . . . . . . . . . .

Direction Generale des Telecommunications . . . . . . . . . . . . . .

Helienic Telecommunications Organization . . . . . . . . . . . .

Ministry of Communications . . . . . . . . . . . . . . .

Compafi;a Telefdnica Nacional de Espafia . . . . . . . . . . . . . . . . . . . . . . .

Swedish Telecommunications Administration . . . . . . . . . . . .

Overseas Telecommunications Commission . . . . . . . . . . . .

Empresa Brasileira de Telecomunicacoes S.A . . . . . . . . . . . .

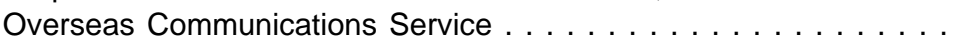

Office of Maritime Economy . . . . . . . . . . . . . . . . .

Ministry of Posts, Telegraphs and Telephones . . . . . . . . . . . .

Beijing Marine Communications and Navigation Company. . .

Regie des Telegraphes et des Telephones . . . . . . . . . . .

Empresa Nacional de Telecomunicaciones . . . . . . . . . . . . . .

General Directorate of Posts and Telecommunications of

Finland
30.73

14.55

11.59

6.96

6.91

3.85

2.47

2.39

2.28

1.94

1.69

1.67

1.67

1.17

1.17

1.10

1.08

0.97

0.97

0.97

0.97

0.72

0.34

0.30

0.30 


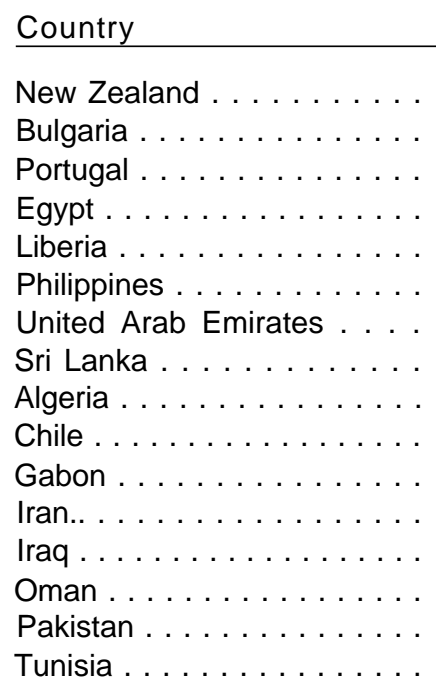

** Asot Feb 6, 1985
Signatory

Investment

share* $^{*}$

percent

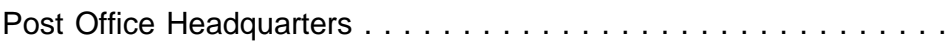

0.21

Shipping Corp. . . . . . . . . . . . . . . . . . . . . . . . . . . . . . . . . . . . . . . . . .

Companhia Portuguese Radio Marconi . . . . . . . . . . . . . . . . . . . . 0.11

National Telecommunications Organization . . . . . . . . . . . . . . . . . 0.07

Republic of Liberia . . . . . . . . . . . . . . . . . . . . . . . . . . . . . . . . . . . . 0.07

Philippine Communications Satellite Corp. . . . . . . . . . . . . . . . . . . . . . . . . . . . . . . . . .

Ministry of Communications . . . . . . . . . . . . . . . . . . . . . . . 0.07

Overseas Telecommunication Service . . . . . . . . . . . . . . . . . 0.06

Ministere des Postes et Teledcommunications . . . . . . . . . . . . . . . . . . . . . . . .

Empresa Nacionai de Telecomunicaciones S.A. . . . . . . . . . . . . . . . 0.05

Telecommunications Internationales Gabonaises . . . . . . . . . . 0.05

Telecommunication Co. of Iran . . . . . . . . . . . . . . . . 0.05

Republic of Iraq . . . . . . . . . . . . . . . . . . . . . . . . . . . . . . . . . . . . . .

Sultanate of Oman . . . . . . . . . . . . . . . . . . . . . . . . . . . . . . .

Pakistan Telegraph and Telephone Department. . . . . . . . . . . . . . . . . . . . . . . . . . . . . . . 05

Republic of Tunisia . . . . . . . . . . . . . . . . . . . . 0.05

\section{APPENDIX 6D.-ARTICLE XIV AND OTHER EXCERPTS FROM THE INTELSAT AGREEMENT RELATING TO SPACE SEGMENT "FACILITIES SEPARATE FROM INTELSAT"}

\author{
Agreement Relating to the \\ International Telecommunications \\ Satellite Organization "INTELSAT" \\ May 19, 1971
}

\section{Preamble}

The States Parties to this Agreement,

Considering the principle set forth in Resolution 1721 (XVI) of the General Assembly of the United Nations that communication by means of satellites should be available to the nations of the world as soon as practicable on a global and nondiscriminatory basis,

Considering the relevant provisions of the Treaty on Principles Governing the Activities of States in the Exploration and Use of Outer Space, Including the Moon and Other Celestial Bodies, and in particular Article I, which states that outer space shall be used for the benefit and in the interests of all countries,

Noting that pursuant to the Agreement Establishing Interim Arrangements for a Global Commercial Communications Satellite System and the related Special
Agreement, a global commercial telecommunications satellite system has been established,

Desiring to continue the development of this telecommunications satellite system with the aim of achieving a single global commercial telecommunications satellite system as part of an improved global telecommunications network which will provide expanded telecommunications services to all areas of the world and which will contribute to world peace and understanding,

Determined, to this end, to provide, for the benefit of all mankind, through the most advanced technology available, the most efficient and economic facilities possible consistent with the best and most equitable of the radio frequency spectrum and of orbital space,

Believing that satellite telecommunications should be organized in such a way as to permit all peoples to have access to the global satellite system and those States members of the International Telecommunication Union so wishing to invest in the system with consequent participation in the design, development, construction, including the provision of equipment, 
establishment, operation, maintenance, and ownership of the system,

Pursuant to the Agreement Establishing Interim Arrangements for a Global Commercial Communications Satellite System,

Agree as follows:

\section{Article 1: Definitions * *}

(k) "public telecommunications services" means fixed or mobile telecommunications services which can be provided by satellite and which are available for use by the public, such as telephony, telegraphy, telex, facsimile, data transmission, transmission of radio and television programs between approved earth stations having access to the INTELSAT space segment for further transmission to the public, and leased circuits for any of these purposes; but excluding those mobile services of a type not provided under the Interim Agreement and the Special Agreement prior to the opening for signature of this Agreement, which are provided through mobile stations operating directly to a satellite which is designed, in whole or in part, to provide services relating to the safety or flight control of aircraft or to aviation or maritime radio navigation;

(1) "Specialized telecommunications services" means telecommunications services which can be provided by satellite, other than those defined in paragraph (k) of this Article, including, but not limited to, radio navigation services, broadcasting satellite services for reception by the general public, space research services, meteorological services, and earth resources services;

\section{Article XIV: Rights and Obligations of Members}

(a) The Parties and Signatories shall exercise their rights and meet their obligations under this Agreement in a manner fully consistent with and in furtherance of the principles stated in the Preamble and other provisions of this Agreement.

(b) All Parties and all Signatories shall be allowed to attend and participate in all conferences and meetings, in which they are entitled to be represented in accordance with any provisions of this Agreement or the Operating Agreement, as well as in any other meeting called by or held under the auspices of INTELSAT, regardless of where they may take place. The executive organ shall ensure that arrangements with the host Party or Signatory for each such confer- ence or meeting shall include a provision for the admission to the host country and sojourn for the duration of such conference or meeting, of representatives of all Signatories entitled to attend.

(c) To the extent that any Party or Signatory or person within the jurisdiction of a Party intends to establish, acquire or utilize space segment facilities separate from the INTELSAT space segment facilities to meet its domestic public telecommunications services requirements, such Party or Signatory, prior to the establishment, acquisition or utilization of such facilities, shall consult the Board of Governors, which shall express, in the form of recommendations, its findings regarding the technical compatibility of such facilities and their operation with the use of the radio frequency spectrum and orbital space by the existing or planned INTELSAT space segment.

(d) To the extent that any party or Signatory or person within the jurisdiction of a Party intends individually or jointly to establish, acquire or utilize space segment facilities separate from the INTELSAT space segment facilities to meet its international public telecommunications services requirements, such Party or Signatory, prior to the establishment, acquisition or utilization of such facilities, shall furnish all relevant information to and shall consult with the Assembly of Parties, through the Board of Governors, to ensure technical compatibility of such facilities and their operation with the use of the radio frequency spectrum and orbital space by the existing or planned INTELSAT space segment and to avoid significant economic harm to the global system of INTELSAT. Upon such consultation, the assembly of Parties, taking into account the advice of the Board of Governors, shall express, in the form of recommendations, its findings regarding the considerations set out in this paragraph, and further regarding the assurance that the provision or utilization of such facilities shall not prejudice the establishment of direct telecommunication links through the INTELSAT space segment among all the participants.

(e) To the extent that any Party or Signatory or person within the jurisdiction of a Party intends to establish, acquire or utilize space segment facilities separate from the INTELSAT space segment facilities to meet its specialized telecommunications services requirements, domestic or international, such Party or Signatory, prior to the establishment, acquisition or utilization of such facilities, shall furnish all relevant information to the Assembly of Parties, through the Board of Governors. The Assembly of Patties, taking into account the advice of the Board of Governors, shall express, in the form of recommendations, its findings regarding the technical compatibility of such fa- 
cilities and their operation with the use of the radio frequency spectrum and orbital space by the existing or planned IN TELSAT space segment.

(f) Recommendations by the Assembly of Parties or the Board of Governors pursuant to this Article shall be made within a period of six months from the date of commencing the procedures provided for in the foregoing paragraphs. An extraordinary meeting of the Assembly of Parties may be convened for this purpose. (g) This Agreement shall not apply to the establishment, acquisition or utilization of space segment facilities separate from the INTELSAT space segment facilities solely for national security purposes.

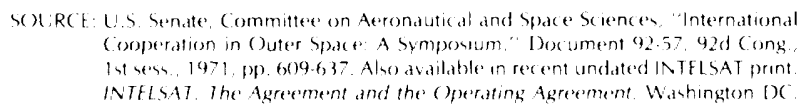




\section{Chapter 7 REMOTE SENSING FROM SPACE}

\section{Contents}

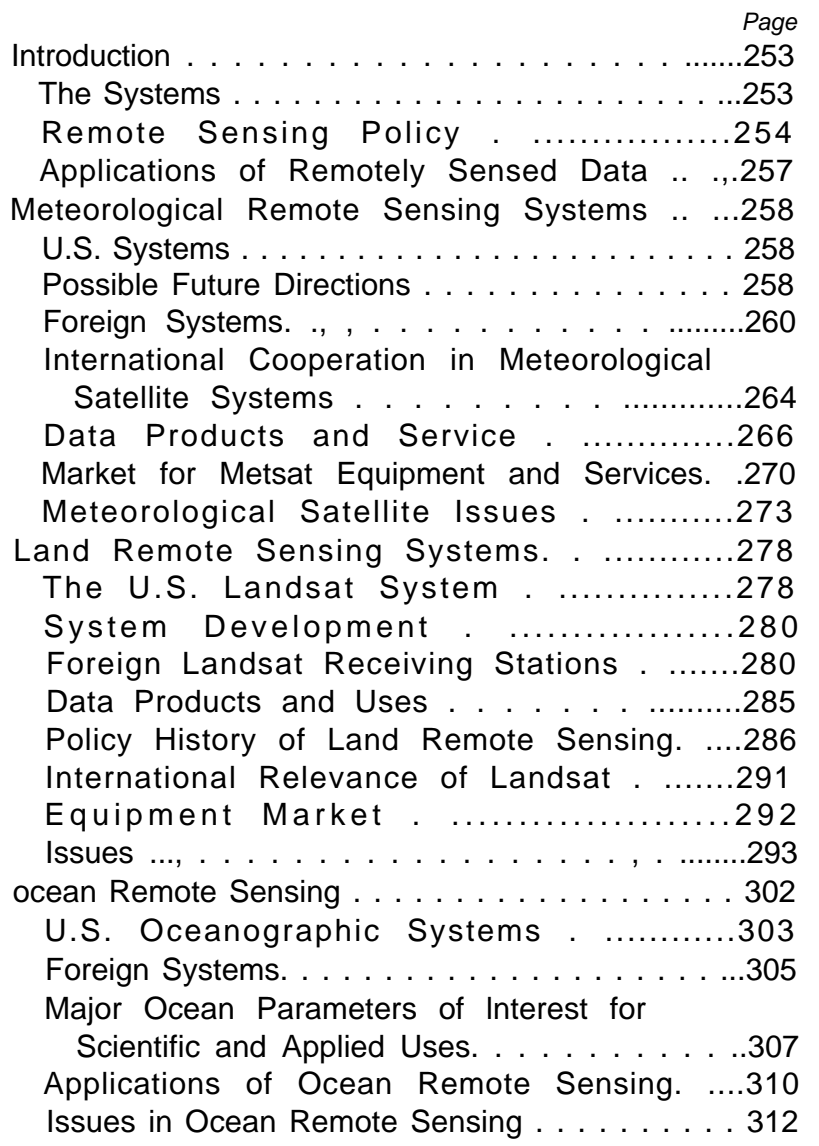

Remote Sensing Policy . . . ...............314 Meteorological Remote Sensing Policy .. Land Remote Sensing Policy . .............319 Options for Continued Financial Support .,.319 Additional Policy Options. , . . . . . . . . . ......321 Cooperation . . . . . . . . . . . . . . . . 322 Ocean Remote Sensing Policy . . . . . . . . . . 323 Appendix 7A.-Satellite Remote Sensing in

Developing Countries . ................325 The Experience of Developing Countries . 325 Institutional Factors Influencing the Use of

Satellite Remote Sensing . . . . . . . . . 328

Political Constraints. . . . . . . . . . . . . . . . 329 Appendix 7B.-U.S. Environmental Satellites, $1960-85$. . . . . . . . . . . . . . . . . . 332

\section{List of Tables}

Tab/e No.

7-I, Countries With APT/HRPT Reception Capabilities. . . . . . . . . . . . . . . 267

7-2. Domestic Users of Meteorological Satellite Data . . . . . . . . . . . . . . 269

7-3. Derived Meteorological Satellite Products . . . . . . . . . . . . . . . . . 269

7-4. National Weather Service Hurricane, International Aviation, and Marine Forecast Programs . . . . . . . . . . . . 269

7-5. Costs for Some Landsat Data Products. . 282 
7-6. Major Imaging Sensors Under

Development by NASA , . . . . . . . . . . . 282

7-7. Foreign Landsat Ground Stations . . . . . . 284

7-8. Categories of Foreign and Domestic Users . . . . . . . . . . . . . . . . . . . 285

7-9. Domestic Distribution of Landsat Products . . . . . . . . . . . . . . . . . . 286

7-10. Customer Profile of Landsat Total Data .297

7-11, Agribusiness Industry Structure Analysis 300

7-12. Geophysical Oceanographic Measurement Design Capabilities for Seasat-A . . . . . . . . . . . . . . . . . 302

7-13, Measurement Needs for Oceanographic Satellites . . . . . . . . . . . . . . . . . 305

7-14, N-ROSS Sensor Capabilities . . . . . . . . . 306

7-15, Oceanographic Data Tactical Operations . . . . . . . . . . . . . . . 4.... 307

7-16. Ice Parameters of Importance in Different Operations and Research Areas . . . . . . . . . . . . . . . . . . . . . 309

7-17. Possible Oceanographic Satellite Applications . . . . . . . . . . . . . 311

7-18. Impacts of Observed Parameters on Commercial Benefits . . . . . . . . . . . 311

7A-1. Agency for International Development Remote Sensing Grants and Projects,

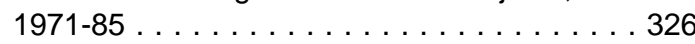

\section{List of Figures}

Figure No.

7-1. Polar-Orbiting and Geostationary Satellites . . . . . . . . . . . . . . . 254
7-2. image of Earth, Received Aug. 8, 1980, by GOES Satellite. . . . . . . . . . . . . . . . 255

7-3. image of Northeast United States Taken in February 1979 by the NOAA-N Series Polar-Orbiting Satellite. . . . . . . . . . . 256

7-4. Image of New York City and Environs Taken by the Thematic Mapper . . . . . . . 257

7-5. Advanced TIROS-N . . . . . . . . . . . . . . 262

7-6. GOES Satellite . . . . . . . . . . . . . . 263

7-7. GOES Geographic Coverage . . . . . . . . . 264

7-8, Path of Geosynchronous Satellite in Inclined Orbit.. . . . . . . . . . . . . . . . 265

7-9. Operational Earth Observation Satellites 268

7-10. One-and Two-Polar Soundings . . . . . . . 276

7-11. Landsat-5 Spacecraft . . . . . . . . . . . . . . 279

7-12, Cutaway View of the Multispectral Scanning System . . . . . . . . . . . . . 280

7-13. Landsat Bands and Electrc)magnetic Spectrum Comparison . . . . . . . . . . . . . . 281

7-14. Thematic Mapper Sensor . . . . . . . . . . . . 281

7-15. Distribution by Foreign Ground Stations 283

7-16. Customer Profile of Landsat Digital and Imagery Products, Fiscal Year 1984 . . . . 287

7-17, Sale of Landsat Imagery Frames and Digital Products . . . . . . . . . . . 296

7-18. The Seasat-A Spacecraft . . . . . . . . . . . 303

7-19, Navy Remote Ocean Sensing Satellite . . 306

7-20. Radar Image of Kuskokwim Bay in Alaska . . . . . . . . . . . . . . . . . . 309 


\section{REMOTE SENSING FROM SPACE}

\section{INTRODUCTION}

The value of viewing Earth from space to provide crucial resource and environmental information on the atmosphere, oceans, and land masses was recognized early in this Nation's development of space technology. It was an obvious extension of remote sensing by aircraft and balloons, technologies that were already well-established. 'Two years after the National Aeronautics and Space Act was signed, the United States received its first images from space taken by the polar-orbiting ${ }^{2}$ weather satellite called the Television and infrared Observation Satellite (TIROS).

This chapter describes the principal remote sensing systems that have been developed by the United States and other countries and those that are now under development. It draws heavily on a technical memorandum published in 1984 in connection with this assessments The chapter explores the primary issues connected with the generation, distribution, and application of remotely sensed data, and assesses various policy options for Congress to consider as it debates the need for remote-sensing technology for the atmosphere, land, and oceans.

\footnotetext{
'I $\mathrm{n}$ general terms, remote sensing is the art of obtaining information about objects, areas or phenomena through analyzing data gathered by devices placed at a distance from the subjects of study. Remote sensing may refer to sensing over short distances, as in medical or laboratory research applications using lasers, or over long distances as in environmental monitoring from satellite platforms using advanced electro-optical instruments. Once the initial data are sensed, they must be analyzed and interpreted either visually or through sophisticated computer analysis.

I I n a polar orbit the satellite is inclined nearly 90 degrees to the Equator. As the satellite orbits, the Earth turns beneath, making possible direct overhead observations of the entire Earth over a given period. The geostationary satellites, by contrast, provide continuous viewing but are limited to providing perpendicular viewing at only one longitude at the equator. All other points on Earth are sensed at some angle. They therefore "see" the polar regions at a highly oblique angle. The orbital elements of the meteorological TIROS satellites are so chosen to allow them to pass over every portion of Earth's surface twice every 24 hours, once passing from north to south, and once passing from south to north.

'Remote Sensing and the Private Sector.. Issues for Discussion (Washington, DC: U.S. Congress, Office of Technology Assessment, OTA-TM-ISC-20, March 1984).
}

\section{The Systems}

The National Oceanic and Atmospheric Administration (NOAA) ${ }^{4}$ operates two civilian systems (fig. 7-1) for making global meteorological observations: a geostationary system (Geostationary Orbiting Environmental Satellite-GOES) using two satellites that continuously monitor weather systems within their field of view (fig. 72);5 and a polar-orbiting meteorological system (Advanced Television and Infrared Observation Satellite-TIROS) that observes meteorological phenomena in more detail over the entire globe from two satellites (fig. 7-3).

NOAA also operates the polar-orbiting U.S. Landsat system, which was developed by the National Aeronautics and Space Administration (NASA), to provide valuable data of high spatial and spectral resolution (fig. 7-4) of Earth's land resources. Data from the system support a variety of applications, including assessing and managing renewable and nonrenewable resources, mapping, and land-use planning. The Landsat system was transferred to NOAA in 1983 and is now managed as an operational system. The Department of Commerce is currently attempting to transfer the Landsat system to private ownership.

Ocean remote sensing systems are the least developed of remote sensing efforts. Although the results from such experimental ocean satellites as Seasat, Nimbus, and the Geodynamic Experi-

\footnotetext{
${ }^{4}$ The development of the weather satellite began in the DOD, but was transferred to NASA in 1959. In 1961 the Weather Bureau was placed in charge of providing an operational weather satellite system. Operational satellite services were moved to the Environmental Science Services Administration in $\mathbf{1 9 6 5}$ and finally to NOAA in 1970. They now reside in the National Environmental Satellite Data and Information Service (N ESDIS), which is part of NOAA ${ }^{5}$ On July 30, 1 g84, GOES-5 failed in orbit. This left the United States with only a single geostationary satellite (the western satellite, GOES-6) to provide data during the critical severe storm seasons of the summer and early fall. To make up (in part) for the loss of information that losing the eastern satellite entailed, NOAA moved GOES-6 to a central location. This meant reduced weather service for Alaska, Hawaii, and the Pacific Trust Territories. GOES-7, the replacement for the failed GOES-5, will not be available for launch until late in 1985 or early 1986
} 
Figure 7-1.-Polar-Orbiting and Geostationary Satellites

Polar orbiting satellites

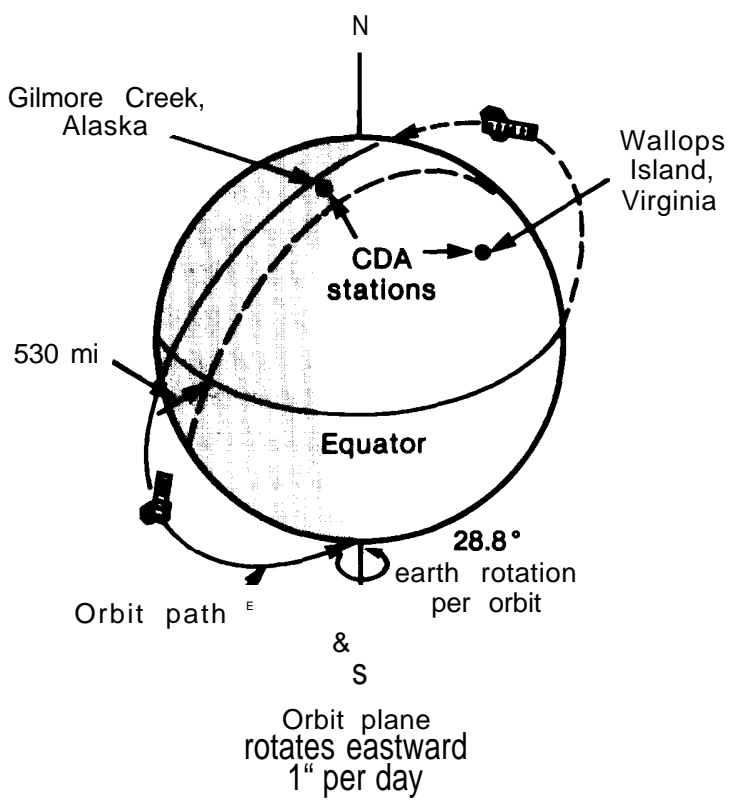

SOURCE: National Oceanic and Atmospheric Administration.

mental Ocean Satellite have created interest in developing remote sensing systems that will provide resource information from the oceans, no civilian operational U.S. system is planned. ${ }^{G}$

Remote sensing from space at present constitutes a small part of a larger array of mapping services provided by terrestrial and airborne devices. ${ }^{7}$ The data acquired from space are now routinely integrated with other remotely sensed data (aircraft and balloons) and terrestrial, air, and water measurements, thus enhancing the value, and expanding the application of both data sets. As discussed in detail below, other countries either operate, or have under development, various remote sensing systems; a few complement U.S. efforts, others will compete with U.S. systems.

${ }^{6}$ The u .S. Navy is planning a system called Navy Remote Ocean Sensing System (N-ROSS) which may be launched in 1988 or 1989. Most data from this system will be available to civilian users through NOAA (see section on Ocean Remote Sensing).

IInfiscal year 1984, sales of Lantsat data made up 34 percent of the total sales of remotely sensed data from thes Data Center in Sioux Falls, SD. Private services alsosense and sell aircraft data.
Geostationary satellites

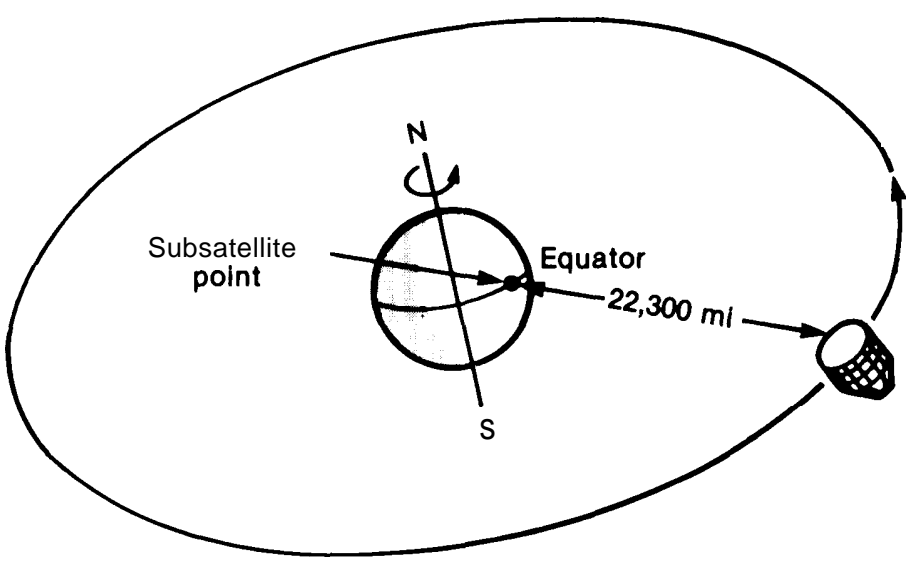

Remote Sensing Policy

Although the United States has led the world in the development and operation of civilian remote sensing systems, this year it will face competition from France for the sale of land remote sensing data products. There is little commercial market for data sales from meteorological systems, but opportunities do exist for broad multinational cooperation in providing meteorological data from space. The United States is exploring the prospect of joining with other Free World space-capable nations in building a cooperative polar-orbiting global meteorological satellite system. Such a venture could strongly enhance the level of service delivered by such systems.

In 1983, the Administration accelerated a process begun in the late 1970s intended to lead to the transfer of the Landsat system from the Federal Government to the private sector. The principal motivation for transferring the system to private hands is that the private sector excels both at innovation and at developing markets for goods and services. The 98th Congress passed the 
Figure 7-2.-image of Earth, Received Aug. 8, 1980, by GOES Satellite

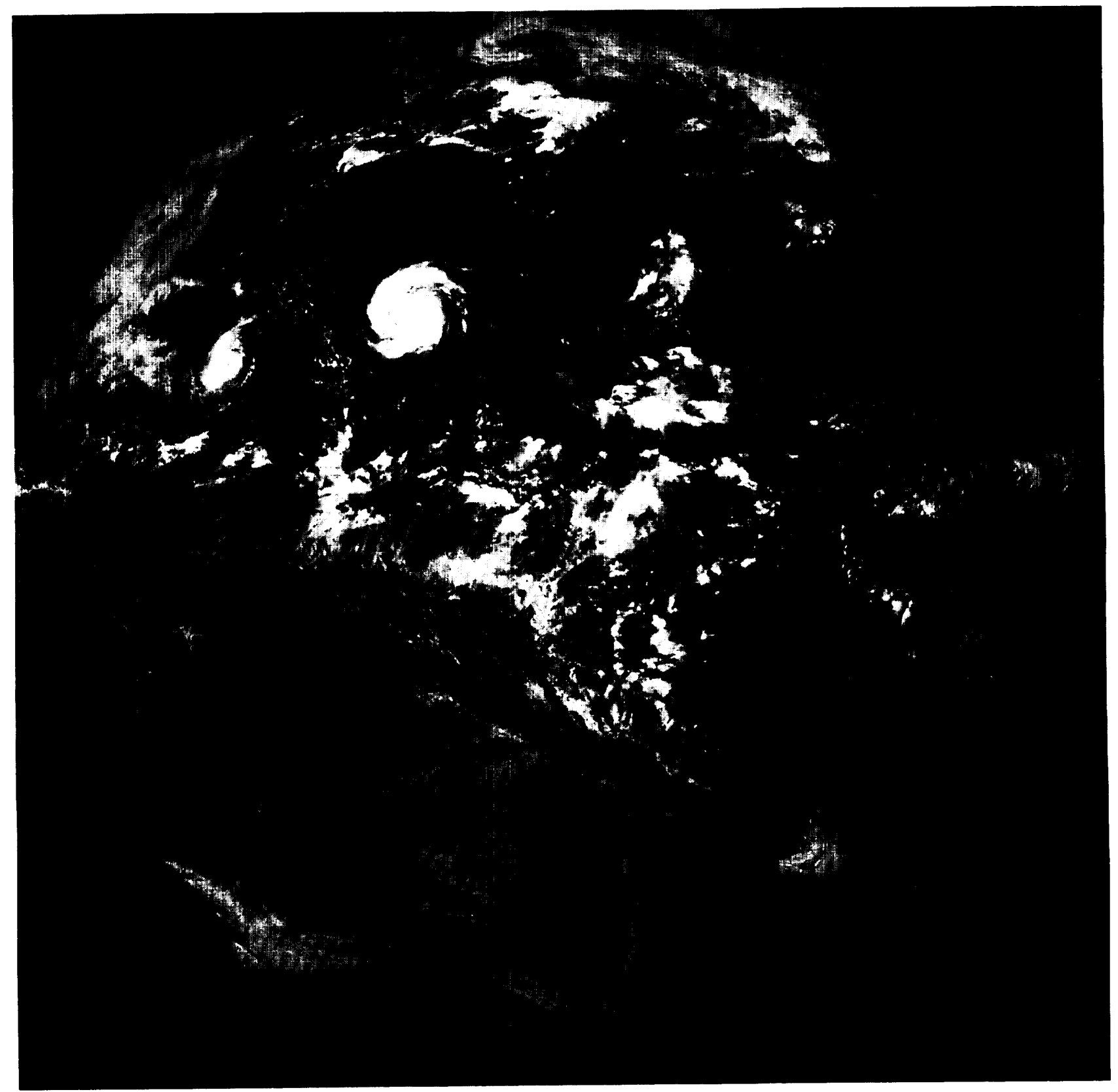

Two hurricanes are clearly visible: Allen in the Gulf of Mexico and Isis just west of Mexico.

SOURCE: National Oceanic and Atmospheric Administration. 
F gu e 73 mage o Northeas Un ed S a es Taken n Fob uary 979 by he NOAA N Se es Po a Orb ng Sa e

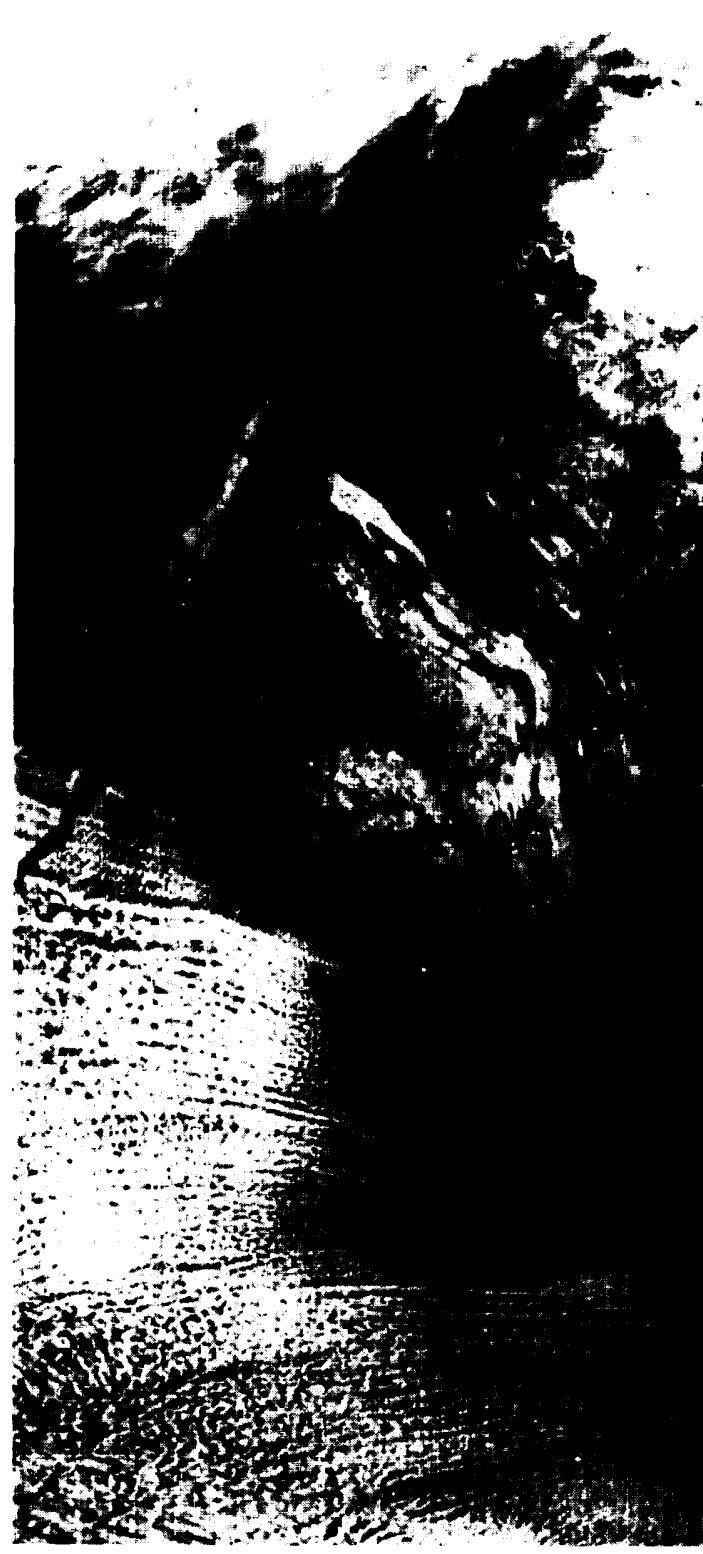

S $w$
G 
Figure 7-4.-image of New York City and Environs Taken by the Thematic Mapper (30-meter resolution)

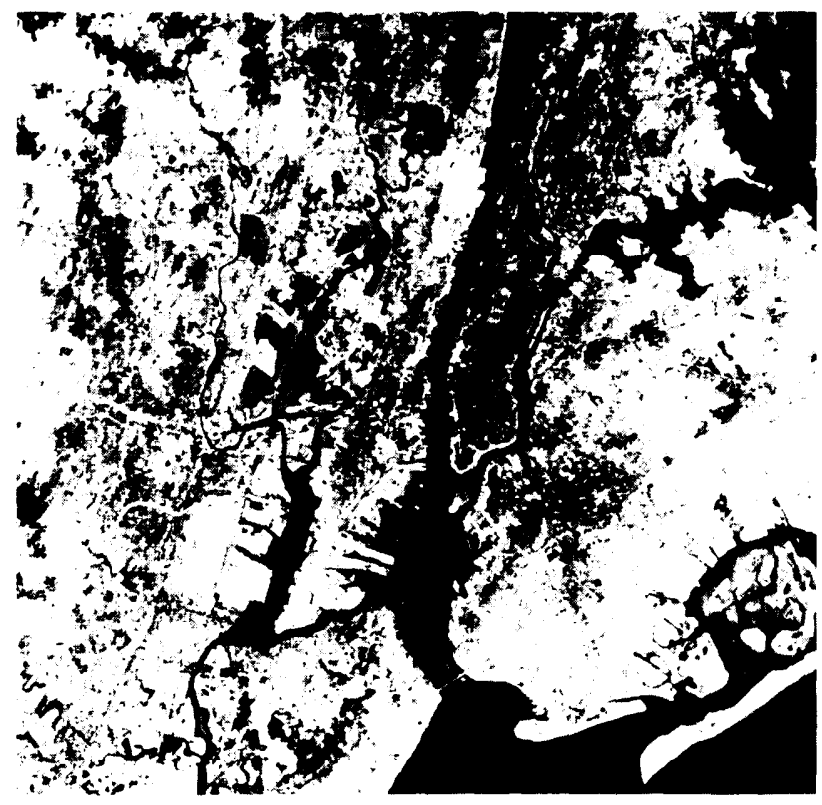

The George Washington and Verrazano bridges are clearly visible.

Landsat Commercialization Act of 1984 (Public Law 98-365) that provides for a phased transfer of the Landsat system (see later section, Policy History of Land Remote Sensing) and authorizes a subsidy to fund part of the capital costs of building and launching a commercial system. As the Department of Commerce implements the provisions of Public Law 98-365, Congress is overseeing the transfer process. The question Congress now faces is whether additional legislation or other measures will be necessary to aid the commercialization process.

Transfer to the private sector raises several questions: 1) whether this course of action will enhance or impede U.S. competitiveness with other nations in this field, 2) whether private firms will eventually develop a self-sustaining business of providing land remote sensing from satellites, 3 ) how the Government might enhance that process, and 4) what transfer model best serves the needs of the United States? If the current transfer process fails to establish a viable commercial operation, Congress will be faced with deciding what to do about it.
A significant international effort has begun in remote sensing of the oceans. Both research and operational satellites are planned by the United States and other nations, making possible joint research and data distribution efforts. The United States is exploring ways in which to coordinate intemational efforts in ocean remote sensing.

\section{Applications of Remotely Sensed Data}

Data from satellite systems have been used for a variety of applications beyond the specific scientific objectives that guided their development. Specifications for meteorological satellites and sensors initially were set to address current and future needs of the National Weather Service for weather forecasting and warning. However, as the technology has evolved, the United States has used these systems to enhance its relations with other countries by integrating instruments provided by other nations into U.S. spacecraft, and by freely sharing data with member nations of the World Meteorological Organization (WMO), a specialized agency of the United Nations formed to coordinate weather services on a global basis. Though the Landsat system has a shorter history, the United States has also used it as an ambassador for U.S. space technology by selling data on a public, nondiscriminatory basis, and through arrangements for direct transmission of Landsat data (on a fee basis) to foreignowned and foreign-operated ground stations.

Satellite remote sensing systems are also important to national security. Though the United States has consistently maintained separate civilian and military systems, the programs have been mutually supportive. In defense and civilian meteorological programs, mutual backup in case of system failures and free data exchange exemplify this support.

Government and civilian market potential vary considerably for the different remote sensing systems. Although the metsats have a long history of operation, these systems are just beginning to develop a commercial value-added data industry. The Federal Government is by far the largest user of meteorological data.g U.S. State and local

B"Transfer of the Civil Operational Earth Observation Satellites to the Private Sector, "U.S. Department of Commerce, February 1983. p. B-24, 
governments, foreign governments, universities, and commercial firms also use these data. Though new applications for meteorological data are being found for assessing crop conditions, scanning the ocean, and for mapping water resources, their potential for expanded use is limited by the need for more complete computer models and by the availability of confirmatory data from higher resolution ocean and land satellite systems.

The market for data from the Landsat system, which have always been sold to users, has remained undeveloped. The Government purchases nearly 50 percent of the Landsat data, but the commercial market for these data remains diffuse, unaggregated, and small. ${ }^{9}$

\footnotetext{
${ }^{9}$ For example, total shipped sales (not counting special charges) for fiscal year 1984 amounted to only $\$ 3,812,128$, 45 percent of which was purchased by Government agencies. Although the cur-
}

Although the potential for applying ocean remote sensing data to problems faced by ocean users is high, only short-term scientific satellite missions have been flown. Much more experimentation with actual data from operational satellite systems will be needed to assess the potential commercial market for data and data products. rent market has historically been small (see table 7- I 4 and fig. 716 for the total Landsat data sales since 1972), these data have never been marketed commercially. Several analysts have predicted that given proper commercial marketing and a favorable Governmental attitude, the future market could be large. Their analysis is in part the basis for believing that land remote sensing could be effectively commercialized. See G. William Spann, statement before the Senate Subcommittee on Science, Technology, and Space of the Committee on Commerce, Science, and Transportation, S. Hrg. 98-747, Mar. 22, 1984.

\section{METEOROLOGICAL REMOTE SENSING SYSTEMS}

\section{U.S. Systems ${ }^{10}$}

NOAA manages two civilian environmental satellite (metsat) systems (see pp. 259, 260, and 261). The TIROS-N series of polar-orbiting satellites (fig. 7-5) provide systematic high resolution global weather observations, both day and night, to meet both U.S. and international data requirements for a global, immediate, and long-range weather forecasting system. The GOES series of geostationary satellites (fig. 7-6) provides continuous viewing of weather systems at visible and infrared wavelengths between $70^{\circ} \mathrm{N}$ latitude and $70^{\circ} \mathrm{S}$ latitude (fig. 7-7), and complements the data received by the TIROS-N series. The GOES satellites provide the weather images seen on television and in the newspapers. Both systems have the ability to collect and transmit data from Earthbased platforms. Both systems are necessary for providing adequate information about weather conditions directly related to U.S. needs.

${ }^{10 S e e}$ NOAA Satellite Programs Briefing, U.S. Department of Commerce, August 1983.

\section{Possible Future Directions}

Continued R\&D on new sensors will enhance the abilities of U.S. satellites to gather useful environmental data. Because much meteorological sensor technology is common to all national systems, new developments are applicable to both foreign and U.S. systems. Experience with microwave sounders' " on Nimbus satellites, as well as on the NOAA-N series, indicates that a new sounder capable of infrared sensing has promise for better soundings in cloudy areas, and better information on atmospheric water vapor and precipitation rates. The proposed 15-channei microwave instrument would give better vertical resolution, particularly in the stratosphere, and would be supplemented with additional channels for sounding water vapor. The United Kingdom, which now provides the microwave instrument on the TIROS-N spacecraft, has expressed interest in providing an advanced sounder with these improved characteristics.

\footnotetext{
"A device fo,measuring atmospheric parameters at different altitudes.
} 
The Advanced TIROS-N series first become operational with the launch of NOAA-8 in March 1983+* The spacecraft is a three-axis stabilized, box-like structure that carries four primary instrument systems for environmental data collection:

- The Advanced Very-Hibh Resolution Radiometer (AVHRR) measures cloud coverage, moisture, and surface temperature at several different wavelengths. It is the only instrument returning images from the Metsat polar-orbiters. AVHRR data are transmitted at very high frequencies (VHF) to Automatic Picture Transmission (APT) stations, which have been in operation for many years, and by S-band to High-Resolution Picture Transmission (HRPT) stations. The latter are newer, more advanced, receivers capable of producing images from digital data at a resolution of $1.1 \mathrm{~km}$. APT stations process analog transmission into imagery with a $4.0 \mathrm{~km}$ spatial resolution.

The TIROS Operational Vertical Sounder (TOVS) is a set of three instruments for temperature/moisture profiles. The High-Resolution Infrared Sounder provides data for calculating temperature from the Earth's surface to the stratosphere, water vapor content at three levels of the troposphere, and total ozone content. The latter two are essential for deriving atmospheric temperature profiles. The Stratospheric Sounding Unit, provided at no cost to the United States by the Meteorological Office of the United Kingdom, senses energy in the part of the carbon dioxide absorption portion of the infrared spectrum to provide temperature information from the stratosphere. The Microwave Sounding Unit provides solid-state, microwave radiometer technology that meteorologists have long sought for making complete atmospheric soundings in the presence of clouds. Because of their wavelength, microwaves are not attenuated by nonprecipitating water droplets. Therefore, this instrument can record temperatures through and beneath most clouds to provide data that complement the other instruments of the TOVS.

- The Space Environment Monitor (SEM) monitors the state of solar activity. Its three sensors measure the energies and intensities of protons, electrons, and ions ejected from the Sun. These data, in conjunction with those obtained by the GOES system, are processed and forwarded to NOAA's Space Environment Laboratory in Boulder, CO, within an hour of spacecraft readout for monitoring of potential effects on terrestrial communications, communication satellite services, electrical power distribution, and high-flying aircraft.

- The ARCOS Data Collection System (DCS). Designed and contributed by the Centre National d'Études Spatiales (CNES) of France, the DCS is similar to the U.S. instrument maintained on its GOES system for collecting and relaying signals from a variety of remotely located terrestrial data platforms that monitor local environmental factors not obtainable by satellite systems alone. One such factor is water flow volume in streams or rivers. The ARCOS instrument differs from the GOES system by offering global and polar coverage along with the capacity to locate drifting platforms, such as balloons, through the use of a Doppler location technique. With ARGOS, new environmental data such as ocean current patterns; measured using drifting buoys, have become available

on a global basis. series was developed by NASA; it monitors emergency radiofrequencles for distress broadcasts from 1 transmitters now carried by some 200,000 aircraft and 6,000 ships in the United States alone. With ? a planned turn-around time of 60 minutes after signal reception, ground forces can conduct rescuee operations with minimal search. The United States, the Soviet Union, Canada, and France are cur-:rently participating in the program. Recently, Bulgaria, Norway, the United Kingdom, and FinlandJ have agreed to participate. The value of a satilite wonitor as part of a global system was provenn with the location of a downed aiferaft in Septept 1982 shortly after the launch of the Soviett COSPAS receiver. The Search and Rescue Sat IIt Teceiver (SARSAT), the first U.S. complementit of the search and rescue system receiver, wat Helltched in March 1983 (on NOAA-8). Althoughh a high false-alarm rate for received signals has plagued the Search and Rescue mission (95 percentt of the total number of distress signals), about 400 persons have been rescued to date (app. A).l.

*NOAA-8 failed in July 1 \$S4 and was replaced in December 1984 by NOAA-9. NOAA-8 is now in partial operation again. 


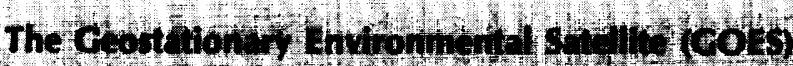

The GOES sytem consists of two geosyrichionous satellite platorms located $36,000 \mathrm{~km}$ over the equator at $75^{\circ} \mathrm{W}$ and $135^{\circ} \mathrm{W}$ tong fudes The p povide poverace of $100 t$ of the wastern hemisphere, except for the polar regions (68 7-7). Partially functioning ealthe cutellites of the foEs series are also maintained in orbit to provida limited operitional support for dh th collecton, wather facsinile sen. ices, and data relay.

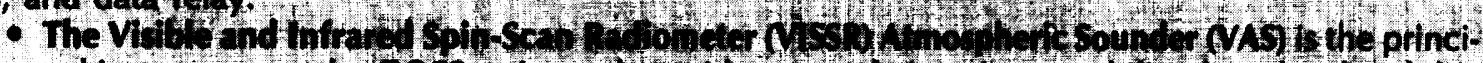

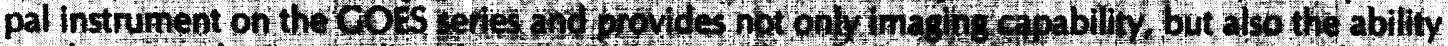
to take atmospheric sounding from gs a hit onary ow The ins thent conains a Ritchey Chretien

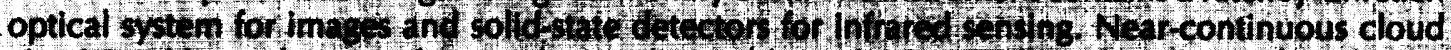
viewing with resolution of 1 to $8 \mathrm{~km}$ in the vidfle and of in in the intrared wavelengths are

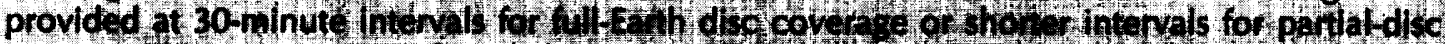

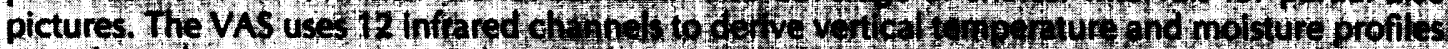

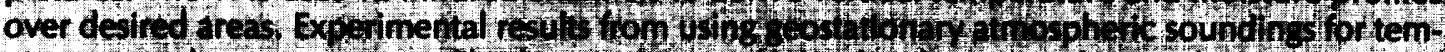

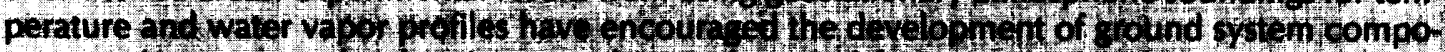

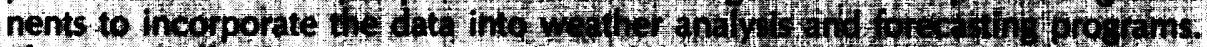

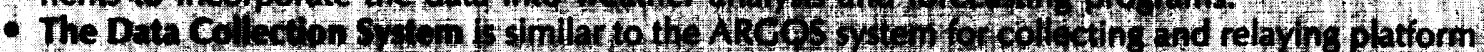

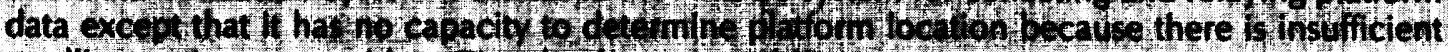

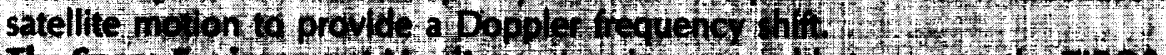

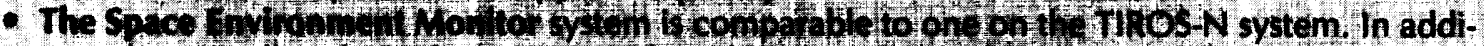

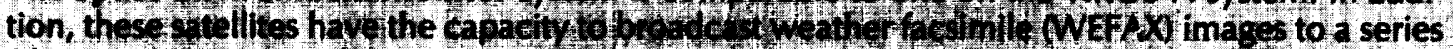

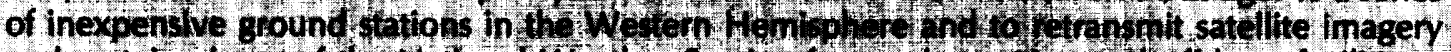
and certain charts of the National Weather service for 4 se by maxhe and offshore facilities.

A second area for development involves increased use of the Visible Atmospheric Sounder (VAS) on geostationary satellites. Tests with the experimental system aboard the GOES satellites suggests the possibility of generating an index for severe weather.

An advanced Ocean Color Imager (OCI), similar to the Coastal Zone Color Scanner (CZCS) instrument flown on the NASA satellite, Nimbus7 , if placed on the polar-orbiters, would provide multispectral scanning of the ocean in the visible, and near-infrared spectral regions, for detection of such ocean phenomena as pigmentation chlorophyll content, and turbidity.

instruments on the TIROS-N satellites collect global data on the radiation processes of the Earth's surface and atmosphere for the Earth Radiation Budget Experiment (ERBE). ${ }^{12}$ The ex-

\footnotetext{
1 2The ERBE experiment will consist of measurements of the total radiation received by Earth and radiation reemitted by Earth. Measurements are being made by a dedicated satellite, the Earth Radiation Budget Satellite (ERBS) which was launched Oct. 5, 1984, and by an Instrument on the NOAA-N series of satellites.
}

change system involved in the absorption and reradiation of solar influx by Earth's surface is a major component of weather analysis. A Solar Backscatter Ultraviolet Radiometer (SBUR) will provide global sensings of the vertical distribution of ozone to assist determination of the effect of human activities on this essential protective shield and to further understanding of the relationship of ozone to weather changes,

Internationally, the principal technological thrust is toward devising more sensitive and stable sensors for polar-orbiting spacecraft, increasing the operational use of the microwave spectrum for atmospheric temperature and humidity measurements, and increasing the use of the Data Collection System for the international hydrological community.

\section{Foreign Systems}

Other nations maintain operational satellite systems for both national purposes and as part of 


\section{Ground-Based Sensor Data}

Remote sensors achieve greater value for weather analysis when combined with data from ground-based measurements. Ground-based sensors can provide data not now obtainable by a satellite-borne sensor, such as surface wind and pressure, rainfall amount, river levels, sea salinity, or subsurface oceanic temperatures. Because the ARGOS system can locate these surface platforms containing ground-based sensors, it is also possible to determine ocean currents and atmospheric winds. Ground-based observations also provide "ground truth" data valuable in verifying and correlating large-scale weather patterns predicted through analysis of satellite observations.

For their data to be useful for weather monitoring, moving platforms, such as ships or aircraft, must be capable of reporting their own position when reporting to geostationary satellites. Fixed platforms can be of three types: 1) self-timed, which report under control of an internal clock on a frequency and time assigned by an opera$\mathbf{t}_{\text {or }} ; 2$ ) interrogated, in which a receiver replaces the clock to allow the satellite ground station to signal for a report on a flexible time schedule; and 3 ) alert, in which a special repmting frequency is allocated for a signal from the platform that some particular phenomenon has exceeded a preestablished threshold. The number of platforms that can be incorporated into the data collection service (DCS) is limited by the time required to interrogate, receive, and relay signals. Still, DCS capabilities have greatly expanded the availability of observations by obtaining data from remote areas not accessible to satellite sensors or ground telecommunication systems.

the international environmental data gathering community:

\section{- European Space Agency (ESA)-Meteosat-}

2. The geostationary satellite, located at $0^{\circ}$ longitude, provides raw imagery of European weather conditions to Europe as well as relaying processed imagery from U.S. geostationary weather satellites. It carries a visible and infrared scanning radiometer, a Data Collection System, and a weather facsimile service (WE FAX). An improved Meteosat is planned for launch in 1985.

- India-1nsat-1. This geostationary satellite provides both telecommunications and limited meteorological data. Visible and infrared images are available every 30 minutes from Insat 1's Very High Resolution Radiometer (VHRR). The spacecraft also has a data collection system. The satellite $1 \mathrm{~B}$, which replaced Insat-IA, was launched successfully by space shuttle Mission 8 in August 1983. The complete operational system will consist of two spacecraft, one at $74^{\prime} \mathrm{E}$ longitude and a second at $94^{\circ} \mathrm{E}$ longitude.

- Japan-Geostationary Meteorological Satellite, GMS-3 (Himawari or Sunflower 3). This was launched by Japan on a Japanese NII launcher in August 1984, and is the third in a series of geostationary meteorological satellites. Located at 140 "E longitude, the satellite carries a visible and infrared radiometer, a space environment monitor, DCS, and WE FAX. The Japanese geostationary satellite is a crucial element in forecasting and warning of typhoon development and subsequent flooding.

- Peoples Republic of China. The Chinese are working on a polar-orbiting and a geostationary meteorological satellite; their launch dates are uncertain.

- The U.S.S.R. polar-orbiting meteorological program consists of two or three METEOR2 series spacecraft that fly a near-polar orbit at a $900 \mathrm{~km}$ height with an orbital inclination of 810. The METEOR-2 carries five sensors: a scanning telephotometer that acquires imagery at visible wavelengths with a $2.0 \mathrm{~km}$ resolution; television-type scanner at the same wavelengths but with $1.0 \mathrm{~km}$ resolution; an infrared scanning radiometer; an 8-channel infrared scanning radiometer that senses the vertical temperature distribution in the atmosphere; and a radiometer that monitors high energy radiation influx from space.

Data available from these instruments provide analysis of the global distribution of clouds and snow and ice cover, global radiation temperature of the surface, cloud-top 
Figure 7-5.-Advanced TIROS.N

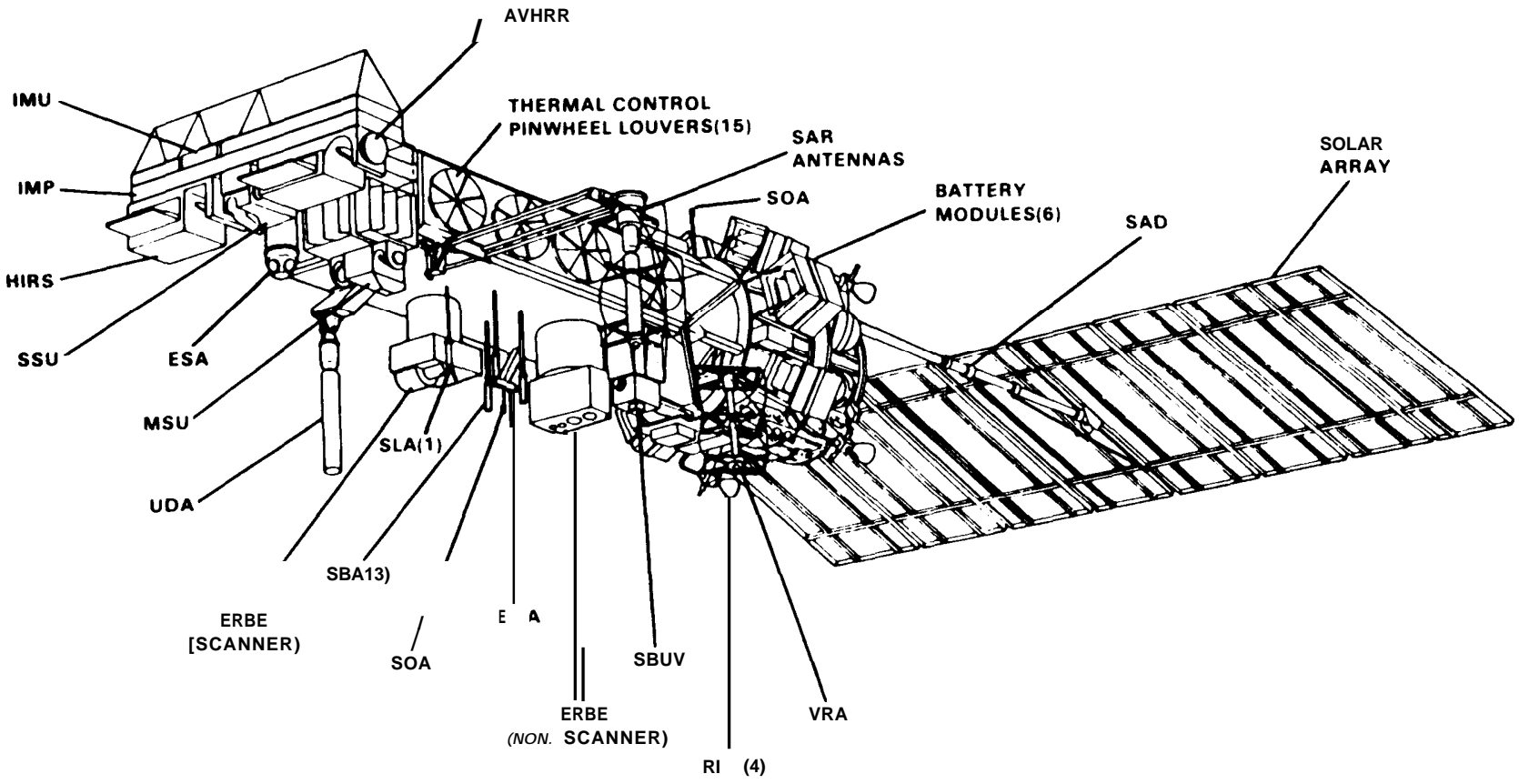

SOURCE. Nat[onal Oceanic and Atmospheric Adm!nistration.

MISSION: Collect global data on cloud cover, surface conditions such as Ice and snow. surface and afmosphenc temperatures. and atmospheric humldtty, measure solar particle flux, collect and relay informatlon from hxad and mowng data platforms, prowde continuous data broadcasts

ORBIT: 833- and 870-km ctrcular, 9889 mclrratlon, 14-14 revsday

SENSORS AND FUNCTIONS:

. Advanced very High Resolutlon Radiometer (AVHRW2)

$1 \mathrm{I}-\mathrm{km}$ resolution. 2600-km swath width Channels Wavelengths $(\mathrm{Km})$

$20725-1 \quad 10$

primary Ueea
Daytime cloud, surface mapping Surface water delineahon. Ice and snow melt

$3 \quad 355-393$

$4 \quad 1030-1130$ mappmg

Sea surface temperature, day and nighl cloud mappmg

5 1150-1250 $\begin{aligned} & \text { Sea surface temperature. day and night } \\ & \text { cloud mappmg }\end{aligned}$
clo

.TIROS Operational Vertlcal Sounder (TOVS):

A 3-sensor atmospheric sounding system

(1) High Resolution Infrared Radiatlon Sounder (HIRS/2) 17 4-km resolution

$1-5 \quad 1495-1397$

6-7 1364-1335

1111

$\begin{array}{ll}9 & 971 \\ \mathbf{1 0 - 1 2} & \mathbf{8 1 6 - 6 7 2}\end{array}$

13-17 457-424

$18-20 \quad 400.069$
Primary Use Carbon dloxlde \& water vapor bands Surface temperature, clouds Total $0_{3}$ concentration

Humldlty profiles, detection of thin cirrus clouds

Temperature profiles

Clouds surface temperatures under partly cloudy skies
(2) Stretospharic Sounding Unit (SSU): 147 3-km resolution Channals Wavelengths (vm) Prtmary Uses 1-3 15 Temperature profiles (3) Microwave Sounding Unit (MSU): 105-km resolution Channela Frequencies

$15031 \mathrm{GHz}$

$3 \quad 5496(+\mathrm{iz}$

$5795 \mathrm{CiHz}$

Temperature soundings through clouds

Space Environment Monitor (SEM): Measures solar particle flux at spacecraft

(1) Total Energy Detector (TED): Solar particle mtensty from 03- to 20-keV

(2) Madlum Energy Proton and EIWron Detector (MEPED): Protons, electrons and lons $\mathrm{m} 30$ - to $60-\mathrm{keV}$ range

ARGOS Data Collection System (DCS) (French): Collectlon and relay of data from fixed or movmg automatic sensor platforms, determmes location of movmg platforms

DIRECT BROADCAST: Contmuousdata broadcasts avadable to any recewmg station wthm range

.Automatic Picture Transmlaaion (APT): Vwble and Infrared Imagery at 4-km resolution VHF broadcasts at 13750 or $13762 \mathrm{MHz}$ Basic ground equipment costs about $\$ 25.000$ (U S ) m 1981

0 tllgh Resolution Picture Transmission (HRPT): V!s!ble and Infrared data at $1 \mathrm{~km}$ resolution S-band broadcasts at 16980 and $17070 \mathrm{MHz}$ Basic ground equlpmer)t costs about $\$ 250000$ (U S ) In 1981

0 Direct Sounder Broedca.t (DSB): TOVS data Iransmftted for use In quantitative programs Broadcast at 13677 or $13777 \mathrm{MHz}$ (Beacon Frequency) and In the HRPT data stream Conventional ground recelwng station required but specialized data processng is necessary 10 produce environmental In formation 
Figure 7-6.-GOES Satellite

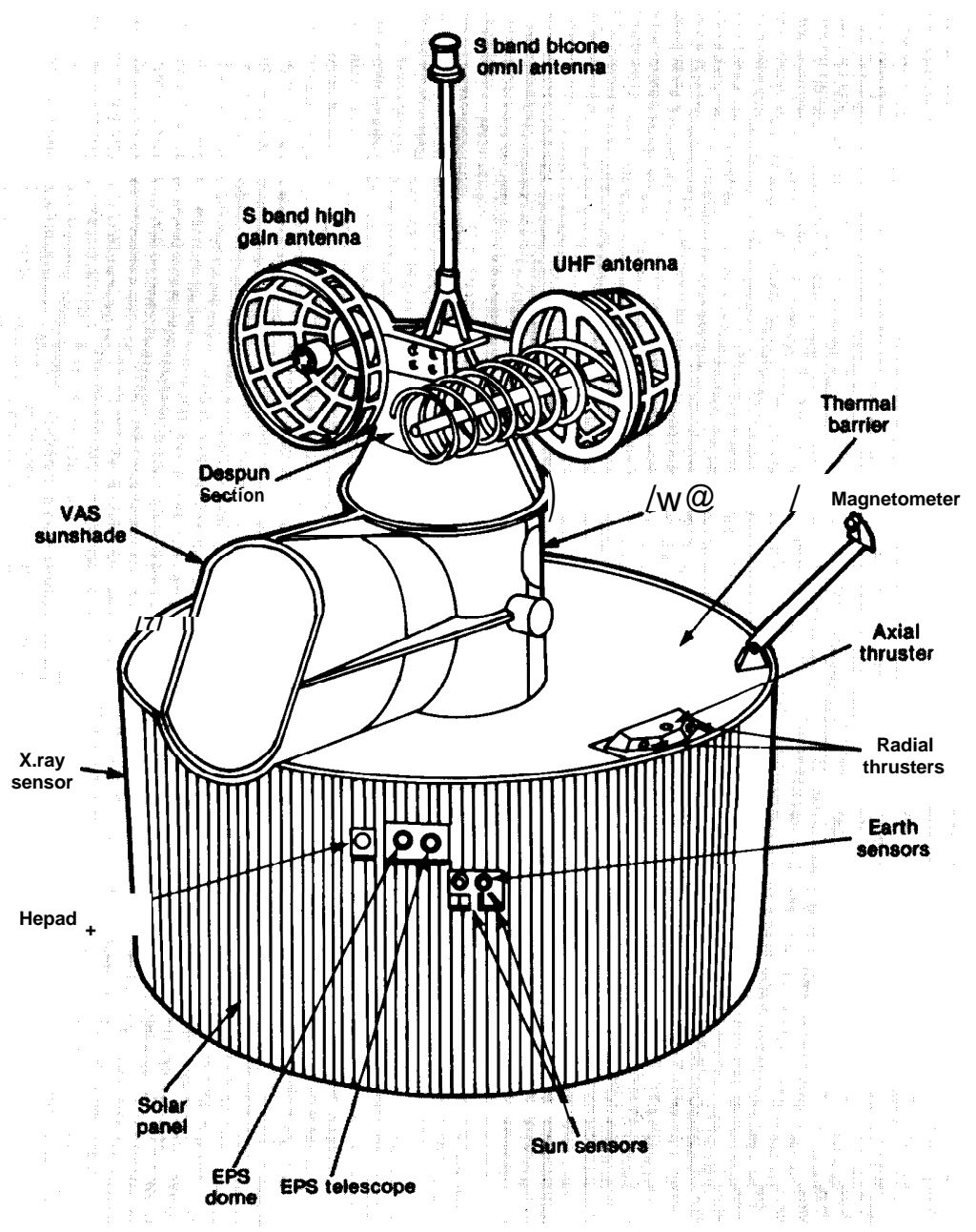

SOURCE: National Oceanic and Atmospheric Administration

MISSION: Repetttwe observations of the earth dsk and overlaying atmosphere ( $n$ the held of wew measurements of solar $x$-rays and the proximate space enwronment, collection and relay of data from platforms at or near the earths surface, broadcast of data and environmental informallon

ORBIT: $35,800-\mathrm{km}$ geosynchronous GOES East over equator at 75 " W GOES West at $135 \mathrm{~W}$

SENSORS AND FUNCTIONS:

- Visible and Infrared Spin Scan Radiometer (VISSR) Atmospheric Sounder (vAS): The VAS is a visible and infrared radiometer capable of providing both multi-spectralımaging and dwell sounding data It possesses eight visible and sIx infrared detectors Positioning a fitter wheel allows selections from among 12 spectral bands wincentral wavelengths between 39 and $15 \mathrm{\mu m}$ VAS scans spectral bands wh centain scans west to east inconjuncention mirror provides pole to pole scanning Resolutions are 1-km in the visible and 7- or 14-km in the infrared depending upon the selection of iR detectors Visible imaging data are provided routinely every 30 minutes by each spacecraft during daylight and infrared $(7-\mathrm{km})$ imagingdata, on the same schedule. are provided day and nıght

. Space Environment Monitor (SEM): Composed of 4 subsystems

( 1 i X-Ray Sensor Provides data on solar $x$-ray activity in two wavelength bands $O$ 5-3 OA and 1-8A

(2) Energy Particle Sensor Determines intensity of charged particle flux in the following ranges
Protons $\quad-08$ to $500 \mathrm{MeV}, 7$ log ranges

Aiphas -32 to $400 \mathrm{MeV}, 6 \mathrm{log}$ ranges

Electrons $=2 \mathrm{MeV}$. 1 range

(3) High Energy Proton and Alpha Detector (HEPAD) Protons in the 379-keV range, alpha particles in the $850-\mathrm{keV}$ range

(4) Magnetometer Monitors magnitude and direction of ambient magnetic field, paralleilfield $(+1200 \gamma)$ and transverse fieid in 4 selectable ranges $( \pm 50 \gamma=100 \gamma,-200 \gamma$, or $\div 400-\gamma)$

Data Collection System (DCS): Relays UHF interrogatıons to and data from sensor platforms reporting environmental data

DIRECT BROADCAST: Broadcasts avallable to any ground station within range

0 WEFAX: Retransmission of processed data at $16910 \mathrm{MHz}$ Along with meteorological charts, GOES imagery at $8-\mathrm{km}$ resolution and NOAA Imagery al 8 to $12-\mathrm{km}$ resolution are transmitted $A$ daily operational message is transmitted that provides schedules and contents A basic ground capability costs about $\$ 8,000(U$ S ) in 198

, Stretched Sensor Data: A retransmission at a reduced rate, of the data burs that occurs during the 20' angular sweep of VAS detectors across the earth that occurs during the 20 ' angular sweep of VAS detectors across the earth
The transmission is on S-band at $16871 \mathrm{MHz} \mathrm{A}$ basic ground station that includes a fimited product capability costs about $\$ 150$ o00(US ) in 1981 
Figure 7-7.-GOES Geographic Coverage

One satellite

Two satellites
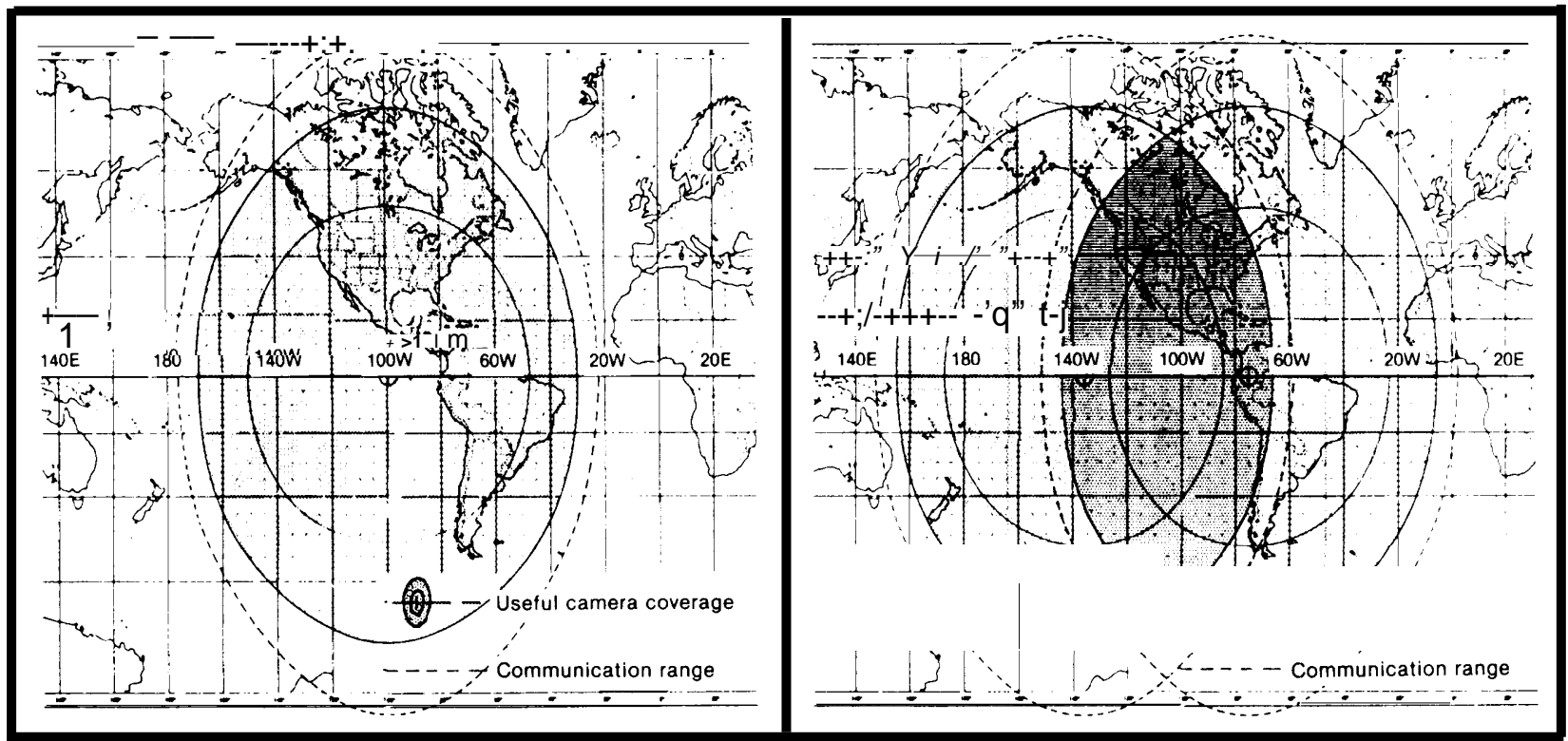

SOURCE: National Oceanic and Atmospheric Administration.

heights; and vertical distribution of temperature. Only the United States and the Soviet Union operate polar-orbiting meteorological spacecraft.

The Soviet Union plans to launch a Geostationary Operational Meteorological Satellite (GOMS) this year, which will carry visible and infrared sensors. It will be stationed at $70^{\circ} \mathrm{E}$ longitude and will have a scanning radiometer operating at visible and infrared wavelengths, DCS, and WEFAX. Soviet designers are investigating the feasibility of operating a geosynchronous satellite inclined by $65^{\circ}$ to the Equator. ${ }^{13}$ The ground track of such a satellite would describe a figureeight pattern (fig. 7-8) and have the dual advantage of spending some time over the Soviet Union, the northern reaches of which are inaccessible to a satellite positioned over the Equator, and also over the Indian Ocean where observations critical to certain Soviet military operations would be possible.

\footnotetext{
I $^{3}$ Nicholas L. Johnson, "The Soviet Year in Space: 1983," Teledyne Brown Engineering, 1984, p. 24.
}

\section{International Cooperation in Meteorological Satellite Systems}

The United States has encouraged direct reception of data (at no cost) from its civilian meteorological satellites on an international basis for over 20 years. There are about 1,000 direct readout stations in over 125 countries (table 7-1). In addition, NOAA sells metsat data products worldwide. Foreign sales of U.S. meteorological value-added data products were about 13 percent of product sales (provided at cost of reproduction) in fiscal year $1984 .^{14}$

The United States cooperates with other nations through the World Meteorological Organization (WMO), a specialized agency of the United Nations whose purpose is to coordinate, standardize, and improve meteorological services throughout the world (see box, p. 268).

The United States has also reached bilateral and multilateral agreements in the form of Memoranda of Understanding with foreign governments

\footnotetext{
${ }_{1}^{4}$ Figure provided by National Environmental Satellite, Data, and Information Service of NOAA.
} 
Figure 7-8. -Path of Geosynchronous Satellite in Inclined Orbit

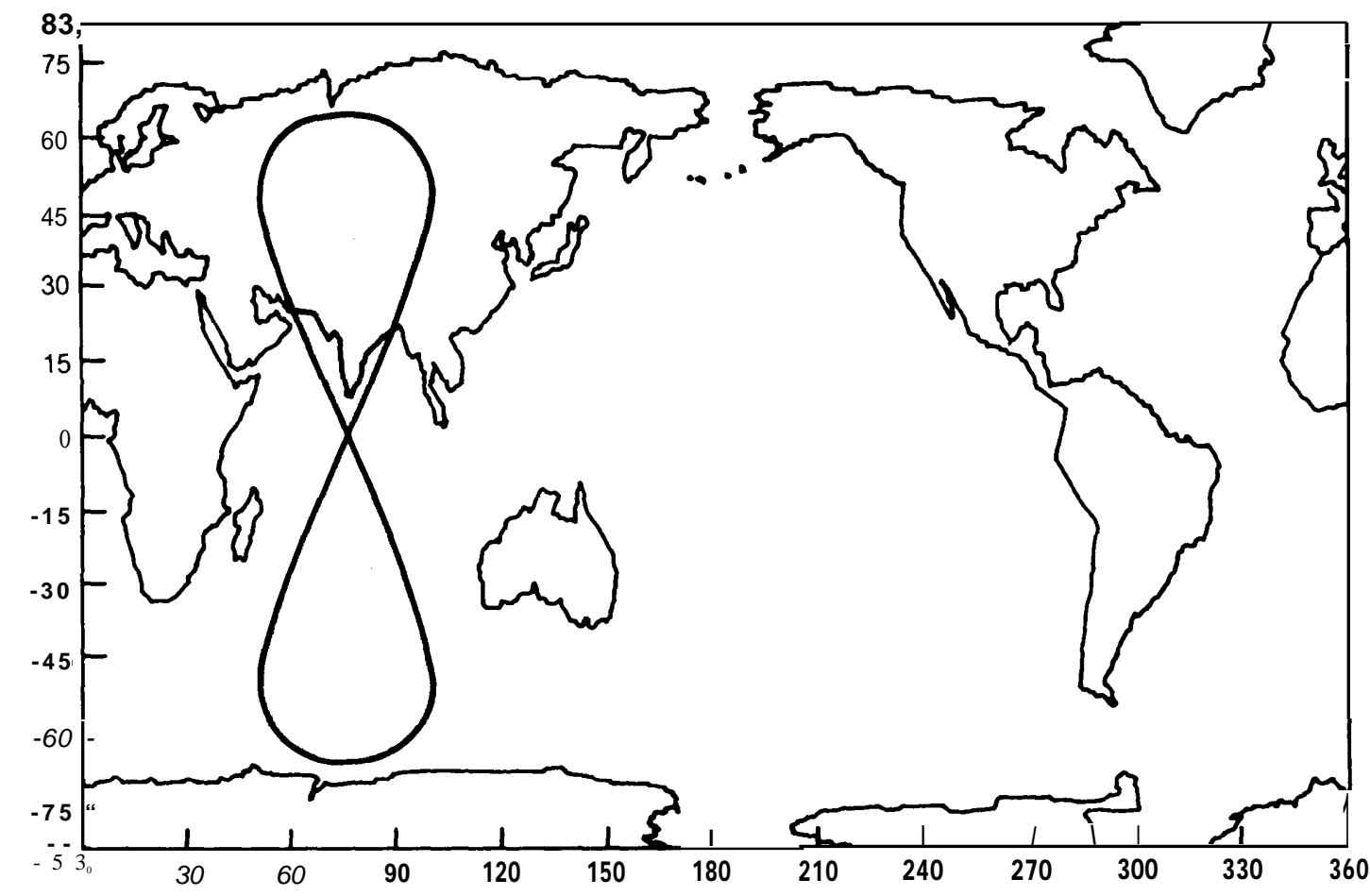

NOTE: A geosynchronous satellite in an orbit inclined $65^{\circ}$ to the Equator would trace out a daily figure eight pattern like the one Illustrated above A geosynchronous satellite in an orbit inclined $65^{\circ}$ to the Equator would trace out a daily figure-eight pattern like the one illustrated above.

SOURCE: N Johnson, "The Soviet Year in Space, 1983," Teledyne Brown Engineering, January 1984, p. 24.

concerning use of the U.S. Data Communications System. In order to be included in the system, foreign projects must be of interest to a U.S. Government agency and must meet certain technical criteria for system use. In some cases, data included in this system may be treated confidentially by the United States. However, all data in the system are available to NOAA.

As mentioned earlier, the United Kingdom has provided the Stratospheric Sounding Unit for the U.S. TIROS-N polar orbiter. The French provide and operate the ARGOS data collection system for the NOAA polar orbiter. These arrangements make the polar-orbiting satellites much more capable than they would be otherwise.

Finally, under an agreement among the United States, Canada, France, and the Soviet Union, the polar orbiting satellites are being used for search and rescue of downed aircraft in remote areas (COSPAS/SARSAT-see app. A).

\section{Data Products and Service}

This section summarizes the data products and services derived from meteorological satellite data that are routinely available through NOAA. All of these data products are available to users around the world either for free (through radio, TV, or telephone) or for purchase on a nondiscriminatory, cost-reimbursable basis from NOAA. Table 7-2 lists the categories of U.S. domestic users of such data. The categories of international users are similar.

\section{Weather}

Table 7-3 summarizes the major weather-related products provided by NOAA. In addition, 


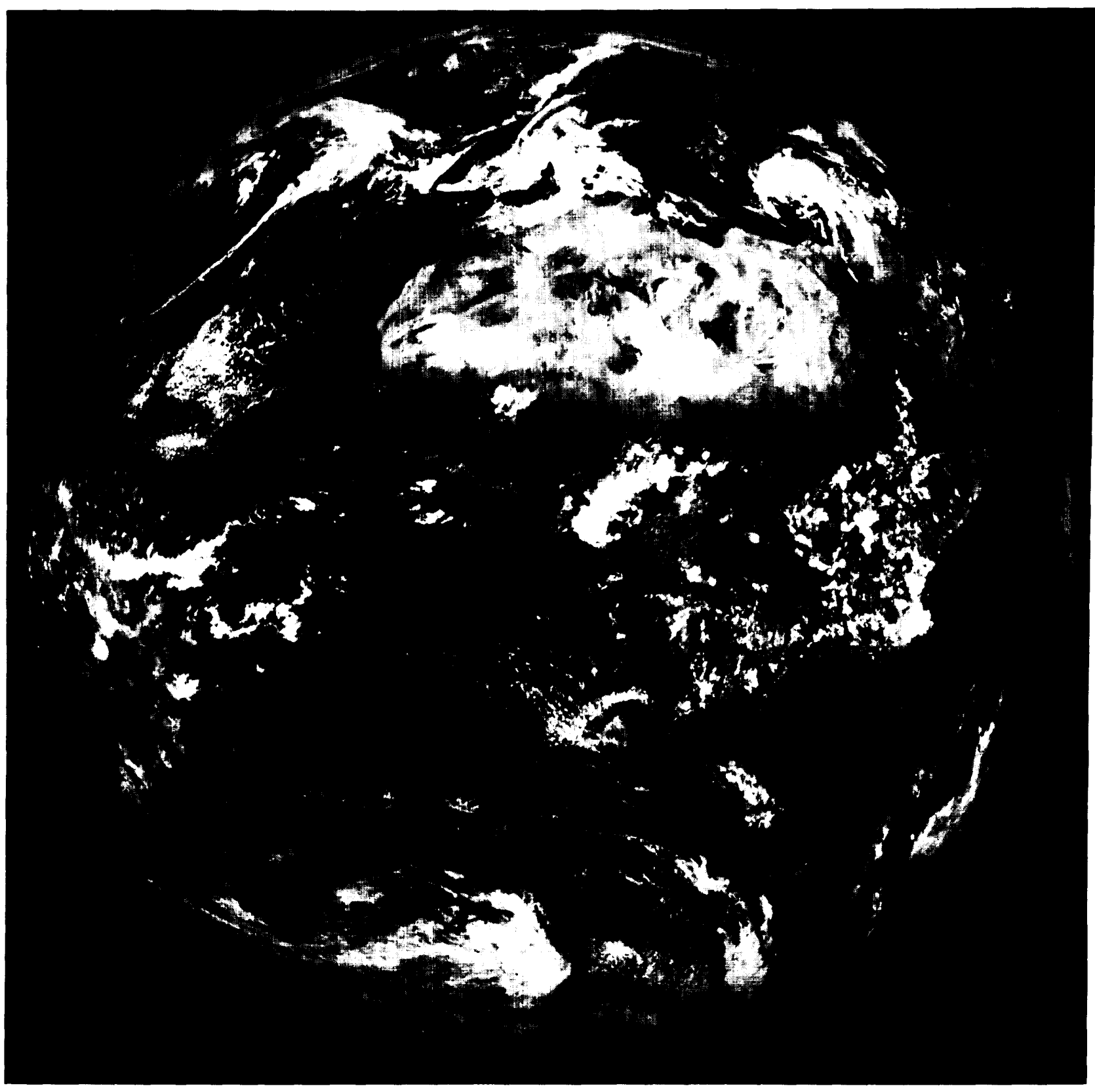

Photo credit: European Space Agency

Visible wavelength image of weather patterns on Earth, as taken by Meteosat, the European geostationary meteorological satellite. Meteosat was developed and built by the European Space Agency. 
Table 7-1. Countries With APT/HRPT Reception Capabilities

\begin{tabular}{|c|c|c|}
\hline Countries with APT facillties: & Ivory Coast & Turkey \\
\hline Afghanistan & Japan & Union of Soviet Socialist Republics \\
\hline Algeria & Jordan & United Arab Emirates \\
\hline Angola (status unknown) & Kenya & United Kingdom \\
\hline Antarctica (USN res.) & Korea (South) & United States \\
\hline Argentina & Kuwait & Upper Volta \\
\hline Australia & Madagascar & Uruguay \\
\hline Austria & Malaysia & Venezuela \\
\hline Azores & Mali & Viet-Nam, Republic of (status unknown) \\
\hline Bahamas & Malta & Yugoslavia \\
\hline Bahrain & Martinique & Zaire \\
\hline Bangladesh & Mauritania & Zambia \\
\hline Barbados & Mauritius & Zimbabwe \\
\hline Belgium & Mexico & Countries with HRPT facilities: \\
\hline Bermuda & Mongolia & Bangladesh \\
\hline Bolivia & Morocco & Belgium \\
\hline Brazil & Mozambique & Brazil \\
\hline Bulgaria & Nepal & Canada \\
\hline Burma & Netherlands & Czechoslovakia \\
\hline Cambodia (status unknown) & Netherlands Antilles & Denmark \\
\hline Cameroon & New Guinea & France \\
\hline Canada & New Zealand & Germany, Federal Republic of \\
\hline Canary Islands & Nicaragua & Greenland \\
\hline Chile & Nigeria & India \\
\hline Colombia & Norway & Indonesia \\
\hline Costa Rica & Oman & Iran \\
\hline Curacao & Pakistan & Italy \\
\hline Czechoslovakia & Papua New Guinea & Japan \\
\hline Denmark & Paraguay & Korea (South) \\
\hline Dominican Republic & People's Republic of China & Malaysia \\
\hline Ecuador & Peru & Mongolia \\
\hline Egypt & Philippines & Netherlands \\
\hline El Salvador & Poland & New Zealand \\
\hline Ethiopia & Portugal & Norway \\
\hline Fiji & Romania & People's Republic of China \\
\hline Finland & Saudi Arabia & Saudi Arabia \\
\hline France & Scotland & Singapore \\
\hline French Guiana & Senegal & South Africa \\
\hline Gambia & Seychelles & Sweden \\
\hline German Democratic Republic & Sierra Leone & Switzerland \\
\hline Germany, Federal Republic of & Singapore & Taiwan \\
\hline Ghana & Somalia & Thailand \\
\hline Greece & South Africa & Tunisia \\
\hline Greenland & South Yemen & Union of Soviet Socialist Republics \\
\hline Guadaloupe & Spain & United Kingdom \\
\hline Guatemala & Sri Lanka & United States \\
\hline Guyana & Sudan & Yemen (South) \\
\hline Honduras & Surinam & \\
\hline Hong Kong & Sweden & \\
\hline Hungary & $\begin{array}{l}\text { Switzerland } \\
\text { Syria }\end{array}$ & \\
\hline $\begin{array}{l}\text { Iceland } \\
\text { India }\end{array}$ & $\begin{array}{l}\text { Syria } \\
\text { Tahiti }\end{array}$ & \\
\hline $\begin{array}{l}\text { India } \\
\text { Indonesia }\end{array}$ & $\begin{array}{l}\text { Tahitı } \\
\text { Taiwan }\end{array}$ & \\
\hline $\begin{array}{l}\text { Indonesia } \\
\text { Iran }\end{array}$ & Tanzania & \\
\hline Iraq & Thailand & \\
\hline Israel & Trinidad and Tobago & \\
\hline Italy & Tunisia & \\
\hline
\end{tabular}

SOURCE" National Oceanic and Atmospheric Administration. 


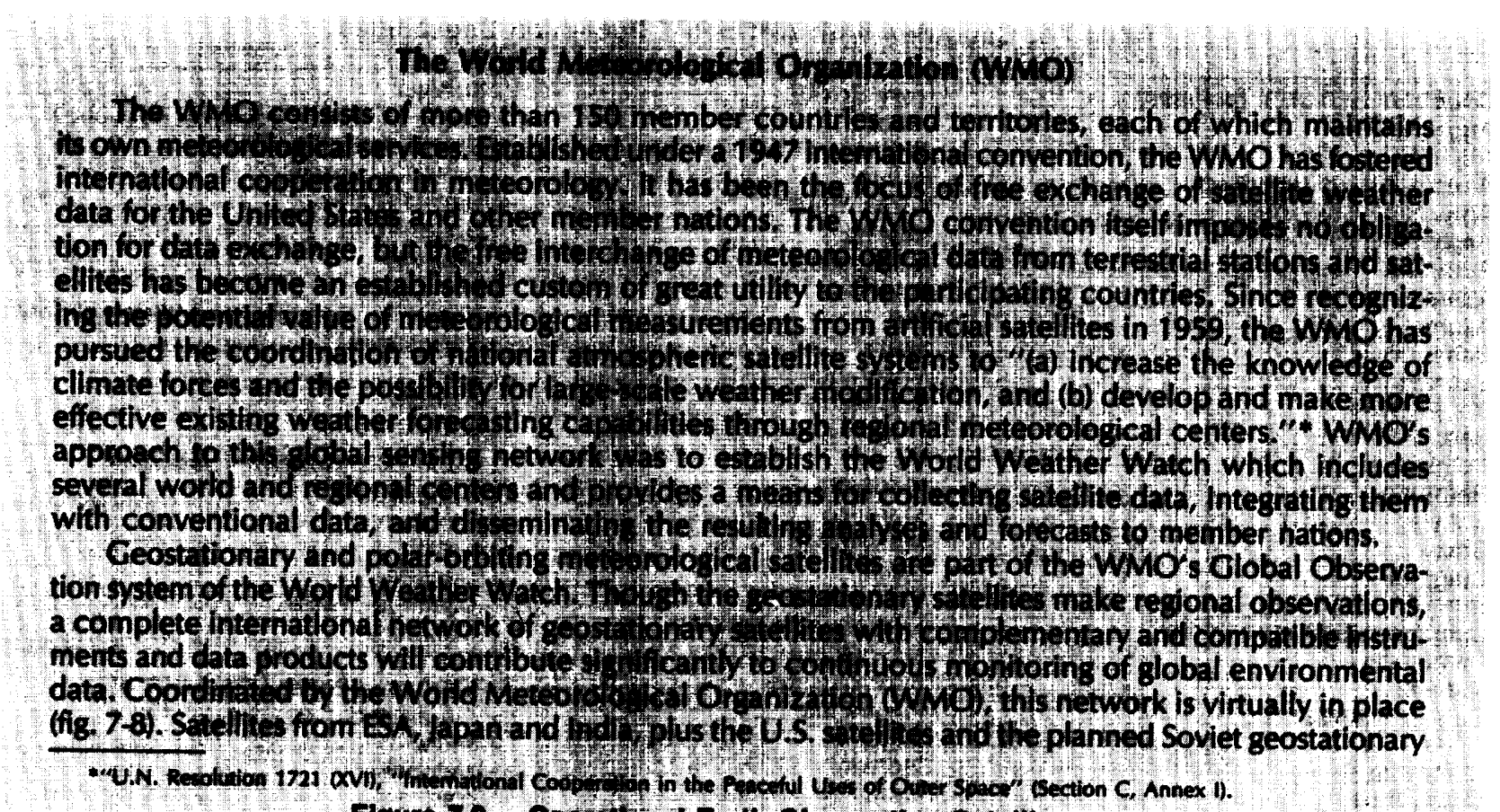

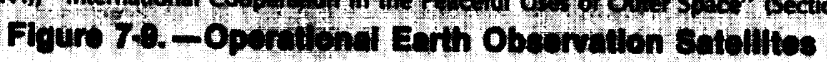

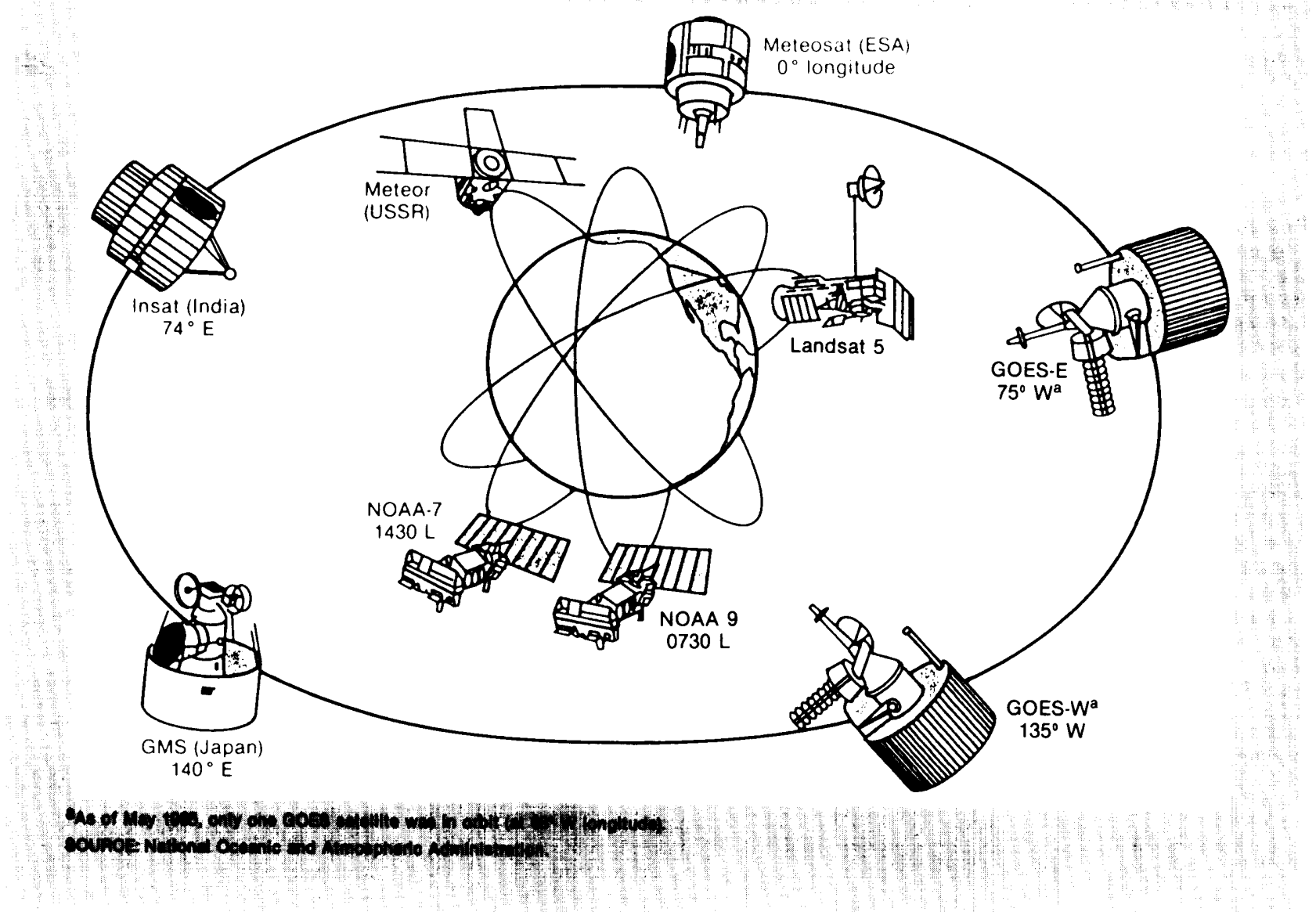


satellite, make up the heart of the World Wudthen oflket. Metsat data received in the United States support the National Weather Servicegeshetroerdefense, and international aviation. Most of the data on the Global Telecommunication \& System come from countries other than the United States.**

In collaboration with the International Council of $\sim \mathrm{ie}<\mathrm{pt|} \sim$ LJaiO $\$$, the WMC) established the Global Atmospheric Research Program (GARP) tonuliowaliopalfprojectse-scale atmospheric data gathering. The principal experiment of this kind was the F@tKb4RP Global Experiment (FGGE), held in the late 1970s, which prompted extensive nat[onal and [@emotional planning for development of meteorological systems. The WMO was assisted in this coa\&?atlve effort by an informal forum of representatives of governments and organizations praposit\&aU\%mch geostationary meteorological satellites, the Coordination of Geostationary Meteoro!ogidill(teGMS), This group was effective in coordinating technical characteristics and operational pr@@qres ofsystems as well as assuring similarity of data transmissions and platform data collection proc +wes. The activities of these organizations led to support of the FGGE in 1978 and to the current glt@a'1 meteorological system.

$\cdot$

**"Satellite Systems in Support ofWMO Programmes and Joint ProgrammecWith Other InternationaOrganizations" prepared by theWMO for Unispace-82, Geneva, January 1982, pp. 20-21.

the National Weather Service (NWS) (table 7-4) combines satellite data with other weather data to develop weather forecasts designed to be useful to a variety of commercial interests, including aviators, farmers, fishermen, fruit growers, and

Table 7.2.-Domestic Users of Meteorological Satellite Data

- NOAA

-National Weather Service Centers and Forecast Offices

-National Ocean Service

-Office of Research

- Department of the Interior

-Bureau of Land Management and Reclamation

-Water Resources Division

- Department of Agriculture

-Soil Conservation Service

-Forestry Service

-Foreign Agriculture Service

- NASA

- Department of Defense

- Agency for International Development

- Department of Transportation

- National Science Foundation, National Academy of Science

- News media

- Commercial users

-Offshore drilling operations

- Ship routing

-Agricultural producers

-Commercial and general aviation

- Vessels at sea

-Fishing industry

- Universities

- Private individuals

Source: National Oceanic and Atmospheric Administration.
Table 7-3.-Derived Meteorological Satellite Products

- Soundings -Temperature profiles from the surface through the stratosphere

Sea Surface Temperature-Global and regional sea surface temperature and water mass analyses

- Ice-Ice analyses of the polar regions and Great Lakes

- Vegetation index - Measure of how "green" a target area appears.

-Rainfa'11" Estimates

Hurricane Classification

- Cloud Motion Winds

Satellite Interpretation Messages

- Tropical Storm Bulletins

Cloud Top Height Data

aThese productsare available in a variety of forms e $\mathrm{g}$, charts, broadcast messages, and imagery

SOURCE: National Oceanic and Atmospheric Administration.

Table 7-4.- National Weather Service Hurricane, International Aviation, and Marine Forecast Programs

- Hurricane forecasts and warnings

International aviation weather services

-Area forecasts

-Inflight advisories (hazardous weather)

-Computer flight planning forecasts

- High seas weather services

-Weather, waves, currents, and sea ice forecasts

- Navigation and operations support

-Forecasts and warnings for U.S. coastal and offshore waters

-Tsunami warnings and advisories

SOURCE: National Oceanic and Atmospheric Administration. 
commercial shippers. The broadest category of weather data users are the millions of ordinary citizens who tune in to or read the daily forecast for guidance in preparing for work and recreation. NOAA and NWS also provide special warning of hurricane, tornado, and other severe weather conditions.

\section{Land and Ocean}

Meteorological remote sensing is not limited solely to weather applications, as the sensors can also measure important land and ocean phenomena throughout the world. Using data derived from channels 1 and 2 of the polar-orbiters' AVHRR to sense visible and near-infrared radiations, the U.S. Department of Agriculture, as well as the United Nations' Food and Agriculture Organization and private value-added corporations, are able to monitor and analyze global crop conditions (see later section on market for land remote sensing data). Identification of urban "heat islands" sensed by the High-Resolution Infrared Sounder assists planners in monitoring metropolitan industrial and population growth. NOAA provides analyses of meteorological satellite observations of snow and ice as both hydrological and oceanographic products.

Hydrological products using the AVHRR and GOES-VISSR instruments include the following at $1 \mathrm{~km}$ resolution: snow coverage observations of selected river basins; regional snow coverage analysis for selected regions of the world; and a northern hemisphere snow and ice chart. These products are valuable for assessing water runoff potential.

Products for oceanographic use include ice charts produced from AVHRR readings for the polar regions and a combination of AVHRR and geostationary VISSR imagery for the Great Lakes region, both to accuracies of $5 \mathrm{~km}$. These analyses are particularly useful in forecasting the limits of the shipping season in particular regions and commercial ship routing, as well as for U.S. Navy and U.S. Coast Guard missions.

Global sea surface temperature (SST) observations are received daily from AVHRR infrared data and the High-Resolution Infrared Radiation Sounder (H IRS-2) data aboard the polar orbiters.
Accuracies of $1.50 \mathrm{C}$ are achieved over 70 percent of the oceans. Regional SST charts, distributed through NOAA Satellite Field Service Stations in Miami, Washington, DC, San Francisco, and Anchorage, are particularly useful to commercial fishermen for locating certain species of fish. Ocean current analyses include thermal front analysis of the waters off the west coast of the United States, which also benefits fishermen by identifying nutrient-rich ocean upwellings attractive to fish. Observations in the infrared using AVHRR can give an accuracy of $5 \mathrm{~km}$ for locating frontal zones. Ocean current navigation is assisted by analyses of polar-orbiter AVHRR infrared and GOES-VISSR imagery of the Gulf stream and "loop currents" in the Gulf of Mexico. The thermal boundaries of these currents and their eddies can be determined with an accuracy of $5 \mathrm{~km}$, which allows fuel savings and reduces hazards for fishing and shipping interests. All of these data products are available for purchase on a nondiscriminatory cost-reimbursable basis from NOAA to users around the world.

\section{Market for Metsat Equipment and Services}

The market for civilian metsat equipment and services can be divided into three categories: the space component, ground station equipment, and various services related to reception and data distribution.

\section{Satellite Manufacturers}

The primary U.S. manufacturers are Hughes Aircraft Corp., which has built the U.S. (GOES) and most of the Japanese (GMS) geostationary satellites, ${ }^{15}$ and RCA Astro-Electronics, which has built the NOAA-N series of polar orbiters. ${ }^{\mathrm{b}}$ The General Electric Corp. built the Nimbus series of research satellites for NASA.

The GOES satellites (4-6) cost approximately $\$ 15$ million apiece and are designed to last about 5 years. ${ }^{17}$ Replacement satellites (GOES-G and

\footnotetext{
${ }^{15}$ The GMS- 2 and Gms- 3 satellites were built by Hughes and Nippon Electric Corp.

${ }^{16}$ RCA alsobui Ids the DMSP satellites for DOD.

17However, GoEs-5 lasted only 3 years. GOES-4 failed even sooner.
} 


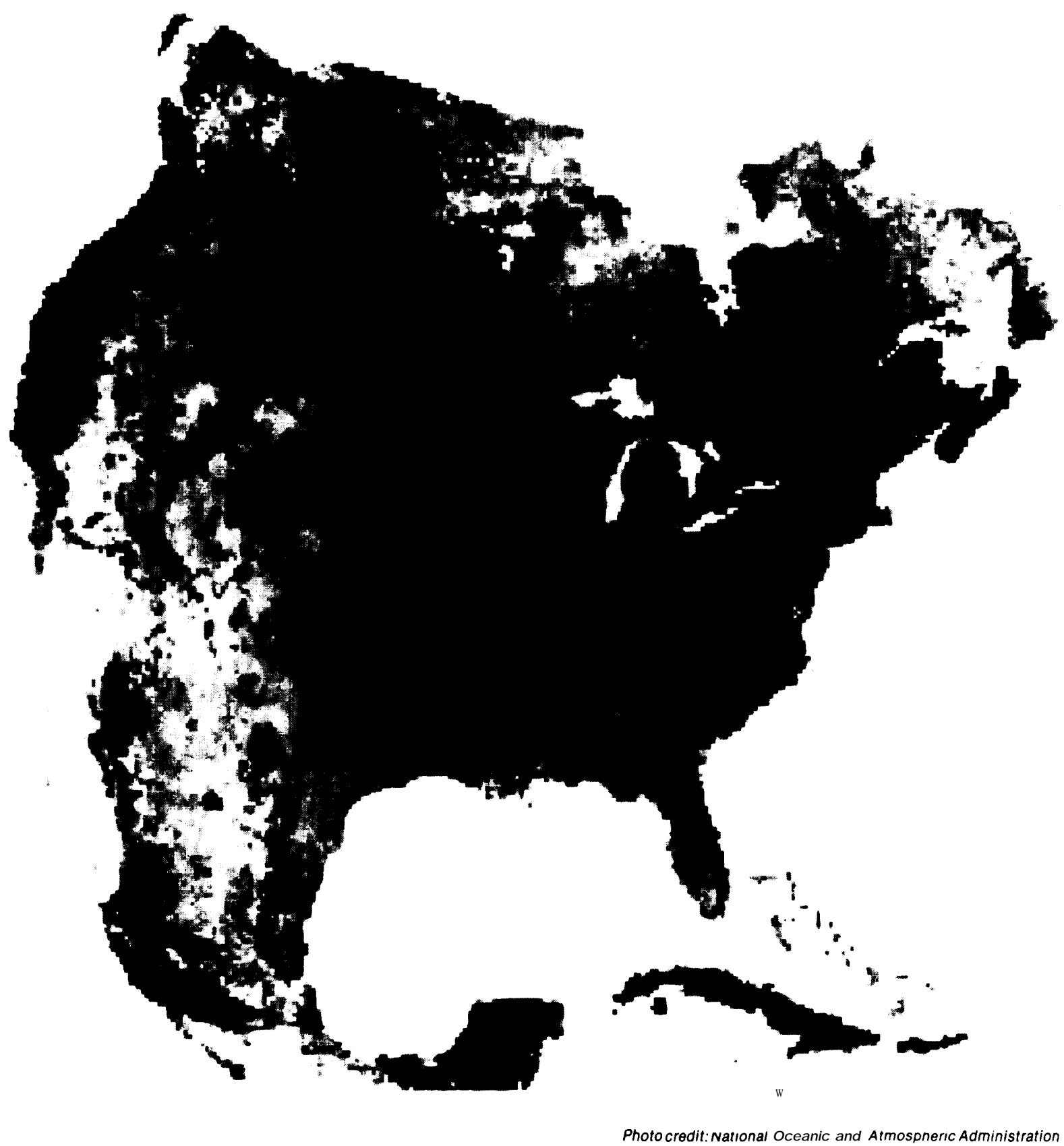

Sixday normalized vegetative index composite made with data from instruments aboard the NOAA-N series polar orbiter. 
GOES-H), built by Hughes, are expected to cost about $\$ 50$ million and will be designed for a similar lifetime. Future satellites in the series, which will be much more capable, will likely cost about $\$ 100$ million apiece. Two GOES satellites are necessary for complete coverage of the United States. The NOAA-N polar orbiters $(\mathrm{H}, 1, \mathrm{~J})$ cost approximately $\$ 45$ million but future models will cost about $\$ 100$ million. Each polar orbiter is designed to last 3 years and two are normally orbiting at any one time.

The European (Meteosat) geostationary satellites, which constitute the satellite portion of Eumetsat, were built by a consortium headed by the French firm Aerospatiale. ${ }^{18}$ Two Meteosat satellites have been launched since 1977. Although Europe has no polar-orbiting system, the United Kingdom and France contribute sensors to the U.S. polar orbiters.

\section{Satellites}

For several reasons, the overall market for meteorological satellites or for individual sensors is likely to remain small and competition highly limited. First, because the complete international geostationary system gives rather good coverage of the world as it is, no sales to countries that do not presently own a system are likely. * Second, because satellites are owned by national governments, countries will tend to purchase satellites from their own vendors.

- The United States. GOES G and H are planned for delivery in late 1985 and mid-1986 respectively. The GOES-Next series of advanced geostationary satellites (five are planned) will be needed in 1989 and beyond, but have not yet been ordered. NOAA-G is planned for launch in 1985. The Advanced NOAA series of polarorbiting satellites are also planned but have not yet been ordered.

\footnotetext{
${ }^{18}$ The other members of the consortium are Matra (France), IGG (United Kingdom), Marconi Space and Defense Systems (United Kingdom), Messerschmitt-Boelkow-Blohm (Federal Republic of Germany), ANT (Federal Republic of Germany), ETCA (Belgium), and Selenia (Italy).

*If China proceeds with its present plans to launch a geostationary and a polar-orbiting satellite, it will likely provide its own satellites as part of its effort to develop a capacity in space technology.
}

- Japan. It plans to launch three additional GMS satellites before the end of the century. ${ }^{19} \mathrm{As}$ noted, it purchased major portions of its previous geostationary satellites from Hughes Aircraft Corp. In the future it may attempt to build its own, or consider purchasing its next satellite from Europe. ${ }^{20}$

- Europe. The third Meteosat satellite is scheduled for launch in an Ariane 4 test flight in July 1986. Three more satellites and parts for building a backup satellite are now on order, and are scheduled for launch in August/September 1987, August 1988, and 1990. The market for Meteosat satellites, which are comparable to the GOES series, is essentially closed to U.S. suppliers.

- International systems. The Europeans and the Japanese may contribute to an international polar-orbiting system, in which case, individual countries will contribute instruments or other subsystems to the system (see section below on issues).

\section{Ground Stations}

The primary characteristic of the metsat ground equipment market is its relatively small size. Yearly international sales are extremely difficult to quantify, but representatives of several U.S. firms interviewed by OTA agreed that total yearly sales amount to less than $\$ 20$ million, more than half from U.S. firms. Total worldwide investment in metsat ground receiving stations now equals at least $\$ 200$ million.

Ground stations consist of the relatively inexpensive APT station (approximately $\$ 40,000$ to $\$ 55,000$ ), the more expensive HRPT station (approximately $\$ 0.5$ million to $\$ 1$ million) and any auxiliary data processing equipment. U.S. ground

\footnotetext{
$1{ }^{9}$ According to current Space Council and NASDA plans, Japan will launch GMS-4 in fiscal year 1989, GMS-5 in fiscal year 1994, and GMS-6 in fiscal year 1999. However, production of none of these has been funded. See "Earth Sensors Further Japan's Efforts," Aviation Week and Space Technology, Iune 25, 1984, pp. 151-57.

${ }^{20}$ Last year, European corporations offered to build a replacement satellite for the Japanese patterned after their own meteosat series. The price for the satellite, not including possible modifications to suit it for operation over Japan, is about $\$ 30$ million. The offer included an additional $\$ 30$ million to $\$ 32$ million to launch it on an Ariane launcher. See "Europe Offers Weather Satellite to Japan," Aviation Week and Space Technology, July 2, 1984, pp. 21-22.
} 
equipment manufacturers also supply receivers for a variety of applications, including civilian and military communications, military meteorological applications, intelligence, and command and control; supplying metsat stations and associated data processing equipment is a small part of their total business.

Foreign suppliers of ground station equipment include MacDonald Dettwiler Association, Inc., of Canada, SEP of France, MBB of West Germany, and NEC of Japan. They compete directly with U.S. firms abroad. U.S. firms compete well in the international market because of superior technology. In the past they have been supported in selling to the developing countries by the involvement of NASA, NOAA, and the U.S. Agency for International Development (AID) in extending the use of metsat technology.

There is little market in the United States for additional ground receivers because of easy access to processed data from the National Weather Service, Except for replacement items, most future market expansion will be in the developing world. However, developing countries already own a large number of installations and their future purchasing power is highly dependent on foreign aid programs, especially for the more expensive H RPTs. Technology transfer restrictions are not a problem, even for the high resolution equipment, because these receivers are not capable of conversion for use with military systems.

The foreign commercial market is dominated by foreign suppliers. Many of the purchases by Third World countries are sponsored by WMO through the World Weather Watch. In these instances, supplier selection is based on the usual purchase considerations, including lowest cost, best technology, and local and international politics. Where foreign aid is used, supplier selection will be heavily influenced by the donor country. The donor's influence can be felt either informally, through recommendations, or more formally, through specifications set to favor the donor country's technology. Selling to some foreign governments can be difficult because they often do not release enough information to allow a U.S. company to bid responsibly. Sometimes it is possible to obtain information through other
U.s firms that are successful bidders on another part of the project (e.g., the satellite builder).

\section{Meteorological Satellite Issues}

What Role Might the Private Sector Play in Enhancing the Utility of U.S. Meteorological Satellite Systems?

Suggestions a few years ago that the U.S. meteorological satellites might be transferred to private ownership raised a number of concerns about the domestic and international effects of such a policy. In March 1983, the Reagan Administration announced that it would seek to transfer both the meteorological and land remote sensing satellite systems to the private sector. This proposal was the result of an offer from COMSAT Corp. to purchase the Landsat system from the Government if the meteorological system was also included .21 Although most aspects of this issue have been resolved in favor of continued Government operation of the metsat systems, the related principle of encouraging private sector involvement in space makes continued discussion of the issue appropriate. The following key concerns relate directly to the transfer proposal:

- Data distribution policy. In order to prepare for the eventuality that metsat data would be sold through a private corporation, the Administration began to explore the feasibility of charging for metsat data. Tentative and unofficial suggestions by U.S. officials in the spring and summer of 1983 that the United States might begin to charge other nations for these data were met with warnings from those countries ${ }^{22}$ that the United States was tampering with well-established, long-term practices and that other countries might reciprocate in kind. These nations felt that such a change of policy would introduce an un-

\footnotetext{
${ }^{21}$ See statement of Joseph V. Charyk, of COMSAT before the Subcommittee on Space Science and Applications of the House Committee on Science and Technology and the Subcommittee on Science Technology, and Space of the Senate Committee on Commerce, Science, and Transportation July 23, 1985. COMSAT argued that if both systems were operated by a single entity, certain economies inherent in system operation, and sales of metsat data, would allow it to build the market for Landsat data while charging roughly what the Government was charging for Landsat data.

22," Satellite Storm Ahead, " Nature, vol. 304, p, 202, 1983.
} 
necessary and potentially destructive competitive element into a smooth functioning cooperative arrangement. Because the United States receives more data through membership in WMO than it supplies to the rest of the world, charging for metsat data would also result in a net cost to the United States. In part because of the outcry from U.S. users of foreign data (especially the Department of Defense (DOD)) as well as from Congress, ${ }^{23}$ the Administration drew back and subsequently reaffirmed earlier commitments to supply meteorological data freely and free of charge to users throughout the world (except for certain special products that are priced at cost).

- Contributions to and from the global system. As noted earlier, the United States has been a member and strong supporter of the World Meteorological Organization since it was founded in 1947. Transfer of metsats to private ownership would have complicated U.S. arrangements with WMO and, in the absence of a formal organization such as INTELSAT or INMARSAT for managing a global meteorological satellite system, a U.S. private firm might have found it extremely difficult to work with the meteorological agencies from other governments.

- Reduction of service. In testimony before the Senate Subcommittee on Science, Technology, and Space in August 1983, representatives from several industries that depend heavily on weather data, including agriculture, aviation, forestry, and marine industries, expressed their reservations about the proposed transfer. They felt that the quality and quantity of service would suffer. Similar concerns were expressed to members of the House Subcommittee on Natural Resources, Agriculture Research, and Environment.

- System hardware. Although the specifications of the meteorological satellite systems are set by NOAA in response to Government and private sector needs, private firms have a major role in designing and building the

\footnotetext{
${ }^{23}$ BothHouse Concurrent Resolution 168, Sept. 19, 1983, and Senate Concurrent Resolution 67, Sept. 19, 1983; 98th Cong., 1st sess., expressed Congress' opposition to sale of metsat data.
}

systems' components. In the future, NOAA might be encouraged to make space available on its satellites (on a fee basis) for instruments that serve particular needs of the private sector and that would be provided by private firms for profit-making data services. In addition to serving domestic needs, such instruments would also be of interest to foreign customers.

- Development of market for metsat data products. In addition to their use in daily weather forecasts from the National Weather Service, data from meteorological satellites support a small, but growing industry devoted to converting data supplied by NOAA to information for a wide variety of public and private interests. These specialized value-added firms provide services as varied as predicting severe impending weather for the benefit of specialized groups, or predicting the best ocean routes for international shipping. Value-added firms have learned how to process metsat data conjointly with land remote sensing data to predict crop yields, both domestically and abroad. ${ }^{24}$ Such information products are expected to be used by the value-added industry to expand the market for data sales from land remote sensing satellites. As the value of these services for metsat data becomes more widely known, this industry is likely to grow.

As a result of these and other considerations, Congress amended appropriations bill H.R. 3222, to prohibit the sale or transfer of the meteorological satellite systems to the private sector. On November 28, 1983, President Reagan signed this bill into law (Public Law 98-1 66), thereby reaffirming that the U.S. meteorological satellite systems would remain in the public sector. ${ }^{25}$

In order to provide appropriate service to data users, NOAA funds limited internal and university research to find new ways to utilize metsat

${ }^{24}$ See, for example, Remote Sensing and the Private Sector, op. cit., app. D. The results of much of this work were reported at a NOAA-sponored conference, "NOAA's Environmental Satellites Come of Age," Mar. 26-28, 1984, Washington, DC.

${ }^{25}$ In addition, the Land sat Commercialization Act of 1984 ( $p$ u b lic Law 98-365) contains a provision that specifically prohibits sale of the meteorological systems. These actions reflect the strength of congressional opposition to the sale of any part of the meteorological satellite system. 
data. ${ }^{26}$ In addition, NOAA provides some specialized value-added services and products (e.g., fruit frost warnings or ocean surface temperatures charts) that might in time be provided profitably by private firms, using the initial satellite weather data as the input. As users gain more experience with using metsat data and linking them to other information sources, it will be important for the Government to avoid competing with the private sector in providing value-added data products, and to find ways to motivate the private sector to provide such services.

\section{What Level of Service From the Polar-} Orbiting Satellites Is Appropriate?

In its effort to reduce the costs of operating the meteorological satellites, the Administration has attempted to move to what is essentially a single polar-orbiting system, thereby saving some of the cost of the second satellite, and a percentage of the operating costs of the entire system. Eliminating one of the polar orbiters would reduce the coverage of the system from once every 6 hours to once every 12 hours for a particular spot on the Earth. For most of the continental United States, a reduction in service would not cause a serious decline in the ability to predict future severe weather. In those areas, conventional data collection systems and the geostationary satellites provide sufficient information. For the Pacific coast, Hawaii, Alaska, and the Pacific Trust Territories, the 6-hour repeat coverage that two polar-orbiting metsats supply is extremely important for timely warning of rapidly changing weather conditions (fig. 7-1 0). None of these areas has access to surface data for the predominately westto-east weather patterns. ${ }^{27}$

As one observer noted, ${ }^{28}$ having a second satellite for backup is also important. Experience

\footnotetext{
26NOAA spends about $\$ 1.25$ million, primarily internally, to develop new products that will use both Landsat and metsat data for agricultural and other renewable resource applications. In addition, it funds R\&D (approximately $\$ 1$ million) at about 6 universities to find new applications for metsat data in a variety of disciplines including severe storms, climate studies, and mesoscale meteorology.

${ }^{27}$ Because the primary weather flow i $\mathbf{n}$ the northern hemisphere is from west to east, information gathered to the west of a geographic area is especially important for weather predictions.

28 Richard J.Reed, statement before $\mathrm{th}_{\mathrm{e}}$ Subcommittee on Science, Technology and Space of the Senate Committee on Commerce, Science, and Transportation, August 1983.
}

with failures aboard Landsat 4 and metsats has demonstrated that even relatively simple satellite subsystems may fail in the harsh conditions imposed by launch or the environment of outer space. If only one polar orbiter were in service, and it failed, there would be no service for a period from the civilian satellite. ${ }^{29}$ When NOAA's GOES-West failed in November 1982, well before it was scheduled to be replaced, NOAA was unable to replace it until June 1983. Only one GOES satellite is now in operation, the GOESEast satellite having failed in July 1984; its replacement cannot be launched before late 1985 or early 1986.

Operating only one polar orbiter would also reduce the data available to the military. Though it has its own system of meteorological satellites, the military makes extensive use of the NOAA system, both to provide data at different times of the day, and to act as an emergency backup to the military system. In the past, the military has had to depend from time to time on the civilian systems for critical weather information.

Although dropping one of the polar-orbiting satellites would not change the form of our cooperation with other nations, such a course of action would significantly reduce the amount and quality of data the United States can supply to other nations for predicting weather conditions. other nations that depend on these data and have purchased receiving stations have expressed dismay that the United States might operate only a single polar orbiter. Furthermore, the United States would not save much money because the cost of operating two polar satellites is very little more than the cost of operating one. NOAA estimates it would save between 10 and 20 percent of its yearly satellite operational costs by dropping one. In round numbers, each copy of the next series of NOAA polar-orbiting satellites, which are designed to last 5 years, is expected to cost about $\$ 100$ million. so

\footnotetext{
${ }^{29}$ Presumably, some data could be provided by the DODDMSP Satellites until a new civilian satellite was launched. However, the data from the two systems are not quite compatible. The quality of results from NOAA's forecasting models are reduced accordingly. Information from the GOES satellites cannot replace information from the polar orbiting satellites (see boxes $A$ and $B$ ).

30The precise unit cost will depend on the total number of satellites purchased at one time, the delivery schedule, and their capability. If service is reduced to one satellite, each one will cost more than if two satellites were orbiting at all times.
} 
Figure 7-10.-One. and Two-Polar Soundings

Two-Polar Soundings Map for O Hour Greenwich Mean Time

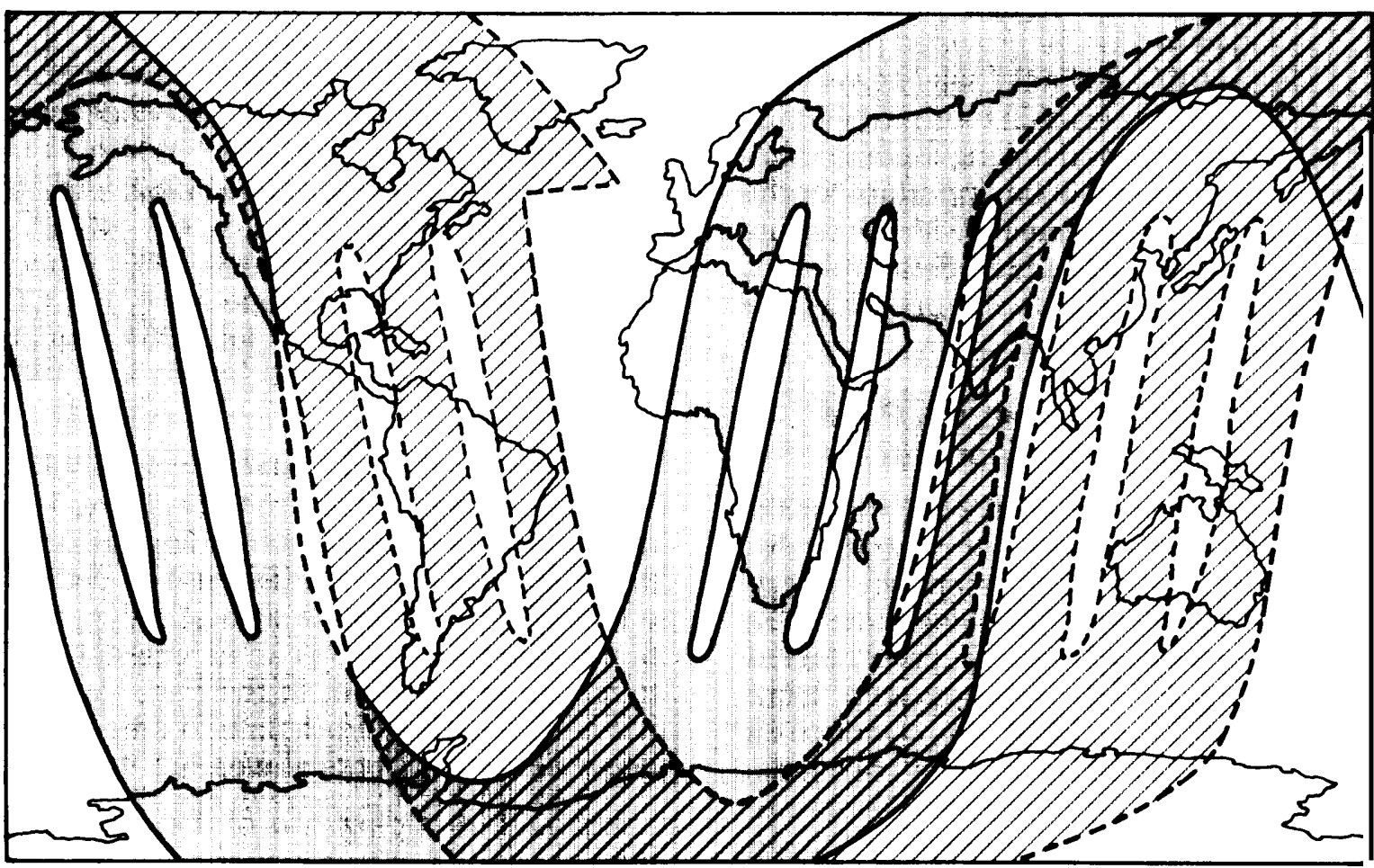

One-Polar Soundings Map for 0 Hour Greenwich Mean Time

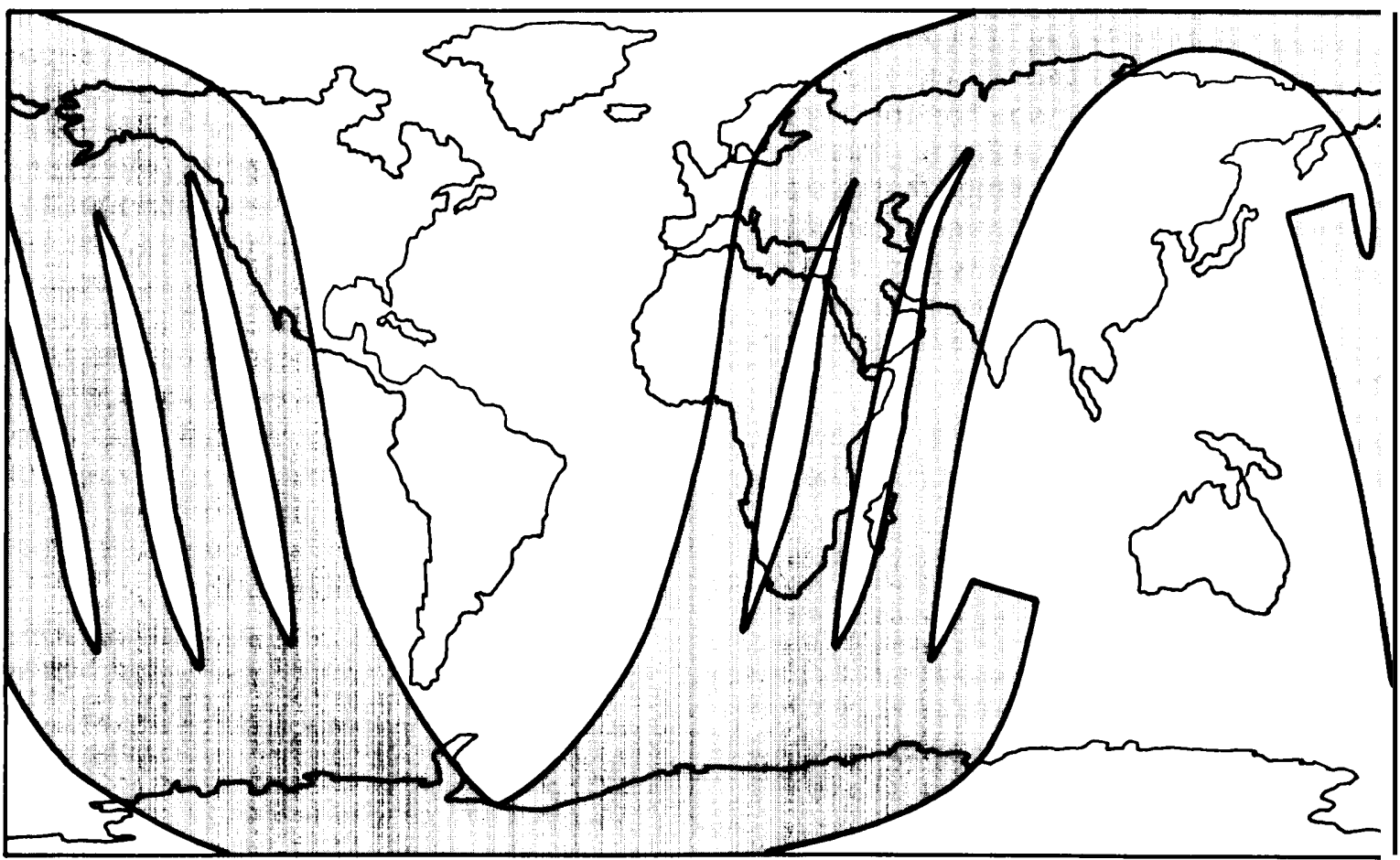

The charts show satellite observational coverage for a 6 -hour period centered at the synoptic observation time of $O$ hour Greenwich mean time.

SOURCE: National Oceanic and Atmospheric Administration. 
Reducing to one polar orbiter would also have had the effect of reducing our commitment to cooperation with Canada, France, and the Soviet Union in the COSPAS/SARSAT Search and Rescue Program (see app. A). The SARSAT receivers, built by France, are carried on the polar orbiters. The optimum system calls for a total of four instruments, one on each of two Soviet polar-orbiting metsats and one on each of two U.S. polar orbiters. Until recently this important international cooperative program was in jeopardy. In October 1984, after considerable debate over the implications of the decision, the United States signed an agreement with the three other primary participants to enter into operational phase of the project, which would extend through $1990 .{ }^{3}$ The Administration was at first reluctant to sign the agreement because it means maintaining a two polar-orbiter system, or building another satellite to carry the emergency beacon. However, the system seems to have proved its worth, having contributed to saving nearly 400 lives since it began experimental operation in September 1982. Hence the Administration yielded to congressional and other pressure to maintain the program. Although the decision improves the chances for maintaining a two polar-orbiter system, it still does not mean its automatic continuation, because it would be possible (for a cost) to build and operate a dedicated satellite for the second beacon. This issue will require continual attention by Congress.

What Level of Cooperation With Other Nations Is Desirable?

In part because of the decrease in the quality of weather monitoring that would result from a reduction from two to one polar orbiters, and in part to share the costs of maintaining satellite weather service, the Administration is exploring the feasibility of establishing a formal cooperative arrangement with other nations. It has formally raised the question at two meetings of the Economic Summit of Industrialized Nations ${ }^{32}$ and

\footnotetext{
${ }_{31}$ See "OMB jeopardizes U.S.-Soviet Satellite Accord, science, Vol. 25, pp. 999-1000, 1984; "Sarsat/Cospas to Operate Through 1990," Aviation Week and Space Technology, Nov. 12, 1984, p. 25. ${ }_{32}$ Foradiscussion of various cooperative mechanisms, see "1 $\mathrm{n}$ ternational Meteorological Satellite System: Issues and Options," National Environmental Satellite, Data and Information Service, National Oceanic and Atmospheric Administration, Nov. 18, 1983.
}

has received favorable responses (see policy discussion below). In addition to meeting daily needs for meteorological data and for sharing the operating costs of the system among its major users, a formal arrangement that would guarantee an internationally based two polar-orbiter system would increase each country's long-term ability to gather operational satellite data. It could also go far toward assuring continuity in spatial and temporal coverage and stimulating technological growth in member countries. ${ }^{33}$ In short, the benefits of establishing a more formal cooperative arrangement seem to be high. Such cooperation could be a major step in improving the quantity and quality of weather-related information throughout the world. In addition, as the appendix on remote sensing in developing countries suggests, the greater use a country makes of meteorological satellite data, the more likely it is to develop uses for land remote sensing data as well.

Several drawbacks to a formal cooperative system exist:

- The United States would lose its unilateral control (through NOAA) over the management of the system. Thus, the U.S. military would lose its unilateral power to preempt civilian satellite operations in time of national emergency. Further, NOAA would also lose the power it now has to alter routine operations to follow particularly severe or dangerous weather developments in the United States. On the other hand, if the alternative is a single polar orbiter, U.S. access to crucial meteorological data (particularly for the military) would be lessened anyway.

- Some technology might be transferred from the United States to industrialized countries which could then use it in economic competition with the United States.

- An international organization might inadvertently become somewhat more cumbersome and require more personnel to operate the system than the current arrangement through WMO now requires.

\footnotetext{
33 Department of Commerce news release, NIC 84-132,Dec. 12 1984
} 
The existence of INTELSAT and INMARSAT, both truly international organizations (see chs. 3 and 6), and the existence of Eumetsat, the European regional organization, suggest that the organizational problems can be solved within reasonable cost goals. Technology transfer also need not necessarily be a major threat. Most of the necessary technology is well understood and already well within the capacity of the industrialized countries. As these countries extend their capabilities, any technological gap is likely to shrink over time, making the problem moot. Nevertheless, all of these concerns would have to be weighed in deciding whether formal cooperation is of overall benefit to the United States and, if so, which form of cooperation would be most appropriate (see policy section).

\section{LAND REMOTE SENSING SYSTEMS}

Land remote sensing in the form of aerial photography is nearly as old as the photographic camera. Cameras have been flown on both balloons and aircraft. During World War II, aerial photography developed into a powerful and vital aid to tactical warfare. Well before the war, photographs taken from the special vantage point afforded by aircraft and balloons found use among such customers as agricultural and land-use planners, archaeologists, foresters, geologists, and geographers. By the early 1960s the interpretation of aerial photography had developed into a small, but highly useful, discipline. With the development of special-purpose photographic emulsions (e.g., infrared), advanced lenses, shutters, and other sensing devices (e.g., sidelooking radar) remote sensing analysts now provide a wider range of products for these customers.

Sensing from aircraft has limitations of coverage, high cost per unit area, as well as the difficulty of controlling lighting conditions. It is not suitable for developing a global data base. In contrast, remote sensing from space possesses several properties that permit the development of a unique global data base for resource inventory and monitoring over time:

- perspective over a range of selected spatial scales;

- selected combinations of spectral bands for categorizing and identifying surface features;

- repetitive coverage over comparable viewing conditions;

- direct measurement based on one set of solar illumination conditions for a wide surface area, data standardized from area to area and from day to day;

- signals suitable for digital storage and subsequent computer manipulation; and

- accessibility over remote and difficult terrain and across political divisions.

Although all of these characteristics contribute to the potential utility of remote sensing from space, the fact that data about Earth's surface arrive i $\mathrm{n}$ digital form suitable for routine computer manipulation is perhaps of greatest importance. Data from space can be routinely combined with other data to generate information products of great utility,

\section{The U.S. Landsat System}

Land remote sensing from space for civilian uses had its origins in a NASA program, begun in 1964.34 After considerable theoretical study, and research and testing of multispectral scanners and other instruments in aircraft, NASA launched the first of five Landsat satellites in $1972 .{ }^{35}$ These satellites follow a polar orbit that takes them over the same spot on Earth at the same time of day every 16 days. The latest in the series is Landsat 5 , which was successfully launched on March 1, 1984, after Landsat 4 began to fail (fig. 7-11). In addition to other experi-

\footnotetext{
${ }^{34}$ For an early policy and institutional history of the Landsat System, see Pamela E. Mack, "Space Science for Applications: the History of Landsat, " in Space Science Comes of Age'Washington, DC.: Smithsonian Institution Press, 1981).

${ }^{35}$ Landsat 1 was originally named Earth Resources Technology Satellite (ERTS-1).
} 
Figure 7-11 .-Landsat.5 Spacecraft

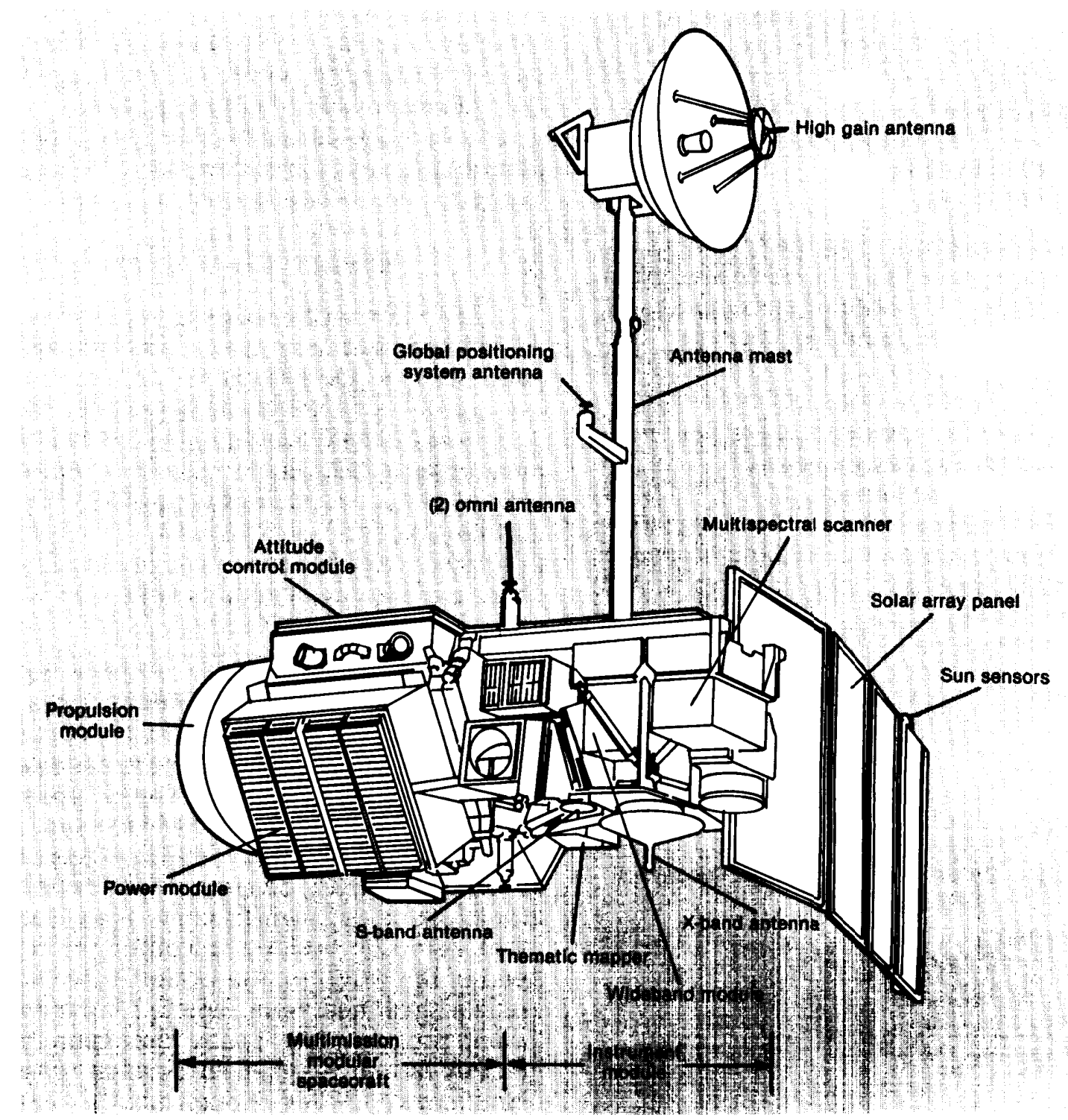

SOURCE: National Oceanic and Atmospheric Administration.

MISSION: Collect remotely sensed multispectral land data broadcast data for receipt at ground stations operating under formal agreements

ORBIT: $705-\mathrm{km}$ sun synchronous 16 day repeat cycle

SENSORS AND FUNCTIONS:

- Multi-spectral Scanner (MSS): The MSS is the specified operational sensor Swath width is $185-\mathrm{km}$ resolution is $80-\mathrm{m}$

sensor
Wavelength

\begin{tabular}{|c|c|}
\hline $\begin{array}{l}\text { avelengths } \\
(\mu \mathrm{m}) \\
05-06\end{array}$ & $\begin{array}{l}\text { Primary Uses } \\
\text { sediment laden water delineation of shallow }\end{array}$ \\
\hline $\begin{array}{l}07 \\
08 \\
08\end{array}$ & $\begin{array}{l}\text { tween land and water. landorms } \\
\text { eric haze vegetation boundary }\end{array}$ \\
\hline
\end{tabular}
between land and water !andiorms
Thematic Mapper (TM): The TM is a NASA experimental sensor li will come on-line operationally after it has been proven by NASA and an appropriate ground system has been constructed It is designed to provide $30-\mathrm{m}$ resolution except for $120-\mathrm{m}$ resolution in the thermal infrared band

sensor
Wevelengths

Primary Uses

(um) 052 Coastal water mapping soll vegetation differentiation $045 \cdot 052$ deciduous coniferous differentiation 052 - 060 Green reflectance by healthy vegetation

063 - 069 Chlorophyll absorption for plant species differentiation

076 - 090 Biomass surveys, water body delineation

155-175 Vegetation moisture measurement

$1040-1250$ Plant heal stress management, other thermal mapoing 208 - 235 Hydrothermal mapping

DIRECT BROADCAST: Broadcasts are orovided for ground stations which have entered into formal agreements covering the receipl and distribution of these data 
mental instruments, each Landsat spacecraft has carried a multispectral scanner (MSS), which has a spatial resolution of 80 meters and senses in four spectral bands (figs. 7-12 and 7-1 3). The Landsat 5 spacecraft carries an MSS and a thematic mapper (TM) sensor (fig. 7-13, which has a spatial resolution of 30 meters $^{3 b}$ and seven spectral bands (fig. 7-14).

The Landsat system is composed of the spacecraft and associated command and control telemetry, ground receiving stations, and processing, copying, storage, and distribution facilities. Landsat data are transmitted from the spacecraft in digital form to ground stations, collected on tape, corrected to remove radiometric and geometric distortions, and sold through the EROS Data Center (Department of the Interior) at Sioux Falls, SD. Data products are available in either image (photographic) form or on computer compatible tapes (CCTS) suitable for additional processing by large computers. Table 7-5 lists current and projected prices for Landsat data products.

In addition to providing data from the Landsat system to users around the world, NASA insti-

\footnotetext{
${ }^{36}$ Except for the 10.4 to 12.5 micron wavelength band which has a spatial resolution of 120 meters.
}

\section{Figure 7-12.-Cutaway View of the Multispectral Scanning System}

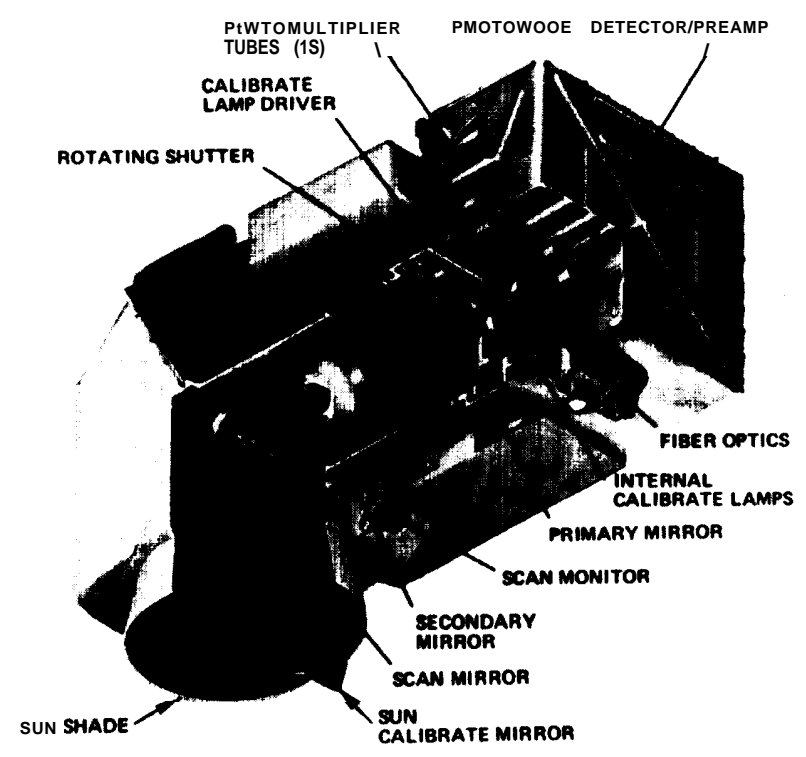

SOURCE: National Aeronautics and Space Administration. tuted a program in the mid-1970s to encourage wider experimentation with the data, and issued grants to a variety of State and local governments, to universities and private nonprofit institutions. As well as providing data free or at extremely low cost to these users and to other Federal agencies, the NASA program also developed computer software for processing the data.

\section{System Development}

NASA has a small continuing program of sensor development for both optical and microwave (radar) sensors. Developmental models for these sensors are to be flown on the Shuttle. There are no plans for the Government to develop free-flying orbital systems in the near term. Both NASA and NOAA are exploring the possibility of a polarorbiting platform as part of the U.S. effort in developing a permanently manned space station. Such a platform is a good candidate for international development.

Table 7-6 lists the major sensors now under development by NASA. Until August 1984, NASA had a program to develop a multispectral linear array (MLA), similar to, but more capable than, the French SPOT sensor. However, under pressure from the Office of Management and Budget $(\mathrm{OMB})$ to reduce overall spending, NASA decided to cut this program, on grounds that it was leading to an operational sensor rather than a research tool. Although NASA is attempting to reinstate part of this research, the United States now has only a small near-term remote sensor development program (see issues discussion below). NOAA has no program to develop sensors for land remote sensing, though it has a small effort in studying applications of metsat and Landsat data.

\section{Foreign Landsat Receiving Stations}

As NASA developed the Landsat system, it encouraged other countries to use the system. Ten countries now own operational receiving stations (fig. 7-1 5). In return for a fee, these foreign sta-

\footnotetext{
${ }^{37}$ JohnH. McElroy and Stanley R. Schneider, "Utilization of the Polar Platform of NASA's Space Station Program for Operational Earth Observations," NOAA Technical Report, NESDIS 12, September 1984.
} 
Figure 7-13.-Landsat Bands and Electromagnetic Spectrum Comparison

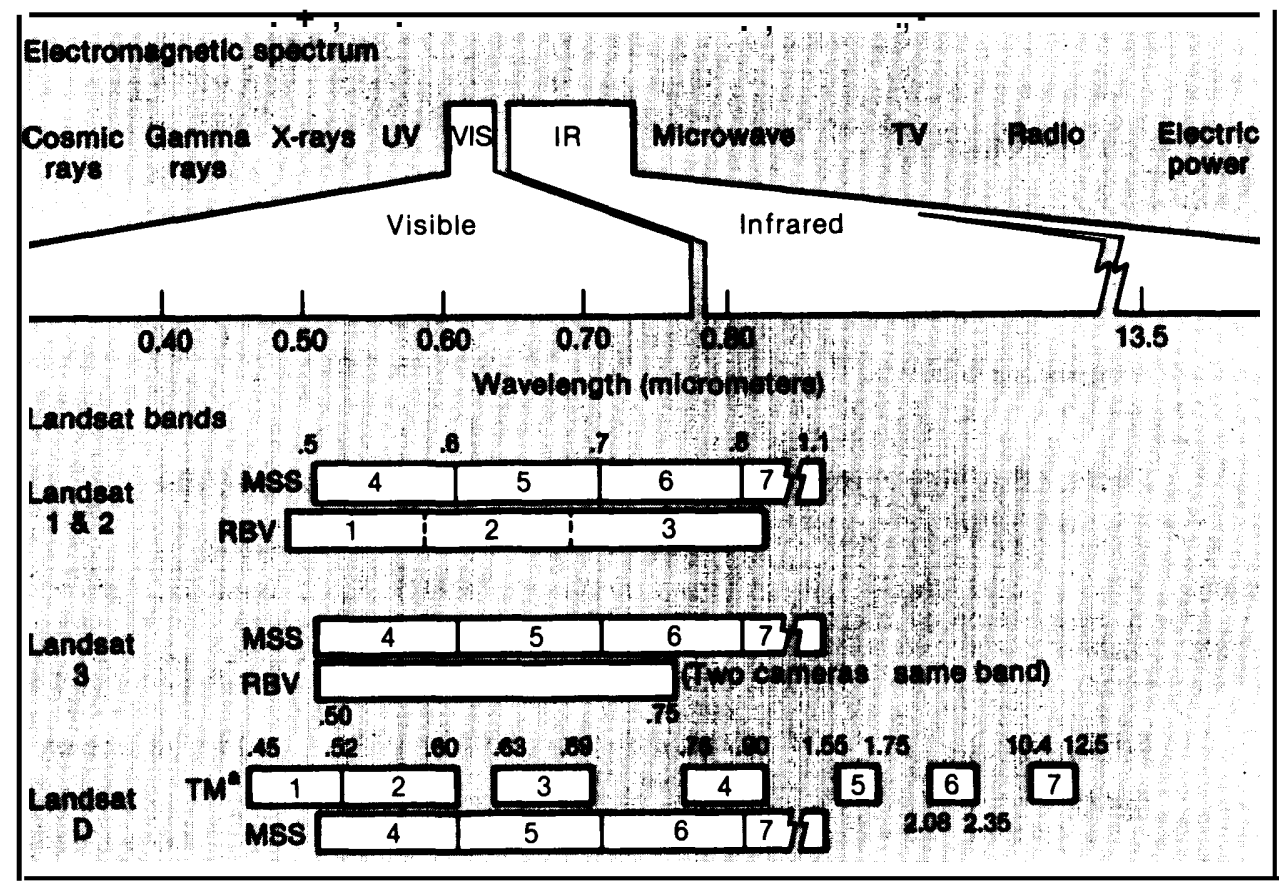

aThematic mapper.

SOURCE: U.S. Geological Survey

Figure 7-14.-Thematic Mapper Sensor

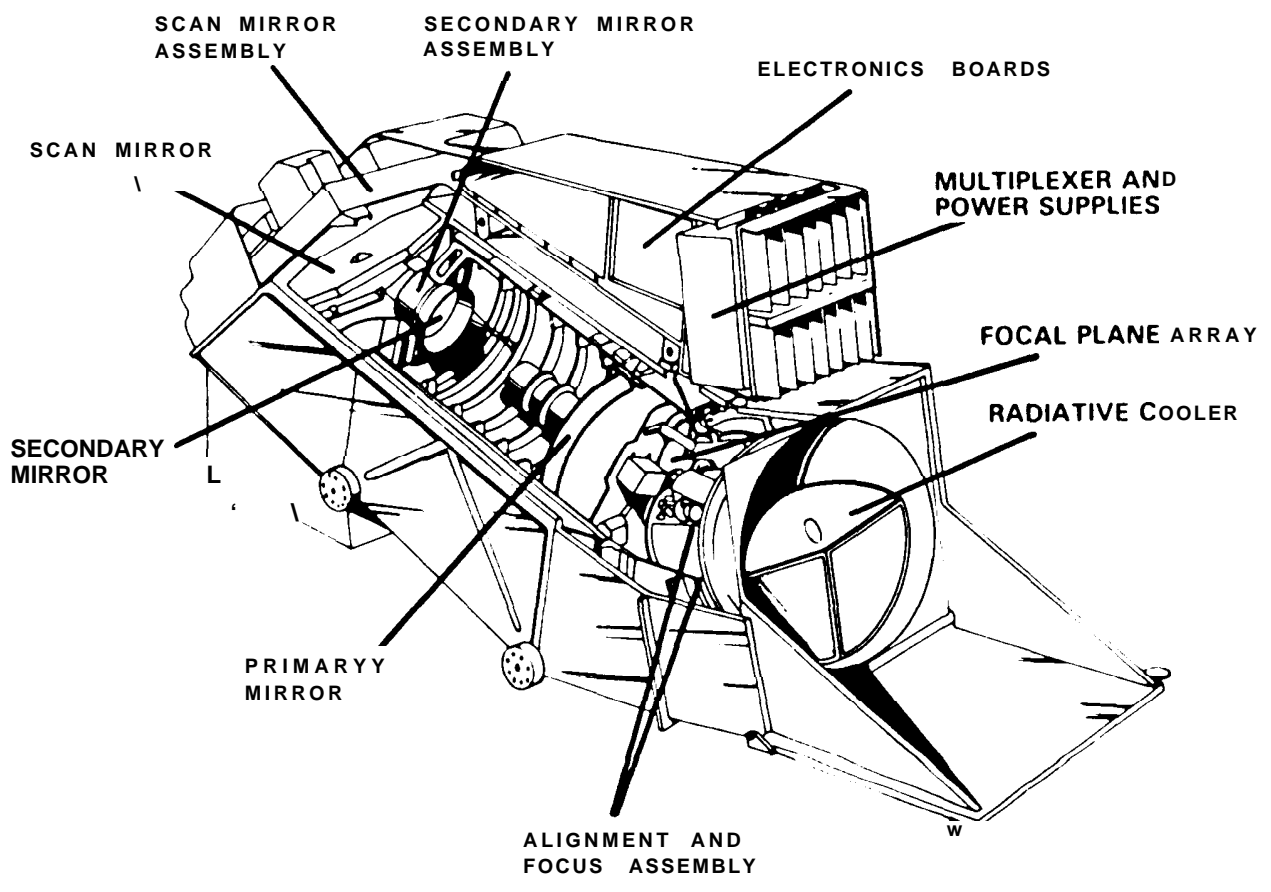


Table 7.5.-Costs for Some Landsat Data Products

\begin{tabular}{|c|c|c|c|c|}
\hline \multirow[b]{2}{*}{ Product } & \multicolumn{4}{|c|}{ cost } \\
\hline & $\begin{array}{l}\text { Until } \\
\text { October } 1981\end{array}$ & $\begin{array}{l}\text { October } 1981- \\
\text { October } 1983\end{array}$ & $\begin{array}{l}\text { October } 1983- \\
\text { February } 1985\end{array}$ & $\begin{array}{c}\text { February } 1985- \\
\text { ??? }\end{array}$ \\
\hline $\begin{array}{l}\text { Multispectral scanner (MSS) computer- } \\
\text { compatible tape (CCT) } \ldots \ldots \ldots \ldots \ldots \ldots \ldots \ldots \\
\text { Thematic mapper (TM) CTT } \ldots \ldots \ldots \ldots \ldots \ldots \ldots \\
\text { TM CCT (quarterly) } \ldots \ldots \ldots \ldots \ldots \\
\text { Color composite image }(1: 250,000 \text { scale): }\end{array}$ & $\begin{array}{cc} & \$ 200 \\
\text { Not } & \text { available } \\
\text { Not } & \text { available }\end{array}$ & $\begin{array}{l}\$ 650 \\
\$ 2,800 \\
\$ 750\end{array}$ & $\begin{array}{l}\$ 650 \\
\$ 3,400 \\
\$ 925\end{array}$ & $\begin{array}{l}\$ 730 \\
\$ 4,400 \\
\$ 1,350\end{array}$ \\
\hline 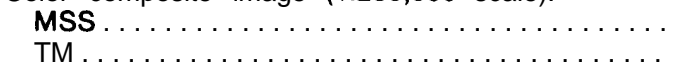 & Not $\begin{array}{c}\$ 50 \\
\text { available }\end{array}$ & $\begin{array}{l}\$ 175 \\
\$ 235\end{array}$ & $\begin{array}{l}\$ 175 \\
\$ 275\end{array}$ & $\begin{array}{l}\$ 195 \\
\$ 290\end{array}$ \\
\hline
\end{tabular}

SOURCE: National Oceanic and Atmospheric Administration.

Table 7-6.-Major Imaging Sensors Under Development by NASA

\begin{tabular}{|c|c|c|c|}
\hline Sensor & Sensor type & Status & Notes \\
\hline Large Format Camera & $\begin{array}{l}30.5 \mathrm{~cm} \text { focal length } \\
\text { camera; stereo capability }\end{array}$ & $\begin{array}{l}\text { Flown on Shuttle flight } 41-\mathrm{G} \text {, } \\
\text { October } 1984\end{array}$ & Used for high-reolution mapping \\
\hline $\begin{array}{l}\text { Shuttle Imaging Radar } \\
\text { (SIR) }\end{array}$ & $\begin{array}{l}\text { Synthetic Aperture Radar } \\
\text { SIR-A }\end{array}$ & $\begin{array}{l}\text { Flown on Shuttle, November } \\
1981\end{array}$ & L-Band microwave \\
\hline & SIR-B & $\begin{array}{l}\text { Flown on Shuttle flight } 41-\mathrm{G} \text {, } \\
\text { October } 1984\end{array}$ & L-Band microwave \\
\hline & SIR-C & Under development & $\begin{array}{l}\text { L-Band and C-Band microwave; } \\
\text { NASA is negotiating with } \\
\text { Germany to provide X-Band } \\
\text { capability in a cooperative } \\
\text { venture }\end{array}$ \\
\hline $\begin{array}{l}\text { Multispectral Linear } \\
\text { Array Experiment }\end{array}$ & $\begin{array}{l}\text { Pointing six-band focal } \\
\text { plane sensor }\end{array}$ & Under development & $\begin{array}{l}\text { Program terminated in August } \\
\text { 1984; portions now reinstated }\end{array}$ \\
\hline $\begin{array}{l}\text { Shuttle Imaging } \\
\text { Spectrometer }\end{array}$ & $\begin{array}{l}\text { High spectral and spatial } \\
\text { resolution spectrometer }\end{array}$ & $\begin{array}{l}\text { Under development for } \\
\text { Shuttle flight in } 1989 / 90\end{array}$ & $\begin{array}{l}\text { Planned eventually for } \\
\text { incorporation into space station } \\
\text { polar-orbiting platform }\end{array}$ \\
\hline
\end{tabular}

tions receive Landsat data sensed over their region and sell or distribute them to local and foreign customers. Until fiscal year 1983, the yearly ground-station fee to NOAA was $\$ 200,000$, but beginning on October 1, 1982, NOAA began to assess a $\$ 600,000$ fee. In addition to the fee, each station pays a small distribution fee to NOAA for the data it sells or otherwise distributes. By signing the Memorandum of Understanding with NOAA, each station owner agrees to abide by the same nondiscriminatory data policy that NASA and NOAA have always followed and that is now mandated by the Landsat Commercialization Act of 1984.

All Landsat receiving stations are capable of receiving MSS data. Some are also able to receive the more sophisticated TM data as well (table 77). Until the complete Tracking Data and Relay
Satellite System (TDRSS) is in place and working,JB foreign ground stations will be the predominant source of Landsat data for regions beyond the U.S. receivers.

\section{Foreign Systems}

As noted earlier, except for limited distribution of remotely sensed land data by the Soviet Union, the United States has been the sole supplier to the rest of the world. Other countries are now developing land remote sensing systems. These

\footnotetext{
${ }^{38}$ Unlike Landsats 2 and 3, Landsats 4 and 5 carry no tape recorders. They therefore depend on transmissions to ground stations as the satellites pass over, or to transmissions through the TDRSS satellites. Only one TDRSS satellite is currently in place and the demands on its time for other uses are great.The second TDRSS satellite is scheduled for launch on the Shuttle in late 1985 or early 1986 and will increase the capability of the Landsat 5 satellite to deliver TM data to users.
} 
Figure 7-15.-Distribution by Foreign Ground Stations (as of Jan. 1, 1985)

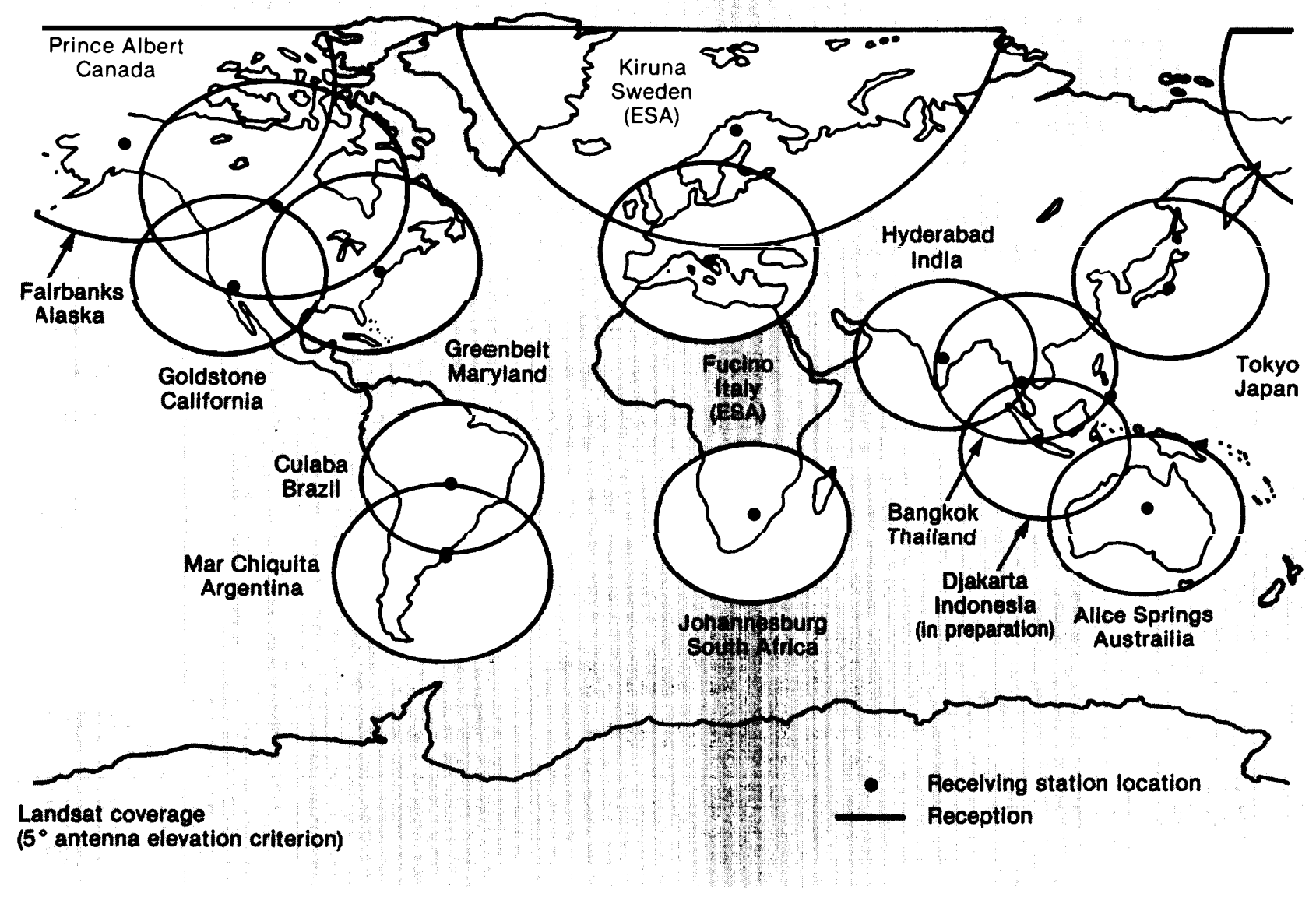

SOURCE: National Oceanic and Atmospheric Administration.

foreign systems rely directly on experience and technology their designers have gained from U.S. $R \& D$ efforts as well as on indigenous capabilities. They are designed primarily to be operational, rather than R\&D, systems. Some will be technically directly competitive with, but different from, the current Landsat system; some will exceed Landsat's capacity to return useful data. ${ }^{39}$ The following summarizes briefly the characteristics of the foreign systems. In order of planned deployment, they are:

- West Germany-Modular Optoekctronic Multispectral Scanner (MOMS) -1984/85).

\footnotetext{
${ }^{39}$ For example, the French SPOT system will have higher resolu tion than is possible from the current Landsat system. It will also have the capacity to return quasi-stereo data to the user. It will, however, have fewer spectral bands, an important consideration in comparing the competitive capabilities of different systems.
}

This instrument was flown on the Shuttle Pallet Satellite (SPAS) developed by Messers chmittBoelkow-Blohm GmbH (MBB) aboard Shuttle flight 7. MBB and the Stenbeck Reassurance Co., Inc., together with the U.S. corporation, SPARX, wanted to market selected 20-meter resolution 2 -color land remote sensing data collected on Shuttle flights beginning in 1985. However, they dropped such plans after NASA informed them that, according to public Law 98-365, the data must be sold on a nondiscriminatory basis. NASA and MBB are holding continuing discussions over a separate venture that would use the MOMS. The West Germans are developing a stereoscopic sensor and have already tested a limited synthetic aperture radar on Shuttle flight 9.

- France-Systeme Probatoire d'Obsixvation de La Terre (SPOT) -1985. Since 1978, 
Table 7-7.-Foreign Landsat Ground Stations

\begin{tabular}{|c|c|c|c|c|}
\hline $\begin{array}{l}\text { Ground station } \\
\text { location }\end{array}$ & Operating agency & Status of $\mathrm{MOU}$ & $\begin{array}{l}\text { MSS data } \\
\text { reception and } \\
\text { processing }\end{array}$ & $\begin{array}{c}\text { TM data } \\
\text { reception and } \\
\text { processing }\end{array}$ \\
\hline Argentina . . . . . Mar Chiquita & $\begin{array}{l}\text { Comision Nacional de } \\
\text { Investigaciones Espaciales (CNIE) }\end{array}$ & signed & yes & no \\
\hline Australia ...... Alice Springs & $\begin{array}{l}\text { Division of National Mapping, } \\
\text { Department of Resources and } \\
\text { Energy (DRE) }\end{array}$ & signed & yes & no \\
\hline Brazil . . . . . . . Cuiaba & $\begin{array}{l}\text { Instituto de Pesquisas Espaciais } \\
\text { (INPE) }\end{array}$ & signed & yes & yes \\
\hline Canada . . . . . . . Prince Albert & $\begin{array}{l}\text { Canada Centre for Remote } \\
\text { Sensing (CCRS) }\end{array}$ & signed & yes & yes \\
\hline European Space & & & & \\
\hline $\begin{array}{r}\text { Agency . . . . . Fucino, Italy } \\
\text { Kiruna, Sweden }\end{array}$ & European Space Agency (ESA) & signed & yes & yes \\
\hline India. ........ H yderabad & $\begin{array}{l}\text { National Remote Sensing Agency } \\
\text { (NRSA) }\end{array}$ & signed & yes & yes \\
\hline Indonesia ${ }^{a}$. . . . . Jakarta & $\begin{array}{l}\text { Indonesian National Institute of } \\
\text { Aeronautics and Space (LAPAN) }\end{array}$ & under negotiation & $\begin{array}{c}\text { no } \\
\text { (expected in } \\
1985)\end{array}$ & no \\
\hline Japan . . . . . . . . Tokyo & $\begin{array}{l}\text { National Space Development } \\
\text { Agency (NASDA) }\end{array}$ & signed & yes & yes \\
\hline $\begin{array}{l}\text { Pakistan ....... . [under development] } \\
\text { Peoples Republic }\end{array}$ & & signed & yes & yes \\
\hline of China ${ }^{\mathrm{b}} . \ldots$ Beijing & Chinese Academy of Science & signed & yes & yes \\
\hline Saudia Arabia, . . [under development] & & signed & yes & yes \\
\hline South Africa . . . Johannesburg & $\begin{array}{l}\text { National Institute for } \\
\text { Telecommunications, Council for } \\
\text { Scientific and Industrial Research } \\
\text { (CSIR) }\end{array}$ & signed & yes & no \\
\hline Thailand . . . . . . Bangkok & $\begin{array}{l}\text { National Research Council of } \\
\text { Thailand (NRCT) }\end{array}$ & under negotiation & yes & no \\
\hline
\end{tabular}

a Not currently operational.

Expected to start operations, fall 1985.

France (through the French space agency CNES) has been planning the world's first commercial remote-sensing satellite service. It expects to fly a series of four satellites. Although the first satellite will not be launched until late 1985, it is currently preparing the sales market through a French company (government-owned in part), SPOT IMAGE, S.A. A Washington-based American subsidiary called SPOT Image Corp. is now developing the U.S. market for SPOT data. The U.S. corporation has flown a successful series of tests from high-altitude aircraft over the United States using sensors designed to simulate the data that will eventually flow from the SPOT system. Customers from U. S., private firms, State governments, and the Federal Government have purchased data sets from these flights. SPOT Image Corp. has an agreement with the Canada Centre for Remote Sensing to receive SPOT data from North America at two stations (Prince Albert and Ottawa).

The SPOT satellite will carry pointable multispectral linear-array sensors capable of resolving images at least as small as 20 meters in three wavelength bands. In addition, the satellite will be capable of 10-meter resolution operating in a panchromatic mode. These are higher resolutions than are possible on Landsat 5 . Because the sensors are pointable, they are capable of producing quasi-stereo images. Although the system is a commercial effort, the French Government is spending a minimum of $\$ 400$ million to $\$ 500$ million to develop the system. CNES will pay for and build the second satellite in the series; SPOT Image will reimburse CNES from sales of SPOT data.

- India-IRS-1985. This low-resolution "semioperational" land remote sensing satellite 


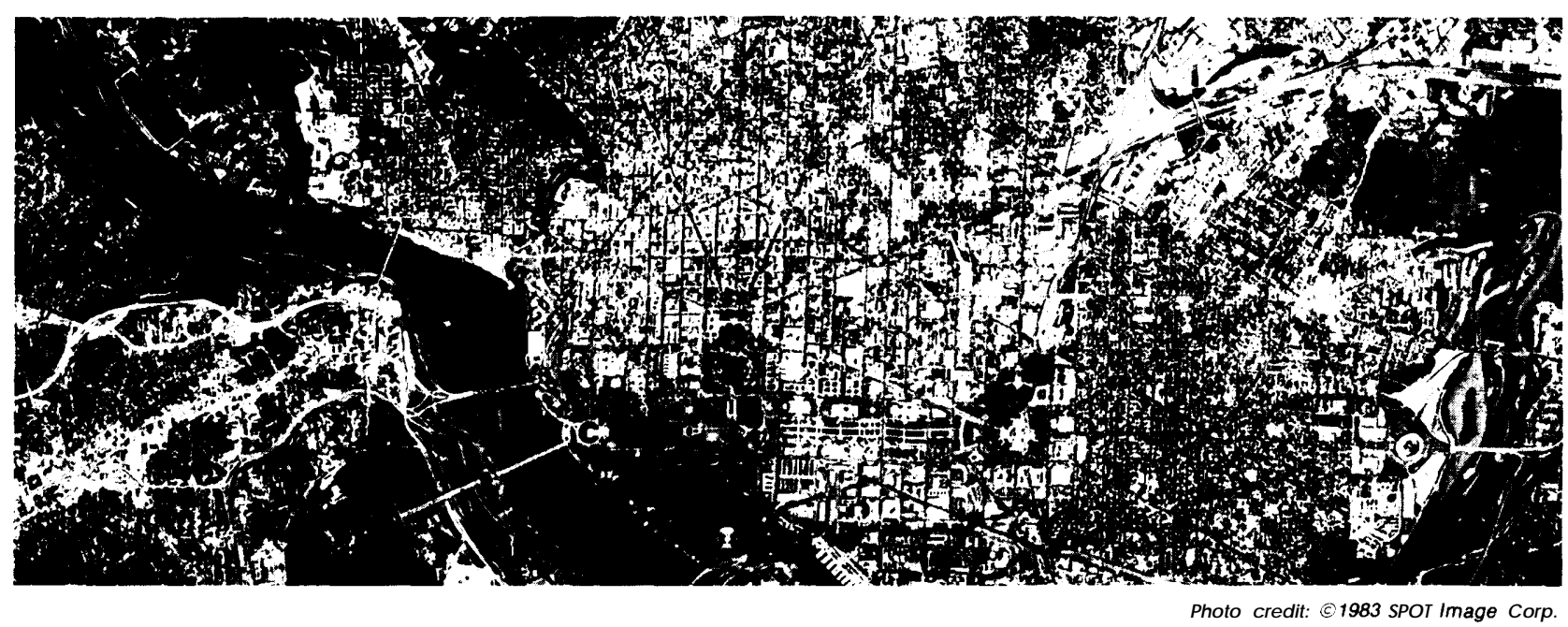

Panchromatic simulated SPOT image of Washington, DC (10 meters resolution), taken July 7, 1983, from an airplane. The SPOT satellite is expected to be launched in "late 1985.

will be built in India but launched by a Soviet launcher. It will carry solid-state sensors.

- Japan Earth Resources Satellite (ERS-1)1991. Its primary mission will be to collect information on renewable and nonrenewable natural resources, including minerals, forests, and crops. ERS-1 will carry a synthetic aperature radar and an optical (visible and infrared) radiometer. It will be launched by an $\mathrm{H}-1$ vehicle. Japan is also building a marine observation satellite (MOS-1) to be launched in 1986 by an $\mathrm{N}-11$ vehicle.

- Brazil. Working on a moderate-resolution land-sensing salellite to be launched in the late 1980s.

\section{Data Products and Uses}

Land remote sensing data are put to a variety of uses for resource mapping, assessment, and management. ${ }^{40}$ Table 7-8 lists the major categories of data users, table 7-9 lists the major customers for data. Figure 7-16 illustrates the broad categories of major users and their relative share of the data market. The EROS Data Center sells data either in digital format (computer compatible tapes, or CCTS) or photographic imagery in

\footnotetext{
${ }^{40}$ For anextended discussion of potential customers and their data needs see Remote Sensing and the Private Sector, chs. 4, 5, 6.
}

Table 7-8.-Categories of Foreign and Domestic Users

- Agriculture (Federal, State, and private): specific sampling areas chosen according to the crop; timedependent data related to crop calenders and the weather patterns

- Forestry (Federal, State, and private): specific sampling areas; twice per year at preselected dates

- Geology and nonrenewable resources (Federal, State, and private): wide variety of areas; seasonal data in addition to one-time sampling

- Civil engineering and /and use (State and private): populated areas; repeat data required over scale of months or years to determine trends of land use

- Cartography (Federal, State, and private): all areas, repeat data as needed to update maps

- Coastal zone management (Federal and State): monitoring of all coastlands at selected dates depending on local seasons

- Pol/ution monitoring (Federal and State): broad, selected areas; highly time-dependent needs both for routine monitoring and in response to emergencies SOURCE: Off Ice of Technology Assessment.

several sizes. For a special additional fee, customers may specify cloud-free scenes or other special attributes. As the section on issues points out, the largest potential market for land remote sensing data products is for information products generated by processing and adding information to the satellite data from other sources (so-called value-added products). 
Table 7-9.-Domestic Distribution of Landsat Products

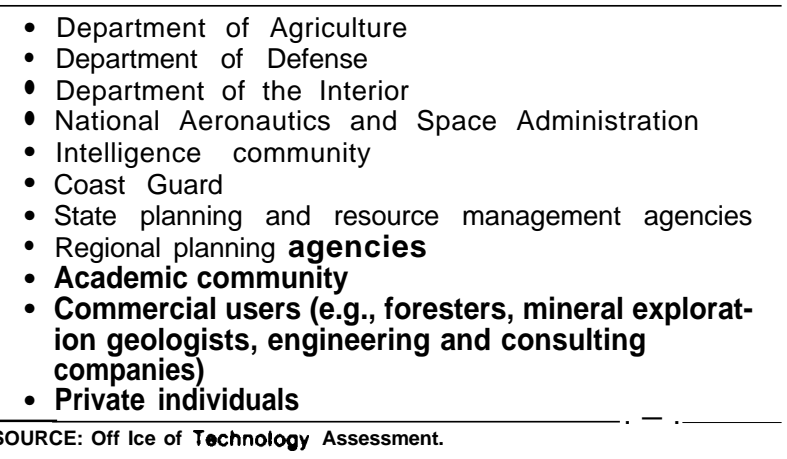

\section{Policy History of Land Remote Sensing}

Although the potential utility of images gathered by satellite of atmospheric conditions and of the surface of the land and ocean were recognized by those conceiving the systems, until recently few considered operating the systems as commercial entities. However, as Federal, State, and local governments, universities, and industrial firms began to work with the data from the Landsat system, they realized that, at the prices charged, 41 these data were often a cost-effective substitute for older (aircraft) methods of gathering Earth resources data. The digital format, wide spatial coverage, and repeatability of the data made possible new applications that could eventually increase the value of the information these data provide. By the late 1970s, some observers postulated that the data might eventually have sufficient commercial value to attract private investment in a remote sensing system. However, it was also clear that the known barriers of high system cost, and technological and economic risk, would have to be drastically reduced if private investors were to be interested in providing a system comparable to Landsat, especially because the initial market for the data was thought to be quite small (see section on issues).

The history of the Landsat system illustrates the difficulties that may attend bringing a Government-developed applications system to opera-

41 Landsat data prices have never reflected the cost of operating the system, much less the costs of developing the sensors in the first place. tional status, let alone to commercial status. The current policy debate over land remote sensing had its genesis in an interagency controversy over who should develop and operate the Government system and what sensors it should contain. In 1966, while NASA and other agencies were experimenting with data derived from a variety of sensors carried in aircraft, the Department of Interior announced a program to fly its own operational satellite. NASA was convinced that considerable flight experimentation was needed with sensors that would be carried on Apollo and Skylab missions. The Interior Department, however, wanted to proceed more directly to operational use of data from a satellite and to shorten the lengthy process of research and development that NASA was contemplating. Yet its specifications for the appropriate sensor differed from those of the Department of Agriculture, which wanted greater spectral discrimination in order to detect crop stress and other agricultural characteristics. Both departments recognized the need to have NASA design and build the satellite, but as they would eventually derive the greatest use from the data generated by the Landsat system, they wanted control over the design of the system because they were aware that "the experimental program would inevitably shape any operational program."

The Bureau of the Budget $(\mathrm{BoB})$ was not convinced of the utility of the Landsat system compared to other data sources, and specified that NASA do only research and development. It also opposed purchase of equipment that would lead to operational use of the system. As the system was flight tested, NASA encouraged Federal, State, and local agencies and private groups to apply the data to their needs, in part to demonstrate to $B o B$ that the data were beneficial. In spite of continued opposition from BoB and its successor, the Office of Management and Budget (OMB), NASA continued to involve data users, both domestic and foreign, in planning for followon satellites and sensors and to encourage the widespread use of the data. The result was a quasi-operational ${ }^{43}$ system, which only partially met

\footnotetext{
${ }^{42}$ Pamela E. Mack, "Space Science for Applications ...., " oP. cit.

${ }^{43}$ Civilian Space Policy and Applications, OTA, p. 13. Article I also states: "The exploration and use of outer space ... shall be carried out for the benefit and in the interest of all countries."
} 
Figure 7-16._Customer Profile of Landsat Digital and Imagery Products (shipped sales), Fiscal Year 1984

3,042 items

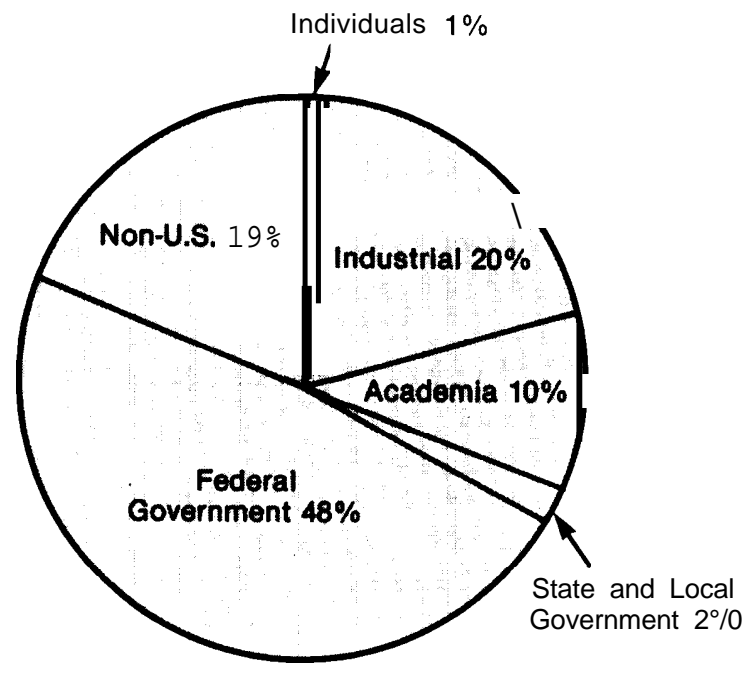

34,964 frames

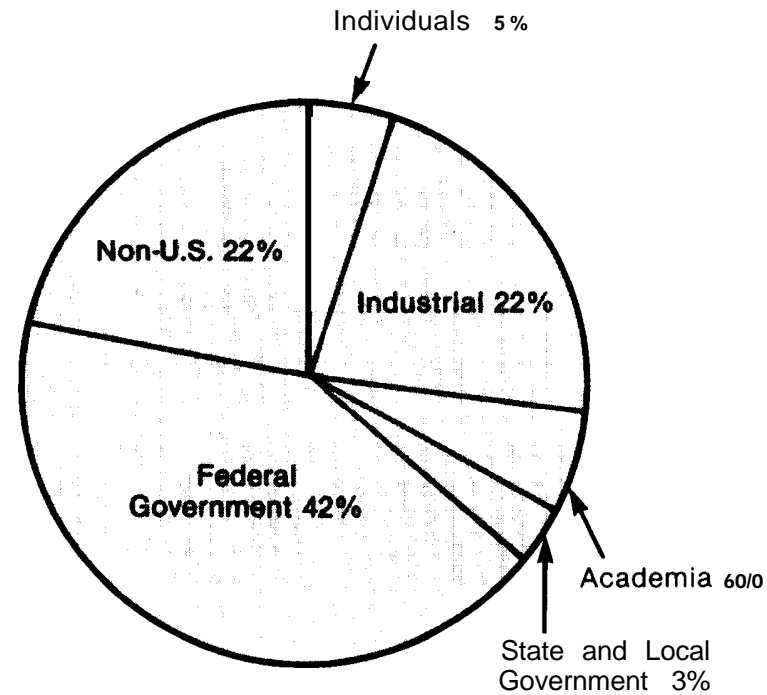

SOURCE: National Oceanic and Atmospheric Administration,
$\$ 1,590,875$

Individuals $1 \%$

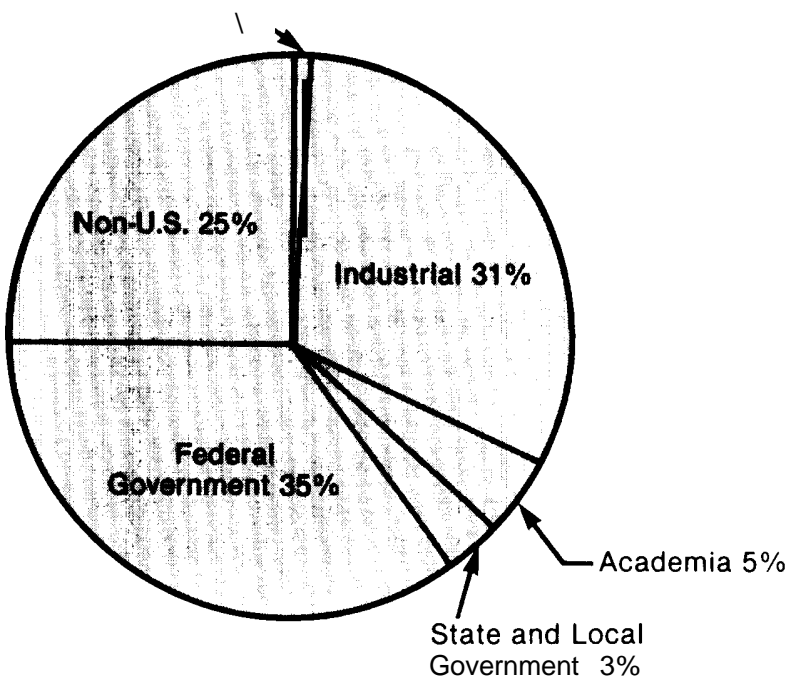

$\$ 2,221,253$

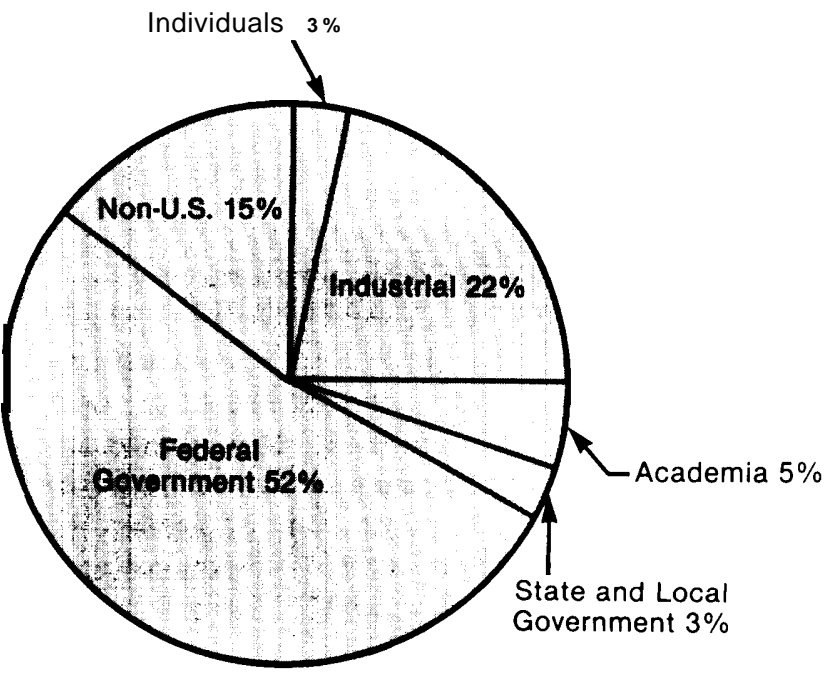


the needs of users. Even though the system has now been transferred to NOAA, and is fully operational, it does not generate sufficient revenue from customers (i.e., a market) to enable the Landsat system to be transferred to the private sector or be commercialized without sizable subsidy.

Transfer of the Government's civilian land remote sensing system to private hands was first considered seriously by policy makers in the drafting of President Carter's 1979 policy statement on space, PD/NSC-54, which amplified the earlier policy directives, PD/NSC-37 and PD/NSC-42. It stated:

Our goal is the eventual operation by the private sector of our civil land remote-sensing activities. Commerce will budget for further work in fiscal year 1981 to seek ways to enhance private sector opportunities. ${ }^{44}$

This statement left open the speed and the means of the transfer but, because it also committed the United States to provide continuity of the data flow from the Landsat system through the 1980s, most observers assumed that transfer to the private sector would take place about 1990. The first stage of that process was to transfer responsibility for operational management of the Landsat program to NOAA. Transfer of the meteorological satellite systems to private ownership was not envisioned by PDNSC-S4.

The Reagan Administration decided early in its tenure to hasten the process of transfer, and announced "the intent of transferring the responsibility [for Landsat] to the private sector as soon as possible. " 45 That statement, too, made no mention of the meteorological systems. Later, in March 1983, the Administration proposed to transfer both the Landsat and the metsat systems to private hands. ${ }^{46}$ Public Law 97-324 mandated

\footnotetext{
“"'Presidential Directive NSC-54," Nov. 16, 1979.

${ }^{45}$ Statement of Joseph Wright, Deputy Secretary, Department of Commerce, to the Subcommittee on Space Science and Applications of the House Committee on Science and Technology, and the Subcommittee on Science, Technology, and Space of the Senate Committee on Commerce, Science, and Transportation, July 22 and 23, 1981.

${ }^{46}$ Statement of Malcolm Baldrige, Secretary of Commerce, to the Subcommittee on Natural Resources, Agricultural Research, and Environment of the House Committee on Science and Technology, Apr. 14, 1983. As discussed earlier, in November 1983, Con-
}

(in Title 11) the Department of Commerce to commission studies and internal analyses to explore and examine the issues raised by transfer of remote sensing from space to the private sector. ${ }^{47}$ None of these reports concluded that rapid transfer was in the best interest of the United States .48

In late 1983, however, the Administration began to draft a request for proposals designed to solicit proposals from private industry to own and operate the current Landsat system and any follow-on. Concurrently, the House Committee on Science and Technology drafted a bill authorizing a phased transfer of the system to the private sector, with the aim of eventually establishing a profit-making satellite land remote sensing industry. On January 3, 1984, the Department of Commerce released its request for proposal (RFP). Seven proposals were received on March 19, 1984.49 It is significant that several of the proposers were partnerships or consortia. Few single firms have the breadth of experience and personnel to design, build, and operate a system as complex as the Landsat system. After evaluating all the proposals in an initial round, in June the Department of Commerce Source Evaluation Board (SEB) found three proposers, EOSAT, Kodak/Fairchild, and Space America, to be within the competitive range required by the RFP. After a second round of evaluation, the Secretary of Commerce selected Eastman Kodak and EOSAT for negotiations with the Department.

gress passed, and the President signed, appropriations bill H.R. 3222 (Public Law 98-166), which contained a provision preventing sale of the Nation's meteorological satellite systems to private hands. The meteorological satellites will continue to be operated as a public service.

47"' Space Remote Sensing and the Private Sector: An Essay," National Academy of Public Administration, March 1983, Department of Commerce contract No. NA-83-SAC-066; "Commercialization of the Land Remote Sensing System: An Examination of Mechanisms and Issues, " ECON, Inc., April 1983, Department of Commerce contract No. NA-83-SAC-00658; "A Study to Examine the Mechanisms to Carry Out the Transfer of Civil Land Remote Sensing Systems to the Private Sector, "Earth Satellite Corp. and Abt Associates, Inc., Department of Commerce contract No. NA-83-SAC-00679.

${ }^{48}$ The assumptions upon which these analyses were based included: 1) maintenance of data continuity, 2) maintenance of U.S. leadership, 3) Landsat-type technology, and 4) maintenance of international obligations.

${ }^{49}$ These were: Earth observing Satellite Co. (EOSAT-a new company to be formed by RCA and Hughes Aircraft); Eastman Kodak; Gee-Spectra Corp.; Miltope Corp. of Melville, NY.; Milton A. Schultz of Williston, ND; Space Access Corp. of Marina Del Rey; Space America Inc. See Space Business News, Mar. 26, 1984, p. 1. 


\section{A Guide to the Land Remote Sensing Commercialization Act of 1984}

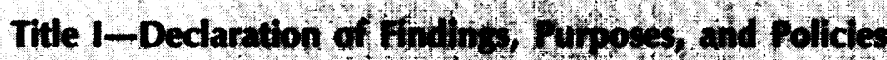

This title presents the tindings of Congres, and establishes the purposes, policies, and definitions of U.S. land remote sering. 1 1 peeifically states that the Act is to "maintain the United States' leadership in civil remote sensin preserve it hational security, and fulfill its international obligations." These purposes, and the following policies. seve as the geheral rationale for most of the provisions of the subsequent titles.

The Act (sec. 103) states that it shall be U.S. poligy a) "to preserve its right to acquire and disseminate unenhanced remotesehsing data, ${ }^{\prime}$ b) , that civilian unenhanced remote-sensing data be made available to all potential users on a nondiscriminatory basis and in a manner consistent with applicable anti-trust laws, and c) "to commerciallze those remote-sensing space systems that properly lend themselves to private sector operation ahd to avold competition by the Government with such commercial operations, while continu hy to presene our national security, to honor our international obligations, and to retain in the Government those remote-sensing functions that are essentially of a public service nature,"

\section{Title 11-Operation and Data Martething L Landat Sydem}

This title calls for the Secretary of Commerce to contract for marketing of unenhaniced data from the current, Government-owned, Landsat system. Its intent is to engage the private sector in aggressively marketing unenhanced Landsat data. Under its terms, "The contractor shall act as the agent of the Secretary by continuing to supply unehhanced dath to forthound stations for the life, and according to the terms, of those agreements between foreign grount tations that are in force on the date of the commencement of the contract."

\section{Title II-Provition of Data Continulty Aher owe Lins}

It is this title that constitutes the core of the transitton of land remote sensing from covernment to private ownership. Its aim (sec. 301 ) is to provide conuhtity of data deliveny 'for 6 yeais after the practical demise of the space segment of the Landsat systen," by providing a subsidy to a private firm to construct and operate a follow-on system. Among the criteria by which a contractor is to be selected (sec. 303) are the contractor's ability to "maintain U.S. Wy Hership in remote sensing," and its ability to develop a market for data.

The Terms of Contract (sec, 304 stipulate that the centuctor must agree to sell data on a nondiscriminatory basis. Further the Government ishall not poylde a guarantee of data purchases from the contractor." In addition, the contractor may utlize (on h 1 soce-available, reimbursable basis) "a civil-

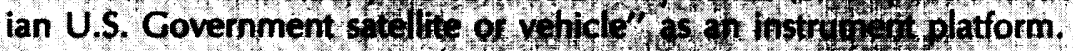

\section{Title IV-Licensing of Privete tenote-senth Space sytoms}

This title essentially recognizes that aldhough the follow on to Landsat may bethe first entity requiring a license, other systems should also be provided 66 , th requires that the owners or operators of the follow-on system and any other rempte ens ing syst th who are "subject to the jurisdiction or control of the United States" obtain a license foro the Sect 10 of Commerce, certifying that the licensee

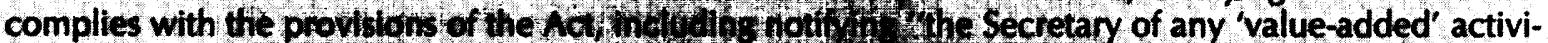

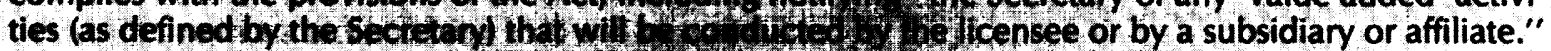

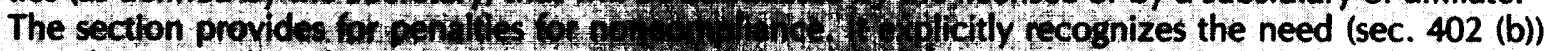
"to observe and implement the intern 7, the United States." Among these interna-

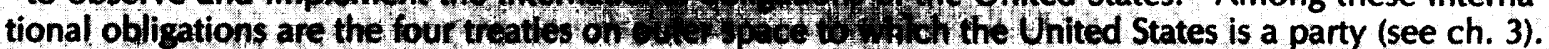

Section 405(a) also specifically states "A private sector party may apply for a license to operate a private remote-sensing space system which utilizes on a space-available basis, a civilian United States Government satellite or vehicle as a platform for such a system." 


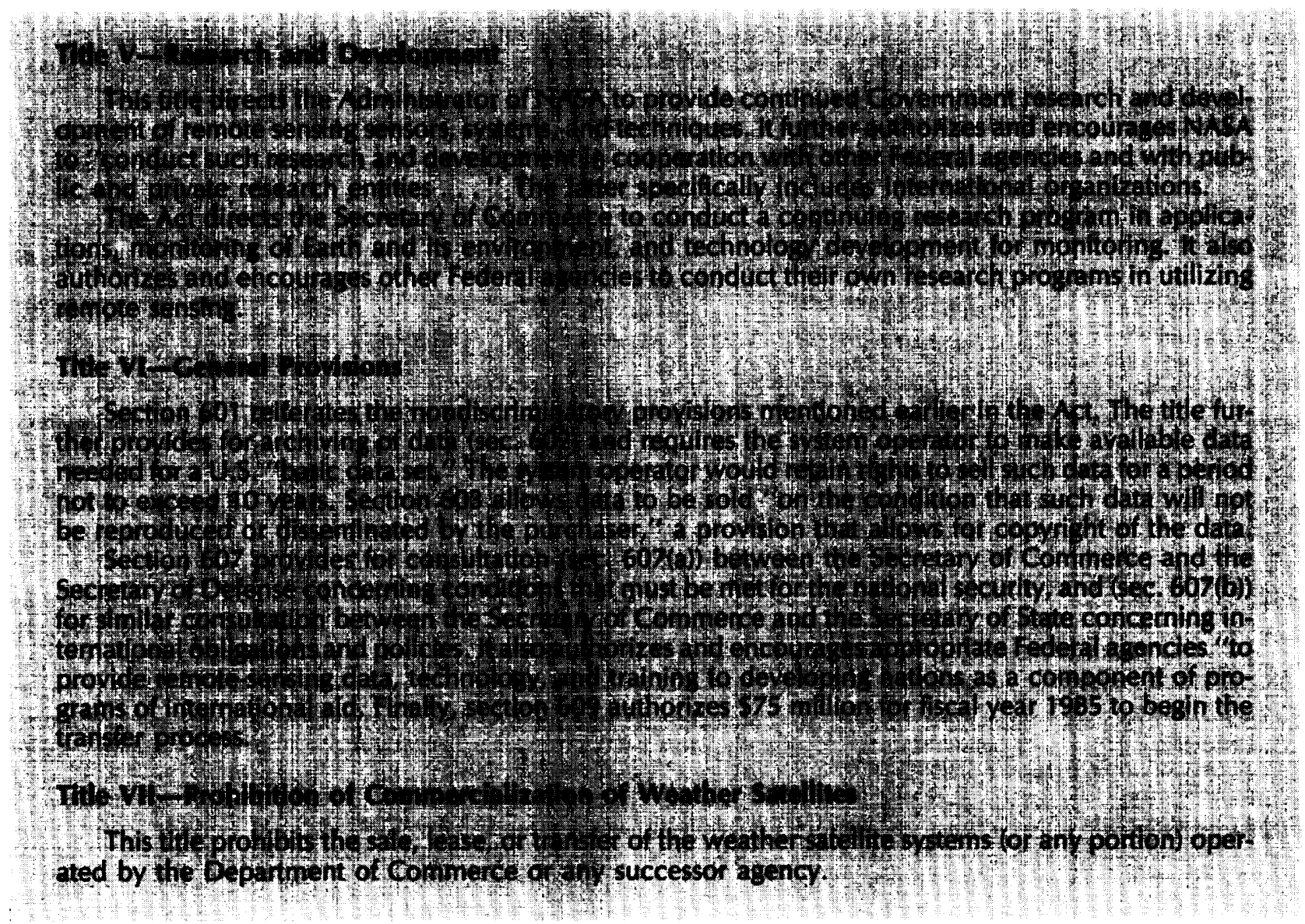

The initial proposals from EOSAT and Kodak/ Fairchild included estimates of nearly $\$ 1$ billion in Government subsidies over a 10-year period in order to take over marketing data from the current Landsat system and to build an advanced new satellite system. EOSAT was prepared to fly a refurbished Thematic Mapper on Landsat 6 and 7 and to develop and launch a more advanced multispectral linear array (MLA) sensor on Landsat 8 and 9. Kodak's proposal called for an entirely new design as a follow-on to Landsat 5 that would move directly to MLA technology. The Department of Commerce found both proposals acceptable technically, but unacceptable from a financial point of view. It invited drastically revised financial plans. Among other matters, the amount of financial risk the two companies were willing to accept was unacceptable.
During this process, H.R. 5155 was reported out of the House Committee on Science and Technology on April 3, 1984, and passed by the entire House April $10 .{ }^{50} \mathrm{~A}$ similar bill (S. 51 55) was under consideration by the Senate Committee on Commerce, Science, and Transportation and passed the Senate May 8, 1984. After a conference and subsequent passage by both Houses, the Land Remote Sensing Commercialization Act of 1984 was signed into law (Public Law 98-365) by President Reagan on July 17, 1984.

In addition to authorizing the commercialization of the U.S. land remote sensing program, and providing for continuation of certain Government

\footnotetext{
${ }^{50}$ Committee Report 98-647 on the Land Remote-Sensing Commercialization Act of 1984, House Committee on Science and Technology.
} 
functions, the Act is noteworthy for being the first piece of major legislation that attempts to set out the legal and regulatory framework for commercial space activity as required by the 1967 Outer Space Treaty (Articles vI and IX). The box summarizes the major provisions of Public Law 98-365. The complete Act is reproduced in appendix C.

The ultimate goal of the transfer of the results of Government R\&D to the private sector is to create a self-sustaining business from all or part of the technology so transferred, with the private sector in full control (except for appropriate regulation) of further development and shaping of the system and products. Realization of this goal would constitute full commercialization of the Government-developed technology. intermediate steps along the way to this end could result in: 1 ) shared control of the technology by Government and the private sector; and/or 2) joint continued development of the technology and its products, through either subsidies, shared investment, or guaranteed Government purchase. Such intermediate steps, in which the system would receive significant Government subsidy, have often been referred to as "privatization."

In passing Public Law 98-365, Congress decided to privatize the Landsat system by first authorizing the Secretary of Commerce to contract with a private firm to market Landsat data as the Government continues to operate the current system (Title II). The Government will also provide a subsidy to enable a private operator to build a system that would provide data continuity for a total of 6 years after the demise of Landsat 5 . Such legislation implicitly expects sufficient market for data to develop within 8 to 10 years to enable a private operation to be self-sufficient.

Among other provisions, Public Law 98-365 authorized up to $\$ 75$ million for fiscal year 1985 as the first installment of a subsidy to aid the eventual commercialization of land remote sensing. The law does not specify the total amount of subsidy necessary, as this was left to the Department of Commerce to work out with a potential contractor. As these corporations were preparing to revise their proposals to respond to the SEB'S concerns, OMB informed the Department of Commerce a subsidy was inappropriate. After consid- erable debate within the Administration, the two agencies agreed on:

1 ) The run-out of Government cost for operating Landsats 4 and 5; plus 2) a maximum of $\$ 250$ million of new budget authority for the commercial follow-on system .51

In August 1984, EOSAT submitted a revised proposal that included only two satellites, both using a Landsat-type sensor (TM), and which, among other things, assumed that the Government would continue its research program in advanced sensors, to support the transition to a more advanced system in the 199os. I n addition, EOSAT included an escape clause that allowed it to withdraw from the contract if sufficient market for data had not developed to support a commercial enterprise. Kodak Corp. declined to submit a revised proposal.

In mid-May 1985, the Department of Commerce announced that it had reached agreement with EOSAT to provide $\$ 250$ million plus launch costs (a total subsidy of about $\$ 290$ million). EOSAT agreed to build and launch two satellites whether or not the market has developed to support a profit-making business. An Administration request for $\$ 125$ million ( $\$ 75$ million for fiscal year 1985 and $\$ 50$ million for fiscal year 1986) to allow EOSAT to begin the process of building Landsat 6 has recently been sent to Congress for action .52

\section{International Relevance of Landsat}

Because the Landsat satellite travels in a polar orbit, which enables it to sense the entire surface of Earth, data from the system necessarily have international implications. Data from both the Landsat and metsat systems have served as constructive instruments of U.S. foreign relations, For example, these data have aided other countries to map, manage, and exploit their own resources; they have also raised the general level of awareness about growing environmental problems throughout the world.

\footnotetext{
51" Report to the Congress (Public Law-98-365 )," Department of Commerce, September 1984.

${ }^{52}$ EOSAT proposed an escape clause in the contract to allow for the possibility that, even with a vigorous marketing effort on its part, insufficient demand for data would develop.
} 
Aircraft or balloons are clearly limited in overflight by national restrictions on sovereign airspace, but spacecraft have no overflight restrictions. According to international treaty, "Outer space ... shall be free for exploration and use by all states." ${ }^{53}$ This principle is understood by the United States and most other nations to mean that nations are free to place in orbit any satellite that does not violate other provisions of the 1967 Outer Space Treaty or other principles of international law. This understanding has been called the "open skies" principle; it is a fundamental principle of the U.S. space program. The United States supports this principle ${ }^{54}$ in part by making civilian remote sensing data available on a nondiscriminatory basis to anyone who wishes to receive them. Through AID, NASA, and NOAA, the United States has been the principal force in setting up foreign regional and national centers capable of processing and interpreting Landsat data. By integrating these data with meteorological and/or ground data of all kinds, these centers aid developing countries coping with the enormous problems of environmental protection and resource management.

Although the private sector is technically capable (given adequate financial incentives) of providing the data promptly to meet the requirements of the Federal Government and other potential customers, commercial objectives may conflict with certain U.S. foreign policy objectives. Constraints on a private firm that are sufficient to protect U.S. foreign policy objectives could well make such an enterprise unprofitable or require a large and continuing Government subsidy to make the enterprise viable.

\section{Equipment Market}

In a manner similar to that for meteorological satellites, the market for land remote sensing equipment and services can be divided into three categories: the space component, ground station

\footnotetext{
${ }^{53} 1967$ Outer Space Treaty. Because of the U.S. example, the nondiscriminatory data distribution policy is now of importance to other countries as well.

${ }^{54}$ John H. Gibbons, "International Implications of Transferring the Landsat System to the Private Sector, " hearing before the Subcommittee on Legislation and National Security of the Committee on Government Operations, Sept. 28, 1983.
}

equipment, and services related to reception and data preprocessing (excluding the value-added industry discussed above).

\section{Satellite Manufacturers}

General Electric Corp. was the prime contractor for the Landsat 4 and 5 satellites, with Fairchild and Hughes Aircraft supplying significant components. If the transfer of the Landsat system to EOSAT is completed by appropriating the necessary subsidy, RCA and Hughes Aircraft Corp. (the two participants in EOSAT) will likely build most of the hardware (two satellites and associated system hardware), with other firms providing portions of it under contract.

The French firm Matra is the prime contractor for the SPOT satellite. Major subsystems and software are provided by Aerospatiale and SEP. The tape recorders are built by the U.S. corporation, Odetics, Inc.

\section{Ground Stations and Receivers}

Many of the same firms that manufacture components of ground stations and receivers for meteorological data reception also sell similar equipment for land remote sensing. The major differences are in the frequencies used for transmission and in the scale of investment for land remote sensing stations. There are now 12 operational Landsat receiving stations and 2 under construction. In addition, there are several SPOT receiving stations under construction. In the next 3 to 4 years, because of the advent of the SPOT system and the European ERS system (see section on ocean remote sensing) there could be as many as eight new receiving stations begun around the world. Several African countries, Iraq, Pakistan, and Saudia Arabia have expressed interest in building receiving stations. Each new station will cost between $\$ 10$ million and $\$ 15$ million. The balance of the market for ground stations, receivers, tape recorders, and the like will be in replacements and in upgrading some stations to receive $X$-Band transmissions from TM and from SPOT. For example, the Canadian Landsat receiving station in Prince Albert is being equipped to receive SPOT data. The Canadian firm MacDonald Dettwiler Association, inc. is providing the equipment for this station and the 
SPOT receiving station in Ottawa. MBB of Germany and NEC of Japan also supply ground station equipment. Yearly international sales in ground receiving equipment may be as high as $\$ 30$ million.

\section{Issues}

\section{What International Issues Are Raised by} Transfer to the Private Sector?

Congress and the Administration, in passing and signing into law Public Law 98-365, have agreed on the broad terms of transfer of the U.S. land remote sensing system to the private sector. Although the current attempts to effect such a transfer arose both from concern for reducing the Federal budget deficit and from the philosophical conviction that the private sector could provide those services more efficiently, the legislation also took into account the broader agenda of U.S. international relations. In general, the successful transfer of Government-developed technology to the private sector is a process that must take place over time, and with strong support from the potential foreign and domestic customers as well as from the policy makers.

As the process of transferring the Landsat system proceeds, it will be important to monitor the reactions of other countries to it, and to continue to approach each of the following issues with imagination and a sensitivity to the real or perceived concerns of other nations. Not only are the political sensitivities of other countries important to the United States, foreign customers are necessary to the financial viability of a private Landsat system. ${ }^{55}$ In addition, the French SPOT system will soon offer customers an alternative choice of data sources.

The following discussion of international issues is summarized from the OTA Technical Memorandum, Remote Sensing and the Private Sector: Issues for Discussion :.56

\footnotetext{
${ }^{55}$ When projected foreign ground station fees are included in the estimates of future income from a land remote sensing system, foreign sales could constitute as much as 39 percent of the revenue from a U.S. system. See "Commercialization of the Land Remote Sensing System: An Examination of Mechanisms and Issues, "ECON, Inc., Prepared for the U.S. Department of Commerce, contract No. NA-83-SAC-00658.

${ }^{56}$ Remote Sensing and the Private Sector: Issues for Discussion, op. cit., ch. 3.
}

- Data sales policies. Landsat data have always been sold to all purchasers on a nondiscriminatory basis. In large part this policy was originally chosen to support the U.S. "open skies" policy and the use of space for peaceful purposes. In practice, selling data on a nondiscriminatory basis has helped to blunt criticism of other activities, such as the operation of classified surveillance satellites. It has also demonstrated U.S. adherence to the principle of the free flow of information. Although some private sector analysts* have argued that owners of remote sensing systems should be allowed to set their own data policies, Public Law 98-365 mandates the policy of nondiscriminatory sales, on the basis that the open skies policy continues to be of importance to the United States.

- Value-added services. Most of the revenue earned from space remote sensing will be earned by the companies that add value to the data by processing, analyzing, adding other information, and interpreting the primary data from space. The value-added companies constitute a small, but growing, specialized industry. The strength of commercial space remote sensing will depend on a strong value-added industry. ${ }^{57}$ Most remote sensing system operators would want to participate in the value-added business.

The availability of high resolution land remote sensing data and the ability to analyze them are potentially powerful tools for resource development. Many developing countries have expressed the concern that allowing the system operator to offer value-added services might give the seller too much power over the acquisition and distribution process. They are concerned that the company or favored customers could, by processing and interpreting these data before delivering them to others, obtain economic leverage over countries that lack their

${ }^{*}$ Cf. Klaus Heiss, statement at hearing before the Subcommittee on Science, Technology, and Space of the Senate Committee on Commerce, Science, and Transportation, Mar. 22, 1984, pp. 83-88.

${ }^{5} 7$ Fred rick B. Henderson, II 1, "The Significance of a Strong Value-added Industry to the Successful Commercialization of Landsat," presented at the 21st Goddard Memorial Symposium, Mar. 2425, 1983. 
own facilities and personnel to interpret the data. Therefore, in order to maintain good relations with developing countries, it may be appropriate for the United States to restrict the private data distributor from entering into the value-added business, or to regulate it closely to prevent such a company from exerting unfair economic leverage over others. Here, foreign perception of economic harm may be as important as actual harm. As competition from foreign or other domestic systems grows, it would be possible to relax such restrictions.

Public Law 98-365 deals with this issue by requiring the firm to "notify the Secretary of any 'value-added' activities (as defined by the Secretary by regulation) that will be conducted by the licensee or by a subsidiary or affiliate" (Sec. 402(b)(6)). The terms of the Act assume that antitrust legislation is sufficient in most cases to deter the corporation from engaging in practices that would either inhibit competition from other U.S. firms or harm U.S. relationships with other nations. If additional legislation is required, as more experience is gained with private operation of land remote sensing, Congress could take remedial action.

- U.S. cooperation with other countries. The Landsat ground stations in 10 foreign countries constitute an eloquent statement of U.S. leadership in successfully applying high technology for the benefit of all mankind. The United States has also participated with industrialized and developing countries in research on applying Landsat data to critical resource and environmental needs. It is essential for the continuing research and development of remote sensing technology, and the growth of the data market, for the United States to maintain its cooperative basic and applied research programs with other countries. [f the transfer is made, it will be particularly important to assure that appropriate Government funding is continued for imperative projects with developing countries.

- International legal issues. Private ownership of the land remote sensing system could lead to suspicions that such data would be used to enable interests outside a sensed country to gain a competitive advantage in knowledge of minerals or other nonrenewable resources, or that information on crop conditions or military activities of states might be sold preferentially to political adversaries. Developing countries are particularly concerned about this possibility, because most lack the indigenous ability to analyze the data (see app. 7A). Some countries have maintained that they should have priority access to data derived from sensing their territory, while others have argued that their consent should be obtained before these data are transferred to third parties.

The United States has consistently opposed efforts to limit the distribution of Landsat data, arguing that remote sensing is a peaceful and beneficial use of space in which the restraints of national sovereignty have no valid application. Further, it has held that the free collection and dissemination of primary data and analyzed information is supported legally and encouraged by the 1967 Outer Space Treaty and article 19 of the U.N. Declaration of Human Rights. The U.S. policies of nondiscriminatory data sales and free flow of information have so far successfully deflected attempts to restrict the right to sense other countries and sell those data to third parties. Although attempts to restrict the flow of remotely sensed data and information are likely to continue in the U.N. and other international fora, the proliferation of civilian remote sensing systems will make it more difficult for such restrictions to gain ascendancy.

What Factors Are Most Important to Market Growth of Land Remote Sensing Data Products?

During its development, land remote sensing was treated as a technology that eventually "would create billions of dollars annually in benefits" to the public. ${ }^{58}$ Actually, benefits of this magnitude have yet to materialize. To many, this departure from stated expectations suggests that

\footnotetext{
58"Commercialization of the Land Remote Sensing System: An Examination of Mechanics and Issues, " op. cit., p. 80,
} 
the potential direct economic benefits of the Landsat program were oversold by some in its early days. In part, large public economic benefits have not followed from Landsat development because agencies have been slow to incorporate these data into their routine operations. ${ }^{\text {sg }}$ Government agencies have bought even less data in recent years than they did at first.

Clearly, although overall data sales have been low, the Landsat system still generates both public and private goods. ${ }^{60}$ Data from the Landsat system have demonstrated to many domestic and foreign users, both inside and outside Government, that these data can be highly effective in meeting large-scale resource information needs.

As the policy section notes, transferring the Landsat system to the private sector may enhance this Nation's competitiveness in land remote sensing by employing industry's skills in marketing and innovation to increase the overall market for data and services. However, without substantial Government subsidy for a land remote sensing enterprise, transfer in itself is not likely to result in a viable commercial business. ${ }^{6}$

If the initial phase of the transfer process in which a private operator markets the data from Landsat 5 proves successful, it will still be necessary to evaluate progress toward a self-sustaining business. If Congress were to decide that sufficient progress had not been made, but the public good aspects were still high, it could still decide to operate a civilian system within the Government. The most important single factor that will determine the viability of a commercial remote sensing enterprise is market growth.

The development of the market for remote sensing data and services will depend on four major factors: the price, availability, utility of the data, and the ability of the information industry to develop cost-effective ways of processing and applying such data to the needs of users.

\footnotetext{
${ }^{59}$ See for example, Remote Sensing and the Private Sector, ch. 5 . ${ }^{60}$ Remote Sensing and the Private Sector, ch. 4.

${ }^{61}$ Although OTA has not done a detailed analysis of costsassociated with developing a land remote sensing system, it appears that a subsidy (including launch costs) between $\$ 350$ million and $\$ 500$ million (depending on the financial risk the private firm is willing to assume) might be needed to reduce the risk of commercial failure to an acceptable level. See also Remote Sensing and the Private Sector, op. cit., ch. 1.
}

- Data prices. Even if it is possible to reduce dramatically the cost of the system's space segment, the costs of handling and correcting the raw data are likely to remain high in the near term because, with current data processing technology, labor costs are a significant proportion of the overall expense of producing corrected Landsat data. Technological advances in large-scale data processing, storage, and retrieval could reduce such costs. Customers for primary data complain that dramatic increases in data prices would reduce their ability to purchase data in the quantities that would be most effective. ${ }^{62} \mathrm{Fig}$ ures on data purchases from the EROS Data Center bear out their concerns. In October 1982 , the beginning of fiscal year 1983, NOAA increased the price of data dramatically (table 7-5). For example, the price for an MSS computer compatible tape (CCT) increased 325 percent, from $\$ 200$ to $\$ 650$. Knowing the price increase was coming, customers purchased more data in the last half of 1982 than they would have otherwise (fig. 7-1 7). Although income from data sales increased in fiscal year 1983, the number of MSS scenes purchased fell to 33 percent of fiscal year 1982 sales (table 7-10). Sales figures for fiscal year 1984 confirm the overall downturn in data sales. Overall income from sales has increased dramatically, however, because OMB has required each agency to account for its data receipts, ${ }^{\text {b3 }}$ and because NOAA has instituted special acquisition charges for cloud-free images or other nonstandard requests. In fiscal year 1983, special acquisition charges amounted to about $\$ 4$ million, or 58 percent of the total income from data sales. In fiscal year 1984, special acquisition charges were $\$ 6,130,275$ or 62 percent of total Landsat data income.

- Availability of data. Customers cite two concerns over-the availability of data: 1 ) data are

\footnotetext{
62See testimony in "Civil Land Remote Sensing Systems," Joint Hearings before the House Subcommittee on Space Science and Applications of the Committee on Science and Technology, and the Senate Subcommittee on Science, Technology, and Space Committee on Commerce, Science, and Transportation, July 22, 23, 1981.

${ }^{63}$ The Foreign Agriculture] Service, for example, Was receiving data directly from NASA through a receiver in Houston.
} 
Figure 7-17.-Sale of Landsat Imagery Frames and Digital Products (shipped sales)

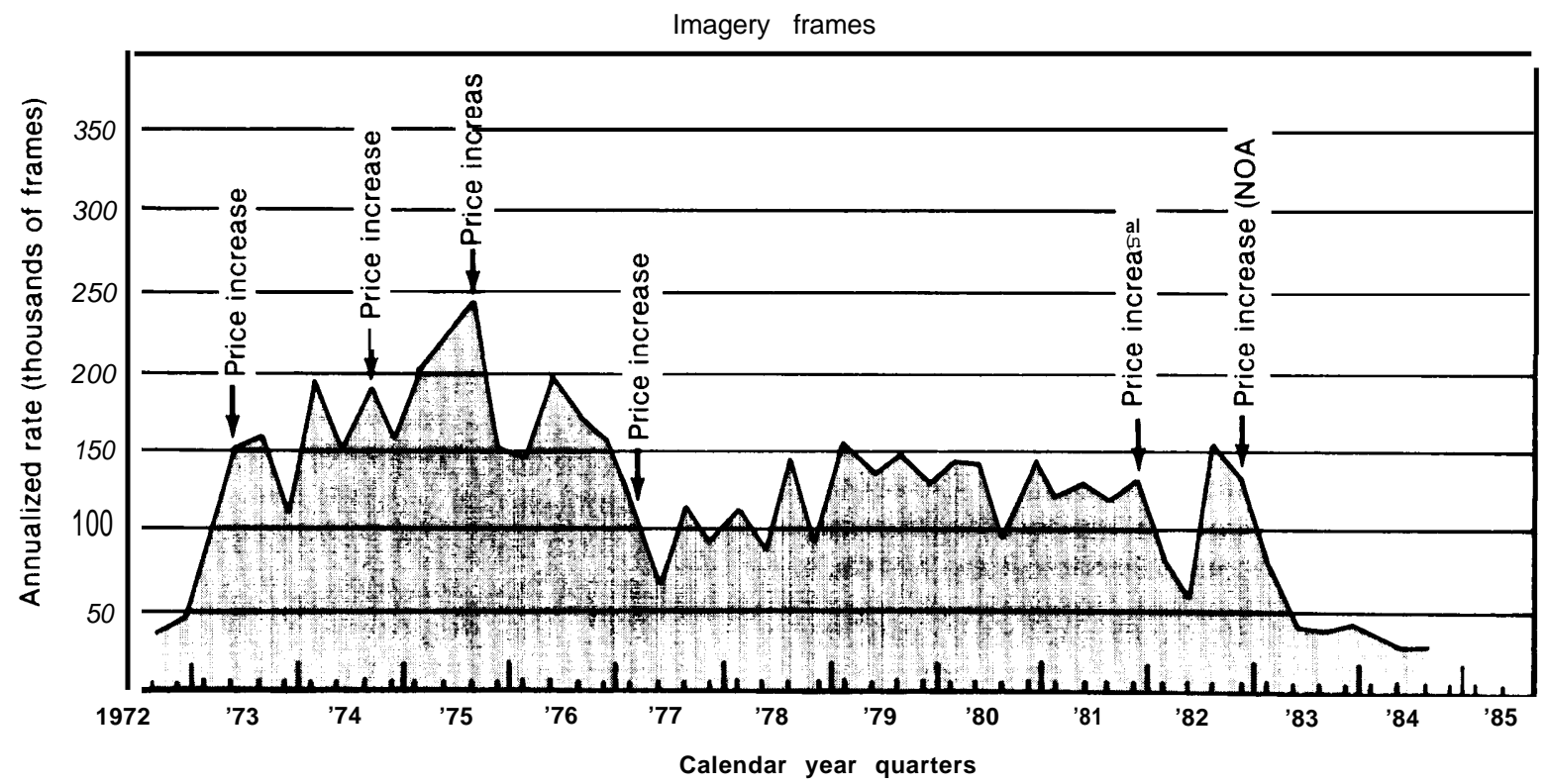

Digital products

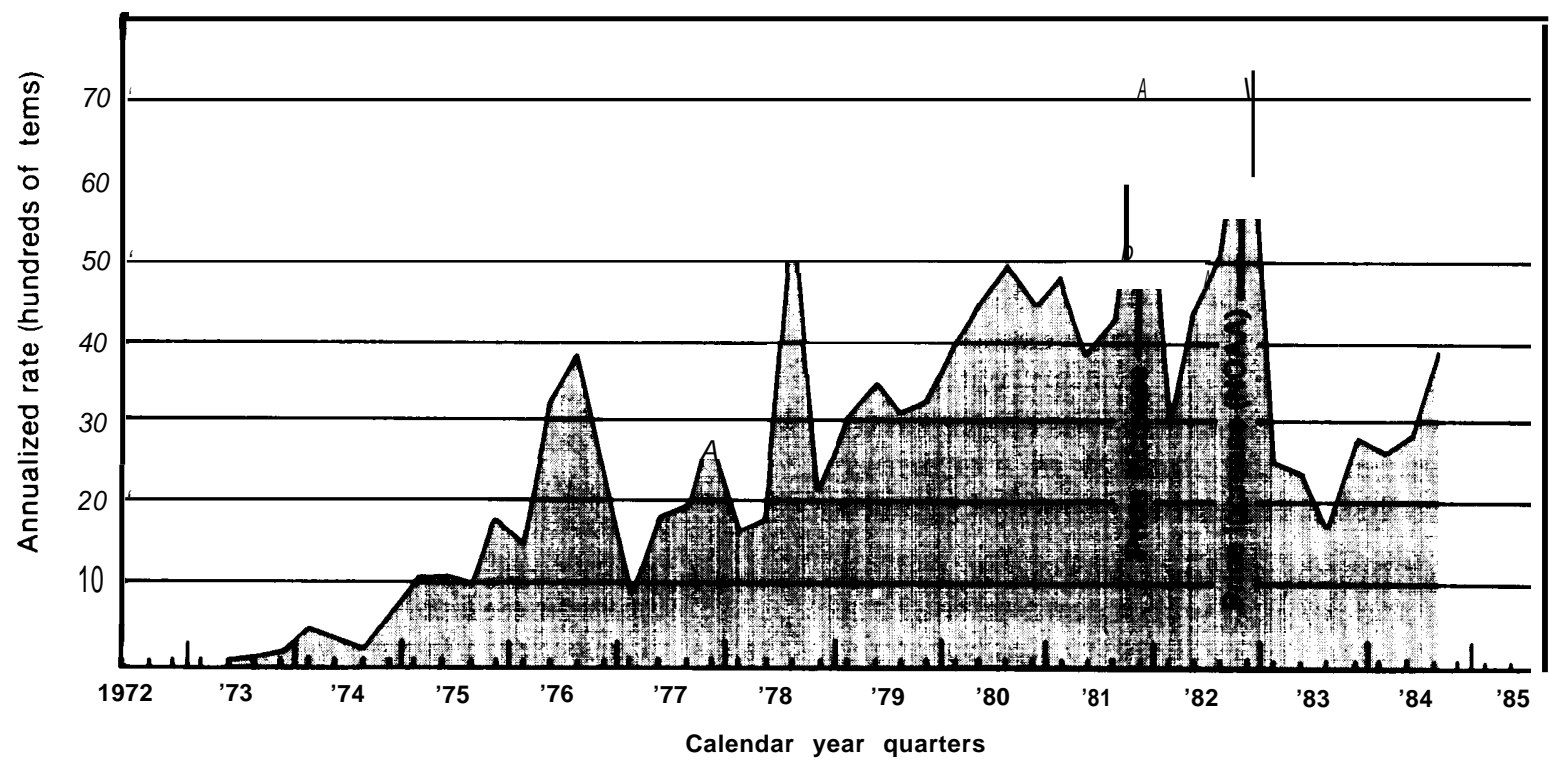

SOURCE: National Oceanic and Atmospheric Administration. 
Table 7=10.-Customer Profile of Landsat Total Data

$\begin{array}{lll}\text { FY 1973 } & \text { FY 1974 } & \text { FY } 1975\end{array}$






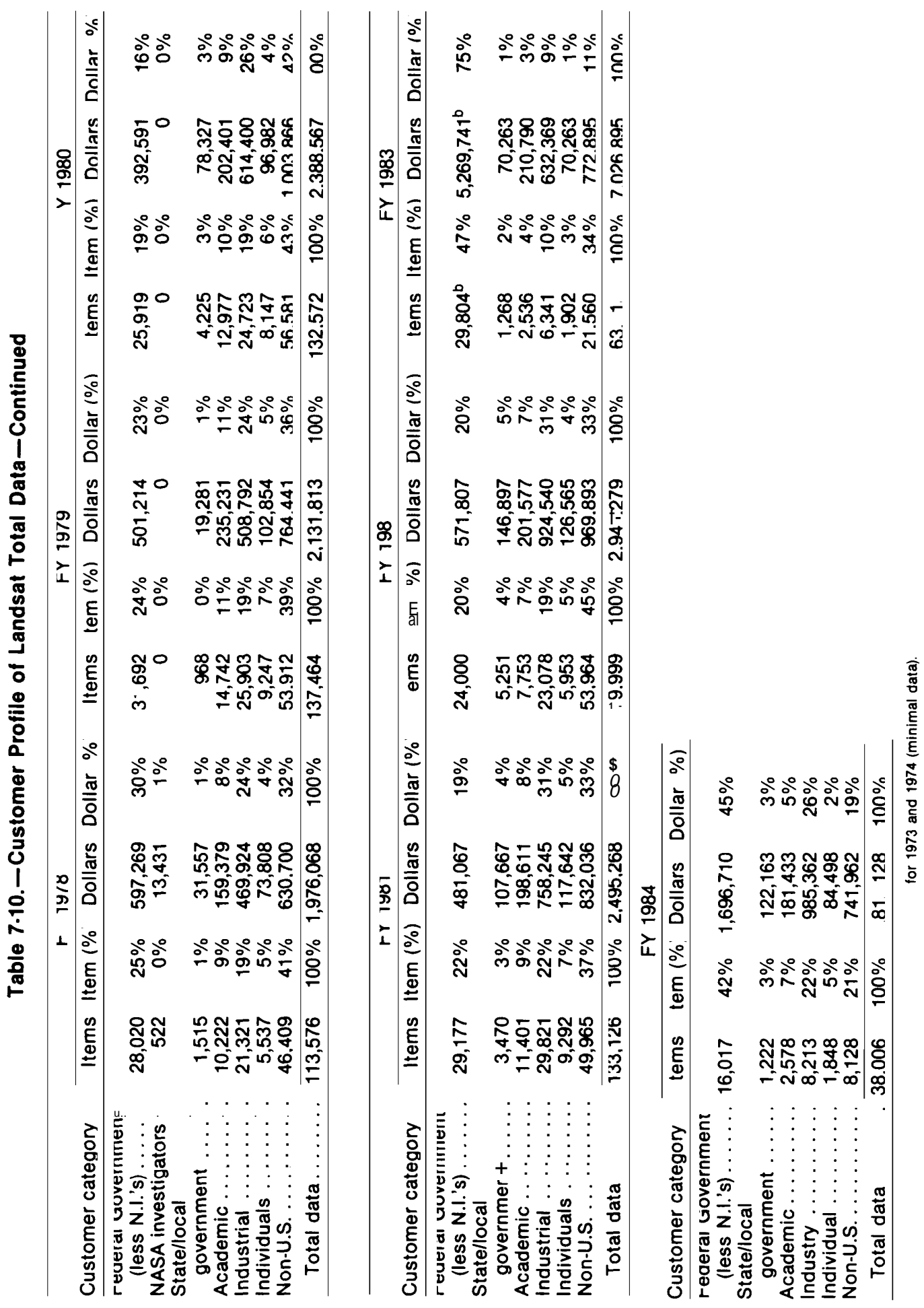


not delivered promptly, (the shortest period between acquisition and delivery from the EROS Data Center is about 2 weeks); and 2) the likelihood of a gap in delivery of data between the demise of Landsat 5 and the deployment of a follow-on satellite.${ }^{\mathrm{b} 4}$ In part because the Landsat system was treated as an R\&D system and declared operational only in 1983, insufficient funding and planning effort was devoted to assuring that customers received data in a timely, continuous manner. This has inhibited full development of those segments of the market (primarily agriculture and other nonrenewable resource management areas) that rely on rapid receipt of the data. Potential users have also been discouraged by the possibility that data from Landsat or a similar U.S. system may not be available in the future.

Until recently, the cost of manipulating data and adding value to them has been high because they have required large, expensive computers and peripheral equipment. Potential customers from all segments of the user community are reluctant to invest in the necessary sophisticated hardware and software as long as the data supply is uncertain.

- Utility of data. The value-added industry consists of a diverse set of service companies or departments of larger (discipline-oriented) industries (e. g., petroleum, mineral, or forestry firms) that take the corrected spacecraft data, manipulate them, and integrate them with other data to create useful sets of information, in the form of maps, tables, or graphs. They are properly considered part of the overall information industry. ${ }^{65}$ information derived from this process may, for example, indicate to the exploration geologist where ground tests for particular forms of minerals should be made, or to the agricultural planner what the extent of weatherrelated stress to a particular crop is likely to be. In addition to the profit-making enterprises that process land remote sensing data,

64 Remote Sensing and the Private Sector, ch. 4.

${ }^{65}$ Donn C. Walklet, "Remote Sensing Commercialization: Views of the Investment Community, "ERIM Conference, May 9-13, 1983. a variety of nonprofit data users also process data for information content. These include universities, State and local governments, and several Federal agencies.

In order for the market for data to increase to the point that it will sustain a self-supporting business, potential customers will have to become convinced of the utility (based on price, availability, and convenience) of data for their needs. Although users in many different fields have experimented (with NASA's help) with the data and written much about their utility, the message has not yet reached the sort of customers needed to sustain a self-supporting business. Unlike most current users, who are conversant with manipulating data on mainframe computers and who have experimented with satellite data, potential customers are more interested in information and "services which directly address their information needs. ${ }^{66}$ They are not customers for Landsat data per se, but for the information derived from linking Landsat data with other resource data. As such they are not unlike the majority of customers for personal computers-individuals who are uninterested in writing their own programs and will only purchase a computer if they can also purchase simple, "user-friendly" software that will meet their needs without modification and with little additional instruction.

For example, as one study has noted, the need to manage and exploit the world's renewable resources more effectively will require "more complete and timely information about soil conditions, crop acreage and yields, water availability, meteorology, and other factors that could benefit or deter resource production ... the farmer, and the government official, and everyone in between is a potential customer for resource information. ${ }^{67}$ At present, the primary customer for Landsat data related to agriculture is the Federal Government, which has a stake in U.S. agricultural productivity. How-

66"Markets for Remote Sensing Data 1980-2000," Terra-Mar, Study for TRW Defense and Space Systems Group, contract No. M624770C2M, November 1982.

67"Markets for Remote Sensing Data 1980-2000," op. cit. 
ity of the MSS sensor. The speed of correcting and delivering the data has also been limited, If the market for primary data is to grow substantially, the system's owner will have to deliver data useful for a broad range of applications, and the value-added industry will have to develop a wide variety of inexpensive data products. At present, although some users can utilize the higher capabilities of the TM data, most cannot. ${ }^{71}$ In other words, as argued above, the data will have to interest a broader category of users than they now do.

\section{Issues for the Future}

It is evident from the earlier summary of foreign systems that other countries, building on the experience gained from U.S. applications technology as well as on their own capabilities, see the development of the full range of remote-sensing satellites as an integral part of their entry into space. In addition to constructing systems that will be competitive with the U.S. Landsat system, they are also engaged in extensive research on how to apply the data.

- Private sector efforts. The success of the private sector in developing a competitive remote sensing system may well depend on the strength and longevity of Government support. Such support could consist of one or more of the following: a direct subsidy, such as has been authorized in Public Law 98-365, support in the form of a guaranteed annual Government purchase of data (specifically prohibited in Public Law 98-365), tax benefits, and/or in continued Government research. Although NASA has a program to develop a variety of advanced sensors that would be tested on the relatively short Shuttle missions, the Government has announced no plans to develop civilian operational systems that would provide data over the long

\footnotetext{
${ }_{71}$ For a discussion of using TM data effectively, see Remote Sensing and the Private Sector, op. cit., pp. 62-65.
}

term with repeat coverage. It will rely primarily on the private sector to develop and maintain a land remote sensing system. Thus, to obtain certain important civilian data, the Government may have to rely on foreign systems. In the absence of strong Government support for a private system, the private sector would be left to compete directly with foreign government-funded enterprises to sell data.

- Remote sensing research. An important aspect of maintaining leadership in land remote sensing is the continuation of research on applying remotely sensed data to resource discovery, analysis, and management. University land remote sensing research is at a low ebb in this country, ${ }^{72}$ in large part because Federal research funds have dried up prematurely. If the market for land remote sensing data were strong, research funding for applications would likely be forthcoming from the private sector in support of its needs. However, the lack of high demand for data, caused in part by the uncertainty over whether land remote sensing activities will continue, has led to reduced private funding for applications research. Neither NASA nor NOAA now have strong land remote sensing research programs, although the Land Remote Sensing Commercialization Act of 1984 authorizes both agencies to continue such research. It is clear, however, that successful commercialization will depend on developing a large variety of methods to turn remotely sensed data, especially the highresolution TM data, into useful information. The decline in U.S. research has taken place at the same time that other nations are developing new remote sensing systems and increasing their research funding on remotesensing applications. These nations are building on the substantial investment that the United States has already made in remote sensing applications.

\footnotetext{
${ }^{72}$ See, for example, Remote Sensin ${ }_{g}$ and the Private Sector, op. cit., pp. 60-61, app. C.
} 


\section{OCEAN REMOTE SENSING}

Observations from space devoted specifically to understanding ocean phenomena were first made visually and photographically by the Mercury program astronauts in the 1960s. Later, infrared radiometers incorporated on the meteorological satellites provided considerable ocean data that were later supplemented by data from a microwave instrument aboard Skylab in 1973. In 1978, NASA launched Seasat, the first dedicated ocean remote sensing satellite, which demonstrated the feasibility of using microwave sensors aboard a spacecraft. Although it failed prematurely, the experimental Seasat returned massive amounts of highly useful data to scientists (table 7-12) and demonstrated that a dedicated oceanographic satellite would serve the needs of commercial and scientific interests and Government agencies.

Because the ocean environment is constantly changing and potentially dangerous, its behavior is of considerable importance to all countries that border on the oceans, and especially to those that maintain large commercial or military fleets. Whether they are primarily concerned about activities within the 200-mile economic zones or have a wider interest in the oceans, all of these countries would benefit from data derived from space-based ocean observations delivered promptly and continuously.

A few countries, notably Canada, Japan, and the European nations (under the auspices of the European Space Agency) are now planning civilian satellite systems specifically dedicated to ocean observations. The Soviet Union has flown several dedicated civilian-military oceanographic satellites. In the United States a joint civilianmilitary National Oceanic Satellite System (NOSS) was proposed for launch in 198673 but was canceled when projected program costs rose to more

73 Technology and oceanography, U.S. Congress, Office of Technology Assessment (Washington, DC: OTA-O-1 41, June 1981).

Table 7=12.-Geophysical Oceanographic Measurement Design Capabilities for Seasat-A

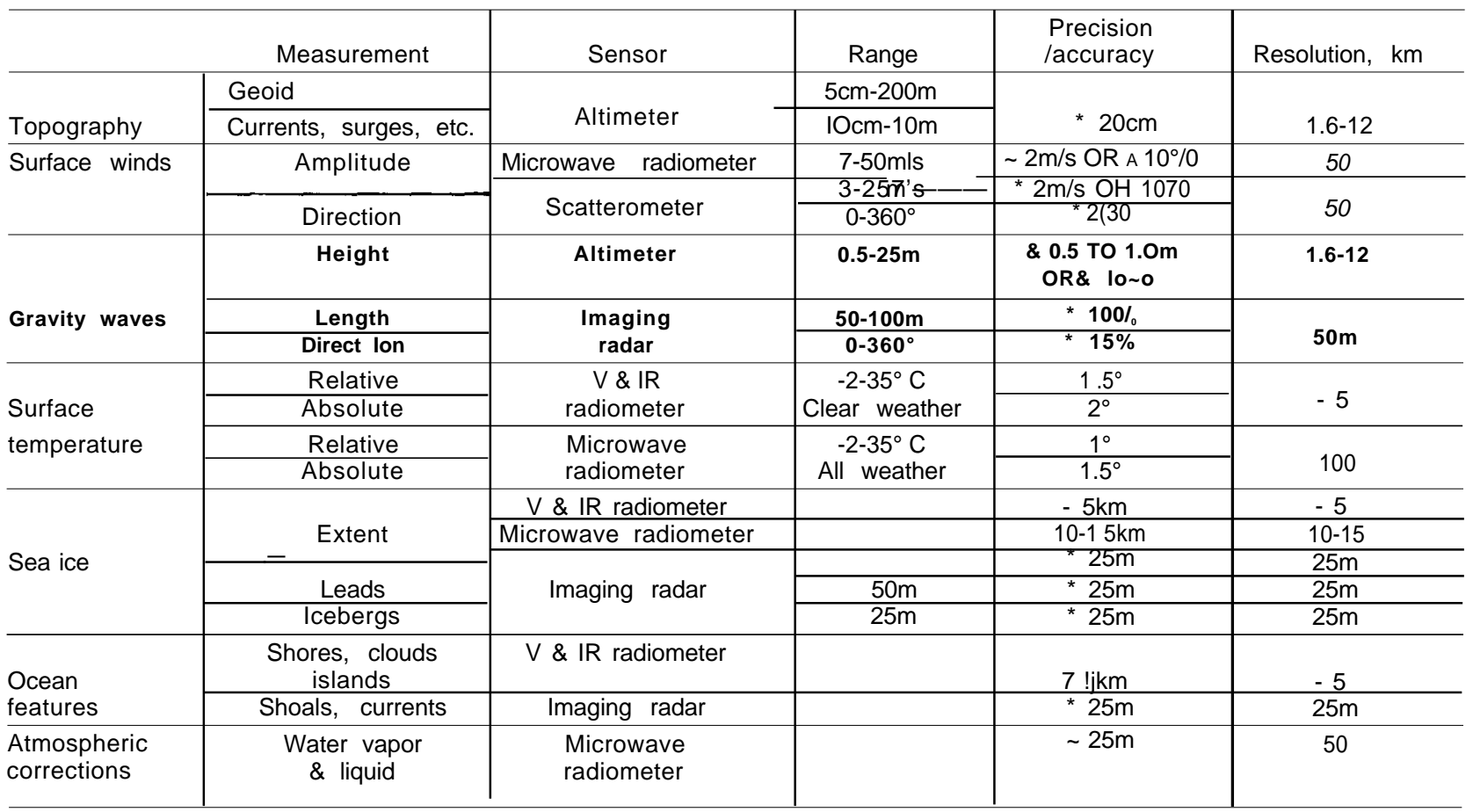


than three-quarters of a billion dollars. No civilian operational ocean satellite is now planned, but the U.S. Navy is developing the Navy Remote Ocean Sensing Satellite (N-ROSS) for Jaunch in 1989. NASA is planning a research satellite (TOPEX/ POSEIDON), with French participation, to measure ocean topography.

This section briefly summarizes the status of ocean observations from space and explores the international issues related to ocean remote sensing.

\section{U.S. Oceanographic Systems}

The technologies necessary for the complement of instruments required for an operational ocean remote sensing system are available and have been tested on a variety of U.S. satellites.

-Seasat-1978. Built by NASA to explore the utility of a satellite devoted to measuring ocean dynamics and topography, Seasat (fig. 7-1 8) lasted only 3 months. However, it returned data of considerable scientific and operational use.

- Nimbus-1\%4-85. The Nimbus series of research satellites were designed by NASA to test new sensors for generating ocean and meteorological data and to collect data of scientific interest. Nimbus-7, the latest in the series, which was launched in 1978, is still operating. It carries a Scanning Multichannel Microwave Radiometer (SMMR) that provides measurements of sea surface temperatures, and a Coastal Zone Color Scanner (CZCS) that provides a measure of biological productivity of the ocean.

-TOPEX/POSEI DON -1990. NASA has proposed to operate, in a joint U.S./French project, a research satellite devoted primarily to highly accurate measurements (to an accuracy of about 2.0 centimeters) of the height of the oceans. The satellite would also carry a microwave radiometer in order to correct for the effects of water vapor in the atmosphere, France would supply a solid-state altimeter and a radiometric tracking system. The altitude of the ocean is crucial to understanding patterns of ocean circulation. The satellite's orbit would allow determination
Figure 7-18.-The Seasat-A Spacecraft

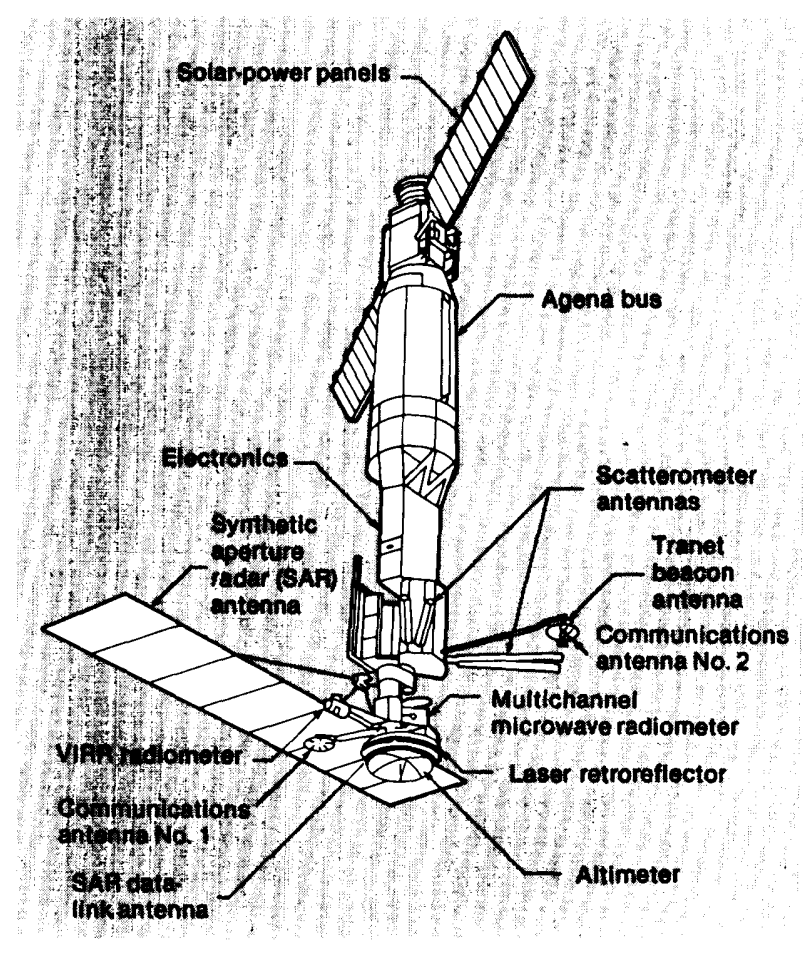

SOURCE: National Aeronautics and Space Administration.

of ocean topography from latitudes 630 north to 630 south. Accurate altitude measurements could lead to better understanding of ocean topography and dynamics, tides, sea ice position, climate and seafloor topography, among other ocean-related qualities. ${ }^{74}$ TOPEX is planned as a new start for fiscal year 1987 and would be in orbit from 1990 to 1993 or later. This schedule would allow altitude data to be gathered at the same time N-ROSS (U.S. Navy) and ERS1 (ESA), which would fly similar orbits, would be sensing data on other ocean parameters. ERS-1 would generate topography data of lower accuracy but it would reach higher latitudes than TOPEX. Together, data from the two satellites would provide considerably more information on ocean topography than either satellite could alone.

${ }^{74,}$ Satellite Altimetric Measurements of the Ocean," Report of the TOPEX Science Working Group, NASA, JPL 1981; Richard Fifield, "The Shape of Earth from Space," New Scientist, Nov. 15, 1984, pp. 46-50. 


\section{[page omitted]}

This page was originally printed on a dark gray background. The scanned version of the page was almost entirely black and not usable. 
- Metsats. The operational meteorological satellites, including the DOD DMSP satellites, have carried instruments that measure ocean parameters of interest to those who study, use, explore, and exploit the oceans' resources. Table 7-13 lists the measurements from satellites that are of particular utility to oceanic concerns.

- Navy Remote Ocean Sensing System (NROSS). N-ROSS is under development by the Navy; as currently configured, the system would employ one satellite (fig. 7-19) deployed in polar orbit, having a design life of 3 to 4 years. Although it is designed to sense parameters of direct interest to the operational needs of the Navy (tables 7-14 and 7-15), the data it returns will also benefit civilian users of the ocean. NOAA plans to collect and distribute these data (except for certain classified information) to the civilian commu nity.

\section{Foreign Systems}

- Japan Marine Observation Satellite-1 (MOS1)-1986. MOS-1 will carry sensors capable of resolving objects 50 meters across in three visible and one infrared (IR) wavelength bands. It will also carry a microwave scanning radiometer and a variable-resolution radiometer (900 to 2,700 meters) with one visible and three thermal IR bands. Although this satellite is being developed primarily for ocean sensing of wave heights, ocean color, and temperature, these data will also be useful for land remote sensing. Japan is also planning a land remote-sensing satellite (ERS1), which it expects to launch by 1990. It will carry a synthetic aperture radar. It has not yet announced plans for distributing or selling data from MOS-1 or ERS-1.

-European Space Agency (ESA) Remote Sensing Satellite (E RS-I)-1987/88. ${ }^{75}$ This satellite is planned primarily for passive microwave sensing of the coastal oceans and weather over the oceans. In addition, it will carry a synthetic aperture radar for active microwave sensing of ice topography or land masses through any cloud cover. However, because of inherent limits of available power aboard the spacecraft, its use over the Arctic regions

\footnotetext{
${ }^{75}$ A. Haskell, "The ERS-1 Programme of the European Space Agency," ESA Journal, vol. 7, 1983, pp. 1-14.
}

Table 7-13.-Measurement Needs for Oceanographic Satellites

\begin{tabular}{|c|c|c|c|c|c|c|}
\hline Measurement & & Range & $\begin{array}{l}\text { Precision } \\
\text { accuracy }\end{array}$ & Resolution & Spacial grid & Temporal grid \\
\hline \multirow[b]{2}{*}{ Topography } & Geoid & $5 \mathrm{~cm}-200 \mathrm{~m}$ & * $10 \mathrm{~cm}$ & IOkm & - & Weekly to monthly \\
\hline & $\begin{array}{l}\text { Currents, } \\
\text { surges, etc. }\end{array}$ & $\begin{array}{l}10 \mathrm{~cm}-10 \mathrm{~m} \\
5-500 \mathrm{~cm} / \mathrm{s}\end{array}$ & $\begin{array}{l}\text { Y } 10 \mathrm{~cm} \\
\text { a } 5 \mathrm{~cm} / \mathrm{s} \\
\end{array}$ & $10-1000 m$ & IOkm & $\begin{array}{c}\begin{array}{c}\text { Twice a day to } \\
\text { weekly }\end{array} \\
\end{array}$ \\
\hline \multirow{4}{*}{ Surface winds } & Open ocean & \multirow{3}{*}{$3-50 \mathrm{mLs}$} & \multirow{3}{*}{$\begin{array}{l}\& 1 \mathrm{TO} 2 \mathrm{~m} / \mathrm{s} \\
\text { OR A } 10 \%\end{array}$} & $10-50 \mathrm{~km}$ & $50-100 \mathrm{~km}$ & \multirow[b]{2}{*}{$2-81 d$} \\
\hline & Amplitude & & & $5-25 \mathrm{~km}$ & $25 \mathrm{~km}$ & \\
\hline & Coastal & & & $\mathrm{l}-5 \mathrm{~km}$ & $5 \mathrm{~km}$ & Hourly \\
\hline & Direction & $0-360^{\circ}$ & $\sim 1() .200$ & - & - & - \\
\hline \multirow{3}{*}{ Gravity waves } & Height & $0.5-20 \mathrm{~m}$ & $\& 0.5 \mathrm{~m}$ & $20 \mathrm{~km}$ & \multirow{3}{*}{$50 \mathrm{~km}$} & 2-81d \\
\hline & Length & $6-1,000 \mathrm{~m}$ & $\begin{aligned} \text { OR } & \sim 10.25 y_{0} \\
& \sim \mathbf{1 0 . 2 5 0 / 0}\end{aligned}$ & \multirow[t]{2}{*}{$3-50 \mathrm{~m}$} & & \multirow[t]{2}{*}{$2-4 / d$} \\
\hline & Direction & $0-360^{\circ}$ & * $10-300$ & & & \\
\hline \multirow{3}{*}{$\begin{array}{l}\text { Surface } \\
\text { temperature }\end{array}$} & Open sea & \multirow{3}{*}{$-2-35^{\circ} \mathrm{C}$} & \multirow{3}{*}{$\begin{array}{cc}0.1-2 & \text { 'relative } \\
3.5-2^{\circ} & \text { absolute }\end{array}$} & $25-100 \mathrm{~km}$ & IOOkm & \multirow{3}{*}{$\begin{array}{l}\text { Daily to weekly } \\
\text { with spectrum of } \\
\text { times of day and } \\
\text { times of year }\end{array}$} \\
\hline & Closed sea & & & $5-25 \mathrm{~km}$ & $25 \mathrm{~km}$ & \\
\hline & Coastal & & & $0.1-5 \mathrm{~km}$ & $5 \mathrm{~km}$ & \\
\hline \multirow{3}{*}{ Sea ice } & Extent and age & 6 me.- yrs. & I-5km & $\mathrm{I}-5 \mathrm{~km}$ & $1-5 \mathrm{~km}$ & weekly \\
\hline & Leads & $50 \mathrm{~cm}$ & $25 m$ & $25 m$ & $25 \mathrm{~m}$ & $2-4 / d$ \\
\hline & Icebergs & $\mathrm{IOcm}$ & $\mathrm{I}-50 \mathrm{~m}$ & $\mathrm{I}-50 \mathrm{~m}$ & $25 m$ & - \\
\hline
\end{tabular}


Figure 7-19.-Navy Remote Ocean Sensing Satellite (N-Ross)

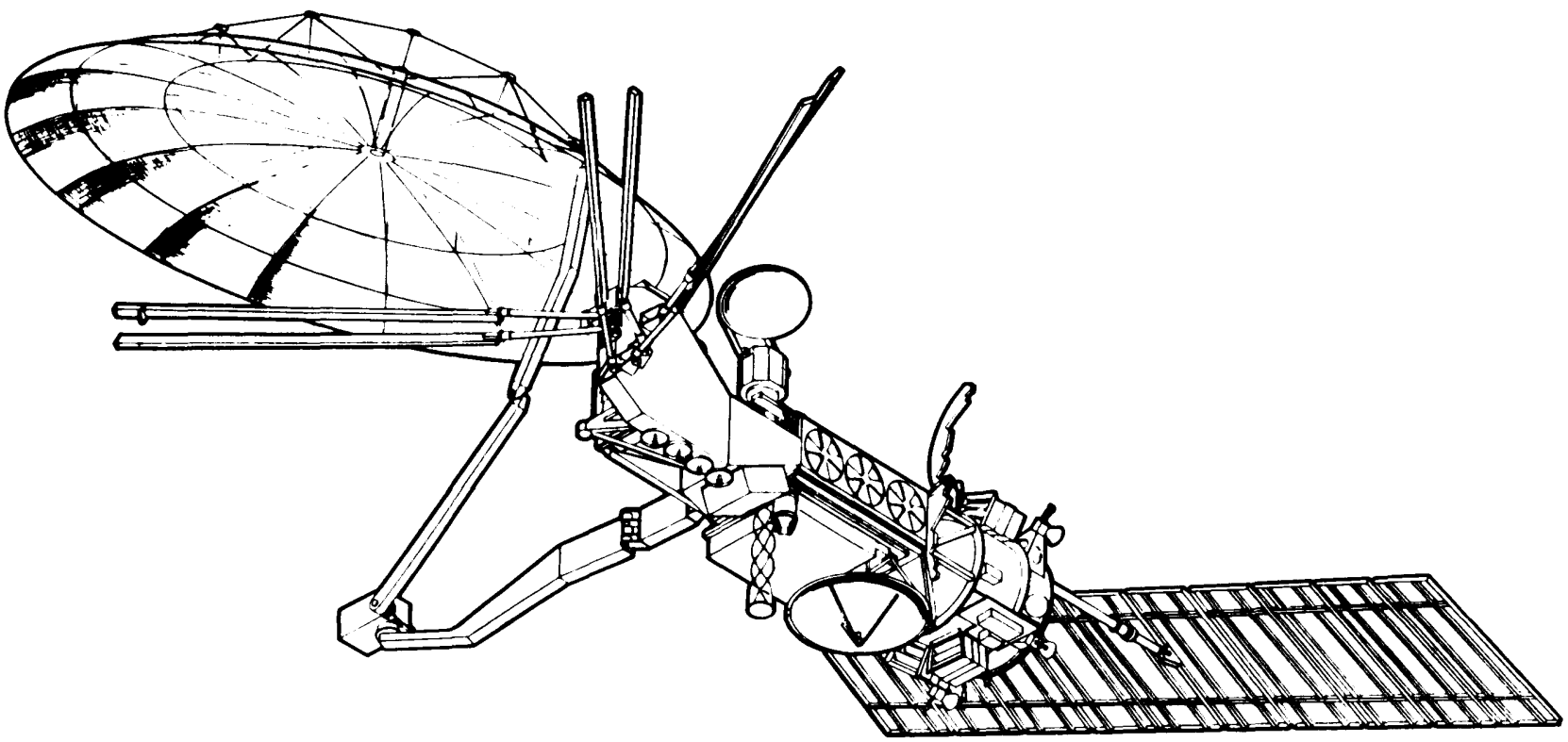

SOURCE: U.S. Navy.

Table 7-14 N-ROSS Sensor Capabilities

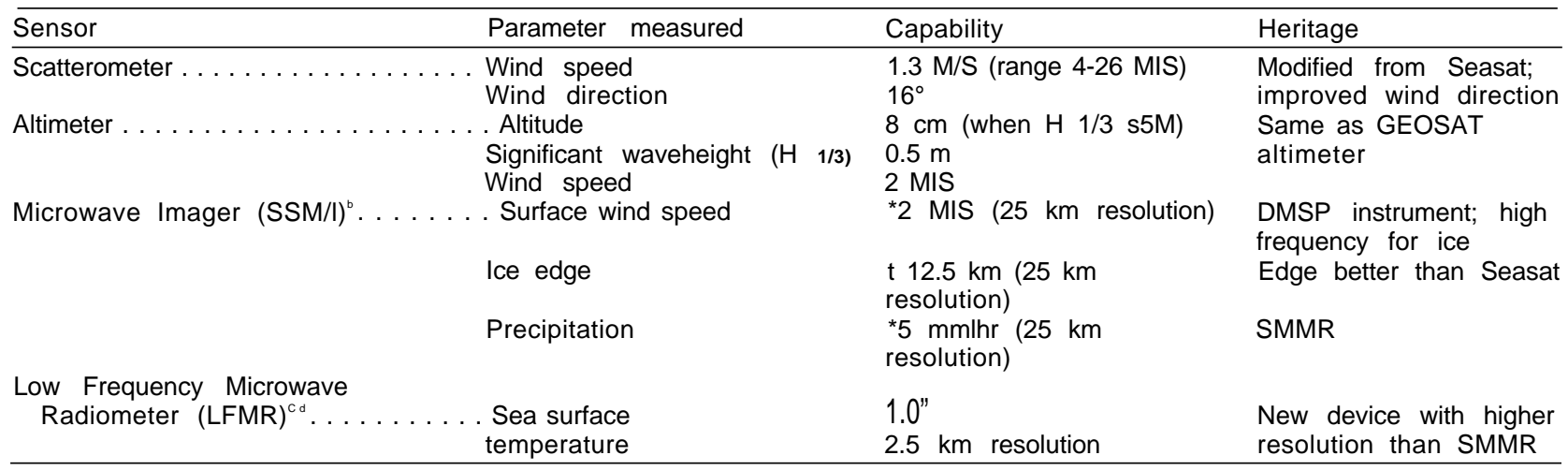

aseasat type sensor.

'New sensor.

${ }_{\mathrm{dD}}^{\mathrm{N}} \mathrm{N}, \mathrm{j}$ Frequency Sensor (5 and $10 \mathrm{GHz}$ ) to be flown as a companion sensor to the SSM/1.

SOURCE: RCA Astro-Electronics.

may be limited. It is the first of a planned series of three satellites to be launched by ESA. It is not yet clear how data from this satellite are to be distributed to other countries (see issues section below).

Canada Radarsat-1990. Under development by Canada for routine observations of polar sea ice, as well as assessments of Can- ada's natural resources, the satellite will provide C-band radar images of Earth's surface. Its primary sensor will be capable of being pointed and will have a spatial resolution of about 30 meters. Because it will operate at microwave frequencies, it will be able to gather information on the surface of Earth through cloud cover. Data from this satel- 
Table 7-15.-Oceanographic Data Tactical Operations

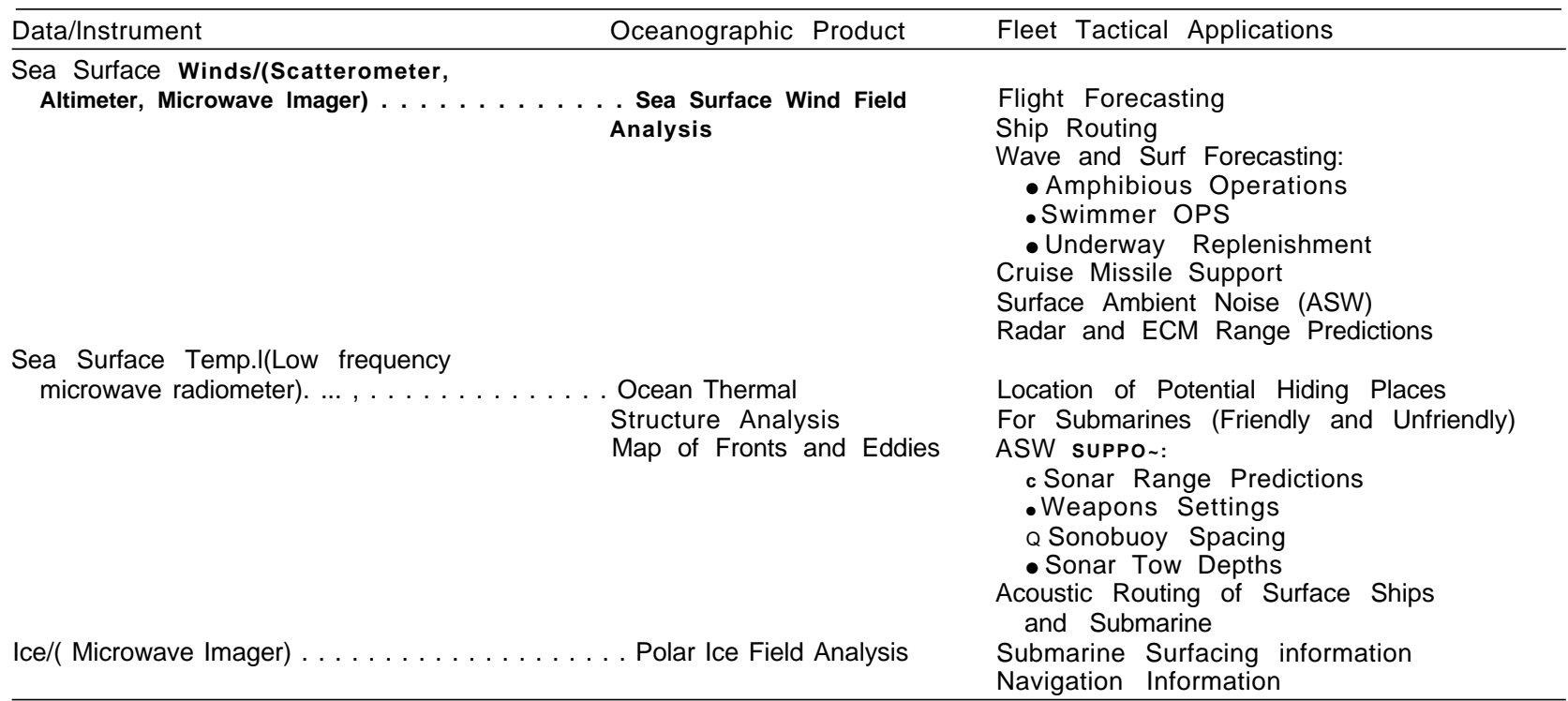

SOURCE' RCA Astro-Electronics.

lite will be available for direct sale or by arrangement through offset programs. In order to reduce its costs, Canada is seeking partners in this venture. The spacecraft will also carry a NASA scatterometer and an optical sensor built either in the United States or Europe.

-U.S.S.R. Oceanographic Satellites Kosmos 1500 (1983) and Kosmos 1602 (1984). ${ }^{76}$ In addition to a low-resolution scanner and a microwave radiometer, Kosmos 1500 carried a side-looking radar that was used to assist Soviet merchant ships trapped in the ice in the Chukchi and East Siberian Seas. ${ }^{77}$ Kosmos 1602 presumably carries a similar complement of instruments. Analysis of data received from these satellites indicates quality comparable to that of the U.S. Seasat.

\footnotetext{
${ }^{76}$ Nicholas L. Johnson, "The Soviet Year in Space: 1984, " Teledyne Brown Engineering, 1985, p. 28.

77 . Shmyganoviskiy, "A Space Pilot for the Nuclear-Powered Icebreakers," Izvestiya, Moscow, Nov. 6, 1983,p. 6; TASS, Moscow, 23 Jan. 1984; "Soviet Cosmos Spacecraft Providing Lane, Sea Imagery," Aviation Week and Space Technology, Nov. 12, 1984,pp. 212-213.
}

\section{Major Ocean Parameters of Interest for Scientific and Applied Uses}

A satellite specifically designed for ocean applications should produce timely, synoptic data of extreme usefulness to researchers, to private enterprise, and to governments.

The following selection of major ocean attributes indicates some parameters that satellites could measure successfully.

\section{Sea Surface Temperature}

Data on sea surface temperatures, gathered by the infrared radiometers aboard the meteorological spacecraft, have been available for two decades. The maps of sea surface temperatures produced from these data demonstrate complex surface temperature patterns that have led to considerable speculation about the physical processes that might cause such patterns. Because they reflect only surface effects (1 millimeter or less) these data alone are of limited use in understanding the physical processes of the deeper layers of the ocean. Yet, higher resolution meas- 


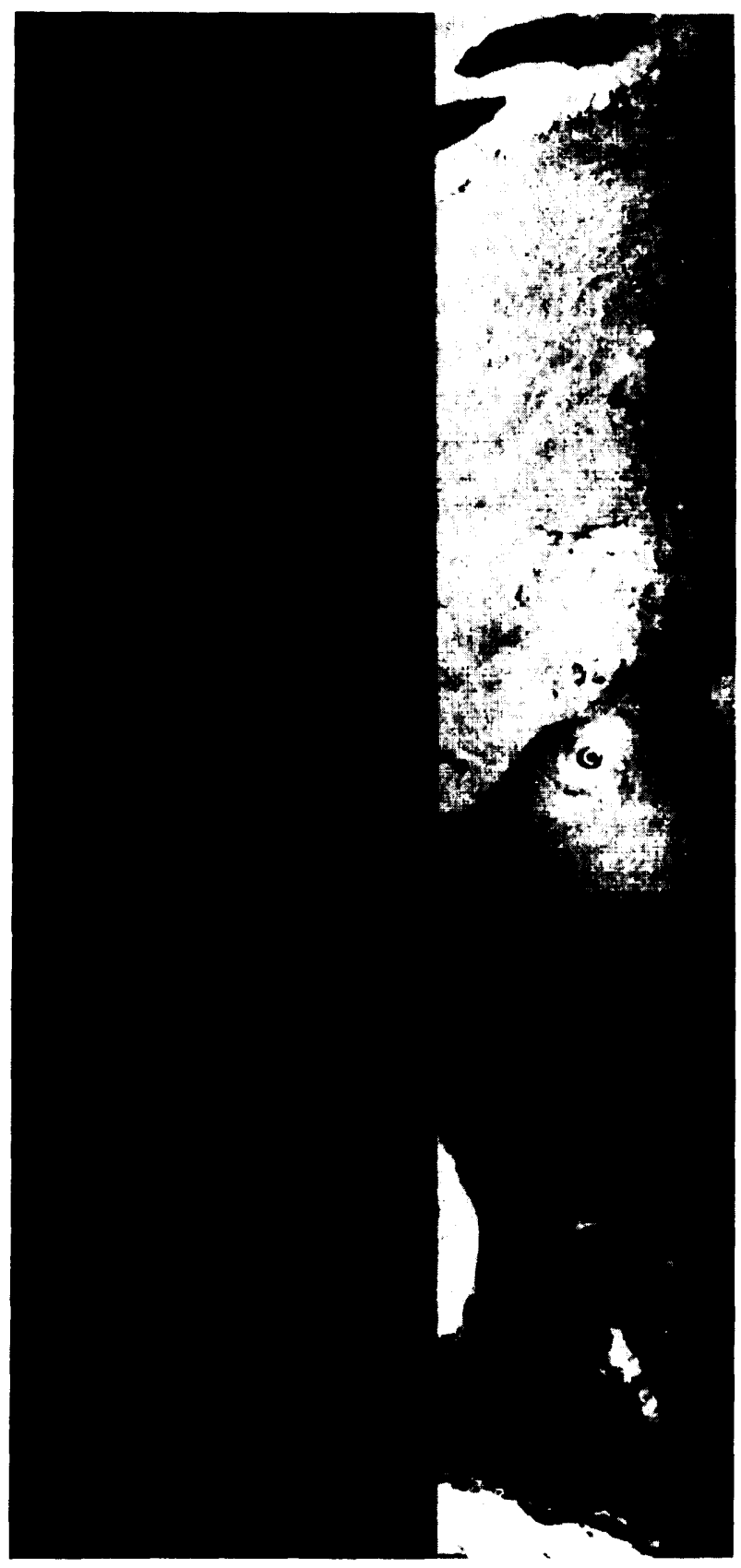

Photo credit: U.S.S.R. Hydromet Office

Images of hurricane Diane off the coast of North Carolina received from the Soviet Cosmos-1500 satellite (Sept. 11, 1984). The lefthand image is from a multichannel scanner. The righthand one is from a side-looking radar operating at $3 \mathrm{~cm}$ wavelength. They were given to NESDIS by engineers at Hydomet in Moscow. urements of water temperatures at the surface, coupled with observations of surface winds and estimates of evaporation and rainfall, would provide better information on heat transport of the oceans. 'B In addition to their scientific interest for climatological studies, many of these physical processes are of interest to the users of the ocean.

\section{Ocean Color}

The polar-orbiting satellite Nimbus-7, launched in 1978, carries a Coastal Zone Color Scanner (CZCS), which measures spectral radiance from ocean waters in thermal, near-infrared, and four visible wavelength bands. Among other considerations, the optical bands were selected according to the optical properties of chlorophyll. The infrared bands provide data on coastal and ocean current temperature. Although no operational sensor is now funded, experiments with the CZCS aboard Nimbus-7 have demonstrated ${ }^{79}$ that the data from such a sensor are potentially of considerable utility in locating areas of fish abundance, $A$ recent report ${ }^{80}$ urged the development of an Ocean Color Imager to start in fiscal year 1987. Such a satellite would yield important scientific information on understanding biological productivity in the oceans.

\section{Sea Ice}

Whether from concern for locating and tracking icebergs as they cross shipping lanes, or from desire to understand the direction of ice type, extent, and drift in polar regions, interest in the distribution and condition of sea ice has increased in recent years (table 7-16).81 Visual observations of sea ice are now collected by the Multispectral Scanner (MSS) and Thematic Mapper (TM) sensors aboard Landsat 5 and by the Very High

\footnotetext{
${ }^{76}$ Brethaton Francis P., "Climate, the Oceans and Remote Sensing," Oceans 24, No. 3, pp. 48-55, 1981.

79"The Marine Resources Experiment Program, (MAREX)," Report of the Ocean Color Science Working Group, NASA-Goddard Space Flight Center, December 1982.

B0" Oceanography From Space: A Research Strategy for the Decade 1985-1 995," Report of the Joint Oceanographic Institutions, Washington, DC. 1984.

${ }^{8}$ 'W. F. Weeks, "Sea Ice: The Potential of Remote Sensing," Oceanus 24, No. 3, pp. 39-47, 1981.
} 
Table 7-16.-Ice Parameters of Importance in Different Operations and Research Areas

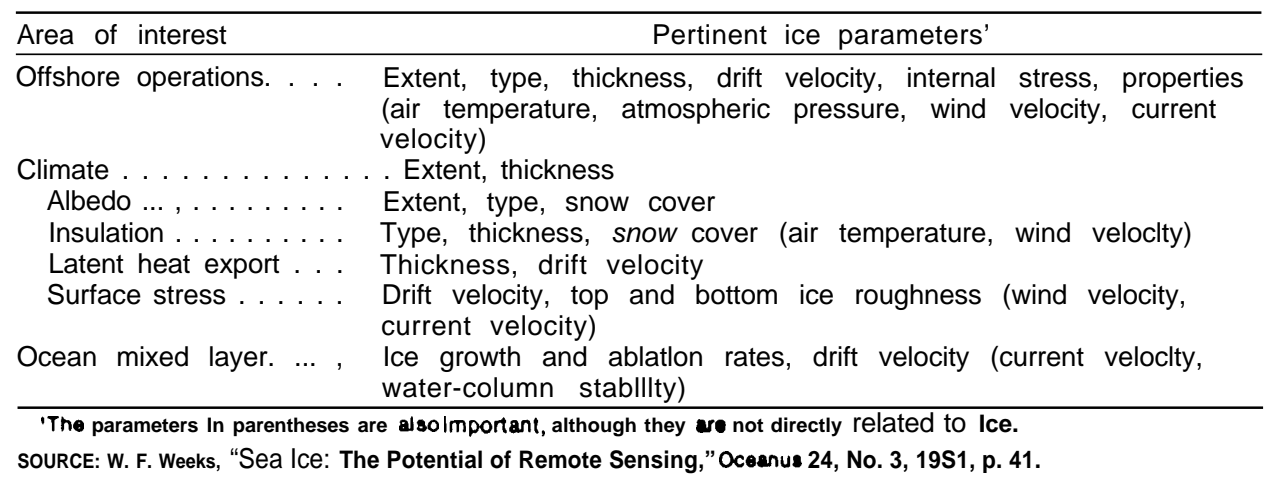

Resolution Radiometer (VHRR) on the NOAA-N series satellites. Although highly useful for determining the extent of ice cover and ice flow, these data are limited by cloud cover and by darkness (at those times of year when the Sun is not visible at high latitudes). Further, the Landsat data are limited by lack of daily coverage, and the NOAA-N data are limited in spatial resolution.

Thermal infrared measurements made by the VHRR infrared sensor on the NOAA-N satellites have some usefulness for determining sea-ice thickness. Although the instrument is limited by cloud cover, it is not limited by lack of sunlight; it is highly useful for low resolution, large-scale measurements of ice movement and extent.

Microwave systems have the advantage that the frequencies at which they operate are limited by neither clouds nor darkness. Both passive and active (radar) systems can be used for mapping and monitoring sea ice, but the passive system suffers from the highly limited resolution available from the relatively small antennas that can be carried aboard a satellite. Nimbus- 5 and Nimbus- 7 carried passive microwave radiometers. No microwave measurements of sea ice are now being taken by the United States.

An active system based on the synthetic aperture radar principle could overcome the problem of low resolution at the price of having to handle high volumes of data. A Synthetic Aperture Radar (SAR) would achieve relatively high resolution along the line of sight at an angle to the nadir by using the satellite motion coupled with digital signal processing techniques to create a synthetic image of Earth's surface. Such systems are an outgrowth of aircraft side-looking aperture radar systems; an L-band SAR was demonstrated on Seasat (fig. 7-20). However, before such an instrument could become operational, methods

\section{Figure 7.20.- Radar Image of Kuskokwim Bay} in Alaska

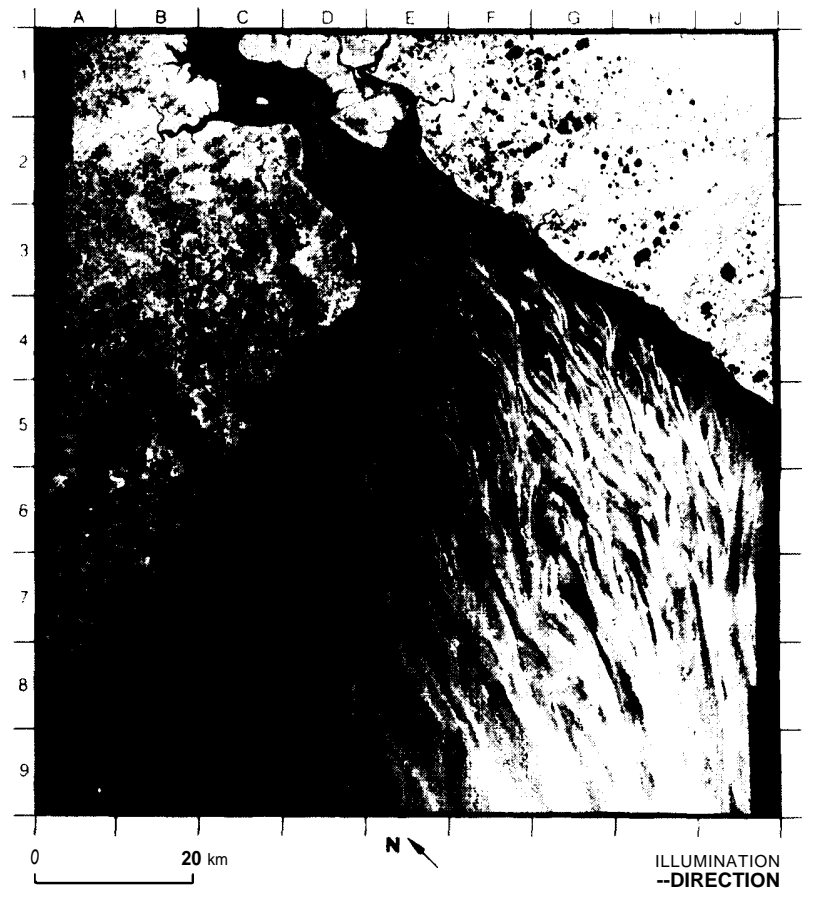

As the Kuskokwim River flows into the Bering Sea, it forms large sediment deposits in Kuskokwim Bay, which are visible as small dark areas separated by channels (bright areas).

SOURCE: Lee-Lueng Fu and Benjamin Holt, "Seasat Views Oceans and Sea Ice With Synthetic-Aperature Radar," NASA Jet Propulsion Laboratory Publication 81-120, Feb. 15, 1982, p. 98. 
would have to be developed to process the data rapidly and turn them into useful products. As noted, Canada and ESA will include an SAR instrument on their satellites, Radarsat, and ERS-1.

A satellite altimeter and a scatterometer are two other examples of active radar systems that could be used to measure ice parameters. An altimeter (e.g., that planned for TOPEX/POSEIDON) could measure the height of the ice with a precision of a few centimeters. Data from a scatterometer would be used to determine ice roughness and the position of sea-ice boundaries.

\section{Wave Heights}

Knowledge of wave height and general wave conditions at a variety of ocean locations is crucial for the safety of ships at sea, and for ocean platforms. Data on waves are also important for understanding and modeling ocean dynamics. Because winds create waves, measurements of wind speed and direction over wide areas can lead to estimates of wave height and condition.

\section{Applications of Ocean Remote Sensing}

Data from satellite remote sensing of the oceans have the potential for providing information for several important applications (table 7-17; table 7-18). The following examples illustrate the potential importance of these data.

\section{Weather and Climate}

The world's climate system is dominated by the behavior of the oceans. Understanding and predicting climate depends directly on understanding ocean temperatures, currents, wave heights, sea level, and sea surface winds, as well as other characteristics. Obtaining comprehensive, periodic, synoptic measurements requires a spaceborne system. Although daily measurements from ships crossing the oceans or from ocean buoys are available to climatologists, such measurements are primarily limited to the major shipping routes or to the coastal areas. The climate-related parameters of vast areas of the ocean remain unobserved except on a sporadic basis.

\section{Marine Transportation}

In ship routing, the most critical parameter to measure is sea state (wave heights). However, winds, currents, fog, rain, etc., are also important. One report suggested that reliable data and analysis of sea state "can reduce ship transit time and therefore save a significant amount of fuel." ${ }^{12}$

The experimental Seasat was used by a U.S. ship routing company in studies that indicated:

... that the use of satellite-derived wind observations can be useful in more accurately locating low-pressure storm centers. This knowledge could reduce vessel transit distances and times. ${ }^{83}$

\section{Offshore Mining: Oil and Gas \\ Exploration and Extraction}

Offshore mining firms could make considerable use of ocean satellites because many of the areas with the richest resource potential are not located in the major shipping lanes and thus are the most poorly observed by conventional means. The deep-ocean-mining industry now is using wind and wave measurements from ship reports in designing equipment and formulating operating plans and schedules. ${ }^{84}$ Various experimenters have suggested that a better climatological information base, which could be provided by satellite, would be put to good use in planning for and operating deep ocean mining projects.

Oil and gas exploration and extraction companies could also use an improved ocean climatological data base for selecting equipment, such as drilling rigs and supply vessels, and in planning offshore operations. * Perhaps the most important use of the satellite data is for improved weather warnings and status of ice information. as

\footnotetext{
${ }^{82}$ Donald Montgomery, "Commercial Applications of Satellite Oceanography," Oceanus 24, No. 3, p. 58, 1981.

${ }^{63} 1$ bid., p. 59.

${ }^{84} 1$ bid., p. 59

* Oil and Gas Technologies for the Arctic and Deepwater (Washington, DC: U.S. Congress, Office of Technology Assessment, OTA$0-270$, May 1985)

85!bid., p. 60.
} 
Table 7-17.-Possible Oceanographic Satellite Applications

\begin{tabular}{|c|c|}
\hline Activity & Application \\
\hline Offshore oil and gas: & $\begin{array}{l}\text { Increased ocean forecast accuracy } \\
\text { Exploration operations } \\
\text { Seismic surveys } \\
\text { Drill ships } \\
\text { Towout operations } \\
\text { Production operations } \\
\text { Crew scheduling } \\
\text { Platform and crew safety } \\
\text { Ice observations } \\
\text { Ice dynamics for platform design criteria } \\
\text { Ice movement for platform and crew safety } \\
\text { Environmental data } \\
\text { Replace platform instrumentation } \\
\text { Subsurface and seabed dynamics } \\
\text { Gas pipeline and applications }\end{array}$ \\
\hline Environmental forecasting: & $\begin{array}{l}\text { Increased observations (particularly in Southern Hemisphere) } \\
\text { Consistent observations } \\
\text { Wave-height measurements } \\
\text { Wind averages }\end{array}$ \\
\hline Marine transportation: & $\begin{array}{l}\text { Increased ocean forecast accuracy } \\
\text { Optimum routing } \\
\text { Port scheduling } \\
\text { Ice observations } \\
\text { Arctic resupply } \\
\text { Vessel/personal safety }\end{array}$ \\
\hline Deep-ocean mining: & $\begin{array}{l}\text { Increased ocean forecast accuracy } \\
\text { Mining operations } \\
\text { Improved tropical storm, storm-track prediction } \\
\text { Mining operations and safety } \\
\text { Historical data base } \\
\text { Unbiased climatology } \\
\text { Mining equipment design } \\
\text { Operational criteria }\end{array}$ \\
\hline Marine fisheries: & $\begin{array}{l}\text { Increased ocean forecast accuracy } \\
\text { Efficient search efforts } \\
\text { Efficient gear operations } \\
\text { Reduced gear losses } \\
\text { Crew and vessel safety } \\
\text { Ice observations/forecasts } \\
\text { Gear losses } \\
\text { Crew and vessel safety }\end{array}$ \\
\hline
\end{tabular}

SOURCE D R Montgomery, “Commercial Applications of Satellite Oceanography," Oceanus 24, 1981, pp. 57.65.

Table 7-18.-Impacts of Observed Parameters on Commercial Benefits

\begin{tabular}{|c|c|c|c|c|}
\hline \multirow[b]{2}{*}{ Application } & \multicolumn{4}{|c|}{ Measurement Parameter } \\
\hline & Wind & Waves & $\begin{array}{r}\text { Sea Surface } \\
\text { Temperature }\end{array}$ & Ice \\
\hline $\begin{array}{l}\text { Ocean Fishing ........... } \\
\text { Marine Transportation . . . } \\
\text { Oil }\end{array}$ & $\begin{array}{l}\text { High } \\
\text { High }\end{array}$ & $\begin{array}{l}\text { High } \\
\text { High }\end{array}$ & $\begin{array}{l}\text { High } \\
\text { Low }\end{array}$ & $\begin{array}{l}\text { Low } \\
\text { Low }\end{array}$ \\
\hline $\begin{array}{c}\text { and Development . . . . . } \\
\text { Arctic Operations . . . . }\end{array}$ & $\begin{array}{l}. \text { High } \\
\text {. High }\end{array}$ & $\begin{array}{l}\text { High } \\
\text { High }\end{array}$ & $\begin{array}{l}\text { Low } \\
\text { Low }\end{array}$ & $\begin{array}{l}\text { High } \\
\text { High }\end{array}$ \\
\hline
\end{tabular}

aHigh in regions where sharp temperature gradients indicate currents.

Dopendency low for present trade routes; will Increase with the movements of arctic resources using ice breakers.

${ }^{C}$ High only In ice prevalent regions.

SOURCE RCA Astro-Electronics 


\section{Surveillance and Enforcement}

With the recent extension of coastal economic zones to 200 miles, all coastal countries, and especially developing ones, would benefit from better surveillance and enforcement programs. Surveillance of cooperative targets-the monitoring of boats legally within a country's 200 -mile economic zone-could be done using the ARGOS system on TIROS-N, This system could monitor cooperative vessels (i. e., those with an appropriate transmitter aboard) and enable a host government to supervise their fishing activities. An uncooperative or illegal foreign fishing vessel, however, must still be apprehended by aircraft or ocean patrol. ${ }^{8 b}$

\section{Fisheries}

Indirect measurements of environmental factors which affect the distribution and abundance of the resource, both temporally and spatially, can be used to indicate areas of high yield. However, using satellite data for commercial fisheries requires that two links be made: 1 ) fish availability must first be correlated with environmental and/or ocean attributes, then, 2) environmental and/or attributes detected from the satellite must lead to information about the potential available food supply.

The following environmental parameters relate to the distribution and abundance of ocean fish:

- Sea surface temperature. Sea surface temperature may be directly related to the distribution and abundance of marine organisms. For instance, studies of Pacific tuna have demonstrated strong correlations between tuna catch and water temperature. Also, strong temperature gradients may indicate the edges of warm and cold water systems. These edges or boundaries usually define currents and mark areas of increased pelagic fish productivity.

- Sea surface salinity. Although sea surface salinity cannot be measured by satellite, measurements of salinity help indicate the

\footnotetext{
${ }^{86}$ Resources Development Associates, Feasibility of Surveillance and Monitoring of Fishing Vessels in Papua New Guinea (Los Altos, CA: RDA, January 1980).
}

distribution and abundance of certain kinds of marine organisms, especially those that spend some portion of their life cycle in the estuarine areas.

- Sea state (wave heights). Sea state becomes an important indicator for current systems when temperature, salinity, and other property gradients are negligible. Because current systems delineate areas of more or less fish productivity and may also possess different sea states, the measurement of sea state may correlate with fish catch.

- Water color and chlorophyll concentrations. Water color variations indicate the boundaries of major current systems. More important, water color has long been used indirectly as an indicator of biological productivity. Detection of water color is primarily used to detect shifts of marine organisms, especially those that spend some portion of their life cycle in the estuarine areas.

- Pollution. Pollution may be considered as an indicator of areas in which fish are not present. it may also indicate where fish and their environment might be endangered. Slicks, foam, and debris lines may also indicate current convergence zones, which may be areas of high productivity.

- Surface objects. Surface objects of interest that may be detected include vessels, buoys, offshore oil platforms, weed-debris lines, marine mammals (whales, porpoises), bioluminescence, and fish schools on or near the surface.

- Other factors. Other environmental data are important, including water clarity and current patterns, but these are usually inferred from the parameters listed above.

\section{Issues in Ocean Remote Sensing}

What Are the Research Needs for

\section{Ocean Remote Sensing?}

There is a strong continuing need for research into ocean phenomena, both to support ocean users (e.g., the maritime industries), and to increase our basic understanding of fundamental ocean processes. Although humans have traveled and studied the oceans since before recorded his- 
tory, our ability to predict future ocean behavior is severely limited by lack of knowledge of how the ocean works and how to model its behavior. Understanding the oceans more thoroughly will also require the collection and processing of vast amounts of data, both from surface observations and from satellites.

The problems of understanding the dynamics of the ocean are similar to those of understanding the dynamics of the atmosphere. The oceans and the atmosphere are both fluids that are heated and cooled by complicated processes and strongly affected by thermal flows from the land masses. Major changes may occur over scales of hours, days, weeks, or even years. The ability to predict future behavior of the oceans requires knowledge of the ocean as it is at any given moment, and how it changes over time. predictions also require the ability to model ocean behavior in large computers and compare those results with observations. Satellites are particularly useful for gathering much of the necessary data because they provide a synoptic view of the oceans at predictable repeat intervals. Observations from ships, although extremely important in verifying satellite records, are scattered both in time and space, and provide poor data sets for modeling ocean behavior. Ocean buoys, though useful for collecting important data, are necessarily few in number and widely scattered throughout the oceans.

How Can We Make the Best Use of the Space Assets of the United States and of Other Countries to Increase Our Knowledge of the Oceans?

As noted earlier in this section, Canada, Japan, and the European Space Agency are designing or building ocean-related satellite systems that are expected to be operational within the next $s$ years. The Navy N-ROSS system, the data from which will be distributed to the civilian community through NOAA, is likely to be operational in the same time period. This is one area in which the increased ability of other countries to compete with the United States technologically by building space systems can lead to closer cooperation. Close cooperation and coordination among countries could provide timely and con- tinuous access to the data from these systems. Most important, substantial cooperation could assure that the data the systems provide are useful to the worldwide community of users. The result of cooperation and coordination could be a system that is of far greater utility than any one nation could provide on its own. NOAA is expending considerable energy to increase cooperation, not least because cooperation may enable the United States to spend lesson its own data collection systems.

Opportunities for cooperation occur in the following areas:

- Coordination of Equator crossing times and repeat cycles. N-ROSS is designed to have a 2-day repeat cycle for measurements. ERS1 will also pass over the same locations every 2 days. If the orbital parameters of both satellites could be properly coordinated, because the sensor complement of the satellites overlaps to a considerable extent, it would be possible to achieve daily global ocean coverage. Such coordination would affect neither the cost nor the national objectives of either satellite system, but could nearly double their value to the participants, if all the data are shared freely .87

As future systems are designed, coordination of the Equator crossing times for satellites could also lead to similar benefits. For example, measurements of ocean color, solar radiation, and ozone content require high Sun angles, and are therefore best taken near noon.

- Cooperation on future satellite missions. As experience is gained with the planned operational and research satellites, potential cooperative missions will begin to suggest themselves. It appears to be in the best interest of the United States to continue a variety of cooperative programs in order to: 1 ) save money on building research and applications systems, and 2) increase the available scientific and operational knowledge base about ocean processes.

\footnotetext{
87, Utilization of the Polar Platform of NASA's Space Station Program for operational Earth Observations," op. cit. (fn 37).
} 
- Building an international polar-orbiting platform. The Europeans have shown considerable interest in providing instruments or funding for an international system of meteorological satellites (see metsat issues above). They and the Japanese have also indicated interest in supplying some part of a space station. Polar-orbiting platforms that could provide a variety of atmospheric, land, and ocean measurements would seem to provide fertile ground for future international cooperation in remote sensing. ${ }^{88}$

What Needs Are There for Collecting, Processing, and Distributing the Primary Data From Satellites?

The ground receiving station, and the data ordering, processing, and distribution facilities are as important to the user of satellite data as are the satellites that gather the data. Therefore, when the funding for ocean remote sensing systems is considered, it is extremely important to include sufficient funds for these ground-based functions, because NOAA must be capable of supplying unenhanced data reliably and efficiently to the user. Some data, such as the position and strength of a large ocean storm, are highly time-dependent and are of no use to the operational user unless supplied immediately after being gathered.

88lbid
Others, relating for example to sea ice position, may change more slowly and allow a time lag of several hours or even days for distribution.

The need for timely delivery of data is as important for research scientists as it is for commercial or Government applications. Sensor characteristics change with time and require recalibration if the data collected are to be of use to the researcher. Data stored for long periods before their intended use may well be unusable because the user was unaware soon enough of small changes in sensor characteristics.

Large-scale experimental programs such as the World Climate Research Program, components of which include the Tropical Ocean Global Atmosphere Program and the World Ocean-Circulation Experiment, ${ }^{89}$ or the International Geosphere-Biosphere Program (IGBP), ${ }^{90}$ will generate large amounts of data from space that must be sifted, analyzed, and integrated with related data gathered at the surface, before being used in experimental models of the oceans and the atmosphere. This process will require sufficient archiving of corrected historical data, and the ability to access them efficiently.

\footnotetext{
${ }^{89}$ "Oceanography From Space: A Research Strategy for the Decade 1984-1 995, " op. cit.

90", Toward an International Geosphere-Biosphere Program: A Study of Global Change," Report of a National Research Council Workshop, Woods Hole (Washington, DC: National Academy Press, July 25-29, 1983).
}

\section{REMOTE SENSING POLICY}

The treatment of current U.S. systems for remote sensing from space presents a particular challenge to policy makers. Although land, ocean, and meteorological remote sensing use related technologies to produce data, for the most part they still serve different constituencies. Consequently each requires a different policy treatment. Further, the three systems have different economic, political, and social characteristics, As the data from these systems find greater use, and their applications increasingly overlap it may be possible to integrate the systems, perhaps on an astronaut-tended polar-orbiting platform. ${ }^{91}$ However,

\footnotetext{
${ }^{91}$ See, for example, the discussion in "Utilization of the Polar Platform of NASA's Space Station Program for Operational Earth Observations," op. cit. (fn 37),
}

analysis of such an integrated approach is beyond the scope of this report.

Policy options for guiding the direction of U.S. meteorological satellite systems exist primarily in the context of cooperative ventures in space, because these spacecraft sense large-scale conditions that generally transcend political boundaries. Small-scale surface features and most signs of human activity do not appear in images produced by metsat sensors. Economic value lies primarily in the data's use in predicting severe weather and climate trends. ${ }^{92}$ Earth resources re-

\footnotetext{
${ }^{92}$ See, for example, $\mathrm{th}_{\mathrm{e}}$ discussion of "EI Nino in the Southern Hemisphere and Its Effects on the Northern Hemisphere, " Remote Sensing and the Private Sector, op. cit, App. 1.
} 
mote sensing systems, whether for land, coastal regions, or the oceans, are specifically designed to be used for assessing, managing, and exploiting renewable and nonrenewable resources. The data collected therefore have direct economic consequences for the sensed country. Consequently, the following policy treatment discusses each system independently.

\section{Meteorological Remote Sensing Policy}

Because weather data collected in one region of the globe are of interest to other regions, the nations of the world, even in time of war, have at least since 1853 treated the gathering and distribution of weather data as a cooperative venture. The primary means of cooperation among nations with respect to meteorological satellite systems has been the sharing of data.

\section{Cooperation}

Four primary policy options are possible: 1) maintain the status quo in polar-orbiting systems and continue to cooperate in providing data to the global meteorological data exchange; 2) maintain the form of our cooperation, but reduce the quantity and quality of data supplied to other countries by operating only one polar orbiter; ${ }^{93}$ 3 ) increase our cooperation with other countries by engaging in additional cooperative projects; and 4) increase the sharing of data from the geostationary satellites with our Western Hemisphere partners.

\section{Maintain Status Quo}

The United States normally operates two civilian polar orbiters and two geostationary satellites. ${ }^{94}$ It could continue to operate both systems and cooperate as in the past by supplying data

\footnotetext{
${ }^{93} \mathrm{~A}$ fifth potentialoption of reducing our cooperative efforts in meteorology by reducing our participation in the WMO is infeasible because the United States would therefore likely lose access to some data it now receives from foreign surface stations.

${ }^{94}$ Note that only one geostationary Satellite is now operating. NOAA plans to launch a replacement for the failed GOES-5 in late 1985 or early 1986. See W. Mitchell Waldrop, "A Silver Lining for the Weather Satellites?" Science, vol. 226, pp. 1289-1291, for a summary of the state of technological and political affairs of the U.S. meteorological satellite systems.
}

to U.S. citizens and other nations at no cost (or at cost of reproduction), while continuing to fly sensors of other countries. The two systems cost about $\$ 7.4$ million in fiscal year 1984 to operate. Each new polar-orbiting satellite will cost about $\$ 100$ million to build and $\$ 30$ million to $\$ 50$ million to launch. ${ }^{95}$

As argued in the next option, this course of action would have the advantage that it would maintain the same data flow that the United States and other countries have experienced in the past, with the consequent benefits that flow from access to such data. It would have the disadvantage of not contributing to a reduction of the budget deficit.

\section{Operate Only One Polar Orbiter}

In its effort to reduce the Government's budget deficit, the Administration has repeatedly tried to reduce the number of polar orbiters from two to one. Eliminating one of the polar orbiters would reduce the coverage of the system from once every 6 hours to once every 12 hours for a particular spot on the Earth. For most of the United States, a reduction in service would not cause a serious decline in the ability to predict severe weather. Conventional data collection systems and the geostationary satellites provide sufficient information. For Hawaii, Alaska, American Samoa, Guam, and the Pacific Trust Territories, however, the 6-hour repeat coverage that two polar-orbiting metsats supply is extremely important for timely warning of rapidly changing weather conditions. None of these areas has access to surface data for the predominantly westto-east weather patterns. ${ }^{96}$

Operating only one civilian polar orbiter would reduce the data available to DOD. Though it has its own system of meteorological satellites (Defense Meteorological Satellite Program or DMSP), DOD makes extensive use of the civilian system, both to provide data at different times of the day,

\footnotetext{
95These figures are approximate and depend highly on the number of satellites contracted for in a single purchase agreement, the number and type of new sensors that are flown, inflation, and future launch prices.

${ }^{96}$ Because th primary weather flow in the Northern Hemisphere is from west to east, information gathered to the west of a geographic area is especially important for weather predictions.
} 
and to act as an emergency backup to the military system. The DMSP can provide a backup of sorts for the civilian satellite. However, because the characteristics of the data from the DMSP are somewhat different from those supplied from the civilian system, its data cannot be used directly in forecasting models.

Nations that depend on metsat data and have purchased receiving stations have expressed their dismay that the United States might operate only a single polar orbiter. Such a course of action would save less money than it might appear because the cost of purchasing and operating two polar satellites is much less than twice the cost of operating one. NOAA estimates it would save less than \$25 million yearly.

The U.S. polar orbiters carry the emergency beacons used in the COSPAS/SARSAT cooperative program with Canada, France, and the U.S.S.R. Until October 1984, the system had been operated as a demonstration program. However, in October 1984, the Administration signed an agreement with the participating countries to continue the program on an operational basis, therefore committing the United States for the immediate future to maintain two polar-orbiting metsats for the COSPAS/SARSAT program. The SARSAT receiver could be flown on a separate small satellite (at an unknown cost), so this agreement does not guarantee continuation of two polar-orbiting metsats.

\section{Joint International System for Polar Orbiters}

The only other nation to operate a polar-orbiting meteorological satellite is the Soviet Union. The two U.S. polar-orbiting satellites provide total global coverage and are the principal source of meteorological data from 80 percent of the globe. They also provide coverage for the high latitude regions, which are not covered by the geostationary satellites, ${ }^{97}$ and for which conventional measurements are particularly sparse. The two-orbiter system benefits all the countries of

\footnotetext{
${ }^{97}$ Although the geostationary satellites can image the full disk of the Earth, their ability to make quantitative measurements of extreme north and south latitudes is limited by the oblique angle at which they sense Earth's surface at these latitudes.
}

the world because of its frequent coverage. A single polar orbiter would result in markedly reduced weather coverage (fig. 7-10).

The United States has suggested to the other OECD nations that:

unlike the situation that existed when the United States initiated the meteorological satellite system, it is now possible for subsystems, systems, and entire satellites to be built, launched, and operated by numerous organizations in many countries. The satellites and instruments are well understood. The data standards that are necessary for worldwide distribution and use of satellite data are in place and thoroughly developed. Interoperability of space systems or subsystems can be readily achieved through procedures that many countries have applied. ${ }^{98}$

NOAA representatives have briefed representatives of other nations about U.S. views on the desirability of jointly providing the second polar orbiter. A joint program would reduce U.S. operating costs and increase U.S. cooperation with other countries.

At the June 1984 Versailles Economic Summit, delegates agreed to discuss cooperating in satellite remote sensing and established the international polar-Orbiting Meteorological Satellite group (IPOMS), the members of which unanimously agreed on the need for two polar orbiters. ${ }^{99}$ Foreign participants were willing to accept more of the financial burden of an advanced polar-orbiting system and to fund new instruments for it.

An agreement to cooperate in building and maintaining a multinational polar-orbiting system would constitute a marked change in the form of international cooperation in meteorological systems. Heretofore, with the exception of two foreign sensors flown on U.S. polar orbiters, data, not sensors, have been shared.

\footnotetext{
98'International Cooperation in Polar-Orbiting Meteorological satellites," NOAA, Apr. 19, 1983.

99"Dual Polar Satellites Draw International Support," Aviation Week and Space Technology, Dec. 10, 1984, p. 27. Members of this group include representatives from Australia, Canada, France, Federal Republic of Germany, Italy, Japan, Norway, the Commission of the European Communities, the European Space Agency, the United Kingdom, as well as the United States (NASA, NOAA, and the Department of State).
} 
U.S. spacecraft manufacturing firms might lose some business as a result of such cooperation. On the other hand, if the choice were between international cooperation on a two polar-orbiting system and a domestic system of only one polarorbiting satellite, they could well do more business with an international system.

Although the nations that might participate are able to contribute to this effort, the United States could face a question of undesirable technology transfer. For certain advanced new sensors and data processing technology, it would be important to structure the agreement so that no technology vital to national security interests be transferred to other countries. Part of this concern could be met by structuring the system in such a way that each country provided its own independently developed sensors in accordance with mutually agreed-upon specifications.

\section{Sharing the Data From}

\section{Geostationary Satellites}

The U.S. geostationary satellites are in a different category from the polar orbiters because they remain stationary over regions centered on the Equator. The data from these satellites, like those

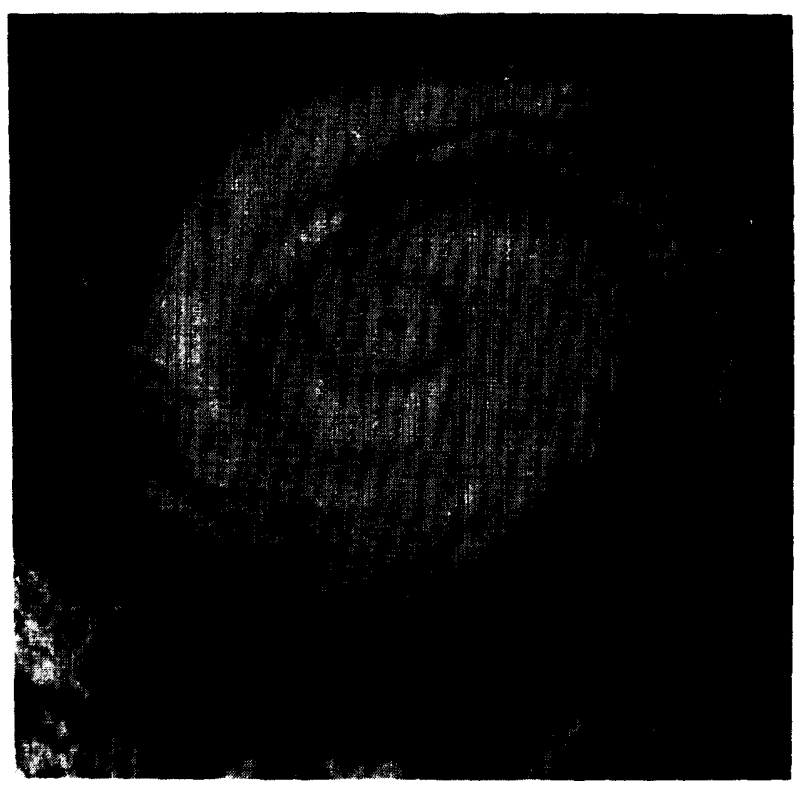

Photo credit: National Oceanic and Atmospheric Administration

Image of Hurricane Allen centered over the Gulf of Mexico received from the GOES satellite stationed at $75^{\circ} \mathrm{W}$ longitude, Aug. 8, 1980. from the polar orbiters, are already shared with the countries of the world. However, unlike the data from the polar orbiters, their data benefit primarily the countries of the Western Hemisphere. Thus, in order to provide development assistance to many of these countries, and further Western Hemisphere relations, it may be in the long-term interest of the United States to support bilateral or multilateral programs to make better use of the data from these satellites. Such programs could take the form of joint research projects to investigate the effects of EI Nino and other large-scale weather patterns that affect the Western Hemisphere.

\section{Competition}

There is no market for sales of primary metsat data because, except for reproduction changes, they are shared freely among nations. ${ }^{100}$ What competition exists for meteorological satellite technology is for ground equipment, but that market is extremely small and is likely to remain so in the future.

Competition for value-added services also exists, but here again the total market is now extremely small. The United States leads in processing metsat data. The value-added market will remain relatively small in the near future, but is likely to continue to develop as techniques for using land and meteorological data for agricultural and hydrological purposes improve. ${ }^{101}$ in time, meteorological sensors will provide more wavelength bands, and have higher resolution; the value-added companies will become more sophisticated in their applications of the data. As a result, processed meteorological data may begin to compete with the use of certain land and ocean remote sensing data both in the United States and abroad. ${ }^{102}$ This could bean important step toward an integrated U.S. remote sensing

\footnotetext{
${ }^{100}$ Country satellite services organizations generally charge (at cost) for data that requires special processing, or for derived products. $101 \mathrm{See}$, for example, discussion at the NOAA-sponsored conference, NOAA's Environmental Satellites Come of Age, Mar. 26-28, 1984. Participants there shared techniques used to utilize environmental satellite data for a variety of tasks once reserved for high resolution data. See also "Metsats Seen Competing withLandsats," Space Business News, May 21, 1984, p. 3.

${ }^{102}$ "Metsats Seen Competing With Landsats," Space Business News, May 21, 1984, p. 3.
} 

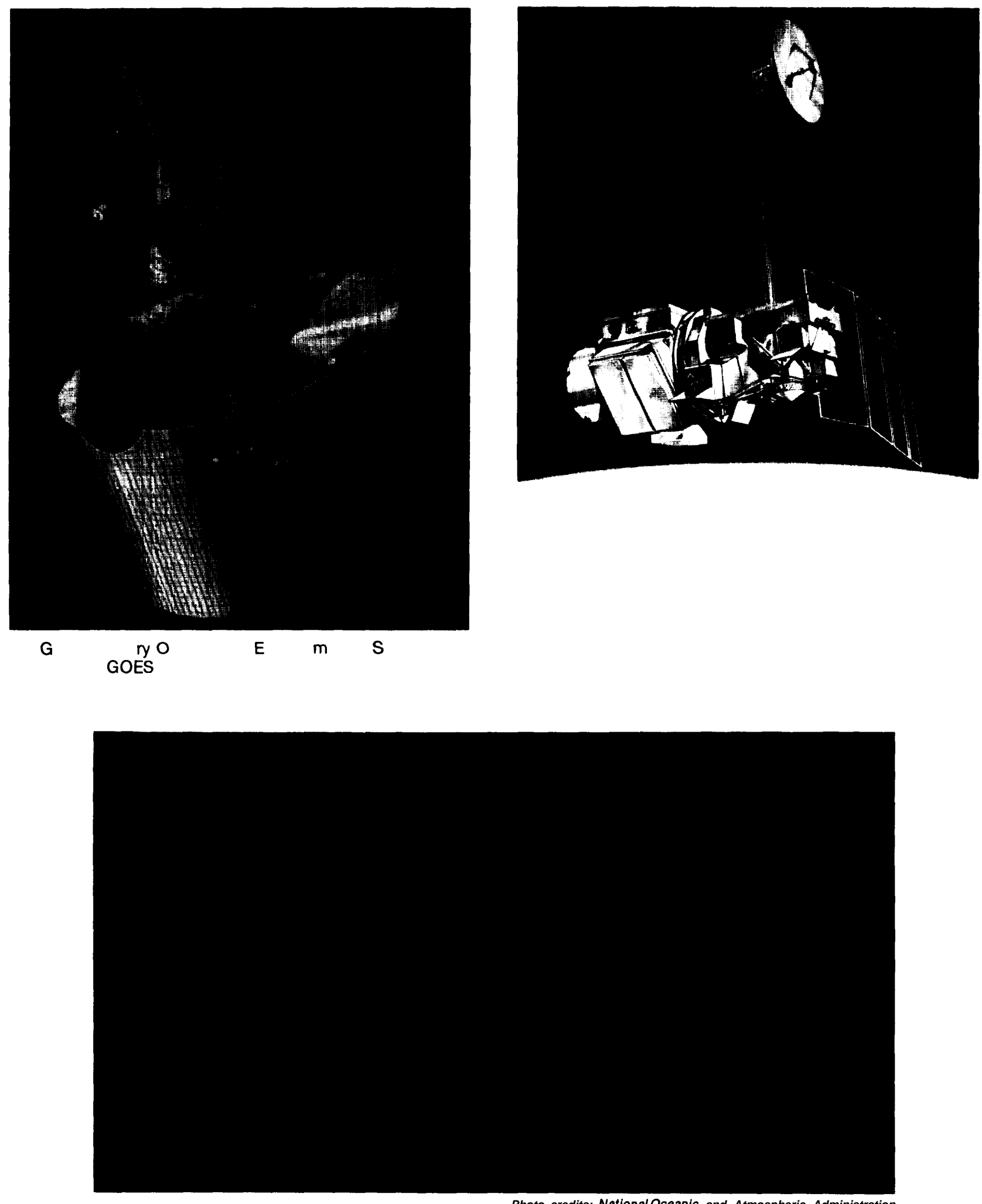

Photo credits: National Oceanic and Atmospheric Administration

NOAA-N series polar-orbiting environmental satellite, artist's conception. 
system that would enhance the U.S. competitive position in remote sensing.

\section{Land Remote Sensing Policy}

The feature that most distinguishes Earth resources remote sensing from meteorological remote sensing is its potential for immediate use in assessing, managing, and exploiting Earth's resources. The potential economic value of the data these systems supply has recently made them a primary subject of competition between nations. Cooperative efforts, though potentially serving an important role, have lessened in importance with the development of competitive foreign systems.

\section{Competition}

The previous analysis in this chapter has shown that the greatest current demand (in volume) for land remote sensing data is for low-cost moderate-resolution (80-meter) MSS data delivered promptly and continuously. The current demand for expensive data is smaller. ${ }^{103}$ Most customers today have neither the experience with high resolution (30-meter) thematic mapper (TM) data nor the processing equipment. In addition, it is not clear that TM data or their equivalent will be cost effective for many tasks. Except for the mineral exploration companies, which can make costeffective use now of the more expensive TM data, relatively few users are willing or able to purchase them. This situation is likely to continue until: 1 ) customers gain confidence that TM or comparable data would be cost effective; and 2) they also gain confidence that the data will be available on a continuous, long-term basis.

Land remote sensing policy is at an important crossroad. As discussed earlier, by creating Public Law 98-365, the Administration and Congress committed the United States to transferring this technology to the private sector. Proponents of transfer hope that the private sector will eventually develop the technology into a self-supporting, commercial operation. However, it is unclear: 1) how much subsidy might eventually be needed, 2) how future research and development needs

\footnotetext{
${ }^{103}$ In the first half of fiscal year 1985, Thematic Mapper data generated about 49 percent of the total income of Landsat data sales from the EROS Data Center.
}

will be met, and 3) whether sufficient demand for data will develop to build a viable market.

Opponents of transfer generally believe the system should continue to be operated in the public interest. They argue that the costs of continuing to provide data are relatively small compared to the cost of putting the system in place. A few observers believe that it is possible to operate a complete land remote sensing system without Government subsidy. ${ }^{104}$ However, they also point out that this could not be done in competition with a Government-subsidized operation.

The following discussion views each policy option from the point of view of how it would serve the overall public interest. The disposition of the Landsat system is likely to affect overall U.S. competitiveness in space, international relations, and the development of the international market for land remote sensing data.

\section{Options for Continued Financial Support}

The Administration and Congress have decided that the public interest will be served by a phased transfer of the Landsat system to private ownership. Although the Department of Commerce has chosen the EOSAT Corp. to operate the current Landsat system and to build two follow-on satel-

\footnotetext{
${ }^{104}$ Most notable among these is Space America, Inc., which was one of the bidders to take over operation of the Landsat program. Space America's approach to land remote sensing is radically different from either EOSAT or Kodak. It has proposed building a system that would be less technically sophisticated than the current Landsat 5 , but would be considerably cheaper and directly responsive to customers' data needs. Operating at $\mathbf{4 0}$ meters resolution in 4 wavelength bands and providing stereoscopic data, its proposed MLA-based satellite would be comparatively light and require little advanced technology development. It would also require relatively little or no Government subsidy. Space America is also developing a data processing system that would integrate satellite aircraft and ground-based data to produce new information products. In proposing such a satellite system, Space America is relying on the premise that the largest market for data will be for inexpensive, moderate resolution data targeted to customers' needs and combined with ground-based data. Its proposed system has been criticized on the grounds that it does not maintain the U.S. technological leadership in remote sensing. However, Space America is convinced that the greatest immediate need is to build a market for the data before moving to more advanced sensors that will generate expensive data. See Diane Josephson, statement at hearing before the Subcommittee on Science and Technology, of the Senate Committee on Commerce, Science, and Transportation, Mar. 22, 1984, S. Hrg. 98-747, pp. 78-82.
} 
lites, and has reached agreement on the contract terms (including amount of subsidy), it will still be necessary for Congress to monitor the process of transfer over the long term.

If EOSAT is able to operate the current system for a period long enough to inspire customer confidence, to provide data promptly at reasonable costs, and to establish a strong market for data, then the transfer has a reasonable chance of succeeding. ${ }^{105}$ However, the subsidy cap of $\$ 250$ million plus launch costs OMB has imposed may limit the ability of EOSAT to establish a self-sustaining corporation within the 10 years of the centract.

This attempt to commercialize land remote sensing is an experiment that has no exact precedent. It may be necessary or desirable to institute additional legislative measures, or to appropriate additional funds for the transfer in later years (beyond that committed in the current contract). Therefore, Congress may wish to pursue one of the following options:

\section{Maintain a High Level of Direct Support for Commercial Land Remote Sensing}

Although the Administration has set a cap on the total subsidy to be paid, Congress might later decide to appropriate an additional subsidy (perhaps $\$ 100$ million to $\$ 150$ million), on the basis that a $\$ 250$ million subsidy allows little margin for maintaining U.S. technological and marketing leadership. The contract with EOSAT has several vulnerabilities that could adversely affect the company's ability to compete effectively. EOSAT will attempt to use high-capacity tape recorders on Landsat 6 and 7 to gather and store data from areas that are not covered by ground receiving stations. However, tape recorders have proven particularly vulnerable to malfunctions in the past (e.g., on Landsats 2 and 3). In addition, MSS-type data will be generated by summing appropriate elements of the TM instrument on board the spacecraft. Not only is this an untried technique, but because there will be no separate MSS instrument, there will be no backup should the TM it-

\footnotetext{
${ }^{105} \mathrm{As}$ noted in the discussion of issues, a strong market for data would imply sufficient revenues to build follow-on satellites beyond Landsat 6 and 7.
}

self fail. (On Landsat 4, when the antenna for the TM failed, it was still possible to receive MSS data through an entirely separate system.) Finally, the rate of data processing planned for the facility at Goddard Space Flight Center has never been reached for the extended periods of time necessary for developing a high-volume market.

Additional funding could allow redundant systems to be built that would reduce the amount of risk posed by these system vulnerabilities. Proponents of additional subsidy argue that the benefits derived from land remote sensing are such that the system should be maintained even if there is a relatively low demand for data. They further offer that Government needs for data to use in monitoring the Nation's renewable and nonrenewable resources and the environment, in the public interest, are great and that more time and funds are needed to learn how to integrate these data into existing programs. ${ }^{106}$

\section{Moderate Additional Subsidy}

The difference between this and the previous option is the level of extra support that is deemed necessary to assure near-term privatization and eventual commercialization of land remote sensing. proponents of this alternative policy would argue that some additional subsidy is appropriate to provide an additional margin of safety for the transfer, but that it should not exceed, say, $\$ 50$ million over the life of the current contract between the private firm and the Government. They further support the need for the private corporation to assume a higher level of financial risk than might be implied in the first option.

\section{No Extra Subsidy}

Such a policy would follow from OMB'S conviction that $\$ 250$ million (plus launch costs) is about the right amount to extend to a private corporation for the first steps of the commercialization process and that holding out the possibility of any greater future subsidy would undermine the creative energies of a corporation that was risking its own capital to build sufficient market for remotely sensed data. Further, it could be

\footnotetext{
106 For a detailed discussion of Government requirements, see Remote Sensing and the Private Sector, op. cit., ch. 5, app. G, H, 1.
} 
argued that if sufficient demand for remote sensing products fails to develop, the field should be left to other nations and the United States should devote its energies to maintaining leadership in other technologies.

\section{Additional Policy Options}

Several other options for promoting U.S. competition in satellite land remote sensing are possible. They are primarily designed to promote the development of a market for the data. As the earlier analysis has shown, the most important factors contributing to the development of demand for remotely sensed data are: 1) continuity and timeliness of data delivery; 2) a strong value-added industry; and 3) continued research and development, both on sensors and other system elements, and on effective application of the data. The last factor is also the major element in contributing to U.S. technological leadership.

\section{Reinstate a Strong Remote Sensing Research Program}

The Remote Sensing Commercialization Act of 1984 calls for both NASA and NOAA to continue research in advanced sensors and in the use of remotely sensed data. ${ }^{107}$ Until about 1982, primarily within NASA, the United States maintained a strong remote sensing research program both for applications of the data, and in sensor development. As the Landsat system began the transition to operational status, NASA began to cut back on its research effort in the expectation that NOAA would be the lead agency in operational land remote sensing. However, NOAA has only a small research program. NASA continued to work on a multispectral linear array to be tested on a future satellite. As discussed earlier (see issues section), NASA terminated fiscal year 1985 research in order to concentrate on developing a much more advanced sensor system. Some Members of Congress and representatives of the industry are concerned that NASA's decision, which was driven by the desire to cut some programs in order to reduce its operating budget, left NASA providing very little research effort for supporting the U.S. competitive stance in land

\footnotetext{
1075ee Public Law 9-365, Title V-Research and Development.
}

remote sensing. NASA officials argue that NASA's role is to continue research on advanced sensors, not to develop sensors that would be used for commercial operations. NASA is now attempting to reinstate part of this research. However, the question of what level of effort is appropriate remains.

In spite of the mandate of Public Law 98-365 for continuing research in land remote sensing, the fiscal year 1985 NOAA budget contains no support for research on operational sensors or on utilization of the data. if the United States is to support the development of a market for the data, maintain its technological lead in civilian applications of remote sensing technology, and promote national prestige in the face of competition from France and other countries, continued research on advanced civilian sensors will be necessary. Some technology developed for reconnaissance satellites might eventually be transferred to civilian use, but as discussed in a previous OTA report, ${ }^{108}$ the steps from military or intelligence use of part or all of a space system to civilian use are long and difficult.

\section{Encourage the Growth of the}

Value-Added Business

There is no straightforward process for transferring complex new technologies from Government laboratories to private industry. Indeed, the experience with Landsat has demonstrated that it can be highly complex and difficult. The biggest impediment to private ownership of land remote sensing is the small market for data from the system.

Gathering land data from space is a major innovation in the remote sensing business; it will take yet more time, money, and considerable attention to building sufficient demand for data to support a self-sufficient private sector operation.

One key to developing a sufficient market is the small value-added industry. ${ }^{109}$ One reason it remains small is that the Government, in certain

\footnotetext{
4IOaCjvj/jan Space Policy and Applications, op. cit., ch. 6.

$109 / \mathrm{t}$ is difficult to estimate how much income the value-added industry generates because many larger firms, such as the oil and gas firms, maintain their own computer processing facilities for converting the data to useful information.
} 
areas, in effect competes with it by maintaining its own data processing and value-added capacity. This may be appropriate in the research and development phase, but inappropriate when the system is to be transferred to private hands and operated as a profitmaking entity. If a strong land remote sensing industry is desired, it will be essential for the Government to reduce its involvement in value-added services and contract for those services that can be supplied by private companies.

\section{Repair Landsat 4}

The virtual certainty of a gap in data delivery between the demise of Landsat 5 and the launch of a private follow-on satellite deeply concerns data users. Some have suggested that it might be possible to eliminate or shorten such a data gap by repairing Landsat 4 , which is still operating, though at sharply reduced capacity. NASA has investigated the feasibility of repairing the Landsat 4 satellite in orbit, as was done with the Solar Maximum Mission repair in April $1984,{ }^{110}$ or bringing it back to Earth, as was done with two communications satellites. However, unlike the Solar Maximum Mission, which operates at altitudes that are accessible to the Shuttle, Landsat 4 would require special efforts to retrieve it and bring it back for repair. ${ }^{111}$ In addition, it does not seem cost effective to repair the satellite. ${ }^{12}$

Because the Landsat satellites follow a near-polar orbit, a Landsat repair mission would have to wait until the Western Test Range at Vandenberg Air Force Base in California is able to accommodate the Shuttle (i.e., in 1986). NASA has no such plans.

\section{Cooperation}

Although competition plays a major role in land remote sensing policy, there is ample opportunity

10"'Orbiter Crew Restores Solar Max," Aviation Week and Space Technology, Apr. 16, 1984, pp. 18-20. See "Astronauts Deploy, Retrieve Satellite," Aviation Week and Space Technology, Nov. 26, 1984, pp. 20-22.

"1The sateilite is designed to operate at an orbit of 380 nautical miles. The shuttle can only reach to about 285 nautical miles above Earth.

$1^{12}$ According to NASA, estimates for the cost of retrieva I and repair, range up to $\$ 250$ million, depending on how extensive refurbishment of Landsat 4 might be. for cooperative efforts as well. These range from coordination of individual country efforts to the possibility of establishing a multilateral consortium to build and operate a system from which remotely sensed data are sold.

\section{Future International Coordination}

The United States participates (through NOAA) in the deliberations of the Landsat Ground Station Operators Working Group and the Committee on Earth Observation Satellites,${ }^{113}$ organizations that coordinate standards for land remote sensing systems and serve as fora for exchanging technical and other remote sensing information. Such coordination will still be important after the Landsat system is transferred to the private sector. If the transfer process continues as planned, it will be important to spell out how private firms would have to interact with the agencies that represent the United States in these organizations. At present, NOAA's plan is to continue to take the lead, with major input from the corporation, and from representatives of the value-added industry.

\section{Multilateral Consortium}

Although the idea has received relatively little attention since it was recommended in a 1977 National Academy of Sciences study, ${ }^{114}$ one feasible option is to establish a land (and ocean) satellite remote sensing system owned and operated by a multinational consortium. One possible form of this option is discussed in detail in an earlier OTA report. ${ }^{115}$ Under such an arrangement, a single management authority with multinational par-

\footnotetext{
$11{ }^{3}$ This group met for the first time in September 1984. It was formed from the Coordination on Land Observing Satellites and the Coordination on Ocean Remote Sensing Satellites, as a result of a recommendation from the Economic Summit panel of experts on remote sensing. It includes entities from the free world that have land or ocean remote sensing systems or plans for building them. ${ }_{114}^{14}$ esources Sensing From Space: Prospects fOr Developing Countries (Washington, DC: National Academy of Sciences 1977); see also Ray A. Williamson, "Commentry on Land, Sea, and Air: Global Implications of the View from Space," Global Implications of Space Activities, AIAAAerospace Assessment Series, vol. 9, 1982; and John L. McLucas, "Whither Landsat," Aerospace America, January 1985, p. 6.

${ }_{11}^{5}$ Civilian Space Policy and Applications, pp. 298-300; A similar option has also been discussed at recent meetings of the U.N. Committee on the Peaceful Uses of Outer Space, though the United States took little part in these deliberations.
} 
ticipation would assume responsibility for global operation of the system, including establishing technical specifications, procuring and operating satellites, and receiving and preprocessing satellite data. This approach would spread the investment risk, as well as encourage other nations to be more aggressive in developing their own internal markets for satellite data. It would also aid the developing countries in establishing their own ability to use remotely sensed data for resource development and help allay their fears of domination of this technology by industrialized countries. A multinational remote sensing corporation could also guarantee that data would continue to be accessible to all countries on a nondiscriminatory basis.

Given the current climate in the U.N. toward remote sensing, and the more important fact that the U.N. is not organized for operational functions, a U.N. consortium seems inappropriate. It would in principle be more feasible to establish a limited consortium among those nations with substantial expertise in remote sensing, similar in form, perhaps, to the INMARSAT structure. Overtures for other countries to cooperate in remote sensing have been made in the past. Now, because France, Japan, and Canada are well along in their planning process for either land or ocean remote sensing satellite systems, their commitment to national systems might make it difficult to interest them in such a multinational system, particularly if it were dominated by the United States. Nevertheless, a multinational system might eventually emerge from the current cooperative arrangements for coordinating and setting system standards.

One major disadvantage of a multinational system is that the United States would no longer be in complete control of its own civilian system. In addition, U.S. suppliers of space system equipment would face certain competition from industries in other countries. Yet, U.S. industry currently possesses a competitive advantage in these areas, which transfer of the Landsat system to the private sector will support. In addition, because the value-added component of the remote sensing industry is projected to be the major revenue source, and the United States is in a relatively strong competitive position in that market too, a cooperative satellite system in which costs were shared could be of overall benefit to the United States.

\section{Development Assistance}

The United States could continue to provide technical assistance to developing countries in the applications of remotely sensed data, even after the Landsat system has been transferred to private hands.

As explained in appendix 7A of this chapter, developing countries face two major barriers to expanding their applications of remotely sensed data: lack of supportive institutions, and lack of training. The United States has attempted to reduce some of these barriers by offering developing countries substantial assistance in applying remotely sensed data to their resource problems. It has set up training programs, regional centers, and has assisted in purchasing data processing equipment.

The U.S. technical assistance programs are largely responsible for the emergence of the international user community. To the extent that an international market exists for satellite remote sensing data, it developed as a result of U.S. aid. Discontinuing such aid would slow the growth of an international market for the data and impede the spread of land remote sensing technology.

\section{Ocean Remote Sensing Policy}

International interest in ocean remote sensing from space in this decade is high and reflects a sense that such systems can serve as useful research tools and provide important operational data for ocean users. Ocean remote sensing, because it is about to pass from research to operational status, presents a substantial opportunity for all nations to gain from cooperative arrangements. The following presents possible policy options for Congress to consider vis-a-vis ocean remote sensing.

Take the lead in organizing and coordinating an international program for collecting and distributing ocean data from space.

International prospects for ocean remote sensing from space present the United States with an excellent opportunity to lead the coordination of 
global efforts. Although the U.S. system is a Navy one (N-ROSS), under arrangements now planned, NOAA will distribute most of the data to the civilian community in the United States and abroad.

NOAA has embarked on an effort to coordinate not only the distribution of data gathered from N-ROSS and other ocean satellites, but also the orbital parameters of the satellites. For example, coordination of the satellite crossing times of N-ROSS with ESA'S ERS-1, if successful, could result in a data set much more useful to the United States and other nations than either ESA or NOAA could accomplish alone. ${ }^{116}$ This appears to be a least-cost approach to obtaining data important to research scientists and to ocean industries. Congress may wish to encourage this effort by specifically directing NOAA to take the lead in organizing and coordinating an international program for collecting and distributing ocean data from space. If it decides to do so, Congress must also authorize and appropriate adequate funds to support acquisition, processing, archiving, and distribution of the data from the various sytems.

\section{Support continued research for advanced ocean sensors and applications.}

In the next decade, NASA plans several major ocean sensing experiments and contemplates many more. ${ }^{117}$ These will contribute vital information to our general knowledge of the oceans. As these experiments proceed, it will be important to examine them for opportunities to develop operational sensors that would serve users of ocean data. Such sensors could be flown on a variety of platforms. For example, it may be appropriate for the Government to fund part or all of the ocean sensors that would be flown on a private land remote sensing satellite. Alternatively, the private sector may wish to build sen-

\footnotetext{
'b"'Utilization of the Polar Plaform of NASA's Space Platform Program for Operational Earth Observation," op. cit.

'17"Oceanography From Space: A Research Strategy for the Decade 1985-1 995, " Report of the Joint Oceanographic Institutions, 1984.
}

sors for obtaining certain specialized ocean data that would be flown on a Government satellite. Finally, as the planning for the space station proceeds, it will be especially important for NASA and NOAA to consider operational sensors appropriate for a polar-orbiting platform, one of the planned elements of the international space station program.

As work on the sensors proceeds, it is just as important to continue research on how to apply the data from research and operational sensors for ocean-related problems. World maritime industries generate billions of dollars of revenue each year. Information about ocean parameters can increase industry productivity and reduce the danger to lives at sea. ${ }^{1118}$ One component of this research should be the development of techniques to utilize meteorological data more effectively in understanding and predicting ocean dynamics. Developing U.S. capability to use ocean data from satellites effectively would help maintain U.S. technological leadership and contribute to the efforts of U.S. value-added firms to generate useful information products for the international maritime market.

\section{Develop a dedicated civilian ocean satellite.}

Through its flights of Seasat in 1978 and the Nimbus series of satellites the United States has demonstrated the utility of ocean remote sensing. In the future it may be appropriate for the United States to operate a dedicated civilian ocean remote sensing satellite. If current attempts to coordinate ocean remote sensing with other nations prove successful, it may be possible to develop an international polar-orbiting platform carrying some sensors dedicated to ocean sensing, or to build a U.S. platform that contains a set of instruments complementary to those of a platform built by other nations. In the latter case, it would be essential to select the orbital parameters of each to allow the satellite to sense Earth at complementary times as well.

\footnotetext{
"s"Oceanography From Space: A Research Strategy for the Decade 1985-1 995," op. cit.
} 


\section{APPENDIX 7A.-SATELLITE REMOTE SENSING IN DEVELOPING COUNTRIES}

Developing countries have made limited use of remote sensing from aircraft for mapmaking or for resource development and management since the 1930s and 194os. When meteorological data from satellites became available in the mid-1960s, developing countries began to take advantage of the opportunity these systems afforded to gather information on current and impending weather conditions.

By contrast, satellite remote sensing for the purposes of resource development, on land or in the ocean, has seen relatively little application in developing countries, primarily because the level of technical sophistication needed to process the data is very high and the hardware and special training costly.

This section decribes the current use of remote sensing data in selected developing countries and investigates the potential these data provide for locating and managing renewable and nonrenewable resources. It identifies the factors that might contribute to the growth of a market for remotely sensed data and data products and suggests ways in which U.S. policies could be improved to the mutual benefit of both the developing countries and the United States.

\section{The Experience of Developing Countries}

As the UNISPACE '82 report notes, "The synoptic view and the possibility of frequent repetitive coverage of large and even inaccessible areas make, for the first time, regional and global monitoring of renewable natural resources and changing environmental phenomena technically feasible and economically attractive. "2 This statement is as true for the developing countries as it is for those industrialized countries that already possess a well-developed industrial and information infrastructure. The problems lie in the ability of developing countries to take advantage of remotely sensed data from space,

\section{Weather and Climate}

Developing countries have made significant use of the availability of weather data supplied by satellite. Synoptic, timely, weather data are of general use to all countries, and are particularly useful in development projects. Beyond their use in warning of particu-

\footnotetext{
' For a related discussion of the potential effects of transfer of the Landsat system to private hands, see Remote Sensing and the Private sector, op. cit. app. A.

"'Report of the Second United Nations Conference on the Exploration and Peaceful Uses of Outer Space, A/CON F.101/10, 1982, para. 168
}

lady stressful conditions, such as severe storms or radical short-term climatic changes, they can also be employed predictively in crop yield models to signal potential crop failure. ${ }^{3}$ Most satellite weather data are readily and routinely available via direct readout to any government agency, nongovernment agency, institution, or individual anywhere in the world within range of the satellites. One need only acquire the proper ground receiving equipment. Neither permission, consent, nor payment is required. Because ground receiving equipment is relatively inexpensive, the meteorological system is highly accessible to most countries of the world. Nearly 100 developing or newly industrialized countries now own APT receiving stations. A few own High Resolution Picture Transmission Stations (H RPT). Many of these countries acquired the stations through the voluntary assistance program initiated by the WMO as part of its traditional effort to aid developing countries in learning to gather and analyze weather data.

\section{Earth Resources}

Few developing countries have made much use of Earth resources data from satellites, in spite of the fact that these data could directly serve their development. The objectives of collecting Earth resources information are to: ${ }^{4}$

1. locate resources;

2. aid in evacuating resource investment;

3. provide information to be used for improving current management of natural resources; and

4. aid in the performance of certain government/ activities (particularly administerig land taxes, etc.).

Although the resource information needs of developing countries are similar to those of the industrialized countries, their experience in attempting to develop an adequate information base is different. Whereas in most industrialized countries detailed maps of all kinds (e.g., political, geologic, hydrologic, agricultural) already exist to provide baseline data for a resource survey, s many developing countries have not even been mapped on the coarsest scale for any

\footnotetext{
${ }^{3}$ See disscussion in section on meteorological remote sensing also, Remote Sensing and the Private Sector, op. cit., app. D.

${ }^{4}$ Orris Herfindel, Natural Resource Information for Economic Development. Resources for the Future, Washington, DC, John Hopkins Press, Baltimore, MD, 1969, pp. 20-21.

${ }^{5} \mathrm{n}$ the $\mathrm{U}$ nited States, for example, even the average citizen may purchase topographic maps from the U.S Geological Survey at scales as detailed as $1: 50,000$. In addition, State, county, and local maps are readily available, as well as direct aerial survey photographs,
} 
reason. Because they lack useful maps, many developing countries can often use the coarse-scale mapping available from Landsat MSS imagery effectively for initial survey of a resource problem. Map scales of $1: 200,000$ are possible with the 80-meter resolution of the MSS sensors aboard Landsat. Application of this minimal record could help define the boundaries of particular resource problems, and identify specific needs for more detailed information. At that stage, aerial photography and ground survey become important.

Data needs are generally divided into two categories of renewable and nonrenewable resources:

- Renewable resources. Some 25 developing countries have used Landsat data together with aerial photographs to gather information on crop or forest statistics. ${ }^{6}$ Because the agricultural production and distribution system reacts slowly to emergency conditions, advance warning of drastic changes in predicted crop production is necessary to prevent either famine or oversupply. For this purpose, the synoptic view of satellites is especially advantageous. These same countries have also used Landsat imagery to monitor water availability and to create maps delineating the uses to which the land is now put, and to assess the renewable natural resources that are available. Most of them feel that as land use intensifies, they will need to put more effort into both shortand long-term planning based on satellite remote sensing.

- Nonrenewable resources. In sharp contrast to the case for renewable resources, large national and multinational firms have led the efforts to integrate Landsat data with aircraft and ground data in the search for valuable minerals in the developing countries. ${ }^{7}$ Efforts to date have resulted primarily in locating oil. Although these firms are willing to search for minerals in various developing countries, they are uninterested in sharing the use of data processing technology because many of their techniques are proprietary.

Most developing countries have received their knowledge and training in the application of remotely sensed data through programs instituted by AID, NASA, and NOAA. Table 7A-1 lists the developing countries that have received aid directly from the United States for satellite land remote sensing and meteorological projects. Other industrialized countries and several multilateral organizations have also been active in supplying similar aid.

\footnotetext{
${ }^{\circ} \mathrm{C}$. K. Paul, "Land Remote Sensing, " Science, 1981

${ }^{\prime} 1$ bid.
}

Table 7A.1.-Agency for International Development Remote Sensing Grants and Projects, 1971.85

\begin{tabular}{lll}
\hline Bangladesh & Kenya & Thailand \\
Bolivia & Lesotho & Tunisia \\
Costa Rica & Mali & Upper Volta \\
Cameroon & Morocco & Yemen \\
Cape Verde & Niger & Zaire \\
Chile & Pakistan & Regiona/ Aid: \\
Ecuador & Peru & Asia \\
Egypt & Philippines & East Africa \\
The Gambia & Senegal & West Africa \\
Haiti & Somalia & Sahel Regional Program \\
Indonesia & Sri Lanka & \\
Jamaica & Switzerland & \\
\hline
\end{tabular}

\section{Gathering Information for Development}

Although developing countries face the same general needs for resource information to aid their development process, the stated needs of individual countries can vary widely. The following programs illustrate the variety of information needs that can be met by using information derived from satellites. They were chosen to be illustrative and are not comprehensive.

\section{TANZANIA}

Much of Tanzania's economic development effort is directed toward agriculture and animal husbandry. Its strongest data requirements include:

- current land use-and land suitability (distribution of vegetation and soil types);

- geologic and groundwater information to help locate additional water sources, increase the efficiency of schemes for well-digging and water impoundment, and to help in siting new villages;

- vegetative cover information for monitoring land and range stress (drought and overgrazing are primary concerns). ${ }^{8}$

\section{VENEZUELA}

Venezuela plans to tap its natural hydroelectric potential in order to develop nonpetroleum energy sources. The planning effort requires extensive surveys to locate potential dam sites. Data required include:

- reconnaissance level maps over an entire region to delineate drainage, watersheds, soils, vegetation and geologic structure;

detailed maps of target areas to determine appropriate dam heights, flow rates, the commercial potential of resources, and detrimental environmental effects. ${ }^{9}$

BNational Academy of Sciences, Remote Sensing From Space: Projects for Developing Countries, (Washington, DC: NAS, 1977), p. 29.

${ }^{9}$ Robert W. Campbell, Jule A. Caylor, and Matthew R. Willard, "Rio Caura Resource Inventory" (Diamond Springs, CA:RDA, 1982). 


\section{COSTA RICA}

Costa Rica's growing industrial and economic base places increasing pressures on agricultural and range land, and in turn, upon the nation's forests. The result is that prime agricultural areas are threatened by urban expansion at the same time that areas predominantly suited to forestry are being converted to marginally productive range and agricultural uses. Costa Rica has expressed a need to monitor and control these changes. ${ }^{10}$

\section{SRI LANKA}

In the mid-1970s Sri Lankan development planners began a program to develop new agricultural land in order to become self-sufficient in agricultural production. Program goals include:

- crop breeding;

- multiple cropping;

- soil conservation;

- improved management of agricultural lands.

Sri Lanka began an agricultural base mapping program to provide information on soils, present vegetation, land use for siting new agricultural areas, and topography for assisting irrigation planning and watershed management. Although earlier maps existed they had not been updated since the early 1960s and they were incomplete. "

\section{PERU}

In Peru, the Officina Nacional de Evaluation de Recoursos Naturales (ONERN) is to provide the Peruvian Government with inventory and evaluation of Peru's natural resources as well as an assessment of the state of the environment and recommendations for its protection. ON ERN'S objectives require extensive resource information:

natural resources inventories oriented to Peru's development and resource management needs;

- natural resources inventories for conservation policy planning;

- studies of the interactions of human and other natural resources, with an emphasis on use and preservation .12

\footnotetext{
${ }^{10} \mathrm{~T}$. K. Cannon, et al., "Application of Remote Sensing Techniques to Forest Vegetation Surveys in Tropical Areas and Urban Fringe Land Use Problems in Coasta Rica," $m$ Proceedings of the Twelfth International Symposium of Remote Sensing of Environment, (Ann Arbor, MI: Environmental Research Institute of Michigan, 1978), p. 2081.

1" Resources Development Associates, "Agricultural Resource Inventory and Base Mapping in Sri Lanka, A Program Evaluation and Assessment, " Los Altos, CA Nov., 1976.

${ }^{12}$ Robert Campbell, et al., Land Use Inventory and Environmental planning Project: Peru (Los Altos, CA: RDA, April 1980).
}

\section{BANGLADESH}

Among other things, Bangladesh's development goals include disaster warning to prevent damage and loss of life from severe storms, as well as increased agricultural production and monitoring of crop production. These two areas generate a need for the following types of resource information:

- cloud patterns and storm warning on a real-time basis;

- data on rainfall, soil moisture, hours of sunshine, and crop stress, in order to monitor crop growth and crop conditions;

- data on land use and land use change to plan better agricultural development and irrigation;

- flood patterns and water levels to plan better cropping patterns.

\section{DOMINICAN REPUBLIC}

Forests represent one of the Dominican Republic's primary natural resources. Before an aerial photographic survey in 1965 and 1966, the Government of the Dominican Republic believed that 40 percent of its total land area was forested, 750,000 hectares in high-quality pine. The survey showed that less than 11.5 percent of the land was actually in forest, and only 215,000 hectares in pine. This information profoundly affected its previous planning estimates. $1^{4}$ Continued observation using satellite data could help the country survey their forest resources on a regular basis.

\section{Potential Fishery Applications}

To date, very little work has been done in developing countries with respect to fisheries development. However, "new developments in marine-related remote sensing, such as synthetic aperture radar for wave studies, microwave radiometers for salinity measurements, and multispectral scanners for chlorophyll mapping"ls present new opportunities for the use of satellites in fisheries development throughout the world.

Although U.S. research on using satellite remote sensing for fisheries is in its infant stages, it has not begun in developing countries. Generally, Landsat's

\footnotetext{
${ }^{13}$ Harvey Newton, et al., Early warning Crop Yield Modelling in Bangladesh (Diamond Springs, CA: RDA, April 1982).

'Organization of American States, "An Exploratory Survey of the Dominican Republic, " in Physical Resources Investigations for Economic Development, A Casebook of OAS Field Experience in Latin America, General Secretariat, Washington, DC, 1969, pp. 212-214.

$15 \mathrm{VicKlemas,}$ "Technology Transfer to Developing Countries: Future Use of Remote Sensing in Biological Marine Resource Development, "Background paper for Ocean Policy Committee, National Academy of Sciences Workshop on Future of International Cooperation in Marine Technology, Science, and Fisheries, La Jolla, CA, Jan. 18-22, 1981.
} 
sensors have very limited application to marine studies; thermal infrared and microwave sensors have shown good potential. While some developing countries receive low-resolution thermal infrared imagery from the GOES satellites, they would not be able to receive and analyze thermal infrared or microwave data of high resolution from ocean satellites if they were flying because they do not possess the high capacity computers needed to process such data. However, these kinds of data are necessary to pursue useful analyses of the coasts and oceans. In addition, as the previous section on ocean remote sensing emphasized, those applications require more research and efforts to demonstrate whether they will work or be cost effective.

The importance of accurate information about natural resources is clear, particularly as developing countries strive for self-sufficiency. Economic development requires discovering what resources are available and then organizing the information so that informed decisions can be made about the development and exploitation of natural resources. The key is the information base. Most developing countries lack a consistent, homogeneous, and complete data base from which to work. They also lack the means to acquire, sift, and analyze the new data they need. The preliminary surveys and maps they have made, largely with the help of the United States and the European countries, represent only the beginning of the long and difficult process of information management. ${ }^{16}$

\section{Institutional Factors Influencing the Use of Satellite Remote Sensing}

A variety of nontechnical factors, including institutional and political ones, affect the use of satellites in developing countries.

\section{Domestic Institutional Factors}

It is in the routine use of data, not its initial collection, that the operational use of remote sensing data meets its toughest test. ' Therefore, in order to determine what type of interpretation and analysis procedures will best serve a developing country's needs, it is necessary to understand what internal institutional and technological capabilities already exist in a given country,

As one report ${ }^{18}$ suggests, prior to the development of self-supporting satellite data users in developing

\footnotetext{
${ }^{16}$ See, for example, "Satellite Remote Sensing for Developing Countries," Proceedings of an EARSel-ESA Symposium, Igls, Austria, Apr. 20-21, 1982 (ESA-SP-1 75)

17 NAS Study, op, cit., P. 117.

${ }^{18}$ HarveyWallender, et al., Technology Transfer and Management in Developing Countries (Cambridge, MA: Ballinger Publishing Co., 1979), ch. 3.
}

countries, an institutional framework to support the use of that data and a capacity for internal problem solving are essential. In the absence of this homework, transferring or selling technology to end-users does little to help them achieve any of their objectives with remote sensing data. Unfortunately, many international technology transfer projects have overemphasized the immediate use of equipment and technologies and have failed to aid in building an infrastructure or internal organization to support continued use of the data. The Wallender study ${ }^{19}$ concluded that efforts to build the technical capabilities associated with later stages of development will fail unless the objectives of earlier stages have been realized.

Because satellite data is likely to be used by many interested parties, including hydrologists, geologists, soils scientists, agricultural specialists, physical planners, or geographers, economies of scale can be realized by promoting multiple uses of satellite data. In other words, "the more numerous and diversified the users of remote sensing are, the more economically feasible it is for a country to sustain a national analysis capability." ${ }^{20}$ In addition, given limited manpower and budgetary resources, a focused resource and environmental information effort is also needed. Many ways of coordinating such activity are possible, depending on the country involved, its needs, resources, and political situation. The transfer agent, whether USAID or some private consulting firm, will not succeed until the developing country has developed an internal organization that can decide on its own to use satellite products and satellite technology. Foreign aid spent on transferring technology (hardware) might be better spent in developing an institutional and organizational infrastructure conducive to using remote sensing data.

\section{The Training Constraint}

Closely related to the development of an effective organizational context is the need to familiarize thoroughly the users of the technology with the technology itself and its value for helping them perform their work. This primarily means training people and coordinating manpower and equipment.

As a review of AID projects in the Sahel pointed out:

[the] factors which impeded the maximum transfer"of technical expertise to the counterparts and the application of results to development programs were: the scant availability of appropriately trained counterpart resource analysts; and the lack of an extended period of practical training and technical assistance after inventory completion, during which expatriate analysts

\footnotetext{
19.bid.

${ }^{20}$ Remote Sensing From Space, op. cit., P. 125.
} 
could gradually withdraw as the host country personnel gained self-sufficiency in the implementation process. These are issues which can and should be accounted for in future resource inventories in Africa. They must be considered in the preliminary stages of project design by the funding agency and the host country, so that adequate time and resources for them are allocated.$^{21}$

In developing countries where trained personnel do not exist, training is critical, not only in resource survey and map interpretation and mapmaking techniques, but also in equipment operation and upkeep. Where a country does not have the personnel or tools to provide upkeep on electronic equipment, it quickly becomes useless.

Training in both general topics and specific subjects is needed. General training includes educating scientists and policy makers about the technology and its limitations and advantages. Such exposure is essential to starting a country on a road toward the adoption of the technology.

Specific training involves coupling the training of specialists in the fields to be explored (e.g., weather, climate, water resources, geology) with training in the interpretation of remotely sensed data. This process may be extensive and take several years. Such training may well consist of courses in the United States, on-the-job training either in the United States or in the host country, and day-to-day interactions between foreign and host country participants.

Training programs of even the best quality may not be successful, however, unless developing countries are able to commit professional personnel on a longterm basis:

In most VVest African countries, the supply of educated scientists and planners is extremely limited. The few specialists who do exist are often quickly cycled through government hierarchies and do not remain in positions where their project experience can be technically or managerially utilized. The shortage of scientists sometimes necessitates that government administrators be given assignments that would be more appropriately filled by people trained in the earth sciences. This was the case in the Volta Basin project where three of the seven counterparts were government administrators or department heads who already had full-time administrative positions and corresponding responsibi lities. ${ }^{22}$

These administrators usually return to their old duties and are unable to continue supporting the use of remote sensing:

program success also requires the full commitment of scientifically trained counterparts for an extended

\footnotetext{
21 Lynda Hall, "Factors in the Effective Utilization of a Landsat Related In ventoryın West Africa" (Baltimore, MD: National Conference on Energy Resource Management, 1982), p. 4.

221 bid, p. 5
}

period immediately following the inventory, during which resource development programs are initiated. The inclusion and funding of this extended implementation period is a critical element of any natural resource inventory. It is also one which has often been overlooked by sponsor agencies in project design. The result is that priorities are shifted, counterparts resume, or are reassigned to other duties, and inventory products are shelved. Development projects may then continue on an ad hoc basis, without the benefit of the management resource. ${ }^{23}$

To develop self-supporting users who can generally solve their own problems, it will be essential to construct long-term, intensive training programs. If training is treated haphazardly, the potential for satellite applications in developing countries will be severely hampered.

In sum, the development of satellite remote sensing users in developing countries will rely on effective technology transfer that encourages these countries permanently to adopt satellite technology. Such technology transfer will be successful only if it assists in the development of an effective organizational context. However, the adoption of satellite technology in developing countries also depends on political factors.

\section{Political Constraints}

During the last decade, the control of information has emerged as a critical component of the NorthSouth debate over a New International Order. In particular, information that is carried across national boundaries without the consent of all parties has been seen by some countries as a threat to their national sovereignty and their "sovereign right" to control information about themselves and their resources (including resources within a 200-mile Extended Economic Zone). Earth resource sensing satellites pose a unique problem because they collect information about one country and disseminate it to many other countries .24

Sovereignty issues have been discussed and debated throughout the legal and political debate in the U. N., focusing on the development of an international regime for Earth resource sensing satellites. The sovereignty debate has centered on the desire of some countries to control the dissemination of data obtained about their country from space. This issue is the heart of the argument in the U.S. debate; a prohibition against open dissemination without consent is contained in an early Argentine-Brazilian draft treaty, and

\footnotetext{
${ }^{23}$ lbid., p. 6.

${ }^{24}$ See discussion on this and sımilarissues in UNISPACE 82 : $\boldsymbol{A}$ Context for International Cooperation and Competition, op. Cit., pp. 24-28,
} 
also in an early French-Russian set of draft principles regarding control of remote sensing from space. ${ }^{25}$

The issue stems from a basic disagreement over control of information. Whereas the United States admits to a nation's sovereignty over its natural resources, it does not agree to a nation's sovereignty over information about those resources, Developing countries fear being exploited by other countries and especially by multinational corporations. The importance of information is dramatically evident in the search for new forms of mutually agreeable relations-new contracts-between multinational corporations and developing countries. Differential access to information and the ability to apply it are crucial elements in bargaining power between multinational corporations and the developing countries.

The United States questions developing countries' concerns over economic exploitation on three grounds:

First, developing countries are entering into mature, mutually beneficial resource exploitation relationships with foreign interests, without forswearing their rights to such ultimate sanctions as nationalization andlor expropriation. Second, the physical control of resources and of access to resource sites are the trump cards, not possession of tentative and unverified data. Third, as developing countries acquire their own remote sensing expertise, whether indigenous or procured from outside consultants, the margin of information disadvantage can lose a good measure of its significance. ${ }^{26}$

The United States further suggests that imposition of some form of restrictive data dissemination regime would create two "classes" of countries; those with data acquisition capabilities and those without. It has argued that this would create more inequality than a regime of open dissemination.

Such a point of view suggests that developing countries should emphasize efforts to develop capabilities to use technology and data relevant to their capacities while working to maintain equal access to worldwide data and information networks. There is, however, a serious tradeoff involved here. If developing countries make:

... vigorous attempts to be integrated into the international data market, many of them may face the prospects of increased dependence on imported technology and equipment; on the other hand, if they stand aloof, they may have the problems associated with a

\footnotetext{
25See U .N. Document A/AC,1/1047 (Oct. 15, 1974), Article IX of Latin America Draft Treaty. Although positions on this issue have shifted, it is still a major point for debate.

${ }^{26}$ Remote Sensing from Space, op. cit., pp. 147-148.
}

very limited access to the rapidly expanding pool of machine-readable data. ${ }^{27}$

The avoidance of this tradeoff will be extremely difficult. It is important, though, that information asymmetries (either real or imagined) be dealt with, because it is likely that an increase in the knowledge and capabilities of developing countries would lead to smoother international negotiations. At present, international negotiations over access to data and information may be clouded with political rhetoric from countries that feel they are at an information disadvantage; perceiving asymmetries in access to information, they tend to block agreement.

Cruise O'Brien and Helleiner suggest that "the consequences of imperfect information are nowhere more dramatic than in the resource sector.." ${ }^{28}$ Private users, with greater information in early stages of resource exploitation, usually strike what appears to be a good bargain. As exploration proceeds and the host government learns more, it may find that it gave away too much early on. This leads to what is known as the "ob solescing bargain." When this occurs, host countries push for renegotiation and, in fact, a great deal of renegotiation has occurred in recent years. ${ }^{29}$ As a result, an impasse "has developed between host governments in developing countries and the resource transnationals (multinationals) which has produced a marked decline in resource exploration and development in the Third World in recent years which is in the interests of neither. ${ }^{30}$

The elimination of information asymmetries might provide a common knowledge base and common ground for negotiation. Increased knowledge in developing countries would enable them to bargain more effectively and efficiently.

The issue of dependence cannot be easily dismissed. Developing countries do not want, for political and practical reasons, to become dependent on one source of resource information vital to their national planning-particularly a source over which they have no control. As dependence increases, the demand for a voice in the planning of the system will grow.

It should be noted that U.S. policies to make data and technology available have to a great extent mitigated the most serious concerns of developed and de-

\footnotetext{
Z'"'Transnational Corporations and Transborder Data Flows: A Technical Paper," U.N.Centre of Transnational Corporations, ST/CTC/23, New York, 1982.

${ }^{28}$ Rita Cruise O' Brien and Gerald Helleiner, "The Political Economy of Information in a Changing International Economic Order," in International Organization 34:4, Autumn 1980, p. 457.

${ }^{29}$ U. . CommissiononTransnational Corporations, "Transnational Corporations in World Development: A Re-Examination," U.N. Economic and Social Council E/C10/28, Mar. 20, 1978.

${ }^{30}$, Favre and H. La Lauch, "Natural Resources Forum," vol.5, No. 4 (Boston, MA: D. Ridel Pub. Co., October 1981), pp. 327-347.
} 
veloping countries who, despite their U.N. posturing, have taken to building satellite remote sensing programs based on Landsat technology. One can see this not only in the French and Japanese remote sensing programs, which will fly Landsat compatible sensors, but also in the developing countries which focus their space activities around remote sensing. The effect of the Landsat system and Landsat policy has been to generate expectations of data continuity. Developing countries are now extremely worried about a cut-off in available data should the Landsat program be terminated. ${ }^{31}$

j! Second UN ISPACE Conference, Draft Report of the Conference, A/CONF.101/3, Mar. 20, 1982., p. 77. 
APPENDIX 7B.-U.S. ENVIRONMENTAL SATELLITES, 1960-85

\begin{tabular}{|c|c|c|c|c|c|}
\hline Satellite & Purpose(I) & Launch & $\begin{array}{l}\text { Average }{ }^{(*)} \\
\text { Altitude }(\mathrm{km})\end{array}$ & $\begin{array}{l}\text { Ceased } \\
\text { Operation }\end{array}$ & Remarks $^{(3)}$ \\
\hline TIROS I & R & $04 / 01 / 60$ & 720 & $06 / 19 / 60$ & $\begin{array}{l}\text { First weather satellite providing cloud } \\
\text { cover photography. }\end{array}$ \\
\hline TIROS 2 & $\mathrm{R}$ & $11 / 23 / 60$ & 672 & 02/01/61 & \\
\hline TIROS 3 & $\mathrm{R}$ & $07 / 12 / 61$ & 760 & $10 / 30 / 61$ & \\
\hline TIROS 4 & $\mathrm{R}$ & $02 / 08 / 62$ & 773 & “06/12/62 & \\
\hline TIROS 5 & $\mathrm{R}$ & $06 / 19 / 62$ & 694 & $10 / 11 / 63$ & \\
\hline TIROS 6 & $\mathrm{R}$ & $09 / 18 / 62$ & 694 & $10 / 11 / 63$ & \\
\hline TIROS 7 & $R$ & 06/19/63 & 645 & 02/03/66 & \\
\hline TIROS 8 & R & $12 / 21 / 63$ & 749 & $01 / 22 / 66$ & First APT satellite. \\
\hline Nimbus 1 & $\mathrm{R}$ & $08 / 28 / 64$ & S/677 & $09 / 23 / 64$ & $\begin{array}{l}\text { Carried AVCS, APT, and High } \\
\text { Resolution Infrared Radiometer for night } \\
\text { pictures. }\end{array}$ \\
\hline TIROS 9 & $\mathrm{R}$ & $01 / 22 / 65$ & S11630 & $02 / 15 / 67$ & $\begin{array}{l}\text { First TIROS satellite in Sun-synchronous } \\
\text { orbit. }\end{array}$ \\
\hline TIROS 10 & 0 & $07 / 01 / 65$ & S1792 & $07 / 03 / 66$ & \\
\hline ESSA 1 & 0 & $02 / 03 / 66$ & S/765 & 05/08/67 & $\begin{array}{l}\text { First satellite in the operational system; } \\
\text { carried } 2 \text { wide-angle TV cameras. }\end{array}$ \\
\hline ESSA 2 & 0 & 02/28/66 & S/1376 & $10 / 16 / 70$ & $\begin{array}{l}\text { Carried APT cameras. APT carried onall } \\
\text { even-numbered ESSA satellites }\end{array}$ \\
\hline Nimbus 2 & $\mathrm{R}$ & $05 / 15 / 66$ & $S / 1136$ & $01 / 18 / 69$ & \\
\hline ESSA 3 & 0 & $10 / 02 / 66$ & $S / 1427$ & $10 / 09 / 68$ & $\begin{array}{l}\text { Carried first AVCS cameras. ABCS } \\
\text { carried on all odd-numbered ESSA } \\
\text { satellites. }\end{array}$ \\
\hline ATS 1 & $\mathrm{R}$ & $12 / 06 / 66$ & G135,765 & $\begin{array}{l}10 / 16 / 72 \\
\text { (pictures) }\end{array}$ & $\begin{array}{l}\text { WEFAX discontinued } \\
\text { December } 31,1978 .\end{array}$ \\
\hline ESSA 4 & 0 & $01 / 26 / 67$ & $\mathrm{~s} / 1373$ & $10 / 06 / 67$ & \\
\hline ATS 2 & $R$ & $04 / 05 / 67$ & - & - & Unstable attitude-data not useful. \\
\hline ESSA 5 & 0 & $04 / 20 / 67$ & S11379 & 02/20/70 & \\
\hline ATS 3 & $\mathrm{R}$ & $11 / 05 / 67$ & G135,815 & $\begin{array}{l}10 / 30 / 75 \\
\text { (pictures) }\end{array}$ & $\begin{array}{l}\text { WEFAX discontinued } \\
\text { December } 31,1978 .\end{array}$ \\
\hline ESSA 6 & 0 & $11 / 10 / 67$ & SI1437 & $11 / 04 / 69$ & \\
\hline
\end{tabular}




\begin{tabular}{|c|c|c|c|c|c|}
\hline Satellite & Purpose(I) & Launch & $\begin{array}{l}\text { Average }{ }_{2}^{(1)} \\
\text { Altitude }(\mathrm{km})\end{array}$ & $\begin{array}{l}\text { Ceased } \\
\text { Operation }\end{array}$ & Remarks $^{(3 \sim}$ \\
\hline ESSA 7 & 0 & 08/16/68 & $\mathrm{s} / 1440$ & 07/19/69 & \\
\hline ESSSA 8 & 0 & $12 / 15 / 68$ & $\mathrm{~S} / 1429$ & 03/12/76 & \\
\hline ESSA 9 & 0 & 02/26/69 & $S / 1456$ & $11 / 15 / 73$ & \\
\hline Nimbus 3 & $\mathrm{R}$ & $04 / 14 / 69$ & $\mathrm{~S} / 1100$ & $01 / 22 / 72$ & $\begin{array}{l}\text { Provided first vertical temperature profile } \\
\text { data of the atmosphere on a global } \\
\text { basis. }\end{array}$ \\
\hline ITOS 1 & $\mathrm{R} / \mathrm{O}$ & $01 / 23 / 70$ & $S / 1456$ & $06 / 17 / 71$ & Second generation prototype. \\
\hline Nimbus 4 & $\mathrm{R}$ & 04/08/70 & $\mathrm{S} / 1108$ & 09/30/80 & \\
\hline NOAA 1 & 0 & $12 / 11 / 70$ & $S / 1438$ & 08/19/71 & $\begin{array}{l}\text { First NOAA funded second generation } \\
\text { satellite. }\end{array}$ \\
\hline ITOS B & 0 & $10 / 21 / 71$ & - & - & Failed to orbit. \\
\hline Landsat 1 & R & 07/23/72 & S/918 & 01/16/78 & \\
\hline NOAA 2 & 0 & $10 / 15 / 72$ & $S / 1460$ & 01/30/75 & $\begin{array}{l}\text { First operational satellite to carryall } \\
\text { scanning radiometer. }\end{array}$ \\
\hline Nimbus 5 & $\mathrm{R}$ & $12 / 12 / 72$ & $S / I I I 0$ & 03/29/83 & \\
\hline ITOS E & 0 & 07/16/73 & - & - & Failed orbit. \\
\hline NOAA 3 & $-0-$ & $11 / 06 / 73$ & $\mathrm{~s} / 1510$ & $08 / 31 / 76$ & $\begin{array}{l}\text { First operational satellite to permi(t direct } \\
\text { broadcast of VTPR data. }\end{array}$ \\
\hline SMS 1 & RIO & $05 / 17 / 74$ & G/35,788 & $01 / 29 / 81$ & $\begin{array}{l}\text { Deactivated. Boosted out of } \\
\text { geosynchronous orbit, }\end{array}$ \\
\hline NOAA 4 & 0 & $11 / 15 / 74$ & $S / 1460$ & $11 / 18 / 78$ & Deactivated. \\
\hline Landsat 2 & $\mathrm{R}$ & $01 / 22 / 75$ & $\mathrm{~S} / 918$ & 03/31/83 & On Standby. \\
\hline SMS 2 & $\mathrm{R} / \mathrm{O}$ & 02/06/75 & $\mathrm{G} / 35,800$ & 08/05/82 & $\begin{array}{l}\text { Deactivated. Boosted out of } \\
\text { geosynchronous orbit. }\end{array}$ \\
\hline Nimbus 6 & $\mathrm{R}$ & $06 / 12 / 75$ & $\mathrm{~s} / 1110$ & 03/29/83 & \\
\hline GOES 1 & 0 & $10 / 16 / 75$ & $\mathrm{G} / 35,796$ & - & $\begin{array}{l}\text { First NOAA operational geostationary } \\
\text { satellite; } 130^{\circ} \mathrm{W} \text { on standby. }\end{array}$ \\
\hline NOAA 5 & 0 & 07/29/76 & $\mathrm{s} / 1511$ & 07/16/79 & Deactivated. \\
\hline GOES 2 & 0 & 06/16/77 & G/35,787 & - & $\begin{array}{l}\text { Second NOAA operational geostationary } \\
\text { satellite; } 113^{\circ} \mathrm{W} \text { supporting Central } \\
\text { WEFAX. }\end{array}$ \\
\hline
\end{tabular}




\begin{tabular}{|c|c|c|c|c|c|}
\hline Satellite & Purpose[l) & Launch & $\begin{array}{l}\text { Average }{ }^{(2)} \\
\text { Altitude }(\mathrm{km})\end{array}$ & $\begin{array}{l}\text { Ceased } \\
\text { Operation }\end{array}$ & Remarks $^{(3)}$ \\
\hline Landsat 3 & $\mathrm{R}$ & $03 / 05 / 78$ & $\mathrm{~S} / 918$ & 03/31/83 & $\begin{array}{l}\text { First Landsat with infrared capability. } \\
\text { Now on standby. }\end{array}$ \\
\hline GOES 3 & 0 & $06 / 16 / 78$ & $\mathrm{G} / 35,784$ & - & On standby. Moving to $135^{\circ} \mathrm{W}$. \\
\hline Seasat 1 & $\mathrm{R}$ & 06/26/78 & 850 & $10 / 10 / 78$ & Electrical failure. \\
\hline TIROS-N & $\mathrm{RIO}$ & $10 / 13 / 78$ & $\mathrm{~S} / 850$ & $02 / 27 / 81$ & Deactivated. \\
\hline Nimbus 7 & $\mathrm{R}$ & $10 / 24 / 78$ & S/954 & - & Carrying Coastal Zone Color Scanner. \\
\hline NOAA 6 & 0 & $06 / 27 / 79$ & $\mathrm{~S} / 807$ & - & $\begin{array}{l}\text { First NOAA funded TIROS-N system } \\
\text { satellite. }\end{array}$ \\
\hline NOAA B & 0 & 05/30/80 & - & - & Failed to achieve an operational orbit. \\
\hline GOES 4 & 0 & 09/09/80 & $\mathrm{G} / 35,782$ & - & $\begin{array}{l}\text { First geostationary satellite to carry the } \\
\text { VISSR Atmospheric Sounder (VAS) } \\
\text { which has now failed. At } 139^{\circ} \mathrm{W} \text {. } \\
\text { Provides west, WEFAX, and DCS. }\end{array}$ \\
\hline GOES 5 & 0 & $05 / 22 / 81$ & G/35,785 & - & $\begin{array}{l}\text { At } 75^{\circ} \mathrm{W} \text {; also carried VAS. Now failed. } \\
\text { Provides east DCS, WEFAX, and relay } \\
\text { of GOES } 6 \text { imagery. }\end{array}$ \\
\hline NOAA 7 & 0 & $06 / 23 / 81$ & $\mathrm{~S} / 847$ & - & $\begin{array}{l}\text { Second NOAA funded TIROS-N system } \\
\text { satellite. }\end{array}$ \\
\hline Landsat 4 & 0 & $07 / 16 / 82$ & S/7oo & - & Carries MSS and TM. \\
\hline NOAA 8“ & 0 & $03 / 28 / 83$ & $\mathrm{~S} / 815$ & 06/12/84 & Had search and rescue capability. \\
\hline GOES 6 & 0 & $04 / 28 / 83$ & $\mathrm{G} / 35,791$ & - & $\begin{array}{l}\text { Alternates between } 98^{\circ} \mathrm{W} \text { and } 108^{\circ} \mathrm{W} \text {. } \\
\text { Only spacecraft with operating VAS. }\end{array}$ \\
\hline NOAA 9 & 0 & $12 / 12 / 84$ & $\mathrm{~S} / 815$ & - & $\begin{array}{l}\text { Has search and rescue capability and } \\
\text { sensors for ozone and earth radiation } \\
\text { budget. }\end{array}$ \\
\hline
\end{tabular}

(I) R. Research; O-Operations; R/O-Operational Prototype.

${ }^{(2)}$ S-Sun-Synchronous; G-Geosynchronous,

) APT-Automatic picture Transmission; AVCS-Advanced Vidicon Camera System; WEFAX-Weather Facsimile; VTPRVertical Temperature Profie Radiometer; VISSR-Visible Infrared Spin-Scan Radiometer; VAS-VISSR Atmospheric Sounder; MSS-Multi Spectral Scanner; TM-Thematic Mapper; DCS-Data Collection System

- NOAA 8 is once again in operation. 
Chapter 8 MATERIALS PROCESSING IN SPACE 


\section{Contents}

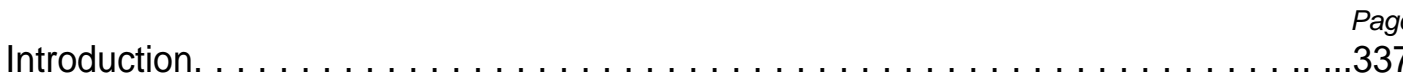

MPS Activities in the United States . . . . . . . . . . . .........................338

NASA Research . . . . . . . . . . . . . . . . . . . . . . . . ................338

The Private Sector... . . . . . . . . . . . . . . . . . . . . . . . . . .........,344

The Scientific Community . . . . . . . . . . . . . . . . . . . . . . . . .......347

Foreign MPS Activities . . . . . . . . . . . . . . . . . . . . . ......348

European Space Agency (ESA) . . . . . . . . . . . . . . . . . . . . ............348

Federal Republic of Germany. . . . . . . . . . . . . . . . . . . . . . . . . . .......349

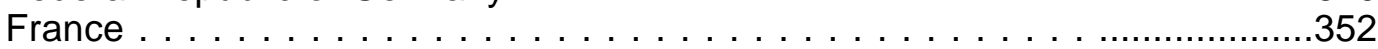

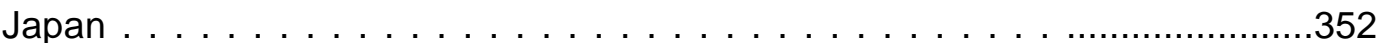

Soviet Union . . . . . . . . . . . . . . . . . . . . . . ...................353

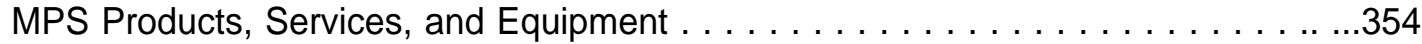

Potential MPS Products . . . . . . . . . . . . . . . . . . . . . . . . . . . . . . . 354

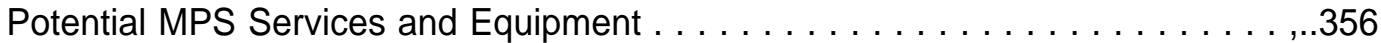

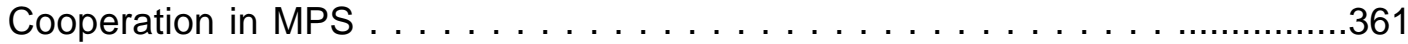

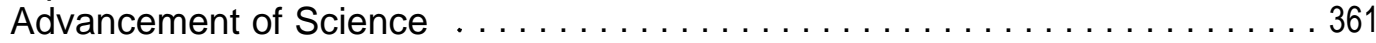

Foreign Policy . . . . . . . ..., . . . . . . . . . . . . . . . . . . 361

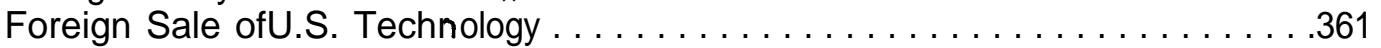

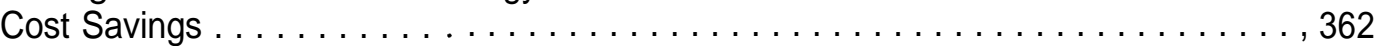

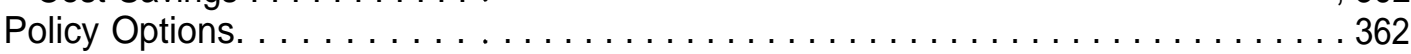

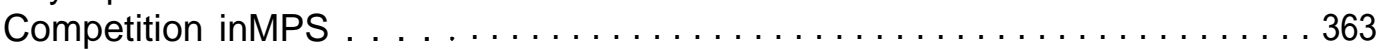

Cooperation . . . . . . . . . . . . . . . . . . . . . . . . . . . . 365

Table

Table No. Page

8-1. Characteristics of Shuttle Payload Carriers . . . . . . . . . . . . . . . . 339

List of Figures

Figure No. Page

8-1. Shuttle Get-Away Special Canister . . . . . . . . . . . . . . . . . . . . . . . ...340

8-2. NASA-Goddard Space Flight Center Hitchhiker Payload Mounted on the Mission-Peculiar Support Structure . . . . . . . . . . . . . . . . . . . . . . 342

8-3. Spacelab Drawing of the Overall Conception of VFW-Fokker/ERNO Spacelab . . . . . . . . . . . . . . . . . . . . . . . . . . . . . . . . ...........342

8-4. ESA Budget for Microgravity Research Program . . . . . . . . . . . . . . . . . . .349

8-5. Budget for Microgravity Research Program . .....................350

8-6. Sketch of the proposed Solaris Orbital Station With One Payload Recovery Capsule Being Ejected for Reentry . ...................353

8-7. Continuous Flow Electrophoresis . . . . . . . . . . . . . . . . . . . 355

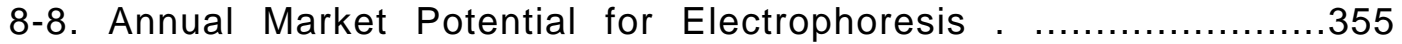

8-9. Demand for Space-Produced GaAs . . . . . . . . . . . . . . . . . . . . 356

8-10. Leasecraft Baseline Concept . . . . . . . . . . . . . . . . . . . ......359

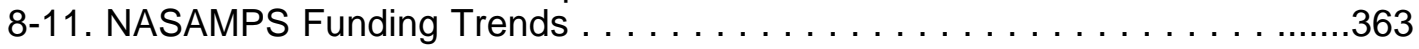




\section{Chapter 8 \\ MATERIALS PROCESSING IN SPACE}

\section{INTRODUCTION}

The primary motivation for pursuing materials science and engineering in space is to use this low-gravity environment for scientific and commercial applications. 1 Removing the effects of gravity offers a new dimension in controlling process variables such as convection, composition, and fluid flow. This may create opportunities for understanding and improving ground-based production methods and, where economical, manufacturing select materials in space.

NASA research on materials processing in space (MPS) research started in the late 1960s with relatively simple demonstration experiments in solidification, fluid dynamics, and electrophoresis conducted during the Apollo missions. Further MPS experiments were carried out during the three Skylab missions and during the ApolloSoyuz Test Project (ASTP). During the hiatus of manned space flight, between Apollo and the Shuttle, NASA continued its MPS research by using the SPAR (Space Processing Applications Rocket) sounding rocket program, drop tubes and towers, and research aircraft flying parabolic trajectories. The majority of future MPS research will be conducted on the Shuttle, free-flying platforms, and eventually on a space station.

Neither the scientific nor the commercial value of materials research in microgravity is fully understood. Although there may be near-term commercial MPS applications (e.g., certain pharmaceutical products), the true value of the microgravity sciences will not be known until years of basic research and significant improvements in space-based hardware have been accomplished. The National Aeronautics and Space Administration's (NASA) MPS program, operating with a modest annual budget (\$27 million in 1985), has identified several scientifically interesting phenomena

\footnotetext{
'The gravitational attraction of Earth on a spacecraft in a 400-km orbit is only about 12 percent less than it would be if it were on the Earth's surface. However, the phenomena of weightlessness occur because the spacecraft and its contents are in a state of free fall. A spacecraft which has achieved orbital velocity has a gravity environment of about 10-7 g (1 ten-millionth of Earth's gravity).
}

with potential commercial value. To date, this program has met with limited success both in attracting private sector participants and in identifying commercially valuable products and services. Nonetheless, there is a strong belief in both the scientific and industrial communities that MPS research will eventually lead to dramatic breakthroughs in terrestrial and space-based products and processes. To assist this process, NASA established an Office of Commercial Programs in September 1984 to provide a focus for NASA research with potential application and to expand U.S. private sector investment in technologies with commercial potential.

MPS research and hardware development are being pursued with interest in Europe and Japan. In Europe, West Germany has long maintained the most vigorous national MPS program; the European Space Agency (ESA) has recently begun to conduct a wide range of MPS activities. European enthusiasm for MPS research stems from ESA'S commitment to the development of Spacelab and, as in the United States, from a belief that basic MPS research may eventually lead to important scientific and economic rewards. As a result of ESA Spacelab and other MPS activities, it is likely that Europe will become an important source of published information on the behavior of materials in microgravity. The Europeans have positioned themselves well to exploit future MPS products and services if they prove commercially valuable. $^{2}$

MPS is not yet an area of international commercial competition: there are no MPS products and the demand for equipment and services is generated primarily by the various government space agencies. The most important international issue in MPS is how to make the most effective use of cooperation to share the costs of research and to realize the benefits of this new technology more quickly.

\footnotetext{
2Foreignability to compete in space manufacturing will depend strongly on availability of the Shuttle to foreign users or on the development of suitable foreign launch vehicles and carriers.
} 
Some of the MPS potential applications for the microgravity environment are: ${ }^{3}$

- Processing of biological materials: Such diverse tasks as the isolation of beta pancreatic cells to determine how the production of insulin is regulated, the isolation of cells from organs that produce various hormones and enzymes such as urokinase and erythropoietin, and the purification of proteins for research and as pharmaceutical products may be accomplished in microgravity. On Earth, convection, sedimentation, and buoyancy inhibit the separation of certain lighter-density materials. In microgravity, separation techniques such as electrophoresis, isoelectric focusing, and suspension cell culturing may be accomplished with greater efficiency and higher purity.

- Production of large perfect crystals: It may be possible to produce certain types of crystals in space for use in semiconductors, solar ceils, infrared detectors, and other electronic devices. On Earth, the chemical homogeneity and size of crystals are limited by convection- and gravity-induced growth defects. It may be possible to control these parameters and minimize defects in the microgravity environment of space.

- Production of glass and ceramics: The microgravity environment may allow the production of special glasses that are useful in optical fibers, high-energy laser applications, and fusion research. Use of containerless proc-

\footnotetext{
'See: Materials Processing in Space, Committee on Scientific and Technological Aspects of Materials Processing in Space, National Research Council, 1978; Materials Processing in Space: Early Experiments (Washington, DC: NASA SP-443, 1980); Materials Processing in the Reduced Gravity Environment of Space, G. E. Rindone (cd.), Proceedings of the Materials Research Society, vol. 9, 1982.
}

essing could eliminate the problems caused by nucleation and reduce trace impurities that limit the applications of high-purity glasses. Such space-based techniques could extend the glass-forming range of many materials and result in new and unique glasses with exotic properties. MPS research may also help to improve glass processing on Earth by providing information on how to eliminate gases in glass, and improving homogeneity through chemical interaction. Ceramics must be prepared by sintering at such high temperatures that they are almost invariably contaminated by the container in which they are made. Containerless processing may offer valuable research opportunities for the preparation of high-purity ceramics.

- Studies of fluid and chemical processes: Such studies would be designed to understand the effects of convection. This research would be applicable to the study of continuous-flow electrophoresis; dendritic growth processes; the growth of very delicate organic crystals; and the nucleation, growth, and coalescence of bubbles, flocculants, colloids and hydroSOIS. Apart from the basic scientific interests, such studies have important applications in many industrial processes.

- Investigation of metals, alloys, and composite materials: Microgravity allows research into the basic properties of pure metals, macrosegregation and microsegregation during solidification of alloys, the role of gravitydriven convection in the microstructure of castings, and the preparation of alloys or composites having components with large density differences. Space-based metallurgical research may result in the development of terrestrially useful products such as hightemperature turbine blades and new battery technologies.

\section{MPS ACTIVITIES IN THE UNITED STATES}

\section{NASA Research}

The NASA MPS program (recently renamed the Microgravity Science and Applications [MSA] Division) is a responsibility of the Associate Admin- istrator for the Office of Space Science and Applications (OSSA) and is directed and administered by the Director, MSA Division, at NASA Headquarters. The Director, assisted by a Scientific Advisory Committee, determines policy, ob- 
jectives, and priorities, and allocates program resources. NASA materials processing research is being conducted at Marshall Space Flight Center, Jet Propulsion Laboratory, Johnson Space Center, Lewis Research Center, and Langley Research Center. There are also approximately 100 university and industrial investigators currently working with NASA on MPS-related projects. '\$ NASA solicits proposals for research tasks from the scientific community and funds them on the basis of merit (established by a peer review process) and relevance to current NASA programs.

NASA's research activities in MPS have focused on the role played by gravity in materials processes and the development of better control of

${ }^{4}$ Hearings on Materials Processing in Space, Before the Subcommittee on Space Science and Applications of the House Committee on Science and Technology, 98th Cong., 1stsess., Statement of Richard Halpern, Director, NASA, Microgravity Science and Applications Division, Sept. 14, 1983. the composition, structure, and morphology of materials processed in space. The MPS program currently supports research in metals and alloys, electronic materials, biotechnology, glasses and ceramics, combustion, and fluid dynamics and transport phenomena. $\mathrm{s}$

NASA still uses sounding rockets, drop-tubes and towers, and research aircraft in its MPS work; however, the Shuttle is, at present, the only means by which to conduct long-duration microgravity research. In order to facilitate Government and private research on the Shuttle, NASA has developed or encouraged the development of a range of Shuttle-related, reusable MPS hardware. Although this equipment is described in greater detail later in this chapter, it is useful for the purposes of this discussion to list the means by which MPS research is or will be carried out (table 8-1).

Slbid.

Table 8.1.-Characteristics of Shuttie Payload Carriers

\begin{tabular}{|c|c|c|c|}
\hline & GAS & HITCHHIKER-G & SPARTAN \\
\hline Telemtry & None & Real-time downllnk of serial data $d$ up to $14 \mathrm{Mbps}$ & None \\
\hline Polnting & 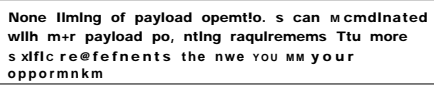 & Shuttle bny pointing possible & z 3 arc-min stellar : $1020.3 \mathrm{~K} . \mathrm{SeC}_{\mathrm{s}_{\mathrm{al} . .,}}$ \\
\hline PayloadSize & 1975 Inches radius 2825 !nches or 1413 inches hqh & Dependtn! on CG & 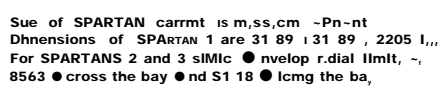 \\
\hline Psyload Wmght & $200 \mathrm{lbs}$ IDO Ibs Or $60 \mathrm{lbs}$ & 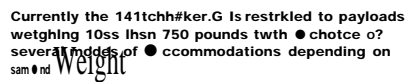 & 500 lbs (for experlmenl) \\
\hline $\begin{array}{l}\text { Last Acc } 8,8 \text { Befo,e } \\
\text { Launch }\end{array}$ & 2-3 months & 2 months & 1 month \\
\hline $\begin{array}{l}\text { F1r8t Access After } \\
\text { Lmdkng }\end{array}$ & 2 weeks & 2-3 weekc & 1 week \\
\hline $\begin{array}{l}\text { Mlaskm Spulallct } \\
\text { Pa ftlclpatlon }\end{array}$ & Dpemte two toggle switchas snd power ontff switch & L)mnti & $\begin{array}{l}\text { Pre-relmti checkout, gwno go } \bullet \text { la!", ch-k } \\
\text { pce.rekease of bltef } \bullet \text { nd payload Cwbeniatlo" } \\
\text { release recapture }\end{array}$ \\
\hline $\begin{array}{l}\text { Fmquoncy of Launch } \\
\text { Oppo@nlty }\end{array}$ & $\begin{array}{l}\text { Approximately SO per yew, } 29 \text { have flown } \bullet \text { s of } \\
\text { Octobol } 1 \text { s } 64\end{array}$ & Currently ooe evefy six months & 2 year bullding to 11 by 1990 \\
\hline Testing fioqulmrnents & $591 *$ & Sdrty & w a y \\
\hline Led T!me & 11.13 month- Lmfore launch & Six mooths from Initiation to Night & In.wwnw-d dependent with $\bullet \mathrm{m}$ nnlmum 0 ! nine rnomh. \\
\hline$\overline{\text { Oocuwmnt*tion }}$ & $\begin{array}{l}\text { Dfswlings, DK.cwkcsl snd m.chankd schemal-cs } \\
\text { chamkal @ nd bkoqcal balance equmtlona. heat flow } \\
\text { dbgrams, smembly } \text { nd handllng procedures } \\
\text { sdety hazard repwls }\end{array}$ & $\begin{array}{l}\text { Oocuwmnlst) On rqukements currently under } \\
\text { development }\end{array}$ & Intertace $\sim$ fmllmn $\bullet$ nd safety pack . \\
\hline M18alon D"ration & Shuttle ftight duration or IImlted by battery supply & Shunk@IUghl dur.tloo & 40 hours \\
\hline Power & Batlwy supply (Customer SUpphd) & $\begin{array}{l}\text { Available through fhe Shuttle } A \text { \$Ingle payload } \\
\text { has } \bullet \text { maximum S00 } \mathbf{W} \bullet \text { vailable the total p8yloads } \\
\text { have } 14 \& 3 \mathrm{w} \bullet \text { vadable }\end{array}$ & Battery Supply (GSFC SuPplled) \\
\hline Upllnk or Oownllnk & None & $\begin{array}{l}\text { An synchronous dowdllnk chwmel } 1200 \text { bsud } \\
\text { An synchronous up41nk } \bullet \text { t } 121 \times 1 \text { baud Medium rate } \\
\text { downllnk channd } 0116 \mathrm{Kbpg} 1014 \mathrm{Mbps}\end{array}$ & None \\
\hline $\begin{array}{l}\text { R.mota Cc."tt,ol } \\
\text { PmsIbkInloa }\end{array}$ & Nom & $\begin{array}{l}\text { A HtichnUmr.G c"slorne, may bend } \bullet \text { Ilmllod number } \\
\text { of bllevel } \bullet \text { nd serld commands } 10 \text { the payload }\end{array}$ & Prgprcqrammed (mlcrocomD"tor) \\
\hline
\end{tabular}

SOURCE: "Attached Shuttle Payload Carriers, Versatile and Affordable Access to Space," NASA, Goddard Space Flight Center, 1984, 


\section{Get-Away Special (GAS) Canisters}

The GAS program was developed by NASA to encourage researchers to take advantage of the unused capacity which exists on most Shuttle flights. GAS canisters, which are little more than hollow cans mounted in some manner on the Shuttle (fig. 8-I), come in two sizes: 5 cubic feet for payloads weighing up to 200 pounds and 2.5 cubic feet for payloads weighing up to 100 pounds. The experimental equipment flown in the canisters is developed by the user subject to NASA safety regulations. Prices charged for flying the GAS canisters are less than full Shuttle prices and range between $\$ 3,000$ and $\$ 10,000$.

\section{Carriers}

Carriers serve a similar goal to that of the GAS program-namely, to maximize the use of the Shuttle bay and reduce the cost of flying small payloads into space. NASA's current carrier program, Hitchhiker, is based on the mission-peculiar support structure (MPESS) developed by Teledyne Brown Engineering for Marshall Space Flight Center (fig. 8-2). Although Hitchhiker is still in the development stage, the MPESS-basically a truss bridge on which GAS canisters or other larger experiments are mounted-was used on Shuttle mission 7. Unlike the GAS canisters or MPESS, Hitchhiker will provide limited power and command and control functions.

Figure 8-1. Stwttle Get-Away Special Canister

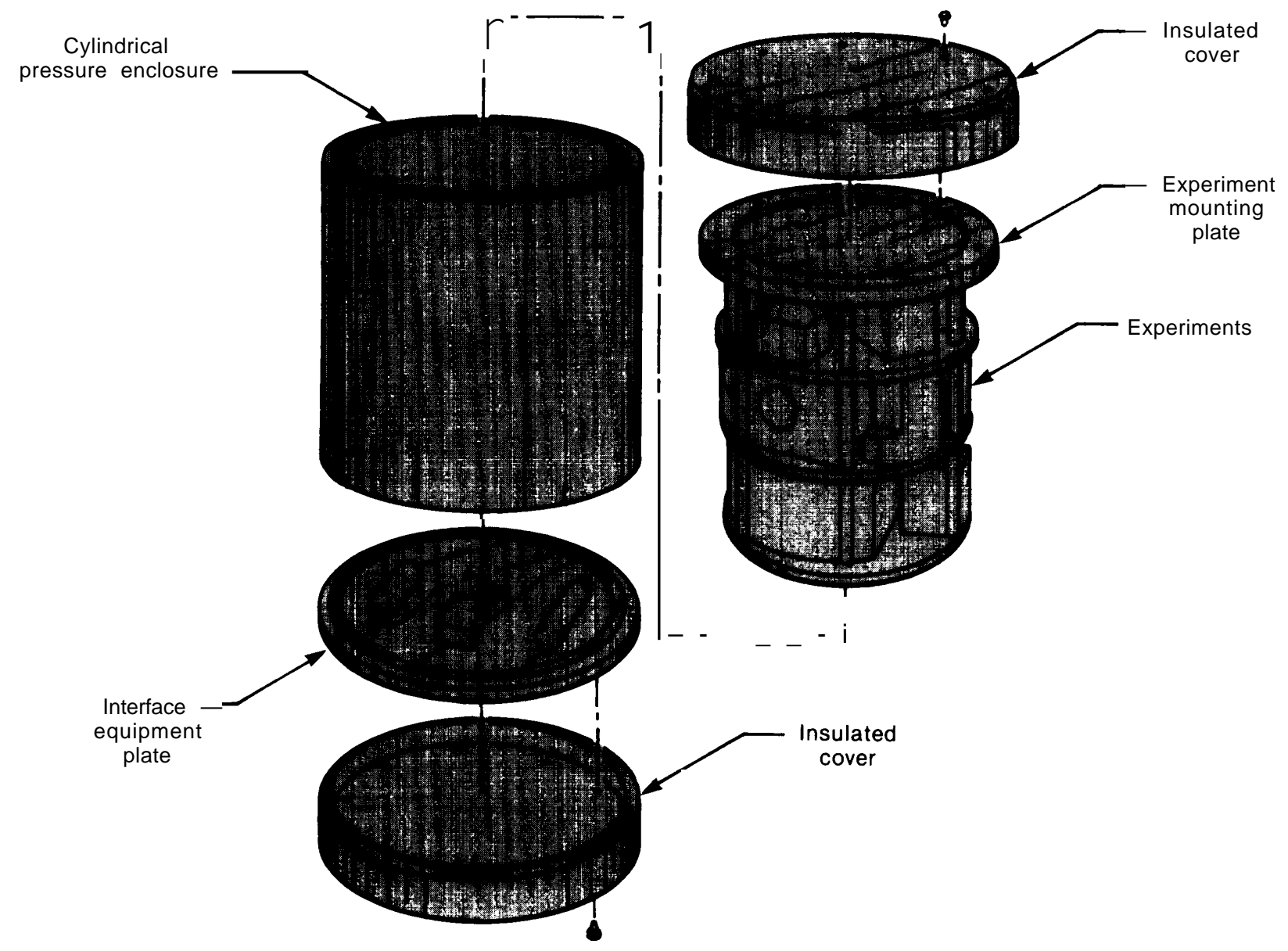

SOURCE: National Aeronautics and Space Administration. 


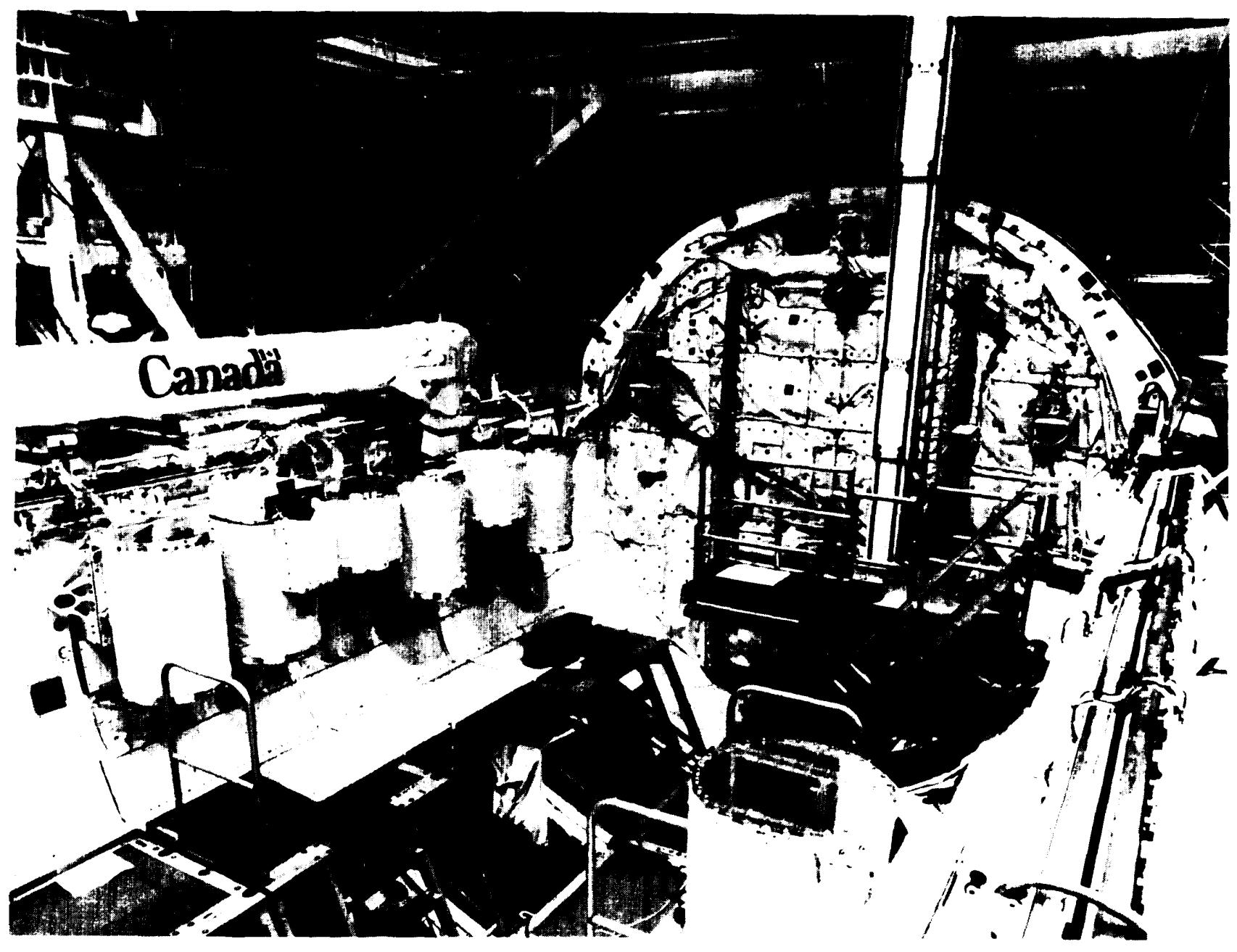

Photo credit: National Aeronautics and Space Administration

This view shows the open cargo bay of the orbiter Challenger in the Orbiter Processing Facility. On the left, the Canadianbuilt Remote Manipulating System can be seen and six of the seven Get-Away Special Canisters are just below it. The other Get-Away Special Canister is in the front right side of the cargo bay.

\section{Spacelab}

The Spacelab is a pressurized module designed to be carried in the Shuttle payload bay. It is a laboratory that allows MPS and other types of research to be done in a "shirtsleeve" environment (fig 8-3). Spacelab was developed by ESA, but pursuant to prior agreements, was transferred to NASA upon completion.

\section{Free-Flyers}

Free-flyers are unmanned carriers designed to be deployed and retrieved by the Shuttle. Such free-flying carriers will allow experimentation in- dependent from Shuttle environmental or time constraints. Relying on technologies originally developed for sounding rockets, NASA has produced a free-flyer called the Spartan. This freeflyer will be used for astronomical and astrophysical payloads which require precise celestial pointing. Spartan will be able to operate independently from the Shuttle for up to 40 hours.

NASA is also working with Fairchild industries to develop a free-flyer called "Leasecraft." The West German Government and the West German firm MB B/ERNO developed the Shuttle Pallet Satellite (SPAS) as the first free-flyer. 
Figure 8-2.-NASA-Goddard Space Flight Center Hitchhiker Payload Mounted on the Mission-Peculiar Support Structure (MPESS)

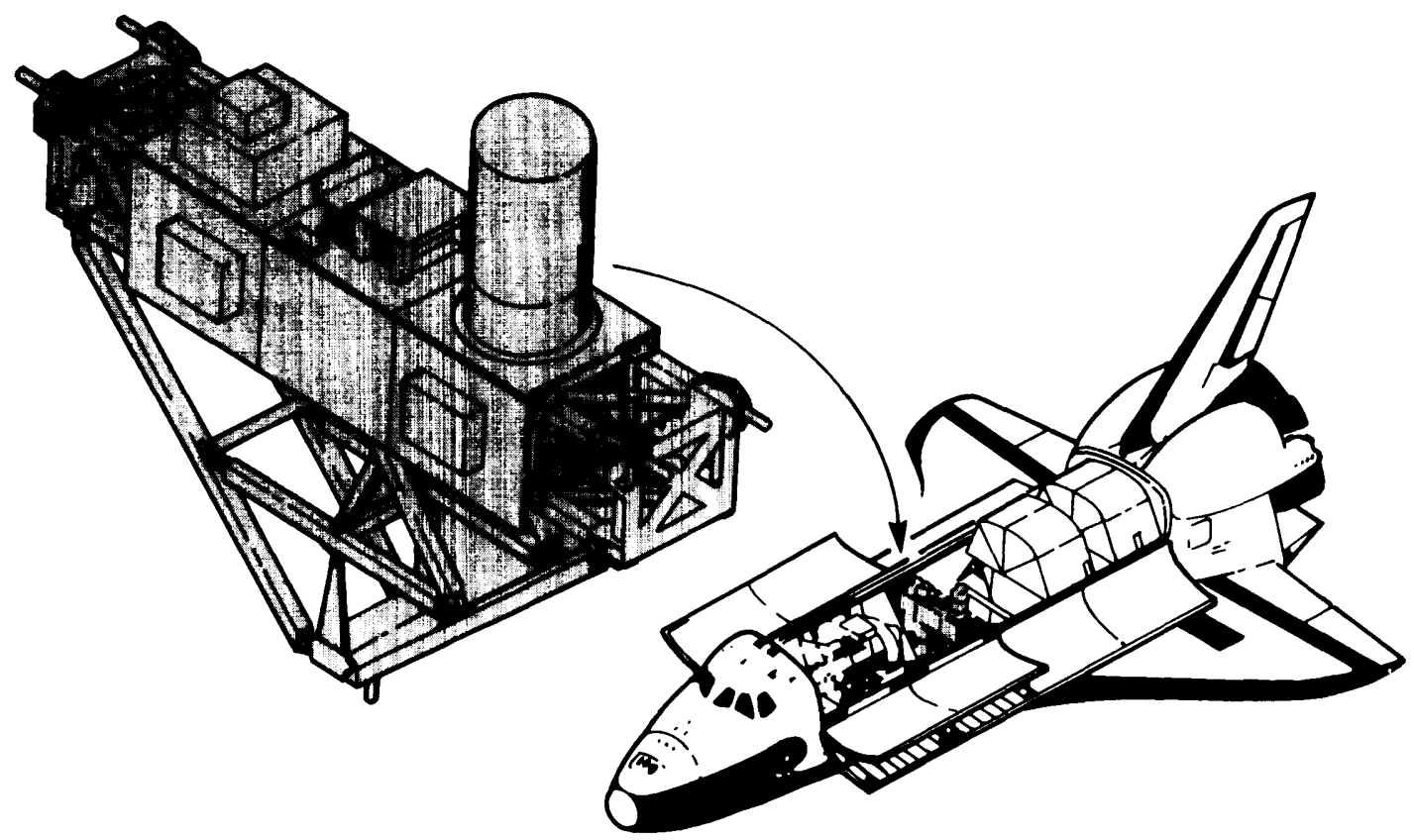

SOURCE: National Aeronautics and Space Administration.

Figure 8-3.-Spacelab Drawing of the Overall Conception of VFW-Fokker/ERNO Spacelab

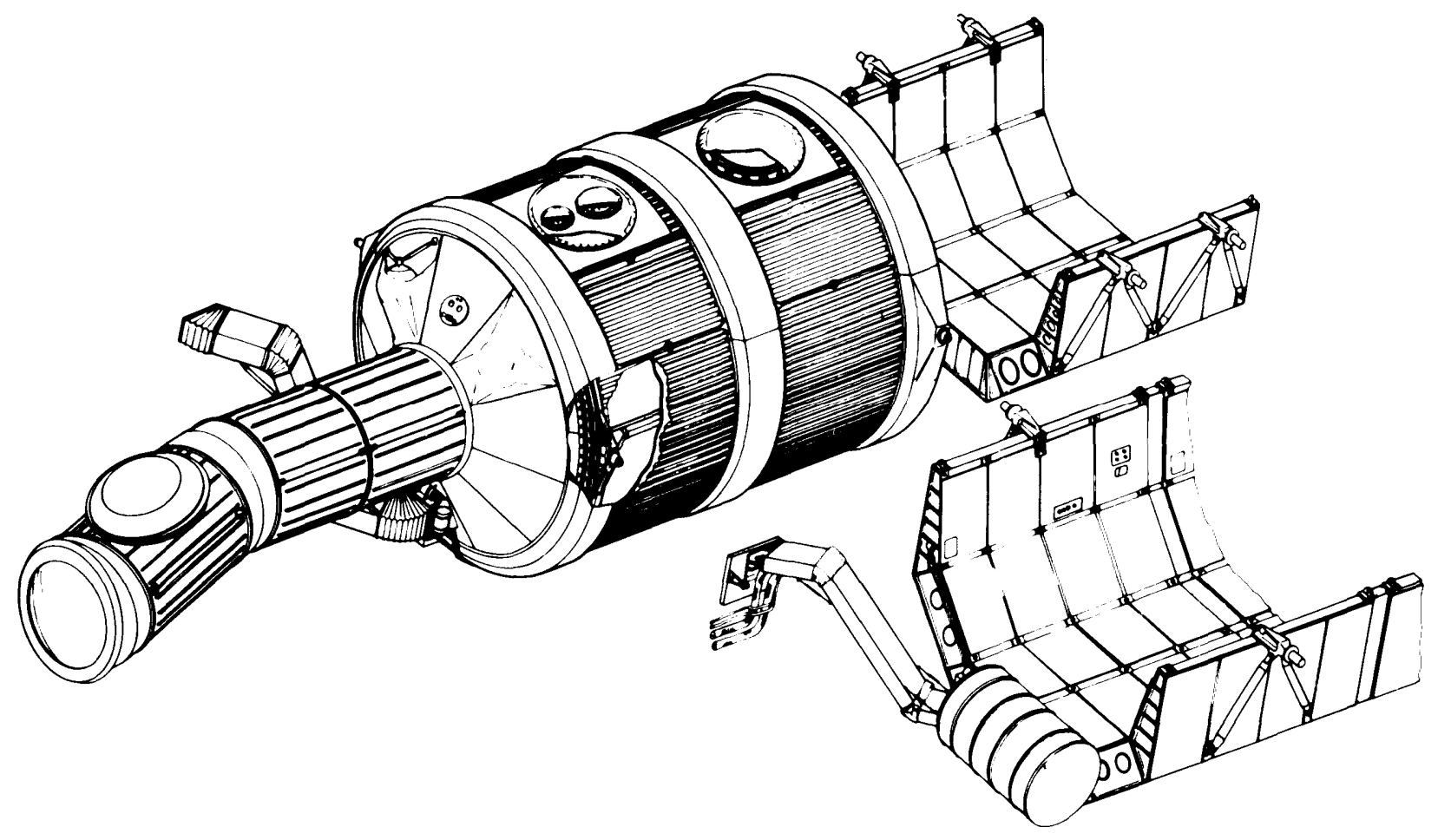

SOURCE: National Aeronautics and Space Administration. 


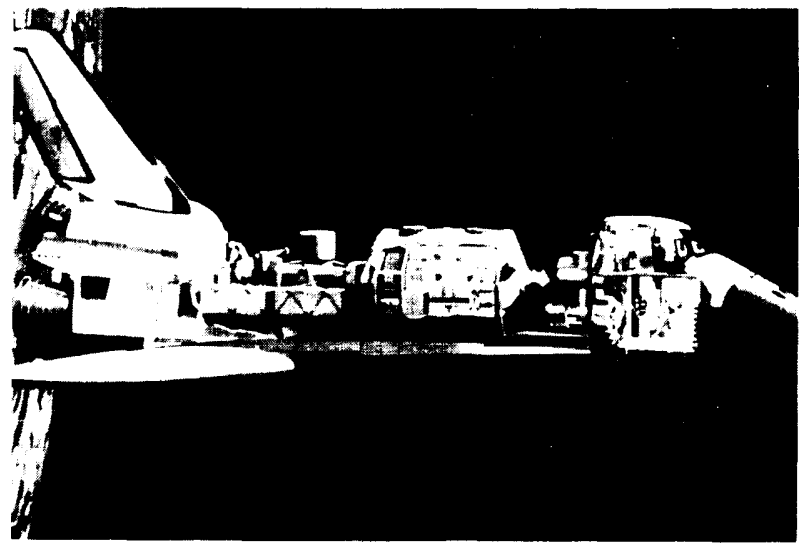

red

E

$S$

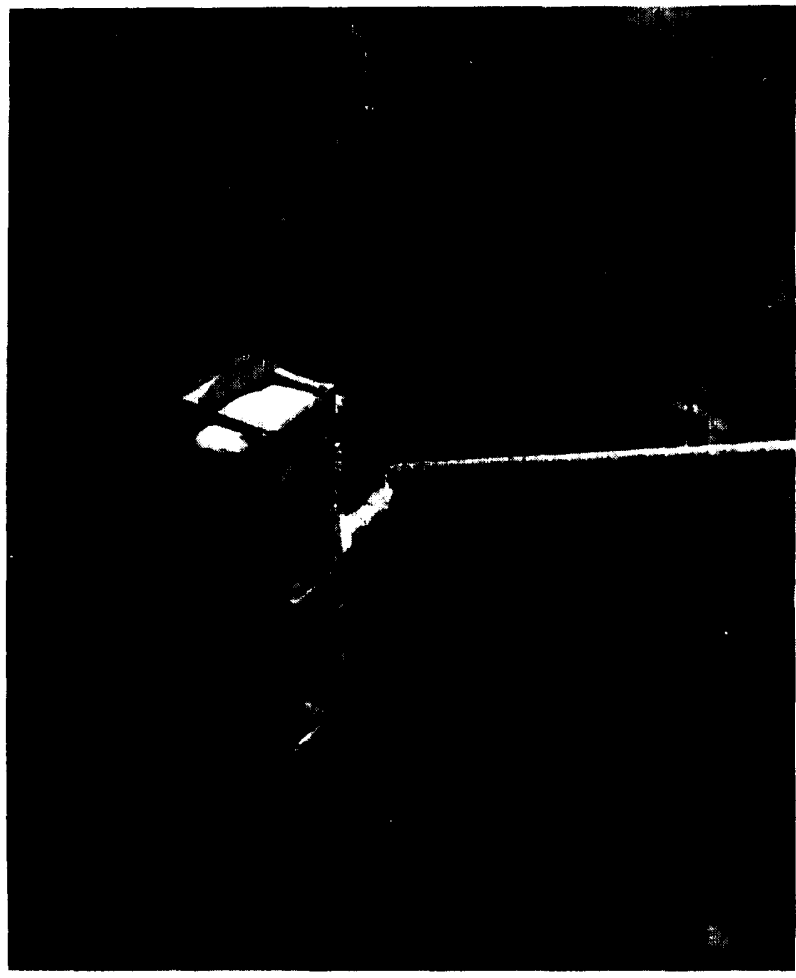

Photo credit: National Aeronautics and Space Administration

The Space Shuttle Challenger's Canadian-built remote manipulator arms grasps the Shuttle pallet satellite (SPAS-01), during proximity operations on June 22 . The scene has within it a few reflections on the window through which it was photographed. SPAS-01 was developed by the West German firm MesserschmittBoelkow-Blohm GmbH (MBB). sible under normal procurement contracts. To accomplish this goal, NASA established the Joint Endeavor Agreement (JEA) and the Technical Exchange Agreement (TEA). These are contractual agreements between NASA and industrial partners to cooperate on the definition, development and, in some circumstances, flight-testing of MPS experiments and hardware. Under these arrangements, no funds are transferred between NASA and the private sector participants. The type of relationship chosen by the private sector participants marks the degree of the signatories' commitment: ${ }^{6}$

- Technical Exchange Agreement (TEA): The TEA is for companies that are interested in the application of microgravity technology, but are not ready to commit to a specific space flight experiment. Under such an agreement, a company may conduct exper-

$$
\text { 6lbid. }
$$

iments in NASA grou rid-based faci lities including drop tubes, drop towers, and aircraft in order to determine whether a more elaborate space experiment is justified. Using the TEA, John Deere and Dupont have processed samples in the Marshall Space Flight Center drop tube and KC-1 35 aircraft. Joint studies of convection in electrodeposition have been carried out by INCO, and studies of the growth and purification of mercury cadmium telluride are in progress with Honeywell's Electro-optical Division. In addition, there are some 20 new research activities that are the functional equivalent of formal TEA-sanctioned projects. Research topics range from pharmaceuticals, to optical fibers, to exotic chemistry.

- Joint Endeavor Agreement (JEA): The JEA is an arrangement whereby NASA and a pri- 
vate sector partner share the costs and risks of developing commercial space ventures. The JEA generally requires a larger financial commitment on the part of the industrial participant than does the TEA. Under a JEA, NASA's partner is expected to develop the experimental apparatus and to provide NASA with limited access to such equipment; NASA, in turn, agrees to provide access to terrestrial facilities and a specified number of space flights. In some cases, data from JEA experiments may be held as proprietary information by the firm. At the end of the JEA, should the venture become commercially viable, the company would have to pay the normal Shuttle price for all future flights. JEAs are now in effect with McDonnell Douglas, Microgravity Research Associates, Fairchild industries, Spaceco, Ltd., 3M Corp., and Martin Marietta. ${ }^{7}$ NASA is currently giving serious consideration to a number of other JEA proposals.

Although only a small portion of NASA's annual MPS budget has been devoted to commercial activities, these activities have been widely publicized by NASA and the popular press. ${ }^{8}$ This publicity has led to disagreements within NASA and the scientific community about the wisdom of emphasizing the yet-unproved commercial value of MPS technology. The potential for development of highly profitable space industries lends support to NASA's desires for stable or increasing science budgets and a space station. On the other hand, NASA recognized that a premature emphasis on yet-unproven technology could damage its reputation in the scientific and manufacturing community and jeopardize future funding for science projects.

\footnotetext{
The Fairchild Industries JEA involves the building and flight-testing of a free-flying platform called "Leasecraft." Although Leasecraft could be used for MPS research or production, it is not limited to this application and may be used as a "common bus" for other payloads.

\&Until recently, only about 3 percent of the NASA MPS budget was devoted to purely commercial activities. This figure is likely to increase substantially as the Office of Commercial Programs increases its scope of operations.
}

The Private Sector

Although there have been some recent indications of increased interest, the initial private sector response to NASA's commercial MPS program was quite reserved. There are several reasons for its reservations: ${ }^{9}$

\section{Absence of Proven Products or Processes}

The commercial value of low-gravity manufacturing remains largely an interesting conjecture; in the absence of conclusive experimental results or existing products, the risks involved are simply too high for most private firms. At least for the near future, the responsibility for proving the technical and economic feasibility of new space technologies will rest on the Government, acting alone or in joint ventures with the private sector.

\section{Few Attractive Investments}

Although a number of MPS products, processes, and services are currently being discussed, few of these are attractive investments. Generally, investments in MPS research involve high costs, considerable risks and long or uncertain lead times before a return on the investment could be realized.

NASA had hoped that the JEA and TEA programs would encourage a wide range of commercial space activities, but only six JEAs have been signed since the programs began in 1980. The first of these was signed in January 1980 with McDonnell Douglas Astronautics Co. (MDAC). Its purpose was to investigate the commercial viability of conducting electrophoretic separations in space; MDAC hoped that new and valuable pharmaceuticals might be developed.

The next JEA, signed in January 1982 with GTI, a California-based electronics firm, was directed towards development of a multiuse metallurgical furnace. This JEA was discontinued in January 1983 because of GTI's inability to market their

\footnotetext{
'U.S. Congress, Office of Technology Assessment, Civilian Space Policy and Applications, OTA-STI-1 77 (Washington, DC: U.S. Government Printing Office, June 1982), pp. 219-220, 224-229.
} 


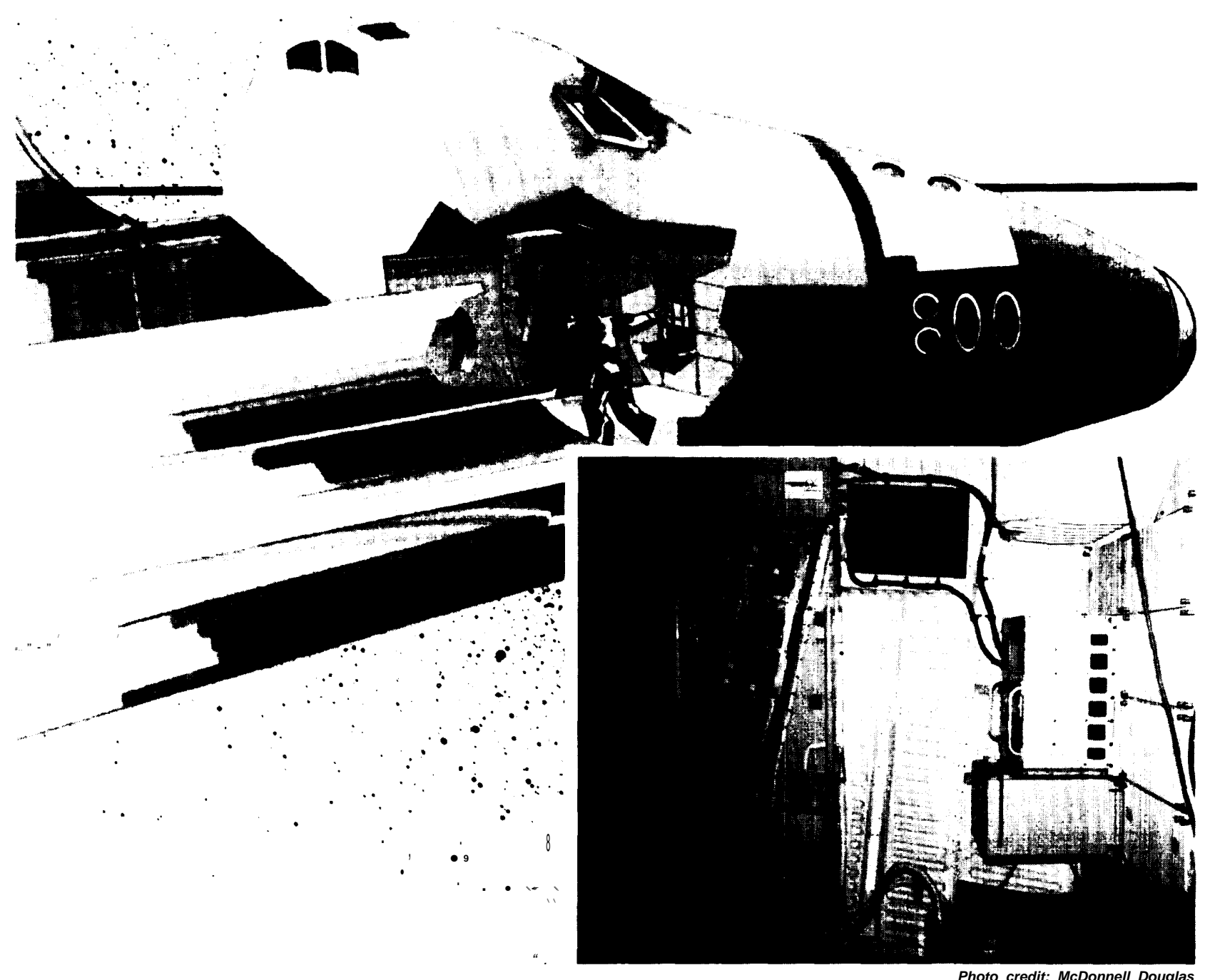

McDonnell Douglas-Ortho continuous electrophoresis device.

concept successful ly..$^{10}$ The third JEA, signed in April 1983 with Microgravity Research Associates (MRA), is directed to the study of gallium arsenide crystal growth. The fourth JEA, with Fairchild industries, has as its subject the design and flightiest of the free-flying Leasecraft, The fifth JEA, with Spaceco, Ltd., is for the development of a Shuttle payload bay environmental monitoring instrument. The next JEA, with the 3M Corp., is for the investigation of organic polymers, crystal growth, and thin film. The most recent JEA, with Martin Marietta, is directed toward research on fluid

${ }^{10}$ Letter from James La Fluer, President, GTI, to James M. Beggs, NASA Administrator, Dec. 23, 1982. dynamics associated in capillary propellant tanks in low gravity.

The JEA program offers many attractive benefits to its participants, such as access to NASA facilities and personnel and free flights on the Shuttle. Still, the limited private sector interest in this program is a clear indication of industry's assessment of the risk involved in pursuing MPS activities.

\section{Entry Costs Are Extremely High}

Access to orbit is very expensive and will continue to be expensive even in the Shuttle era, particularly if compared with the costs of demonstrat- 
ing the commercial viability of most Earth-based innovations. A Delta-class MPS payload including integration expenses may involve flight costs in excess of $\$ 15$ million. This additional expenditure, incurred well before commercial feasibility has been established, is a departure from normal product development on Earth. The recurring costs associated with payload integration and space flight, added to the costs of starting materials, flight hardware (potentially tens of millions of dollars) and personnel, suggests that a commercial space venture would have to be assured of very high revenues before it became an attractive investment.

Although the JEA reduces startup costs by offering a limited number of free space flights (MDAC is promised 8, MRA is promised 7) a commercial venture must be able to pay its own costs after the JEA is terminated. Therefore, the cost of gaining access to the Shuttle or a space station will have a significant impact on the level of private industrial participation in MPS activities.

\section{Fear of Terrestrial Competition}

Some potential investors believe that whatever can be done in space will eventually be achievable more cheaply on Earth. Though the microgravity environment of space cannot be duplicated, new technologies have been developed which do minimize the effects of gravity on Earth. In 1980, a U.S. firm, working with NASA, developed a container-less processing system for making special glass products. ' I In this system, glass is suspended within a chamber by sound beams in a process called acoustic levitation. Similarly, new gel electrophoresis and recombinant DNA techniques may one day be able to accomplish more cheaply on Earth what McDonnell Douglas is trying to accomplish with continuous-flow electrophoresis in space.

\section{Private Sector Does Not Control} Means of Access to Space

Access to launches, launch assurances, availability of support facilities, and the cost of space transportation may all be influenced by nonbusiness considerations such as changes in an admin-

\footnotetext{
I'/ndustry Week, Mar. 3, 1980, P. 90
}

istration's space policy, national security constraints, or fluctuations in congressional and public support. If necessary space facilities are not available when needed, the resulting costly delays could be fatal to a new commercial program.

\section{Markets for Some Space \\ Products Are Underdeveloped}

Unlike innovations that emerge in response to existing or clearly possible market opportunities, some space-based products or processes may have to create new markets. The absence of a welldefined market makes it difficult to project potential sales or return on investment; this makes it difficult to attract the financial backing necessary for such endeavors.

The difficulties encountered by GTI in its attempts to market a metallurgical furnace for research purposes make this problem especially clear. At the conclusion of a 9-month marketing effort GTI had no firm offer to fly a metallurgical sample in its furnace. Some observers have remarked that GTI erred in making a commitment to a furnace that was not versatile enough to capture the entire market in experimental solidification. Others have suggested that 9 months was too short a time in which to expect to build a market, that their price was too high $(\$ 15,000$ to $\$ 20,000$ per sample) and that their expectation of a 3-year return on investment was unrealistic. All of these criticisms reflect the difficulty of a firm's trying to define a market while already involved in the complex tasks of technology development and the management of a space-based business venture.

It would appear that the strength of the MDAC and MRA Joint Endeavor Agreements stem at least partially from the fact that the products being developed-new drugs and semiconductor materials-are intended for the large, well-defined, and dynamic pharmaceuticals and electronics markets.

Lack of Understanding of the Space Environment

Many industries that may eventually benefit from future space research are simply unaware of what microgravity has to offer them. Scientists and engineers have not been educated in the use 
of the microgravity environment and therefore may not investigate how the absence of gravity could aid their work. For their part, managers tend to focus on development time, risk, and potential returns on investment. As discussed above, space innovation does not seem attractive from this perspective. Although formal, quantitative project selection techniques can be used to project such factors as rates of return and pay-out periods, in the final analysis the decision to invest in new technology is a strategic choice that depends primarily on a corporate manager's business and technical judgments. The business community's lack of understanding about MPS makes it difficult for potential commercial space activities to compete with other, more traditional, investment opportunities.

\section{The Scientific Community}

NASA relies heavily on the scientific community, both industrial and university, to generate ideas for experiments and to provide direction and review for ongoing activities. NASA accepts unsolicited proposals from the scientific community for studies, theoretical and experimental research, or minor developments. Space flight experiments must be proposed in response to specific "Announcements of Opportunity" or "Dear Colleague" letters. NASA also sponsors science working groups to coordinate the interaction between NASA-funded investigators, scientists, engineers from universities, industry, and government labs and flight hardware contractors and NASA personnel.

NASA's initial enthusiasm for MPS research and its emphasis on the commercial potential of inspace processing found little immediate support in the scientific community. In 1978, NASA requested the Space Applications Board (SAB) of the National Research Council to review the MPS program. To accomplish this task, the National Research Council formed the Committee on Scientific and Technological Aspects of Materials Processing in Space (STAMPS). The STAMPS report concluded: ${ }^{2}$

The early NASA program for processing materials in space has suffered from some poorly

\footnotetext{
${ }^{12}$ Materia/s Processing in Space, op. cit., p. 5.
}

conceived and designed experiments, often done in crude apparatus, from which weak conclusions were drawn and, in some cases, overpublicized. Nevertheless, there is opportunity for meaningful science and technology developed from experiments in space provided that problems proposed for investigation in space have from the outset a sound base in terrestrial science or technology and that the proposed experiments address scientific or technical problems and are not motivated primarily to take advantage of flight opportunities or capabilities of space facilities (emphasis in original).

Since publication of the STAMPS report, NASA has worked to implement the report's recommendations. NASA requested the Universities Space Research Association (USRA) to assist in the organization and coordination of basic science working groups and to involve a larger segment of the scientific community in MPS research, ' ${ }^{3}$ Since then, the USRA has sponsored science working groups, seminars, and workshops in the areas of bioprocessing, combustion sciences, containerless processing, fluids and transport phenomena, and solidification processes. Under NASA's direction, USRA has also established contacts with U.S. industry and various professional associations that share similar basic science interests.

The USRA working groups have also attempted to coordinate their activities with scientists from ESA and other nations interested in MPS. In 1983, USRA entered into an agreement with NASA and ESA to act as a liaison between the MPS science working groups of the two space agencies .14 USRA has encouraged joint ventures between ESA and NASA principal investigators, and the sharing of experimental facilities.

\footnotetext{
${ }^{13}$ USRA is a private nonprofit corporation that was organized in 1969 by the National Academy of Sciences and is presently composed of 54 universities. It is chartered to provide a means through which universities and other research organizations may cooperate with one another, with the Government of the United States, and with other organizations toward the development of knowledge associated with space science and technology. USRA is further chartered to acquire, plan, construct, and operate laboratories and other facilities for research, development, and education associated with space science and technology.

${ }^{14} \mathrm{H}$ earıngson Materials Processing in Space, Before the Subcommittee on Space Science and Applications of the House Committee on Science and Technology, 98th Cong.,1st sess., Statement of Dr. Guy Rindone, Universities Space Research Association, Sept. 14, 1983.
} 


\section{FOREIGN MPS ACTIVITIES}

\section{European Space Agency (ESA)}

European interest in microgravity research began primarily as an outgrowth of ESA's commitment to Spacelab. Spacelab is ESA's largest cooperative project with NASA, involving European expenditures over the last 10 years of approximately $\$ 1$ billion. ESA was responsible for designing and building Spacelab, and in December 1981, delivered to NASA, free of charge, the first flight unit. The first Spacelab mission flew in November 1983 and involved a joint EuropeanAmerican crew conducting a variety of test projects. Although West Germany has been the main financial contributor, providing over 50 percent of the budget, all ESA member states (except the Republic of Ireland and Sweden), and one of its associate member states (Austria) have participated in the Spacelab development program. The West German firm MBB/ERNO is the prime contractor for Spacelab; it was assisted in its development activities by some 40 other European companies. At the height of the development phase, an industrial work force of about 2,000 was employed on the program .15

Spacelab will provide opportunities to conduct space-based experimentation in both the physical and biological sciences. It consists of a pressurized module capable of being carried in the payload bay of the Space Shuttle and allowing experimenters to work at a variety of projects in a shirtsleeve environment. Additional pallets are also available which can be placed in the Shuttle bay to allow equipment to be exposed directly to the vacuum and radiation of space.

In early 1982, eight ESA member states agreed to undertake a Spacelab Follow-on Program .16 The most important element of this program is the development of a European Retrievable Carrier (EURECA), to be launched and retrieved by the Space Shuttle. Funding for this program also covers the flight costs and development of the core payload for the first mission, which will con-

\footnotetext{
${ }^{15}$ European Space Agency, Europe Into Space, Paris, January 1983, p. 36.

${ }^{16}$ They were:Belgium, Denmark, Federal Republic Of Germany, Italy, Spain, Switzerland, and the United Kingdom.
}

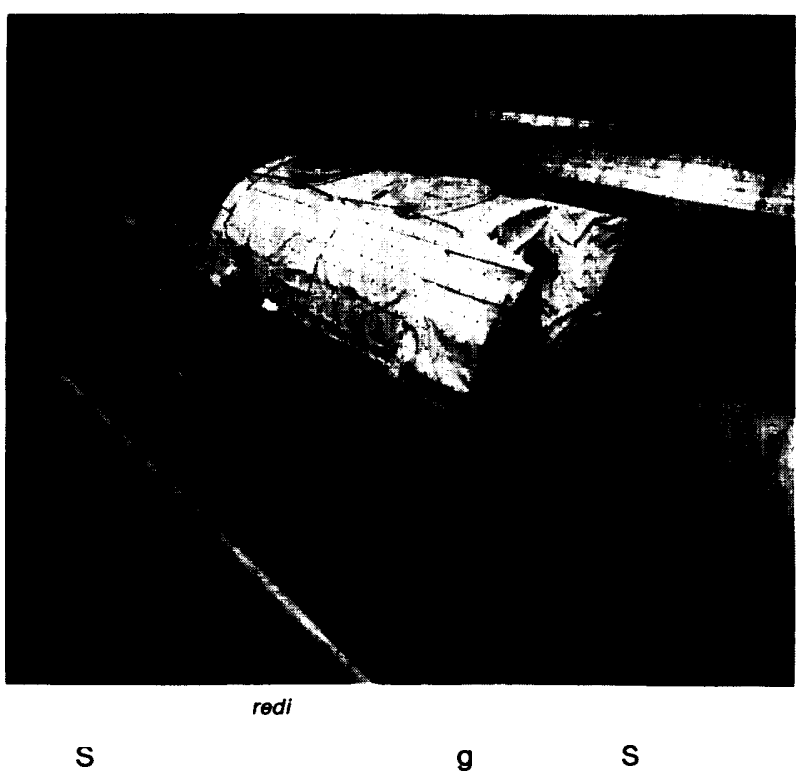

centrate on microgravity research. The first flight is scheduled for launch in April 1987 and retrieval in September 1987.

EURECA is a reusable payload carrier designed to carry a payload mass of up to $1,200 \mathrm{~kg}$ and to remain in orbit for 6 months. After deployment into space from the Shuttle, an on board propulsion unit will place the carrier into a higher orbit where the drag on its large solar arrays will be low. Once in its operational orbit, the payload will be switched on and operated by remote control. Although the experiments will be highly automated, they will nevertheless be monitored from the ground. By the end of its mission EURECA's orbit will have degenerated to the point where it can be recovered by the Shuttle. The spacecraft will then be brought back down to Earth, along with its payload equipment and processed material samples, for refurbishment for its next mission.

In addition to the Spacelab program, ESA, in January 1982, established its Microgravity Program to encourage basic MPS research (fig. 8-4). The experiments proposed to date can be divided into two main areas: life sciences, in which researchers can study the effects of reduced gravity on living organisms, including man; and ma- 


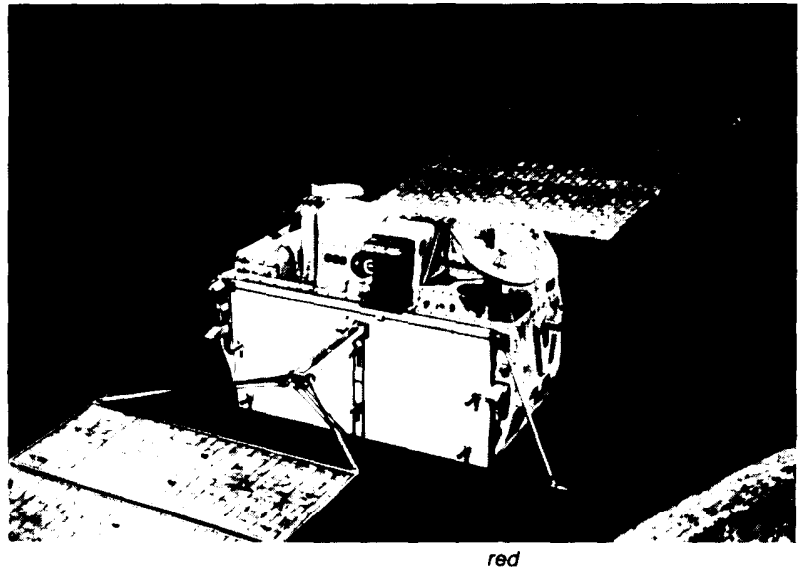

E RE ES

F gu e 84 ESA Budge $\circ$ M og a y Resea ch Program $^{a}$

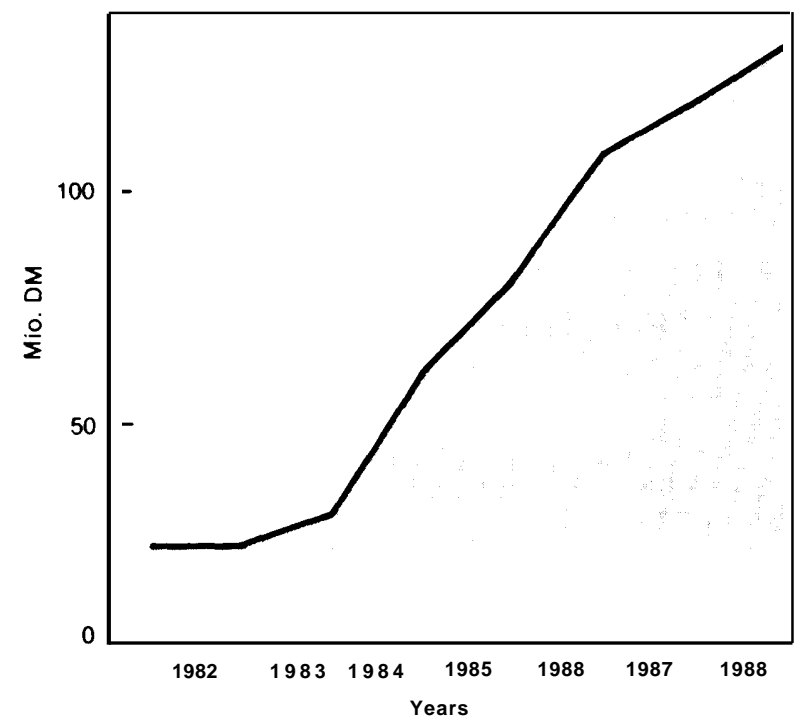

a June $1982 \cdot 2.460 \mathrm{DM}$ S1;U.N. Monthly Bulletin of Statistics, August 1982. SOURCE: MBB/ERNO

terial sciences, in which the behavior of fluids, crystals, glasses, and metallurgical systems can be studied. In order to meet these objectives, ESA has concentrated on four main program elements:

1. Sounding Rockets: ESA participates in TEXUS, the West German and Swedish sounding rocket program. It had a share of the payload on two flights each year since 1982, with further flights planned for the forthcoming years. Future ESA experiments on TEXUS will concentrate on the fields of metallurgy and fluid physics. ${ }^{17}$

2. Biorack: The Biorack is a multiuser experimental facility for investigating cell and molecular biology, botany, and radiobiology in the weightless environment of the Spacelab module. The Biorack consists of a "glovebox" for handling experiments, a cooler/ freezer unit to protect specimens prior to launch and after landing, incubators, and a centrifuge to simulate gravity for reference purposes. ${ }^{18}$ The firms MATRA, BTM, and Dornier have responsibility for developing the thermal conditioning units; Fokker is building the "glovebox;" and MBB/ERNO, with several subcontractors, is building the single rack equipment. ${ }^{19}$ The Biorack will be flown on the West German D-1 Spacelab mission in 1985.

3. Fluid Physics Module: Also designed to be flown in the Spacelab module is the Fluid Physics Module, which will be used to study materials in suspended liquid form (floating zones) in the microgravity environment. A fluid physics module was flown on Spacelab1 and an improved version is planned for the D-1 Spacelab flight in 1985.

4. Materials Sciences Double Rack: This microgravity research facility was developed by West Germany and flown on the first Spacelab mission. West Germany has since turned over responsibility for the Double Rack to $E S A$; it is scheduled to be reflown on the West German D-1 Spacelab mission.

Although classified as a Spacelab follow-on program, the first EURECA payload will be almost entirely devoted to material and life sciences and therefore will contribute considerably to ESA'S Microgravity Program.

\section{Federal Republic of Germany}

West Germany has an aggressive national MPS program and also conducts research with ESA or bilaterally with other countries. The Ministry for Research and Technology (BMFT) coordinates

1'ESA Annual Report, 1982, P. 54.

${ }^{8}$ ! bid., p. 52.

'g lbid. 


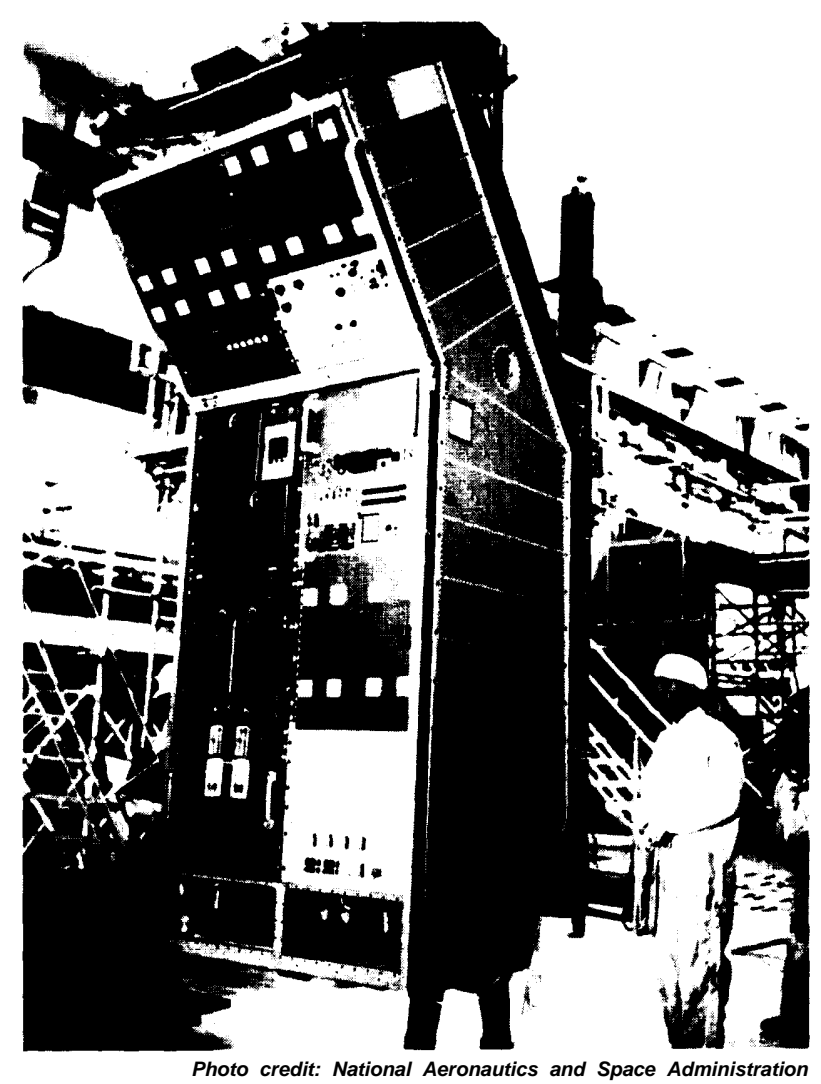

Europeandeveloped life sciences mini lab for Spacelab.

and funds most West German R\&D efforts. Projects are managed by the German Aerospace Research Establishment (DFVLR), which directs government engineering and test centers, and by the German Research Association (DFG), a self-governing organization that allocates funds from various public and private sources to universities and scientific societies. ${ }^{20}$ West Germany's major aerospace firms also play a key role in initiating and funding research projects.

Germany has placed a strong emphasis on materials science and life science experiments in its space program. Since the West German firm $\mathrm{MBB} / \mathrm{ERNO}$ is the prime contractor for Spacelab, and West Germany is the major financial contributor (54.9 percent), German interest in Spacelab exploitation has been high. In addition,

\footnotetext{
20, Review of National and Cooperative Space Activities for the Calendar Year 1980," UNCOPUOS, A/AC.105/286/Add.1., Feb. 19, 1981, pp. 34-35.
}

chemicals and materials processing have traditionally been areas of German technical and industrial leadership.

The Ministry for Research and Technology provided approximately $\$ 50$ million for MPS work from 1978 to 1981 and is authorized to spend about $\$ 100$ million more between 1982 and 1985 (fig. 8-5). These figures represent the total West German federal commitment to MPS research. They do not include the contributions of private research programs, other related space activities, or terrestrial materials research. Over the past several years, the West German Government has endeavored to shift a part of the practical research burden to other sources, principally commercial and industrial organizations, and to use available government funds to sustain basic research programs.

The German MPS program is intended to meet the as-yet largely undefined needs of the user community by conducting a wide variety of basic research projects. The ultimate goal of government support is substantial involvement of West German industry in such areas as chemistry, process technology, metals, composite materials, and crystals .21

Early West German MPS experiments were carried on the 1975 Apollo-Soyuz manned mission.

21 "Commercialization of Materials Processing and Manufacturing in Space, "TRW, Defense and Space Systems Group, Apr. 14, 1981, p. 26.

Figure 8-5.-Budget for Microgravity Research Program'

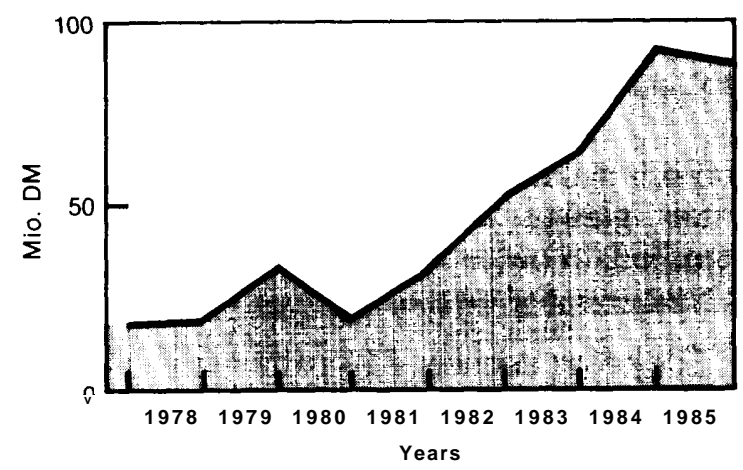

'June 1982- 2.460DM = 1\$; UN. Monthly Bulletin of Statistics, August 1982. SOURCE: MBB/ERNO. 
Several methods are now used: suborbital sounding rockets, small self-contained payload packages (so-called "getaway specials") attached to the space Shuttle, and full-scale Spacelab missions. The Germans are examining future flight opportunities using free-flying automatic experimental units for longer periods of time than can be attained with the present Shuttle/Spacelab system. Primary elements of the West German MPS Program are: ${ }^{22}$

- TEXUS (technological experiments u rider microgravity): Certain experiments are being flight-tested using British-built Skylark sounding rockets. Since 1977, TEXUS launches have flown over 100 MPS experiments. The program presently calls for two TEXUS launches per year. A number of experimental facilities are already available to users, and more will be added as demand increases. The TEXUS program began as a cooperative project with Sweden, using the Kiruna range as a launch site; since 1982, ESA has also participated in TEXUS. West German experiments have also flown on U.S. SPAR sounding rockets.

- MAUS (autonomous materials science experiments in microgravity): The MAUS program employs standardized containers similar to those NASA makes available to its "GetAway-Special" (GAS) customers and instruments derived from the TEXUS program to conduct small MPS experiments on the Shuttle. The BMFT has paid for 25 GAS flights; one was used on STS-5 and the rest will be used at a rate of 2 to 4 a year over the coming years. The BMFT has also purchased six GAS canisters which they modified for use on other carriers. On STS-7, three MAUS experiments in GAS canisters were attached to the OSTA-2 structure, and two experiments mounted on the SPAS structure. Two further MAUS experiments were flown on SPAS during the SPAS reflight mission, STS-11. The West German companies MBB/ERNO, KaiserThrede, and Dornier have reserved GAS flight opportunities. In addition, the West

\footnotetext{
${ }^{22}$ Gottfried Greger, "The German Material Processing in Space Activities, " paper presented at The Twentieth Goddard Memorial Symposium, NASA Goddard Space Flight Center, Mar. 17-18, 1982.
}

German Oberth Society, which promotes space research, has reserved a flight.

- Spacelab: West Germany is supporting major experiments on Spacelab and was responsible for the development of the Materials Science Double Rack (MSDR), a materials processing laboratory. A West German-sponsored Spacelab mission, D-1, is scheduled for 1985 . The D-1 will carry experiments for the West German Space Program, ESA, France, Italy, and NASA. Informations from all the D-1 experiments, except NAVEX, a proprietary communication and navigation experiment, will be freely disseminated. Planning has already begun for a D2 mission which will be devoted primarily to microgravity research.

- SPAS (Shuttle pallet satellite): SPAS is a carrier which may be operated either in the Shuttle bay or in a free-flying mode. SPAS was developed by MBB/ERNO as a com-

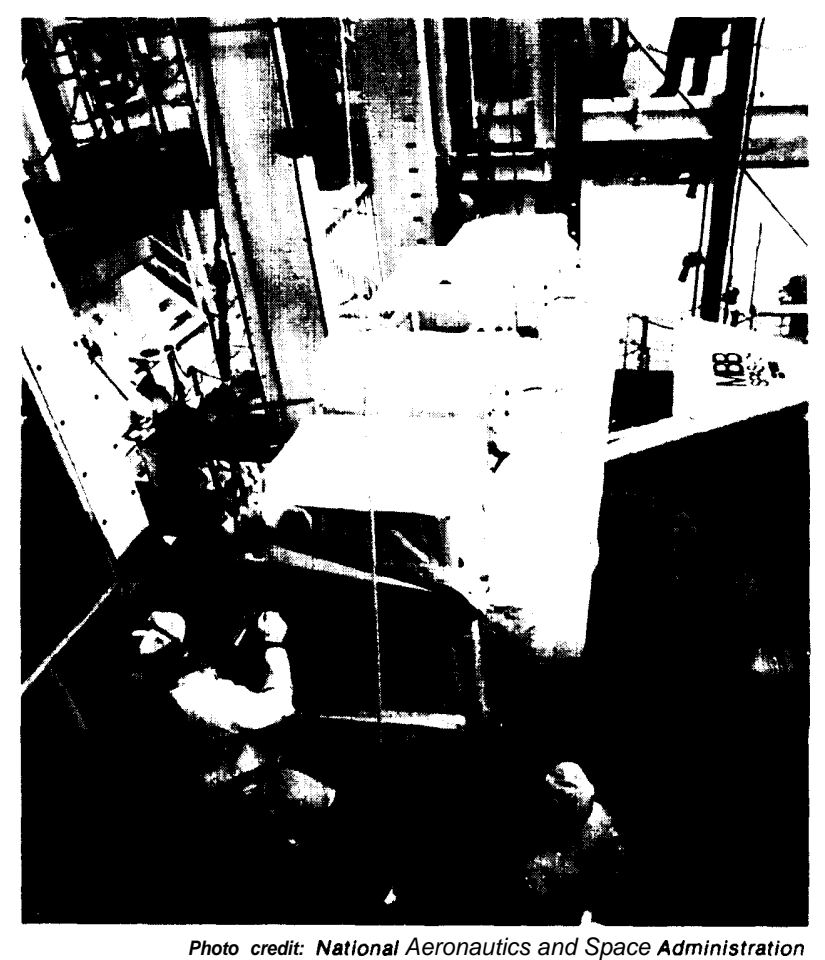

View of SPAS (Shuttle Pallet Satellite) prior to flight on STS-7. The payload consists of a beam like structure which fits across the cargo bay and contains both self. contained power and attitude control systems which allow it to be deployed and retrieved by the orbiter's remote manipulator arm. 
pany-funded venture with financial assistance from the BMFT. It is the first of a new generation of free-flyers designed to take advantage of the present and future needs for long-duration facilities in space. SPAS is able to supply limited power, cooling, and utilities to a payload. It currently has no propulsion system but has a modest stationkeeping capability. The first SPAS was launched on STS-7 to test the deployment ability of the Shuttle remote manipulator. SPAS was reflown but not deployed on STS11 in February 1984.

- EURECA (European retrievable carrier): Although it is an ESA project, the prime contractor for the EURECA is MBB/ERNO and West Germany will supply the major share of the funding. EURECA is based on the SPAS structural concept but will have greater payload capacity, power, cooling, and a propulsion system.

\section{France}

French MPS activities are modest in scope, with a budget of approximately $\$ 1$ million to $\$ 2$ miliion per year. Bilateral materiais processing experiments have been conducted with West Germany and the U.S.S.R. A France-Soviet crystal growth and solidification experiment was carried out aboard the Soviet manned laboratory, Salyut6 , several more experiments were conducted on Salyut-7 and future cooperative MPS research is anticipated. French experiments on crystal growth and the dynamics of metal alloy solidification were conducted on Spacelab-1. in addition, the French Atomic Energy Commission (CENG) and NASA are planning a cooperative project called MEPHISTO (Materiel pour l'Etude des PhEnomenes Interessant de la Solidification sur Terre et en Orbite). ${ }^{23}$ Through this project the CENG is developing a metallurgical furnace to be used in the NASA MPS program. CNES has also requested to fly, on a reimbursable basis, a crystal growth experiment on Spacelab-3.

\footnotetext{
${ }^{23}$ J. J. Favier, Y. Malmejac, et al., "MEPHISTO: Research Equipment for the Study of Solid/Liquid Interface Destabilization in Metal Alloys, "33d Congress of the International Astronautical Federation, Sept. 27-Oct. 2, 1982, Paris, France.
}

In general, the French effort is smaller and more research-oriented than the West German. CNES has studied since 1978 an ambitious program called "Solaris," an unmanned orbital space station which would be able to conduct MPS experiments, perhaps on a commercial basis (fig. 8-6). Solaris could be orbited by an Ariane-4 launcher, offer about 1s kilowatts of power and in-orbit data processing, and operate for up to 15 years. There has been no significant movement to pursue the Solaris concept. This seems to be the result of the French preoccupation with Ariane development, the belief that MPS does not offer near-term commercial opportunities, and a recent change in French policy that acknowledges the usefulness of man in space for some types of experimentation. Recent French interest in the Hermes (see ch. 5) manned, reusable space plane, would seem to confirm this trend. The Hermes would likely be useful for MPS research and for launching and recovering freeflying platforms.

It is conceivable that Hermes or Solaris might be accepted as a major project for ESA during the 1990s, thereby spreading the cost and stimulating MPS research activities in a number of member countries not presently pursuing such investigation. These projects not only create increased demand for Ariane launchers, but offer European alternatives to participation in a U. S.developed space station.

\section{Japan}

Japanese MPS activities began in 1973 with an experiment flown on Skylab. Further research is being conducted on the Space Shuttle, Spacelab and the TT-500-A, a Japanese suborbital rocket. The TT-500-A first flew in September 1980; since that time, five additional flights have been accomplished. The Japanese have also reserved one-half of a Spacelab flight in 1988 (the First Materials Processing Test, or FMPT). Project selection and hardware development for this flight are currently under way; at present, ${ }^{45}$ materials processing experiments and 17 life science experiments are plan ned. ${ }^{24}$

\footnotetext{
${ }^{24}$ A.Sawaoka, "JapaneseEfforts Towards Materials Processing in Space," Manufacturing in Space, L. Kops (cd.), The Winter Annual Meeting of the American Society of Mechanical Engineers, Boston, MA, Nov. 13-18, 1983, PED-Vol 11, p. 40.
} 
Figure 8-6.-Sketch of the Proposed Solaris Orbital Station With (top centre) One Payload Recovery Capsule Being Ejected for Reentry

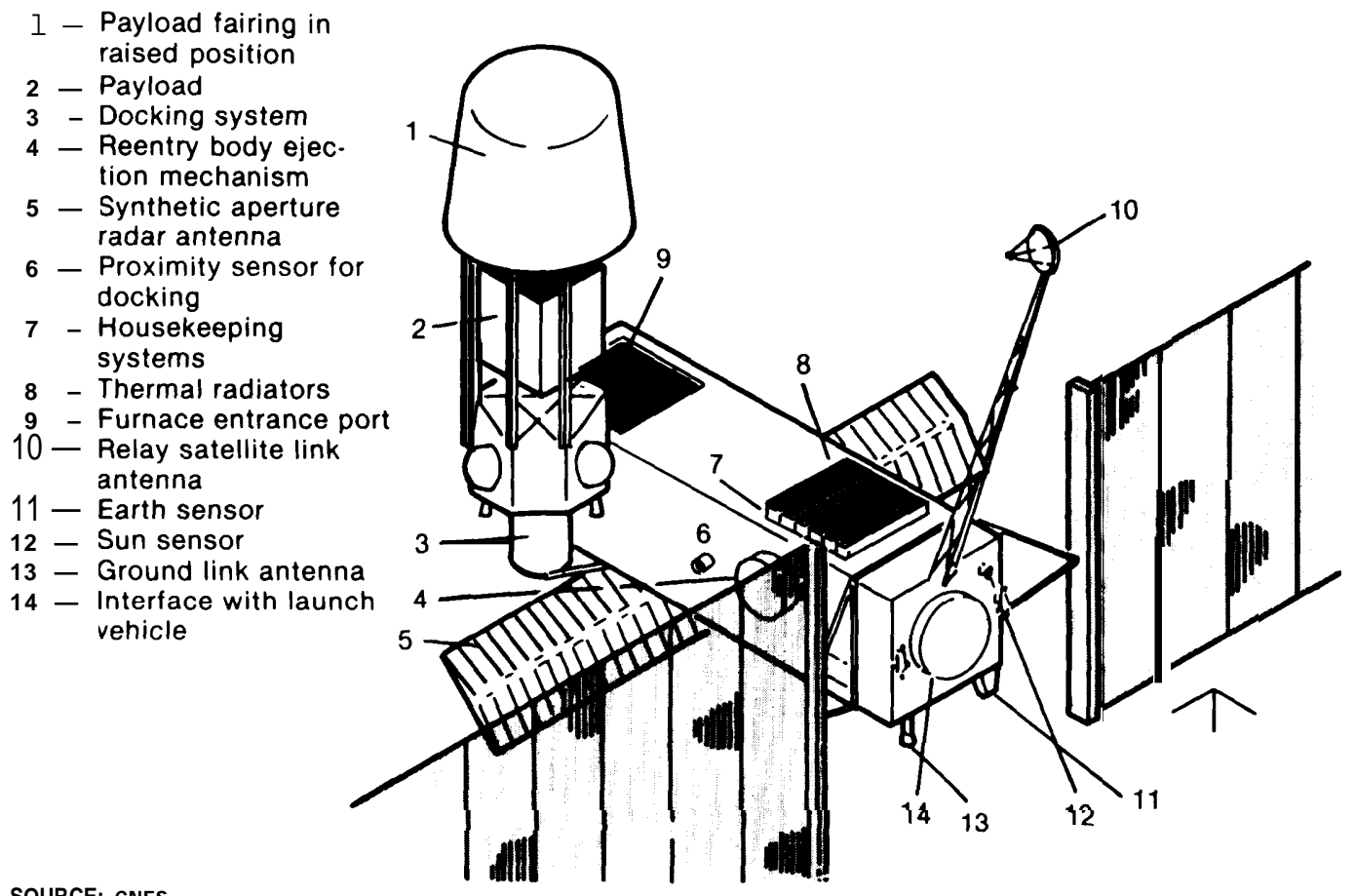

SOURCE: CNES

In 1982, Japan's Council for Science and Technology advised the Prime Minister that MPS was one of the scientific fields meriting urgent research attention .25 The Science and Technology Agency (STA) was then given responsibility for organizing a 5-year research program. The first 2 years are to be spent conducting basic and theoretical research; the third and fourth years are reserved for terrestrial experimentation to result in the development of the flight hardware for the FMPT, which would occur in the fifth year. Although the STA has primary responsibility for the Japanese MPS program, a committee has been established to coordinate STA activities with those of other government agencies (e.g., NASDA), universities, and the private sector.

The Japanese have no current plans to build a separate platform, such as Solaris, or a freeflying carrier, such as SPAS or EURECA. However, Japan has expressed a willingness to cooperate

${ }^{25} 1$ bid., p. 41 with NASA on the development of a space station.

\section{Soviet Union}

MPS experiments have had a high priority on recent Soviet space flights, especially aboard the Salyut- 6 and Salyut-7 orbiting laboratories. ${ }^{26} \mathrm{Re}-$ search has been conducted in both materials processing and the life sciences. Two furnaces, the Splav-01 and the Kristall, have been used to conduct experiments on semiconductors, crystal growth, alloys, glasses, and metal oxides. Samples have been returned to Earth for detailed analysis. Approximately 300 to 350 Soviet scientists are reported to be actively engaged in materials research related to space processing. ${ }^{27}$

26B.Belitsky, "Soviet Manned Space Flight 20 Years On, "Space flight, vol. 23, No. 5, May 1981, pp. 154-155.

27"U.S. Must Spend More to Maintain Lead in Space Technology, " GAO-FGMSD-80-32 (Washington, DC: U.S. General Accounting Office, Jan. 31, 1980), p. 21, 
The Soviets have also conducted research into electrophoretic separation techniques in space. Reports indicate that these experiments are similar to those presently being conducted by NASA and McDonnell Douglas. ${ }^{28}$

${ }^{20}$ T. Chesanova, Space Biotechnology Experiment Furthers Work on Superpure Vaccines, Leningradskaya Pravda, May 22, 1983, No., 119, p. 4, COI. 1-3. (Abstract: Daily SNAP, June 8, 1983).

\section{MPS PRODUCTS, SERVICES, AND EQUIPMENT}

It is impossible to make accurate predictions about the future size and vitality of the markets for MPS products, services, and equipment. The potential for the development of an MPS industry in the United States and elsewhere is dependent on a variety of factors including continued government-funded basic research, availability of reliable low-cost space transportation, access to medium- or long-term MPS facilities such as freeflyers or a space station, competition from terrestrial processes, and serendipitous discovery of commercially viable MPS products.

Other countries have demonstrated considerable interest in MPS research and hardware development; this could eventually translate into competition for the U.S. private sector. The U.S. commitment to development of an MPS science community, the existence of the Shuttle, and NASA's encouragement of commercial space activities give the United States important advantages. These advantages will diminish over the next several decades as access to space becomes more routine and the understanding of the advantages and limitations of microgravity technology become more widely known.

\section{Potential MPS Products}

Basic MPS research in the United States and elsewhere has, to date, produced only one marketable product. ${ }^{29}$ As knowledge of the microgravity environment increases, it is possible that major unforeseen scientific advances as important as penicillin or microcircuits may result. Such advances could conceivably revolutionize existing terrestrial markets and create entirely new markets. Just as it was difficult to assess the im-

\footnotetext{
${ }^{29}$ The product is monodisperse latex spheres. It was manufac tured by Particle Technologies in a Getaway Special Canister. The spheres are used in various medical calibration techniques.
}

portance of the first computer or airplane to the economy of the United States, it is difficult to estimate the future role for MPS products. On the other hand, not all new technologies can be successfully commercialized. Nuclear power and supersonic transportation are examples of technologies which offered great promise but have had limited commercial success.

The most likely candidates for commercialization now appear to be certain pharmaceutical products and crystals for use in the electronics industry.

\section{Pharmaceuticals}

The separation of biological materials using techniques such as electrophoresis can be significantly enhanced in the near-zero gravity environment of space. Electrophoresis is the movement of particles in solution when they are placed under the influence of an electric field (fig. 8-7); because particles have different charges and sizes, they will move at different speeds away from one electrode towards another with an opposite charge. This natural movement allows the segregation and isolation of different components of a mixture.$^{30}$ On Earth, gravity reduces both the usable concentration and quantity of the material being separated. Tests performed on STS-4 (June 1983) as part of the MDAC/NASA Joint Endeavor Agreement demonstrated 125 times greater concentrations and 463 times greater quantities than could be obtained from equivalent ground-based units. ${ }^{31}$

\footnotetext{
${ }^{30}$ See generally, D. W. Richman, "EOS-Electrophoresis Operations in Space-A Promising New Era of Business in Space," Manufacturing in Space, L. Kops (cd.), The Winter Annual Meeting of the American Society of Mechanical Engineers, Boston, MA, Nov. 13-18, 1983.

${ }^{3}$ Ibid., p. 141.
} 
Figure 8-7.-Continuous Flow Electrophoresis

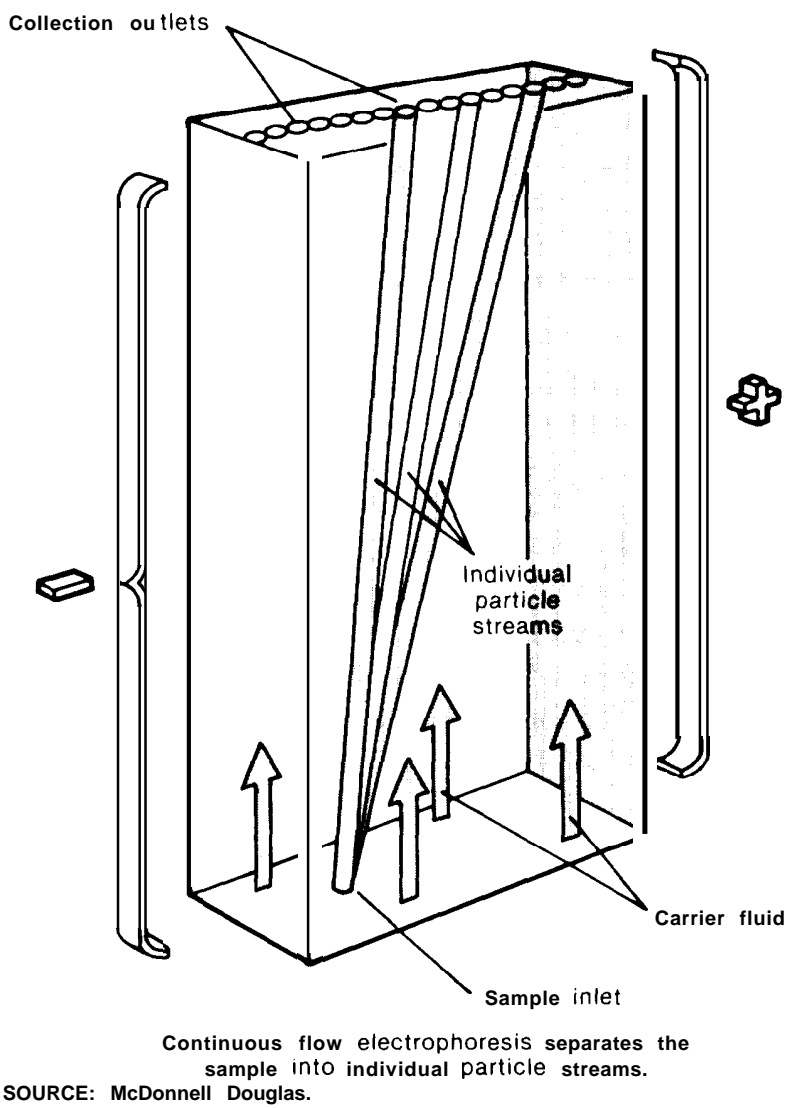

Before signing its JEA with NASA, MDAC-in conjunction with its industrial partner-Ortho Pharmaceuticals-conducted a market analysis to determine potential commercial applications for electrophoresis. This analysis led to the identification of 12 pharmaceutical products that might profitably be produced in space. MDAC estimated the annual domestic market for these products to be in excess of $\$ 7$ billion (fig. 8-8). ${ }^{32}$ According to MDAC, these are conservative estimates based on the capture of 25 percent of the projected annual domestic market of each product.

\section{Crystals}

Semiconductor device technology requires reasonably priced, single-crystal wafers that meet

\footnotetext{
32," Space Station Needs, Attributes, and Architectural Options, " McDonnell Douglas Astronautics Co., Huntington Beach, CA, NASA contract NASW-3687, Task 1, April 1983, pp. 36-39.
}

Figure 8-8.-Annual Market Potential for Electrophoresis

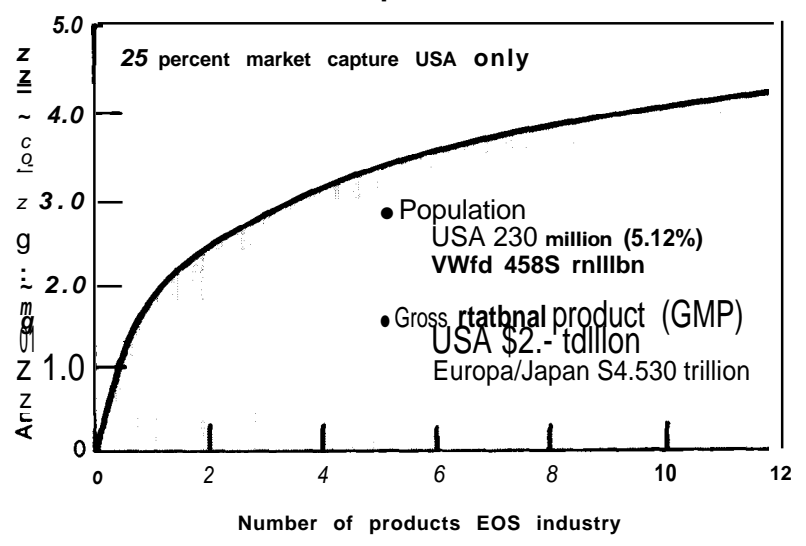

SOURCE: McDonnell Douglas.

specifications for crystalline and chemical perfection. ${ }^{33}$ Although silicon remains the material of primary interest to the electronics industry, attention has also been directed towards starting materials such as gallium-arsenide (GaAs) and mercury-cadmium-telluride ( $\mathrm{HgCdTe})$. Today, the chemical and crystalline imperfections of these materials make them only marginally suitable for device fabrication. It is possible that significant improvements in the properties and yields of semiconductor materials can be achieved by producing them in space.

NASA researchers have performed a number of experiments on these materials and NASA has entered into a JEA with Microgravity Research Associates to investigate the commercial production of GaAs crystals. High-quality GaAs crystals might be used for: $:^{34}$

- very high-speed microwave circuits (1 O to $150 \mathrm{gHz}$;

- radiation-resistant, high-speed signal processing on missiles;

- high-speed signal processing with integral lasers for readout through fiber optics; and

- semiconductor radar arrays on airplanes and satellites.

${ }^{33}$ A. F. Witt, "The Impact of Space Research on Semiconductor Crystal Growth Technology," Manufacturing in Space, L. Kops (cd.), The Winter Annual Meeting of the American Society of Mechanical Engineers, Boston, MA, Nov. 13-18, 1983, p. 43.

34, Commercial Utilization of a Space Station: New Business Opportunities" (Downey, CA: Rockwell International, SSD 83-0046, March 1983), pp. V-2-V-16. 
The primary initial purchasers of space-produced GaAs crystals would be the military; it is possible, though not certain, that the civilian electronics industry would also be a major purchaser of GaAs crystals. Figure 8-9 illustrates the potential future demand for space-produced GaAs crystals; because of the complex and rapidly changing nature of the electronics industry, and the potential for competition from terrestrially manufactured GaAs crystals, no attempt is made here to assess the accuracy of the figures presented.

\section{Potential MPS Services and Equipment}

\section{U.S. Activities}

Recent experience with NASA and private sector MPS experiments has revealed that:

- There is a weak but discernible demand for reasonably priced research facilities for inspace experiments; this demand may expand as the applications for in-space research become more widely known.

- There is a need for MPS equipment such as carriers and furnaces, both for specific applications and for basic research.

- At present, the long lead time between conceptualization and flight of an experiment and the cost of custom-fitting each experiment into the Shuttle are barriers to greater use of the Shuttle as a research tool.

These findings indicate that there may be opportunities for the private sector profitably to offer MPS services and equipment. Most of the Technical Exchange Agreements (TEAs, discussed above) between NASA and industry have been designed to gain a better understanding of terrestrial phenomena. John Deere \& Co. entered into a TEA in 1981 to study the solidification of cast iron. The purpose of this research was to gain a better understanding of how the graphite formation of cast iron influences the metal's properties.

Figure 8-9.-Demand for Space.Produced GaAs (millions of dollars)

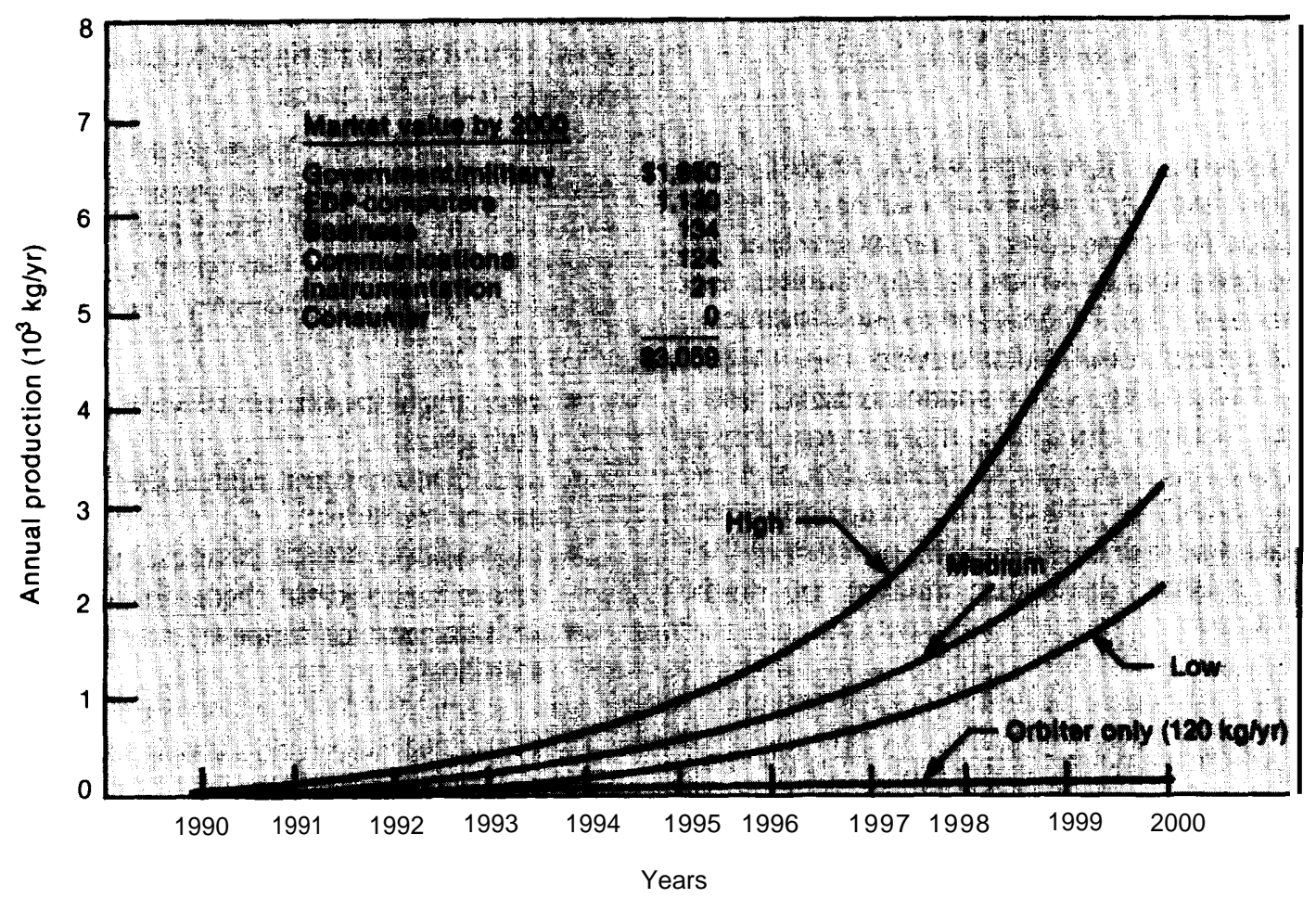

SOURCE: MCDonnell Douglas. 
INCO Research \& Development Center, Inc., signed a TEA with NASA in 1982 to investigate the basic properties of electroplating. Similarly, Dupont entered into a TEA in 1982 to explore the catalytic properties of alloys. Such activities indicate a potentially broad industrial interest in obtaining low-cost experimental data. This opens up a number of opportunities for private sector operation of service-oriented activities, such as the provision of generic test equipment, common-use buses to fly small user-specific experiments, and integration services to reduce the complexity of NASA/private sector interaction.

If one accepts this interim goal, the question then becomes how best to pursue it. One way is to focus on reducing the cost of experimental results per sample, thereby increasing both the pool of potential users and the amount of information obtained over a given period of time. This basic approach was unsuccessfully attempted in GTI's Joint Endeavor Agreement with NASA. GTI had intended to fly on the Shuttle a metallurgical research furnace designed to accommodate a large number of experimental samples. Under the terms of the JEA, the furnace was to have been flown four times at NASA's expense in order to assess its commercial viability. GTI's clients would have had the opportunity to obtain data from samples of their choice at a fraction of the cost of fielding their own instruments (discussed above).

One U.S. firm, Instrumentation Technology Associates, Inc. (ITA), has announced that it wishes to enter the MPS equipment market by selling standardized experimental modules which would fit into NASA's GAS canister. ITA plans to offer customers the option of the module structure by itself, a complete module with experiment avionics and lease of a complete module for a flight, or rental space inside a canister flown by ITA. ${ }^{35}$

Another private firm is investigating the practicality of a fee-for-service laboratory to operate in conjunction with the U.S. space station. Such a laboratory would allow customers to buy a number of days or hours of time to perform experiments. It would eliminate the need for frequent Shuttle flights and would allow a degree

\footnotetext{
${ }^{35}$ Aviation Week and Space Technology, Ju ne 25, 1984
}

of interaction between scientist and experiment that is not now possible. ${ }^{36}$

JEA proposals submitted in 1983 to NASA by Ball Aerospace and Teledyne Brown Engineering suggested another approach to MPS service development. Under each of these proposals, the private sector participant would provide a carrier to fit in the cargo bay of the Shuttle. These carriers would supply utilities such as power, cooling, and telemetry; NASA payloads and payloads of opportunity would be attached to the carrier at any of a number of common use "ports."

Each of these JEAs requested the opportunity to assume the marketing and integration functions for all future MPS experimental payloads. The integration (preparation of payload and placement into Shuttle) of MPS payloads is considered essential to each of these JEAs, since this would provide an assured source of income while building the commercial market for this service. Integration for MPS payloads is currently being conducted under contract for NASA by Teledyne Brown Engineering.

NASA's reluctance to decide between the Ball and Teledyne proposals was based in part on the applicants' request that NASA experiments be flown on commercial carriers, and in part on NASA's interest in developing what eventually became the Hitchhiker program.

NASA's JEA with Fairchild Industries is another opportunity for a private sector-provided MPS service. The Shuttle and the Shuttle/Spacelab combination have three important limitations:

1. The movements of crew members aboard the Shuttle cause micro-accelerations which can interfere with results of certain MPS experiments.

2. Shuttle flight duration is only 10 days or less, and many experiments will require longer periods of microgravity.

3. The Shuttle does not have adequate power for certain MPS applications.

\footnotetext{
36"Booz-Allen, Weinberg Report on Space-Business Prospects, " Space Business News, Jan. 2, 1984, p. 4.
} 
Fairchild plans to develop a small platform called "Leasecraft" which could provide an alternative to Shuttle/Spacelab activities (fig. 8-10). Leasecraft is a spacecraft bus designed to provide services such as power, communications, data handling, and propulsion for attitude control. The customer supplies the payload-in this case, an MPS experiment or production facility-which is then attached to the Leasecraft. The Leasecraft is then launched aboard the Shuttle and transferred to a free-flying mode for an indefinite amount of time. The Shuttle would service the Leasecraft, supplying it with new feedstock and returning processed materials to Earth. Leasecraft is not designed to be returned to Earth to be refitted with new cargo, as is the EURECA or SPAS, nor is it designed to operate in the Shuttle bay as would the carriers proposed by Ball and Teledyne.

Fairchild proposes to provide customers with a turnkey operation. It would handle all arrangements for launch, servicing, and return of processed materials from space. The customer would not own, but rather would lease this spacecraft. It is possible that McDonnell Douglas' electrophoresis operations will provide the first customer for the Leasecraft.

\section{Foreign Activities}

West German and ESA activities in the development of "carriers" and "free-flyers" allow them to offer commercial MPS services similar to those proposed by Ball, Teledyne, and Fairchild. The West German SPAS and ESA'S EURECA reflect an important European commitment to the development of space facilities that are Shuttlecompatible yet reasonably independent of U.S. budgetary and political influence.

When MBB began developing the SPAS, it hoped, like Fairchild, to offer a turnkey service to customers willing to pay a broker to provide the payload structure and Shuttle integration and to do the necessary flight negotiations with NASA. In addition to MPS payloads, MBB also expects to use the SPAS as a bus for national and European scientific, application, and communication satellites.
When NASA began to consider developing a carrier that could fly on short-notice, spaceavailable basis (a concept which has had several names and is currently known as "Hitchhiker"), MBB/ERNO informally proposed the use of SPAS. NASA's indecision regarding its own carrier needs, the JEA proposals of Teledyne and Ball, and a general reluctance to engage in quasi-commercial activities with foreign partners have prevented a positive response to this suggestion.

The MBB/ERNO "payload support system" (PASS) has already been flown eight times on West German MAUS missions. The PASS fits inside a standard NASA GAS canister and includes an experiment mounting structure, main power battery, experimental control units, housekeeping sensors, and data evaluation units. MBB/ ERNO is now marketing the standardized support system developed for the MAUS program to NASA get-away-special customers. ${ }^{37}$

The ESA project, EURECA, although smaller and less powerful than Fairchild's Leasecraft, would offer similar utilities (e.g., power, cooling, propulsion, attitude control, and telemetry). However, Fairchild will be developing only the spacecraft bus (the Leasecraft); ESA, in addition to developing the bus (EURECA) will also provide multi use MPS hardware. The first EURECA flight, planned for October 1987, will carry a payload of six experimental facilities, three of which were developed for Spacelab. ${ }^{38}$

These instruments and the majority of the initial EURECA missions are oriented toward building basic scientific knowledge of physical phenomena in microgravity. Applications experiments are now being left to various national programs working in association with private firms. ESA would like to fly the EURECA about once every 2 years, and is discussing with NASA a cooperative arrangement to provide sufficient ex-

\footnotetext{
37"MBB Sells GAS Payload Support, "Space Business News, Jan. 30, 1984, p. 8.

381) An automatic mono-ellipsoidal mirror furnace for crystal growth experiments (developed for Spacelab); 2) a solution-growth facility for diffusion-controlled crystal growth (developed for Spacelab); 3) a protein crystallization facility (developed for Spacelab); 4) a multifurnace assembly; 5) an automatic gradient-heating facility; and 6) a multiuser life-sciences facility.
} 
Figure 8-10.-Leasecraft Baseline Concept

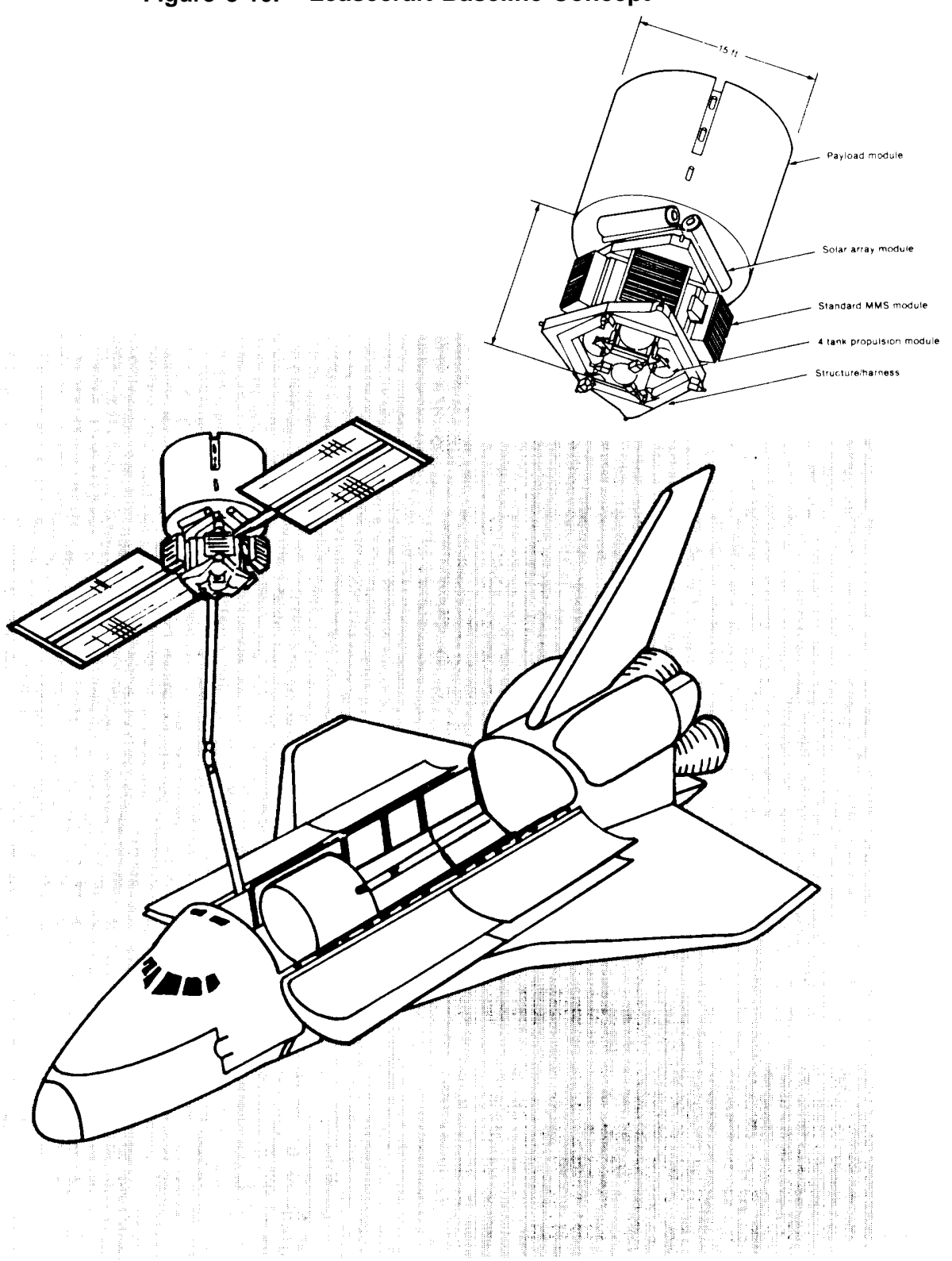

Fairchild Leasecraft satellite with a McDonnell Douglas biological processing unit is grappled here by the manipulator arm. The barrel-shaped resupply module on top containing processed material will be removed and replaced by the new module in the payload bay that contains raw biological material for processing. 
periments and funding to maintain this level of activity .39 ESA is also investigating the potential for commercial use of EURECA and has considered transferring the responsibilities for the carrier to a private firm .40

The primary buyers of carriers, free-flyers, and other MPS equipment are government space agencies such as NASA, DFVLR, and ESA. The sellers in this market are, for the most part, aerospace corporations working under contract for national space agencies. At present, most firms involved in MPS research, such as MDAC, 3M, and MRA in the United States and MBB/ERNO in West Germany, have designed and built their own test equipment.

The vitality of a future market in MPS equipment will depend on developments in commercial products and services. For example, should McDonnell Douglas develop a pharmaceutical which can be profitably produced in space, it would be necessary to graduate from Shuttle operations to a free-flyer. MDAC estimates that it might need anywhere from 8 to 14 free-flyers to engage in a successful commercial venture. It has considered the Fairchild Leasecraft, a Hughesdesigned free-flyer, MBB's SPAS, and the EURECA. MDAC has also considered developing and building its own free-flyer. A similar scenario can be imagined for any of the proposed space products discussed above, all of which would need more than the Shuttle to engage in successful commercial operations.

The demand for Shuttle-compatible carriers and related experimental equipment will most likely increase steadily throughout the decade, The percentage of this equipment which is available commercially as opposed to through government space agencies will depend on the success of current and future private sector proposals to conduct the integration and marketing of experimental services.

Development of the SPAS and ESA commitment to EURECA ensure at least a limited European presence in the international MPS equipment market. The extent of this presence is dependent on:

\footnotetext{
${ }^{39}$ ]. M. Lenorovitz, "ESA Offers EURECA Platform for Shuttle, " Aviation Week and Space Technology, Oct. 24, 1983, p. 75.

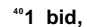

- Political considerations: Should ESA adopt a "buy European" attitude towards MPS research, it is conceivable that EURECA could become the carrier of choice for all European MPS experiments.

- Technical considerations: Commercial MPS operations will have specific needs for power, telemetry, and other vital utilities. McDonnell Douglas has indicated that, as presently configured, neither the existing SPAS nor the proposed EURECA could meet its power demands. The Fairchild Leasecraft, if developed, would seem to be able to meet these needs. European participation in the future MPS equipment market will be based, in part, on the ability to compete technically with the U.S. private sector.

- Market considerations: To date, Fairchild industries has been unable to attract customers to its Leasecraft concept. It is possible that it will be many years before there is a strong demand for commercial MPS production equipment. The EURECA'S ability to fly numerous small payloads and the existence of multiuse experimental equipment may make it the carrier of choice for conducting precommercial flight tests.

- Financial considerations: Assuming a rough technical equivalence between U.S. and European MPS equipment, competition will be based on cost. This may be significantly influenced by direct or indirect government subsidies. Such subsidies may be the incidental result of government R\&D policies or the direct result of a policy to promote the sale of this equipment.

- U.S. domestic policy: The Shuttle is, at present, the primary means by which to conduct MPS research and manufacturing. The Europeans are therefore subject to U.S. policy decisions regarding access to and cost of Shuttle services. Unless Europe develops an alternative to the Shuttle for MPS research (e.g., the Hermes vehicle), the commercial success of European MPS endeavors may depend on U.S. domestic space transportation policies. It is important to note that in other important space technologies (space transportation, communication satellites, and remote sensing) the Europeans have chosen not to rely exclusively on U.S. technology. 


\section{COOPERATION IN MPS}

There is substantial foreign interest in microgravity research. Since the United States controls the Shuttle, Spacelab, and other hardware essential to this research, it is a desirable partner for cooperation. It is important to examine the value of such cooperation to the U.S. space program, and, more generally, to long-term commercial and foreign policy interests.

\section{Advancement of Science}

The primary reason for pursuing international cooperation in MPS is to advance the microgravity sciences. Since NASA was founded it has pursued a vigorous program of international cooperation in the space sciences. ${ }^{41}$ Recently, as missions have become more complex and expensive, and therefore more infrequent, a broad international interest in space science has allowed important scientific work to go forward which could not have been done by the United States alone. As the space programs of the Europeans and Japanese continue to grow in size and sophistication, so will the importance of international cooperation in the space sciences.

Shuttle Mission 7 provided an excellent example of international cooperation in MPS research. ${ }^{42}$ On this mission, NASA entered into an agreement with $\mathrm{MBB} / \mathrm{ERNO}$, a private West German firm, to use the SPAS to test the Canadian remote manipulator system. Although NASA and MBB entered into a formal contract for reimbursement for the flight of the SPAS, the cost was discounted to reflect the value to NASA of having the SPAS as a test article. Also on STS-7, three MAUS units were flown as a part of an experiment by NASA's Office of Space and Terrestrial Applications (OSTA-2). NASA and BMFT agreed that the OSTA-2 flight opportunity would be matched by the reflight of the Materials Experiment Assembly (MEA) on the West German D-1

\footnotetext{
${ }_{41}$ See generally: u .S. Congress, Office of Technology Assessment, UNISPACE '82: A Context for International Cooperation and Competition, OTA-TM-ISC-26 (Washington, DC: U.S. Government Printing Office, March 1983), app. B.

${ }^{42}$ Craig Covault, "Shuttle 7 to Carry Multinational Payload," Aviation Week and Space Technology, May 6, 1983, pp. 52-57.
}

Spacelab mission. In both instances, flights were arranged on a "no exchange of funds" basis.

\section{Foreign Policy}

Development of space technology is a demanding and highly visible undertaking in which nations have traditionally invested substantial amounts of financial and political capital. MPS is certainly no exception to this general rule. The potential benefits of cooperative MPS research are not limited to such tangible items as monetary return or technical advances, but include such intangibles as national prestige and the desirability of maintaining stable relationships with other countries. Decisions about the level of international cooperation that NASA wishes to pursue will undoubtedly influence the investments and programs of other countries. To the extent that NASA's decisions have a negative effect on the space programs of other countries, they may be less willing to support U.S. foreign policy objectives in space and elsewhere.

With the exception of terrestrial facilities and sounding rockets, the Shuttle is the only nonSoviet means available for the conduct of microgravity investigations. As a result, foreign space hardware has been designed to take advantage of the special characteristics of the Shuttle. Such hardware includes the ESA Spacelab and all of its laboratory equipment, the future EURECA, West Germany's SPAS and MA US canisters, and France's MEPHISTO furnace. Future decisions regarding Shuttle and Spacelab pricing and availability should be made with the understanding that other countries have also made substantial economic and political investments in this technology.

\section{Foreign Sale of U.S. Technology}

Until recently, the United States held a virtual monopoly on the sale of space services and equipment. Now, even though the demand for such products is increasing, so is the number of capable suppliers. It is, therefore, important to examine what role international cooperation might play in the promotion of these U.S. space goods and services. 
As a result of the unique characteristics of the Shuttle and past NASA cooperative projects, most foreign MPS research will rely in some part on U.S. facilities. It might be possible to translate this reliance into an economic advantage for the United States. To the extent that foreign MPS programs remain dependent on the Shuttle, Shuttle use is expanded and the cost of similar U.S. projects is reduced. Policies that discourage foreign use of the Shuttle by charging high prices for its use or limiting access serve to increase the rate of speed at which alternatives to the Shuttle will be developed.

Currently NASA and the private sector have discussed the development of a range of MPS hardware, including carriers, experimental equipment such as furnaces, and free-flyers. Cooperative programs that encourage the use of U.S. hardware increase the potential for eventual sales of such hardware.

\section{Cost Savings}

As a result of their interest in Spacelab and in MPS generally, the European countries and Japan have developed, or are in the process of developing, valuable experimental hardware. Much of it is designed to be reflown and can support a number of experiments. In recent years, NASA resources have been directed primarily to the completion and flight testing of the Shuttle. As a result, in select areas of MPS research the United States is behind in the development of useful hardware. This fact has caused NASA to suggest the creation of an International Microgravity Lab (IML) to allow the international sharing of MPS flight equipment,

The IML concept, developed by NASA's Spacelab Flight Division, envisions that the United States can reduce the cost of Shuttle flights and the "rent" of Spacelab as a means to gain access to European hardware. Discussions have focused on the life science and materials hardware (primarily the ESA Biorack and West Germany's Materials Science Double Rack), though the freeflyers, SPAS and EURECA may eventually enter the negotiations. The Europeans have responded favorably to initial NASA inquiries, and there are feasibility studies under way on both sides of the Atlantic.

The assumption underlying the IML is that most current MPS research seeks scientific knowledge about the microgravity environment. Given this common goal, the IML would reduce duplicative activities, allow cost sharing-particularly with regard to experimental hardware-and encourage use of the Spacelab and the creative interchange of ideas. Whether or not the IML is approved, it raises an important issue. Unless the United States is prepared to commit more of its public and private resources to space than it does now, it cannot hope to maintain preeminence in all aspects of MPS technology. Given the likely constraints on the Federal budget, international cooperation will play an increasingly important part in future MPS projects.

\section{POLICY OPTIONS}

In the near future, the United States will have to make important decisions concerning the proper roles of international cooperation and competition in the microgravity sciences. So far, commercial sales in MPS have been limited to the hardware supplied to NASA and foreign space agencies for experimental purposes. Competition between the U.S. private sector and foreign suppliers-either private sector or government-does not yet exist. However, the MPS research of ESA, and of France, West Germany, and Japan, clearly indicates the intention to pursue potential commercial MPS applications. It is important that the U.S. Government begin to consider whether, and 
to what extent, it will support the commercial interests of the U.S. private sector should international competition become a reality.

The United States could obtain valuable technical and financial assistance if it expanded its cooperative MPS efforts. In theory, international cooperation should be encouraged in basic scientific investigations or in areas in which the United States can benefit from foreign research (e.g., basic biomedical research and research in solidification) and discouraged in areas that might have near-term commercial applications or in which the United States holds a clear technological lead (e.g., continuous-flow electrophoresi\$ and containerless processin . The distinction between these areas are, in practice, difficult to make and must depend on the unique characteristics of individual projects.

\section{Competition in MPS}

In most terrestrial markets the U.S. Government has tried to foster an international environment congenial to the open competition of enterprises. The preeminent role of governments in development of space technology, and the political and military sensitivit of much of this technology, have made it difficult to adopt similar policies toward commercial space activities. Given the cost and the complexit of doing research in space, it is unlikely that the private sector could pursue commercial MPS activities without some support from the Government. This assured role of Government makes it difficult to argue for free and open competition among commercial concerns. The question then becomes, what should be the nature and scope of Government intervention in future MPS markets?

Strategies for competition can focus either on increased support for U.S. industries or on the creation of barriers to foreign firms wishing to conduct microgravit research or sell space products. Support for U.S. industry can be increased either through a greater commitment to basic research or through direct support of industries or specific companies. A commitment to basic research would involve actions such as:

- Increase funding for NASA research: Historically, NASA'S MPS budget has been modest when compared to other NASA science and application programs. The proposed 1986 budget reflects a significant increase (fig. 8-1 1).

- Encourage university and industrial support by established "research centers": The House Committee on Science and Technology in its report on the 1984 NASA authorization bill recommended an increase of $\$ 5$ million to be used "in part to establish at a university a center for basic research in the separation and purification of organics. "

\footnotetext{
41 House Committee on Science and Technology, Authorizing Appropriations to the National Aeronautics and Space Administratio for Fiscal Year 1984, H.R. Report No. 98-65, 98th Cong., 1st sess. 1983 ,
}

Figure 8-11. - NASA MPS Funding Trends (millions of dollars)

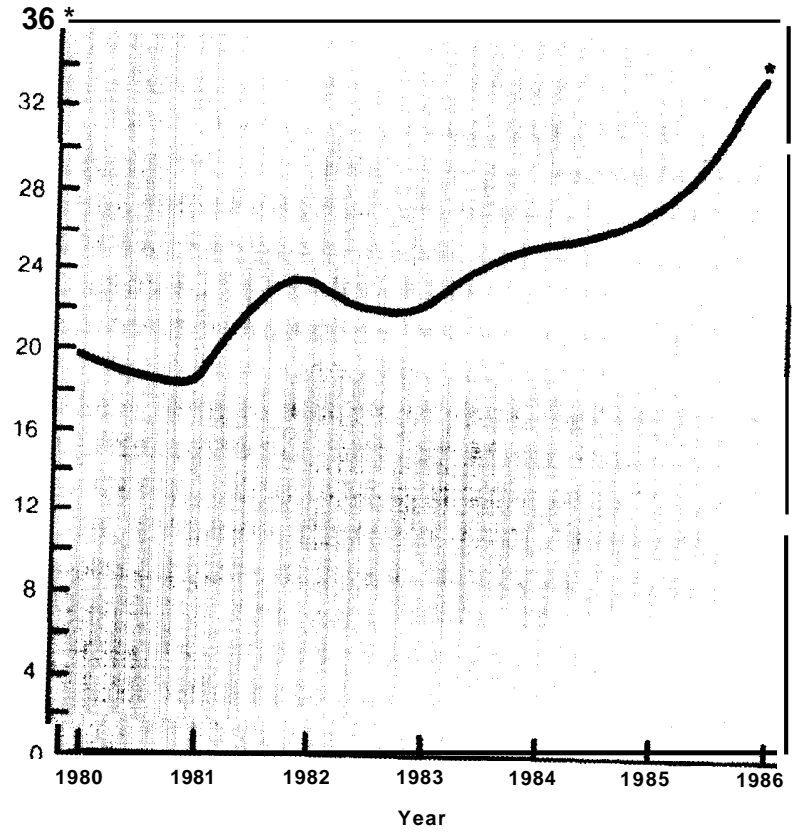

"Budget request, 
Such a center could provide a focal point for research in biological separation presently being conducted by NASA, various universities, and the private sector. A similar center was successfully established by NASA at MIT to conduct research in materials and has received substantial private sector support. As other areas of microgravity research show promise, these too could be supported by research centers.

- Develop and encourage use of in-space research facilities: Such facilities wouldinclude Spacelab and carriers for short-term research, and free-flyers and eventually a space station for long-duration and commercial operations.

Increasing research activities would generate basic knowledge about microgravity, thereby creating an environment conducive to commercial exploitation. It is also possible to support directly industries or specific companies in their efforts to find commercial applications for microgravity. A decision to do this might entail:

- Expansion of current Joint Endeavor Agreement program: NASA's JEA program is a partnership between industries interested in MPS and the Government. Current JEAs are conducted as "no exchange of funds" agreements whereby the private sector participants must pay for their own research and hardware development. The JEA might be expanded to allow for partial Government funding of such ventures.

- Encourage firms to engage in joint research ventures in MPS: The Government may choose to alter regulations or change laws to permit joint research ventures among firms in ways that may currently be prohibited. In the alternative, the Government could encourage the formation of organizations such as the Semiconductor Research Cooperative to do research into the application of microgravity science.

- Financial support for private sector: Such support could include Government loans, Government-subsidized loans, or Government loan guarantees to companies attempting to produce and market new products.
These loans could be structured so that they were paid back if the enterprise was successful and forgiven if it failed.

- Tax incentives: Tax credits could be given for capital expenditures made in space manufacturing, similar to how they have been used in the past for solar energy work. In the alternative, income derived from the sale of space products could be made tax-exempt for a number of years.

- Provide guaranteed Government markets: By providing a guaranteed market for MPS products and equipment, the only risks remaining to the supplier are those involving development and production. This could be an interim step between a traditional contract arrangement with NASA and complete commercialization.

An alternative or parallel strategy for supporting U.S. commercial activities is one which emphasizes the creation of barriers to foreign competition in MPS equipment, products, and services. Such a strategy might include such elements as:

- Limiting access to Shuttle and Spacelab: The United States has almost complete control over the price and availability of the facilities necessary to carry out MPS research. Although it may not be politically or scientifically desirable, it would be possible to bring foreign MPS activities to a virtual standstill by exercising this control.

- Encouraging "buy American" practices: NASA could require that all U.S. research in MPS be conducted with hardware developed in the United States. This would reduce demand for European-developed free-flyers such as the SPAS and EURECA. NASA could also bring strong pressure to bear on its JEA partners to make sure that they conducted their early commercial operations with U.S. hardware.

- Offer subsidized or guaranteed loans to purchasers of U.S. products and hardware: Should products such as new pharmaceutical result from current MPS research, the Government could encourage their sale in foreign markets by offering attractive finan- 
cial arrangements-thereby assuring that U.S. firms will capture the largest market share. A similar policy could be implemented with regard to the sale of hardware such as free-flyers.

- Establish trade barriers to protect infant industries: Should foreign hardware or product manufacturers prove more successful than their U.S. counterparts, trade barriers could be established to slow their entry into U.S. markets.

- Government entry as supplier: In the absence of adequate private sector interest, the Government could enter as supplier. This would probably be done only under extreme circumstances, such as if the MPS product or hardware had a strong relationship to national security.

Although it would be possible to implement such policies, there is, at present, little reason to do so. It is possible that such strategies might do serious damage to our relationship with our allies and might preclude other cooperative space activities. Too immediate a concern with competition would accomplish little in the way of protecting U.S. private interests and could do much to injure the international reputation of the United States.

\section{Cooperation}

Most MPS research in the United States and in other countries seeks basic scientific knowledge. Given this common goal, the primary reasons for engaging in cooperative activities are to reduce duplicative activities, to share costs, to encourage the creative cross-fertilization of ideas and to generate goodwill between nations. In addition, such cooperation reinforces the philosophical goals of the 1958 NASA Act and in the 1967 Outer Space Treaty which sought to encourage cooperation and ensure that space was used "for the benefit of all mankind. "

A decision to emphasize cooperation in MPS research could take several different forms:

- NASA formal agreements: To date, formal cooperative activities in MPS have been limited, but have covered a wide range of activ- ities. Foreign researchers, acting on behalf of their own space agencies or as NASA principal investigators (PIs), have made use of U.S. facilities such as drop tubes and towers, airplanes flying parabolic trajectories, SPAR sounding rockets, and, most recently, the Space Shuttle. Formal agreements have also been used by NASA to obtain valuable MPS-related hardware such as the ESA-developed Spacelab, which allows "hands-on" access to material and life science experiments, and the Canadian remote manipulator which allows the Shuttle to deploy and retrieve MPS payloads.

Opportunities for formal cooperation in future MPS activities are numerous. ${ }^{44}$ As a result of their MPS activities, the European nations and Japan have developed, or are developing, hardware which could be useful to NASA research efforts. Particularly noteworthy are the Materials Science Double Rack and the Biorack developed for use on Spacelab, ${ }^{45}$ and the SPAS and EURECA free-flyers. Japanese interest in MPS and, specifically, in space bioprocessing technology, may also present the United States with opportunities for joint development or shared use of hardware.

Formal cooperative ventures, such as the International Microgravity Lab (discussed above), could be used to form international research teams to investigate specific MPS phenomena. Such teams might initially concentrate on use of the Spacelab. NASA could encourage greater participation in its research efforts by foreign Pls and encourage foreign space agencies to grant NASA scientists similar treatment.

- Informal cooperation at the level of the national space agency: Informal agency cooperation offers an administratively simple, lowcost and low-visibility method of encourag-

\footnotetext{
${ }^{44}$ The space station, currently under study by NASA, offers significant opportunities for formal international cooperation. This subject is discussed in detail in the OTA report Civilian Space Stations and the U.S. Future in Space, OTA-STI-241 (Washington, DC: U.S. Government Printing Office, November 1984).

${ }^{45}$ Spacelab Mission 1 Experiment Descriptions, P. D. Craven(ed.) (Marshall Space Flight Center, AL: NASA, November 1981 ), NASA TM-82448.
} 
ing cooperation on shared scientific goals. For this reason, NASA has developed informal working arrangements with numerous foreign space agencies. In MPS, NASA has been receptive to informal consultations with the scientists and program managers of other space agencies and has generally facilitated the international flow of information.

Specifically, NASA has encouraged its MPS Science Working Groups to interact with their counterparts from other countries, to share their experience, and to help define program goals. This unstructured cross-fertilization of ideas has contributed substantially to the dissemination of knowledge essential to the success of MPS projects. Although PIs at NASA have exclusive access to data from their experiments for 1 year, after this time they are required to deposit the data, in a usable form, in the National Space Science Data Center. This information is then freely available to all interested parties.

A more focused method of encouraging international cooperation might entail greater use of the various Science Working Groups, or some other organization, to coordinate research activities. The Science Working Groups play primarily an informational role, but they could be encouraged to take a greater part in organizing specific project interactions, identifying useful hardware and coordinating joint projects. It is important that the group given this responsibility be familiar with the details of specific projects to ensure the relevance of cooperative activities.

- Informal communication among scientists: A great deal of information is transferred by individual scientists as a result of their personal and professional relationships. There has been an active dialog in the scientific community on MPS, and the subject has been explored in numerous technical and scientific papers. A decision to encourage informal international communication among scientists might involve such activities as sponsoring symposia and making available funds necessary for travel. [n addition, formal arrangements involving the coordination of Science Working Groups or guest investigator programs would have the indirect effect of increasing the informal interaction among scientists.

- Cooperation in multinational fora: The United Nations Committee on the Peaceful Uses of Outer Space (COPUOS) has been the principal multinational forum for debate of space issues. Although there is some current dissatisfaction with the United Nations (see ch. 3) and its committees, U.S. participation in COPUOS has in the past been beneficial. Should the United States wish to avoid purely "international" space programs and their attendant political problems, the United Nations may still play an important role. For example, one of the seven proposals for multilateral cooperation presented by the United States at the UN ISPACE '82 Conference was an intergovernmental meeting of experts in the use and management of space technology.

On February 4, 1983, NASA and Columbia University cosponsored the first such meeting. About 100 representatives from 40 countries and international organizations attended and discussed technical space problems in an informal multilateral forum devoid of the usual U.N. political issues, The success of this first meeting indicates that it might be a useful tool for coordinating international activities with regard to specific technologies such as MPS. ${ }^{47}$

There is no simple formula for deciding the appropriate level of international cooperation to pursue in MPS research. A well-structured and resource-conscious MPS program will undoubtedly wish to engage in some cooperative activities. Although the extent of international cooperation must depend on the unique characteristics of individual projects, some effort should be made to place these individual decisions in a coherent policy framework. At minimum, such a policy should ensure that:

1. The benefits of cooperation are in reasonable proportion to the costs. The term "benefits"

\footnotetext{
46See:UNISPACE'82: A Context for International Cooperation and Competition, op. cit.

${ }^{4}$ lbid., app. C.
} 
should include tangible items such as monetary return or technical advances and intangibles such as national prestige and the value of maintaining stable international relationships. The potential "costs" may be a loss of domestic jobs, contracts for services and hardware, and a potential competitive advantage in world markets.

2. There is no negative impact on similar private sector efforts. If the private sector is to be encouraged to take a greater share of the financial and technical risk associated with MPS research and hardware development, international cooperative ventures must not compete with them commercially.

3. The objectives and program responsibilities are clearly defined. Formal MPS cooperative ventures should have well-defined technological goals and should deal in advance with sensitive questions of data retention, patent rights, and proprietary information. The technical, human, and financial resources of the participants should be examined to assure that the costs of the research can be lowered and effectively shared. 
Chapter 9

SPACE SCIENCE 


\section{Contents}

$\begin{array}{rlr}\text { Page } & \end{array}$

Introduction. . . . . . . . . . . . . . . . . . . . . . . . ..............371

Cooperative Ventures in Space Science:

The Opportunity and the Challenge . . . . . . . . . . . . . ................372

Competition in Space Science: The Shifting Balance.. . .................373

Prevailing Issues in Space Science . . . . . . . . . . . . . . . . . . . ......4.\$.375

International Cooperation in Space Science. ... .. ${ }_{0} \ldots \ldots \ldots \ldots \ldots \ldots \ldots \ldots \ldots$

Historical Overview . . . . . . . . . . . . . . . . . . . . . . . . . . .........377

Current or Planned Programs . . . . . . . . . . . . . . . . . . . . . . . . 382

Outlook for Future International Cooperation . ......................384

The Role of Competition in Space Science . .......................386

Prospects for a "SpaceScience Race" . . . . . . . . . . . . . . . . . . . . . ........386

Current Ranking of Participants . . . . . . . . . . . . . . . . . . . . . . .....387

Tradeoffs Between Competition and Cooperation . ....................388

Markets for Hardware and Services: Space Science as Growth industry .. ...389

International Trade Factors . . . . . . . . . . . . . . . . . . . . . . . . . . . . . . ...389

Space Science in Developing Countries . . . . . . . . . . . . . . . . . . . . . 390

The Allure of Space Science . . . . . . . . . . . . . . . . . . . . . . . . . . 390

Difficulty of Joining the Space Club. . . . . . . . . . . . . . . . . . ....391

Space Science in the 1980s and 1990s: A Vital Concern . ..................391

Policy Options. . . . . . . . . . . . . 4 . . . . . . . . . . . . . ...................392

Cooperation With the Soviet Union . . . . . . . . . . . . . . . . . . .392

Project Continuity . . . . . . . . . . . . . . . . . . . . . . . . . . .....393

Choosing Specialization . . . . . . . . . . . . . . . ........ . ...........39393

Technology Transfer . . . . . . . . . . . . . . . . . . . . . . ...............393

\section{Table}

Table No. Page

9-1. International Cooperative Ventures in Space Sciences . ................379 


\section{Chapter 9 \\ SPACE SCIENCE}

\section{INTRODUCTION}

A substantial part of the research activity carried out in space is directed, not at the achievement of economic benefits and commercial applications, but at the purely scientific study of phenomena in and from space. This broad field of endeavor, known as space science, began to develop many years before the advent of orbiting satellites; from the 1940s on, scientists used sou riding rockets and balloons to loft instruments and animals above most of the insulating and protective blanket of atmosphere to acquire data about the space environment. These studies contributed to an ever-increasing body of knowledge about outer space. By contrast, over the past quarter-century, Earth-orbiting and interplanetary spacecraft have been the catalyst for an explosive growth of knowledge in this field.

The rapid expansion of space science has produced a number of component disciplines and subdiscipline. For organizational purposes, the National Aeronautics and Space Administration (NASA), which funds most space science research, divides space science into three areas: 1 ) physics and astronomy, 2) planetary exploration, and 3) life sciences.

- Physics and astronomy encompasses the study of the structure and dynamics of the Sun, solargenerated phenomena such as the solar wind, and other features of the near-Earth interplanetary environment such as the magnetosphere and incident cosmic rays. Also included in this area are some of the most compelling and exciting investigations in any scientific field: the study of astronomical objects by means of telescopes and other space-borne instruments. These objects include not only our own Sun and the multitude of stars and other condensed objects of the Milky Way Galaxy, but also the gas and dust between these stars, and finally the vast swarm of galaxies extending out to the edge of the visible universe.

Observations from space take advantage of the entire spectrum of electromagnetic radiation to acquire much more extensive data on

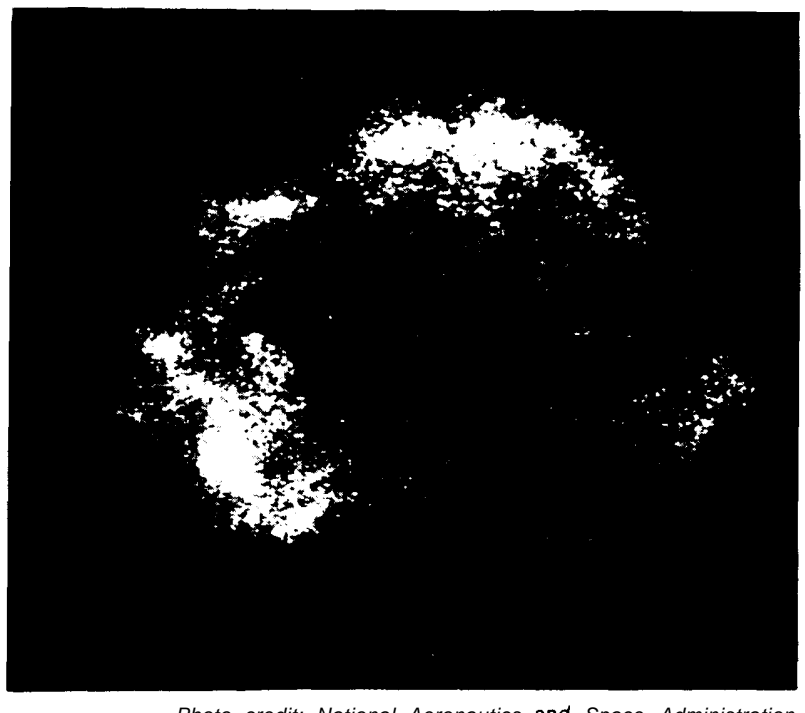

Photo credit: National Aeronautics and Space Administration

X-ray image from NASA's High Energy Astronomy Observatory (H EAO-2) of remnant of exploding supernova in the constellation Cassiopeia. Scientists estimate that the star from which this cloud of expanding hot gas derives originally exploded in A.D. 1657.

large- and small-scale cosmic processes than can be taken from the ground, where only optical and radio wavelengths are received. Access to all regions of the spectrum as well as the removal of atmospheric distortion has produced, in the span of a few years, a major revolution in our understanding of the nature, origin, and evolution of the universe and its component matter.

- Planetary exploration is the study of the planets of our solar system and their satellites, the asteroids, and the comets. Activities in this area include the dramatic unmanned exploratory missions to the surface or environs of other planets, and the manned lunar landings. investigations of the surface features and (if possible) composition are made along with studies of the planetary atmosphere and magnetosphere, if they are present. These observations are combined with data regarding orbital mechanics and rotational characteristics to pro- 
vide an understanding of the planet's internal composition and dynamics, and thus its origin and evolution.

- Life sciences are generally subdivided into biomedical research (the study of the effect of space environmental factors on man) and space biology (the effect of these factors on plants and animals). Separate but related areas are planetary biology, the study of the origin and distribution of life in the universe, and global biology, which examines the impact of life on our own planetary environment. important areas of research are the effects of prolonged exposure to microgravity and ionizing radiation on humans and animals, and the study of plant developmental processes in space under artificial lighting. One objective of the latter research is the development of advanced life support systems. Because of the difficulties associated with supporting life in space, ground-based simulation studies are especially important in the space life sciences.

Although research in each of these areas produces results that have great intrinsic value in adding to our understanding of the cosmos and our place within it, this research is not pursued solely for its own sake. Space science provides much of the research base that underlies the development of applications-oriented programs discussed in earlier chapters. The subdiscipline of solar-terrestrial physics, for example, forms a direct bridge between solar research (physics and astronomy program) and Earth applications such as communications, navigation, and meteorology. Studies of planetary magnetic fields, magnetospheres, and ionospheres have a direct relevance to corresponding research in Earth's plasma envelope and upper atmosphere.

In the long term, planetary studies also offer the possibility of habitation and minerals exploitation. Life sciences research offers a wealth of potential applications, from the prolongation of human stay-times in space, to the pursuit of space agriculture and partly closed life support, to the development of new medical treatments, diagnostic techniques, and devices. Instruments and sensors developed in every area of space science eventually find their way into commercial appli- cation. Thus, programs in space science are a necessary basis for any nation's activity in space. Nations that wish to pursue practical or commercial activities in space on their own must first either pursue a program of space science themselves, or have access to the technology and basic data that emerge from the conduct of such a program.

\section{Cooperative Ventures in Space Science: The Opportunity and the Challenge}

As was discussed in chapter 3 , the United States has engaged in a vigorous program of international cooperative ventures in space. When all forms of joint activity are taken into account, NASA alone has concluded over 800 agreements with over 100 countries.

From the standpoint of individual projects, the most notable single area of U.S. international space cooperation has been the space sciences. ${ }^{2}$ It was apparent from the beginning that cooperation in this field offered many advantages, from the point of view of both the United States (the leader and principal in these ventures) and the cooperating nations. On the technical and political level, the appeal of multinational space science stems from the global sphere of operations of satellites, and from the global and universal perspective necessitated by operations in space.

More practically, the enormous cost of pursuing space science has been a strong argument for sharing the economic burden among as many nations as efficiency permitted. In effect, if NASA does not have enough money to pursue a project alone, by cooperating with other countries it may actually create opportunities to undertake research it could not otherwise have done. The pooling of scientific and technical talent offered another strong advantage, and was allied with the

\footnotetext{
125 Years of NASA International Programs, NASA report, January 1983.

2UNISPACE'82: A Context for International Cooperation and Competition-A Technical Memorandum (Washington, DC: U.S. Congress, Office of Technology Assessment, OTA-TM-ISC-26, March 1983), p. 68.
} 
value to the United States of building scientific/ technical strength among its allies. These advantages were not restricted to the United States and its partners, but applied as well to the Soviet Union-the other leading nation in the early decades of space activity -in its dealings with its client states and a few other nations through the Intercosmos program.

Now, as technical capability for the independent conduct of space science has spread to the European Space Agency (ESA) and many of its member nations, to Japan, and potentially to some developing countries, the benefits of cooperation are coming into play for a wider range of nations.

Conversely, the disadvantages of joint pursuit of science in space are also being felt more widely and perhaps more acutely. Prominent among these are the problems attendant upon planning for and conducting long-term joint development activities, during which any number of economic and national policy imperatives may intervene to disrupt schedules and commitments. Differences in managerial style, and the difficulties in achieving satisfactory management of parallel development programs, produce another set of problems.

As cooperative partners in space sciences are increasingly likely to be competitors in other scientific or industrial fields (or even in other areas of space activity), the issue of technology transfer is becoming a matter of increasing concern. This is especially true in light of the possibility that cooperative ventures may entail lost opportunities for indigenous scientists and indigenous technology development.

\section{Competition in Space Science: The Shifting Balance}

\section{The First 15 Years}

After World War II, one of the crucial factors setting the stage for the "space race" of the 1960s was the fact that most of the expatriated European scientists and engineers came to the United States, while the Soviet Union acquired the bulk of the surviving German V-1 and V-2 rockets (along with some technicians and engineers). The influx of talent on the one hand and hardware on the other probably led to the development, throughout the 1950s, of a broader based expertise in the essential space technologies in the United States, contrasted with an accelerated launcher capability in the U.S.S.R. The surprise launching of Sputnik in 1957 galvanized the latent capabilities of the American space community into focusing on achievement and dominance in space.

The emphasis on manned spaceflight throughout the 1960s, culminating in lunar landing and exploration, obscured (and to some extent impeded) developments in space science. Although the lunar missions were certainly "planetary," science was secondary to the engineering accomplishments involved. Yet from the beginning of both programs the science return was impressive.

The U.S.S.R. led initially. The second Sputnik, launched a month after the first, carried substantial geophysical and radiation-sensing instrumentation as well as a life support system and biomedical instrumentation for monitoring the effects of spaceflight environmental factors on its live payload, a dog. The third Soviet satellite, launched shortly after the first two American successes, was a $1 \%$-ton orbiting geophysical laboratory. By late 1959, the U.S.S.R. had struck the Moon (Luna 2) and photographed its far side (Luna 3). In 1961 the manned orbital missions began, with a return of important biomedical data.

Soviet planetary satellites launched before the end of that year had already provided data on solar and cosmic radiation across the electromagnetic spectrum and on the upper atmosphere. However, between 1960 and 1965 a total of 18 planetary missions to Venus and Mars failed to return any planetary data, primarily because of contamination problems. ${ }^{3}$

The American space science effort got off to a slower start, but had a higher success rate. Significant data were returned by the second Mariner mission to Venus, in 1962. Likewise, the second mission to Mars, in 1964, provided pictures

\footnotetext{
${ }^{3}$ Soviet Space Programs, 1966-70, Congressional Research Service, Science and Technology Division, 1971, p. 166.
} 
and data. However, a long series of Pioneer missions to the Moon, beginning in 1958, was unsuccessful. Not until 1964, with the Ranger series of TV-equipped hard landings, were U.S. lunar missions fruitful. Meanwhile, the Explorer series of Earth and space science satellites was highly successful. Explorer 1, for example, discovered the existence of ionized particles trapped in Earth's magnetic field (the so-called Van Allen radiation belts); subsequent Explorer missions paralleled the Soviet program in space science.

In manned spaceflight, Project Mercury lagged its Soviet counterpart: the first U.S. orbital flight did not occur until considerably after the second Soviet orbital mission had taken place. Not until the advent of Gemini in 1965 did the U.S. program gain momentum and surpass (perhaps in late 1966) the Soviet effort. The Soviets later regained this lead in the mid-1970s, as the U.S. Skylab program was concluded and the Salyut program got fully under way.

\section{Dynamics of Competition}

Despite the size of the U.S. investment in the manned program during its first decade, the science return was relatively small. Like its Soviet counterpart, its primary aim was national prestige, not science. In the post-Apollo era, however, the U.S. manned program has been more careful to build in significant science components from the beginning planning stages of its missions. The U.S. space science program also came into its own in the 1970s, highlighted by the Viking missions to Mars and the launch of the Voyager spacecraft to the outer planets. The mid-1970s saw funding peaks for space science missions, but these were followed by drastic budget reductions later in the decade. ${ }^{4}$ Meanwhile, the Soviet Union established a dominant position in manned orbital operations through the series of Salyut space stations. The continuity of the Salyut program exemplifies the pattern of U.S.-Soviet competition in all space activities, including space science: the Soviets are able to sustain a steady, long-term commitment in any area of space activity they view as supportive of their long-term goals; the

${ }^{4}$ Space Science Research in the United States-A Technical Memorandum (Washington, DC: U.S. Congress, Office of Technology Assessment, OTA-TM-STI-19, September 1982), p. 41.
U.S. program, being subject to the annual congressional budget process, is more likely to undergo short-term perturbations. ${ }^{5}$ Thus, although the U.S. space science missions were more sophisticated than were those of the Soviets, Soviet space science capabilities continued to grow, particularly with the increasing use of Salyut as a platform for research

The strong position of power occupied by the U.S.S.R. Academy of Sciences ensures that basic science will not be ignored.' The fact that the U.S.S.R. is sending a mission to Halley, that it is continuing to conduct missions to Venus, and that it plans a flyby of the Martian Moon Phobos in 1988, is strong evidence of its continuing interest in science. However, Soviet space activities in recent years have in general become in-

${ }^{5}$ Salyut: Soviet Steps Toward Permanent Human Presence in Space-A Technical Memorandum (Washington, DC: U.S. Congress, Office of Technology Assessment, OTA-TM-STI-14, December 1983), p. 3.

'AlainDupas, "Un Programme Spatial en PleinRenouveau," La Recherche, November 1984, pp. 1420-1427.

'Soviet Space Programs: 1976-80 (Part I), Congressional Research Service, December 1982, p. 157.

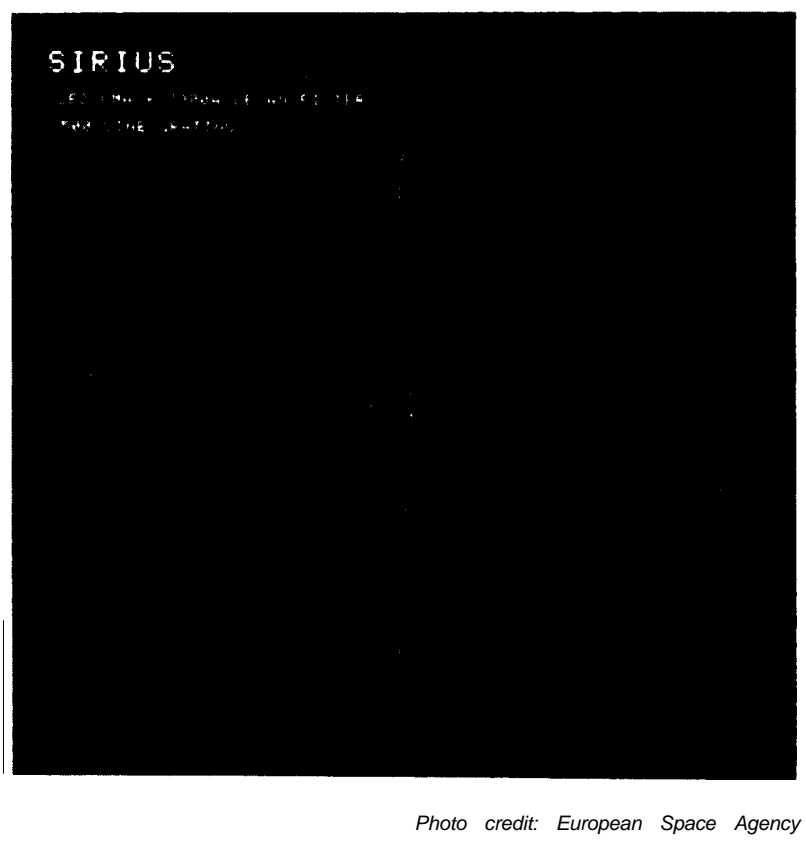

Spectra of Sirius $A$, the brightest star in the sky, and of Sirius B, its white dwarf companion. The X-ray spectrum of the white dwarf is the vertical line. The first and second order ultra-violet spectra of Sirius $\mathrm{A}$ are along the horizontal. 
creasingly applications-oriented, and the flight of large-scale, advanced-technology U.S. and European space observatories and planetary probes (both independent and joint) will probably not be matched by the Soviets for some years.

The broad cooperative activity of the United States with its allies in space since 1961 has seeded and stimulated the growth of space science and the associated technologies in many of the nations involved, to the point at which some of their capabilities rival our own. Among ESA member nations, the United Kingdom is highly astronomy-oriented; both West Germany (FRG) and France have strong space science capabilities, and are prime movers within ESA in this field. On roughly one-sixth of NASA's budget, ESA has launched a substantial $X$-ray satellite (Exosat) on a U.S. Delta launcher and will soon launch a cometary mission (Giotto), a $30-\mathrm{cm}$ telescope (Hipparcos), and a solar-polar orbiter (ISPM), as well as conduct numerous Spacelab science experiments. ISPM is a joint NASA/ESA mission with experiments from both sides, and will be launched on the Shuttle.

Japan is also emerging as a contender in space sciences. Although its primary focus has been on development of commercial applications satellites, the Institute of Space and Astronautical Science (ISAS), responsible for Japanese space activities, sustains a level-of-effort in space science of one launch per year, on average. On less than one-tenth of the NASA space science budget, recent and upcoming achievements of ISAS include an X-ray optical/radio satellite (Hakucho), a solar flare sensor (Hinotori), a larger X-ray satellite (Tenma, or Astro-B), a cometary mission (Planet-A), and an even larger X-ray detector (AstroC), mounted jointly with the United Kingdom. In developing its capabilities in space science Japan has not relied heavily on cooperative missions with the United States, although much of the supporting technology has been derived from U.S. commercial construction of large portions of its Earth-sensing and communications satellites.

These developments lead to the conclusion that active competition in the space sciences is only now becoming possible. The more nations that possess the capability of developing space technology, the more cooperative options there are. Nations will also decrease their dependence on the traditional center of activity, the United States. In this context, a number of factors come into play in determining the scope and direction of future competition:

- the value of space science as compared with other space activities (e. g., remote sensing and communications);

- the overall space capability of a nation (e.g., launch capability);

- reliability (in terms of schedule, costs, and quality of services and hardware);

- both national and world economic factors (i.e., the relative affordability of space science among nations); and

- institutional factors within nations (e.g., governmental commitment and support, management framework).

\section{Prevailing Issues in Space Science}

\section{Competition}

The potential for more open competition in space science is related to the increase in the world market for space services in general. For example, the possession of space transportation systems and/or orbiting research platforms is a key factor in the competitive position of a nation with regard to all areas of space activity. The ability to develop cost-effective specialized instrumentation and equipment is also an important market factor in every area.

In the absence of commercial interchange, the competition between the United States and the U.S.S.R. has heretofore been primarily the pursuit of prestige. However, the increase in cooperative activity between the U.S.S.R. and France in recent years suggests that competition between East and West may increasingly occur in the form of competition for cooperative activity with others. An overall tendency toward the "loosening up" of Soviet space policy would accelerate this trend. This issue is particularly important with regard to Third World countries. 


\section{Developing Countries}

The overall issue of how to involve developing countries in space science will become increasingly pressing in coming years. Most of the interest of these countries in space relates to applications-oriented activities, but the need to build a domestic infrastructure for such activities will inevitably dictate some involvement in space science, at least on a modest scale. For the spacecapable nations, the problem of how to accomplish this integration at minimal cost and without doing damage to existing programs must be addressed.

\section{Long-Term Agenda for Space Science}

Development of a rational, long-term agenda for science missions as related to science objectives is a continuing issue for each of the spacefaring nations. It is of particular importance as more nations enter the space arena. Given the pervasive sharing of data, at least in the West, duplication of missions is pointless; yet the decision as to who conducts what missions is an increasingly complex one, and involves issues of competition as well as cooperation. Such agendas are regularly drawn up in the United States, but there is no assurance that they can be adhered to. The difference between annual budget funding in the United States and, for example, mission funding within ESA, is a critical one from the point of view of U.S. scientists and potential partners alike.

Along with the issue of program planning goes the separate consideration of maintaining an appropriate balance between space science and applications. This is done now on a largely subjective basis, but the trend toward more expensive science missions and an intensifying competition in the applications area may upset the balance, necessitating a more formal means of assessing the value and interlinkages of each. This is potentially of greatest importance for space science, where the value of findings cannot be easily quantified.

\section{Economic Impact of Space Science}

Space science is conducted predominantly by means of sensing and detecting equipment, with data being generated and transmitted by means of advanced electronic systems. The ground tracking and receiving stations are sophisticated facilities, relying on computer systems for most essential functions. Thus, space science is a high technology endeavor, very much a part of the most vigorous sector of our present-day economy. The actual and potential economic impact of space science as both a producer and purchaser of goods and services should be examined. ESA has conducted studies (now somewhat dated) of the economic benefits of space business to ESA contractors.a Comparable analyses were conducted for NASA by Chase Econometrics in 1975, but no studies specific to space science contracts have ever been done.

\section{Education and Training}

Differences in education and training of scientists and engineers among the space-faring nations constitute another issue. In the United States the system for producing space scientists relies heavily on academic graduate training at a few universities under individual faculty researchers. Additional training occurs on-the-job in industrial project teams. Government contracts provide this system's principal means of support. Yet the unevenness of funding provided to these laboratories and industrial groups in recent years, as a result of funding cuts and a decrease in the overall number of missions, has endangered the system.g

In this regard, an 18-percent increase in the overall space science budget for 1984 was a healthy sign, with new missions such as the Extreme Ultraviolet Explorer and the Venus Radar Mapper entering the budgetary picture. The 1985 budget provides for even larger increases in space science funding-about ${ }^{21}$ percent-including the Mars Geoscience Climatology Orbiter, the Upper Atmosphere Research Satellite (UARS), and the scatterometer for the Navy's NROSS satellite as new starts in 1985.

\footnotetext{
${ }^{8}$ Economic Benefits of ESA Contracts, ESABR-02, European Space Agency, October 1979.

'Space Science Research in the United States-A Technical Memorandum (Washington, DC: U.S. Congress, Office of Technology Assessment, OTA-TM-STI-19, September 1982), pp. 8, 22.
} 
Especially encouraging in these recent budgets are the substantial increases in funding for continued data analysis of astronomy and planetary missions, as this support is crucial for the maintenance of research groups. The planned space station will hold many opportunities for space science over the long term. In addition, the Shuttle will present numerous opportunities for smallscale instrument development projects, thus broadening opportunities for education and training at U.S. "centers of excel lence."

\section{INTERNATIONAL COOPERATION IN SPACE SCIENCE}

\section{Historical Overview \\ U.S./Soviet Cooperative Efforts*}

Given the persistence of enmity, suspicion, and political competitiveness between the United States and the Soviet Union, the overall level of cooperation in space activities has been remarkable. The primary basis for cooperation has been a "1972 Intergovernmental Agreement on Cooperation in the Exploration and Use of Outer Space for peaceful purposes, "entered upon as the period of U.S./Soviet detente began. This agreement provided for: 1 ) development of compatible rendezvous and docking systems for testing on a joint U.S./Soviet manned flight, and 2) establishment of Joint Working Groups in four scientific areas:

- Space Meteorology;

- Study of the Natural Environment;

- Near-Earth Space, the Moon, and Planets; and

- Space Biology and Medicine.

The first part of the agreement resulted in the 1975 Apollo-Soyuz Test Project (ASTP), which probably represents the high-water mark of U. S./ Soviet cooperation in space. However, although some joint biological experiments were conducted on board, ASTP was of far greater political than scientific value.

Scientific cooperation with the Soviets has been less dramatic but quite substantive, particularly i $n$ the planetary and life sciences. The planetary working group has held numerous joint meetings and information exchanges relating to solarplanetary physics and lunar and planetary exploration. Lunar samples from several Apollo and

*U.S.-Soviet Cooperation in Space-A Technical Memorandum (Washington, DC: U.S. Congress, Office of Technology Assessment, OTA-TM-STI-27, in press),
Luna sample return missions have been exchanged (including a 2-meter core sample from a 1976 Luna mission). Beginning in 1978, missions to Venus (Soviet Venera and U.S. Pioneer Venus) have been coordinated and data exchanged. This has been particularly beneficial for U.S. scientists in view of the vigor and success of the Soviet Venera program, which has included transmission of color photographs from the planet's surface.

Probably the most comprehensive cooperation, however, has been in space biology and medicine. Three unmanned Soviet Cosmos biosatellites launched in 1975, 1977, and 1978 carried numerous U.S. biological experiments in a broad range of areas, including simulated gravity experiments (via an on board centrifuge). These flights were a valuable opportunity for American space life scientists in a period when no U.S. manned missions (or comparable biological missions) were being flown. Equally important has been the cooperation in ground-based studies, such as the 1978/79 Joint Bed rest Study conducted to standardize procedures for weightlessness simulation in the laboratory. Further significant exchanges took place at the 1980 Joint Symposium on Vestibular Problems and the 1981 Joint Symposium on Cardiovascular Changes Resulting from Spaceflight.

The decision not to renew the May 1977 intergovernmental Agreement in 1982 (see ch. 3) meant that the Joint Working Groups were no longer constituted. Cooperative activity had for the most part dwindled down to a "baseline level" of routine data exchange and interpersonal scientific communication through letters and at international scientific meetings. It is clear that cooperation in space science, as in other areas, between the United States and the U.S.S.R. is tied 
to the overall level of diplomatic exchange and political relations between the two countries. ${ }^{10}$ Scientists on both sides generally regretted this earlier loss of opportunity. However, recent legislation (Public Law 98-562) signed by President Reagan in October 1984, calls for a renewal of the 1972-77 agreement, and may presage a new level of cooperative science activity between the two nations.

The most durable area of cooperation is in the life sciences, where the United States participated in another Cosmos biosatellite mission in December 1983 (the United States supplied medical monitoring equipment and procedural advice for this primate mission). CAT-scan bone data from Salyut missions are still being supplied to NASA. NASA's Director of Life Sciences attended an international Gravitational Physiology Meeting in the U.S.S.R. in 1983, and exchanges between Working Group members continue on an informal basis. Some results of Venera 13 and 14 were received in early 1982 (including the photographs mentioned earlier), and data from two Venus radar mappers launched in June 1983 (Venera 15/ 16) were presented at an international conference in the United States.

\section{U.S. Cooperative Efforts With Other Parties}

Beginning in the late 1940s, the United States actively sought and sponsored Canadian and European participation in its embryonic space research program. Such activities were numerous throughout the 1950s, and were heavily subsidized by the United States. * By 1962, cooperative space science projects were being conducted not only on sounding rockets and balloons, but also on orbiting spacecraft.

In the years since, such activities have continued to expand, to the point at which all U.S. space science efforts now involve some foreign participation (if data exchanges, guest investigator programs, etc., are counted). The roster of U.S. partners has grown to include most of the major

\footnotetext{
10Soviet Space program: 1976-80 (Part 1), Congressional Research Service, December 1982, pp. 5, 202, 209, 219-20.

*Frank McDonald, NASA Chief Scientist, refers to this period as "a sort of Marshall Plan in space."
}

Western European nations, as well as Japan, Australia, New Zealand, India, Pakistan, Israel, Greece, Peru, Brazil, and Argentina. The offer of a cooperative shuttle flight mission was extended by the President to the People's Republic of China in May 1984. Table 9-1 shows that an increasing number of major U.S. space science missions are truly joint missions, involving foreign-built spacecraft or on board instruments, and foreign principal investigators. It is clear from the table that the United States has been the leading instigator of cooperative missions in space science, even considering the Soviet-bloc cooperative Intercosmos missions, which are not itemized here.

The table also depicts the variety of structures for joint projects-bilateral, multilateral, hosted experiments, etc. Chapter 3 introduced the fact that NASA prefers bilateral to multilateral efforts. ${ }^{11}$ Missions such as the International Sun-Earth Explorers (ISEE), which involved the development of separate spacecraft, or the International Radio Astronomy (I RAS), which entailed building separate major components, have proved to be among the smoothest joint undertakings.

The United States has a number of motives for stressing cooperation in space science. Some of these are altruistic-e.g., the desire to extend both knowledge of the space environment and benefits of space science to as many nations as possible, and the wish to foster a cooperative atmosphere among nations. Some are economicprincipally, the desire to share costs. And some are political: the desire to broaden diplomatic relations with others, to demonstrate U.S. competency and strength, to strengthen our allies technically and economically, and to foster their greater security and independence. It should be noted that these motivations are equally applicable to any other form of cooperative space activity.

However, the benefits of cooperative space science are not always clear-cut. For example, it is difficult to assess the economic benefits to the United States of foreign participation on U.S. missions, especially where foreign gains out of the project may have exceeded contributions. In

\footnotetext{
1/ See UNISPACE'82: A Context for Cooperation and Competi-
} tion, op. cit., app. B. 
Table 9-1. - International Cooperative Ventures in Space Sciences

\begin{tabular}{|c|c|c|c|}
\hline $\begin{array}{l}\text { Launch } \\
\text { year }\end{array}$ & Mission name & $\begin{array}{l}\text { Cooperating } \\
\text { countries }\end{array}$ & Space science objectives \\
\hline 1962 & Ariel-1 & U. SJU.K. & Measure energy spectrum of cosmic rays, solar X-rays \\
\hline 1962 & Ariel-11 & U. S./U.K. & Measure galactic radio noise, micrometeoroid flux \\
\hline 1967 & $\begin{array}{l}\text { Orbiting Solar Observatory-4 } \\
(0 \mathrm{~s} 0-4)\end{array}$ & U.s. ${ }^{a}$ & Measure solar $\mathrm{X}$-ray distribution, $\mathrm{H}_{\mathrm{e}}$ emission \\
\hline 1968 & $\begin{array}{l}\text { Orbiting Geophysical } \\
\text { Observatory-5 (OGO-5) }\end{array}$ & U.K. ${ }^{a}, \mathrm{FF}$ & $\begin{array}{l}\text { Determine direction of incidence of primary cosmic } \\
\text { rays and density itemperature of } \mathrm{H} \text { in geocorona }\end{array}$ \\
\hline 1969 & $0 s 0-5$ & U.K. $.^{a}, F F$ & $\begin{array}{l}\text { Measure solar X-ray flux and self-reversal of Lyman- } \\
\text { Alpha line }\end{array}$ \\
\hline 1969 & 0S0-6 & U.K. ${ }^{\mathrm{a}}, \mathbf{I t}^{\mathrm{a}}$ & Study solar $\mathrm{H}_{\mathrm{e}}$ resonance, $\mathrm{X}$-ray and gamma radiation \\
\hline 1969 & Apollo-1 1 & Switz ${ }^{\mathrm{a}}$ & Measure composition of solar wind \\
\hline 1969 & Apollo-12 & Switz ${ }^{a}$ & Measure composition of solar wind \\
\hline 1971 & Ariel-IV & U. K./U.S. & Measure VLF radiation and cosmic radio noise \\
\hline 1971 & Barium Ion Cloud Probe & FRG/U.S. & $\begin{array}{l}\text { Barium release to stimulate action of solar wind on } \\
\text { comet tail }\end{array}$ \\
\hline 1971 & APollo-14 & Switz ${ }^{a}$ & Measure composition of solar wind \\
\hline 1971 & Apollo-15 & Switz ${ }^{a}$ & Measure composition of solar wind \\
\hline 1972 & Apollo-16 & Switz ${ }^{2}$ & Measure composition of solar wind \\
\hline 1972 & $\begin{array}{l}\text { Orbiting Astronomical } \\
\text { Observatory-3 (OAO-3) }\end{array}$ & UัK.à & $\begin{array}{l}\text { Study stellar ultraviolet and X-ray emissions (project } \\
\text { also known as Copernicus) }\end{array}$ \\
\hline 1972 & A EROS & FRGAJ.S. & $\begin{array}{l}\text { Measure solar extreme UV and correlate with upper- } \\
\text { atmosphere components }\end{array}$ \\
\hline 1972 & Apollo-16 & $F_{R G}{ }^{a}, F P$ & BIOSTACK I (effects of CR on selected biosystems) \\
\hline 1972 & Apollo-17 & $\mathrm{FRG}^{\mathrm{a}}$, FF & BIOSTACK II (effects of CR on selected biosystems) \\
\hline 1973 & Skylab & FP, Switz & $\begin{array}{l}\text { Sky survey, distribution of galaxies and ionized } \\
\text { hydrogen; and solar wind analysis }\end{array}$ \\
\hline 1974 & $\begin{array}{l}\text { Astronomical Netherlands } \\
\text { Satellite (ANS) }\end{array}$ & Neth/U.S. & UV photometry and X-ray emissions \\
\hline 1974 & Ariel-V & U. K./U.S. & Conduct X-ray sky and survey and locate sources \\
\hline 1974 & Helios-1 & FRG/U.S./It/Aus & $\begin{array}{l}\text { Measure micrometeoroid flux, study solar X-rays and } \\
\text { mass, and planetary orbits }\end{array}$ \\
\hline 1975 & Apollo-Soyuz Test Project & U.S./U.S.S.R. & $\begin{array}{l}\text { Rendezvous and docking test included joint biological } \\
\text { studies }\end{array}$ \\
\hline 1975 & Apollo-18 & $\mathbf{F R G}^{\mathrm{a}}$ & BIOSTACK-111 experiment aboard U.S. craft in ASTP \\
\hline 1975 & Aryabhata & India/U.S.S.R. & Solar and upper atmospheric research \\
\hline 1975 & Cosmos 782 & U.S. S.R. & $\begin{array}{l}\text { Eleven U.S. experiments aboard (including } \\
\text { centrifugation) }\end{array}$ \\
\hline 1975 & $0 \mathrm{~S} 0-8$ & F F & Spectrographic study of solar chromosphere \\
\hline 1976 & Helios-2 & FRG/U.S./It/Aus & $\begin{array}{l}\text { Measure micrometeroid flux, study solar X-rays and } \\
\text { mass, and planetary orbits }\end{array}$ \\
\hline 1977 & $\begin{array}{l}\text { International Sun-Earth Explorer-1 } \\
\text { (ISEE-I) }\end{array}$ & U. SJESA & $\begin{array}{l}\text { Coordinated spacecraft studied magnetosphere, } \\
\text { interplanetary space, and their interaction }\end{array}$ \\
\hline 1977 & ISEE-2 & ESAW.S. & $\begin{array}{l}\text { Coordinated spacecraft studied magnetosphere, } \\
\text { interplanetary space, and their interaction }\end{array}$ \\
\hline 1977 & SIGN E-3 & U. S. S. R.IFr & Observatory with telescopes for locating CR sources \\
\hline 1977 & Cosmos 936 & U.S.S.R. ${ }^{b}$ & Seven U.S. biological experiments \\
\hline 1977 & Cosmos 936 & U.S. S. R.IFr & French biological experiments aboard \\
\hline 1978 & ISEE-3 & $\mathrm{FRG}^{\mathrm{a}}, \mathrm{FF}, \mathrm{Neth}^{\mathrm{a}}$ & Solar wind composition and mapping; comet flyby \\
\hline 1978 & Pioneer Venus-2 & $\mathrm{FRG}^{\mathrm{a}}, \mathrm{FP}$ & Atmospheric and cloud studies at Venus \\
\hline 1978 & $\begin{array}{l}\text { NASA Heliocentric Mission } \\
\text { (ISGE-3) }\end{array}$ & U.K,a & Solar proton behavior in interplanetary space \\
\hline 1978 & Cosmos 1129 & U.S.S.R. ${ }^{b}$ & Fourteen U.S. biological experiments \\
\hline 1978 & Cosmos 1129 & U.S.S.R.IFr & French biological experiments aboard \\
\hline 1978 & $\begin{array}{l}\text { International Ultraviolet Explorer } \\
\text { (IUE) }\end{array}$ & U. S. IESAW.K. & UV spectroscopy \\
\hline 1979 & $\begin{array}{l}\text { High Energy Astronomical } \\
\text { Observatory-3 (H EAO-3) }\end{array}$ & $\mathrm{F} @, \mathrm{Dk}^{\mathrm{a}}$ & Study galactic CR composition \\
\hline 1979 & Hakucho & Japan $^{b}$ & Optical and radio observations of X-ray stars \\
\hline 1980 & Solar Maximum Mission (SMM) & U. S./NethW. K. ${ }^{a}$ & Solar hard X-ray imaging spectrometry \\
\hline 1982 & SoyUz T-7 & U.S.S.R.IFr & Biomedical tests, "Aelita" diagnostic device \\
\hline 1983 & $\begin{array}{l}\text { Infrared Astronomical Satellite } \\
\quad \text { (IRAS) }\end{array}$ & Neth/U.S.W. K. & Conduct IR sky survey \\
\hline
\end{tabular}


Table 9-1.-International Cooperative Ventures in Space Sciences-Continued

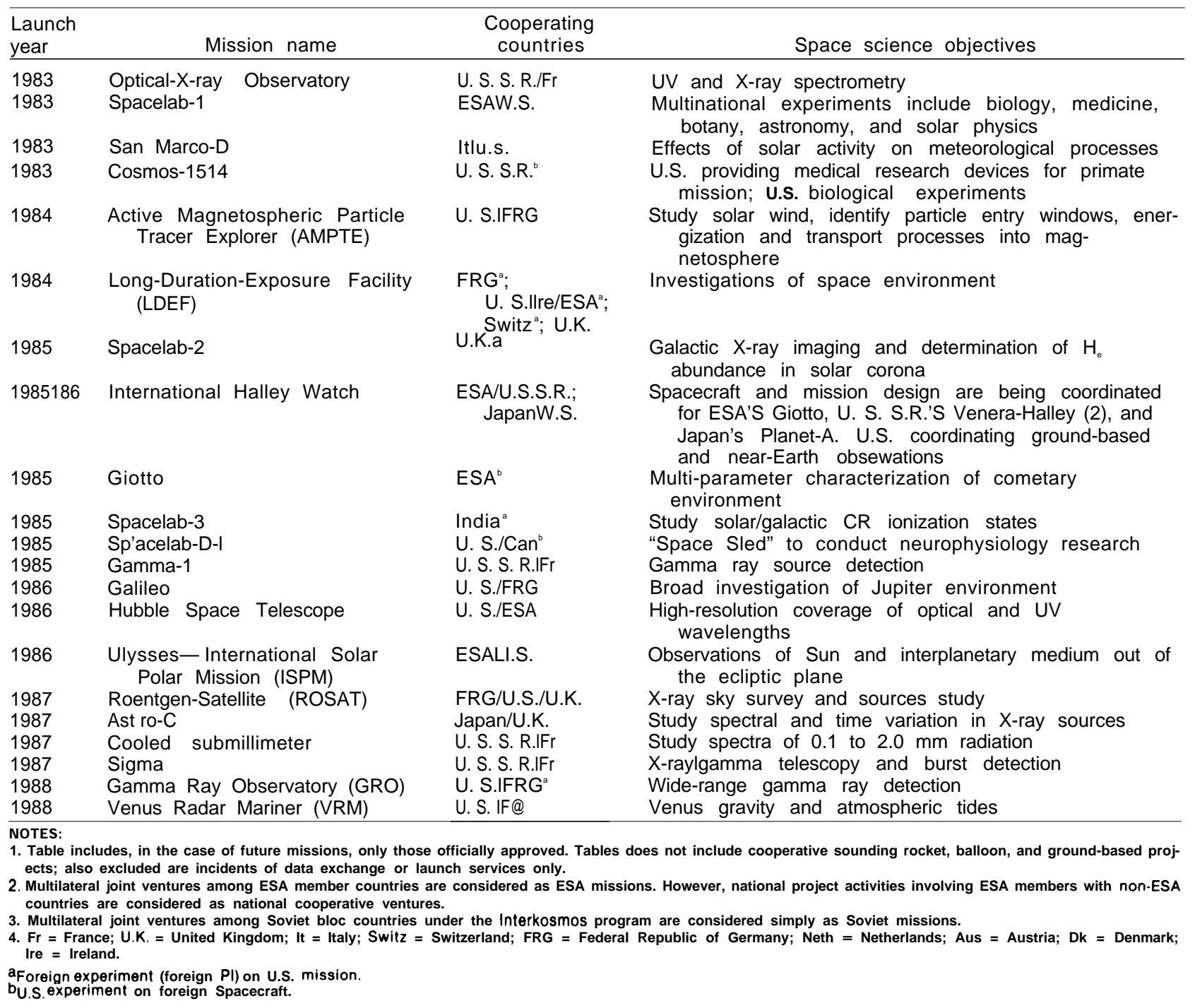

the present era the latter has not been a large consideration. NASA solicits foreign proposals along with domestic ones, and selection of experiments is made "blind. " NASA officials insist that only the best science is flown. However, some U.S. scientists often object that any inclusion of foreign experiments is detrimental to U.S. scientific interests: U.S. teams lose valuable opportunities for support, and opportunities for U.S. development of technology are also lost. There is also the frequent complaint that NASA's periodic difficulty in funding science on American missions (particularly in the case of Spacelab) means that, in effect, the American taxpayer has paid for providing inexpensive science opportunities in space to researchers of other nations.

However, as the technical capabilities of our partners have increased, the scientific payoff from cooperation has become increasingly evident. The network of three satellites in ISEE (see table), for example, was significantly enhanced by the inclusion of the ESA satellite as well as by the foreign experiments present on all three spacecraft. 
The one fact that has lent potency to many of these criticisms in the past, however, has been the lack of reciprocity for U.S. scientists as principal investigators on ESA missions. ${ }^{12} E S A$ has now agreed to permit U.S. proposals in response to its Announcements of Opportunity. There is now a quota which is determined on a case-bycase basis, and procedures for carrying out the new policy are being implemented. Officials of both ESA and NASA feel that the bottleneck will now be NASA's ability to fund U.S. experiments on ESA missions.

\section{Soviet Cooperative Efforts}

With Other Parties

The U.S.S.R. entered the cooperative arena in space science more than 10 years after the United States. Its primary vehicle for international cooperation is the Intercosmos program, which was constituted in 1967 (with the first launch in 1969) to coordinate joint activities with Eastern European and other communist countries. The scientific program includes space physics and life sciences, in addition to more applications-oriented space research. Over the first several years a few scientific satellites were flown under the Intercosmos label, but the focus of the program appeared to be more political than genuinely scientific or even genuinely cooperative.

But the Intercosmos program took on added dimension in 1976 when it was integrated into the manned spaceflight program. Under this plan, cosmonauts from the member countries fly, one by one, on Soviet missions to the orbiting Salyut space station. Thus far, these have been "visiting crews, "dedicated to specific science objectives and typically lasting 8 days. The foreign cosmonaut is a "flight engineer" or "research engineer" (not the commander). Instruments or experiments developed by the Intercosmos member country $\mathrm{u}$ rider Soviet direction are flown up for use during the mission. The program appears to have been highly successful and advantageous for the Soviets, in the sense that they have gained much political capital vis-a-vis the' participating countries.

I'Space Science Research in the United States, op.cit.
Apart from the Soviet bloc countries, Soviet cooperative activities in space have extended only to the United States, France, India, and Sweden. The relationship with France has been especially fruitful, and has involved quite substantive missions: an observatory for locating cosmic ray sources (SIGNE 3, 1977); life sciences experiments onboard Cosmos 936 and 1129 (1 977/78); instruments on the Lunokhod landers, Mars, and Venera spacecraft; and a UV spectrographic instrument on the Prognoz station. Aread 3 (August 1981) has returned data on magnetosphereionosphere coupling; the UFT spacecraft, an optical and X-ray astronomy observatory was launched in March 1983. Plans for a joint Soviet/French mission to Venus in which Frenchmade balloons would be released into the atmosphere were recently altered to enable the Soviet spacecraft to continue on to Halley's comet (see discussion of the International Halley Watch below).

But the most striking cooperative project was the inclusion in 1982 of a French cosmonaut in the second crew to visit Salyut-7. A substantial element of the mission was the installation of a French medical diagnostic device, Aelita-1, aboard the station. ' 3 Gamma 1, a high-energy gamma ray observatory (1986), Sigma, a more sophisticated gamma ray facility (1987), and a cooled submillimeter telescope (1987).'4 Plans for a Venus/asteroid lander in 1991 will probably involve France as well. ' 5

France has engaged in this cooperation with the Soviets in a spirit of objective pragmatism. The French space science community has been able to make great strides through access to Soviet launchers and the well-developed Soviet space program. Meanwhile, French technical skills have significantly enhanced the Soviet capability, particularly in astronomy and the application of electronics. The U.S.S.R. has also been able to gain considerable diplomatic advantage through the relationship with a major Western nation, and has

\footnotetext{
${ }^{13}$ According torecent agreements, the same device will beflown aboard the U.S. Shuttle when a French astronaut participates in a U.S. mission in 1985.

${ }^{14} \mathrm{Nigel}$ Hen best, "Astronomy-The Next Space Race, "New SC1entist, Mar. 31, 1983.

${ }_{1}^{5}$ Aviation Week and Space Technology, Apr. 1,1985, pp. 18-20.
} 
capitalized on opportunities afforded by U.S. space science program cuts. ${ }^{16}$ The collaboration appears to have been mutually satisfying overall, although private discussions reveal some dissatisfaction on the French side with Soviet bureaucratic processes.

The other major Soviet cooperative activity with a non-Communist nation has been with India. With the exception of the first Indian satellite, Aryabhata (1975), dedicated to solar and atmospheric studies, and an Indo-Soviet balloon experiment in gamma ray astronomy in 1979, the joint projects have been applications-oriented. However, an Indian cosmonaut visited the Salyut7 station in April 1984.

Beginning in the early 1970 s, India has parlayed a very modest investment in space into a creditable program which is now nearing self-sufficiency. To do so it has relied on assistance primarily from the United States, the U. S. S. R., and France, and on a substantial pool of domestic scientific talent. In the process it has successfully maintained a balance between independence and cooperation, becoming a model for Third World countries not only in the development of a space program, but also in dealing with the superpowers. It is partly India's leadership role in the Third World that attracts Soviet attention, for India represents a lever by which the space-related organizations at the U.N. can be influenced.

\section{European Space Agency: Cooperative Outlook}

Through ESA, the advanced European nations have been able to mount a space program comparable in scale with those of the United States and the U. S. S.R. ${ }^{17}$ Although a primary area of endeavor is space science, ESA's budget (currently about 16 percent of NASA's) permits it to launch a medium-class space science mission only every 18 months. Cooperative activity, with the United States and with individual member nations, increases considerably the rate of participation in space science.

\footnotetext{
${ }^{16}$ Soviet Space Programs: 1976-80, op. Cit., pp. 288-289.

${ }^{7}$ For a full discussion of ESA's evolution and its programs, see Civilian Space Policy and Applications (Washington, DC: U.S. Congress, Office of Technology Assessment, OTA-STI-177, June 1982), pp. 176-187.
}

Because of its limited budget, ESA has had to conduct a more focused science program than the United States or the U.S.S.R.-mostly astrophysics and astronomy, and some life sciences. (Since space life sciences work falls within the "optional" category of programs, it tends to be dominated by individual nations, principally France.) The Giotto mission to Halley in 1985 will be the agency's first planetary mission. Also, no autonomous manned space activities have been attempted (the German payload specialist aboard Spacelab 1, Shuttle flight 9, was the first ESA astronaut). Nevertheless, ESA's accomplishments in space science have been considerable. Cooperative missions such as International Ultraviolet Explorer (IUE, 1978) and International Sun-Earth Explorer (ISEE, 1977/78) have produced some of the best science, and have been virtually textbook cases of international joint ventures.

The subject of reciprocity for American principal investigators on ESA missions has already been discussed. One point relative to that issue, and to ESA's long-term resistance on it, is that (unlike NASA) ESA does not save money when American experiments are flown; rather, the member countries do, on a proportional basis. Therefore, the loss of opportunity to a prospective European principal investigator looms much larger as a factor. ESA has ultimately agreed with NASA's position that its program has reached maturity, and that U.S. assistance over the years must now begin to be, in a sense, paid back.

\section{Current or Planned Programs}

As was pointed out earlier in this chapter, because of the increasing capabilities of space-faring nations as a whole, cooperative ventures are increasingly common and increasingly affect the competitive balance of the nations involved in space and space science. The following brief case studies illustrate the ways in which this dynamic is being altered.

\section{Infrared Astronomical Satellite (IRAS)}

This trilateral mission was launched in January 1983 , and was the first major astronomical satellite launched since 1978. A short-lived survey telescope, IRAS was first conceived by the Dutch 
but, at nearly $\$ 300$ million, was not affordable as a national project. The Netherlands approached the United States for assistance, and the cost was split three ways among the Netherlands, the United States, and the United Kingdom. The spacecraft was built by the Netherlands, with the United States providing a cryogenically cooled infrared telescope and detectors, and the United Kingdom providing the ground control and operations facility. The United States launched IRAS. Although the detectors aboard the satellite functioned as planned for only 11 months, ${ }^{18}$ it returned a wealth of new scientific data on infrared objects that were previously unobservable.

${ }_{18}^{18}$ The liquidheliumused to cool the infrared detectors boils away over time, limiting the life of the detector to the lifetime of the available helium coolant.

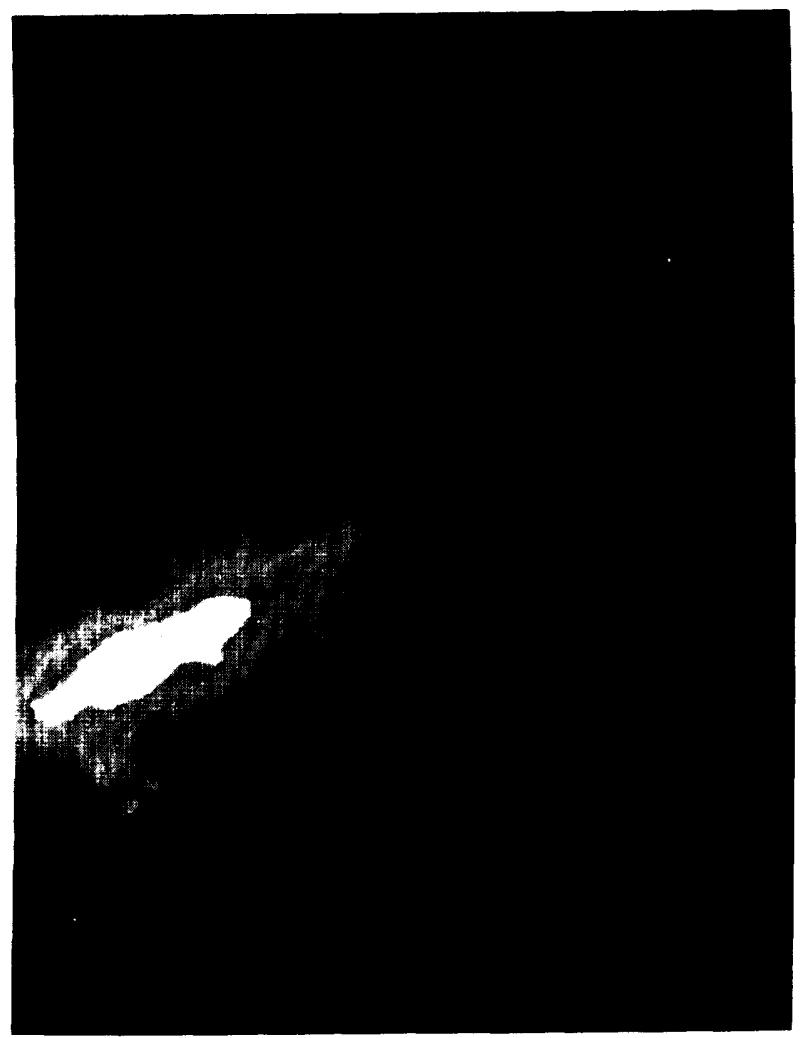

Photo credit: National Aeronautics and Space Administration

Infrared image of the center of the Milky Way galaxy taken from the Infrared Astronomical Satellite (IRAS). The Netherlands and the United Kingdom participated with the United States in this survey mission.
Significant IRAS findings include:

- a suspected burned-out comet,

- dust in the asteroid belt,

- a ring of interstellar dust and solid particles orbiting the star Vega, and

- infrared-emitting galaxies.

\section{International Halley Watch (IHW)}

This designator refers to the network of groundbased observations and data coordination that NASA will provide during the Halley missions in 1985-86. NASA will fund several international observational networks in addition to its own Deep Space Network; these will form the link between Earth-based and in situ observations of the comet ephemeris (positional data). NASA will also make supporting observations from Earth orbit via a collection of ultraviolet telescopes aboard the Shuttle, known as Astro-1.

Until mid-1982, there was a possibility that NASA would fund a Halley Earth Return Mission. That mission was not approved, so four spacecraft will travel to the vicinity of Halley: ESA'S Giotto, two Soviet Venus-Halley (Vega 1 \&2) spacecraft, and Japan's Planet-A. This will be a first planetary mission for both ESA and Japan. NASA's decision not to mount a mission was based partly on the fact that large quantities of in situ data will be collected by the already planned missions. In addition, NASA is supporting U.S. co-investigators on nearly every Giotto experiment. Interestingly enough, a U.S. instrument is being flown aboard one of the Soviet Vega spacecraft. ${ }^{19}$

There has been considerable multinational communication among these participants (including NASA), and an "Inter-Agency Consultative Group" has been established to coordinate encounter strategy and other matters relating to the space missions. A "Spacecraft Navigation and Mission Optimization Group" within this organization will provide the link between IHW ground observations and imaging data obtained aboard the various spacecraft. Data acquired from the U.S.S.R. Vega 1 probe will provide posi-

\footnotetext{
${ }^{19}$ John Noble Wilford, "U.S. Device Riding Soviet Spacecraft," New York Times, 12/21/84, p. A.1.
} 
tional data needed by ESA's Giotto spacecraft in its attempt to come within 1,000 kilometers of the comet's nucleus. The Vega spacecraft will precede Giotto by several days, allowing its observations of the comet to be used in a final course correction of Giotto.

\section{Space Telescope (ST)}

This is one of only two large U.S. astronomical satellites currently approved (the other is the Gamma Ray Observatory). Due for launch in 1986, it will be the most important telescope of the decade, putting in space a 2.4-meter telescope with an innovative "honeycomb" mirror. Instruments at the focal plane will include two cameras, a spectrograph, and a photometer to cover the UV and optical spectrum. ESA is contributing a Faint Object Camera, in the development of which seven countries are participating. ESA will also provide the solar array and ground operations support. In return, ESA astronomers will receive 15 percent of the observing time.

This telescope will be able to detect objects perhaps 100 times fainter than are observable with ground instruments, and is designed to last at least 15 years. NASA Administrator Beggs terms it "literally ... a cooperative effort of the world's astronomical community. ${ }^{" 20}$ An important element of this cooperation is the creation by the United States of the Space Telescope Science institute, in which scientists from many countries are working to ensure thorough dissemination and analysis of ST data.

\section{Astro-C}

This will be the third in a series of increasingly large and sensitive Japanese X-ray satellites. Unlike its predecessors, however, Astro- $C$ is a joint mission between Japan and the United Kingdom. Japan prefers the autonomy of a national mission-its space science budget, roughly as large as ESA's, will usually permit it. The United Kingdom also prefers national projects, but has not had one since about 1977. It has, however, had considerable X-ray experience in the Ariel series, so Japan asked it to develop the very large detec-

\footnotetext{
${ }^{20}$ AnInterview with James M. Beggs, Sky \& Telescope, o c t o b e r 1982, p. 332 .
}

tor, to be accompanied by smaller Japanese detectors similar to those already flown. The United Kingdom is now a "junior partner" in almost every current joint astronomical mission.

\section{International Solar Polar Mission (ISPM)}

Planned initially as a completely joint ESA/U.S. mission, ISPM became something of an international cause celebre when the United States canceled the most important part of its side of the mission. The mission was to consist of two spacecraft (one from each agency) which would fly well out of the plane of the solar system to cross the north and south poles of the Sun. When NASA was faced, in the Reagan Administration's first budget, with a large reduction, it became necessary to cut either the Galileo mission, ST, or ISPM. ISPM was tapped-that is, the U.S. spacecraft was canceled. However, the United States will still launch the ESA satellite, provide tracking and data relay, and fund a number of experiments on the remaining satellite.

The European reaction was unexpectedly strong and outraged. ESA had spent $\$ 100$ million on the project, and was counting on the unique stereoscopic view of solar phenomena made possible by two satellites. In addition, European scientists planning to fly experiments on the U.S. craft lost their opportunities. The affair has since cooled down, although it is even now a sore point raised as an example of the dangers of international cooperation on a major project.

\section{Outlook for Future International Cooperation}

In some respects, the era of small-scale missions performing valuable space science is nearly over. All new planetary missions and all manned and most biological missions are expensive; the next generation of cooled IR and X-ray observatories will also be expensive. State-of-the-art missions in space science will increasingly require multifunding cooperation in order to be done. ROSAT, Galileo, GRO, Starlab, FUSE, OPEN, ISTP (see table 9-1 )-the list of planned and proposed joint ventures is long-and U.S. commitment to cooperate remains strong. The President's "National Space Policy," announced in July 1982, reaf- 


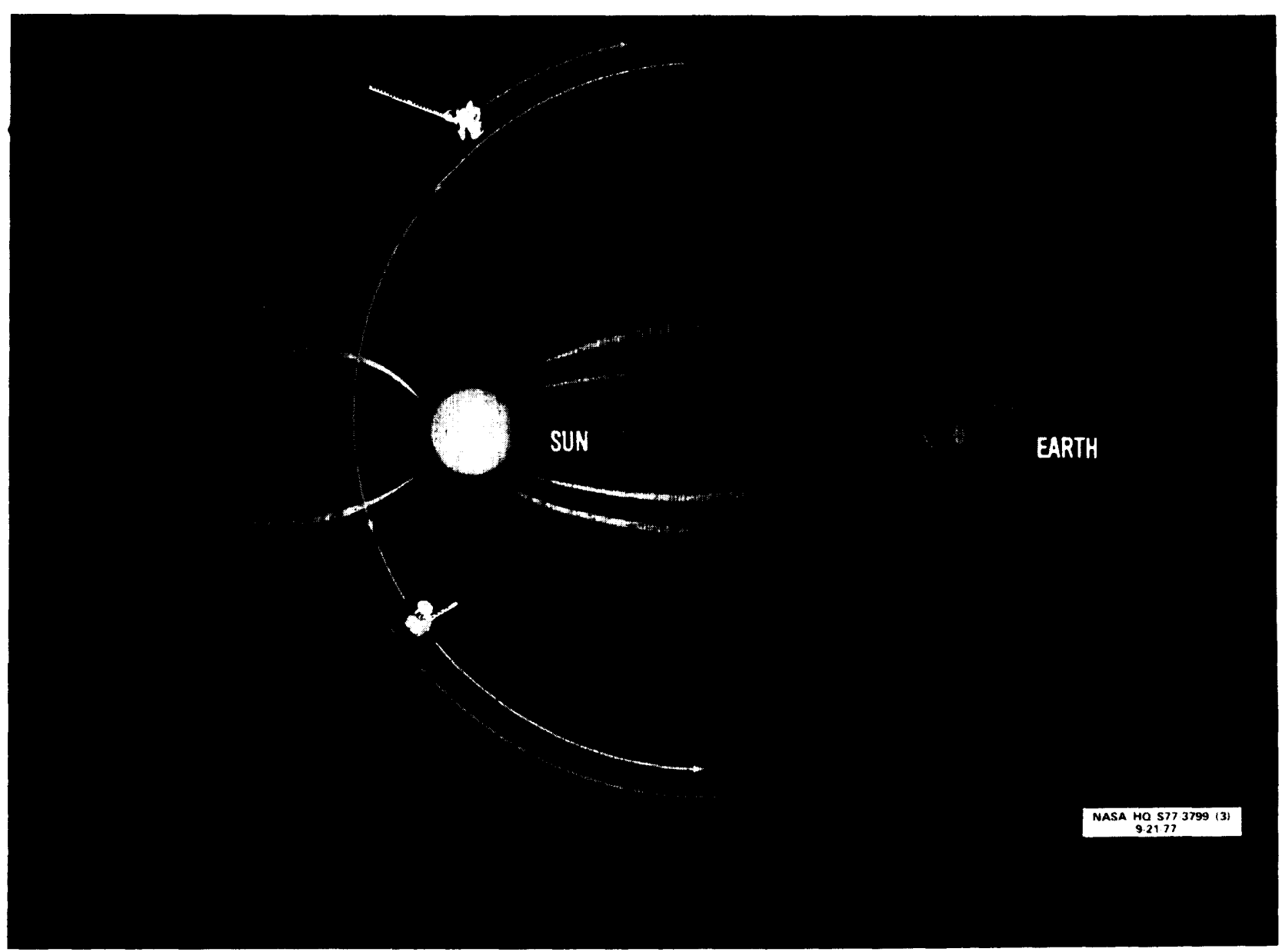

Photo credit" National Aeronautics and Space Administration

Artist's conception of the International Solar Polar Mission in its original configuration. NASA and ESA were to have flown two separate satellites, each in opposite directions over the Sun's poles. There will now be a single ESA satellite with participation from the United States. In this drawing the solar wind (cosmic rays emitted by the Sun) is depicted by the snake-like trail emanating from the Sun. The arrows indicate material that the Sun emits from its polar regions.

firmed the need to "promote international cooperative activities in the national interest" as a basic goal. This goal was reemphasized in the State of the Union Address delivered in January 1984, in which the President expressed his expectation that "NASA will invite other countries to participate" in a U.S. space station effort.

The concerns provoked by ISPM and by U.S. budgetary uncertainties in general have brought about a change in outlook more than behavior: "We learned a great deal about the U.S. budgetary processes, " as ESA'S Washington representative puts it. ". . . We shall be more cautious in the future about drawing up agreements. "NASA's
Director of International Affairs, Kenneth Pedersen, asserts that there are three assurances that NASA can offer ESA: 1) the ISPM experience, with its repercussions, makes it less likely that similar events will take place in the future; 2) budgetary austerity means that only top-priority (and therefore not expendable) science projects will be approved; and 3) space science is on the upswing within NASA.

Jointly coordinated planning and management will probably be essential in the future. One approach is the current activity of a Joint Working Group of the NAS Space Science Board and the Space Science Committee of the European Science 
Foundation toward establishing a framework for the joint conduct of future planetary exploration. These discussions include formulation of a strategy in terms of science goals and missions, and definition of a desirable approach to long-term cooperation.

The broadening of cooperation will inevitably require the leading countries in space to deal on a policy level with the pressure from Third World countries for participation, as expressed recently by some members of the Committee on the Peaceful Uses of Outer Space (COPUOS), delegates to UN I SPACE '82, and attendees at the February 1983 Intergovernmental Meeting of Space
Technology Experts. ${ }^{2} \sim$ This consideration is not as directly relevant to space science, however, as it is in the areas of launcher development and applications-oriented space activity. Nevertheless, it will play a role in the space sciences, particularly in light of the Soviets' apparent willingness to train and fly cosmonauts from developing countries (e.g., India). The United States must remain cooperative in order to remain competitive.

21UNISPACE'82: AContext for International Cooperation and Competition, op. cit.

\section{THE ROLE OF COMPETITION IN SPACE SCIENCE}

It is a truism, certainly in our free market system, that competition promotes better performance. This applies in space science as well, whether on a national level, between research teams and laboratories, or on an international level, between space agencies. But competition in space science works to the advantage of some more than others. There are many factors at work other than sheer technical and scientific capability. Institutional and economic variables on the national level come equally into play. For example, the amount of funding allocated is obviously a major factor. But also important is the degree of governmental commitment to an endeavor that will not immediately produce revenues or increase the standard of living of the populace.

This "willingness to take a risk" is essential; if, for example, a country provides governmental support for the training of graduate students in astrophysics, then that activity is more likely to flourish competitively. The style of management accorded space science R\&D and missions operations is another important factor; a cumbersome, multilayered bureaucracy will not allow efficient conduct of space science. Long-range planning is also crucial: it must include realistic goals, an intelligent assessment of scientific priorities, and a shrewd appraisal of foreign plans. The degree to which scientific opinion enters into the planning process is also a factor.
All of these factors combine to shape a country's competitive posture. It may then be asked, does a country's competitive strength, gauged by these criteria, determine its standing among nations participating in space science? Are there clear winners and losers on the international scene?

\section{Prospects for a "Space Science Race"}

The answer to that question, for the moment, appears to be "no." In large part this is because two of the principal players, the United States and the U. S. S. R., have for decades had the game essentially to themselves. They have competed, but only at times "head-to-head," and in any event there was no actual prize to win, beyond political prestige. Each nation has essentially cultivated its own group of proteges. In the case of the West, some of these client nations have only recently begun to acquire a degree of self-sufficiency in the support of space science programs. There is not yet adequate scope or momentum in these programs to surpass the United States in any area.

Space science missions are selected out of a common pool of ideas that, in most cases, have been around for more than a decade. There is no element of surprise. There is certainly no point in duplication of missions, or in racing to launch. 
A case in point is ESA's decision to build an Infrared Space Observatory (ISO), which will be similar in performance to NASA's planned Shuttle Infrared Telescope Facility (SIRTF). The likely outcome is two separate missions with overlapping but independent experiments to prevent too much duplication. In general, scientific data are shared fully in the West, and it is to the benefit of all concerned to continue doing so. The continuing flow of information even between East and West makes this point clear.

To say that there appears to be no scientific space race in prospect is not to say that competitive factors have no impact. institutional commitment and funding levels will inevitably affect the rate, efficiency, quality, and economy of missions mounted and science performed. The positive image and reputation for reliability thus gained would then make a country an attractive cooperative partner, not only in space science but in the more commercial areas of space activity as well.

One further point that should be made is that it is only i $n$ the planetary sciences that there are tangible "prizes" to be won. Soviet spokesmen have consistently hinted at an agenda consisting of: 1 ) permanent manned presence in Earth orbit, 2) colonization of the Moon, and 3) manned missions to Mars. ${ }^{22}$ The first step is already a reality, for all practical purposes. Any resumption of an active "space science race" between the United States and U.S.S.R. would likely focus on the second. However, science would only be incidental to such a contest.

\section{Current Ranking of Participants}

It was pointed out earlier that technical, economic, and institutional factors determine a nation's "competitive posture" for space science, and that this affects its ranking among nationsalthough historical factors are at this point predominant. The following is a brief assessment of the ranking of the four major entities in space science:

\footnotetext{
${ }^{22}$ Salyut: Soviet Steps Toward Permanent Human Presence in Space, op. cit., p. 4.
}

- United States. The United States is clearly the overall leader in space science. This is true even in view of the fact that only one mission (Solar Max) was launched between 1978 and 1983, while resources were being focused on the space shuttle. U.S. current weaknesses in X-ray astronomy will be rectified (it is hoped) by the proposed Advanced X-Ray Astronomical Facility (AXAF); but at any rate will be improved by participation in the German ROSAT mission. The languishing planetary program will be revived by the Galileo mission to Jupiter and by the Venus Radar Mapper (a new start in 1984) and a proposed Mars Geoscience/Climatology mission (a new start in 1985). Life sciences is being resumed in earnest on Spacelab, with two dedicated Spacelab life sciences missions tentatively scheduled for 1985 and 1986.

- European Space Agency. ESA's development in space science during the 1970s was rapid, as demonstrated by the ESRO and HEOS satellites, and especially by COS-B, a highly successful gamma ray satellite. A number of important joint missions with the United States augmented its autonomous programs in astronomy and astrophysics, which are now being continued with Exosat and Hipparcos. ESA's venture to Halley's comet is its first planetary mission. On the basis of technological sophistication and diversity of science, ESA is ahead of the U.S. S. R., although not by a wide margin.

- Soviet Union. The Soviet Union ranks ahead of Japan principally on the basis of its highly successful Venera series. Using vacuum-tube technology to withstand the planet's high surface temperature, this program has been impressive. Another strong mission is Venera-Halley, which will drop probes to Venus and continue on to rendezvous with the comet. The U.S.S.R. is also advanced in the life sciences, both animal and plant-chiefly because of the huge number of man-hours in space that its Salyut program has afforded. The Soviet effort in astronomy relies to a great extent on French technical capability.

- Japan. This country is fourth, but is probably moving the fastest. It currently has a narrowly 


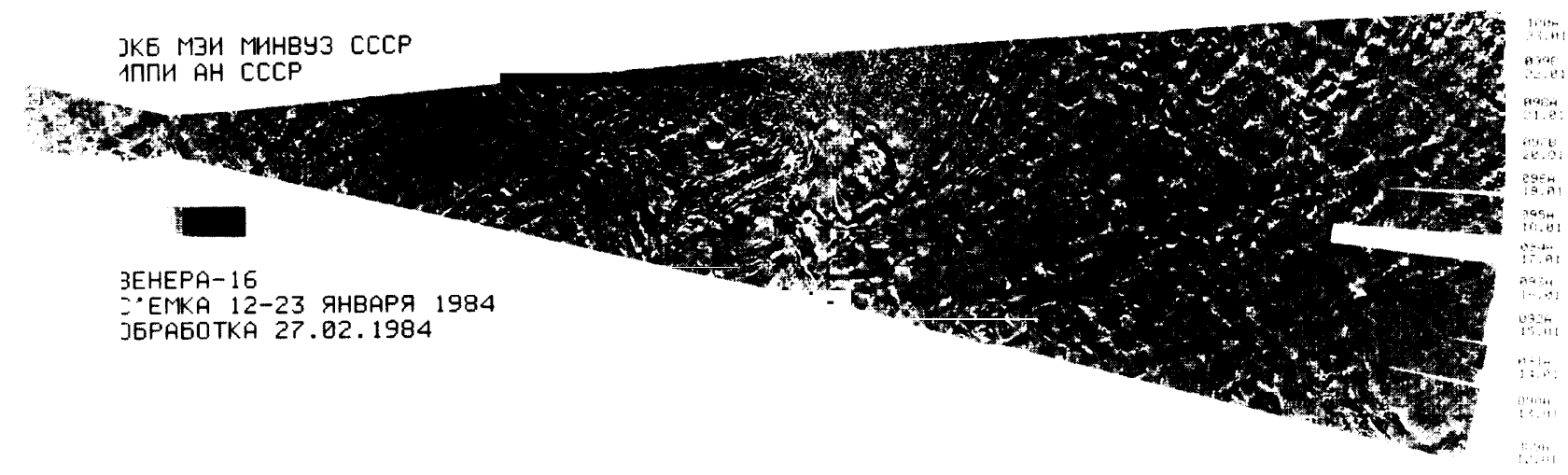

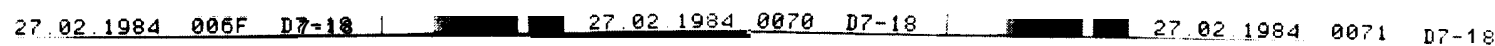

Photo credit: Institute of Space Research, U.S.S.R. Academy of Sciences

Radar image of surface of Venus from Soviet Venera 16 spacecraft, January 1984.

focused program of solar-terrestrial and astrophysics research. The Planet-A mission to Halley will be its first planetary mission. Japan has about one-tenth of NASA's budget for space expenditures, and like NASA's, the overall budget has not grown substantially in recent years. I $\mathrm{n}$ Japan, space science research is conducted by the Institute of Space and Astronautical Science (I SAS), a division of the Ministry of Education. Although the budget for space science has increased substantially in recent years, most of the increase has gone for the construction of a new campus on the outskirts of Tokyo. Thus, of the $\$ 80$ million fiscal year 1983 budget for ISAS, $\$ 58.5$ million went for space science and observations and $\$ 0.5$ million for the highaltitude balloon program, with the remaining \$21 million for various overhead costs; the increase for space science and observations in the fiscal year 1984 budget was a modest 4.3 percent, bringing its total to some $\$ 60.9$ million. With the advent of a U.S. space station, Japanese spending for space science could be expected to rise more sharply. A Japanese space official estimates that Japan is 5 years behind ESA and 15 years behind the United States in space science. The new ISAS facilities, however, should position Japan well for future efforts to overtake ESA.

\section{Tradeoffs Between Competition and Cooperation}

The conduct of space science in a cooperative yet increasingly competitive atmosphere gives rise to some crucial policy issues. For example, the reduction of opportunities for U.S. space scientists In recent years brings to a sharper focus the criticisms of our open policy toward foreign proposals. There is a tendency toward a protectionist attitude among scientists, who view some collaborative efforts as "giveaway s." The only answer to this is to ensure that foreign experiments win approval on their own merits in every case, and that foreign governments pay their full share of every joint project. Yet policy decisions may occasionally override these considerations, particularly in the case of Third World countries. A policy for dealing with this issue will be required.

There is, as yet, no formal policy for dealing with the issue of technology transfer. Currently such decisions are made on a case-by-case basis, and there is room for error here. Such a policy will be difficult to implement, because the concerns are specific to each case. Often, there is no problem because the technology is packaged in such a way that it cannot be compromised. But the growth of cooperative activity (e.g., between the French and the Soviets) increases the risk of loss from both primary and second-party 
transfer. Our cooperative partners in space science are increasingly likely to be our industrial competitors.

\section{Markets for Hardware and Services: Space Science as Growth Industry}

In recent years the most vigorous and dynamic areas of the U.S. economy have been the hightech fields: electronics, data processing, communications, robotics. The conduct of state-of-theart space science relies to a great extent on these fields, and on specialized applications such as high-quality optics and sensors. The value of this endeavor to the stimulation of further growth in these fields, and thus in the economy, has not yet been estimated. However, in the context of an overall NASA space science budget of $\$ 1,030$ million (fiscal year 1985), it is clearly considerable.

What are the essential products and services at issue? They fall into three categories:

- Instrumentation. This category includes all sensing devices and associated hardware mounted on a scientific spacecraft: telescopes (including mirrors, lenses, housings, and mechanisms for placing instruments at the focal plane); detectors (e.g., gamma ray, $X$-ray, IR) and spectrographs, cameras, and associated systems such as cryogenic cooling apparatus. Major variables affecting cost and availability include spectral resolution and sensitivity.

- Spacecraft. This is essentially the development of numerous variations on a theme, with main components being the mounting platform, an electrical bus for powering the instruments, and a system for thermal control. The technology is fairly standardized. One area where R\&D is still quite active is in the search for ways to improve pointing accuracy and stability (accomplished by feedback loops between the instruments and the attitude control system). The improvement of on board computer technology in terms of storage capacity and data rates is another developing area. Most systems (e.g., gyroscopes) are not particularly competitive in terms of technology. U.S. manufacturers dominate the field internationally, and are closely grouped in the sense of product capabilities, performance, and quality. The real competition here is in price and reliability.

- Data Processing. This category includes all computer systems and facilities on the ground for reception, analysis, and dissemination of spacecraft data. This area is the least relevant to a discussion of the national and international markets, since most U.S. missions do not require new facilities but rely on existing equipment at JPL (planetary $\mathrm{m}$ issions) and Goddard Space Flight Center. Because this is the least critical area relative to mounting space science missions, large differences in ground-link data processing capability among nations have relatively little effect on space capability. (A case in point is the U. S. S. R., which has only in the past 2 years modernized its ground control facilities approximately to a mid-1970's level of U.S. computer technology.) Nations with no capability (e. g., The Netherlands) generally exchange scientific data for tracking and data processing services.

\section{International Trade Factors}

There are 13 U.S. space systems manufacturers, with two or three times that number supplying major components. Of these, only five have ever manufactured space science spacecraft: Hughes, Boeing, TRW, Grumman, and Ball Bros. * This fact indicates as well as any other statistic the small size of the market in this area relative to that for launchers, applications satellites, and military systems. In dollar terms, the domestic market amounts to about 85 percent of the NASA space science budget in any given year (e. g., roughly $\$ 716$ million in fiscal year 1984), for systems, components, and data analysis.

The main point to be made is that, although there is a national market, there is only a very small international market in space science technology. Boeing has contracted to Sweden to build the Viking satellite, at a cost of $\$ 9$ million to $\$ 10$ million. Ball Bros. manufactured parts of the IRAS spacecraft. The total annual U.S. sales to foreign

\footnotetext{
* RCA and GE, however, have built research satellites for Earth science m issions.
} 
countries, including components and spares, does not exceed $\$ 50$ million, and in some years is less than $\$ 20$ million. Foreign space programs are generally required-whether implicitly or explicitly-to keep their business at home. It is significant that no U.S. company has foreign sales representatives for these systems.

Foreign companies' sales to the United States are even more limited. The solar arrays on Space Telescope will be built by British Aerospace. The German firm Telefunken manufactures traveling wave tubes that have been bought by U.S. manufacturers for use in on board communications systems. Zeiss is a competitor of Perkin-Elmer in optics. But in general, U.S. companies are far ahead of their foreign counterparts in the development of space science satellites and systems.

One development having potential implications for the stimulation of a market in this area is Boeing's development of MESA, a "generic" platform satellite similar to that being supplied to Sweden. Their approach is to offer a low-cost, standardized bus and then to assist scientists in shaping the experiment to fit within its parameters. Boeing is marketing this system internationally with the help of Arianespace and Matra, the French space companies.

\section{SPACE SCIENCE IN DEVELOPING COUNTRIES}

\section{The Allure of Space Science}

Any discussion of this topic must be prefaced by an acknowledgment that the interest so vocally expressed by Third World countries in greater participation in space activities is explicitly an interest in the "practical" side of space: television and telephone communications for business, educational, medical and other purposes; remote sensing of their terrain and weather; launcher services, etc. Chapters 3, 6, and 7 in particular address these major aspects of the subject. Astronomy or planetary exploration for their own sake are "luxuries" that the Third World cannot yet contemplate.

Yet there is a small but essential role for space science in the context of Third World aspirations. Even though developing countries are particularly interested in the economic and practical benefits of space activity, they are not unaware of the fundamental value of space science: $:^{23}$

It is sometimes argued that basic science in general, and space science in particular, are not important in a world pressed by practical problems. This is not correct. Besides the fundamental argument that an understanding of the universe is important in its own right, it is also true

\footnotetext{
${ }^{23}$ Report of the SecondUnited Nations Conference on the Exploration and Peaceful Uses of Outer Space, Vienna, Aug. 9-12, 1982.
}

that initiatives in space applications have most often been taken by people who were earlier motivated by their interest in space science.

Space science offers the ability to build the necessary skills and knowledge, the research groups, the facilities-the infrastructure for space applications. It also offers a model for the kind of largescale cooperation with the primary space nations that is needed to build and sustain an applications program. The following "directions to follow" are excerpted (and summarized) from the UN ISPACE Forum report: ${ }^{24}$

1. Obtaining Scientific and Technical Capabilities:

- Training of scientific/technical personnel by:

- inviting foreign experts;

- training in foreign countries; and

- participating in seminars, conferences, summer study sessions, etc.

- Such training should be strengthened through locally conducted space experiments (usually cooperative and modest).

- Training must not be overspecialized. Basic training in electronics, optics, computer sciences, etc., is essential.

\footnotetext{
${ }^{24,}$ Relevance of Space Science for Development, " in the Conclusions from the UN ISPACE Forum, Vienna, Aug. 4-6, 1982, pp. 2-3.
} 
- Training of high-level scientific and technical teams should be emphasized over training of individual specialties.

2. Fostering International Cooperation:

- Smaller countries, of modest means, can develop a major space capability only by forming into groups (e.g., ESA, Intercosmos).

- Developing nations can participate in the space activities of industrialized countries by:

- studying data from foreign satellites,

- developing their own receiving stations,

- participating in balloon or sounding rocket experiments,

- participating as guest investigators in foreign projects, and

- developing instruments for flight aboard foreign spacecraft.

- Development of regional space research centers and facilities could provide benefits at a low cost.

\section{Difficulty of Joining the Space Club}

One of the expressed motivations underlying U.S. cooperative activities in space is the political one of winning friends and influencing nations. This rationale certainly applies in those areas of the world where the diplomatic balance is less certain than it is among our major allies.
Thus, our past cooperative ventures in space science with countries such as India, Pakistan, Peru, and Brazil have a larger significance than their purely scientific content would indicate.

As was noted earlier, because of the great increase in cost of space science projects there is likely to be more cooperation in the future. An increase in cooperative activity in general will make the pressure from the Third World for participation more significant. Competition for cooperative activity as a po/itica/ tool is therefore likely to be an increasingly important factor on the world scene. president Reagan's offer in early 1984 to fly an astronaut from the People's Republic of China is certainly a case in point, though subsequent discussion of this possibility has focused on ensuring a substantive science return with space plasma physics as the most likely subject of joint investigation.

Although many developed nations (and ESA) may eschew cooperative arrangements in which the outlay is one-sided-as it will necessarily be in the case of space science-the United States probably cannot afford to overlook the political side of these activities. At the very least, policymakers should be aware of the value of low-level scientific activities in building part of the infrastructure needed for participating in applications, and should make this consideration part of any long-term policy regarding the involvement of developing nations in our space program.

\section{SPACE SCIENCE IN THE 1980s AND 1990s: A VITAL CONCERN}

As an enterprise, space science has not had quite the drama of the manned space programs of the 1960s and early 1970s; likewise, the interest in commercialization in space may overshadow its achievements in the public mind. Yet space science has a healthy future. The reaction to the Viking photographs, and especially to the Voyager revelations and IRAS discoveries, showed that there is a lively public fascination with basic discovery in space. The findings of the space telescope may have a similar impact. There is a strong base of public support for space science in the United States, one that will help to pre- serve this essential undertaking from long-term budgetary decline.

As a foundation for applications in space, space science will continue to be a most useful tool for diplomacy. Space science will also continue to be one of the small drivers of the most advanced elements of our national industry and economy, fueling innovation and growth in many areas. This will be particularly important as private investment in space expands.

Finally, it may be that space science will prove valuable as an offset to military competition in 
space, providing an outlet for the competition for strength and prestige and, more important, of- fering a vehicle for cooperation that could once again have a part in some future version of detente.

\section{POLICY OPTIONS}

\section{Cooperation With the Soviet Union}

As was pointed out earlier in this chapter, the history of Soviet cooperation with the United States in space science has been surprisingly strong. Yet, at any point in this history, the future has always been unpredictable. The United States has traditionally left the door open to cooperation, and the U.S.S.R. has occasionally taken advantage of the invitation. There has generally been little prelude to such initiatives. They are opened by the Soviets on an informal basis, usually through scientific exchange, as global politics appear to permit.

In 1982 the United States decided not to renew the 1972/77 Intergovernmental Agreement, This decision undoubtedly had some of the intended diplomatic impact on the U. S. S. R., but it also eliminated opportunities for U.S. scientists and stifled what had been a fruitful area of international exchange on many levels. At this point, the scientific value of reestablishing that interchange may exceed the political value of continuing to interdict it. Although the political benefits to be gained by cooperating with the Soviets appear relatively small, * $s$ the scientific benefits of cooperating in certain subfields of space science could be well worth the effort. In the previous agreement, the two primary areas of scientific cooperation were in projects studying space biology and medicine and the Moon, planets, and near-Earth space. Of the two, the most substantive and successful cooperation was in the life sciences.

Scientists actually involved in these exchanges believe that the overall success of the collaborations in life sciences can be attributed to:

\footnotetext{
${ }^{25} /$ ssues in U.S. Soviet Cooperation in Space, Office of Tech nology Assessment, in press.
}

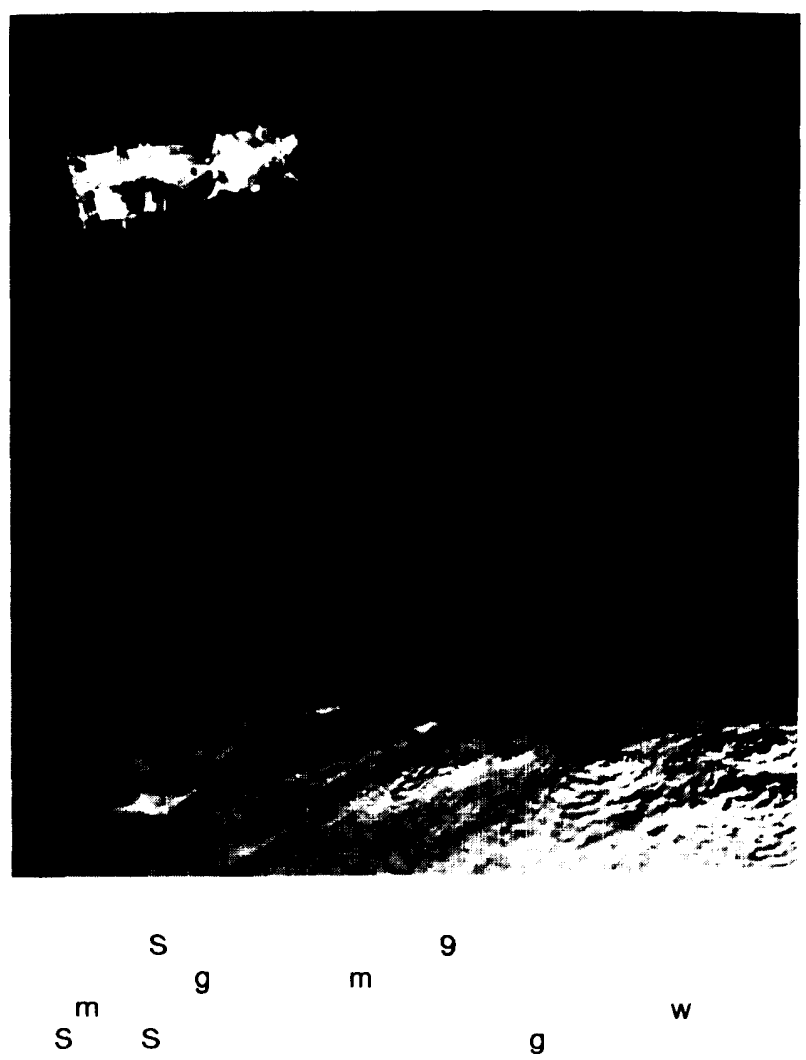

1. a focus on well-defined and specific scientific objectives;

2 , the selection of areas of complementary abilities, which provides strong motivations to continue to cooperate once a project is started;

$3_{4}$ the selection of instrumentation that did not raise concerns about technology transfer;

4. institutional organization that gave officials on both sides the autonomy to decide how to implement plans; and

5. the development of mutual confidence, knowledge, and goals among working groups over a long period of cooperation. 
In the planetary category, the strongest areas of cooperation were in lunar studies, the exploration of Venus, and solar-terrestrial physics. The exchange of lunar samples and cartographic data provided both sides with a range of information unobtainable by either program alone.

As noted above, however, Public Law 98-562 proposes a limited renewal of U.S./U.S.S.R. cooperation. Such cooperation, if renewed, should be based primarily on the lessons learned from previous cooperative programs,

\section{Project Continuity}

From a political standpoint, the most important thing the United States can do to maintain its position of leadership in space science is to provide assurances to cooperative partners that our commitments will be kept. The $\mathrm{u} n \mathrm{i}$ lateral decision of the United States to reduce sharply its role in ISPM continues to be mentioned as an example of U.S. unpredictability in cooperative efforts. Assurances may have to take the form of multiyear funding for international missions, so that they are not subject to the vagaries of annual budgeting. Although U.S. political institutions are not structured in such a way as to make multiyear funding generally either particularly desirable or feasible, given the importance of our relationships with our allies, providing multi-year funding for certain specific space projects may be appropriate.

\section{Choosing Specialization}

Given the peculiar competitive environment of space science, i n which "racing" others for spe- cific accomplishments is counterproductive, competition is likely to take the form of long-term jockeying for areas of specialization (e.g., astronomy, planetary missions). Manned planetary missions (supported by life sciences research) ultimately hold the greatest strategic importance; it is this area that the Soviets appear to be emphasizing. Yet astronomy and astrophysics are perhaps more important to the advancement of related Earth-bound technologies and to the acquisition of knowledge essential to Earth-sensing and meteorological applications.

\section{Technology Transfer}

The United States may embark on a program to build long-term infrastructure in space for manned activities. ${ }^{26}$ If so, such a program will certainly include some space science research. Many of these space science projects, and indeed, certain components of this infrastructure, may include cooperative efforts with other countries. It will be important for the United States to work out policies governing technology transfer to ensure that we do not give away our competitive edge, while cooperating as fully as possible with others.

\footnotetext{
${ }^{26}$ Civilian Space Stationsand the U.S. Future in Space (Washington, DC: U.S. Congress, Off Ice of Technology Assessment, OTA STI-241, November 1984).
} 
Chapter 10 POLICY ALTERNATIVES 


\section{Contents}

Introduction. . . . . . . . . . . . . . . . . . . . . . . . . . . . . . . .......397

Space Policy and National Objectives . . . . . . . . . . . . . . . . . . ....397

Setting Goals and objectives . . . . . . . . . . . . . . . . . . . . . . . .......399

Approaches to Competition . . . . . . . . . . . . . . . . . . . . . . . ...........400

Principal Elements of Competition Policy in Space-Related Activities. ., .. ...401

Approaches to International Competition . . . . . . . . . . . . . . . . . . . ........403

Elements of Cooperative Policies . . . . . . . . . . . . . . . . . . . . . . . 408

Emphasize Cooperation That Contributes to the Technological Goals of the

United States . . . . . . . . . . . . . . . . . . . . . . . . . . . . ....................409

Emphasize Political Benefits of Space Technology . ...................410

Participation in International Organizations . .....................411

Provide Assistance to Developing Countries. . . . . . . . . . . . . . . . . . . 411

Establish International Organizations to Provide Space Services. . . . . ......4412

The Relationship Between Cooperation and Competition . ................413

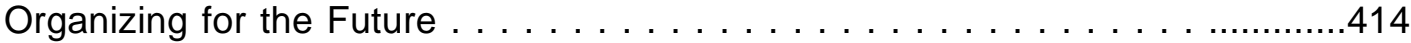

Maintenance of U.S. Leadership . . . . . . . . . . . . . . . . . . . . . ...............414

Scientific Research and Technology Development, . . . . .................415

Commercial Application and Development of Space Industries . ...........415

International Commercial Competition . . . . . . . . . . . . . . . . . . . .........416

International Cooperation. . . . . . . . . . . . . . . . . . ..................4416

Responsibility for Individual Technologies . . . . . . . . . . . . . . . . . . . .4417

Conclusion . . . . . . . . . . . . . . . . . . . . . . . . . . . . . ....419 


\section{Chapter 10 POLICY ALTERNATIVES}

\section{INTRODUCTION}

The policy by which the U.S. civilian space program has developed was first articulated in the 1958 National Aeronautics and Space Act (NAS Act), which provided broad guiding principles for U.S. space activities. The Act authorized the formation of the National Aeronautics and Space Administration (NASA) and declared that "activities in space should be devoted to peaceful purposes for the benefit of all mankind" (sec. 101 (b)). It specifies, among other things, that NASA should conduct its space activities so as to contribute to:

- the preservation of the role of the United States as a leader in aeronautical and space science and technology and in the application thereof to the conduct of peaceful activities within and outside the atmosphere; and

- cooperation by the United States with other nations and groups of nations i n work done pursuant to this Act and in the peaceful application of the results thereof.

Where necessary, Congress has enacted other specific legislation, such as the Communications Satellite Act of 1962,2 which created the Communications Satellite Corp. (COMSAT) and aided in establishing INTELSAT, ${ }^{3}$ or took other legislative measures to advance the civilian uses of space. ${ }^{4}$ All of these measures have built on the provisions of the NAS Act.

The broad policy principles of the NAS Act have allowed each successive Administration considerable latitude in deciding how to imple-

\footnotetext{
1 National Aeronautics and Space Act of 1958, as amended, sec. 102 (c), Public Law 85-568, 85th Cong., H.R. 12575, July 29, 1958.

${ }^{2}$ Communications Satellite Act of 1962, Public Law 87-624, 87th Cong.,H.R. 11040, Aug. 30, 1962.

${ }^{3}$ Communications Satellite Act of 1962, Amendment: International Maritime Satellite Communications Act, Title V, Public Law 95-564, No v. 1, 1978.

${ }^{4}$ For a more detailed discussion see: U.S. Congress, Office of Technology Assessment, Civilian Space Policy and Applications, OTASTI-177 (Washington, DC: U.S. Government Printing Off Ice, June 1982), ch. 10. Congress also enacted the National Science and Technology Policy, Organization and Priorities Act of 1976 (Public Law 94-282), which, among other things, authorized the formation of the Office of Science and Technology Policy,
}

ment its basic provisions. Over the past 27 years, the Act has been amended from time to time, but its basic guiding principles, including the above references to competition and cooperation, have remained intact. According to most observers, because of its generality, the NAS Act remains an appropriate overall guide for the Nation's civilian space activities. s Nevertheless, the terms on which the United States and other nations operate in space have altered dramatically over the years. As the analysis of previous chapters has emphasized, the emergence of commercial and governmental competition from other industrialized nations in space, the increasing interest of the U.S. private sector in space investments, concern over access of U.S. firms to foreign spacerelated markets, and changes in the climate of cooperation with both developed and developing countries, raise several important policy questions:

1. What new national goals and objectives, if any, are needed to sustain the general principles of the NAS Act in the 1990s?

2. What alternative approaches or strategies should be considered by Congress in implementing these goals and objectives?

3. What are the appropriate roles of individual Government agencies, including NASA, in carrying out future space policy and conducting governmental space activities?

4. What is the appropriate role of Government in supporting and" regulating private sector activities in space?

\section{Space Policy and National Objectives}

The use of space technology is undergoing a period of rapid and significant change. Because decisions concerning many domestic space-re-

\footnotetext{
5See, for example, Finding 2, Sec. 202 of Public Law 98-361, which states, "The National Aeronautics and Space Act of 1958 has provided the policy framework for achieving this success (of the U.S. space program), and continues to be a sound statutory basis for national efforts in space."
} 
lated issues necessarily affect decisions over international issues related to foreign competition and cooperation, domestic and international concerns must be considered simultaneously. Examples of such domestic issues include the deregulation of the communications industry, the efforts to transfer space-based land remote sensing to private ownership, the development of a commercial space transportation industry, and the development of commercial products from research on materials processing in space. The necessary interaction of domestic and international issues has produced a complex, and sometimes conflicting, matrix of policies. For example:

- our desire to benefit from the technology developed in the space programs of other developed countries and our commitment to assisting developing countries suggest increased cooperation. Yet, our desire to limit the transfer of technology to economic as well as political competitors, maintain U.S. technological leadership, and ensure that the economic benefits of U.S.-developed technology flow directly to the U.S. economy, suggest a more restrictive international stance.

- U.S. commitment to free trade and open markets supports policies of reducing Government subsidies of space industries and eliminating "buy-national" practices. Yet most countries, including the United States, use "buy-national" policies to support fledgling space industries and develop valuable experience with space technology.

- The United States encourages the participation of the private sector in all aspects of space technology development and application. Yet, in such important areas as space transportation and remote sensing, the Government's own programs have created barriers to the successful commercialization of these technologies.

- The NAS Act gives NASA responsibility not only for developing untried technologies but also for supporting critical U.S. competitive and cooperative goals, including commer- cialization of space tech nology. ${ }^{6}$ Yet the political and economic dimension of space technology already exceeds the purview of any one Government agency ${ }^{7}$-let alone one dedicated to the demanding task of research and development of intricate and advanced space technology.

- The United States espouses the virtues of commercial competition in satellite communication services, yet foreign policy interests may cause it to restrict U.S. satellite firms wishing to compete in international facilities markets,

There is no single resolution of these sometimes conflicting policies. This report has explored the application of these and other policies as they relate to specific space technologies, Because the path from initial conception to a mature technology capable of governmental, commercial, or scientific application is a complicated one, involving many decisions of the Government and the private sector, it is clear that no single set of policies can ever be sufficient to govern all space technologies. The development of space goals and the policy strategies chosen to pursue them must follow an evolutionary process, responding to specific technical as well as social, economic, and political problems.

One end of the spectrum of policies related to space technology applies directly to questions of technology R\&D and Government programs; the other applies to the development of domestic commercial space industries and to their success in international markets. In the latter, space policy may serve as a component of more general industrial policies. As the debates over transfer of remote sensing to the private sector, or over the appropriate U.S. response to private competition with INTELSAT, have shown, proposed commercial space ventures may raise important issues

\footnotetext{
${ }_{6}^{6}$ Public Law 98-361 amends the NAS Act to give NASA responsibility for commercializing space technology.

In addition to NASA, the Departments of Agriculture, Commerce, Interior, and State as well as the Agency for International Development, the Federal Communications Commission, and the National Science Foundation, all have some responsibility for portions of our overall civilian space program.
} 
of foreign policy. In some instances, it will be necessary to choose between the claims of private commercial interests and the demands of diplomacy and international relations.

These considerations underscore the need for a new national debate and consensus on the $\mathrm{Na}$ tion's important goals and objectives in space. Given the current confusion which exists regarding the future of space technology and the role of space policy as it relates to other national policies, including industrial policies, well-articulated goals would do much to focus the space debate and increase the likelihood of resolving specific problems. Once specific goals are articulated, it will be easier to identify specific objectives to carry us from where we are today to where we would like to be a decade or two from now. In time, as relevant technical, economic, social, and political changes occur, these goals will have to be reexamined and, where appropriate, revised in the light of such changes.

\section{Setting Goals and Objectives}

In framing the NAS Act, Congress in 1958 recognized the need for ongoing high-level policy review by establishing the National Aeronautics and Space Council (NASC), which was chaired first by the President, and later by the Vice-President and included the Secretaries of State and Defense, the Administrator of NASA, and the Chairman of the Atomic Energy Commission. Its responsibilities included surveying all U.S. space activities, both civilian and military, developing a comprehensive program for Government agencies, and coordinating all Government space programs. The Council oversaw the U.S. space program during the critical years of the Apollo project.

The Nixon Administration abolished the NASC in 1973, in part because of a shift in emphasis after completion of the Apollo project that placed the Office of Management and Budget (OMB) closer to the center of space policy decisions. President Carter assigned formal responsibility for space policy coordination to a National Security Council Policy Review Committee for space (PRCspace), chaired by the director of the Office of Science and Technology Policy (OSTP). President
Reagan established a Senior Interagency Group for space (SIG-space) under the chairmanship of the Assistant to the President for National Security Affairs.

The way in which space policy has developed in the last decade reflects a generally reduced congressional role. As the organization and conduct of space policy became centered in the White House, the twin goals of providing for national security and limiting increases in the Federal budget tended to be the most important determinants of national space policy. A strong indication of these trends is the central role played by OMB in White House policy reviews, and the membership of SIG-space: NASA, the Departments of Defense, State and Commerce, the Office of the Special Assistant to the President for National Security Affairs, the Central Intelligence Agency, the Joint Chiefs of Staff, and the Arms Control and Disarmament Agency. Of these, all but NASA and Commerce are primarily concerned with national security and foreign policy.

Much of the success of the NAS Act can be ascribed to the fact that the Act was a bipartisan, broadly representative response to the perceived threat of early Soviet successes in space. It represented a national consensus on outer space. Although the international use of space has changed radically over the years, since the NASC was disbanded there has been no broadly constituted national review of this Nation's long-term goals and objectives in space. Recent reviews conducted within the executive branch have been useful for focusing attention on the near-term needs of the space program, but they have been dominated by individuals within NASA and the aerospace community and have often been influenced by immediate political and budgetary issues. According to many observers, it is now appropriate to institute a national debate that includes a wider range of U.S. industry and society and focuses on the long-term goals and objectives for outer space. ${ }^{8}$

Recent interest in commercial opportunities in space and concern over U.S. leadership has led

\footnotetext{
${ }^{8}$ U.S. Congress, Office of Technology Assessment, Civilian Space Stations and the U.S. Future in Space, OTA-STI-241 (Washington, DC: U.S. Government Printing Office, November 1984).
} 
to increased congressional involvement in space policy. The 98th Congress formulated and passed three major bills:

- Public Law 98-361, provisions of which: 1) amend the NAS Act to require NASA to "seek and encourage, to the maximum extent possible, the fullest commercial use of space, " and 2) establish a National Commission on Space; ${ }^{9}$

- Public Law 98-365, * an act which provides for transfer of space-based land remote sensing to the private sector (see ch. 7); and,

- Public Law 98-575,** an act to encourage the commercialization of expendable launch vehicles (ELVS) and related services. In addition, bills dealing with satellite communications have also been introduced by several Members.

Many observers, including OTA, $1^{\circ}$ have suggested that, given the increasing number of governmental and private users of space technology, and the emergence of foreign commercial competition, any body established to recommend policy should be as diverse and broadly based as possible. The National Commission on Space is expected to, among other things, help the United States:

1. define the long-range needs of the Nation that may be fulfilled through the peaceful uses of outer space;

\footnotetext{
${ }^{9}$ Public Law 98-361 directed the President to establish a National Commission on Space within $\mathbf{9 0}$ days of its enactment. The bill was signed by the President on July 16, 1984. On Mar. 29, 1985, the President announced the Commission appointees.

${ }^{10}$ See, for example, Civilian Space Policy and Applications, op. cit., ch. 10 ; J. H. Gibbons, testimony before the Subcommittee on Space Science and Applications of the House Committee on Science and Technology, Aug. 4, 1982 and Oct. 18, 1983; T. F. Rogers, testimony before the Subcommittee on Science, Technology and Space of the Committee on Commerce, Science, and Transportation, Mar. $1,1984$.

*Text in app. C.

* *Text in app. D.
}

2. maintain the Nation's preeminence in space science, technology, and applications;

3. promote the peaceful exploration and utilization of the space environment; and

4. articulate goals and develop options for the future direction of the Nation' s-civilian space program. $^{11}$

The Commission's term is just 1 year. This will probably be sufficient to determine important new goals and objectives for the U.S. space program and to lay the groundwork for further policy discussion. However, it may be appropriate to extend the Commission's term beyond 1 year in order to assure continued broad-based discussion of these goals and objectives.

In addition to developing recommendations for goals and objectives, it may be appropriate for the Commission to suggest strategies by which those goals and objectives might be carried out. ${ }^{12}$ The previous chapters illustrate the potential (beyond satellite communications) for commercial application and the opportunities for international cooperation in the various space technologies. In all cases, effective policy decisions can be made only after careful analysis of the individual characteristics of the individual technologies. Moreover, a range of broad "strategies" articulated by the Commission would aid the development of policy for individual technologies. The following sections summarize elements of competitive and cooperative approaches.

\footnotetext{
'Title II, Public Law 361, the National Aeronautics and Space Administration Act of 1984.

12 The OTA assessment, Civilian Space Stations and the U.S. Future in Space, op. cit., suggests a list of goals and objectives that such a commission, if appointed, might wish to consider.
}

\section{APPROACHES TO COMPETITION}

Like other U.S. industries, space-related industries contribute to the overall economy by producing goods and services, by providing employment and tax revenue, and by making export sales. Like other industries, they are affected by Government policies of many kinds, but they also have certain unique characteristics related to the Nation's overall goals for space. As a result, the 
development of the U.S. space program has led to the formulation of distinct "space policies" that set these industries apart from other U.S. industries. This section identifies the principal elements of U.S. policies for competition in space-related endeavors and then assembles them into four more or less coherent approaches to international competition.

\section{Principal Elements of Competition Policy in Space-Related Activities}

As discussed in chapter 4 and in the individual technology chapters, U.S. policy toward international competition involves policies directed toward international trade, noncommercial programs, and R\&D.

International Trade Policy

in Space-Related Industries

U.S. post-war international trade policy has generally been to work for fair and open trade. To further this goal, the United States has been a leading proponent of international trading rules embodied in multilateral or bilateral agreements. Although most international agreements regulating market access, subsidies, and government procurement apply only to a limited extent to trade in space-related equipment and even less to services, the fair trade principles involved are reasonably clear and relevant. One day they may be applied more thoroughly to trade in spacerelated goods and services.

If free trade principles come to dominate spacerelated trade, the pricing of Ariane and Shuttle, as well as market access to telecommunications equipment procurement, is likely to be affected. Even at present, while the general trade principles have only a small direct effect on these and similar issues, they are the measuring device by which unfair practices are identified. When agreements or understandings are reached among governments in the space arena, they tend to draw on these principles.

According to fair trade principles, market forces should determine market events in most cases. Governments should not "load the dice" against particular sellers but rather should construct "lev- el playing fields" for all market participants. The specific principles basically deal with various kinds of subsidy and favoritism. "Most favored nation" treatment (no discrimination among foreigners) and "national" treatment (no discrimination between foreigners and residents once in the local market) mean that sellers from all countries should be able to compete for nongovernment, domestic sales on equal terms, once the relevant tariffs have been paid and other entry terms complied with. Export subsidies, below-market credit terms, or subsidized costs are now generally regarded as unfair. Further, favoritism in government procurement toward national firms is considered, in principle, to be an illegitimate practice in an open trading regime. As earlier chapters have shown, these concepts are unevenly applicable or applied, even when they have been incorporated into agreements, especially to hightechnology sectors such as space. Nevertheless, they are widely recognized to incorporate the basic concepts of fairness in international trade.

Open trade is not always the objective of governments. In exporting big-ticket items in advanced-technology sectors, such as space transportation contracts or telecommunication satellites, making the sale may be considered more important than defending the open trading regime. When this is the case, as it often is, governments resort to subsidies, encourage discriminatory treatment at home and in third countries, and compete vigorously through political horsetrading.

A complicating factor is that trade policy is not the only or even the principal reason why governments intervene or act in advanced technology sectors. They underwrite or carry out R\&D of both commercial and noncommercial relevance when they believe that reliance on market forces does not make good public policy. For instance, it has been plausibly argued that private firms tend to underinvest in R\&D because, among other reasons, they may be unable to profit sufficiently from their investment when their competitors can easily copy the technology once developed. It has also been argued that firms are unwilling to take large risks with long time horizons (see ch. 4). To correct for these deficien- 
cies in the private economy, governments may have good reason to engage in product-oriented $R \& D$, even when it is of direct benefit only to particular industries.

Certain governments, and certain opinion sectors in all countries, espouse industrial policies designed to stimulate particular industries-in this case, space-related industries-for the conscious purpose of making them more competitive internationally. They argue that government interventions, such as targeted R\&D programs, subsidies, import protection, antitrust relaxation, and discriminatory government procurement stimulate "sunrise" high-technology sectors striving to become industries, by shielding them from international competition until they become competitive.

Even if the focus of industrial policies is primarily domestic, they affect international trade as well. Subsidies in the name of domestic industrial policy are subsidies nonetheless. When they are implemented in pursuit of legitimate domestic economic objectives, however, it becomes more difficult to identify them as unfair trading practices. They are therefore less likely to be contained by general agreements or be the subject of bilateral ones. Nevertheless, the more commercially developed the technology, and the greater the impact of government support on international sales, the more likely it is that this support will come to be identified as an unfair trade practice that can be placed on the table when trade negotiations occur, or one that should be matched in kind in the interest of fair international competition.

$R \& D$ support is undoubtedly one of the most difficult policies to subject to an international trade regime. Little agreement exists on whether it is a threat to the open trading system, even when it is designed to improve the international competitiveness of national industries. We have noted international trade effects of subsidized $R \& D$ in each of the four technologies discussed in this report. In satellite communications, international trade considerations are among the principal arguments in favor of the Advanced Communications Technology Satellite (ACTS) research program (ch. 6).

\section{Noncommercial Competition for Leadership}

U.S. policy toward international competition in space also involves significant noncommercial competitive aspects summarized as "leadership" (or preeminence" when this leadership is striking). The United States has derived substantial foreign-policy benefits from its space activities. Beyond the foreign policy benefits that the United States has obtained from noncommercial leadership, the public has derived the direct intangible benefit of national pride and the scientific benefits of space research. Any strategy toward international competition must deal with the noncommercial dimension of competition as well as the commercial one.

As the history of INTELSAT indicates (chs. 3 and 6 ), there is a clear relationship between cooperation and leadership. The United States is a valuable partner for future cooperation because it has achieved high technological status and capability.

\section{Research and Development}

U.S. policy toward space R\&D draws on several different motivations. At the simplest level, aside from motives of international competition, the Government spends funds on basic and applied space research because of the direct satisfaction citizens derive from accomplishing major engineering feats in space or gaining knowledge of the universe. As space research is directed toward application, the competitive motivations become more prominent.

The Government is also motivated to stimulate space research by the fact that, without a Government program, certain speculative research in potentially commercializable technologies might not be done by private firms. If firms cannot effectively gain ownership over the research results, they are understandably reluctant to finance research.

The problem of ownership arises when research results financed by a private firm flow into the public domain and are used free by competitors. 
For example, research personnel move freely among U.S. firms and bring the fruits of their research with them. They may also set up their own firms in competition with their previous employers. The firm in question is then at a financial disadvantage. If no firm (or industry joint venture) is willing to do particular kinds of research for the whole industry, it may be appropriate for the Government to do it for the good of society. As an extension of this line of reasoning, NASA has long maintained that the direct and indirect "spinoffs" of NASA R\&D have produced returns to society well in excess of the Government investment. An individual firm might not be able to capture similar returns, even if it could protect its research, because the expected profit from an innovation may be small compared to the investment. The Government may be able to justify the program because of the spinoffs.

Another rationale for Government support of space research is the trade-related industrial policy motivation referred to above. According to this line of reasoning, if the U.S. Government fails to take an active role in some research areas, foreign research programs will give foreign producers of space-related goods and services an unfair advantage. Countervailing U.S. Government R\&D subsidies are one answer to such research abroad, but foreign governments, in turn, often justify their research programs as a means of countering ongoing U.S. civilian and military space research. In their eyes, research funding of military space programs constitutes an implicit subsidy of some U.S. civilian projects.' ${ }^{3}$

One key motivation for the Government to carry out and finance space R\&D is to support various Government activities. For example, much of the motivation for the Shuttle or for land remote sensing research was to meet Government needs, both military and civilian, for space transportation and remotely sensed data.

Although the different motivations for doing $R \& D$ are conceptually separate, most of them,

\footnotetext{
${ }^{13}$ See nowever, Civilian Space Policy and Applications, op.cit., ch.5. The process of transfer of innovative ideas from the military context to civilian products is often fraught with delay and other difficulties. There is no one-to-one correspondence between military funding for research and technological benefits to the civilian population.
}

in fact, come into play at some stage in most space research programs and shape the direction of the program in direct or subtle ways. It is therefore often not possible to determine precisely which motivation led to a particular project. The inability to classify projects neatly is also reinforced by the fact that ongoing projects often attempt to gain support from more than one constituency as they progress.

\section{Approaches to International Competition}

Previous chapters have identified additional specific measures that may be appropriate for a given technology. With these measures and the previous discussion of this chapter as background, this section discusses four broad alternative approaches:

- Stimulate substantial exploitation of space.

- Continue to seek U.S. preeminence in space.

. Let market forces predominate where possible.

- Keep Government financial outlay low.

\section{Stimulate Substantial Exploitation of Space}

This approach employs the three principal elements of policy discussed above for the overall purpose of stimulating the development of space for its own sake. Those who favor substantial development view exploration and scientific, $R \& D$, and commercial uses of space all as valid reasons to move to the last "frontier." But more than that, they tend to see space development as a national imperative that should be supported by as broad a coalition as possible. To realize this goal, they favor an eclectic policy approach: do whatever "works" best (as long as it happens in space)and be ready to change when necessary. As they see it, the more actors on the space stage, and the more influential and permanent they are, the better. Under such conditions, international competition among countries is seen as the stimulus to achieve a greater presence in space,

In this approach, commercial space endeavors are welcome, its proponents would usually support the trade policy preferences of such firms 
with respect to organizing competition in spacerelated industries. They view serious conflict within the "space community" over Government policies as undesirable, and seek industry consensus, particularly among U.S. actors. In their view, conflict even in international commercial competition should ideally be kept at a low level, and each international competitor should have a role. In other words, public squabbles among commercial competitors should not be allowed to undercut public confidence in the overall space effort.

To stimulate the exploitation of space the Government, in addition to conducting its own $R \& D$, could support space industries by means of loans, subsidized loans, or loan guarantees to companies attempting to produce and market new products. One proposal suggests that Government loans be provided for high-risk projects from which private capital shies away. ${ }^{14} \mathrm{~A}$ These loans would be paid back if the enterprise succeeded and forgiven if it failed. Such a policy might even extend Government-subsidized or Governmentguaranteed loans to foreign purchasers of U.S. space products and services. The Government might also offer short-term trade protection on the grounds that infant industries need to mature in the domestic market before they can compete successfully in international markets.

Competition for leadership with other countries in both commercial and noncommercial programs is viewed by those whose aim is to stimulate space development as a benign activity in the service of all mankind. As a dramatic element, competition for leadership can increase support for the space program in the public and boost morale in the participants. Cooperation on large projects is especially welcome because it could release significant amounts of resources for use on still other important activities.

Because exploration, space science, and R\&D directly stimulate the use of space, Government R\&D programs would usually be preferred over the subsidizing of space-related exports as a

\footnotetext{
${ }^{14}$ See the Space Industrialization Act of 1979 (H. R. 2337), hearings before the Subcommittee on Space Science and Applications of the House Committee on Science and Technology, 96th Cong., 1 st sess., 1979.
}

means of promoting private sector competitiveness, and thus involvements. In addition, transferring costly Government-supported development projects to commercial sponsorship would be doubly welcome. In the first place, Government funds would be freed up to address concerns that the private sector cannot be expected to meet. Second, and perhaps more important, the private sector would thereby become more involved, thus making the structure of the space sector more closely resemble that of other, already successful economic sectors. Unless it undermined unity in the coalition of space interest groups, those supporting the space-development approach would be likely to favor some form of subsidized space transportation as a general way for the government to support space development.

The major problem with this approach is that the links of space policy to other areas of public policy are tenuous; "more is better" is not a fully adequate prescription for public policy.

\section{Continue to Seek U.S. Preeminence in Space}

Although multiple motivations are involved here, as in the previous approach, seeking preeminence emphasizes the political and commercial benefits that proponents believe will flow both from a successful U.S. national civilian space program and from growing U.S. commercial space activities. In defining this approach, one must first define preeminence-is it dominance across the board in space activities? or could "leadership" in most important activities satisfy the criterion? When the space programs of other nations (except for the Soviet Union) were small or nonexistent, the United States was the preeminent space power, however defined. Now, however, with the emergence of large national space programs abroad, each of which seeks to make its own mark, what U.S. "preeminence" is to mean, for actual policy determination, needs to be clearly defined, in order to formulate and evaluate an achievable approach. For the purposes of this discussion, "preeminence" will mean the achievable goal of leadership in most important civilian space activities.

Although competition in military space activities has recently assumed greater importance, ci- 
viiian space competition with the Soviet Union continues to be important. Preeminence over the Soviet civilian space program, in this approach, is an important political goal and can be achieved through a continuing large commitment of resources.

Preeminence in noncommercial competition with the national space programs of non-Communist countries is also a goal. One major objective of this competition is to ensure that the United States will lead in commercially important space technologies and therefore also in experimental technologies that are expected to lead to commercial products. But the goal is broader than this. Proponents of this approach believe that the United States should use its resources to retain leadership in most space activities, commercial or not. The use of Government agencies to produce subsidized commercial services (e.g., NASA as the principal world provider of space transportation services) is consistent with such a stance because a U.S. subsidy makes it more costly for other countries to offer effective competition.

If the entry of U.S. firms in an industry that had been dominated by Government led to phasing out subsidized production (e.g., in ELVS), foreign governmental or commercial competition that had been deterred by the subsidy might then emerge and threaten U.S. preeminence. For instance, proponents of this approach argue that full cost pricing of the Shuttle, which accounted for all the risks and operating costs that a private firm would have to factor in, could enable Arianespace to capture an even larger share of the market than they now have and thereby damage U.S. preeminence. They therefore tend to oppose full cost pricing for the Shuttle, even if it largely prevents the U.S. private space transportation industry from developing.

In general, proponents of U.S. preeminence in space are less concerned with the commercial viability of a project than some others; they are prepared to recommend subsidies to cover revenue shortfalls, and see commercial ventures as vehicles to express U.S. leadership.

In terms of trade policy, these considerations tend toward a mercantilist position. Those who favor the approach of preeminence tend to favor clear U.S. dominance in the commercial uses of space. They would want to assure this by, first, reserving the large U.S. market for domestic space producers by the usual means this is accomplished-price/quality dominance where possible, as in communication satellite production, and subsidy and Government procurement restrictions where it is not, as in remote sensing and materials processing. They might also want to restrict access by other nations to the Shuttle.

Second, in export markets, these proponents would urge open trade, in which space industries are brought under the general coverage of relevant international trading rules when U.S. producers have price/quality dominance, but work for government-to-govern ment market sharing agreements and/or export credit and other forms of subsidy when they do not. R\&D subsidies targeted to achieve a goal of enhancing the competitiveness of U.S. producers of space goods and services would have a major role in this approach, both because of the sunrise-industry characteristics of many space technologies and because it allows an easy coalition with those favoring substantial space development for its own sake.

Like the space-development approach, this is an approach in which "more is better," and the links to broader political and economic policies are not always explicitly considered. When Congress favors financing a large and growing program, strategies built around substantial development and preeminence fit together well. When resources are scarce, however, the implicit conflict between groups espousing the two positions leads to much more stressful bargaining. Neither group can then achieve all its important objectives.

For instance, the influence of the space-development strategists may result in advanced technology that gains little significance in the actual market. Conversely, politically attractive projects to construct manned demonstration systems favored by those seeking preeminence may crowd out the more developmentally significant ones favored by the space-development point of view. The crowding out of other NASA programs by the Apollo program in the 1960s and the Shuttle program in the 1970s are examples of this latter conflict. 


\section{Let Market Forces Predominate Where Possible}

Letting market forces predominate is a well-defined approach for potentially commercializable activities, including their R\&D phase. It can be combined with the noncommercial elements of other approaches to form rather diverse overall strategies. The hallmark of this approach is the idea that, as a rule, Government should not invest heavily in activities that the private sector is in a position to pursue. This stance is supported by the belief that markets for products and services in the U.S. economy can usually be relied on to signal which activities are socially useful, According to this reasoning, if the private sector is not willing to fund a development project as conceived by NASA, the project probably should not be carried out, at least in that form. Outside of R\&D, Government's role is envisaged as simply to do its best to assure a fair, workably competitive marketplace, domestically and internationally, for those firms that wish to compete in selling space-related goods and services.

Consumers of space products and services, in the rationale of this approach, would be expected to pay prices that recover the full cost of providing them. With certain exceptions, such as meteorological data products, products and services that private firms would not provide at the unsubsidized prices are judged to be less valued by society than those that private markets do produce. They have not passed the market test. Contrary judgments about social value, which would allow government to overrule the dictates of the market, would have to show that, in the instance involved, the market was not reflecting the preferences of potential buyers, that there was some other market failure involved, or that government involvement would produce a clear-cut political benefit that was worth the outlay.

As discussed earlier in this section, Government $R \& D$ activities have a clear rationale when private firms cannot expect to establish full property rights in the fruits of research. When this is the case, private firms are likely to underinvest. The more basic the research, the riskier it is, or the larger the time until commercial payoff, the less adequate the performance of private firms,
Government outlays intended to promote technological progress may include: funds to improve scientific and engineering education, direct conduct of basic and applied research with potential industrial applications, sponsorship of such research in universities or industries, transfer of research findings from Government programs (e.g., military) to the private sector, joint Government-industry research ventures, or special tax treatment for private research.

Consistent with this approach, then, is the idea that as prospective $R \& D$ results come to look more commercializable, Government-supported research can move from Government-performed research (e.g., NASA research laboratories) to Government-funded research (e.g., ACTS program) to Government-subsidized research (e.g., NASA's Joint Endeavor Agreements) to no significant Government involvement at all. Thus, this approach is consistent with a large government $R \& D$ role in the early stages of technological development that diminishes as markets develop.

One benefit of an approach that depends on market signals is that it sets space policy in the context of overall economic policy. Attention to space technology becomes just one component of the U.S. approach to high-technology R\&D. As high-technology industries, space-related industries would expect to benefit from a general policy of fostering R\&D. But under a policy of broad support, they would not be singled out for more favorable treatment than that received by other high-technology industries. They would still be expected to sink or swim in the marketplace.

Large demonstration projects, in particular, are less likely to be undertaken under this approach. Its proponents do not regard failure to invest heavily in a particular Government development prototype as evidence of the unwillingness of the private sector to invest in the technology per se. They argue that scientists and Government officials might incorrectly substitute their ideas of potential demand for those of entrepreneurs, financial analysts, and insurance executives, thereby distorting technological processes.

Previous chapters have also made the point, in the case of certain public goods like meteorological remote sensing, that private markets 
would be unlikely to produce the socially desirable kinds and amounts of weather data. Therefore, Government production or subsidy is justified as an exception.

An approach where market forces are allowed to predominate requires clear signals from the Government to allow markets to work well for society. In a sector where Government involvement has been high, firms and investors that might be willing to invest on a commercial basis $r$-night hold off in the hope of receiving a subsidy. In part, their reluctance to start might also reflect their fear that competitors would subsequently receive a subsidy or that the Government itself might undertake the project in competition with them. The cost of waiting in these circumstances would generally be low. Because no firm would make a move until the Government acted, waiting would not disadvantage them.

Many proponents of an approach depending on market forces would undoubtedly prefer open, fair international trade in space goods and services, but others, despairing in obtaining it, might favor countervailing subsidies or restrictions on U.S. market access to match foreign restrictions. This approach can only lead to a partial strategy for achieving national goals. It does not apply, for instance, to noncommercial competition.

As long as make, buy, or contract decisions for Government use, including those designed to increase U.S. prestige, are made with prudent contracting controls this approach has little inherent conflict with an approach of preeminence in space. in practice, however, the two approaches are typically in conflict. Those who favor a market strategy tend to want to leave the development of most commercializable space systems, particularly their form, to the market, whereas those favoring an approach of preeminence would typically be loathe to entrust the fate of valued projects to the uncertain decisions and timing of private companies.

In contrast, the approach of depending on market forces would seem to be compatible with one favoring substantial space development, as long as dependence on markets produces a vigorous private sector. In practice, however, proponents of substantial space development tend to be impatient with letting market forces lead the way. Their concept of commercialization tends to be one in which Government takes the lead in developing prototypes. They are usually in natural alliance with those favoring an approach of preeminence.

\section{Keep Government Financial Outlay Low}

The low-outlay approach is the final competitive approach. It is competitive in the sense that as total outlay on civilian space-related Government activity is reduced, certain aspects of the other options become infeasible. Sharply limiting the available funds more or less defines a set of possible policy options. in particular, an effective policy to match the R\&D, production or export-credit subsidies of other countries would become impossible without substantial funding, as would subsidized Government production of space-related goods and services for U.S. consumption, such as Shuttle transportation. Consequently, a low-outlay approach tends toward one that depends on market forces.

Proponents of this approach would argue that most needed research would be funded by the private sector. If the market would not support the research, it was probably not needed and therefore should not be done. Only a limited amount of R\&D would be funded, and, in particular, few large, expensive projects would be undertaken by the Government. The allocation among various types of projects-those that would develop space, those that would bring political benefits, and those that would bring industrial policy benefits-would depend on the alliances their proponents could make. One possible alliance might be among the proponents of space development, market forces, and low-outlay. In this case, NASA would tend to concentrate on more basic $R \& D$ and avoid building prototypes and use less expensive methods of technology transfer. One potential drawback of this approach is that it might put U.S. industry directly in competition with government-supported foreign industry.

Even though the low-outlay approach is incompatible with expensive "sunrise" industry indus- 
trial policy, it is not necessarily incompatible with the low-cost protectionist elements of this policy. Several retaliatory weapons to punish unfair trading practices by other space-capable countries exist that are not costly in budget terms: tariffs, quotas, boycotts, standards harassment, and government procurement restrictions. These could effectively restrict foreign access to the U.S. market, although they would usually increase prices for U.S. users. They might be utilized, in retaliation for foreign subsidies in both U.S. and third-country markets, under Section 301 of the Trade Act of 1974 or other existing trade laws,

Somewhat ironically, protectionist restrictions even have a role in securing free international trade in space-related goods and services. They could be used as bargaining chips in bilateral and multilateral negotiations to create a more liberal international regime.

In the low outlay approach, cooperating with other countries in space applications (e.g., remote sensing), space science, and exploration of outer space assumes even greater importance than in the other competitive approaches. A highly active program of cooperation would be necessary to maintain a level of technological leadership otherwise unavailable in this approach.

\section{ELEMENTS OF COOPERATIVE POLICIES}

International cooperation in civilian space activities may serve a variety of goals:

1. sharing the costs of expensive projects;

2. increasing exchange of scientific knowledge and U.S. access to foreign technology;

3. promoting international understanding;

4. coordinating potentially conflicting international activities (e.g., the use of the electromagnetic spectrum for telecommunications);

5. providing services on a multinational basis (e.g., through INTELSAT or INMARSAT);

6. regulating international trade in space-related goods and services;

7. providing assistance to developing countries;

8. improving political relations; and, indirectly,

9. promoting U.S. exports.

At different points in the history of its space program, the United States, acting through NASA, the National Oceanic and Atmospheric Administration (NOAA), the Department of State, National Telecommunications and Information Administration (NTIA), Federal Communications Commission (FCC), and U.S. Agency for international Development (AID), has pursued some or all of these goals. Yet, as noted in the introduc- tion to this chapter and in chapter 3 , increased international competition and changes in the outlook of the developing countries have altered the international environment for cooperation. In light of these changes, and the fact that the private sector has demonstrated increased interest in commercial space activities, a reassessment of U.S. policies for space cooperation is in order. The key question in such a reassessment must be, under what circumstances and in which technologies does cooperation serve the long-term political and economic interests of the United States?

This section identifies a range of cooperative approaches that the United States has taken in the past, and discusses their use in today's climate. The options presented here are not mutually exclusive; indeed, an effective overall policy would include aspects of each. Some potential cooperative approaches would be inconsistent with certain of the competitive approaches described in the previous section. The opportunities for cooperation also vary considerably across the range of technologies studied in this report. The suitability of various approaches for cooperation varies accordingly. 


\section{Emphasize Cooperation That Contributes to the Technological Goals of the United States}

Given the enormous cost of space research and exploration, and the recent space accomplishments of other countries, the United States cannot hope to remain a leader in every aspect of this technology, unless it actively seeks cooperative ventures. International cooperation is one means by which the United States can participate in numerous expensive projects. NASA's largest cooperative project, Spacelab, cost the European Space Agency (ESA) in excess of $\$ 1$ billion and is perhaps the best example, to date, of the monetary value of international cooperation, For budgetary reasons, the alternative to an ESA Spacelab was not a less capable U.S. spacelab, but rather no Spacelab at all. Additionally, Canadian expenditures (over $\$ 100$ million) for the Shuttle's highly successful remote manipulator arm freed the United States from this Shuttle expense. Not counting Spacelab, NASA has estimated that other countries have contributed over $\$ 2$ billion to U.S. objectives in space over the last 25 years through cooperative programs. ${ }^{15}$

Joint technology development programs raise a unique set of difficulties. A cooperative policy that stressed common technological goals would focus almost entirely on projects with nations having reasonably advanced space programs. Such cooperative projects with developed countries, however, increase the likelihood of inadvertently transferring commercially useful technology to them and increase the possibility that foreign firms will be able to compete more effectively with U.S. firms in commercial space markets. In addition, when dealing with new technologies it is often desirable to reduce the administrative complexity of research; cooperative projects tend to increase the difficulty of technology development. For these reasons NASA has traditionally avoided joint production arrangements with other countries for essential hardware. As discussed elsewhere in this report, however,

\footnotetext{
$1^{5}$ U.S. Congress, Office of Technology Assessment, U.S. Government Printing Office, UN/SPACE '82: A Context for Cooperation and Competition, OTA-TM-ISC-26 (Washington, DC: March 1983), app. B.
}

the industrialized countries are increasingly capable in space technology and are concerned about transferring the fruits of their research to the United States.

In the near future, the largest single area in which the United States will cooperate with the industrialized countries is in building and using permanently inhabited space infrastructure, including a so-called space station. The United States has already signed cooperative agreements with Canada, ESA, and Japan for the design phase of NASA's space station program. As planning for the development and operation of the space station(s) proceeds, the various modes of cooperation should be carefully studied. Possible cooperative options are detailed in the OTA report, Civilian Space Stations and the U.S. Future in Space. ${ }^{\text {tb }}$

Emphasizing joint technology development programs makes it difficult to define a meaningful role for many developing countries. Yet including them in cooperative activities could give them an opportunity to engage in the pursuit of space technology and thereby ease current difficulties in the United Nations and make international consensus on issues such as frequency and spectrum allocation easier to obtain.

It is important to assess whether an international cooperative venture is truly in the long-term interest of the United States. Short-term budgetary or political pressures should not be allowed to affect adversely the long-term viability of important national programs. Yet, any policy on cooperation should be designed to allow access to foreign technology and expertise where they would materially benefit U.S. programs. In the near future the major space powers will have to make critical decisions concerning the level of international cooperation they wish to pursue. The United States may wish to limit cooperation to the investigation of basic scientific phenomena or the development of discrete components (e.g., the shuttle remote manipulator) so as not to conflict with the potential commercial activities of the U.S. private sector. To add to the subtlety of

\footnotetext{
${ }^{16}$ See for example, Civilian Space Stations and the U.S. Future in Space, op. cit., app. C.
} 
the decision process, it should be noted that U.S. corporations sometimes find that international joint ventures (e.g., AT\&T and Olivetti) enhance their overall international competitive ability.

\section{Emphasize Political Benefits of Space Technology}

How can the United States reap the maximum advantage from current and future cooperative activities? The possession of highly visible, technologically advanced industrial capacities, such as the ability to produce and use space technology, carry with them certain foreign policy benefits. The precise nature of these benefits, although difficult to define, is usually measured in terms of increased "prestige and influence." Cooperating with the United States on space projects (or, for that matter, on any high-technology project) can create the perception that, by working with the United States, nations are "on the winning team," and can create an incentive for such nations to compromise with the United States on both space and nonspace issues if they believe that such cooperation earns them the advantage of long-term access to advanced technology or other bilateral support.

Using space technology for peaceful purposes to accomplish diplomatic goals is a complex task that is pat-t of a larger diplomatic picture. international space policy in the United States has evolved slowly over the years, changing in response to technological developments and the global political environment. For example, the Apollo-Soyuz Test Project, a U.S.-Soviet cooperative project, was a reflection of the era of detente.17 The Carter Administration's emphasis on the use of science and technology as tools for development led to increased assistance in space technology to developing countries.

If the use of international cooperative efforts in space to accomplish diplomatic ends is desirable, then it is appropriate to consider what Government organization is appropriate. The present arrangement divides the policy responsibility for

\footnotetext{
ISee Issues in U.S./U.S.S.R. Cooperation in Space (Office of Technology Assessment, technical memorandum, in press) for a discussion of the Apollo-Soyuz cooperation and the political and technical issues surrounding cooperation with the Soviet Union.
}

international space activities among the Department of State (foreign affairs and international organizations); the Department of Commerce (operational remote sensing [NOAA], international satellite communications INTIA], and trade-related activities); NASA (space R\&D, science, and transportation); the FCC (regulation of U.S. international satellite communications); and the National Security Council (national defense). Considerable confusion now exists over who has jurisdiction in any given issue involving more than one of these elements, as do most international space activities. As a result, the task of using science and technology for diplomacy has often been considered of secondary importance.

Most of the day-to-day work of putting international space policy into practice has fallen to NASA and NOAA. The FCC and the Department of State have overseen commercial satellite communications. NASA's role as an R\&D organization compels it to seek partners with which it can accomplish technological goals, and is, therefore, less inclined to focus on the broad foreign policy implications of decisions. NOAA's interest in maximizing the collection and distribution of critical atmospheric and land remote sensing data has led it to seek broad operationa/agreements with its counterparts in other countries. It therefore focuses on operational goals rather than on diplomatic issues. The FCC and the Department of State have jointly formulated U.S. positions in bilateral and multilateral negotiations related to satellite communications.

The State Department, as the foreign policy organ of the Government, pursues relationships that accomplish diplomatic tasks and is responsible for overseeing U.S. treaty obligations (see ch. 3). Lacking NASA's, NOAA's, and the FCC's expertise in space technology, it has traditionally deferred to their judgment on most international space activities. Although the Department of State consults regularly with NASA and NOAA on the one hand, and the FCC on the other, the success of this coordination depends heavily on the personalities of the individuals involved.

Using civilian space activities more aggressively to pursue broad U.S. foreign policy interests, including the reduction of international tensions, 
would require the Department of State to increase substantially its technical expertise and the continuity-both policy and human-of its responsibilities in space. ${ }^{18}$ This would require, at a minimum, adding staff with substantial experience in space technology.

\section{Participation in International Organizations}

As the analysis of chapter 3 indicates, in the face of a changing international environment in which the influence of the United State ss shrinking, the United States seems to have three broad options to consider in its participation in the international organizations dealing with space such as the International Telecommunication Union (ITU), the Committee on the Peaceful Uses of Outer Space (COPUOS), and, more generally, the United Nations General Assembly:

1. Adopt a more flexible approach, emphasizing diplomacy and a willingness to compromise in areas where critical U.S. interests are not at issue. Attempt to build broadly based coalitions within the organizations. Establish immediately a permanent technical presence at the U.S. Mission to the U.N.

2. Take an increasingly confrontational posture, using the threat of withdrawal in an attempt to prevent decisions contrary to U.S. interests. Emphasize building coalitions of likeminded nations, or establishing alternative organizations. Where possible, tie decisions on space issues to other U.S. policies on financial and technical assistance thereby acquiring leverage in negotiations.

3. Drastically reduce or end U.S. participation in international organizations if they stray too far from U.S.-supported policies, and establish U.S.-led, permanent ad hoc multinational or bilateral arrangements where necessary.

\footnotetext{
${ }^{18}$ The State Department has recently made somemoves to strengthen its expertise in space and other technology fields, and to place greater importance on science and technology in diplomacy. See John Walsh, "Shultz Signals Backing for Science Attach\&, " Science, vol. 226, 1984, pp. 518-51 9; Also, Otho Eskin, hearings before the House Subcommittee on Space Science and Applications of the Committee on Science and Technology, July 25, 1984.
}

The United States has tended toward following option 2 in recent years on the premise that other countries have politicized these international bodies. However, tying decisions on space issues to other policies carries with it the very risk of politicizing these organizations that the United States seeks to avoid. In developing policies toward international organizations dealing with space issues, it is also important to understand that each of these organizations have markedly different operational agendas and should be treated separately.

Option 3 may not be advisable in those instances where for technical reasons, cooperation is a virtual necessity. For example, current U.S. participation in ITU helps to guarantee interference-free access to the radio spectrum for satellite communications. The assignment of a particular frequency is of little value if others feel free to use it for purposes that cause critical interference. There are no sanctions to force compliance with ITU decisions. Consequently, the United States, as well as other ITU members, rely on the voluntary agreement and cooperation of other nations to refrain from interfering with its assigned use of the spectrum.

\section{Provide Assistance to Developing Countries}

The United States could take the position that its competitive interests limit the number of desirable cooperative opportunities with the other space-capable nations. Cooperative activities with the developing countries, on the other hand, might be pursued with renewed vigor in order to spread U.S. influence abroad. As a first principle, the United States has always recognized its responsibility to contribute to the welfare and development of the Third World. However, such programs may also provide indirect economic, political, and strategic benefits to the United States. Strengthening the scientific and technical capabilities of the developing world may promote the growth and expansion of important markets, provide new outlets for U.S. goods and services, and orient the indigenous scientific and engineering community toward the United States. 
The United States has considerable experience in providing technological assistance. Its meteorological satellites have been used for global weather coverage since the early 1960s, and the Landsat Earth remote sensing system has been in operation since 1972 under a policy whereby the United States has sold imagery to any country for little more than the price of reproduction. NASA and AID have cooperated in giving developing counties valuable training in the use of Landsat data. In another example, NASA and AID used the ATS [advanced technology satellite] series of experimental direct broadcasting satellites in the mid-1970s to carry out several important studies in India, South America, and the Pacific, which demonstrated the usefulness of satellite communications to deliver programs to rural areas. *

The principal cooperative space activities with the developing world are in remote sensing and telecommunications. ${ }^{*}$ * These could be coordinated with other assistance programs and be made more responsive to the abilities and expressed needs of recipient nations. Such programs would likely include a large educational component, and would present only minimal technology transfer problems. It would be unlikely to interfere with other AID, NASA, and NOAA goals and programs.

Although the United States has the technical and institutional means to carry out an expanded program of assistance using space technology, serious questions remain concerning the desirability of such a course of action. The current official attitude of the United States (primarily within the Administration) toward many Third World countries is one of profound mistrust. In the view of many, Third World demands for access to technology and space resources, and its support for larger political agendas, such as the New World Information order or the New International Economic Order, threaten such important American

\footnotetext{
${ }^{*} T$ The countries that participated in these projects contributed to them as well.

${ }^{\star \star}$ The U.S. Government can provide certain technology to developing countries, but it does not own or control all space-related technology these countries might wish to acquire. Much of it is privately owned and would need to be licensed from private owners by individual countries.
}

ideals as free speech and free enterprise. Such Third World demands have diminished the desire of some U.S. policy makers to support multinational technology transfer programs.

The United States has several methods available for pursuing cooperative programs. The first, already used extensively, is an emphasis on bilateral, as opposed to multilateral, assistance programs. This allows projects more closely related to individual country needs and assures some degree of accountability for both participants. Another method, introduced at the ITU Plenipotentiary Conference in Nairobi in 1982, is the use of private U.S. firms to pursue development goals. The U.S. Telecommunications Training Institute was established to promote the planning and operation of telecommunication and information systems in developing countries. Because private U.S. firms provide the training, equipment, and funding for the Institute, its operation is unlikely to be subverted solely for political or ideological motivations.

\section{Establish International Organizations to Provide Space Services}

Once a technology has been developed and its value proven, the question then arises of how best to apply the benefits of this technology. This has generally led to debate over whether the private sector or the government is best suited to manage the applications phase of the technology. Particularly important for this discussion is the role that international cooperation in the form of intergovernmental consortia can play in this process.

When INTELSAT was established, its advocates considered the system to be the most effective way of quickly bringing the benefits of satellite communications to much of the world. Now, with the rise of potential private sector competitors, the cons as well as the pros of an internationally governed monopoly in satellite communications are being discussed (see ch. 6). A similar analysis might be used in relation to remote sensing. Although land remote sensing is now seen as an area of international competition, it may turn out that the raw satellite data is less marketable than communications services, at prices that 
provide an adequate return on investment, and will remain more of a public, than a private, good. If so, then it might be appropriate to attempt to organize an international body to collect and distribute the data free or at low prices (see ch. 7). Such an organization might pool international resources to maintain a single system of satellites, which no single nation would invest in alone, but from which all participants would benefit. Alternatively, the national members might agree to specialize in particular types of satellite facilities and data collection they would provide to all users at low prices. All would benefit from an international division of labor. ${ }^{19}$

19 ndeed, suchan organization was suggested as one of the Policy options of Civilian Space Policy and Applications, op. cit., ch. 10, pp. 298-300. NOAA is now attempting to organize a variation
There may be instances (e.g., to save system costs) where the United States would benefit by actively pursuing the formation of international consortia. Presumably, such a course would be followed only in the absence of financial interest by the private sector in a new technology, or where the foreign policy benefits of such an organization clearly outweighed its negative effects on the formation of a free market.

of such a cooperative venture in ocean remote sensing among Canada (Radarsat), ESA (ERS-1), Japan(MOS-1), and the United States (NROSS), in which NOAA would take the lead in gathering, processing, and distributing data sets globally.

\section{THE RELATIONSHIP BETWEEN COOPERATION AND COMPETITION}

Few elements of either governmental or private sector space activities are either purely cooperative or purely competitive. Indeed, the motivations for cooperation or competition are driven primarily by economic and political factors and are often closely intertwined. As this report has emphasized throughout, cooperative projects are often undertaken, in part, for competitive purposes. For example, part of the U.S. political motivation in cooperating with developing countries is to demonstrate the willingness of the United States to share its knowhow with these countries i n competition with the Soviet Union. On the other side of the coin, the enhanced ability of Europe and Japan to compete economically with the United States in offering space goods and services makes them more attractive cooperative partners for major projects such as an international polar-orbiting remote sensing platform or a permanently inhabited space station.

In developing policies for the U.S. space program it is important to recognize not only the roles played by cooperation and competition, but also how each may enhance the effectiveness of the other. The four approaches to international competition discussed in the section on competition-stimulate the substantial exploitation of space, continue to seek U.S. preeminence in space, let market forces dominate, and keep Government financial outlay low-would be improved by one or more of the cooperative elements explored in the section on cooperation. For example, although the French will soon be offering remotely sensed data from their SPOT system, in competition with data from the U.S. Landsat system, it is nevertheless in the best interests of both countries to cooperate on setting data standards, format, and other aspects of the two systems. In doing so, both countries may gain in political prestige and even in access to markets.

However, cooperation and competition do not necessarily enhance one another. For example, governmental cooperation with other countries, particularly technologically advanced ones, may make competition more difficult for U.S. firms. As mentioned in several places in this report, cooperation with Europe and Japan raises the specter of outward technology transfer that could strengthen their ability to offer space goods and services in direct competition with the United States. This argues for structuring cooperative projects in such a way as to reduce the negative effects of unwanted technology transfer. However, as other countries reach parity with the 
United States in certain technologies, or even surpass it, the United States will have something to gain from them. This is the case now in some narrow areas (e.g., in building manned space habitats). Therefore, in structuring cooperative agreements, it will also be important for the United States to consider what technology it might gain from other countries.

As the United States structures its cooperative activities in space between now and the end of the century, and faces greater competition from other space-capable nations, it will be important for policy makers to consider the interactions of cooperation and competition in each international project on which the United States embarks. In order to compete effectively with other nations in space science and space applications, it is necessary to cooperate. On the other hand, in order to cooperate most effectively, it is necessary to be able to compete as well.

\section{ORGANIZING FOR THE FUTURE}

The NAS Act, in addition to establishing the basic guidelines for the Nation's space activities, authorized the formation of NASA and assigned it the responsibility for the "aeronautical and space activities sponsored by the United States. "As a result, except for satellite communications, during the past quarter century most civilian programs and policies dealing with space have tended to focus primarily on NASA. Operating under a broad mandate to pursue excellence in space technology, NASA had a major hand in developing the technology for three industriessatellite communications, remote sensing, and space transportation; it is currently working on a fourth-materials processing in space. Yet, despite NASA's successes, it is unlikely that the agency can continue to be the primary focus of civilian space activities as commercial interests in space become stronger. NASA by itself is ill-equipped to deal with such complex issues as international commercial competition, trade pol- icy, domestic health, safety, and economic regulation, and tax policy, all of which will have essential roles in the development of vital U.S. space industries.

An important aspect of future national policy for space will be the manner in which the responsibility for various space activities is divided among the various Federal agencies. This responsibility is essentially of two types, first, the broad responsibility for the maintenance of U.S. "leadership" in space; this is inherently a shared responsibility which requires the effective coordination of Government agencies and the private sector and, second, the responsibility for the use and successful commercial application of individual space technologies. This latter responsibility can probably be most effectively carried out when a designated agency has the responsibility for a specific technology.

\section{MAINTENANCE OF U.S. LEADERSHIP}

The NAS Act specifically calls for the United States to preserve its role "as a leader in aeronautical and space science and technology and in the application thereof. .."This has often been interpreted to imply that the United States should be preeminent in all space activities, a point of view appropriate to the early days of the U.S. civilian space program. However, as the scope of space activities has increased, other countries have developed expertise in space, and costs have risen dramatically. It may now be more appropriate for the United States to attempt to maintain its leadership in many, rather than all, areas of space technology, and to choose areas on which it will focus its efforts. Whichever ones are chosen, successful coordination among Gov- 
Appendixes 

structing permanent space infrastructure ${ }^{23}$ or remote sensing ${ }^{24}$ or materials processing ${ }^{25}$ as well as the role of space technology in development assistance programs.

If successful, such an interdepartmental assessment might result in a 5- or 10-year program of action, a more formal division of responsibilities, and a clearer understanding of the long-term problems likely to be faced individually and collectively by various Government organizations.

\section{Responsibility for Individual Technologies}

The commercial success of specific space technologies will depend to some degree on how the Government organizes to support, and, where necessary, to regulate these activities. Although coordination of Government agencies remains an important task, the success of specific space industries may depend, at least initially, on the active participation of a lead agency. The role played by the Civil Aeronautics Board (CAB) and the continued role of the Federal Aviation Administration (FAA) in commercial aviation, the activities of the FCC in telecommunications, are all examples of Federal agencies assisting in the development of new industries.

Much has been written about the potential negative effects of regulation on industry. However, the potential danger to the public posed by some space technologies, and their ability to affect international relations suggest that some form of Government intervention will be necessary. ${ }^{26}$

Decisions regarding which agencies should be responsible for which space technologies should be a function of the maturity of the technology and the industry and their relationship to like terrestrial activities. Because these conditions differ with each technology discussed in this report it is useful to examine them separately.

\footnotetext{
${ }^{2}$ See, for example, the discussion in Civilian Space Stations and the U.S. Future in Space, op. cit., app. c.

${ }^{24}$ See CivilianSpace Policy and Applications, op. cit., ch. 10.

${ }^{25} \mathrm{See}$ R. Da] bello and S. Finer, "Prospects for International Cooperation in Materials Processing Technologies, "33rd International Astronautical Congress, Paris, September 1982.

26The 1967 Space Treaty makes states responsible for their Own actions or the actions of their citizens.
}

- Satellite communications is a mature technology; it was incorporated into the overall communications industry almost from the start. The relationship of satellite communications to the private sector has been close from the beginning. In the pre-commercial period, Bell Laboratories and other telecommunications entities carried out significant $R \& D$ on communication satellites that predated NASA's activities, and the technology transfer that took place has been a two-way phenomenon, fruitful to the R\&D programs of both NASA and the private sector. Because a large market for intercontinental telecommunications services was already a certainty and because a well-developed regulatory structure already existed for the industry, a clear natural division of responsibilities existed among the FCC, NASA, and the Department of State. Only recently have problems come to be perceived.

The Satellite Communications Act of 1962 (building on the Communications Act of 1934) ratified the natural division of labor among these agencies: the FCC would regulate communications carriers, interstate and internationally; the Department of State would lead or instruct U.S. representation in international institutions concerned with satellite communications (e.g., COPUOS, ITU, and INTELSAT); and NASA would do satellite communications R\&D. NASA phased out most of this latter activity in the early 1970s, based on the expectation that the satellite equipment industry would do its own R\&D (see ch. 6).

Recently, as technological change and deregulation allowed a vigorous domestic industry to develop and look for access to international service markets and as foreign satellite equipment manufacturers started to make inroads into U.S. and world markets, the neat division of labor has become less adequate. In the early 1980s, new Government actors came to play a larger part in international telecommunications policy: NTIA in the Department of Commerce, the Office of Telecommunications Policy in the Department of State, the U.S. Trade Representative's Office, not to mention the Nation- 
al Security Council, the Department of Defense, the Council of Economic Advisors, the Department of Justice, and the Federal Courts. NASA has also increased its involvement in communication satellite research for reasons relating to international trade and the international resource of the geostationary orbit. With all the executive branch agencies involved, a Senior Interagency Group and the White House came to play coordinating roles. Even so, Congress has complained of executive branch disarray.

The size and maturity of the telecommunications industry both in the United States and foreign countries, and the increasing interdependence of the world economy, make it almost certain that the tasks for which the U.S. Government must organize will continue to be complex and, even more than in other large mature economic sectors, will defy easy organizational solutions.

- Remote sensing is a mature technology directed toward a yet infant industry. After operational authority for Landsat was transferred from NASA to NOAA, NASA's involvement in this technology was sharply reduced. NASA now primarily conducts limited advanced $R \& D$ in high-resolution sensors (see ch. 7). The Government's primary concern now is to encourage the development of an economically viable private industry. Unlike satellite communications, the market for remote sensing services is small and the private sector has been reluctant to invest in this technology without some form of Government assistance.

The Land Remote Sensing Commercialization Act of 1984 (Public Law 98-365) designates the Department of Commerce as the lead agency for future remote sensing activities. Among other things, this Act instructs Commerce to encourage private sector participation, establish a licensing system for prospective entrants, ensure compliance with domestic and international law (with guidance from the Department of State), establish appropriate regulation, and protect national security interests (with guidance from DOD). The legislation also directs NASA and NOAA to continue R\&D activities in remote sensing and encourages the Secretaries of Interior and Agriculture to con- tinue research into the application of remote sensing data.

Advocates of this legislation argued that designating the Department of Commerce as the lead agency improved the probability that a remote sensing industry could develop. By providing a single point of contact within the Government, interested parties know where to make their application for systems development, and where to express their ideas and grievances. The goal, as is also demonstrated in space transportation, is to establish a focal point for the still diffuse private sector interest in commercial space activities. The experience that the Department of Commerce has gained (through NOAA) makes it the logical agency to oversee the private development of a remote sensing industry. ${ }^{27}$

- Space transportation is, in some respects, both a mature technology and industry. Mature space transportation systems (ELVS) and a mature market (communication satellites to geostationary orbit) both exist; the issue now is how to encourage private sector entry while NASA fulfills other important Government needs. Two competing positions are maintained; one encourages NASA to compete for commercial launch services and the other instructs the Department of Transportation (DOT) to promote the development of a private industry (see ch. 5). As a result of this policy competition and its own long-term needs for space transportation services, NASA remains effectively the only actor in space transportation services.

An Office of Commercial Space Transportation has been formed within the Department of Transportation. ${ }^{28}$ The Expendable Launch Vehicle Commercialization Act established DOT as the lead agency for commercial space transportation. This legislation is designed to promote and accomplish goals similar to Public Law 98-365 discussed above for remote sensing. DOT would license private operators, draft regulation for launch activities and, after consultation with other

\footnotetext{
${ }^{27}$ Still t. be worked out is the thorny problem of who is to regulate use of the Shuttle for private sector or foreign remote sensing systems. See, for example, "SPARX Fly Over U.S.-German Space Venture," Science, vol. 227, pp. 617-619, 1985.

${ }^{28}$ Public Law 98.575 was signed into law Oct. 30, 1984
} 
relevant agencies (e.g., NASA, DOD, and the Department of State), determine whether such activities are in the public interest, are safe, and are in the national security and foreign policy interests of the United States. DOT, in consultation with the Department of State, is also responsible for determining whether private launch companies conform to U.S. treaty obligations.

- Materials processing in space (MPS) is a set of embryonic technologies directed towards known markets. NASA remains the most significant actor in the development of these technologies and in the attempt to encourage private sector participation in their creation. Without NASA support it is unlikely that MPS research would go forward in this country. No lead agency has been designated to encourage the development of a materials processing industry nor does one seem necessary.

Should commercially viable MPS products be discovered, MPS would probably follow the commercialization pattern of satellite communications rather than remote sensing and space transportation, because MPS products currently under investigation, such as pharmaceuticals and crystals for electronic applications, are-like satellite communications services-directed toward large and growing commercial markets.

In most instances it will be obvious which Government agencies should take the lead on regulating MPS products. For example, regulation of pharmaceuticals made in space would be the responsibility of the Food and Drug Administration (FDA).

\section{CONCLUSION}

There is no single set of space policies capable of adequately responding to the challenges the Nation will face as a result of its scientific and commercial activities in space. This chapter suggests that the United States should, at a minimum, develop the institutional means to achieve consensus on future space goals and to revise these goals when circumstances so dictate. In order to survive over time, such goals must be, to the greatest extent possible, independent of shortterm budgetary and political influences. ${ }^{29}$ The Na- tional Space Commission may offer a means by which to accomplish this objective.

Because goals must alter as milestones are reached or circumstances change, it may also be appropriate to adopt "strategies" for approaching competitive and cooperative goals in space. Correctly articulated, such strategies could provide continuity and an important middle ground between the basic principles of the NAS Act and future space goals,

\footnotetext{
${ }^{29}$ See Civilian Space Stations and the U.S. Future in Space, op. cit.
} 
A newly operational satellite-borne search and rescue system now markedly increases the chances of being rescued when lost at sea or in remote land areas. Until recently an experiment' in space technology development and international cooperation, COSPAS/ SARSAT has been responsible for saving nearly 400 human lives and 10 dogs, since the first rescue took place in September 1982, The participants in the experiment were the National Oceanic and Atmospheric Administration (NOAA) and the National Aeronautics and Space Administration (NASA) for the United States, the Department of Communications of Canada, the National Center for Space Studies (CNES) of France, and the Soviet Ministry of Merchant Marine (MORFLOT). In the operational phase, NOAA has the lead for the United States.

The United States, Canada, and France have spent about $\$ 53$ million on satellite equipment and ground stations to operate the Search and Rescue Satellite (SARSAT) system. Canada and France supply the SARSAT receiver. The United States supplies the spacecraft on which it flies and the testing and integration. A Soviet system, COSPAS, is designed to interoperate with SARSAT. The first two satellites to be equipped with receivers for emergency search were low-altitude Soviet navigation satellites. Beginning with NOAA-8, the advanced TIROS-N series of NOAA polar orbiting meteorological satellites now also carry search and rescue receivers. $z$

Receivers on board the satellites detect the emergency radio beacons (operating at $121.5 \mathrm{MHz}$ ) from downed aircraft or ships and boats in distress. The beacon's signal is re-transmitted to a ground station, which analyzes the signal to determine the location of the beacon. The small frequency shift caused by the relative velocity of the orbiting satellite and the emergency radio transmitter on Earth (the so-called Doppler effect), enables system operators to determine (within 12 to 15 miles accuracy) the position of the emergency radio transmitter. Search and rescue teams can then be dispatched to the area from which the distress signal was sent.

The type of beacon used so far for rescues is carried by over 200,000 aircraft and 7,000 vessels in the

\footnotetext{
1 Development ot COSPAS/SARSAT was begun in 1977. I n October 1984 the United States, Canada, France, and the Soviet Unionsigned an agreement to begi $n$ the operationa I phase of COSPAS/SARSATI $\mathbf{n} 1985$ and to extend the program through 1990 See "SARSAT/COSPAS to Operate Through 1990," Aviation Week and Space Technology, Oct. 15, 1985, pp. 24-25

${ }^{2}$ Although NOAA-8 has experienced serious operational difficulties over the past year, $t$ is now operational again and the SAR package IS now work Ing satisfactorily.
}

United States alone. ${ }^{3}$ The signal from this common beacon is only usable when the satellite is in the line of sight of both the beacon and the ground station. An experimental system on the satellites (operating at $406 \mathrm{MHz}$ ) uses a more sophisticated emergency beacon that carries a code identifying the type of aircraft or ship, the nature of the distress, the elapsed time since the accident, the registry number, and beacon identification. In addition to direct relays, the more sophisticated one can be subjected to signal-processing on board the satellite, stored, and re-transmitted to a ground station later on. The higher frequency signal will also permit higher accuracy location (1 to 3 miles) of the emergency transmitter. The first rescue using the $406 \mathrm{MHz}$ transmitter took place early in 1985.

Norway and the United Kingdom participate in the program by providing a ground station. Bulgaria, Denmark (MOU in process), and Finland participate as experimenters, with no indigenous ground stations. Other countries, including Argentina, Australia, Brazil, Chile, the People's Republic of China, Saudia Arabia, Singapore, Taiwan, Thailand, and Venezuela have expressed interest in the program.

The four original nations-the United States, Canada, France, and the Soviet Union-are discussing means by which the system could gain still broader international acceptance after 1990, when its transitional operational period ends. The possible means include: operating the system through an existing international organization; creating a new organization specifically to operate the system; or continuing the present four-party arrangement. At the present time, the countries favor expanding to a total of 10 to 15 parties in a new organization after the current MOUs expire in 1990,

The chief near-term problem faced by the COSPAS/ SARSAT project has been posed by Administration policy on the polar-orbiting system on which the SARSAT transponder flies. The frequent global coverage planned for the system was predicated on keeping the necessary equipment aboard four satellites at a time-two Soviet and two U.S. The two Soviet satellites are in orbit. The Office of Management and Budget (OMB) has repeatedly attempted to limit NOAA to operating one polar-orbiting meteorological satellite at a time, although Congress has each year restored the necessary funds in its yearly authoriza-

$3_{A}$ major problem with the system so far has been a vast number ot false alarms-about 97 percent of the signals received. 
tion and appropriations procedures. However, in signing the agreement with the other principal countries in Leningrad in October 1984, the United States has now committed itself to maintain two SARSAT receivers in orbit. AS OMB has made clear, this does not necessarily commit the United States to maintaining both polar-orbiting meteorological satellite. It could fly the instrument on another polar-orbiting satellite, for example, on one of the Air Force Defense Meteorological Satellite Program spacecraft-an option earlier rejected because of a desire to keep the international segments of the project entirely civilian in character. It could also be flown on a small dedicated satellite at a cost of approximately $\$ 30$ million for the first copy and about $\$ 15$ million for subsequent models. ${ }^{4}$

Another technical-economic problem is to bring about conversion from the present emergency beacon equipment on aircraft and ships to the more sophisticated (and perhaps costlier) equipment needed

\footnotetext{
4Source: Preliminary study by Applied Physics Laboratory, Johns Hopkins University for NASA,
}

for the most effective operation of the COSPAS/ SARSAT system. In 1970 Congress passed a law requiring that general aviation aircraft carry an Emergency Locator Transmitter; in 1972 the National Transportation Safety Board recommended that the Coast Guard and the Federal Communications Commission (FCC) require ocean-going vessels to carry an Emergency Position-Indicating Radio Beacon. These are the beacons now usable by COSPAS/SARSAT satellites when they are in the line of sight both of the craft in distress and the ground station. There is so far no plan either for U.S. regulations or for international standards to require the new, more sophisticated beacon.

Efforts are underway to make use of the new beacons on a voluntary basis. It would be difficult to mandate carriage of $406 \mathrm{MHz}$ for general aviation and small boats. It is likely to become mandatory for large ships (1,600 gross tons and above) operating under International Maritime Organization (IMO) convention. The Radio Subcommittee of IMO voted 17-4 in favor of $406 \mathrm{MHz}$ for the frequency to be used in the float-free emergency procedures required by IMO in the Future Global Maritime Distress and Safety System. 


\section{ALTERNATIVE FORMS OF INDUSTRY ORGANIZATION IN THE UNITED STATES}

Although the general rule is that competition (despite its imperfections) is the preferred form of industry organization in the United States, there are two principal exceptions to this rule where competition cannot be expected to produce a socially desirable outcome, industries with decreasing costs and industries or governments producing certain public goods. The organization of these industries competitively would result in the misallocation of society's resources. Economic regulation of decreasing cost industries (those where important cost savings could be obtained by concentrating production in a single plant and where, up to a point, bigger plants would provide still greater cost savings as demand grows) is justified as a substitute for competition on the grounds that monopoly would otherwise naturally emerge and produce an antisocial result. This is the first major exception to the general rule that competition is preferred. Government provision of "public goods," technically defined, the second major exception, is justified on the grounds that the unsubsidized private market would not produce them at all or would produce them below the socially desirable level.

\section{Regulated Industries}

Regulated public utilities producing water, electricity, rail transportation, and local telephone service, for example, are industries where the average cost of production decreases so rapidly with the size of the firm that when such an industry has shaken out, according to a widely accepted theory, there will be only one firm left. The largest producer would be able to outcompete all others and drive them out of business. Its size would be that of the whole market, and its cost of production would be less than any potential smaller entrant. Hence new entrants would be deterred, and the firm would be a "natural monopoly." A natural monopoly has the same twin evils that all unregulated monopolies are said to be notorious for: excessive prices and inadequate output.

To be sure, natural monopolies are contestable markets in the straightforward sense that a competitor could challenge the incumbent for the whole market, but the process of contestation might be highly disruptive while it occurs, and lengthy periods of costly production at less than optimal scale might occur.
When the natural monopoly was reestablished (perhaps by the new entrant), society would be in the original position of suffering the effects of monopoly.

For these reasons, the public utility industries have usually been organized in the United States as regulated monopolies within certain geographical boundaries. Prices set by a public regulatory body, are typically set under a rationale that attempts to provide investors no more than a fair return on assets and thus avoid monopoly profits.

Because prices cannot be maintained at regulated levels without controlling production to a greater or lesser degree, regulatory bodies usually also erect a rather intricate control mechanism over physical operations.

Regulation often leads to two kinds of inefficiency. First, politically motivated cross-subsidization between classes of consumers leads to wasteful consumption for those benefited, or to overcautious conservation, for those penalized. Second, the whole regulatory structure may create incentives for managers to please the regulators rather than the market. Rather large inefficiencies can develop in these circumstances.

These inefficiencies are likely to be greatest when the regulated monopolist need not fear contestation or competition at the fringes of the industry, because of regulatory controls on entry in these fringe areas. In the communications industry, for example, communications equipment manufacturers were for many years not allowed to sell telephones to consumers in competition with the manufacturing arm of the regulated monopoly. This undoubtedly retarded product development and technology absorption.

In the United States in recent years, deregulation has been embarked upon in a number of instances when opinion has shifted to the belief that competitive or contestable markets can regulate the formerly regulated industries, as in the current deregulation of long-distance communications. During the process of deregulation, cross-subsidization and inefficient production structures may become serious barriers to its completion. This is because the beneficiaries of the cross-subsidization, and many of the affected management groups, stand to lose from it and resist the changes politically.

Business entities, which would benefit from deregulation, may also muddy the waters during the period 
of partial deregulation by attempting to secure crosssubsidization that had not existed before, now in the name of deregulation.

Regulation, as an alternative to competition, therefore is a difficult form of organization, both in implementing it and ending it.

\section{Governmental Provision of Public Goods}

A second type of noncompetitive industry organization is used in the United States in the case of "public goods" because competitive markets would result in the absence of production or in production at inadequate levels. "Public good" is the technical term in economic theory for a good or service for which it is impossible or undesirable for reasons of efficiency to charge consumers in the normal way. ${ }^{1}$ Examples of public goods are streets, national defense, police services, weather forecasts, and various informational activities of government.

It may be impossible to charge for a good or service, for instance, as in the case of national defense, because a person does not have to purchase it in order to consume it. There is no way to deny people access to the service on the condition that they pay for it. Therefore there are no market signals to tell society how much to produce.

In a second case, it may be undesirable to charge for a good or service because, although it is possible to deny the consumer access if he or she does not pay, the costs of collection borne by the consumer, the producer, or society at large may be disproportionately large compared to the extra cost of providing the service to the consumer.

An example of a service of this type is the daily weather forecast. While this could be organized on a pay-TV basis, the costs of doing so are considered to be disproportionately large. First of all, the cost to the weather service of one more viewer seeing the forecast is zero. Given this fact, the collection costs that would be borne by the consumer in terms of price and inconvenience and by the pay-TV operator are obviously disproportionate to the zero cost of servicing the additional consumer,

There would also bean extra cost to society at large as well, according to prevailing belief. If the general public were not informed about weather dangers, according to this view, society as a whole would suffer avoidable costs from weather disasters. For both of

\footnotetext{
I Pu blic goods are a lso referred to by various authors as "social goods' or "collective goods,"
}

these reasons, therefore, weather forecasts are provided to the public without charge.

In these examples, and in the case of public goods in general, reliance on the private market would result in production not taking place at all, or if it does take place, taking place at an inadequate level when compared to what society would be willing to pay for.

Public goods can be produced at socially efficient levels by either the government or the private sector, but since financing of production is not possible from sales revenue, production would have to be subsidized if it were to be produced by the private sector at the socially efficient level.

\section{Mixed Public/Private Goods}

Some goods and services can be part public good and part private good. This is the case when a good can be sold in the usual way by making those who "consume" it pay for it. These private purchases, potential or actual, constitute the private good part. There may also be spillover benefits to the general public from the good's consumption that cannot be charged for. These benefits constitute the public good part.

An example of this is public education. It would be possible to charge parents for educating their children and the collection costs would not be disproportionately large. The decrease in benefits to the general public that would occur, however, is widely considered to be so large that it justifies the free provision of primary and secondary education. Elementary and secondary education is, therefore, provided straightforwardly as a public good.

At the university level, however, user charges are generally imposed in public universities so as to finance at least partially the private benefits of students. Students are not allowed to attend without paying fees, but the remainder of the State universities' budgets, over and above student fees, is paid for from government tax revenues on the justification that enhanced culture and economic growth are public goods. It would not be possible to charge each member of the general public for enhanced culture and economic growth and deny them access to them if they did not pay. Public higher education is, thus, a mixed public/private good.

\section{Marginal Cost Pricing}

We can be more precise in discussing economic efficiency. Economic efficiency is defined in the textbook case as production at the level where the consumer of the last unit is willing to pay the cost of producing 
it ("the marginal cost") but no more. We recognize it as the efficient production level when at that price and at that level there are no excess inventories and no unsatisfied potential consumers who would be willing to buy.

Larger or smaller production could not be sold at a price equal to marginal cost. Some other price would have to be charged to sell all the goods produced. This other price would either result in an economic loss to the producing entity or to consumers, including those who would be needlessly priced out of the market. In either case, there would be social loss. Although this exposition of the economic theory of production is very brief, it can be encapsuled in the the general rule that, for a given distribution of wealth, price should equal marginal cost for social efficiency in production.

In ordinary real-world private markets, workable competition is thought to produce prices that do not depart too far from marginal cost in the long run. This occurs because workably competitive industries, under antitrust regulation, are neither natural monopolies nor monopolies or combines based on conspiracy. At prices based on marginal cost, such industries are self-financing as well in the sense that revenues exceed costs (except during periods of industry stress such as recessions).

Decreasing-cost industries, on the other hand, are not self-financing with marginal-cost pricing. I $\mathrm{n}$ certain declining-cost industries, in fact, marginal cost is far enough below average cost, even in the long run, that a second strong efficiency argument (in addition to the natural-monopoly argument) can be made against unsubsidized private provision of the good or service. If the price charged to all consumers is set equal to the average cost, the pricing rule for breakeven operation when only a single price is charged, the last consumer would have to pay more than the cost of servicing him or her. In this case a number of potential consumers, who should have been serviced if the industry were operating efficiently, will have been priced out of the market. Production would then be higher cost than desirable from efficiency considerations because the plant would be too small. Thus, resources would be wasted.

If the industry were to be self-financing, however, the price would have to be at least equal to the average cost, even though the extra cost of servicing a customer might be well below the average cost. Decreasing cost industries, therefore, need to be subsidized, if production is to be at the economically efficient level, where the good is priced equal to the cost of producing the last unit (the marginal cost). This subsidy can be justified as a means of providing a public good distributed free to the public-the public good of increased economic efficiency.

While the subsidization of private, decreasing cost industries has in some instances been done, it is ordinarily not politically feasible to do it and, when questions of the distribution of income and wealth are considered, may indeed not be socially desirable. Other mechanisms, to be discussed below, are used instead to ameliorate the efficiency loss that comes from charging users a price based on average cost rather than on marginal cost,

\section{The Functional Similarity of Mixed Public/Private Goods and Goods of Decreasing Cost Industries}

In both public-good and decreasing-cost industries, the cost of servicing an additional consumer is well below the average cost of servicing all consumers. In the case of the pure public good, the cost of servicing an additional consumer is zero; in the case of mixed public/private goods, the marginal cost may be significantly below average cost. The same situation occurs in the case of decreasing-cost industries. Hence, the problem of determining industry organization and pricing strategy is functionally the same in both cases.

\section{industry-Organ ization/Pricing Strategies}

The problem of public-good/decreasi rig-cost industries has been handled in American industrial organization in three ways: First, when the misallocation of social resources is thought to be small, the solution is to ignore the problem, since the cures, government regulation and subsidy, are themselves difficult social processes with which to achieve economic efficiency. Private competitive organization continues to be the norm in these cases. On the other hand, when the divergence between long-run marginal cost and longrun average cost is so large that it cannot be ignored, two principal alternative methods have traditionally been used in the United States.

The first is to subsidize production, which then may be carried out either by a governmental or private entity. Subsidization, of course, has political limits having to do with the distribution of benefits unevenly across social groups. It may be thought of as unfair and, hence, politically unsupportable. Nevertheless, the production of a large fraction of the gross national product is, in fact, subsidized by government-from space research and development to interstate highways to public education. Depending on the item in- 
volved, the unfairness of uneven distribution of benefits in these cases is apparently considered minor, unavoidable, worth it, or compensated for by the progressive tax system.

The second method used to ameliorate the problem is to mandate certain kinds of nonmarket pricing by regulation. These special pricing schemes are used where subsidization is ruled out and total costs must be recovered from consumers but where the regulatory agency desires to minimize the efficiency drawbacks of average-cost pricing.

As a condition of survival, private firms do recover total costs over the long run. The norm in the general private economy is also that consumers are charged a single price (for the same good or service in the same quantity) or something close to it depending on the degree of monopoly power exercised by firms in the market. Charging a single price to all consumers may be inefficient for decreasing cost industries, however, when total cost recovery is specified. To try and ameliorate this inefficiency, pricing schemes that involve different prices for different customers or different prices for the first and last units consumed by a given consumer, have commonly been prescribed for regulated utilities. The idea is to avoid pricing some of the consumption out of the market that would have been attracted by marginal cost pricing but still recover total costs from consumers.

Such devices as two-part tariffs, where there is a certain monthly charge but where price per unit consumed is low, and price discrimination, where different classes of customers are charged different rates, are among the devices use to keep production and consumption closer to optimal under full cost recovery than it would be under unitary pricing.

\section{Space Markets Can Be Analyzed With These Concepts}

Markets for space-related goods and services can be analyzed according to these concepts. Among the equipment and services treated in this study-in space transportation, materials processing, satellite communications, and remote sensing-can be found examples of normal goods, public goods, and decreasingcost, industry goods. As "commercialization" alternatives are considered, this mode of analysis may be useful in formulating public policy toward industrial organization in each case. 
Public Law 98-365

98th Congress

\section{An Act}

To establish a system to promote the use of landremotesensing satellite data, and for other purposes.

J uly 17,1984

'[H.R. 5155]

Beit enacted by the Senate and the House of Representatives of the United States of America in Co $\sim{ }_{8}$ e as the "land Remom assembled, That this Act may ::Ii-gemote nming Commercialization Act of $\sim$ o merCi liM-

tion Act of 1984.

TITLE I-DECLARATION Of findings PURPOSES, AND Communications and telecommunications. 15 Usc 4201

FINDINGS

SEc. 101. The Congress finds and declares thatCongress.

(1) the continuous civilian collection and utilization of land $I^{\mathrm{s}}{ }^{\mathrm{sc}} \mathbf{4 2 0 1}$ remote-sensin data from space are of major benefit in managing the Earths natural resources and in planning and conducting many other activities of economic importance;

(2) the Federal Government's experimental Landsat system Land@ system. has established the United States as the world leader in land remote-sensing technology;

(S).the national interest of the United States lies in maintainiing international leadership in civil remote sensing and in broadly promoting the beneficial use of remote-sensing data;

(4) land remote sensing by the Government or private parties Defense and of the United States affects international commitments and national policies and national security concerns of the United States; security.

(5) the broadest and most beneficial use of land remotesensing data will result from maintaining a policy of nondiscriminatory access to data;

(6) competitive, marketdriven private sector involvement in land remote sensing is in the national interest of the United States;

(7) use of land remote-sensing data has been inhibited iy slow market development and by the lack of assurance of data continuity;

(8) the private sector, and in particular the "value-added" industry, is best suited to develop land remote-sensing data markets;

(9) there is doubt that the private sector alone can currently develop a total land remote-sensing system because of the high risk and large capital expenditure involved;

(10) cooperation between the Federal Government and private industryan help assure both data continuity and United States leadership;

(11) the time is now appropiate to initiate such cooperation with phased transition to a fully commercial system;

(12) such cooperation should be structured to involve the minimum practicable amount of support and regulation by the 
98 STAT. 452

PUBLIC LAW 98-365-JULY 17, 1984

Federal Government and the maximum practicable amount of competition by the private sector, while assuring continuous availability to the Federal Government of land remote-sensing data;

(13) certain Government oversight must be maintained to assure that private sector activities are in the national interest and that the international commitments and policies of the United States are honored; and

(14) there is no compelling reason to commercialize meteorological satellites at this time.

\section{PURPOSES}

15 USC 4202. SEC. 102. The purposes of this Act are to-

(1) guide the Federal Government in achieving proper involvement of the private sector by providing a framework for phased commercialization of land remote sensing and by assuring continuous data availability to the Federal Government;

(2) maintain the United States worldwide leadership in civil

Defense and national security.

15 USC 4203.

Defense and national security.

15 USC 4204. remote sensing, preserve its national security, and fulfill its international obligations;

(3) minimize the duration and amount of further Federal investment necessary to assure data continuity while achieving commercialization of civil land remote sensing;

(4) provide for a comprehensive civilian program of research, development, and demonstration to enhance both the United States capabilities for remote sensing from space and the application and utilization of such capabilities; and

(5) prohibit commercialization of meteorological satellites at this time.

\section{POLICIES}

SEc. 103. (a) It shall be the policy of the United States to preserve its right to acquire and disseminate unenhanced remote-sensing data.

(b) It shall be the policy of the United States that civilian unenhanced remote-sensing data be made available to all potential users on a nondiscriminatory basis and in a manner consistent with applicable antitrust laws.

(c) It shall be the policy of the United States both to commercialize those remote-sensing space systems that properly lend themselves to private sector operation and to avoid competition by the Government with such commercial operations, while continuing to preserve our national security, to honor our international obligations, and to retain in the Government those remote-sensing functions that are essentially of a public service nature.

\section{DEFINITIONS}

SEc. 104. For purposes of this Act:

(1) The term "Landsat system" means Landsats 1,2,3,4, and 5 , and any related ground equipment, systems, and facilities, and any successor civil land remote-sensing space systems operated by the United States Government prior to the commencement of the six-year period described in title III.

(2) The term "Secretary" means the Secretarv of Commerce. 
(3)(A) The term "nondiscriminatory basis" means without preference, bias, or any other special arrangement (except on the basis of national security concerns pursuant to section 607) regarding delivery, format, financing, or technical considerations which would favor one buyer or class of buyers over another.

( ) The sale of data is made on a nondiscriminatory basis only if (1) any offer to sell or deliver data is published in advance in such manner as will ensure that the offer is equally available to all prospective buyers; (ii) the system operator has not established or changed any price, policy, procedure, or other term or condition in a manner which gives one buyer or class of buyer de facto favored access to data; (iii) the system operator does not make unenhanced data available to any purchaser on an exclusive basis; and (iv) in a case where a system operator offers volume discounts, such discounts are no greater than the demonstrable reductions in the cost of volume sales. The sale of data on a nondiscriminatory basis does not preclude the system operator from offering discounts other than volume discounts to the extent that such discounts are consistent with the provisions of this paragraph.

(C)The sale of data on a nondiscriminatory basis does not require (i) that a system operator disclose names of buyers or their purchases; (ii) that a system operator maintain all, or any particular subset of, data in a working inventory; or (iii) that a system operator expend equal effort in developing all segments of a market.

(4) The term "unenhanced data" means unprocessed or minimally processed signals or film products collected from civil remote-sensing space systems. Such minimal processing may include rectification of distortions, registration with respect to features of the Earth, and calibration of spectral response. Such minimal processing does not include conclusions, manipulations, or calculations derived from such signals or film products or combination of the signals or film products with other data or information.

(5) The term "system operator" means a contractor under title II or title III or a license holder under title IV.

\section{TITLE II-OPERATION AND DATA MARKETING OF LANDSAT}

\section{OPERATION}

SEc. 201. (a) The Secretary shall be responsible for-

(1) the Landsat system, including the orbit, operation, and disposition of Landsats $1,2,3,4$, and 5 ; and

(2) provision of data to forei ground stations under the terms of agreements between tr e United States Government and nations that operate such ground stations which are in force on the date of commencement of the contract awarded pursuant to this title.

b) The provisions of this section shall not affect the Secretary's authority to contract for the operation of part or all of the Landsat system, so long as the United States Government retains-

(1) ownership of such system;

(2) ownership of the unenhanced data; and 
(3) authority to make decisions concerning operation of the system.

CONTRACT FOR MARKETING OF UNENHANCED DATA

SEC. 202. (a) In accordance with the requirements of this title, the Secretary, by means of a competitive recess and to the extent provided in advance by appropriation Icts, shall contract with a United States private sector arty (as defined by the Secretary) for the marketing of unenhancJ data collected by the Landsat system. Any such contract-

(1) shall provide that the contractor set the prices of unenhanced data;

(2) may provide for financial arrangements between the Secretary and the contractor including fees for operating the system, payments by the contractor as an initial $f=$ or as a percentage of sales receipts, or other such considerations;

( ) shall provide that the contractor will offer to sell and dehver unenhanced data to all potential buyers on a nondiscriminatory basis;

(4) shall provide that the contractor pay to the United States Government the full purchase price of any unenhanced data that the contractor elects to utilize for purposes other than sale;

(5) shall be entered into by the Secreta only if the Secretary has determined that such contract is likeYy to result in net cost savings for the United States Government; and

(6) may be reaward competitively after the practical demise of the space segment of the Landsat system, as determined by the Secretary.

(b) Any contract authorized by subsection (a) may specify that the contractor use, and, at his own expense, maintain, repair, or modify, such elements of the Landsat system as the contractor finds necessary for commercial operations.

(c) Any decision or proposed decision by the Secretary to enter into any such contract shall be transmitted to the Committee on Commerce, Science, and Trans rtation of the Senate and the Committee on Science and Technorogy of the House of Representatives for their review. No such decision or proposed decision shall be implemented unless (A) a period of thirty calendar days has passed after the receipt by each such committee of such transmittal, or (B) each such committee before the expiration of such period has agreed to transmit and has transmitted to the Secretary written notice to the effect that such committee has no objection to the decision or proposed decision. As part of the transmittal, the Secretary shall include information on the terms of the contract described in subsection (a).

(d) In defining "United States private sector party" for purposes of this Act, the Secretary may take into account the citizenship of key personnel, location of assets, foreign ownership, control, influence, and other such factors.

\section{CONDITIONS OF COMPETITION FOR CONTRACT}

SEc. 203. (a) The Secretary shall, as part of the advertisement for the competition for the contract authorized by section 202, identify and publ ish the international obligations, national security concerns (with appropriate protection of sensitive information), domestic 
legal considerations, and any other standards or conditions which a private contractor shall be required to meet.

(b) In selecting a contractor under this title, the Secretary shall consider-

(1) ability to market aggressively unenhanced data;

(2) the best overall financial return to the Government, including the potential cost savings to the Government that are likely to result from the contract;

(3) ability to meet the obligations, concerns, considerations, standards, and conditions identified under subsection (a);

(4) technical competence, including the ability to assure continuous and timely delivery of data from the Landsat system;

(5) ability to effect a smooth transition with the contractor selected under title III; and

(6) such other factors as the Secretary deems appropriate and relevant.

(c) If, as a result of the competitive process required by section Rewrt 202(a), the Secretary receives no proposal which is acceptable under the provisions of this title, the Secretary shall so certify and fully report such finding to the Congress. As soon as practicable but not later than thirty days after so certifying and reporting, the Secretary shall reopen the competitive process. The period for the subsequent competitive process shall not exceed one hundred and twenty days. If, after such subsequent competitive process, the Secretary receives no proposal which is acceptable under the provisions of this title, the Secretary shall so certify and fully report such finding to the Congress. In the event that no acceptable proposal is received, the Secretary shall continue to market data from the Landsat system.

(d) A contract awarded under section 202 may, in the discretion of the Secretary, be combined with the contract required by title III, pursuant to section 304(b).

\section{SALE OF DATA}

SEc. 204. (a) After the date of the commencement of the contract 15 USC 4214 described in section 202(a), the contractor shall be entitled to revenues from sales of copies of data from the Landsat system, subject to the conditions specified in sections 601 and 602 .

(b) The contractor may continue to market data previously generated by the Landsat system after the demise of the space segment of that system.

$$
\text { FOREIGN GROUND STATIONS }
$$

Sec. 205. (a) The contract under this title shall provide that the 15 USC 4215 , contractor shall act as the agent of the Secretary by continuing to supply unenhanced data to foreign ground stations for the life, and according to the terms, of those agreements between the United States Government and such foreign ground stations that are in force on the date of the commencement of the contract.

(b) Upon the expiration of such agreements, or in the case of foreign ground stations that have no agreement with the United States on the date of commencement of the contract, the contract shall provide- 
98 STAT. 456

(1) that unenhanced data from the Landsat system shall be made available to foreign ground stations only by the contractor; and

(2) that such data shall be made available on a nondiscriminatory barns.

\section{TITLE III-PROVISION OF DATA CONTINUITY AFTER THE} LANDSAT SYSTEM

PURPOSES AND DEFINITION

15 Usc 4221.

Contracts with ${ }_{15}$ Usc 4222.

15 USC 4223.
SEC. 301. (a) It is the purpose of this title-

(1) to provide, in an orderly manner and with minimal risk, for a transition from Government operation to private, commercial operation of civil land remotesensing systems; and

(2) to provide data continuity for six ears after the practical demise of the space segment of the LanL $t$ system.

(b) For purposes of this title, the term "data continuity" means the continued availability of unenhanced data-

(1) including data which are from the point of view of a data user-

(A) functionally equivalent to the multispectral data generated by the Landsat 1 and 2 satellites; and

(B) compatible with such data and with equipment used to receive and process such data; and

(2) at an annual volume at least equal to the Federal usage during f cal year 1983 .

(c) Data continuity may be provided using whatever technologies are available.

\section{DATA CONTINUITY AND AVAILABILITY}

SEc. 302. The Secretary shall solicit proposals from United States private sector parties (as defined by the Secretary pursuant to section 202) for a contract for the development and operation of a remote-sensing space system capable of providing data continuity for a period of six years and for marketing unenhanced data in accordance with the provisions of sections 601 and 602. Such proposals, at a minimum, shall specify-

(1) the quantities and qualities of unenhanced data expected from the system;

(2) the projected date $u \sim n$ which operations could begin;

(3) the -number of satilhtes to be constructed and their expected hfetlmes;

(4) any need for Federal funding to develop the system; (5) any percentage of sales receipts or other returns offered to the Federal Government;

(6) plans for expanding the market for land remote-sensing data; and

(7) the pro ed procedures for meeting the national security concerns anr international obligations of the United States in accordance with section 607 .

\section{AWARDING OF THE CONTRACT}

SEC. 303. (a)(l) In accordance with the $r$ uirementa of this title, the Secretary shall evaluate the proposals Described in section 302 and, by means of a competitive process and to the extent provided in 
advance by appropriation Acts, shall contract with the United States private sector party for the capability of providing data continuity for a period of six years and for marketing unenhanced data.

(2) Before commencing s ace operations the contractor shall obtain a license under title IV.

(b) AS part of the evaluation described in subsection (a), the \& :t.a shall analyze the expected outcome of each proposal in

(1) the net cost to the Federal Government of developing the recommended system;

(2) the technical competence and financial condition of the contractor;

(3) the availability of such data after the expected termination of the Landsat system;

(4) the quantities and qualities of data to be generated by the recommended system;

(5) the contractor's ability to supplement the requirement for data-continuity by adding, at the contractor's expense, remotesensing capabilities which maintain United States leadership in remote sensing;

(6) the potential to expand the market for data;

(7) expected returns to the Federal Government based on any percentage of data sales or other such financial consideration offered to the Federal Government in accordance with section 305;

(8) the commercial viability of the proposal;

(9) the proposed procedures for satisfying the national security concerns and international obligations of the United States;

(10) the contractor's ability to effect a smooth transition with any contractor selected under title II; and

(11) such other factors as the Secretary deems appropriate and relevant.

(c) Any decision or proposed decision by the Secretary to enter Con=ess. into any such contract shall be transmitted to the Committee on Commerce, Science, and Transportation of the Senate and the Committee on Science and Technorogy of the House of Representatives for their review. No such decision or proposed decision shall be implemented unless (1) a period of thirty calendar days has passed after the receipt by each such committee of such transmittal, or (2) each such committee before the expiration of such period has agreed to transmit and has transmitted to the Secretary written notice to the effect that such committee has no objection to the decision or proposed decision. As part of the transmittal, the Secretary shall include the information specified in subsection (a).

(d) If, as a result of the competitive process required by this Rewrt. section, the Secretary receives no proposal which is acce table under the provisions of this title, the secretary shall so certi! and fully report such findin to the Congress. As soon as practicab Ke but not later than thirty fys after so certifying and reporting, the Secretary shall reopen the competitive process. The period for the subsequent competitive process shall not exceed one hundred and eighty days. If, after such subsequent com titive process, the Sem+ tary receives no proposal which is acceptarle under the provisions of this title, the Secretary shall so certify and full report such finding to the Congress. Not earlier than ninety days a/ter such certification and report, the Secretary may assure data continuity by procure- 
98 STAT. 458

PUBLIC LAW 98-365-JULY 17, 1984

ment and operation by the Federal Government of the necessary systems, to the extent provided in advance by appropriation Acts.

\section{TERMS OF CONTRACT}

15 USC 4224.

SEC. 304. (a) Any contract entered into pursuant to this title(1) shall be entered into as soon as practicable, allowing for the competitive procurement process required by this title;

(2) shall, in accordance with criteria determined and ub lished by the Secretary, reasonably assure data continuity or a period of six years, beginning as soon as practicable in order to minimize any interruption of data availability ;

( ) $s h \sim 1$ provide that the contractor wilr offer ti $=11$ and dehver unenhanced data to all potential buyers on a nondiscriminatory basis;

(4) shall not provide a guarantee of data purchases from the contractor by the Federal Government;

(5) may provide that the contractor utilize, on a spacc+available basis, a civilian United States Government satellite or vehicle as a platform for a civil land remote-sensing space system, if-

(A) the contractor agrees to reimburse the Government immediately for all related costs incurred with respect to such utilization, including a reasonable and proportionate share of freed, platform, data transmission, and launch Costs; and

(B) such utikdon would not interfere with or otherwise compromwe intended civilian Government missions, as determined by the agency responsible for the civilian platform; and

(6) may provide financial support by the United States Government, for a portion of the capital costs required to rovide data continuity for a period of six years, in the form d loans, loan guarantees, or a ment.a pursuant to section 305 of the Federal Property an! Kdministrative Services Act of 1949 (41 U.S.C. 255).

(b)(l) Without regard to whether any contract entered into under this title is combined with a contract under title II, the Secretary shall promptly determine whether the contract entered into under this title reasonably effectuates the pur

Such determination shall be submit $x \mathrm{tl} \%{ }^{\mathrm{d}} \mathrm{P}$ z \% \& $\mathrm{t} !: \% \mathrm{l}^{\mathrm{e}} \mathrm{t}:$ : Congress, together with a full statement of the basis for such determination.

(2) If the Secretary determines that such contract does not reasonably effectuate the requirements of title II, the Secretary shall promptly carry out the provisions of such title to the extent provided in advance in appropriations Acts.

\section{MARKETING}

15 USC 4225 .

SEC. 305. (a) In order to promote aggressive marketing of land remote-sensing data, any contract entered into pursuant to this title may provide that the percentage of sales paid by the contractor to the Federal Government shall decrease according to stipulated increases in sales levels.

(b) After the six-year period described in section 304(aX2), the contractor may continue to sell data. If licensed under title IV, the 
contractor may continue to operate a civil remote-sensing space system.

\section{REPORT}

SEC. 306. Two ears after the date of the commencement of the 15 usc 4226. six-year period (escribed in section 304(a)(2), the Secretary shall report to the President and to the Congress on the progress of the transition to fully private financin, ownership, and operation of remotesensing space systems, toget ier with any recommendations for actions, including actions necessary to ensure United States leadership in civilian land remote sensing from space.

\section{TERMINATION OF AUTHORITY}

SEc. 307. The authority granted to the Secreta by this title shall Is usc d T terminate ten years after the date of enactment o'this Act.

\section{TITLE IV-LICENSING OF PRIVATE REMOTE-SENSING SPACE SYSTEMS}

GENERAL AUTHORITY

SE C. 401. (a)(l) In consultation with other appropriate Federal Is usc d I agencies, the Secretary is authorized to license private sector parties to o rate private remotesensing space systems for such period as the !\&cretary may specify and in accordance with the provisions of this title.

(2) In the case of a private space $s$ stem that is used for remote sensing and other purposes, the aut $\{$ ority of the Secretary under this title shall be limited only to the remote-sensing operations of such space system.

(b) No license shall be granted by the Secretary unless the Secretary determines in writing that the applicant will comply with the requirements of this Act, any regulations issued pursuant to this Act, and any applicable international obligations and national security concerns of the United States.

(c) The Secretary shall review any application and make a deter- Review date mination thereon within one hundred and twenty days of the receipt of such a plication. If final action has not occurred within such time, the $L$ retary shall inform the applicant of any pending issues and of actions required to remlve them.

(d) The Secretary shall not deny such license in order to protect any existing licensee from competition,

\section{CONDITIONS FOR OPERATION}

SEC. 402. (a) No person who is subject to the jurisdiction or control lb USC $4 Z 42$. of the United States may, directly or through any subsidiary or affiliate, operate any private remote-sensing space system without a license pursuant to section 401.

(b) Any license issued pursuant to this title shall specify, at a minimum, that the licensee shall comply with all of the requirements of this Act and shall-

(1) operate the system in such manner as to preserve and :;O $\mathrm{S}$;land promote the national security of the United States and to observe and implement the international obligations of the "ecurity", United States in accordance with section 607; 
98 STAT. 460

PUBLIC LAW 98-365-JULY 17, 1984

(2) make unenhanced data available to all potential users on a nondiscriminatmy basis;

(3) upon termination of operations under the license, make disposition of any satellites in space in a manner satisfactory to the President;

(4) promptly make available all unenhanced data which the Secretary may $r$ uest pum.mnt to section 602;

(5) furnish the\% ecretary with complete orbit and data collection characteristics of the system, obtain advance approval of any intended deviation from such characteristics, and inform the Secretary immediately of any unintended deviation;

(6) notify the Secretary of any agreement the licensee intends to enter with a foreign nation, entity, or consortium involving foreign nations or entities;

(7) permit the inspection by the Secretary of the licensee's equipment, facilities, and financial records;

(8) surrender the license and terminate operations upon notification by the Secretary pursuant to section 403(a)(I); and

(9)(A) notify the Secretary of any "value added" activities (as defined by the Secretary by regulation) that will be conducted by the licensee or by a subsidiary or affiliate; and

(B) if such activities are to be conducted, provide the Secre tary with a plan for compliance with the provisions of this Act concerning nondiscriminatory access.

ADMINISTRATIVE AUTHORITY OF THE SECRETARY

15 USC 4243.

SEC. 403. (a) In order ti carry out the responsibilities specified in this title, the Secretary may-

(1) grant, terminate, modify, condition, transfer, or suspend licenses under this title, and upon notification of the licensee may terminate licensed operations on an immediate basis, if the Secretary determines that the licensee has substantially failed to comply with any provision of this Act, with any regulation issued under this Act, with any terms, conditions, or restrictions of such license, or with any international obligations or national security concerns of the United States;

(2) inspect the equipment, facilities, or financial records of any licensee under this title;

(3) provide penalties for noncompliance with the requirements of licenses or regulations issued under this title, including civil penalties not to exceed $\$ \mathbf{1 0 , 0 0 0}$ (each day of operation in violation of such licenses or regulations constituting a separate violation);

(4) compromise, modify, or remit any such civil penalty;

(5) issue subpenas for any materials, documents, or records, or for the attendance and testimony of witnesses for the purpose of conducting a hearing under this section;

(6) seize any object, record, or report where there is probable cause to believe that such object, record, or report was used, is being used, or is likely to be used in violation of this Act or the requirements of a license or regulation issued thereunder; and

(7) make investigations and inquiries and administer to or take from any person an oath, affh-mation, or affidavit concerning any matter relating to the enforcement of this Act.

(b) Any applicant or licensee who makes a timely request for review of an adverse action pursuant to subsection (a)(l), (a)(3), or 
(a)(6) shall be entitled to adjudication by the Secretary on the record after an opportunity for an agency hearing with respect to such adverse action. Any final action by the Secretary under this subsection shall be subject to judicial review under chapter 7 of title 5 , United States Code.

REGULATORY AUTHORITY OF THE SECRETARY

SEc. 404. The Secretary may issue regulations to carry out the Is UsC 4244 provisions of this title. Such regulations shall be promulgated only after public notice and comment in accordance with the provisions of section 553 of title 5, United States Code.

\section{AGENCY ACI'IVITIES}

SEC. 405. (a) A private sector party may apply for a license to 15 usc 4245 operate a private remotesensing space system which utilizes, on a space-available basis, a civilian United States Government satellite or vehicle as a platform for such system. The Secretary, pursuant to the authorities of this title, may license such system if it meets all conditions of this title and-

(1) the system operator agrees to reimburse the Government immediately for all related costs incurred with respect to such utilization, including a reasonable and proportionate share of freed, platform, data transmission, and launch costs; and

(2) such utilization would not interfere with or otherwise compromise intended civilian Government missions, as determined by the agency responsible for such civilian platform.

(b) The Secretary may offer assistance to private sector parties in finding appropriate opportunities for such utilization.

(c) To the extent provided in advance by appropriation Acts, any Federal agency may enter into agreement for such utilization if such agreements are consistent with such agency's mission and statutory authority, and if such remotesensing space system is licen\& by the Secretary before commencing operation.

(d) The provisions of this section do not apply to activities carried out under title $V$.

(e) Nothing in this title shall affect the authority of the Federal Communications Commission pursuant to the Communications Act of 1934, as amended (47 U.S.C. 151 et seq.).

47 USC 609.

\section{TERMINATION}

SW. 406. If, five years after the expiration of the six-year period 15 USC 4246 described in section 304(a)(2), no private sector party has been licensed and continued in operation under the provisions of this title, the authority of thia title shall terminate.

\section{TITLE V-RESEARCH AND DEVELOPMENT}

CONTINUED FEDERAL RESEARCH AND DEVELOPMENT

SEc. 501. (a)(l) The Administrator of the National Aeronautics and 15 USC 4261. Space Administration is directed to continue and to enhance such Administration's programs of remote-sensing research and development.

(2) The Administrator is authorized and encouraged to- 
(A) conduct experimental space remotesensing programs (including applications demonstration programs and basic research at universities);

(B) develop remotesensing technologies and techniques, including those needed for monitoring the Earth and its environment; and

(C) conduct such research and development in cooperation with other Federal encies and with public and private research entities (includ ing private industry, universities, State and local governments, foreign governments, and international organizations) and to enter into arrangements (including joint ventures) which will foster such cooperation.

b)(l) The Secretary is directed to conduct a continuing program

(A) research in a placations of remote-sensing;

(B) mondmng o !the Earth and its environment; and

(C development of technology for such monitoring.

(2) Such program may include support of basic research at universities and demonstrations of applications.

(3) The secretary is authorized and encouraged to conduct such research, monitoring, and development in cooperation with other Federal agencies and with public and private research entities (including private industry, universities, State and local governments, foreign governments, and international organizations) and to enter into arrangements (including joint ventures) which will foster such cooperation.

(c)(1) In order to enhance the United States ability to manage and utilize its renewable and nonrenewable resources, the Secretary of Agriculture and the Secretary of the Interior are authorized and encouraged to conduct programs of research and development in the applications of remote sensing using funds appropriated for such purposes.

(2) Such programs may include basic research at universities, demonstrations of applications, and cooperative activities involving other Government agencies, private sector parties, and foreign and international or animations.

(d) Other Fdereral agencies are authorized and encouraged to conduct research and development on the use of remote sensing in fulfillment of their authorized missions, using fun"\& appropriated for such purposes.

Report. $\quad$ (e) The Secretary and the Administrator of the National Aeronautics and Space Administration shall, within one year after the date of enactment of this Act and biennially thereafter, jointly develop and transmit to the Congress a report which includes (1) a unified national plan for remotesensing research and development applied to the Earth and its atmosphere; (2) a compilation of progress in the relevant ongoing research and development activities of the Federal agencies; and (3) an assessment of the state of our knowledge of the Earth and its atmosphere, the needs for additional research (including research related to operational Federal remote-sensing space programs), and opportunities available for further progress.

USE OF EXPERIMENTAL DATA

15 USC 4262. SEC. 502. Data gathered in Federal experimental remote-sensing space programs may be used in related research and development programs funded by the Federal Government (including applications 
programs) and cooperative research programs, but not for commercial uses or in competition with private sector activities, except pursuant to section 503 .

SALE OF EXPERIMENTAL DATA

SEC. 503. Data gathered in Federal experimental remote-sensing lb USC dz :I space programs may be sold en bloc through a competitive process (consistent with national security interests and international obligations of the United States and in accordance with section 607) to any United States entity which will market the data on a nondiscriminatory basis.

\section{TITLE VI-GENERAL PROVISIONS}

NONDISCRIMINATORY DATA AVAILABILITY

SEC. 601. (a) Any unenhanced data generated by any system public

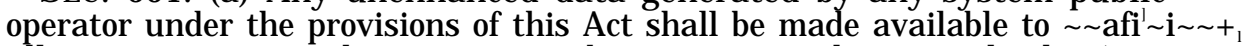
all users on a nondiscriminatory basis in accordance with the " requirements of this Act.

(b) Any system operator shall make publicly available the prices, policies, procedures, and other terms and conditions (but, in accordance with section $104(3)(C)$, not necessarily the names of buyers or their purchases) upon which the operator will sell such data.

ARCHIVING OF DATA

SEC. 602. (a) It is in the public interest for the United States Is USC $\sim \sim$ Government-

(1) to maintain an archive of land remote-sensing data for historical, scientific, and technical purposes, including longterm global environmental monitoring;

(2) to control the content and scope of the archive; and

(3) to assure the quality, integrity, and continuity of the archive.

(b) The Secretary shall provide for long-term storage, maintenance, and upgrading of a basic, global, land remote-sensing data set (hereinafter referred to as the "basic data set") and shall follow reasonable archival practices to assure proper storage and preservation of the basic data set and timely access for parties requesting data. The basic data set which the Secretary assembles in the Government archive shall remain distinct from any inventory of data which a system operator may maintain for sales and for other purposes.

(c) In determining the initial content of, or in upgrading, the basic data set, the Secretary shall-

(1) use as a baseline the data archived on the date of enactment of this Act;

(2) take into account future technical and scientific developments and needs:

(3) consult with and seek the advice of users and producers of remote-sensing data and data products;

(4) consider the need for data which may be duplicative in terms of geographical coverage but which differ in terms of season, spectral bands, resolution, or other relevant factors; 
98 STAT. 464

Public availability.

15 USC 4273

15 USC 4274

15 USC 4275 .
PUBLIC LAW 98-365-JULY 17, 1984

(5) include, as the Secretary considers appropriate, unenhanced data generated either by the Landsat system, pursuant to title III, or by licensees under title IV;

(6) include, as the Secretary considers appropriate, data collected by foreign ound stations or by foreign remote-sensing space systems; anf

(7) ensure that the content of the archive is developed in accordance with section 607.

(d) Subject to the availability of appropriations, the Secretary shall request data needed for the basic data set and pay to the providing system operator reasonable costs for reproduction and transmission. A system operator shall promptly make requested data available in a form suitable for processing for archiving.

(e) Any system operator shall have the exclusive right to sell all data that the operator provides to the United States remote-sensing data archive for a period to be determined by the Secretary but not to exceed ten years from the date the data are sensed. In the case of data generated from the Landsat system prior to the implementation of the contract described in section 202(a), any contractor selected pursuant to section 202 shall have the exclusive right to market such data on behalf of the United States Government for the duration of such contract. A system operator may relinquish the exclusive right and consent to distribution from the archive before the period of exclusive right has expired by terminating the offer to sell particular data.

(f) After the expiration of such exclusive right to sell, or after relinquishment of such right, the data provided to the United States remote-sensing data archive shall be in the public domain and shall be made available to requesting parties by the Secretary at prices reflecting reasonable costs of reproduction and transmittal.

(g) In carrying out the functions of this section, the Secretary shall, to the extent practicable and as provided in advance by appropriation Acts, use existing Government facilities.

NONREPRODUCTION

SEc. 603. Unenhanced data distributed by any system operator under the provisions of this Act may be sold on the condition that such data will not be reproduced or disseminated by the purchaser.

REIMBURSEMENT FOR ASSISTANCE

SEc. 604. The Administrator of the National Aeronautics and Space Administration, the Secretary of Defense and the heads of other Federal agencies may provide assistance to system operators under the provisions of this Act. Substantial assistance shall be reimbursed by the operator, except as otherwise provided by law.

\section{ACQUISITION OF EQUIPMENT}

SEc. 605. The Secretary ma, by means of a competitive process, allow a licensee under title $I 6$ or any other private party to buy, lease, or otherwise acquire the use of equipment from the Landsat system, when such equipment is no longer needed for the o ration of such system or for the sale of data from such system. OFlcials of other Federal civilian agencies are authorized and encouraged to cooperate with the Secretary in carrying out the provisions of this section. 
SEC. 606. (a) Within thirty days after the date of enactment of this Act, the President (or the President's delegee, if any, with authority over the assignment of frequencies to radio stations or classes of radio stations operated by the United States) shall make available for nongovernmental use spectrum presently allocated to Government use, for use by United States Landsat and commercial remotesensing space systems. The spectrum to be so made available shall conform to any applicable international radio or wire treaty or convention, or regulations annexed thereto. Within ninety days thereafter, the Federal Communications Commission shall utilize appropriate procedures to authorize the use of such spectrum for nongovernmental use. Nothing in this section shall preclude the ability of the Commission to allocate additional spectrum to commercial land remote-sensing space satellite system use.

(b) To the extent required by the Communications Act of 1934, as amended (47 U.S.C. 151 et seq.), an application shall be filed with the Federal Communications Commission for any radio facilities involved with the commercial remote-sensing space system.

(c) I! is the intent of Congress that the Federal Communications Commlsslon complete the radio licensing process under the Communications Act of 1934, as amended (47 U.S.C. 151 et seq.), upon the application of any private sector party or consortium operator of any commercial land remote-sensing space system subject to this Act, within one hundred and twenty days of the receipt of an application for such licensing. If final action has not occurred within one hundred and twenty days of the receipt of such an application, the Federal Communications Commission shall inform the applicant of any pending issues and of actions required to resolve them.

(d) Authority shall not be required from the Federal Communications Commission for the development and construction of any United States land remote-sensing space system (or component thereof), other than radio transmitting facilities or components, while any licensing determination is being made.

(e) Frequency allocations made pursuant to this section by the Federal Communications Commission shall be consistent with international obligations and with the public interest.

\section{CONSULTATION}

SEc. 607. (a) The Secretary shall consult with the Secretary of Defense on all matters under this Act affecting national security. The Secretary of Defense shall be responsible for determining those conditions, consistent with this Act, necessary to meet national security concerns of the United States and for notifying the Secretary promptly of such conditions.

(b)(l) The Secretary shall consult with the Secretary of State on all matters under this Act affecting international obligations. The Secretary of State shall be responsible for determining those conditions, consistent with this Act, necessary to meet international obligations and policies of the United States and for notifying the Secretary promptly of such conditions.

(2) Appropriate Federal agencies are authorized and encouraged to provide remote-sensing data, technology, and training to developing nations as a component of programs of international aid.
President of US. 15 USC 4276.

47 USC 609

Defense and national security, 
98 STAT. 466

PUBLIC LAW 98-365-JULY 17, 1984

(3) The Secretary of State shall romptly report to the Secretary any instances outside the United States of discriminatory distribution of data.

(c) If, as a result of technical modifications imposed on a system operator on the basis of national securit concerns, the Secretary, in consultation with the Secretary of De/ènse or with other Federal agencies, determines that additional costs will be incurred by the system operator, or that past development costs (including the cost of capital) will not be recovered by the system operator, the Secretary may require the agency or agencies requesting such technical modifications to reimburse the system operator for such additional or development costs, but not for anticipated profits. Reimbursements may cover costs associated with required changes in system performance, but not costs ordinarily associated with doing business abroad.

\section{AMENDMENT TO NATIONAL AERONAUTICS AND SPACE ADMINISTRATION AUTHORIZATION, 1983}

SEc. 608. Subsection (a) of section 201 of the National Aeronautics

${ }_{15}$ Usc 1517

note.

15 USC 4278

15Usc 1517 note. and Space Administration Authorization Act, 1983 (Public Law 97. 324; 96 Stat. 1601) is amended to read as follows:

"(a) The Secretary of Commerce is authorized to plan and provide for the management and opdration of civil remote-sensing space systems, which may include the Landsat 4 and 5 satellites and associated ground system equipment transferred from the National Aeronautics and Space Administration; to provide for user fees; and to plan for the transfer of the operation of civil remote-sensing space systems to the private sector when in the national interest.".

\section{AUTHORIZATION OF APPROPRIATIONS}

SEc. 609. (a) There are authorized to be appropriated to the Secretary $\$ 75,000,000$ for fwal year 1985 for the purpose of carrying out the provisions of this Act. Such sums shall remain available until expended, but shall not become available until the time periods specified in sections $202(\mathrm{c})$ and 303 (c) have expired.

b) The authorization provided for under subsection (a) shall be in addition to moneys authorized pursuant to title II of the National Aeronautics and Space Administration Authorization Act, 1983.

\section{TITLE VII-PROHIBITION OF COMMERCIALIZATION OF WEATHER SATELLITES}

\section{PROHIBITION}

SEC. 701. Neither the President nor any other official of the Government shall make any effort to lease, sell, or transfer to the private sector, commercialize, or in any way dismantle any portion of the weather satellite systems operated by the Department of Commerce or any successor agency. 
FUTURE CONSIDERATIONS

SEC. 702. Regardless of any change in circumstances subsequent to 15 USC 4292. the enactment of this Act, even if such change makes it appear to be in the national interest to commercialize weather satellites, neither the President nor any official shall take any action prohibited by section 701 unless this title has first been repealed.

Approved J uly 17, 1984.

HOUSE REPORT No. 98-647 (Comm. on Science and Technology).

SENATE REPORT No. 98-458 (Comm. on Commerce, Science, and Transportation).

CONGRESSIONAL RECORD, Vol. 130 (1984):

Apr. 9, considered and passed House.

June 8 , considered and passed Senate, amended.

June 28, House concurred in Senate amendment with an amendment.

June 29, Senate concurred in House amendment.

WEEKLY COMPILATION OF PRESIDENTIAL DOCUMENTS, vol. 20, No. 29 (1984): July 17, Presidential statement. 
Public Law 98-575

98th Congress

\section{An Act}

To facilitate commercial space launches, and for other purposes.

Be it enacted by the Senate and House of Representatives of the United States of America in Congress assembled,

$$
\text { SHORT TITLE }
$$

SECTION 1. This Act may be cited as the "Commercial Space Launch Act'.

\section{FINDINGS}

SEC. 2. The Congress finds and declares that-

( $U$ the peaceful uses of outer space continue to be of great value and to offer benefits to all mankind;

(2) private applications of space technology have achieved a significant level of commercial and economic activity, and offer the potential for growth in the future, particularly in the United States;

(3) new and innovative equipment and services are being sought, created, and offered by entrepreneurs in telecommunications, information services, and remote sensing technology;

(4) the private sector in the United States has the capability of developing and providing private satellite launching and associated services that would complement the launching and associated services now available from the United States Government;

(5) the development of commercial launch vehicles and associated services would enable the United States to retain its competitive position internationally, thereby contributing to the national interest and economic well-being of the United States;

(6) provision of launch services by the private sector is consistent with the national security interests and foreign policy interests of the United States and would be facilitated by stable, minimal, and appropriate regulatory guidelines that are fairly and expeditiously applied; and

(7) the United States should encourage private sector launches and associated services and, only to the extent necessary, regulate such launches and services in order to ensure compliance with international obligations of the United States and to protect the public health and safety, safety of property, and national security interests and foreign policy interests of the United States.

$$
\text { PURPOSES }
$$

$\mathrm{SEC}$. 3. It is therefore the purpose of this Act-

(1) to promote economic growth and entrepreneurial activity through utilization of the space environment for peaceful purposes;

\author{
$\frac{\text { Oct. } 30.1984}{\text { [H.R. 3942] }}$
}

Commercial

Space

Launch Act.

49 USC app. 2601

note.

49 USC app.

2601.

49 USC 2602. 
98 STAT. 3056

PUBLIC LAW 98-575-OCT. 30, 1984

(2) to encourage the United States private sector to provide launch vehicles and associated launch services by simplifying and expediting the issuance and transfer of commercial launch licenses and by facilitating and encouraging the utilization of Government developed space technology; and

(3) to designate an executive department to oversee and coordinate the conduct of commercial launch operations, to issue and transfer commercial launch licenses authorizing such activities, and to protect the public health and safety, safety of property, and national security interests and foreign policy interests of the United States.

DEFINITIONS

49 USC app. 2603.
SEC. 4. For purposes of this Act-

(1) "agency" means an executive agency as defined by section 105 of title 5, United States Code;

(2) "launch" means to place, or attempt to place, a launch vehicle and payload, if any, in a suborbital trajectory, in Earth orbit in outer space, or otherwise in outer space;

(3) "launch property" means propellants, launch vehicles and components thereof, and other physical items constructed for or used in the launch preparation or launch of a launch vehicle;

(4) "launch services" means those activities involved in the preparation of a launch vehicle and its payload for launch and the conduct of a launch;

(5) "launch site" means the location on Earth from which a launch takes place, as defined in any license issued or transferred by the Secretary under this Act, and includes all facilities located on a launch site which are necessary to conduct a launch;

(6) "launch vehicle" means any vehicle constructed for the purpose of operating in, or placing a payload in, outer space and any suborbital rocket;

(7) "payload" means an object which a person undertakes to place in outer space by means of a launch vehicle, and includes subcomponents of the launch vehicle specifically designed or adapted for that object;

(8) "person" means any individual and any corporation, partnership, joint venture, association, or other entity organized or existing under the laws of an State or any nation;

(9) "secretary" means the \& xretary of Transportation;

(10) "State", and "United States" when used in a geographical sense, mean the several States, the District of Columbia, the Commonwealth of Puerto Rico, American Samoa, the United States Virgin Islands, Guam, and any other commonwealth, territory, or possession of the United States; and

(11) "United States citizen" means-

(A) any individual who is a citizen of the United States; (B) any corporation, partnership, joint venture, association, or other entity organized or existing under the laws of the United States or any State; and

(0 any corporation, partnership, joint venture, association, or other entity which is organized or exists under the laws of a foreign nation, if the controlling interest (as defined by the Secretary in regulations) in such entity is 
PUBLIC LAW 98-575-OCT. 30, 1984

98 STAT. 3057

held by an individual or entity described in subparagraph (A) or(B).

GENERAL RESPONSIBILITIES OF THE SECRETARY AND OTHER AGENCIES

SEc. 5. (a) The Secretary shall be responsible for carrying out this $\$ \sim 0 \sim S C a_{p p}$. Act, and in doing so shall-

(1) encourage, facilitate, and promote commercial space

launches by the private sector; and

(2) consult with other agencies to provide consistent applica-

tion of licensing requirements under this Act and to ensure fair

and equitable treatment for all license applicants.

b) To the extent permitted by law, Federal agencies shall assist the Secretary, as necessary, in carrying out this Act.

\section{REQUIREMENT OF LICENSE FOR PRIVATE SPACE LAUNCH OPERATIONS}

SEC. 6. (a)(l) No person shall launch a launch vehicle or operate a $\$: 0 \sim S C a_{p p}$. launch site within the United States, unless authorized by a license issued or transferred under this Act.

(2) No United States citizen described in subparagraph (A) or (B) of section 4(11) shall launch a launch vehicle or operate a launch site outside the United States, unless authorized by a license issued or transferred under this Act.

(3)(A) No United States citizen described in subparagraph (C) of section 4(11) shall launch a launch vehicle or operate a launch site at any place which is both outside the United States and outside the territory of any foreign nation, unless authorized by a license issued or transferred under this Act. The preceding sentence shall not apply with respect to a launch or operation of a launch site if there is an agreement in force between the United States and a foreign nation which provides that such foreign nation shall exercise jurisdiction over such launch or operation.

(B)(i) Except as provided in clause (ii) of this subparagraph, this Act shall not apply to the launch of a launch vehicle or the operation of a launch site in the territory of a foreign nation by a United States citizen described in subparagraph (C)of section 4(11).

(ii) If there is an agreement in force between the United States International and a foreign nation which provides that the United States shall agyeerne" exercise jurisdiction over the launch of a launch vehicle or operation of a launch site in the territory of such nation by a United States citizen described in subparagraph (C)of section 4(11), no such United States citizen shall launch a launch vehicle or operate a launch site in the territory of such nation, unless authorized by a license issued or transferred under this Act.

(b)(l) The holder of a launch license under this Act shall not launch a payload unless that payload complies with all requirements of Federal law that relate to the launch of a payload. The Secretary shall ascertain whether any license, authorization, or other permit required by Federal law for a payload which is to be launched has been obtained.

(2) If no payload license, authorization, or permit is required by any Federal law, the Secretary may take such action under this Act as the Secretary deems necessary to prevent the launch of a payload by a holder of a launch license under this Act if the Secretary determines that the launch of such payload would jeopardize the 
public health and safety, safety of property, or any national security interest or foreign policy interest of the United States.

(c)(1) Except as provided in this Act, no person shall be required to obtain from any agency a license, approval, waiver, or exemption for the launch of a launch vehicle or the operation of a launch site.

(2) Nothing in this Act shall affkct the authority of the Federal Communications Commission under the Communications Act of 1934 (47 U.S.C. 151 et seq.) or the authority of the Secretary of Commerce under the Land Remote-Sensing Commercialization Act of 1984 (15 U.S.C. 4201 et seq.).

\section{AUTHORITY TO ISSUE AND TRANSFER LICENSES}

49 USC app 2606 .

49 USC app. 2607.

49 USC app. 2608.
SEC. 7. The Secretary may, consistent with the public health and safety, safety of property, and national security interests and foreign policy interests of the United States, issue or transfer a license for launching one or more launch vehicles or for operating one or more launch sites, or both, to an applicant who meets the requirements for a license under section 8 of this Act. Any license issued or transferred under this section shall be in effect for such period of time as the Secretary may specify, in accordance with regulations issued under this Act.

\section{LICENSING REQUIREMENTS}

SEC. 8. (a)(1) All requirements of Federal law which apply to the launch of a launch vehicle or the operation of a launch site shall be requirements for a license under this Act for the launch of a launch vehicle or the operation of a launch site, respectively, except to the extent provided in paragraph $(2)$.

(2) If the Secretary determines, in consultation with appropriate agencies, that any requirement of Federal law that would otherwise apply to the launch of a launch vehicle or the operation of a launch site is not necessary to protect the public health and safety, safety of property, and national security interests and foreign policy interests of the United States, the Secretary may by regulation provide that such requirement shall not be a requirement for a license under this Act.

(b) The Secretary may, with respect to launches and the operation of launch sites, prescribe such additional requirements as are necessary to protect the public health and safety, safety of property, and national security interests and foreign policy interests of the United States.

(c) The Secretary may, in individual cases, waive the application of any requirement for a license under this section if the Secretary determines that such waiver is in the public interest and will not jeopardize the public health and safety, safety of property, or any national security interest or foreign policy interest of the United states.

\section{LICENSE APPLICATION AND APPROVAL}

SEC. 9. (a) Any person may apply to the Secretary for issuance or transfer of a license under this Act, in such form and manner as the Secretary may prescribe. The Secretary shall establish procedures and timetables to expedite review of applications under this section and to reduce regulatory burdens for applicants. 
(b) The Secretary shall issue or transfer a license to an applicant if the Secretary determines in writing that the applicant complies and will continue to comply with the requirements of this Act and an regulation issued under this Act. The Secretary shall include in suci license such conditions as may be necessary to ensure compliance with this Act, including an effective means of on-site verification that a launch or operation of a launch site conforms to representations made in the application for a license or transfer of a license. The Secretary shall make a determination on any application not later than 180 days after receipt of such application. If the Secreta has not made a determination within 120 days after receipt of suct application, the Secretary shall inform the applicant of any pending issues and of actions required to resolve such issues.

(c) The Secretary, any officer or employee of the United States, or any person with whom the Secretary has entered into a contract under section 14(b) of this Act may not disclose any data or information under this Act which qualifies for exemption under section 552(b)(4) of title 5, United States Code, or is designated as confidential by the person or agency furnishing such data or information, unless the Secretary determines that the withholding of such data or information is contrary to the public or national interest.

SUSPENSION, REVOCATION, AND MODIFICATION OF LICENSES

SEC. 10. (a) The Secretary may suspend or revoke any license $\sim: O \sim S C$ a issued or transferred under this Act if the Secretary finds that the 1 . licensee has substantially failed to comply with any requirement of this Act, the license, or any regulation issued under this Act, or that the suspension or revocation is necessary to protect the public health and safety, safety of property, or any national security interest or foreign policy interest of the United States.

(b) Upon application by the licensee or upon the Secretary's own initiative, the Secretary may modify a license issued or transferred under this Act, if the Secretary finds that the modification will comply with the requirements of this Act.

(c) Unless otherwise specified by the Secretary, any suspension, revocation, or modification by the Secretary under this section-

(1) shall take effect immediately; and

(2) shall continue in effect during any review of such action under section 12 of this Act.

(d) whenever the Secretary takes any action under this section, the Secretary shall notify the licensee in writing of the Secretary's finding and the action which the Secretary has taken or proposes to take regarding such finding.

\section{EMERGENCY ORDERS}

SE C. 11. (a) The Secretary may terminate, prohibit, or suspend Prohibition. immediately the launch of a launch vehicle or the operation of a 49 USC app launch site which is licensed under this Act if the Secretary deter- ${ }^{2 \mathrm{G}} \mathbf{1}^{0}$ mines that such launch or operation is detrimental to the public health and safety, safety of property, or any national security interest or foreign policy interest of the United States.

b) An order terminating, prohibiting, or suspending any launch or operation of a launch site licensed by the Secretary under this Act shall take effect immediately and shall continue in effect during any review of such order under section 12. 
98 STAT. 3060

$\$ I_{\curvearrowright} \mathrm{SC}$ app.

49 USC app. 261 '2.

49 USC app. 2513,

49 USC app. 2614.
PUBLIC LAW 98-575-OCT. 30, 1984

\author{
ADMINISTRATIVE AND JUDICIAL REVIEW
}

SEC. 12. (a)(I) An applicant for a license and a proposed transferee of a license under this Act shall be entitled to a determination on the record after an opportunist for a hearing in accordance with section 554 of title 5, United \&ates Code, of any decision of the Secretary under section 9(b) to issue or transfer a license with conditions or to deny the issuance or transfer of such license. An owner or operator of a payload shall be entitled to a determination on the record after an opportunity for a hearing in accordance with section 554 of title 5, United States Code, of any decision of the ? ::etary under section 6(b)(2) to prevent the launch of such pay-

(2i A licensee under this Act shall be entitled to a determination on the record after an opportunity for a hearing in accordance with section 554 of title 5, United States Code, of any decision of the Secretary-

(A) under section 10 to suspend, revoke, or modify a license; or

(B) under section 11 to terminate, prohibit, or suspend any

launch or operation of' a launch site licensed by the Secretary.

-) Any final action of the Secretary under this Act to issue, transfer, deny the issuance or transfer of, suspend, revoke, or modify a license or to terminate, prohibit, or suspend any launch or operation of a launch site licensed by the Secretary or to prevent the launch of a payload shall be subject to judicial review as provided in chapter 7 of title 5, United States Code.

REGULATIONS

SEC. 13. The Secretary may issue such regulations, after notice and comment in accordance with section 553 of title 5, United States Code, as maybe necessary to carry out this Act.

\section{MONITORING OF ACTIVITIES OF LICENSEES}

SEC. 14. (a) Each license issued or transferred under this Act shall require the licensee-

(1) to allow the Secretary to place Federal officers or employees or other individuals as observers at nnlaunch site used by the licensee, at any production facility or assembly site used by a contractor of the licensee in the production or assembly of a launch vehicle, or at any site where a pa load is integrated with a launch vehicle, in order to monitor ti e activities of the licensee or contractor at such time and to such extent aa the Secretary considers reasonable and necessary to determine compliance with the license or to carry out the responsibilities of the Secretary under section 6(b) of this Act; and

(2) to coo rate with such observers in the performance of monitoring runctions.

(b) The Secretary may, to the extent provided in advance by appropriation Acts, enter into a contract with any person to carry out subsection (a)(l) of this section.

USE OF GOVERNMENT PROPERTY

SEC. 15. (a) The Secretary shall take such actions as may be necessary to facilitate and encourage the acquisition (by lease, sale, transaction in lieu of sale, or otherwise) by the private sector of 
PUBLIC LAW 98-575-OCT. 30, 1984

launch property of the United States which is excess or is otherwise not needed for public use and of launch services, including utilities, of the United States which are otherwise not needed for public use.

(b)(l) The amount to be paid to the United States by any person who acquires launch property or launch services, including utilities, shall be established by the agency providing the property or service, in consultation with the Secretary. In the case of acquisition of launch property by sale or transaction in lieu of sale, the amount of such payment shall be the fair market value. In the case of an other type of acquisition of launch property, the amount of suci! payment shall bean amount equal to the direct costs (including any specific wear and tear and damage to the property) incurred by the United States as a result of the acquisition of such launch property. In the case of any acquisition of launch services, including utilities, the amount of such payment shall be an amount equal to the direct costs (including salaries of United States civilian and contractor personnel) incurred by the United States as a result of the acquisition of such launch services.

(2) The Secretary may collect any payment for launch property or launch services, with the consent of the agency establishing such payment under paragraph (l).

(3) l'he amount of any payment received by the United States for launch property or launch services, including utilities, under this subsection shall be deposited in the general fund of the Treasury, and the amount of a payment for launch property (other than launch property which is excess) and launch services (including utilities) shall be credited to the appropriation from which the cost of providing such property or services was paid.

(c) The Secretary may establish requirements for liability insurance, hold harmless agreements, proof of financial responsibility, and such other assurances as may be needed to protect the United States and ita agencies and personnel from liability, loss, or injury as a result of a launch or operation of a launch site involving Government facilities or personnel.

\section{LIABILITY INSURANCE}

SEC. 16. Each person who launches a launch vehicle or operates a \&\#C app. launch site under a license issued or transferred under this Act shall have in effect liability insurance at least in such amount as is considered by the Secretary to be necessary for such launch or operation, considering the international obligations of the United States. The Secretary shall prescribe such amount after consultation with the Attorney General and other appropriate agencies.

\section{ENFORCEMENT AUTHORITY}

SEc. 17. (a) The Secretary shall enforce this Act. The Secretary $\$ \sim 1 \sim s c a_{p p}$. may delegate the exercise of any enforcement authority under this Act to any officer or employee of the Department of Transportation or, with the approval of the head of another agency, any officer or employee of such agency.

(b) In carrying out this section, the Secretary may-

(1) make investigations and inquiries, and administer to or take from any person an oath, affhmation, or affidavit, concerning any matter relating to enforcement of this Act; and

(2) pursuant to any lawful process- 
98 STAT. 3062

49 Usc app, 2617. 49 LJS(: app
$261 \mathrm{X}$,

Defense and national security. 4:) US(' app. 261!).
PUBLIC LAW 98-575-OCT. 30, 1984

(A) enter at any reasonable time any launch site, production facility, or assembly site of a launch vehicle, or any site where a payload is integrated with a launch vehicle, for the purpose of inspecting any object which is subject to this Act and any records or reports required by the Secretary to be made or kept under this Act; and

(B) seize any such object, record, or report where there is probable cause to believe that such object, record, or report was used, is being used, or is likely to be used in violation of this Act.

PROHIBITED ACTS

SEC. 18. It is unlawful for any person to violate a requirement of this Act, a regulation issued under this Act, or any term, condition, or restriction of any license issued or transferred by the Secretary under this Act.

\section{CIVIL PENALTIES}

SEC. 19. (a) Any person who is found by the Secretary, after notice and opportunity to be heard on the record in accordance with section 554 of title 5, United States Code, to have committed any act prohibited by section 18 shall be liable to the United States for a civil penalty of not more than $\$ 100,000$ for each violation. Each day of a continuing violation shall constitute a separate violation. The amount of such civil penalty shall be assessed by the Secretary by written notice. The Secretary may compromise, modify, or remit, with or without conditions, any civil penalty which is subject to imposition or which has been imposed under this section.

(b) If any person fails to pay a civil penalty assessed against such person after the penalty has become final or if such person appeals an order of the Secretary and the appropriate court has entered final judgment in favor of the Secretary, the Secretary shall recover the civil penalty assessed in any appropriate district court of the United States.

(c) For purposes of conducting any hearing under this section, the Secretary may (1) issue subpoenas for the attendance and testimony of witnesses and the production of relevant papers, books, documents, and other records, (2) seek enforcement of such subpoenas in the appropriate district court of the United States, and (3) administer oaths and affirmations.

\section{CONSULTATION}

SEC. 20. (a) The Secretary shall consult with the Secretary of Defense on all matters, including the issuance or transfer of each license, under this Act affecting national security. The Secretary of Defense shall be responsible for identifying and notifying the Secretary of those national security interests of the United States which are relevant to activities under this Act.

(b) The Secretary shall consult with the Secretary of State on all matters, including the issuance or transfer of each license, under this Act affecting foreign policy. The Secretary of State shall be responsible for identifying and notifying the Secretary of those foreign policy interests or obligations of the United States which are relevant to activities under this Act.

(c) The Secretary shall consult with other agencies, as appropriate, in order to carry out the provisions of this Act. 
PUBLIC LAW 98-575-OCT. 30, 1984

REIJITIONSHIP TO OTHER LAWS AND INTERNATIONAL OBLIGATIONS

SEc. 21. (a) No State or political subdivision of a State may adopt Prohibitions. or have in effect any law, rule, regulation, standard, or order which 49 USC app. is inconsistent with the provisions of this Act. Nothing in this Act shall preclude a State or a political subdivision of a State from adopting or putting into effect any law, rule, regulation, standard, or order which is consistent with this Act and is in addition to or more stringent than any requirement of or regulation issued under this Act. The Secretary may, and is encouraged to, consult with the States to simplify and expedite the approval of space launch activities.

(b) A launch vehicle or payload shall not, by reason of the launching of such vehicle or payload, be considered an export for purposes of any law controlling exports.

(c) $\mathrm{N}: \mathrm{IhiI}_{\text {in }}$ in this Act shall apply to-

(A) launch or operation of a launch vehicle,

(B) operation of a launch site, or

(C) other space activity,

carried out by the United States on behalf of the United States; or

(2) any planning or policies relating to any such launch, operation, or activity.

(d) The Secretary shall carry out this Act consistent with any obligation assumed by the United States in any treaty, convention, or agreement that may be in force between the United States and any foreign nation. In carrying out this Act, the Secretary shall consider applicable laws and requirements of any foreign nation.

\section{REPORT ON LEGISLATION}

SEC. 22. (a) Not later than the last day of each fiscal year ending Re ort. after the date of enactment of this Act and before October 1, 1989, $L_{\sim_{z l}}{ }^{\text {sc a p }}$ the Secretary shall submit to the Committee on Science and Technology of the House of Representatives and the Committee on Commerce, Science, and Transportation of the Senate a report describing all activities undertaken under this Act, including a description of the process for the application for and approval of licenses under this Act and recommendations for legislation that may further commercial launches.

(b) Not later than July 1, 1985, the Secretary shall submit to the Committee on Science and Technology of the House of Representatives and the Committee on Commerce, Science, and Transportation of the Senate a report which identifies Federal statutes, treaties, regulations, and policies which may have an adverse effect on commercial launches and include recommendations on appropriate changes thereto.

\section{SEVERABILITY}

SEc. 23. If any provision of this Act, or the application of such \#\&;SC $a_{p p}$. provision to any person or circumstance, is held invalid, the remainder of this Act and the application of such provision to any other person or circumstance shall not be affected by such invalidation. 


\begin{tabular}{|c|c|c|c|}
\hline $\mathrm{GHz}$ & $\begin{array}{l}\text { - gigahertz (91 billion cycles per } \\
\text { second) }\end{array}$ & $\mathrm{kHz}$ & $\begin{array}{l}\text {-kilohertz (1 ,000 cycles per } \\
\text { second) }\end{array}$ \\
\hline GMS & $\begin{array}{l}\text {-Geostationary Meteorological Sat- } \\
\text { ellite (Japan) }\end{array}$ & LACIE & $\begin{array}{l}\text {-Large Area Crop Inventory Ex- } \\
\text { periment }\end{array}$ \\
\hline GNP & -gross national product & Landsat & -land remote-sensing satellite \\
\hline GPS & $\begin{array}{l}\text {-global positioning satellite (some- } \\
\text { times NAVSTAR/GPS-DOD) }\end{array}$ & LDC & $\begin{array}{l}\text { system } \\
\text {-less developed country }\end{array}$ \\
\hline $\begin{array}{l}\text { GSO } \\
\text { HDDT-high }\end{array}$ & $\begin{array}{l}\text {-geostationary orbit } \\
\text {-density digital tape }\end{array}$ & LEO & $\begin{array}{l}\text {-low-Earth orbit (up to approxi- } \\
\text { mately .soo km) }\end{array}$ \\
\hline HI AND HII & $\begin{array}{l}\text {-Japanese expendable launch ve- } \\
\text { hicles being developed by }\end{array}$ & MARI SAT & $\begin{array}{l}\text {-International Maritime Satellite } \\
\text { Organization }\end{array}$ \\
\hline & NASDA & MELCO & -Mitsubishi Electric Co. \\
\hline $\mathrm{HF}$ & -high frequency & METEOSAT & -meteorological satellite devel- \\
\hline $\mathrm{Hz}$ & $\begin{array}{l}\text {-hertz; a unit of frequency equal } \\
\text { to one cycle per second }\end{array}$ & $\mathrm{MHz}$ & $\begin{array}{l}\text { oped by ESA } \\
\text { - megahertz }\left(1 \mathrm{O}^{\mathrm{b}} \text { cycles per }\right.\end{array}$ \\
\hline IAA & -International Academy of As- & & second) \\
\hline IAEA & $\begin{array}{l}\text { tronautics } \\
\text {-International Atomic Energy }\end{array}$ & MITI & $\begin{array}{l}\text {-Ministry of International Trade } \\
\text { and Industry (Japan) }\end{array}$ \\
\hline IAF & $\begin{array}{l}\text { Agency } \\
\text {-International Astronautical Fed- }\end{array}$ & MLA & $\begin{array}{l}\text {-multispectral-li near array (solid } \\
\text { state) }\end{array}$ \\
\hline & eration & MOS & -Maritime Observation Satellite \\
\hline IBS & -INTELSAT Business Service & & (Japan) \\
\hline ICBM & -intercontinental ballistic missile & MOU & -Memorandum of Understanding \\
\hline IC C P & $\begin{array}{l}\text {-Committee on Information, Com- } \\
\text { puter and Communications Pol- } \\
\text { icy }\end{array}$ & $\begin{array}{l}\text { MPS } \\
\text { MPTS }\end{array}$ & $\begin{array}{l}\text { - materials processing in space } \\
\text { - microwave power transmission } \\
\text { system }\end{array}$ \\
\hline Icsu & $\begin{array}{l}\text {-International Council of Scientific } \\
\text { Unions }\end{array}$ & MSS & $\begin{array}{l}\text {-multispectral scanner (on } \\
\text { Landsat) }\end{array}$ \\
\hline IEEE & $\begin{array}{l}\text {-Institute of Electrical and Elec- } \\
\text { tronics Engineers }\end{array}$ & $\mathrm{N}-1 \&$ \& & $\begin{array}{l}\text {-Expendable launch vehicles de- } \\
\text { veloped by NASDA }\end{array}$ \\
\hline IFRB & $\begin{array}{l}\text {-International Frequency Registra- } \\
\text { tion Board }\end{array}$ & NACA & $\begin{array}{l}\text {-National Advisory Committee for } \\
\text { Aeronautics }\end{array}$ \\
\hline IHW & $\begin{array}{l}\text {-International Halley Watch } \\
\text {-International Institute of Space }\end{array}$ & NACP & $\begin{array}{l}\text {-North Atlantic Consultative } \\
\text { Process }\end{array}$ \\
\hline & $\begin{array}{l}\text {-International Institute of Space } \\
\text { Law }\end{array}$ & NACPWG & -North Atlantic Consultative Proc- \\
\hline ILA & -International Lawyers Association & & ess (NACP) and its working \\
\hline IMCO & $\begin{array}{l}\text {-Intergovernmental Maritime Con- } \\
\text { sultative Organization }\end{array}$ & NAS & $\begin{array}{l}\text { groups } \\
\text {-National Academy of Sciences }\end{array}$ \\
\hline INMARSAT & $\begin{array}{l}\text {-International Maritime Satellite } \\
\text { Organization }\end{array}$ & NASA & $\begin{array}{l}\text {-National Aeronautics and Space } \\
\text { Administration }\end{array}$ \\
\hline INTERSP & K-Communist bloc satellite system & NAS Act & -National Aeronautics and Space \\
\hline IPDC & $\begin{array}{l}\text {-International Program for the De- } \\
\text { velopment of Communication }\end{array}$ & NASDA & $\begin{array}{l}\text { Act of } 1958 \\
\text { - National Space Development }\end{array}$ \\
\hline IRAC & -Interdepartment Radio Advisory & & Agency (Japan) \\
\hline IRS & $\begin{array}{l}\text { Committee } \\
\text {-Indian Remote-Sensing Satellite }\end{array}$ & NATO & $\begin{array}{l}\text {-North Atlantic Treaty Organi- } \\
\text { zation }\end{array}$ \\
\hline ISAS & $\begin{array}{l}\text {-Institute for Space and Aeronauti- } \\
\text { cal Sciences (Japanese) }\end{array}$ & $\begin{array}{l}\text { NEC } \\
\text { NESDIS }\end{array}$ & $\begin{array}{l}\text {-Nippon Electric Corp. } \\
\text {-National Environmental Satellite, }\end{array}$ \\
\hline ISPM & -International Solar Polar Mission & & Data, and Information Service \\
\hline ISRO & $\begin{array}{l}\text {-Indian Space Research Organi- } \\
\text { zation }\end{array}$ & NIEO & $\begin{array}{l}\text {-New International Economic } \\
\text { Order }\end{array}$ \\
\hline ITU & $\begin{array}{l}\text {-International Telecommunication } \\
\text { Union }\end{array}$ & NOAA & $\begin{array}{l}\text {-National Oceanic and Atmos- } \\
\text { pheric Administration }\end{array}$ \\
\hline JEA & $\begin{array}{l}\text {-Joint Endeavor Agreement } \\
\text { (NASA) }\end{array}$ & N-ROSS & $\begin{array}{l}\text {-Navy Remote Ocean Sensing Sat- } \\
\text { ellite }\end{array}$ \\
\hline
\end{tabular}




\begin{tabular}{|c|c|c|c|}
\hline $\begin{array}{l}\text { NSF } \\
\text { NTAA }\end{array}$ & $\begin{array}{l}\text {-National Science Foundation } \\
\text {-National Telecommunications } \\
\text { and Information Agency (DOC) }\end{array}$ & SKYLAB & $\begin{array}{l}\text {-U.S. space laboratory, placed in } \\
\text { orbit in the early } 197 \text { os and now } \\
\text { disintegrated }\end{array}$ \\
\hline NTT & $\begin{array}{l}\text {-Nippon Telegraph \& Telephone } \\
\text { Co. (public corporation for Japa- } \\
\text { nese communications) }\end{array}$ & $\begin{array}{l}\text { SLAR } \\
\text { Solaris }\end{array}$ & $\begin{array}{l}\text { - side looking airborne radar } \\
\text {-proposed French free-flying, auto- } \\
\text { mated, industrial processing }\end{array}$ \\
\hline NWIO & -New World International Order & & station \\
\hline OAS & -Organization of American States & SPACE LAB & —space laboratory which fits into \\
\hline $\mathrm{Ocl}$ & -Ocean Color Imager & & the shuttle's cargo bay and was \\
\hline ODA & —official development assistance & & developed as part of a coopera- \\
\hline OECD & $\begin{array}{l}\text {-Organization for Economic Coop- } \\
\text { eration and Development }\end{array}$ & SPAS & $\begin{array}{l}\text { tive project with ESA and NASA } \\
\text {-Shuttle Pallet Satellite (a deploya- }\end{array}$ \\
\hline OES & $\begin{array}{l}\text {-Bureau of Oceans and Environ- } \\
\text { mental and Scientific Affairs, De- } \\
\text { partment of State }\end{array}$ & & $\begin{array}{l}\text { ble carrier developed by MBB } \\
\text { and first flown aboard the space } \\
\text { shuttle in 1983) }\end{array}$ \\
\hline OMB & $\begin{array}{l}\text {-Office of Management and } \\
\text { Budget }\end{array}$ & SPOT & $\begin{array}{l}\text {-SystSme Probetoire Observation } \\
\text { de la Terre (French land remote- }\end{array}$ \\
\hline ORB-85 & $\begin{array}{l}-1985 \text { meeting of the ITU to con- } \\
\text { sider use of the geostationary } \\
\text { orbit }\end{array}$ & SPOT IMAGE & $\begin{array}{l}\text { sensing system) } \\
\text { — semi-private French organization } \\
\text { responsible for production, oper- }\end{array}$ \\
\hline OSAD & $\begin{array}{l}\text {-U. N. Outer Space Affairs Di- } \\
\text { vision }\end{array}$ & & $\begin{array}{l}\text { ations, marketing, and sales of } \\
\text { SPOT services }\end{array}$ \\
\hline $\begin{array}{l}\text { OTA } \\
\text { OTRAG }\end{array}$ & $\begin{array}{l}\text {-Office of Technology Assessment } \\
\text {-Orbital Transport und Raketen }\end{array}$ & SSTDMA & $\begin{array}{l}\text { - satellite switched time division } \\
\text { multiple access }\end{array}$ \\
\hline & $\begin{array}{l}\text { Aktiengesellschaft (German pri- } \\
\text { vate firm) }\end{array}$ & $\begin{array}{l}\text { SSTO } \\
\text { STS }\end{array}$ & $\begin{array}{l}\text {-single stage to orbit space vehicle } \\
\text {-U.S. Space Transportation System }\end{array}$ \\
\hline PAM & $\begin{array}{l}\text {-Payload Assist Module used to } \\
\text { boost satellites into GSO from } \\
\text { the main launch vehicle }\end{array}$ & TAT & $\begin{array}{l}\text {-transatlantic telephone, designa- } \\
\text { tion given to a series of undersea } \\
\text { communication cable facilities }\end{array}$ \\
\hline $\begin{array}{l}\text { PRC } \\
\text { PRC (Space) }\end{array}$ & $\begin{array}{l}\text {-People's Republic of China } \\
\text {-Policy Review Committee on } \\
\text { Space established by Presidential }\end{array}$ & $\begin{array}{l}\text { TDMA } \\
\text { TDRSS }\end{array}$ & $\begin{array}{l}\text {-time division multiple access } \\
\text {-Tracking and Data Relay Satellite } \\
\text { System }\end{array}$ \\
\hline & directive in May 1978 & TE & -Technical Exchange Agreement \\
\hline PROTON & $\begin{array}{l}\text { —expendable launch vehicle of the } \\
\text { U.S.S.R. }\end{array}$ & $\begin{array}{l}\text { TITAN } \\
\text { TM }\end{array}$ & $\begin{array}{l}\text {-DOD expendable launch vehicle } \\
\text {-thematic mapper (on Landsat) }\end{array}$ \\
\hline PTT & $\begin{array}{l}\text {-post, telephone, and telegraph } \\
\text { administrations }\end{array}$ & $\begin{array}{l}\text { TVRO } \\
\text { U.K. }\end{array}$ & $\begin{array}{l}\text {-television receive only } \\
\text {-United Kingdom }\end{array}$ \\
\hline RARC & $\begin{array}{l}\text {-Regional Administrative Radio } \\
\text { Conference }\end{array}$ & $\begin{array}{l}\text { U.N. } \\
\text { UNCSTD-U. }\end{array}$ & $\begin{array}{l}\text {-United Nations } \\
\text {-Conference on Science, Technol- }\end{array}$ \\
\hline RESTEC & $\begin{array}{l}\text {-Remote Sensing Technology Cen- } \\
\text { ter (Japan) }\end{array}$ & UNDP & $\begin{array}{l}\text { ogy, and Development } \\
- \text { U. N. Development Program }\end{array}$ \\
\hline $\begin{array}{l}\text { RF } \\
R \& D\end{array}$ & $\begin{array}{l}\text {-radio frequency } \\
\text {-research and development }\end{array}$ & $\begin{array}{l}\text { UNDRO } \\
\text { UNEP }\end{array}$ & $\begin{array}{l}\text {-U. N. Disaster Relief Organization } \\
\text {-U. N. Environment Program }\end{array}$ \\
\hline RMS- & $\begin{array}{l}\text { n-Remote Manipulator System de- } \\
\text { veloped by SPAR Aerospace for } \\
\text { use on the U.S. Shuttle }\end{array}$ & $\begin{array}{l}\text { UNESCO } \\
\text { UNGA }\end{array}$ & $\begin{array}{l}\text {-U. N. Education Science and Cul- } \\
\text { tural Organization } \\
\text {-U.N. General Assembly }\end{array}$ \\
\hline $\begin{array}{l}\text { SALYUT } \\
\text { SBS } \\
\text { SCOUT }\end{array}$ & $\begin{array}{l}\text {-U.S.S.R. space station } \\
\text {-Satellite Business System } \\
\text { - small expendable launch vehicle }\end{array}$ & UN ISPACE '8' & $\begin{array}{l}2-1982 \text { U.N. Conference on the Ex- } \\
\text { ploration and Peaceful Uses of } \\
\text { Outer Space }\end{array}$ \\
\hline & & & -U.S. Department of Agriculture \\
\hline SIG (Space) & $\begin{array}{l}\text {-Senior Interagency Group-Space } \\
\text { (within White House) }\end{array}$ & $\begin{array}{l}\text { USGS } \\
\text { Uslscs }\end{array}$ & $\begin{array}{l}\text {-U.S. Geological Survey (DOI) } \\
\text {-U.S. international service carriers }\end{array}$ \\
\hline SITE & $\begin{array}{l}\text {-Satellite Instructional Television } \\
\text { Experiment (India) }\end{array}$ & USTTI & $\begin{array}{l}\text {-U.S. Telecommunications Train- } \\
\text { ing Institute }\end{array}$ \\
\hline
\end{tabular}


VAN -value-added networks

VHF

WARC

WHO

WIPO
- very high frequency

-World Administrative Radio Conference (conducted by ITU)

-World Health Organization

-World Intellectual Property Organization
WMO -World Meteorological Organization (U. N. Agency)

Wul

-Western Union International, Inc., subsidiary of $\mathrm{MCl}$ Communications Corp. 
Index 
ACTS. See Advanced Communications Technology Satellite Program.

Advanced Communications Technology Satellite (ACTS) Program, 13, 149, 164, 193-198, 206-207

Advanced research and development, 12-13, 193-198

Advanced Television and Infrared Observation Satellite (TIROS), 253, 258-260, 312

Advanced Very-High Resolution Radiometer (AVHRR), 259, 270

Aerojet-General, 119

Aerojet Tech Systems, 109

Aerospatiale, 60, 73, 272, 292

Agreement Governing the Activities of States on the Moon and Other Celestial Bodies, 47

Agreement on the Rescue of Astronauts, the Return of Astronauts, and the Return of Objects Launched Into Outer Space, 46

AID. See U.S. Agency for International Development.

Al D/SAT, 41, 179

Air Force, 10, 106, 107, 109, 121

Alcatel-Thompson/Telspace, 165

Apogee and Maneuvering Stage (AMS), 109

AMS. See Apogee Maneuvering Stage.

Apollo-Soyuz Test Project (ASTP), 39, 350, 377

Arabsat, 60, 181, 190, 200

ARGOS Data Collection System, 259, 266, 312

Ariane, 5, 8, 10, 71, 75, 110-111, 116, 122, 124, 126, 128-133, 135

Arianespace, S. A., 8, 73, 87, 116, 126, 129-135, 390

ASLV launch vehicle, 120

ASTP. See Apollo-Soyuz Test Project.

Astro-C, 384

Astrotech Space Operations, 109

AT\& T, 89, 91, 104, 155, 160, 185

AT\&T Communications, 154

Atlas-Centaur launch vehicles, 105-106, 120, 124, 132, 138

ATS-6 communications satellite, 38, 39, 41, 179

AVHRR. See Advanced Very-High Resolution Radiometer.

Ball Aerospace, 357

Ball Bros., 389, 390

Battelle, 124, 126-127

Beggs, James M., 130, 135

Bilateral cooperation, 28

developing countries, 59, 179-180

materials processing in space, 352

meteorological remote sensing, 264-265

National Aeronautics and Space Administration activities, $36,39-40$

satellite communications, 169-170, 179-180, 203, 204

space transportation activities, 119-120, 138

trade related, $11,85,89,190$

Biorack, 349

Black Brant sounding rocket, 122

BoB. See Bureau of the Budget.

Boeing, 107, 121, 389, 390

Brasilsat, 190
Brazil, 41, 120, 125, 190, 285

Bristol Aerospace Ltd., 87, 122

British Aerospace, 51, 390

British Telecom, 156, 160

BTM, 349

Bureau of the Budget (BoB), 2, 286

Business data services, 167

Cable \& Wireless, Ltd., 154, 159, 186, 187

Cable facilities, 14, 91, 123, 149, 152, 154, 159, 176-177, 185-187, 201-203

California Microwave, 166, 167

Canada, 37, 44

remote sensing activities, 16, 39, 266, 277, 292-293, 306-307, 310

satellite communications activities, 161, 163, 179

space station activities, 40

space transportation activities, 122

Canada Centre for Remote Sensing, 284

Carriers, 340

Centaur G, 109, 121, 122

Center for Telecommunications Development, 178

Centre National d'Etudes Spatiales (CNES), 73-74, 111,284, 352

China, 39, 59, 120, 125, 261, 378

CITEL, 171

Citicorp, 90, 155

CNES. See Centre National d'Etudes Spatiales.

Coastal Zone Color Scanner (CZCS), 303, 304, 308

Columbia University, 366

Commercial competition

Federal agency role, 416

INTELSAT and, 6, 8, 11, 13, 91, 148, 149, 161, 180-184, 198-200, 202-203

international trading rules, 83, 85-86

leadership in, 405

materials processing in space, 94-95

policy options, 403-407

political transition factors, 95

remote sensing, 92-94

satellite communications, services, 89-92, 180-188

satellite equipment, 188-193, 205-206

space sciences equipment, $389-390$

space transportation, $86-89,125-136,141-143$

U.S. policy, 401-402

See a/so Competition; Market structure

Commercial cooperation, 60-61

Commercialization

Federal agency coordination, 415-416

land remote sensing, 14-15, 254, 257-258, 283, 284, 286, 288, 292-295, 299-301, 319-322

materials processing in space, 16, 17, 337, 343-347, $354-360,362,364$

satellite communications advanced techology, 193-198

space transportation, 8-10, 103, 105-107, 109, 111, 116, $117,119-122$

Commercial Space Launch Act (Public Law 98-575), 10 
Committee on Earth Observation Satellites, 322

Committee on Scientific and Technological Aspects of Materials Processing in Space (STAMPS), 347

Committee on the Peaceful Uses of Outer Space (COPUOS), $41,44-47,51,52-53,55-57,366$

Communications Research Center (CRC), 37

Communications Satellite Act of 1962 147, 148, 177, 417

Communications Satellite Corp. See COMSAT.

Communications Technology Satellite (CTS), 37, 179

Competition

cooperation and, 60-61, 413-414

description of, $3,5-6$

economic, 68-70, 95

European Space Agency program, 67, 70-73

Federal agency coordination, 416

French program, 73-75

government role in, $65-66$

Japanese program, 77-83

land remote sensing, 14, 301, 319-322

materials processing in space, 16, 17, 94-95, 337, 363-365

meteorological remote sensing, 273, 275, 317, 319

military, 68, 69

overview, 26-27

policy options, 403-408

political, 66-69, 95

remote sensing, 92-94

satellite communications, 5-6, 10-12, 89-92, 149, 157-161, 167, 180-193

satellite equipment, 11-12, 162, 164, 167-168, 188-193, 205-206

space science, 19, 373-375, 386-390

space transportation applications, 8, 10, 86-89

U.S. policy, 21, 401-403

West German program, 75-77

See a/so Commercial competition; Market structure

COMSAT, 49, 51, 89, 148, 149, 154, 155, 168, 185, 193 , 200-201, 273

COMSAT General Corp., 50, 51

Conestoga launch vehicles, 121

Continental Telephone, 155

Convention on International Liability for Damage Caused by Space Objects, 46, 47

Convention on Registration of Objects Launched Into Outer Space, $46-47$

Cooperation

competition and, 60-61, 413-414

European Space Agency program, 43-44

Federal agency coordination, 416-417

issues in, 52-61

land remote sensing, 38, 294, 322-323

materials processing in space, $16,17,61,352,353,358$, 360-363, 365-367

meteorological remote sensing, 38, 43, 51-52, 61, 264 , $266,275,277-278,315-317$

ocean remote sensing activities, 16, 61, 303, 307, 310, 313-314, 323-324

overview, 28

policy options, $21,408-413$

satellite communications, $13-14,47-49,148,150,168-180$
Soviet program, 7, 28, 39, 41-43, 45-47, 173, 266, 352, $377-378,381-384,392-393$

space science, $18-19,61,373-373,375,377-386$

space transportation, $137-138$

U.S. program, 6-7, 33, 35-41, 53-58, 60, 70

See a/so specific organizations.

COPUOS. See Committee on the Peaceful Uses of Outer Space.

Cosmos satellites, 377,378

COSPAS/SARSAT, 16, 39, 259, 266, 277, 316

CRC. See Communications Research Center.

Credit subsidies, 85-86, 191-192

Cryogenic fuels, 112

Crystals, 338, 355-356

CTS. See Communications Technology Satellite.

Customer-premises Earth stations, 166, 167-168

Cygnus, 182

CZCS. See Coastal Zone Color Scanner.

D'Allest, Frederic, 130

Data Collection System (DCS), 259-261

DBS. See Direct broadcast satellites.

DCS. See Data Collection System.

Defense Meteorological Satellite Program (DMSP), 315-316

Delta launch vehicles, 104-105, 119-121, 124, 132, 138

Delta Transfer Stage, 109, 121

Department of Agriculture, 20, 270, 286, 418

Department of Commerce, 15, 20, 21, 253, 288, 290-291, 418

Department of Defense (DOD), 35, 122, 137, 315-316

Department of Interior, 20, 286, 418

Department of State, 20, 21, 41, 47, 91, 410-411, 416, 417, 419

Department of Transportation (DOT), 20, 21, 126, 418-419

Developing countries

geostationary orbit allocation issue, 13, 48-49, 174-176

land remote sensing issues, 15, 293-294, 323

policy options toward, $7,411-412$

remote sensing activities, 15, 16, 41, 52, 273

satellite communications activities, 50, 150, 170-172, $177-180, \quad 184,208-209$

satellite equipment trade, 86, 167, 191

space science activities, 19, 376, 386, 390-391

space technology development, 28, 40-41, 58-60

U.N. activities, 5, 55, 56

Direct broadcast satellites (DBS), 55, 73, 123

DMSP. See Defense Meteorological Satellite Program.

DOD. See Department of Defense.

Dolphin launch vehicles, 113, 121

Dornier, 349, 351

DOT. See Department of Transportation.

Dupont, 343, 357

Earth Radiation Budget Experiment (ERBE), 260

Earth remote sensing. See Land remote sensing.

Earth Resources Satellite Data Analysis Center (ERS-DAC), 81

Earth Resources Satellites (ERS), 285, 305, 310, 313

Earth stations, 164-168, 178, 179, 185, 191, 194

Economic competition, 68-70, 95 
ECS. See European Communications Satellites.

Education and training, 38-39, 376-377

EEC. See European Economic Community.

Eisenhower, Dwight D., 35, 36

ELDO. See European Launcher Development Organization.

Electromagnetic services, 193

Electrophoresis, 354-355

ELV. See Expendable launch vehicles.

EOSAT Corp., 15, 288, 290, 291, 319-320

Equatorial Communications Co., 166, 168

ERBE. See Earth Radiation Budget Experiment.

EROS Data Center, Sioux Falls, SD, 41, 280, 285, 298, 299

ERS. See Earth Resources Satellites.

ERS-DAC. See Earth Resources Satellite Data Analysis Center. ERSO. See European Space Research Organization.

ESA. See European Space Agency.

EURECA (European Retrievable Carrier), 348, 352, 358, 360

European Communications Satellites (ECS), 72

European Economic Community (EEC), 133, 167

European Launcher Development Organization (ELDO), 43, 70

See a/so European Space Agency

European Retrievable Carrier. See EURECA.

European Space Agency (ESA), 5, 27

competitive activities, 67, 70-73

cooperative activities, 28, 36-38, 43-44, 375, 381

developing country assistance, 59

formation of, 70-71

materials processing in space activities, 17, 76-77, 337, $347-349,358,360$

meteorological remote sensing activities, 261, 272

ocean remote sensing activities, 16, 305-306, 310, 313, 314

satellite communications activities, 72-73, 163, 194

space science activities, 19, 375, 376, 381-385, 387

space transportation program, 67, 110-111, 116, 122, 128-134

European Space Research Organization (ERSO), 43, 67, 70 See a/so European Space Agency

Eutelsat, 166, 181, 200

Ex-Im Bank. See U.S. Export-import Bank.

Expendable Launch Vehicle Commercialization Act, 418-419

Expendable launch vehicles (ELVS). See Space transportation.

Export controls, 192-193

Export subsidies, 85-86, 191-192

Facilities regulation, 184-187, 202-203

Fairchild, 167, 292

Fairchild Industries, 341, 344, 345, 357-358, 360

FCC. See Federal Communications Commission.

Federal agency coordination, 20-21, 415-417

Federal agency responsibility, 414, 417-419

Federal Communications Commission (FCC)

satellite communications activities, 13-14, 91-92, 123, 147,

$153,154,161,181-183,185,186,200-201,203$

space activities role, 20, 21, 410, 417

Federal Republic of Germany. See West Germany.
Fiber optics, 14, 91, 123, 152, 154, 159, 176-177, 186, 201-203

Finance Satellite, 182

First Materials Processing Test (FMPT), 352-353

Fisheries applications, 304, 312

Fluid Physics Module, 349

FMPT. See First Materials Processing Test.

Fokker, 349

Ford Aerospace, 60, 162-163

Ford Aerospace \& Communications, 190

France

land remote sensing activities, 14, 283-284

materials processing in space activities, 352

meteorological satellite activities, 16, 39, 266, 277

ocean remote sensing, 303

satellite communications activities, $72,73,159,163,190$, 194

Soviet cooperation, 41, 381-382

space program, 5, 66, 67, 73-75

space science activities, 19, 375, 381-382

space transportation activities, $67,70,71,125$

Free-flyers, 341, 351-353, 358-359

Frequency reuse techniques, 194

Fujitsu, 168

G-77. See Group of 77 .

GaAs. See Gallium-arsenide crystals.

Gagarin, Yuri, 66

Gallium-arsenide (GaAs) crystals, 355-356

GARP. See Global Atmospheric Research Program.

GAS canisters. See Get-away special canisters.

GATT codes, 11, 85, 96, 190

General Dynamics, 10, 87, 105-106, 109, 120, 121

General Electric Corp., 90, 155, 270, 292

Geostationary Operational Meteorological Satellite (GOMS), 264

Geostationary orbit allocation, 13, 48-49, 173-177

Geostationary Orbiting Environmental Satellite (GOES) system, 253, 258, 260, 270, 272, 275, 317

Get-away special (GAS) canisters, 340, 351

Global Atmospheric Research Program (GARP), 52, 269

GOES system. See Geostationary Orbiting Environmental Satellite system.

GOMS. See Geostationary Operational Meteorological Satellite.

Government competitors

meteorological data, 275

space transportation, 87, 138-139, 142, 143

Government subsidies

materials processing in space, 364-365

policy issues, 401-402

policy options, 404-407

remote sensing, 93, 94, 291, 320-321

satellite communications, 205, 206

space transportation, 130-134, 141

Ground-based projects, 38

Ground-based sensors, 261

Ground stations and receivers, 272-273, 292-293

Group of 77 (G-77), 55, 57-59 
Grumman, 389

GTE, 89, 154, 155, 167

GTI, 344-346, 357

Guidance systems, 113

Harris Corp., 166

Hermes, 110, 352

High-Resolution Infrared Sounder (H RIS-2), 270

Hitchhiker, 340, 358

Honeywell, Electro-optical Division, 343

House Committee on Science and Technology, 290

House Subcommittee on Natural Resources, Agriculture Research, and Environment, 274

HRIS-2. See High-Resolution Infrared Sounder.

$\mathrm{H}$ series launch vehicles, 119-120

Hughes, 81, 114, 162, 389

Hughes Aircraft Corp., 13, 51, 162, 190, 193, 196, 270, 272, 292

Hughes Communications Galaxy, Inc., 195-196

Hybrid rockets, 113

IBM, 89, 155, 165

ICSU. See International Council of Scientific Unions.

IMCO. See Intergovernmental Maritime Consultative Organization.

IML. See International Microgravity Lab.

IMO. See International Meteorological Organization.

INCO Research \& Development Center, Inc., 357

Independent Commission for Worldwide Telecommunica-

India tions Development, 178

developing country assistance, 59

land remote sensing, 284-285

meteorological remote sensing, 261

satellite communications activities, 38, 58

Soviet cooperation, 28, 41, 382

space science activities, 382

space transportation activities, 120, 125

Indonesia, 41

Inertial guidance systems, 114

Inertial upper stage (IUS), 107, 109, 121, 122

Infrared Astronomical Satellite (IRAS), 18, 382-383

INMARSAT (International Maritime Satellite Organization), 6-8, 50-51, 117, 124, 172-173, 192

Insat 1, 261

Institute of Space and Aeronautical Sciences (ISAS), 117, 375,388

Instrumentation Technology Associates, Inc. (ITA), 357

INTELSAT (International Telecommunications Satellite Organization)

competition and, 6, 8, 11, 13, 91, 148, 149, 161, 180-184, 198-200, 202-203

developing country assistance, 177-178

satellite operations, 114, 123, 154, 162-163, 167

U.S. participation issues, 11, 13, 172, 173

INTELSAT Agreement of 1973, 147, 180, 181

Intercosmos, 42-43, 67-68, 381

Intergovernmental Agreement on Cooperation in the Exploration and Use of Outer Space for Peaceful Purposes, 377,392
Intergovernmental Maritime Consultative Organization (IMCO), 50

International Astronautical Federation, 42

International Council of Scientific Unions (ICSU), 52

International Halley Watch, 18, 39, 40, 383-384

International Maritime Satellite Organization. See INMARSAT.

International Meteorological Organization (IMO), 51 See a/so World Meteorological Organization

International Microgravity Lab (IML), 17, 362, 365

International organizations politicization, 68, 150, 170-173, 207-208, 411-412

International Polar-Orbiting Meteorological Satellite (I POMS) group, 316

International Solar Polar Mission (ISPM), 18-19, 384

International Telecommunications Satellite Organization. See INTELSAT.

International Telecommunication Union (ITU), 7, 13-14, 47-49, 57-58, 170-171, 178, 207-208

ITU Region 2 Regional Administrative Radio Conferences, 171

International trade

materials processing in space and, 365

policy options, 405, 407, 408

satellite equipment, 83, 85-86, 89, 95, 188-193, 205-206

U.S. policy, 401-402

International trading rules satellite services, $86,89,149$, 180-188

Intersputnik, 42, 67-68

IPOMS. See International Polar-Orbiting Meteorological Satellite group.

IRAS. See Infrared Astronomical Satellite.

IRIS. See Italian Research Interim Stage.

IRS, 284-285

ISAS. See Institute of Space and Aeronautical Sciences.

ISPM. See International Solar Power Mission.

ITA. See Instrumentation Technology Associates, Inc. Italian Research Interim Stage (IRIS), 122

Italy, 72, 73, 122, 163, 194

ITT, 89, 155, 166, 192

ITU. See International Telecommunication Union.

IUS. See Inertial upper stage.

Japan

competitive activities, 5, 85

developing country assistance, 59

land remote sensing activities, 81, 285

materials processing in space activities, 17, 352-353, 365

meteorological remote sensing activities, 78, 80, 261, 272

ocean remote sensing activities, 16, 81, 305, 314

satellite communications activities, 11, 80-81, 160, 162,

$163,165,167,168,190-191,194,205$

space program, $5,66,77-83$

space science activities, $19,28,78,375,383,384,387-388$

space station activities, 40

space transportation, 8, 80, 117, 119-120, 125, 138

japanese National Research Institute for Metals, 37

JEA. See Joint Endeavor Agreements.

John Deere \& Co., 343, 356

Johnson, Lyndon B., 35 
Joint Endeavor Agreements (JEA), 6, 343-346, 354-355, 357-358, 364

Ka-band systems, 12-13, 81, 175, 176, 193-197

Kaiser-Threde, 351

KDD. See Kokusai Denshin Denwa.

Kennedy, John F., 66

Kodak/Fairchild, 288, 290

Kokusai Denshin Denwa (KDD), 156

Kosmos, 307

Lambda rockets, 117

Land remote sensing

applications, 258, 301

commercial cooperation, 60-61

commercialization, 14, 15, 254, 257-258, 283, 284, 286 , 288, 292-295, 299-301, 319-322

competition, 14, 301, 319-322

cooperation, 38, 294, 322-323

data products and uses, 285, 293-295, 299-301

development of, 278

equipment market, 292-293, 323

foreign receiving stations, 280,282

foreign systems, 282-285

international role, 291-292

market structure, 93-94, 285, 293-295, 299-301

overview, 14-15, 253

policy options, 15, 319-323

private sector, $14-15,93,254,257,283,284,286,288$, 292-294, 301, 319-322

research and development, 280, 290, 294, 301, 321

U.S. policy, 286, 288-291

U.S. system, 253, 278-280

Land Remote Sensing Commercialization Act of 1984 (Public Law 98-365), 15, 257, 282, 289-290, 294, 321, 418

Landsat applications, 258

Landsat Ground Station Operators Working Groups, 322

Landsat system, 28, 41, 52, 94, 308, 309

data products, 285, 293-295, 299-301

description, 253, 278-280

Federal agency coordination, 415

foreign receiving stations, $38,280,282$

international role, 291-292

issues, 293-301

overview, 14-15

private sector transfer, 93, 254, 257, 286, 288, 293-294, 319-322

satellite 4 repair, 322

Launch vehicles. See Space transportation.

Leadership competition

cooperative activities and, 409

Federal agency coordination, 414-419

materials in space processing, 362

policy options, 404-405

space science, 387,393

space transportation, $136,138,141$

U.S. policy, 402

Leasecraft, $341,345,358,360$

Life sciences, 372, 377, 378, 387, 392

Liquid Propulsion Module (LPM), 109

Liquid rockets, 112-114
Lodge, Henry Cabot, 45

Long March launch vehicles, 120

LPM. See Liquid Propulsion Module.

M/A Corn, 166

MacDonald Dettwiler Association, Inc., 273, 292-293

McCormack, John W., 35

McDonnell Douglas, 89, 94, 105, 107, 109, 119, 155, 344

McDonnell Douglas Astronautics Co. (MDAC), 121, 344, $346,354-355,358,360$

Maitland Commission, 178

Marec satellites, 71, 72

Marine Observation Satellite (MOS-1), 305

Marine transportation applications, 310

Market structure

Earth stations, 164-167

land remote sensing, 93-94, 285, 292-295, 299-301

materials processing in space, 94-95, 360, 362

meteorological remote sensing, 93, 270

satellite communications services, 89-92, 147-148, 153-160

satellite equipment, 162-163

space science related industries, $389-390$

space transportation, $86-89$

Martin Marietta, 10, 87, 106, 109, 121, 344, 345

Materials processing in space (MPS)

application potential, $338,354-360$

commercialization, 16, 17, 337, 343-347, 354-360, 362, 364

competition, 16, 17, 94-95, 337, 363-365

cooperative activities, $16,17,61,352,353,358,360-363$, 365-367

European Space Agency activities, 17, 76-77, 337, $347-349, \quad 358,360$

Federal agency responsibility, 419

France 352

Japan, 17, 352-353, 365

launch service demand, 124

leadership role, 362

market structure, 94-95, 360, 362

NASA research, $16,17,94,337-344,347,348,352-358$, 360-366, 419

overview, 16-17, 337

policy options, 362-365

private sector, 337, 343-347, 354-358, 363-365

research and development, 16-17, 76-77, 337

scientific community involvement, 347, 363-364, 366

Soviet Union, 17, 353-354

West German activities, 76-77, 337, 341, 348-352, 358, 361

Materials Sciences Double Rack, 349

Matra, 73, 292, 349, 390

Matsushita, 168

MAUS, 351, 358, 361

MBB. See Messerschmitt-Boelkow-Blohm GmbH.

MBB/ERNO, 341, 348, 349, 351-352, 358, 361

$\mathrm{MCl}, 89,154,155$

MDAC. See McDonnell Douglas Astronautics Co.

MEPHISTO (Materiel pour l'Etude des Phenomenes Interessant de la Solidification sur Terre et en Orbite), 352 Merrill Lynch, 90, 155 
MESA, 390

Messerschmitt-Boelkow-Blohm GmbH (MBB), 273, 283, 358

METEOR-2, 261

Meteorological remote sensing

applications, 257-258

competition, 273, 275, 317, 319

cooperative activities, 38, 43, 51-52, 61, 264, 266, 275, 277-278, 315-317

data products and service, 266, 269-270, 274

foreign systems, 260-261, 264

japan, 78, 80, 261, 272

market structure, 93, 270, 272-273

ocean measurements, 305

overview, 15-16

policy options, 16, 315-319

private sector, 15, 273-275

research and development, 258, 260

service level issue, 275, 277

U.S. systems, 253, 258

Meteor satellites, 43

Meteosat-2, 261, 272

Metsats (meteorological satellites). See Meteorological remote sensing.

Microgravity Research Associates (MRA), 344-346, 355

Microgravity Science and Applications (MSA) Division, 338

Microwave sounders, 258, 266, 309

Military competition, 68, 69

Mission-peculiar support structure (MPESS), 340

MitsubishilCOMSAT, 168

Mitsubishi Electric, 190

Mitsubishi Industries, 119

Mitterrand, Francois, 73

MLA. See Multispectral linear array.

Modular Optoelectronic Multispectral Scanner (MOMS), 283

Molniya satellites, 42

MOMS. See Modular Optoelectronic Multispectral Scanner.

MOS-1. See Marine Observation Satellite.

Motorola, 193

MPESS. See Mission-peculiar support structure.

MPS. See Materials processing in space.

MRA. See Microgravity Research Associates.

MSA Division. See Microgravity Science and Applications Division.

Mu launchers, 117, 119

Multilateral cooperation

developing country assistance, 59-60, 177-179

meteorological remote sensing, 264-265

satellite communic tions related, 177-179, 204

Soviet, 41-43

trade rules, 85-86, 89

See a/so specific organizations.

Multilateral coordination

land remote sensing, 322-323

Multispectral camera, 43

Multispectral linear array (MLA), 280, 284

NACP. See North Atlantic Consultative Process.

NASA. See National Aeronautics and Space Administration, NAS Act. See National Aeronautics and Space Act.

NASC. See National Aeronautics and Space Council.
NASDA. See National Space Development Agency.

National Advisory Committee for Aeronautics, 35. See a/so National Aeronautics and Space Administration.

National Aeronautics and Space Act of 1958 (NAS Act), 20-21, 25, 33, 35-36, 141, 397, 399, 414

National Aeronautics and Space Administration (NASA)

cooperative activities, 7, 21, 28, 33, 36-40, 44, 137, 352, 353, 361, 366

land remote sensing activities, 14, 15,278,280,286-288, $301,321,418$

materials processing in space activities, 16, 17, 94, 337-344, 347, 348, 352-358, 360-366, 419

meteorological remote sensing activities, 273

ocean remote sensing activities, 16, 302-304, 307, 324

private sector cooperation, 6

satellite communications activities, 12-13, 149-150, 163, $164,174,193-198,417,418$

space activities role, 20-21, 397, 410, 414-41

space science, 371, 372, 376, 378, 380, 384, 385

space transportation activities, 8-10, 87, 88, 103-109, $120-122,126,128-136,138-139,142,143,418$

National Aeronautics and Space Council (NASC), 399

National Commission on Space, 19-20, 400

National Oceanic and Atmospheric Administration (NOAA) land remote sensing activities, 14, 15, 253,280, 282,295, $301,321,322,418$

meteorological remote sensing activities, 93, 253, 258, $264,266,270,273-275,277,316$

ocean remote sensing activities, 16, 304, 305, 313, 324

remote sensing systems, 253

space activities role, 7, 28, 33, 410

National Oceanic Satellite System (NOSS), 302

National Research Council, 347

National Research Council of Canada, 107

National space Development Agency (NASDA), Japan, 28, 117, 119

National Weather Service (NWS), 269-270

Navy Remote Ocean Sensing Satellite (N ROSS), 16, 303, 305,313

NEC. See Nippon Electric Co.

Netherlands, 37-38, 383

Netherlands' Delft Technical Institute, 37-38

Nimbus satellites, 303, 304, 308

Nippon Electric Co. (NEC), 80-81, 165, 167, 168, 191

Nippon Telegraph \& Telephone (NI_I_), 80,81,85, 190, 191

Nissan Motors, 117

NOAA. See National Oceanic and Atmospheric Administration.

NOAA satellites, 258, 259, 272, 309

North Atlantic Consultative Process (NACP), 173, 186

NOSS. See National Oceanic Satellite System.

NROSS. See Navy Remote Ocean Sensing Satellite.

$\mathrm{N}$ series launch vehicles, 119

NTT. See Nippon Telegraph \& Telephone,

NWS. See National Weather Service.

Oberth Society, 351

Ocean color data, 304, 308, 312

Ocean Color Imager (OCl), 260 
Ocean remote sensing

applications, 258, 304, 310-312

cooperative activities, 16, 61, 303, 307, 310, 313-314, 323-324

data potential, $307-310$

foreign systems, 305-307

issues, $312-314$

overview, 16, 253-254

policy options, 323-324

research and development, 312-313, 324

U.S. systems, 302-305

OCl. See Ocean Color Imager.

Odetics, Inc., 292

OECD. See Organization for Economic Cooperation and Development.

Office of Commercial Programs, 337

Office of Management and Budget (OMB), 134, 140, 193, 280, 286, 291, 298, 320, 399

Office of Space and Terrestrial Applications, 361

Office of the U.S. Trade Representative, 131

Offshore mining applications, 310

Oil and gas exploration and extraction applications, 310

OMB. See Office of Management and Budget.

ORB'85, 13, 48-49, 173

Orbital Sciences Corp., 87, 109

Organization for Economic Cooperation and Development (OECD), 85, 86, 97-98, 173, 191

OECD Arrangement on Officially Supported Export Credit, $85,86,97-98,191$

OECD Understanding on Export Credits for Ground Satellite Communication Stations, 191

Orion Satellite Corp., 154, 182, 184

Ortho Pharmaceutical, 94, 355

OSAD. See Outer Space Affairs Division.

OTRAG (Orbital Transport-u nd-Raketen Aktiengesellschaft), 87, 122

Outer Space Affairs Division (OSAD), 55

Page, 166

Palapa, 181

PAM. See Payload assist modules.

Pan American Satellite, 182

Payload assist modules (PAM), 107, 109, 121, 122

Peace-Sat Network, 41

PEFCO. See Private Export Funding Corp.

People's Republic of China. See China.

Perkin-EImer, 390

Peru, 41

Pharmaceuticals, 354-356

Philippines, 41

Physics and astronomy, 371, 372

Planetary exploration, 371-372, 377, 387, 393

Polar-orbiting meteorological systems, 253, 258, 259, 272, 275-277, 315-317

Polar-orbiting platform, 314, 324

Policy

competition, 21, 400-408

cooperation-competition relationship, 413-414

developing country assistance, $7,411-412$

goals and objectives, 19-20, 399-400 land remote sensing, 286, 288-291

leadership maintenance and, 414-419

problems, 397-398

regulatory framework, 397

remote sensing, 254, 257

satellite communications, 147, 149-150, 168-169

space transportation, 138-139

Policy options

competition, 403-408

cooperation, 21, 408-413

Federal agency coordination, 20-21, 415-417

Federal agency responsibilities, 414, 417-419

land remote sensing, 15, 319-323

materials processing in space $362-365$

meteorological remote sensing, 16, 315-319

ocean remote sensing, 323-324

satellite communications, $198-210$

space transportation, 127-128, 140-143

Political competition, 66-69, 95

Post, telephone, and telegraph agencies (PTTs), 11, 85, 90, 91, 148, 155-156, 159, 161, 163, 167, 187-188, 190

Preeminence. See Leadership competition.

Private Export Funding Corp. (PEFCO), 133

Private sector

Federal agency coordination, 21

land remote sensing activities, 14-15, 93, 254, 257, 283, $284,288,290-294,301,319-322$

materials processing in space activities, 337, 343-347, 354-358, 363-365

meteorological remote sensing activities, 15, 273-275

ocean remote sensing activities, 16

research and development, 6, 194-195, 197, 206, 207, 401-402, 406, 407

satellite communications activities, 6, 89, 90, 149, 161, 180-184, 198-200

space activity role, $6,27,65$

space transportation activities, 8-10, 120-123, 125-126, $129,131,132,136,138-139,141-143$

U.S. treaty obligations and, 47

Propulsion systems, 172-173

Proton launchers, 116-117

PSLV launch vehicles, 120

PITs. See Post, telephone, and telegraph agencies.

Quistgaard, Erik, 132

Radarsat, 306-307, 310

R\&D. See Research and development.

RCA, 89, 154, 155, 162-163, 166, 182, 193, 292

RCA Astro-Electronics, 270

Reagan, Ronald, 8, 125-126, 137-138, 141-142, 183, 274, 384-385

Remote sensing

applications, 257-258

commercial cooperation, 60-61

competition, 92-94

developing countries, 15, 16, 41, 52, 273

Federal agency responsibility, 418

foreign ground stations, 38

Japan, 81 
market structure, 92-94

policy, 254, 257

Soviet, 43

systems, 253-254

See a/so Land remote sensing; Meteorological remote sensing; Ocean remote sensing.

Research and development (R\&D)

Japan, 78

land remote sensing, 280, 290, 294, 301, 321

materials processing in space, 16-17, 76-77, 337

meteorological remote sensing, 258, 260

ocean remote sensing, 312-313, 324

policy options, 404, 406, 407, 415

private sector, 6, 194-195, 197, 206, 207, 401-402, 406, 407

remote sensing, 15

satellite communications, 149-150, 163, 193-198, 206-207

satellite equipment, 163-164, 206-207

trade subsidy factors, $85,401-403$

U.S. policy, 402-403

See a/so Space science.

Rockwell International, 106, 126-127, 134

Rural Satellite Program, 41

SACl, 41

Salyut space station, 42, 43, 352, 353, 381

Sapwood-A launchers, 116

SAR. See Synthetic Aperture Radar.

Satellite communications

commercial cooperation, 60

commercialization, 193-198

competition, 5-6, 10-12, 89-92, 149, 157-161, 167, 180-193

cooperation, 13-14, 47-49, 148, 150, 168-180

demand for, 11, 150-153

developing country assistance, 50, 150, 170-172, 177-180,

184, 208-209

domestic market competition, 157-160

facilities regulation issues, 184-187, 201-203

Federal agency responsibilities, 417-418

foreign market competition, 160-161

Japan, 11, 80-81, 156, 160, 162, 163, 165, 167, 168, 190-191, 194, 205

launch service demand, $122-124$

market structure, 89-92, 147-148, 153-160

policy issues, 147, 149-150, 168-169

policy options, 198-210

private sector activities, 6, 89, 90, 149, 161, 180-184, 198-200

research and development, 12-13, 149-150, 163, 193-198, 206-207

trade issues, $180-188$

U.S. providers, 187-188, 203-204

Satellite equipment

competition, 11-12, 162, 164, 167-168, 188-193, 205-206

land remote sensing, 292-293, 323

market structures, 162-163

meteorological satellites, 270-273

research and development, 163-164, 206-207 space science, $389-390$

trade issues, 188-193, 205-206

Satellite Instructional Television Experiment (SITE), 38,41,58

Satellite switched time division multiple access (SSTDMA), 194

SBUR. See Solar Backscatter Ultraviolet Radiometer

Scanning spot beams, 194, 196

Science Working Groups, 366

Scientific Atlanta, 166, 167

Sea ice data, 308-310

Search and Rescue Satellite System. See COSPAS/SARSAT.

Sea surface temperature (SST) data, 270, 307-308, 312

Seasat, 16, 302, 303, 310

SEM. See Space Environment Monitor.

Senate Committee on Commerce, Science, and Transportation, 290

Senate Committee on Foreign Relations, 39

Senate Subcommittee on Science, Technology, and Space, 274

Senior Interagency Group for Space (SIG space), 19, 399, 418

Sensor development, 280, 283, 324

SEP, 73, 273, 292

Shell Oil, 90, 155

Shuttle, 8, 122, 124

cooperative activities, 33, 44, 70, 137

description, 106, 126

materials processing in space activities, 339, 340, 348, 357, 361-362, 364

policy options, 10, 140-143

prices, 9-10, 128-136

upper stages, 107, 109

use policy, 138-139

Shuttle Pallet Satellite (SPAS), 341, 351-352, 358, 361

SIG space. See Senior Interagency Group for Space.

SITE. See Satellite Instructional Television Experiment.

SLC. See Submarine Lightwave Cable Co.

SLV-3 launch vehicle, 120

Solar Backscatter Ultraviolet Radiometer (SBUR), 260

Solaris, 352

Solid rockets, 112-114

Sonda launch vehicles, 120

Sounding rockets, 17, 38, 117, 122, 349

Soviet Union

competitive activities, 6, 66-68

cooperative activities, 7, 28, 39, 41-43, 45-47, 173, 266, $352,377-378,381-384,392-393$

materials processing in space activities, 17, 352-354

meteorological satellite activities, 16, 41, 43, 261, 264, 266

ocean remote sensing, 302, 307

remote sensing activities, 43

satellite communications activities, 42, 173

space program, 65, 66-68

space science activities, 19, 41, 373-375, 377-378, $381-384,386,387,392-393$

space transportation, 116-117

Space America, 288

Spaceco Ltd., 344, 345

Space Environment Monitor (SEM), 259, 260 
Space expenditures, 65-66, 73, 75, 81

Spacelab, 5, 28, 44, 71, 341, 348, 349, 351, 352, 361, 362, 364,409

Space science

competition, $19,373-375, \quad 386-390$

cooperation, $18-19,61,372-373,375,377-386$

future role, $391-392$

issues, $375-377$

leadership in, 387, 393

overview, 371-372

policy options, 392-393

programs, 382-384

Space Services Inc. (SS1), 87, 121

Space Shuttle. See Shuttle.

Space station program, 40, 314, 343-344, 353, 409

Space Task Group (STG), 137

Space telescope (ST), 384, 390

Space Telescope Science Institute, 384

Space transportation

Ariane program, 110-111, 116

buyers, 122-124

commercialization, 8-10, 103, 105-107, 109, 111, 116, $117,119-122$

competition, 8, 10, 86-89, 125-136

cooperative activities, $137-138$

demand for, 123-124, 126-128

Federal agency responsibility, 20, 21, 418-419

Japan, 19, 28, 78, 375, 383, 384, 387

launch vehicle technology, 112-114

leadership in, 136, 138, 141

market structure, $86-89$

National Aeronautics and Space Administration launch vehicles, 103-109

policy options, 127-128, 140-143

potential government sellers, 116-120

potential private sellers, 120-122

pricing issue, 129-134

private sector, 8-10, 120-123, 125-126, 129, 131, 132, 136, 138-139, 141-143

trade rules, 89

U.S. policy, 138-139

Space transportation competition

demand, 123-124, 126-128

development of, 125-126

effects of, 134-136

nature of, $128-134$

Space WARC. See World Administrative Radio Conference.

SPAR Aerospace, 107, 163, 190

Spartan, 341

SPARX, 283

SPAS. See Shuttle Pallet Satellite.

SPOT (Systeme Probetoire d'Observation de la Terre), 14, 27, 60, 75, 93-94, 283-284, 292-293

SPOT Image Corp., 284

SPOT Image, S. A., 73, 93, 94, 284

SS1. See Space Services Inc.

SST. See Sea surface temperature data.

SSTDMA. See Satellite switched time division multiple access.

ST. See Space telescope.
STAMPS. See Committee on Scientific and Technological Aspects of Materials Processing in Space.

Starstruck, Inc., 87, 113, 121

State of Alaska Medical Network, 41

Statsionar satellites, 42

StenGeck Reassurance Co., Inc., 283

STG. See Space Task Group.

Stockman, David, 135

Stratospheric Sounding Unit, 258, 266

Submarine Lightwave Cable Co. (SLC), 154, 186

Subsidized credit, 85-86, 191-192

Support systems, 113-114

Sweden, 349, 351, 39o

Synthetic Aperture Radar (SAR), 309-310

Systeme Probetoire d'Observation de la Terre (SPOT). See SPOT.

Tanks, 113-114

TCl. See Transpace Carriers, Inc.

TEA. See Technical Exchange Agreements.

Technical Exchange Agreements (TEA), 343, 356-357

Technology transfer

cooperation and competition risks, 60

developing countries and, 28

materials processing in space, 61

private sector and, $41 \mathrm{~s}$

remote sensing, 273, 277, 278, 317

satellite communications, 173

space science, 393

Telecommunications. See Satellite communications.

Teledyne Brown Engineering, 340, 357

Telefunken, 390

Telesat Canada, 154

Television receive-only (TVRO) Earth stations, 166, 168

Texas Instruments, 90, 155

TEXUS, 349, 351

Thant, U, 46

Thomson-CSF, 73

3M Corp., 344, 345

TIROS. See Advanced Television and Infrared Observation Satellite.

TIROS Operational Vertical Sounder (TOVS), 259

Titan launch vehicles, 10, 106, 113, 121, 138

TOPEX/POSEIDON, 303

TOS. See Transfer Orbit Stage.

TOVS. See TIROS Operational Vertical Sounder.

Transatlantic systems, 11, 13, 91, 128-184, 202-203

Transfer Orbit Stage (TOS), 109, 121, 122

Transpace Carriers, Inc. (TCI), 87, 89, 120-121, 131-132

Treaty on Outer Space (Treaty on Principles Governing the Activities of States in the Exploration and Use of Outer Space, Including the Moon and Other Celestial Bodies), 44, 46, 47, 288, 292

TRW, 193, 389

TVROS. See Television receive-only Earth stations.

Unisat satellite, 160

UN ISPACE '82, 7, 49, 53, 366, 390-391

United Brands, 89, 155, 182 
United Kingdom, 71-73, 90, 91, 156, 159, 160, 163, 258 $266,375,384$

United Nations, 44, 51-58, 60, 170-171. See a/so Committee on the Peaceful Uses of Outer Space; International Telecommunication Union; world Meteorological Organization.

Universities Space Research Association (USRA), 347

University of Bern, Switzerland, 37

University of Hawaii, 41

University of West Indies, 41

Upper stages, 107-109, 114, 121-122

U.S. Agency for International Development (AID)

international cooperation activities, 7, 28, 33, 39-41, 180, 209, 273

U.S. Data Communications System, 266

U.S. Export-Import Bank (Ex-Im), 133, 134, 192, 206

U.S. Geological Survey, 41

U.S.-Japanese Agreement on Space Activities, 119

U.S. Navy, 16, 303, 305

USRA. See Universities Space Research Association.

U.S.S.R. See Soviet Union.

U.S. Telecommunications Training Institute (USTTI), 59, 179-180, 412

U.S. Thiokol, 119

U.S. Trade Act of 1974, 131

USTTI. See U.S. Telecommunications Training Institute.

Value-added services, 257, 264, 274-275, 293-294, 299-301 $317,321-323$
VAS. See Visible Atmospheric Sounder.

Visible and Infrared Spin-Scan Radiometer (VISSR), 260,270

Visible Atmospheric Sounder (VAS), 260

VISSR. See Visible and Infrared Spin-Scan Radiometer.

Von Braun, Wernher, 66

Wave height data, 310, 312

Weather data products, 266, 269, 310

Western Union Telegraph Co., 89, 154, 155, 174, 175

West Germany

land remote sensing, 283

materials processing in space activities, 76-77, 337, 341, 348-352, 358, 361

satellite communications activities, 72, 73, 163, 194

Spacelab activities, 5, 71, 7s

Space program, 66, 70, 75-77

space science activities, 375

space transportation activities, 128

WMO. See World Meteorological Organization.

World Administrative Radio Conference 1985-88 (Space WARC), 13, 48-49, 150, 171, 173-177

World Bank, 179

World Meteorological Organization (WMO), 43, 51-52, 264, 268, 273, 274

World Weather Watch, 268-269, 273

Zeiss, 390 